\title{
ADULT, JUVENILE AND LARVAL FISH IN THE VICINITY \\ OF THE J. H. CAMPBELL POWER PLANT, EASTERN LAKE MICHIGAN, 1978
}

D. J. Jude, G. R. Heufelder, H. T. Tin, N. A. Auer,

S. A. Klinger, P. J. Schneeberger, T. L. Rutecki, C. P. Madenjian, P. J. Rago

\author{
Under contract with \\ Consumers Power Company \\ David J. Jude, Project Director
}

\footnotetext{
Great Lakes Research Division

The University of Michigan

Ann Arbor, Michigan
} 



\section{ACKNOWLEDGEMENTS}

Results of this study, appearing here in published form, were made possible by a grant from Consumers Power Company (Jackson, Michigan) through their Environmental Services Department. We would like to take particular note of the special genial relationship we enjoy with our two liasions, Ibrahim Zeitoun and John Gulvas. To Abe we remain thankful for his continued support, interest, constructive criticism and review of this report. John is acknowledged for many tangibles, such as ordering gear, coordinating equipment use, running down data on plant design and pump flows and for many more intangibles. We appreciate his continued interest and concern about our progress.

We are saddened to report the departure of Bruce Bachen to the Alaskan wilderness. His legacy as author, computer programmer, field trip leader and innovator helped shape the form of the present report and the direction of ongoing studies. His contributions and consultations after he changed jobs are hereby gratefully acknowledged.

Jack Krueger, Campbell Plant Manager and Bill Turpin were very cooperative and helpful in solving problems that arose regarding security, facilities and access to plant operation designs and flow rates. Bob Grindler is thanked for the many favors he performed making our research site more livable.

We would like to thank Herbert Norder and Roy Glutting, not only for permission to cross their property giving us access to Lake Michigan beach stations near the Plant, but also for their continued interest and congeniality toward members of our research team. The captains (Edward Dunster, Richard Thibault) and mates (Ear1 Wilson, Glen Tompkins) aboard the R/V Mysis are appreciated for their work during all cruises, particularly those high wave-high wind days when good food and humor helped us complete our activities on schedule. Cliff Tetzloff, marine superintendent, organized Mysis schedules and coordinated sampling trips; his cooperation and help made our tasks easier.

Harvey Blankespoor, professor at Hope College, Holland, helped us during winter months by trudging through the snow and performing critical entrainment and impingement sampling, a task also performed by Joe Van Ark. We would also like to thank Harv for the time he spent in our behalf recruiting persons to do sampling at Campbell during times when we could not. In addition to these people, a large number of temporary research assistants aided us in completing the field work and in processing the adult and fish larvae samples back at the laboratory. We are indebted to these people for their perseverance, enthusiasm and good attitudes despite the sometimes routine nature of sample processing. Among people who assisted were the following: John Alfred-Ockiya, Steve Arnold, Paul Busman, Melanie Cunningham, Doug Denison, Mike Enk, Ron Gamble, Brian Guth, Janet Huggard, Paul Kostecki, Jeff Laufle, Joan Lapham, Richard Mackelin, Sherry Middlemis, George Noguchi, Janice Pappas, Dave Smith and Jim Wojcik. The next group of people not only assisted with field and laboratory work, but were also intimately involved 
with the task of preparing final copies of tables, figures and appendixes for this report. They included: Jeff Braunscheidel, Laura Black, Sheryl Corey, Loren Flath, John Hartung, Phil Hirt, Gerard Lillie, Pam Mansfield, Cora Rubitschun, Francis Sikoki and Lori Weiss. Special thanks to Nancy Thurber, in charge of the laboratory, for her efforts in coordinating the processing of larval and adult fish samples and to Cora Rubitschun who also shouldered part of that responsibility.

For some of the computer processing and plots that appear in the report, we are grateful to Steve Wineberg, Ann Amundsen and George Te, who have worked on various aspects of data analysis and histogram figures through many phases of this study. Greg Godun provided statistical consultation on some problems of data analysis.

The thankless job of typing, hereby acknowledged and appreciated, fell mainly to Martha Strogen (an earlier version) and Jan Farris and Debby Barsky (the present version). Many of the tedious tables were rendered into readability by Ellen Siford and Lori Weiss. We thank them for their fortitude.

Steve Schneider provided guidance, coordinated typists and procured a speedy printer for copies of this report. Frank Tesar coordinated the loan of some critical equipment (sled, motors) from another project for our use and critically reviewed this entire report. His many poignant comments and professional editing are very much appreciated. We thank James Diana, Assistant Professor from the School of Natural Resources, University of Michigan who also took time to review this entire report and provided us with many useful suggestions. We thank John Armstrong of Coastal Zone Management Laboratory for continued permission to use the 22-ft Boston Whaler and 19-ft Sea Ray. Reeve Bailey, Museum of Zoology, University of Michigan and John Dorr III, Great Lakes Research Division are acknowledged respectively for their aid in identifying difficult minnow species, young salmonids and larval fish.

Nelson Navarre deserves our gratitude for his behind the scenes handling of a number of administrative, budget and equipment problems. Lastly we would like to requite with praise the efforts of Sherry Stapleton and Judy Farris, who collectively tame the jungle of paper work associated with our time cards, travel advances and supply requests. 
TABLE OF CONTENTS

ACKNOWLEDGEMENTS. . . . . . . . . . . . . . . . . . . . . iii

INTRODUCTION. • . . . . . . . . . . . . . . . . . . . . . 1

STUDY AREA. . . . . . . . . . . . . . . . . . . . . . . . 3

METHODS. . . . . . . . . . . . . . . . . . . . . 8

Seining . . . . . . . . . . . . . . . . . . 8

Gillnetting . . . . . . . . . . . . . . . . . . 8

Trawling. . . . . . . . . . . . . . . . . . . . 8

Missing Samples... . . . . . . . . . . . . . . 10

Impingement . . . . . . . . . . . . . . . . . . . 10

Game Fish Population Study. . . . . . . . . . . . . . . 11

Fish Larvae Tows. . . . . . . . . . . . . . . . . 12

Sled Tows . . . . . . . . . . . . . . . . . . 18

Entrainment .. . . . . . . . . . . . . . . . . . . 18

Production Foregone Estimates Due to Entrainment and

Impingement. . . . . . . . . . . . . . . . 20

Fish Egg and Larvae Processing. . . . . . . . . . . . . 30

Fish Larvae Total Length-Body Depth Relationship. . . . . . . 31

Laboratory Analysis of Juvenile and Adult Fish. . . . . . . . 32

Data Processing and Calculations. . . . . . . . . . . . 32

Definition of Terms . . . . . . . . . . . . . . . . . 33

Statistics.... . . . . . . . . . . . . . . 34

RESULTS AND DISCUSSION. . . . . . . . . . . . . . . . . 35

Statistics. . . . . . . . . . . . . . . 35

Adult and Juvenile Fish . . . . . . . . . . . . . 60

Major Species. . . . . . . . . . . . . . . 70

Alewife. . . . . . . . . . . . . . . 70

Rainbow Smelt.................... 102

Spottail Shiner. . . . . . . . . . . . . . . 130

Unidentified Coregoninae . . . . . . . . . . . 160

Yellow Perch . . . . . . . . . . . . . . . 176

Golden Shiner. . . . . . . . . . . . . . 205

Trout-perch. . . . . . . . . . . . . . . . 211

Bluntnose Minnow .................. . 231

Johnny Darter. . . . . . . . . . . . . . . . 237

Largemouth Bass. . . . . . . . . . . . . . . 243

Emerald Shiner.................... 251

Black Crappie. . . . . . . . . . . . . . . 261

Pumpkinseed. . . . . . . . . . . . . . . . 266

Minor Species. . . . . . . . . . . . . . . . . 268

Ninespine Stickleback. . . . . . . . . . . . 268

White Sucker . . . . . . . . . . . . . 272

Slimy Sculpin. . . . . . . . . . . . . . . 274

Lake Trout ....................... 277 
Gizzard Shad. . . . . . . . . . . . . . 280

Brown Trout . . . . . . . . . . . . . . 282

Brook Silverside. . . . . . . . . . . . . 284

Rock Bass . . . . . . . . . . . . . . . . 284

Coho Salmon . . . . . . . . . . . . . . 286

Longnose Sucker . . . . . . . . . . . . . . 287

Bluegill. . . . . . . . . . . . . . . . 288

Banded Killifish. . . . . . . . . . . . . . 290

Northern Pike . . . . . . . . . . . . . 290

Chinook Salmon. . . . . . . . . . . . . 293

Carp. . . . . . . . . . . . . . . . . 294

Tadpole Madtom. . . . . . . . . . . . . . 295

Smallmouth Bass .................. 296

Rainbow Trout ... . . . . . . . . . . 297

Bowfin. . . . . . . . . . . . . . . . 298

Round Whitefish . . . . . . . . . . . 298

Lake Whitefish. . . . . . . . . . . . . 299

Walleye . . . . . . . . . . . . . . . . 299

Yellow Bullhead . . . . . . . . . . . . . 300

Brown Bullhead. . . . . . . . . . . . . . 301

Golden Redhorse . . . . . . . . . . . . . 302

Burbot. . . . . . . . . . . . . . . 302

Fathead Minnow. . . . . . . . . . . . . 303

Grass Pickerel. . . . . . . . . . . . . 303

Silver Redhorse . . . . . . . . . . . . 303

Mottled Sculpin . . . . . . . . . . . . . 304

Quillback................... . 304

Shorthead Redhorse. . . . . . . . . . . 304

Channel Catfish . . . . . . . . . . . . 305

Creek Chub. . . . . . . . . . . . . . . 305

Black Bullhead. . . . . . . . . . . . . 306

Common Shiner . . . . . . . . . . . . . . 306

Goldfish. . . . . . . . . . . . . . . . 306

Sand Shiner .. . . . . . . . . . . . 307

Warmouth. . . . . . . . . . . . . 307

Iowa Darter . . . . . . . . . . . . . 307

Lake Chubsucker . . . . . . . . . . . . 308

Freshwater Drum . . . . . . . . . . . . . 308

Central Mudminnow . . . . . . . . . . . 308

White Crappie . . . . . . . . . . . . . 309

Blackside Darter. . . . . . . . . . . . . 309

Logperch. . . . . . . . . . . . . . . 309

Pirate Perch................... 309

Sea Lamprey . . . . . . . . . . . . . . . . 310

Chestnut Lamprey. . . . . . . . . . . . . . 310

Spotted Gar . . . . . . . . . . . . . . . 310

Green Sunfish . . . . . . . . . . . . . 310 
Impingement. . . . . . . . . . . . . . . . . . 311

Game Fish Population Study . . . . . . . . . . . . 326

Fish Larvae and Entrainment Study. . . . . . . . . . . 330

Alewife . . . . . . . . . . . . . . . . 331

Cyprinidae Complex. . . . . . . . . . . . . . . 367

Unidentified Cyprinidae . . . . . . . . . . 367

Spottail Shiner . . . . . . . . . . . . . 384

Bluntnose Minnow. . . . . . . . . . . . . 389

Golden Shiner . . . . . . . . . . . . . 389

Emerald Shiner. . . . . . . . . . . . . 389

Carp. . . . . . . . . . . . . . . . 390

Goldfish. . . . . . . . . . . . . . . 395

Yellow Perch. . . . . . . . . . . . . . . . 396

Centrarchidae Complex . . . . . . . . . . . . 415

Black Crappie . . . . . . . . . . . . . . 416

Unidentified Pomoxis spp. . . . . . . . . . . 416

Unidentified Lepomis spp. . . . . . . . . . . . . 417

Pumpkinseed . . . . . . . . . . . . . 4 420

Bluegill. . . . . . . . . . . . . . . 422

Largemouth Bass . . . . . . . . . . . . 4422

Smallmouth Bass . . . . . . . . . . . . 422

Rainbow Smelt . . . . . . . . . . . . . . . 423

Burbot. . . . . . . . . . . . . . . . . 4445

Trout-perch . . . . . . . . . . . . . . . . 456

Fourhorn Sculpin. . . . . . . . . . . . . . 457

Unidentified Cottidae. . . . . . . . . . . . . 457

Johnny Darter .. . . . . . . . . . . . . . . 459

Ninespine Stickleback . . . . . . . . . . . . 459

Unidentified Coregoninae. . . . . . . . . . . . . . 460

Unidentified Catostomidae . . . . . . . . . . . . 460

Logperch. . . . . . . . . . . . . . . . . 4461

Gizzard Shad. .. . . . . . . . . . . . . 4 461

Brook Silverside. . . . . . . . . . . . . . 462

Brown Bullhead. . . . . . . . . . . . . . . 462

Damaged Larvae. . . . . . . . . . . . . . . 462

Unidentified Pisces . . . . . . . . . . . . . 482

Fish Eggs . . . . . . . . . . . . . . . . . 4 483

Yearly Entrainment Summary. . . . . . . . . . . . 495

Fish Larvae Total Length-Body Depth Relationship . . . . . . 502

Production Foregone Estimates due to Entrainment and

Impingement . . . . . . . . . . . . . . . 508

GENERAL SUMMARY AND CONCLUSIONS. . . . . . . . . . . . . 550

LITERATURE CITED . . . . . . . . . . . . . . . . . . 559

APPENDIXES . . . . . . . . (Microfiche - Inside Back Cover) 

INTRODUCTION

Presented herein is a detailed discussion of data derived from our 1978 field monitoring of larval, juvenile and adult fish in the vicinity of the J.H. Campbell Plant. These results will be integrated with 1977 data, which were incomplete because sampling was initiated in May. These data, and those from 1979 will form the basis for ascertaining effects of the present onshore water intake and discharge of Units 1 and 2 on Pigeon Lake and Lake Michigan fish populations. They will also form the preoperational data base for evaluating the aquatic impact of a new unit, Unit 3, presently under construction. This new unit will have offshore water intake and discharge structures and our data will be used to evaluate the potential effect of this unit as well as documenting impacts the plant may have, if any, after Unit 3 achieves "on-line" status. This report is concerned with establishing patterns of behavior and distribution for larval, juvenile and adult fish. Plant effects are evaluated through our entrainment, impingement and production foregone studies. A separate report (Winnell and Jude 1979) characterizes the benthos and sediments in the study area.

During 1978, field distributions of larval fish were monitored in Lake Michigan and in Pigeon Lake. Entrained fish larvae were also sampled regularly from the discharge canal of the plant. The diel pattern of entrainment was documented, and an estimate of the weekly entrainment rates calculated based on water flow through the plant. Adult fish populations were examined both in Lake Michigan (using trawls, gill nets and seines) and in Pigeon Lake (using gill nets and seines) to determine the spatial and temporal distribution of fish species in the area, when and possibly where they spawn, whether Pigeon Lake is used as a spawning ground and nursery area and what important or endangered species inhabit the Campbell Plant environs.

Adult and juvenile fishes which come in with the cooling water and are collected on the Campbell Plant traveling screens were monitored for one 24-h period each week. Abundance, species composition, sex and breeding condition of these fish were determined and weekly projections of total impingement based on time were made. To complement the impingement results, we conducted a study to derive a population estimate for largemouth bass and northern pike in Pigeon Lake. These estimates, derived from mark and recapture techniques, will be used to evaluate the significance of the loss through impingement of these important sport fish. To put into perspective the meaning of entrainment of larval fish and impingement of adult fish, we constructed a model which calculates the "production foregone" due to these fish losses. The model was used to generate estimates of biomass which would have been produced, had the fish lost been allowed to complete their life cycle. Sensitivity analyses and comparisons of these biomass loss estimates were contrasted with commercial fish catch statistics for each species affected.

Along with the growing need for electrical power is the concomitant requisite to evaluate the environmental costs of producing that power. This report is an attempt to supply the information necessary to evaluate the present impact of two operating units and hopefully provide data to assist in the 
decisions regarding the third. Results of this study will document the spatial and temporal distributions of fish larvae and juvenile and adult fish and establish the magnitude of entrainment and impingement at the J.H. Campbe11 Plant. 
The J.H. Campbell Power Plant is located on the eastern shore of Lake Michigan in Port Sheldon Township (T6N, R6W) Ottawa County, Michigan (Fig. 1). Land immediately surrounding the $3.24 \mathrm{~km}^{2}$ site is classified as "dune" area and is characterized by high sand dunes and bluffs (U.S. Army Corps of Engineers 1971). Within an $8-\mathrm{km}$ radius of the plant, land is used primarily for agriculture and forestry. The aquatic habitat immediate to the plant exhibits considerable variation.

Situated directly south of the plant is Pigeon Lake, the natural collecting basin for the Pigeon River before it enters Lake Michigan. The drainage area of the Pigeon River (approximately $155 \mathrm{~km}^{2}$ ) supplies an average flow of 1.12-1.26 m3/s to Pigeon Lake (Water Resources Commission 1968). The power plant water usage of $18.7 \mathrm{~m} 3 / \mathrm{s}$ for cooling condensers causes the natural flow of Pigeon Lake into Lake Michigan to be directed through the plant. Lake Michigan water is thus used to supplement Pigeon Lake water which is then drawn into the plant and discharged (after being heated 9-10 C) by way of a canal approximately $1 \mathrm{~km}$ north of the entrance of Lake Michigan to Pigeon Lake. Two stone jetties ( 366 --m long) were constructed at the entrance of Lake Michigan to Pigeon Lake to maintain a passage from Pigeon Lake to Lake Michigan and thus ensure adequate flow of intake water to the plant. During winter months, this channel is kept from icing over by recirculation of discharge water from the plant. Heated water is piped along the north jetty and released into the canal.

The shoreline of Pigeon Lake reflects the general use of the lake as a recreational resource. A public access boat ramp maintained by the Michigan Department of Natural Resources (MDNR), as well as privately-owned ramps and docks are used extensively during spring, summer and fall. Undoubtedly much of the navigational use of Pigeon Lake is due to its access to Lake Michigan. The depth of Pigeon Lake (0.3-1.2 m for more than one-third of its area) as we11 as its extensive aquatic vegetation preclude extensive use by all but shallow-draft vessels. The deepest part of the lake, located in the western portion, is $7.5 \mathrm{~m}$; there is a moderately deep channel $(2.1-5.7 \mathrm{~m})$ following the southern shoreline, which accomodates many docking facilities.

Lake surveys conducted by MDNR as well as sporadic newspaper accounts indicate that Pigeon Lake is heavily fished in winter months with notable success. The river connected to Pigeon Lake also sustains a sport fishery. In October 1964, the river and its tributaries were treated to control sea lampreys. Stream surveys conducted by the MDNR in 1969 on Pigeon River (T6N, R15W) indicated populations of brown trout were present.

In order to concentrate our sampling efforts in areas which had more potential for being affected by the Campbe11 Plant, the sampling scheme used during 1977 (Jude et a1. 1978) was modified for the 1978 field season. In Pigeon Lake, this resulted in the deletion of stations $\mathrm{T}$ and $\mathrm{Y}$ which are influenced by the Pigeon River (Fig. 2). Although these stations provided valuable information as to the more riverine species which occasionally entered Pigeon Lake, it was deemed unnecessary to monitor these stations for an additional year. 


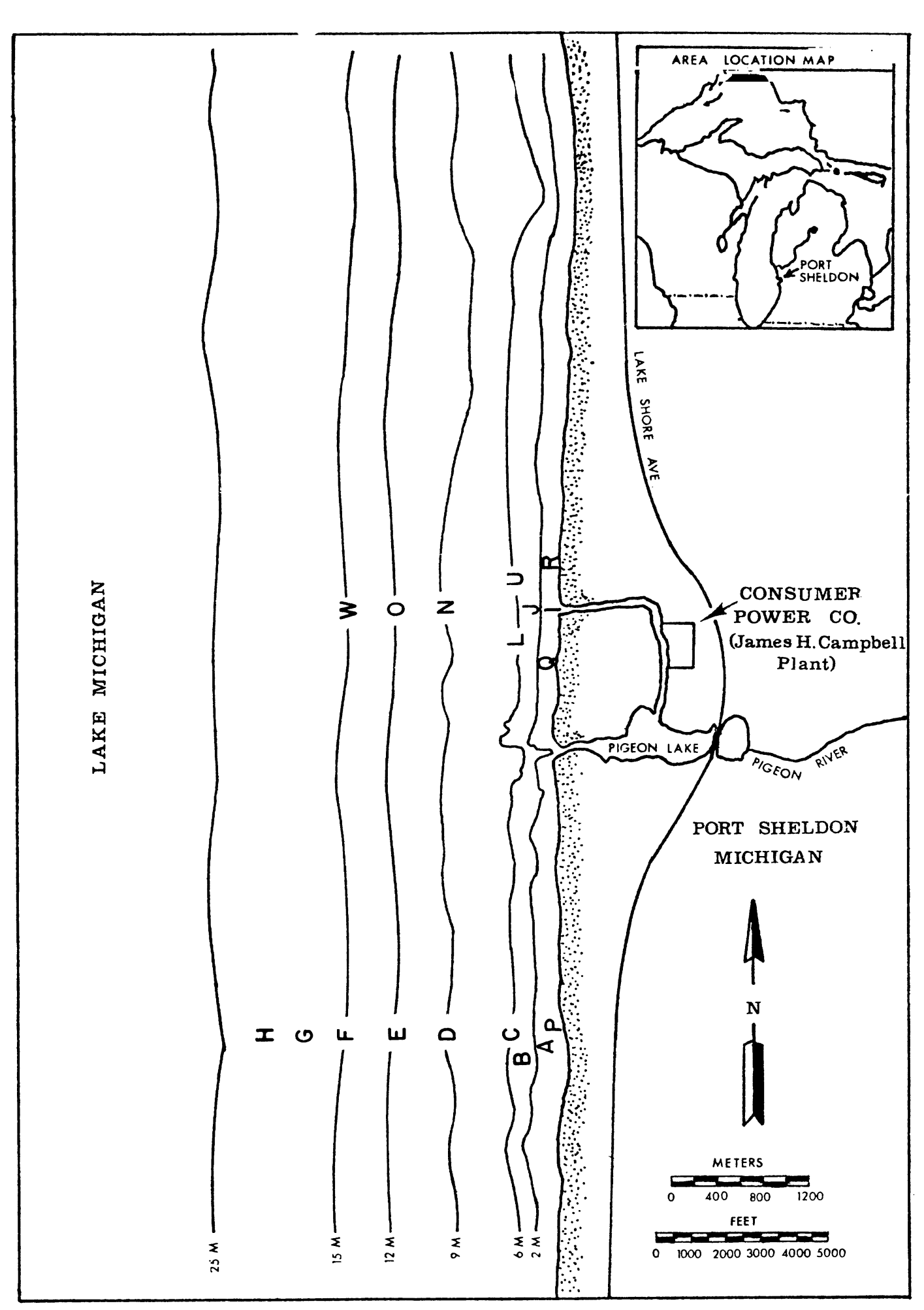

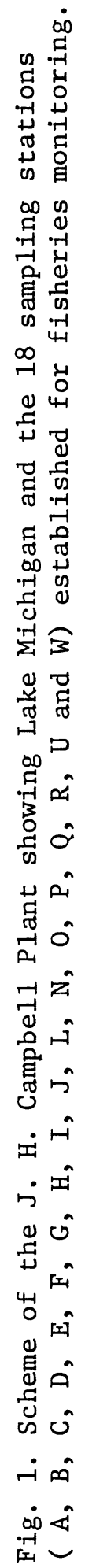




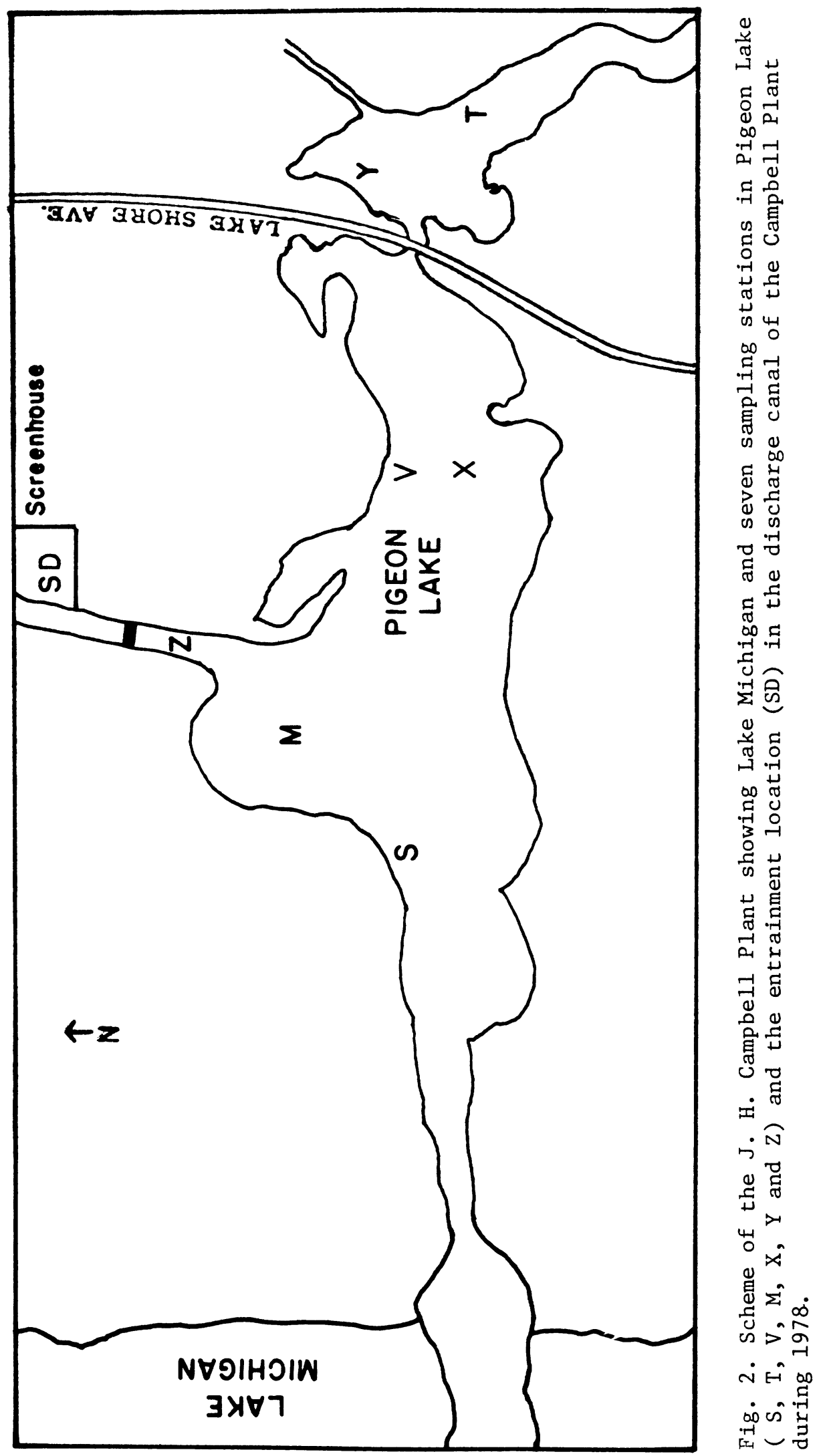


Sampling during 1978 was continued in the "undisturbed" part of Pigeon Lake which included beach station $V$ and open water station X (Fig. 2). Vegetation was dense at these stations during late spring-autumn, and the bottom type was composed of soft peat (Consumers Power 1975). Two additional stations ( $M$ and $S$ ), influenced by inflowing Lake Michigan water, were also located in Pigeon Lake. Station M (Fig. 2) was approximately $7 \mathrm{~m}$ deep and lacked the dense vegetation observed at station $X$. Due to activities of Bultema Dock and Dredge Company, the area designated as beach station $S$ during 1977 (Jude et al. 1978) was relocated approximately $100 \mathrm{~m}$ further along the Pigeon Lake shoreline toward Lake Michigan (Fig. 2). As during 1977, this beach station had a fine-sand bottom and steep slope, which restricted the seinable shoreline. In general, the characteristics of this station were comparable to its 1977 counterpart with the possible exception of less vegetation at the modified site.

One open water station was located in the intake canal (station $\mathrm{Z}$ Fig. 2) which connects Pigeon Lake with the plant's present (Units 1 and 2) cooling water system. This station was established to monitor numbers of larval fish and eggs just before they are drawn into the power plant. The intake canal is approximately $400 \mathrm{~m}$ long and $21 \mathrm{~m}$ wide, with a maximum depth of $3 \mathrm{~m}$.

Directly west of the Campbell Plant is the shoreline of Lake Michigan. Again, this water resource finds extensive recreational and navigational use. Fishing in the area of the discharge canal is popular throughout the winter months due to the attraction of fish to the warm water of the discharge area. Swimming in the area of the discharge canal is prohibited due to unpredictable currents. Lake Michigan depth contours run roughly parallel to shore in the immediate area.

Six stations were chosen at a sequence of depth contours approximately $3.1 \mathrm{~km}$ south of the power plant in Lake Michigan (Fig. 1). This reference transect was chosen for its position outside the influence of the present and projected thermal plume and intake channel. Data from these stations are invaluable in describing "normal" trends in fish distribution occurring in Lake Michigan. Stations A - F (south transect) ranged in depth from $1.5 \mathrm{~m}$ at station $A$ to $15 \mathrm{~m}$ at station $\mathrm{F}$, with intervening stations $\mathrm{B}$ to $\mathrm{F}$ separated by 3-m depth intervals.

Seven additional stations were chosen in the area immediate to the present and proposed discharge (Fig. 1). This transect was chosen to monitor fish distribution in the area affected by the present discharge and potentially affected by the proposed discharge. Stations I, J, L, N, O, U and W (north transect) ranged in depth from $1.5 \mathrm{~m}$ at station $I$ to $15 \mathrm{~m}$ at station $W$. Two $6-\mathrm{m}$ stations were chosen at this north transect. Station L $(6 \mathrm{~m})$, located approximately $0.3 \mathrm{~km}$ south of the proposed discharge, and station $\mathrm{U}(6 \mathrm{~m})$ approximately $0.3 \mathrm{~km}$ north of the discharge were chosen to aid in monitoring the projected thermal plume and its effect on pelagic fish movement. Station $\mathrm{U}$ will be referred to as $6 \mathrm{~m}-\mathrm{N}$ discharge throughout the text. Station $\mathrm{L}$ will be referenced as $6 \mathrm{~m}-\mathrm{N}$, except when referring to surface gill nets when for clarity it will be designated $6 \mathrm{~m}-\mathrm{S}$ discharge. 
of the three Lake Michigan beach stations established, one (station P Fig. 1) was chosen in the vicinity of the south open water transect (approximately $3.1 \mathrm{~km}$ south of the plant) to act as a reference station in the shoreline area.

The two additional stations in the vicinity of the present discharge canal (station Q approximately $0.6 \mathrm{~km}$ south of the discharge and station $R$ approximately $0.6 \mathrm{~km}$ north of the discharge - Fig. 1) aid in monitoring the present thermal plume and its effect on shoreline fish movements.

Sampling of benthic macroinvertebrates and sediments in Lake Michigan in the vicinity of the J.H. Campbell Plant was also conducted on three dates in 1978: 18 April, $20 \mathrm{July}$ and 17 October. Results are presented in a separate publication (Winnell and Jude 1979). 
METHODS

SEINING

Seining was performed using a $0.6-\mathrm{cm}(.25-\mathrm{in})$ mesh nylon seine, $15.2 \mathrm{~m}$ $\mathrm{x} 1.8 \mathrm{~m} \mathrm{(50} \mathrm{ft} \mathrm{x} 6 \mathrm{ft}$ ) including a $1.8-\mathrm{m}(6-\mathrm{ft})$ bag. The seine was hauled parallel to shore for a distance of $61 \mathrm{~m}$ (200 ft). Duplicate non-overlapping hauls were performed both day and night at all seining stations. Monthly seining was performed from April through November at three beach stations in Lake Michigan and two beach stations in Pigeon Lake (Table 1 and Figs. 1 and 2).

In Lake Michigan hauls were performed against the current, when possible. During times when waves and current did not permit seining against the current, hauls were made in the direction of the current. Pigeon Lake stations had very little current, and the direction of seining was southwest to northeast at station $\mathrm{V}$ and north to south at station $\mathrm{S}$.

\section{GILLNETTING}

Nylon experimental gill nets $36.6 \mathrm{~m} \mathrm{x} 1.8 \mathrm{~m}$ (120 ft $\times 6 \mathrm{ft}$ ) were set once a month for approximately $12 \mathrm{~h}$ during daylight and $12 \mathrm{~h}$ during the night. Each gill net was composed of 12 panels, with each panel starting at $1.3-\mathrm{cm}$ (.5-in) bar mesh and proceeding in $0.6-\mathrm{cm}(.25-\mathrm{in})$ increments up to $7.6-\mathrm{cm}$ (3-in) mesh, with the last panel having 10.2-cm (4-in) mesh. Two of these nets fastened end to end were set together and considered replicates. All gill nets were set parallel to shore in Lake Michigan and perpendicular to shore in Pigeon Lake. In Lake Michigan, bottom gill nets were set at the 1.5-, 3-, 6-, 9- and 12-m depth contours on the reference transect $3.1-\mathrm{km}$ south of the plant (also referred to as the south transect) and at the 6-m depth contour opposite the present discharge channel (Table 1 and Fig. 1). Surface gill nets, which were identical to bottom gill nets except for additional floats, were set in Lake Michigan at the 6-m station at the south transect and at two 6-m stations off the present discharge channel. Surface gill net sets at the 9- and 12-m south transect stations, which were set from June-August 1977, were discontinued during 1978. In Pigeon Lake, bottom gill nets were set at open water station M (6 m) (Table 1 and Fig. 2).

\section{TRAWLING}

Bottom trawling was performed monthly from April through December in Lake Michigan using the University of Michigan's R/V Mysis. All trawls were made at an average speed of $4.8 \mathrm{~km} / \mathrm{h}(3 \mathrm{mph})$. Duplicate 10 -min hauls were performed at the 6-,9-, 12- and 15-m depth contours on a transect $3.1 \mathrm{~m}$ south of the plant and at the $6-\mathrm{m}$ and $9-\mathrm{m}$ depth contours between the present discharge channel and the Pigeon Lake entrance to Lake Michigan (Table 1 and Fig. 1). Hauls were performed at $3 \mathrm{~m}$ at the south transect during periods of reduced wave height. Trawling was done once during the day and once at night at all stations. A semi-balloon, nylon otter trawl having a 4.9-m (16-ft) headrope and a 5.8-m $(19-f t)$ footrope was used. The body and cod end of the net were composed of 
$1.9-\mathrm{cm}(0.75-\mathrm{in})$ and $1.6-\mathrm{cm}(0.62-\mathrm{in})$ bar mesh respectively, while the cod end interliner was $0.63-\mathrm{cm}(0.25-$ in $)$ stretch mesh. All trawl hauls were taken parallel to shore following the station depth contour. Two replicate samples were obtained at each station by once trawling south to north and then trawling north to south.

Table 1. Proposed monthly sampling series for adult fish at selected stations in Pigeon Lake and Lake Michigan near the J. H. Campbell Plant, Port Sheldon, Michigan, 1978.

\begin{tabular}{cclll}
\hline \multicolumn{5}{c}{ Maximum } \\
Station & $\begin{array}{l}\text { Beach } \\
\text { Depth (m) }\end{array}$ & $\begin{array}{l}\text { Surface } \\
\text { Seining } \\
\text { Gillnetting }\end{array}$ & $\begin{array}{l}\text { Bottom } \\
\text { Gillnetting }\end{array}$ & $\begin{array}{l}\text { Bottom } \\
\text { Trawling }\end{array}$ \\
\hline Pigeon Lake & & & & \\
M & 6.0 & & $\mathrm{X}$ & \\
$\mathrm{S}$ & 1.5 & $\mathrm{X}$ & & \\
$\mathrm{V}$ & 1.5 & $\mathrm{X}$ & &
\end{tabular}

Lake Michigan

\begin{tabular}{|c|c|c|c|c|}
\hline A & 1.5 & & & $\mathrm{X}$ \\
\hline B & 3.0 & & & $\mathrm{X}$ \\
\hline$C$ & 6.0 & & $\mathrm{X}$ & $\mathrm{X}$ \\
\hline D & 9.0 & & & $\mathrm{X}$ \\
\hline $\mathrm{E}$ & 12.0 & & & $\mathrm{X}$ \\
\hline $\mathrm{F}$ & 15.0 & & & \\
\hline $\mathrm{U}$ & 6.0 & & $\mathrm{X}$ & \\
\hline $\mathrm{L}$ & 6.0 & & $\mathrm{x}$ & $\mathrm{X}$ \\
\hline $\mathrm{N}$ & 9.0 & & & \\
\hline$P$ & 1.5 & $\mathrm{X}$ & & \\
\hline Q & 1.5 & $\mathrm{x}$ & & \\
\hline $\mathrm{R}$ & 1.5 & $\mathrm{X}$ & & \\
\hline
\end{tabular}

$\mathrm{X}=$ Duplicate sampling (seines, gill nets or trawls). 
MISSING SAMPLES

The proposed monthly sampling series for Pigeon Lake and Lake Michigan consisted of 28 trawl hauls, 14 duplicate gill net sets, 6 duplicate surface gill net sets and 20 beach seine hauls. While it was hoped that proposed fishing could be performed every month, this was not always possible due to inclement weather, accidents or construction activity in the area. Within reasonable time constraints, effort was made to reschedule sampling which was deleted because of inclement weather. Unfortunately, 10 samples were lost before they could be examined. For consistency of computer filing programs, these samples were carefully reconstructed from field record sheets which were filled in when samples were collected. Data from fish collected at similar times and locations (replicates) as those in lost samples, were used to reconstruct missing length, weight and sexual condition data. Fo1lowing is a summary of samples missing from the proposed monthly sampling series in 1978 (number of missing observations in parentheses, reconstructed samples marked by an asterisk):

1. April - night trawls at L (2), day gill net at $A^{*}$ (1), day surface gill nets at $U$ (2).

2. May - night gill net at $M^{*}(1)$.

3. June - night traw1 at $N^{*}(1)$.

4. July - day surface gill net at $U^{*}$ (1), night surface gill net at L (1).

5. August - day traw1 at $B *(1)$.

6. October - night traw1 at $D^{*}(1)$, day seines at $\mathrm{P}^{*}$ and $\mathrm{S}^{*}(2)$.

7. November - day gill nets at $B^{*}$ and $E^{*}(2)$, night surface gill nets at $\mathrm{C}, \mathrm{L}$ and $\mathrm{U}(6)$.

\section{IMPINGEMENT}

Impingement sampling at the J.H. Campbell Plant was conducted once per week for $24 \mathrm{~h}$ from January through December 1978. Four samples covering each 24-h period were designated as follows; day - 0900 to 1700 , dusk - 1700 to 2200, night - 2200 to 0500 and dawn - 0500 to 0900. Projected monthly impingement totals were calculated based on weekly samples. An average daily total for our sampling dates each month was determined and then multiplied by the number of days in the month.

Intake screens were washed immediately prior to the beginning of the first sampling period (day). Screens were then washed and samples collected at 1700, 2200, 0500 and 0900 during the period from April to December. During January, February, March and one period in November, fish were collected only once (rather than four times each week), $24 \mathrm{~h}$ after washing the screens. Fish were processed in the same manner as fish collected in field samples (see METHODS - LABORATORY ANALYSIS OF JUVENILE AND ADULT FISH).

Condenser cooling water for Campbell Units 1 and 2 is obtained via a 400-m long intake canal extending from the plant to Pigeon Lake. The intake structure is located on the east side of the forebay which is at the north end of the intake channel. Vertical iron trash bars spaced $60 \mathrm{~mm}$ (2 3/8 in) apart 
are located at the face of the screenhouse. The intake screens consist of two Rex Traveling Screens (Rex Chain Belt, Inc.), located in the screenhouse.

Condenser cooling water for Unit 1 is provided by two vertical Peerless pumps (mode1 66MF) rated at $227 \mathrm{~m}^{3} / \mathrm{min}(60,000 \mathrm{gpm})$ at a head of $7.3 \mathrm{~m}$ and $290 \mathrm{rpm}$. Cooling water for Unit 2 is obtained with two vertical Foster-Wheeler pumps (type 60MFA4) which provide $341 \mathrm{~m}^{3} / \mathrm{min}(90,000 \mathrm{gpm})$ each at a head of $7 \mathrm{~m}$ and $352 \mathrm{rpm}$. An average of 1,634,000 $\mathrm{m}^{3}$ of water per day was pumped in 1978.

Fish and debris collected on the traveling screens are removed by rotating and washing the screens with a high-pressure water spray. Fish and debris removed fall into a concrete sluiceway and travel to a central collection basket. The cooling water, after passing through the condensers is discharged to Lake Michigan via a 1097-m 1ong, 21-m wide discharge canal.

In winter, a warm-water recirculation system pumps warm discharge water to the Pigeon Lake jetties (which extend into Lake Michigan) to prevent ice build-up that can restrict cooling water availability from Lake Michigan. A two-speed pump is employed that carries either $132 \mathrm{~m} 3 / \mathrm{min}(35,000 \mathrm{gpm})$ or $265 \mathrm{~m} 3 / \mathrm{min}(70,000 \mathrm{gpm})$. Pumping normally begins when inlet temperature drops below $4 \mathrm{C}$.

\section{GAME FISH POPULATION STUDY}

A mark and recapture study was initiated in 1977 to estimate the population sizes of three species of game fish in Pigeon Lake and to assess impingement effects on these species. Continuing this study, northern pike, largemouth bass and smallmouth bass were marked and released in 1978. Scale samples were taken for northern pike and largemouth bass to establish age-length relationships.

An electrofishing boat (Coffelt Electronics Company Inc. - Model VVP-15) was used to collect most fish. The generator was designed to deliver $300 \mathrm{~V}$, pulsating DC current to minimize the number of deaths due to shocking. Stunned fish were brought aboard by dip net and held in a live-well during recovery. Other gear used to capture fish were hoop nets and hook and line. The hoop net was $106.7 \mathrm{~cm}$ in diameter with $3.8-\mathrm{cm}$ bar mesh in front and $2.5-\mathrm{cm}$ bar mesh in the rear. Wings were 4.6-m long, $1.2-\mathrm{m}$ deep and had 3.8-cm bar mesh netting. The hoop net was set for $24-$ to 48 -h periods during regularly scheduled shocking trips. Fish caught with hook and line were also used in the study. Northern pike greater than $299 \mathrm{~mm}$ total length (TL) and largemouth (and smallmouth) bass greater than $219 \mathrm{~mm}$ TL were tagged with spaghetti tags inserted in the epaxial muscle below the dorsal fin. Spaghetti tags (Floy Tag \& Manufacturing) were designated with individual numbers and the address of Consumers Power Company in Jackson, Michigan. Smaller pike (175-299 mm) and bass (175-219 mm) were marked by a different fin clip for each sampling period.

Fish were marked during five periods between 6 September 1978 and 25 October 1978. Each period was 2-3 days. All shocking was done at night because of higher catch-per-unit-effort; each trip lasted 4-9 h. Areas in Pigeon Lake which contained high concentrations of fish varied from one collection 
period to the next, but were heavily fished when encountered. Because Pigeon Lake gradually narrows at its upstream end to become Pigeon River and the distinction is by no means exact, an arbitrary upper boundary was designated (Fig. 3). When fish were tagged, the species, length, weight and area of capture were noted. Recaptured fish were examined for tag number and this information recorded with the area of capture. To assess angling mortalities, a collection box was established at the Michigan Department of Natural Resources (MDNR) launching area to recover tags in fish caught by fishermen. No tags were found in the box, but one tag from a smallmouth bass was received in the mail. Observations made during the study period in the Pigeon Lake area indicated little fishing success among the few fishermen seen, even though earlier in the summer, significant angling pressure and greater success was observed. It was assumed that fish mortality during months of the mark and recapture study was low enough to satisfy assumptions (Ricker 1975) necessary to make a population estimate. Scale samples from northern pike and largemouth bass were taken, pressed on plastic slides and read on a scale reader to assess age-length relationships.

\section{FISH LARVAE TOWS}

Fish larvae, arbitrarily defined as any fish less than $2.54 \mathrm{~cm}$ total length, were collected using a $0.5-\mathrm{m}$ diameter, nylon plankton net of no. 2 mesh (363-micron aperture). Larvae were sampled in Pigeon Lake, Lake Michigan and the intake canal of the Campbell Plant. Entrainment samples were taken from the discharge canal of the Campbell Plant. A Rigosha flowmeter (Rigosha and Co. Ltd., 10-4 Kajicho 1-Chome, Chiyoda-Ku, Tokyo, 101 Japan) attached to the center opening of the plankton net was used to calculate volume of water sampled. When flowmeters were not available or stopped functioning, average flowmeter values were computed from readings available from the same stations at other times or from stations of comparable depth. Suspect flowmeter readings were deleted when accuracy was questionable. Out of 1,352 fish larvae samples collected in 1978, 22 either had no flowmeter readings or readings were suspect and required the computation and insertion of an average flowmeter reading. Many of the suspect or lost readings were from beach tows collected in Pigeon Lake. These stations were choked with aquatic macrophytes during most of the summer making net towing without fouling by plants extremely difficult. Three fish larvae tows were poorly preserved with formalin which resulted in the deterioration of the sample and subsequent loss of information. These samples were: $\mathrm{N}-6 \mathrm{~m}$ night, 2 August; W-4 m day, 27 April; and C-4 m night, 1 July 1978. Al1 meter revolutions were converted to volume filtered using 1 revolution $=15$ liters. Flowneters were calibrated in a swimming pool by various personnel walking a measured distance with a flowmeter attached to a $0.5-\mathrm{m}$ diameter hoop without the net (see Jude et a1. 1979).

Duplicate surface tow samples were collected at the seining stations in Lake Michigan ( $\mathrm{P}, \mathrm{Q}$ and $\mathrm{R}-\mathrm{Fig} .1$ ) and Pigeon Lake ( $\mathrm{S}$ and V - Fig. 2). Three people simultaneously hand-towed two nets for a distance of approximately $61 \mathrm{~m}(200 \mathrm{ft})$ in Lake Michigan and $30 \mathrm{~m}$ in Pigeon Lake once during the day and once at night. Beach tows were performed twice in June, July and August and once in April, May and September. Pigeon Lake beach stations were also 


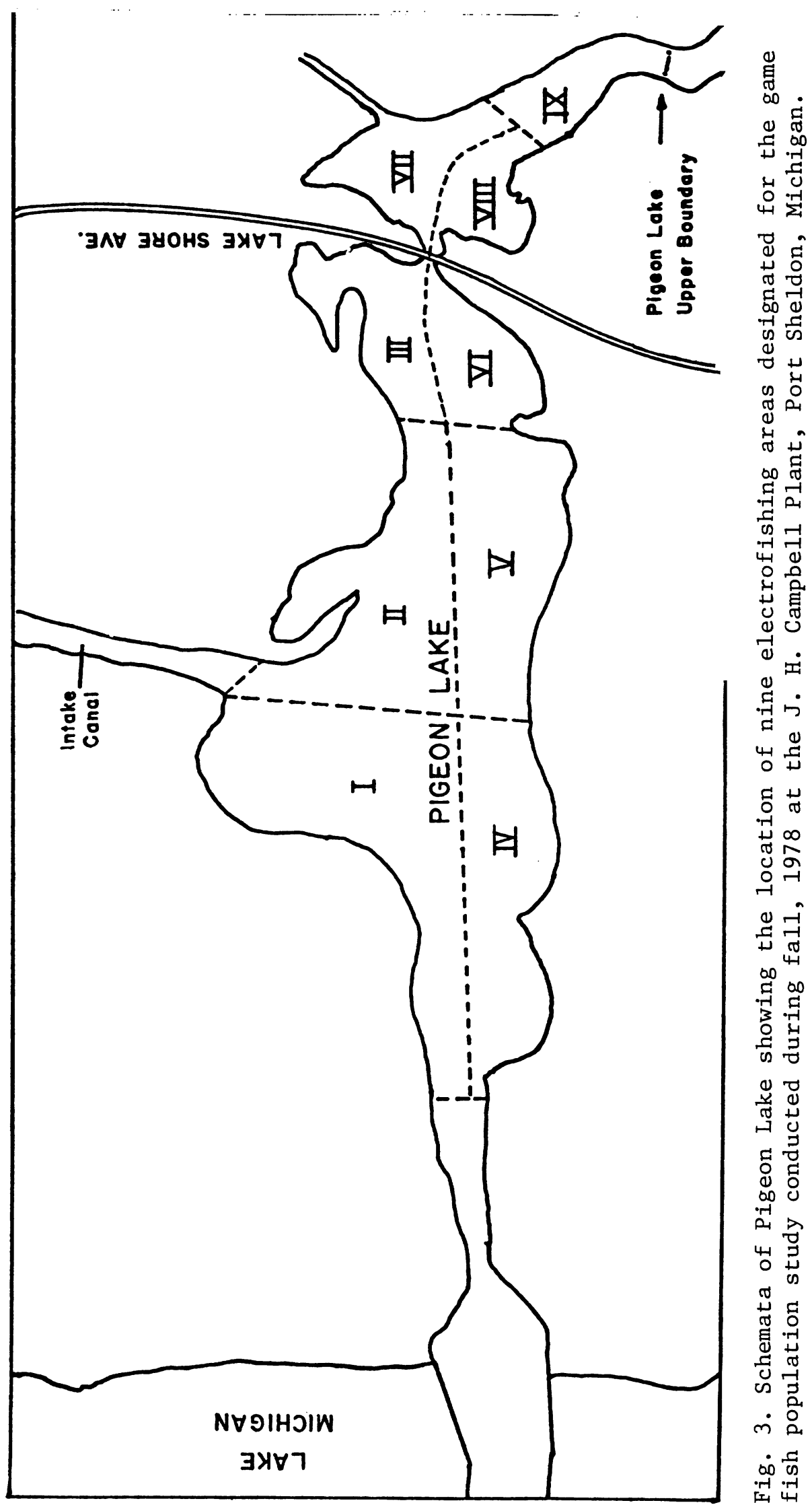


sampled in October and November.

Horizontal 5-min fish larvae tows were also performed at discrete depths parallel to shore at the remaining 2 stations in Pigeon Lake ( $M$ and X), 12 stations in Lake Michigan (A, B, C, D, E, F, I, J, L, N, O and W) and 1 station ( $Z$ ) in the intake canal (see Table 2 for actual depths sampled at each station). Open water fish larvae samples were collected from these selected stations in Lake Michigan and Pigeon Lake during the day and night twice in June, twice in July, twice in August and once in April, May and September.

Larvae tows in Pigeon Lake and the intake canal were collected from a 6-m long outboard motor boat. Open water fish larvae tows in Lake Michigan were collected from the University of Michigan's R/V Mysis as follows:

1) Plankton net with attached mason jar and depressor lowered to desired depth [average ship speed: $3-6 \mathrm{~km} / \mathrm{h}$ or $2-4 \mathrm{mph}$ ]

2) Plankton net towed horizontally for 5 min starting at the desired depth which was obtained by measuring wire angle and trigonometrically calculating the amount of cable to be released to reach desired depth

3) Plankton net hauled to surface and washed using a water hose from the Mysis

4) Contents rinsed into the wide-mouth glass ( 0.47 liter) mason jar, preserved ( $40 \mathrm{~m} 1$ of buffered $10 \%$ formaldehyde), labeled and sealed

Total numbers of larvae captured in all tows (other than surface tows) were adjusted to compensate for upper strata contamination. The adjustment procedure is outlined in Fig. 4. The method consists of sequential subtraction of numbers of larvae from the lower water depth levels based upon densities observed in upper water strata. We assumed that larvae were homogeneously distributed within a water stratum and that nets passing through a particular stratum from a lower level would catch larvae in proportion to the volume of water filtered. Larvae from all tows conducted below the surface stratum which were probably caught during the vertical haul following termination of the horizontal tow, were removed via calculation from the final total larvae density presented. We assumed that contamination occurring while lowering the net was negligible. The effects of differential vertical distribution due to larvae size was mitigated by stratifying larvae from each sample into $0.5-\mathrm{mm}$ length intervals. A total of 5.1 length intervals were defined for fish larvae.

Vertical net hauls, conducted in a 3.6-m deep swimming pool, were used to estimate the volume of water filtered per meter of vertical tow. Mean volume filtered was $0.48 \mathrm{~m}^{3}(28 \pm 0.52 \mathrm{SE}$ revolutions) yielding a correction factor of $0.18 \mathrm{~m}^{3}$ water filtered/meter of vertical haul. An example of this adjustment procedure is presented in Table 3.

Length-frequency histograms were prepared for various combinations of the larval fish data. Data were presented as a percentage of the total based on densities. Thus, collection of two different size larvae $(n=2)$ and presentation of these data would not necessarily yield a histogram showing $50 \%: 50 \%$. 


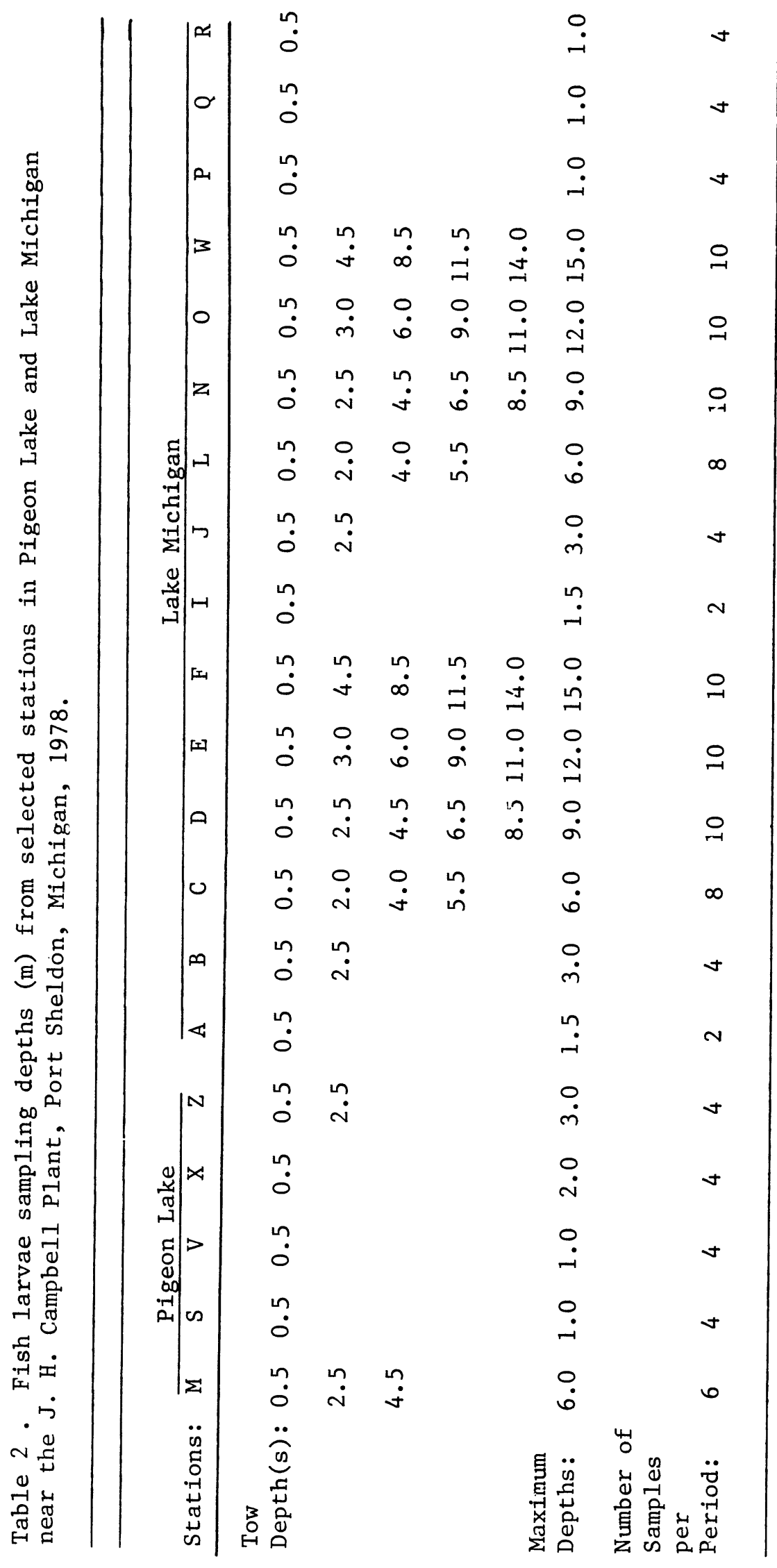




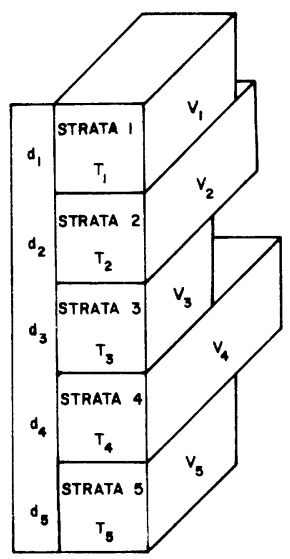

\section{CALCULATION PROCEDURE:}

1. Convert current meter reading to volume filtered $\left(\nabla_{1}\right)$

2. Stratify total larval $\left(\mathrm{T}_{i}\right)$ catch for each sample depth interval into $\mathrm{n} 0.5$-mm length intervals, denoted by $\mathrm{N}_{i}, \mathrm{~m}$.

$$
\text { Thus, } T_{i}=\sum_{m=1}^{n} N_{i, m}
$$

3. Calculate average concentration of larvae of length class $m$ in the first stratum for a11 $\mathrm{m}$.

Thus, $\overline{\mathrm{c}}_{1, \mathrm{~m}}=\left(\mathrm{N}_{1, \mathrm{~m}} / \mathrm{v}_{1}\right) 1000$

4. Begin interative calculation of adjusted average concentrations of larvae for each depth stratum where

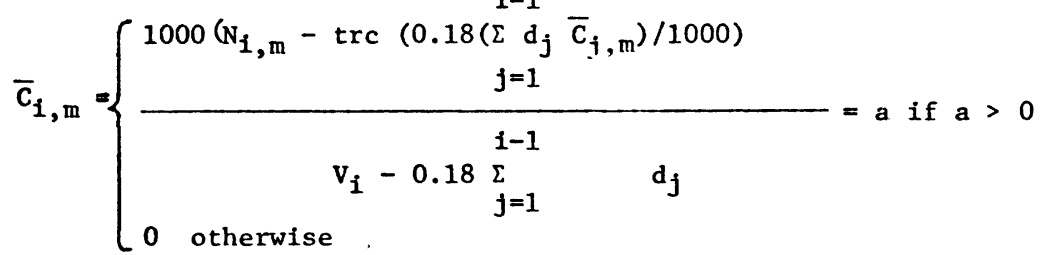

where $d_{i}=$ vertical depth of water in the $i$-th water stratum

$\mathrm{D}=$ total depth of water column 5

$$
D=\sum_{i=1} d i
$$

$T_{i}=$ total uncorrected catch of larvae in the $i$-th water stratum.

$N_{i, m}=$ total uncorrected catch of larvae of the $m$-th size class caught in the i-th water stratum.

$v_{1}=$ estimates volume of water filtered by not towed in stratum $i$.

$(0.18)=$ correction factor expressed in terms of volume of water filtered/meter of vertical tow.

i.e.,

$$
\text { units }=\frac{\mathrm{m}^{3}}{\mathrm{~m}}=\mathrm{m}^{2}
$$

$\operatorname{trc}(\cdot)=$ function which truncates argument to nearest non-negative integer number.

$\mathbf{C}_{\mathbf{1}, \mathrm{m}}=$ adjusted average concentration of larvae of the $\mathrm{m}$-th length class in the $j$-th depth stratum.

Fig. 4. Schematic representation of adjustment calculations for upper level contamination in larvae samples. Blocks represent varying quantities of water filtered in five different water strata. 


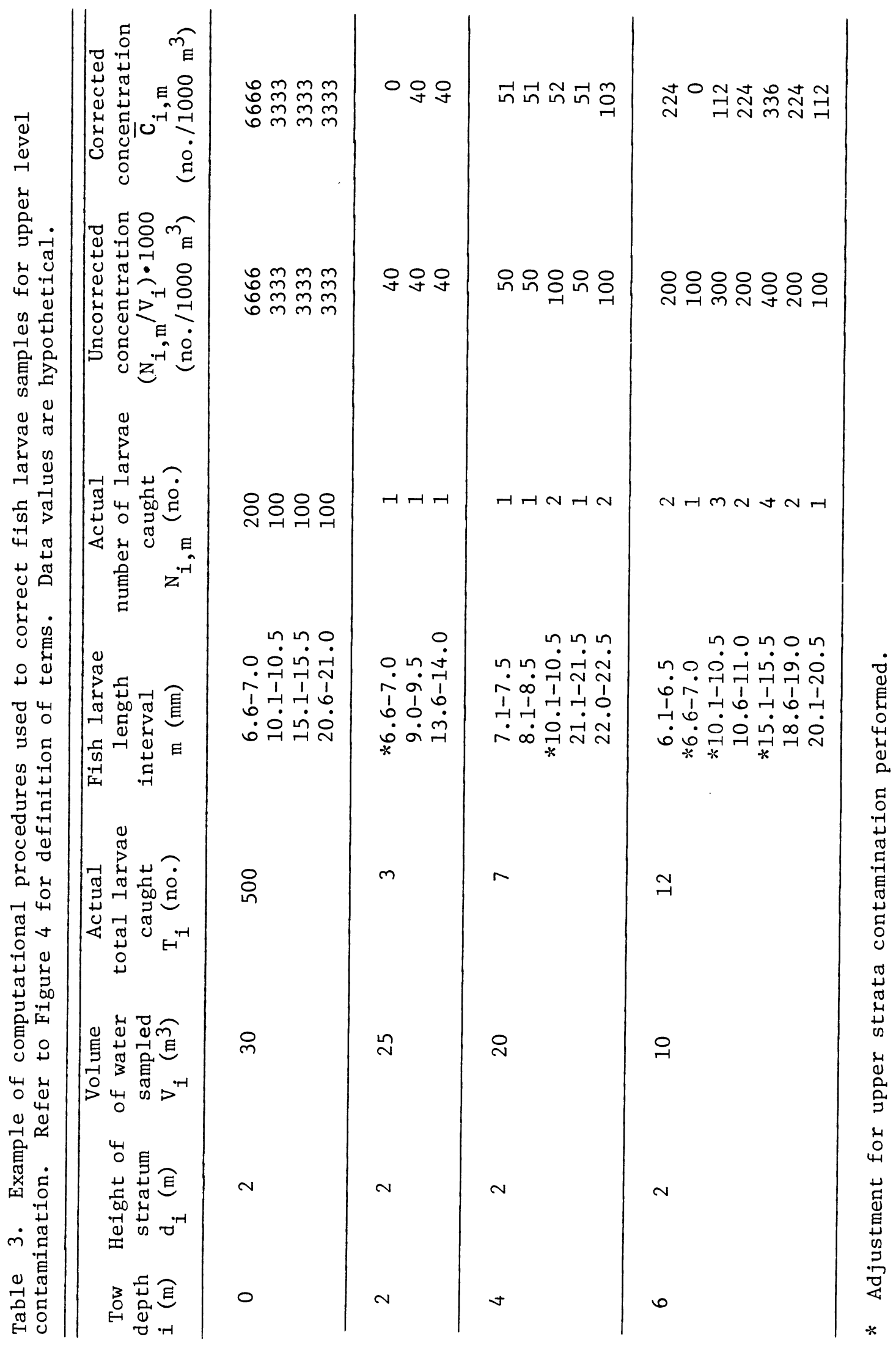




\section{SLED TOWS}

Bottom tows were performed with a benthic fish larvae sled equipped with a flowmeter (Jude et al. 1978) (Fig. 5). A single 5-min sled tow was performed once during the day and once at night at all stations in Lake Michigan when time and weather permitted. Day and night sled tows were conducted coincident with other fish larvae tows at all Lake Michigan stations with the exception of station $\mathrm{R}$ ( $\mathrm{N}$ discharge). No sled tows were taken in Pigeon Lake. One sample from the 14 August 1978 sled tow at night at station $B(1.5 \mathrm{~m}-\mathrm{S})$ was lost due to inadequate sample preservation.

\section{ENTRAINMENT}

Design of the entrainment sampling scheme for the Campbell Project was based on previous experience and physical structure of the intake and discharge forebays at the plant. Condenser cooling water for the Campbe11 Plant is drawn from Pigeon Lake and Lake Michigan via an intake channe1 connecting the plant's present intake structure and the north shore of Pigeon Lake. After passage through either Unit 1 or Unit 2 condensers, cooling water is discharged to Lake Michigan via a discharge channel approximately $1,100-\mathrm{m}$ 1ong, 21-m wide and 2.1-m deep. Water is heated approximately 9-10 C (Consumers Power Co. 1975), then discharged. Weekly entrainment sampling was performed using a net equipped with a flowmeter which was lowered into the condenser discharge canal of either Unit 1 or Unit 2 (contingent upon operation) for $10 \mathrm{~min}$. A heavy weight $(18 \mathrm{~kg}$ ) was necessary to keep the net below the water surface. Four replicates were taken once during the day and once at night on a weekly basis from January to March. From April to September, four replicates were taken weekly once during the dawn, day, dusk and night periods. Samples were also collected during these periods three times during October and November and once during December. The periods of dawn and dusk were defined as $1 \mathrm{~h}$ before and after sunrise and sunset. Sunrise and sunset times were obtained from the Nautical Almanac Office (1978), United States Naval Observatory, Washington, D.C. Daylight and dark hours were calculated also using this information.

Entrainment results were presented as number of fish eggs or larvae entrained per period (four periods per $24 \mathrm{~h}$ ) derived by the formula:

$$
\mathrm{N}=\mathrm{D} \times \mathrm{V} \times \mathrm{T}
$$

where:

$\mathrm{N}=$ number of fish eggs or larvae entrained per period.

$D=$ Density of fish eggs or larvae entrained per $1000 \mathrm{~m}^{3}$ (see METHODS, FISH LARVAE PROCESSING).

$\mathrm{V}=$ volume of water in thousands of $\mathrm{m}^{3}$ pumped per hour by the plant. These values were calculated using plant pump ratings.

$T=$ number of hours of each period at the sampling site located at approximately $43 \mathrm{~N}$ latitude. The number of daylight hours was considered to be the period between $1 \mathrm{~h}$ after sunrise and $1 \mathrm{~h}$ before sunset. The number of hours of darkness was considered to be the 

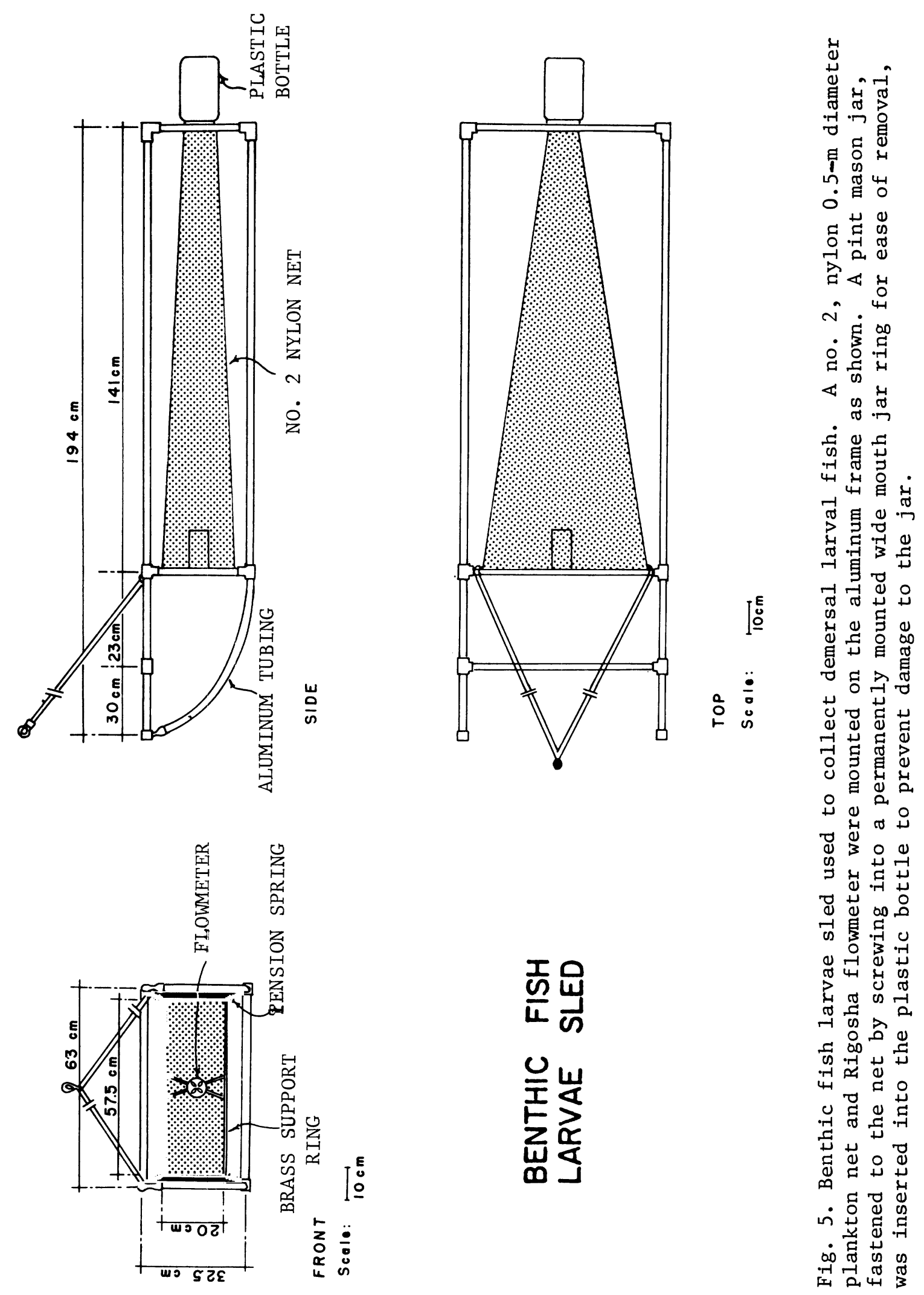
period between $1 \mathrm{~h}$ after sunset and $1 \mathrm{~h}$ before sunrise. The periods of sunrise and sunset were both arbitrarily defined by 2-h duration.

The above calculations were based on the following assumptions:

1) The pumping rate remains constant throughout the 24-h period.

2) The density of eggs or larvae entrained remains the same during each of the four periods. Variations of this density may, however, occur during each diel period.

Total estimated entrainment losses for the entire year were calculated in two different manners, depending in which section the data were used. For the production foregone calculations (see RESULTS - PRODUCTION FOREGONE ESTIMATES DUE TO ENTRAINMENT AND IMPINGEMENT), tota1 entrainment losses were estimated by calculating the average density of each species and group of larvae found in the 16 samples ( 4 day, 4 night, 4 dusk, 4 dawn) collected each week. This average density was then multiplied by the volume of water estimated pumped through the plant (see Appendix 14). For the entrainment section (see RESULTS - YEARLY ENTRAINMENT SUMMARY), a more precise estimate was desired. This was obtained by calculating the average density $(n=4)$ of each species and group of larvae collected in each period (day, dusk, night, dawn). These densities were multiplied by the amount of water pumped through the plant during that period. The total numbers of entrained larvae from each of the four periods (day, dawn, night, dusk) were then summed to get the total loss for each week. Weekly totals were summed to obtain the yearly estimate.

of the 648 entrainment samples collected, flowmeter revolutions were not recorded for 39 samples due to clogging or malfunction of the meter. Average monthly values were used in these cases. Meter revolution data for 114 samples from September were lost when log sheets were inadvertently misplaced. Meter revolution values for dates which had none were obtained by averaging values from dates within the same month for which there were readings, and from days which had comparable flow. Fortunately, few larvae were entrained in september.

\section{PRODUCTION FOREGONE ESTIMATES DUE TO ENTRAINMENT AND IMPINGEMENT}

\section{Int roduction}

The production of a population over a finite interval is defined as the total elaboration of biomass irrespective of its fate (Ivlev 1966). Production includes not only biomass accumulated by those individuals alive at the end of the time interval, but also biomass of those individuals who died before the end of the time interval. Thus, production results from the interaction of two fundamental processes: growth and mortality. The actual mechanisms underlying the interactions of growth and mortality are very complicated and little understood. A number of methods have been devised which permit easy estimation of production by assuming that growth and mortality are independent processes which act in a linear or exponential fashion. See Chapman (1973) for an introduction 
to methods of estimating production. Production losses due to Campbell Plant operation were calculated using the procedure given in Ricker (1975, pp. 16-18). In this procedure, growth and mortality are assumed proportional to the weight of an average individual and number of individuals at time $t$ respectively.

$$
\begin{aligned}
& \frac{d \bar{W}}{d t}=G \bar{N} \\
& \frac{d N}{d t}=-Z N
\end{aligned}
$$

Where $\bar{W}=$ average weight of an individual $(N \bar{W}=B)$

$\mathrm{G}=$ instantaneous rate of increase in weight

$\mathrm{N}=$ number of individuals

$\mathrm{Z}=$ instantaneous rate of mortality

$B=$ total biomass at time $t, B=N W$

In integrated form average weight and population size change as exponential functions of time as presented below:

$$
\begin{aligned}
& \bar{W}_{t}=\bar{W}_{0} e^{G t} \\
& N_{t}=N_{0} e^{-Z t}
\end{aligned}
$$

Where $\bar{W}_{t}=$ average weight of individual at time $t$

$$
\begin{aligned}
& \overline{\mathrm{W}}_{\mathrm{O}}=\text { average weight of individuals at time } t \\
& \mathrm{~N}_{\mathrm{t}}=\text { number of individuals at time } \mathrm{t} \\
& \mathrm{N}_{\mathrm{O}}=\text { number of individuals at time } \mathrm{o}
\end{aligned}
$$

Given these expressions for $\bar{W}$ and $N$, the production of biomass over an interval $\Delta t$ is given by:

$$
\mathrm{P}=\overline{\mathrm{GB}}
$$

Where $\mathrm{P}=$ production or total growth in weight of fish during the year including growth in the part of the population which dies before the year is finished

$\bar{B}=$ average biomass of the age class over the interval of production. Since biomass (B) is the product of mean weight $(\bar{W})$ and numbers $(N)$, both of which are functions of time, the mean biomass over a unit interval $(\Delta t)$ can be obtained from the mean value theorem of calculus:

$$
\begin{aligned}
& \bar{B}=\int{ }_{t_{0}}^{t_{B}} f_{0} e^{(G-Z) t} d t \\
& \bar{B}=\frac{B_{0}\left(e^{G-Z}-1\right)}{G-Z}
\end{aligned}
$$

Where $\mathrm{B}_{\mathrm{O}}=$ initial biomass of population at time $t_{0}$

$$
=\mathrm{N}_{\mathrm{O}} \overline{\mathrm{W}}_{\mathrm{O}}
$$




$$
\begin{aligned}
& t_{o}=\text { initial time of production interval } \\
& t_{f}=\text { final time of production interval } \\
& \Delta t=t_{f}-t_{0}=1
\end{aligned}
$$

For relatively short intervals the approximations in equations (3) and (4) are considered satisfactory. However, as the time interval approaches $1 \mathrm{yr}$ or more, the production estimates may be only gross approximations to true production (Chapman 1973).

By adding a subscript to $P, G, Z$ and $\bar{B}$ we can calculate the production of a particular age or size class (i). Thus

$$
\begin{aligned}
P_{i} & =G_{i} \bar{B}_{i} \\
& =\frac{G_{i} N_{i} \bar{W}_{i}\left(e^{\left(G_{i}-Z_{i}\right)}-1\right)}{G_{i}-Z_{i}}
\end{aligned}
$$

Since we are interested in the production foregone by the entrainment and impingement of fish the problem can be recast as follows: Given that an entrained or impinged fish is of age $j$, what would that fish have produced over its remaining life span? Let $P_{j}$ denote production foregone due to the entrainment of a fish of age $j$ so

$$
P_{j}=\sum_{i=j}^{t} G_{i} \bar{B}_{i}
$$

Where: $t_{\max }=$ maximum age obtained by a species of fish.

Equation (6) implies that $N$ and $\bar{W}$ are known or can be obtained via equation (2). For entrainment and impingement calculations, $N_{i}$ and $\bar{W}_{i}$ must be estimated using a recursive form of equations $(2 a, 2 b)$ such that:

$$
\begin{aligned}
& \bar{W}_{i}=\bar{W}_{i-1} e^{G_{i}} \\
& N_{i}=N_{i-1} e^{-Z_{i}}
\end{aligned}
$$

The total production foregone due to entrainment and impingement of larvae, juveniles and adults is given by:

$$
P_{T}=\sum_{j=t}^{t}{ }_{\min }{ }_{\sum}^{t}{ }^{t} \max _{G_{i}} \bar{B}_{i}
$$

Where: $\quad t_{\text {min }}=$ age of newly hatched larvae $=0$

$\left(t_{\min }\right.$ is used for the sake of generality)

\section{Estimation of Parameters}

The calculation of production foregone is an intuitively appealing measure of the impact of the Campbe11 Plant. However, like many interesting models, 
estimation of parameters for equation (8) may be exceedingly difficult. The following factors will introduce bias into the calculation of $\mathrm{P}_{\mathrm{T}}$ :

(i) Most fish have not been aged in this study; consequently a site-specific age-length key was not available. mated.

(ii) Total weight of fish impinged by $10-\mathrm{mm}$ length class has not been esti-

(iii) Mortality rates have rarely been estimated for Lake Michigan adult fish populations.

(iv) Due to gear sampling problems, mortality of very young fish and larvae has rarely been estimated directly. Rather, indirect methods have generally been used.

(v) Mortality and growth are dynamic processes which change in response to intra- and inter-specific relationships as well as to environmental changes. Thus literature values developed in other studies at other times may have little relevance to the current study.

The biases presented in (i) through ( $v$ ) cannot be circumvented entirely. The strategy will be to use a "best" estimate of a particular parameter and then perform a sensitivity analysis of its effect on the resulting production estimate. The term "best" is not defined in any rigorous statistical sense. Rather it refers to our qualitative judgements on a suitable value. The following numbered paragraphs outline the algorithm which was used to estimate production foregone due to operation of the Campbell Plant.

(1) The length frequencies of larvae entrained and adult fish impinged were converted to age and weight frequencies.

(a) Length frequencies of larvae were converted to age frequencies by examining the cumulative length-frequency distribution of larvae from entrainment samples. Those larvae less than a certain length $\ell_{c r}$ were called prolarvae $\left(\mathrm{N}_{\mathrm{b} 1}\right)$.

Those larger than $\ell_{\mathrm{cr}}$ were called postlarvae $\left(\mathrm{N}_{\mathrm{al}}\right)$.

$$
\begin{aligned}
\mathrm{N}_{\mathrm{b} 1}= & \sum_{i=0}^{c \mathrm{~N}_{i}} \\
& \ell_{\mathrm{Na1}}=\sum^{1 \mathrm{arv}} \quad \ell_{\mathrm{cr}}+1
\end{aligned}
$$

Where: $\mathrm{N}_{\mathrm{b} 1}=$ number of prolarvae

$\mathrm{N}_{\mathrm{a} 1}=$ number of postlarvae

$\mathrm{N}_{i}=$ number of individuals of length $i$

$\ell_{\text {larv }}=$ maximum length of larvae

See previous section (ENTRAINMENT) for methods of calculating the estimated entrainment losses for 1978 .

(b) The length frequencies of juvenile and adult fish were converted to age frequencies by using age-length keys taken from unpublished data of the Great Lakes Fishery Laboratory, Ann Arbor, Michigan. An age-length key gives the fraction of fish in size class $m$ which are members of age-group $i$. Let $a_{i, m}$ be 
the $i-t h$ row and $m-t h$ column element of the matrix $\underline{A}$ where $i=t_{\min }$ to $t_{\max }$ and $\mathrm{m}=\ell_{\min }$ to $\ell_{\max }$ where $\ell_{\min }$ and $\ell_{\max }$ are the minimum and maxi-

mum length classes considered. If the vectors $\underline{N}_{\mathrm{L}}$ and $\underline{\mathrm{N}}_{\mathrm{A}}$ represent the numbers of individuals in $\left(\ell_{\max }-\ell_{\min }+1\right)$ length classes and $\left(t_{\max }-t_{\min }+1\right)$ age-groups respectively then

$$
\underline{\mathrm{N}}_{\mathrm{A}}=\underline{\mathrm{AN}}_{\mathrm{L}}
$$

Where: $\underline{N}_{A}$ is a $\left(t_{\max }-t_{\min }+1\right) \times 1$ vector

$$
\underline{N}_{\mathrm{L}} \text { is a }\left(\ell_{\max }-\ell_{\min }+1\right) \times 1 \text { vector }
$$

$$
\underline{\mathrm{A}} \text { is a }\left(\mathrm{t}_{\max }-\mathrm{t}_{\min }+1\right) \times\left(\ell_{\max }-\ell_{\min }+1\right) \text { matrix }
$$

In summation notation:

$$
\mathrm{n}_{\mathrm{A}, \mathrm{i}}=\sum_{\mathrm{m}=\ell_{\min }^{\max }}^{\mathrm{m}_{i, \mathrm{~m}}} \mathrm{n}_{\mathrm{L}, \mathrm{m}} \text { for } \mathrm{i}=\mathrm{t}_{\min } \text { to } \mathrm{t}_{\max }
$$

Where: $n_{A, i}=i-t h$ element of $\underline{N}_{A}$, i.e. number of individuals of age $i$

$\mathrm{n}_{\mathrm{L}, \mathrm{m}}=\mathrm{m}$-th element of $\underline{\mathrm{N}}_{\mathrm{L}}$; i.e. number of individuals in length class $\mathrm{m}$ The problems of using age-length keys have recently been addressed by Kumar and Adams (1977).

(c) The mean weight of prolarvae and postlarvae were estimated by weighing a number of preserved prolarvae and postlarvae specimens for each species. Length statistics for sampled prolarvae and postlarvae were also given. If $\mathrm{F}(\mathrm{m})$ represents the length-frequency distribution of the cumulative larvae entrainment samples, then the mean weight of a prolarvae $\left(\bar{W}_{\mathrm{a} 1}\right)$ and postlarvae $\left(\overline{\mathrm{W}}_{\mathrm{b} 1}\right)$ is given by:

$$
\begin{aligned}
\overline{\mathrm{W}}_{\mathrm{b} 1} & =\sum_{\mathrm{m}=\ell_{\min }}^{\ell} \mathrm{cr} \overline{\mathrm{W}}_{\mathrm{m}} \mathrm{F}(\mathrm{m}) \\
\overline{\mathrm{W}}_{\mathrm{a} 1} & =\sum_{\mathrm{m}=\ell_{\mathrm{cr}}}^{\ell_{\mathrm{arv}}}+1 \overline{\mathrm{W}}_{\mathrm{m}} \mathrm{F}(\mathrm{m})
\end{aligned}
$$

respective1y, where $\bar{W}_{m}$ is the measured mean weight of larvae in the $m$-th length class.

(d) The mean weight of an age-group was estimated by converting length to weight using a length-weight relationship and then developing a weighted-average weight based upon the length frequency of fish from the impingement sample. The mean weight of a fish of length $\mathrm{m}$ is given as:

$$
\begin{aligned}
\bar{W}_{\mathrm{m}} & =\mathrm{G}(\mathrm{m}) \\
& =a \mathrm{~m}^{\mathrm{b}}
\end{aligned}
$$


The mean weight of fish of age $i\left(\bar{W}_{i}\right)$ is given as:

$$
\overline{\mathrm{W}}_{i}=\sum_{\mathrm{m}=\ell_{\mathrm{L}, \mathrm{i}}}^{\ell_{\mathrm{m}, \mathrm{i}}} \mathrm{G( \textrm {m } )}
$$

Where: $b_{m, i}=$ fraction of fish of length $m$ in age $i$

$\ell_{L, i}=$ minimum length class of fish of age $i$

$\ell_{U, i}=$ maximum length class of $\mathrm{fish}$ of age $i$

The major problem with estimation of $\bar{W}_{i}$ follows from the difficulty in choosing $\mathrm{G}(\mathrm{m})$. First, the length-weight relationship for fish varies with sex and season. Due to production of eggs, females tend to be somewhat heavier than males of the same length. Also, the annual reproductive cycle, variations in temperature, food availability and other factors result in large variations in parameters a and $b$ for both sexes as well as immature fish. By examining only the cumulative annual length frequency these rather significant variations are ignored, which results in further bias. Another bias involves the selection of a representative length-weight relation for all sexes over the entire year. The length-weight regression was based upon the GLRD data base for environmental studies at the D.C. Cook Nuclear Power Plant (Jude et al. 1975, 1979).

(2) The instantaneous rate of growth for age class $i$ is given by:

$$
G_{i}=\ln \left(\bar{W}_{i}\right)-\ln \left(\bar{W}_{i-1}\right)
$$

(3) Mortality estimates for both larval and adult fishes were by far the most difficult parameters to obtain. Recent estimates of mortality for Lake Michigan stocks are nearly nonexistent (E.H. Brown and L. Wells, personal communication, Great Lakes Fishery Laboratory, U.S. Fish and Wildlife Service, Ann Arbor, Michigan). Consequently some rather involved calculations, based upon numerous assumptions were used to estimate mortality. A modified equivalent adult model (Horst 1975, Goodyear 1978) was used to estimate an overall mortality rate from egg to adult. Then, in conjunction with literature estimates, the unknown agespecific mortality rates were computed. Basically, the Horst model assumes an equilibrium population in that the "average" female fish will reproduce exactly two adults (one male and one female) over its lifetime. Thus survival from egg to adult is simply two times the inverse of the mean adult fecundity $\left(\bar{F}_{a}\right)$. As noted by Goodyear (1978), $\overline{\mathrm{F}}_{\mathrm{a}}$ has often been estimated as the simple average of the minimum and maximum fecundity of fish in the reproductive stock. While fecundity generally increases with age and length, the relationship is not linear. Furthermore, the numbers of an age class will always decrease over time. Hence, there are always fewer larger fish than smaller fish in a stable population. Goodyear suggested that $\overline{\mathrm{F}}_{\mathrm{a}}$ be estimated by discounting the age of length-specific fecundity by the appropriate survival rate. 
Thus

$$
\bar{F}_{a}=\sum_{j=t_{r}}^{t_{\max }} S_{j} E_{j}
$$

Where: $s_{j}=$ survival probability from recruitment to age $j$

$$
E_{j}=\text { average fecundity of mature females of age } j
$$

$t_{\mathrm{r}}=$ age at recruitment

$t_{\max }=$ maximum age

The $S_{j}$ were derived from the literature. Age-specific fecundity $\left(E_{j}\right)$ was derived from empirical length-fecundity relationships and the frequency of length classes within an age-group.

$$
E_{j}=\sum_{m=\ell_{L, j}}^{\ell} b_{m, j} E(m)
$$

Where: $b_{m, j}=$ fraction of fish of length $m$ in age $j$

$$
E(m)=\text { empirical function relating length and fecundity }
$$

$\ell_{U, j}=$ maximum length of fish within age $j$

$\ell_{L, j}=$ minimum length of fish within age $j$

Given $\overline{\mathrm{F}}_{\mathrm{a}}$ as defined in equation (16) the total survival rate from egg to adult is given by:

$$
S=\frac{2}{\overline{\mathrm{F}}_{\mathrm{a}}}
$$

The total survival rate $S$ is simply the product of age-specific survival rates $S_{i}$

$$
S=\pi_{i=t_{\min }}^{t_{\max }} S_{i}
$$

Where: $S_{i}=$ probability of survival during life stage $i$

An unknown survival rate, say $\mathrm{S}_{\mathrm{x}}$ can be estimated as:

$$
\left.S_{x}=S / \prod_{\substack{i=t_{\text {min }} \\ i \neq x}}^{t_{\text {max }}} S_{i}\right)
$$


If $\mathrm{S}_{\mathrm{X}}$ is the product of two or more age or life stage specific survival rates then some assumption about the distribution of survival rates between age-groups must be made. If $\mathrm{p}_{i}$ is the fraction of $\mathrm{S}_{\mathrm{x}}$ applied to age $i$ then

$$
s_{i}=\exp \left(\ln \left(s_{x}\right) \cdot p_{i}\right)
$$

Where: $\quad \sum \mathrm{p}_{\mathrm{i}}=1$

Equation (21) allows partitioning of $\mathrm{S}_{\mathrm{X}}$ over several age-groups or life stages.

\section{Sensitivity Analyses}

Sensitivity of the model to changes in parameter estimates was examined by calculating the partial derivatives of total production $\mathrm{P}_{\mathrm{T}}$ with respect to the parameter of interest. Although a large number of equations were used to derive parameters and initial conditions for the model, only three variables were of basic interest in the model. These were stage- and age-specific survival rates $\left(S_{i}\right)$, mean weights $\left(\bar{W}_{i}\right)$ and estimated numbers killed by the plant $\left(N_{i}\right)$. Factors such as length-specific fecundity, fraction of a length class or a specific age-group and length-weight relations all have an effect on the production estimate but only through $\mathrm{S}_{i}, \mathrm{~W}_{i}$ or $\mathrm{N}_{i}$.

The partial differentials of $\mathrm{P}_{\mathrm{T}}$ (as defined in equation 8) were evaluated using a computer program. The partials of $\mathrm{P}_{\mathrm{T}}$ (equation 8) with respect to $\mathrm{S}_{i}$, $\bar{W}_{i}$ and $N_{i}$ can be written analytically but they are extremely cumbersome and unwieldy. Note that $\bar{W}_{i}$ affects not only the biomass estimates but also the instantaneous growth rate. The algorithm for the computer procedure is outlined below:

Let $\mathrm{P}_{\mathrm{T}}(\mathrm{I})$ represent the production estimate corresponding to our initial parameter estimates and $\mathrm{P}_{\mathrm{T}}(\mathrm{D})$ correspond to the production estimate for the perturbed system. Then for any parameter specified, sensitivity of the model can be thought of as the percent change in production with respect to percent change in the parameter.

$$
\text { Thus } \begin{aligned}
\tilde{P}_{T} & =\% \Delta P_{T}=\frac{\left(P_{T}(D)-P_{T}(I)\right)}{P_{T}(I)} 100 \\
\tilde{V} & =\% \Delta V=\frac{(D-I)}{I} 100
\end{aligned}
$$

Where I and D represent the original and altered parameter values respectively. More specifically the variable $\mathrm{D}$ can be thought of as $\overline{\mathrm{W}}_{i}{ }^{\prime}=\overline{\mathrm{W}}_{i}+\Delta \overline{\mathrm{W}}_{i}$ or $\mathrm{S}_{i}{ }^{\prime}=$ $\mathrm{S}_{i}+\Delta \mathrm{S}_{i}$ or $\mathrm{N}_{i}{ }^{\prime}=\mathrm{N}_{i}+\Delta \mathrm{N}_{i}$. Plotting $\tilde{\mathrm{P}}_{\mathrm{T}}$ vs. $\tilde{\mathrm{V}}$ is an effective means of indicating the most sensitive parameters. In nearly all of these plots, $\mathrm{P}_{\mathrm{T}}$ was a linear function of the parameter value with an intercept of zero. Although the actual partials of $\mathrm{P}_{\mathrm{T}}$ are complex, the resultant response could generally be represented as: 


$$
\begin{aligned}
& \frac{\partial \mathrm{P}_{\mathrm{T}}}{\partial \mathrm{S}_{i}}=\mathrm{a}_{i} \mathrm{~S}_{i} \\
& \frac{\partial \mathrm{P}_{\mathrm{T}}}{\partial \overline{\mathrm{W}}_{i}}=\mathrm{b}_{i} \overline{\mathrm{W}}_{i} \\
& \frac{\partial \mathrm{P}_{\mathrm{T}}}{\partial \mathrm{N}_{i}}=c_{i} \mathrm{~N}_{i}
\end{aligned}
$$

where $a_{i}, b_{i}$ or $c_{i}$ are simple constants and have been called the sensitivity coefficients for purposes of this report. These are strictly empirical measures of model sensitivity and valid only over the domain of the altered parameter. Survival and growth rates were examined over $\pm 25 \%$ in steps of $1 \%$ of the initial value, whereas estimates of numbers impinged and entrained were allowed to vary $\pm 50 \%$ in steps of $2 \%$. Thus, a total of 51 total production estimates were computed for each parameter. The sensitivity coefficients were calculated via a least squares procedure. Each sensitivity coefficient is the least squares estimate of the slope of $\tilde{P}_{\mathrm{T}}$ vs. $\tilde{\mathrm{V}}$. To examine the nonlinearity of the production function, sensitivity coefficients were computed over four subranges of V (i.e., -25 to $-1 \%, 1$ to $+25 \%,-12$ to $+12 \%$ and -25 to $25 \%$ for $\mathrm{S}_{i}$ and $\overline{\mathrm{W}}_{i}$ and -50 to $0 \%$, 0 to $+50 \%,-25$ to $25 \%$ and -50 to $+50 \%$ for $\mathrm{N}_{i}$ ) (see Fig. 6 ).

Sensitivity coefficients may be analyzed as follows: given a certain percent change in a parameter ( $i . e ., \% \Delta S_{i}, \% \Delta W_{i}$ or $\% \Delta N_{i}$ ), the resulting percent change in total production is given by multiplying the parameter change by $a_{i}, b_{i}$ or $c_{i}$ as applicable.

Preliminary analyses of model sensitivity for the D.C. Cook Nuclear Plant (Rago 1978) and Campbel1 Plant indicated that the model was most sensitive to changes in first-year survival. To investigate this sensitivity, total production was computed for 15 different first-year survival rates. Not only was the overal1 first-year survival rate critical but also the partitioning of mortality among prolarvae, postlarvae and age 0 -fish had a profound effect on the overall production estimate. For each overall survival rate, 42 different partitionings were examined.

The overall first-year survival was varied between $10 \%$ to $.00061 \%$. Each adjacent survival rate was $\frac{1}{2}$ the preceding; in other words, the $n$-th survival rate was $S_{n}=0.10 / 2(n-1)$. Survival was partitioned to the prolarvae and postlarvae and age-0 fish using the following scheme: (1) The fraction of the first-year survival attributable to prolarvae deaths was set at $0.9,0.8,0.7,0.6,0.5$ and 0.4 . (2) For each of these values, the ratio of the fraction attributable to postlarvae and age- 0 fish was set at $1: 1,3: 2,2: 1,3: 1,1: 3,1: 2$ and $2: 3$. For example if $40 \%$ of the mortality occurred in the prolarval stage and the split between postlarvae and age 0 was $2: 3$ then the fractions would be $0.4,0.24,0.36$ respectively. Assuming that the first-year survival rate was $5 \%$, the actual survival rates to be used in the model were computed as follows: 


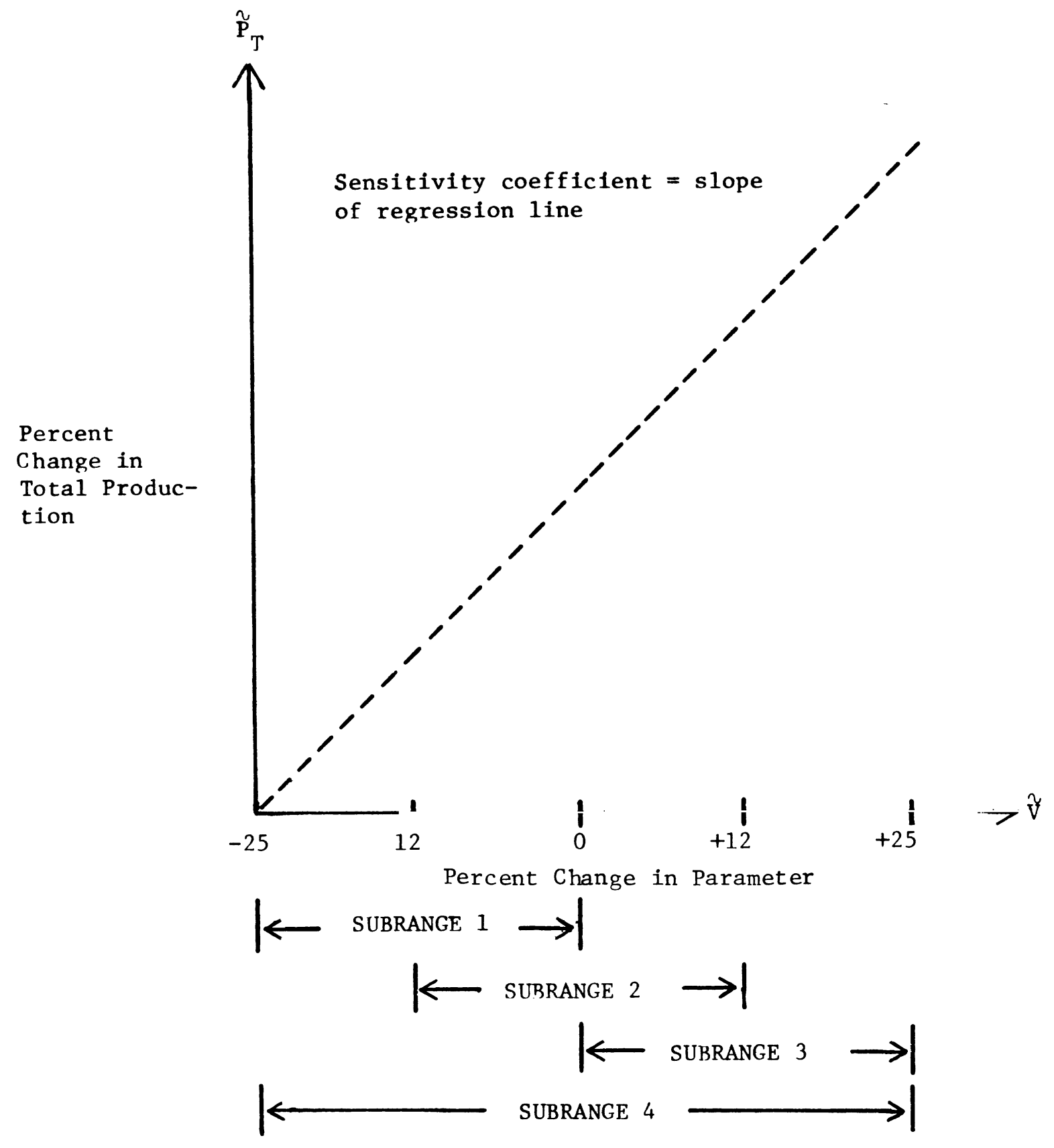

Fig. 6. Schematic representation of calculation of sensitivity coefficients for production foregone estimates. Coefficients were estimated over four sub-intervals of the percent change in the parameter $\widetilde{\mathrm{V}}$. 
Let $\mathrm{Z}=-\ln (.05)$

then $\mathrm{S}_{\mathrm{PRO}}=\exp (-.40 \mathrm{Z})$

$\mathrm{S}_{\mathrm{PST}}=\exp (-.24 \mathrm{Z})$

$\mathrm{S}_{\text {JUV }}=\exp (-.36 \mathrm{Z})$

Where: $\mathrm{S}_{\mathrm{PRO}}=$ prolarvae survival rate

$\mathrm{S}_{\mathrm{PST}}=$ postlarvae survival rate

$\mathrm{S}_{\text {JUV }}=$ juvenile fish survival rate

Recapitulating, 15 different first-year survival rates were hypothesized. For each rate the fraction of annual mortality attributable to prolarvae was varied between 0.9 and 0.4 in steps of 0.1 . For each of these cases, the remaining mortality was divided between postlarvae and age-0 fish using seven different splits. Thus a total of 630 (15 $\times 6 \times 7)$ different production estimates were computed.

These data were then examined via a stepwise multiple linear regression program in which total production was regressed upon the survival estimates and their cross products. The model used was:

$$
\mathrm{P}_{\mathrm{T}}=\mathrm{B}_{0}+\mathrm{B}_{1} \mathrm{~S}_{\mathrm{PRO}}+\mathrm{B}_{2} \mathrm{~S}_{\mathrm{PST}}+\mathrm{B}_{3} \mathrm{~S}_{\mathrm{JUV}}+\mathrm{B}_{4} \mathrm{~S}_{\mathrm{PRO}} \mathrm{S}_{\mathrm{PST}}+\mathrm{B}_{5} \mathrm{~S}_{\mathrm{PST}} \mathrm{S}_{\mathrm{JUV}}+\mathrm{B}_{6} \mathrm{~S}_{\mathrm{PRO}} \mathrm{S}_{\mathrm{PST}} \mathrm{S}_{\mathrm{JUV}}
$$

Where: $P_{t}=$ total production foregone

$\mathrm{S}_{\text {PRO }}=$ survival through the prolarval stage to the postlarval stage

$\mathrm{S}_{\text {PST }}=$ survival through the postlarval stage

$\mathrm{S}_{\mathrm{JUV}}=$ survival through the age-0 or juvenile stage

$B_{i}=$ least squares regression estimate

It must be noted that no statistical inference can be drawn from these regression estimates. The variables are not random variables. Rather they are the output of a deterministic model. The regression merely serves a convenient means of summarizing model sensitivity.

\section{FISH EGG AND LARVAE PROCESSING}

Fish eggs and larvae were removed from samples with the aid of a dissecting binocular microscope. In late 1978 a staining technique using Lignin Pink was employed for use with some of the samples difficult to pick because of vast amounts of algae and/or detritus. This stain was used sparingly but did expedite larval extraction. Larvae samples were first washed with tap water using a screened bucket. Dilute acid was then added and the sample remained in the acid for $45 \mathrm{~min}$. The acid was then rinsed from the sample with tap water and the stain added. After at least $1 \mathrm{~h}$ of staining the sample was rinsed again with tap water and examined. The development and refinement of this technique will be continued in 1979 . 
Once larvae were extracted from the samples, they were measured to the nearest $0.1 \mathrm{~mm}$ (total length), except when samples contained more than 20 larvae of any one species, at which time lengths were determined to the nearest $0.5 \mathrm{~mm}$. Number, species and 1ength of larvae as well as number of eggs found were entered on coding forms and later keypunched to allow for computer data processing. A computer program was developed to adjust numbers of larvae and eggs to number per $1000 \mathrm{~m}^{3}$ of water filtered using flowmeter readings. See METHODS - FISH LARVAE TOWS for details.

Knowledge of fish populations and spawning times in southeastern Lake Michigan, specimen comparisons with those stored in the Great Lakes Regional Fish Larvae Collection and the taxonomic works of Dorr et al. (1976), Hogue et a1. (1976), Lippson and Moran (1974), Ne1son and Cole (1975) and Jude et a1. (1979) were used in larval fish identifications.

Problem areas exist in some species identifications at the larval leve1 and some identifications are still tentative. Alewife and gizzard shad could not be distinguished from one another once yolk sac absorption had taken place. Most minnow larvae (spottail, bluntnose, golden shiner and emerald shiner) were difficult to distinguish at lengths less than $9 \mathrm{~mm}$. Separation of longnose and white suckers was also difficult. For a continued description of these problematic areas, see species sections in RESULTS AND DISCUSSION - FISH LARVAE AND ENTRAINMENT STUDY.

\section{FISH LARVAE TOTAL LENGTH-BODY DEPTH RELATIONSHIP}

Total lengths and body depths were measured for certain species of larva1 fishes (defined as any fish less than $25.4 \mathrm{~mm}$ ) common to Lake Michigan near the J.H. Campbe11 Power Plant, Port Sheldon, Michigan. Species evaluated included: alewife, carp, Cottus spp., johnny darter, rainbow smelt, spottail shiner, trout-perch and yellow perch. With existing taxonomic keys, it was not possible to distinguish between larvae of two sculpin species (Cottus cognatus and Cottus bairdi) found near the J.H. Campbe11 Plant. Specimens were obtained from the Great Lakes Regiona1 Fish Larvae Collection (Great Lakes Research Division, University of Michigan) and from larvae collected between 1974 and 1978 near the J.H. Campbel1 and D.C. Cook Power Plants (Jude et al. 1975, 1978). Al1 larvae were preserved in $5 \%$ buffered formaldehyde solution.

Total length and body depth (measured at the point of greatest depth, including yolk sac) of each larva were measured to the nearest $0.1 \mathrm{~mm}$ under a 10X binocular microscope. Scatter plots and simple linear regressions were produced for body depth vs. total length using Michigan Interactive Data Analysis System (MIDAS) (Fox and Guire 1973). Ninety-five percent confidence bands were calculated and plotted for regression lines.

Regressions were used to calculate total length of larvae corresponding to body depths of $0.5,1.0$ and $2.0 \mathrm{~mm}$ for each species. These length values were then compared to cumulative length frequencies for some of the most common species of larvae entrained during 1978 at the Campbell Plant. From these comparisons, the percentage of fish larvae that could have been either excluded or entrained with the employment of $0.5-, 1.0-$ and $2.0-\mathrm{mm}$ screen mesh sizes was estimated. 


\section{LABORATORY ANALYSIS OF JUVENILE AND ADULT FISH}

Each replicate from seine, gill net and trawl catches was labeled and kept separate in plastic bags. Fish were processed fresh when time permitted, or otherwise frozen at the Campbell Plant or on board the R/V Mysis (traw1 catches). For laboratory examination, fishes in each bag were thawed, separated by species, then grouped into size classes. When large numbers of a particular size class for an unusually abundant species were present, a subsample was randomly selected from the group and the remaining fish weighed (herein referred to as the mass weight) and discarded. The following data on each fish were recorded: total length (to the nearest millimeter, caudal fin pinched), weight (to the nearest $0.1 \mathrm{~g}$ using a P1000 Mettler balance), sex, gonad condition, presence or absence of food in the stomach, fin clips, lamprey scars and evidence of diseases and parasites. Large $\mathrm{fish}$ and $\mathrm{fish}$ in the mass weight (over $1000 \mathrm{~g}$ ) were weighed with a hanging scale spring balance (K023G Chatillon) to the nearest $20 \mathrm{~g}$.

Gonad condition of adult fish was described according to five stages of development: 1) underdeveloped, 2) moderately developed - for female, eggs discernible, but not fully ripe, 3) ripe, 4) ripe-running - sex products exiting with application of moderate pressure 5) spent. Other gonad conditions recorded included: 6) immature, 7) unable to ascertain sex on adult fish, 8) reabsorbed eggs - for female fish, 9) fish decomposed or mutilated so that sex was impossible to determine.

All fish were identified to species using Hubbs and Lagler (1958), Trautman (1957), Scott and Crossman (1973) and Eddy (1957) with the exception of the genus Coregonus (subgenus Leucichthys). Satisfactory keys for this subgenus do not exist because of unsettled questions on the validity of several species (Scott and Crossman 1973) and the possibility of their introgression (Wells and McLain 1973). The only adult Leucichthys that can be positively identified is the lake herring, Coregonus artedii. Other Leucichthys, adult or juvenile, were pooled as unidentified coregonids (code XC). These were believed to be mostly bloaters, C. hoyi.

\section{DATA PROCESSING AND CALCULATIONS}

For each adult and juvenile fish examined the following information was recorded on a 75-column coding form, one fish per line: date and time of sample collection, type of gear, day or night series, station, species code, a unique incrementing number, length, weight, sex, gonad condition and presence or absence of food in the stomach.

Data on subsampled fish were recorded on consecutive lines each having a subsampling code. Special columns were reserved for the corresponding mass weight. Computer programs search for subsampled lots and calculated number of fish processed, their mean weight and the total number of mass-weighed fish not examined. Mass-weighed fish were proportionally assigned to length intervals based on the number of fish found in each length interval. Fish were divided visually by length into many narrow size classes when originally subsampled to minimize error associated with this reconstruction of sample length frequencies. 
Fisheries data were keypunched, then read onto computer disks and tapes. For the bulk of our statistical analyses, we used the Michigan Interactive Data Analysis System (MIDAS) which was developed by the Statistical Laboratory of the University of Michigan. From our computer programs, we obtained summary statistics on seasonal gonad condition, temperature-catch relationships, catches by month, gear type, station and day and night series and length-frequency histograms.

Gill nets were set for as close to $12 \mathrm{~h}$ as possible when there was available daylight or darkness. Due to unpredictable weather conditions and changing day length, however, actual time gill nets were fished varied from $5 \mathrm{~h} 10 \mathrm{~min}$ to $15 \mathrm{~h} 25 \mathrm{~min}$. Gill net catches for calculating statistics were adjusted to approximate numbers caught per $12 \mathrm{~h}$ by assuming that catch was a linear function of time. The above assumption is not completely valid as gill net catch-per-unit-time might be expected to decrease as the net fills with fish, but increased accuracy could not justify the cost of determining a precise relationship for each species.

\section{DEFINITION OF TERMS}

Adult fish length intervals - for figures describing total lengths of adult fish, individuals were assigned to $10-\mathrm{mm}$ intervals. For example, the $30-\mathrm{mm}$ length interval would include fish from 26 to $35 \mathrm{~mm}$.

Beach zone - refers to that area of water, usually less than $1.5 \mathrm{~m}$, that is accessible to wading during seining and fish larvae sampling activities. Includes only beach stations.

Fish larvae - any larval fish less than or equal to $25.4 \mathrm{~mm}$ in total length.

Fry - any fish greater than $25.4 \mathrm{~mm}$ in total length caught in plankton nets. Fish were usually $25.5-100 \mathrm{~mm}$.

Inshore - refers to that area of water between the shoreline and $21 \mathrm{~m}$.

Larval fish length intervals - for figures describing total lengths of larval fish, a specimen was assigned to $0.5-\mathrm{mm}$ intervals based on total length. For example, larvae $0.3 \mathrm{~mm}$ would be assigned to the interval $0.5 \mathrm{~mm}$ (which includes all larvae $0.1-0.5 \mathrm{~mm}$ ), $5.6 \mathrm{~mm}$ larvae would be assigned to the interval $6.0 \mathrm{~mm}$ (which encompasses 5.6-6.0-mm larvae).

Nearshore - refers to that area of water less than or equal to $3 \mathrm{~m}$ and includes Lake Michigan stations P, A, B, Q, R, I, J and Pigeon Lake stations $\mathrm{V}, \mathrm{S}, \mathrm{X}$ and $\mathrm{Z}$.

Offshore - term for that area of water, not beach zone, $21 \mathrm{~m}$ deep or greater. There are no stations in this zone. Same as deepwater.

Open water- refers to that area of water, not beach zone and includes all stations $6 \mathrm{~m}$ to $21 \mathrm{~m}$ which were usually sampled by boat and which usually had no or very few aquatic macrophytes present. They included Lake Michigan 
stations C, D, E, F, L, N, O, W and Pigeon Lake station M.

Transition zone - area of water from 1.5 to $3 \mathrm{~m}$.

Zone of influence - that area of Lake Michigan aquatic habitat actually or potentially affected by the presence of the intake and discharge structures of Units 1 and 2 and Unit 3 (future) and their associated withdrawal and discharge of cooling water.

YOY - young-of-the-year - fish in their first year of life.. They become yearlings January 1 .

Water temperature intervals - catch of adult fish was assigned to 2-C water temperature intervals for the purposes of establishing temperature-catch relationships. For example, the 3-C temperature interval would include fish caught between 2.0 and $3.9 \mathrm{C}$.

\section{STATISTICS}

BMD 8V was used to perform the analyses of variance (Statistical Research Laboratory 1975). The Michigan Interactive Data Analysis System (MIDAS, Fox and Guire 1973) was used for analyses of ANOVA residuals. Residuals, defined as the difference between the cell mean and actual data value, were examined to determine how we1l ANOVA model assumptions were met (Draper and Smith 1966). An ALGOL program was written to compute the LDTR (Least Detectable True Ratios). 
RESULTS AND DISCUSSION

\section{STATISTICS}

Int roduction

One objective of this study is to monitor fish populations at different locations in the vicinity of the J.H. Campbell Plant to see how abundances of fish populations vary with year and to detect differences in fish abundances between the reference area and the zone of influence (area of Lake Michigan affected by the intake of cooling water and discharge of heated water). Catch-per-unit-of-effort (CPE) is considered an index to abundance and thus replicate trawl, gill net and seine samples provide estimates of the relative abundance of these fish populations. Note that $\mathrm{CPE}$ is an index of numerical abundance and not an absolute measure of population size. Each sample represented one unit of effort. One unit of trawling effort was defined as a 10-min tow, one unit of gill net effort was defined as one lift of one replicate of the net adjusted to a standard 12-h fishing period and one unit of seining effort was defined as a 61-m sweep parallel to shore with the seine. There are many problems equating units of effort of one gear type to effort units of another, so abundance indices for different gear types are not directly comparable (Lawrie and Rahrer 1973). However, CPE values for different gear types may provide complementary information about a particular fish population. For example, individual fish which might avoid trawls might be captured by gill nets. Conversely, fish which are too small to be captured in gill nets are likely to be caught with seines and trawls. Although the data were analyzed separately for each gear type for a particular species, the aggregate of the results for all gear types was reviewed for that species.

\section{Design and Analysis Considerations}

Statistical analyses were performed on catch data of the six most abundant species of fish collected during field sampling in Lake Michigan. They included: spottail shiner, alewife, rainbow smelt, yellow perch, trout-perch and bloater (unidentified coregonids). Differences in fish abundance between the reference area and the zone of influence were examined using analysis of variance (ANOVA). These analyses will hopefully provide information to determine what impact the power plant may be having on fish populations. The experimental designs (Table 4) were analyzed as completely crossed, factorial models with YEAR (for some designs), MONTH, STATION (or AREA), DEPTH (in some designs) and TIME OF DAY as design variables. All factors were considered fixed. The response variable was either number of fish per unit of effort or a transform thereof. We transformed raw data by taking $\log _{10}$ of the sum of CPE plus one. The addition of one insured inclusion of zero values of CPE in the transformed data. This transformation was designed to reduce data variance so ANOVA assumptions might be more closely met.

The factorial ANOVA designs were chosen according to species, gear type and presence of zero values in data (Table 4). The YEAR factor was examined for each gear type to see if population abundances were changing significantly 


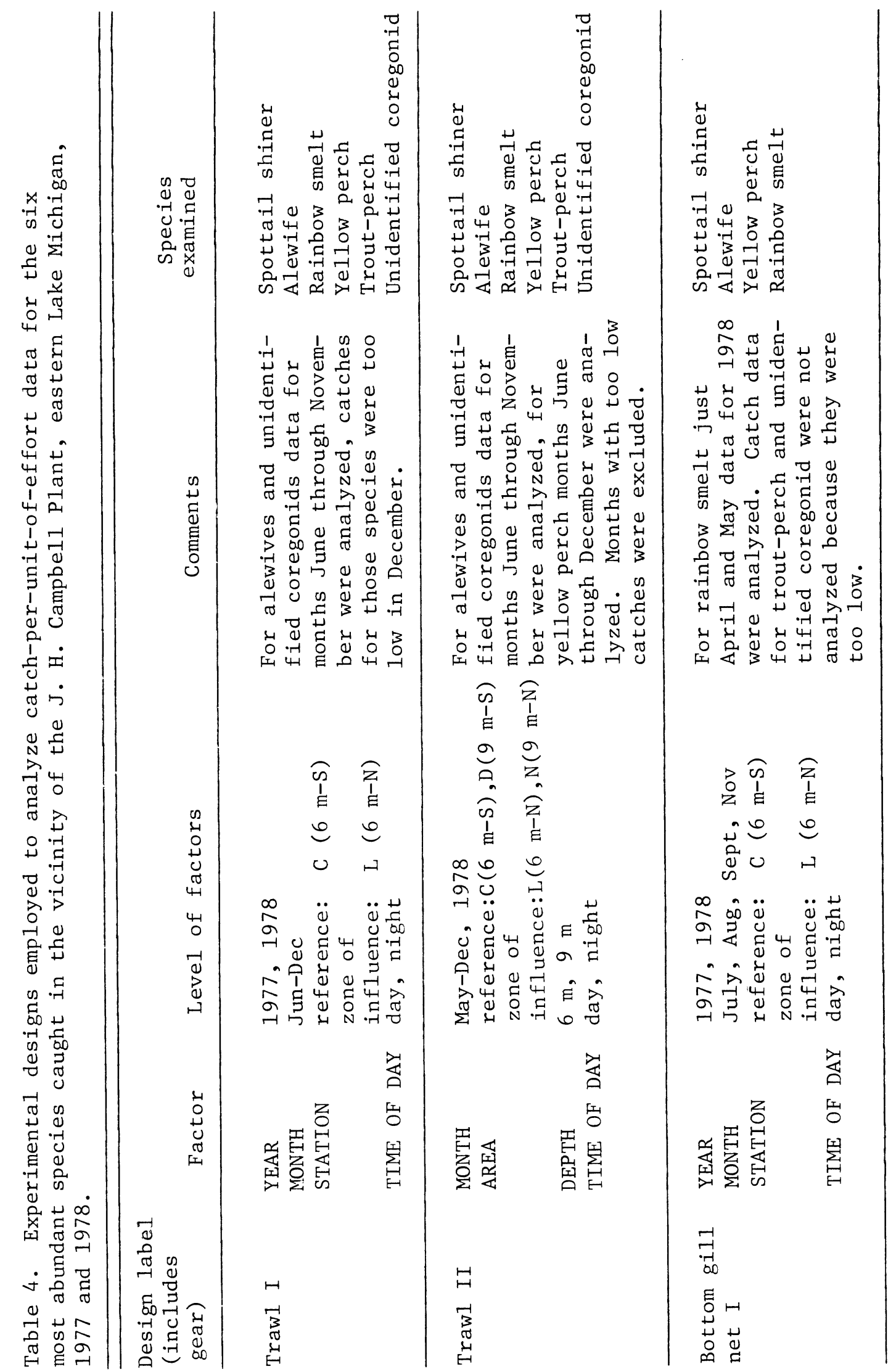




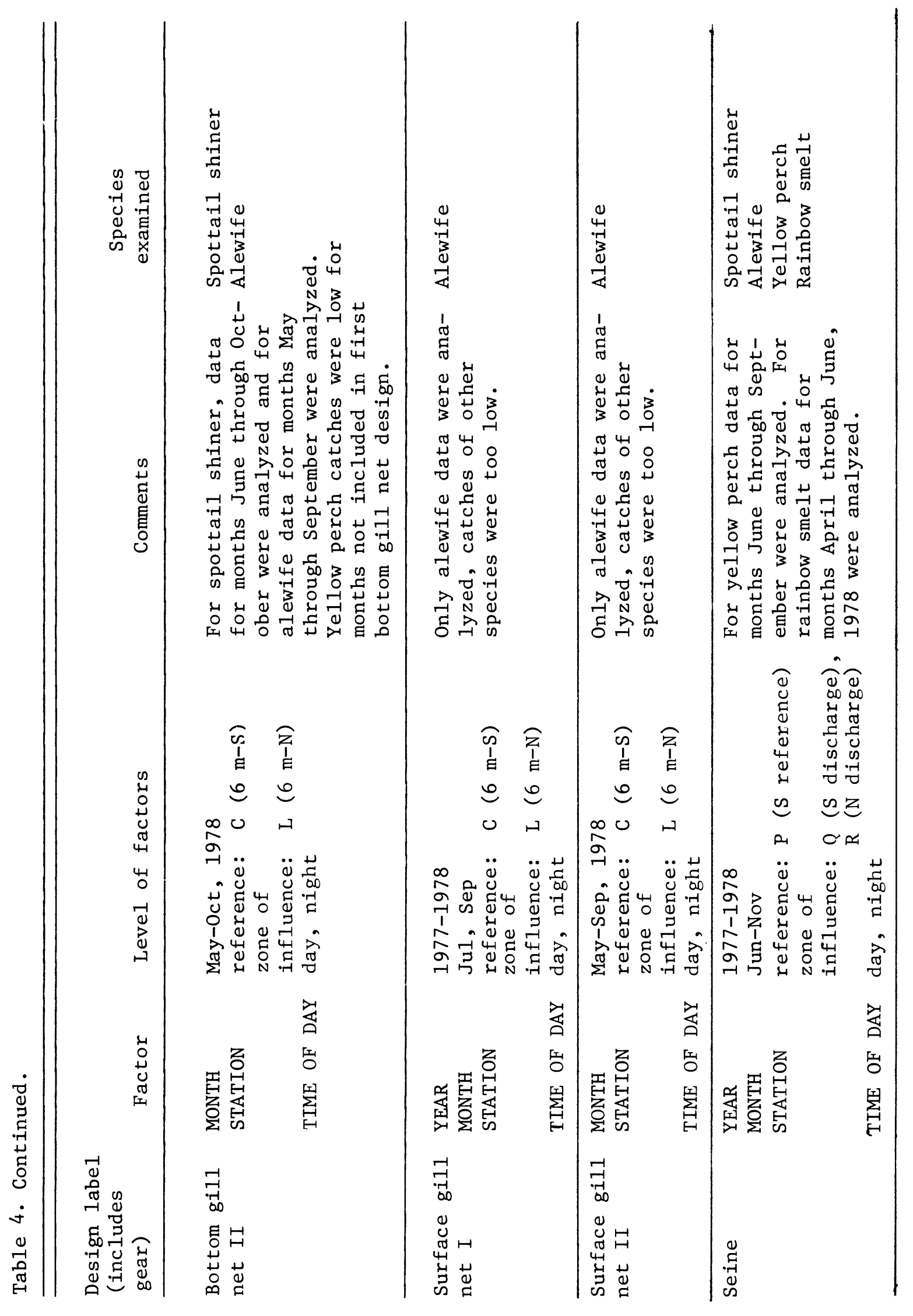


between the $2 \mathrm{yr}$. The MONTH factor was expected to explain a considerable amount of variation attributable to seasonal changes in fish abundance. The STATION factor was designed to account for differences between the reference station $\mathrm{C}(6 \mathrm{~m}-\mathrm{S})$ and the zone of influence station $\mathrm{L}(6 \mathrm{~m}-\mathrm{N})$ for trawl and gill net models, while for seining, this factor was intended to account for differences between beach reference station $\mathrm{P}(1 \mathrm{~m}-\mathrm{S})$ and treatment stations $Q$ (S discharge) and station $R$ ( $N$ discharge). AREA was used in the second trawl design to examine differences between the reference area [stations $C$ $(6 \mathrm{~m}-\mathrm{S})$ and $\mathrm{D}(9 \mathrm{~m}-\mathrm{S})$ ] and the zone of influence [stations $\mathrm{L}(6 \mathrm{~m}-\mathrm{N})$ and $\mathrm{N}(9 \mathrm{~m}-\mathrm{N})]$. DEPTH was used in this design to compare abundances between the 6- and 9-m contours. The data for these stations were analyzed only for 1978 because traw1 samples were not collected at station $\mathrm{N}(9 \mathrm{~m}-\mathrm{N})$ in 1977 . TIME OF DAY was employed in a11 of the designs and was intended to account for diel migrations into and out of the study area. A main effect or an interaction was considered significant if the actual $\alpha$ for its statistical test was less than .01 (actual $\alpha<.01$ ); the main effect or interaction was considered highly significant if the actual $\alpha$ for its test was less than .001 (actual $\alpha<.001$ ).

Assumptions for the ANOVA model are: 1) residuals are normally distributed, 2) variances of the population are constant for all partitions of the populations and 3 ) observations are statistically independent. Balanced factorial ANOVA are robust to the assumptions of normality and homogenous variances. In other words, moderate departure from these assumptions do not completely invalidate results of the model. Violation of the independence assumption may have more serious consequences.

Given that these assumptions are met, sensitivity of the ANOVA model to detect the alternate hypothesis can be calculated. In this study, we were interested in detecting significant differences between stations (or areas). The least detectable true change (LDTC) is the minimum difference in a mean abundance between stations (or areas) that can be detected by our experimental design. The formula for LDTC, as presented by Jude et a1. (1975) which we used is as follows:

$$
\delta=s(2 / n)^{\frac{1}{2}}\left(t_{\alpha, \nu}+t_{2(1-P), \nu}\right)
$$

Where: $\delta=$ least detectable true change (LDTC)

$s=$ within cell standard deviation of the ANOVA (i.e., the square root of the mean square error)

$\mathrm{n}=$ number of observations in each of the two groups being compared

$\alpha=$ significance leve1

$\mathrm{t}=$ student's t-statistic

$\nu=$ degrees of freedom for the error sum of squares of the ANOVA

$\mathrm{P}=$ power (the probability that a true difference will be judged significant by the ANOVA test)

Results for all ANOVA models (Table 4) were computed using both raw and log-transformed data. Data for all species and gear types were initially screened by calculating mean catch (which was equal in value to mean CPE since effort for collecting any one sample was always one), its variance and percentage 
of zero values in the design matrix. Summary statistics for those data sets considered amenable to further statistical analyses (Table 5) showed that percentage of zero catches for these data usually exceeded $25 \%$. Consequently, distribution of values was generally bimodal with modes at zero and near the geometric means. The transformation did, however, yield residuals which were slightly closer to meeting ANOVA assumptions than residuals from raw-data values. Unless stated otherwise, future references to abundance when discussing the ANOVA results will refer to geometric mean abundance derived from log-transformed data. Geometric means for various partitions of the data were derived by back transforming cell means from $\log _{10}$ transformed data. For example, if $\bar{x}$ represents the mean catch for log-transformed data, then $x=10^{\bar{x}}$ is the geometric mean catch. Use of log-transformed data can yield cell means which are not in the same ranking order as cell means from the original data. If so, the geometric means will also differ in ranking order since the exponential function is monotonic.

When using log-transformed data, the LDTC or $\delta$ is expressed as the change in the logarithm of fish numbers and not in terms of the actual numbers of fish. Back transforming $\delta$ yields $10^{\delta} ; 10^{\delta}$ represents the ratio of the mean number of fish per unit effort plus one for reference station $C$ (or the reference area) to that for experimental station $L$ (or the zone of influence in the case of the second trawl design). In the transformed coordinate system (i.e., log-transformed system) changes will be detectable if $\left|\bar{x}_{C}-\bar{x}_{L}\right|>\delta$ where $\mathrm{x}_{C}$ and $\mathrm{x}_{\mathrm{L}}$ refer to the log-transformed mean catches at stations $C$ and $\mathrm{L}$ respectively. In the original coordinate system, differences are detectable whenever:

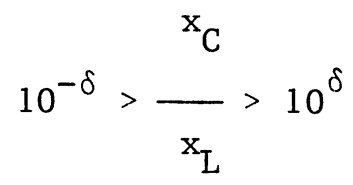

We sha11 refer to the quantity $10^{\delta}$ as the least detectable true ratio (LDTR).

Results from the first ANOVA model for trawls showed significant differences between years 1977 and 1978 for catches of spottail shiners, trout-perch and bloaters. For each of these species, particularly the bloater, the 1978 geometric mean abundance was significantly higher than the 1977 geometric mean abundance (Table 6). MONTH effects were significant for all species as were the YEAR $x$ MONTH interactions. Peaks in geometric mean monthly abundance were mainly due to peak catches in YOY geometric abundance; months of peak catch may be shifted from year to year (Fig. 7). There were no significant STATION effects, except possibly for rainbow smelt whose geometric abundance at station $\mathrm{L}(6 \mathrm{~m}-\mathrm{N})$ may be significantly greater than that for reference station C (6 m-S). STATION entered into only one significant two-way interaction (MONTH $x$ STATION for yellow perch) and only a few significant three-way interactions. An unusually high number of yellow perch were caught by trawl at station $C(6 \mathrm{~m}-\mathrm{S})$ in September 1978 and this is reflected in the significant interaction (Fig. 8). The night geometric abundance was significantly higher than the day geometric abundance for all species except yellow perch. TIME OF DAY differences were most noticeable for trout-perch and spottail shiner. The MONTH $\mathrm{x}$ TIME interaction was significant for all species, particularly spottail shiner and trout-perch. 
Table 5. Descriptive statistics for catch-per-unit-of-effort (CPE) data used in the experimental designs for the six most abundant species caught in the vicinity of the J. H. Campbell Plant, eastern Lake Michigan for years 1977 through 1978. $\mathrm{N}$ is number of samples in the experimental design, $\mathrm{X}$ is the mean number of fish caught per one unit of effort for the data set.

\begin{tabular}{|c|c|c|c|c|c|}
\hline \multirow[b]{2}{*}{ Design } & \multirow[b]{2}{*}{$\mathrm{N}$} & $\begin{array}{c}\text { Maximum } \\
\text { catch }\end{array}$ & \multirow[b]{2}{*}{$\overline{\mathrm{x}}$} & \multirow{2}{*}{\multicolumn{2}{|c|}{\begin{tabular}{lc}
\multicolumn{2}{c}{ Percentage of } \\
Standard & zero catch \\
deviation & data
\end{tabular}}} \\
\hline & & no. fish & & & \\
\hline \multicolumn{6}{|l|}{ TRAWL I } \\
\hline Spottail shiner & 112 & 158 & 9.7 & 24.3 & 43.8 \\
\hline Alewife & 96 & 4287 & 149.6 & 560.8 & 21.9 \\
\hline Rainbow smelt & 112 & 1017 & 99.5 & 178.9 & 8.9 \\
\hline Yellow perch & 112 & 90 & 3.8 & 11.3 & 53.6 \\
\hline Trout-perch & 112 & 63 & 8.0 & 15.4 & 53.6 \\
\hline Unidentified coregonid & 96 & 107 & 9.6 & 20.7 & 46.9 \\
\hline \multicolumn{6}{|l|}{ TRAWL II } \\
\hline$\overline{\text { Spottail shiner }}$ & 128 & 158 & 8.2 & 22.4 & 42.2 \\
\hline Alewife & 96 & 4287 & 237.6 & 686.0 & 31.2 \\
\hline Rainbow smelt & 128 & 1028 & 129.5 & 215.6 & 10.9 \\
\hline Yellow perch & 112 & 90 & 3.4 & 11.2 & 64.3 \\
\hline Trout-perch & 128 & 63 & 9.4 & 15.9 & 43.8 \\
\hline Unidentified coregonid & 96 & 503 & 23.6 & 56.6 & 25.0 \\
\hline \multicolumn{6}{|l|}{ BOTTOM GILL NET I } \\
\hline Spottail shiner & 64 & 155 & 11.6 & 27.7 & 51.6 \\
\hline Alewife & 64 & 195 & 15.0 & 41.1 & 40.6 \\
\hline Yellow perch & 64 & 25 & 4.9 & 6.1 & 34.4 \\
\hline Rainbow smelt & 16 & 58 & 14.4 & 17.5 & 18.8 \\
\hline \multicolumn{6}{|l|}{ BOTTOM GILL NET II } \\
\hline Spottail shiner & 40 & 155 & 27.0 & 43.6 & 42.5 \\
\hline Alewife & 40 & 185 & 22.7 & 46.0 & 12.5 \\
\hline \multicolumn{6}{|l|}{ SURFACE GILL NET I } \\
\hline$\overline{\text { Alewife }}$ & 32 & 213 & 33.4 & 47.2 & 18.8 \\
\hline \multicolumn{6}{|l|}{ SURFACE GILL NET II } \\
\hline Alewife & 40 & 213 & 23.8 & 43.2 & 37.5 \\
\hline \multicolumn{6}{|l|}{ SEINE } \\
\hline Spottail shiner & 144 & 1678 & 92.5 & 251.1 & 20.1 \\
\hline Alewife & 144 & 6174 & 276.2 & 797.3 & 27.8 \\
\hline Yellow perch & 96 & 266 & 4.8 & 27.6 & 69.8 \\
\hline Rainbow smelt & 36 & 88 & 15.9 & 25.1 & 44.4 \\
\hline
\end{tabular}




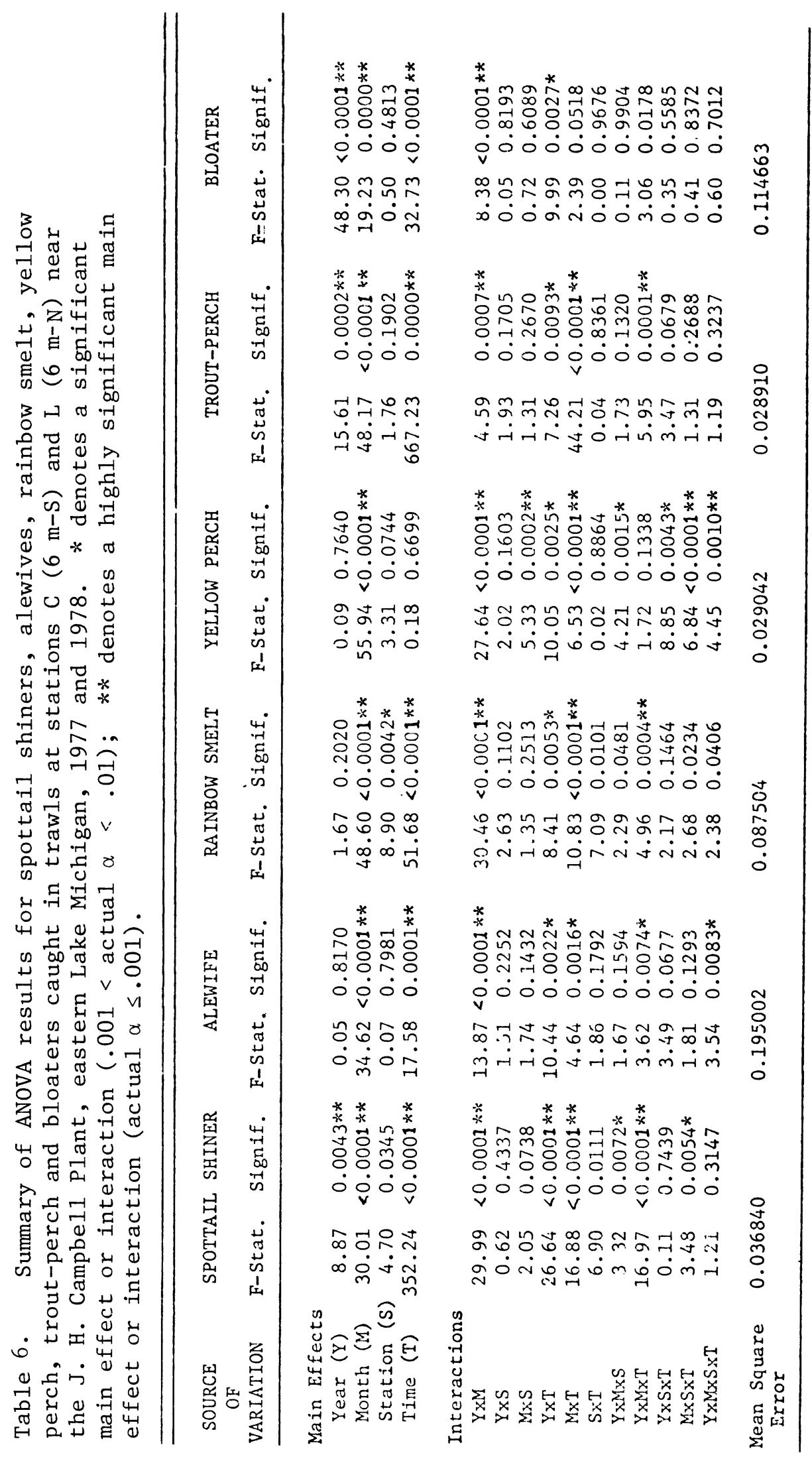



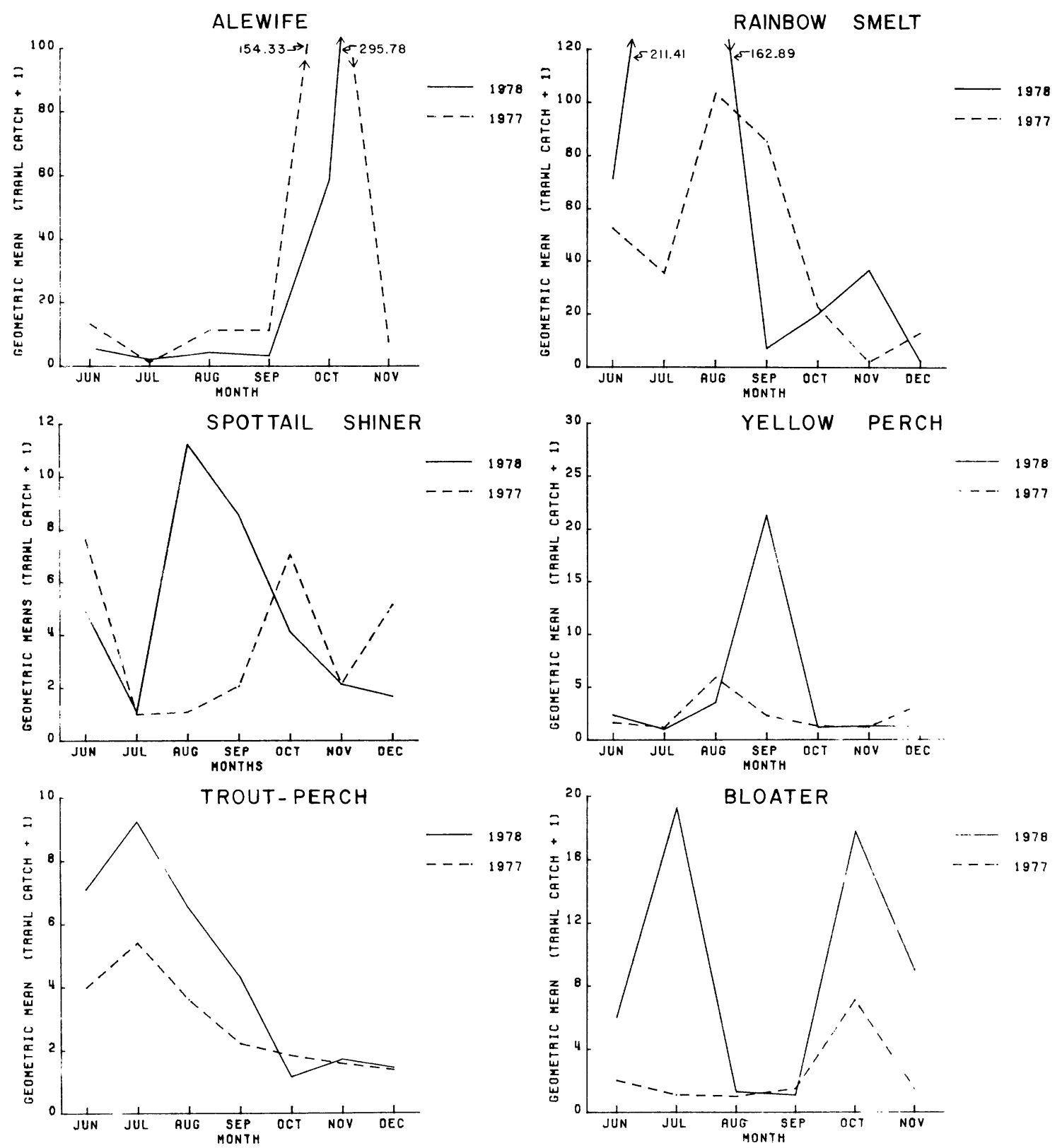

Fig. 7. Geometric mean number (plus one) of spottail shiners, alewives, rainbow smelt, yellow perch, trout-perch and bloaters caught in trawls at stations $\mathrm{C}\left(6_{\mathrm{m}-\mathrm{S})}\right.$ and $\mathrm{J}(6 \mathrm{~m}-\mathrm{N})$ near the J. H. Campbell Plant, eastern Lake Michigan, 1977 and 1.978. Graphs show the month effect. 

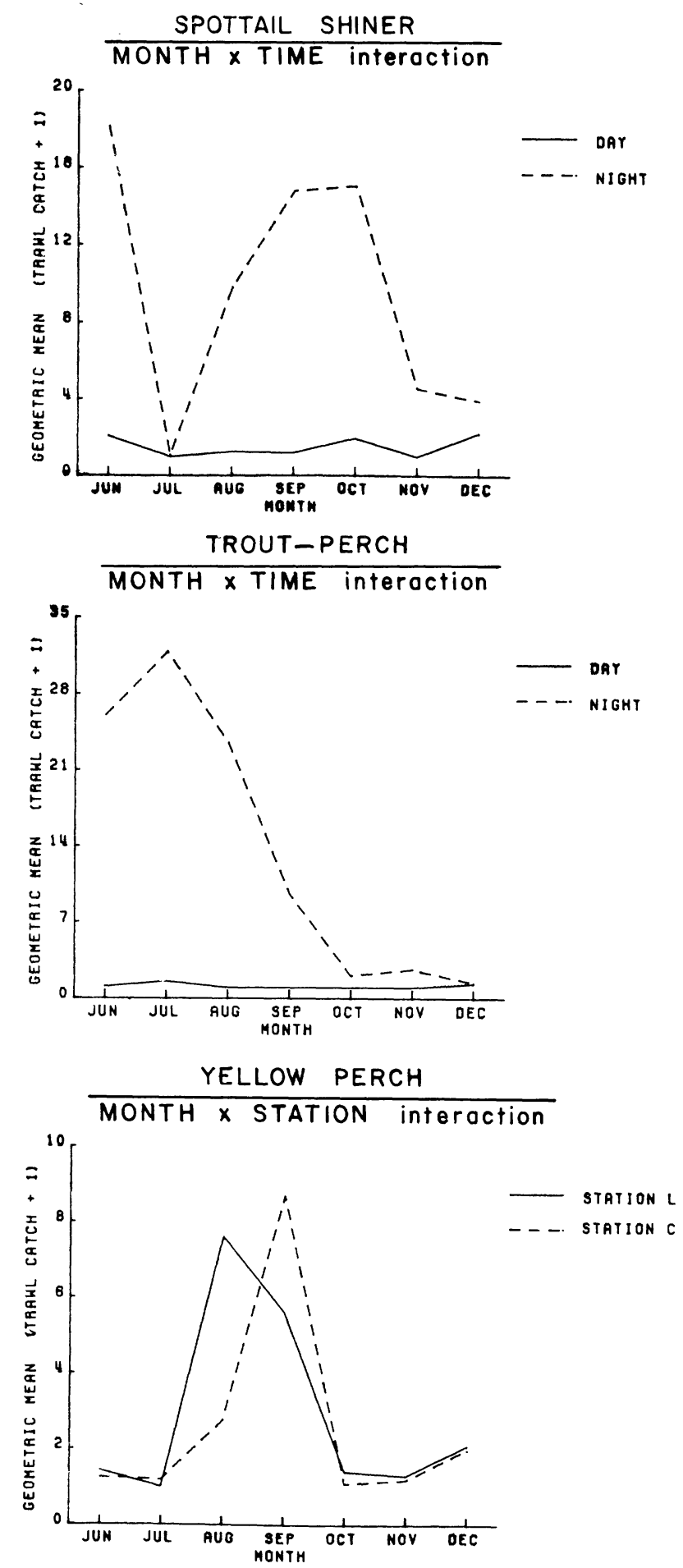

Fig. 8. Geometric mean number (plus one) of spottail shiners, yellow perch and trout-perch caught in trawls at stations $C(6 \mathrm{~m}-\mathrm{S})$ and $\mathrm{L}(6 \mathrm{~m}-\mathrm{N})$ near the J. H. Campell plant, easterr Iake Michigan, 1977 and 1978. 
Geometric mean CPE for trout-perch was uniformly low for day catches over all months; whereas, night catches varied considerably among months (Fig. 8). The YEAR $\times$ TIME interaction was also significant for all species examined in this first traw1 design.

The second traw1 design (Table 4) included the factors AREA, [ reference stations $\mathrm{C}$ and $\mathrm{D}$ ( 6 and $9 \mathrm{~m}-\mathrm{S}$, respectively) and zone of influence stations $\mathrm{L}$ and $\mathrm{N}$ (6 and $9 \mathrm{~m}-\mathrm{N}$, respectively)], DEPTH, MONTH and TIME OF DAY. Again, geometric mean abundances showed significant differences among months for all species (Table 7); peak catch months were characterized by high geometric abundance of YOY (Fig. 9). There were no significant differences between areas, although AREA entered three significant two-way and several three-way interactions which confounded interpretation of the AREA factor. The MONTH $x$ AREA interaction for smelt was characterized by a higher catch at the zone of influence area in September than at the reference area for September (Fig. 10). DEPTH may be an important factor in distribution of yellow perch and bloaters with more yellow perch caught at $6-\mathrm{m}$ stations and more bloaters caught at 9-m stations. Geometric abundances of spottail shiner and trout-perch were higher at $9-\mathrm{m}$ than at 6-m stations during the day, while at night, abundances were higher at 9-m stations (Fig. 10). Al1 species except yellow perch were captured in significantly higher geometric abundances at night than during the day for the general study area; diel differences were pronounced particularly for trout-perch and spottail shiner. The MONTH $x$ TIME interaction was significant for all species. This interaction for rainbow smelt was characterized by an unusually high geometric abundance during the day in July 1978 (Fig. 10).

Results of the first design (Table 4) for bottom gill net ANOVAs showed mean abundance was higher in 1978 than in 1977 for spottail shiner and alewife; yellow perch mean abundance was not significantly different between years (Table 8). There were significant MONTH effects for all species. Spottail shiner abundance was high from July through August in 1978 and moderately high in September 1977, while alewife showed peaks in July 1978 and September 1977 (Fig. 11). Yellow perch geometric abundance was relatively high for July 1977 and August through September 1978. Rainbow smelt abundance was highest in April. The YEAR $\mathrm{x}$ MONTH interaction was significant for spottail shiner, alewife and yellow perch. STATION effects were not significant for any of the species studied; however, STATION entered several significant firstorder interactions, most notable were the YEAR x STATION interactions for alewife and yellow perch. In 1977, considerably more alewives were caught at 6-m station $L$ zone of influence than at station $C$ (reference area), but in 1978 the mean geometric abundance was similar between the two stations. For yellow perch the abundance at reference station $\mathrm{C}$ was substantially higher than that for station L; but in 1978 abundance at station $C$ was approximately the same as at station L (Fig. 12). Again, results for spottail shiner showed a significantly greater geometric mean abundance at night than during the day. Rainbow smelt exhibited similar diel differences. The MONTH x STATION interaction was also significant for alewife and yellow perch. YEAR $\mathrm{x}$ TIME and MONTH $x$ TIME interactions were highly significant for alewife. Relatively large numbers of alewives were caught in gill nets during the day in september 1977 at station L $(6 \mathrm{~m}-\mathrm{N})$ and at night in July 1978 at both reference station C and L (Fig. 12). 

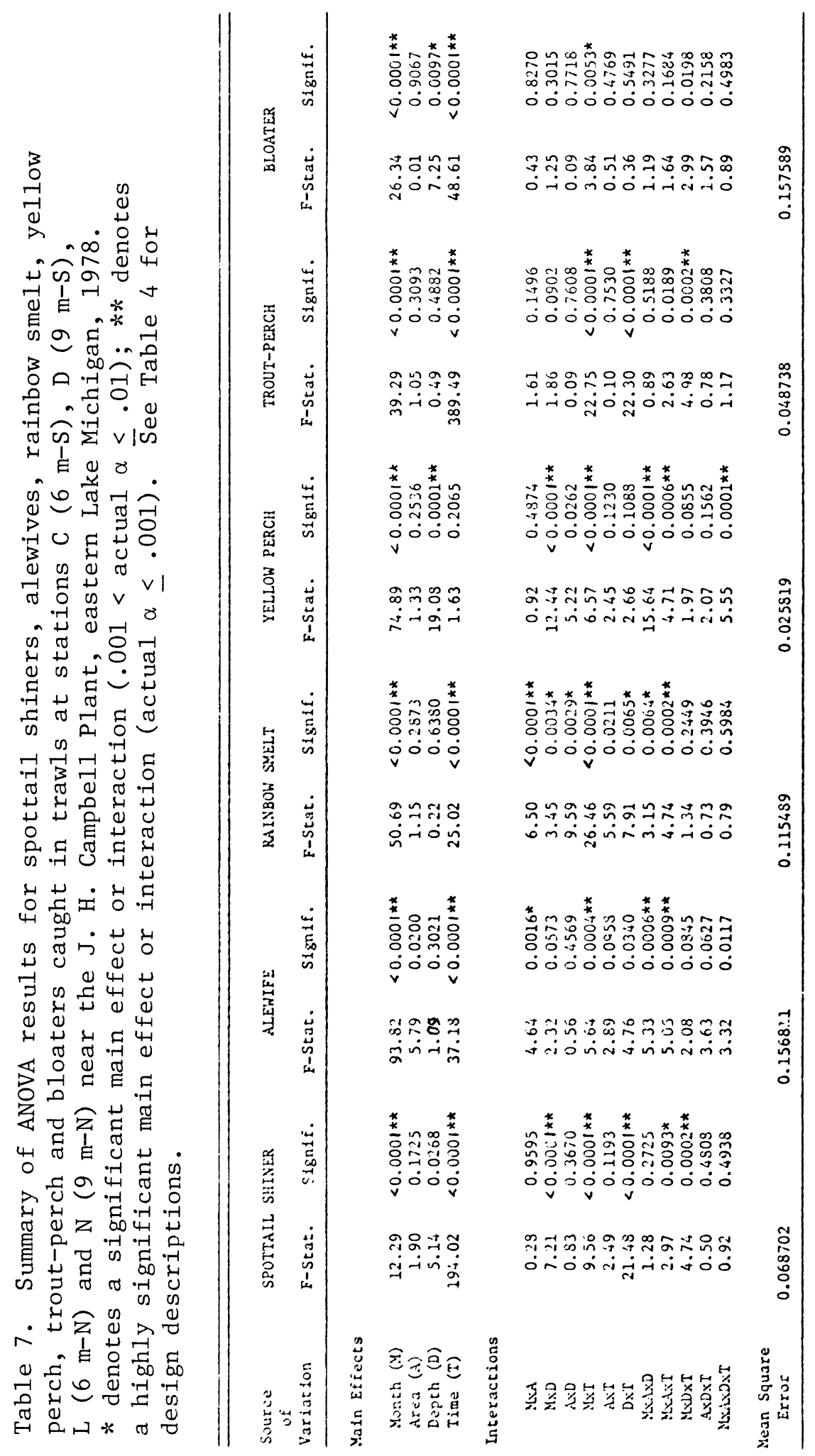

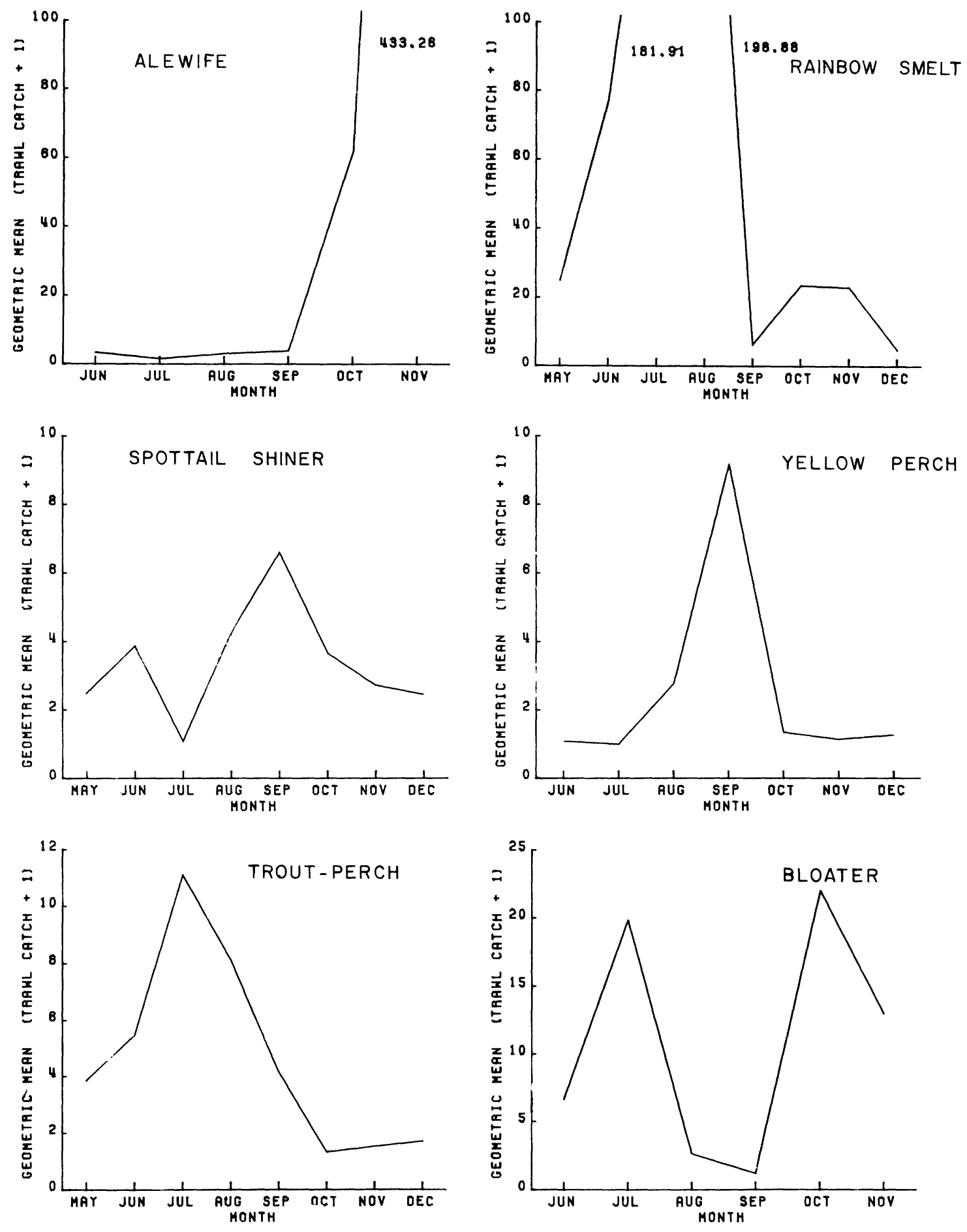

Fig. 9. Geometric mean number (plus one) of spottail shiners, alewives, rainbow smelt, yellow perch, trout-perch and bloaters caught in trawls at stations $C(6 \mathrm{~m}-\mathrm{S}), \mathrm{D}(9 \mathrm{~m}-\mathrm{S}), \mathrm{L}(6 \mathrm{~m}-\mathrm{N})$ and $\mathrm{N}(9 \mathrm{~m}-\mathrm{N})$ near the J. $\mathrm{H}$.

Campbel1 Plant, eastern Lake Michigan, 1978 only. Graphs show the month effect. 

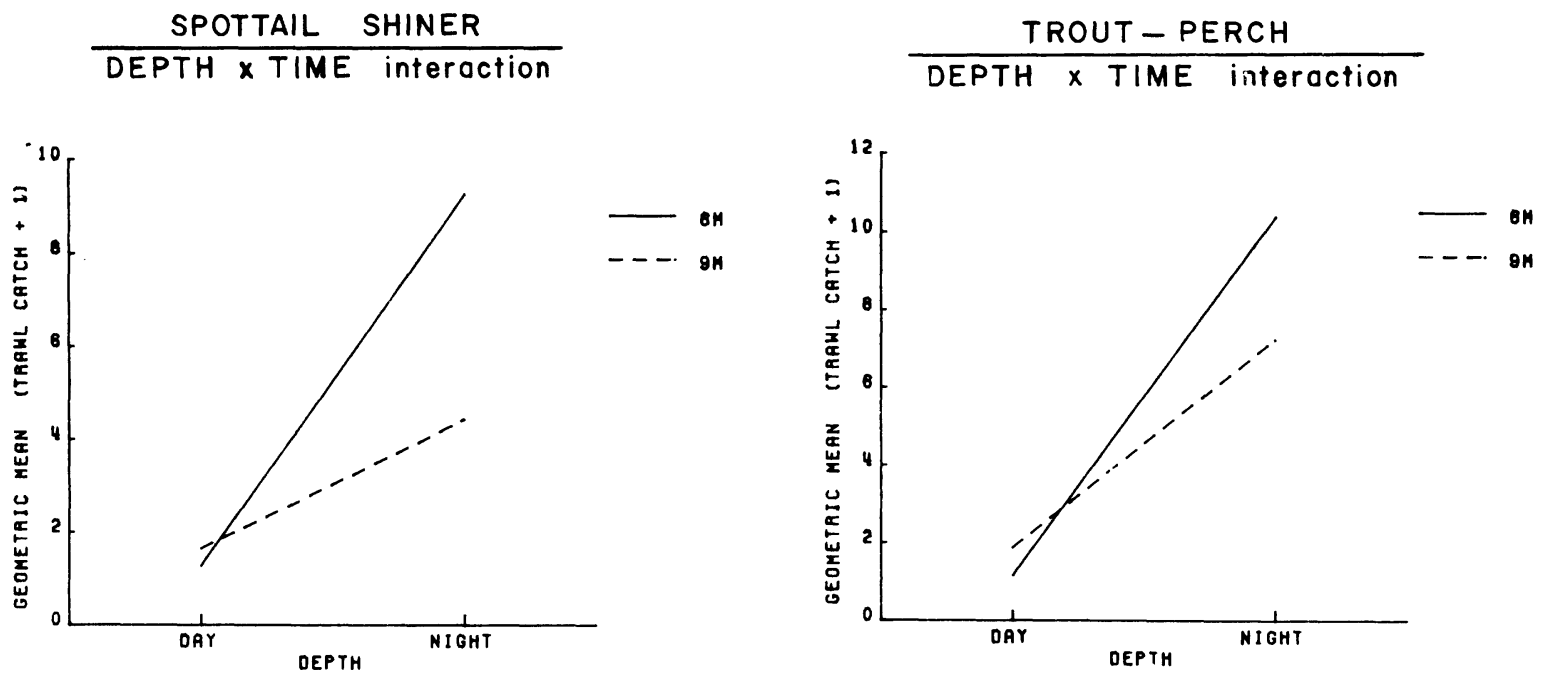

RAINBOW SMELT

MONTH $\times$ TIME interaction

RAINBOW SMELT

MONTH X AREA interaction
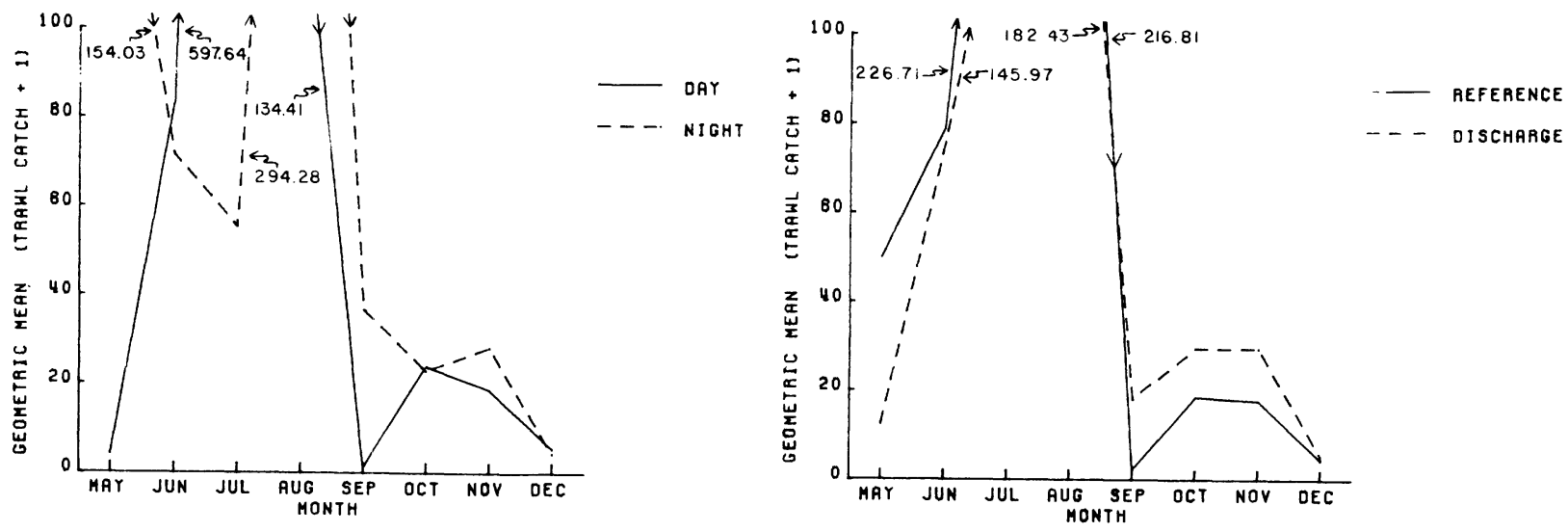

Fig. 10. Geometric mean number (plus one) of spottail shiners, rainbow smelt and trout-perch caught in trawls at stations $C(6 \mathrm{~m}-\mathrm{S}), \mathrm{D}(9 \mathrm{~m}-\mathrm{S})$, $\mathrm{L}(6 \mathrm{~m}-\mathrm{N})$ and $\mathrm{N}(9 \mathrm{~m}-\mathrm{N})$ near the J. H. Campbell plant, eastern Latie Michigan, 1978 only. 


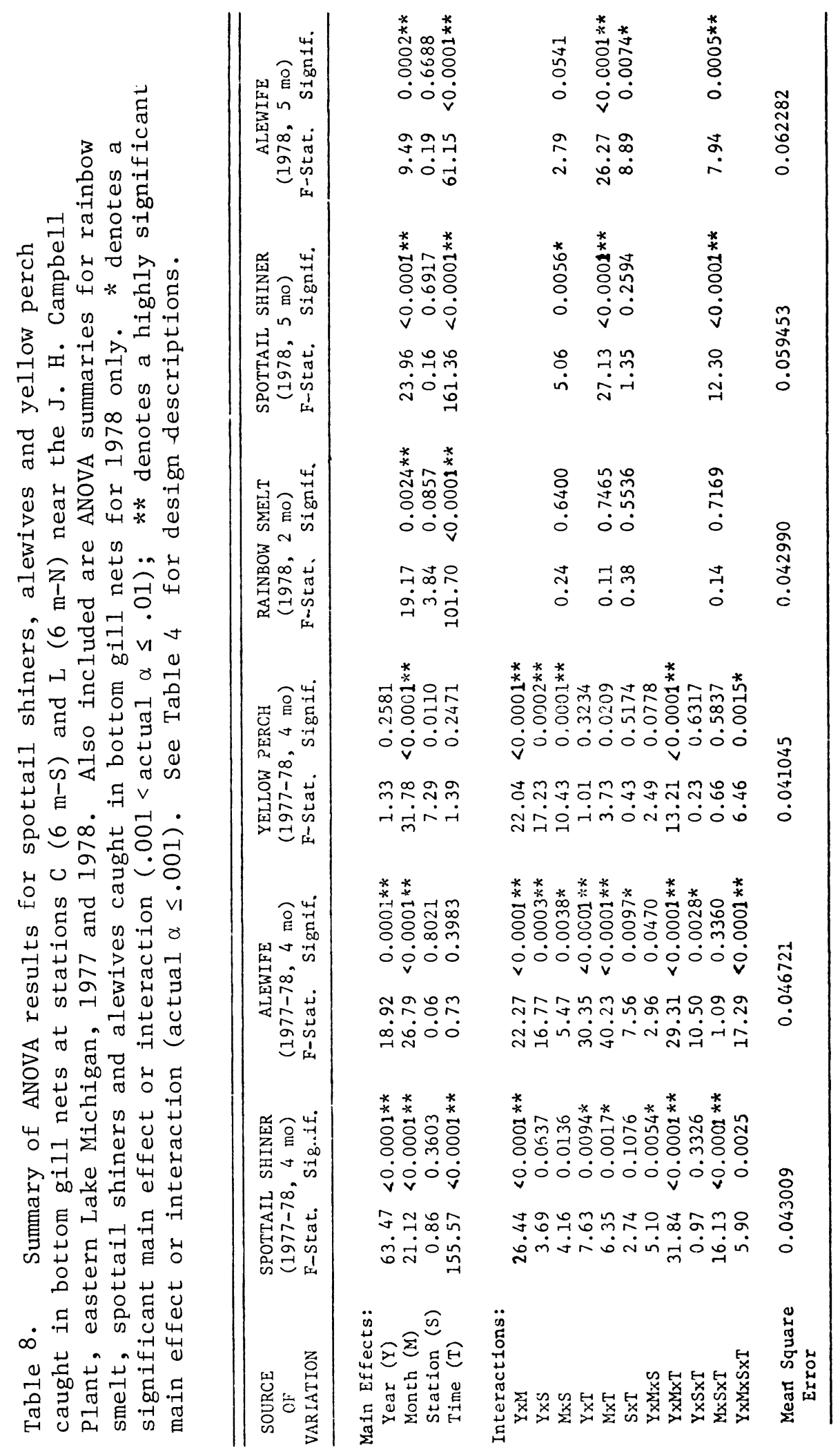



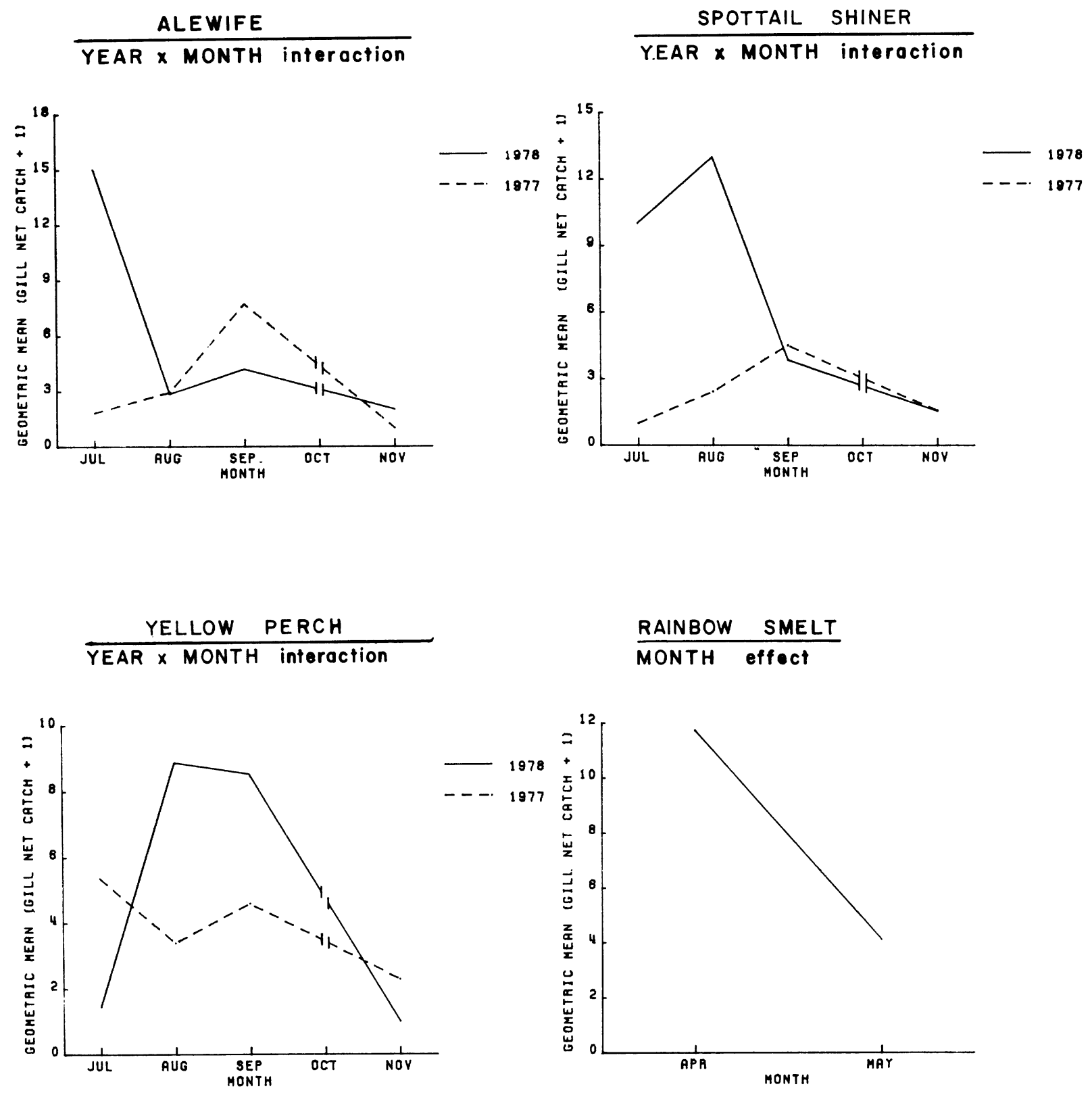

Fig. 11. Geometric mean number (plus one) of spottail shiners, alewives, yellow perch and rainbow smelt caught in hottom gill nets at stations $C(6 \mathrm{~m}-\mathrm{S})$ and L $(6 \mathrm{~m}-\mathrm{N})$ near the J. H. Campbell Plant, eastern Jake Michigan, 1977 and 1978 . 
ALEWIFE

YEAR $\times$ STATION interaction

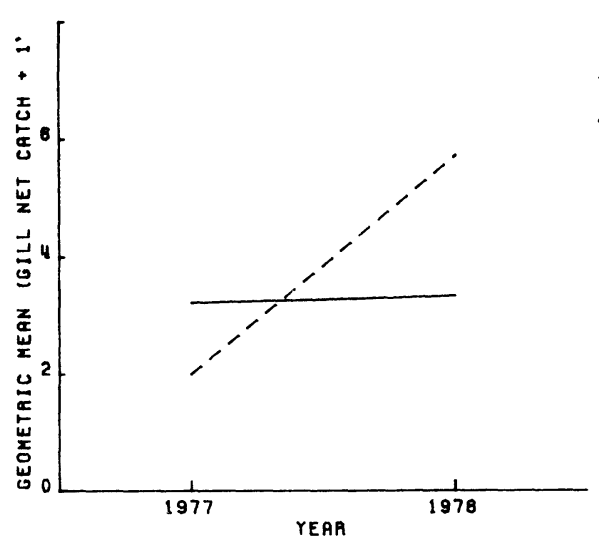

ALEWIFE

YEAR $\times$ TIME interaction

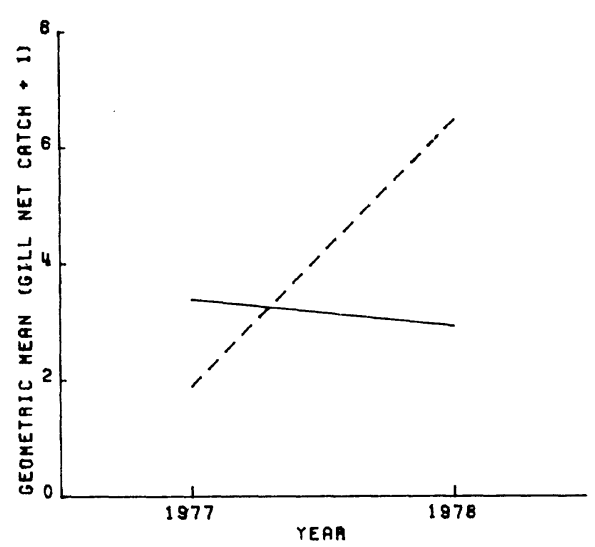

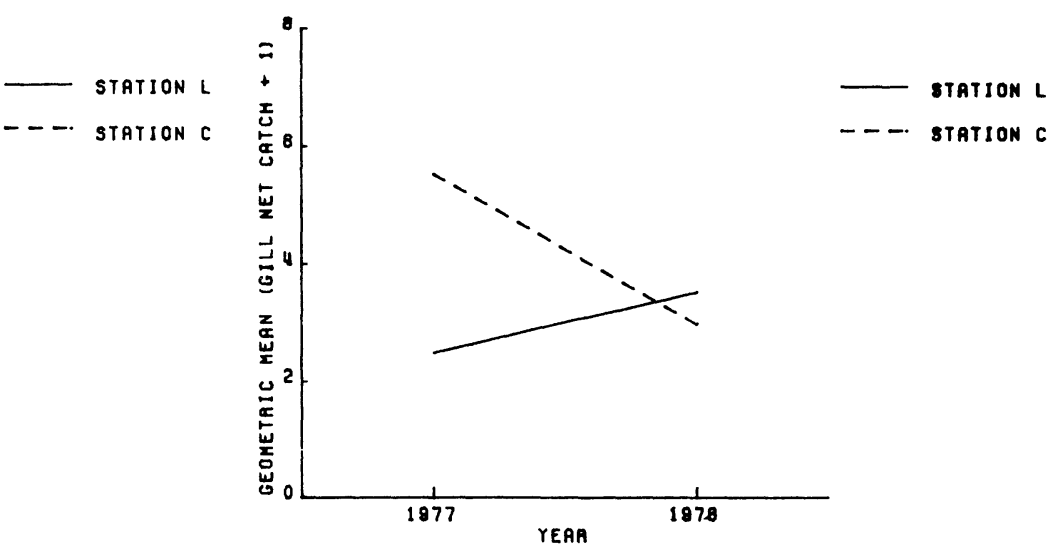

ALEWIFE

MONTH $\times$ TIME interaction

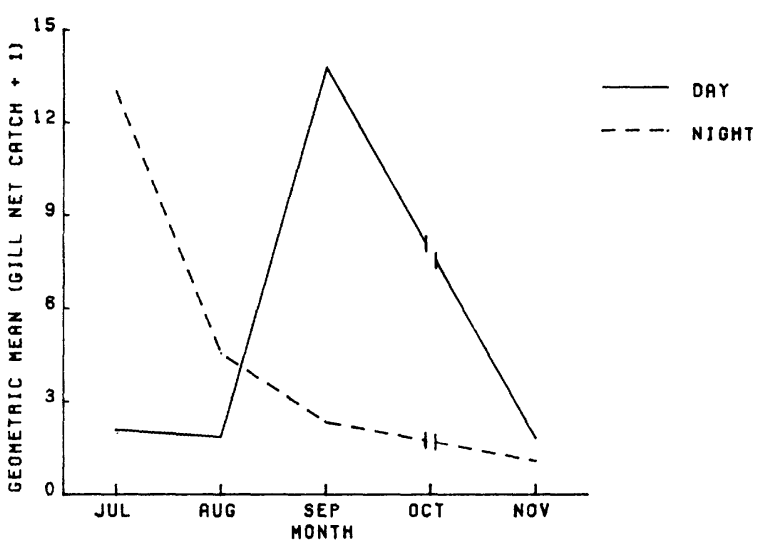

Fig. 12. Geometric mean number (plus one) of alewives and yellow perch caught in bottom gill nets at stations $C(6 \mathrm{~m}-\mathrm{S})$ and $\mathrm{L}(6 \mathrm{~m}-\mathrm{N})$ near the J. H. Campbel1 Plant, eastern Iake Michigan, 1977 and 1978 . 
A second design for bottom gill nets which included more months for 1978 than the first design, was analyzed for spottail shiner and alewife. Results were similar to those for the first bottom gill nets design (Table 8). Again, MONTH effects were significant, whereas STATION effects were not. Night catches were significantly higher than day catches for alewife. July through September were peak catch months for spottail shiner while July was the peak month for alewife (Fig. 13).

Only alewives were caught in sufficient numbers in surface gill nets to permit analysis of variance. The first design included YEAR, MONTH, STATION and TIME of DAY as factors. The only significant effect found was TIME, with higher abundance at night than during the day; no significant interactions appeared (Table 9). There were no STATION differences. Results from a second design using more months (just 1978 data) showed TIME and MONTH to be the only significant main effects (Table 9). Monthly abundance means for alewives showed a peak in July for 1978 data (Fig. 13).

Data for seines showed considerable variation. The YEAR effect was pronounced for alewife; alewife YOY abundance was not nearly as high in 1978 as it was in 1977 at the three beach stations (Table 10). MONTH proved to be significant for all species as did the YEAR $x$ MONTH interaction for spottail shiner, alewife and yellow perch (Fig. 14). STATION was a significant effect for all species except yellow perch. For alewife and spottail shiner, the geometric mean abundance was highest for beach station $\mathrm{R}$ ( $\mathrm{N}$ discharge) and lowest for station $P$ (S reference), while for smelt abundance was highest for station Q (S discharge) and lowest for reference station $P$. The Scheffé complex contrast (Scheffé 1959) of (P) vs. (Q, R) performed for each of these species showed that abundance for the $Q, R$ grouping was greater than that for $P$. The MONTH $x$ STATION interaction was also significant for those three species. Night abundance was significantly greater than day abundance for yellow perch and rainbow smelt. Smelt catches examined showed no YOY smelt were caught in the beach zone during April through June. The MONTH x TIME interaction appeared to be the strongest interaction for spottail shiner, alewife and yellow perch caught in seines. This interaction was not significant for rainbow smelt. YOY were caught in the seines between August and October (even November) and were caught in highest number during the day, unlike adults and yearlings which were caught mainly at night (Fig. 15). The MONTH x STATION interaction was particularly significant for rainbow smelt; note the high catch at station $Q$ in May (Fig. 15).

The LDTRs (Least Detectable True Ratios) calculated are ratios involving geometric mean number of fish. Power analyses involving least detectable true ratios showed that most sampling designs employed could probably detect increases in mean abundance from one station (or area) to another in the range of $15 \%$ to $50 \%$ and decreases from $13 \%$ to $33 \%$ (for $\alpha=0.01$ and Power $=0.95$ ) (Table 11). Overall, LDTRs were highest for surface gill nets. Among species, power to detect significant changes was lowest for alewives irrespective of gear used, which may be related to alewife migration and highly variable recruitment of their young. The trawl was probably the best gear for assessing impacts of plant operation. LDTRs for spottail shiner, yellow perch and trout-perch were very similar. Given that assumptions of the power analyis have been met, 


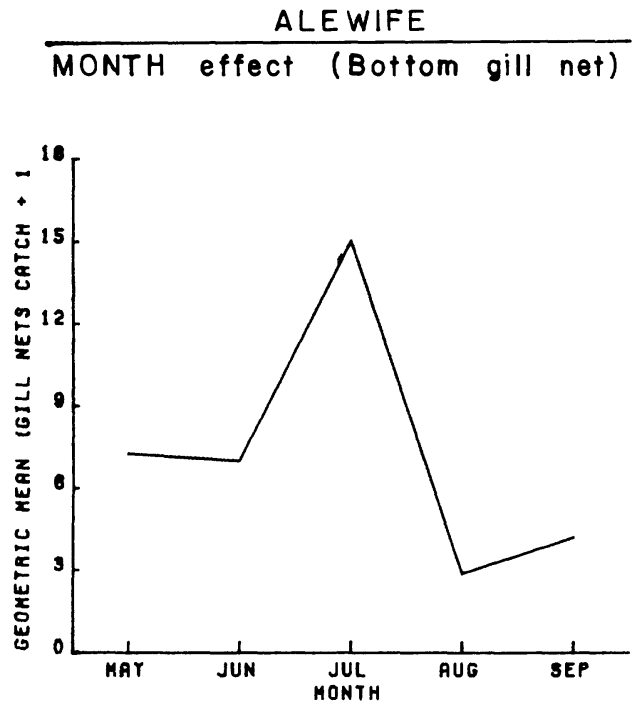

ALEWIFE MONTH effect (Surface gill net)

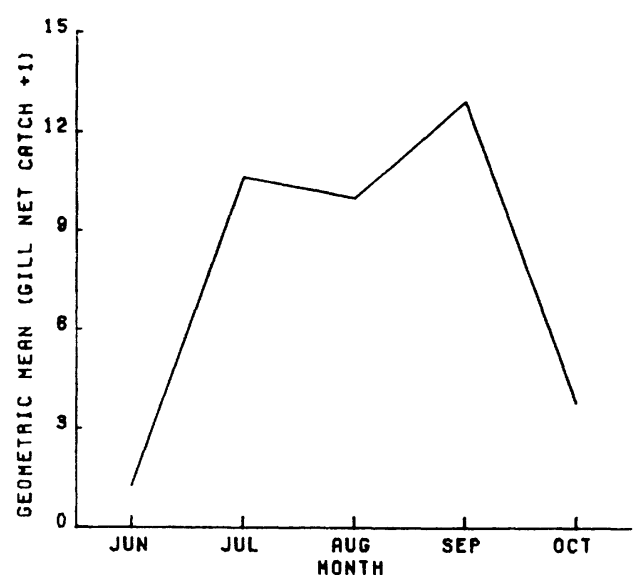

ALEWIFE
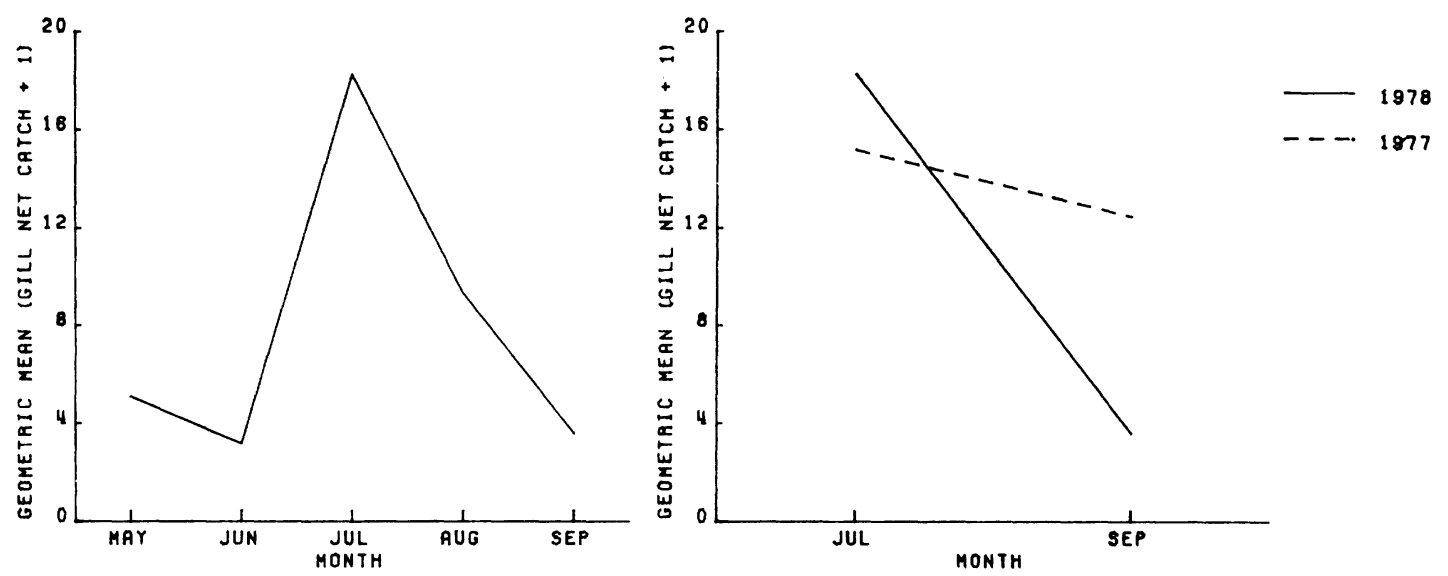

Fig. 13. Geometric mean number (plus one) of spottail shiners and alewives caught in bottom gill nets at stations $C(6 \mathrm{~m}-\mathrm{S})$ and $\mathrm{L}(6 \mathrm{~m}-\mathrm{N})$ near the J. H. Campbell Plant, eastern Lake Michigan, 1978 only. Also geometric mean number (plus one) of alewives caught in surface gill nets in 1977 and 1978; and geometric mean number (plus one) of alewives caught in surface gill nets in 1978 on $1 \mathrm{y}$. 
Table 9. Summary of ANOVA results for alewives caught in surface gill nets near the J. H. Campbell Plant, eastern Lake Michigan for 1977 through 1978 and 1978 only. * denotes a significant main effect or interaction (.001 < actual $\alpha \leq .01) ; * *$ denotes a highly significant main effect or interaction (actual $\alpha \leq .001$ ).

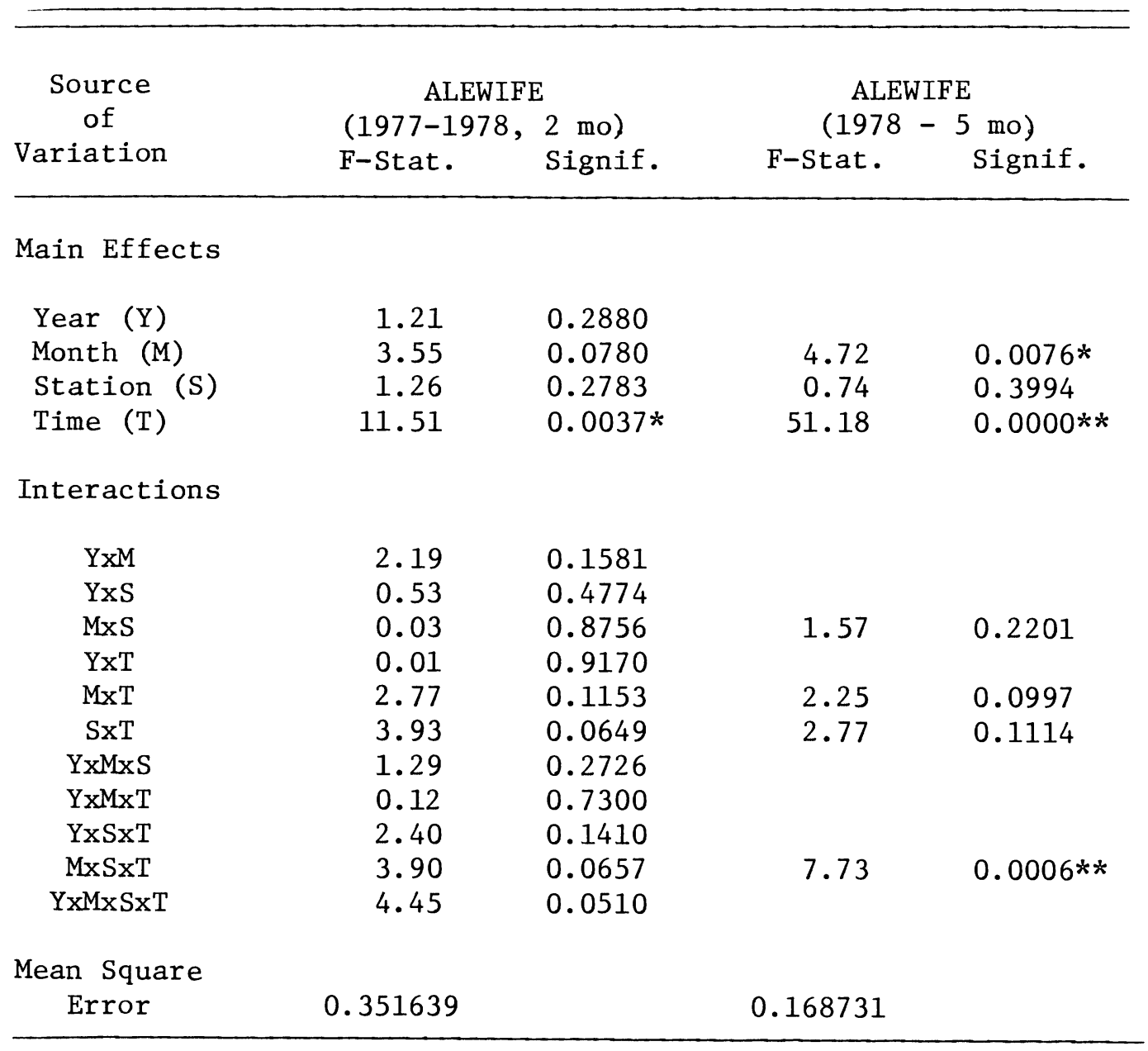


ज्ञन

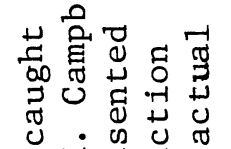

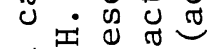

导咯造

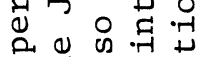

过

年 40

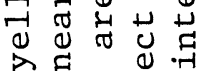

곤대

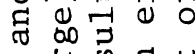

क ⿹

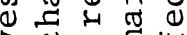

论

3

元之姿䎡

क

की

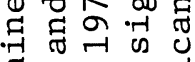

क人的出

$-10000$

ช

던

on

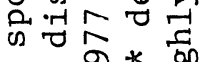

मृथ 0 *

फ

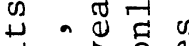

국요

की

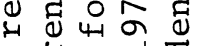

मो

苨出焉 $00 *$

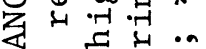

山

出定

究的空

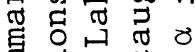

直.

का

के

$\therefore$ त क त

응

๑ ثै ثㄷㅇㅇ

윰

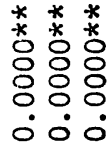

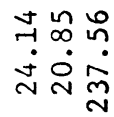

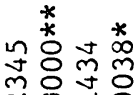

$0 \dot{00}$

영 ซै

番

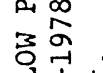

南苟

त्र

นุํํํำำ

-in่

草草草

잉ㅇㅇㅇ

000.

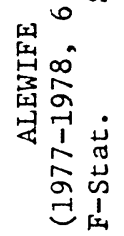

ํํㅇำ

กี่

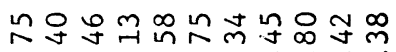

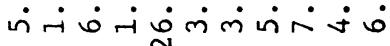

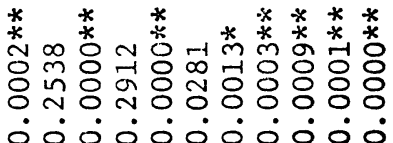

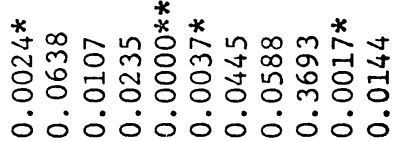

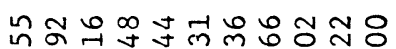
மं $\dot{\sim} \dot{m}$ in

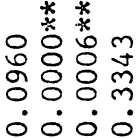

*

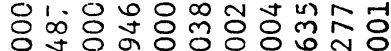

○ं $\dot{0} 0 \dot{0} 0 \dot{0} 0 \dot{0}$

跑

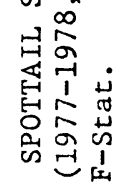

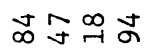

inं

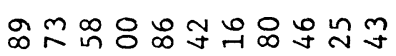

तुं

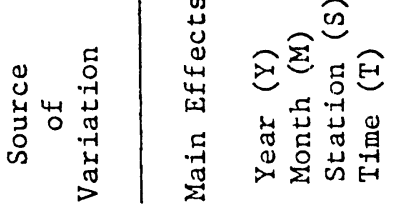

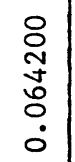

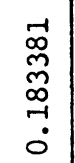

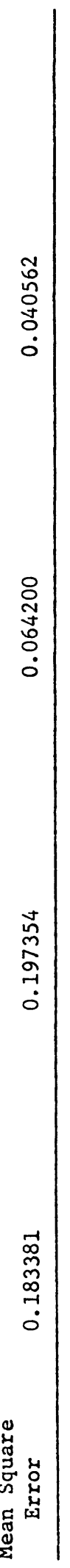



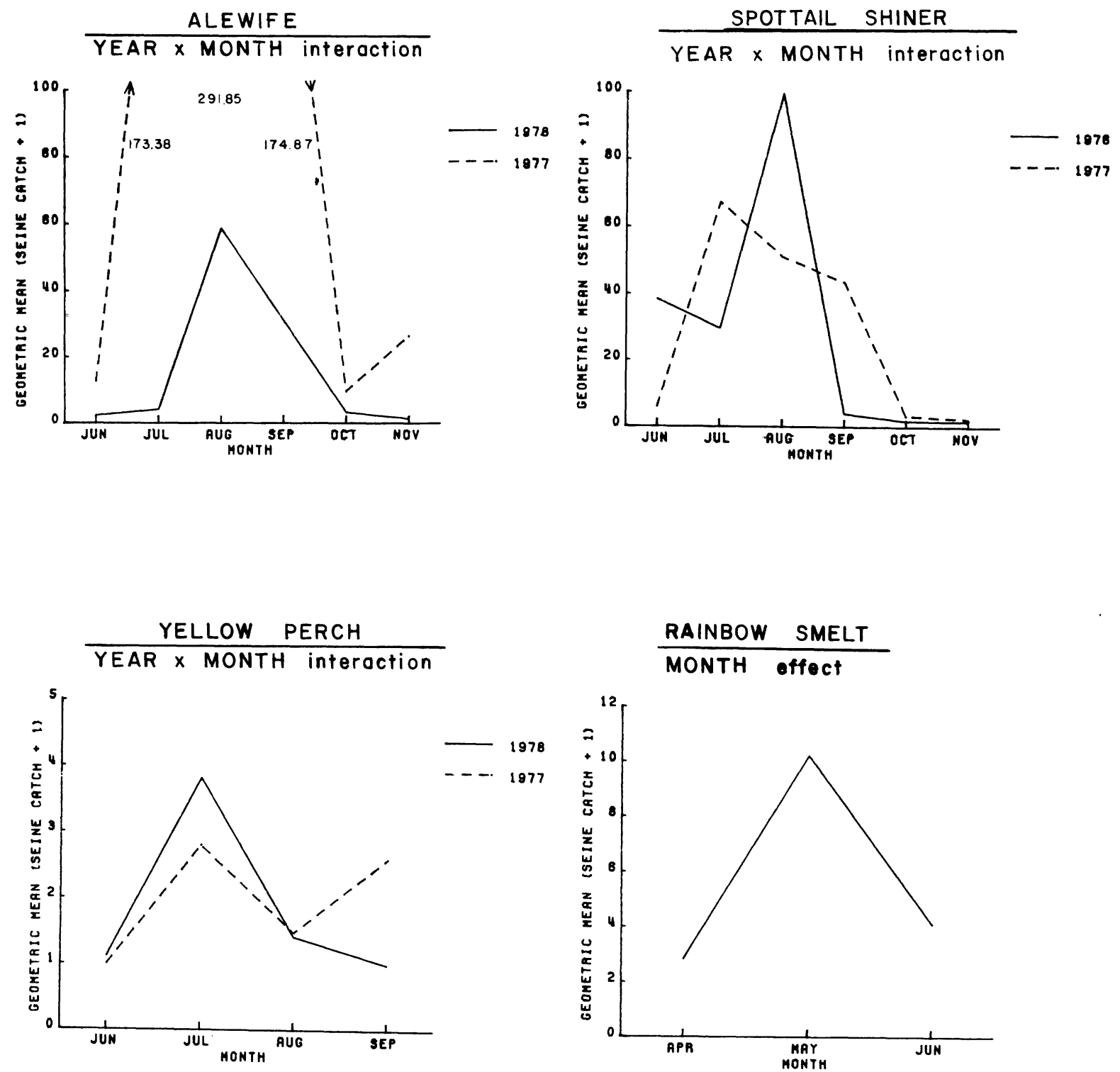

Fig. 14. Geometric mean number (plus one) of spottail shiners, alewives and yellow perch caught in seines at stations $P$ (S reference), Q (S discharge) and $R$ (N discharge) near the J. H. Campbell Plant, eastern Iake Michigan, 1977 and 1978. Also geometric mean number (plus one) of rainbow smelt caught in seines, 1978 on1y. 
ALEWIFE

MONTH X TIME interaction

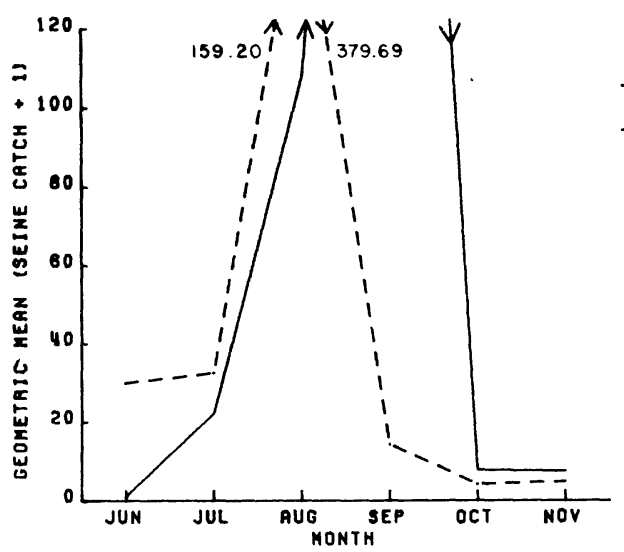

YELLOW PERCH

MONTH X TIME interaction

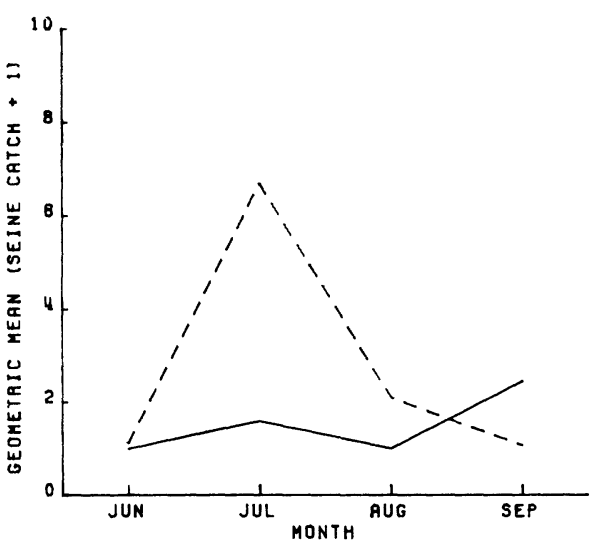

SPOTTAIL SHINER

MONTH $\times$ TIME interaction

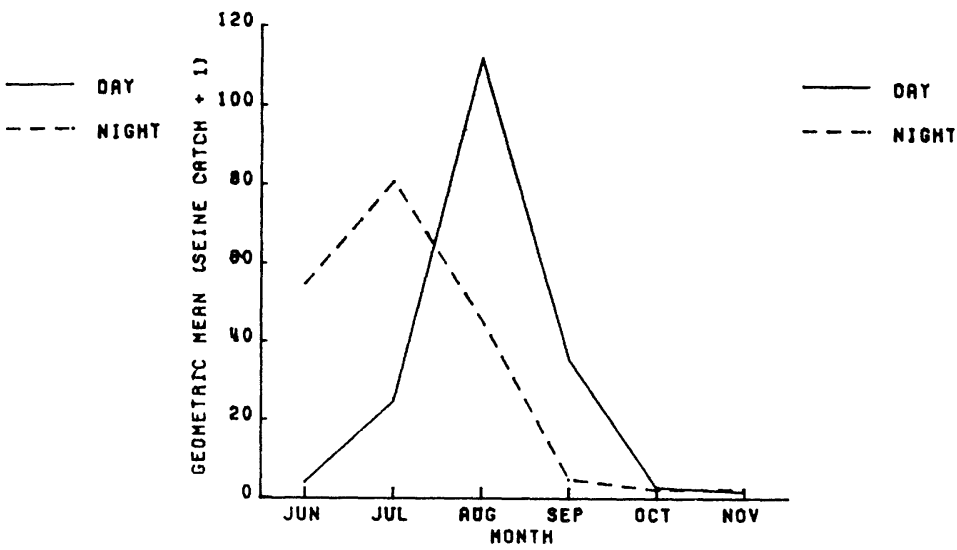

RAINBOW SMELT

MONTH $X$ STATION interaction
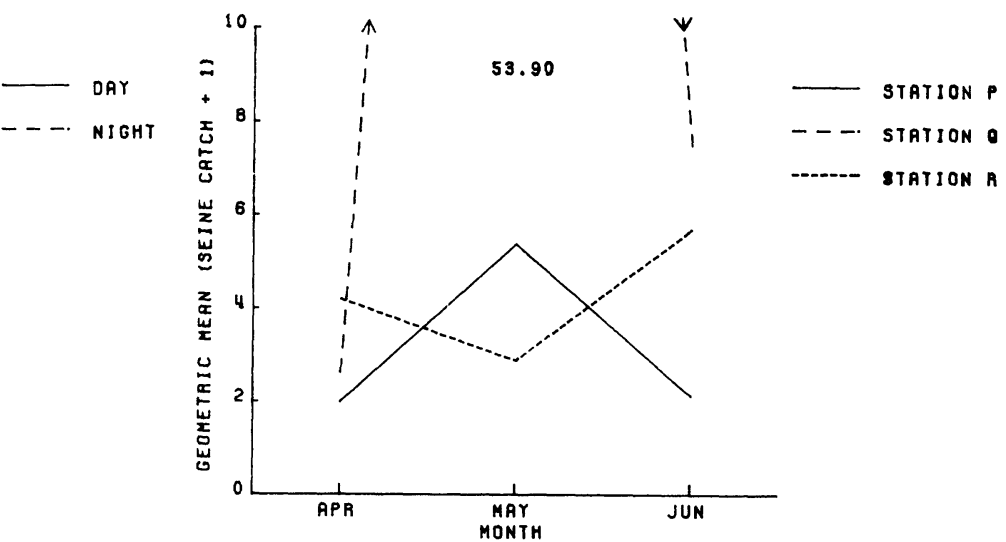

Fig. 15. Geometric mean number (plus one) of spottail shiners, alewives and yellow perch caught in seines at stations $P$ ( $S$ reference), $?$ ( $S$ discharge) and $\mathrm{R}$ (N discharge) near the J. H. Campbell Plant, eastern Lake Michigan, 1977 and 1978. Also geometric mean number (plus one) of rainbow smelt caught in seines 1978 only. 


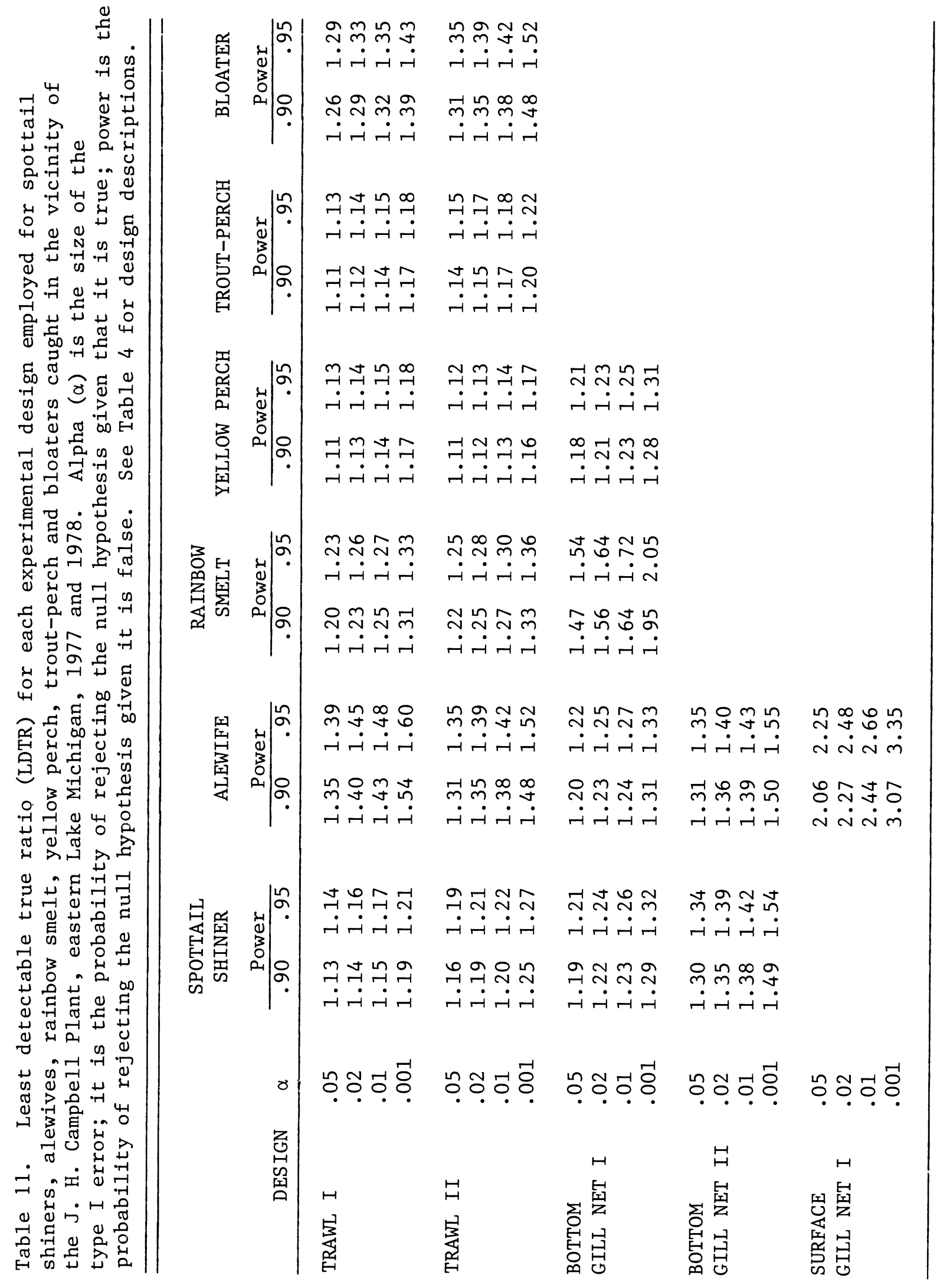




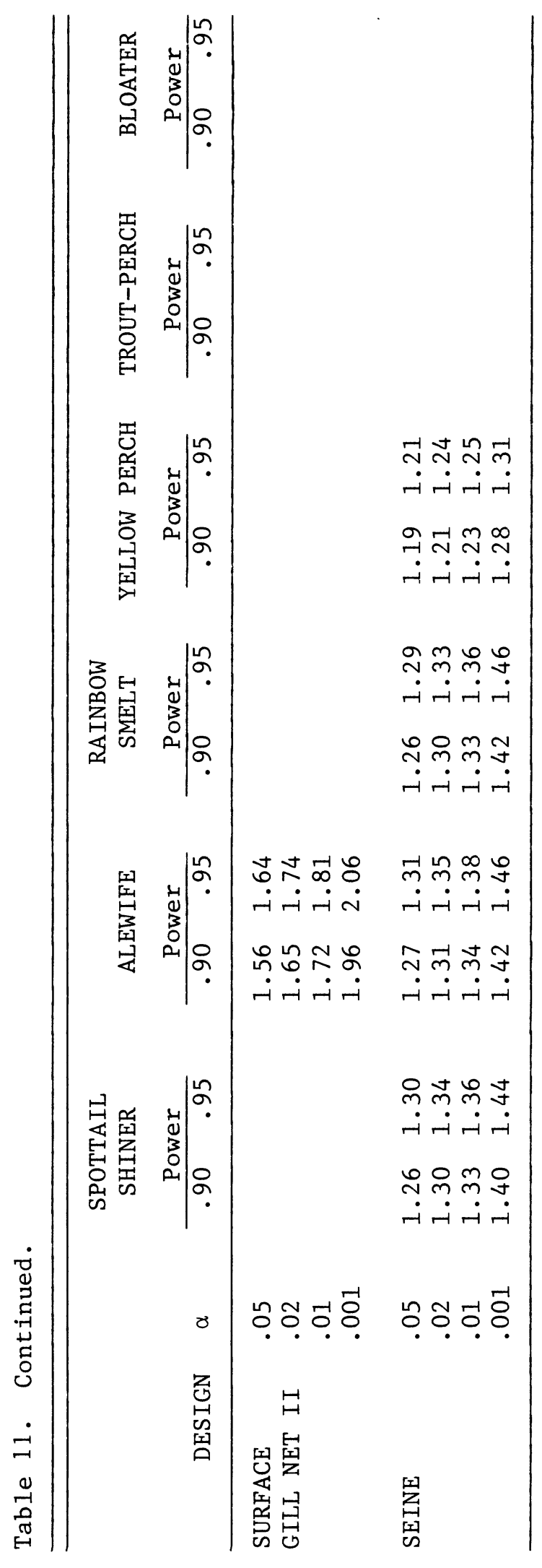


changes in catch exceeding $22 \%$ and $-18 \%$ should be detectable for these species. For rainbow smelt, this range is about $30 \%$ and $-23 \%$. For bloaters, the LDTR is quite high with changes not being detected unless outside the $42 \%$ and $-30 \%$ range. Changes in mean alewife catch of 1 ess than $48 \%$ and greater than $-32 \%$ could not be detected by the given experimental design. This effect is not a reflection of the adequacy of the experimental design, but rather an indication of the naturally high variations in abundance of alewives within the inshore zone.

Lake Michigan is subject to biological, chemical and physical processes which may bring about changes in fish populations. This makes assessing potential plant impact very difficult. Further compounding this difficulty, during 1978 dredging began in the discharge area for construction of an offshore intake and discharge system for Unit 3 of the Campbell Plant. The effects of this dredging on fish populations in the zone of influence area are unknown. Unusually high YOY trawl catches were taken in 1978 from experimental station L (6 m-N) for spottail shiner (September, night) and alewife (October, night).

Despite all of these complications, some general patterns emerged from the analyses. Month effects were significant for all designs except the first surface gill net design. These effects were related to spawning activity, inshore migration (perhaps for feeding) and to recruitment of YOY fish. YOY fish made up almost the entire catch for the large catch peaks observed during August through October, and for alewife, November. Several species showed significant year differences. Apparently, 1978 abundance of spottail shiner was significantly higher than in 1977 as shown by trawl and bottom gill net ANOVAs. Sampling efficiency was believed to be the same for both study years. The trawl ANOVA also showed an increase in trout-perch abundance from 1977 to 1978. Bloaters exhibited the most dramatic increase between the $2 \mathrm{yr}$; their abundance increased near the Campbel1 Plant and is considered to be increasing lake-wide. Alewives were significantly less abundant in the beach zone in 1978 than in 1977. Reasons for the consistently higher alewife YOY catch in the beach zone in 1977 are not clear. It may be that alewives did not produce a strong year class in 1978 .

There are no STATION (or AREA) differences for the trawl or gill net designs, except for significantly higher abundance of rainbow smelt at station $\mathrm{L}$ and at station $\mathrm{C}$. The AREA effect was found to be insignificant for rainbow smelt in the second trawl design. There was a lack of significant STATION (or AREA) differences for the traw1 and gill net designs based on data from 1977 and 1978 (preoperational years). Thus, any differences in species abundances discovered between stations (or areas) for trawl or gill net designs in future operational years will suggest a plant effect on that fish population attributable to Unit 3. STATION differences did appear in the seine design analysis for spottail shiner, alewife and rainbow smelt. Abundance at the beach station group $(Q, R)$ near the present onshore discharge was significantly higher than at reference station $P$. This may be linked with higher water temperatures at beach stations $Q$ and $R$ than at $P$ or perhaps stations $Q$ and $R$ are preferred habitat because of their proximity to the discharge canal and the warm water that comes from it. These differences may also prove to be due to wide natural variation between stations as data from more years are 
added to the data set. TIME OF DAY differences may be due to 1) horizontal movements within or out of the sampling area, 2) vertical movements within the water column or 3 ) avoidance of fishing gear during daylight. Depth may be a significant factor for yellow perch (caught mainly at $6 \mathrm{~m}$ ) and bloaters (caught mainly at $9 \mathrm{~m}$ ). Depth effects were masked by time for spottail shiner and trout-perch since these fish appeared to move into shallower water at night and are in deeper water during the day.

Interactions were difficult to analyze for these data, especially secondand third-order interactions. The strongest interactions were, generally, YEAR $\mathrm{x}$ MONTH and MONTH $\mathrm{x}$ TIME. The significant YEAR $\mathrm{x}$ MONTH interaction reflected different spawning and resultant YOY recruitment peaks between years. In the case of gill nets, interactions reflected movement inshore or offshore possibly for spawning, but also for feeding. The MONTH $x$ TIME interactions may be attributed to 1) relatively low day catch throughout the year, but widely varying night catch (i.e., for spottail shiner and trout-perch), 2) a few (or just one) unusually high day or night catches during one month (i.e., for rainbow sme1t), 3) an upwelling drastically decreasing or increasing the abundance of fish and 4) abundance of a certain age-group at a particular depth contour dependent upon time of day, e.g., catches in seines for alewives and spottail shiners. Adults and yearlings present in spring and early summer in the beach zone were caught mostly at night, while YOY in late summer and fall were caught mostly during the day. For rainbow smelt, no YoY, only adults, were caught in April and May (with a few YOY caught in June); only these three months were included in the design and this MONTH $x$ TIME interaction was not significant.

In summary, ANOVA provided some insight into the biology of the species studied despite the many complications in studying inshore fish populations of Lake Michigan. STATION (or AREA) differences may provide some information on plant impact. The ANOVA is limited by three assumptions, a crucial one being the independence of observations which is probably violated for data from these fish populations. Time series analysis is recommended when sufficient data become available to make such an analysis worthwhile. Time series analysis takes advantage of non-independence of observation and has been shown to be a helpful tool in environmental monitoring (Box and Tiao 1975). Unfortunately, this technique requires several years of data.

\section{ADULT AND JUVENILE FISH}

\section{Introduction}

This section contains adult and juvenile fish data from collections made during 1978 in the vicinity of the J.H. Campbell Plant. Due to the complexity of the systems, analyses of data from Lake Michigan and Pigeon Lake are presented separately.

A systematic list of all species collected in this study (Table 12) contains common and scientific names and is arranged alphabetically by family. Designated species codes, as well as information on where each species was caught is also included. In Pigeon Lake, 46 different fish species were collected; 35 were observed from Lake Michigan catches. Sixty-four species of adult fish representing 21 families were collected from the study area during 1978 . Total 
Table 12. Scientific name, common name and abbreviations for all species of fish captured from Campbell Plant study areas January through

December 1978. An X denotes presence in Lake Michigan, Pigeon Lake and/or impingement samples. Names assigned according to Bailey et al. 1970 .

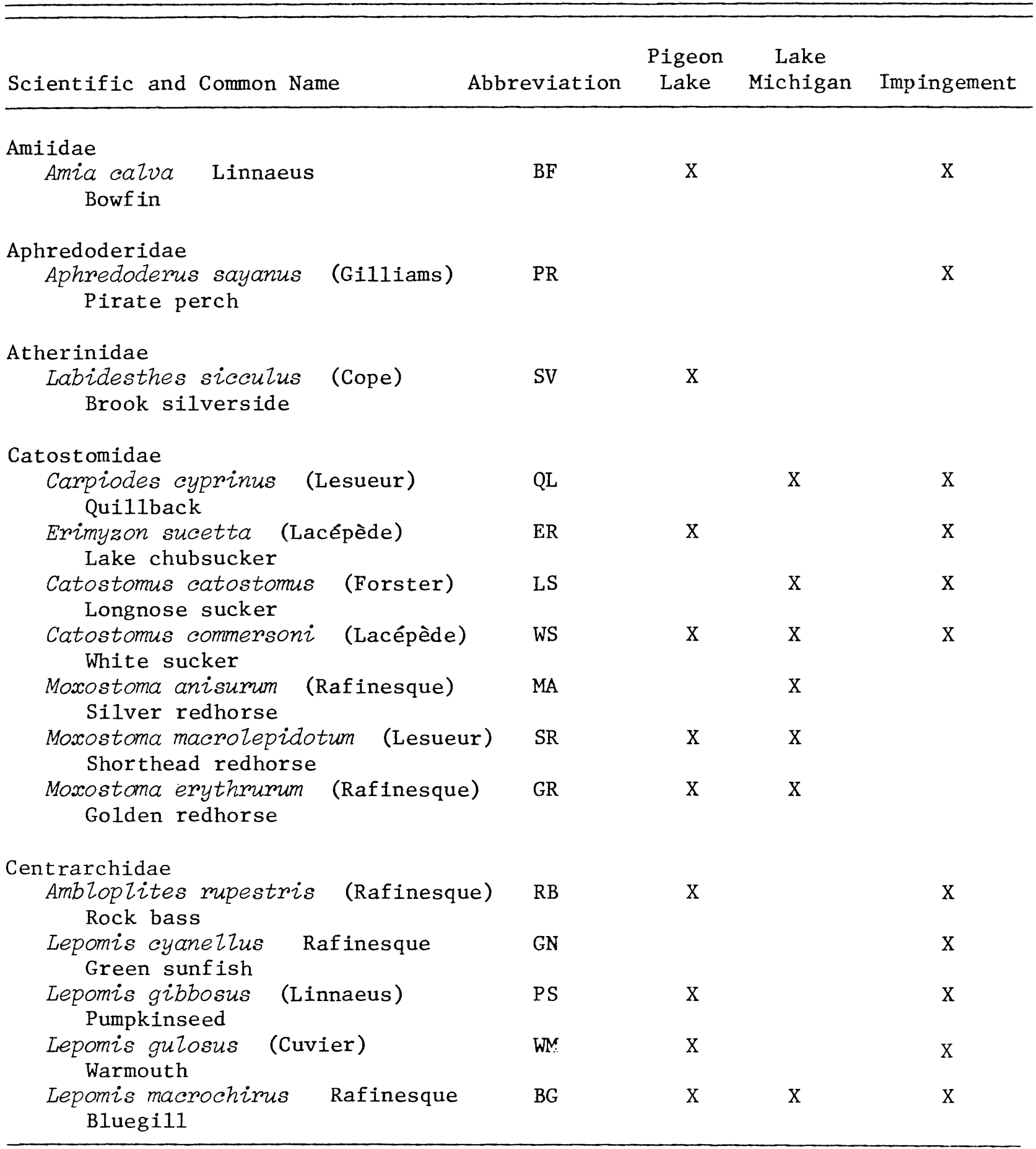


Table 12. Continued.

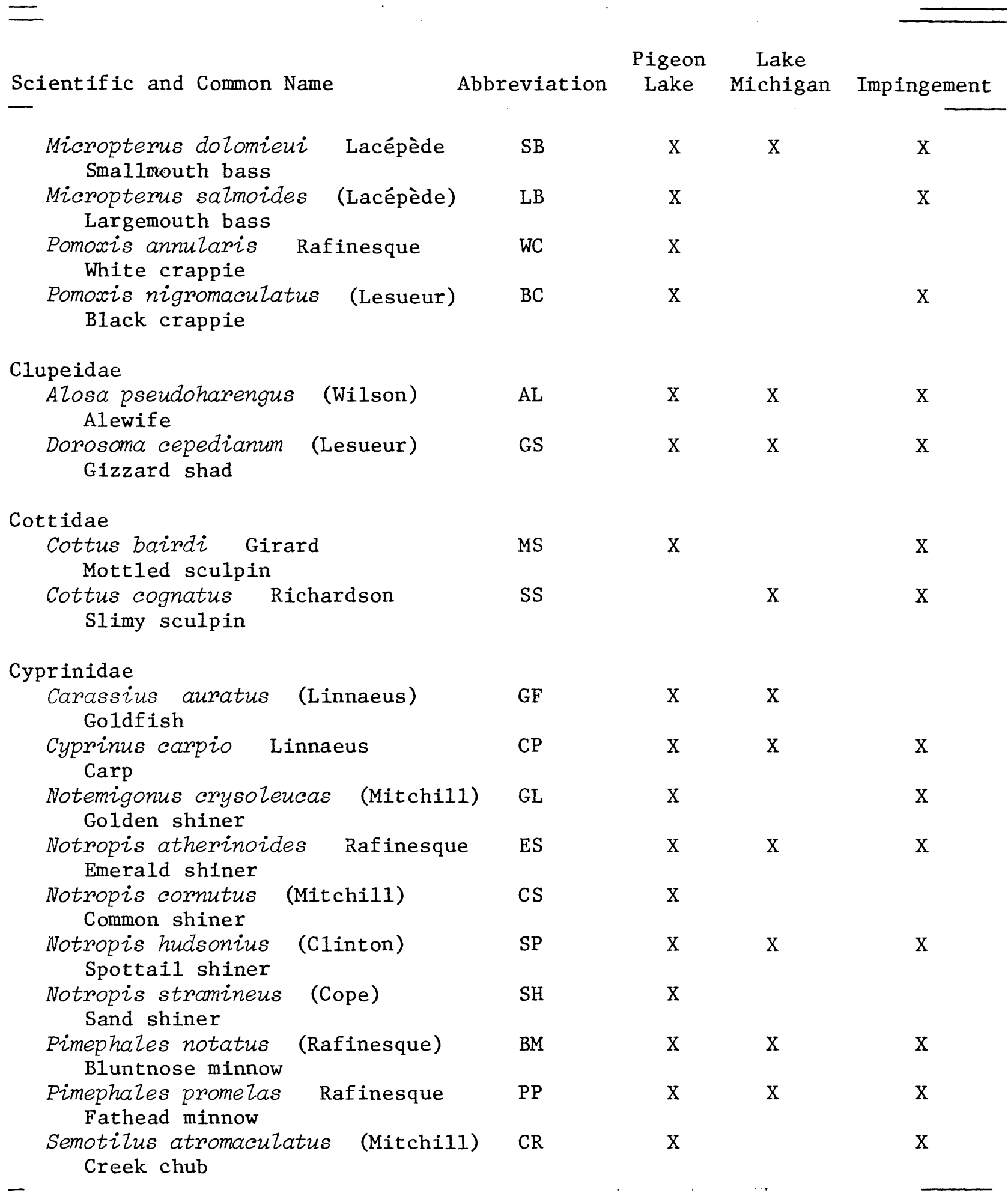


Table 12. Continued.

\begin{tabular}{|c|c|c|c|c|}
\hline Scientific and Common Name & eviation & $\begin{array}{l}\text { Pigeon } \\
\text { Lake }\end{array}$ & $\begin{array}{l}\text { Lake } \\
\text { Michigan }\end{array}$ & Impingement \\
\hline \multicolumn{5}{|l|}{ Cyprinodontidae } \\
\hline $\begin{array}{l}\text { FunduZus diaphanus (Lesueur) } \\
\text { Banded killifish }\end{array}$ & $\mathrm{BK}$ & $\mathrm{X}$ & & \\
\hline \multicolumn{5}{|l|}{ Esocidae } \\
\hline $\begin{array}{l}\text { Esox americanus vermiculatus Lesueur } \\
\text { Grass pickere1 }\end{array}$ & GP & $\mathrm{X}$ & & $\mathrm{X}$ \\
\hline $\begin{array}{l}\text { Esox Zucius Linnaeus } \\
\text { Northern pike }\end{array}$ & NP & $\mathrm{X}$ & $\mathrm{X}$ & $\mathrm{X}$ \\
\hline \multicolumn{5}{|l|}{ Gadidae } \\
\hline $\begin{array}{l}\text { Lota Zota (Linnaeus) } \\
\text { Burbot }\end{array}$ & $\mathrm{BR}$ & & $\mathrm{X}$ & $\mathrm{X}$ \\
\hline \multicolumn{5}{|l|}{ Gasterosteidae } \\
\hline $\begin{array}{l}\text { Pungitius pungitius (Linnaeus) } \\
\text { Ninespine stickleback }\end{array}$ & NS & $\mathrm{X}$ & $\mathrm{X}$ & $\mathrm{x}$ \\
\hline \multicolumn{5}{|l|}{ Ictaluridae } \\
\hline $\begin{array}{l}\text { Ictalurus melas (Rafinesque) } \\
\text { Black bullhead }\end{array}$ & $\mathrm{BB}$ & $\mathrm{X}$ & & $\mathrm{X}$ \\
\hline $\begin{array}{l}\text { Ictalurus natalis (Lesueur) } \\
\text { Yellow bullhead }\end{array}$ & YB & $\mathrm{X}$ & & $\mathrm{X}$ \\
\hline $\begin{array}{l}\text { Ictalums nebulosus (Lesueur) } \\
\text { Brown bullhead }\end{array}$ & $\mathrm{BN}$ & $\mathrm{X}$ & & $\mathrm{X}$ \\
\hline $\begin{array}{l}\text { Ictalurus punctatus (Rafinesque) } \\
\text { Channel catfish }\end{array}$ & $\mathrm{CC}$ & & $\mathrm{X}$ & $\mathrm{X}$ \\
\hline $\begin{array}{l}\text { Notumus gyrinus (Mitchill) } \\
\text { Tadpole madtom }\end{array}$ & MT & $\mathrm{X}$ & & $\mathrm{X}$ \\
\hline \multicolumn{5}{|l|}{ Lepisosteidae } \\
\hline $\begin{array}{l}\text { Lepisosteus oculatus (Winche11) } \\
\text { Spotted gar }\end{array}$ & SG & & & $\mathrm{X}$ \\
\hline \multicolumn{5}{|l|}{ Osmeridae } \\
\hline $\begin{array}{l}\text { Osmerus mordax (Mitchill) } \\
\text { Rainbow smelt }\end{array}$ & SM & $\mathrm{X}$ & $\mathrm{X}$ & $\mathrm{X}$ \\
\hline \multicolumn{5}{|l|}{ Percidae } \\
\hline \multicolumn{3}{|l|}{$\begin{array}{l}\text { Stizostedion vitreum vitreum (Mitchill)WL } \\
\text { Walleye }\end{array}$} & $\mathrm{X}$ & $\mathrm{X}$ \\
\hline $\begin{array}{l}\text { Etheostoma nigrum Rafinesque } \\
\text { Johnny darter }\end{array}$ & JD & $\mathrm{X}$ & $\mathrm{X}$ & \\
\hline $\begin{array}{l}\text { Etheostoma exile (Girard) } \\
\text { Iowa darter }\end{array}$ & $\mathrm{EE}$ & $\mathrm{X}$ & & \\
\hline $\begin{array}{l}\text { Perca flavescens (Mitchill) } \\
\text { Yellow perch }\end{array}$ & YP & $\mathrm{X}$ & $\mathrm{X}$ & $\mathrm{X}$ \\
\hline
\end{tabular}


Table 12. Continued.

\begin{tabular}{|c|c|c|c|c|}
\hline Scientific and Common Name & bbreviation & $\begin{array}{l}\text { Pigeon } \\
\text { Lake }\end{array}$ & $\begin{array}{l}\text { Lake } \\
\text { Michigan }\end{array}$ & Impingement \\
\hline $\begin{array}{l}\text { Percina caprodes (Rafinesque) } \\
\text { Logperch }\end{array}$ & LP & & & $\mathrm{X}$ \\
\hline $\begin{array}{l}\text { Percina maculata (Girard) } \\
\text { Blackside darter }\end{array}$ & $\mathrm{BD}$ & $\mathrm{X}$ & & \\
\hline \multicolumn{5}{|l|}{ Percopsidae } \\
\hline $\begin{array}{l}\text { Percopsis omiscomaycus (Walbaum) } \\
\text { Trout-perch }\end{array}$ & $\mathrm{TP}$ & $\mathrm{X}$ & $\mathrm{x}$ & $\mathrm{X}$ \\
\hline \multicolumn{5}{|l|}{ Petromyzontidae } \\
\hline $\begin{array}{l}\text { Ichthyomyzon castaneus Girard } \\
\text { Chestnut lamprey }\end{array}$ & CL & & & $\mathrm{X}$ \\
\hline $\begin{array}{l}\text { Petromyzon marinus Linnaeus } \\
\text { Sea lamprey }\end{array}$ & SL & & & $\mathrm{X}$ \\
\hline \multicolumn{5}{|l|}{ Salmonidae } \\
\hline $\begin{array}{l}\text { Coregonus clupeaformis (Mitchill) } \\
\text { Lake whitefish }\end{array}$ & $\mathrm{LW}$ & & $\mathrm{x}$ & \\
\hline $\begin{array}{l}\text { Coregonus spp. } \\
\text { Unidentified coregonids }\end{array}$ & $\mathrm{XC}$ & & $\mathrm{X}$ & $\mathrm{X}$ \\
\hline $\begin{array}{l}\text { Oncorhynchus kisutch (Walbaum) } \\
\text { Coho salmon }\end{array}$ & $\mathrm{CM}$ & $\mathrm{X}$ & $\mathrm{x}$ & $\mathrm{X}$ \\
\hline $\begin{array}{l}\text { Oncorhynchus tshawytscha (Walbaum) } \\
\text { Chinook salmon }\end{array}$ & $\mathrm{CH}$ & $\mathrm{X}$ & $\mathrm{X}$ & $\mathrm{X}$ \\
\hline $\begin{array}{l}\text { Prosopium cylindraceum (Pallas) } \\
\text { Round whitefish }\end{array}$ & $\mathrm{RW}$ & & $\mathrm{x}$ & \\
\hline $\begin{array}{l}\text { Salmo gairdneri Richardson } \\
\text { Rainbow trout }\end{array}$ & $\mathrm{RT}$ & $\mathrm{X}$ & $\mathrm{x}$ & $\mathrm{X}$ \\
\hline $\begin{array}{l}\text { Salmo trutta Linnaeus } \\
\text { Brown trout }\end{array}$ & BT & & $\mathrm{x}$ & $\mathrm{X}$ \\
\hline $\begin{array}{l}\text { Salvelinus namaycush (Walbaum) } \\
\text { Lake trout }\end{array}$ & LT & $\mathrm{X}$ & $\mathrm{X}$ & $\mathrm{X}$ \\
\hline $\begin{array}{l}\text { Sciaenidae } \\
\text { Aplodinotus grunniens } \\
\text { Freshwater drum }\end{array}$ & FD & & $\mathrm{X}$ & $\mathrm{x}$ \\
\hline $\begin{array}{l}\text { Umbridae } \\
\text { Umbra limi (Kirtland) } \\
\text { Central mudminnow }\end{array}$ & MM & $\mathrm{X}$ & & \\
\hline
\end{tabular}


species for the combined 1977-1978 studies is 67. Percent contribution of each species to total catch (all gear types combined) for each lake was calculated; alewives comprised $49 \%$ of the Lake Michigan catch (Table 13), while spottail shiner dominated Pigeon Lake samples (24.5\% - Table 14).

For purposes of our analyses, a species was designated major if it represented more than $1 \%$ of the total catch for either lake. For Lake Michigan, major species included: alewife, rainbow smelt, spottail shiner, unidentified coregonids, trout-perch and yellow perch. Major species in Pigeon Lake included: spottail shiner, golden shiner, yellow perch, bluntnose minnow, alewife, largemouth bass, emerald shiner, black crappie, johnny darter and pumpkinseed. Remaining species in the catch for each lake were designated common when 100 or more specimens were collected and minor if fewer than 100 were taken.

Species were treated differently, depending on abundance in our samples. Discussions of major species included seasonal, spatial and diel distributions of various size and age-groups. We attempted to explain the results of the study on the basis of biologial and physical considerations and compared our findings with those available in the literature. Gonad data were used to identify spawning periods and explain distribution and were only presented for major and common species. Numbers of fish examined for gonad condition that are presented in each gonad table reflected the number of fish actually processed. Due to our subsampling procedures (see METHODS - LABORATORY ANALYSIS OF JUVENILE AND ADULT FISH), gonad data could be biased since the most numerous size intervals of fish were underrepresented. Data from some major species are presented concerning water temperatures where a particular size fish was most often caught. Using length-frequency histograms, we were able to separate YOY from adults and compare each group's distribution and behavior. Biological aspects related to temperature preference, predation and feeding habits were discussed when pertinent. Statistical analyses were done for major species in Lake Michigan to determine differences between months, stations C (6 m-S) and $\mathrm{L}(6 \mathrm{~m}-\mathrm{N})$ and time of day (see RESULTS AND DISCUSSION - STATISTICS). When enough data were available, size range, spatial and diel behavior patterns, spawning times and catch-temperatures were discussed for common and minor species.

Monthly catch results for each gear type by lake for all species (Tables 15-20) showed that among gear types, seine catches were highest in Lake Michigan with 10,917 fish collected. Bottom and surface gill nets captured 9157 and 2062 fish respectively and trawls caught 68,848 fish. Alewives comprised the highest percentage numerically (49) of the catch from combined gear types in Lake Michigan. Only two gear types (bottom gill nets and seines) were employed in Pigeon Lake. Seine samples contained $9540 \mathrm{fish}$ of which $26.0 \%$ were spottail shiners and $23.0 \%$ were golden shiners. Bottom gill nets only captured $475 \mathrm{fish}$; $51 \%$ were alewife and $32.6 \%$ were yellow perch. Species numbers by size interval were compiled for each month by lake for all sampling gear combined (Appendix 6). For major species in Lake Michigan and Pigeon Lake, monthly length-frequency distributions were plotted for each gear type (Appendix 7). Limnological and weather data recorded during the sampling periods are shown by gear type in Appendixes 1, 2 and 3. Impingement samples at the J.H. Campbell Plant in 1978 were comprised mostly of gizzard shad (55\% of 
Table 13. Summary of all fish species caught by all gear types in Lake Michigan near the J. H. Campbell Plant, eastern Lake Michigan, April-December 1978.

\begin{tabular}{|c|c|c|c|c|c|c|c|c|c|c|c|}
\hline \multirow[b]{2}{*}{ SPECIES } & \multicolumn{9}{|c|}{ MONTHS } & \multirow[b]{2}{*}{$\frac{\text { SOM }}{446 \%}$} & \multirow[b]{2}{*}{$\frac{50.7072 L}{19.038}$} \\
\hline & APR & $\frac{\text { MAT }}{880}$ & $\frac{501}{565}$ & 3712 & $\frac{A^{\prime \prime} f_{6}}{T^{293}}$ & $\frac{50 p}{1956}$ & बता & $\frac{107}{26846}$ & $\frac{D P C}{6}$ & & \\
\hline $\begin{array}{l}\text { ALEWIFE } \\
\text { RAINBOW SMELT }\end{array}$ & 1093 & $\begin{array}{l}8040 \\
4045\end{array}$ & $\begin{array}{r}366 \\
2492\end{array}$ & $565 ?$ & 6216 & 2270 & 1116 & $\begin{array}{l}1083 \\
1083\end{array}$ & $359^{\circ}$ & 25328 & 27.838 \\
\hline $\begin{array}{l}\text { SPOTTAIL SHINER } \\
\text { SPIN }\end{array}$ & 26 & 425 & 3093 & $42 ? 2$ & 3479 & 1045 & 245 & 142 & 105 & 12754 & 14.029 \\
\hline UN IDENTIF IED COREGONID & 0 & 5 & 191 & 540 & 2.73 & 19 & 1666 & 479 & 18 & 3121 & 3.430 \\
\hline TROUT-PERCH & 11 & $32 n$ & $\begin{array}{r}452 \\
8\end{array}$ & $\begin{array}{l}357 \\
142\end{array}$ & 400 & 204 & 22 & $\begin{array}{l}56 \\
19\end{array}$ & 19 & 1841 & 2.023 \\
\hline $\begin{array}{l}\text { YELLOW PERCH } \\
\text { NINESPINE ST ICKLEBACK }\end{array}$ & ${ }_{5}^{8}$ & 33 & $143^{\mathrm{A}}$ & $\begin{array}{l}142 \\
151\end{array}$ & $\begin{array}{c}x+3 \\
30\end{array}$ & $\begin{aligned} 539 \\
0\end{aligned}$ & $\begin{array}{r}28 \\
2\end{array}$ & $\begin{array}{r}19 \\
0\end{array}$ & $\begin{array}{r}29 \\
0\end{array}$ & $\begin{array}{r}1778 \\
414\end{array}$ & $\begin{array}{l}1.185 \\
0.455\end{array}$ \\
\hline $\begin{array}{l}\text { NINESINE STIICKLEBACK } \\
\text { JOHNY DARTER }\end{array}$ & 0 & 29 & 48 & 35 & 29 & .6 & 52 & 36 & 6 & $\begin{array}{l}414 \\
362 \\
-152-10\end{array}$ & $\begin{array}{l}0.455 \\
0.398\end{array}$ \\
\hline $\begin{array}{l}\text { WHITE SUCKER } \\
\text { WHAN }\end{array}$ & 0 & 39 & 29 & 78 & $T R$ & 79 & 5 & 11 & 0 & 319 & 0.351 \\
\hline $\begin{array}{l}\text { SLIMY SCULPIN } \\
\text { SL }\end{array}$ & 61 & $12^{\circ}$ & 13 & 37 & a & 0 & $n$ & 1 & 34 & 279 & 0.397 \\
\hline LAKE TROUT & 31 & 32 & 22 & 15 & & 2 & 96 & 53 & 0 & 258 & 0.284 \\
\hline GIZZARD SHAD & 0 & 0 & $?$ & 1 & 5.5 & 59 & 15 & 18 & 32 & 189 & 0.208 \\
\hline BROWN TROUT & 41 & 23 & 20 & 11 & 4 & $\begin{array}{l}5 \\
0\end{array}$ & & 7 & 0 & 114 & 0.125 \\
\hline $\begin{array}{l}\text { LONGNOSE SUCKER } \\
\text { CHO SALMON }\end{array}$ & 3 & $\begin{array}{l}31 \\
7\end{array}$ & 19 & $\begin{array}{l}16 \\
\text { if }\end{array}$ & $?$ & $\frac{9}{7}$ & $\frac{2}{3}$ & 3 & $\begin{array}{l}0 \\
0\end{array}$ & $\begin{array}{l}73 \\
56\end{array}$ & 0.080 \\
\hline $\begin{array}{l}\text { COHO SALMON } \\
\text { EMERALD SHINER }\end{array}$ & 2 & $n$ & $\begin{array}{r}19 \\
3\end{array}$ & is & if & 27 & $n^{3}$ & 4 & 0 & $\begin{array}{c}56 \\
50\end{array}$ & $\begin{array}{l}0.062 \\
0.055\end{array}$ \\
\hline $\begin{array}{l}\text { EMERALD SHINER } \\
\text { CHINOOK SALMON }\end{array}$ & $\begin{array}{l}0 \\
4\end{array}$ & 1 & 13 & 7 & ? & 3 & 0 & 1 & 然 & 29 & 0.032 \\
\hline BLUNTNOSE MINNOW & 0 & 0 & 0 & $n$ & 1 & 13 & 0 & 1 & 0 & 15 & 0.016 \\
\hline CARP & 2 & 1 & 0 & $n$ & 7 & 2 & 1 & 0 & 0 & 13 & 0.014 \\
\hline ROUND WHITEFISH & 1 & 1 & 2 & $n$ & 3 & 0 & : & 1 & 1 & 10 & 0.011 \\
\hline RAINBOW TROUT & 2 & 2 & 3 & ? & $?$ & 0 & 1 & 4 & 0 & 9 & 0.010 \\
\hline $\begin{array}{l}\text { LAKE WH ITEF ISH } \\
\text { WALLEYE }\end{array}$ & 4 & 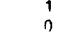 & $?$ & $i_{n}$ & $\begin{array}{l}1 \\
h \\
\end{array}$ & o & $\begin{array}{l}n \\
n \\
n\end{array}$ & $\begin{array}{l}n \\
n\end{array}$ & 0 & 9 & $\begin{array}{l}0.010 \\
0.008\end{array}$ \\
\hline $\begin{array}{l}\text { WALLEYE } \\
\text { SILVER REDHORSE }\end{array}$ & 0 & $n$ & 0 & $n$ & a & 4 & ? & $?$ & 0 & 4 & $\begin{array}{l}0.008 \\
0.004\end{array}$ \\
\hline $\begin{array}{l}\text { Q } \\
\text { QUILLBACK }\end{array}$ & 0 & 0 & 1 & $n$ & 2 & 1 & $?$ & 0 & 0 & 4 & 0.004 \\
\hline BURBO & 0 & 0 & & ? & 1 & n & $?$ & 1 & 0 & & 0.004 \\
\hline GOLDEN REDHORSE & 0 & 0 & n & 1 & n & 3 & n & 0 & 0 & & 0.004 \\
\hline CHANNEL CATFISH & 0 & $n$ & $n$ & $\hat{n}$ & 1 & 2 & $?$ & $?$ & 0 & 3 & 0.003 \\
\hline BLUEG ILL & ? & ? & 0 & $\hat{n}$ & 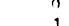 & 1 & 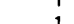 & 0 & 0 & $\frac{2}{2}$ & 0.002 \\
\hline $\begin{array}{l}\text { NORTERN PIIKE } \\
\text { SMALMOUTH BAS }\end{array}$ & 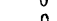 & 0 & $n$ & $n$ & 1 & 1 & 0 & 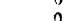 & 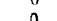 & 2 & 0.002 \\
\hline $\begin{array}{l}\text { SMALLMOUTH BASS } \\
\text { SHORTHEAD REDHORSE }\end{array}$ & 0 & $n$ & 1 & $n$ & ? & $n$ & 0 & 0 & 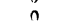 & 1 & 0.002 \\
\hline FATHEAD MINNOW & ? & $n$ & 0 & $n$ & 1 & 0 & 0 & 0 & 0 & 1 & 0.001 \\
\hline FRESHWATER DRUM & 0 & $n$ & 0 & $n$ & $n$ & 1 & n & $n$ & 0 & 1 & 0.001 \\
\hline GOLDFISH & 0 & 0 & $?$ & 1 & ? & ? & 0 & 0 & 0 & 1 & 0.001 \\
\hline TOTALS & 1313 & 6008 & 7116 & 15933 & 12552 & 6216 & 12577 & 29767 & 502 & 90994 & \\
\hline
\end{tabular}

Table 14. Summary of all fish species caught by all gear types in Pigeon Lake, April-December 1978.

\begin{tabular}{|c|c|c|c|c|c|c|c|c|c|c|c|}
\hline \multirow[b]{2}{*}{ SPECIES } & \multicolumn{9}{|c|}{ MONTHS } & \multirow[b]{2}{*}{ som } & \multirow[b]{2}{*}{ SOP TOTAL } \\
\hline & $A P R$ & $\sin y$ & JUN & $\mathrm{JTL}$ & ATH & Spp & OCT & Nov & nPC & & \\
\hline $\begin{array}{l}\text { SPOTTAIL SHINER } \\
\text { GOIDEN SHINER }\end{array}$ & 23 & 266 & 79 & 327 & 56 & 929 & $6 \sqrt{64}$ & 97 & n & 2456 & \\
\hline $\begin{array}{l}\text { GOLDEN SHINER } \\
\text { YELLOW PERCH }\end{array}$ & $\begin{array}{r}1168 \\
126\end{array}$ & 976 & 2 & $\begin{array}{l}17 \\
277\end{array}$ & 11 & 10 & ? & 35 & 0 & 2220 & $\begin{array}{l}22.167 \\
17.683\end{array}$ \\
\hline $\begin{array}{l}\text { YELLOW PERCH } \\
\text { BLUNTNOSE MINNOW }\end{array}$ & $\begin{array}{l}126 \\
169\end{array}$ & 312 & 541 & $\begin{array}{r}377 \\
6,3\end{array}$ & 470 & $? 6$ & 45 & 33 & 5 & 1771 & $\begin{array}{r}17.683 \\
8.627\end{array}$ \\
\hline $\begin{array}{l}\text { BLUNTNOSE MINNOW } \\
\text { ALEWIFE }\end{array}$ & $\begin{array}{r}169 \\
7\end{array}$ & $\begin{aligned} 172 \\
n\end{aligned}$ & $\begin{array}{l}15,1 \\
137\end{array}$ & $\begin{array}{r}5,3 \\
4>7\end{array}$ & $\begin{array}{r}120 \\
19\end{array}$ & $\begin{array}{l}3 \\
3\end{array}$ & 20 & 166 & $n$ & $\begin{array}{l}864 \\
605\end{array}$ & $\begin{array}{l}8.627 \\
6.041\end{array}$ \\
\hline & 1 & 27 & $\begin{array}{r}137 \\
43\end{array}$ & $\begin{array}{l}427 \\
234\end{array}$ & 127 & $79^{3}$ & 3 & 12 & $\begin{array}{l}1 \\
0\end{array}$ & 532 & $\begin{array}{l}6.041 \\
5.312\end{array}$ \\
\hline $\begin{array}{l}\text { LARGEMLUTH BASS } \\
\text { EMERALD SHINER }\end{array}$ & 70 & 3 & $?$ & 1 & 0 & 5 & 339 & 39 & 0 & 466 & 4.553 \\
\hline BLACK CRAPPIE & 1 & 1 & 16 & $\therefore$ & 121 & 47 & 1 & 5 & $n$ & 246 & 2.456 \\
\hline $\begin{array}{l}\text { JOHNNY DARTER } \\
\text { J }\end{array}$ & 21 & $5 n$ & 21 & 39 & 79 & 12 & 12 & 4 & 0 & 236 & 2.356 \\
\hline PUMPKINSEED & 3 & 21 & 39 & 30 & 15 & a & 0 & $n$ & 0 & 114 & $1.13 R$ \\
\hline BROOK SILVERSIDE & 0 & 1 & 1 & 1 & 37 & 3n & 2 & 5 & 0 & 80 & 0.709 \\
\hline ROCK BASS & 3 & 3 & 36 & 16 & 11 & 2 & 5 & $n$ & 0 & 76 & 0.759 \\
\hline BLUEG I LL & 1 & 3 & 13 & 15 & in & 5 & 5 & 0 & 0 & $\tau_{2}$ & 0.519 \\
\hline BANDED KILLIFISH & 1 & 0 & 0 & 0 & in & 7 & $n$ & 3 & 0 & 51 & 0.509 \\
\hline $\begin{array}{l}\text { NINESPINE STICKLEBACK } \\
\text { NTE }\end{array}$ & 19 & $2 ?$ & 0 & 2 & $n$ & $n$ & $n$ & $n$ & 0 & 43 & 0.429 \\
\hline NORTHERN PIKE & 7 & 3 & 3 & 4 & 13 & 4 & 3 & 3 & 2 & 42 & 0.419 \\
\hline COHO SALMON & 0 & 1 & 17 & $n$ & n & $n$ & 0 & 0 & 0 & 19 & 0.180 \\
\hline TADPOLE MADTOM & 2 & $?$ & 10 & ? & $?$ & 1 & 1 & $n$ & $n$ & 16 & 0.160 \\
\hline TROUT-PERCH & 1 & 11 & 0 & 0 & $n$ & 1 & $n$ & 1 & 1 & 15 & 0.150 \\
\hline SMALLMOUTH BASS & 1 & 2 & ? & 4 & $\tau_{1}$ & 0 & $n$ & $n$ & 0 & 14 & 0.140 \\
\hline $\begin{array}{l}\text { BOWFIN } \\
\end{array}$ & 4 & 0 & $?$ & 4 & $?$ & ? & 1 & 0 & $n$ & 13 & 0.130 \\
\hline RAINBOW SMELT & 3 & 6 & $\ddot{n}$ & $n$ & 1 & 0 & $n$ & $n$ & 0 & 10 & 0.100 \\
\hline $\begin{array}{l}\text { CARP } \\
\text { CATE }\end{array}$ & 1 & $n$ & 0 & 1 & h & $n$ & $n$ & ? & n & a & 0.090 \\
\hline LAKE TROUT & ? & 0 & 0 & $?$ & $n$ & $n$ & 7 & 0 & 0 & 7 & 0.070 \\
\hline $\begin{array}{l}\text { BROWN BULLHEAD } \\
\text { BROW }\end{array}$ & 2 & 1 & , & $n$ & 1 & $n$ & 0 & 0 & n & 6 & 0.050 \\
\hline RAINBOW TROUT & 0 & 0 & 3 & $?$ & ? & $n$ & 1 & 0 & 0 & 5 & 0.0 fon \\
\hline WHITE SUCKER & 1 & 2 & 0 & 1 & 2 & 0 & $n$ & 0 & $n$ & 5 & 0.050 \\
\hline YELLOW BULLHEAD & 3 & 0 & 4 & 0 & n & $n$ & $n$ & ? & n & 7 & 0.070 \\
\hline MOTTLED SCULPIN & 0 & $n$ & 0 & $n$ & $n$ & $n$ & 3 & 1 & 0 & 4 & 0.040 \\
\hline GRASS PICKEREL & 0 & 1 & 1 & 1 & ? & 0 & $n$ & $i$ & 0 & 4 & 0.040 \\
\hline CHINOOK SALMON & 1 & $n$ & 1 & $n$ & $?$ & 1 & ? & $n$ & $n$ & 3 & 0.030 \\
\hline FATHEAD MINNOW & 2 & 1 & $n$ & ? & i & 0 & 0 & $?$ & 0 & 3 & 0.030 \\
\hline SHORTHEAD REDHORSE & 0 & $n$ & 1 & n & $n$ & 2 & $n$ & ? & $n$ & 3 & 0.030 \\
\hline $\begin{array}{l}\text { CREEK CHUB } \\
\text { CRE }\end{array}$ & 0 & $n$ & 3 & $n$ & $n$ & 0 & ? & $?$ & $n$ & 3 & 0.030 \\
\hline BLACK BULLHEAD & 0 & 1 & $n$ & 1 & $?$ & 0 & 0 & $n$ & 2 & 2 & 0.020 \\
\hline $\begin{array}{l}\text { WARMOUTH } \\
\text { WATLA }\end{array}$ & 0 & $i$ & $n$ & 1 & $n$ & 0 & i & ? & 0 & $?$ & $0.0 ? 0$ \\
\hline COMMON SHINER & 1 & 1 & ? & ? & & 0 & $n$ & ? & ? & $?$ & 0.020 \\
\hline BLACKSIDE DARTER & 0 & 0 & 0 & 1 & $n$ & $n$ & $n$ & ก & 0 & 1 & 0.010 \\
\hline SAND SHINER & ) & 0 & 0 & $n$ & ? & 1 & 1 & $n$ & & 2 & 0.720 \\
\hline GIZZARD SHAD & 0 & 0 & $n$ & $n$ & 1 & 0 & $n$ & $n$ & $n$ & 1 & 0.010 \\
\hline WHITE CRAPPIE & 0 & 0 & 1 & ? & 0 & 0 & 0 & 0 & $n$ & ; & 0.010 \\
\hline GOLDEN REDHORSE & 0 & 0 & 1 & $n$ & $?$ & $n$ & $n$ & 0 & $n$ & 1 & 0.010 \\
\hline GOLDFISH & 1 & 0 & $n$ & ? & ? & $n$ & ? & $n$ & ? & 1 & 0.010 \\
\hline CENTRAL MUDMINNOW & $n$ & 1 & ? & ? & $n$ & $n$ & $n$ & i & $n$ & 1 & 0.010 \\
\hline LAKE CHUBSUCKER & 0 & 1 & $n$ & n & ? & $n$ & & ? & ? & 1 & 0.010 \\
\hline IOWA DARTER & 1 & $n$ & ? & $n$ & $n$ & $n$ & $n$ & $n$ & $n$ & 1 & 0.010 \\
\hline TOTALS & 1658 & 1998 & $112^{9}$ & 1454 & 1140 & 1247 & 1060 & 409 & q & 10015 & \\
\hline
\end{tabular}


Table 15. Summary of all fish species caught by bottom gill nets in Lake Michigan near the J. H. Campbell Plant, eastern Lake Michigan, April-November 1978 .

\begin{tabular}{|c|c|c|c|c|c|c|c|c|c|c|c|}
\hline \multirow[b]{2}{*}{ SPECIES } & \multicolumn{9}{|c|}{ MONTHS } & \multirow[b]{2}{*}{ sun } & \multirow[b]{2}{*}{ SOD TOTAL } \\
\hline & APP & $M A Y$ & JIN & $\mathrm{JTL}$ & $\mathrm{A} 1 \mathrm{G}$ & SPP & $\mathrm{OCT}$ & Nov & $\mathrm{nFC}$ & & \\
\hline SPOTTAIL SHINER & 7 & 166 & 1454 & 1719 & $2 \times 2$ & 202 & 53 & 30 & 0 & 3901 & 42.601 \\
\hline ALEWIFE & 3 & 488 & 114 & 2377 & 94 & 219 & 11 & 52 & 0 & 3378 & 35.890 \\
\hline RAINBOW SMELT & .22 & 143 & 7 & $1 \mathrm{k}$ & 12 & 51 & R & 13 & 0 & 582 & 6.356 \\
\hline YELLOW PERCH & 5 & 1 & 3 & 23 & 176 & 199 & 6 & 13 & 0 & 426 & 4.652 \\
\hline WHITE SUCKER & 0 & 33 & 29 & 29 & $6 a$ & 78 & 5 & 11 & 0 & 249 & 2.719 \\
\hline LAKE TROUT & 30 & 23 & 18 & 10 & 5 & 2 & 57 & 52 & $n$ & 207 & 2.261 \\
\hline GIZZARD SHAD & 0 & 0 & 0 & 1 & 53 & 45 & 7 & 18 & 0 & 124 & 1.354 \\
\hline BROWN TROUT & 36 & 16 & 16 & 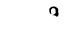 & 4 & 4 & 3 & 7 & 0 & 95 & 1.037 \\
\hline LONGNOSE SUCKER & 1 & 29 & 9 & 16 & 1 & 7 & 2 & 3 & 0 & 68 & 0.743 \\
\hline TROUT-PERCH & 0 & 3 & 1 & $n$ & 2 & 9 & h & $? 4$ & 0 & 45 & 0.499 \\
\hline COHO SALMON & 1 & 2. & 0 & 1 & 2 & 4 & 2 & 1 & 0 & 13 & 0.142 \\
\hline UNIDENTIFIED COREGONID & 0 & 0 & 9 & 3 & 7 & $n$ & 0 & 1 & 0 & 11 & 0.120 \\
\hline ROUND WHITEFISH & 1 & 1 & 2 & $?$ & $?$ & 0 & 1 & 1 & 0 & 8 & 0.087 \\
\hline JOHNNY DARTER & 0 & 0 & 0 & 0 & n & 0 & $a$ & $n$ & $?$ & 9 & 0.087 \\
\hline CARP & 0 & 0 & n. & $\eta$ & 5 & 2 & 0 & $?$ & 0 & 7 & 0.076 \\
\hline LAKE WHITEFISH & 4 & 0 & 1 & $n$ & 1 & 0 & $n$ & 0 & 0 & 6 & 0.066 \\
\hline CHINOOK SALMON & 1 & 1 & 1 & $n$ & $n$ & 2 & $n$ & 1 & 0 & 6 & 0.066 \\
\hline RAINBOW TROUT & 0 & 1 & $?$ & $?$ & $?$ & n & 1 & 4 & 0 & 6 & 0.066 \\
\hline SILVER REDHORSE & 0 & 0 & $n$ & $n$ & $n$ & 4 & 0 & $n$ & $n$ & 4 & 0.044 \\
\hline GOLDEN REDHORSE & 0 & $n$ & $n$ & 1 & $?$ & 3 & 0 & 0 & 0 & 4 & 0.044 \\
\hline QUILLBACK & 0 & 0 & $n$ & $n$ & $?$ & 1 & 0 & n & $n$ & 3 & 0.033 \\
\hline NORTHERN PIKE & 0 & 0 & $n$ & 0 & 1 & 0 & 1 & $n$ & 0 & 2 & 0.022 \\
\hline FRESHWATER DRUM & 0 & 0 & 0 & $n$ & $n$ & 1 & 0 & $n$ & 0 & 1 & $n .011$ \\
\hline CHANNEL CATFISH & $?$ & 0 & 0 & $?$ & $?$ & 1 & 0 & $n$ & 0 & 1 & 0.011 \\
\hline SHORTHEAD REDHORSE & 0 & $n$ & 1 & ? & $n$ & 0 & 0 & 0 & $n$ & 1 & 0.011 \\
\hline SMALLMOUTH BASS & 0 & $n$ & $n$ & $n$ & 0 & 1 & $n$ & $n$ & $n$ & 1 & 0.011 \\
\hline TOTALS & 411 & 907 & 1655 & $42 ? .4$ & 6834 & 945 & 181 & $25 n$ & 0 & 9157 & \\
\hline
\end{tabular}

Table 16. Summary of all fish species caught by surface gill nets in Lake Michigan near the J. H. Campbell Plant, eastern Lake Michigan, April-November 1978 .

\begin{tabular}{|c|c|c|c|c|c|c|c|c|c|c|c|}
\hline \multirow[b]{2}{*}{ SPECIES } & \multicolumn{9}{|c|}{ MONTHS } & \multirow[b]{2}{*}{$s \pi M$} & \multirow[b]{2}{*}{ SOP TOTAL } \\
\hline & APR & MAY & TTN & $J^{n L} \mathrm{~L}$ & Ant: & SRP & OCT & Nov & DEC & & \\
\hline SPOTTAIL SHINER & 0 & 29 & Тक & & 1 & $\pi$ & a & 0 & $n$ & 202 & 9.796 \\
\hline ALEWIFE & 15 & 370 & 254 & 75,9 & 177 & 131 & 7 & $n$ & $n$ & 1712 & 83.026 \\
\hline RAINBOW SMELT & 5 & 66 & $?$ & $?$ & 1 & 1 & 2 & ? & 0 & 77 & 3.734 \\
\hline LAKE TROUT & 1 & 9 & 1 & $n$ & $n$ & 0 & 20 & 0 & ? & 31 & 1.503 \\
\hline GIZZARD SHAD & 0 & $n$ & ? & 0 & 12 & 3 & 1 & $n$ & 0 & 16 & 0.776 \\
\hline COHO SALMON & 1 & 0 & 1 & 1 & $n$ & 3 & 1 & $n$ & 0 & 7 & 0.339 \\
\hline BROWN TROUT & $n$ & 1 & 3 & 1 & n & 1 & n & ? & 0 & 5 & 0.291 \\
\hline CHINOOK SALMON & 3 & 0 & 1 & 1 & 2 & 0 & 0 & $n$ & $n$ & 5 & 0.242 \\
\hline CHANNEL CATFISH & 0 & 0 & ? & ? & 1 & 1 & 0 & n & $n$ & 2 & 0.097 \\
\hline TROUT-PERCH & 0 & 1 & $n$ & $n$ & 9 & ? & 0 & $n$ & 0 & 1 & 0.049 \\
\hline LAKE WHITEFISH & 0 & 1 & $n$ & $?$ & 9 & n & $?$ & ? & $n$ & 1 & 0.048 \\
\hline WHITE SUCKER & 0 & 1 & $n$ & $n$ & ? & 0 & 0 & ? & $n$ & 1 & 0.048 \\
\hline LONGNOSE SUCKER & 0 & 1 & 0 & $?$ & $n$ & 0 & $n$ & $n$ & $n$ & 1 & 0.048 \\
\hline TOTALS & 25 & 478 & 429 & $7 F A$ & 177 & 140 & 31 & $n$ & $n$ & 2062 & \\
\hline
\end{tabular}


Table 17. Summary of all fish species caught by seines in Lake Michigan near the J. H. Campbell Plant, eastern Lake Michigan, April-November 1978.

\begin{tabular}{|c|c|c|c|c|c|c|c|c|c|c|c|}
\hline \multirow[b]{2}{*}{ SPECIES } & \multicolumn{9}{|c|}{ MONTHS } & \multirow{3}{*}{$\frac{\text { sun }}{6873}$} & \multirow{3}{*}{$\frac{\text { SOP TOTAL }}{62.957}$} \\
\hline & APR & MAY & $\sin$ & TIL & ATr & SEP & $\mathrm{OCT}$ & 807 & DEC & & \\
\hline SPOTTAIL SHINER & 11 & 146 & 1249 & 3405 & 2731 & 213 & 19 & 10 & 0 & & \\
\hline ALEWIFE & 3 & a & 55 & 79 & 1258 & 1077 & 509 & 9 & 0 & 2999 & 27.471 \\
\hline RAINBOW SMELT & 73 & 379 & 119 & 3 & 3 & 5 & 3 & 7 & 0 & 592 & 5.423 \\
\hline YELLOW PERCH & 0 & 0 & 2 & 113 & 13 & 0 & $n$ & 1 & 9 & 129 & 1.182 \\
\hline TROUT-PERCH & 8 & 10 & 28 & 3 & 15 & 0 & 0 & 5 & 0 & 78 & 0.714 \\
\hline WHITE SUCKER & 0 & 4 & 1 & 37 & 17 & 0 & 0 & $n$ & $n$ & 57 & 0.522 \\
\hline EMERALD SHINER & $n$ & 0 & 3 & 0 & 16 & 27 & 0 & 4 & 0 & 50 & 0.458 \\
\hline COHO SALMON & 0 & 5 & 17 & 14 & 0 & $n$ & 0 & 0 & 0 & 36 & 0.330 \\
\hline CHINOOK SALMON & 0 & 9 & 11 & 5 & 0 & 0 & 0 & 0 & 0 & 16 & 0.147 \\
\hline BLUNTNOSE MINNOW & 0 & ? & ? & 0 & 1 & 13 & 0 & 0 & 0 & 14 & 0.128 \\
\hline BROWN TROUT & 5 & 5 & 1 & 1 & 3 & 0 & 0 & 0 & 0 & 13 & 0.119 \\
\hline NINESPINE STICKLEBACK & 5 & 2. & 4 & 0 & $n$ & 0 & $n$ & $?$ & 0 & 11 & 0.101 \\
\hline LAKE TROUT & 0 & $n$ & $n$ & $n$ & 0 & 0 & 9 & 1 & 0 & 10 & 0.092 \\
\hline WALLEYE & n & $n$ & 0 & n & 5 & 0 & 0 & $n$ & 0 & 5 & 0.055 \\
\hline GIZZARD SHAD & o & $n$ & 0 & $n$ & 1 & 3 & 3 & 0 & 0 & 6 & 0.055 \\
\hline CARP & 2 & 1 & $?$ & ? & 2 & 0 & 0 & 0 & 0 & 5 & 0.046 \\
\hline UNIDENTIFIED COREGONID & 0 & $n$ & 2 & $n$ & 0 & 3 & 0 & 0 & 0 & 5 & 0.046 \\
\hline JOHNNY DARTER & $n$ & ? & ? & $n$ & $?$ & 0 & $n$ & 0 & 0 & 4 & 0.037 \\
\hline SLIMY SCULPIN & 1 & 1 & $n$ & 1 & $n$ & 0 & 0 & 0 & 0 & 3 & 0.027 \\
\hline RAINBOW TROUT & 2 & 1 & 0 & 0 & 0 & 0 & 0 & 0 & 0 & 3 & 0.027 \\
\hline LONGNOSE SUCKER & 0 & 1 & 0 & n & n & 1 & 0 & 0 & 0 & 2 & 0.018 \\
\hline GOLDFISH & 0 & $n$ & 0 & 1 & $n$ & 0 & $n$ & 0 & 0 & 1 & 0.009 \\
\hline SMALLMOUTH BASS & 0 & $n$ & $n$ & ? & 1 & $n$ & $n$ & 0 & 0 & 1 & 0.009 \\
\hline FATHEAD MINNOW & 0 & 0 & $n$ & $n$ & 1 & 0 & $n$ & n & 0 & 1 & 0.209 \\
\hline QUILLBACK & o & $n$ & 1 & n & $n$ & 0 & $n$ & 0 & 0 & 1 & 0.009 \\
\hline BLUEGILL & $?$ & $n$ & $?$ & $n$ & 0 & 1 & $n$ & $n$ & 0 & 1 & 0.009 \\
\hline TOTALS & 110 & 574 & 1494 & 2754 & 4052 & 1343 & 543 & 37 & $n$ & 10917 & \\
\hline
\end{tabular}

Table 18. Summary of all fish species caught by trawls in Lake Michigan near the J. H. Campbell Plant, eastern Lake Michigan, April-November 1978.

\begin{tabular}{|c|c|c|c|c|c|c|c|c|c|c|c|}
\hline \multirow[b]{2}{*}{ SPECIES } & \multicolumn{9}{|c|}{ MONTHS } & \multirow{3}{*}{$\begin{array}{r}\text { SUA } \\
36529\end{array}$} & \multirow{3}{*}{$\begin{array}{l}\text { Sop TOTAI. } \\
53.056\end{array}$} \\
\hline & $\mathrm{APR}$ & MAY & .178 & J7I, & A'TG & 5.P. & OCT & 107 & DPC & & \\
\hline$\overline{\text { ALEWIFE }}$ & 0 & 13 & 143 & 320 & 64 & 479 & 9778 & 26775 & 5 & & \\
\hline RAINBOW SMELT & 693 & 3458 & 2.364 & 6633 & 5200 & $2 ? 12$ & 1103 & 1063 & 351 & 24077 & 34.971 \\
\hline UNIDENTIFIED COREGONID & $n$ & 5 & 189 & 537 & 195 & 16 & 1665 & 478 & 18 & 3105 & 4.510 \\
\hline SPOTTAIL SHINER & 8 & 85 & 215 & $?$ & 477 & 530 & 173 & 93 & 105 & 1789 & 2.507 \\
\hline TROUT-PERCH & 3 & 2.97 & 423 & 354 & 323 & 195 & 16 & 27 & 19 & 1717 & 2.494 \\
\hline YELLOW PERCH & 3 & 2 & 3 & $\kappa$ & 113 & 340 & 22 & 5 & 29 & 523 & 0.760 \\
\hline NINESFINE STICKLEBACK & 0 & 31 & 139 & 151 & 30 & 0 & 2. & $n$ & 0 & 403 & 0.585 \\
\hline JOHNNY DARTER & 0 & 29 & 46 & 36 & 87 & 56 & 54 & 35 & 6 & 350 & 0.508 \\
\hline SLIMY SCULPIN & 60 & 128 & 13 & 31 & 2 & 0 & 0 & 1 & 34 & 276 & 0.401 \\
\hline GIZZARD SHAD & 0 & 0 & 0 & $?$ & 0 & 7 & 4 & 9 & 32 & 43 & 0.062 \\
\hline WHITE SUCKER & 0 & 1 & 0 & 19 & 0 & 1 & 0 & $n$ & 0 & 12 & 0.017 \\
\hline LAKE TROUT & 0 & 0 & 3 & 5 & 2 & 0 & 0 & n & 0 & 10 & 0.015 \\
\hline BURBOT & 0 & 0 & $n$ & $n$ & 1 & $n$ & $?$ & 1 & 0 & 4 & 0.006 \\
\hline LAKE WHITEFISH & 0 & $n$ & 1 & 1 & $n$ & 0 & n & 0 & 0 & 2 & 0.003 \\
\hline LONGNOSE SUCKER & 0 & 0 & 0 & $n$ & 1 & 1 & 0 & 0 & 0 & 2. & 0.003 \\
\hline CHINOOK SALMON & 0 & 0 & 0 & 1 & n & 1 & 0 & $n$ & 0 & 2 & 0.003 \\
\hline ROUND WHITEFISH & 0 & $n$ & $n$ & $n$ & 1 & $n$ & $n$ & $n$ & 1 & 2 & 0.073 \\
\hline WALLEYE & 0 & $n$ & 0 & $?$ & $?$ & $n$ & 0 & $n$ & 1 & 1 & 0.001 \\
\hline BLUNTNOSE MINNOW & 0 & $n$ & 0 & $n$ & $n$ & 0 & 0 & 1 & 0 & 1 & 0.001 \\
\hline CARP & 0 & 0 & $n$ & ? & 0 & 0 & 1 & 0 & 0 & 1 & 0.001 \\
\hline BLUEGILL & 0 & $n$ & 0 & $n$ & n & 0 & 1 & n & n & 1 & 0.001 \\
\hline TOTALS & 767 & 4049 & 3539 & QกR? & 7514 & 3888 & $11 \times 22$ & 28490 & $6 \cap 2$ & 69849 & \\
\hline
\end{tabular}


Table 19. Summary of all fish species caught by bottom gill nets in Pigeon Lake near the J. H. Campbell Plant, eastern Lake Michigan, Apri1-December 1978.

\begin{tabular}{|c|c|c|c|c|c|c|c|c|c|c|c|}
\hline \multirow[b]{2}{*}{ SPECIES } & \multicolumn{9}{|c|}{ MONTHS } & \multirow[b]{2}{*}{ sin } & \multirow[b]{2}{*}{ SOF TOTAL } \\
\hline & $A P R$ & MAY & JUN & JTL & $A O G$ & SP,P & OCT & Nov & DEC & & \\
\hline ALEWIFE & 7 & 0 & 112 & 110 & $?$ & $n$ & 0 & 0 & 0 & $23 R$ & 50.105 \\
\hline YELLOW PERCH & 9 & 42 & 29 & 14 & 25 & 4 & 18 & a & 5 & 155 & 32.532 \\
\hline NORTHERN PIKE & 6 & 1 & 2 & 0 & 3 & 3 & 3 & 2 & 2 & 29 & 5.895 \\
\hline SPOTTAIL SHINER & 0 & 6 & 7 & $n$ & 5 & 0 & 1 & $n$ & 0 & 19 & 4.000 \\
\hline LAKE TROUT & 0 & 0 & 0 & $n$ & $n$ & 0 & 7 & $n$ & 0 & 7 & 1.474 \\
\hline WHITE SUCKER & 0 & 1 & 0 & 1 & 2 & $n$ & 0 & $n$ & 0 & 4 & 0.942 \\
\hline BLACK CRAPPIE & 0 & $n$ & 0 & $n$ & $n$ & 3 & 0 & 0 & $n$ & 3 & 0.632 \\
\hline SHORTHEAD REDHORSE & 0 & 0 & 1 & $n$ & $n$ & 2 & 0 & $n$ & 0 & 3 & 0.632 \\
\hline BOWF IN & 0 & 0 & n & 3 & $n$ & 0 & $n$ & 0 & 0 & 3 & 0.532 \\
\hline TROUT-PERCH & 0 & 0 & 0 & 0 & 0 & 0 & 0 & 1 & 1 & 2 & 0.421 \\
\hline RAINBOW SMELT & 2 & 0 & ? & $n$ & 3 & 0 & $n$ & 0 & 0 & 2 & 0.421 \\
\hline ROCK BASS & 0 & 0 & ? & 0 & 1 & 0 & 1 & 0 & 0 & 2 & 0.421 \\
\hline RAINBOW TROUT & 0 & 0 & n & $n$ & $n$ & 0 & 1 & 0 & 0 & 1 & 0.211 \\
\hline BROWN BULLHEAD & 0 & 0 & ? & $n$ & 1 & 0 & ? & 0 & 0 & 1 & 0.211 \\
\hline CHINOOK SALMON & 0 & 0 & $n$ & $n$ & $n$ & 1 & $n$ & 0 & 0 & 1 & 0.211 \\
\hline PUMPKINSEED & 0 & 1 & n & 0 & $n$ & 0 & 0 & $n$ & 0 & 1 & 0.211 \\
\hline GIZZARD SHAD & 0 & 0 & n & $n$ & 1 & 0 & 0 & $n$ & 0 & 1 & 0.211 \\
\hline LAKE CHUBSUCKER & $n$ & 1 & $n$ & $n$ & $n$ & 0 & $n$ & ? & 0 & 1 & 0.211 \\
\hline CARP & 1 & 0 & $n$ & 0 & $\eta$ & $n$ & 0 & 2 & 0 & 1 & 0.211 \\
\hline BLUEGILL & 0 & 0 & $n$ & $n$ & 1 & 0 & $n$ & 0 & 0 & 1 & 0.211 \\
\hline LARGEMOUTH BASS & 0 & 0 & 0 & 0 & $n$ & 0 & 1 & 0 & 0 & 1 & 0.211 \\
\hline TOTALS & 25 & 52 & 151 & 137 & 45 & 13 & 32 & 12 & B & 475 & \\
\hline
\end{tabular}

Table 20. Summary of all fish species caught by seines in Pigeon Lake near the J. H. Campbell Plant, eastern Lake Michigan, Apri1November 1978.

\begin{tabular}{|c|c|c|c|c|c|c|c|c|c|c|c|}
\hline \multirow[b]{2}{*}{ SPECIES } & \multicolumn{9}{|c|}{ MONTHS } & \multirow[b]{2}{*}{ SUM } & \multirow[b]{2}{*}{$Y=T \cap T A L$} \\
\hline & $A P R$ & MAT & Jาv & $\mathrm{JTI}$ & Aगत & $S \geqslant P$ & nCT & MOV & $D P C$ & & \\
\hline SPOTTAIL SHINER & $2^{q}$ & 260 & $7 ?$ & $3 ? 7$ & 51 & 929 & $6 \pi 3$ & 97 & 0 & 2437 & 25.545 \\
\hline GOLDEN SHINER & 1168 & 976 & 2 & 17 & 11 & 10 & 0 & 35 & $n$ & 2220 & 23.270 \\
\hline YELLOW PERCH & 117 & $27 \mathrm{~F}$ & 512 & 17.3 & 445 & 22 & 27 & $? 4$ & 0 & 16,16 & 16.939 \\
\hline BLUNTNOSE MINNOW & 169 & 172 & 159 & ? & 127 & 3 & $? 3$ & $16 \mathrm{~K}$ & 0 & 864 & 9.057 \\
\hline LARGEMOUTH BASS & 1 & 27 & 43 & 234 & 127 & 79 & A & 1) & n & 5,31 & 5.566 \\
\hline EMERALD SHINER & 79 & $?$ & $n$ & 1 & $n$ & 6 & 339 & 19 & 0 & 465 & 4. 825 \\
\hline ALEWIFE & 0 & 0 & 25 & 319 & 19 & 3 & 1 & 1 & $n$ & 367 & 3.947 \\
\hline BLACK CRAPPIE & 1 & 1 & 16 & .3 & 121 & 144 & 1 & 6 & ? & 243 & 2.547 \\
\hline JOHNNY DARTER & 21 & 50 & 21 & $3 a$ & 79 & 12 & 12 & 4 & 0 & 235 & 2.474 \\
\hline PUMPKINSEED & 3 & $2 n$ & 39 & 29 & 15 & a & ? & $n$ & 0 & 113 & 1.194 \\
\hline BROOK SILVERSIDE & $n$ & 1 & 1 & 1 & in & 39 & ? & h & 0 & की & 0.839 \\
\hline ROCK BASS & 3 & 3 & 36 & 15 & $1 n$ & 2 & 14 & $n$ & 0 & 74 & 0.776 \\
\hline BANDED KILLIFISH & 1 & 0 & $n$ & $n$ & in & 7 & $n$ & 3 & $n$ & 51 & 0.535 \\
\hline BLUEGILL & 1 & 3 & 13 & 15 & $a$ & 5 & 5 & $n$ & n & 51 & 0.535 \\
\hline NINESPINE STICKLEBACK & 19 & $2 ?$ & $n$ & 2 & n & $n$ & $n$ & 0 & n & 43 & 0.451 \\
\hline COHO SALMON & 0 & 1 & 17 & n & ? & $n$ & $n$ & 0 & 0 & 19 & 0.189 \\
\hline TADPOLE MADTOM & 2 & $?$ & 10 & n & ? & 1 & 1 & ก & 0 & 15 & 0.169 \\
\hline SMALLMOUTH BASS & 1 & 2 & 2 & 4 & s & 0 & n & 0 & $n$ & 14 & 0.147 \\
\hline NORTHERN PIKE & 1 & $?$ & 1 & 4 & 4 & 1 & $n$ & 1 & 0 & 14 & 0.147 \\
\hline TROUT-PERCH & 1 & 11 & $?$ & $n$ & $n$ & 1 & $n$ & $n$ & $n$ & 13 & 0.136 \\
\hline BOWF IN & 4 & n & 2 & 1 & ? & $n$ & 1 & ? & $n$ & 10 & 0.105 \\
\hline RAINBOW SMELT & 1 & 6 & $n$ & $n$ & 9 & $n$ & ? & 0 & ? & 9 & 0.084 \\
\hline CARP & i) & 0 & $n$ & 1 & 5 & $n$ & ? & ? & 0 & 7 & 0.073 \\
\hline BROWN BULLHEAD & 2 & 1 & 2 & n & ? & $n$ & $n$ & $n$ & $n$ & 5 & 0.052 \\
\hline RAINBOW TROUT & 0 & 0 & 3 & $?$ & 1 & 0 & ? & n & 0 & 5 & n. 052 \\
\hline YELLOW BULLHEAD & 3 & 0 & 4 & $n$ & ? & $n$ & 0 & $n$ & n & 7 & 0.073 \\
\hline MOTTLED SCULPIN & 0 & 0 & $i$ & 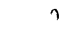 & ? & 0 & 3 & 1 & ? & 4 & 0.0112 \\
\hline GRASS PICKEREL & $n$ & 1 & 1 & 1 & n & $n$ & $n$ & 1 & 0 & is & 0.042 \\
\hline CREEK CHUB & 0 & 0 & 3 & n & ? & n & $n$ & ? & 0 & 3 & 0.031 \\
\hline FATHEAD MINNOW & 2 & 1 & ? & n & ○ & $n$ & $?$ & n & 0 & 3 & 0.071 \\
\hline WHITE SUCKER & 1 & 1 & n & $n$ & n & $n$ & ? & $n$ & 0 & 2 & 3.021 \\
\hline WARMOUTH & $n$ & 1 & n & 1 & ר & ? & n & $n$ & 0 & 2 & 0.021 \\
\hline CHINOOK SALMON & 1 & 0 & 1 & n & ? & $n$ & $n$ & n & $n$ & 2 & 0.021 \\
\hline BLACK BULLHEAD & $n$ & 1 & $n$ & 1 & n & $n$ & $n$ & n & $n$ & ? & 0.721 \\
\hline SAND SHINER & 0 & 0 & $?$ & ? & ? & 1 & 1 & n & $?$ & ? & $0.0>1$ \\
\hline COMMON SHINER & 1 & 1 & 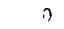 & $n$ & i & n & $n$ & $n$ & n & 2 & 0.721 \\
\hline BLACKSIDE DARTER & 0 & $n$ & 0 & 1 & ר & $n$ & $n$ & $?$ & $n$ & $?$ & 0.010 \\
\hline CENTRAL MULMINNOW & 0 & 1 & $n$ & $n$ & n & $n$ & 1 & ? & $n$ & 1 & 0.010 \\
\hline WHITE CRAPPIE & 0 & 0 & 1 & n & , & n & ? & $?$ & 0 & 1 & 0 \\
\hline IOWA DARTER & 1 & 0 & ? & n & ) & ) & n & n & ? & 1 & 0.010 \\
\hline GOLDFISH & 1 & 0 & $n$ & n & n & $n$ & n & n & $n$ & 1 & 0.010 \\
\hline GOLDEN REDHORSE & $n$ & $n$ & 1 & $n$ & ? & ? & $?$ & i & ? & 1 & 0.010 \\
\hline TOTALS & 16.33 & 1346 & 278 & $13 ? 1$ & 1111 & 12314 & 1023 & 395 & $n$ & 35187 & \\
\hline
\end{tabular}


total numbers) and alewife (33\% of total); all other impinged species individually made up less than $5 \%$ of the total impingement catch (Table 21).

During 1978, five species were collected in Pigeon Lake that were not present in 1977 samples, including the central mudminnow, blackside and Iowa darters and common and sand shiners. Four species which occurred in 1977 samples, but were absent from 1978 collections were: northern hogsucker, bigmouth shiner, lake sturgeon and longnose dace. Occurrence of each of these species in 1977 was rare (one fish of each species) (Jude et a1. 1978). An impingement sample in 1979 included a flathead catfish Pylodictus olivaris.

\section{Major Species}

Alewife--

Introduction--Alewives were the most abundant species caught during the 1978 sampling program in Lake Michigan accounting numerically for $49 \%$ of the total catch (Table 13). In Pigeon Lake, the alewife was the fifth most abundant species representing $6 \%$ of the total catch (Table 14). In 1977 (Jude et a1. 1978) alewives were again the most abundant species caught in Lake Michigan ( $64 \%$ of total catch). In Pigeon Lake, however, alewives were more abundant in 1977, representing $34 \%$ of the total. Alewife numbers appear to be declining somewhat in Lake Michigan according to Campbel1 Plant data (this report) and Cook Plant data (Jude et al. 1979). Their populations certainly are considerably less now than peak levels attained in 1966 (Brown 1972). Perhaps, as discussed by Smith $(1968,1970)$, alewives are reaching equilibrium levels in Lake Michigan.

\section{Seasonal distribution--}

Apri1--Few alewives were caught in Apri1; 21 in Lake Michigan (10 males and 11 females) and 7 ( 5 males and 2 females) in Pigeon Lake (Appendix 6). Adult alewives in Lake Michigan show a seasonal migration, concentrating in deep water during winter months and migrating into shallower water usually by mid-April, depending on water temperature (Wells 1968). Alewives had probably just begun moving into the inshore area near the Campbel1 Plant by the time of April sampling. Most alewives caught in Lake Michigan during April were collected in the vicinity of the discharge canal of Units 1 and 2; 14 at station $\mathrm{L}(6 \mathrm{~m}-\mathrm{N})$ and 1 at station $\mathrm{U}(6 \mathrm{~m}-\mathrm{N}$ discharge). Two were caught in bottom gill nets at station $\mathrm{L}$ and three were seined at beach station Q (S discharge). Only one alewife was taken from south transect stations; it was taken in a bottom gill net at station A $(1.5 \mathrm{~m}-\mathrm{S})$. A11 alewives were caught at night, indicative of a nocturnal shoreward migration, a pattern also noted by Jude et al. (1979) near the Cook Plant.

Water temperatures at south transect stations were not different from temperatures near the discharge at the north transect. The higher number of alewives caught there may indicate that a small resident population may inhabit the discharge canal the entire year.

May--By May, alewives had moved into the area near the Campbell Plant with 


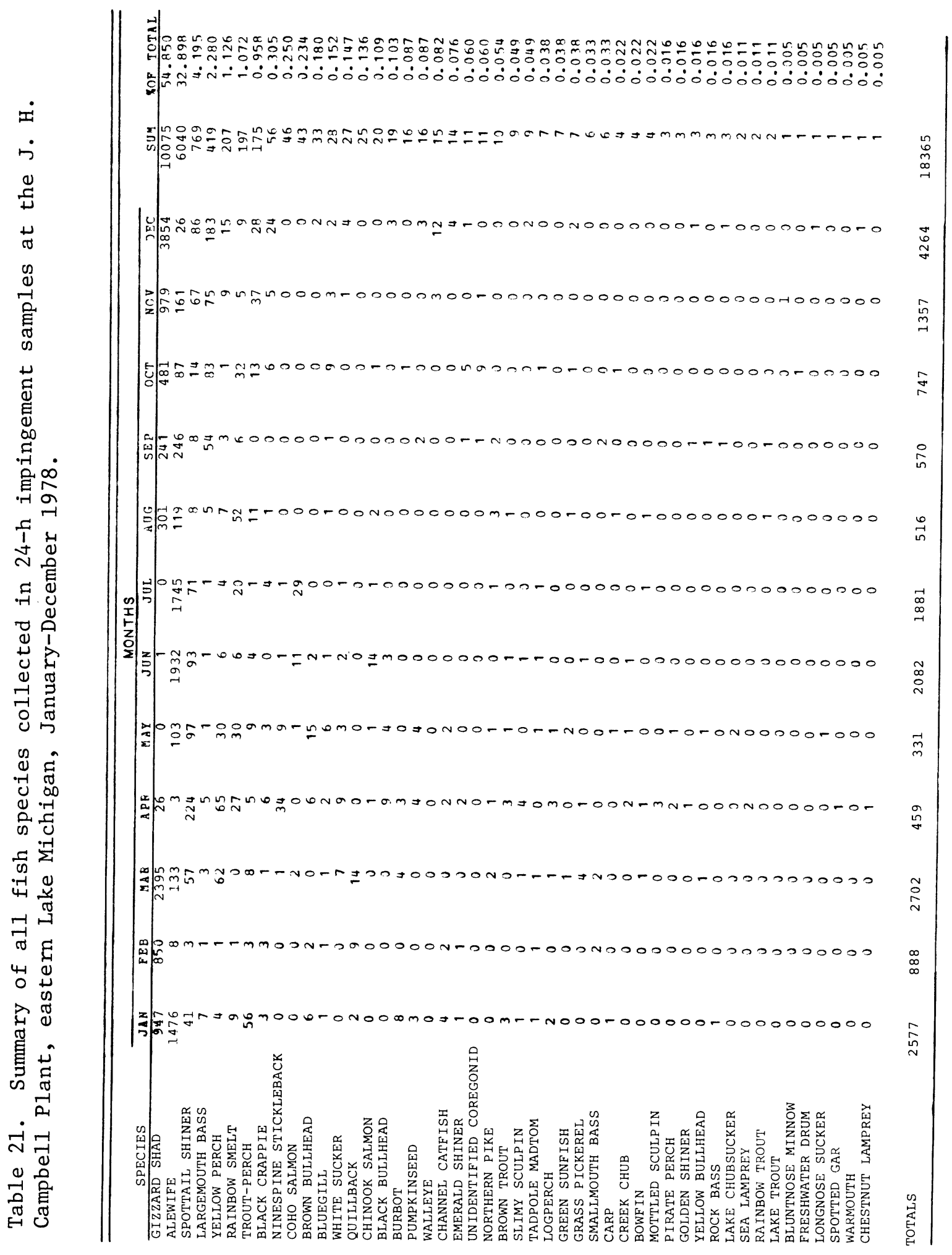


880 adults caught during Lake Michigan sampling (Appendix 6), while none were caught in Pigeon Lake. Gonad data indicated that spawning had not yet begun, since most alewives had either slightly or moderately developed gonads (Table 22). Mean length of alewives caught was $171 \mathrm{~mm}$ (range: 75 to $224 \mathrm{~mm}$ ). Kissil (1974) reported that males predominated during early stages of the spawning migration. Our data indicated that equal numbers of males and females were present throughout the spawning season. Most alewives were caught at night in surface and bottom gill nets. Trawls and seines accounted for less than $3 \%$ of the total catch in May.

of the south transect stations in May, station A (1.5 m-S) night bottom gill nets caught the highest number (77) of alewives with numbers of fish decreasing with increasing station depth (Figs. 16, 17). North transect stations showed greater numbers of alewives present than south transect stations. Night bottom gill nets at station $\mathrm{L}(6 \mathrm{~m}-\mathrm{N})$ near the present thermal discharge caught the highest number of alewives (267) of any station in May; numbers of alewives caught at station $L$ were much higher than the catch at reference station $\mathrm{C}(6 \mathrm{~m}-\mathrm{S})$ (20 fish). Night surface gill net catches were slightly greater at station $\mathrm{L}$ than at reference station $\mathrm{C}$ ( 69 and 44 , respectively). Night surface gill net catches at station $U$ ( $6 \mathrm{~m}-\mathrm{N}$ discharge) were very high, 257 alewives (Fig. 18).

Table 22. Monthly gonad conditions of alewives caught during 1978 in Lake Michigan near the J. H. Campbell Plant, eastern Lake Michigan. A11 fish examined in a month were included except poorly received specimens.

\begin{tabular}{|c|c|c|c|c|c|c|c|c|c|c|}
\hline \multirow{2}{*}{$=$} & \multirow[b]{2}{*}{ Gonad condition } & \multirow[b]{2}{*}{ Apr } & \multirow[b]{2}{*}{ May } & \multirow[b]{2}{*}{ Jun } & \multirow[b]{2}{*}{ Jul } & \multirow[b]{2}{*}{ Aug } & \multirow[b]{2}{*}{ Sep } & \multirow[b]{2}{*}{ Oct } & \multirow[b]{2}{*}{ Nov } & \multirow{2}{*}{$\mathrm{Dec}$} \\
\hline & & & & & & & & & & \\
\hline \multirow{5}{*}{ Males } & Slight development & 9 & 98 & 8 & 70 & 58 & 79 & 6 & 43 & \\
\hline & Mod. development & 1 & 37 & 32 & 93 & 5 & 29 & 3 & & \\
\hline & We11 developed & & 7 & 88 & 90 & 2 & 1 & & & \\
\hline & Ripe-running & & & 50 & 21 & 1 & & & & \\
\hline & Spent & & 1 & 13 & 55 & 15 & 25 & & & \\
\hline \multirow{5}{*}{ Females } & Slight development & 10 & 62 & 2 & 21 & 31 & 47 & 1 & 3 & \\
\hline & $\begin{array}{l}\text { Mod. development } \\
\text { We11 developed }\end{array}$ & & 75 & 30 & 46 & 5 & 7 & 3 & 3 & \\
\hline & $\begin{array}{l}\text { We11 developed } \\
\text { Ripe-running }\end{array}$ & & 8 & 116 & 149 & 1 & 1 & & & \\
\hline & $\begin{array}{l}\text { Ripe-running } \\
\text { Spent }\end{array}$ & & & 35 & 51 & 3 & & & & \\
\hline & $\begin{array}{l}\text { Spent } \\
\text { Absorbing }\end{array}$ & 1 & 2 & 6 & $\begin{array}{r}25 \\
5\end{array}$ & 11 & 13 & & & \\
\hline Immature & & & 6 & 25 & 62 & 302 & 432 & 755 & 907 & \multirow[t]{2}{*}{6} \\
\hline Unable $t$ & o distinguish & & 21 & 9 & 43 & 75 & 64 & 25 & 107 & \\
\hline
\end{tabular}



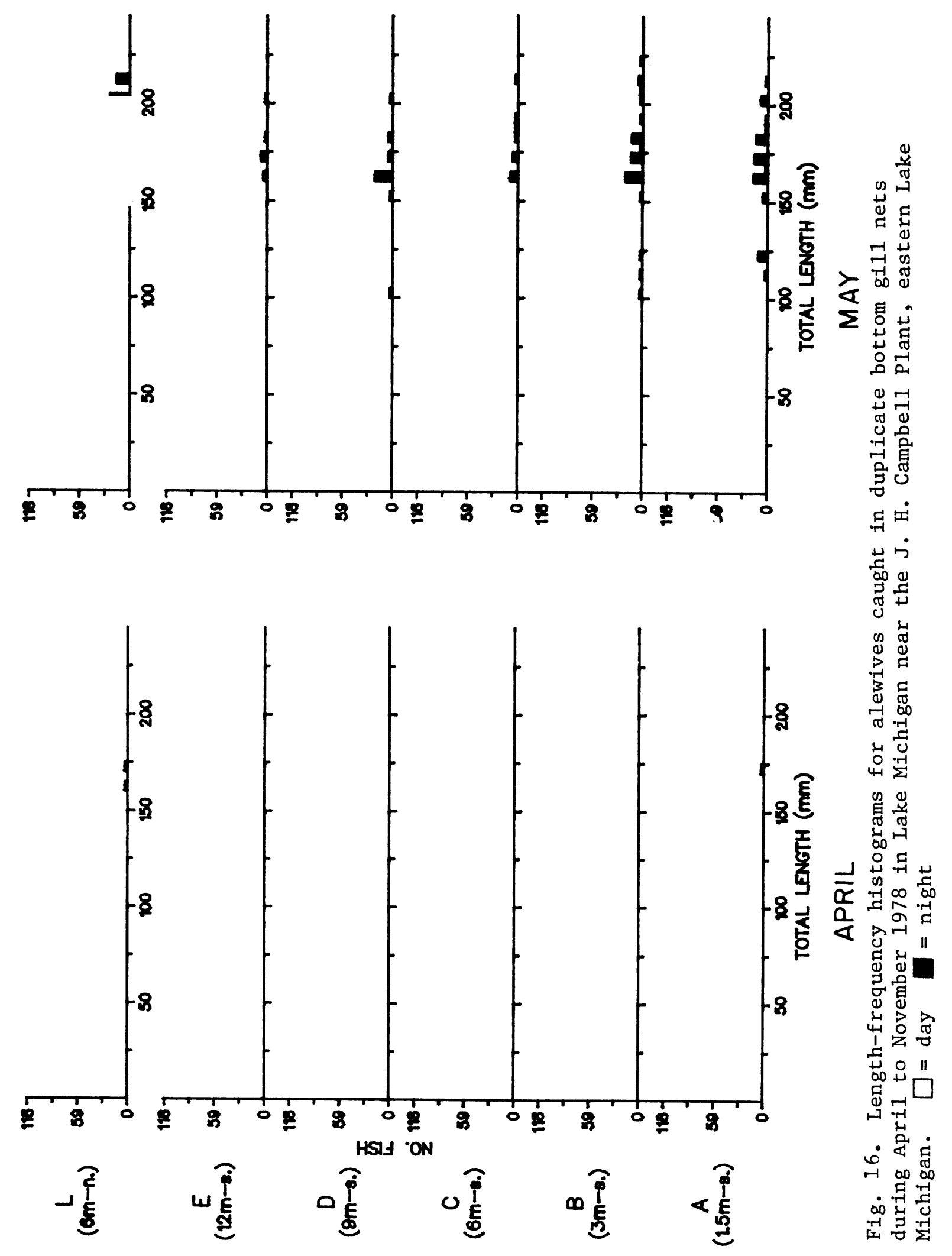

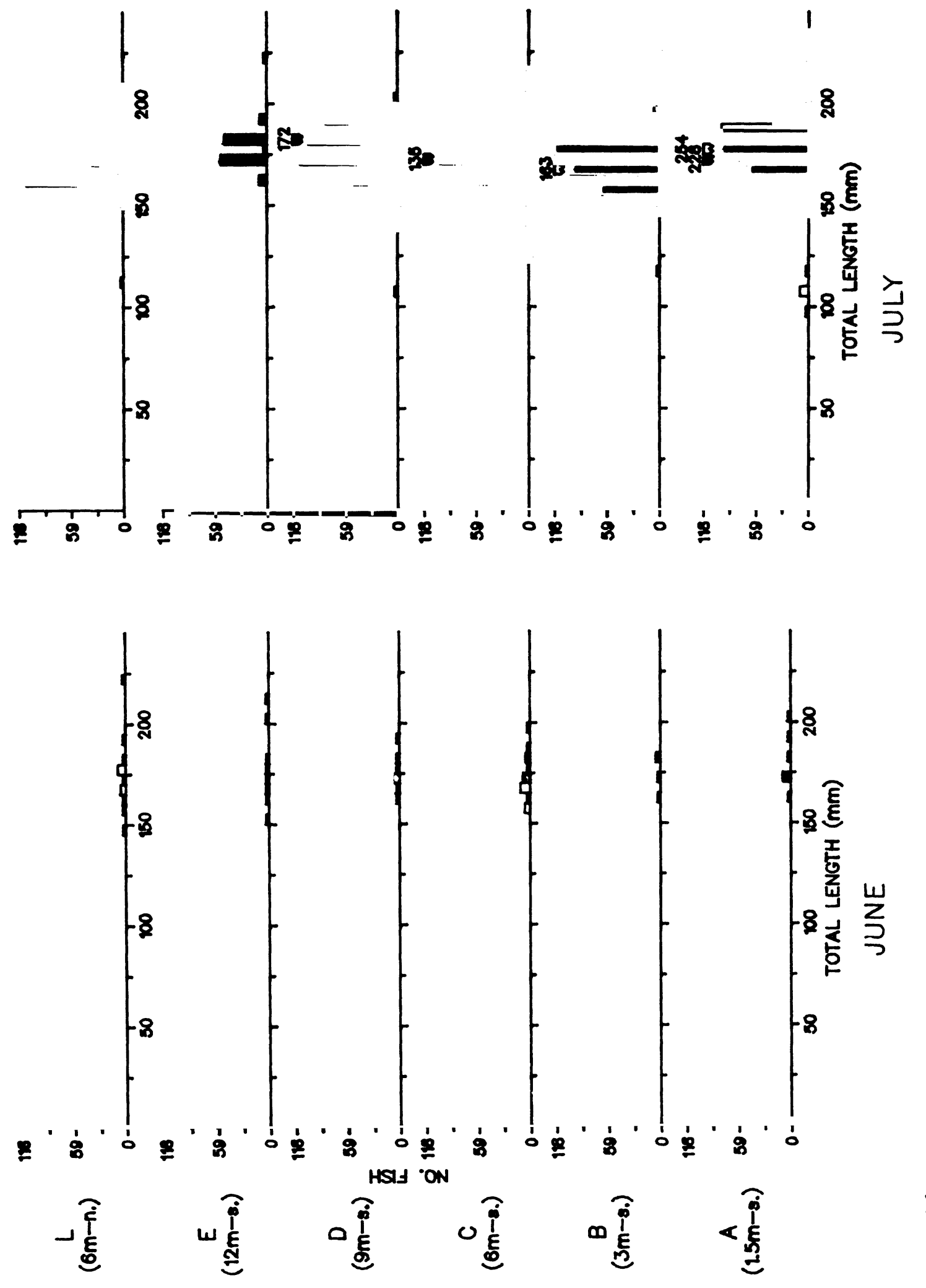

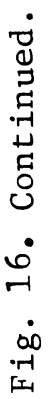



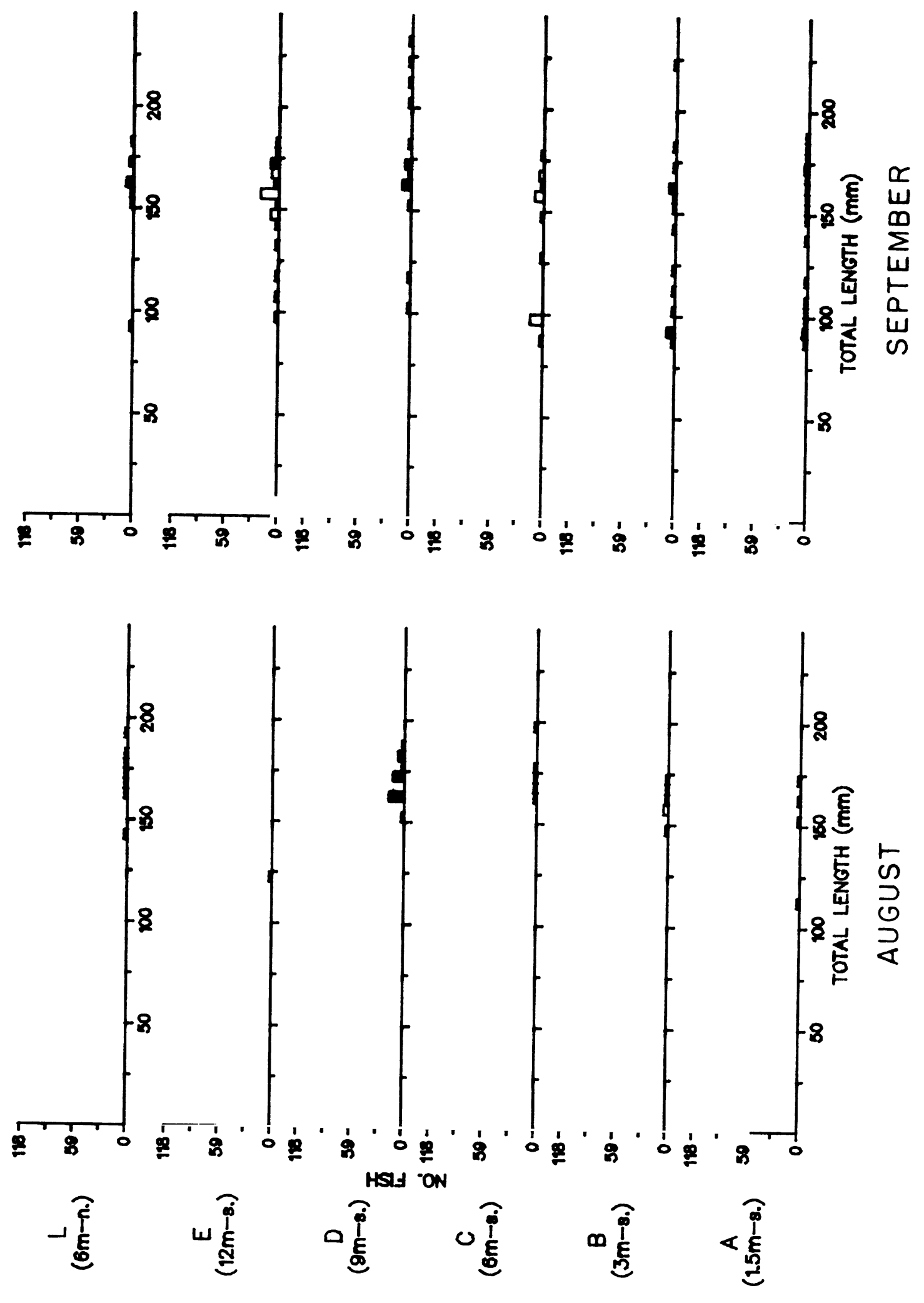

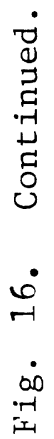



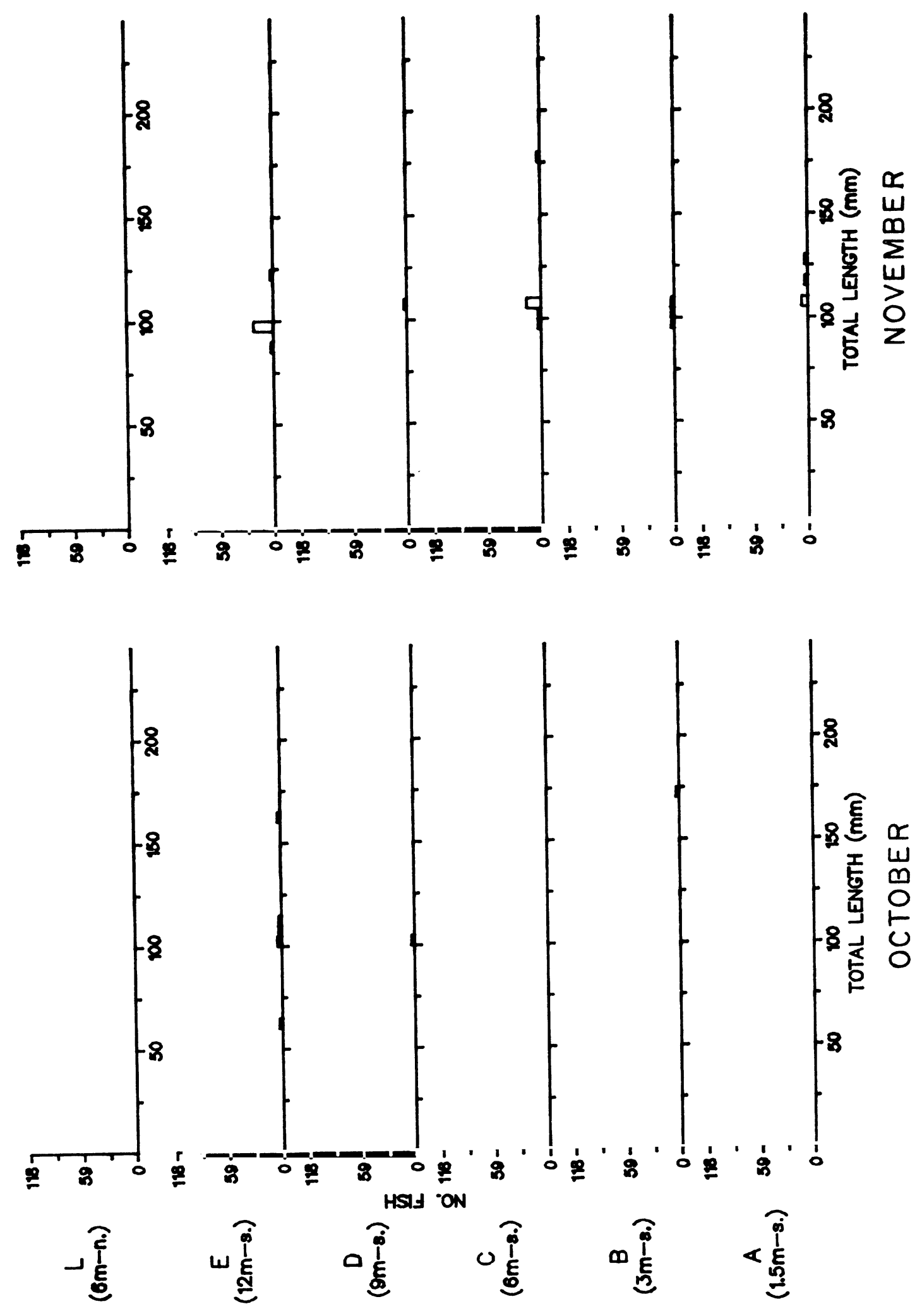

ت્ટુ 


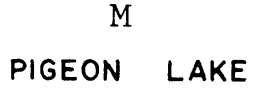

$L(6 m-N)$

C $(6 m-5)$

B $(3 m-5)$

A $(1.5 m-S)$
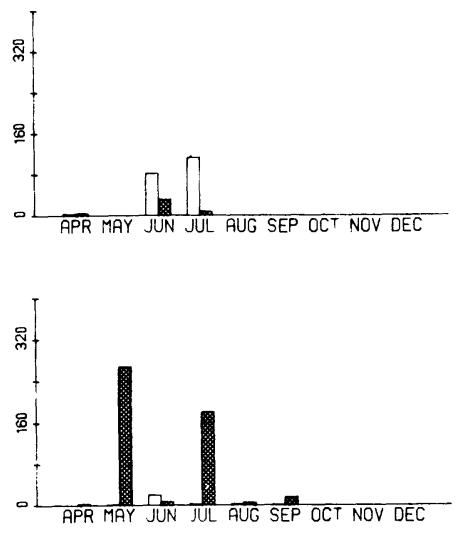

i

t

따

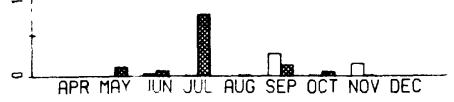

杰
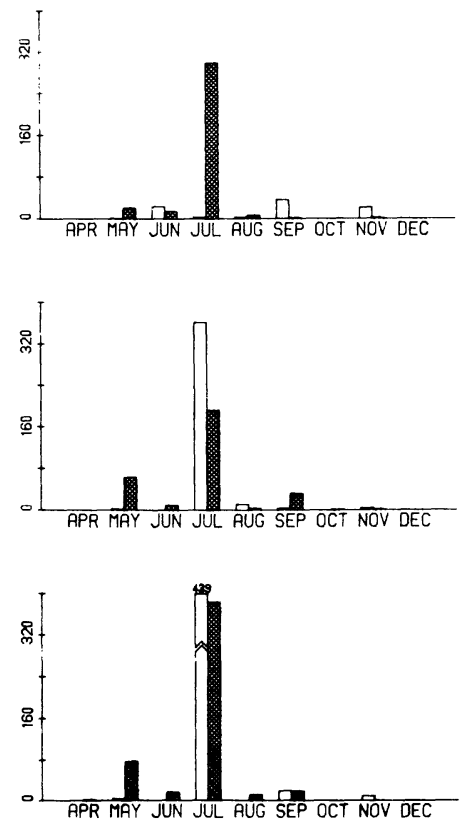

Fig. 17. Total number of alewives caught in duplicate bottom gill nets fished during day and night once per month April to November 1978 in Lake Michigan and Pigeon Lake near the J. H. Campbell Plant, eastern Lake Michigan. $\square=$ day $\square^{\prime}=$ night 

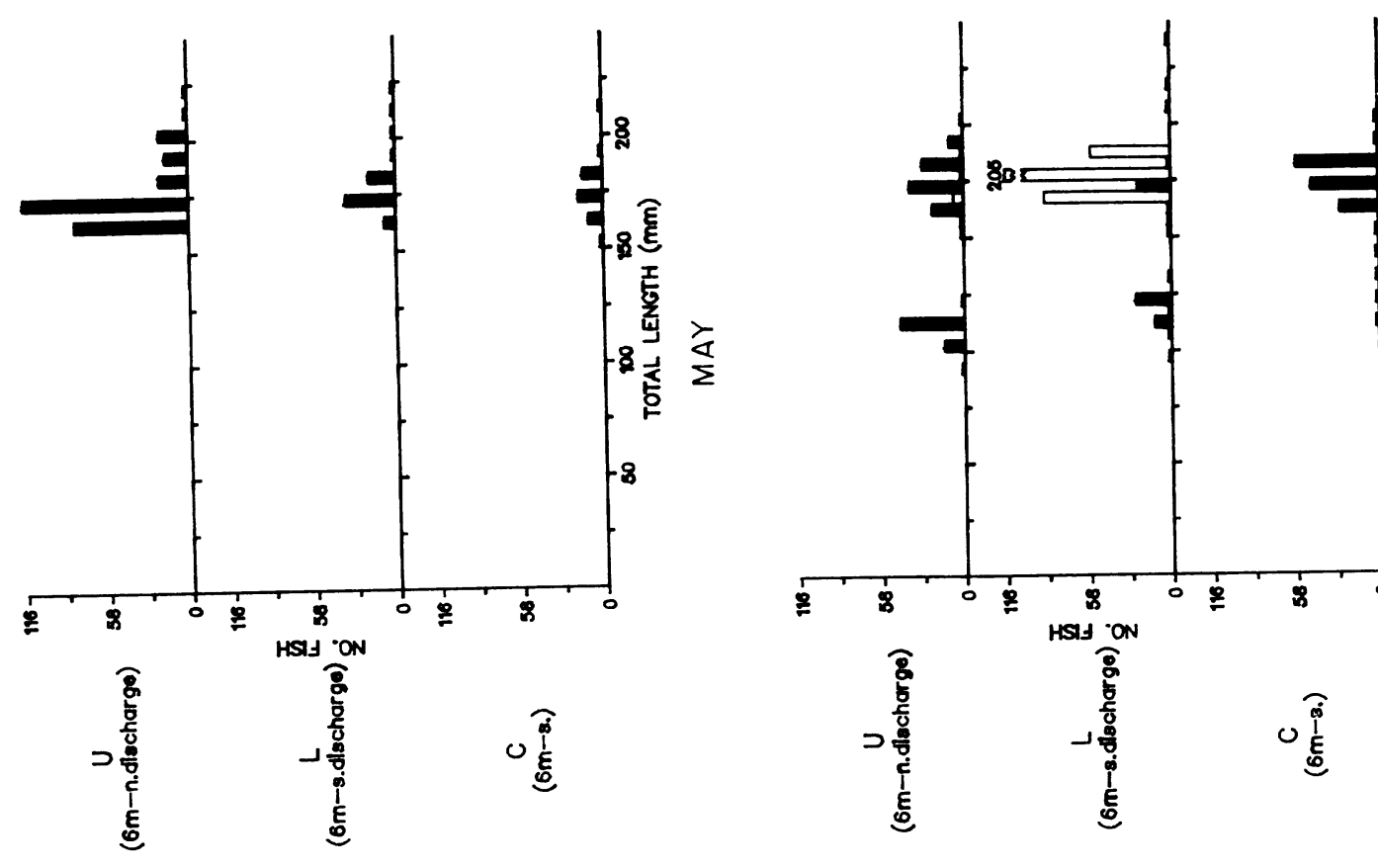

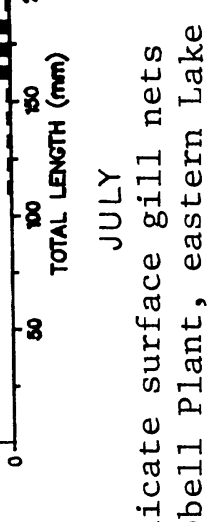

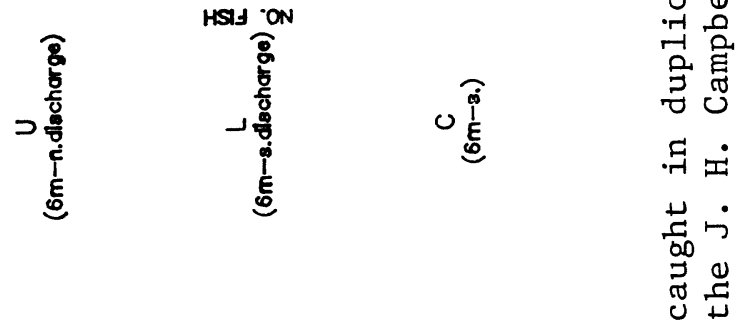

$\begin{array}{ll}0 \\ 0 \\ 0 & 0 \\ 0\end{array}$

.

故

崩
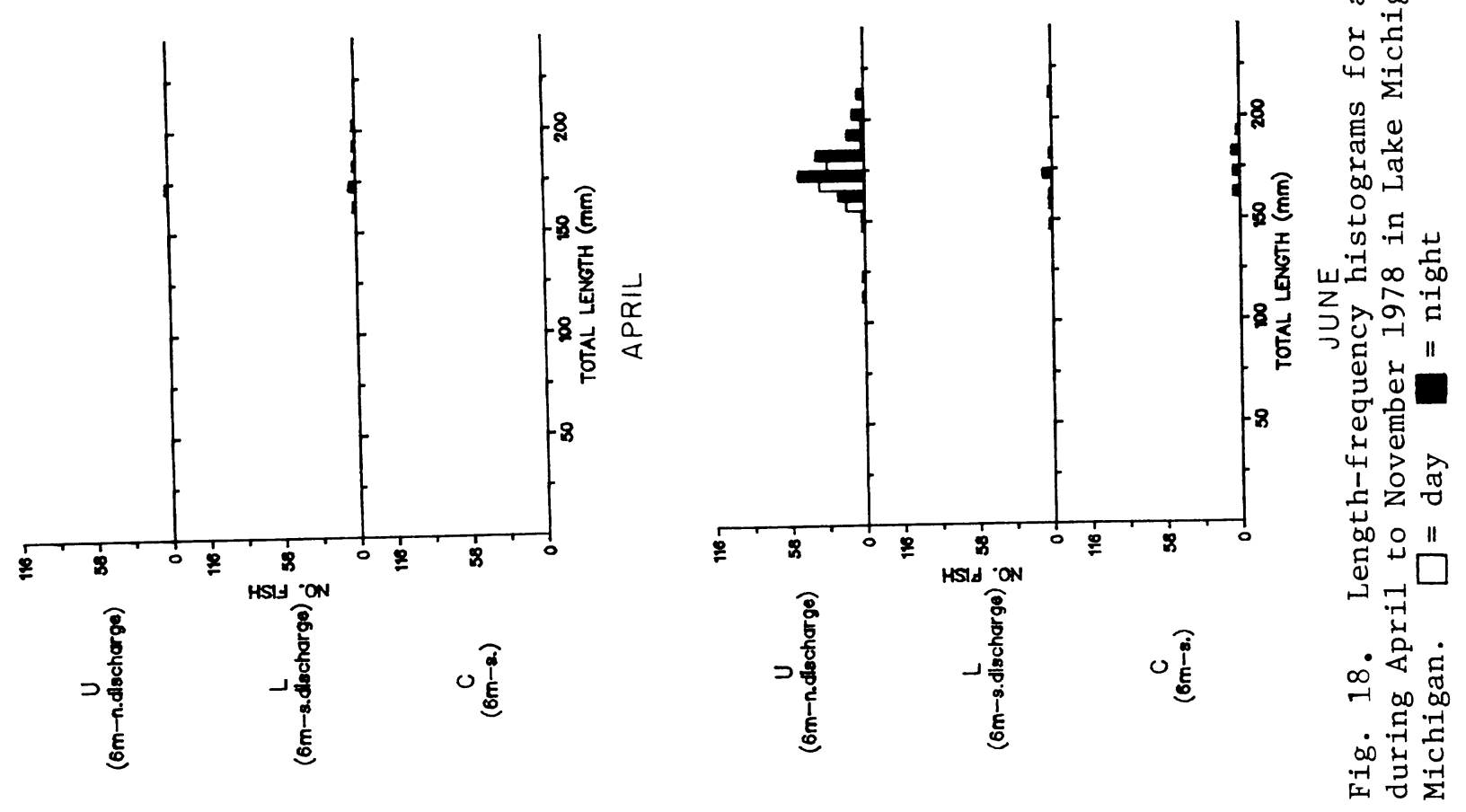

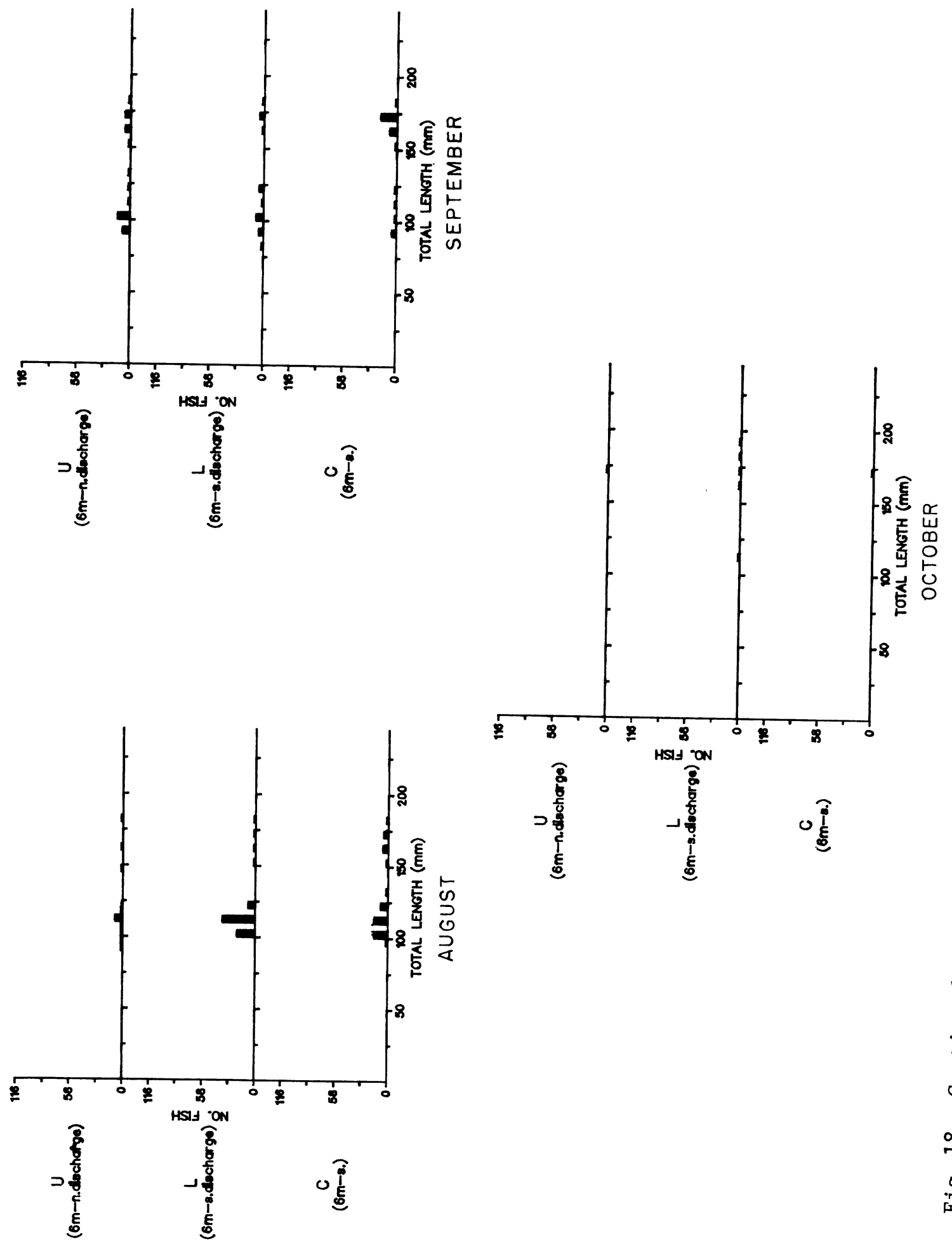

 
On the basis of these gill net catches and because seining at beach station Q ( $\mathrm{S}$ discharge) produced the only alewives caught in seines, we concluded alewives were concentrating in the area of the present plant discharge. Water temperatures at the two sampling transects (south and north) were not consistently different, eliminating temperature as an explanation for this apparent concentration. Spawning alewives were observed in the discharge canal in June. Thus, high numbers of alewives concentrating in that vicinity in May could be related to fish searching for spawning sites or being attracted to currents in the area.

June--In Lake Michigan, fewer adult alewives were caught in June (566) than in May (880) (Appendix 6). In June, however, unlike May, alewives were collected in Pigeon Lake (137) (Appendix 6). Fewer adults were present in Lake Michigan in 1978 than in 1977 when 2198 alewives were collected. In contrast, more alewives were caught in Pigeon Lake in 1978 (137 caught) than 1977 when only 15 were taken.

Gonad data for June (Tables 22 and 23) indicated that spawning was occurring in both Lake Michigan and Pigeon Lake. Most alewives examined had well-developed gonads and some were already spent.

Mean length of alewives caught in Lake Michigan was $171 \mathrm{~mm}$ the same as in May. Cooper (1961) reported that larger alewives were the first to migrate inshore for the spawning run. As the migration progressed, average adult size decreased. This phenomenon was not yet evident during June for Lake Michigan alewives.

Table 23. Monthly gonad conditions of alewives caught during 1978 in Pigeon Lake near the J. H. Campbell Plant, eastern Lake Michigan. A11 fish examined in a month were included except poorly received specimens.

\begin{tabular}{|c|c|c|c|c|c|c|c|c|c|c|}
\hline & Gonad condition & Apr & May & Jun & Jul & Aug & Sep & Oct & Nov & Dec \\
\hline Males & $\begin{array}{l}\text { Slight development } \\
\text { Mod. development } \\
\text { Weli developed } \\
\text { Ripe-running } \\
\text { Spent }\end{array}$ & $\begin{array}{l}4 \\
1\end{array}$ & & $\begin{array}{r}14 \\
25 \\
6 \\
3\end{array}$ & $\begin{array}{l}3 \\
2 \\
9\end{array}$ & & & & & \\
\hline Females & $\begin{array}{l}\text { Slight development } \\
\text { Mod. development } \\
\text { We11 developed } \\
\text { Ripe-running } \\
\text { Spent } \\
\text { Absorbing }\end{array}$ & 2 & & $\begin{array}{r}2 \\
12 \\
22 \\
5\end{array}$ & $\begin{array}{r}1 \\
13\end{array}$ & & & & & \\
\hline Immature & & & & 1 & 10 & 17 & 3 & 1 & 1 & \\
\hline Unable $t$ & o distinguish & & & & 1 & 2 & & & & \\
\hline
\end{tabular}


Bottom gill net data indicated that alewives were still inshore in June, although they were slightly more abundant at stations $\mathrm{C}(6 \mathrm{~m}-\mathrm{S})$ and $\mathrm{L}(6 \mathrm{~m}-\mathrm{N})$ than at the shallower stations as was found in May. Trawl catches were also greatest at stations $\mathrm{C}$ and L (respectively 35 and 40 day and night combined). The largest catch of alewives in any gear during June was taken in surface gill nets at station $\mathrm{U}(6 \mathrm{~m}-\mathrm{N}$ discharge) where 82 and 141 were collected during day and night, respectively (Fig. 19).

As in May, water temperature differences did not appear to be the reason for the concentration of alewives in the vicinity of the present thermal discharge. Observation of numerous spawning adults in the discharge canal during June strongly suggests that these fish moved into the area to spawn.

No alewives were collected in Lake Michigan day seines. At night, low numbers of adult alewives were taken in seine hauls at beach stations $P$ ( $S$ reference) and $Q$ (S discharge). At beach station $R$ ( $N$ discharge), seining yielded 45 adults. This nocturnal shoreward movement was noted in 1977 (Jude et al. 1978) and near the D.C. Cook Plant, southeastern Lake Michigan (Jude et a1. 1975).

In Pigeon Lake, more alewives were caught in bottom gill nets at station M (influenced by Lake Michigan) during the day (81) than at night (31) (Fig. 20). Higher day than night catches is consistent with alewives' mostly demersal distribution during the day. No alewives were collected in day seines. Night seine samples from beach stations $\mathrm{S}$ (influenced by Lake Michigan) and V (undisturbed Pigeon Lake) contained 19 and 6 adults respectively. Since 11 of these fish were ripe-running, it indicates that spawning was occurring during June in Pigeon Lake. No alewives were collected in May in Pigeon Lake.

July--In Lake Michigan, the highest numbers of adult alewives were caught during July compared to other months in 1978. In 1977, July catches of adult alewives showed a decline from numbers caught in June as those fish that had already spawned were moving from the area. In 1978, YOY had not yet appeared in Lake Michigan samples in contrast to 1977 when large numbers of YOY were collected in July samples. Apparently, peak spawning and recruitment of YOY in 1978 were approximately 1 mo behind similar activities in 1977 since July data for alewives in Lake Michigan showed many fish with well-developed gonads (Table 22). Mean adult length in July was again $171 \mathrm{~mm}$. However, in addition to a greater number of large adults $(>150 \mathrm{~mm})$, more alewives in the 100-150-mm length interval were caught in July than in previous months (Appendix 6). Appearance of these smaller adults agrees with observations of Cooper (1961) concerning the later inshore movement of smaller adults.

An upwelling occurred between $17 \mathrm{July}$ when night gill nets were set and $19 \mathrm{July}$ when day gill nets were set. Water temperatures during day sets dropped $10 \mathrm{C}$ compared to temperatures observed during night sets (Appendix 1). These water temperature differences were reflected in the catch of alewives. Large numbers of alewives were caught at night in bottom gill nets at all depths from 1.5 to $12 \mathrm{~m}$. During the day, only stations $A(1.5 \mathrm{~m}-\mathrm{S})$ and $B(3 \mathrm{~m}-\mathrm{S})$ showed large catches of alewives. This daytime shoreward movement was most likely due to the upwelling. Stations $A(1.5 \mathrm{~m})$ and $B(3 \mathrm{~m})$ had the warmest temperatures 

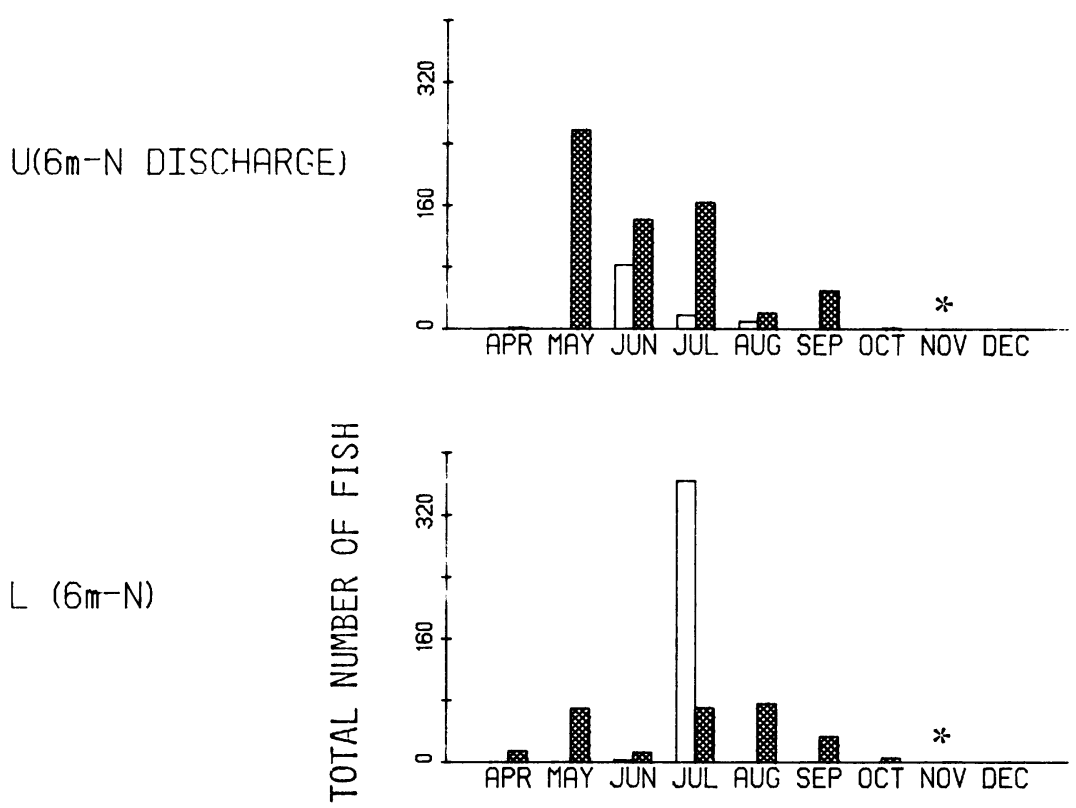

C $(6 m-5)$

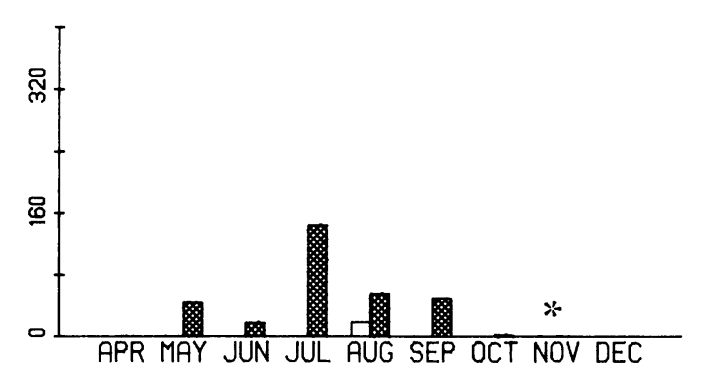

Fig. 19. Total number of alewives caught in duplicate surface gill nets fished during day and night once per month April to November 1978 in Lake Michigan near the J. H. Campbell Plant, eastern Lake Michigan. $\square=$ day $\square=$ night $*=$ no night sampling performed 

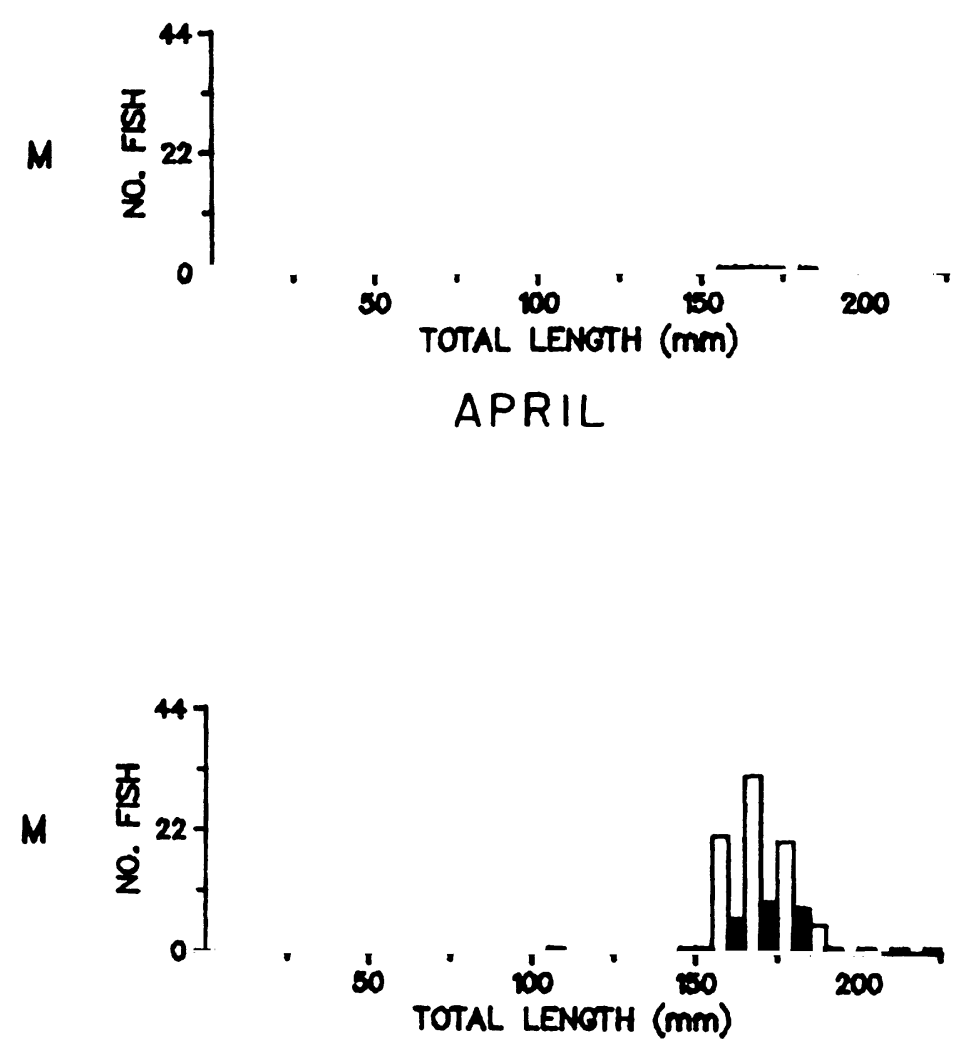

JUNE

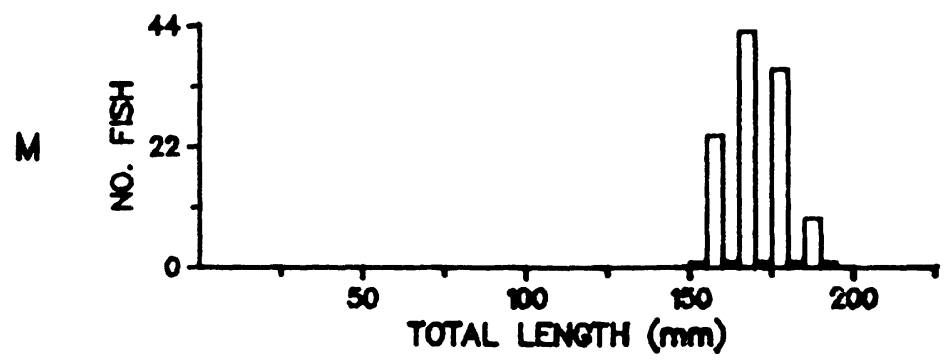

JULY

Fig. 20. Length-frequency histograms for alewives caught in duplicate bottom gill nets during April to December 1978 in Pigeon Lake near the J. H. Campbel1 Plant, eastern Lake Michigan. $\square=$ day $\square=$ night 
available and alewives moved inshore seeking warmer water. Surface gill net catches also reflected this temperature change. No alewives were caught in day surface gill nets at station $C(6 \mathrm{~m}-\mathrm{S})$ where the temperature was $8.0 \mathrm{C}$, but 364 were caught at station $\mathrm{L}(6 \mathrm{~m}-\mathrm{N})$ and 17 at $\mathrm{U}(6 \mathrm{~m}-\mathrm{N}$ discharge) where water temperatures were $13.8 \mathrm{C}$ due to the influence of the thermal discharge (Fig. 18).

July trawl catches were low at all stations, both day and night, except at station B ( $3 \mathrm{~m}-\mathrm{S})$ where 35 alewives were caught during the day and 265 at night (Figs. 21, 22). Trawling was done after water temperatures had dropped due to the upwelling and alewives were probably again seeking warmer inshore water.

Adult alewives were seined at all Lake Michigan beach stations at night. During the day, alewives were found only at beach station Q (S discharge). Presence of alewives in the area of the present discharge indicates use of the discharge canal as a spawning area.

YOY were collected for the first time in 1978 in Pigeon Lake (Fig. 23, 24). They were caught in day seines at beach station S (influenced by Lake Michigan). None were caught at night. This offshore movement by YOY at night was also observed in 1977 and by Jude et al. (1975) in southeastern Lake Michigan near the Cook Plant. Adult alewives were caught in bottom gill nets at open water station M (influenced by Lake Michigan) (Fig. 20). Most of these adults examined were ripe-running or spent indicating that spawning was ending in Pigeon Lake. Numbers of YOY collected in Pigeon Lake in 1978 (318) were much lower than in July 1977 (6757).

One possible explanation for the differences seen in YOY abundance between 1977 and 1978 in Pigeon Lake could be the change in location of beach station S (influenced by Lake Michigan). In 1978, station S was moved farther west toward Lake Michigan. The new location is in the main flow of water coming into Pigeon Lake from Lake Michigan and is a less sheltered environment than the location of station $\mathrm{S}$ in 1977. This more exposed habitat may be less suitable for YOY alewife and as a result, fewer were caught. Whether the reduction in YOY caught in Pigeon Lake reflected an actual decline in alewife recruitment for 1978 or was only a result of different sampling locations, is difficult to determine.

August--In Lake Michigan, catches of adult alewife were low at all stations (Appendix 6). The largest catch (75) was in a night surface gill net at station $\mathrm{L}(6 \mathrm{~m}-\mathrm{N})$. In late summer and fall, adult alewives move away from shore to deeper water (Wells 1968). The decline in numbers of adults caught by us in August probably reflects migrations offshore from the sampling area.

YOY were caught for the first time in Lake Michigan during August in seine hauls at all beach stations (Appendix 7). With the exception of station Q (S discharge), more YOY were caught in day seines than night seines showing the same trend toward nocturnal offshore movement as was observed in Pigeon Lake in July (Fig. 23). The larger night catches at beach station $Q$ may have resulted from movement of YOY out of the discharge canal.

Trawl catches of alewives were low in August and were comprised totally of 


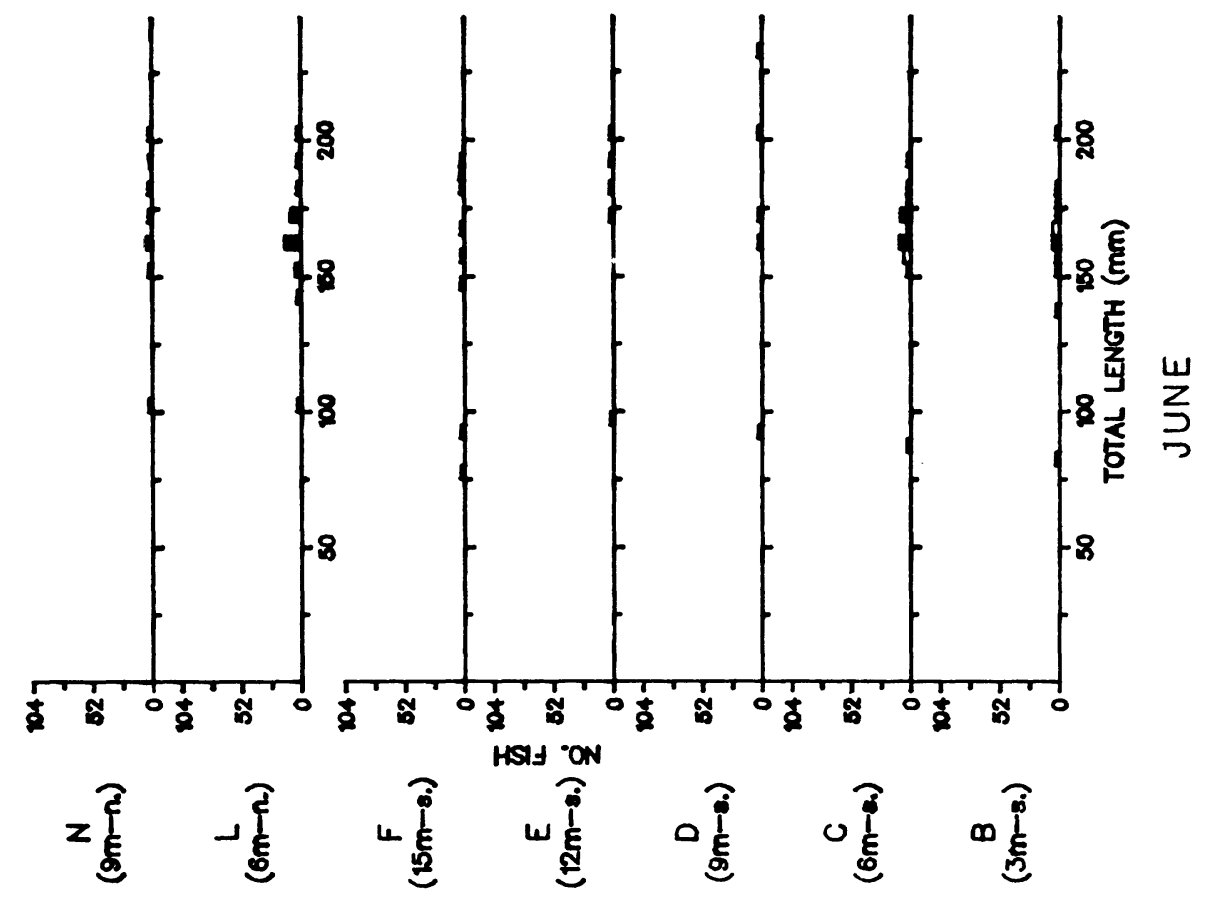

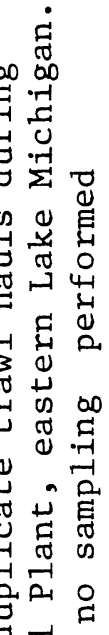

च 거

+

苨

党

田

का

$>0$

3 造

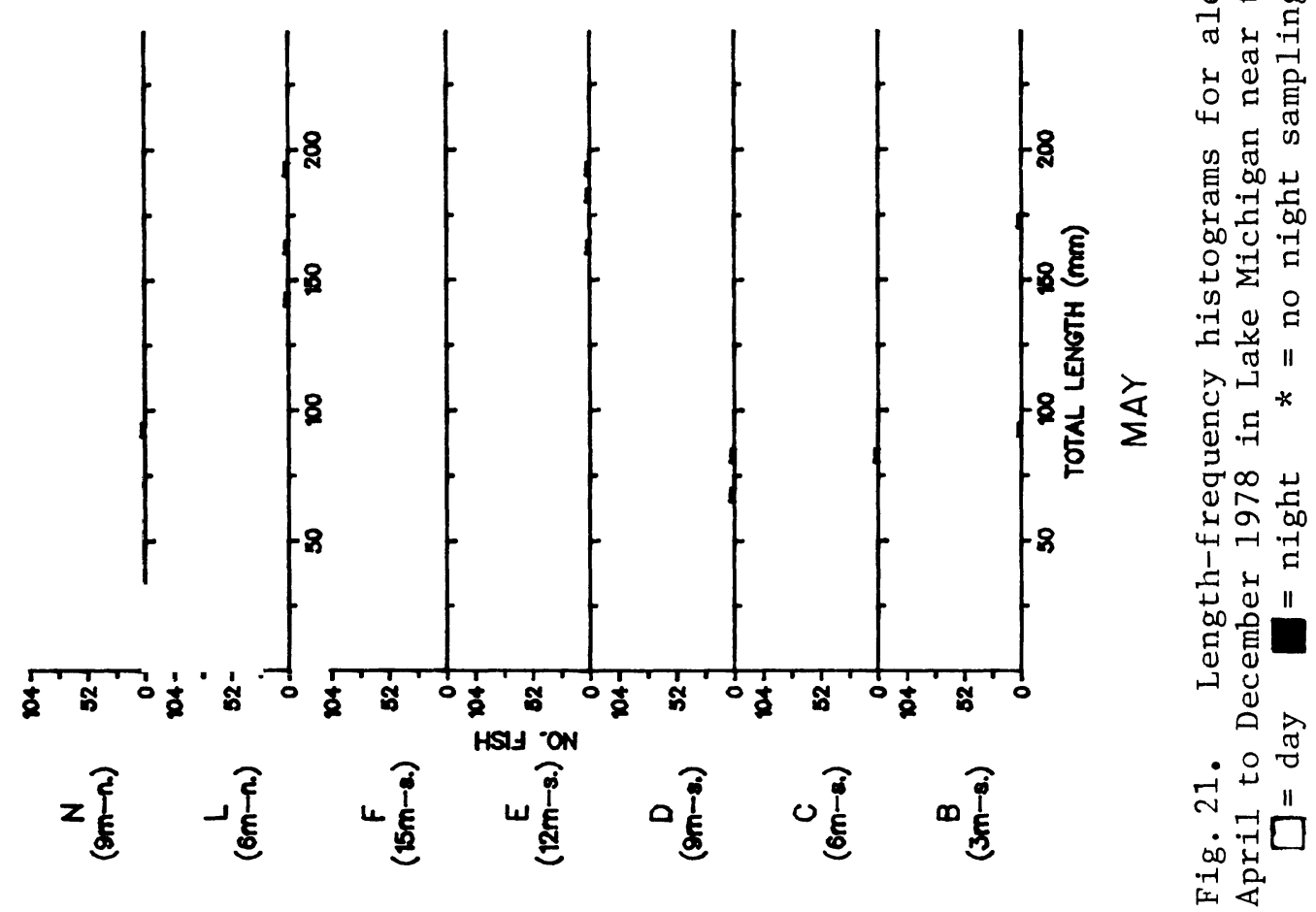



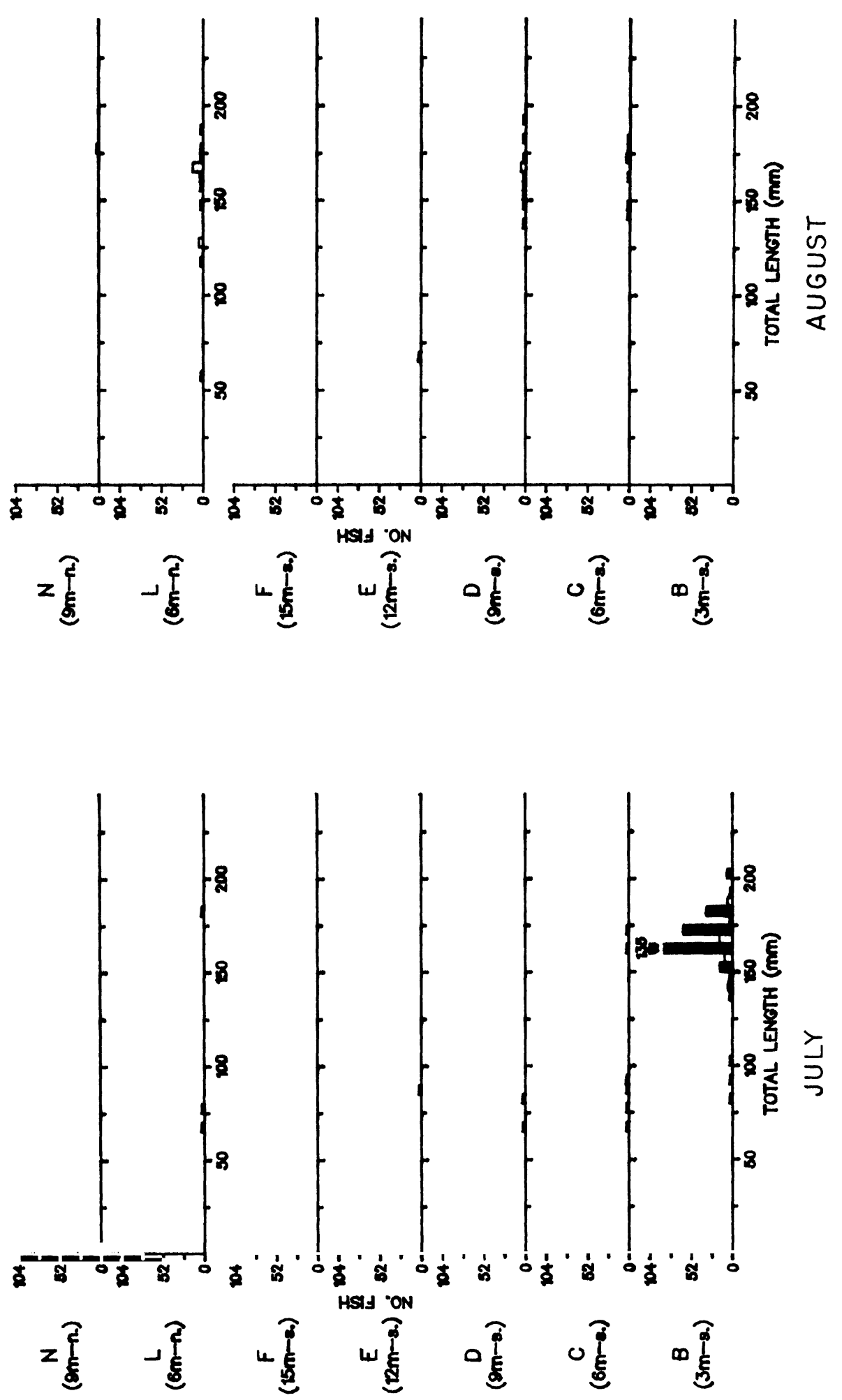

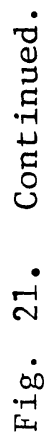



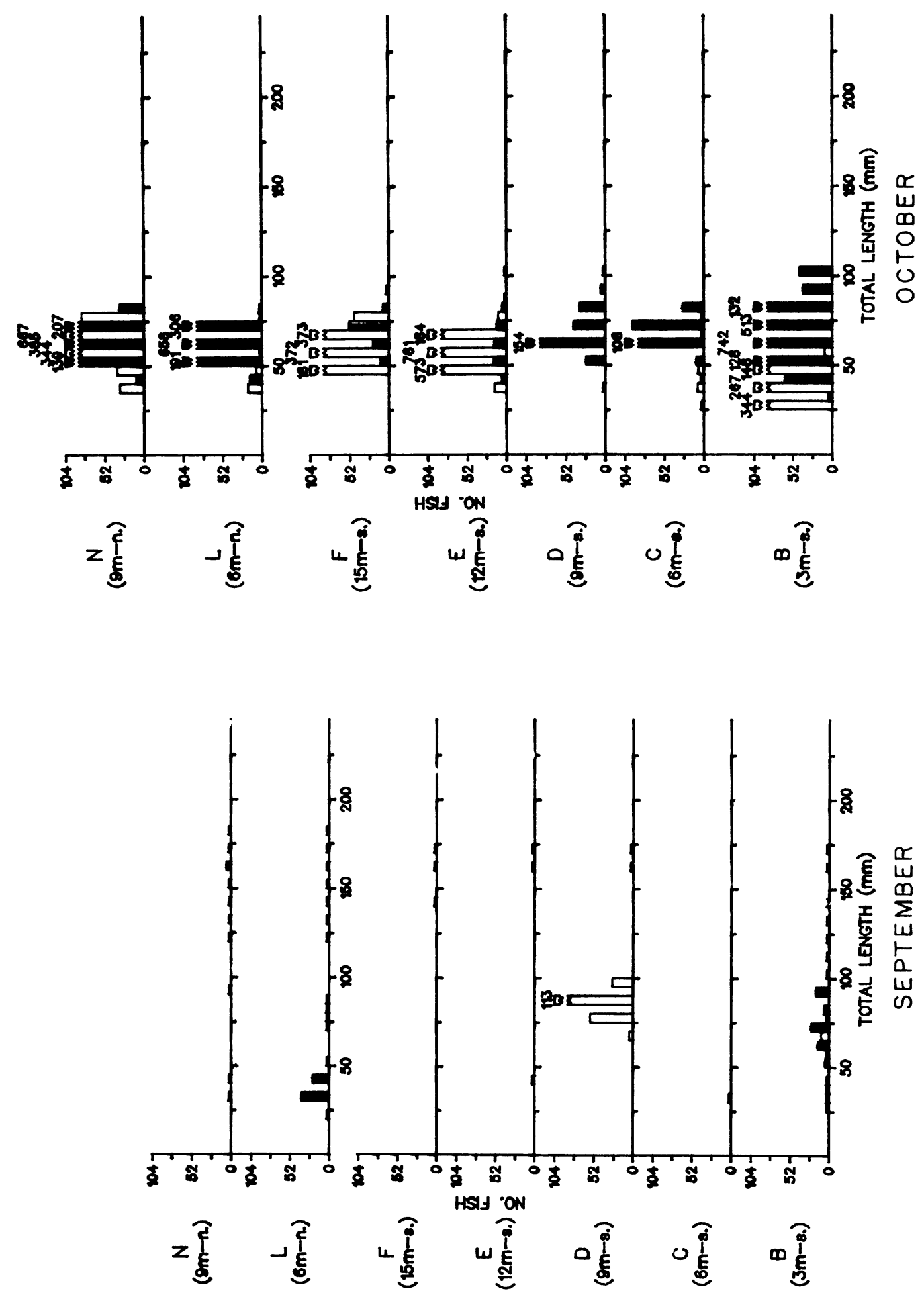

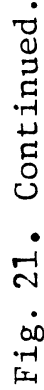



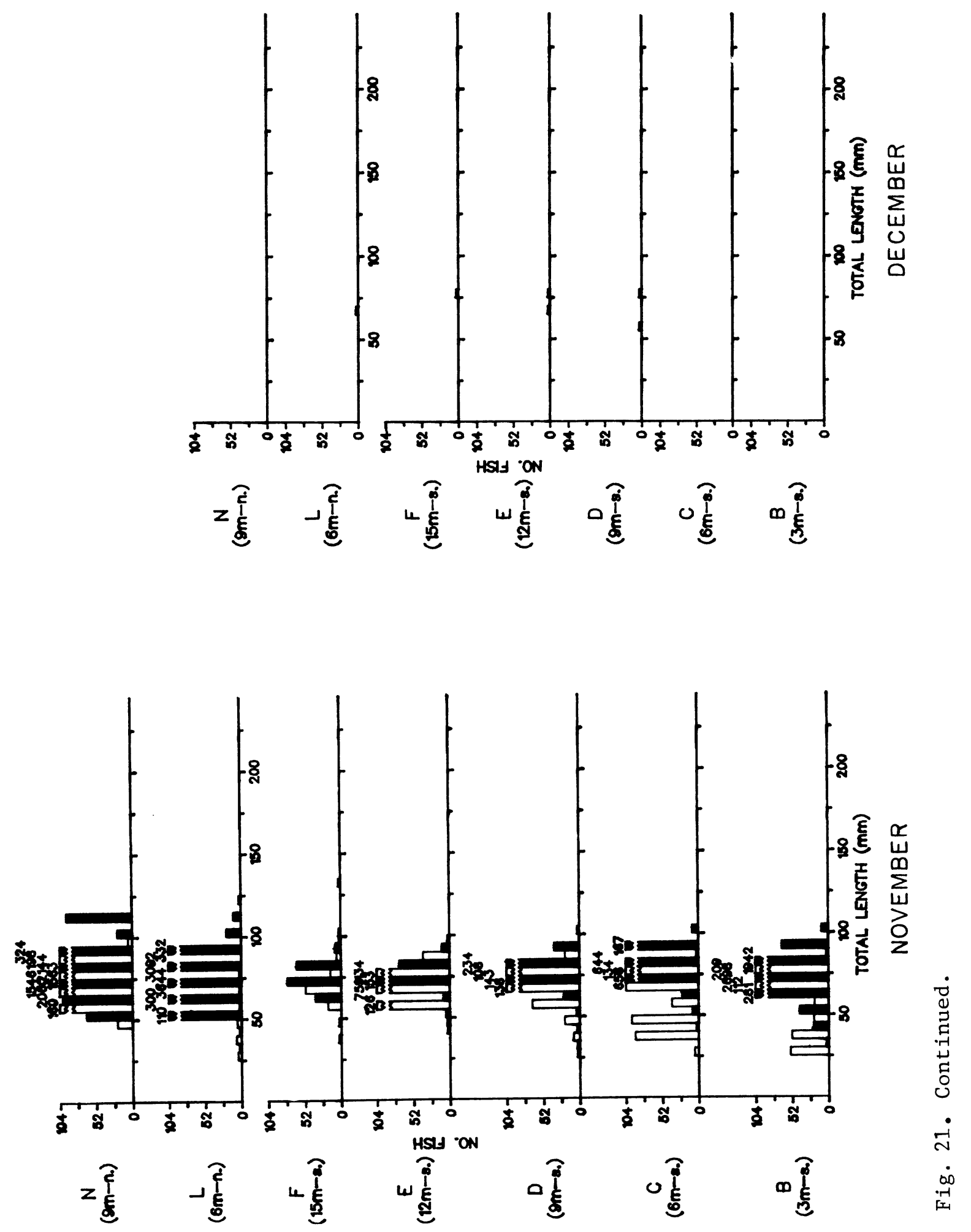
$N(9 m-N)$

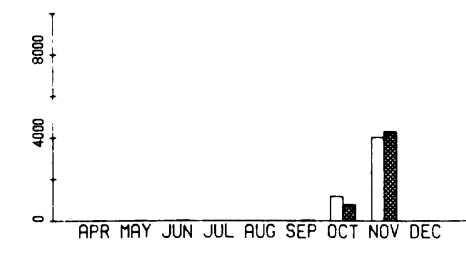

$L(6 m-N)$

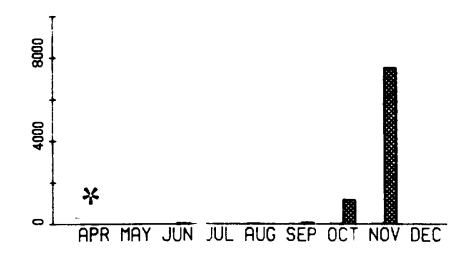

$F(15 m-S)$

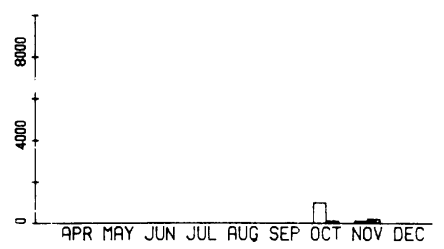

$F(12 m-5)$

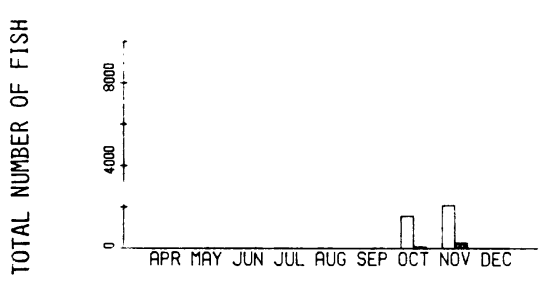

D $(9 m-S)$

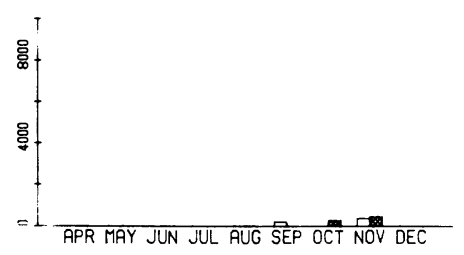

C $(6 m-5)$
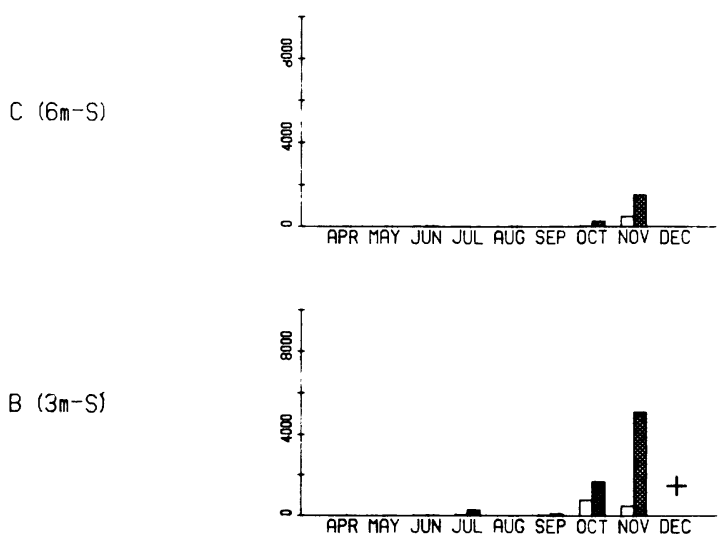

Fig. 22. Total number of alewives caught in duplicate trawl hauls during day and night once per month April to December 1978 in Lake Michigan near the J. H. Campbell Plant, eastern Lake Michigan.

$\square=$ day $\square=$ night $*=$ no night sampling performed

$+=$ no sampling performed. 


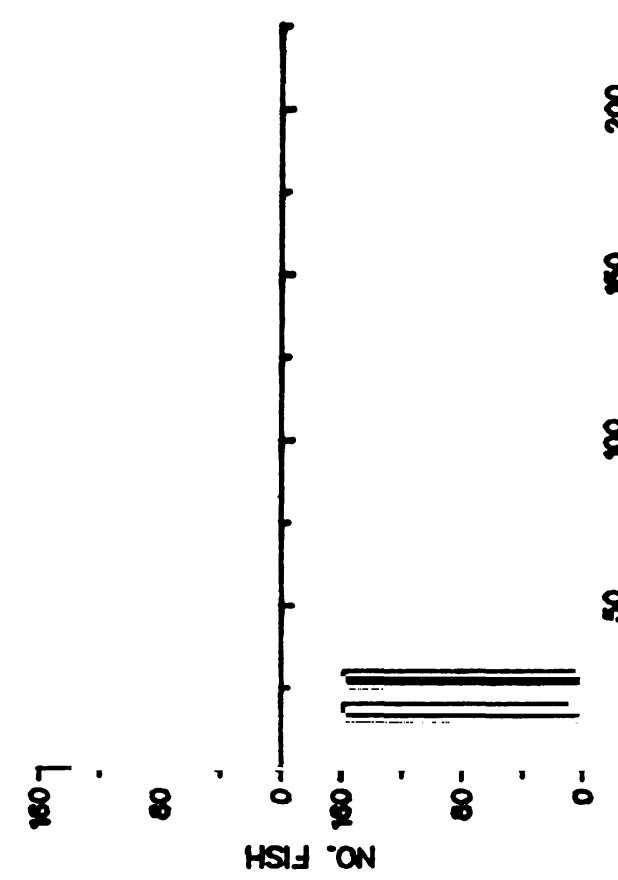

$>$

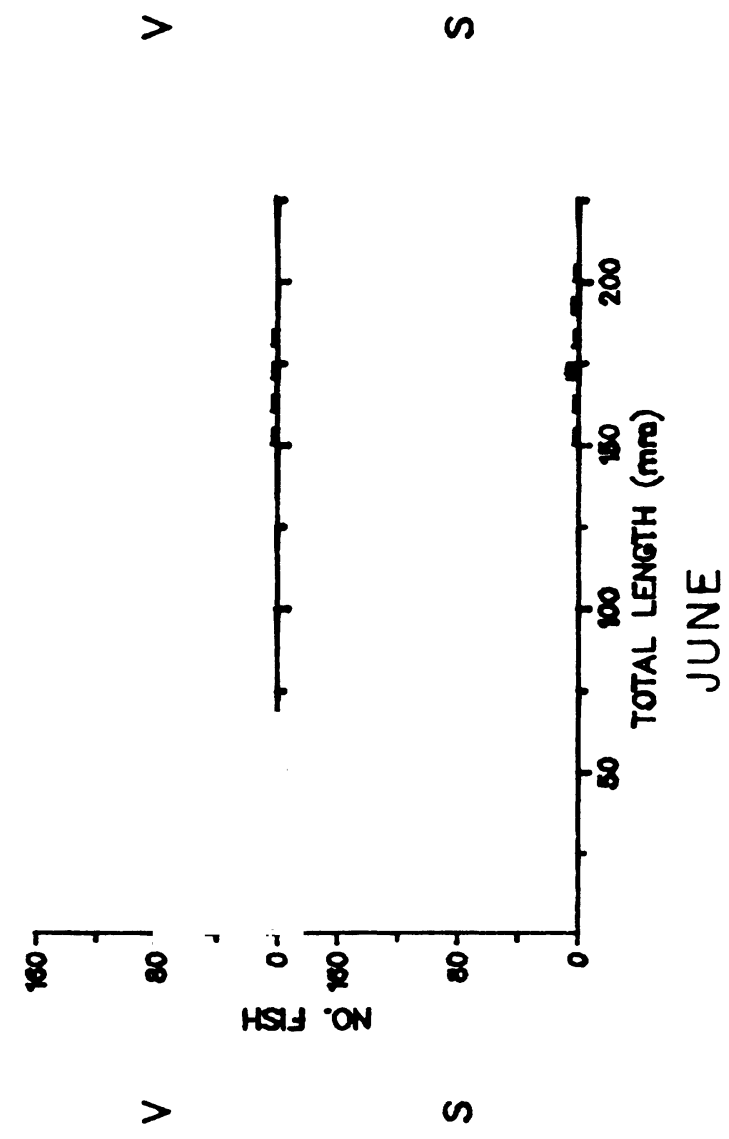

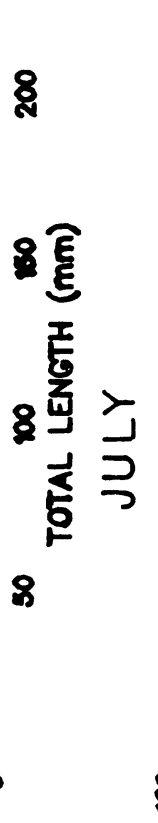

8
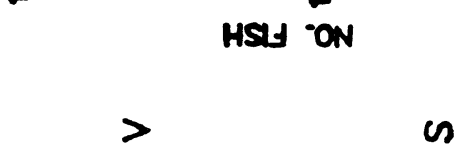

$n$
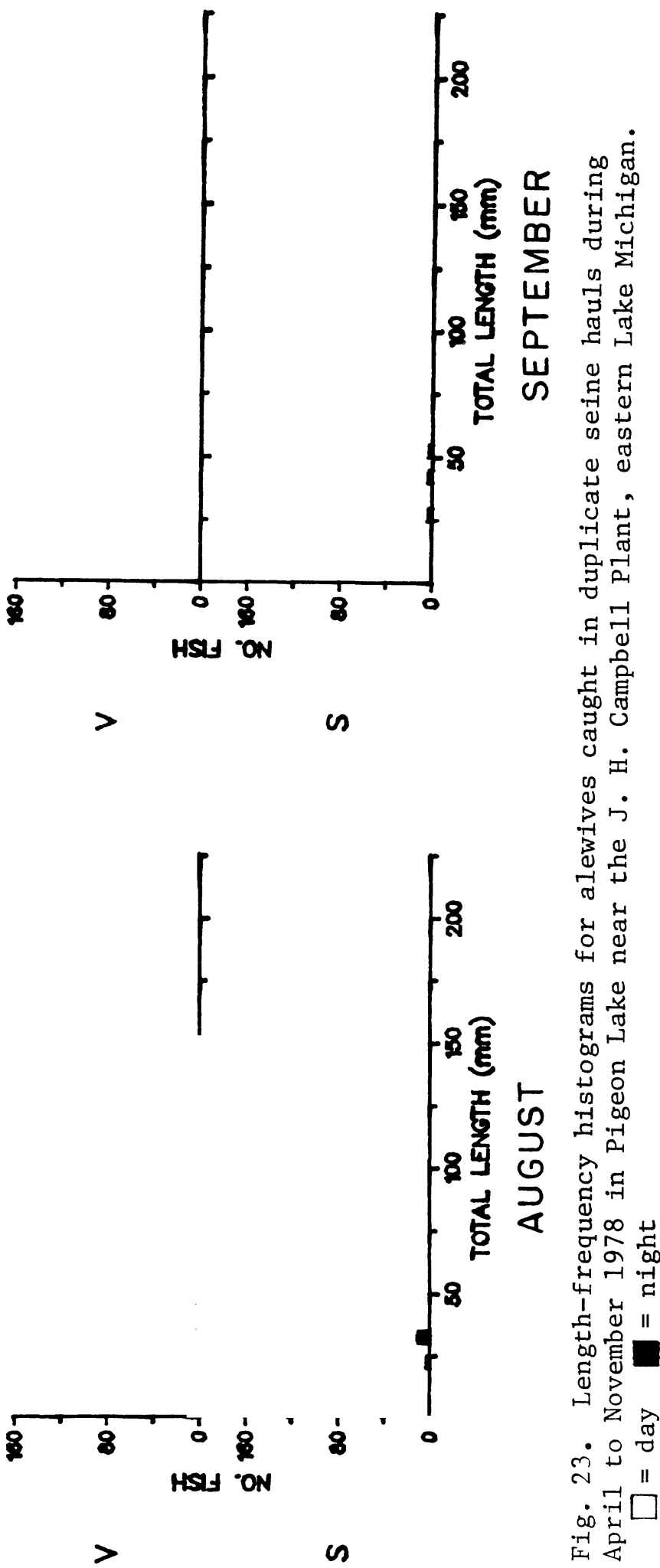

$\infty$ हี

ti

吾

क

疍嵒

( $)$

䄵

๑)

$\pi$

엄

욤

닥

-

营葛

可

我

d 0

$\stackrel{1}{\circ}$

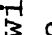

氙 号

历

मे

फ

氠

ชั

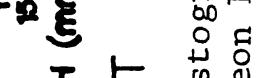

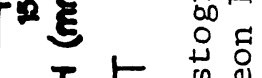

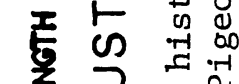

8 争 $\supset$ म

ᄀ

合文

㟧

क्षे ने 
8

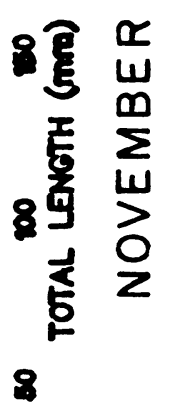

8 8 0 is 8 ON
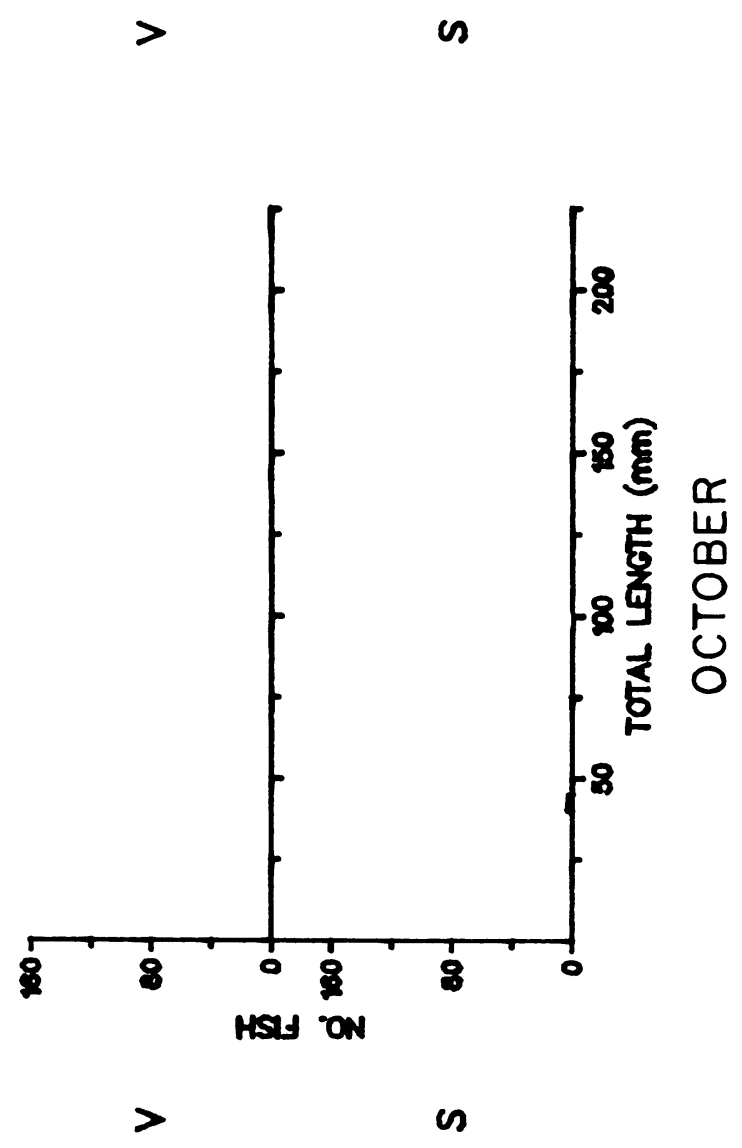

ت્ટ

$\underset{v}{m}$ 


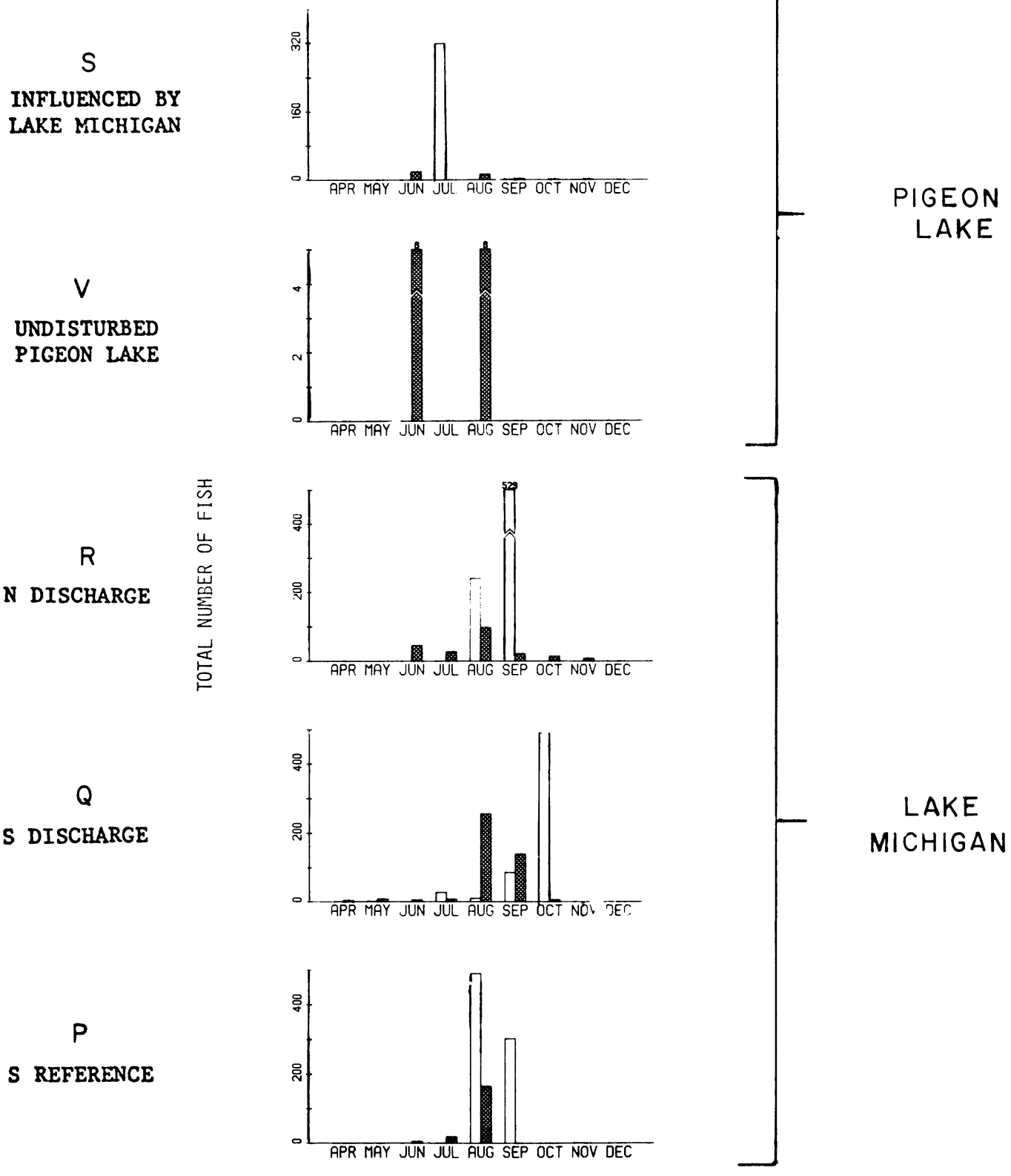

Fig. 24. Total number of alewives caught in duplicate seine hauls during day and night once per month April to November 1978 in Pigeon Lake (stations $S$ and $V$ ) and Lake Michigan (stations $P, Q, R$ ) near the J. H. Campbell Plant, eastern Lake Michigan. $\square=$ day $\square=$ night 
adults. YOY appeared to be inhabiting the area from the beach out to the $3-\mathrm{m}$ contour.

Most Lake Michigan alewives caught in August had undeveloped or spent gonads (Table 22). Spawning had apparent1y ended by mid-August.

No adult alewives were collected in Pigeon Lake in August. With spawning completed, adults apparently moved out of Pigeon Lake to deeper water in Lake Michigan. Small numbers of YOY alewives (13 and 6, respectively) were collected in night seines at beach stations $\mathrm{S}$ (influenced by Lake Michigan) and V (undisturbed Pigeon Lake). None were taken in day seines.

September--Catches of adult alewives were low during September in Lake Michigan (Appendix 6). YOY were caught in beach seines and trawls. In Pigeon Lake, no adults were collected and only three YOY were caught in beach seines at beach station S (influenced by Lake Michigan) (Appendix 7). Spawning had ceased by this time in Lake Michigan according to gonad data (Table 22); no fish with ripe gonads were found.

Bottom gill net data indicated that adult alewives were scattered throughout the area from 3 to $12 \mathrm{~m}$ as they were caught at every station. Trawls showed YOY were present inshore at station $B(3 \mathrm{~m}-\mathrm{S})$ and in the area of the discharge at station $\mathrm{L}(6 \mathrm{~m}-\mathrm{N})$. Alewives that appeared to be yearlings $(75-104 \mathrm{~mm})$, according to length data given by Norden (1967) were caught in relatively large numbers (203) in day trawls at station $C(6 \mathrm{~m}-\mathrm{S})$ and also at station $B(3 \mathrm{~m}-\mathrm{S})$ (Appendix 7). Surface gill nets at stations D $(9 \mathrm{~m}-\mathrm{S}), \mathrm{L}(6 \mathrm{~m}-\mathrm{N})$ and $\mathrm{U}(6 \mathrm{~m}-\mathrm{N}$ discharge) also caught yearling alewives as well as a small number of larger adults. Most alewives caught in surface gill nets were caught at night indicating a nocturnal movement off the bottom. With the exception of one adult at beach station $\mathrm{R}$ ( $\mathrm{N}$ discharge), seining in Lake Michigan collected only YOY. As in August, more YOY were caught during the day except at station Q (S discharge) where night catches were greater (Fig. 25).

Appearance of YOY in traw1 samples during September indicated some movement of YOY out of the beach zone, but they still remained in shallow water. This trend toward offshore movement by YOY as well as adults was also noted in September 1977 (Jude et al. 1978).

The peak in YOY abundance during September 1977 was not evident during September 1978. The apparent later spawning in 1978 plus the later initial appearance of YOY in field samples showed that peak YOY abundance occurred later during 1978.

October--As in October 1977, almost all adult alewives migrated from the Lake Michigan study area (Appendix 6). Catches of YOY were much greater than during previous months. Only one alewife was collected in Pigeon Lake, a YOY caught in a night seine at beach station $S$ (influenced by Lake Michigan).

Very few alewives were caught in either bottom or surface gill nets in Lake Michigan. The small size of YOY prevented these fish from being susceptible 


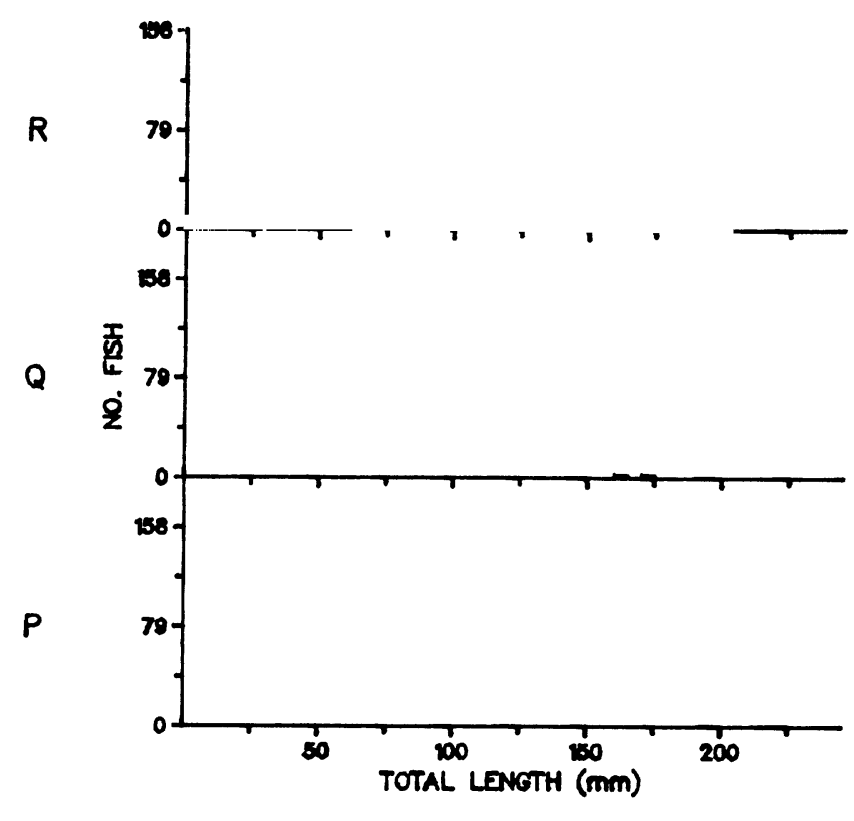

APRIL

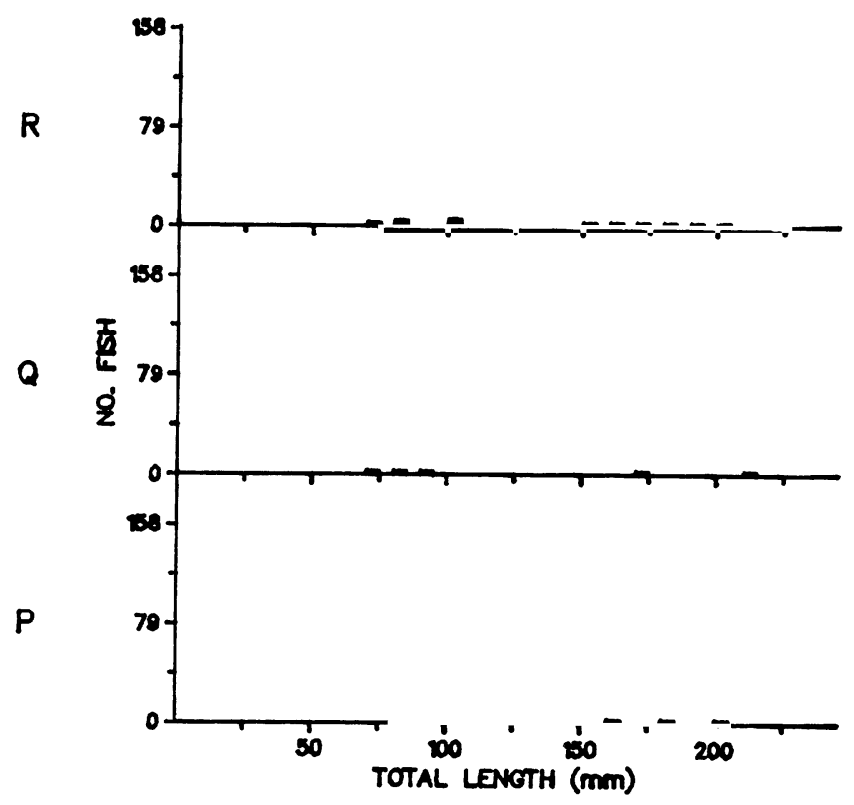

JUNE

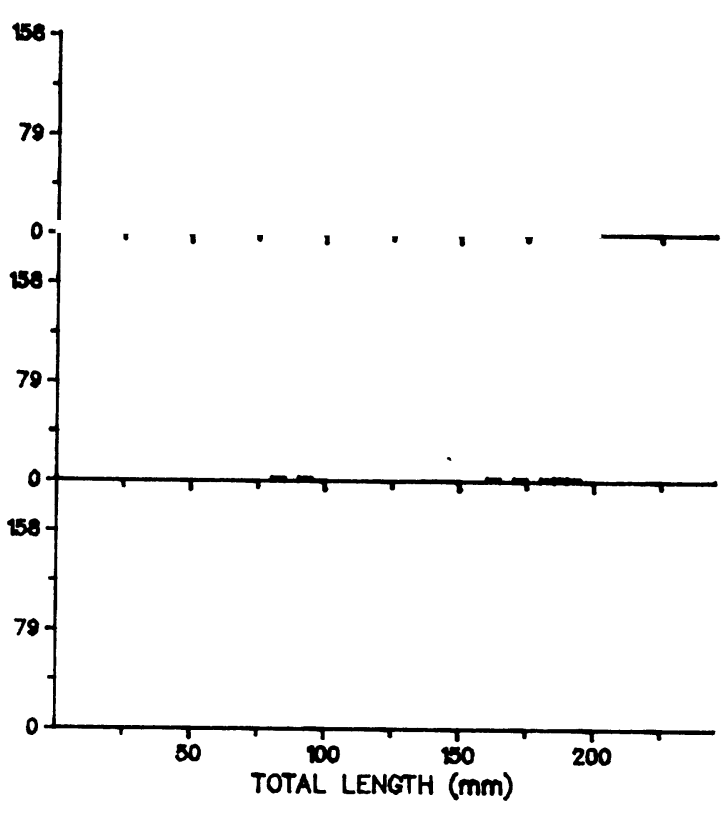

MAY

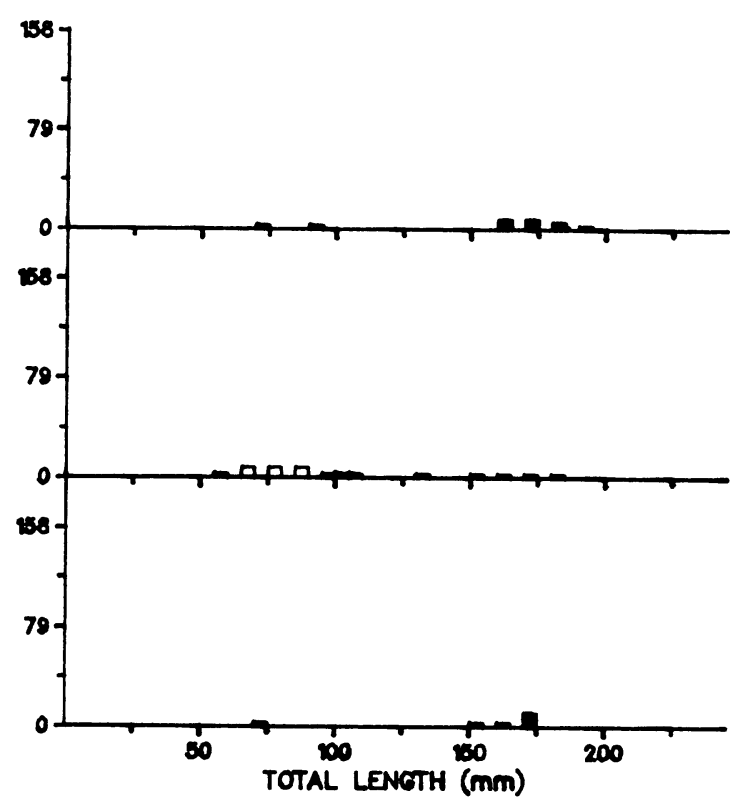

JULY

Fig. 25. Length-frequency histograms for alewives caught in duplicate seine hauls during April to November 1978 in Lake Michigan near the J. H. Campbell Plant, eastern Lake Michigan. $\square=$ day $\square=$ night 


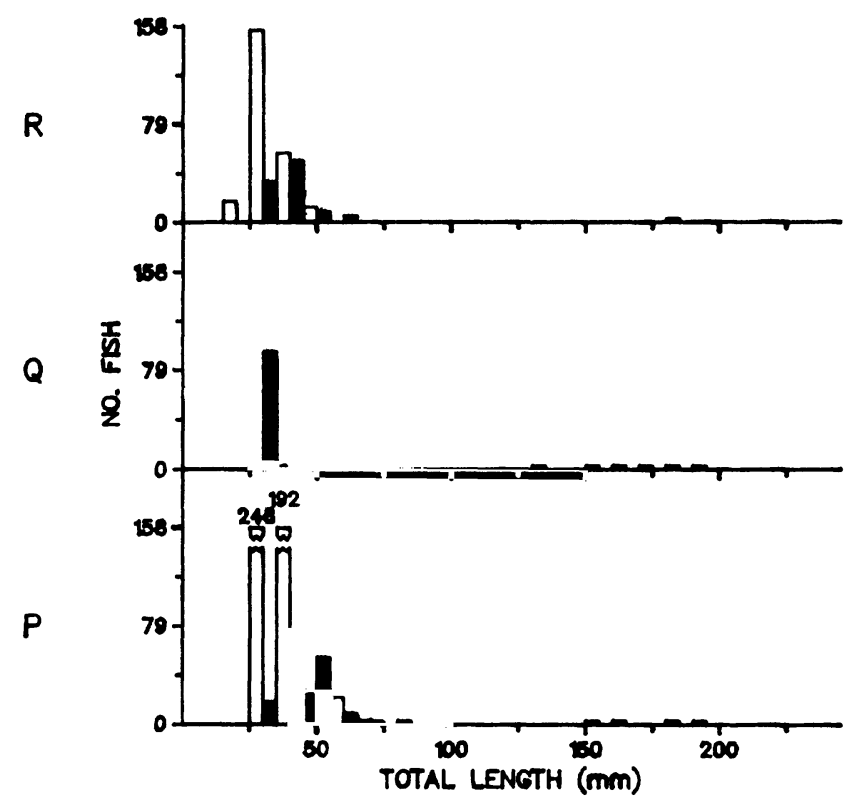

AUGUST

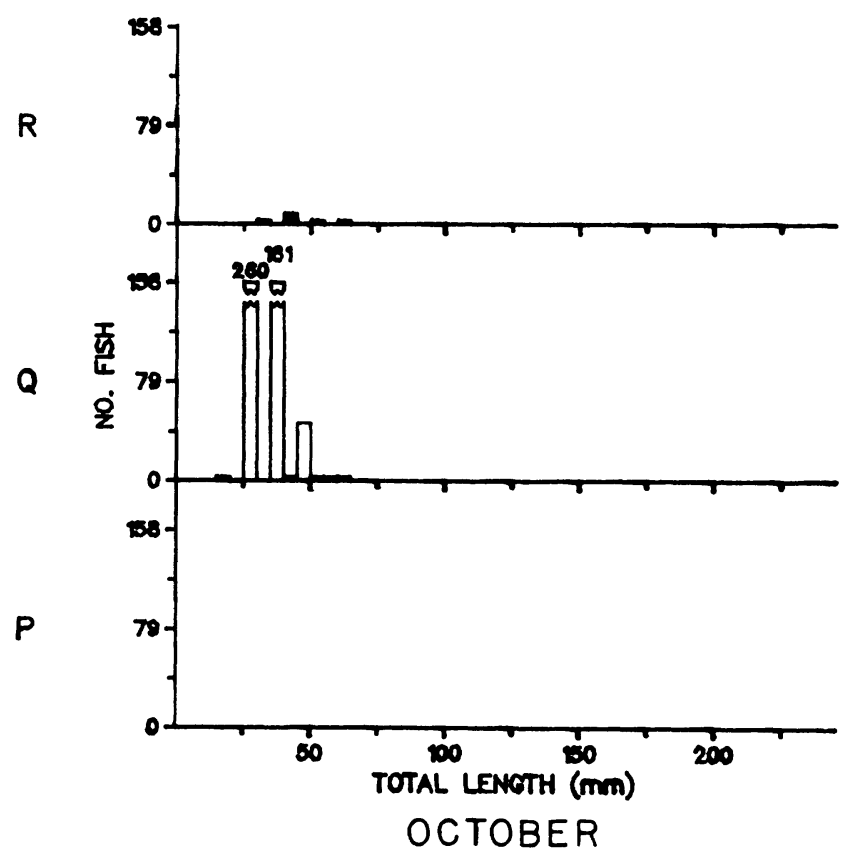

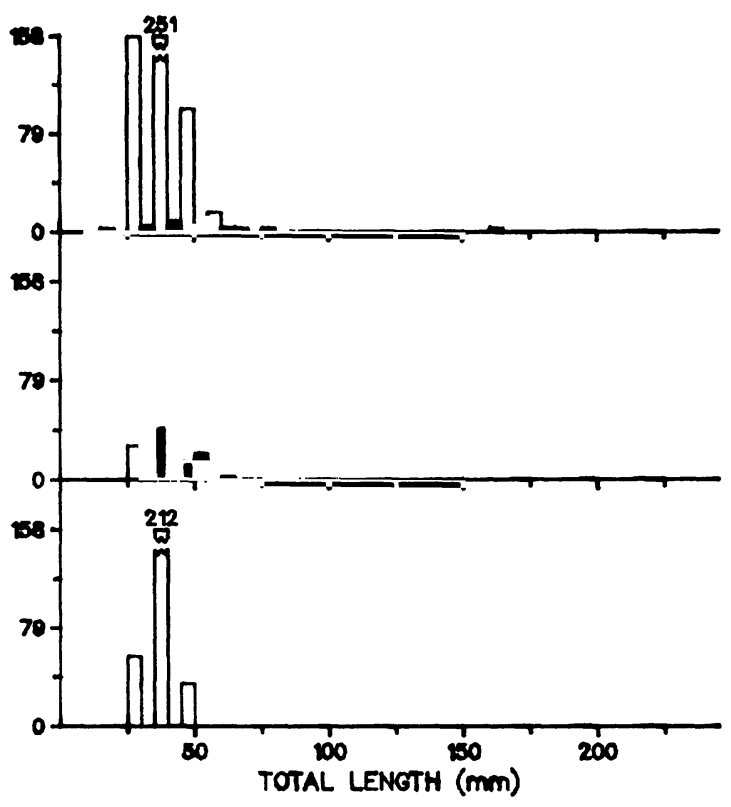

SEPTEMBER

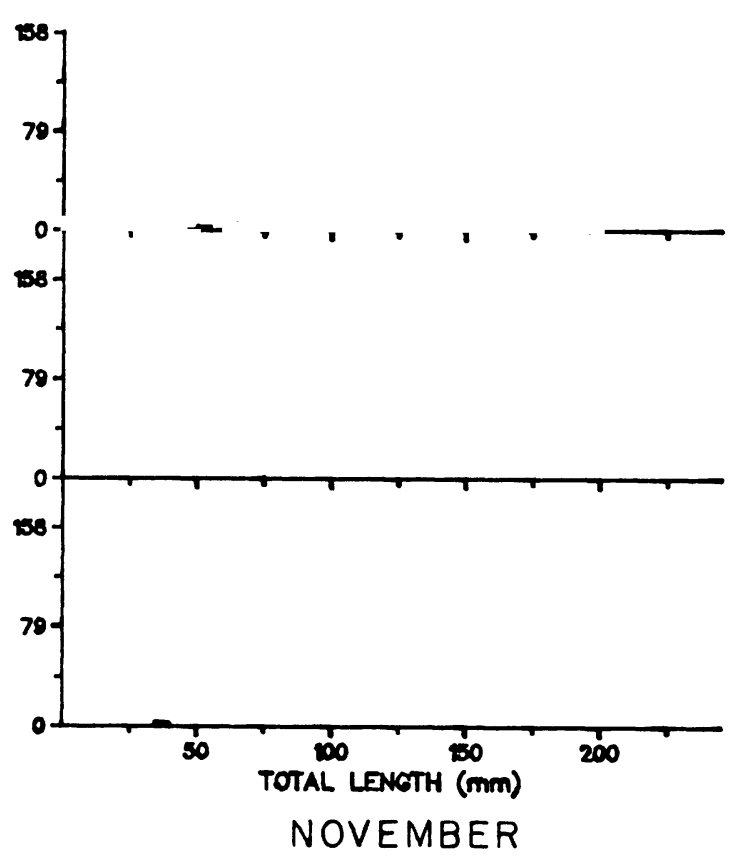

Fig. 25. Continued. 
to gill nets, and as a result, gill netswere an effective sampling gear only for older and larger fish.

Traw1 samples in September were comprised exclusively of YOY (Fig. 21). A striking distributional pattern became apparent when day and night catches at different depths were compared. At night, large numbers of YOY (1666) were caught at nearshore station B $(3 \mathrm{~m}-\mathrm{S})$. Numbers of YOY alewives caught generally decreased as station depth increased. At station $\mathrm{F}(15 \mathrm{~m}-\mathrm{S})$ on $1 \mathrm{y}$ 94 alewives were collected. During the day, largest catches of YOY at the south transect were at 12-m station $\mathrm{E}$ (1546) and 15-m station F (972) with the exception of a large catch (769) at 3-m station B. Examination of alewife length frequencies for the shallow-water group compared to the deeper-water group revealed a segregation by size. Mean length of YOY alewife at 3-m nearshore station $B$ was $38 \mathrm{~mm}$. At deeper stations $\mathrm{E}(12 \mathrm{~m})$ and $\mathrm{F}(15 \mathrm{~m})$, mean lengths were $57 \mathrm{~mm}$ and $62 \mathrm{~mm}$, respectively. Large numbers of YOY (489) were collected in day seines at beach station Q (S discharge). None were collected at other beach stations during the day. Mean length of these YOY was $32 \mathrm{~mm}$. Reasons for the presence of YOY alewives at beach station Q (S discharge), but not at beach stations $\mathrm{P}$ (S reference) or $\mathrm{R}$ ( $\mathrm{N}$ discharge) may either reflect the patchy distribution of alewife schools resulting in very different catches or could be a result of alewife spawned in the discharge canal migrating into the lake. Currents produced by the combination of winds and the plume of the discharge canal might cause the direction of flow to be predominately south. Such an occurrence may have induced the concentration of alewives in the area of station $Q$, and hence the high catch observed. In contrast to this distribution, at night, length frequencies of YOY caught at all depths were very similar. Mean length at $3-\mathrm{m}$ station $B$ was $65 \mathrm{~mm}$ and at $15-\mathrm{m}$ station $\mathrm{F}$ it was $66 \mathrm{~mm}$. Although not completely understood, this size-segregated daytime distribution may be due to possible gear avoidance, the distribution of prey items, or an orientation to some other physical feature of the environment (e.g., light intensity).

Traw1 catches of YOY at stations $\mathrm{L}(6 \mathrm{~m}-\mathrm{N})$ and $\mathrm{N}(9 \mathrm{~m}-\mathrm{N})$ were larger than catches at corresponding depths at south transect stations $\mathrm{C}(6 \mathrm{~m}-\mathrm{S})$ and $\mathrm{D}(9 \mathrm{~m}-\mathrm{S})$. More were caught during the night than during the day. At station L, 32 YOY were collected during the day (mean length $46 \mathrm{~mm}$ ) and 1172 at night (mean length $61 \mathrm{~mm}$ ). At 9-m station $\mathrm{N}, 1162$ YoY were collected in day trawls (mean length $66 \mathrm{~mm}$ ) and 773 at night (mean length $61 \mathrm{~mm}$ ). A similar size distribution pattern observed at south transect stations also occurred at north transect stations. Smaller YOY were found closer to shore during the day; whereas, at night, sizes of alewives collected at the various depth contours were more similar. The greater abundance of YOY at north transect stations $\mathrm{L}$ and $\mathrm{N}$ may be an indication of their preference for the warmer water near the present discharge canal or perhaps they are remaining near the area they were spawned.

Water temperature differences in October between all stations were less than $1 \mathrm{C}$, thereby eliminating temperature as an explanation for this YOY alewife distribution disparity between transects. As YOY increased in size, they appeared to seek deeper water. YOY caught during September in beach seines averaged about $39 \mathrm{~mm}$; no YOY were caught in trawls suggesting that they 
had not yet reached a size where they moved into deeper water. Sizes of YOY caught inshore in October were similar to those caught in September.

Larger YOY alewives in October remained farther offshore during the day, then appeared to move closer to shore at night. Small YOY present near shore during the day were not caught in comparable numbers at night. Data from previous months suggest a nocturnal offshore movement by small YOY. If these fish move offshore at night, but remain pelagic, they would not be as vulnerable to trawling and a smaller catch would result.

November--November sampling in Lake Michigan produced the largest catches of alewives for the entire year (Appendix 6). A11 were YOY with the exception of one adult captured in a bottom gill net at station $\mathrm{C}(6 \mathrm{~m}-\mathrm{S})$. In Pigeon Lake, only one alewife was caught, a YOY at beach station S (influenced by Lake Michigan). Pigeon Lake, therefore, does not appear to have an overwintering population of alewife.

Low numbers of large YOY (mean length $103 \mathrm{~mm}$ ) were caught in bottom gill nets set during the day in Lake Michigan at south transect stations B $(3 \mathrm{~m}-\mathrm{S})$ through $\mathrm{E}(12 \mathrm{~m}-\mathrm{S})$. None were caught at north transect station $\mathrm{L}$ $(6 \mathrm{~m}-\mathrm{N})$. Night bottom gill nets caught only three alewives. Due to weather, night gill nets were set 1 wk later than day nets. In that time, larger alewives appeared to have moved from the area. No alewives were caught in surface gill nets during November. (Note: in Appendix 7, under Alewife, Lake Michigan catches during November, the Bottom Gill Net label should be where the Surface Gill Net label is and vice versa.) One YOY was caught in a day seine at beach station $\mathrm{P}$ (S reference) and eight were caught in night seines at beach station $\mathrm{R}$ (N discharge).

Traw1s caught large numbers of YOY alewife in November (Fig. 21). At south transect stations, day catches were greatest (2060) at station E (12 m-S). At night, the greatest number of YOY (5063) were caught at station B ( $3 \mathrm{~m}-\mathrm{S})$. North transect trawls at station L $(6 \mathrm{~m}-\mathrm{N})$ caught on $1 \mathrm{y} 26$ YOY during the day, but 7515 at night. Station $\mathrm{N}(9 \mathrm{~m}-\mathrm{N})$ had more equal abundance of YOY during the day and at night (4009 and 4296, respectively).

Some size segregation of alewives was evident during November. Mean lengths of YOY were generally less at nearshore stations than deeper stations during the day. At station B $(3 \mathrm{~m})$, mean YOY length was $65 \mathrm{~mm}$ and at station $\mathrm{E}$ $(12 \mathrm{~m})$ it was $75 \mathrm{~mm}$. No difference was seen at night. The catch at station $\mathrm{L}$ $(6 \mathrm{~m}-\mathrm{N})$ during the day was the lowest of all trawl samples; mean length of Yor caught was $37 \mathrm{~mm}$. Night samples at station L and both day and night samples at station $\mathrm{N}(9 \mathrm{~m}-\mathrm{N})$ collected larger alewives (mean lengths $74-77 \mathrm{~mm}$ ).

As in October, alewives tended to be found in deeper water during the day, moving inshore at night. Trawls at stations $\mathrm{L}(6 \mathrm{~m})$ and $\mathrm{N}(9 \mathrm{~m})$, in the vicinity of the present onshore discharge, caught the greatest numbers of alewives of any station trawled in November (with the exception of day trawls at station $\mathrm{L})$. Water temperatures at stations $\mathrm{L}$ and $\mathrm{N}$ were not different from temperatures observed at south transect stations. These larger catches at north transect 
stations may again reflect the attractive influence (which could be currents) of the discharge canal on populations of YOY. Another possible explanation for higher YOY abundance at stations $\mathrm{L}$ and $\mathrm{N}$ may be increased food supply in the area. Although quantitative abundance data do not exist, zooplankton with a mortality rate of approximately $16 \%$ are carried with the cooling water (Consumers Power 1975). In addition to these zooplankters, dredging activities in the discharge area may stir up bottom materials releasing benthic organisms into the water column.

December--Six alewives were caught in day trawls in Lake Michigan; all were YOY. No gillnetting or seining was done this month. Most alewives appeared to have left the study area. No sampling was done in Pigeon Lake in December. Presence of these YOY at Lake Michigan stations during December (five at 9- to 15-m stations at the reference transect and one at $6 \mathrm{~m}$ at the north transect) demonstrates that some alewife apparently venture into nearshore water. Water temperatures at this time ranged from 1 to $3.5 \mathrm{C}$.

Temperature-catch relationships--In Lake Michigan, $83 \%$ of all alewives caught were collected at temperatures of 10-14 C. The range of temperatures at which alewives were caught was 1-26 C (Fig. 26). YOY tended to be found more often at higher temperatures than adults, which agreed with findings of Otto et a1. (1976) and Jude et al. (1979). They found YOY had a higher temperature preference than did mature fish.

Other considerations--Alewives are an important forage species for many Lake Michigan predators, especially salmonids. Examination of stomach contents from piscivorous fish collected in this study showed that lake trout, brown trout, rainbow trout and coho salmon fed extensively on alewives. Other species which were found to feed on alewife were northern pike, burbot, yellow perch and smelt.

Impingement--During 1978, 6040 alewives were recorded from impingement samples collected at the Campbell Plant resulting in a projected estimate for 1978 of 45,722 fish. Alewife impingement was highly variable throughout the year, ranging from $3 \mathrm{fish} / 24 \mathrm{~h}$ collected in April to 1932/24 h in June (Appendix 9).

A large number of alewives (1192/24 h) were impinged during the first week of January. The impingement of such large numbers during this month suggests a source other than Pigeon Lake. Field sampling in Pigeon Lake throughout 1978 indicated that alewives began to move out of the lake in August and by November only one was caught. The possibility exists that alewives were present in the discharge canal and moved into the intake canal via the open gate between the intake and discharge canals. This movement up the discharge canal and subsequent high impingement rates have also been noted for gizzard shad.

Impingement was relatively low from February through May, ranging from $1 / 24 \mathrm{~h}$ to 114 alewives $/ 24 \mathrm{~h}$ collected in weekly samples. Beginning in June, impingement began to increase. June corresponds with alewife spawning in Pigeon Lake. Highest number of alewives sampled was $1301 / 24 \mathrm{~h}$ during the week of 20 June. 


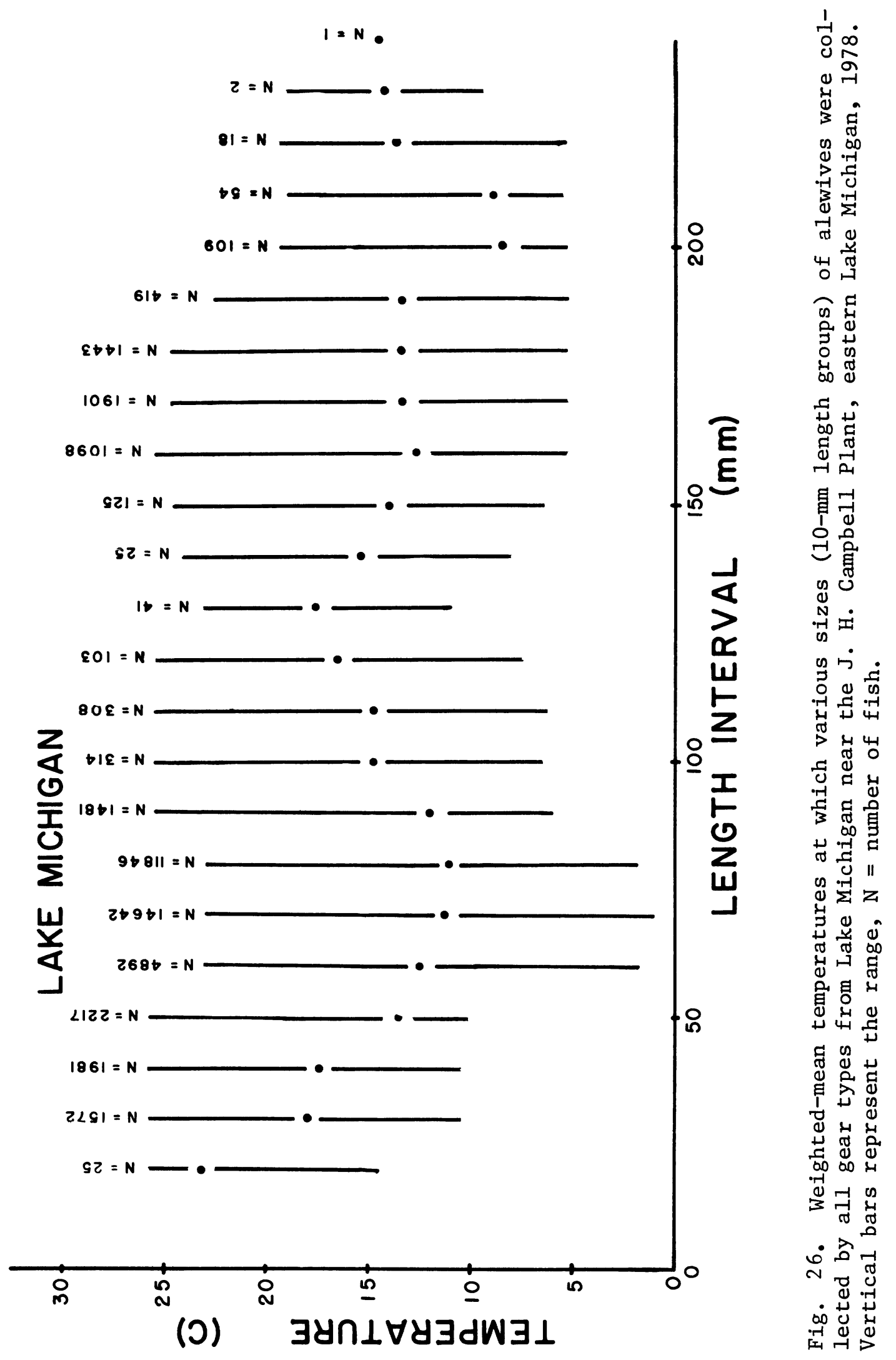


Total number of alewives collected in impingement samples during June was 1932 fish which upon expansion of the number actually collected during four 24-h periods to an estimated number impinged for June yielded 14,490 alewives.

July impingement was also high, but was declining by the end of the month. Highest number impinged was $830 \mathrm{fish} / 24 \mathrm{~h}$ during the week of $4 \mathrm{July}$. Total number collected in impingement samples during July was 1745 alewives making the estimated total number of alewives impinged during July 13,523.

Gonad data of impinged alewives in July showed many had well-developed gonads (Table 24). Some were already spent. These data indicated that alewives were impinged as they moved into Pigeon Lake to spawn. After July, during the remainder of the year, each weekly sample contained less than 100 alewives/24 h, with the exception of 184 alewives/24 h collected on 19 September 1978 (Appendix 9).

Table 24. Monthly gonad conditions of alewives collected in impingement samples during 1978 at the J. H. Campbell Plant, eastern Lake Michigan. All fish examined in a month were included except poorly received specimens.

\begin{tabular}{|c|c|c|c|c|c|c|c|c|c|c|c|c|c|}
\hline & Gonad condition & Jan & Feb & Mar & Apr & May & Jun & Jul & Aug & Sep & Oct & Nov & Dec \\
\hline Males & $\begin{array}{l}\text { S1ight development } \\
\text { Mod. development } \\
\text { Weli developed } \\
\text { Ripe-running } \\
\text { Spent }\end{array}$ & & & & 1 & $\begin{array}{r}25 \\
12 \\
1 \\
1\end{array}$ & $\begin{array}{l}34 \\
49 \\
48 \\
10 \\
19\end{array}$ & $\begin{array}{r}52 \\
67 \\
41 \\
1 \\
42\end{array}$ & $\begin{array}{r}17 \\
3 \\
4 \\
13\end{array}$ & 1 & 2 & $\begin{array}{l}1 \\
1\end{array}$ & 1 \\
\hline Females & $\begin{array}{l}\text { Slight development } \\
\text { Mod. development } \\
\text { Weli developed } \\
\text { Ripe-running } \\
\text { Spent } \\
\text { Absorbing }\end{array}$ & & & & $\begin{array}{l}1 \\
1\end{array}$ & $\begin{array}{r}17 \\
18 \\
1 \\
3\end{array}$ & $\begin{array}{r}12 \\
75 \\
70 \\
41 \\
14 \\
1\end{array}$ & $\begin{array}{r}18 \\
52 \\
107 \\
8 \\
60 \\
5\end{array}$ & $\begin{array}{l}7 \\
3 \\
4\end{array}$ & 1 & $\begin{array}{l}1 \\
1\end{array}$ & 1 & \\
\hline Immature & & & & & & 5 & 29 & 43 & 37 & 65 & 78 & 82 & 21 \\
\hline Unable $t$ & o distinguish & 110 & 8 & 59 & & 7 & 14 & 9 & 8 & 1 & 3 & 4 & 6 \\
\hline
\end{tabular}


Low numbers of adult alewives impinged after July agreed with field sampling in Pigeon Lake which showed few adult alewives remained there after the end of spawning in August. Beginning in August, YOY alewives (21-42 mm) were collected in impingement samples. YOY were impinged through December, when their sizes ranged from 49 to $75 \mathrm{~mm}$. Very few YOY alewives were collected after July by seining in Pigeon Lake. By August, YOY in Pigeon Lake may have moved far enough offshore so they were not vulnerable to seining. However, they were not large enough to be susceptible to bottom gill nets at $6-\mathrm{m}$ station M (influenced by Lake Michigan), since none were collected. Those YOY collected in late November and December may have originated in the discharge canal and entered the intake forebay via a gate used in diverting warm water to the jetties to keep them ice-free. Only one alewife (about $50 \mathrm{~mm}$ ) was collected during Pigeon Lake field sampling during November-December 1978. Total estimated number of alewives impinged during 1978 was 45,722. Sizes of adult alewives impinged were similar to those collected in field samples. For further discussion of alewife impingement and its impact, see RESULTS AND DISCUSSION - IMPINGEMENT.

Plant impacts--The major impacts on alewife populations due to operation of Units 1 and 2 of the Campbell Plant are the entrainment of larvae and impingement of juveniles and adults which will be discussed in detail elsewhere. Briefly, 49,804,000 larvae were entrained, while 45,722 juveniles and adults were impinged.

These losses represented a certain unknown percentage of the Lake Michigan populations of larvae, juveniles and adults, which undoubtedly is very low. Our production foregone estimates (see RESULTS AND DISCUSSION PRODUCTION AND IMPINGEMENT) attempted to place these losses into perspective and we clearly felt alewives killed by the plant represented a very small part of the Lake Michigan population as well as the commercial catch of alewives during 1978. There has been a decline in the number of alewives collected in 1978 when compared with 1977 catches. However, we feel this decline is a lake-wide effect and have seen a similar decline at the Cook Plant (unpublished data). Evaluating these impacts is further complicated by the presence of alewives both in Pigeon Lake and Lake Michigan and the difficulty in weighing the losses sustained against the production of alewife larvae and YOY that occurs in Pigeon Lake which acts as a spawning site and nursery for alewife. Undoubtedly, Pigeon Lake would not be a suitable reproductive habitat for alewife without the large volumes of cool Lake Michigan water which courses through the lake and into the Campbell Plant.

Summary--In April, few alewives were found in the sampling area near the Campbell Plant. During May, alewives began moving inshore in Lake Michigan. No alewives were caught in Pigeon Lake. By June, alewives were found in Pigeon Lake and spawning had begun in both Lake Michigan and Pigeon Lake.

YOY first appeared in July in Pigeon Lake; none were found in Lake Michigan. Many adults were caught in Lake Michigan in July; most with well developed gonads. Peak spawning appeared to be later in 1978 than in 1977. 
By August, adults were beginning to move away from the study area in Lake Michigan. No adults were caught in Pigeon Lake. YOY were caught during August in the beach zone of Lake Michigan. In September, YOY had moved into deeper water, now being caught in trawl hauls as well as seines. Few adults remained in the study area. Spawning was apparently over by this time.

YOY were very abundant in Lake Michigan during October. Their distribution was characterized by size segregation during the day with smaller YOY found nearshore. Size of alewives collected increased with depth. At night, size distribution was more uniform over all sampling depths. Few adults were caught in Lake Michigan. Only one YOY was collected in Pigeon Lake.

November sampling produced the highest catches of alewives of the year; a11 were YOY, except one. Some size-depth segregation was seen again. Largest numbers of YOY were caught at north transect stations in the vicinity of the present plant discharge. Alewives appeared to have left Pigeon Lake for the winter as only one YOY was collected there.

By December, most alewives had left the Lake Michigan study area. Only six YOY were caught this month. YOY tended to be found at warmer temperatures than adults.

Impact of Units 1 and 2 on alewife was mainly entrainment of larvae and impingement of adults. Loss of these fish must be weighed against the importance of Pigeon Lake as an alewife spawning and nursery area.

Rainbow Sme1t--

Introduction--Origina1ly restricted to the Atlantic coastal drainage, rainbow smelt are now established, through introductions, in all the Great Lakes and several inland lakes (Scott and Crossman 1973). This species is commercially exploited in Lake Michigan, with a major fishery located in the northern part of the lake and in Green Bay, Wisconsin (Jaiyen 1975). Rainbow smelt genera1ly occur in lower abundance in the southern portion of Lake Michigan (Becker 1976). Sport fishing for smelt is largely restricted to dipnetting in tributary streams during spawning runs (Robinson 1973).

Rainbow smelt were the second most abundant fish collected in our study area, representing $16.4 \%$ of the total Lake Michigan catch in 1977 (Jude et a1. 1978) and $27.8 \%$ in 1978 (Table 13). Our 1978 smelt catch of 25,328 specimens was nearly double the 1977 level $(12,898)$. This increase was due in part to catches from April and May 1978; no sampling was performed during these months in 1977. Larger catches of smelt during June and July also accounted for a major portion of the increased 1978 catch.

Only a small number of smelt were collected in Pigeon Lake and from the traveling screens of Units 1 and 2 at the Campbell Power Plant. Trawls were the most effective gear for sampling smelt.

Seasonal distribution--Rainbow sme1t 1ive in relatively deep water during 
most of the year except during spring when they move to shallow areas of lakes or into tributary streams to spawn. Seasonal distribution of adult, yearling and YOY smelt in our study area has been described for the period June-December 1977 (Jude et al. 1978). In 1978, discussion of the seasonal distribution covers the period April-December.

April--The smelt spawning season varies considerably depending on weather conditions, in particular temperature and possibly other factors (Van Oosten 1940, Rupp 1959). In southeastern Lake Michigan peak smelt spawning usually occurred in April when water temperature reached $10 \mathrm{C}$ (Jude et a1. 1978). In 1977, based on YOY data, we concluded that smelt spawning in our study area took place during April and early May (Jude et al. 1978). Gonad data (Table 25) indicated that in 1978 spawning was in progress during the 24-26 April sampling period.

Table 25. Monthly gonad conditions of rainbow smelt caught during 1978 in Lake Michigan near the J. H. Campbell Plant, eastern Lake Michigan. All fish examined in a month were included except poorly received specimens.

\begin{tabular}{|c|c|c|c|c|c|c|c|c|c|c|}
\hline & Gonad condition & Apr & May & Jun & Jul & Aug & Sep & Oct & Nov & Dec \\
\hline Males & $\begin{array}{l}\text { Slight development } \\
\text { Mod. development } \\
\text { Wel1 developed } \\
\text { Ripe-running } \\
\text { Spent }\end{array}$ & $\begin{array}{r}2 \\
45 \\
187 \\
6 \\
1\end{array}$ & $\begin{array}{r}66 \\
8 \\
7 \\
2 \\
49\end{array}$ & $\begin{array}{r}57 \\
7\end{array}$ & $\begin{array}{r}99 \\
4\end{array}$ & $\begin{array}{l}38 \\
11\end{array}$ & $\begin{array}{r}14 \\
1\end{array}$ & $\begin{array}{l}1 \\
5 \\
2\end{array}$ & $\begin{array}{l}1 \\
2 \\
1\end{array}$ & \\
\hline Females & $\begin{array}{l}\text { Slight development } \\
\text { Mod. development } \\
\text { We11 developed } \\
\text { Ripe-running } \\
\text { Spent } \\
\text { Absorbing }\end{array}$ & $\begin{array}{r}63 \\
45 \\
7\end{array}$ & $\begin{array}{r}12 \\
4 \\
9 \\
10 \\
36\end{array}$ & $\begin{array}{r}15 \\
3 \\
3\end{array}$ & $\begin{array}{r}80 \\
1\end{array}$ & 6 & $\begin{array}{l}1 \\
5\end{array}$ & $\begin{array}{l}5 \\
2 \\
1\end{array}$ & $\begin{array}{r}1 \\
11 \\
1\end{array}$ & 1 \\
\hline Immature & & 436 & 706 & 884 & 534 & 461 & 161 & 383 & 348 & 211 \\
\hline Unable tc & o distinguish & 2 & 160 & 46 & 166 & 195 & 5 & 3 & 1 & \\
\hline
\end{tabular}

Highest monthly catches of adult smelt (450) occurred in April (Figs. 27 and 28). Spawning activity in our study area, as indicated by the number of adults collected, seemed relatively less intense compared to the peak spawning observed in April 1973 near the Cook Plant, southeastern Lake Michigan (Jude et a1. 1975). 
$L(6 m-N)$

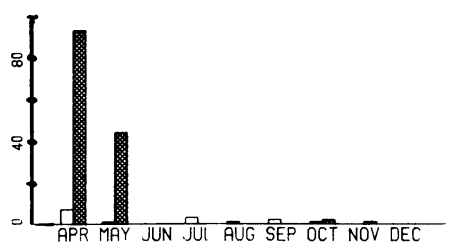

$E(12 m-S)$

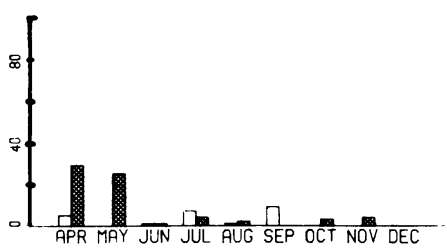

D $(9 m-S)$

C $(6 m-5)$

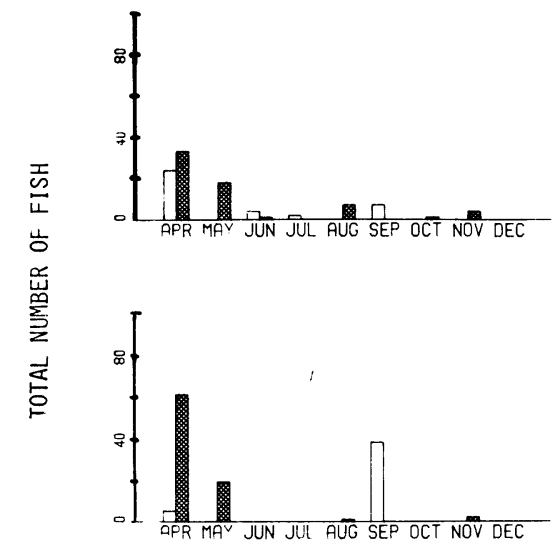

$B(3 m-5)$

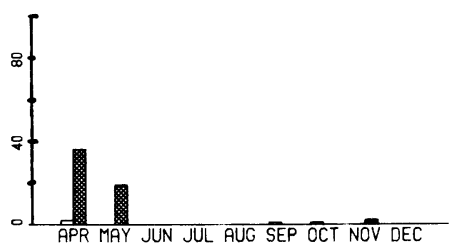

$A(1.5 \mathrm{~m}-\mathrm{S})$

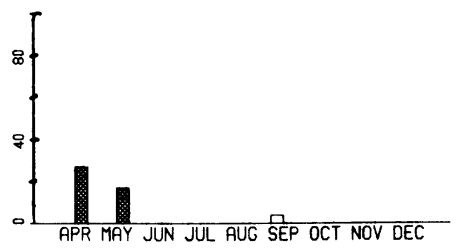

Fig. 27. Total number of rainbow smelt caught in duplicate bottom 8ilj nets fish during day and night once per month April to Novernber 1978 in Lake Michigan near the J. H. Campbell Plant, eastern Lake Michigan. $\square=$ day $\square=$ night 


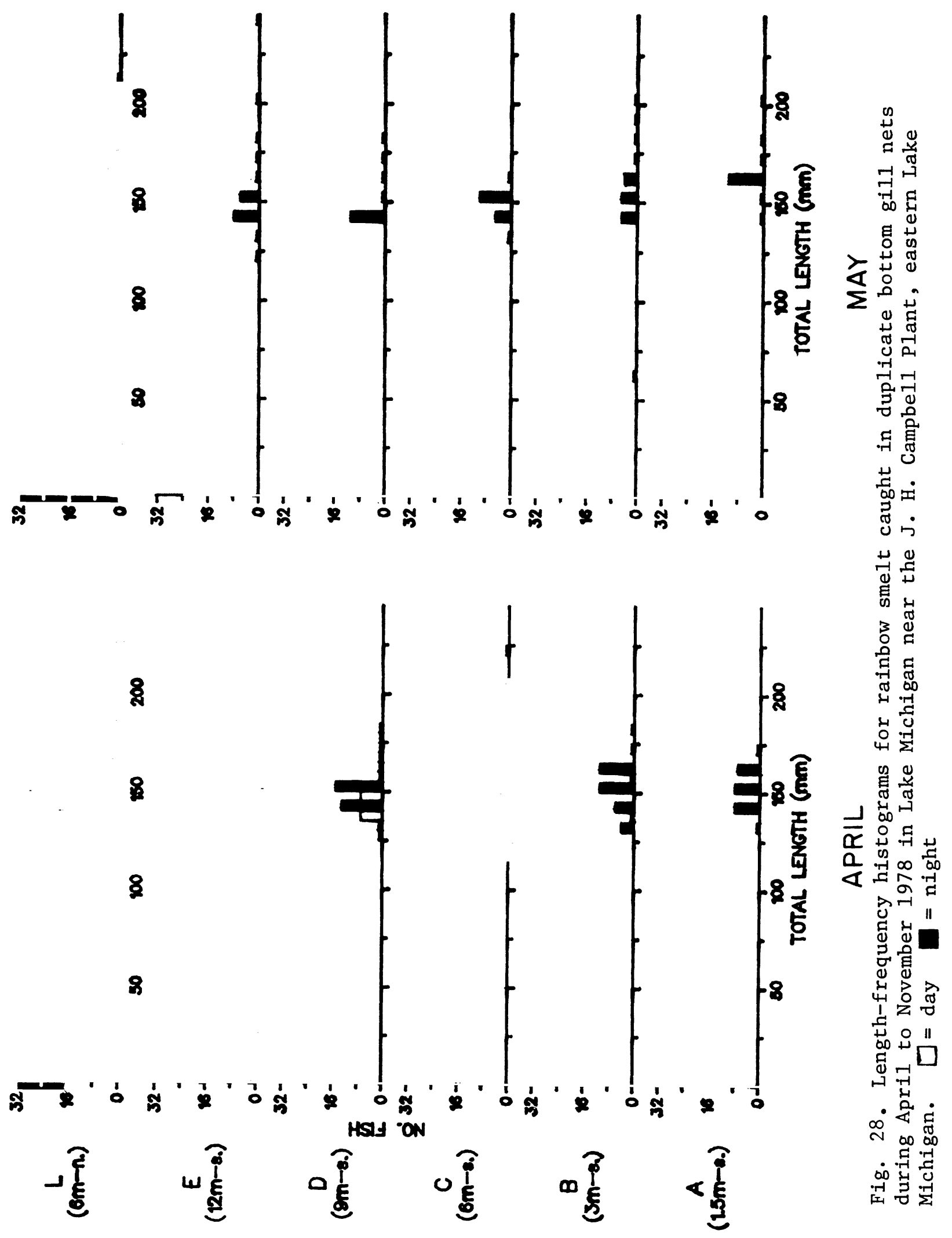



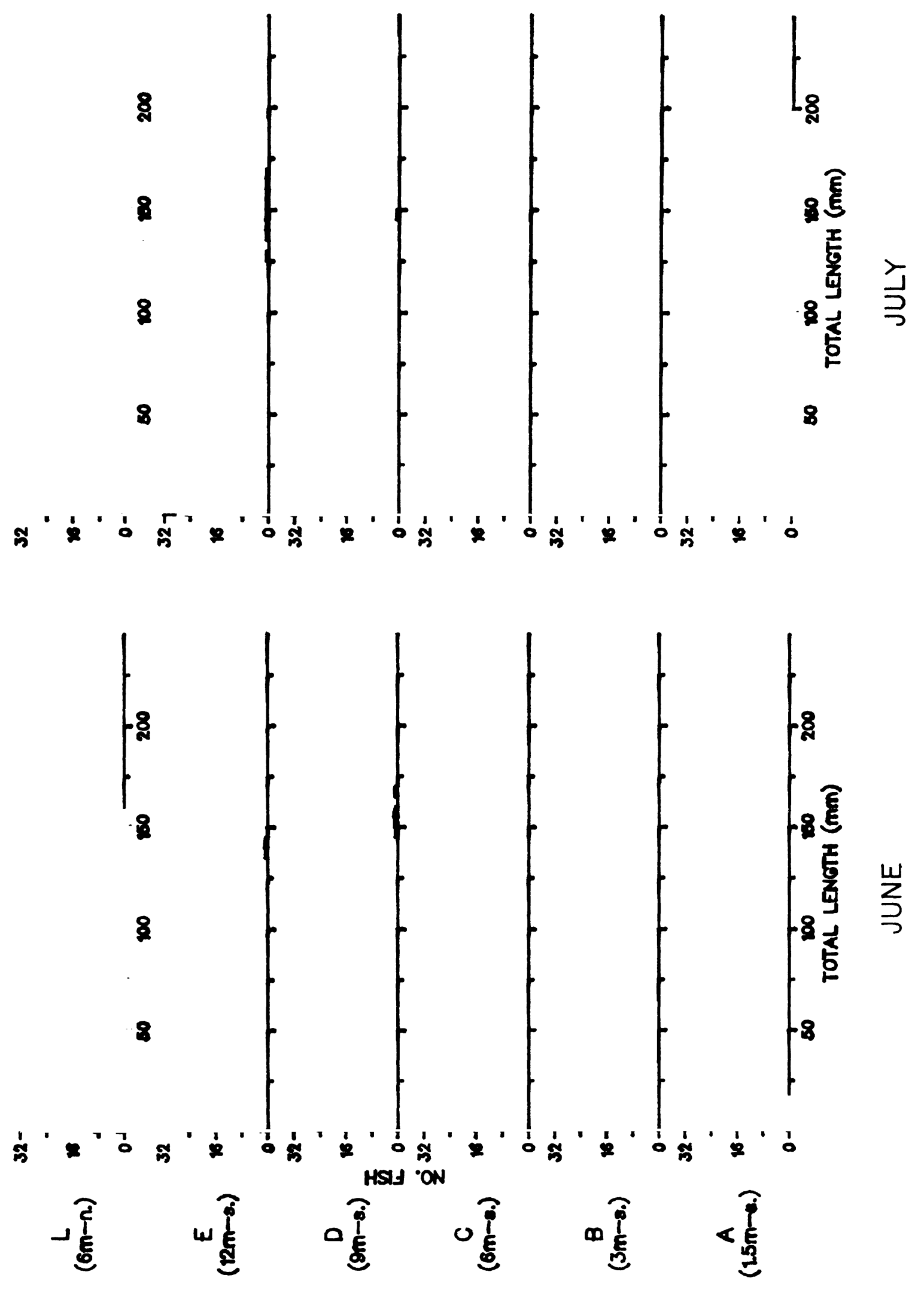

苟 

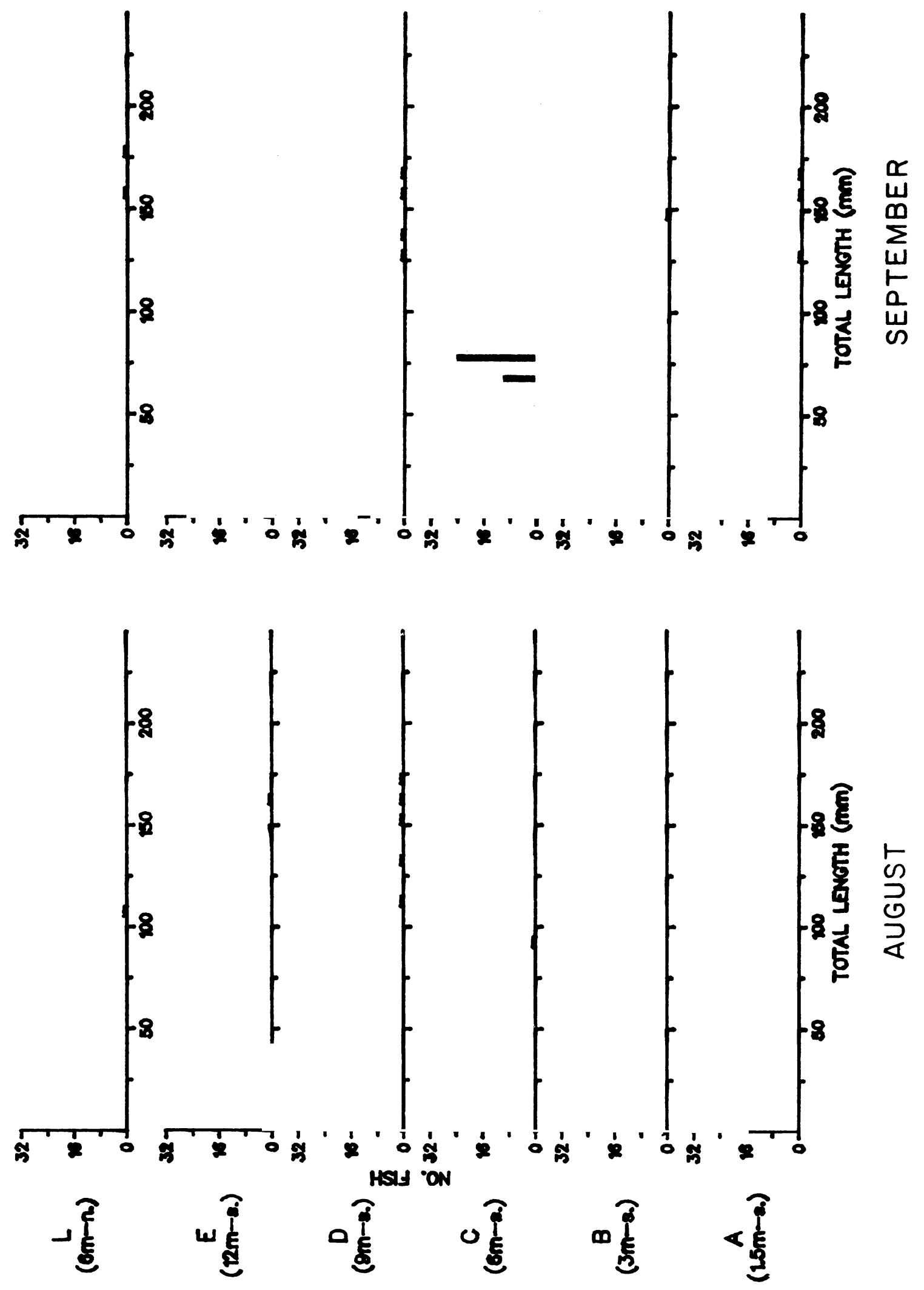

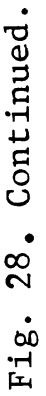



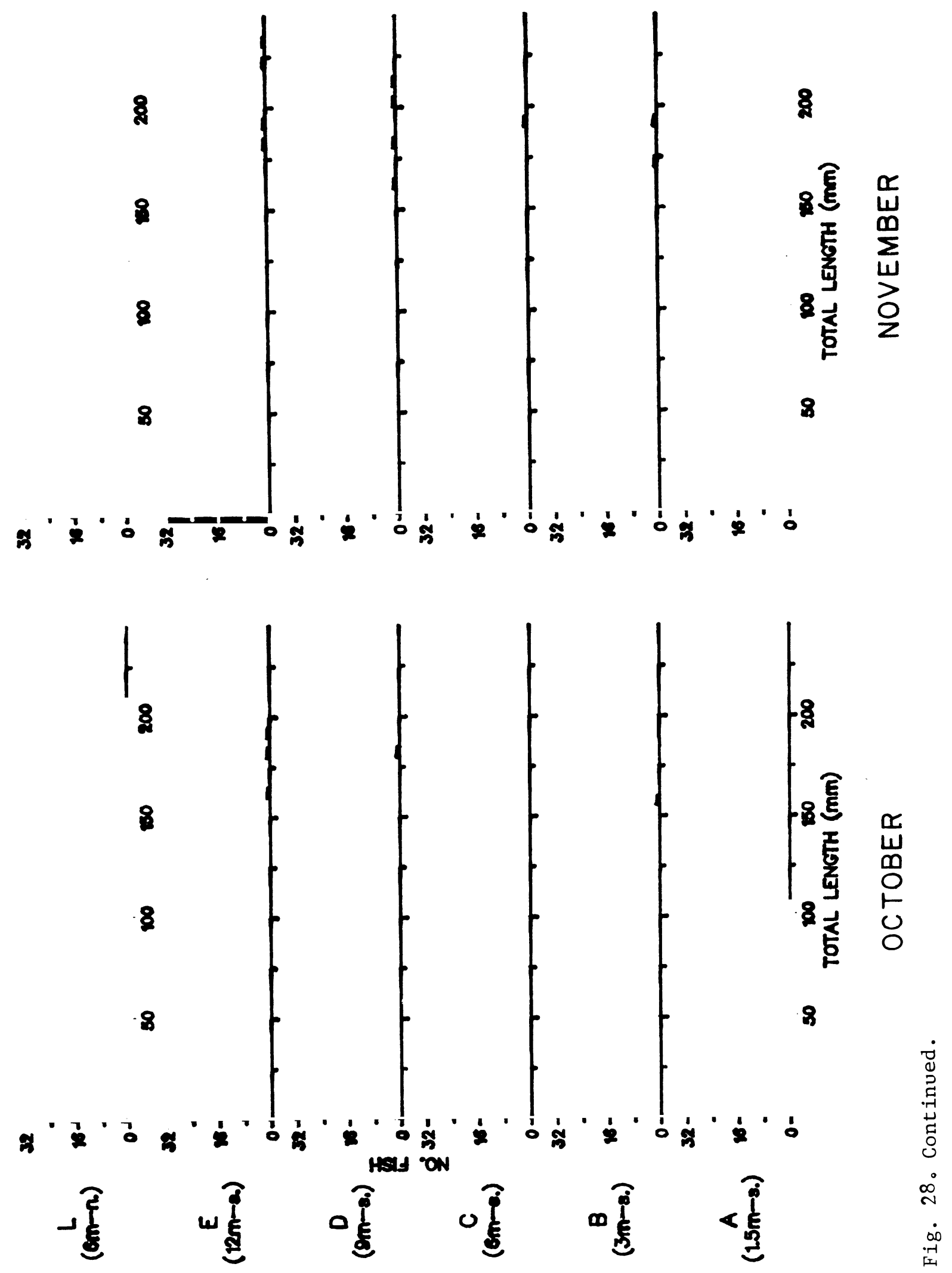
At night, adult smelt (120 mm and larger) occurred at all depths sampled in the study area with an appreciable number (49) being caught in seine hauls (Figs. 28 and 29). Highest night catches were taken in bottom gill nets at $6 \mathrm{~m}$ (Fig. 27). During the day, adult smelt appeared to remain outside the 3-m contour, with the highest concentration at $9 \mathrm{~m}$ (Fig. 28). This diel distribution agreed with the reported pattern of smelt spawning runs which consisted of a nearshore movement at night and a return to offshore areas at daybreak (Van Oosten 1940). More adults were caught at night than during the day probably because of the predominantly nocturnal spawning activity and net avoidance during daylight. Low day catches may also be due to the dispersal of large smelt into deep water during the day. In Lake Michigan, Daly and Wiegert (1958) reported that smelt returned to depths of 24-72 m during the day.

During April, night catches of adult smelt were almost seven times higher at beach station Q (S discharge) than at beach station $\mathrm{R}$ (N discharge) or beach station $\mathrm{P}$ (S reference) (Fig. 30). Factors influencing this distribution of adult smelt were not know. Water temperatures at stations $\mathrm{P}(7.5 \mathrm{C}), \mathrm{Q}(7.8 \mathrm{C})$ and $R(6.5 \mathrm{C}$ ) were within the range most preferred by adult smelt (see TemperatureCatch Relationship).

Yearling smelt, like adults, started to move inshore during spring. They occurred in modest numbers inside the 9-m depth contour during April and May near the Cook Plant, southeastern Lake Michigan (Jude et al. 1975). In Lake Superior largest number of yearlings were caught in water less than $15 \mathrm{~m}$ during April (Dryer 1966). In our study area 643 yearlings 40-110 mm were collected during April, most in trawls (Fig. 31). A small number (24) were caught in seine hauls (Fig. 29) suggesting little utilization of the beach zone by yearlings. Bottom and surface gill nets captured no yearlings (Appendix 7). This size group was probably too small to be sampled by gill nets during spring.

Night distribution of yearlings extended from the beach zone to $15 \mathrm{~m}$ or deeper with highest concentrations at $9 \mathrm{~m}$ (Fig. 31). Yearlings appeared to remain in relatively deep water during the day, being caught only from 6 to $15 \mathrm{~m}$ (Fig. 31). Highest day catches occurred at $9 \mathrm{~m}$. More yearlings were caught at night than during the day. Catches at station $\mathrm{L}(6 \mathrm{~m}-\mathrm{N})$ appeared lower than at reference station $\mathrm{C}(6 \mathrm{~m}-\mathrm{S})$ (Fig. 32) because night trawling was not performed at station L. Like adults, yearlings tended to be more common at beach station Q (S discharge) than at beach station $R$ ( $N$ discharge) or $\mathrm{P}$ (S reference).

May--Catches of adult smelt (120 mm and larger) in May in Lake Michigan were lower than in April (Appendix 6). This decline may be due to a reduction of the adult population in the inshore area during May following departure of some adults to deeper water. Wells (1968) indicated that most adult smelt were found at $27 \mathrm{~m}$ by 5 May and $36 \mathrm{~m}$ by the end of May in eastern Lake Michigan, off Saugatuck, Michigan. In Lake Erie, Ferguson (1965) recorded increasing catches of adult smelt in deeper water during May.

of the 341 adults collected in May in Lake Michigan, 50\% were caught in bottom gill nets (Appendix 7, Fig. 28), the remaining catches were made up largely by trawls and surface gill nets (Figs. 31 and 33). Seines captured only a small 


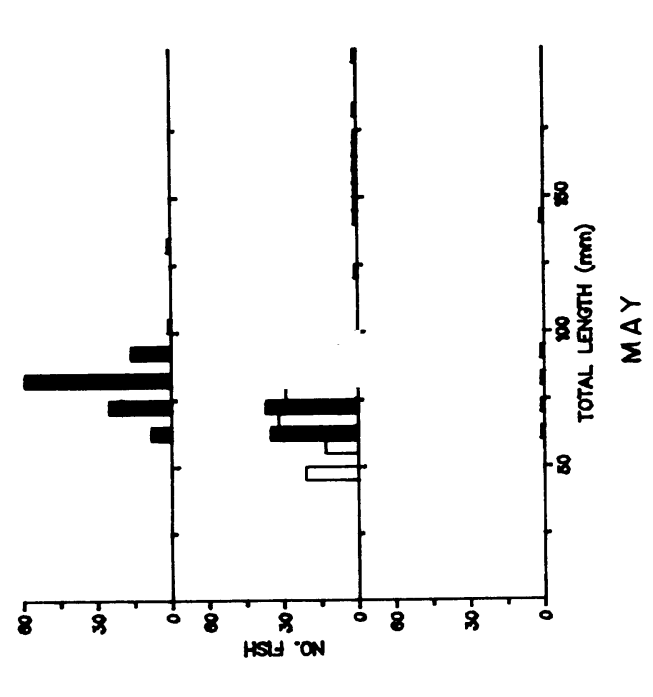

$\propto$

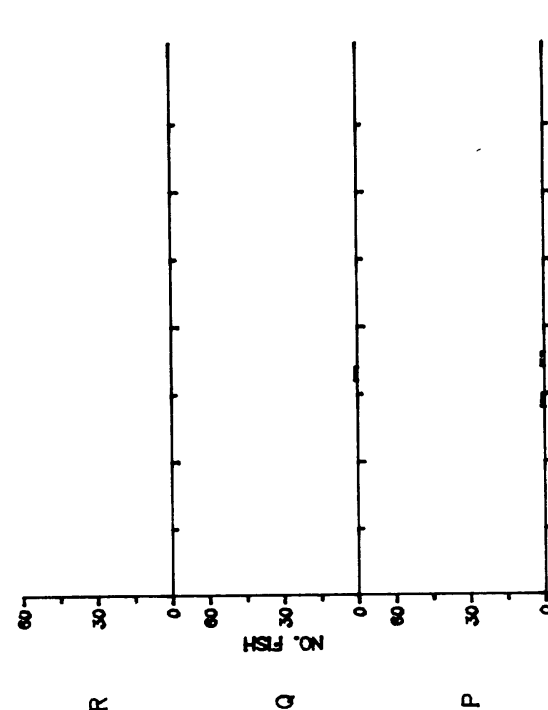

茟

$8 \quad$ a

ह 胥

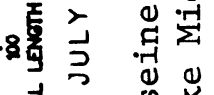

रे क कू

$8 \quad \stackrel{0}{0}$

峁

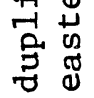

ت્ન

岂管

范

0 नु

岑

藏

吕

芩ら

过

म

㝳
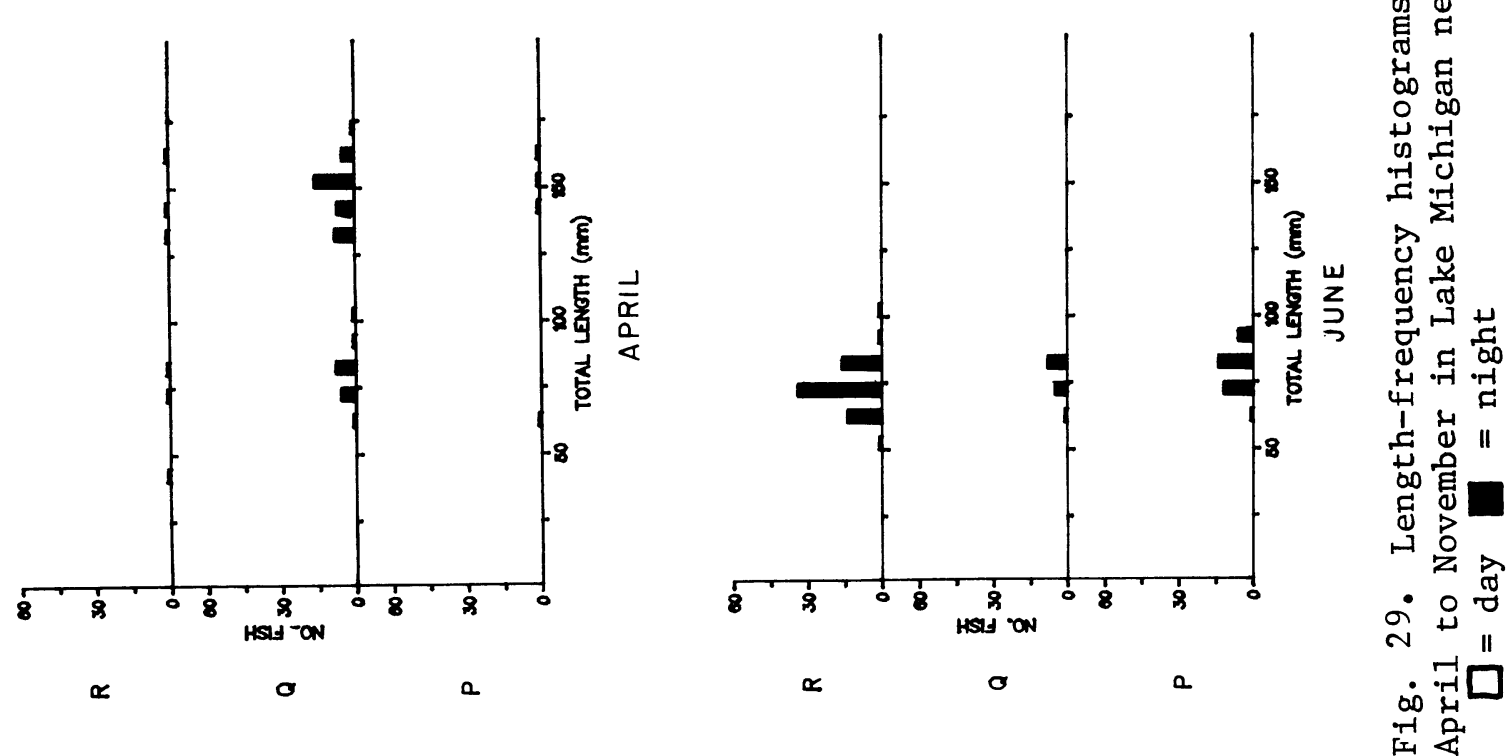

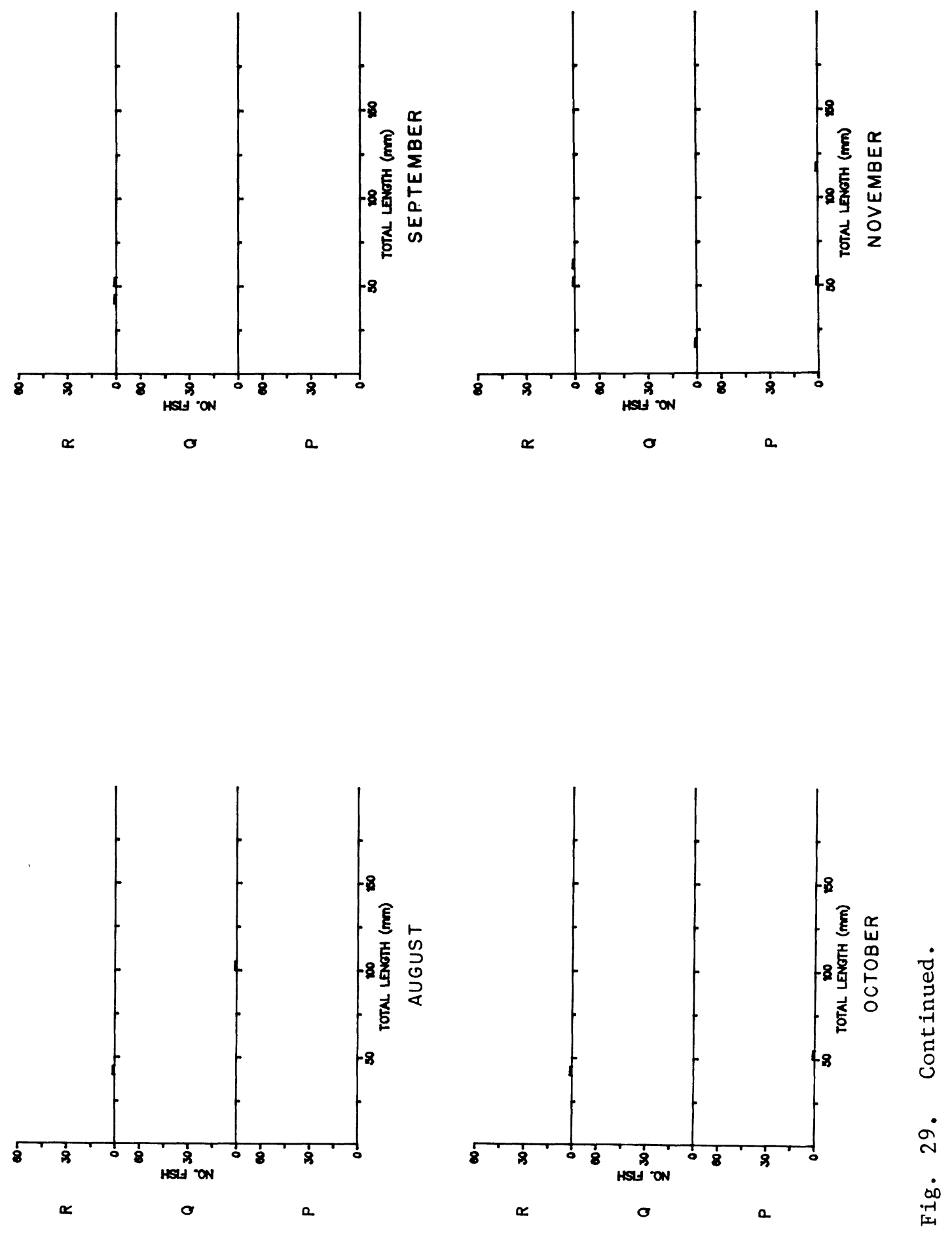


\section{$\mathrm{R}$ \\ N DISCHARGE}

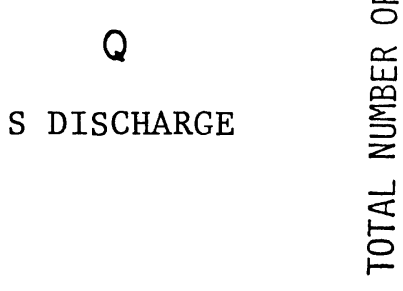

$P$

S REFERENCE
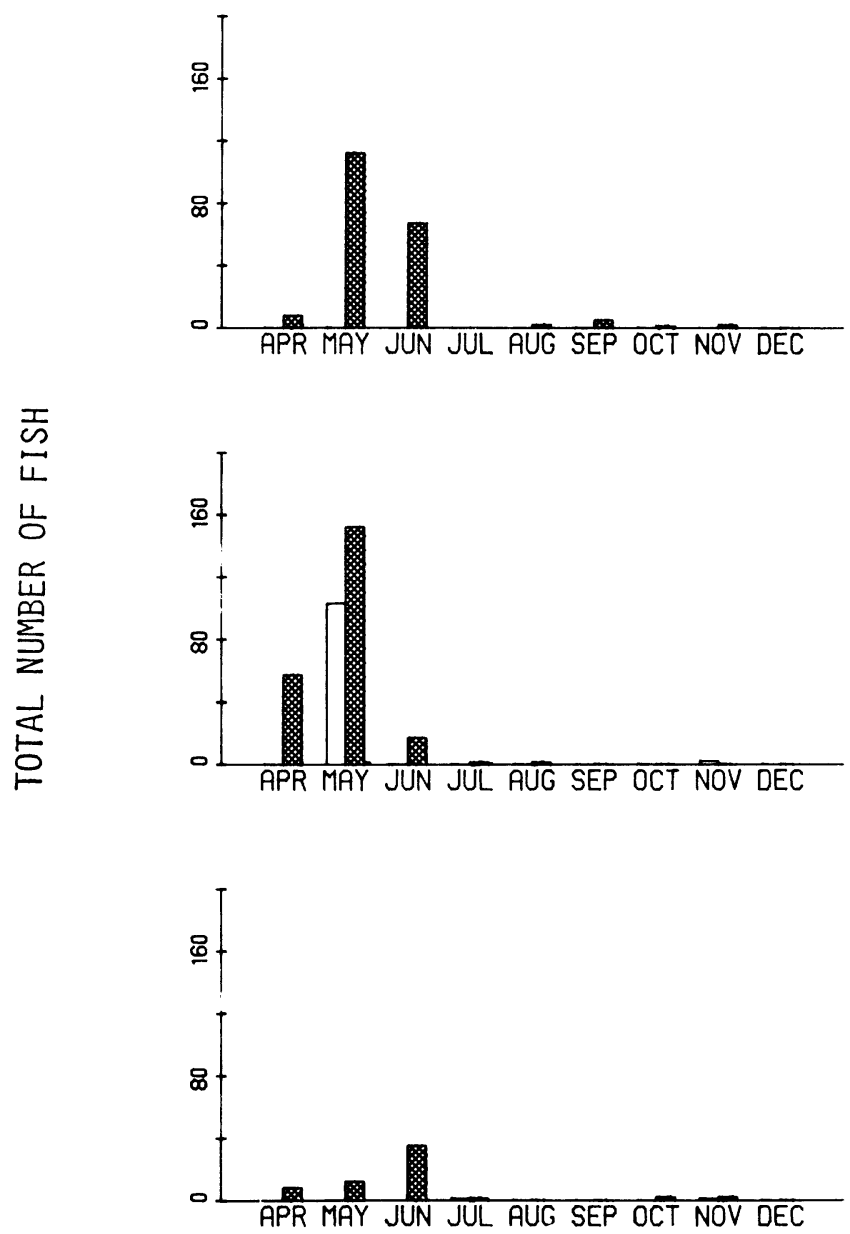

Fig. 30. Total number of rainbow smelt caught in duplicate seine hauls during day and night once per month April to November 1978 in Lake Michigan near the J. H. Campbell Plant, eastern Lake Michigan. $\square=$ day $\square=$ night 


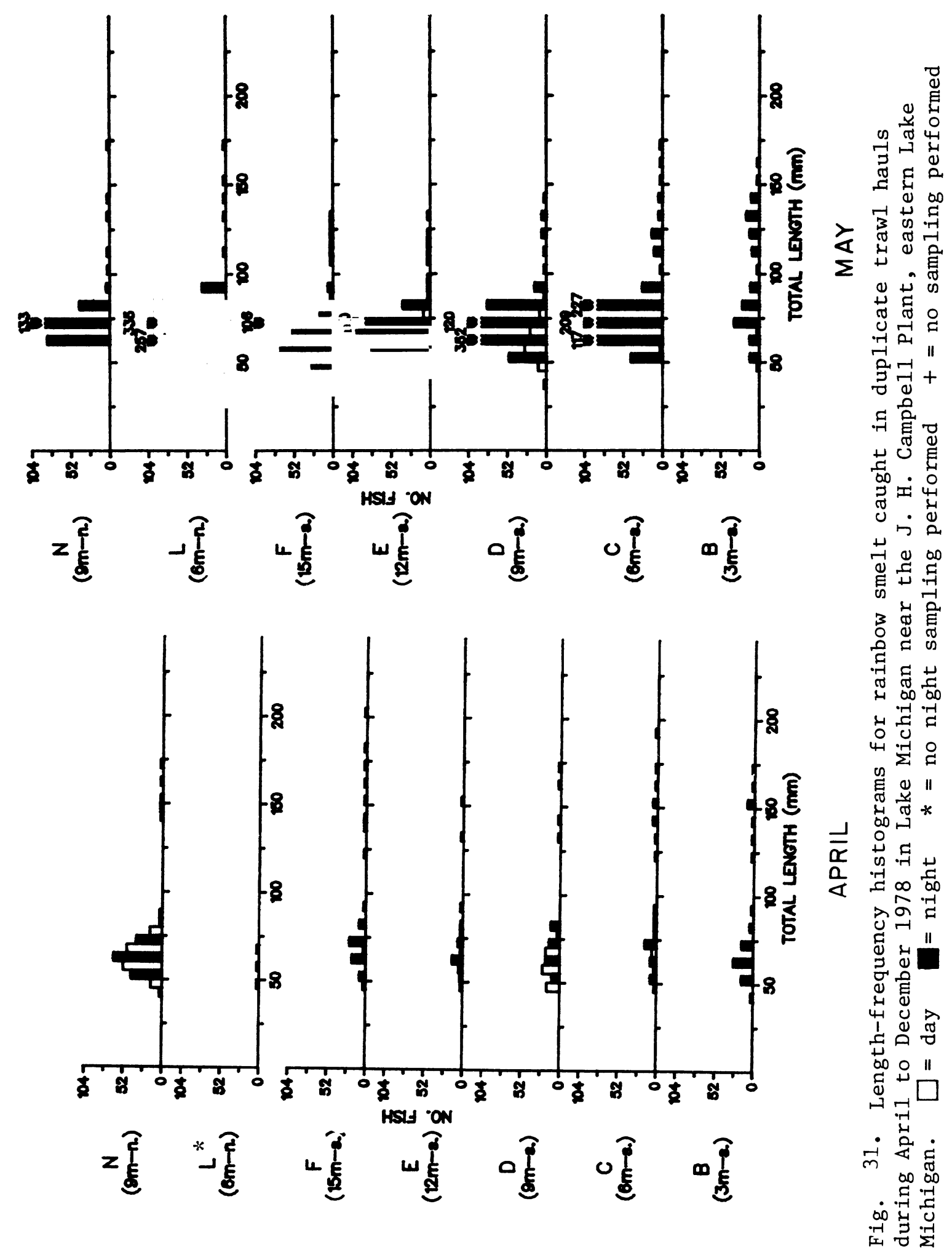




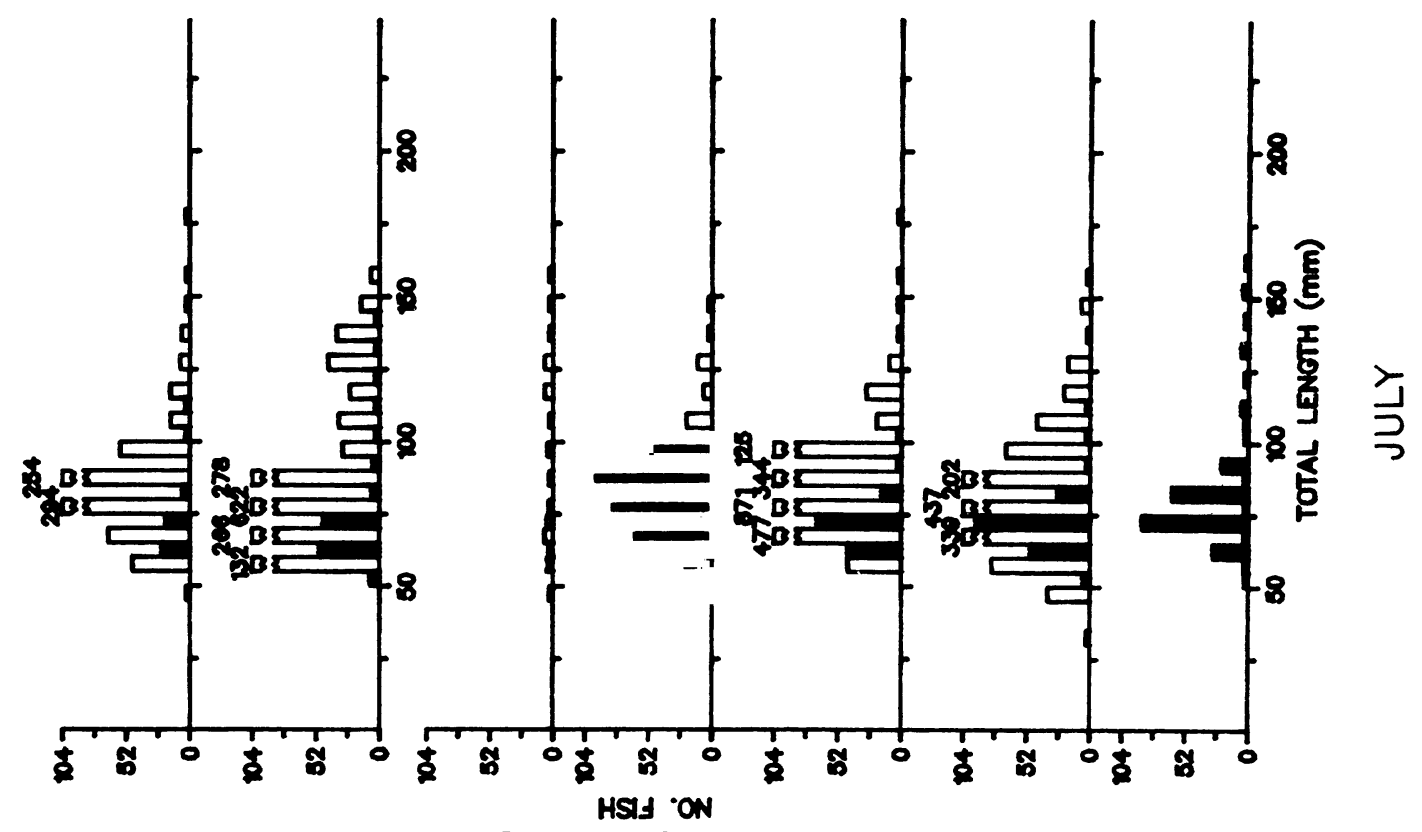

z

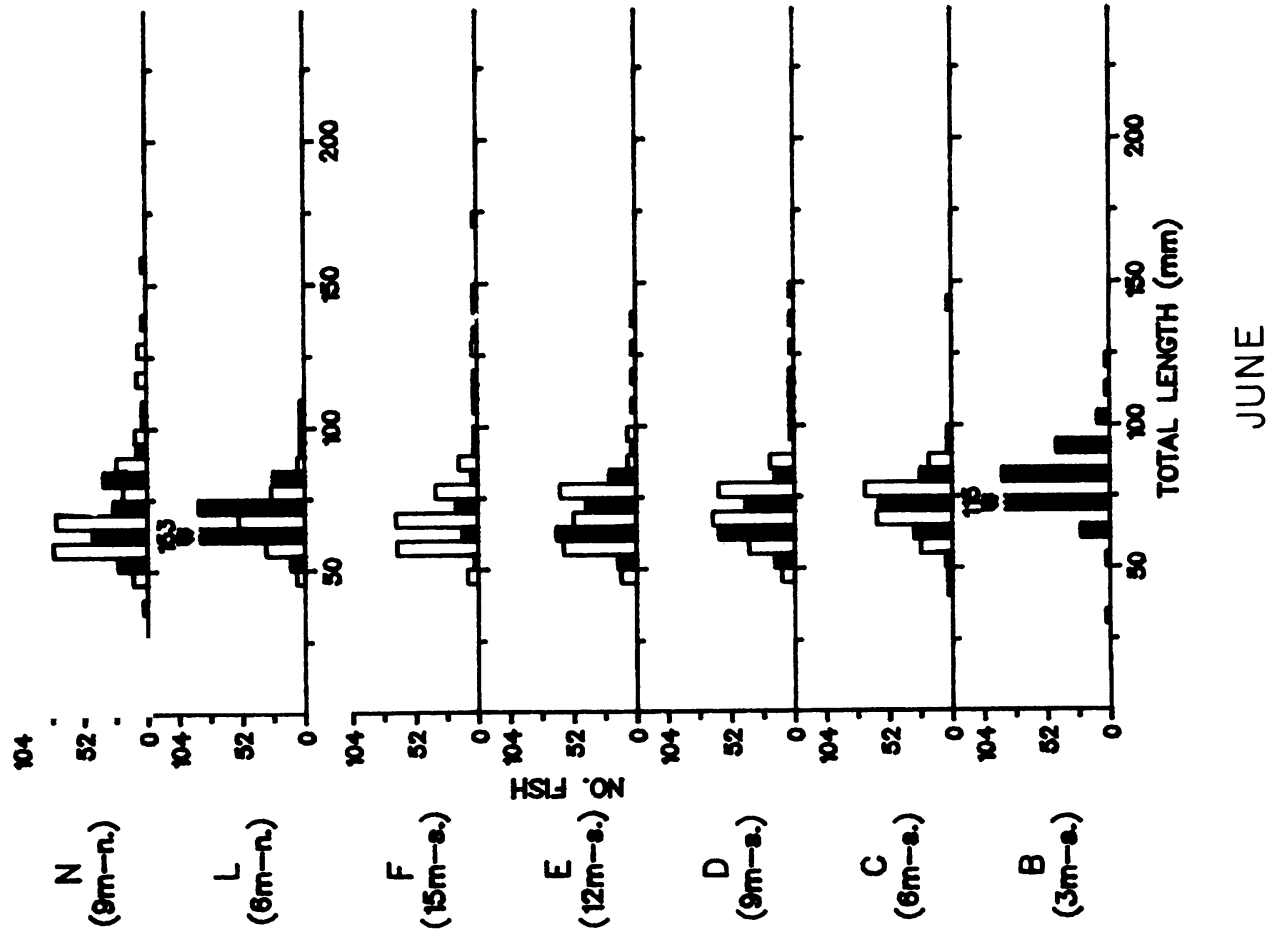

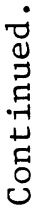

mं

唒 

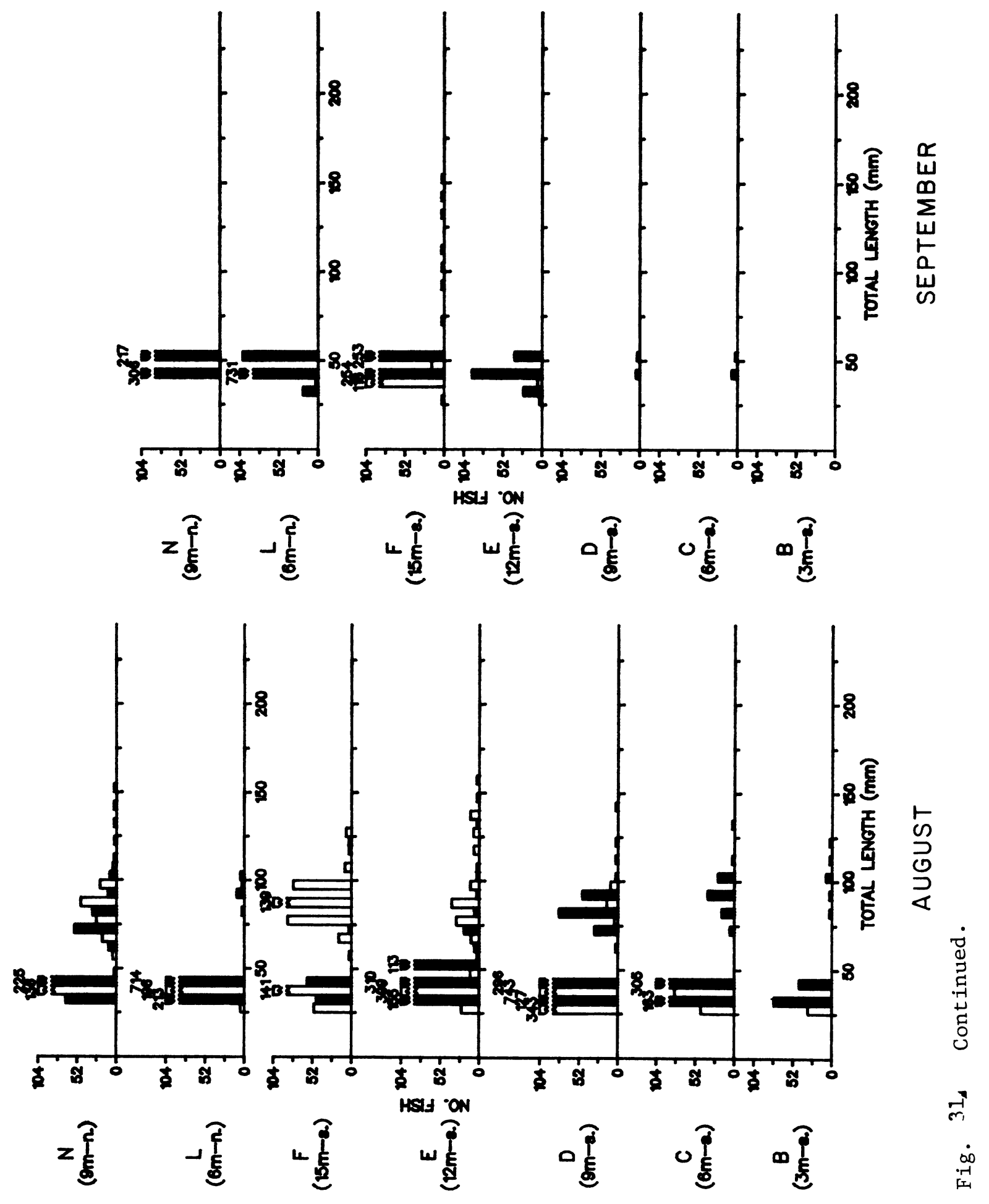


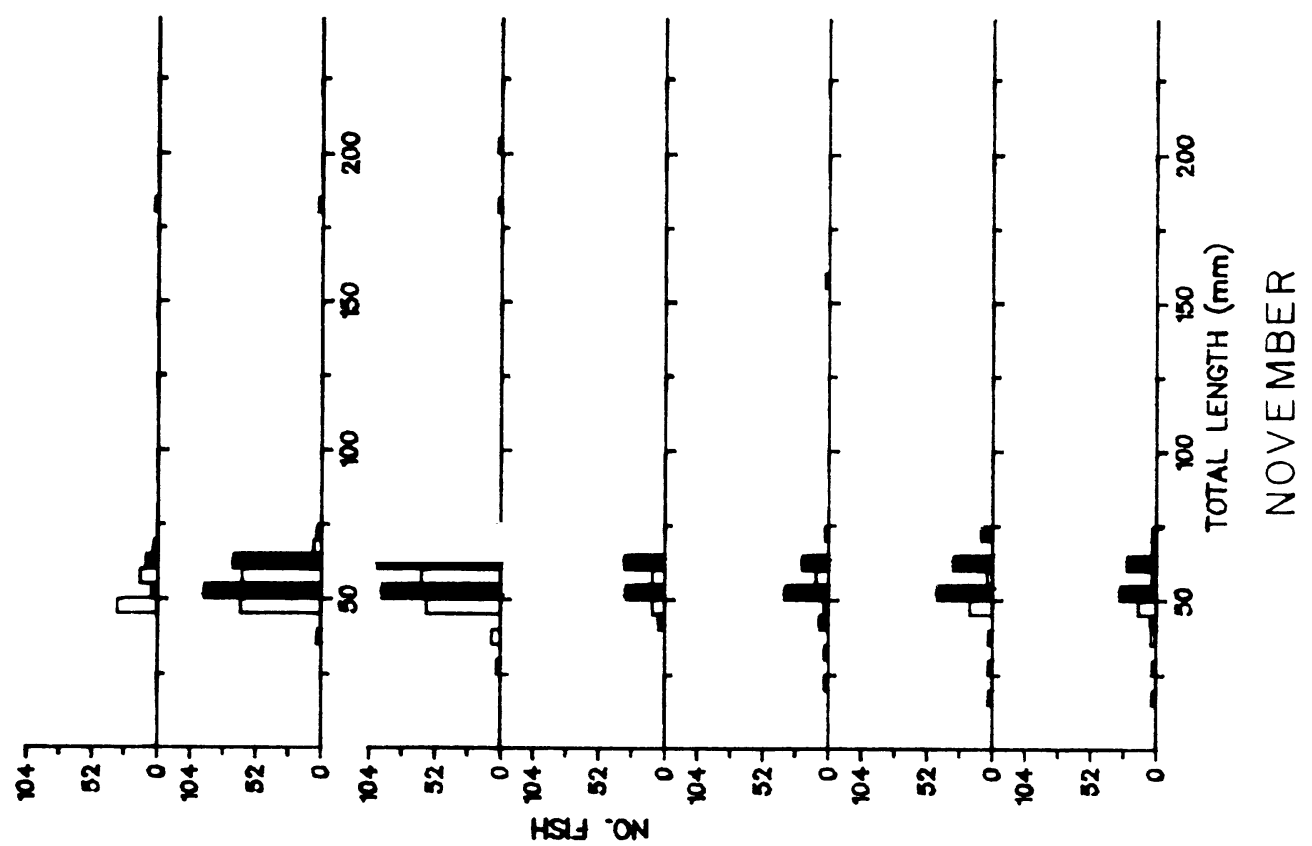

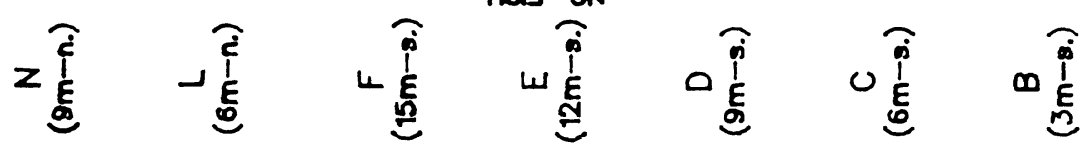

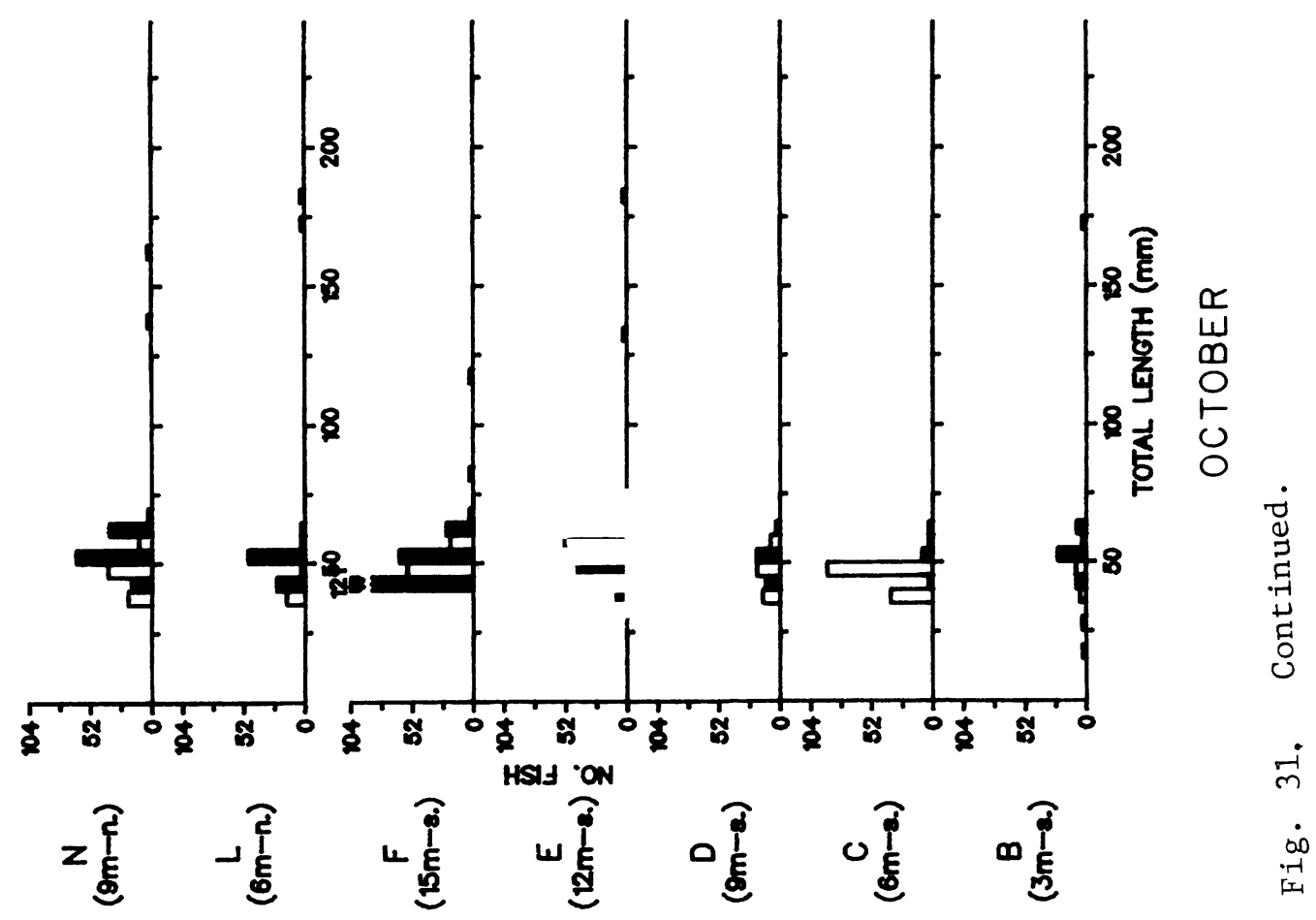




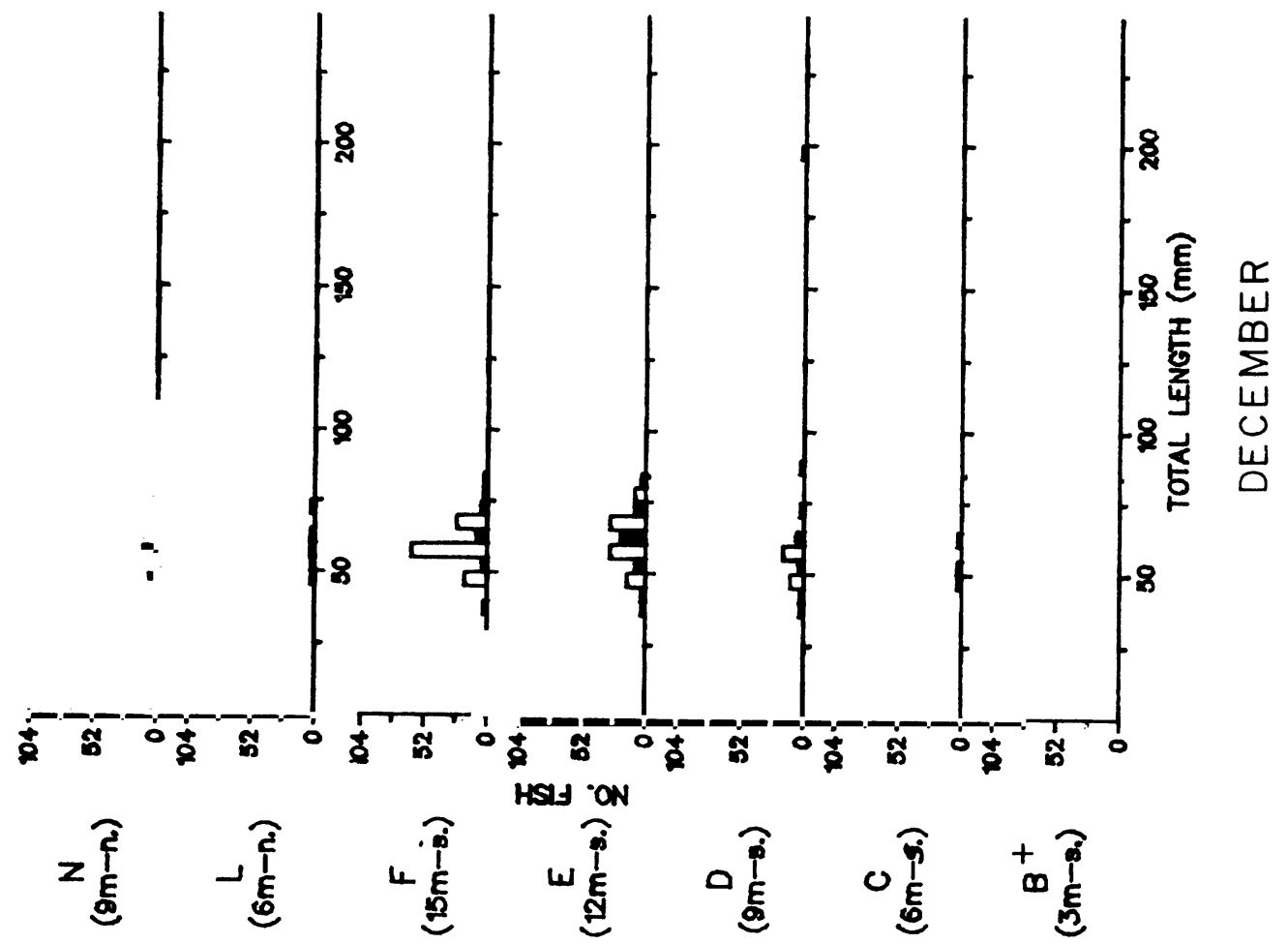

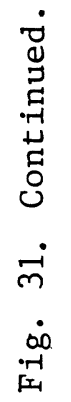


$N(9 m-N)$

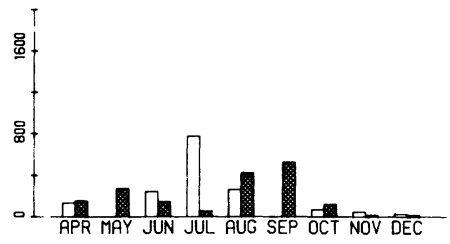

$L(6 m-N)$

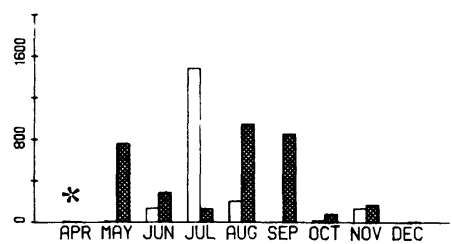

$F(15 m-S)$

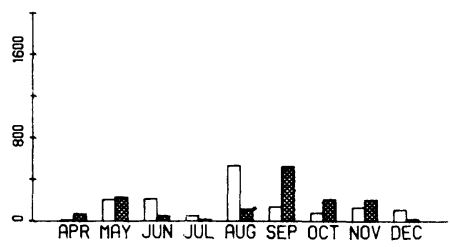

$E(12 m-S)$ 焉

$D(9 m-5)$

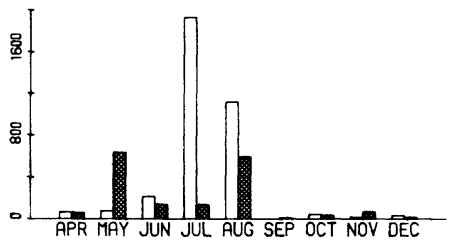

$(6 m-5)$

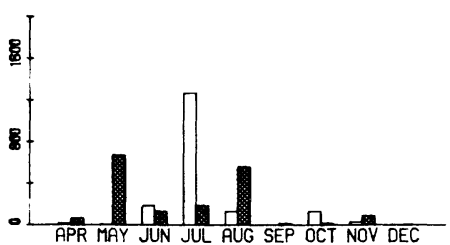

B $(3 m-5)$

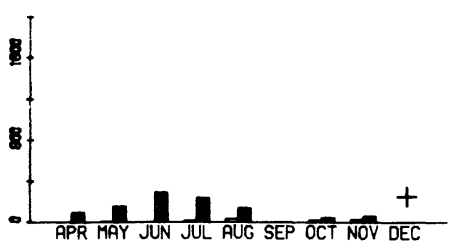

Fig. 32. Total number of rainbow smelt caught in duplicate trawl hauls during day and night once per month April to December 1978 in Lake Michigan near the J. H. Campbell Plant, eastern Lake Michigan. $\square=$ day $\square=$ night $*=$ no night sampling performed $+=$ no sampling performed 

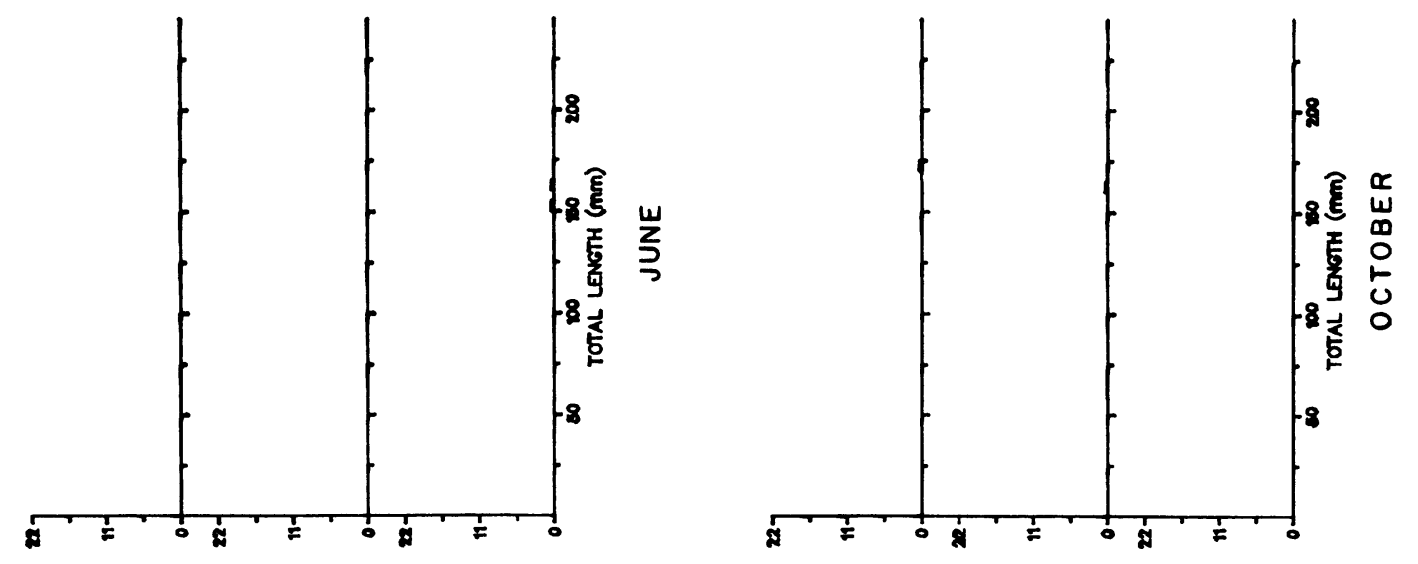

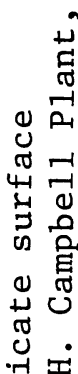
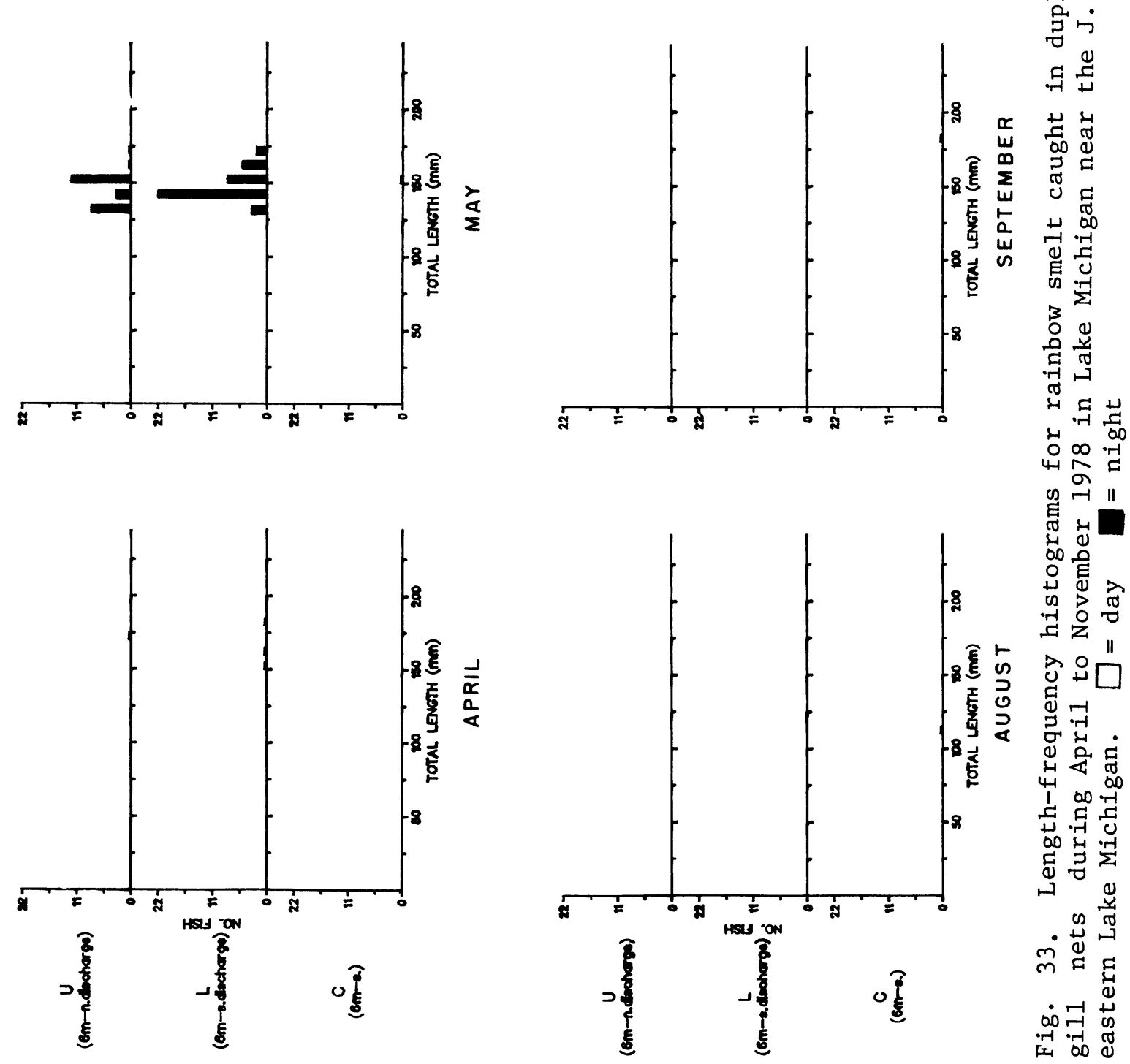
number of adults in May. At night, adults appeared to be evenly distributed from 1.5 to $12 \mathrm{~m}$ and became less common at $15 \mathrm{~m}$ (Figs. 28 and 31). Low night catches of adults in the beach zone in May compared with high catches in April may be related to decreased spawning activity. As was found during April, more adults were caught at night than during the day.

Gonad data (Table 25) indicated that spawning was continuing in our study area during the 15-17 May sampling period. The large number of smelt that had spawned compared to those still showing well developed and ripe-running gonads (Table 25, 25 A) suggested that spawning was tapering off by this time.

Table 25A. Monthly gonad conditions of rainbow smelt caught during 1978 in Pigeon Lake near the J. H. Campbell Plant, eastern Lake Michigan. All fish examined in a month were included except poorly received specimens.

\begin{tabular}{|c|c|c|c|c|c|c|c|c|c|c|}
\hline & Gonad condition & Apr & May & Jun & Jul & Aug & Sep & Oct & Nov & Dec \\
\hline Males & $\begin{array}{l}\text { Slight development } \\
\text { Mod. development } \\
\text { We11 developed } \\
\text { Ripe-running } \\
\text { Spent }\end{array}$ & & $\begin{array}{l}1 \\
1 \\
1 \\
1 \\
6\end{array}$ & & & & & & & \\
\hline Females & $\begin{array}{l}\text { Slight development } \\
\text { Mod. development } \\
\text { Well developed } \\
\text { Ripe-running } \\
\text { Spent } \\
\text { Absorbing }\end{array}$ & $\begin{array}{l}1 \\
1 \\
1\end{array}$ & 5 & & & & & 1 & & \\
\hline Immature & & 1 & 4 & & & 1 & & & & \\
\hline Unable $t$ & o distinguish & & 1 & & & & & & & \\
\hline
\end{tabular}

Catches of adult smelt at beach station Q (S discharge) were higher than at beach station $\mathrm{R}$ ( $\mathrm{N}$ discharge) or $\mathrm{P}$ (S reference) (Fig. 29). As was found in April, there appeared to be no correlation between water temperatures and the number of adults collected at these three stations. There was, however, a large number of yearlings seined at stations $Q$ and $R$ in the vicinity of the present discharge, while very few were collected at reference station $P$ (south transect). Apparently, some factor (physical substrate or currents) made the discharge area more attractive to yearling smelt. Surface gill net catches of adult smelt in May (66) were the highest recorded catches of adult smelt in this gear type (Fig. 34). All smelt collected in surface gill nets were caught at night confirming the observations made by Ferguson (1965) on movements of adult smelt to upper layers during darkness. Both surface and bottom gill nets captured more 

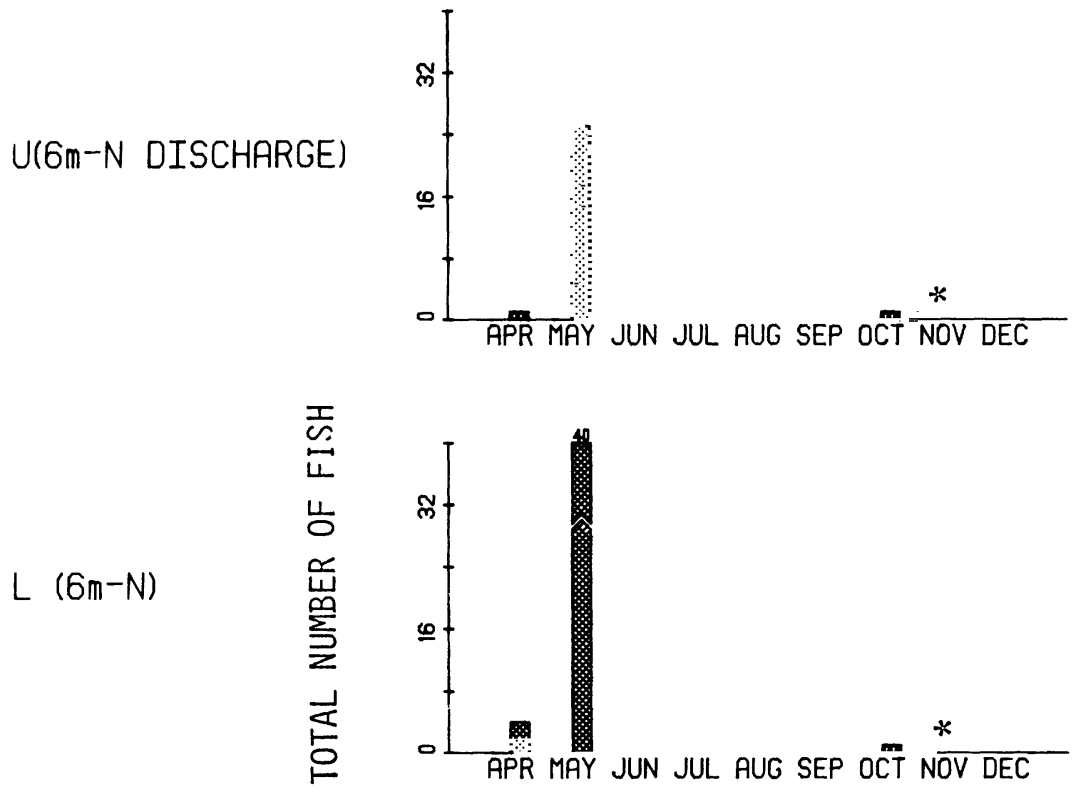

$L(6 m-N)$

C $(6 m-5)$

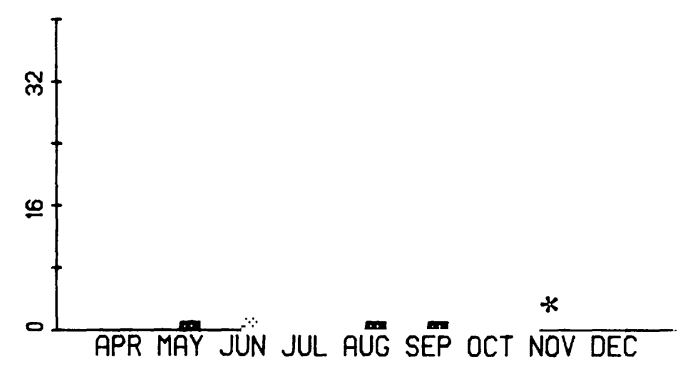

Fig. 34. Total number of rainbow smelt caught in duplicate surface gill nets fished during day and night once per month April to November 1978 in Lake Michigan near the J. H. Campbell Plant, eastern Lake Iíichigan. $\square=$ day $\square=$ night $*=$ no night sampling performed 
smelt at station $\mathrm{L}(6 \mathrm{~m}-\mathrm{N})$ than at reference station $\mathrm{C}(6 \mathrm{~m}-\mathrm{S})$. Reasons for this catch difference were not known. Water temperatures taken at fishing time at these two stations were not substantially different (Appendix 1).

During May, yearlings (40-100 mm) were caught mostly in trawls (Fig. 31); relatively few individuals were taken in seine hauls (Fig. 29). Except for an incidental catch of a $60-\mathrm{mm}$ specimen in a bottom gill net, no other smelt yearlings were gillnetted.

Inshore movements of yearlings observed in April appeared to be continuing at an increasing rate during May. All stations in the study area yielded higher catches of yearlings in May than in April (Figs. 29 and 31). Day catches of yearlings were low from the beach zone to $6 \mathrm{~m}$ with a sharp increase from 9 to $15 \mathrm{~m}$ (Fig. 31). Highest day catches occurred at $12 \mathrm{~m}$. Yearlings tended to move closer to shore at night than during the day. At night, yearlings occurred from the beach zone to $15 \mathrm{~m}$ or deeper, with highest concentrations at 6 and $9 \mathrm{~m}$ (Fig. 31). Night catches from the beach zone to $9 \mathrm{~m}$ were much higher than day catches at corresponding depths (Fig. 31).

Like adults, yearlings seemed to be more attracted to beach station $Q$ (S discharge) than station $\mathrm{R}$ ( $\mathrm{N}$ discharge) or $\mathrm{P}$ ( $\mathrm{S}$ reference). Yearlings occurred in appreciable numbers both at night and during the day at station Q, but were found only at night at station R (Fig. 29). Substantially lower numbers of yearlings were caught at reference station $P$ than at the two other beach stations. Apparently, presence of the thermal discharge in the area served to attract yearling smelt to these stations.

June--June catches of adult smelt declined sharply from May levels (Appendix 6). Of the 54 adults collected in June, 7 were caught in bottom gill nets (Fig. 28), 2 in surface gill nets (Fig. 33) and 45 in trawls (Fig. 31). No adult smelt were taken in seine hauls. Unlike the previous 2 mo, more adults were caught during the day (45) than at night (9).

Scarcity of adult smelt in June, also observed in 1977 (Jude et a1. 1978), suggested that by this time, the bulk of the adult populations had left our study area for deeper water. Most adults collected in 1978 (50 of 54) and in 1977 (Jude et a1. 1978) occurred at $9 \mathrm{~m}$ or deeper (Figs. 31 and 28). This distribution agreed with Jude et a1. (1975) who found low numbers of adults in June inside the 9-m contour near the Cook Plant, southeastern Lake Michigan.

Absence of adults with well developed or ripe-running gonads (Table 25) indicated that the spawning season was over before the 16-17 June sampling period. Catches of a small number of adults with spent gonads (Table 25) and an interesting occurrence of small rainbow smelt larvae (5-7 mm) during late June-early Ju1y, (see RESULTS AND DISCUSSION - FISH LARVAE AND ENTRAINMENT STUDY, Rainbow Sme1t) suggested that some spawning or hatching of eggs spawned earlier was still taking place during early June. June spawning appeared unusually late compared to the reported spawning season of smelt in the Great Lakes (Van Oosten 1940; Becker 1976; Daly and Wiegert 1958; Jude et a1. 1975) and in Maine lakes (Rupp 1958). In the Miramichi River, however, smelt spawning took place from late April to early June and hatching occurred from the third week of May to late July (McKenzie 1958). 
Yearlings $60-110 \mathrm{~mm}$ were mostly caught in trawls during June (Appendix 7). A small number were taken in seine hauls (Fig. 29), but none were caught in gill nets (Figs. 28 and 33). At night, yearlings occurred from the beach zone to $15 \mathrm{~m}$ and were most common at $3 \mathrm{~m}$ (Fig. 29, 31). As was found in April and May, yearlings remained in deeper water during the day, being caught only from 6 to $15 \mathrm{~m}$. Our data (Jude et al. 1978) showed a similar diel distribution of yearlings with a nearshore movement at night and a retreat to deeper water during the day. This distribution pattern may however, reflect daytime net avoidance in the shallow areas of the lake.

Catches of yearlings in June were markedly lower than in May (Figs. 31 and 29) probably because a portion of the yearling population had moved offshore, beyond our sampling stations. Jude et al. (1975) caught relatively few yearlings in June inside the 9-m contour in southeastern Lake Michigan. In Lake Erie, MacCallum and Regier (1970) found large numbers of yearlings at $18 \mathrm{~m}$ or deeper. The higher water temperatures in the study area in June (from 8.3 to $14.8 \mathrm{C}$ ) compared to the 5.0-8.5 C range recorded in May, may cause this offshore movement of yearlings.

June catches of yearling smelt in 1978 were nearly double those of June 1977 (Jude et al. 1978). This increase was probably due to the higher abundance of yearlings in the inshore area in 1978. Unlike previous months, more yearlings were caught at beach station $\mathrm{R}$ (N discharge) than at beach station $Q$ ( $S$ discharge). As in April and May, water temperatures taken at fishing time at these two stations (13.5 C at station $\mathrm{R}$ and $13.0 \mathrm{C}$ at station Q) were not greatly different.

July--During July, most adult smelt (mostly over $120 \mathrm{~mm}$ ) were caught in trawls (Fig. 31). Only a few were caught in surface and bottom gill nets and none were seined (Figs. 33, 28 and 29). Adults were caught only at 3, 6 and $9 \mathrm{~m}$ at night (Figs. 31 and 28). During the day, they occurred from 3 to $15 \mathrm{~m}$ and were most common at $6 \mathrm{~m}$. Day catches were higher than night catches. Catches of adult smelt in July were substantially higher than in June (Figs. 28 and 3.1). Adult smelt probably returned to the inshore water because of decreased bottom temperatures in July $(6.5-10.0 \mathrm{C})$ compared to June bottom temperatures (8.3-14.3 C - Appendixes 1 and 3 ) as a result of an upwelling.

During July, adult smelt were usually confined to deep water. In northern Lake Michigan adult smelt were most commonly caught at 27-51 $\mathrm{m}$ in summer (We11s 1968). Low catches of adults in our study area in July 1977 suggest a similar summer distribution. More adults were caught in July 1978 than in July 1977 because of the return of some adults to the inshore area due to an upwelling.

Most yearlings were collected in trawls (Fig. 31). A small number were seined (Fig. 29) and none were gillnetted (Figs. 28 and 33). Day catches of yearlings increased rapidly from 12 specimens at station $B(3 \mathrm{~m}-\mathrm{S})$ to a maximum of 1880 at station $\mathrm{D}(9 \mathrm{~m}-\mathrm{S})$ and declined sharply at deeper stations (Fig. 31). At night, yearlings tended to occur closer to shore and were most commonly caught at $3 \mathrm{~m}$ (Fig. 31). Night catches generally declined in deeper water. More yearlings were caught during the day than at night. 
Catches of yearlings in July were much higher than in June (Appendix 6 and 7). Like adults, yearlings probably followed upwelled cold water to the nearshore area. July catches in 1978 were more than 10 times the July catches in 1977 (Jude et al. 1978).

Only one YOY smelt ( $30 \mathrm{~mm})$ was caught in July 1978 (Fig. 31). In 1977, 374 YOY 30-40 mm were taken in July, suggesting there were more early spawners in 1977.

August--On1y 63 adult smelt (over $120 \mathrm{~mm}$ ) were caught in August. Of these, 53 were collected in trawls, 9 in bottom gill nets and 1 in a surface gill net. More adults were caught during the day than at night.

The decrease in adult smelt catches in August compared to July catches probably resulted from dispersal of adult populations into deeper water following warming of inshore water. Bottom temperatures which ranged from 6.5 to $10.0 \mathrm{C}$ in July, had increased to 8-24 C in August (Appendix 3). Comparable numbers of adults as were collected at Campbell in August 1978 were also caught in August 1977 in the study area (Jude et al. 1978). Adult smelt were also scarce in August near the Cook Plant southeastern Lake Michigan (Jude et al. 1975).

Yearling catches dropped sharply from the July peak (Fig. 31). Most yearlings collected during August were caught in trawls at all stations showing them to be widespread at this time. A few yearlings were taken in seine hauls and bottom gill nets (Figs. 29 and 28).

Diel distribution of yearlings was related to water temperature. Both during the day and at night yearlings were scarce inside the 6-m contour, where bottom temperatures ranged from 20.6 to $24.0 \mathrm{C}$ (Appendix 1). Peak day and night catches occurred at 15 and $9 \mathrm{~m}$ (Fig. 31) where bottom temperatures were 8 and $13 \mathrm{C}$ respectively. These temperatures were lower than those found at most stations in the study area (Appendix 3).

Decline of yearling catches in August was probably due to departure of most yearlings to deeper parts of the lake to avoid warmer inshore water. Offshore movement of yearlings in summer was also observed in southeastern Lake Michigan (Jude et al. 1975) and in Lake Erie (Ferguson 1965). During thermal stratification, yearlings were also reported to remain near the thermocline and the upper part of the hypolimnion (MacCallum and Regier 1970; Dryer 1966). August catches of yearlings were higher in 1978 than in 1977 suggesting a larger yearling population inhabited inshore water during August 1978.

Catches of YOY $30-50 \mathrm{~mm}$ peaked in August with most caught in trawls (Fig. 31). Only a small number were taken in seine hauls (Fig. 29). Unlike adult and yearling distribution, YOY distribution in the inshore area during August appeared to be little affected by water temperature. Despite relatively warm water in the shallow area, YOY occurred in large numbers from 3 to $15 \mathrm{~m}$ both during the day and at night. During the day, they appeared to concentrate at stations $\mathrm{D}(9 \mathrm{~m}-\mathrm{S})$ and $\mathrm{E}(12 \mathrm{~m}-\mathrm{S})$ where bottom temperatures ranged from 14.2 to $24 \mathrm{C}$ (Appendix 3). Highest night catches were taken at 6-12 m where bottom temperatures ranged from 13 to $21 \mathrm{C}$ (Appendix 3). A similar distribution 
of YOY smelt was observed in the study area in 1977 (Jude et al. 1978). Low seine catches confirmed the scarcity of YOY in the beach zone which was also reported from previous studies (Jude et a1. 1975; 1978).

In 1977 largest catches of YOY also occurred during August (Jude et a1. 1978) suggesting the bulk of spawning took place at approximately the same time during both years. The higher number of YOY caught in 1977 (7250) compared to 1978 catches (5020) probably resulted from higher abundance of the 1977 year class.

September--Adult catches continued to decline in September (Appendix 6) because most adults had reached deep water by this time. Those that were collected were caught at $6 \mathrm{~m}$ or deeper (Figs. 31 and 28). Of the 29 adults collected, 22 were caught in bottom gill nets, 6 in trawls and 1 in a surface gill net. September catches of adult smelt were higher in 1977 (150) than in 1978 (29) probably because of an upwelling of colder water in the study area in 1977 (Jude et al. 1978). Bottom temperatures ranged from 5.1 to $9.3 \mathrm{C}$ in September 1977 and from 15.6 to $21.5 \mathrm{C}$ in 1978.

Yearling catches in September sharply declined from their level in August (Fig. 31) as most yearlings had probably left for deeper water. In southeastern Lake Michigan Jude et al. (1975) caught only a small number of yearlings at 6 and $9 \mathrm{~m}$ during September. In Lake Erie, yearlings were most common at $21 \mathrm{~m}$ or deeper by late August (MacCallum and Regier 1970).

More yearlings were caught in September 1977 than in September 1978. Like adults, yearlings were probably attracted to the cold inshore water during September 1977. Relatively high water temperatures in September 1978 restricted the distribution of yearlings to deeper stations. Of the 46 yearlings collected in September, 38 were caught in bottom gill nets and 8 in trawls, all at $6 \mathrm{~m}$ or deeper.

Catches of YOY began to decline in September (Fig. 31). A few YOY were caught in night seine hauls at beach station $\mathrm{R}$ ( $\mathrm{N}$ discharge). YOY were found at night and during the day from 6 to $15 \mathrm{~m}$ with highest abundance at $15 \mathrm{~m}$ (Fig. 31). In 1977, YOY in our study area started to move to deeper water in September (Jude et al. 1978). Offshore movement of YOY also occurred during early fall in southeastern Lake Michigan (Jude et a1. 1975) and in Lake Erie (MacCallum and Regier 1970). The decrease of YOY catches in September and their concentration at the deepest station indicated offshore movement of YOY was underway in our study area during September 1978. Approximately the same number of YOY were caught in September 1977 (Jude et a1. 1978) and September 1978 (Appendix 6).

October, November and December--Most yearlings and adults were confined to deep water in the fall. In Lake Erie, both size groups were mixed at $36 \mathrm{~m}$ in October (Ferguson 1965). As was found in 1977, adult and yearlings were scarce in our study area in fall 1978. The number of smelt above $100 \mathrm{~mm}$ (yearlings and adults) collected in October, November and December were respectively 20, 20 and 1 (Appendix 6). 
YOY smelt also retreated to deep water in the fall. Wells (1968) reported catching most YOY at $18-36 \mathrm{~m}$ in October in eastern Lake Michigan off Saugatuck, Michigan. Decline of YOY catches in October, November and December in our study area (Fig 31) agreed with the above observations. In October and November, YOY were caught from 3 to $15 \mathrm{~m}$ during the day and at night (Fig. 31). Highest day catches occurred at $6 \mathrm{~m}$ in 0ctober and at $15 \mathrm{~m}$ in November. Peak night catches of YOY were found at $15 \mathrm{~m}$ during both months. In December a small number of YOY were collected at $6 \mathrm{~m}$ or deeper, being most common at $12 \mathrm{~m}$ during the day and $15 \mathrm{~m}$ at night. During these $3 \mathrm{mo}$, YOY tended to concentrate at deeper stations suggesting offshore movement was continuing during the fall.

The fish population study conducted in 1977 (Jude et al. 1978) revealed that smelt were not Pigeon Lake residents. Very few smelt entered this tributary water during 1977 (Jude et al. 1978). These observations agreed with our 1978 findings. During April 1978, only three smelt were caught in Pigeon Lake. Of these, two were females showing ripe-running and well-developed gonads; both were caught in bottom gill nets at $6-\mathrm{m}$ station $M$ (influenced by Lake Michigan). The third was a $60-\mathrm{mm}$ yearling seined at beach station $\mathrm{S}$ (influenced by Lake Michigan). In May six rainbow smelt, 43-79 mm were collected in Pigeon Lake, three at beach station $S$ and three at beach station $V$ (undisturbed Pigeon Lake). The only other smelt collected in Pigeon Lake during the rest of the study period was a $40-\mathrm{mm}$ YOY seined in August at beach station $\mathrm{S}$.

Temperature-catch relationship--As has been discussed in the previous section (Seasonal Distribution) water temperature was a major causal factor affecting the seasonal distribution of various size groups of smelt in the study area and may account for some variations in monthly catches between 1977 and 1978. Catch differences at various sampling stations can not however usually be explained by water temperature data collected. Approximately $80 \%$ of all adults were caught at water temperatures of 4-10 C (Fig. 35). Yearlings tended to occur in slightly warmer water than adults. Approximately $87 \%$ of the yearlings collected were caught in water temperatures between 6 and $12 \mathrm{C}$. Catch temperatures of yearlings and adults generally agreed with our 1977 data. Wells (1968) reported a similar range of preferred temperature (6-14 C) for smelt in eastern Lake Michigan.

Temperature-catch data from 1977 and 1978 indicated that YOY smelt $50 \mathrm{~mm}$ or less were caught in warmer water than adults or yearlings (Fig. 35). Eighty-five percent of the YOY collected in 1978 occurred in water temperatures $10-22 \mathrm{C}$.

Impingement--During the period January 1974-March 1975, 552 rainbow smelt were found in weekly collections from traveling screens at the J.H. Campbell Plant (Consumers Power Company 1975). Smelt appeared to be less frequently impinged in later years. Only 130 smelt of various sizes occurred in weekly impingement samples during the period June-December 1977 (Zeitoun et al. 1978). In our 1978 12-mo study, 197 smelt including 76 adults, 51 yearlings and 70 YOY were removed from the traveling screens. This resulted in a projected estimate for the year of 1333 smelt impinged. 


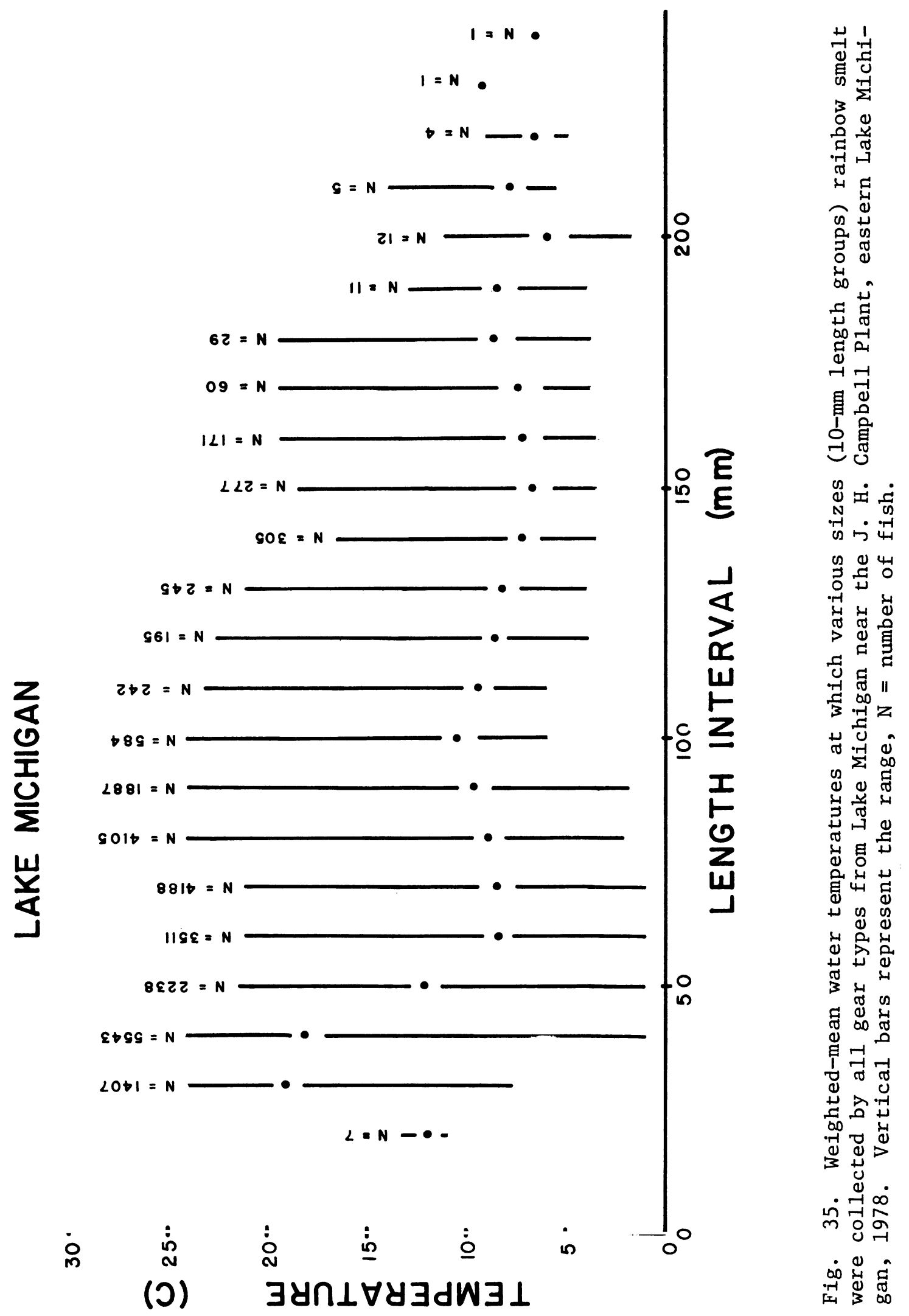


A11 10 smelt collected from impingement samples during January and February were yearlings 60-90 mm (Appendix 8). The 1977 adult and juvenile fish data (Jude et a1. 1978) indicated a small population of YOY inhabited inshore water during December. Some of these smelt, after recruitment to the yearling group, probably still remained inshore in winter and were more vulnerable to impingement than adults during this period. No rainbow smelt were impinged in March.

Although appreciable numbers of yearlings moved inshore during April and May, very few entered Pigeon Lake (see Seasonal Distribution). This distributional behavior explained the low number (14) of yearlings collected in impingement samples at the Campbell Plant during April and May 1978 (Appendix 8). Forty-three of the 72 adult smelt impinged in 1978 were collected in April and May indicating that adults were most vulnerable to impingement during the spawning season. Most adults in April and May impingement collections had well developed or ripe-running gonads (Table 26). It also indicates that some adult smelt entered Pigeon Lake possibly for spawning purposes.

Table 26. Monthly gonad conditions of rainbow smelt collected in impingement samples during 1978 at the J. H. Campbell Plant, eastern Lake Michigan. All fish examined in a month were included except poorly received specimens.

\begin{tabular}{|c|c|c|c|c|c|c|c|c|c|c|c|c|c|}
\hline & Gonad condition & Jan & Feb & Mar & Apr & May & Jun & Ju1 & Aug & Sep & Oct & Nov & Dec \\
\hline Males & $\begin{array}{l}\text { S1ight development } \\
\text { Mod. development } \\
\text { Well developed } \\
\text { Ripe-running } \\
\text { Spent }\end{array}$ & & & & $\begin{array}{l}1 \\
2 \\
9\end{array}$ & $\begin{array}{l}6 \\
6 \\
3\end{array}$ & $\begin{array}{l}2 \\
1\end{array}$ & $\begin{array}{l}1 \\
1 \\
3\end{array}$ & 1 & & $\begin{array}{l}2 \\
2 \\
1\end{array}$ & & $\begin{array}{l}1 \\
1\end{array}$ \\
\hline Female & $\begin{array}{l}\text { Slight development } \\
\text { Mod. development } \\
\text { Well developed } \\
\text { Ripe-running } \\
\text { Spent } \\
\text { Absorbing }\end{array}$ & & & & $\begin{array}{l}1 \\
1 \\
4 \\
2\end{array}$ & $\begin{array}{l}1 \\
2 \\
1 \\
2\end{array}$ & & & & & 2 & 4 & $\begin{array}{l}1 \\
1\end{array}$ \\
\hline Immatur & & & & & 6 & 6 & 3 & 15 & 48 & 6 & 22 & & 5 \\
\hline Unable & o distinguish & 9 & 1 & & 1 & 3 & & & 3 & & 3 & & 2 \\
\hline
\end{tabular}

Adult smelt were less frequently impinged than other major species in the study area such as alewife and spottail because smelt only occasionally entered Pigeon Lake. A considerably higher number of adults (395) were collected during April and May 1974 (Consumers Power Company 1975) suggesting that Pigeon Lake may have been more heavily utilized as a spawning ground during that year.

From June through December 1978, only 36 yearlings and 34 adults were 
collected from the traveling screens. This low impingement conformed with the scarcity of adults and yearling in Pigeon Lake during this period.

Entrainment sampling revealed that large numbers of YOY smelt approximately 26.0-50.0 mm were drawn into Campbel1 P1ant, mostly during August and September (see RESULTS AND DISCUSSION - FISH LARVAE AND ENTRAINMENT STUDY, Rainbow Sme1t). Impingement of YOY sme1t however, was relatively low because most YOY were still small enough to pass through traveling screens during these 2 mo. Most impinged YOY (48 of 70) were collected in August impingement samples. This peak impingement rate coincided with the high abundance of YOY in the inshore water of Lake Michigan. Remaining impinged YOY were collected in September, October and December. The total number of rainbow smelt impinged in 1978 was estimated at 1333, including approximately 858 adults and yearlings and 475 YOY. Because most YOY were not retained by the traveling screens, total number of YOY drawn into the plant may be best estimated from entrainment sampling. Rainbow smelt appeared to be impinged more frequently at the Palisades Plant near South Haven on eastern Lake Michigan where 4616 adults were collected during 30 December 1972-29 June 1973.

Plant impacts--As with alewife, the impact of Units 1 and 2 on smelt populations is mainly a function of the magnitude of entrainment of larvae and fry $(1,527,730)$ and impingement of juveniles and adults (1333). Certainly 1333 juvenile and adult smelt are a miniscule number compared to the Lake Michigan population or the commercial or sport catch of smelt. These comparisons and estimates of production foregone due to entrainment and impingement losses are covered elsewhere. Regarding our results, more smelt were collected during 1978 than 1977 (even disregarding 1978 April and May catches) so we have been unable to show any declines in smelt populations that were attributable to plant operation to date.

Other considerations--YOY smelt reached a modal length of $40 \mathrm{~mm}$ in August and September, $50 \mathrm{~mm}$ in October and November and $60 \mathrm{~mm}$ in December (Appendix 6). Identical growth rate was recorded in the study area during the summer and fall during 1977 (Jude et al. 1978). In Gull Lake, Michigan, YOY smelt grew to approximately the same size $(60 \mathrm{~mm})$ by December (Burbidge 1969).

As expected, no size increase of YOY smelt occurred during winter months. In April, yearlings were the same size (modal length, $60 \mathrm{~mm}$ ) as YOY in December (Appendix 6) (Jude et al. 1978). Yearlings reached a modal length of $70 \mathrm{~mm}$ in May and June, $80 \mathrm{~mm}$ in July and $90 \mathrm{~mm}$ in August. This growth rate was comparable to growth rate of southeastern Lake Michigan yearlings which grew to a modal length of $90 \mathrm{~mm}$ by September (Jude et a1. 1975).

Rainbow smelt were only sparingly utilized as forage by predatory fish species in our study area. In 1977 and 1978, very few lake trout and brown trout examined had smelt in their stomachs. During 1978, YOY smelt were found in a few yellow perch and burbot stomachs. A low degree of cannibalism also occurred among rainbow smelt in 1977 and 1978.

Summary--Rainbow smelt were the second most abundant species collected in Lake Michigan. In the study area, smelt spawned mostly during late April and 
early May. Some spawning also took place during late May and early June. Offshore movements of adult smelt started in May. Adult catches peaked in April and generally declined during late spring and summer except for a slight increase in July. Only a few adults were caught during fall. Most adults were caught at 6 and $9 \mathrm{~m}$ during spring and summer.

Catches of yearlings generally increased during spring and early summer with highest catches taken during July. Yearlings moved offshore in August and were almost completely absent from inshore areas during fall. Yearlings were most common at 6 and $9 \mathrm{~m}$ during spring and summer.

Catches of YOY peaked in August and began to decline in September as a result of offshore movements. An appreciable number of YOY however, continued to inhabit inshore water throughout fall. High concentrations of YOY occurred at 6 and $9 \mathrm{~m}$ during August and 12 and $15 \mathrm{~m}$ during September and remaining fall months.

Rainbow smelt of all sizes exhibited diel horizontal migration with a movement to shallow water at night and a return to deeper water during the day. Adults and yearlings were caught mostly in water temperatures 6 to $14 \mathrm{C}$. Young-of-the-year $50 \mathrm{~mm}$ and less occurred in warmer water than larger smelt. Variations of yearling and adult catches may be in part influenced by water temperature.

Low numbers of adults and yearlings were impinged during 1978. YOY 26.0-50.0 $\mathrm{mm}$ were drawn into the plant at a relatively high rate, but most passed through the traveling screens and appeared in entrainment samples.

\section{Spottail Shiner--}

Introduction--The spottail shiner is one of the favorite bait and forage fish in larger midwestern lakes and rivers (Hubbs and Cooper 1936). In Lake Erie, it was found frequently in the stomachs of walleye (Parsons 1971). It is also utilized as food by northern pike (Hunt and Carbine 1951), lake trout (Wright 1968) and yellow perch (Nursall 1973). Although spottail shiners were found in the stomachs of walleye, brown trout, northern pike, yellow perch, burbot and black crappies caught in the vicinity of the Campbell Plant they are not as important as smelt and alewife as a forage species. Food web evaluations for fish in Indiana waters of Lake Michigan have not revealed the spottail shiner as a significant prey fish; none were ever found in yellow perch, lake trout, coho salmon or alewife (McComish 1975, McComish and Miller 1975). Studies by Jude et al. (1975, 1979) and We1ls and House (1974) found that although abundant in Lake Michigan, spottail shiners appear to play only a minor role as forage for larger predatory species. Due to the great abundance of alewives, few cyprinids are currently ingested by salmonids in Lake Michigan (Chiotti 1973).

The spottail shiner is also an indicator of water quality. Trautman (1957) reported a decrease in numbers of this species in Lake Erie due to turbidity. The spottail shiner is relatively intolerant of siltation and polluted water (Yager 1976). 
An understanding of the ecology of spottails in Lake Michigan is valuable because of its abundance, potential importance as a forage species and as a water quality indicator. It seems that abundance of this species could be locally affected by construction activities in the discharge area in Lake Michigan and the west side of Pigeon Lake. Data from the 1979 study will be required to document any changes in distribution due to construction activity.

Catches of spottail shiners in Lake Michigan increased from 7,883 in 1977 to 12,764 in 1978 despite little change in sampling effort. In Pigeon Lake, the reverse was true; catches declined from 4,457 in 1977 to 2,456 in 1978. Deletion of station $\mathrm{T}$ and a change in location of station $\mathrm{S}$ may have influenced numbers collected in 1978.

\section{Seasona1 distribution--}

April--Spottail shiners were collected in very low numbers (26) in Lake Michigan during April (Figs. 36-37). Seining at beach stations Q (S discharge) and $R$ ( $N$ discharge) accounted for seven and four spottails respectively; none were caught at beach station $P$ (S reference) (Fig. 38). Eight spottails were caught in bottom trawls (Fig. 39) of which six were caught in $9 \mathrm{~m}$ or deeper water. Only seven spottail shiners were caught in bottom gill nets (Fig. 40); five were caught in $6 \mathrm{~m}$ or deeper water.

The low concentrations of spottail shiners in the vicinity of the Campbell Plant in April is typical of their spring distribution in southern Lake Michigan and suggests that the inshore migration was in its initial stages during April 1978. Jude et al. (1975) found that spring inshore migrations to 9 and $6 \mathrm{~m}$ began in March and continued into April. Wells (1968) found spottail shiners moved to shallower depths during summer $(6-10 \mathrm{~m})$ and deeper depths $(6-34 \mathrm{~m}$ and sparingly $50 \mathrm{~m}$ ) during winter. Spottails were uncommon in the nearshore waters of east central Lake Michigan (near Ludington, Michigan) during April 1975 (Anderson and Brazo 1978).

The catch of spottails in Pigeon Lake was also low in April (28 fish were caught). All were caught in seines with equal distribution (14 fish) at beach stations $\mathrm{S}$ (Lake Michigan influenced) and V (undisturbed Pigeon Lake) (Fig. 41).

In contrast to the small numbers of spottails collected in April field samples, 224 were collected (total estimated for the month was 1680) during impingement sampling in April (see RESULTS AND DISCUSSION - IMPINGEMENT STUDY Spottail Shiner). Because of the small numbers of spottails caught in Lake Michigan in April, these fish most likely were Pigeon Lake residents.

May--A marked increase over April in the number of spottail shiners caught was observed during May in Lake Michigan (Figs. 36-37). Of the 425 spottails collected, 166 were caught in bottom gill nets, 146 by seine, 85 in bottom trawls and 28 in surface gill nets. These data indicated that the spottail migration into shallower water had been nearly completed by May. Considering bottom gill net catches $136 \mathrm{fish}$ or $71 \%$ were caught in $3 \mathrm{~m}$ of water or less (Fig. 40). Nearly 

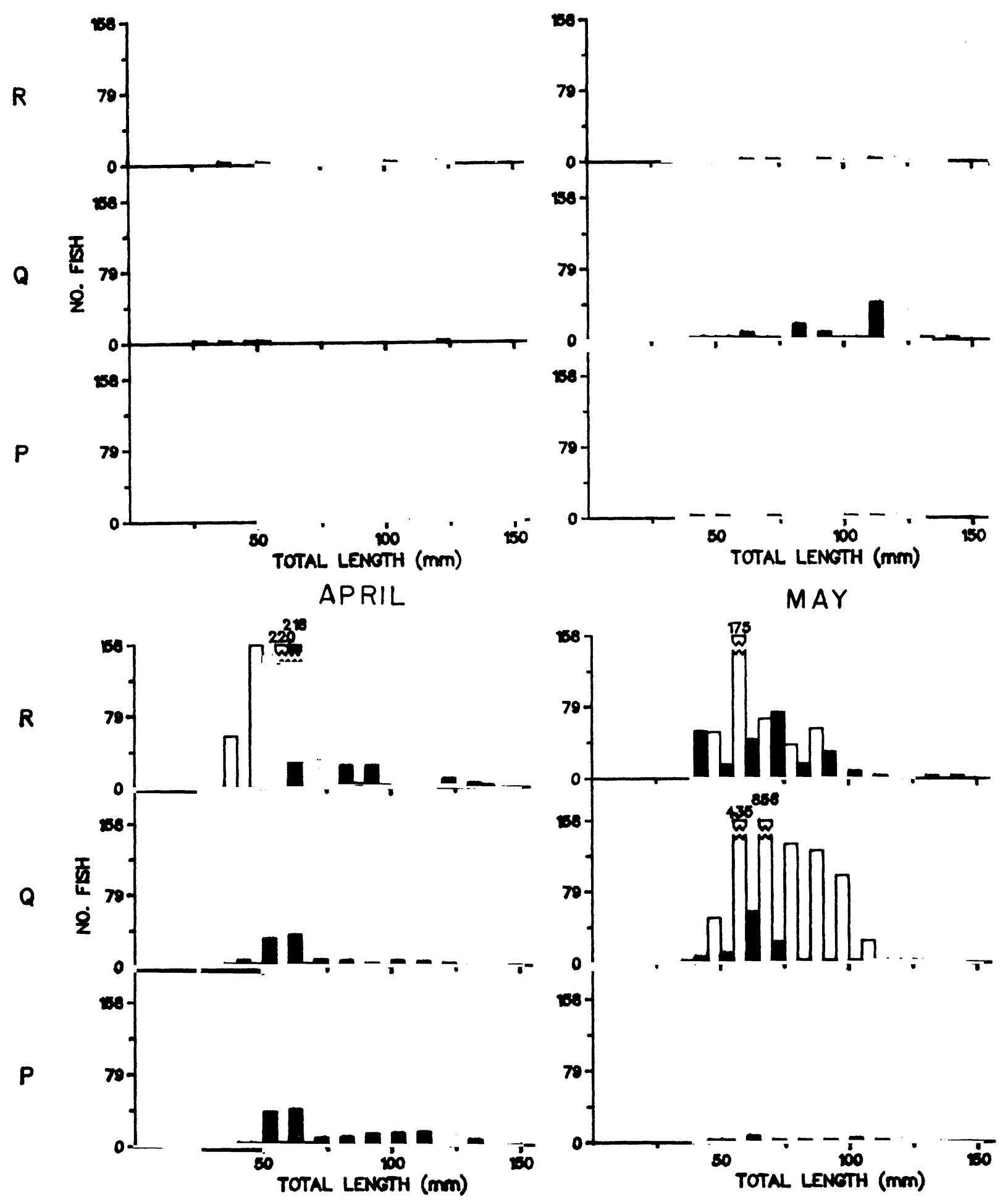

\section{JUNE}

JULY

Fig. 36. Length-frequency histograms for spottail shiners caught in duplicate seine hauls during April to November 1978 in Lake Michigan near the J. H. Campbell Plant, eastern Lake Michigan. $\square=$ day $\square=$ night 


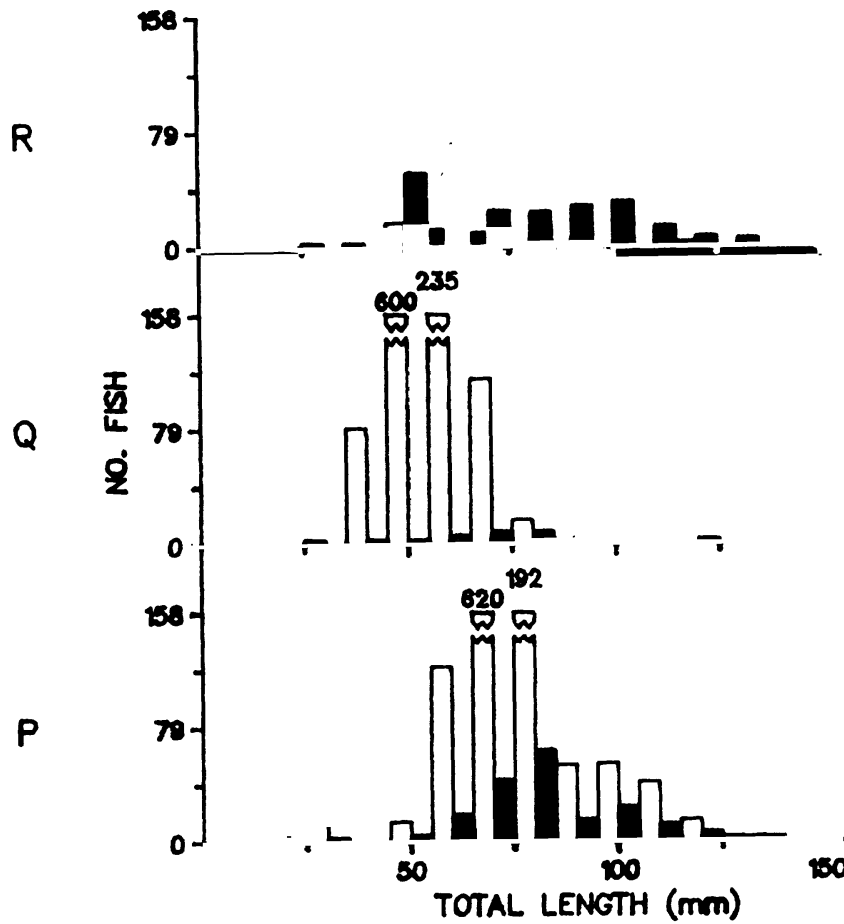

AUGUST

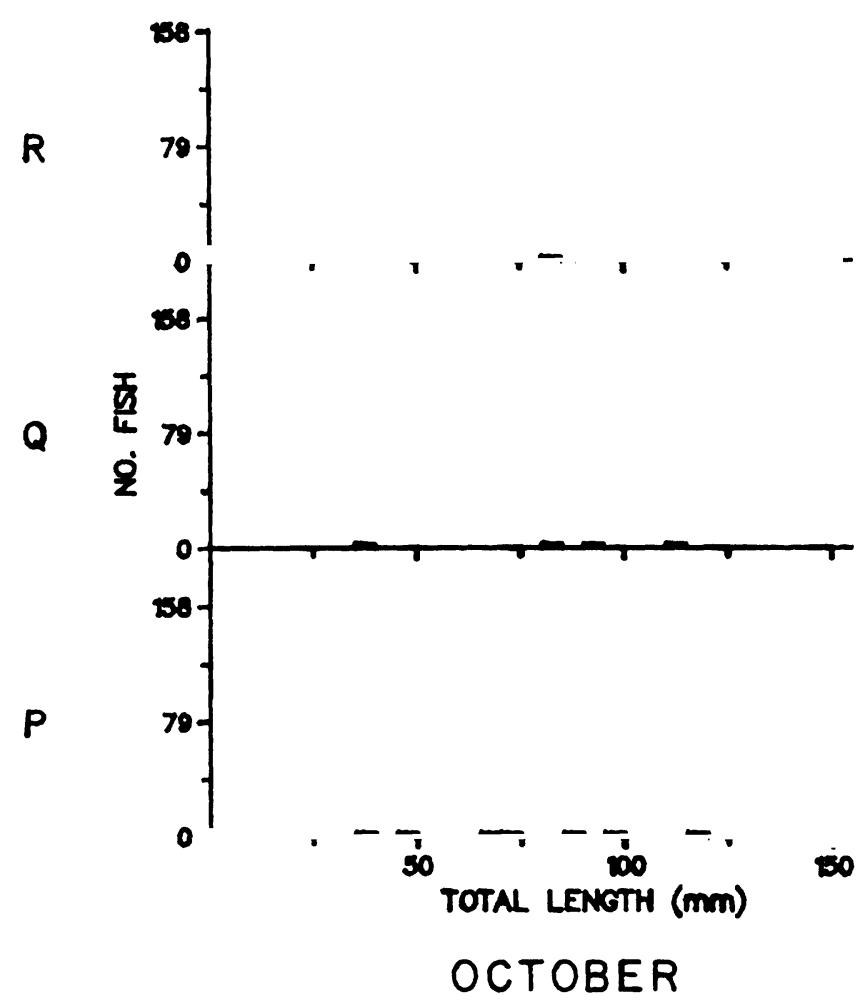

Fig. 36, Continued.
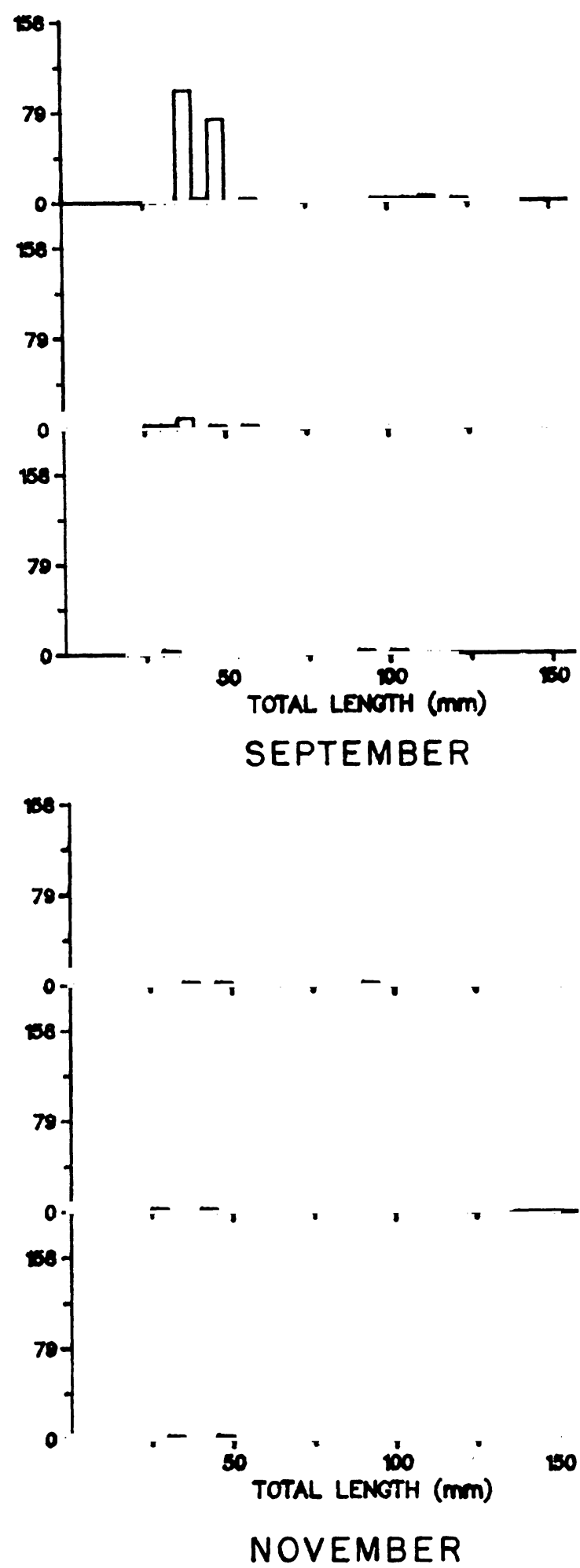

NOVEMBER 


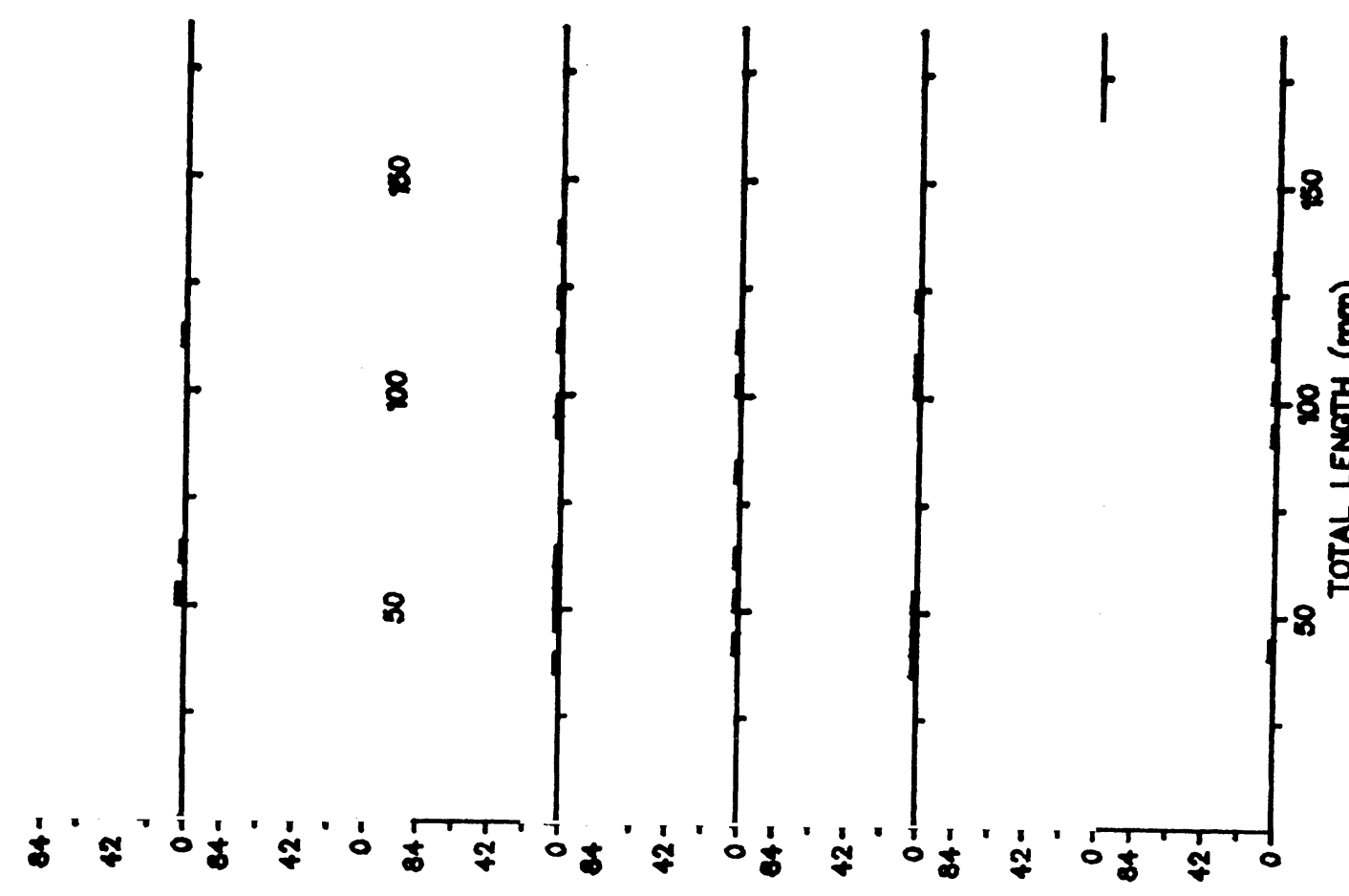

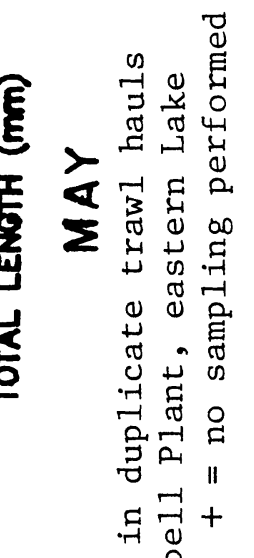

苍葛

วิ

का 㟧

氙的怘

壳界

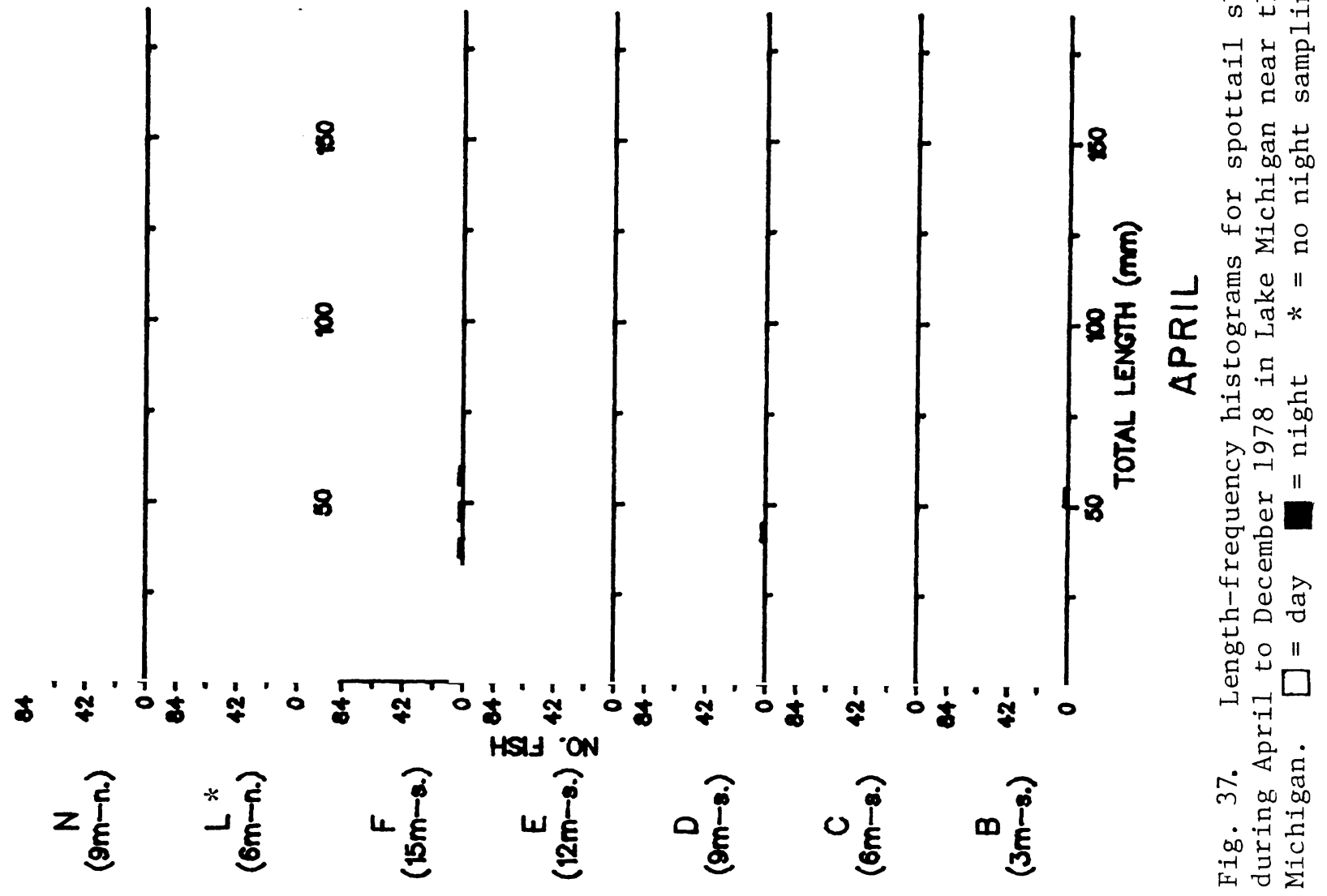



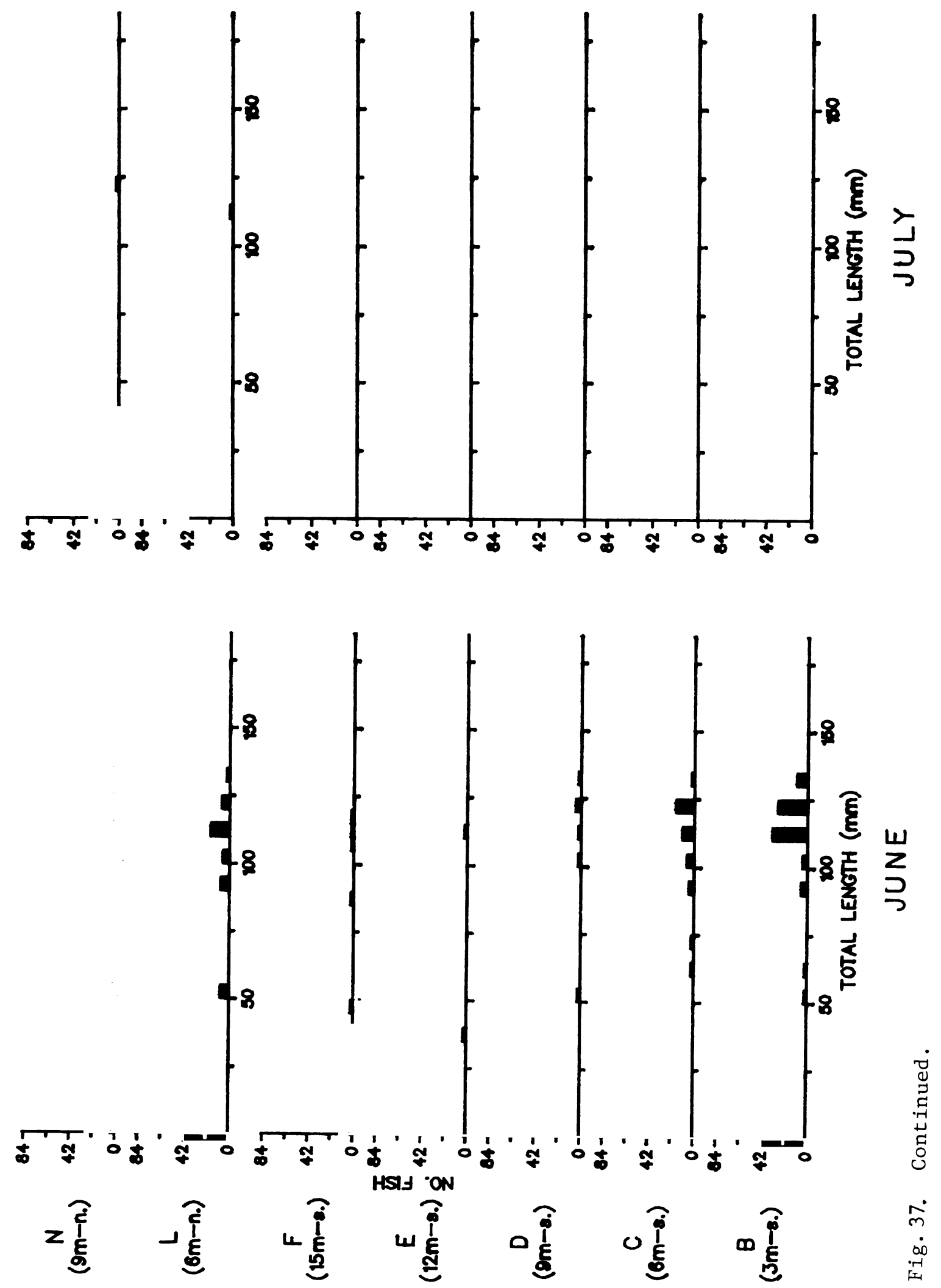

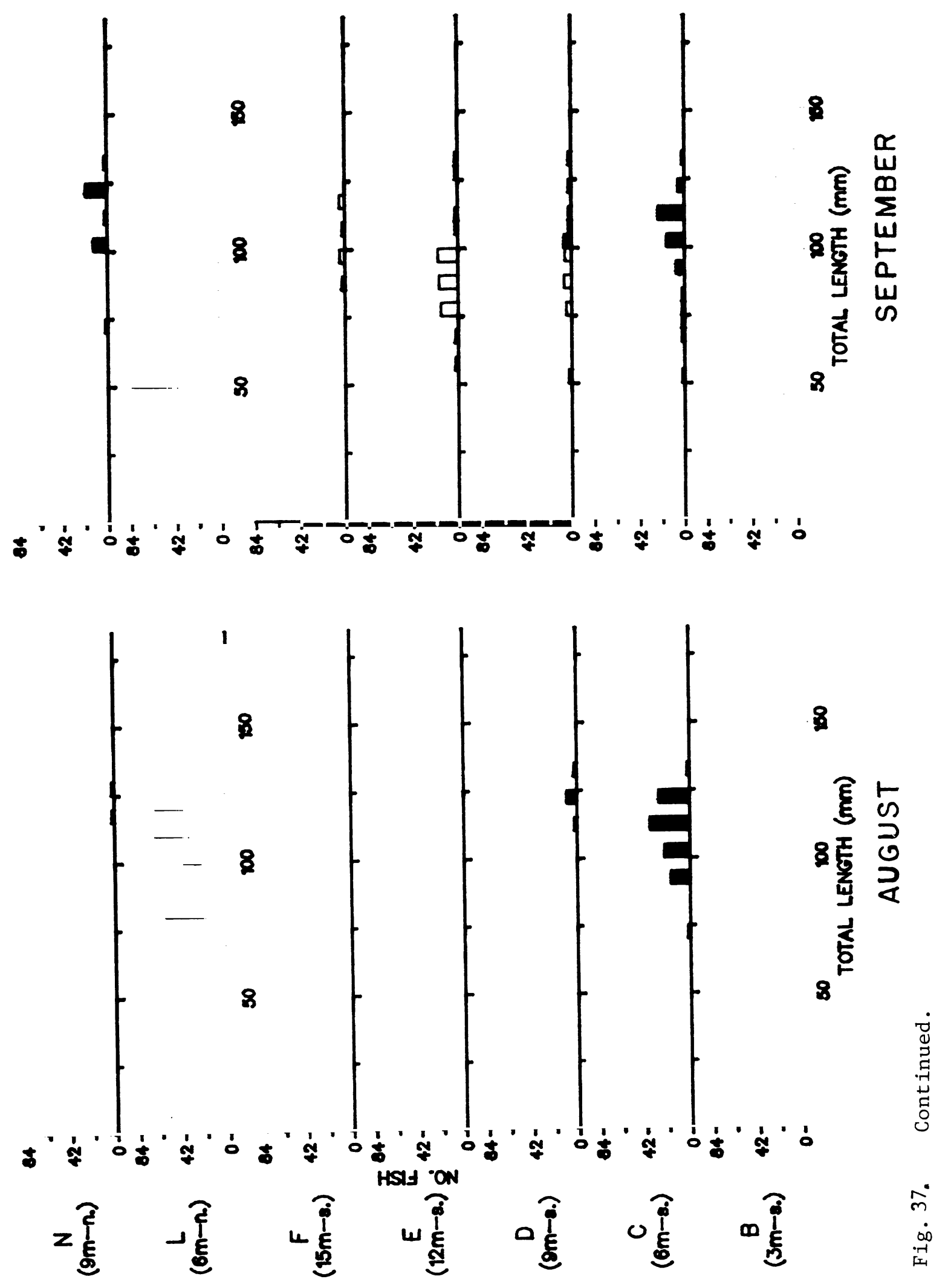

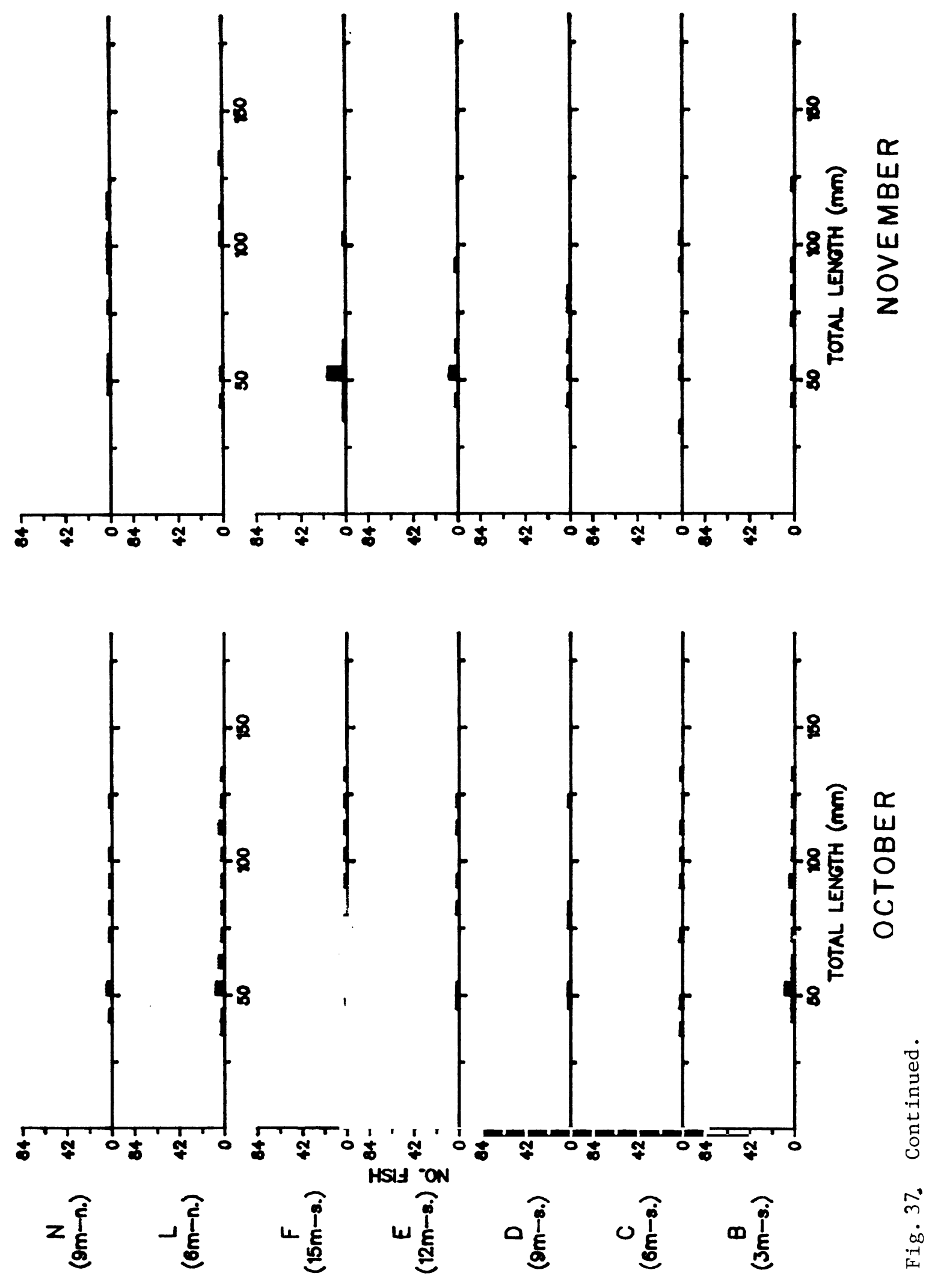


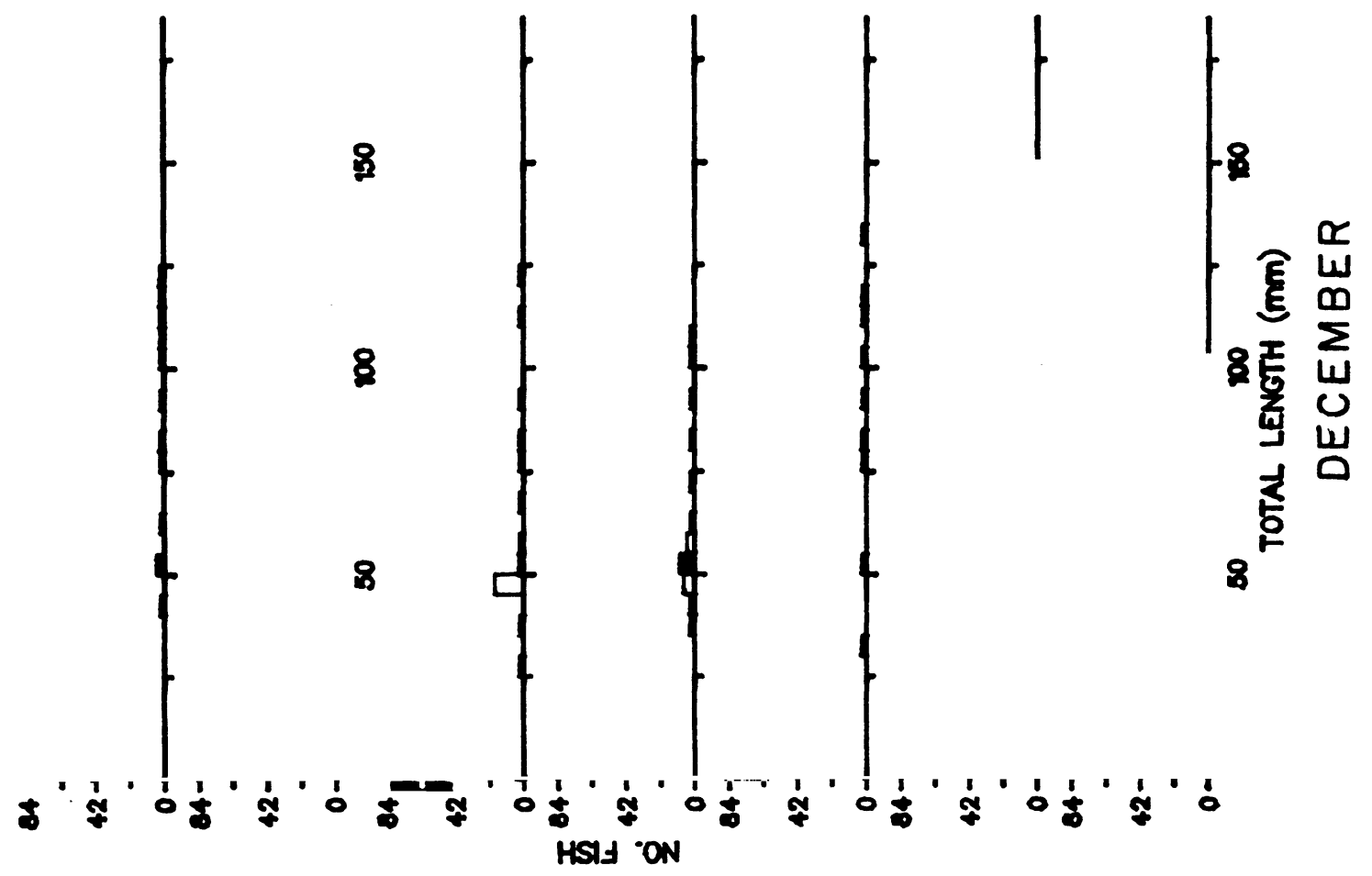

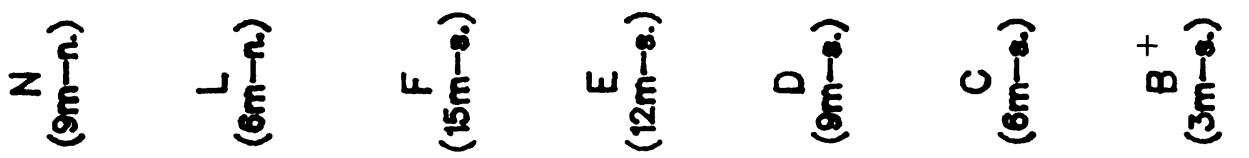

苞

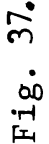




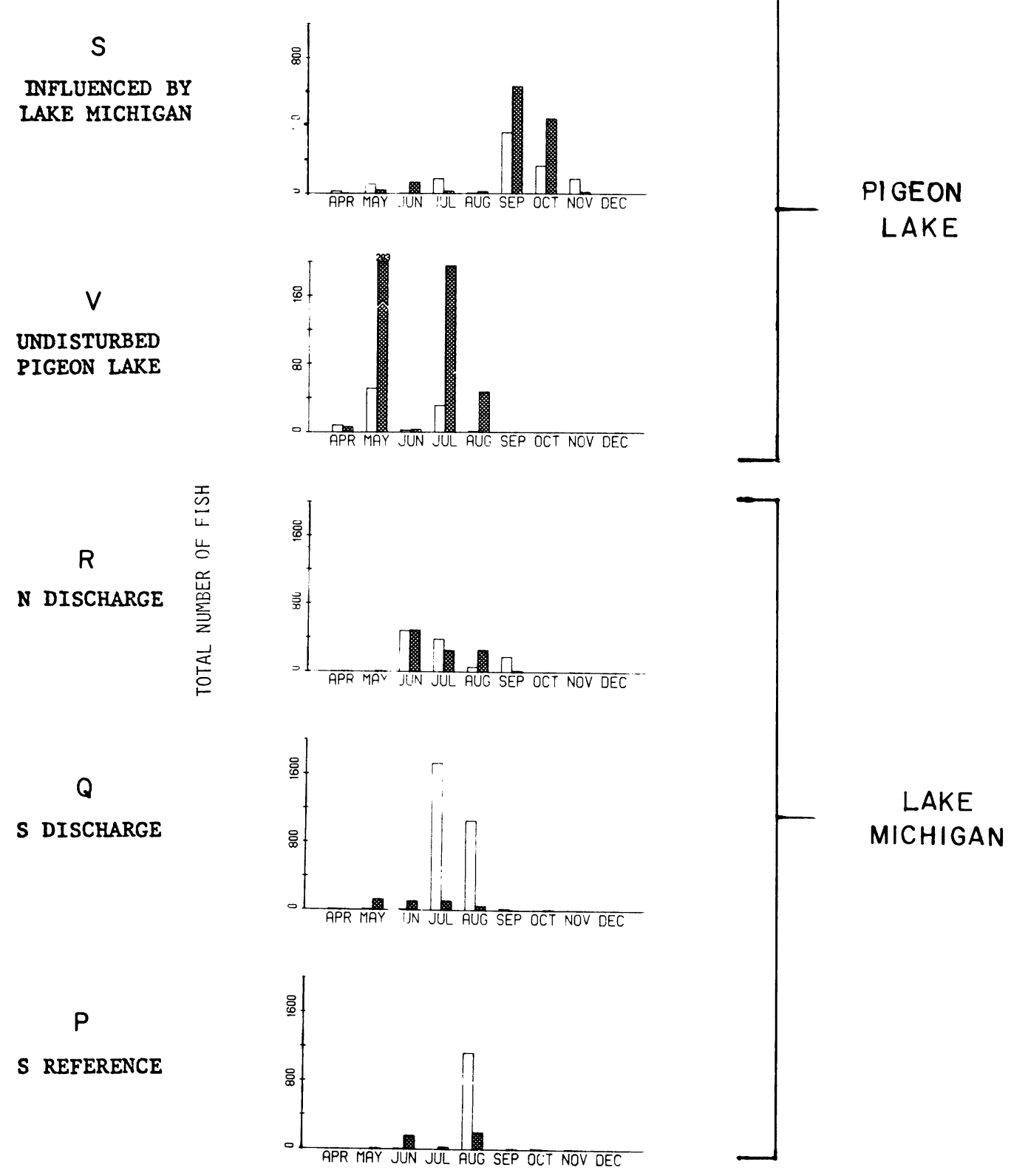

Fig. 38. Total number of spottail shiners caught in duplicate seine hauls during day and night once per month April to November 1978 in Pigeon Lake (stations $\mathrm{S}$ and $\mathrm{V}$ ) and Lake Michigan (stations $\mathrm{P}, \mathrm{Q}, \mathrm{R}$ ) near the J. H. Campbell Plant, eastern Lake Michigan. $\square=$ day $\square=$ night 
$N(9 m-N)$

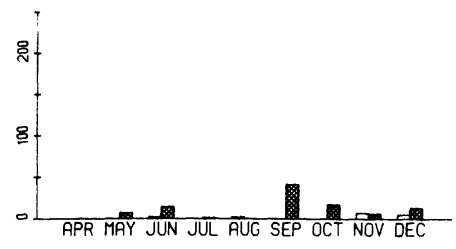

$L(6 m-N)$

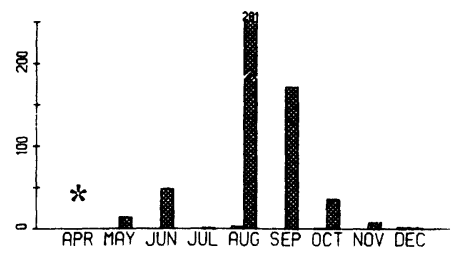

$F(15 m-S)$

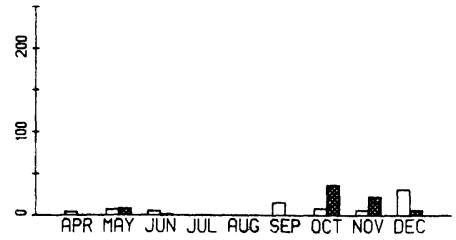

$E(12 m-S) \quad$

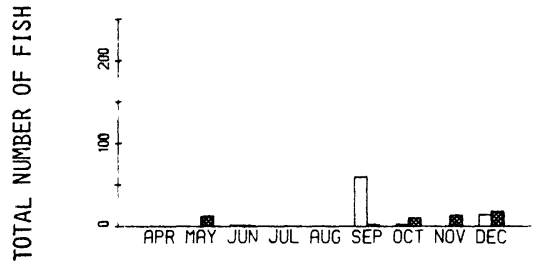

D $(9 m-S)$

品

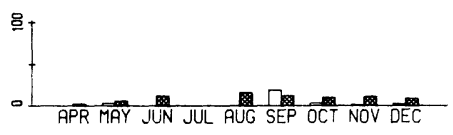

C $(6 m-5)$

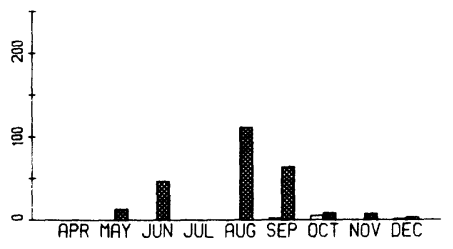

$B(3 m-S)$

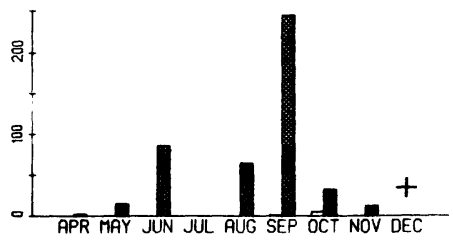

Fig. 39. Total number of spottail shiners caught in duplicate trawl hauls during day and night once per month April to December 1978 in Lake Michigan near the J. H. Campbell Plant, eastern Lake Michigan. $\square=$ day $\square=$ night $*=$ no night sampling performed $+=$ no sampling performed 


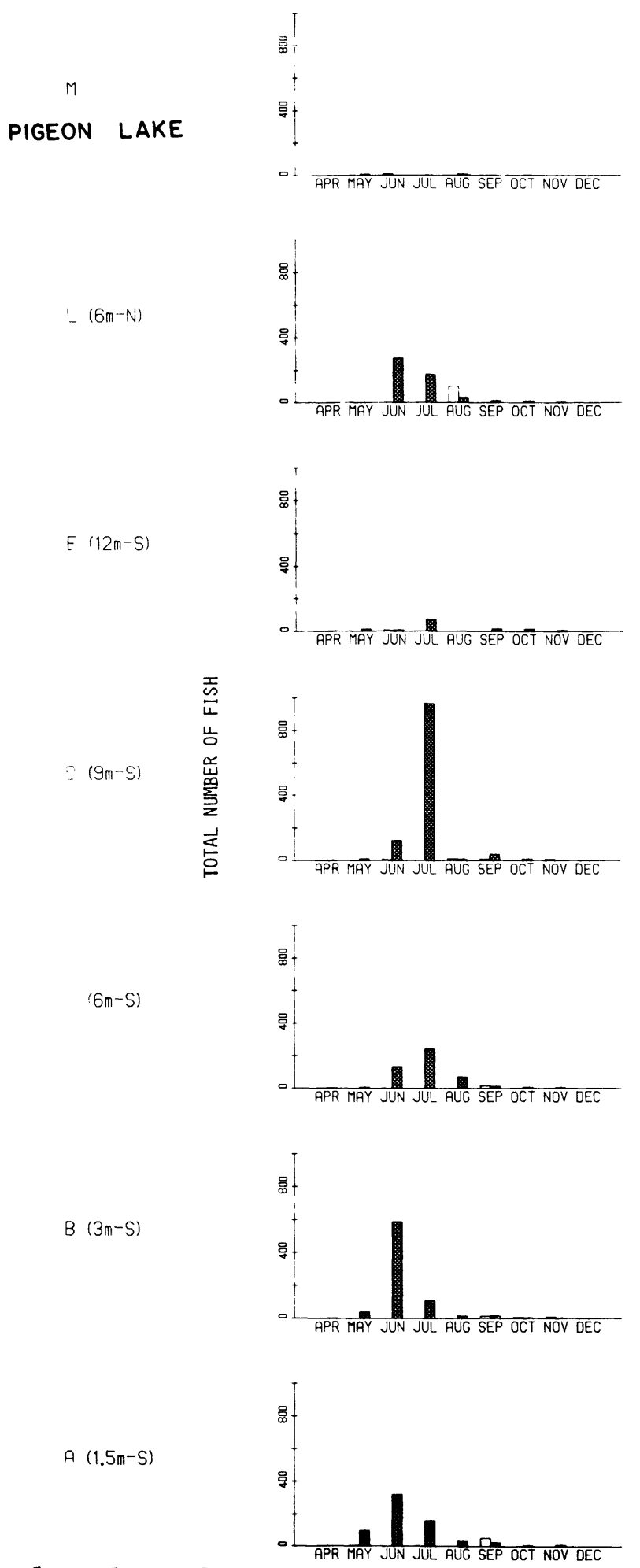

Fig. 40. Total number of spottail shiners caught in duplicate bottom gill nets fished during day and night once per month April to November 1978 in Lake Michigan and Pigeon Lake near the J. H. Campbell Piant, eastern Lake Michigan. $\square=$ day $\square=$ night 


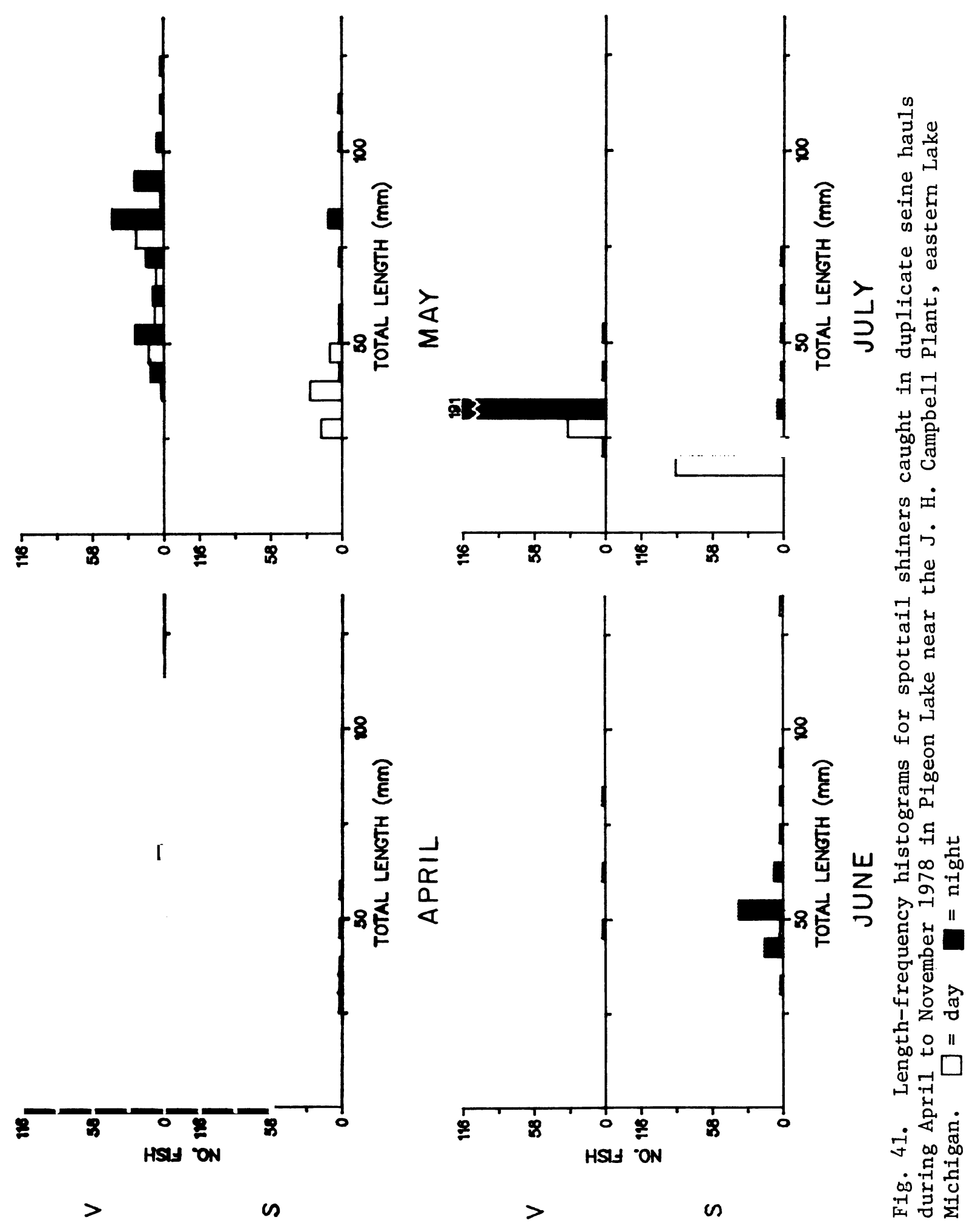



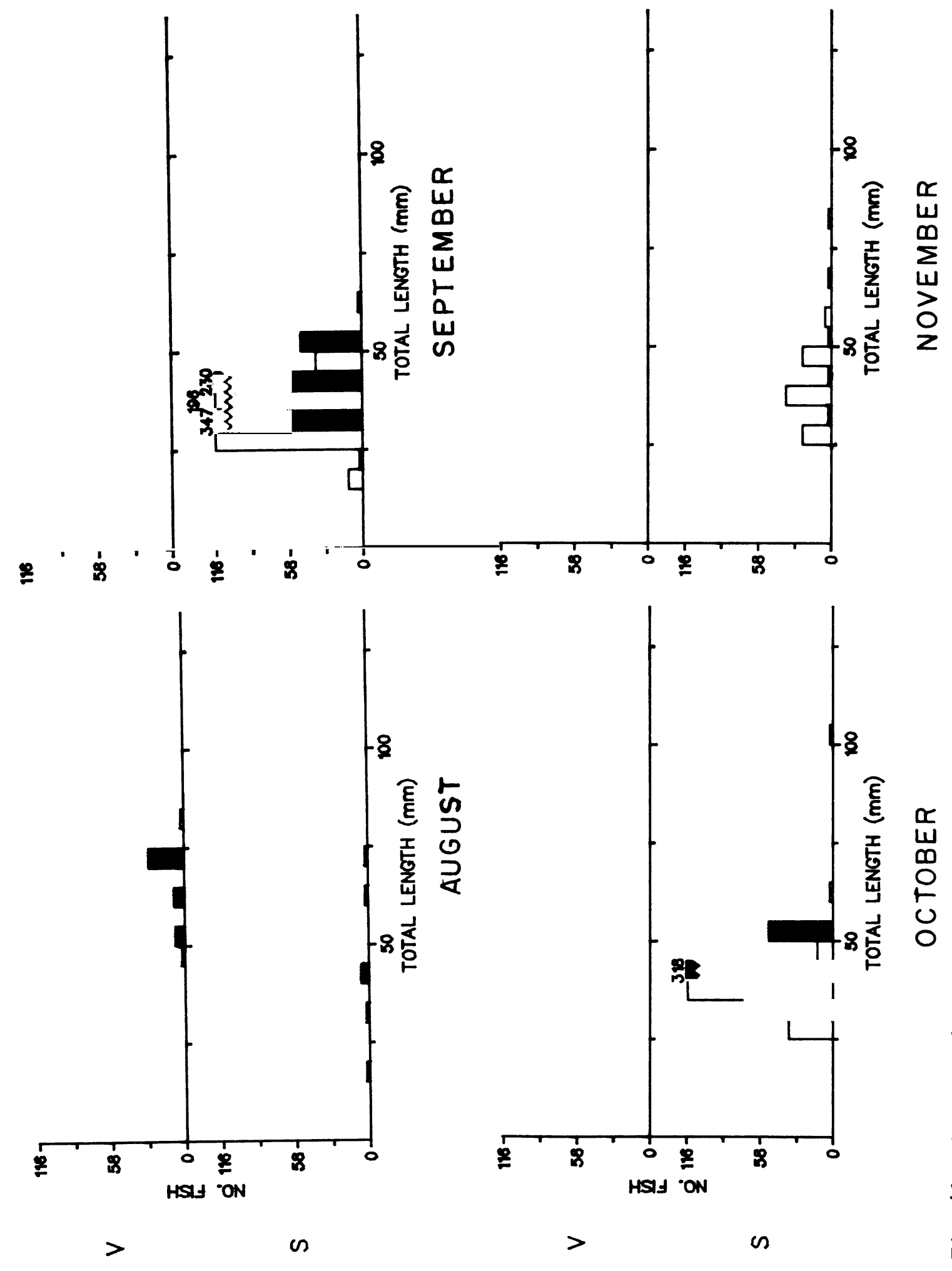

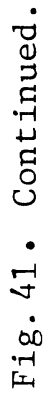


half of the spottails caught in trawls were taken from $6 \mathrm{~m}$ of water or less. Examination of length-frequency data from trawls in May indicates no definite separation of size groups by water depth (Fig. 37). Jude et al. (1975) found spottails moved to the 6- and 9-m depths by May and We11s (1968) described a definite shoreward movement in eastern Lake Michigan by 5 May. Beach seine catches were comprised mostly of larger fish, 80-120 mm (Fig. 36), which according to Wells and House (1974) would be age-groups 2 and 3, indicating that larger and more mature fish led the inshore migration. Gill net data from May also indicated that spottail shiners longer than $100 \mathrm{~mm}$ were most abundant at 1.5 and $3 \mathrm{~m}$ (Fig. 42). Five ripe-running (Table 27) female spottails were collected from Lake Michigan in May, suggesting that spawning activity commenced in May during 1978.

Table 27. Monthly gonad conditions of spottail shiners caught during 1978 in Lake Michigan near the J. H. Campbell Plant, eastern Eake Michigan. All fish examined in a month were included except poorly received specimens.

\begin{tabular}{|c|c|c|c|c|c|c|c|c|c|c|}
\hline & Gonad condition & Apr & May & Jun & Jul & Aug & Sep & Oct & Nov & Dec \\
\hline Males & $\begin{array}{l}\text { Slight development } \\
\text { Mod. development } \\
\text { We11 developed } \\
\text { Ripe-running } \\
\text { Spent }\end{array}$ & & $\begin{array}{r}35 \\
18 \\
6\end{array}$ & $\begin{array}{r}120 \\
120 \\
31 \\
6 \\
13\end{array}$ & $\begin{array}{r}88 \\
21 \\
24 \\
1 \\
43\end{array}$ & $\begin{array}{r}150 \\
30 \\
8\end{array}$ & $\begin{array}{r}99 \\
31 \\
1 \\
13\end{array}$ & $\begin{array}{l}25 \\
15\end{array}$ & $\begin{array}{r}19 \\
8\end{array}$ & $\begin{array}{r}12 \\
2\end{array}$ \\
\hline Females & $\begin{array}{l}\text { Slight development } \\
\text { Mod. development } \\
\text { We11 developed } \\
\text { Ripe-running } \\
\text { Spent } \\
\text { Absorbing }\end{array}$ & $\begin{array}{l}2 \\
6 \\
1\end{array}$ & $\begin{array}{r}11 \\
40 \\
74 \\
5 \\
4\end{array}$ & $\begin{array}{r}21 \\
53 \\
149 \\
38 \\
5\end{array}$ & $\begin{array}{r}10 \\
8 \\
24 \\
8 \\
43\end{array}$ & $\begin{array}{r}55 \\
12 \\
1 \\
1 \\
32 \\
21\end{array}$ & $\begin{array}{r}68 \\
15 \\
2\end{array}$ & $\begin{array}{r}15 \\
28 \\
1\end{array}$ & $\begin{array}{r}6 \\
10\end{array}$ & $\begin{array}{l}3 \\
8\end{array}$ \\
\hline Immature & & 16 & 58 & 223 & 129 & 171 & 103 & 89 & 68 & 76 \\
\hline Unable $t$ & o distinguish & 1 & 31 & 63 & 73 & 228 & 100 & 56 & 5 & 3 \\
\hline
\end{tabular}

Nearly all spottails (90\%) caught in beach seines during May were caught at beach station Q (S discharge) (Fig. 36). These fish were caught at night when water temperature was $7.5 \mathrm{C}$; the day temperature at this station was $12.5 \mathrm{C}$. A suspected shift in the flow of the thermal plume probably caused this day/night temperature difference. The night temperature may have been taken outside the plume while the seine passed through it, resulting in the large catch of spottails, which were concentrated in the warmer water.

Gill nets set at the surface caught 28 spottails at $6-\mathrm{m}$ north station $\mathrm{L}$ (south of discharge) at night during May when water temperatures were $6.5 \mathrm{C}$ at the surface and $6.9 \mathrm{C}$ at the bottom (Fig. 43). Occurrence of spottails at the 

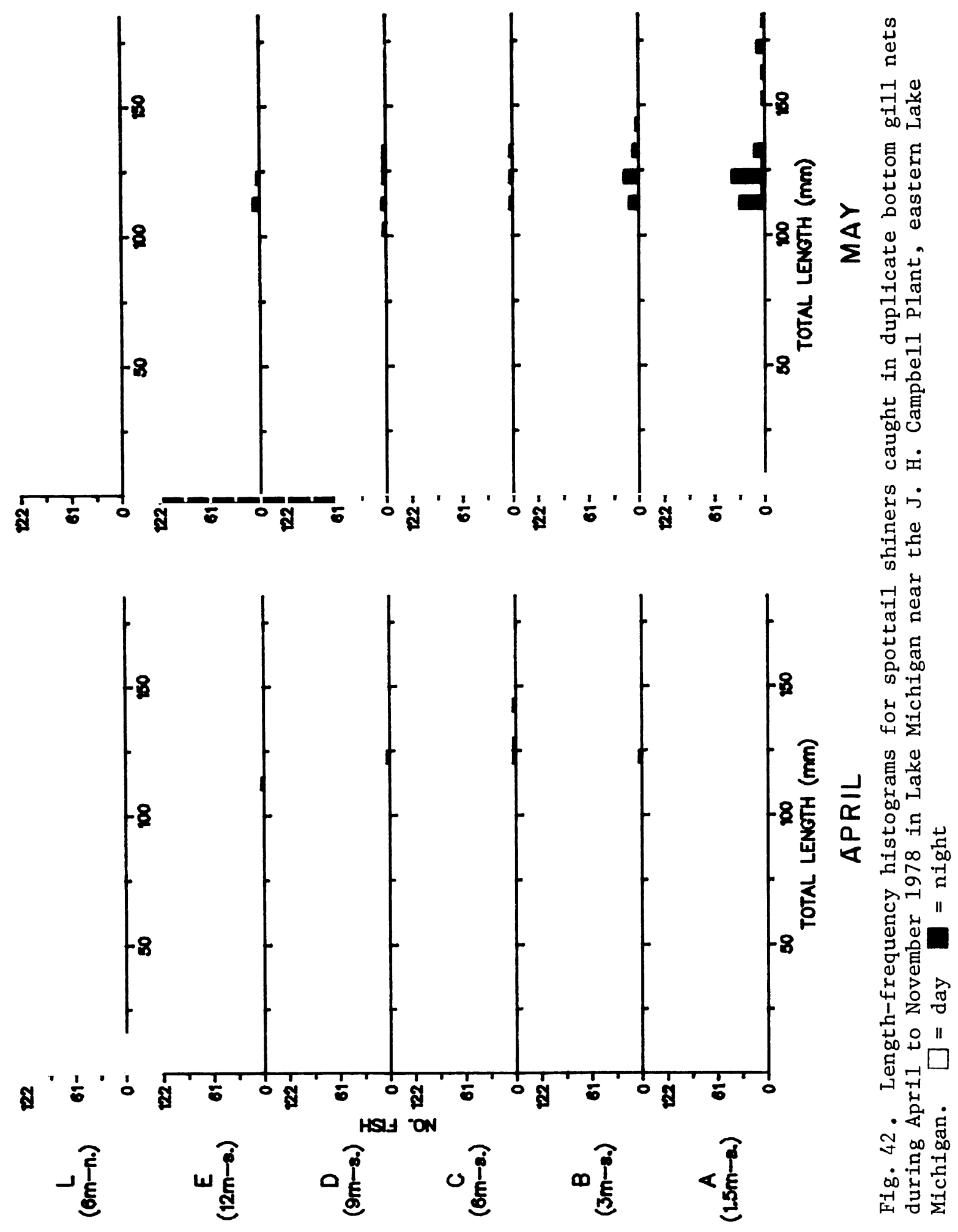

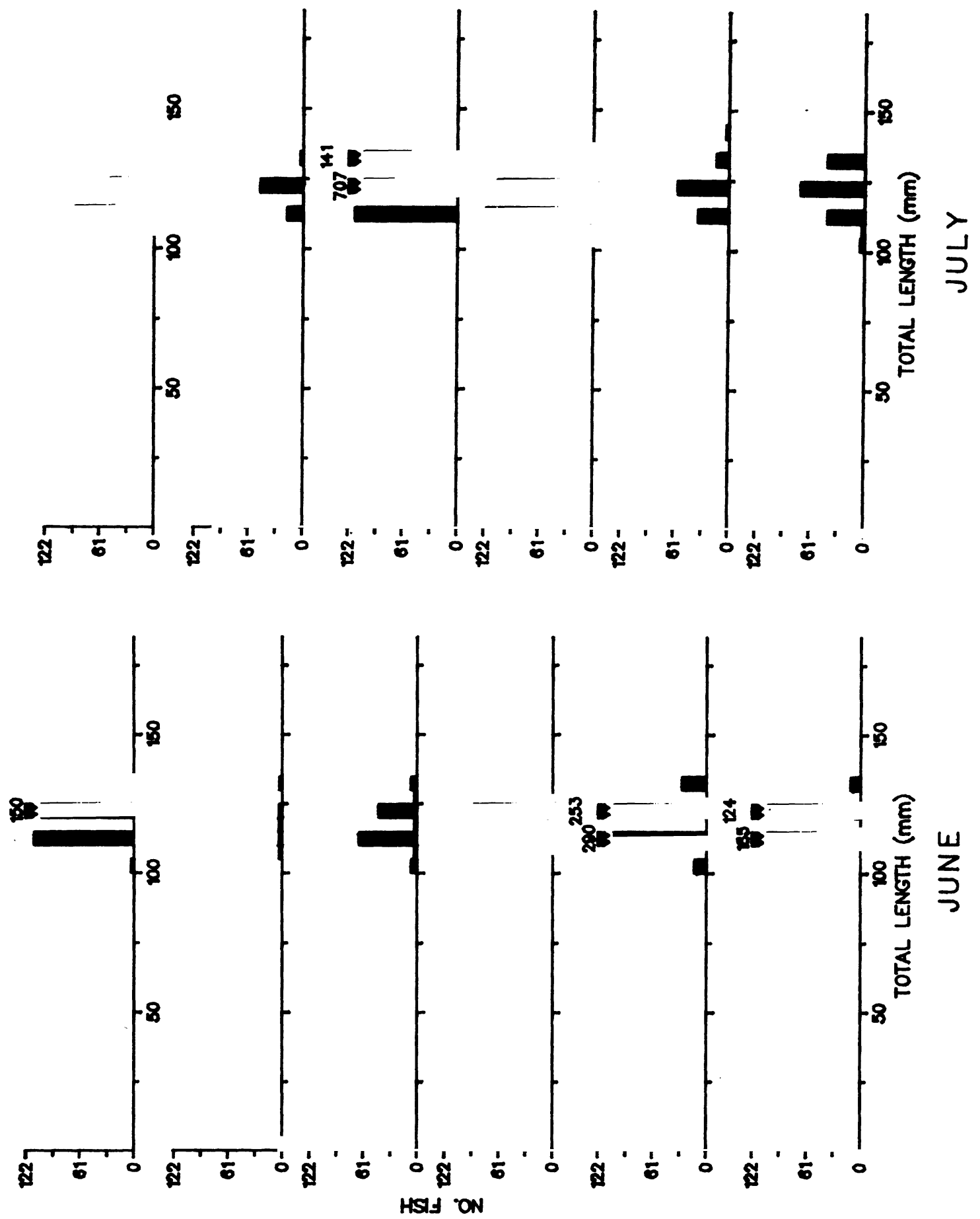

Ð

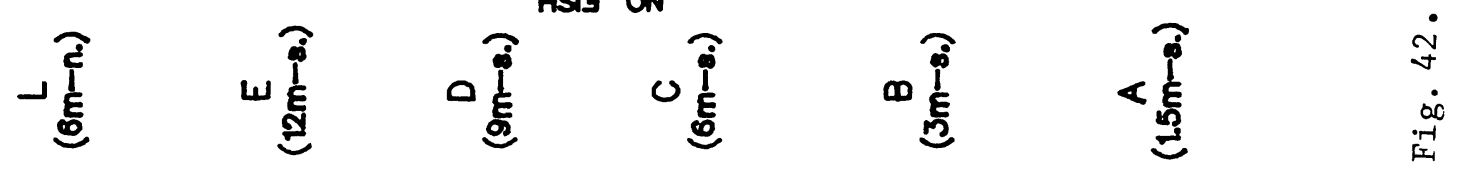



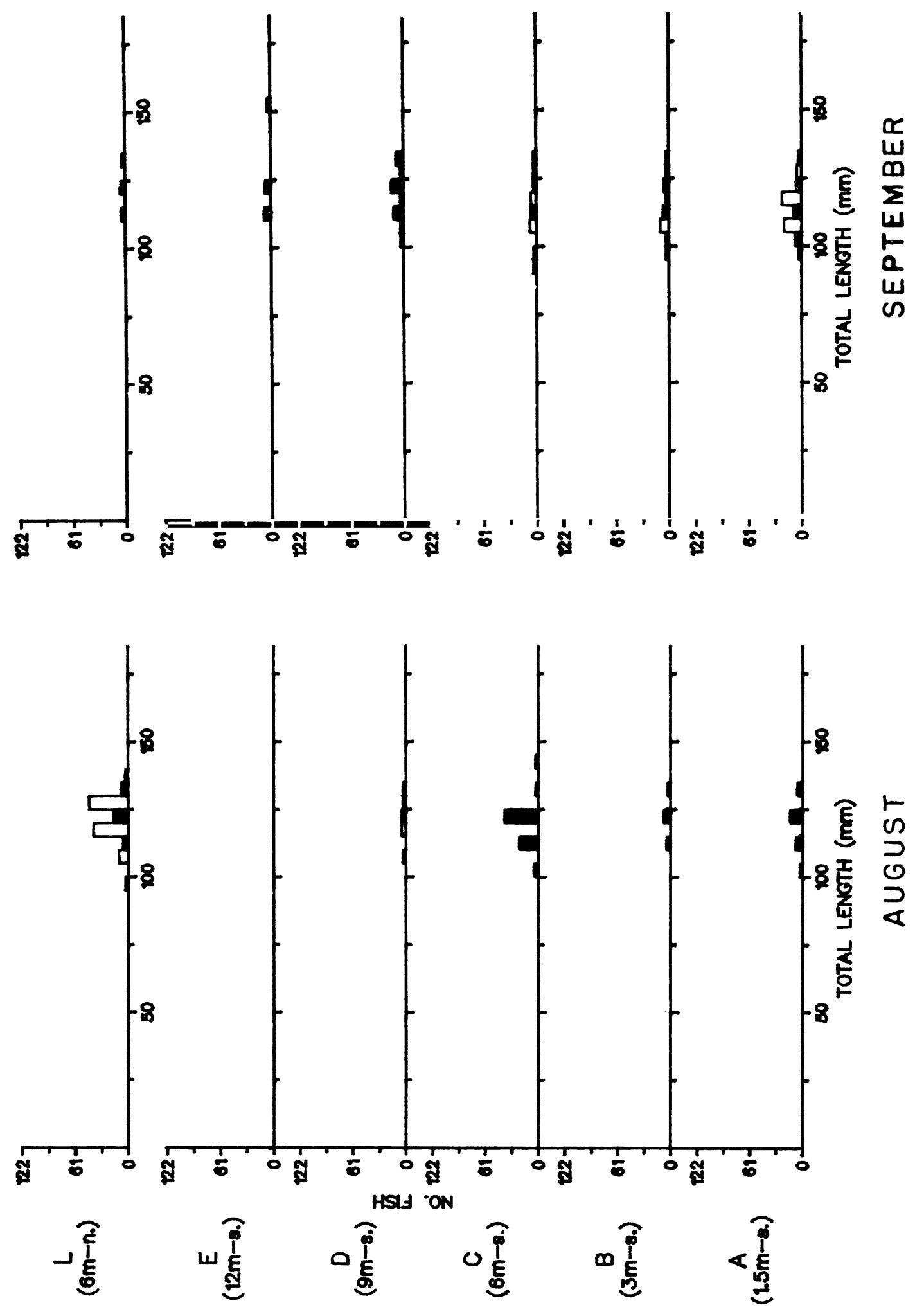

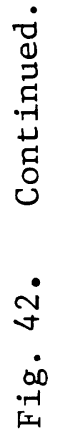



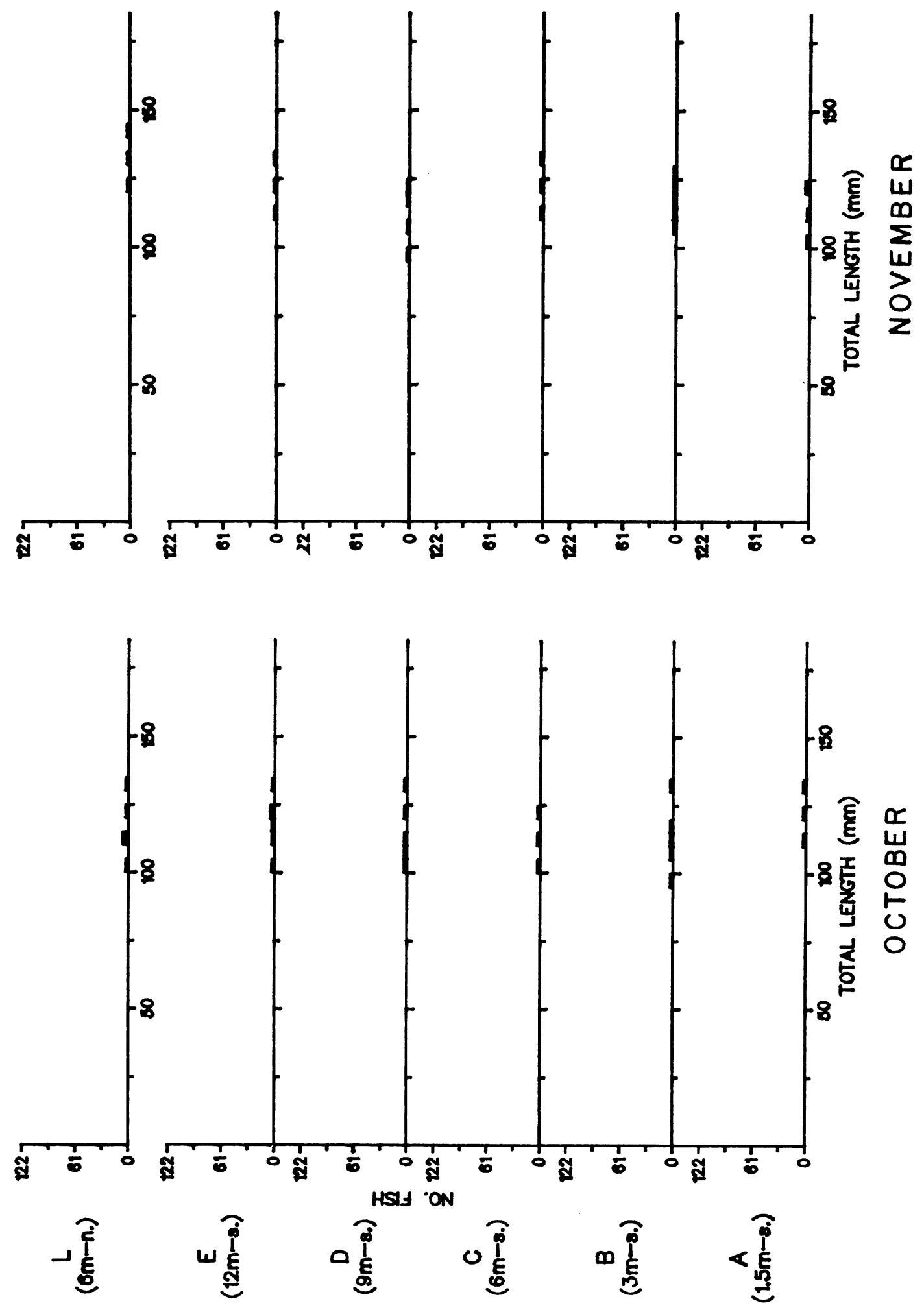

ن 

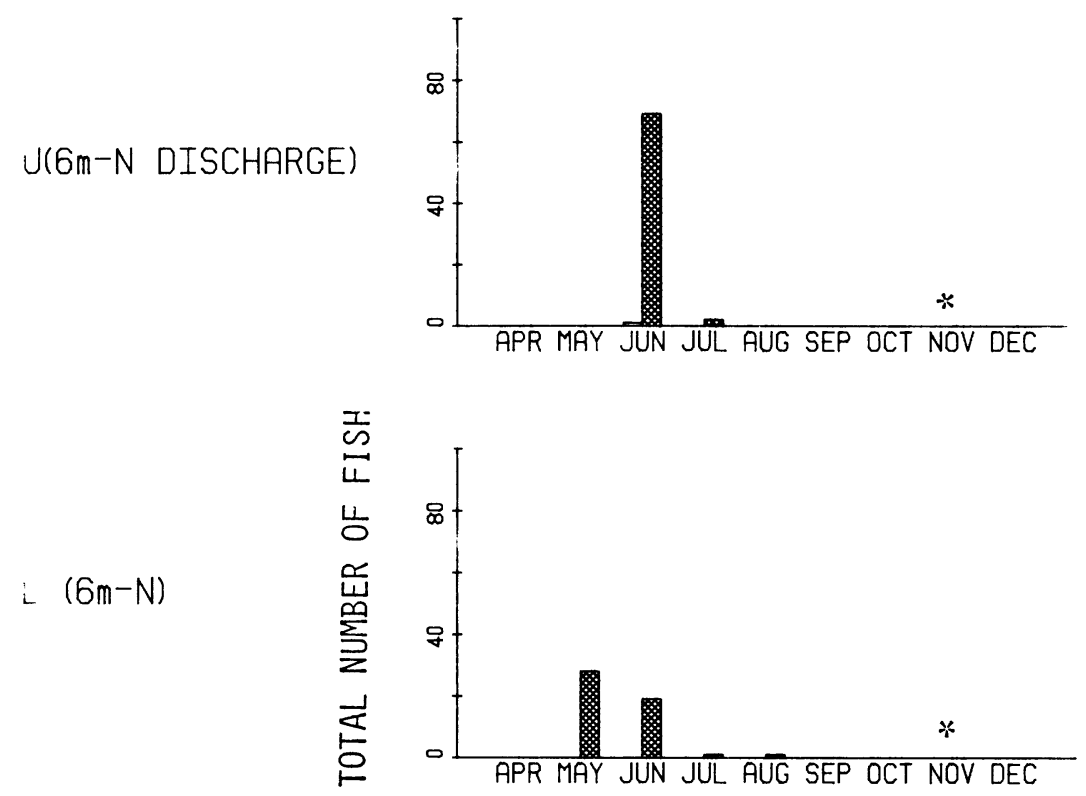

C $(6 m-5)$

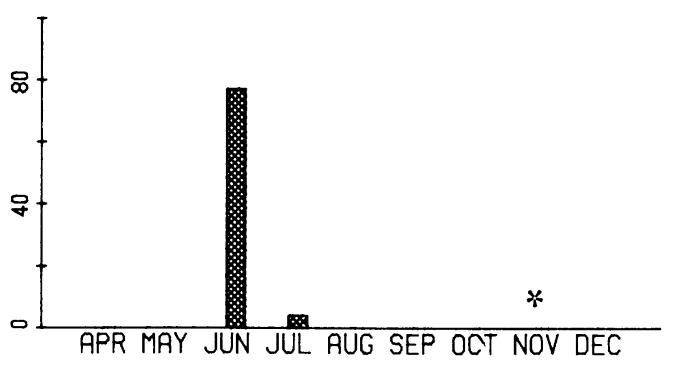

Fig. 43. Total number of spottail shiners caught in duplicate surface gill nets fished during day and night once per month April to November 1978 in Lake Michigan near the J. H. Campbell Plant, eastern Lake Michigan. $\square=$ day $\square=$ night $\star=$ no night sampling performed 
surface is an unusual behavior for this species. It is described as a benthic minnow by Scott and Crossman (1973), Wells and House (1974) and Anderson and Brazo (1978). It is not known for certain why spottails were caught at the surface, but spawning, feeding or avoidance behavior are some explanations. At the Cook Plant in southeastern Lake Michigan, SCUBA divers observed spottails spawning on the intake structure $4.5 \mathrm{~m}$ above the bottom in $9 \mathrm{~m}$ of water (Jude et al. 1975). Nursall (1973) observed spottails feeding at the surface in a northern Alberta lake, particularly when it was calm. Spottails have been collected occasionally in midwater trawls at night in Lake Erie (unpublished data, Great Lakes Fishery Laboratory).

Catch of spottails in Pigeon Lake (Figs. 41 and 44) increased significantly from April (28) to May (184). All but six fish, which were gillnetted at station $M$ (Lake Michigan influenced), were collected by seining. As water temperature increased spottails moved into the shallow beach zones. At beach station $S$ (Lake Michigan influenced) 74 spottails were caught (Fig. 41); most were yearlings $50 \mathrm{~mm}$ or less in length. At undisturbed Pigeon Lake beach station V, 104 spottails were collected, the majority of which were also yearlings. In contrast to Lake Michigan catches numbers of fish caught at both Pigeon Lake beach stations were equally divided between night and day. The large amount of vegetation at these stations may reduce net avoidance during the day and produce larger catches.

June--In contrast to last year's study (Jude et al. 1978) when 559 spottails were caught during June in Lake Michigan, 3083 were taken from Lake Michigan in June 1978 (Appendix 6). Night gill nets set during June 1978, which were not set in June of the 1977 study, accounted for 1607 spottails (Fig. 40). These additional sets accounted for most of the increased 1978 catch.

Beach seines (Fig. 38) accounted for 1284 spottails, 968 of which were caught at beach station $\mathrm{R}$ (N discharge). This station accounted for most of the June catch in our 1977 study (Jude et a1. 1978). There was an almost equal day/night distribution of spottails at beach station $\mathrm{R}$ (N discharge); 481 were caught during the day and 487 at night. Temperatures during day seining in June were $15.0 \mathrm{C}$ at beach station $\mathrm{P}$ (S reference), $21.0 \mathrm{C}$ at $\mathrm{Q}$ and $21.7 \mathrm{C}$ at $\mathrm{R}$ (discharge stations). The large catch at beach station $\mathrm{R}$ (N discharge) could be due to the warmer water at this station. Jude et al. $(1978,1979)$ and Wells (1968) have shown that spottails preferred the warmest water available in Lake Michigan. Day catches at beach stations $P$ (S reference) and Q (S discharge) were small, 8 and 9 respectively in contrast to night catches of 156 and 107, possibly due to net avoidance. A similar pattern was observed during our 1977 study (Jude et a1. 1978) and by Scott and Crossman (1973). All sizes of juvenile and adult spottails (35-145 mm) were caught in June seine hauls, with the majority being 45 to $115 \mathrm{~mm}$ (Fig. 36). In southeastern Lake Michigan, juveniles appeared to associate with adult spottails in their temporal and spatial ranging (Jude et a1. 1975).

Bottom gill nets accounted for 1454 spottails during June, al1 but 12 were collected at night. Almost all fish (91\%) were caught in $6 \mathrm{~m}$ of water or less. Stations A $(1.5 \mathrm{~m}-\mathrm{S})$ and $\mathrm{B}(3 \mathrm{~m}-\mathrm{S})$ had the largest gill net catches with 

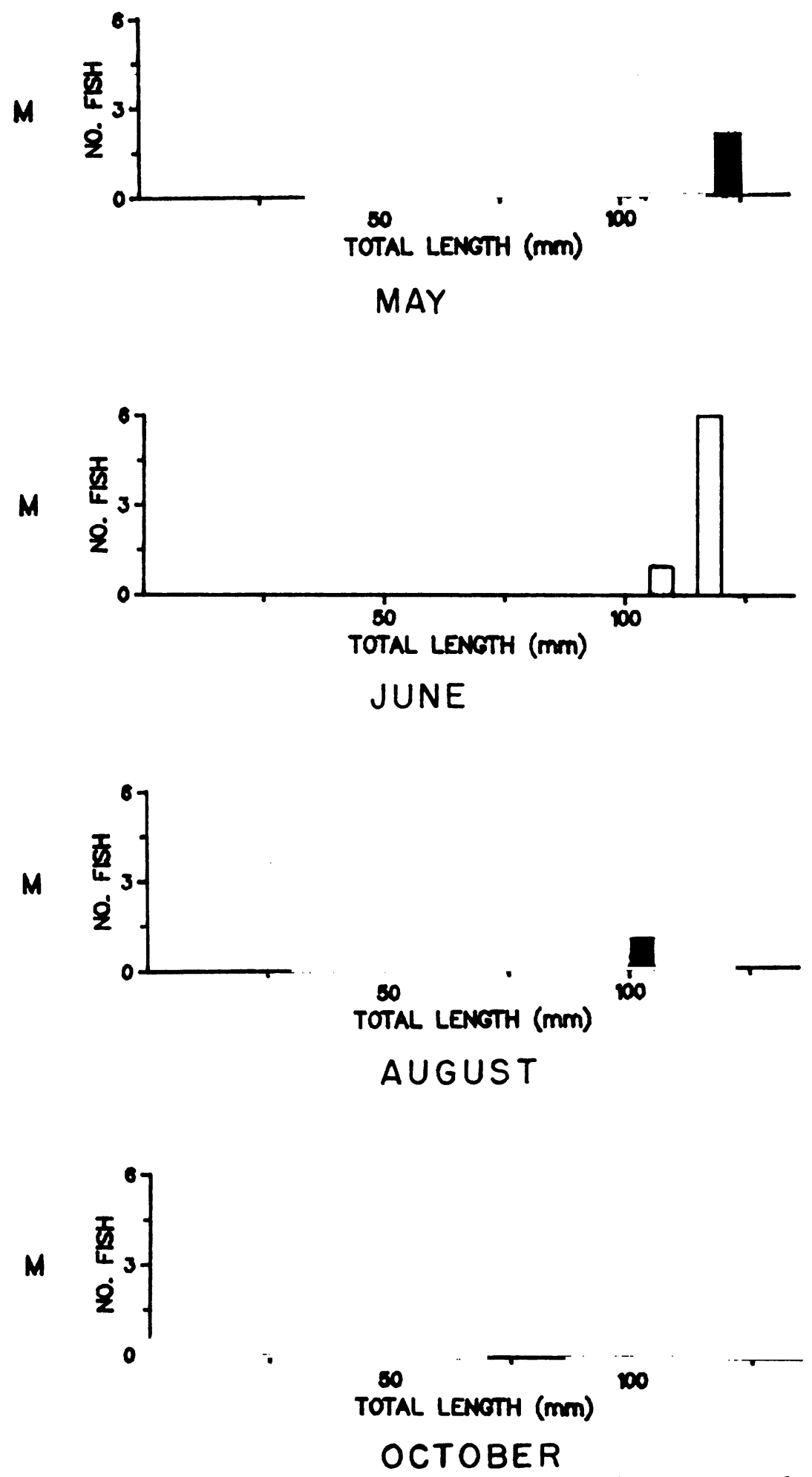

Fig.44. Length-frequency histograms for spottail shiners caught in duplicate bottom gill nets during April to December 1978 in Pigeon Lake near the J.H. Campbell Plant, eastern Lake Michigan. $\square=$ day $\square=$ night 
320 and 585 respectively; all fish, 105-135 mm, were caught at night (Fig. 42). This high concentration of adult fish at stations $A$ and $B$ in June was probably the result of spawning activity. Gonad development data (Table 27) indicated that spawning occurred from May through August and the highest concentrations of spottail larvae were collected in July from Lake Michigan (see RESULTS AND DISCUSSION - FISH LARVAE AND ENTRAINMENT STUDY, Spottail Shiner). Examination of larval data also indicated that there was considerable spawning in June.

June trawl catches (Fig. 39) demonstrated a pattern of distribution similar to that shown by bottom gill net data; $82 \%$ ( $179 \mathrm{fish}$ ) of the spottails caught in bottom trawls in June were caught in $6 \mathrm{~m}$ of water or less; south transect stations $\mathrm{B}(3 \mathrm{~m})$ and $\mathrm{C}(6 \mathrm{~m})$ accounted for 85 and 46 spottails, while north transect station $\mathrm{L}(6 \mathrm{~m})$ accounted for 48 spottails. The size range of trawled spottails was $35-130 \mathrm{~mm}$ with most being in the $80-130 \mathrm{~mm}$ size range (Fig. 37). As with bottom gill net catch, almost all trawled spottails were collected at night.

Spottail shiners were caught in surface gill nets at all three stations (Fig. 45); 77 were caught at $6-\mathrm{m}$ south transect station $\mathrm{C}, 19$ at $6-\mathrm{m}$ south discharge station $\mathrm{L}$ and 70 at $6-\mathrm{m}$ north discharge station $U$. All but one were caught at night; size range was $105-135 \mathrm{~mm}$.

In contrast to 1977 when no spottails were collected during June in Pigeon Lake, 79 were caught during June 1978. Most fish (67) were seined at Lake Michigan influenced beach station S; 5 were caught at Pigeon Lake undisturbed station $\mathrm{V}$ and 7 were gillnetted during the day at Lake Michigan influenced, 6-m station M. Size range of fish caught in seines was $25-115 \mathrm{~mm}$ with most between 45-55 mm. Gonad development data (Table 28) coupled with occurrence of large concentrations of spottail larvae (see RESULTS AND DISCUSSION - FISH LARVAE AND ENTRAINMENT STUDY, Spottail Shiner) in Pigeon Lake in early July suggest that spawning was occurring during June in Pigeon Lake.

July--Peak abundance of spottail shiners in Lake Michigan collections occurred in July with a catch of $4222 \mathrm{fish}$. Beach seines caught $2495 \mathrm{fish}$, bottom gill nets 1718, surface gill nets caught 7 , and 2 were collected in bottom trawls.

Day seine catches of spottails ranged from 1 at south reference beach station $P$ to 481 at north discharge station $R$ and 1725 at south discharge station Q. Respective water temperatures at these stations were $16.0,18.0$ and $19.0 \mathrm{C}$. The large differences in seine catches between the north and south transects is most likely due to the warmer water at north transect beach stations $Q$ and $R$.

Night seine catches (Fig. 36) were minimal with the exception of south discharge station $\mathrm{R}$ where 487 were collected. This station had the warmest water temperature $(15 \mathrm{C})$ of the three beach stations at night, once again demonstrating the selection by spottail shiners of the warmest water available. 

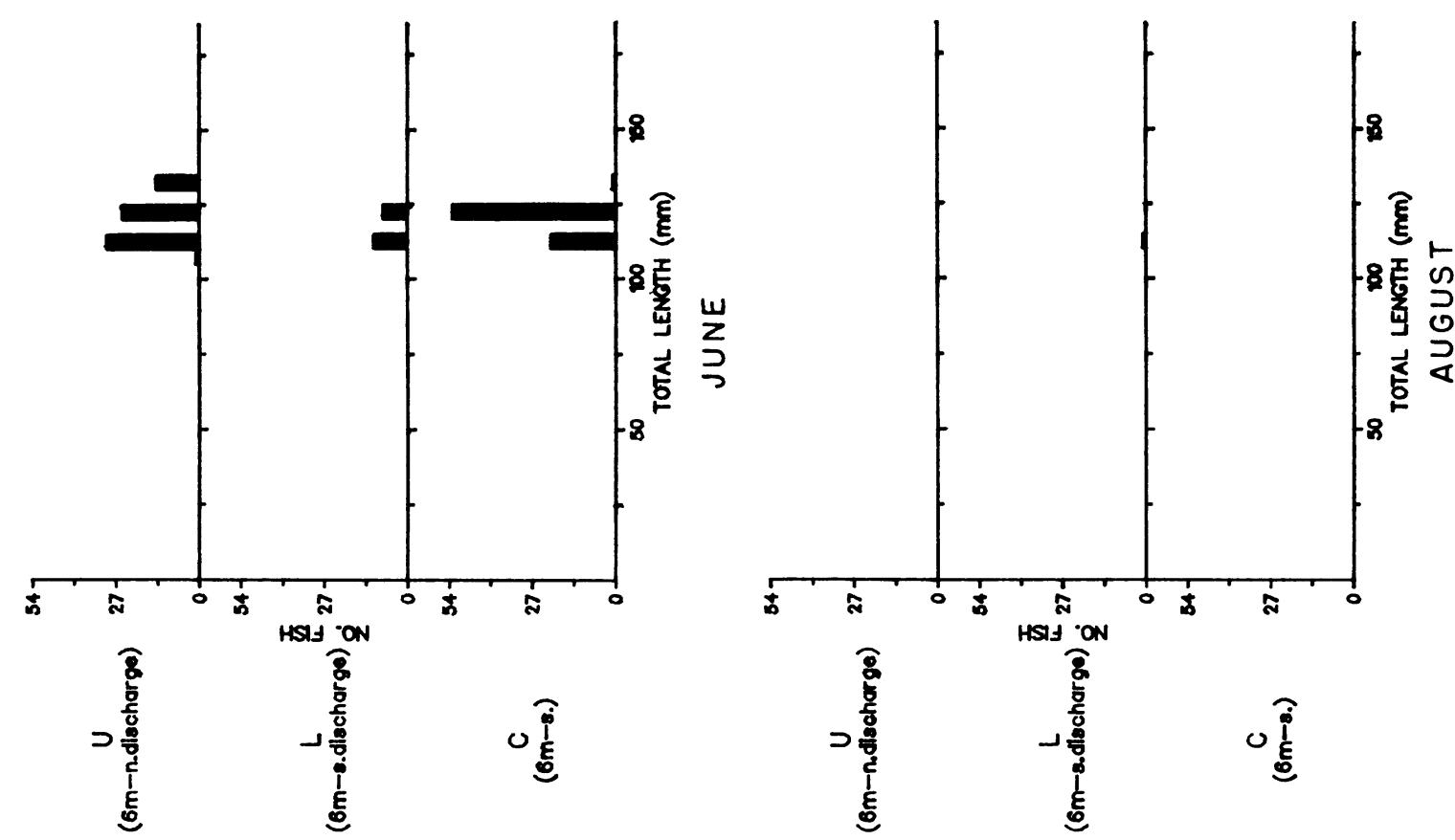

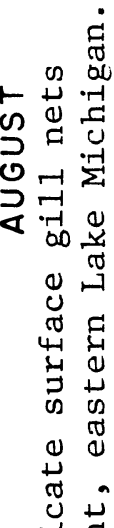

담

त

감

䓌会

ป

$\infty$ 疒

峁

党
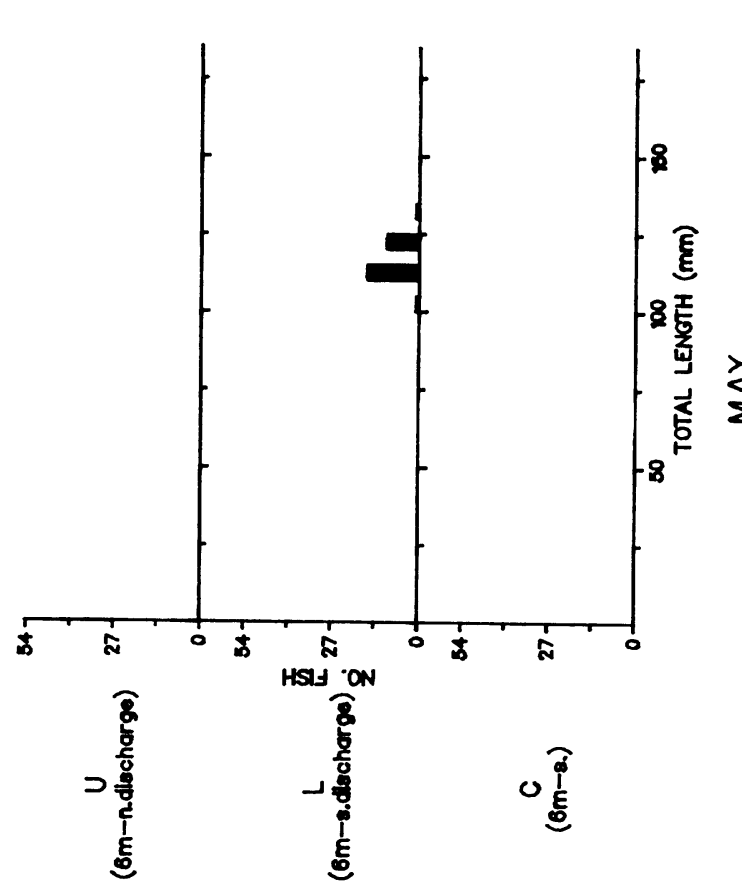

O

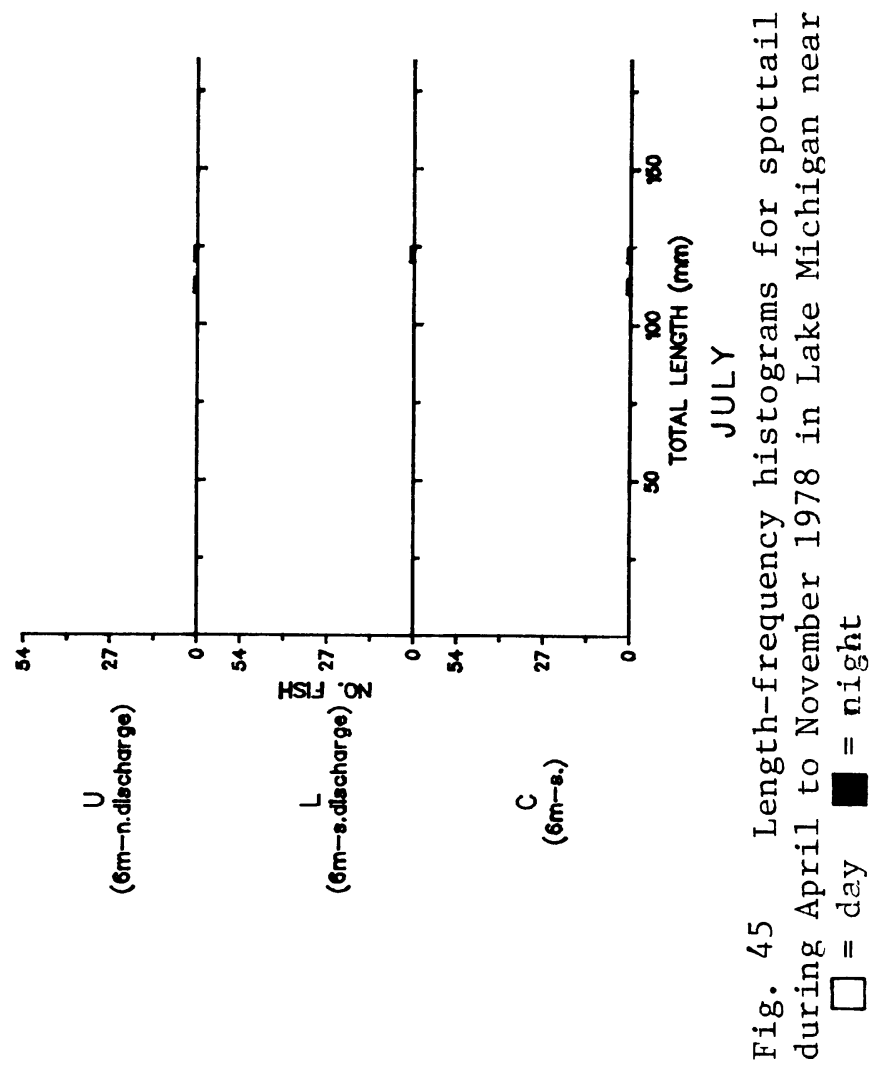


Table 28. Monthly gonad conditions of spottail shiners caught during 1978 in Pigeon Lake near the J. H. Campbell Plant, eastern Lake Michigan. All fish examined in a month were included except poorly received specimens.

\begin{tabular}{|c|c|c|c|c|c|c|c|c|c|c|}
\hline & Gonad condition & Apr & May & Jun & Jul & Aug & Sep & Oct & Nov & Dec \\
\hline Males & $\begin{array}{l}\text { S1ight development } \\
\text { Mod. development } \\
\text { We11 developed } \\
\text { Ripe-running } \\
\text { Spent }\end{array}$ & $\begin{array}{l}5 \\
1\end{array}$ & $\begin{array}{r}22 \\
2 \\
1\end{array}$ & $\begin{array}{l}4 \\
7\end{array}$ & 1 & $\begin{array}{l}1 \\
1 \\
1\end{array}$ & & & 2 & \\
\hline Females & $\begin{array}{l}\text { Slight development } \\
\text { Mod. development } \\
\text { We11 developed } \\
\text { Ripe-running } \\
\text { Spent } \\
\text { Absorbing }\end{array}$ & $\begin{array}{l}2 \\
1\end{array}$ & $\begin{array}{r}6 \\
7 \\
13\end{array}$ & $\begin{array}{r}1 \\
2 \\
25 \\
2 \\
1\end{array}$ & & 2 & & $\begin{array}{l}1 \\
1\end{array}$ & 1 & \\
\hline Immature & & 16 & 87 & 28 & 41 & 25 & 108 & 100 & 40 & \\
\hline Unable $t$ & o distinguish & 3 & 77 & 12 & 6 & 7 & 2 & 1 & & \\
\hline
\end{tabular}

Gill net and trawl data (Fig. 39-40) suggested that spottails were concentrated in the beach zone during the day. Only one spottail was collected in day gill nets and none were trawled during the day; net avoidance may have been partly responsible for the small day catch. An upwelling occurred on $17 \mathrm{July}$ when day gillnetting and trawling were performed. In response to this influx of cooler water, spottails remained in the area of the plant discharge. The warmer discharge water of beach stations Q (S discharge) and $R$ ( $N$ discharge) probably served as a refuge area for these fish during the upwelling. All but two of the fish caught during day seining (2109) in July were taken from stations $Q$ and $R$ where water temperatures were $10 \mathrm{C}$ warmer than any of the other stations.

The largest July night catch of spottails (963 fish) was taken in bottom gill nets at south reference station D $(9 \mathrm{~m})$; these fish were all large adults 105-135 mm (Fig. 42). Lesser numbers of smaller spottails (95-120 mm) were taken at south transect stations A $(1.5 \mathrm{~m})$ and $B(3 \mathrm{~m})$. Wells (1968) found that larger spottails in Lake Michigan (near Saugatuck, Michigan) tended to be at the deeper end of the spottail concentration throughout the year. About $80 \%$ of the spottails we gillnetted in July were in 6 or $9 \mathrm{~m}$ of water and were larger than the fish caught at shallower stations (Fig. 42). Only two spottails were trawled in July and seven were taken in surface gill nets. There were no spottails taken in June from either trawls or surface gill nets during 
our 1977 study (Jude et al. 1978).

Occurrence of ripe-running fish (Table 27) indicated that some spawning occurred in July. Large concentrations of larval spottails (see RESULTS AND DISCUSSION - FISH LARVAE AND ENTRAINMENT STUDY) were collected in August suggesting that July was the month of maximum spawning activity.

In contrast to Lake Michigan seine hauls where alı sizes of juvenile and adult spottails were collected (Fig. 41), in Pigeon Lake mostly sma11 20-25 mm fish, believed to be YOY, were seined at Lake Michigan influenced station S. Station S was a preferred habitat for YOY spottails in 1977 (Jude et a1. 1978). Presence of these YOY fish suggest that spottails may have spawned during May 1978 in Pigeon Lake. Spottails also spawned in Pigeon Lake during May of 1977 (Jude et a1. 1978). The common pattern of many species of fish spawning first in Pigeon Lake, then later in Lake Michigan, was confirmed for spottail shiners.

August--Large numbers (3471 fish) of spottail shiners were also collected in August; a total catch second only to July (4222) was recorded (Appendix 6). As was the case in June and July, the greatest numbers of fish were collected in beach seines.

Although all sizes $(20-145 \mathrm{~mm})$ of spottails were caught in August seine hauls, the majority (76\%) were small fish between 20 and $85 \mathrm{~mm}$ (Fig. 36, 41). Wells and House (1975) noted that in Lakes Erie and Michigan, spottails preferred shallow, warm water and that smaller fish tended to inhabit shallower water than larger fish. Our gill net and trawl data (Figs. 42 and 39) indicated that most larger fish were found in deeper water.

As in July, the bulk of fish collected in beach seines were caught during the day. Day catches at stations $P$ (S reference) and south discharge station $Q$ were quite similar with 1126 and 1054 collected respectively; only 53 fish were caught at north discharge station $\mathrm{R}$ during the day. Water temperatures at beach stations during the day were $23.0 \mathrm{C}$ at reference station $P, 25.3 \mathrm{C}$ at $\mathrm{Q}$ and 25.7 at $\mathrm{R}$.

Night seine catches were low in comparison to day seine hauls; 255 were caught at north discharge station $R, 156$ at south reference station $P$ and 49 at south discharge station $Q$. The diel catch difference for seine hauls in July and August suggested a movement by spottails during the night from the beach zone to deeper water. Anderson and Brazo (1978) noted that spottails in east-central Lake Michigan occurred in the surge-zone in greatest numbers just before sunset. It seems plausible that these fish were heavily concentrated in the beach zone during the day and when feeding was finished at dusk, they moved just out of the beach zone to the 1.5-2-m area. Price (1963) found that spottails in Lake Erie fed mostly in the morning with feeding activity decreasing through the day. Bottom gill net and trawl data (Fig. 37-42) showed larger spottails present at 1.5 and $3 \mathrm{~m}$; however, small fish were most likely between the beach zone and $3 \mathrm{~m}$ at night in July and August. Our gillnets only sample adult spottails effectively. 
Drastic differences occurred between bottom gill net catches of July and August. Only 262 fish were caught in bottom gill nets in August in contrast to 1718 in July. Water temperatures were very warm in August; ranging from $25.7 \mathrm{C}$ in the beach zone to $21.1 \mathrm{C}$ at $6 \mathrm{~m}$. Because of this broad zone of warm water spottails may have been moving parallel to shore through the warm water and thereby avoiding our gill nets which were set parallel to shore. Almost all (92) spottails caught in gill nets during August were caught at night in $6 \mathrm{~m}$ of water or less (Appendix 7).

Traw1 data (Fig. 39) also indicated that spottails were distributed throughout the warm-water zone in August; $96 \%$ of trawled fish were taken from $6 \mathrm{~m}$ or less; most were caught at $6 \mathrm{~m}$ where water temperature was $21 \mathrm{C}$. Adults, mostly $85-125 \mathrm{~mm}$, were caught in the trawls (Fig. 37). Wells and House (1974) indicated that spottails caught in the deeper water of Lake Michigan were larger and older than fish caught from shallower areas.

In August smaller spottails were in the shallow beach zone while larger fish were in deeper water out to $6 \mathrm{~m}$. Some spawning activity also occurred in August as evidenced by the presence of a ripe-running female. Thus, in Lake Michigan spawning took place from May through August 1978.

During August 66 spottails were collected in Pigeon Lake (Figs. 41 and 44). Most (47) were seined at night with the largest catch at undisturbed Pigeon Lake station $\mathrm{V}$; five adults were gillnetted at $6-\mathrm{m}$ station $\mathrm{M}$. The catch at Lake Michigan influenced station $S$ was made up of YOY and juvenile fish (Fig. 41).

September--Moderate numbers of spottails (986 fish) were caught in Lake Michigan in September, which was a substantial decline in catch from June, July and August when 3083, 4222 and 3471 were caught. This decline may have been the result of the spottail annual fall migration to deeper water. We11s (1968) documented the movement of spottails into deeper water in October in southeastern Lake Michigan. Anderson and Brazo (1978) found peak numbers of spottails in June in east-central Lake Michigan (near Ludington, Michigan) and a sharp decrease in September. The initial stages of this migration were probably occurring in September 1978 in the vicinity of the Campbell Plant.

Bottom trawl collections, which accounted for $64 \%$ of the September catch, suggested a random distribution of fish throughout the study area. Largest catches occurred at $6-\mathrm{m}$ north station $\mathrm{L}$ (284 $\mathrm{fish}$ ) and $3-\mathrm{m}$ south station $\mathrm{B}$ (246 fish). Water temperatures of 20.4 and $21.5 \mathrm{C}$ at 3 and $6 \mathrm{~m}$ were the warmest in the area trawled (Appendix 3) again demonstrating the selection by spottails of the warmest available water. Most fish caught in trawls during September were YOY and yearlings, 35-105 mm (Fig. 37). Price (1963) noted that spottails in western Lake Erie grew to $80 \mathrm{~mm}$ in their first year. Jude et a1. (1979) found the YOY from southeastern Lake Michigan were $30-60 \mathrm{~mm}$ in September 1974. Because of the early occurrence of spawning in 1978 compared to other years, spottails reached $70-90 \mathrm{~mm}$ by late September when trawling was performed.

Beach seine hauls clearly demonstrated that adult spottails had vacated 
the beach zone in September. On1y $213 \mathrm{fish}$ were seined in September; 98\% were YOY with a size range of $25-55 \mathrm{~mm}$ (Fig. 36). Most fish were caught during the day at north discharge station $\mathrm{R}$ (177 fish) when water temperature was $18.7 \mathrm{C}$. Concentrations of mostly YOY spottails were also caught in the beach zone during September 1977 (Jude et a1. 1978).

Bottom gill net data showed that adult spottails were at $6 \mathrm{~m}$ or less during the day. Largest catches were at 1.5 and $6 \mathrm{~m}$ (Fig. 42). At night spottails were scattered throughout the sampling area. The largest catch was taken at $12 \mathrm{~m} ; 14 \mathrm{fish}$ were caught at $15 \mathrm{~m}$ suggesting a nocturnal preference for deeper water by adults during september. Bottom gill net catches from September 1977 were very similar to the 1978 September catch (Jude et al. 1978).

A dramatic increase in catch of spottails over previous months occurred during September in Pigeon Lake (Figs. 38 and 41) where 986 spottails were caught. This was the largest catch of spottails for any month in Pigeon Lake and was due entirely to the appearance of large numbers of YOY fish, 25-55 mm (Fig. 41). All of these fish were collected from beach station $\mathrm{S}$ (influenced by Lake Michigan); 630 at night and 359 during the day. No spottails were seined at Pigeon Lake beach station V. Station $\mathrm{S}$ was found to be the preferred habitat of spottails in Pigeon Lake in 1977 (Jude et a1. 1978). The large number of YOY along with the large concentrations of spottail shiner larvae and fry (see RESULTS AND DISCUSSION - FISH LARVAE AND ENTRAINMENT STUDY, Spottail Shiner) collected at station $S$ indicate that it is also an important nursery area for this species.

October--Catch of spottails from Lake Michigan decreased considerably compared to September. October catch was $245 \mathrm{fish}$ while 1045 were caught in September. The migration to deeper water was nearing its completion in October. By 14 October, spottail shiners in southeastern Lake Michigan had migrated to water as deep as $21 \mathrm{~m}$ (We1ls 1968). Numbers of spottails caught also declined sharply during October (Jude et al. 1978). A similar offshore migration in the fall was documented by Jude et al. (1979) in the vicinity of the Cook Plant.

Bottom trawls accounted for the largest catch among gear types in October (173 fish); most were caught at night. During the day the majority of fish were probably in deep water outside our sampling area. There was a mixture of YOY and adult fish in trawl catches; fish ranged from 35 to $125 \mathrm{~mm}$ with about equal numbers of YOY and adult fish (Fig. 37). Almost $80 \%$ of the fish caught in trawls came from $6 \mathrm{~m}$ or deeper.

Spottails were nearly absent from the Lake Michigan beach zone in October. Only $19 \mathrm{fish}$, all YOY or yearlings, were caught in seine hauls (Fig. 36).

Modest numbers of spottails (53 fish) were caught mostly at night in bottom gill nets set in October. The majority (83\%) of the gill net catch was taken from $6 \mathrm{~m}$ or more.

In Pigeon Lake, large numbers of YOY spottails (603) were collected at 
beach station $\mathrm{S}$ in October (Fig. 41). Fish seined at station $\mathrm{S}$ were 20-45 mm; none were caught at station V. Because of net avoidance night catches (441) were greater than day catches (162).

November and December--Catches of spottails declined with the approach of winter. In November 142 were collected while 103 were taken in December when trawling was the only sampling performed. The distribution of fish in November was similar to that observed in October. Very few fish were caught in beach seines (Fig. 38), while traw1 and bottom gill net data indicated that most fish had moved to deeper water; $57 \%$ of the traw1 and gill net catch was taken from stations $9 \mathrm{~m}$ or deeper (Figs. 39 and 40). December traw1 data indicated that spottails were concentrated at $12 \mathrm{~m}$ or more, where $70 \%$ of the catch was taken. Although all sizes of YOY and adults $(35-125 \mathrm{~mm})$ were caught in Lake Michigan during November and December, most were YOY from 25-50 $\mathrm{mm}$ suggesting that YOY fish were the last to migrate into deeper water.

Moderate numbers of YOY spottails (size range $25-50 \mathrm{~mm}$ ) were seined in Pigeon Lake during November. A11 were caught at station S suggesting that they had not yet moved into deeper water. Occurrence of YOY in field and impingement samples (see RESULTS AND DISCUSSION - IMPINGEMENT STUDY, Spottail Shiner) during late fall, when the Lake Michigan spottail population was far offshore suggests that there is a resident population of spottails in Pigeon Lake. Impingement data from the Campbel1 Plant during 1974-1975 (Consumers Power Company 1975) and 1977 (Zeitoun et a1. 1978) showed that spottail shiners were present in Pigeon Lake during all fall and winter months.

Temperature-catch relationships--YOY and yearling spottails preferred warmer water than older adults in both Lake Michigan and Pigeon Lake (Fig. 46). Wells and House (1974) indicated that larger and older spottails preferred deeper and cooler water than smaller and younger spottails. In our 1977 study (Jude et al. 1978) similar correlations between temperature and size of spottails collected were observed in Pigeon Lake and Lake Michigan.

Nearly $81 \%$ of the spottails caught in Lake Michigan were collected at a temperature of 15-23 C. Jude et a1. (1975, 1979) collected the majority of their spottails at 16-22 C and 11-17 C. Our field sampling data for 1978 indicated that spottail shiners usually selected the warmest water available to them.

Plant impacts--Spottail shiners, like most cyprinids, have a relatively short life span, produce large quantities of eggs and as a result, sometimes produce large year classes. As a consequence, in certain years, a large number of larvae are produced and sometimes entrained. Similarly, large numbers of adults are impinged. Spottails are one of the less important fish according to the standards of man since they are seldom preyed on by the piscivores of Lake Michigan. In addition, they are not a sport fish, but are necessary links in the food web of Pigeon Lake and Lake Michigan. During 1978, 23,740 spottail larvae were entrained, which is probably an underestimate, since many of the unidentified cyprinids entrained could have been spottails. In addition, 5,673 juveniles and adults were impinged. To date, our 1977 and 1978 

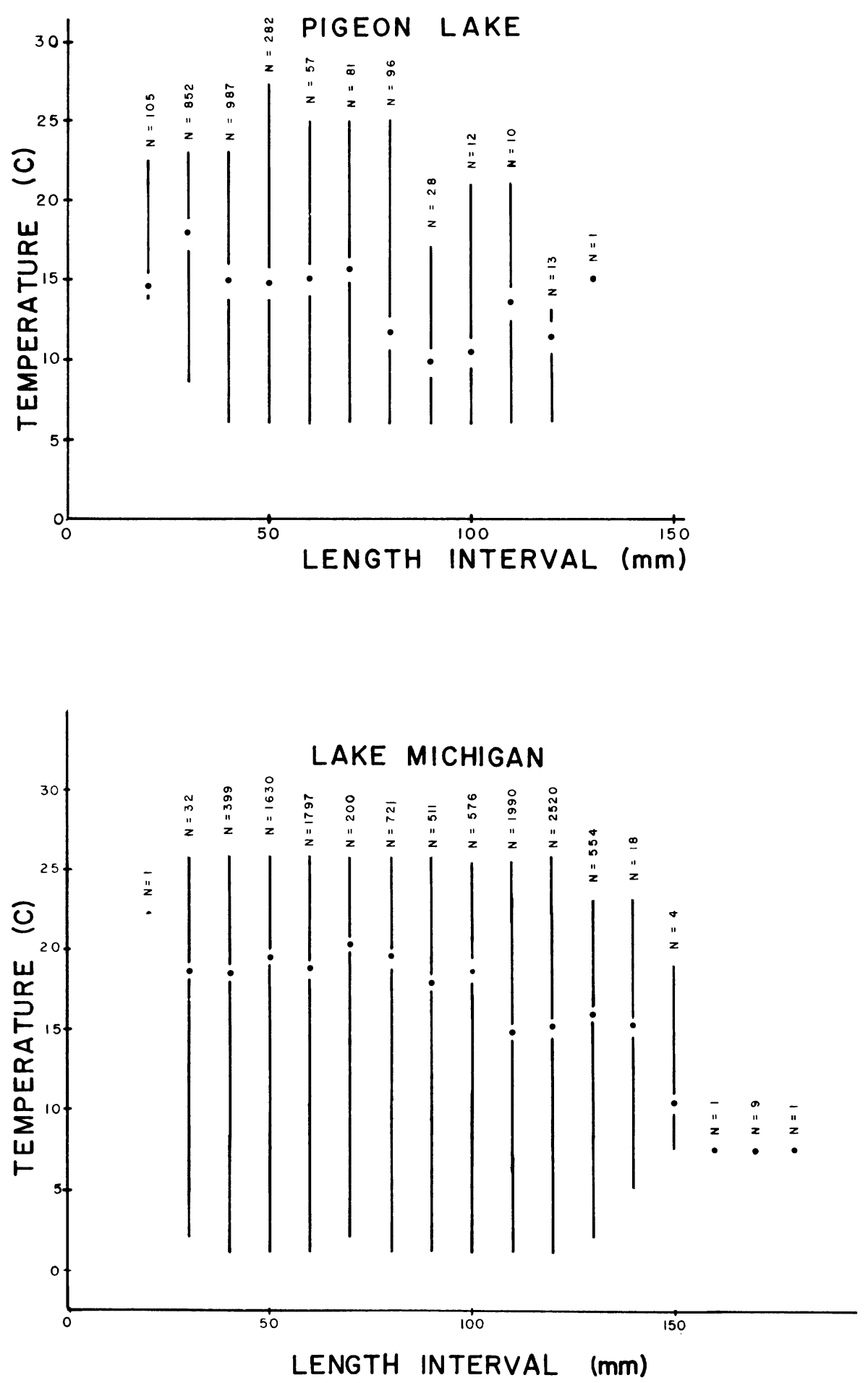

Fig. 46 Weighted-mean water temperatures at which various sizes (10-mm length groups) of spottail shiners were collected by all gear types from Lake Michigan and Pigeon Lake near the J. H. Campbel1 Plant, eastern Lake Michigan, 1978. Vertical bars represent the range, $\mathrm{N}=$ number of $\mathrm{fish}$. 
studies have shown that populations in Lake Michigan stayed about the same in 1978 and 1977 or maybe even increased. In Pigeon Lake, catches were lower in 1978, but deletion and changes in station location plus the habitat perturbation in Pigeon Lake caused by the mooring and moving of barges associated with construction of the intake and discharge structure were most likely the cause, rather than any effects of plant operation. Any assessment is occluded by the uniqueness of the Lake Michigan-Pigeon Lake ecosystem. Source of entrained larvae and impinged fish could be Lake Michigan or Pigeon Lake. In addition, any depletion in populations of certain species in Pigeon Lake would either be replenished from immigrants from Lake Michigan or population shifts within the lake, making precise statements of effect difficult. However, to date, with the data we have, no great changes in spottail populations have been documented.

Summary--Spottail shiners were the most abundant species caught in Pigeon Lake (24\% of total catch) and third most abundant in Lake Michigan ( $14 \%$ of total catch). During May in Lake Michigan large adults moved inshore to spawn; spawning activity continued into August. Spawning occurred in May and June in Pigeon Lake.

Peak abundance of spottails in Lake Michigan occurred during July and August. Larger fish were concentrated at $6 \mathrm{~m}$ in June, 6 and $9 \mathrm{~m}$ in July, and 3 and $6 \mathrm{~m}$ in August. YOY and yearling fish were found in the beach zone during summer.

September was the month of peak occurrence of spottails in Pigeon Lake when large numbers of YOY were recruited to our gear; these fish remained abundant through November. We suspect there is a resident population of spottails in Pigeon Lake and that the west side serves as an important nursery area.

Numbers of spottails caught in Lake Michigan decreased sharply in September and continued to do so throughout the fall. With onset of the fall migration to offshore waters, spottails were nearly absent from the beach zone during October while the majority of spottails trawled in November and December were YOY concentrated at 9 and $12 \mathrm{~m}$.

YOY and yearling spottails were caught in shallower and warmer water than larger adult fish; most were caught at temperatures of 15-23 C. Spottails were not an important forage species in eastern Lake Michigan.

Unidentified Coregoninae--

Introduction--Difficulty in identifying species of the genus Coregonus, particularly individuals less than $180 \mathrm{~mm}$, was discussed by Jude et al. (1975, 1978). These authors felt most unidentified coregonids were probably bloaters, Coregonus hoyi, based on the works of Wells and Beeton (1963) and Baumgart and Schultz (1974), though some unidentified coregonids from Lake Michigan were suspected to be lake herring, C. artedii. Young-of-the-year in 1977 appeared in trawl hauls in October and November, indicating early spring hatching, which is characteristic of bloaters. Lake herring spawn in late November-December 
(Scott and Crossman 1973).

Growth--Data collected from both the J.H. Campbell and D.C. Cook

Power Plant studies indicate that two distinct year classes were present in Lake Michigan during 1978 (Fig. 47). From these data, it was deduced that coregonids caught in June, July and August 1978 were probably yearlings spawned in early 1977. The group of coregonids caught in October and November 1978 were more than likely YOY spawned in February and March 1978. Wells (1966) caught 8- to 15-mm bloater larvae from April to August 1964, with peak catches occurring in late June and early July. In Lake Michigan, bloaters were found to reach approximately $100 \mathrm{~mm}$ in their first year of life (Wells 1966). Dryer and Beil (1968) and Jobes (1949) found bloaters to reach 99 and $76 \mathrm{~mm}$ in their first year of life in Lake Superior and Lake Michigan, respectively.

From data collected at the J.H. Campbell Plant in 1978, it can be seen (Fig. 47) that coregonids caught in November and December, most likely YOY, averaged $83 \mathrm{~mm}(\mathrm{SE}=0.4, \mathrm{~N}=475)$ and $86 \mathrm{~mm}(\mathrm{SE}=2.3, \mathrm{~N}=18)$ respectively. Those fish caught in June, July and August (yearlings) averaged $166 \mathrm{~mm}$ (SE $=1.2$, $\mathrm{N}=203$ ) by August of their first year of life and could be projected to reach $175 \mathrm{~mm}$ or more by November. This information suggests a low growth rate for bloater young, a deep, cold-water species.

Seasonal distribution--Immature coregonids (bloaters) became the fourth most abundant species in the vicinity of the J.H. Campbell Plant in 1978, contributing $3.4 \%$ to the total fish catch for Lake Michigan (Table 13). From May through December 1978, 3121 bloaters were taken by seine $(0.1 \%)$, bottom gill nets $(0.4 \%)$ and traw1 (99.5\%) (Appendix 7 ). Unidentified coregoninae collected in 1978 ranged in length from 33 to $243 \mathrm{~mm}$. Only 7 of the 3121 coregonids were greater than $160 \mathrm{~mm}$. Twenty-nine of these coregonids were in good condition and determined to be mature; 7 were females and 22 were males. In 1977 only 461 bloaters were taken from June through December (Jude et a1. 1978). No adult or juvenile unidentified coregonids were collected from Pigeon Lake in either 1977 or 1978.

Two coregonid larvae were taken in June of 1978. These larvae were recovered in $8-\mathrm{m}$ plankton net tows; a $14.5-\mathrm{mm}$ specimen at station $\mathrm{F}$ (15 m-S) and an $11.0-\mathrm{mm}$ larvae at station $\mathrm{W}(15 \mathrm{~m}-\mathrm{N})$. Three other unidentified coregonid larvae, 11.2 to $14.2 \mathrm{~mm}$, were entrained during April and May 1978 (see RESULTS AND DISCUSSION - FISH LARVAE AND ENTRAINMENT STUDY, Unidentified Coregoninae).

Abundance of bloaters in the vicinity of the D.C. Cook Nuclear Power Plant also showed dramatic changes from 1977 to 1978. From 1973 to 1977, catches of unidentified coregonids in standard series sampling near the Cook Plant averaged $146 \mathrm{fish}$. In 1978 however, 1335 young bloaters were collected (unpublished data).

April, May--Immature coregonids were first captured in the study area during May. Five were trawled at night, all at Lake Michigan south transect stations D (9 m-S), E (12 m-S) and F (15 m-S) (Fig. 48). Water temperatures at time of capture were 6.0 to $6.5 \mathrm{C}$. Average length of these fish was $76 \mathrm{~mm}$ $(\mathrm{SE}=5.1, \mathrm{~N}=5)$, yet lengths ranged from 64 to $94 \mathrm{~mm}$. Since these young fish 

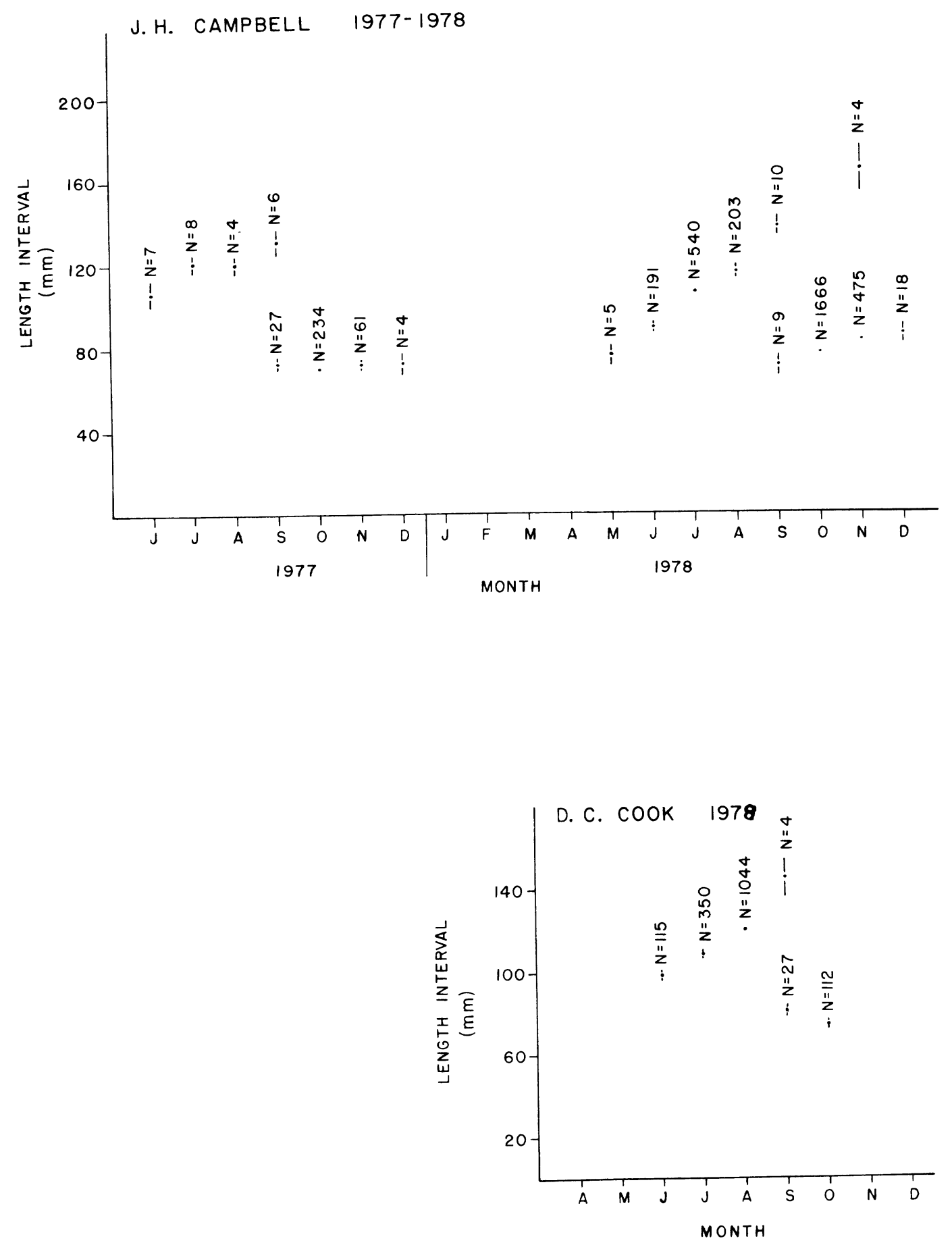

Fig. 47. Monthly average length of unidentified coregonids collected in all sampling gear types in the vicinity of the J. H. Campbel1 and D. C. Cook Plants during 1978 and the J. H. Campbell Plant in 1977. Bar indicates standard error, $N=$ number of observations. 

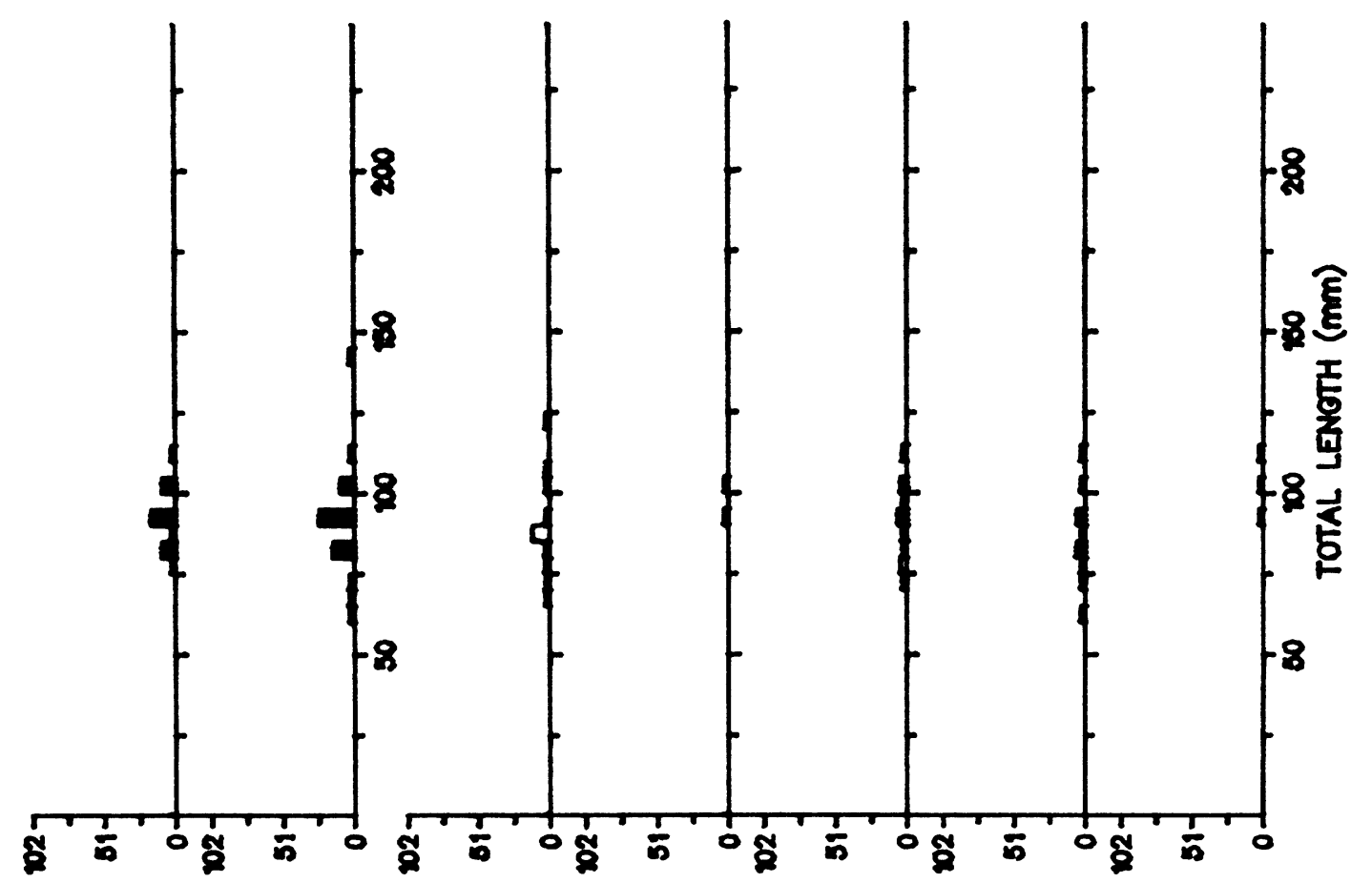

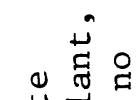
के II w. 닥 Z뭉요 ○ 引

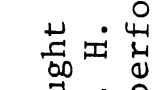

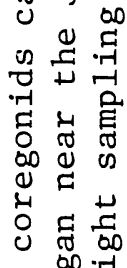
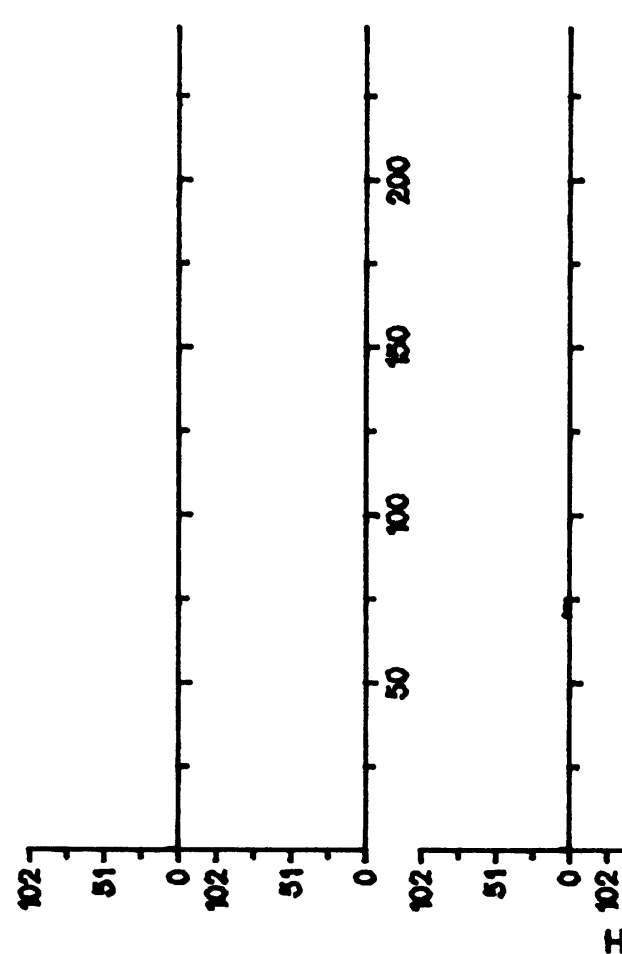

$z E_{E}^{\xi}-\frac{\xi}{d}$

ᄂ

แ $\frac{\text { है }}{\mathrm{N}}$

$0 \stackrel{\$}{E}$

$0 \overbrace{\tilde{0}}^{8}$

$m \overbrace{\tilde{D}}^{0}$

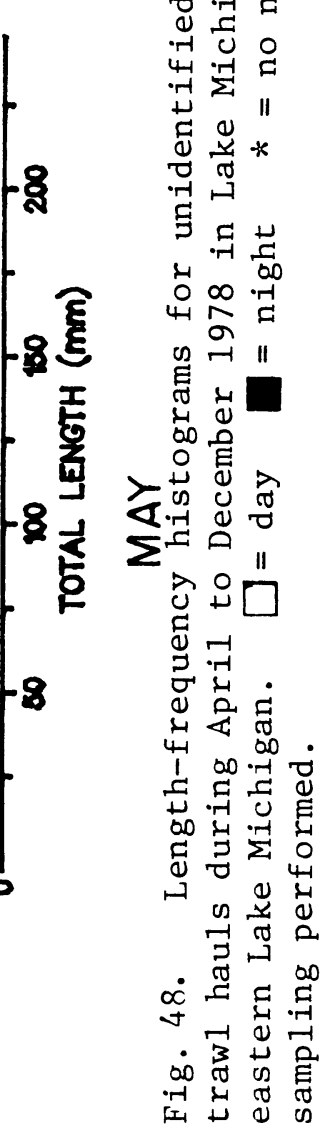



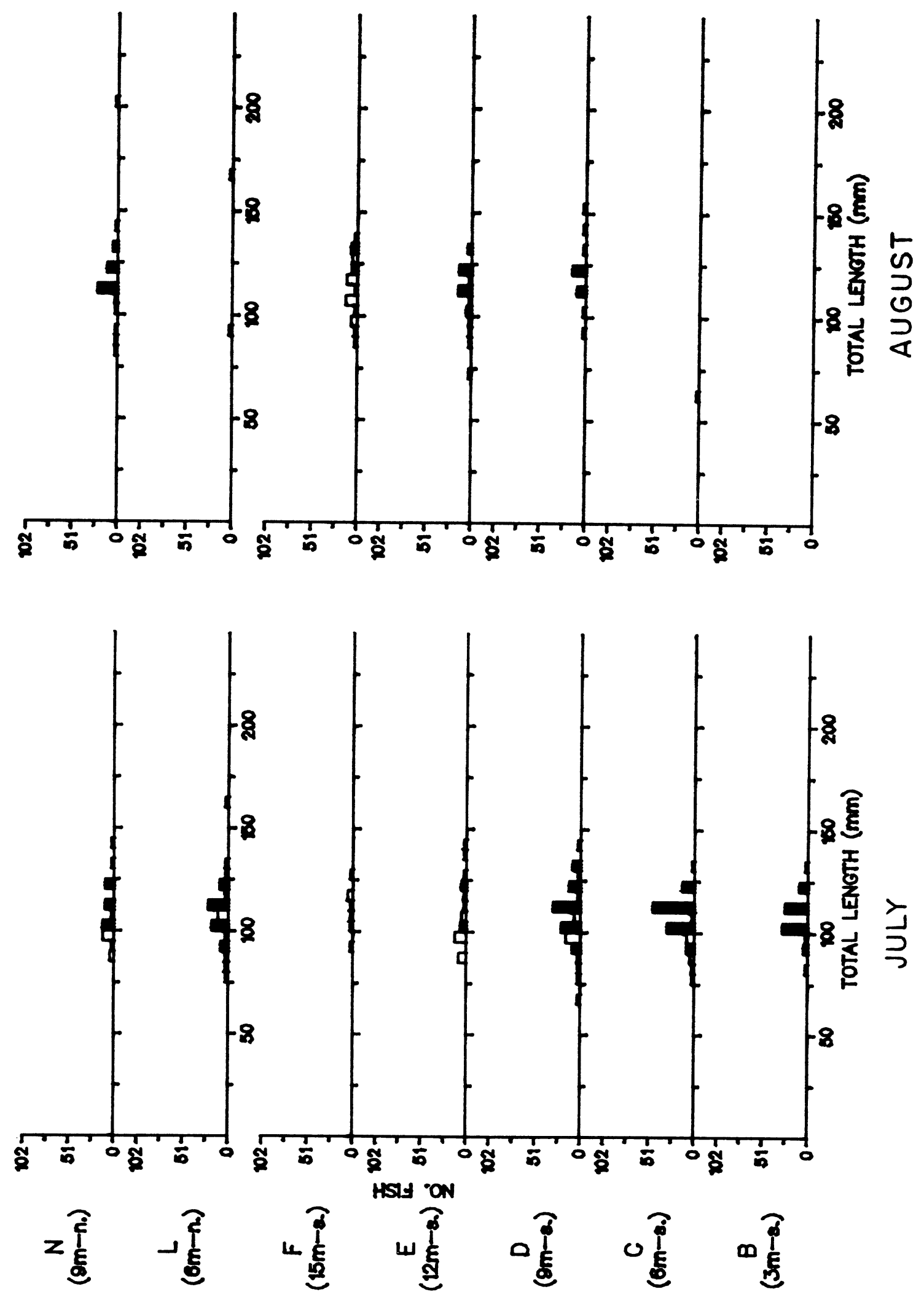

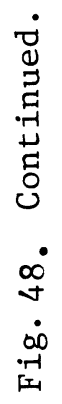



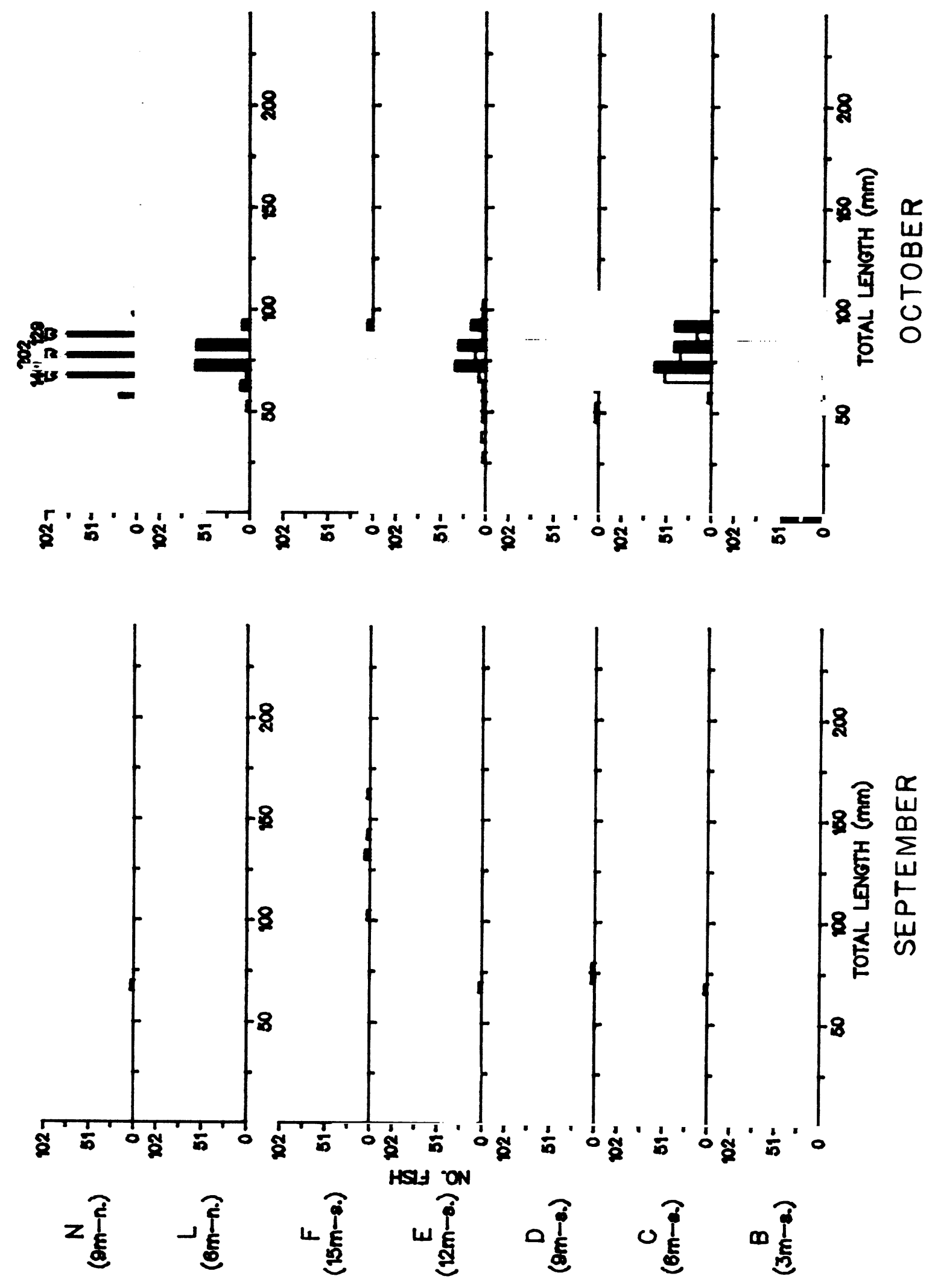

ت્ટ 

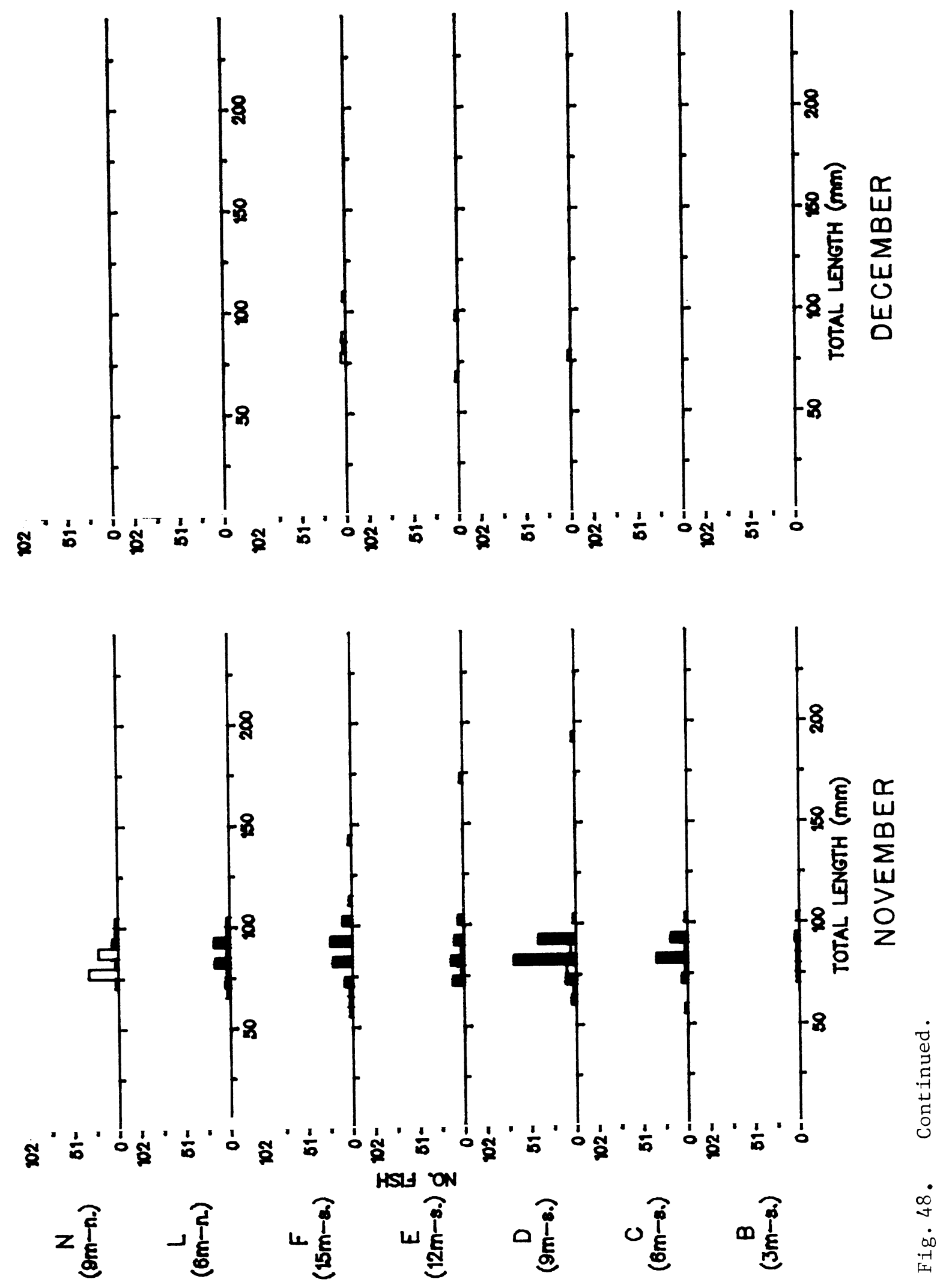
were first taken only at our deepest sampling stations it may indicate that they were moving inshore as water warmed. These fish were probably yearling bloaters spawned in the spring of 1977 (Fig. 47).

June--In June young coregonids appeared in seine catches as well as traw1 hauls (Figs. 49, 50, 51). A 52-mm fish was seined at beach station Q ( $\mathrm{S}$ discharge) and a $66-\mathrm{mm}$ fish was seined at beach station $\mathrm{R}$ (N discharge). Both were captured at night at water temperatures of 13.0-13.5 C.

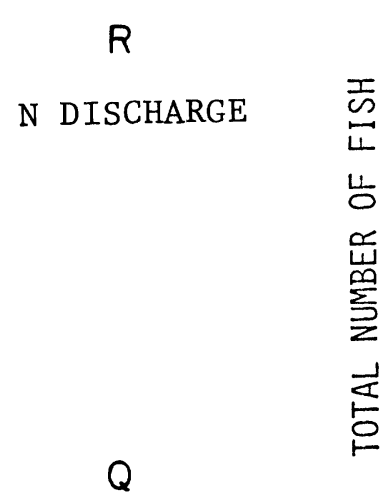

S DISCHARGE
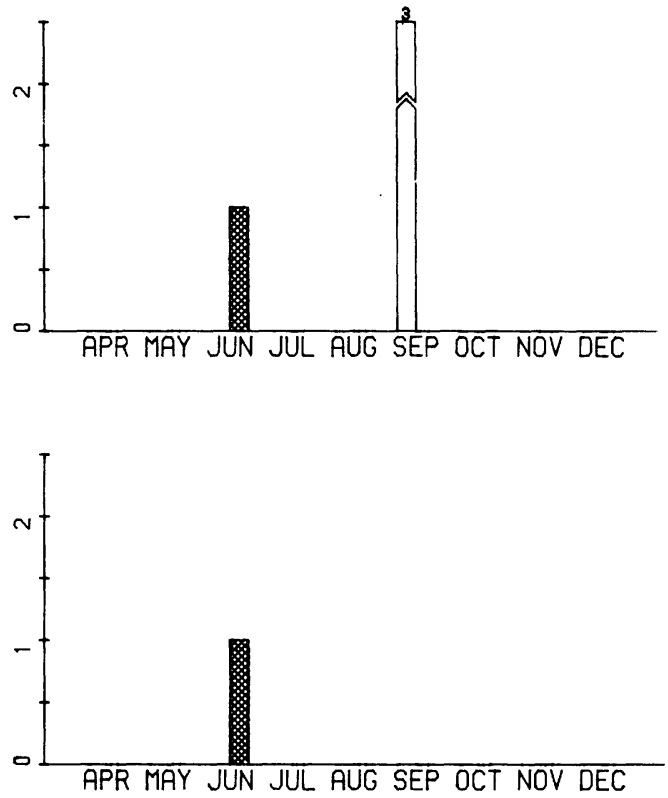

Fig. 49. Total number of unidentified coregonids caught in duplicate seine hauls during day and night once per month April to November 1978 in Lake Michigan near the J. H. Campbell Plant, eastern Lake Michigan. = day = night

Immature coregonids were collected at all stations trawled in Lake Michigan. At the south transect 82 coregonids were collected in trawl hauls, while at the north transect 61 were captured at station $\mathrm{L}(6 \mathrm{~m}-\mathrm{N})$ and 46 at station $\mathrm{N}(9 \mathrm{~m}-\mathrm{N})$ (Fig. 48). Temperatures along the two transects were similar and ranged from 8.3 to $12.0 \mathrm{C}$.

Of the 107 immature bloaters taken at north transect stations, 100 were collected at night at stations $\mathrm{L}(6 \mathrm{~m})$ and $\mathrm{N}(9 \mathrm{~m})$ when water temperatures were 8.9-10.2 C. Forty-six immature coregonids were caught at the comparable south transect stations $\mathrm{C}(6 \mathrm{~m})$ and $\mathrm{D}(9 \mathrm{~m}) ; 33$ at night when water temperatures were 9.5-10.8 C. Average length of all young coregonids caught in June was $89 \mathrm{~mm}(\mathrm{SE}=0.8, \mathrm{~N}=191-\mathrm{Fig} .47)$. These fish were again probably yearlings showing approximately $13-\mathrm{mm}$ growth since May. 

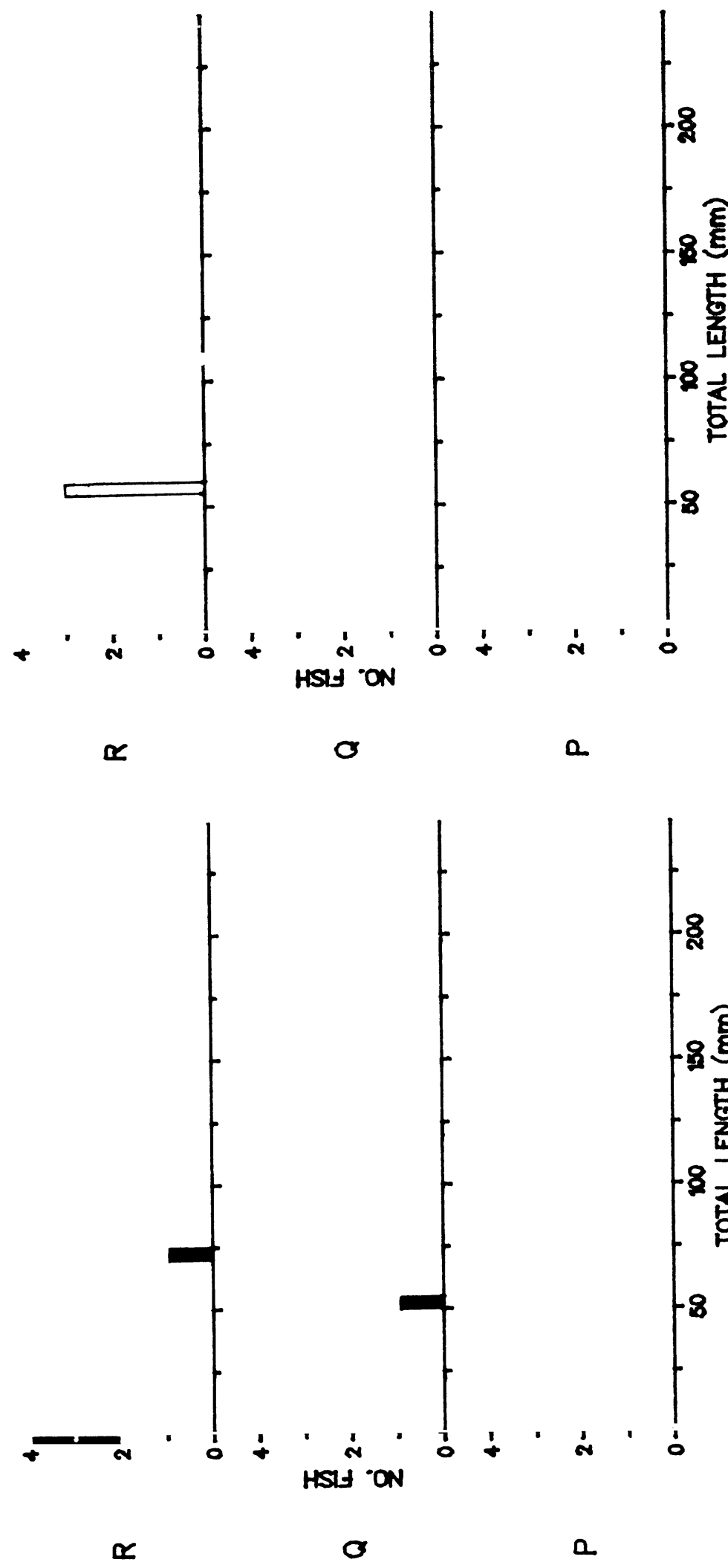

a.

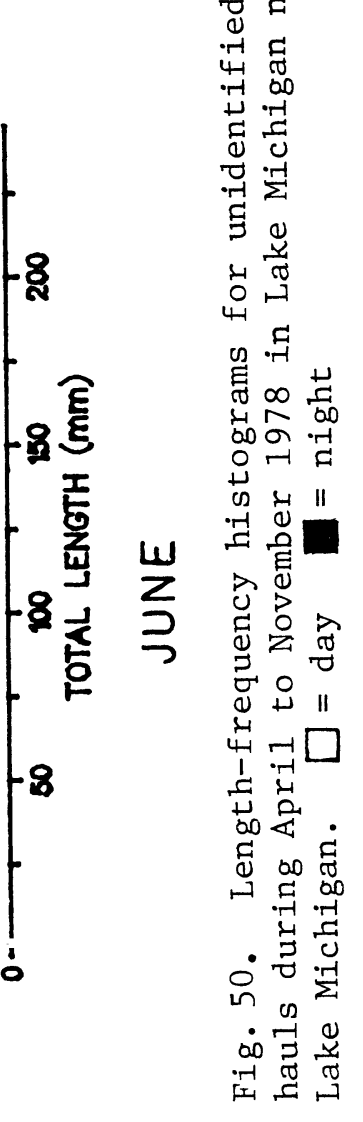


$N(9 m-N)$

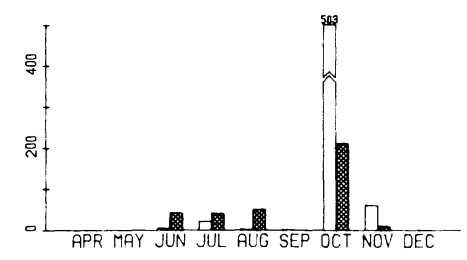

L. $(6 m-N)$

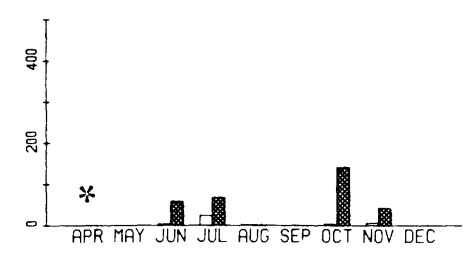

F (15m-s)

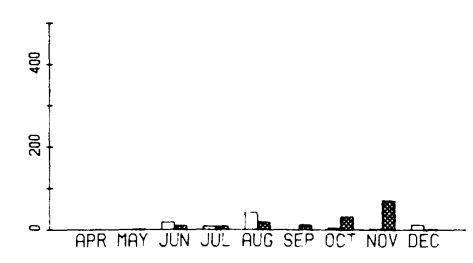

F $(12 m-S)$ 岁

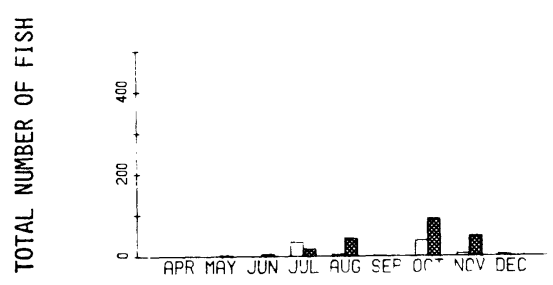

] $(9-5)$

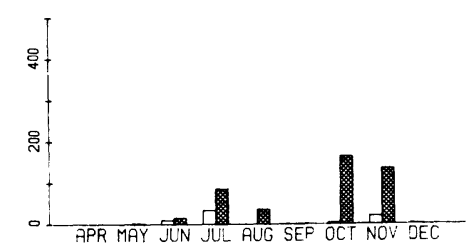

$=(6 m-5)$
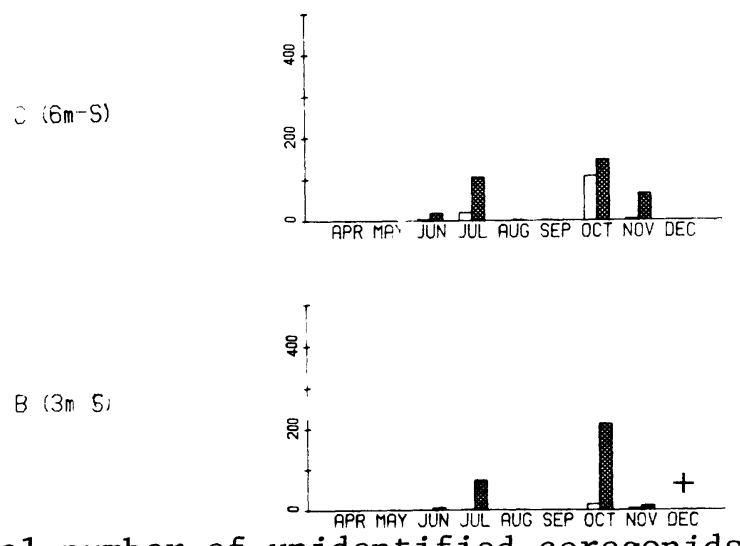

Fig. 51. Total number of unidentified coregonids caught in duplicate traw1 hauls during day and night once per month April to December 1978 in Lake Michigan near the J. H. Campbell Plant, eastern Lake Michigan.

$\square=$ day $\square=$ night,$*=$ no night sampling performed $+=$ no sampling performed. 
July--During July three immature bloaters were recovered from bottom gill nets at south transect stations $C(6 \mathrm{~m}), \mathrm{D}(9 \mathrm{~m})$ and $\mathrm{E}(12 \mathrm{~m})$ as well as in trawl hauls at all stations ( 6 to $12 \mathrm{~m}$ ) (Figs. 48 and 52 ). In gillnets a 128-mm yearling was collected at station $\mathrm{C}(6 \mathrm{~m}-\mathrm{S})$, a $110-\mathrm{mm}$ individual came from station $\mathrm{D}(9 \mathrm{~m}-\mathrm{S})$ and a $125-\mathrm{mm}$ fish was caught at station $\mathrm{E}(12 \mathrm{~m}-\mathrm{S})$. Water temperature at time of capture ranged from 6.2 to $16.0 \mathrm{C}$.

The greatest catch of yearling bloaters occurred in July. Of 385 trawled along the south transect, 291 (76\%) were taken at night at water temperatures between 6.8 and $10.0 \mathrm{C}$. At the north transect, 92 were taken at station $\mathrm{L}(6 \mathrm{~m})$ and 61 at station $\mathrm{N}(9 \mathrm{~m})$; again most (107 of 153) were taken in water 8.0-11.5 C. Average length of all young coregonids taken in July was $106 \mathrm{~mm}(\mathrm{SE}=0.5, \mathrm{~N}=540)$, which is a $15-\mathrm{mm}$ gain in length from those taken in June (Fig. 47).

August--During August 203 immature bloaters were captured. Seven were taken in a night bottom gill net set at station D ( $9 \mathrm{~m}-\mathrm{S})$ (Fig. 53). This set appeared to be on the border of the thermocline at night, since bottom trawl temperatures were $18.5 \mathrm{C}$, while night larval sled tows showed a cooler temperature of approximately $8.9 \mathrm{C}$. These gillnetted fish were probably inhabiting the cool water below the thermocline and were trapped in the gill net as the thermocline oscillated between 9 and $15 \mathrm{~m}$.

Trawling along the south transect captured one immature coregonid at station C $(6 \mathrm{~m}), 36$ at station D $(9 \mathrm{~m}), 46$ at station $\mathrm{E}(12 \mathrm{~m})$ and 59 at station F (15 m) (Fig. 48). Of the 142 immature coregonids collected along the south transect in August, 97 were taken at night in water 8 to $13.0 \mathrm{C}$. Along the north transect only two fish were trawled at station $\mathrm{L}(6 \mathrm{~m})$ where water temperatures were 21.0 to $22.5 \mathrm{C}$. Fifty of the $52 \mathrm{fish}$ taken at station $\mathrm{N}(9 \mathrm{~m}-\mathrm{N})$ (Fig. 51 ) were captured at night in water $15 \mathrm{C}$. Average length of all coregonids caught in August was $116 \mathrm{~mm}(\mathrm{SE}=1.2, \mathrm{~N}=203)$, which is approximately $10 \mathrm{~mm}$ greater than those fish caught in July.

September--Bloater yearlings commonly collected from May to August were almost completely absent from the area in September. Only ten fish belonging to this age-group were collected. Average length of these fish was $138 \mathrm{~mm}(\mathrm{SE}=3.9, \mathrm{~N}=10)$, a gain of $22 \mathrm{~mm}$ since August (Fig. 47). A11 ten were trawled at station $F(15 \mathrm{~m}-\mathrm{S})$ at night at a water temperature of $15.6 \mathrm{C}$. Abundance of YOY bloater was also low in September. On1y nine were collected, three from a day seine at beach station $\mathrm{R}$ (N discharge) where the water was $18.7 \mathrm{C}$ and six from traw1s at stations $\mathrm{C}$ (1), D (2), E (1), F (1) and $N$ (1) at temperatures ranging from 15.6 to $20.0 \mathrm{C}$ (Fig. 51). These nine fish ranged from 57 to $97 \mathrm{~mm}$ averaging $71 \mathrm{~mm}(\mathrm{SE}=4.2, \mathrm{~N}=9)$. These fish were undoubtedly bloaters spawned in early 1978. According to Wells (1966) larvae 8 to $15 \mathrm{~mm}$ were most abundant in southeastern Lake Michigan in late June-early July. If this size larvae grew approximately $15 \mathrm{~mm}$ a month, they would easily attain $60 \mathrm{~mm}$ by September.

October--YOY bloaters were most abundant in the study area during October. A11 1666 trawled were $110 \mathrm{~mm}$ or less, 994 of these being caught at night (Appendix 6). Most (648) of those trawled along the south transect (810) were taken at 


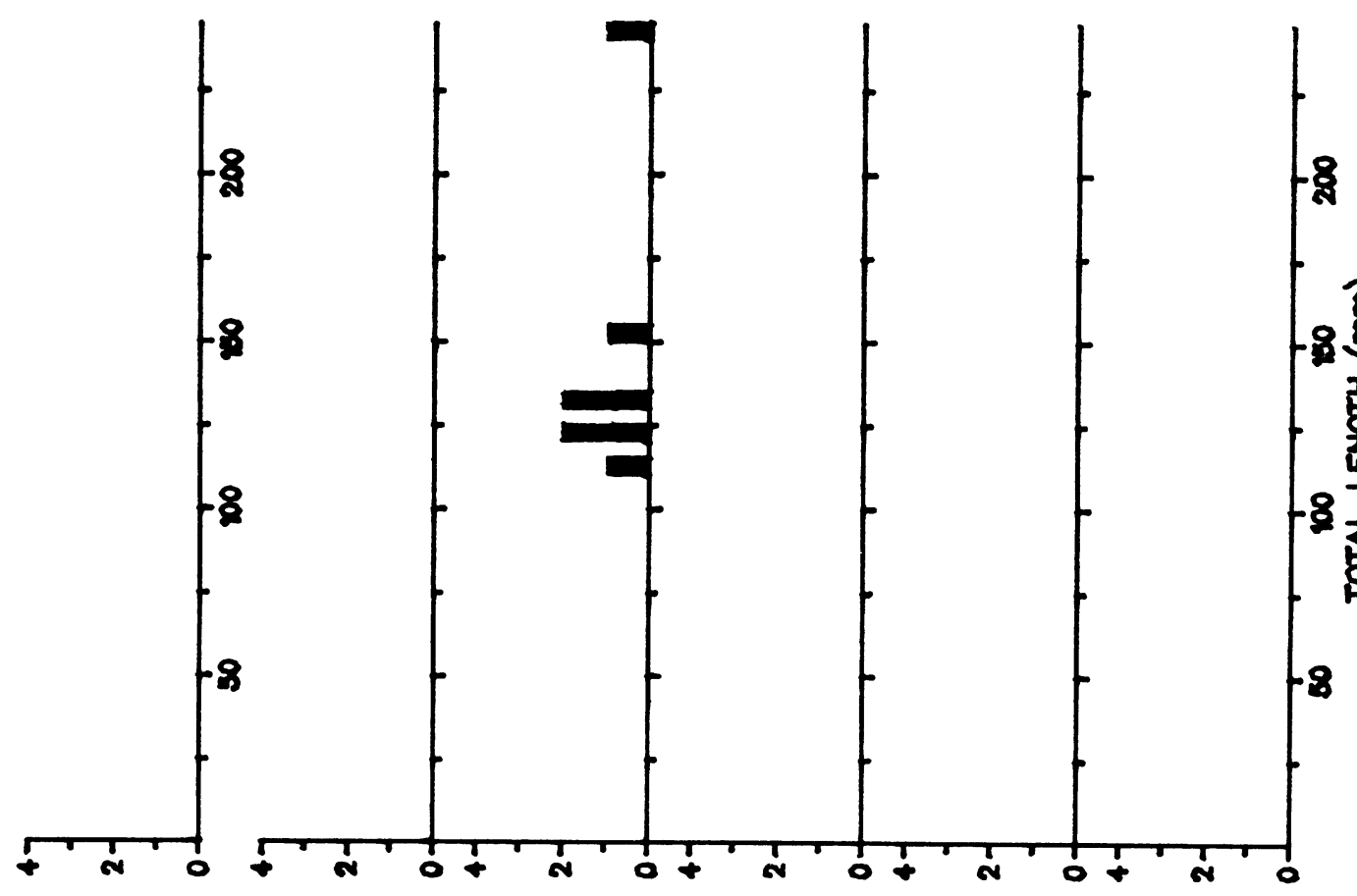

8

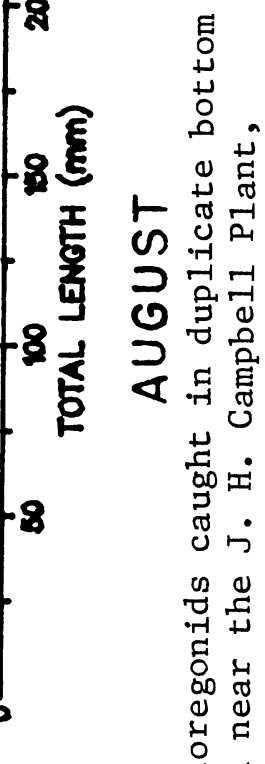

U

प0

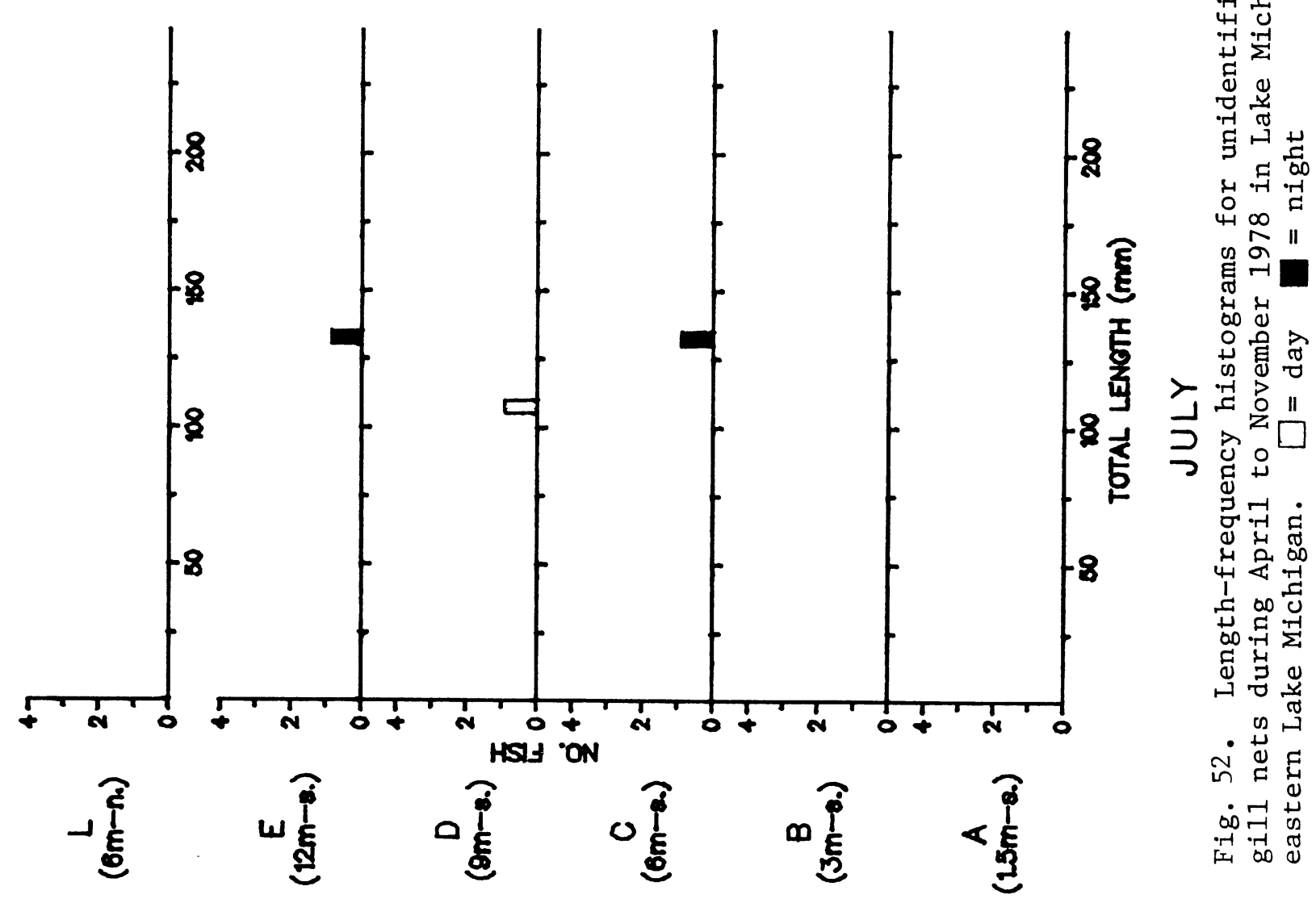




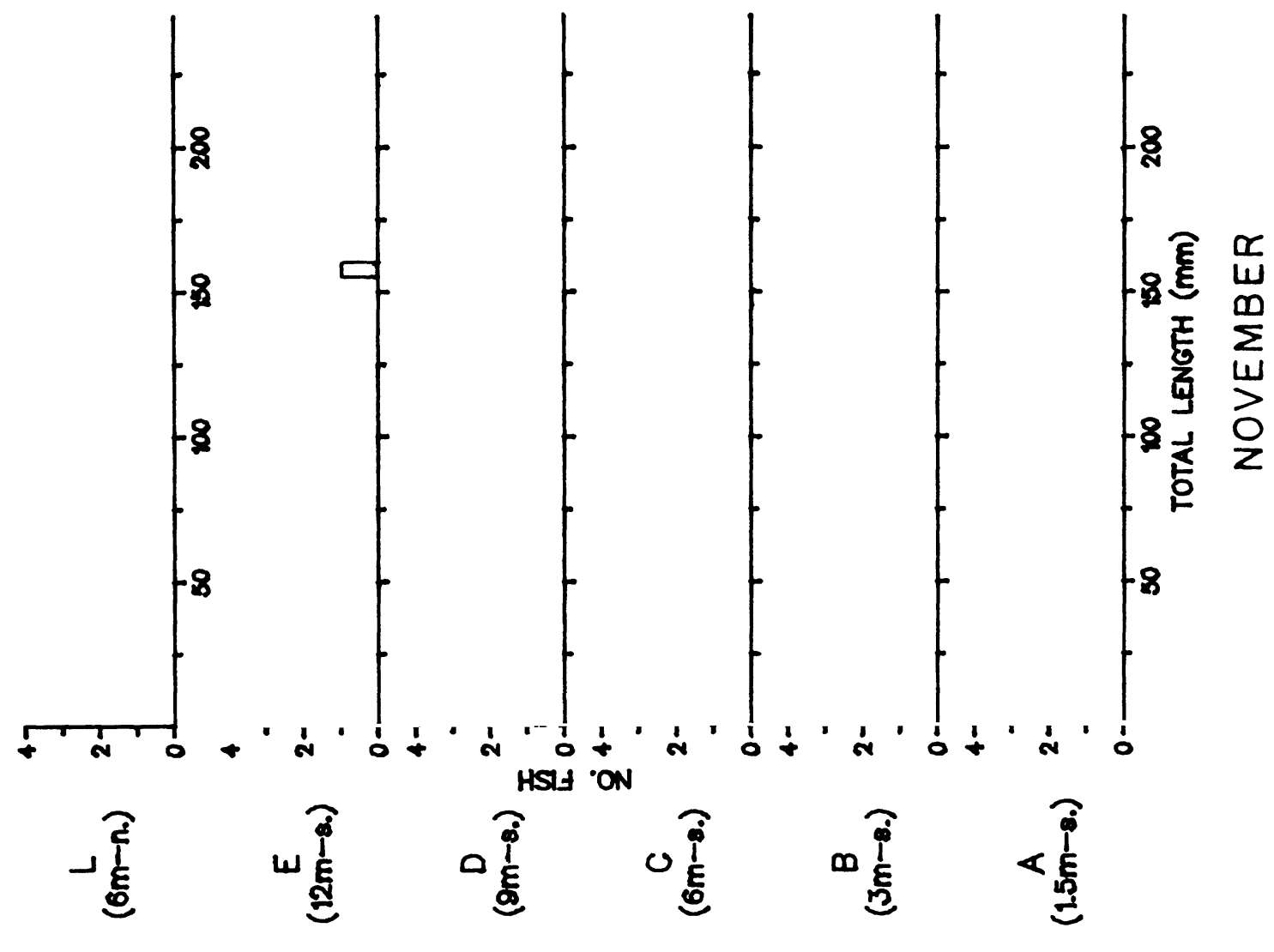

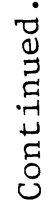

थ 
$E(12 m-S)$
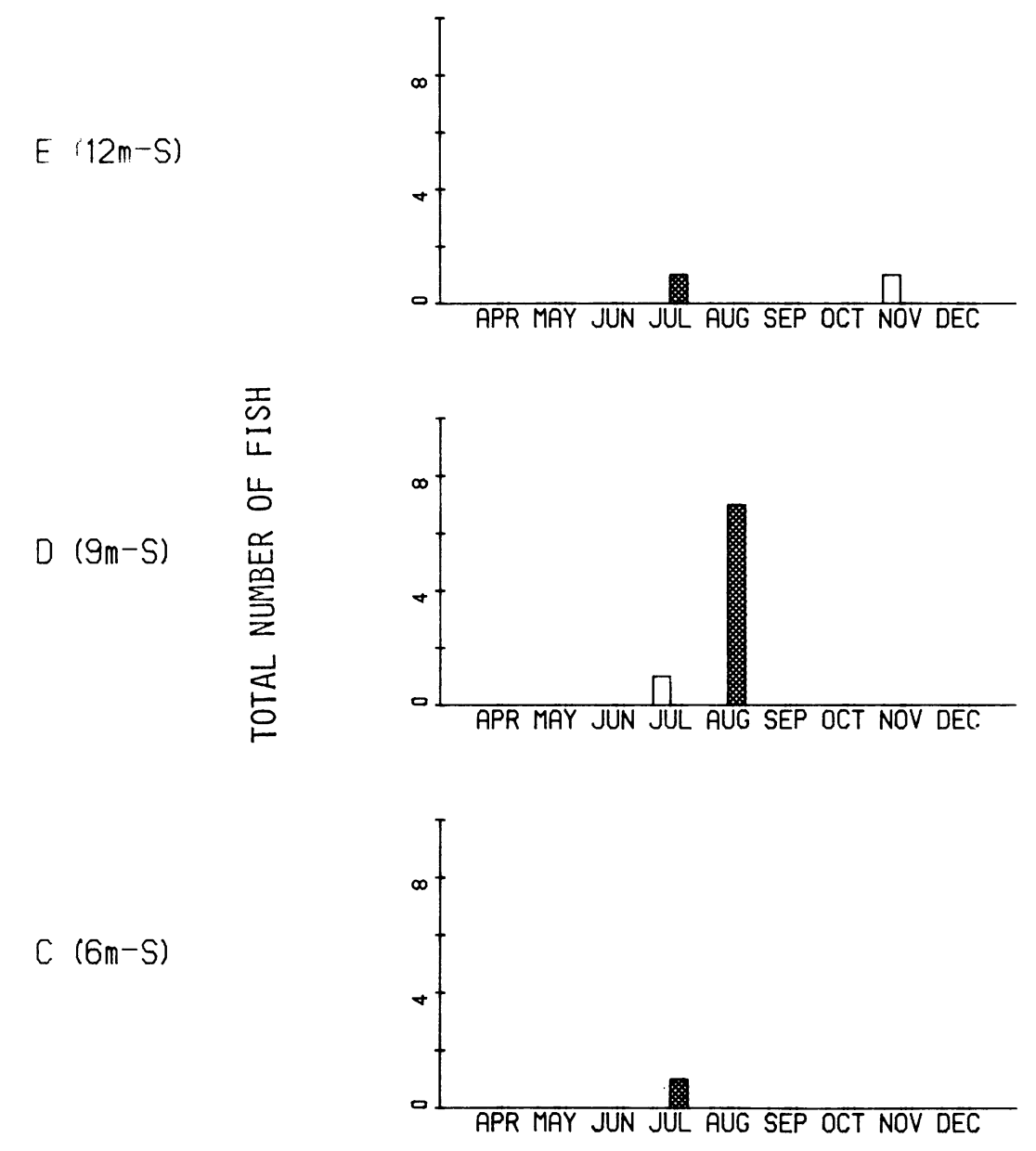

Fig. 53. Total number of unidentified coregonids caught in duplicate bottom gill nets fished during day and night once per month April to November 1978 in Lake Michigan near the J. H. Campbe11 Plant, eastern Lake Michigan. $\square=$ day $\square=$ night 
3,6 and $9 \mathrm{~m}$ (Fig. 51). Water temperatures at time of capture averaged 12.8$18.0 \mathrm{C}$. Along the north transect 143 young coregonids were trawled at station $\mathrm{L}(6 \mathrm{~m})$ and 713 at station $\mathrm{N}(9 \mathrm{~m})$. Water temperatures during trawling were $12.2-13.0 \mathrm{C}$.

The coregonids caught in October averaged $77 \mathrm{~mm}(\mathrm{SE}=0.2, \mathrm{~N}=1666)$ (Fig. 47), an average increase of $8 \mathrm{~mm}$ from those taken in September. Small bloaters although spawned in deep water may inhabit shallower water than larger individuals during some months (Jobes 1949).

November--In November, 479 unidentified coregonids were captured; of these all but four were smaller than $100 \mathrm{~mm}$. A single large $(115 \mathrm{~mm})$ individual was taken at station $\mathrm{E}(12 \mathrm{~m}-\mathrm{S})$ in a bottom gill net set during the day; water temperature was $11.0 \mathrm{C}$ (Fig. 52). Three more large individuals were trawled, one at each of the three deepest south transect stations, D (190 mm), E (169 mm) and $\mathrm{F}(140 \mathrm{~mm})$ (Fig. 48). These fish averaged $165 \mathrm{~mm}(\mathrm{SE}=10.4, \mathrm{~N}=4)$ and may be yearlings. The remaining fish (475) which were less than $110 \mathrm{~mm}$ were trawled at north and south transect stations. Along the south transect most YOY bloaters were trawled at 9-m station D (Fig. 48). Water temperatures were 10.8 to $11.5 \mathrm{C}$. Along the north transect, 48 YOY were taken at station $\mathrm{L}$ $(6 \mathrm{~m})$ and 70 at station $\mathrm{N}(9 \mathrm{~m})$ also at water temperatures of 10.5 to 11.5 C. These small individuals ranged in length from 60 to $110 \mathrm{~mm}$ and averaged $83 \mathrm{~mm}(\mathrm{SE}=0.4, \mathrm{~N}=475)$ (Fig. 47). Cooler water temperatures may be the reason why these YOY gained only $6 \mathrm{~mm}$ from October to November.

December--In December few immature coregonids were collected. Two were trawled at station $\mathrm{D}(9 \mathrm{~m}-\mathrm{S})$ during the day at $2.0 \mathrm{C}$ and 13 were trawled at station $\mathrm{F}(15 \mathrm{~m}-\mathrm{S})$, all but 1 in the daytime at $3.5 \mathrm{C}$ (Fig. 48). These 18 fish ranged in size from 74 to $111 \mathrm{~mm}$ averaging $86 \mathrm{~mm}(\mathrm{SE}=2.3, \mathrm{~N}=18)(\mathrm{Fig} .47)$.

Temperature-catch relationships--The group of yearling bloaters caught from June to August usually inhabited water ranging from 6.5 to $13.0 \mathrm{C}$, but were most often found at 8.0 to $11.0 \mathrm{C}$ (Fig. 54). YOY in October and November were caught at slightly higher temperatures of 10.8 to 13.0 (Fig. 54).

Impingement--No coregonids were impinged in 1977 (Zeitoun et al. 1978) or during the 1974-1975 sampling conducted by Consumers Power Company (1975). In our 1978 studies however, 11 immature coregonids were collected in impingement samples at the J. H. Campbell Plant, one in September, nine in October and one in November. These fish ranged from 57 to $93 \mathrm{~mm}$ and averaged $75 \mathrm{~mm}(\mathrm{SE}=2.5, \mathrm{~N}=11)$. From these data, a total of 69 unidentified coregonids were estimated to have been impinged in 1978 (see RESULTS AND DISCUSSION - IMPINGEMENT). These fish were probably YOY spawned earlier in the year.

At the D.C. Cook Nuclear Power Plant 3688 immature coregonids were collected in impingement samples during 1978 (unpublished data). Prior to that year, impinged immature coregonids increased from 1 in 1973 to a high of 84 in 1977. Most unidentified coregonids collected at the Cook Plant in 1978 were impinged in July and August. These individuals averaged $115 \mathrm{~mm}(\mathrm{SE}=0.2, \mathrm{~N}=3411)$ and $120 \mathrm{~mm}(\mathrm{SE}=1.0, \mathrm{~N}=164)$ and may well be the group composed of yearling bloaters as discussed earlier. 

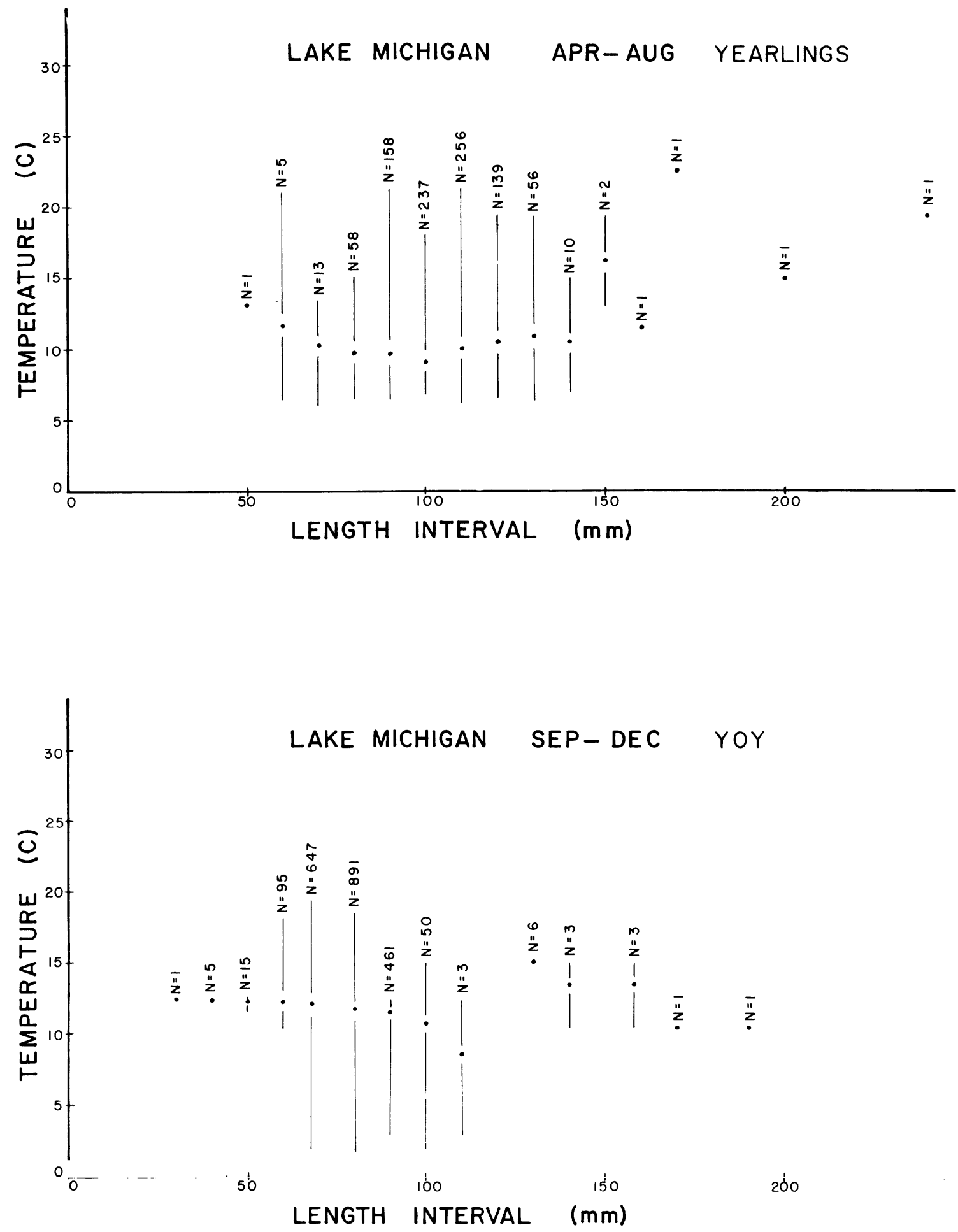

Fig. 54. Weighted-mean water temperatures at which various sizes (10-mm length groups) of unidentified coregonids were collected by all gear types from Lake Michigan near the J. H. Campbell Plant, eastern Lake Michigan, 1978. Vertical bars represent the range, $\mathrm{N}=$ number of $\mathrm{fish}$. 
Summary--The unidentified coregonids in Lake Michigan appear to be composed of two recent year classes of bloaters. Those caught in June, July and August were probably yearlings hatched in early February or March 1977. The fish caught in October and November were YOY bloaters hatched earlier in 1978. Each of the two groups exhibited a definite temperature preference which appeared different from one another. YOY bloaters inhabited water 10.8 to $13.0 \mathrm{C}$ while yearlings seemed to prefer 8.0 to $11.0 \mathrm{C}$ water. The collection of young bloaters increased significantly from 1977 to 1978 in the area of both the J.H. Campbell and D.C. Cook Power Plants (see RESULTS AND DISCUSSION STATISTICS). This trend appears to be continuing in 1979 as Wells (Great Lakes Fisheries Laboratory, U.S. Fish and Wildlife Service, Ann Arbor, Michigan unpublished data) found yearling bloaters common in traw1 catches at depths of 5 to $46 \mathrm{~m}$ near Saugatuck, Michigan (32 km south of the Campbell Plant).

\section{Yellow Perch--}

Introduction--Historically, yellow perch have been important in Lake Michigan as a commercial species since the 1880's and as a sport fish since at least the 1920's (Wells 1977). In a summary of commercial, sport and survey catches, Wells (1977) reported that perch populations in all areas of Lake Michigan declined in the early and mid 1960's. Prior to this time, perch production fluctuated without conspicuous trend from 1954 to 1959, although year to year changes were occasionally considerable. Recent sport catch data (Wells 1977) indicated increased catches of yellow perch have occurred in southeastern Lake Michigan from 1970 to 1975, but restoration of perch populations to pre-1960 levels seems unlikely. Decline in the perch population in Lake Michigan has been related to invasion of the non-native alewife (Smith 1970 and Wells 1970). It is believed that, by its abundance, the alewife has physically displaced the yellow perch from nearshore areas, and hence hindered reproduction. This possibility was further suggested by the production of a strong yellow perch year class during 1969 in southeastern Lake Michigan, when alewife abundance was low (We11s 1977).

Yellow perch are very common to the area near the Campbell Plant and comprised $1.2 \%$ (1078 fish) of the Lake Michigan catch and 17.7\% (1771 fish) of the Pigeon Lake catch during 1978 making this species the sixth-most abundant species in our Lake Michigan samples and third-most abundant in our Pigeon Lake collections (Tables 13 and 14). Yellow perch from bottom gill nets made up $8.8 \%$ of the Pigeon lake catch and $39.5 \%$ of the Lake Michigan catch (Tables 19 and 15). Seined yellow perch comprised $91.2 \%$ of the catch in Pigeon Lake and $12.0 \%$ of the Lake Michigan catch (Tables 20 and 17). Trawling, which was only performed in Lake Michigan, accounted for $48.5 \%$ of the yellow perch catch (Table 18). Comparison of these percentages with those of 1977 was difficult because of deletion of some Lake Michigan and Pigeon Lake stations in 1978, as well as differing times of initial sampling.

Yellow perch in the area of the J.H. Campbell Plant offer a rather unique opportunity to study a single species which exhibits two distinct life history patterns within relatively close areas. We believe that within Pigeon Lake there is a population of yellow perch somewhat distinct from that of Lake Michigan. Jude et al. (1978) inferred from their larval fish data that spawning 
of yellow perch in Pigeon Lake during 1977 occurred in late April-early May. Preliminary observations of yellow perch eggs during April 1978 and 1979 suggested a similar spawning time in Pigeon Lake during 1978-79. Studies by Jude et al. (1978) as well as numerous other studies reporting on the seasonal movement of yellow perch in Lake Michigan (Wells 1968, Brazo et al. 1975, Jude et al. 1975) indicate that for the most part, yellow perch in Lake Michigan move into shallow water and spawn during late May-early June. Larval yellow perch which were collected at Lake Michigan stations during mid-May are not believed to have been spawned there. The evidence for this contention is twofold. First, very few adults were observed at inshore Lake Michigan stations in April. Additional evidence suggests that perch larvae caught in Lake Michigan in mid-May may have come from the discharge canal, either originating there or originating in Pigeon Lake and passing through the plant. Both Pigeon Lake field samples and entrainment samples at this time contained high concentrations of yellow perch larvae. Current measurements taken concident with Lake Michigan larval fish samples in mid-May indicated that alongshore current at that time was moving water from north to south; thus, larvae coming from the discharge canal would be dispersed directly off or to the south of the canal, as was observed (see RESULTS AND DISCUSSION - FISH LARVAE AND ENTRAINMENT STUDY, Yellow Perch). Thus, one obvious 1ife-history difference between yellow perch in Lake Michigan and perch in Pigeon Lake is time of spawning. This difference is probably related to the earlier warming of water which occurs in Pigeon Lake, and may differ from year to year depending on warming trends in Lake Michigan and Pigeon Lake.

Another difference between the two perch populations is related to the physical characteristics of Pigeon Lake. Due to Pigeon Lake's maximum depth of $7 \mathrm{~m}$, yellow perch in this body of water can not retreat to greater depths ( $>90 \mathrm{~m})$ which was reported by Wells (1968) to occur in Lake Michigan. Observations of ice fishing success indicate that yellow perch in Pigeon Lake may overwinter or at least feed during winter at depths of about $3 \mathrm{~m}$.

It should be noted that the extent of interaction between the two populations of yellow perch is unknown, but studies now in progress should yield valuable data about their interrelationships. It is possible that some Lake Michigan yellow perch in their seasonal movements inshore enter Pigeon Lake to spawn. Perch larvae from eggs deposited in Pigeon Lake by Lake Michigan perch, as well as perch larvae entering Pigeon Lake from Lake Michigan with cooling water (and are not entrained) interact in a presently unknown fashion with Pigeon Lake yellow perch populations. Conversely it is also possible that yellow perch spawned in Pigeon Lake may disperse into Lake Michigan.

Due to the suspected differences in the two populations of yellow perch, seasonal abundance and distributional trends of yellow perch in Lake Michigan and Pigeon Lake will be discussed separately. The particular intake system used by the Campbell Plant as well as the common occurrence of yellow perch in both Lake Michigan and Pigeon Lake makes difficult any speculations on the origin of impinged yellow perch. For this reason, the discussion of impingement losses of yellow perch will follow discussion of this species in each system. These water-body differences in perch populations also have important implications for the foregone production calculation, which makes all of its comparisons with 
Lake Michigan fisheries data. In fact, perch are relatively more numerous and generally smaller in Pigeon Lake, thus entrainment and impingement impacts should be related to Pigeon Lake populations.

\section{Seasonal distribution - Lake Michigan--}

April, June--Near the Campbell Plant in Lake Michigan, spring sampling during April-June 1978, indicated relatively few yellow perch were present at depths of $18 \mathrm{~m}$ or less (Figs. 55-57). Studies by Wells (1968) in southeastern Lake Michigan during 1964 indicated that, although some yellow perch were trawled at $9 \mathrm{~m}$, most yellow perch from February to early May were at intermediate depths (18-22 m). Brazo et al. (1975) in a study in central Lake Michigan (near Ludington, Michigan) during 1972 found that yellow perch were in deeper water $(24 \mathrm{~m})$ during early April. These authors indicated that migration of male perch into 6-12 $\mathrm{m}$ had occurred by 21 May when water temperatures were 6-7 C. Our results more closely agree with those of Jude et al. (1979) who found in studies near the D. C. Cook Plant, southeastern Lake Michigan, that very few adults were caught in April and May in water depths up to $9 \mathrm{~m}$, despite water temperatures near 6-7 C. Although these data might suggest little or no yellow perch spawning in Lake Michigan near the Campbell Plant, larval fish data (see RESULTS AND DISCUSSION FISH LARVAE AND ENTRAINMENT STUDY, Yellow Perch) indicate a considerable number of larvae were present in late June at both north and south transects, with larvae concentrated near north transect beach stations. Jude et al. (1979) also reported larvae in the area of the Cook Plant at depths $<9 \mathrm{~m}$ even though evidence for adults spawning in the area was limited. They suggested transport of larvae by currents from spawning areas adjacent to Lake Michigan might explain the presence of larval yellow perch. In our study area low numbers of ripe yellow perch (Table 29) caught in April-June in Lake Michigan may suggest a similar transport mechanism for larval yellow perch.

Due to the late date of initial sampling during 1977 (commenced in June), only data collected in June of 1977 and 1978 can be compared. During June 1977 adult yellow perch were abundant at $12-15 \mathrm{~m}$ as evidenced by both traw1 (34 caught) and gill net data (58 caught). Of those caught during June 1977, many exhibited advanced gonadal development and 12 of the 67 were ripe-running.

During June 1978 only eight yellow perch (all gear combined) were caught in the study area (Appendix 6). This decrease in number of yellow perch caught in June 1978 compared with June 1977 may indicate that our sampling did not coincide with the peak spawning period of yellow perch during 1978.

July--Catch of yellow perch in trawls in Lake Michigan did not change appreciably between June and July, and remained at low levels (Fig. 58). Although the gill net catch of yellow perch during July was also low, there was some indication of the movement of larger yellow perch $(>175 \mathrm{~mm})$ into depths of $1.5-6 \mathrm{~m}$ (Fig. 59). There were, however, pronounced increases in numbers of yellow perch seined at Lake Michigan beach stations (Fig. 60), with the greatest increases observed at north beach stations $\mathrm{R}$ ( $\mathrm{N}$ discharge) and $\mathrm{Q}$ (S discharge). Lengthfrequency data (Fig. 60) indicated that most of these yellow perch in the beach zone were yearlings $(<100 \mathrm{~mm})$. Jude et al. (1979) found a similar concentration of yearlings near the beach zone in the vicinity of the Cook Plant during July 1974. 
M M

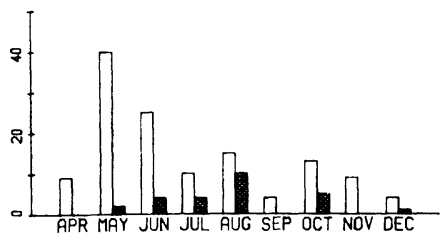

$L(6 m-N)$

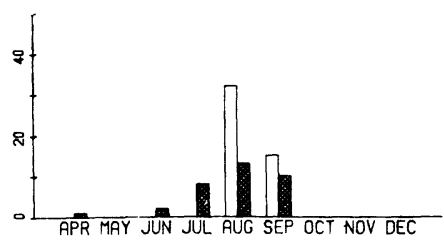

$E(12 m-S)$

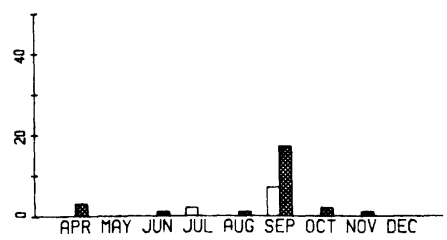

D $(9 m-S)$

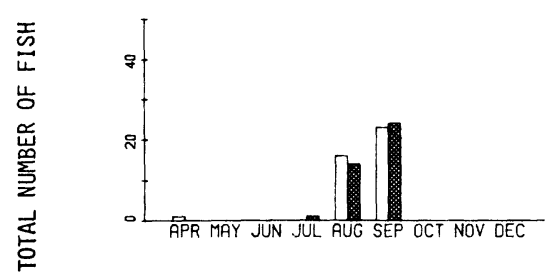

C $(6 m-5)$

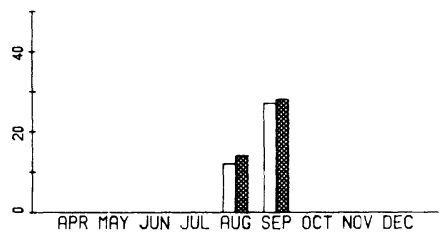

$B(3 m-5)$

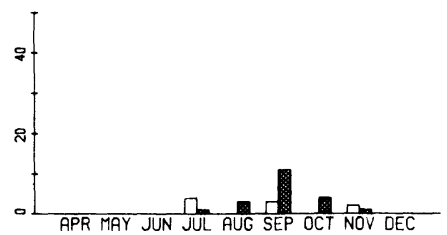

$A(1.5 m-S)$

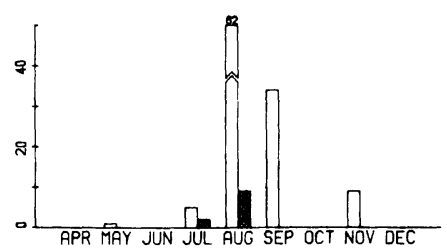

Fig. 55. Total number of yellow perch caught in duplicate bottom gill nets fished during day and night once per month April to November 1978 in Lake Michigan and Pigeon Lake near the J. H. Campbell Plant, eastern Lake Michigan.

$$
\square=\text { day } \square=\text { night }
$$


$v(9 m-N)$

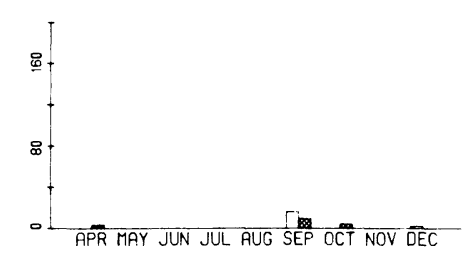

L. $: 6 m-N)$

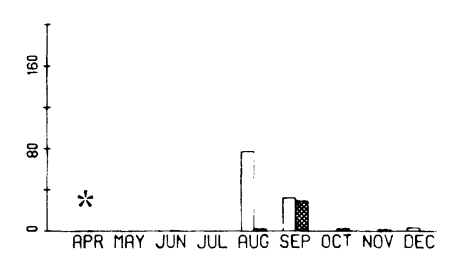

F (15m-S)

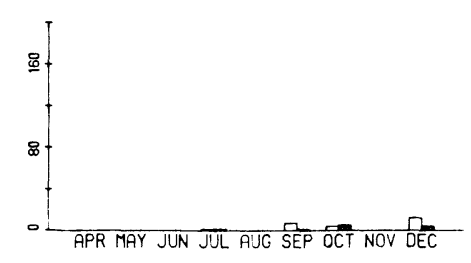

$E(12 m-5)$

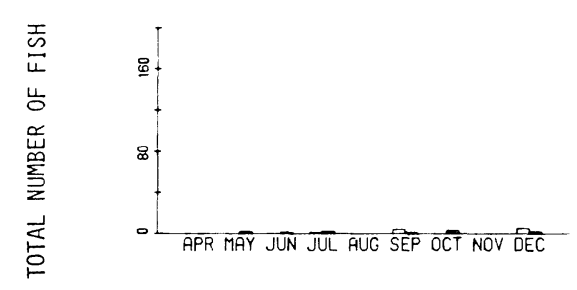

U $(9 m-5)$

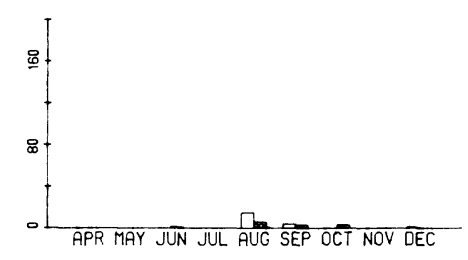

c. $(6 m-s)$

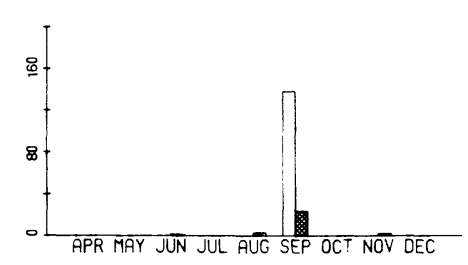

B (3m-5)

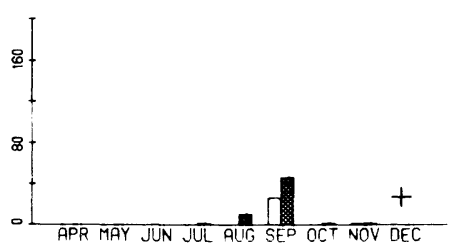

Fig. 56. Total number of yellow perch caught in duplicate trawl hauls during day and night once per month April to December 1978 in Lake Michigan near the J. H. Campbel1 Plant, eastern Lake Michigan.

$\square=$ day $\square=$ night $*=$ no night sampling performed, $+=$ no sampling performed. 


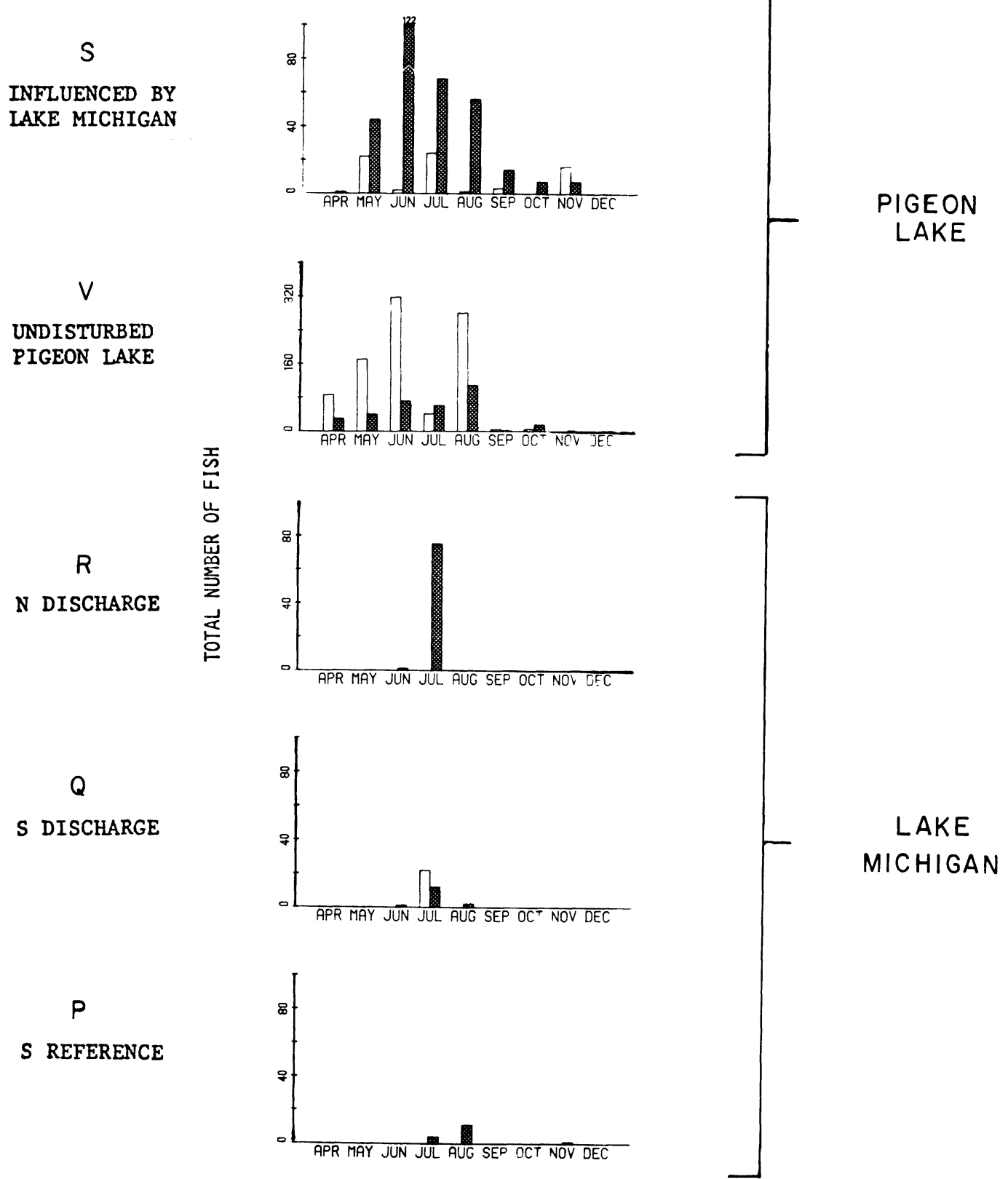

Fig. 57. Total number of yellow perch caught in duplicate seine hauls during day and night once per month April to November 1978 in Pigeon Lake (stations $\mathrm{S}$ and $\mathrm{V}$ ) and Lake Michigan (stations $\mathrm{P}, \mathrm{Q}, \mathrm{R}$ ) near the J. $\mathrm{H}$. Campbel1 Plant, eastern Lake Michigan. $\square=$ day $\square=$ night 

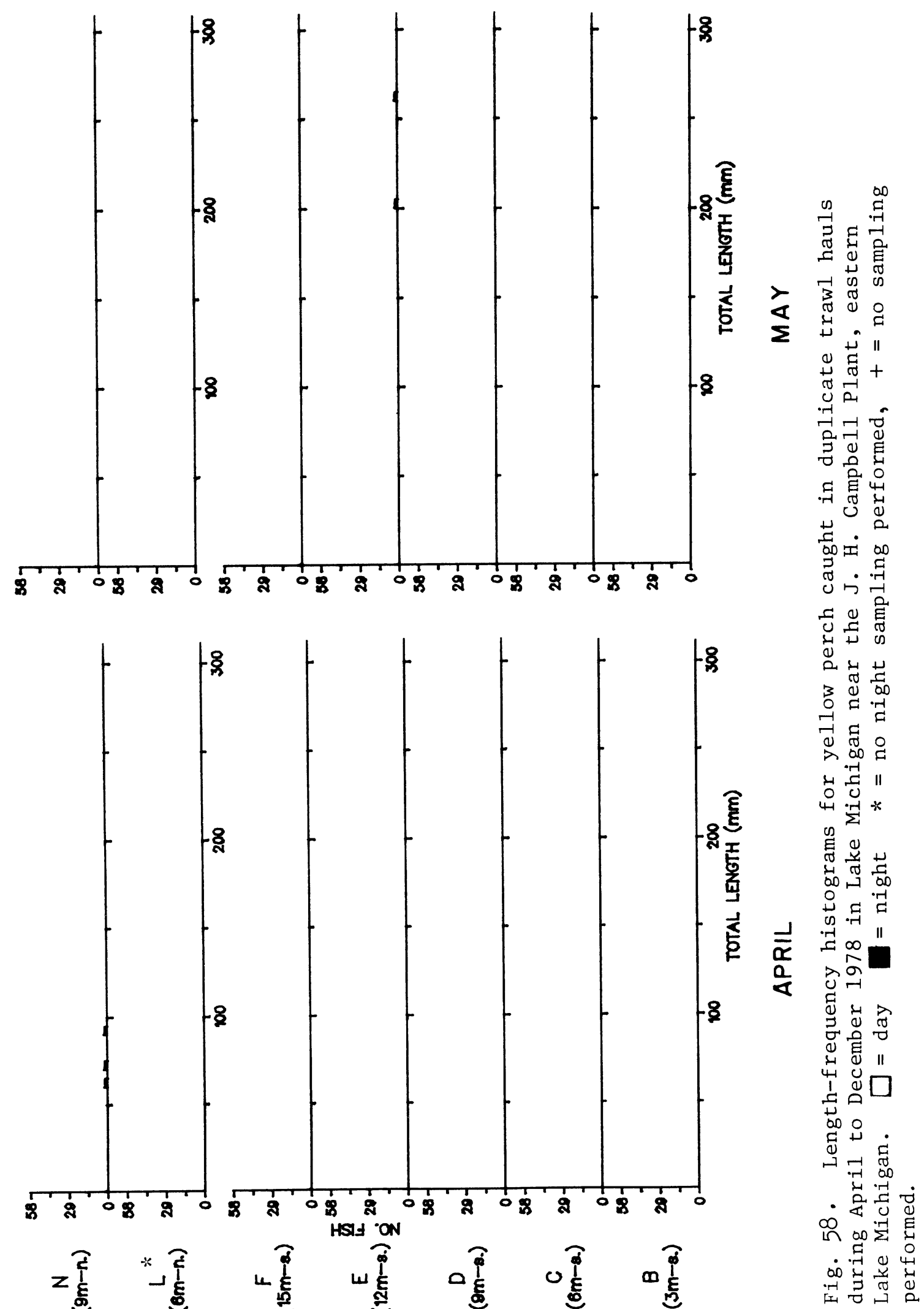

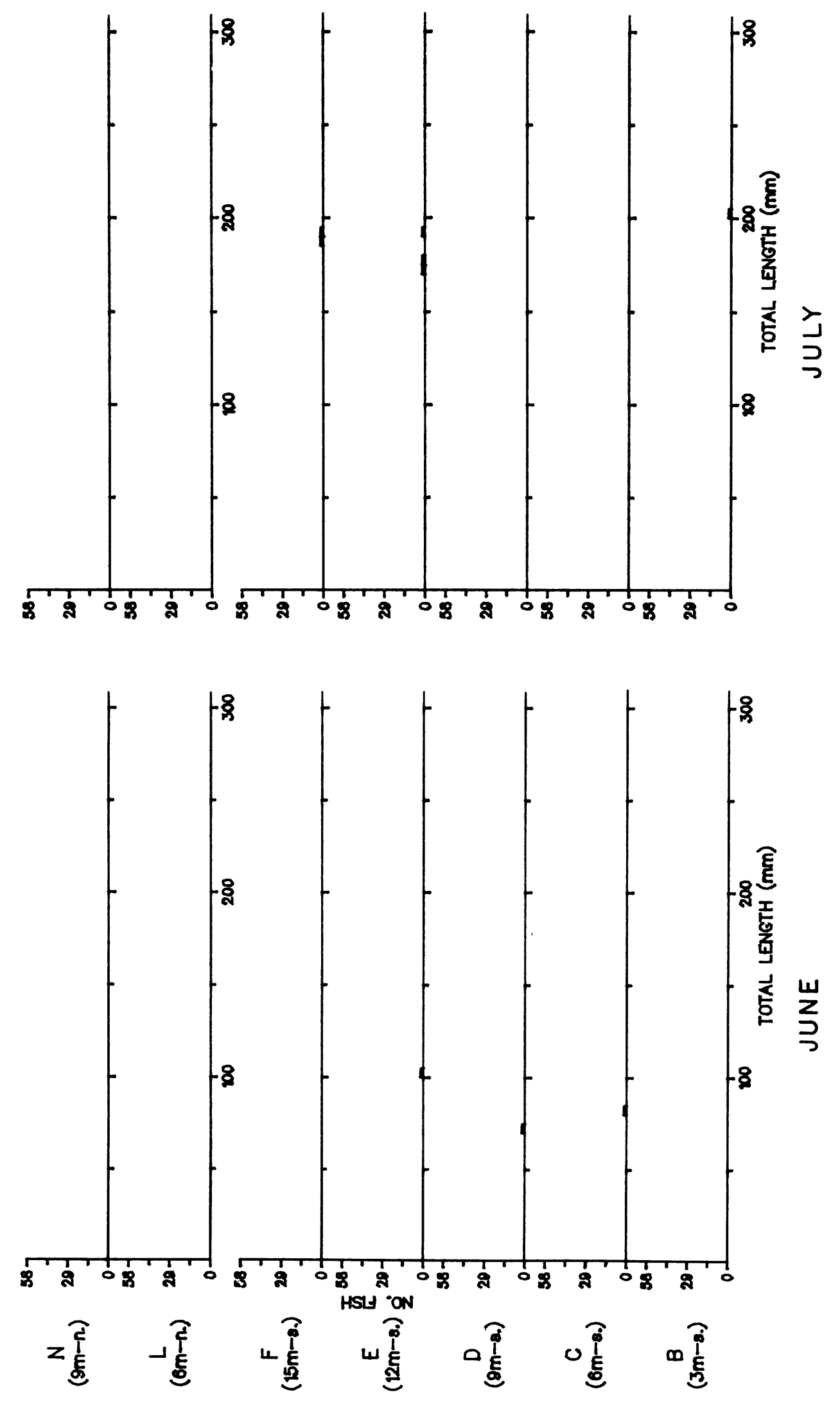

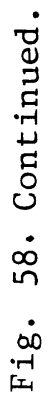



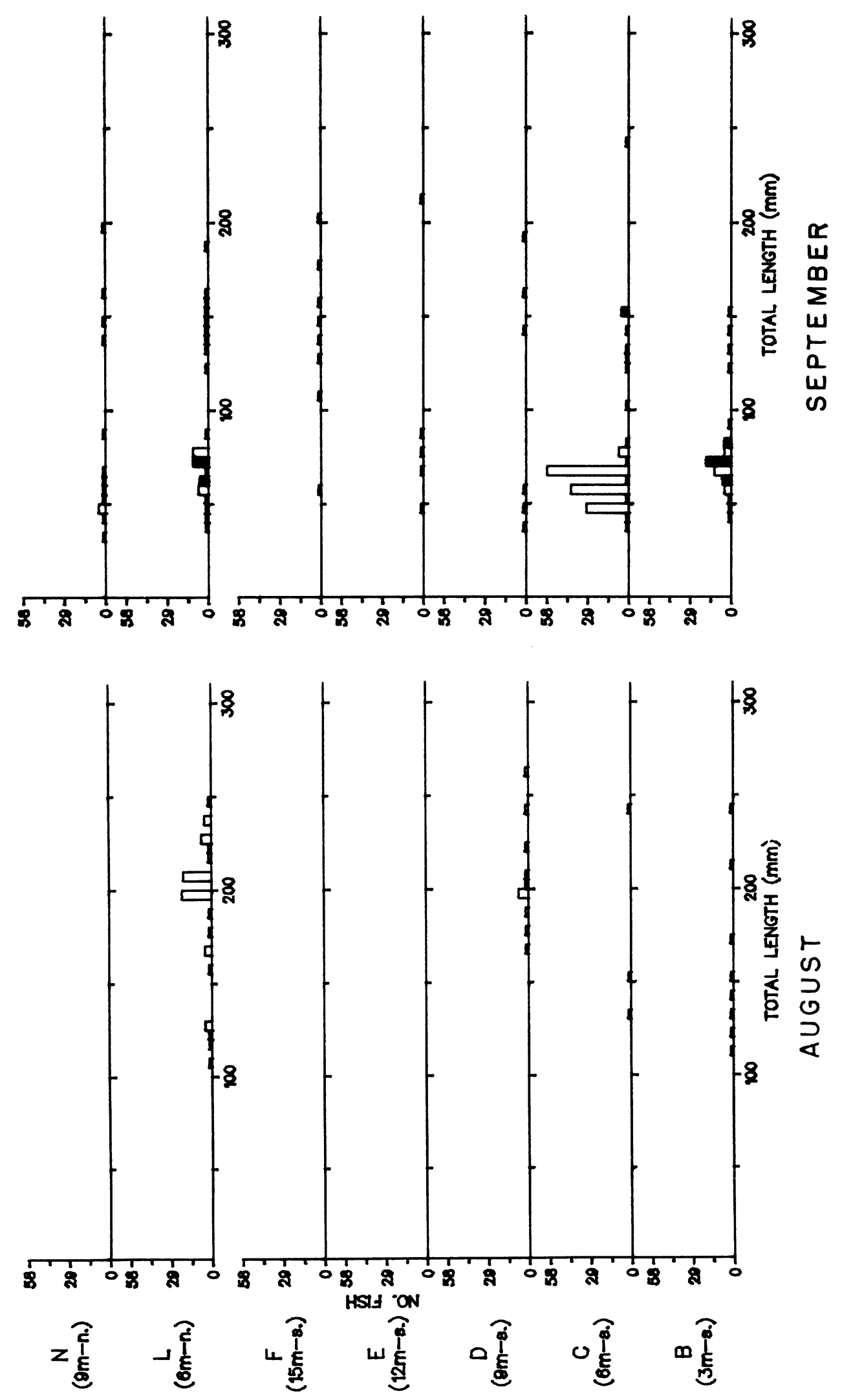

ت્ટ

$\stackrel{\infty}{\circ}$

. 

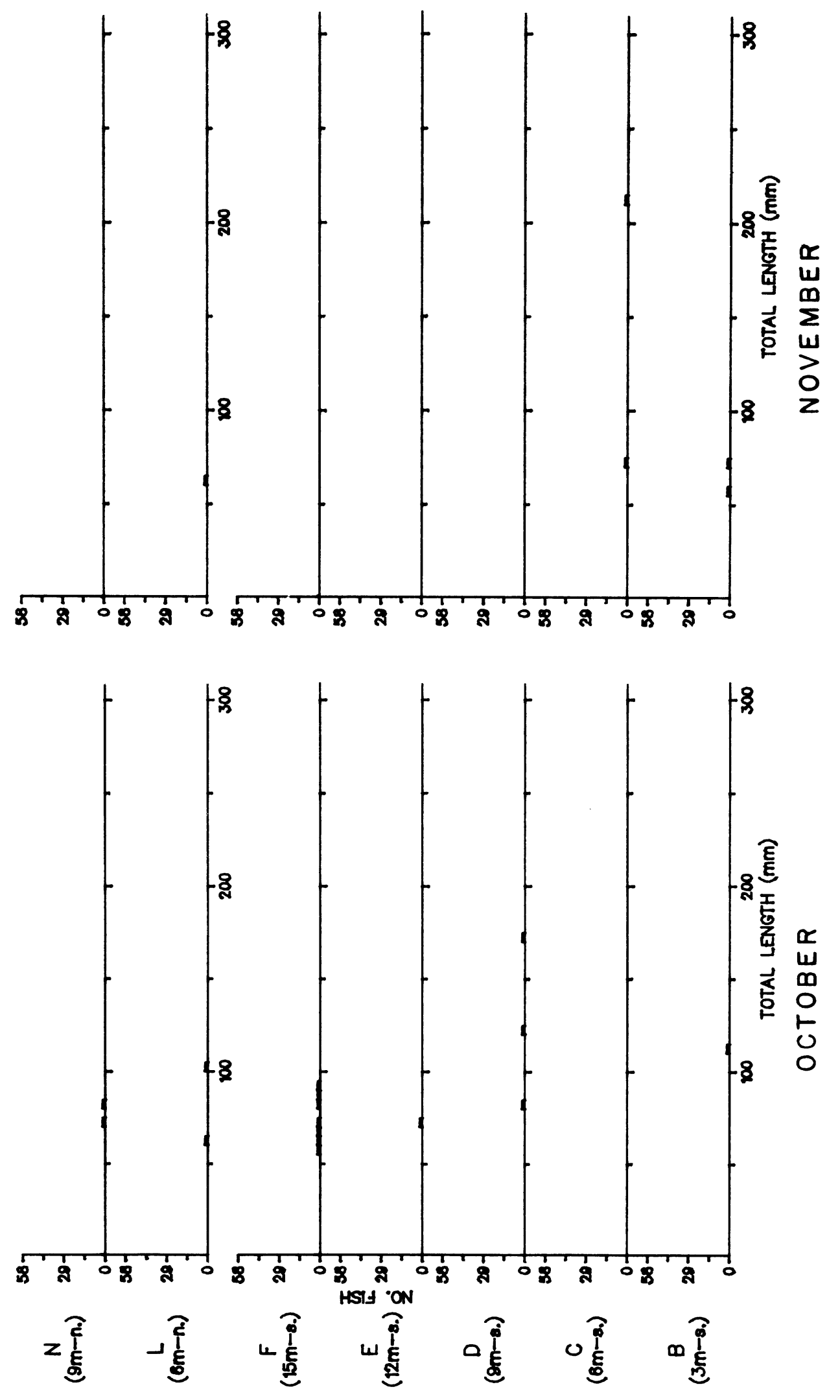

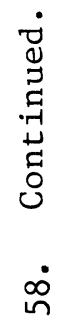

के 


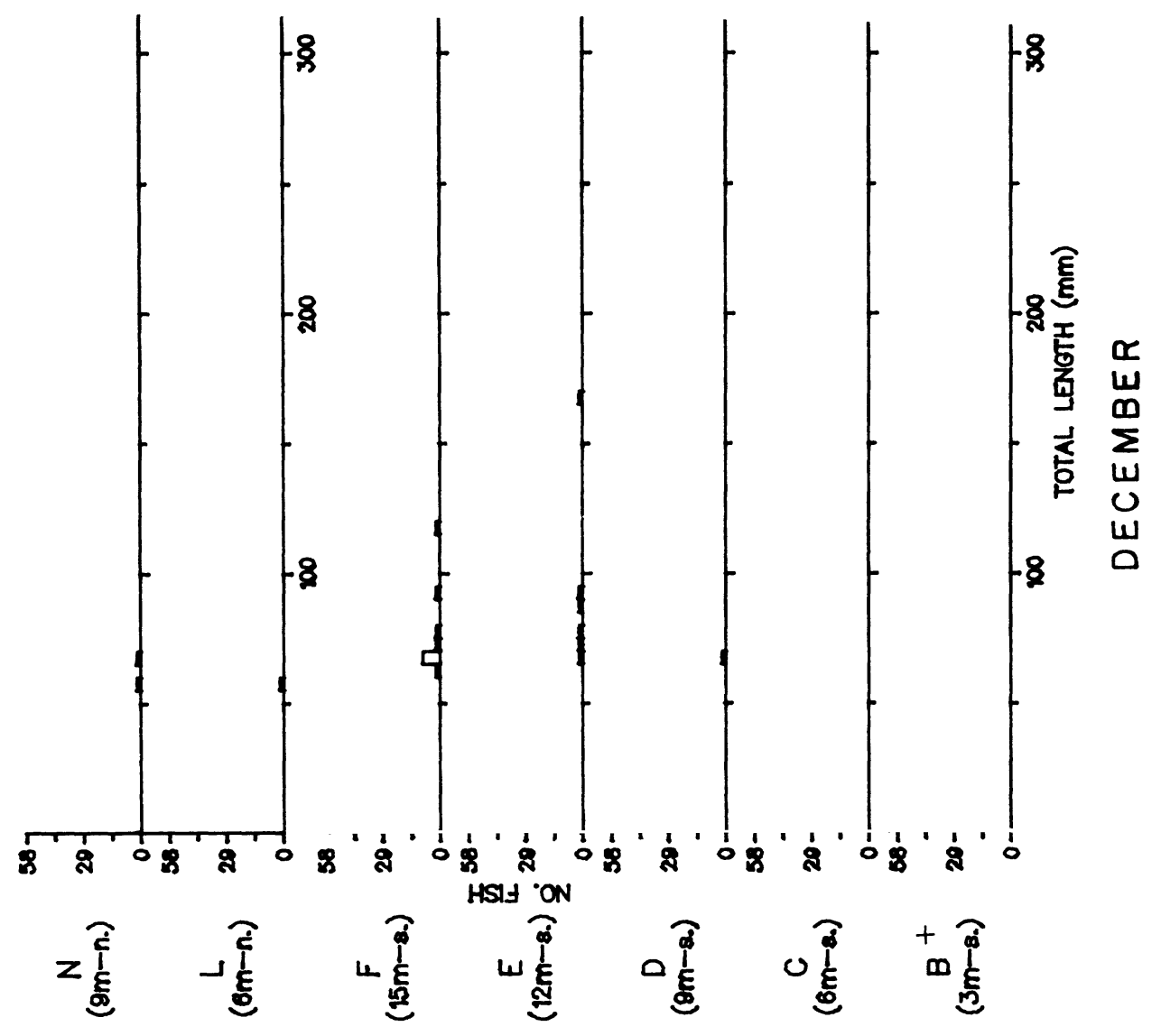



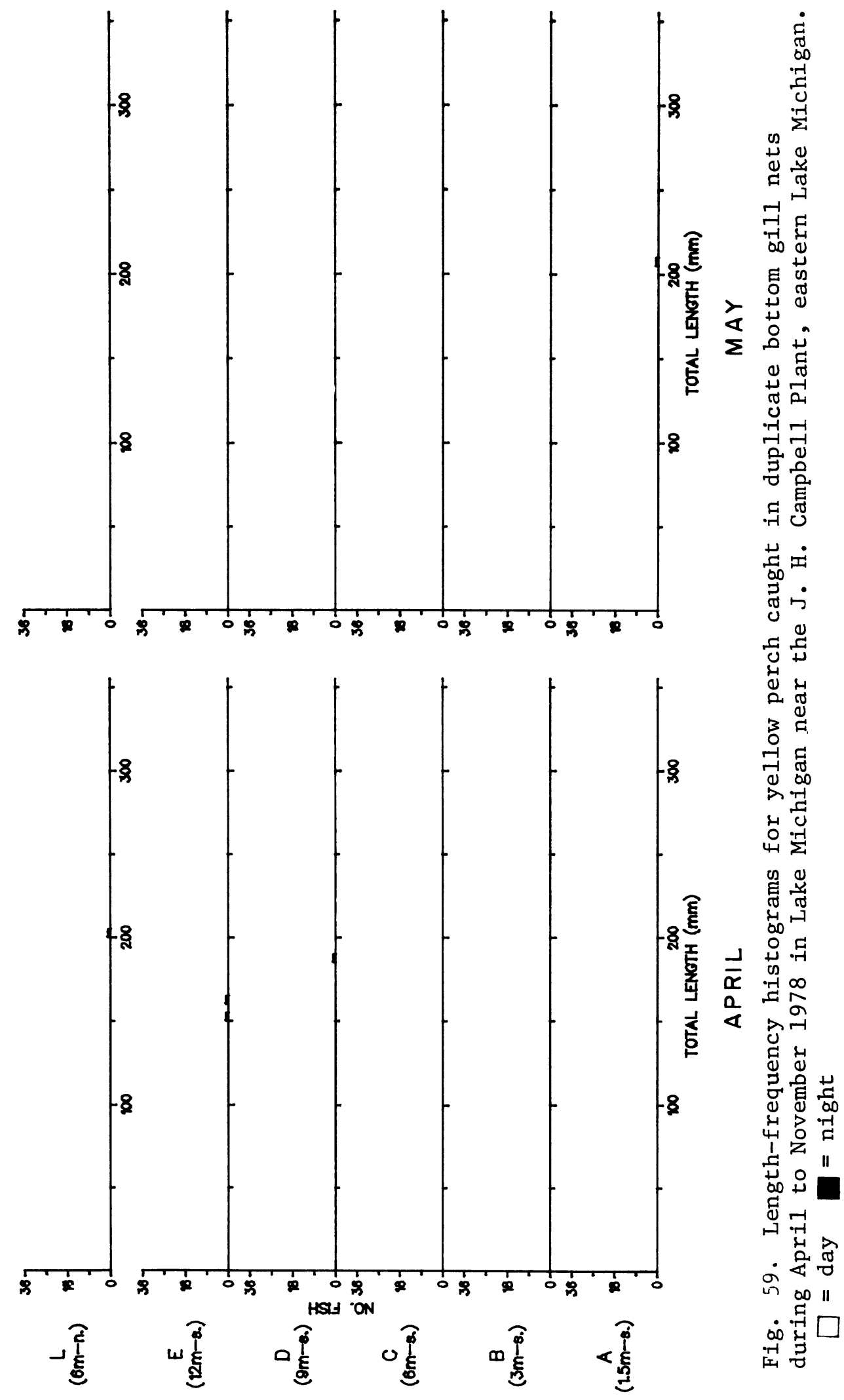

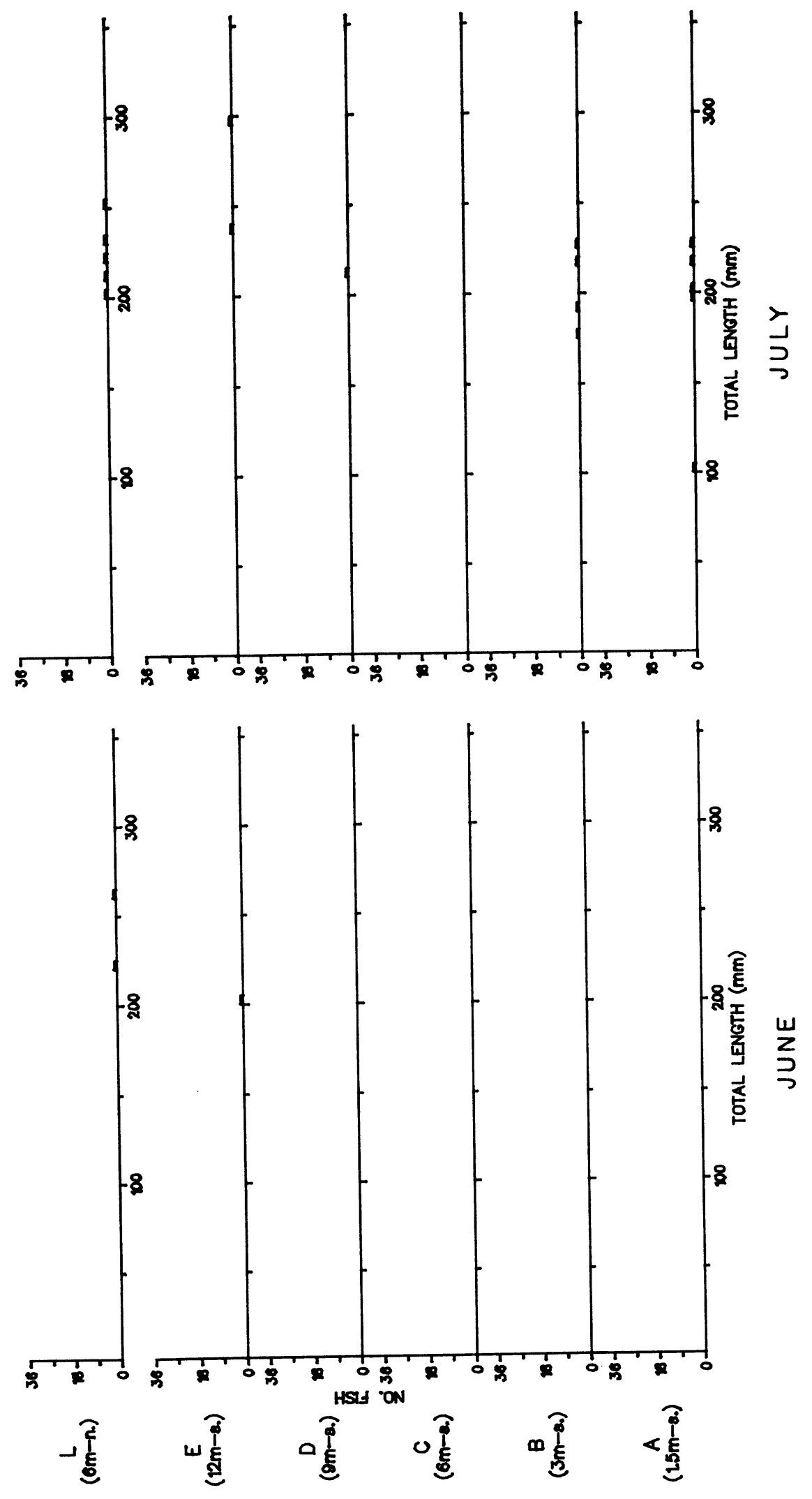

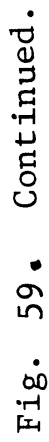



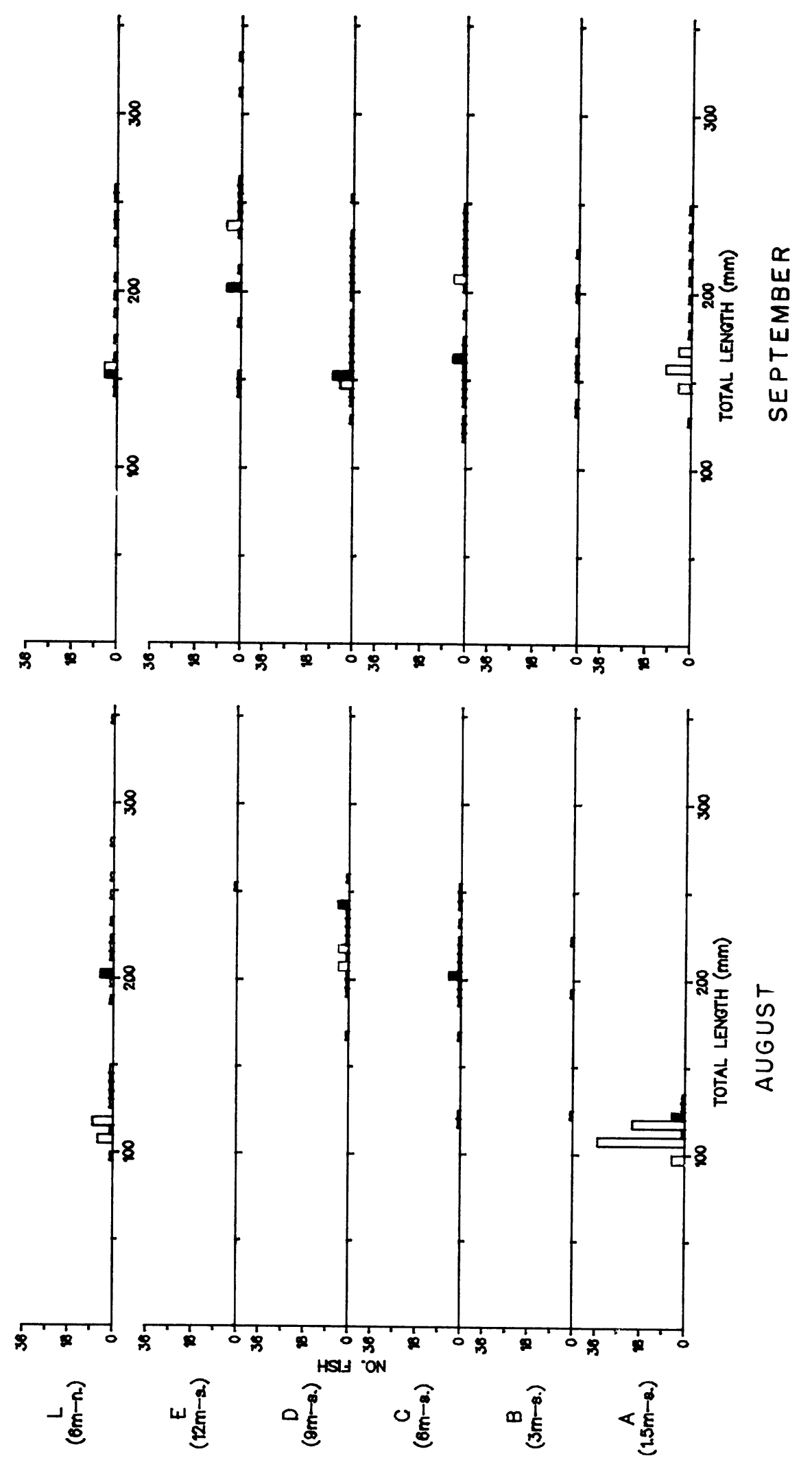

ن

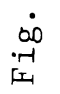



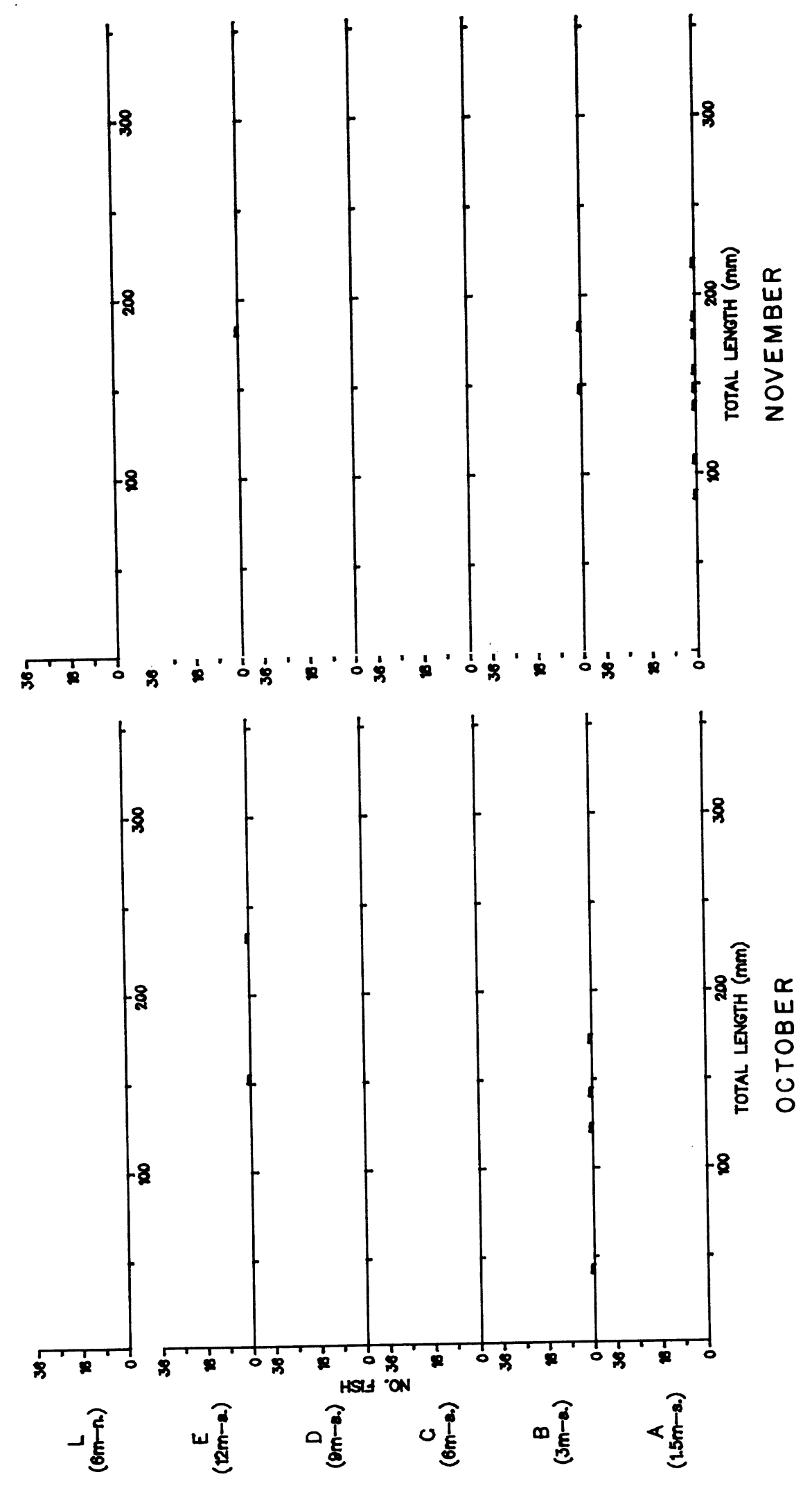

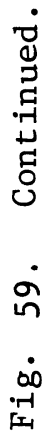



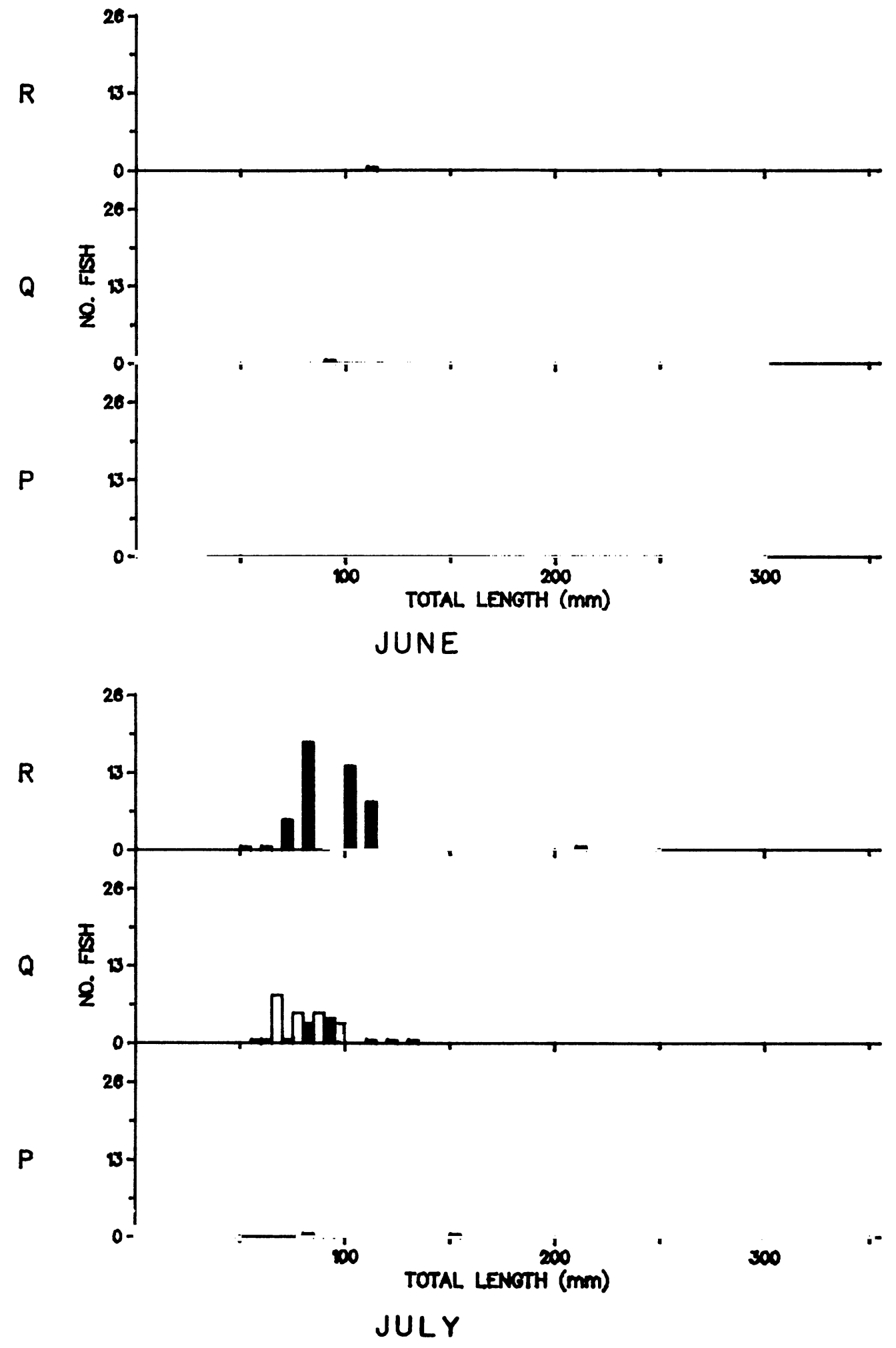

Fig. 60. Length-frequency histograms for yellow perch caught in duplicate seine hauls during April to November 1978 in Lake Michigan near the J. H. Campbell Plant, eastern Lake Michigan.
$\square=$ day
$=$ night 

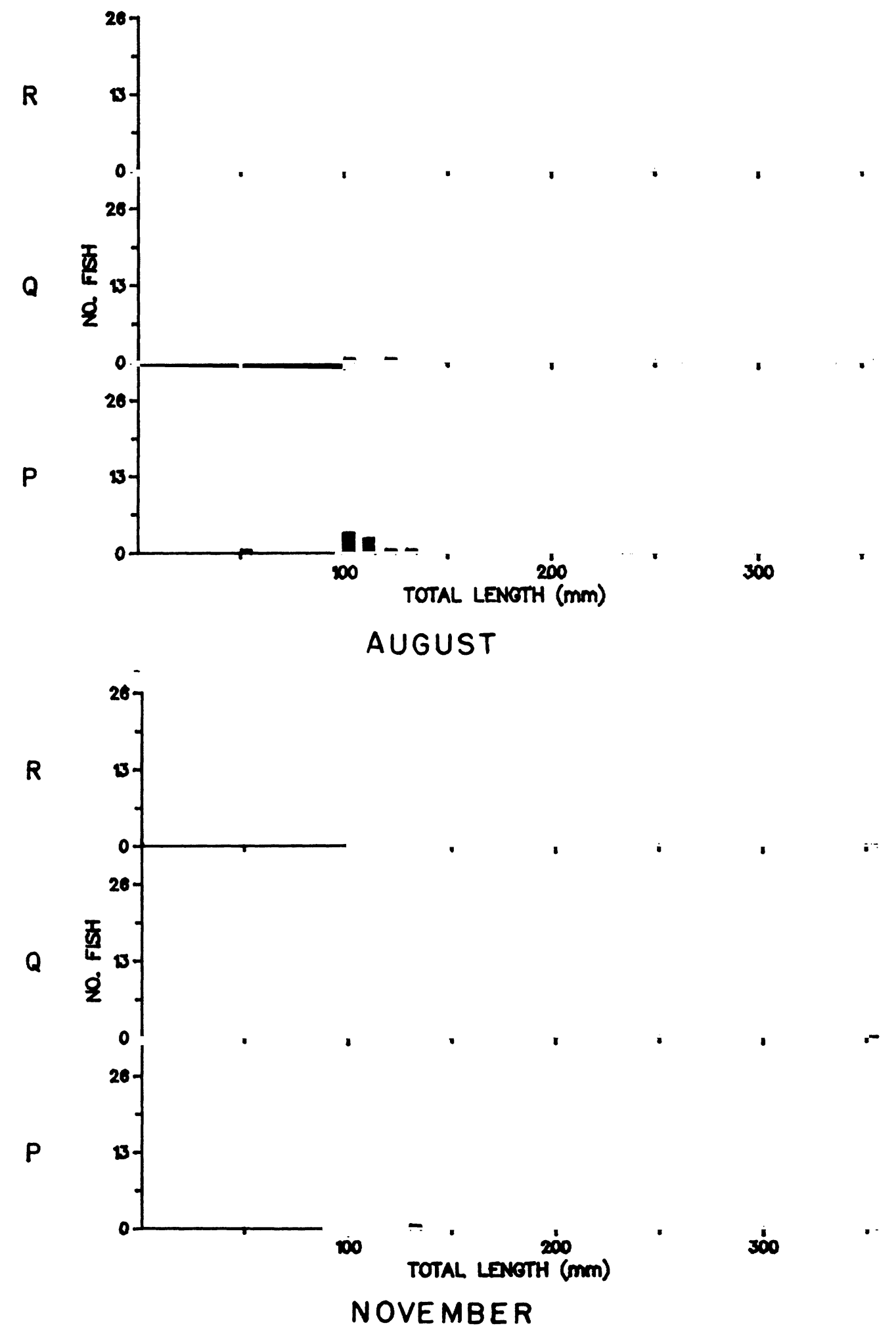

Fig. 60. Continued. 
Table 29. Monthly gonad conditions of yellow perch caught during 1978 in Lake Michigan near the J. H. Campbell Plant, eastern Lake Michigan. All fish examined in a month were included except poorly received specimens.

\begin{tabular}{|c|c|c|c|c|c|c|c|c|c|c|}
\hline & Gonad condition & Apr & May & Jun & Ju1 & Aug & Sep & Oct & Nov & Dec \\
\hline Males & $\begin{array}{l}\text { Slight development } \\
\text { Mod. development } \\
\text { We11 developed } \\
\text { Ripe-running } \\
\text { Spent }\end{array}$ & $\begin{array}{l}1 \\
2 \\
2\end{array}$ & 2 & $\begin{array}{l}1 \\
2\end{array}$ & $\begin{array}{r}25 \\
11 \\
5\end{array}$ & $\begin{array}{r}84 \\
30 \\
5 \\
35\end{array}$ & $\begin{array}{r}45 \\
76 \\
8 \\
2\end{array}$ & $\begin{array}{l}7 \\
2 \\
1\end{array}$ & $\begin{array}{l}1 \\
7 \\
1\end{array}$ & $\begin{array}{l}3 \\
1\end{array}$ \\
\hline Females & $\begin{array}{l}\text { Slight development } \\
\text { Mod. development } \\
\text { Well developed } \\
\text { Ripe-running } \\
\text { Spent } \\
\text { Absorbing }\end{array}$ & 1 & 1 & & $\begin{array}{r}19 \\
2\end{array}$ & $\begin{array}{r}40 \\
2 \\
1 \\
13\end{array}$ & $\begin{array}{r}51 \\
58 \\
3 \\
2\end{array}$ & $\begin{array}{l}2 \\
2\end{array}$ & $\begin{array}{l}4 \\
1\end{array}$ & 2 \\
\hline Immature & & 2 & & 3 & 35 & 14 & 179 & 13 & 4 & 24 \\
\hline Unable $t$ & o distinguish & & & & 3 & 19 & 3 & 1 & 1 & \\
\hline
\end{tabular}

As with our data, they also observed a paucity of yearling perch in concurrent trawl hauls at depths to $9 \mathrm{~m}$.

The reason for such decided differences in the numbers of yellow perch seined in July 1978 at north and south transect beach stations is unknown. Water temperature differences (Appendix 2) were probably not the cause, since temperatures at station $P$ (S reference), where lowest numbers of perch were seined, were only $1 \mathrm{C}$ lower than at station $\mathrm{R}$ ( $\mathrm{N}$ discharge) where highest numbers of yellow perch were collected. It is possible that yellow perch at north beach stations were congregating in response to increased availability of food organisms. Dredging in the area of proposed discharge during 1978 may have dislodged many benthic organisms and made them available as food for perch. Another possibility which might explain the increased number of yellow perch near the discharge stations is that increased turbidity, caused by dredging, increased the efficiency of our gear.

A comparison of July catch data of yellow perch in 1977 with those of 1978 revealed somewhat similar distributional trends, but definite differences in abundance between years were noted. During July 1977, 31 yellow perch from various age-groups were seined at Lake Michigan beach stations. Seining in July 1978 caught 113 yellow perch (Fig. 60) most of which were yearlings (less than $100 \mathrm{~mm}$ ). Gill net data from July 1977 and 1978 indicated that yellow perch in July were generally distributed at $6 \mathrm{~m}$ or shallower. During both July 1977 and 
1978, perch found at these depths were mostly over $160 \mathrm{~mm}$ (Appendix 7 and Jude et al. 1978), which according to data summarized by McComish (1978), would indicate an age of 2 yr or older. During July 1978, however, only 23 perch were gillnetted (Fig. 59) and 6 perch were trawled (Fig. 58), compared to July 1977 when 111 perch were gillnetted and 5 were trawled.

The high degree of variability inherent in gill net and trawl data makes it difficult to draw conclusions about population changes between years. McComish (1978) in a study of yellow perch population characteristics in Lake Michigan observed substantial variation in trawl hauls and gill net catches even on the same dates. This author attributed variability in trawl catch to seasonal population availability, gear characteristics and the non-random distribution of the population. Our gill net variation was attributed to small sample size, disturbance in the sample area, possible population differences between locations and seasonal effects. Catch-per-unit-effort in a study by McComish (1978) was influenced by water temperature, seasonal temperature variability (thermocline position and mixing) and seasonal and diurnal movement of perch. Thus it is possible that variability in our catch of yellow perch between years was probably greatly affected by the warming trend in the lake, as well as was time of thermocline establishment.

August--Seine hauls in Lake Michigan during August 1978 indicated decreased numbers of yellow perch in the beach zone at north beach stations, and an increased number of perch caught at south beach station P (S reference) (Fig. 60). It is evident that, at least in the area of the discharge, an offshore movement of yearlings, which were present in July, had occurred. This was further documented by occurrence of yearlings (100-140 mm) in bottom gill nets at station $\mathrm{L}(6 \mathrm{~m}-\mathrm{N}$ discharge). Yellow perch from older year classes were also caught in gill nets at station $L$ in August (Fig. 59). Trawl data taken at this 6-m north station also indicated that yearling yellow perch mixed with larger perch, were relatively abundant at this depth (Fig. 58). No yellow perch were trawled at the 9-m station (N). At south transect beach station $P$ (S reference) there was also evidence of a movement of yearling yellow perch to deeper water, even though their occurrence in the beach zone was also indicated. Bottom gill net data from south transect stations indicated relatively high numbers of yearling perch were present at $1.5 \mathrm{~m}$, with one yearling collected at $3 \mathrm{~m}$ and another at $6 \mathrm{~m}$. Older age-group yellow perch were most abundant at 6 and $9 \mathrm{~m}$; only one yellow perch was gillnetted at $12 \mathrm{~m}$. Traw1 data (Fig. 58) closely paralleled this trend, showing some yearling yellow perch mixed with older yellow perch at $3 \mathrm{~m}$. Older yellow perch were most common at $9 \mathrm{~m}$ on the south transect. No yellow perch were trawled at 12 and $15 \mathrm{~m}$ at the south transect.

September--The first major occurrence of YOY yellow perch in 1978 samples was observed in September. At this time, YOY were most abundant at $6 \mathrm{~m}$ at both north and south transects as evidenced by trawl data (Fig. 58). YOY were also abundant at station $B(3 \mathrm{~m}-\mathrm{S})$ indicating that in general this size class of yellow perch was probably most abundant at 3-6 $\mathrm{m}$. September seine hauls in Lake Michigan indicated that yellow perch did not frequent the beach zone (Fig. 60). Gill net catch data suggested that the majority of perch from most age groups were located in water 6-12 m (Fig. 59). Yearling yellow perch however exhibited a substantial abundance at shallower $(1.5$ and $3 \mathrm{~m})$ depths. 
Distributional patterns of yellow perch in September differed considerably between 1977 and 1978. YOY yellow perch were abundant in beach seines during September 1977, but absent in 1978 (Fig. 60). It was also evident during September 1977 that most yellow perch were at $6 \mathrm{~m}$ or less; whereas, a distribution to depths of $15 \mathrm{~m}$ was observed in September 1978.

The reason for these distributional differences between 1977 and 1978 may be related to temperature. During September 1977 water temperatures at Lake Michigan stations were $<10 \mathrm{C}$ with the exception of beach stations where temperatures were $>10 \mathrm{C}$. At this time, yellow perch seemed to aggregate near warmer water temperatures. In September 1978, water temperatures at Lake Michigan stations were mostly $>15 \mathrm{C}$. This temperature difference may have allowed for a more even offshore distribution, not restricted by cooler temperatures.

October--Catch of yellow perch in October 1978 decreased substantially compared with September. Again, beach seine hauls in October 1978 indicated that yellow perch had migrated from the beach zone to deeper water (Fig. 60). net and traw1 data showed sporadic occurrence of yellow perch at 3-15-m depths (Fig. 58 and 59). Although decreased numbers preclude making definitive statements about distributional trends, YOY did appear to be more abundant at 12 and $15 \mathrm{~m}$. Observations in October 1977 also showed an absence of yellow perch from the beach zone as well as sporadic occurrence of perch at depths $6-15 \mathrm{~m}$ ( $3 \mathrm{~m}$-station $\mathrm{B}$ was omitted in October 1977). These findings agree closely with data collected by Jude et al. (1979) near the Cook Plant. Wells (1968) reported that adult yellow perch moved into deeper water $(>18 \mathrm{~m})$ in autumn.

November--Although no adult yellow perch were caught by Wells (1968) at depths less than $18 \mathrm{~m}$ in southeastern Lake Michigan in November 1964, our gill net data indicated that some adult yellow perch do occasion shallower depths (Fig. 59). Twelve of the 13 adult yellow perch gillnetted were caught at 1.5 and $3 \mathrm{~m}$; the additional 1 was netted at $12 \mathrm{~m}$. Although a greater number of yellow perch (37) were gillnetted in November 1977, compared with November 1978 (13 caught), a similar sporadic occurrence of adult yellow perch at depths 1.5$12 \mathrm{~m}$ was observed in both years. These results concur with those of Jude et a1. (1979) who found that near the Cook Plant the bulk of the adult yellow perch population was probably at depths greater than $9 \mathrm{~m}$, but some yellow perch schools entered shallower water. YOY yellow perch were also observed in the Campbell Plant study area in trawl hauls at station $B(3 \mathrm{~m}-\mathrm{S})$ and $\mathrm{C}(6 \mathrm{~m}-\mathrm{N})$ indicating that some of the YOY population remained inshore possibly throughout winter (Fig. 58). Traw1 data collected during November 1977 near the Campbel1 Plant also indicated some YOY remained inshore at this time. Jude et a1. (1979) found a similar occurrence of many YOY in impingement samples at the D.C. Cook Plant in November 1978, confirming the inshore presence of YOY.

December--Traw1 data collected in 1978 and 1977 showed that some YOY were present at $15 \mathrm{~m}$ or less in December. During 1978, however, YOY appeared to be distributed deeper (12 and $15 \mathrm{~m}$ ) in December (Fig. 48) compared with December 1977 when YOY were more abundant at less than $12 \mathrm{~m}$ depths. Observations of both years validated the occurrence of at least part of the YOY population inshore during December and possibly throughout winter months. 


\section{Seasona1 distribution - Pigeon Lake--}

April--In contrast to the low numbers of yellow perch caught in Lake Michigan during April, yellow perch were abundant in the shallow areas of Pigeon Lake (Figs.61 and 62). Such high numbers of yellow perch in Pigeon Lake when the majority of yellow perch in Lake Michigan were at depths greater than $18 \mathrm{~m}$, is partial support for the contention that there are two, somewhat distinct, perch populations in the area of the Campbell Plant.

Within Pigeon Lake, seine hauls indicated that there was a substantial difference in the abundance of yellow perch between Lake Michigan influenced, beach station $\mathrm{S}$, where only 1 yellow perch was caught and station $\mathrm{V}$, located in the undisturbed Pigeon Lake area, where 116 perch were caught. The reason for this pronounced difference in catch between beach stations in Pigeon Lake is probably related to temperature and characteristics of the habitats. During April sampling water temperature at beach station $S$ (influenced by Lake Michigan) averaged $8.5 \mathrm{C}$, compared with station $\mathrm{V}$ (undisturbed Pigeon Lake) where water temperatures averaged $10.5 \mathrm{C}$. The warmer temperature at station $\mathrm{V}$ as well as its more gradual slope and more abundant cover may be attractive to yellow perch.

Gonad data (Table 30), as well as our observations of yellow perch egg masses in 1978 and 1979 suggest that some spawning activity may also be occurring in April in Pigeon Lake. In comparing the two sampling sites, beach station $\mathrm{V}$ would appear to be a habitat more conducive to egg and larval survival because of more abundant cover and warmer temperatures.

Table 30. Monthly gonad conditions of yellow perch caught during 1978 near the J. H. Campell Plant, eastern Lake Michigan. All fish examined in a month were included except poorly received specimens.

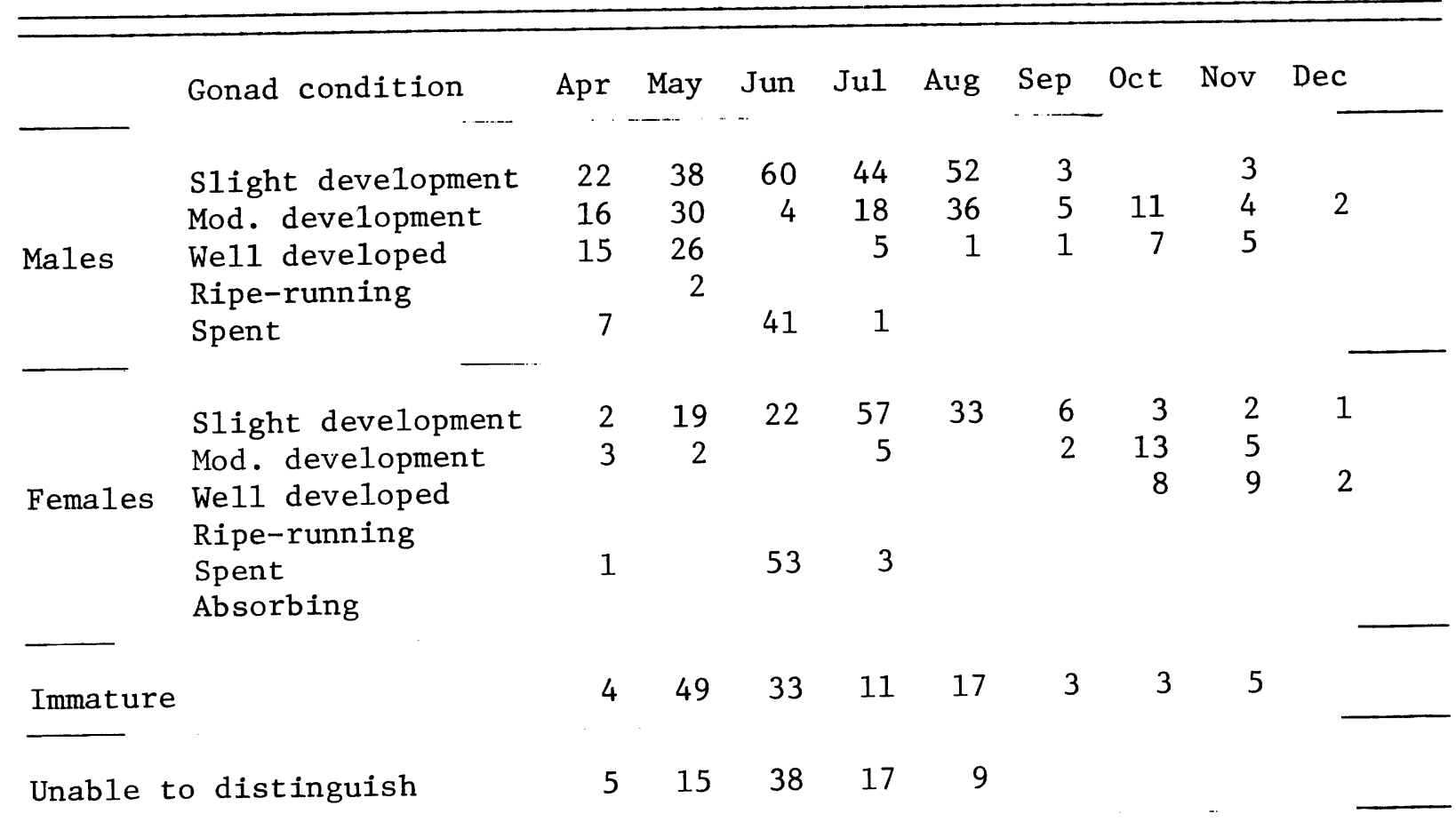




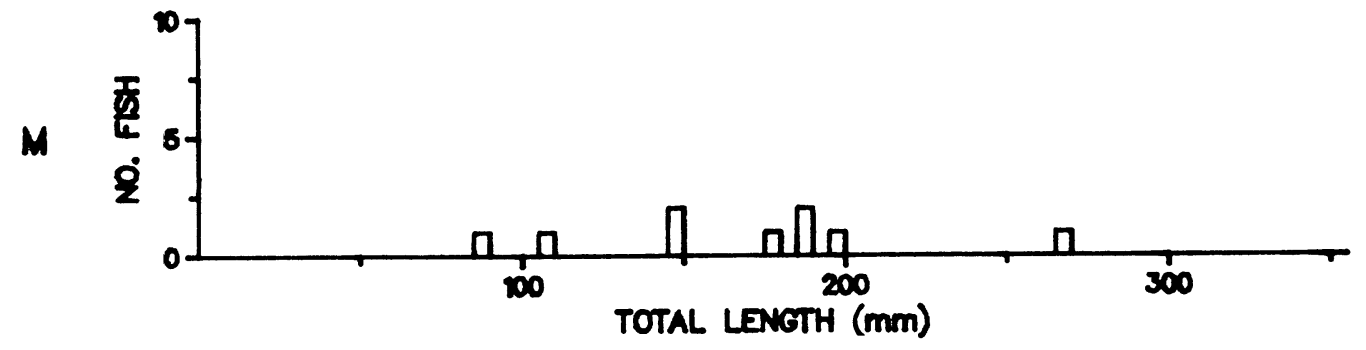

APRIL

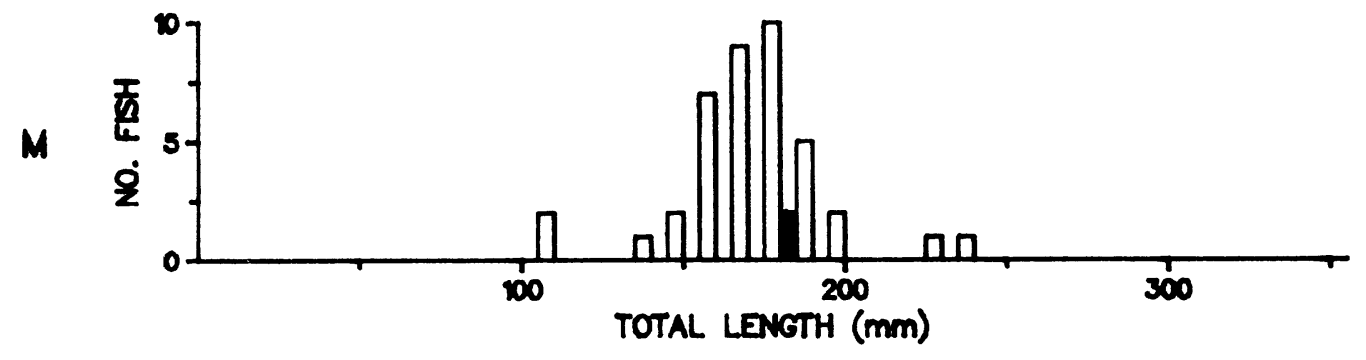

MAY

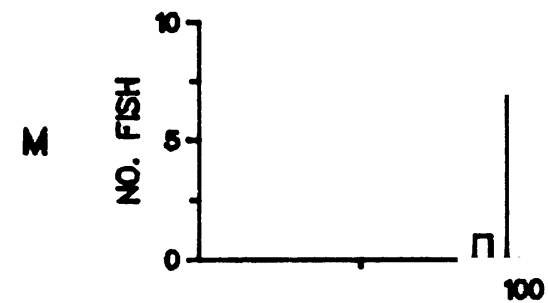

100
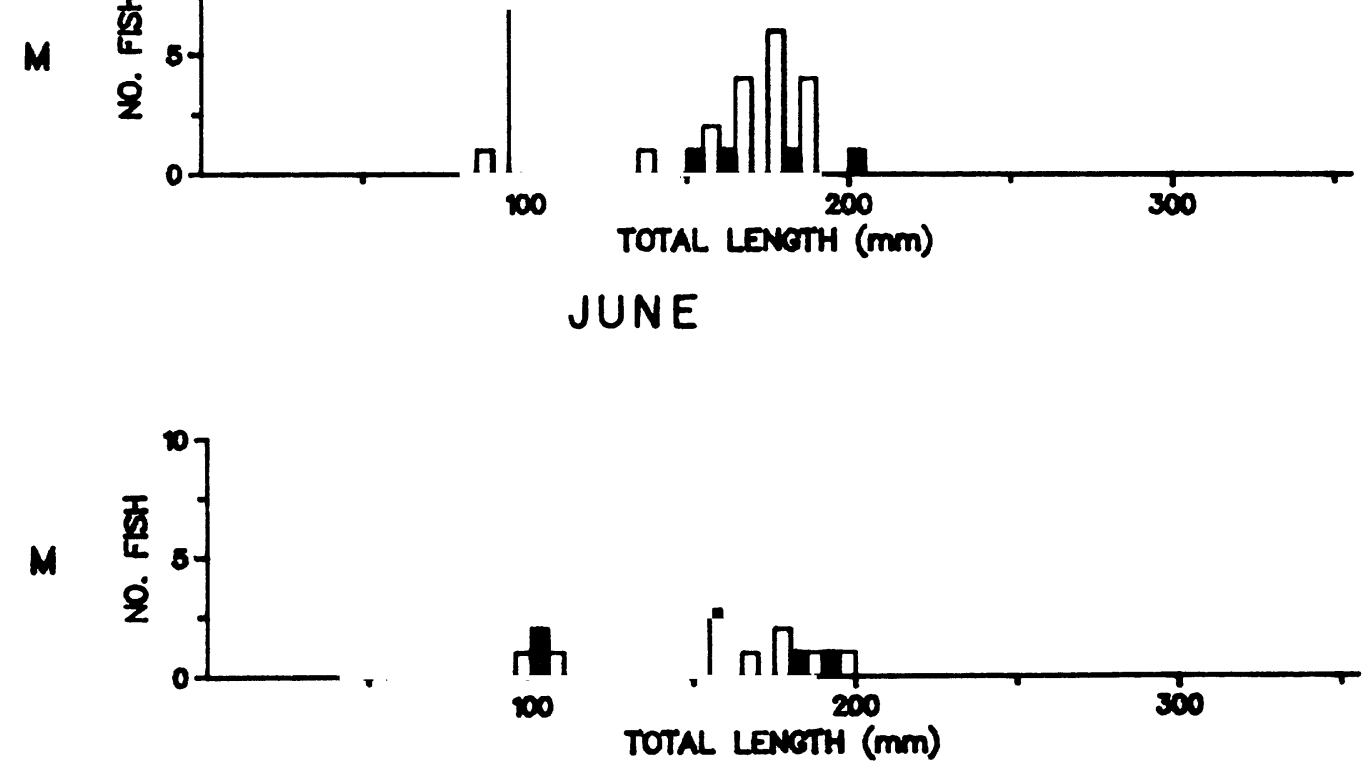

\section{JULY}

Fig. 61. Length-frequency histograms for yellow perch caught in duplicate bottom gill nets during April to December 1978 in Pigeon Lake near the J. H. Campbel1 Plant, eastern Lake Michigan. $\square=$ day $\square=$ night 


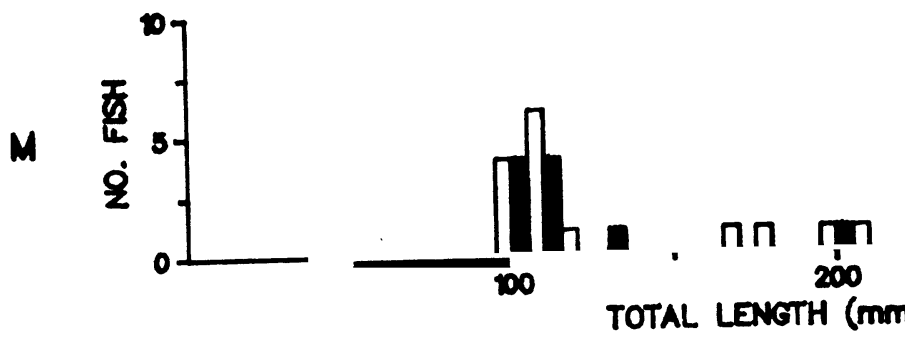

$3 \dot{00}$

*I AUGUST

M

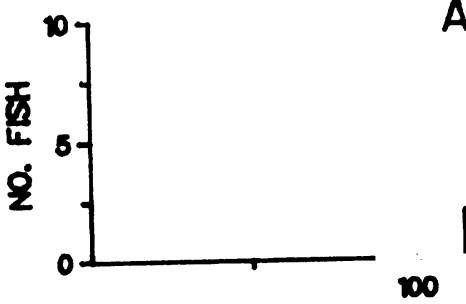

$\prod \prod$

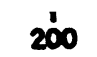

300

SEPTEMBER

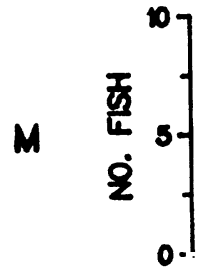
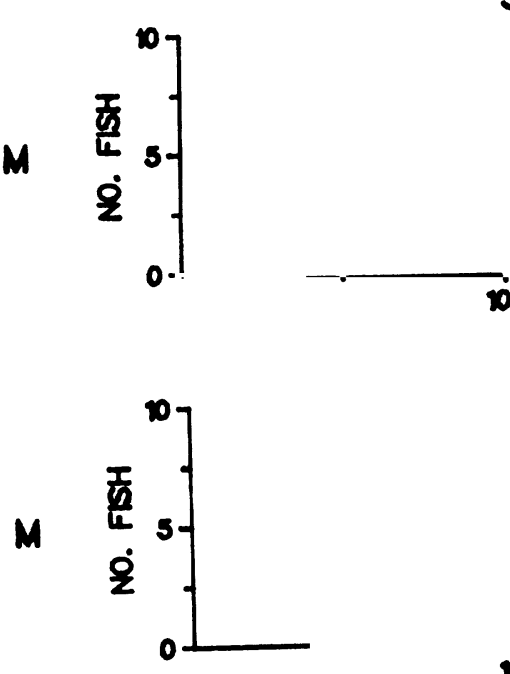

m TOTAL LENGTH $(\mathrm{mm})$

$\stackrel{100}{300}$ OCTOBER I. 

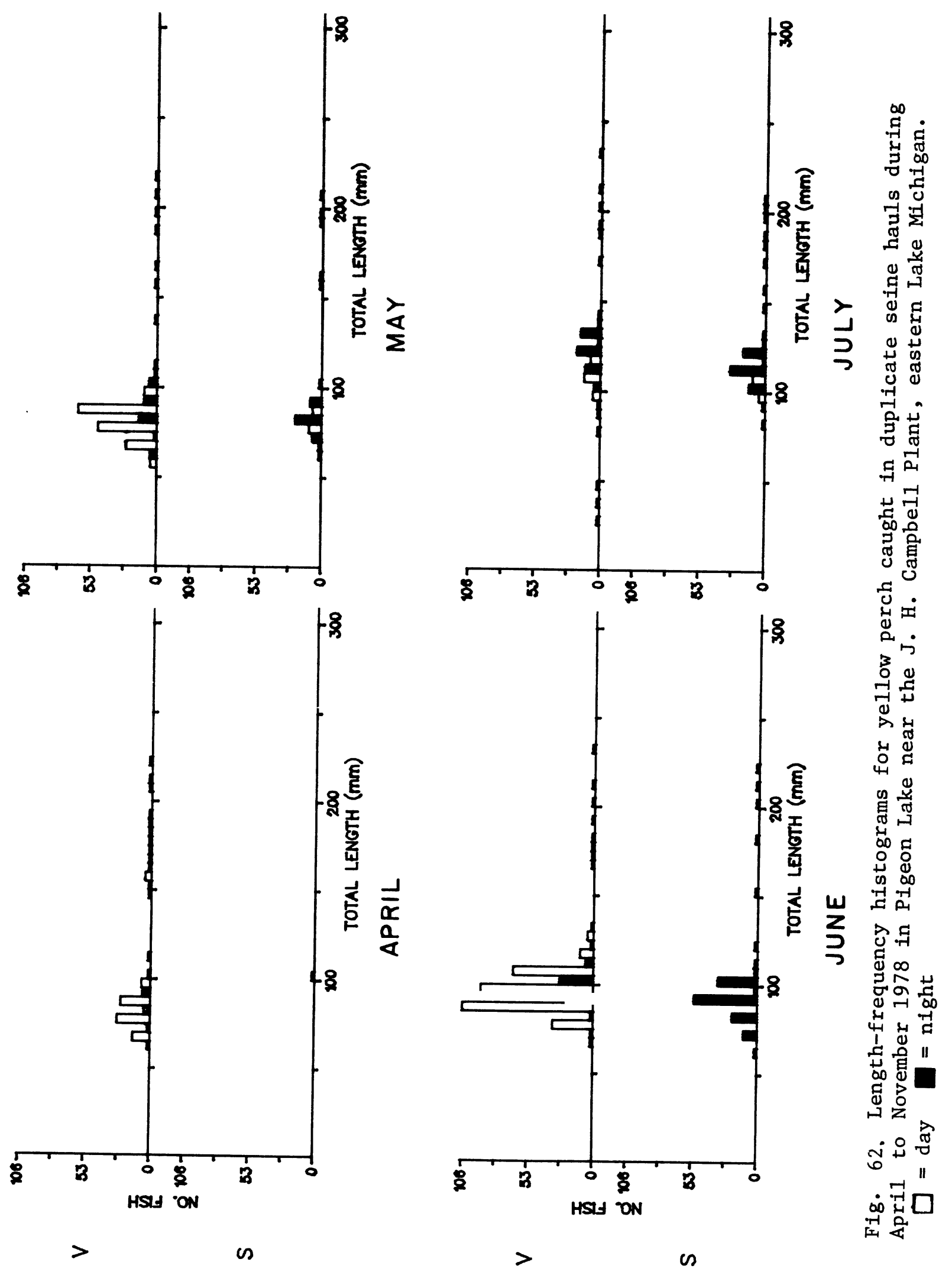

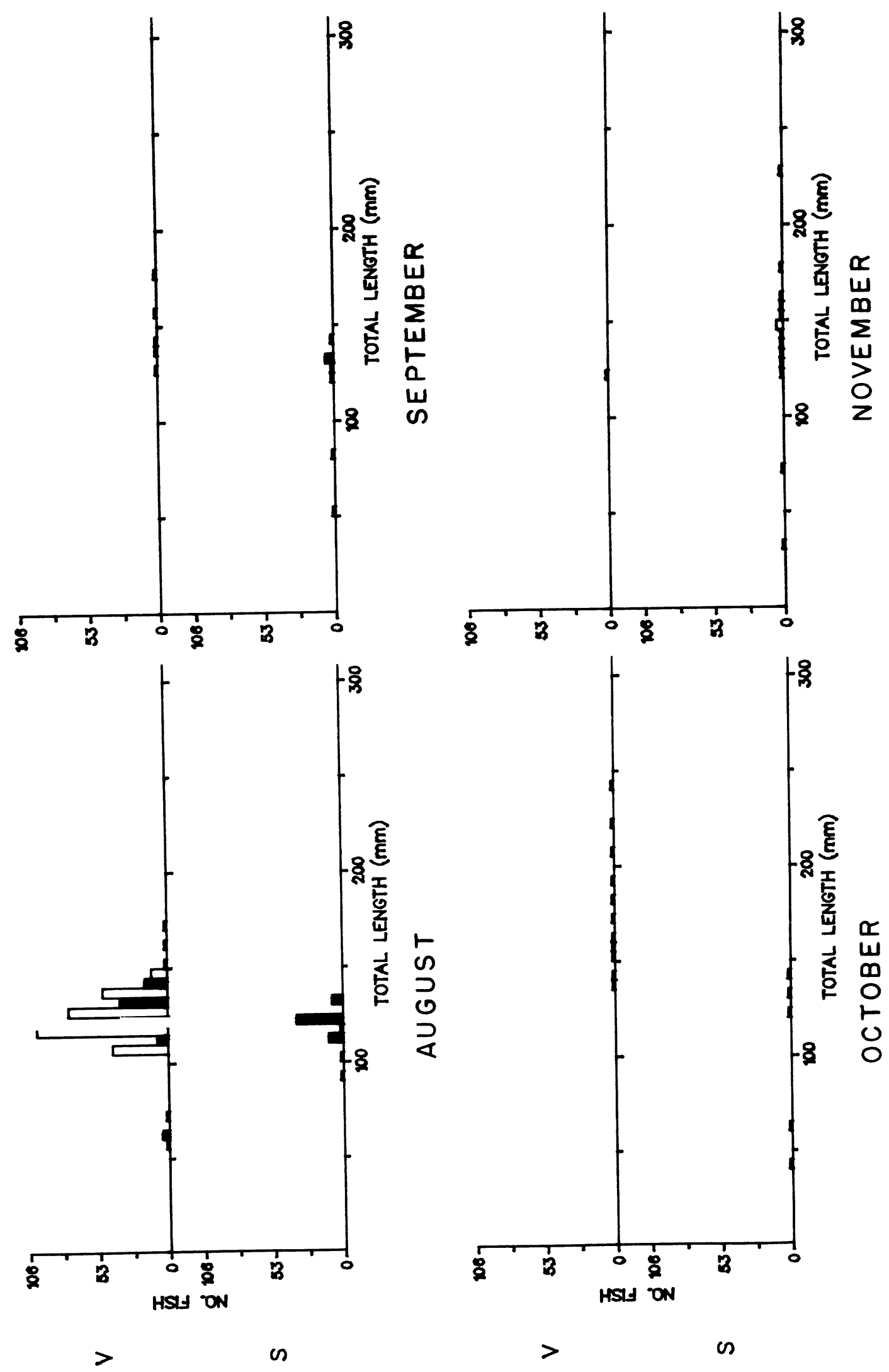

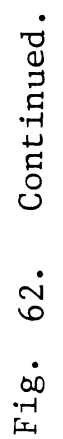


Although there were many larger older yellow perch collected at station $\mathrm{V}$ in April, the dominant age-group represented was yearling (60-110 mm length interva1). The extent to which yearlings participate in spawning activity is unknown. McComish (1975) reported that 99\% of the yearling male yellow perch and $50 \%$ of the females were sexually mature. Gill nets in Pigeon Lake at station $\mathrm{M}$ (influenced by Lake Michigan) in April caught nine yellow perch from various age groups indicating the presence of perch in the deepest area of Pigeon Lake in April (Fig. 61). It is unknown whether yellow perch from Lake Michigan entered Pigeon Lake to spawn in April, but it is possible that some yellow perch caught in Pigeon Lake in April were migrating into the protected areas of Pigeon Lake from Lake Michigan in search of suitable spawning habitat.

May--Increased numbers of yellow perch were observed at all adult fish sampling sites in Pigeon Lake in May (Figs. 61 and 62). Again, yellow perch from various size groups were abundant at beach station $\mathrm{V}$ (undisturbed Pigeon Lake), with yearlings being the dominant age-group represented. Yearling yellow perch were also abundant at beach station S (influenced by Lake Michigan) during May, where only one was seined in April. This substantial increase in numbers of perch caught at all Pigeon Lake stations in May may be the result of increased activity associated with warmer spring temperatures. Increased spawning activity in May was indicated by the observation of two ripe-running male perch (Table 30); however, the relative lack of females in samples was surprising.

June--The trend of increasing abundance of yellow perch at beach stations in Pigeon Lake continued during June (Fig. 62). Again, the dominant age-group in seine hauls was yearlings, with older age-groups consistently represented by fewer numbers. A slight decrease in numbers of yellow perch caught at Pigeon Lake station M (influenced by Lake Michigan) in June, was observed (Fig. 61). Gonad data (Table 30) from Pigeon Lake in June indicated that spawning activity was probably completed by this time, as the majority of perch were either spent or had only slight gonad development.

July--Relative to June, decreased numbers of yellow perch were observed during July at both Pigeon Lake beach stations and station M (influenced by Lake Michigan) (Figs. 61 and 62). The reason for this decline is not known, but may reflect natural variation inherent in our sampling design. It is evident from our data, that even in warmer months, yearling yellow perch remained in the shallower regions of Pigeon Lake. Seine hauls at station V (undisturbed Pigeon Lake) in June gave the first indication of the presence of YoY yellow perch in the area, since four were caught. No YOY were seined at station $S$ (influenced by Lake Michigan) in July.

During July when yearling perch from Lake Michigan were observed in the Lake Michigan beach zone, it was possible that some of these perch entered Pigeon Lake. The extent of interaction should be elucidated by studies now in progress.

August--Catch of yellow perch at beach station $\mathrm{V}$ (undisturbed Pigeon Lake) during August exceeded all other months in which collections were made (Figs. 57 and 62). Again, yearlings dominated the catch. Nine YOY yellow perch were also seined at station V (undisturbed Pigeon Lake) in August; at station S 
(influenced by Lake Michigan) yearling yellow perch were also present, but in reduced numbers compared with July. There was an absence of perch longer than $175 \mathrm{~mm}$ at both Pigeon Lake beach stations in August, which may indicate a movement of larger yellow perch from shallow water in August. Numbers of yellow perch caught in gill nets in August at station $M$ (influenced by Lake Michigan) increased over July catches. This seems primarily due to capture of yearlings which may be moving out of the beach area around station $S$ (as evidenced by decreased perch catch at station $S$ in August compared to July). Catch of larger yellow perch in gill nets at station $M$ showed a decrease in August (Fig. 61), continuing a trend toward decreasing abundance which was observed from June through December.

September--Catch of yellow perch in beach seine hauls during September in Pigeon Lake showed substantial decreases from August levels (Fig. 62). Yearlings were the most common age-group represented, with some YOY yellow perch also caught at station S (influenced by Lake Michigan). Again, no large perch (greater than $185 \mathrm{~mm}$ ) were seined at beach stations in September. Only four yellow perch were gillnetted in Pigeon Lake during September at station $M$ (influenced by Lake Michigan); they were all apparently yearlings (Fig. 61).

Distribution of the majority of the yellow perch population in SeptemberDecember is not well documented. Occasionally higher catches of yellow perch were sporadically recorded during October sampling at beach Station $\mathrm{V}$ (undisturbed Pigeon Lake) and during November at station S (influenced by Lake Michigan). For the most part, yellow perch abandoned the shore areas as autumn approached. Continued catches at station $M$ (influenced by Lake Michigan) indicated that some perch overwintered in this deep area of Pigeon Lake. It is known from observations of ice fishing success that yellow perch occupy to some extent a moderately deep area (approximate depth $2-3 \mathrm{~m}$ ) south of station $\mathrm{V}$ (undisturbed Pigeon Lake) during winter months. It is possible that this area, which we do not sample, is the area that the bulk of yearlings, so abundant in August, moved to in September. Larger perch, which become more infrequent in seine hauls after July may move either into the deep area near station $\mathrm{M}$ or to the moderately deep area south of station $\mathrm{V}$ (undisturbed Pigeon Lake).

Impingement--Impingement data collected at the J.H. Campbel1 Plant from January 1974 through March 1975 (Consumers Power 1975), and June-December 1977 (Zeitoun et al. 1978) showed that in general yellow perch were impinged at rates of less than $10 \mathrm{fish} / 24 \mathrm{~h}$ throughout the periods sampled with the exception of a few sporadic occurrences of higher impingement rates (up to $61 / 24 \mathrm{~h}$ ). In our study, impingement of yellow perch exceeded $10 / 24 \mathrm{~h}$ on only three sampling dates. Our results seem to indicate that some aspect of this species other than their seasonal migrations and movement was responsible for their sporadic impingement at higher rates.

Dates in 1978 when highest numbers of yellow perch were impinged were: 30 March (61 yellow perch impinged), 11 April (42 perch impinged) and 16 May (21 perch impinged). Seasonal movement of yellow perch as deduced from field collections suggested no causes for these periodic increases in perch impingement. Impingement observations made preceeding and subsequent to the days of greater 
yellow perch impingement indicated no gradual increase in numbers of perch impinged on preceeding dates and no gradual tapering of numbers of perch caught on subsequent days, as would be expected if the cause of high impingement was some natural seasonal movement of perch into the area.

It is probable that the occasional high numbers of yellow perch impinged at the Campbell Plant was the result of chance entrance of yellow perch schools into intake structures. Gonad data from impinged yellow perch showed that some perch impinged during April were ripe-running. This suggests that perch with well developed or ripe-running gonads originated in Pigeon Lake since they exhibited similar gonad conditions (Table 30). Although origin of the other yellow perch impinged can not be confirmed, it is probable that they were also part of the Pigeon Lake population.

Temperature - catch relationships--In 1977 and 1978 water temperature at time of capture for any one size group of yellow perch varied considerably. In Pigeon Lake, there was some tendency of larger fish to be caught at lower water temperatuses; however, Lake Michigan data showed no conspicuous trend. McCauley and Read (1973) indicated that older yellow perch tended to select cooler temperatures than younger perch acclimated to the same temperature. Jude et al. (1979) observed that smaller perch $(60-120 \mathrm{~mm})$ were most of ten caught at water temperatures 16-19 C and larger perch 230-330 mm at 14-17 C.

Plant impacts--There are endemic populations of yellow perch in Lake Michigan and in Pigeon Lake. These populations do not overlap significantly, except for the introduction of Lake Michigan perch larvae into Pigeon Lake during June, the usual Lake Michigan hatching period for perch, which is later than Pigeon Lake perch. Impacts the plant has on these two relatively distinct populations must be evaluated accordingly. The Pigeon Lake perch population is much higher $(17.7 \%$ of the total catch) relative to other species than is the Lake Michigan perch population (1.2\%). Pigeon Lake is also a much more productive lake than Lake Michigan; however, a large part of the Pigeon Lake population is comprised of what appear to be yearlings (Appendix 6) with few large adults in the population. Reasons for this could be overfishing or possibly stunting. In 1979 we plan to collect yellow perch from Pigeon Lake and Lake Michigan for age analysis to determine if Pigeon Lake yellow perch are stunted. In Lake Michigan, there is a more balanced distribution of adults with larger individuals well represented in catches. Pigeon Lake adults annually produce large numbers of eggs, both because Pigeon Lake is productive and there is a large number of spawning individuals per unit area. The reverse is probably true in Lake Michigan. Spawning grounds are poorly known and the annual larval production on a density basis is much less in Lake Michigan compared to Pigeon Lake. Added to these factors is the suggested competitive effect by alewives (adult and larvae) on yellow perch larvae (Smith 1970). It is our feeling that once Lake Michigan perch larvae survive the early mortality factors, they grow well, first feeding on an abundance of benthic organisms and alewife eggs, then switching to alewife when they are large enough.

Keeping these basic differences between the two populations in mind, it is important to evaluate the impact of the plant on the appropriate population. Loss of larvae or adults from Pigeon Lake is less serious than a similar loss from Lake Michigan, because there appear to be large numbers of larvae produced 
each year in Pigeon Lake and the adult population there may be stunted. During 1978, over 16 million larvae were entrained by the J.H. Campbell Plant. Of these, 16,200,000 larvae were entrained during May, which is the spawning season for Pigeon Lake perch; the remainder were entrained during June $(205,000)$ and July $(30,800)$, the spawning season for Lake Michigan perch. In our production foregone calculations, we made no distinctions between area of origin of yellow perch larvae and assumed that all came from Lake Michigan (see RESULTS AND DISCUSSION - PRODUCTION FOREGONE DUE TO ENTRAINMENT AND IMPINGEMENT). A1most all the production foregone was due to entrainment of prolarvae and postlarvae. The lost biomass, $27,676 \mathrm{~kg}$, was worth $\$ 49,851$ according to 1978 commercial fish prices.

The projected total impingement loss of yellow perch for 1978 was 1,519 fish, with March (480), April (487) and May (186) months of major impingement. These months are also the prespawning and spawning season for Pigeon Lake perch and to a smaller degree (May), Lake Michigan adults. Thus, we believe that most impinged juveniles and adults also originated from the Pigeon Lake population, again lessening the impact on the respective populations.

Regarding the Lake Michigan perch population, we feel the entrainment of over 235 thousand larvae and the impingement of probably no more than 300 juveniles and adults had an unmeasurable effect on the population. In Pigeon Lake, as noted in 1978, a large portion of the population was comprised of yearlings. These fish as YOY dominated 1977 catches. Comparisons of numbers of perch caught in 1978 vs. 1977 are complicated by the deletion of station T, a productive station, in 1978. However, even taking this into consideration, yellow perch catches during June-December $1978(1,327)$ were probably comparable to 1977 catches $(2,459)$. Data from 1979 and 1980 will be required to verify our conclusions, but based on what we have collected to date, we feel the Pigeon Lake perch population has not suffered a serious decline due to operation of the J.H. Campbell Plant.

Summary--Yellow perch were abundant in the area of the Campbell Plant in 1978 comprising $1.2 \%$ of the Lake Michigan catch and $17.7 \%$ of the Pigeon Lake catch. Sampling in Lake Michigan from April to June indicated yellow perch were common at the beach zone, and some indication of movement of larger adults (greater than $175 \mathrm{~mm}$ ) into depths $<18 \mathrm{~m}$ was established. August catch showed that yearling yellow perch were caught less frequently in the Lake Michigan beach zone. Yearling yellow perch, as well as older perch were most common at $1.5-9 \mathrm{~m}$ in August. The first catch of YOY yellow perch in Lake Michigan was observed in September when they were common at 3-9 m. Older yellow perch showed a more even distribution at 1.5-12 $\mathrm{m}$ in Lake Michigan. October sampling in Lake Michigan showed YOY yellow perch at 9-15 $\mathrm{m}$ with a sporadic occurrence of larger fish at 3-12 m. Lake Michigan gill net and seine data in November however, indicated that yellow perch did occasion $1.5 \mathrm{~m}$ in autumn. YOY yellow perch were the prominent year class observed in catches during December trawls, indicating that this year class may remain inshore throughout winter months.

In Pigeon Lake during April, yearling yellow perch were more abundant in the area near beach station $V$ (undisturbed Pigeon Lake) than beach station $S$ (influenced by Lake Michigan). This distributional difference was probably 
related to water temperature. Catch of yellow perch at gill net station $M$ (influenced by Lake Michigan) was low (only nine caught) in April. From May to July catch of yellow perch in Pigeon Lake was similar with large seine catches dominated by yearling perch. Gill net catches at 6-m station $M$ showed a trend toward decreased numbers caught from May through July. YOY yellow perch were first caught in seine hauls in Pigeon Lake during July.

During August yearling yellow perch were still abundant at Pigeon Lake beach stations; however, older perch were noticeably absent. Older yellow perch may have left the Pigeon Lake beach zone and moved into deeper sections of Pigeon Lake. Data collected from September to November showed that YOY, yearlings and older yellow perch were present at beach stations in Pigeon Lake in decreased abundance relative to catches during summer months. The occasional observation of yellow perch in gill nets at station $M$ as well as observations of ice-fishing success indicate that yellow perch move into deeper water (2-7 m depth) during cooler months, but may occasion beach areas.

Impingement of yellow perch at the Campbell Plant exceeded $10 \mathrm{fish} / 24 \mathrm{~h}$ on only three dates sampled during 1978. Days of highest impingement did not coincide with any seasonal movement of yellow perch. We believe this was the result of random movements of schooling perch into the intake structure.

Golden Shiner--

Introduction--In 1978 the second most abundant fish species caught in Pigeon Lake was the golden shiner. None were caught in Lake Michigan. A11 2220 fish were seined (Fig. 63). April and May accounted for $96 \%$ of the catch. Most of the golden shiners were collected at beach station $\mathrm{V}$ (undisturbed Pigeon Lake). Smaller numbers of fish were caught at beach station $S$ (influerced by Lake Michigan). In 1977, numbers of golden shiners caught at beach station $\mathrm{T}$ (Pigeon River station excluded from 1978 sampling scheme) far exceeded catches from other locations. Indeed a greater number of golden shiners were collected in 1977 ( $92 \%$ at station $\mathrm{T}$ ) than in 1978, even though sampling was not performed during April or May 1977 (months of greatest catch in 1978).

Golden shiners between 40 and $170 \mathrm{~mm}$ were collected, but most fell between 50 and $100 \mathrm{~mm}$. According to Cooper (1935) golden shiners from 50 to $70 \mathrm{~mm}$ (standard length) are mature.

Seasonal distribution--In April and May adult golden shiners (most of them 50-100 mm) (Fig. 64) had begun congregating (probably over spawning grounds) near beach station $\mathrm{V}$ (undisturbed Pigeon Lake) (Fig. 63). Water temperatures in April were between 10.5 and $12.5 \mathrm{C}$ at station $\mathrm{V}$ and most of the $108 \mathrm{fish}$ examined in April had slightly or moderately developed gonads (Table 31). A few had well developed gonads.

A drastic reduction in the numbers of golden shiners collected in field samples (2 fish) occurred in June (Fig. 63). It would seem that spawning had occurred sometime between the May and June field sampling dates and that adults vacated the spawning grounds for deeper water soon after spawning. Golden shiners spawn from June to August in Michigan according to Scott and Crossman (1973). 


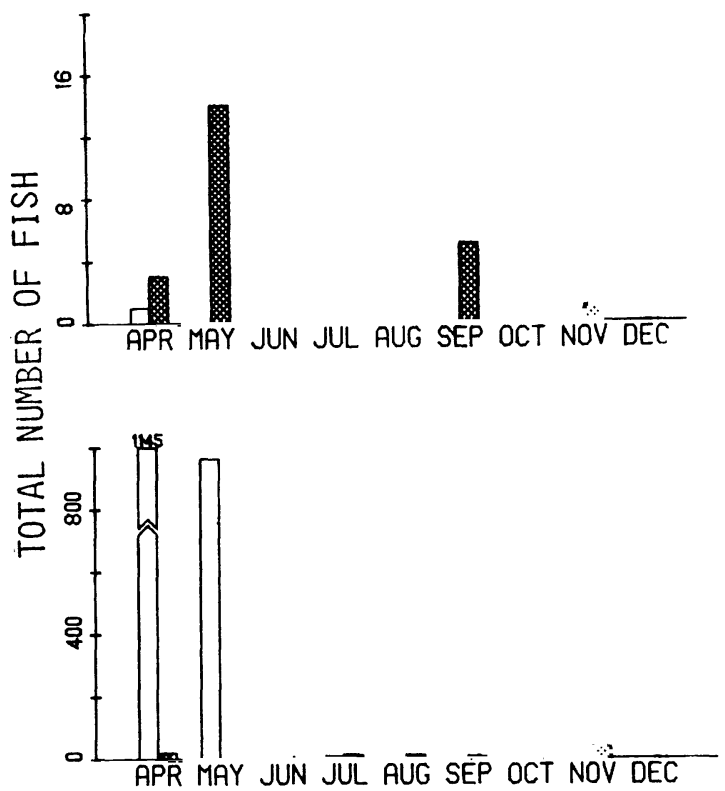

Fig. 63. Total number of golden shiners caught in duplicate seine hauls during day and night once per month April to November 1978 in Pigeon Lake near the J. H. Campbell Plant, eastern Lake Nichigan. $\square=$ day $\square=$ night

Table 31. Monthly gonad conditions of golden shiners caught during 1978 in Lake Michigan near the J. H. Campbell Plant, eastern Lake Michigan. All fish examined in a month were included except poorly received specimens.

\begin{tabular}{|c|c|c|c|c|c|c|c|c|c|c|}
\hline & Gonad condition & Apr & May & Jun & $\mathrm{Jul}$ & tug & Sep & Oct & Nov & Dec \\
\hline Males & $\begin{array}{l}\text { Slight development } \\
\text { Mod. development } \\
\text { Well developed } \\
\text { Ripe-running } \\
\text { Spent }\end{array}$ & $\begin{array}{r}25 \\
8 \\
1\end{array}$ & $\begin{array}{r}21 \\
2\end{array}$ & & $\begin{array}{l}5 \\
4 \\
1\end{array}$ & 2 & 1 & & 2 & \\
\hline Females & $\begin{array}{l}\text { Slight development } \\
\text { Mod. development } \\
\text { We11 developed } \\
\text { Ripe-running } \\
\text { Spent } \\
\text { Absorbing }\end{array}$ & $\begin{array}{r}18 \\
12 \\
1\end{array}$ & $\begin{array}{r}13 \\
12 \\
7\end{array}$ & 2 & 1 & & & & 5 & \\
\hline Immature & & 23 & 15 & & 3 & & 9 & & 20 & \\
\hline Unable $t$ & o distinguish & 20 & 30 & & 3 & 9 & & & 9 & \\
\hline
\end{tabular}



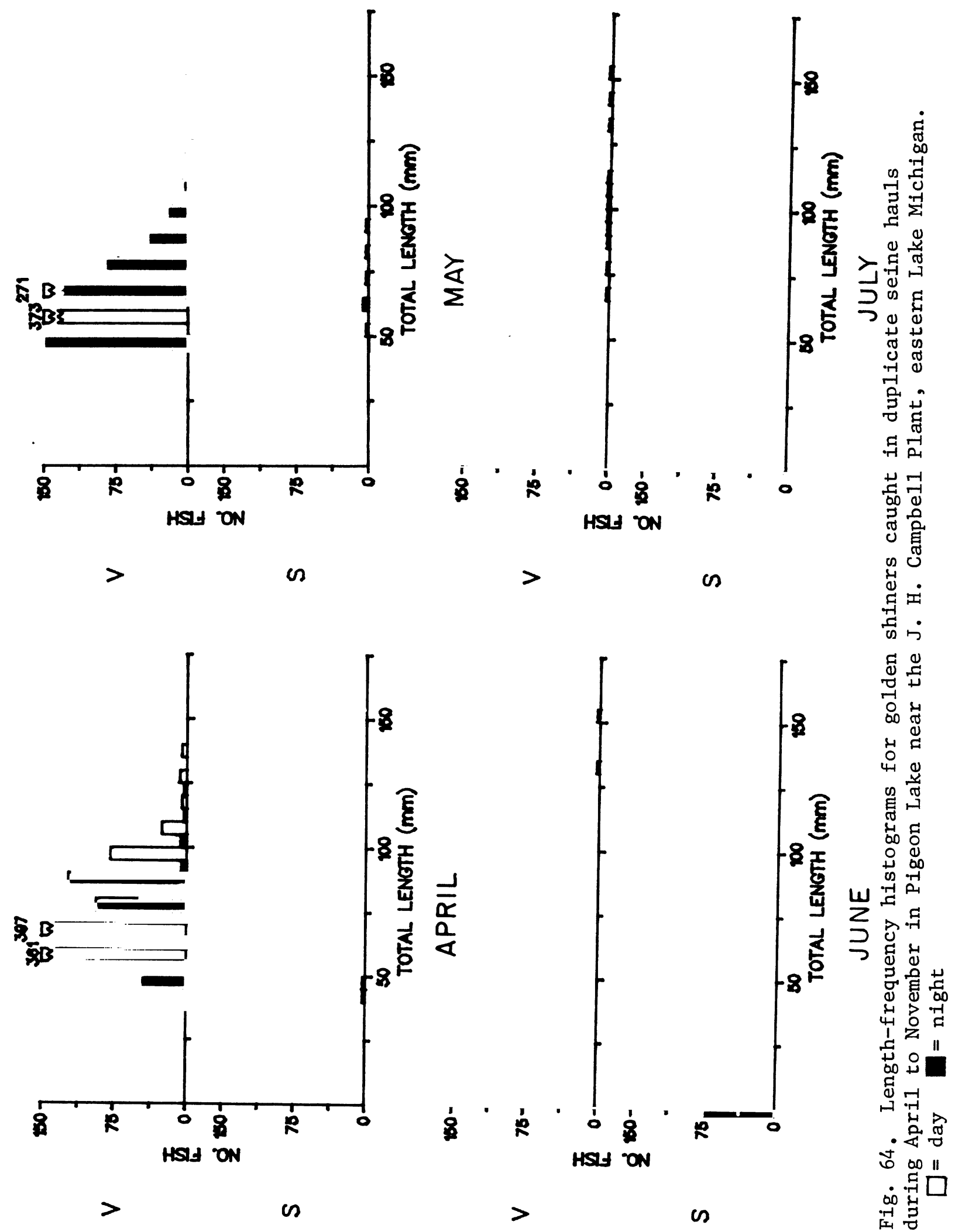


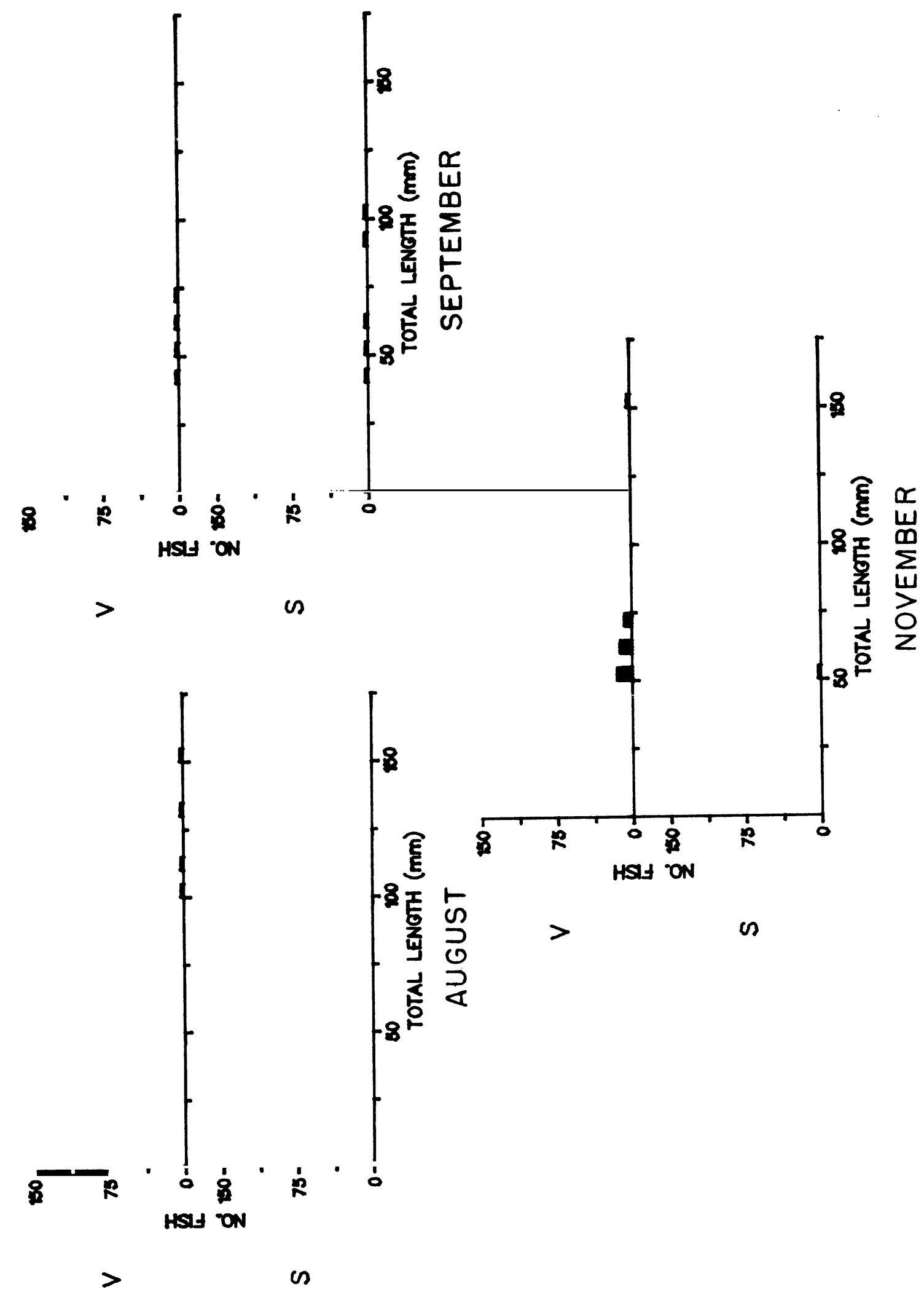

苍

ชั

a 
A late May-early June spawning by this species was assumed to have occurred in Pigeon Lake in 1977 (Jude et al. 1978). Number of golden shiners caught increased slightly in July as 17 fish from 70 to $100 \mathrm{~mm}$ were seined (Fig. 64). These fish may have been late spawners, or they may have been searching for food or avoiding predators in the vegetation of the shallow water. Although no golden shiners were identified in stomach contents of piscivorous fish, they are reported as forage fish for the young of certain game species (Scott and Crossman 1973). Water temperature in July was around $20 \mathrm{C}$.

In August, 11 golden shiners between 100 and $150 \mathrm{~mm}$ were caught in night seine hauls (Fig. 64). Water temperature was $25 \mathrm{C}$. Again searching for food or avoidance of predators may explain the presence of these few fish in the beach zone. Golden shiners examined in August were in too poor condition to determine gonad condition (Table 31).

Ten golden shiners $(40-100 \mathrm{~mm})$ were seined in September (water temperature $19 \mathrm{C}$ ), half at station $\mathrm{S}$ and half at station V (Fig. 64). Nine of these fish were immature (Table 31). Cooper (1935) found that differences in length of the growing season and mean annual temperature affect golden shiner growth and that once maturity is achieved, further growth is inhibited. Thus it is difficult to speculate how many of the immatures collected were YOY exhibiting good growth or yearlings exhibiting poor growth.

No golden shiners were caught in October and it appeared that all size groups had moved to deeper water for the winter (water temperature had dropped to $10.5 \mathrm{C}$ ). However, 35 golden shiners between 50 and $70 \mathrm{~mm}$ (plus one 150-mm individua1) were caught at night in November (Fig. 64). Again it was uncertain whether or not these fish were YOY. Water temperature was $10.5 \mathrm{C}$ in November. By December golden shiners moved to deeper water as none were caught in field samples.

Impingement--Only three golden shiners were found in 24-h impingement samples in 1978; one fish each in April (70 mm), September (100 $\mathrm{mm}$ ) and December $(70 \mathrm{~mm})$. Estimates from these impingement samples indicated that on $1 \mathrm{y} 21$ golden shiners were impinged during 1978. No golden shiners were observed in impingement samples from June-December 1977 (Zeitoun et al. 1978), however 22 were collected in impingement sampling conducted from January 1974-March 1975 (Consumers Power 1975).

Temperature-catch relationships--Ninety-eight percent of the golden shiner catch came from water between 11 and $17 \mathrm{C}$. Other golden shiners were caught in water from 9 to $25 \mathrm{C}$. Larger golden shiners were caught at slightly higher temperatures than smaller golden shiners (Fig. 65), but this is probably more a reflection of gear bias and seasonality of temperature than of a sizetemperature preference relationship. 


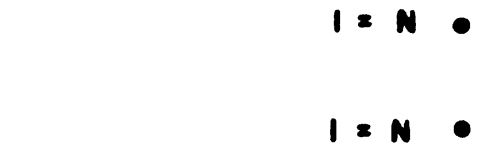

$$
L=N
$$

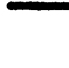

$$
\theta=N
$$

$s 1=N$

$Z 1=N$

$O t=N$

$\frac{1}{1}$

SII $=\mathbf{N}$

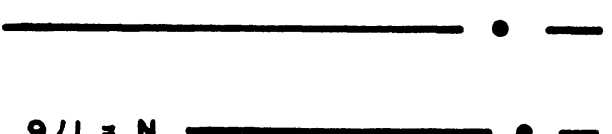

$z$
0
$\frac{1}{0}$
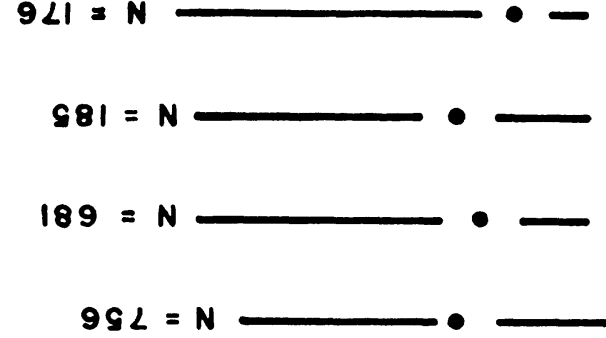

$812=N$

$$
S=N
$$

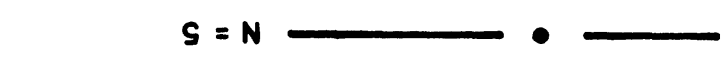

$\begin{array}{ll}\vdots & \dot{1} \\ m & \text { n }\end{array}$

인

í

(0) $\exists y n \perp \forall \forall \exists d W \exists \perp$

$0^{0}$

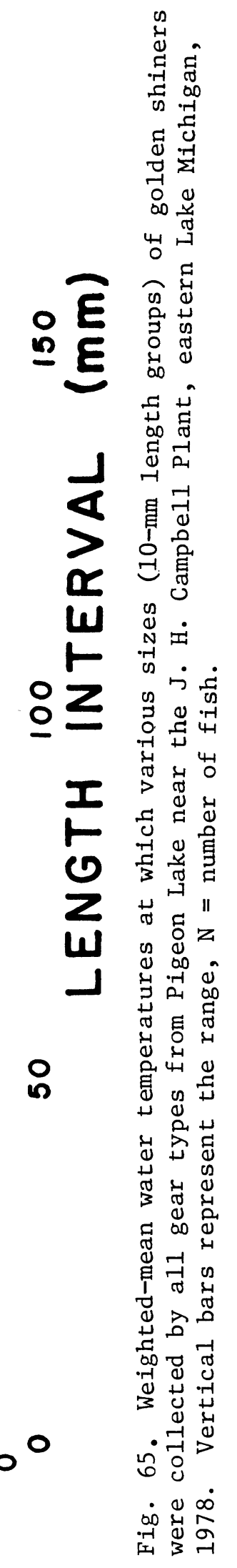


Summary--The catch of golden shiners at beach stations $\mathrm{V}$ (undisturbed Pigeon Lake) and S (influenced by Lake Michigan) increased significantly from 1977 to 1978. Golden shiners were most abundant in the area of the J.H. Campbell Plant during April and May 1978. Individuals caught at this time appeared to be near spawning condition, most being seined at Pigeon Lake station $V$. A few large larvae and fry were recovered at Pigeon Lake stations $\mathrm{S}$ and $\mathrm{X}$ (undisturbed Pigeon Lake) during July 1978.

Trout-perch--

Introduction--Trout-perch inhabit all the Great Lakes and a few of the larger inland lakes (Hubbs and Lagler 1958). In Lake Michigan this species occurs most commonly in shoal areas, but may range into water as deep as $94 \mathrm{~m}$ (House and We11s 1973).

Trout-perch were one of the more common species near the Campbell Plant and were caught mostly from Lake Michigan. Trout-perch made up approximately $1.1 \%$ of the total catch in Lake Michigan in 1977 and slightly more than $2 \%$ in 1978. Trout-perch during 1977 and 1978 were caught mostly in trawls. Only a small number of trout-perch were collected in Pigeon Lake during 1978; few were impinged on the traveling screens of the Campbe11 Plant.

\section{Seasona1 distribution--}

Apri1--Trout-perch remained in deepwater during winter. In February, they were found at depths from 23 to $37 \mathrm{~m}$ in eastern Lake Michigan (We11s 1968). Inshore migration of trout-perch started in spring. During April, Jude et al. (1975) caught small numbers of trout-perch at $9 \mathrm{~m}$ or shallower water in southeastern Lake Michigan. Trout-perch were also scarce near the Campbell Plant during April (Figs. 66, 67 and 68). Eleven trout-perch, including six adults $(70-110 \mathrm{~mm}$ ) and five yearlings $(40-65 \mathrm{~mm})$, were collected in our study area in April (Table 13).

Trout-perch were reported to spawn from May to August in Lake Erie (Kinney 1950) and in Lower Red Lake, Minnesota (Magnuson and Smith 1963). Gonad data (Table 32) indicated that trout-perch spawning took place from April to September in the study area. Occurrence of small larvae in May and September (see RESULTS AND DISCUSSION - FISH LARVAE AND ENTRAINMENT STUDY, Trout-perch) confirmed this extended spawning season of trout-perch.

During early spring trout-perch were probably attracted to warm water in shallow areas since all 11 trout-perch collected in April were caught from $6 \mathrm{~m}$ or shallower water. Most trout-perch (seven) were seined at beach station Q (S discharge) where water temperature $(7.8 \mathrm{C}$ ) was higher than was observed at other nearshore areas (Appendixes 1, 2 and 3).

May--Trout-perch catches rose sharply in May (Fig. 66-68) due undoubtedly to increased inshore migrations. They were caught by all gear, but only low numbers were taken in seines (Fig. 66), bottom gill nets (Fig. 67) and surface gill nets. During May and remaining months of the study, most trout-perch were caught at night (Appendix 6) confirming the pronounced nocturnal habit of 
$\mathrm{R}$

$\mathrm{N}$ DISCHARGE

Q

S DISCHARGE

$P$

S REFERENCE
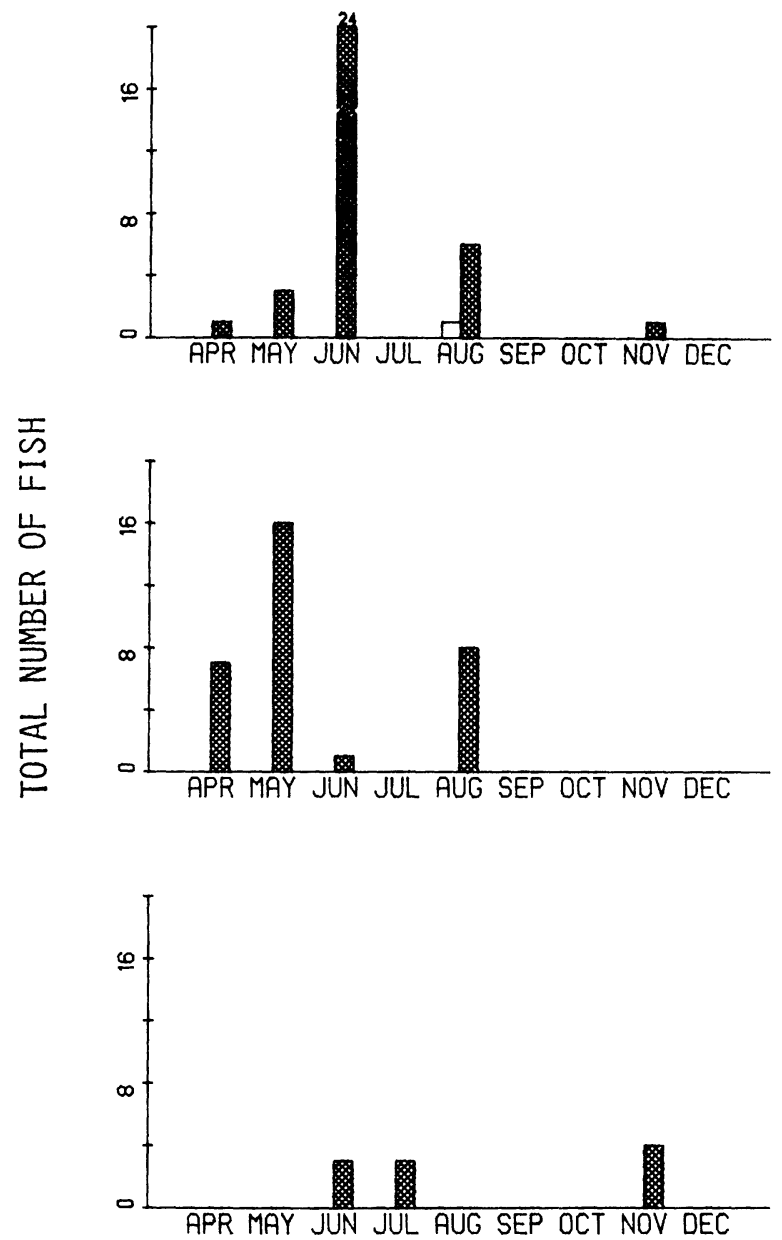

Fig. 66. Total number of trout-perch caught in duplicate seine hauls during day and night once per month April to November 1978 in Lake Michigan near the J. H. Campbell Plant, eastern Lake Michigan. $\square=$ day $\square=$ night 
$L \cdot 6 m-N)$

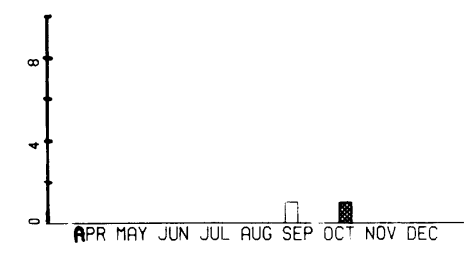

$E(12 m-S)$

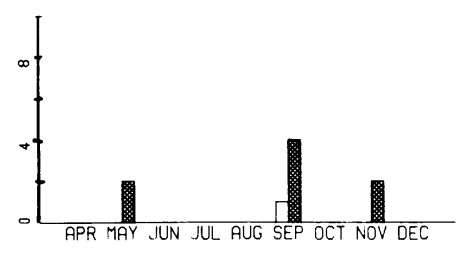

D $9 m-5)$

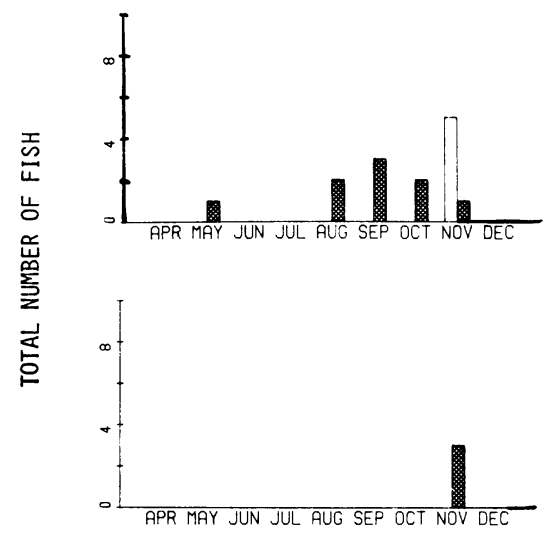

B $(3 m-5)$

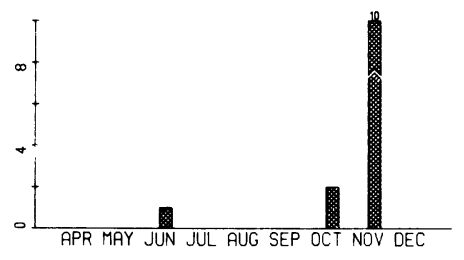

A $(1.5 m-s)$

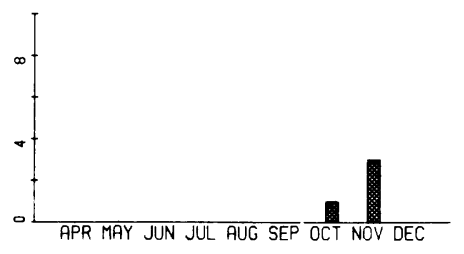

Fig. 67. Total number of trout-perch caught in duplicate bottom gill nets fished during day and night once per month April to November 1978 in Lake Michigan near the J. H. Campbe11 Plant, eastern Lake Michigan. $\square=$ day $\square=$ night 
$N(8 ; N)$

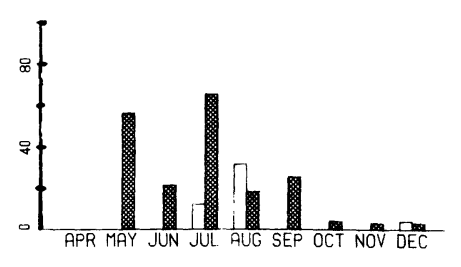

$L(6 m-N)$

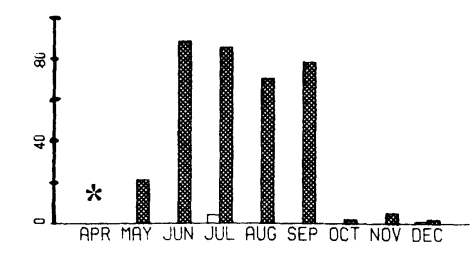

$F(15 m-s)$

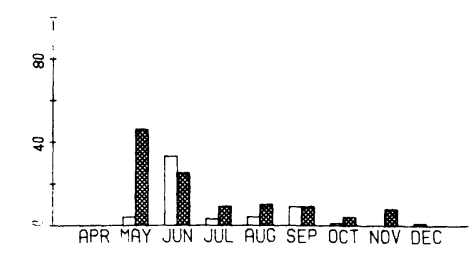

$E(12 m-5)$

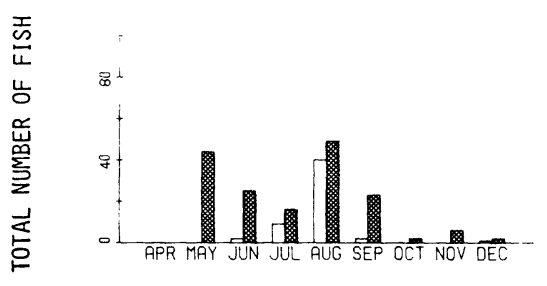

$0(9 m-5)$

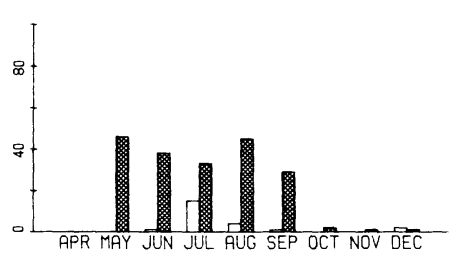

C $(6 m-5)$

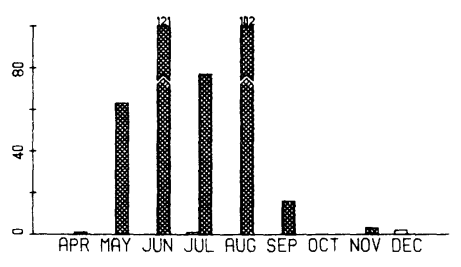

$B(3 m-5)$

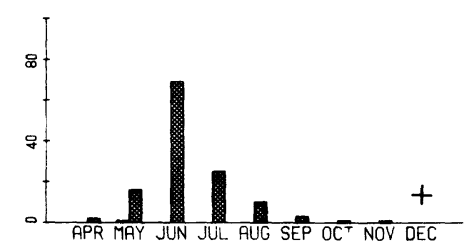

FIg. 68. Total number of trout-perch caught in duplicate trawl hauls during day and night once per month April to December 1978 in Lake Michigan near the J. H. Campbell Plant, eastern Lake Michigan. $\square=$ day $\square=$ night $*=$ no night sampling performed, $+=$ no sampling performed. 
Table 32. Monthly gonad conditions of trout-perch caught during 1978 in Lake Michigan near the J.H. Campbell Plant, eastern Lake Michigan. All fish examined in a month were included except poorly received specimens.

\begin{tabular}{|c|c|c|c|c|c|c|c|c|c|c|}
\hline & Gonad condition & Apr & May & Jun & $\mathrm{Jul}$ & Aug & Sep & Oct & Nov & Dec \\
\hline Males & $\begin{array}{l}\text { Slight development } \\
\text { Mod. development } \\
\text { Well developed } \\
\text { Ripe-running } \\
\text { Spent }\end{array}$ & 1 & $\begin{array}{l}36 \\
53 \\
22\end{array}$ & $\begin{array}{r}48 \\
41 \\
32 \\
7 \\
2\end{array}$ & $\begin{array}{l}36 \\
45 \\
24 \\
11\end{array}$ & $\begin{array}{r}47 \\
82 \\
12 \\
4\end{array}$ & $\begin{array}{r}50 \\
20 \\
10 \\
3\end{array}$ & $\begin{array}{l}3 \\
3\end{array}$ & $\begin{array}{l}4 \\
8 \\
2\end{array}$ & 5 \\
\hline Females & $\begin{array}{l}\text { Slight development } \\
\text { Mod. development } \\
\text { Well developed } \\
\text { Ripe-running } \\
\text { Spent } \\
\text { Absorbing }\end{array}$ & $\begin{array}{l}1 \\
1\end{array}$ & $\begin{array}{r}24 \\
44 \\
42 \\
2 \\
1\end{array}$ & $\begin{array}{l}29 \\
36 \\
32 \\
15 \\
14\end{array}$ & $\begin{array}{l}18 \\
37 \\
39\end{array}$ & $\begin{array}{l}29 \\
53 \\
16 \\
\\
8 \\
2\end{array}$ & $\begin{array}{r}33 \\
29 \\
4\end{array}$ & $\begin{array}{l}2 \\
6 \\
2\end{array}$ & $\begin{array}{r}1 \\
33 \\
5\end{array}$ & $\begin{array}{r}10 \\
4\end{array}$ \\
\hline Immature & & 7 & 13 & 52 & 48 & 35 & 12 & 2 & 3 & \\
\hline Unable $t$ & dictimalob & 1 & 19 & 19 & 13 & 9 & 8 & & & \\
\hline
\end{tabular}

this species (Scott and Crossman 1973).

During May and most other months trout-perch exhibited a diel migration similar to that observed in 1977 which consisted of a movement to shallow areas at night and a return to deepwater during the day. At night adults ( $70 \mathrm{~mm}$ and larger) were caught at all depths sampled, the majority being found at $6 \mathrm{~m}$ and deeper water (Fig. 66 and 68). During the day a few adults occurred at 9 to $15 \mathrm{~m}$ (Fig. 67 and 68 ) which could partially be explained by daytime net avoidance. Of the 19 adults caught in the beach zone during May, most (16) were seined at beach station Q (S discharge) (Fig. 69). Contrary to April results, there appeared to be no correlation between water temperature and trout-perch distribution in the beach zone during May. Water temperatures taken at seining time were approximately the same at the three beach stations (Appendix 2). More trout-perch with ripe-running and spent gonads were caught in May than in April indicating an increase of spawning activity as the spawning season progressed.

Yearlings were relatively scarce in May, since only 12 yearlings in the 30-60-mm interval were collected (Appendix 6), all from $9 \mathrm{~m}$ or deeper. Yearling catches were substantially lower than catches of older fish during this month. Like adults, catches of yearlings occurred mostly at night. 

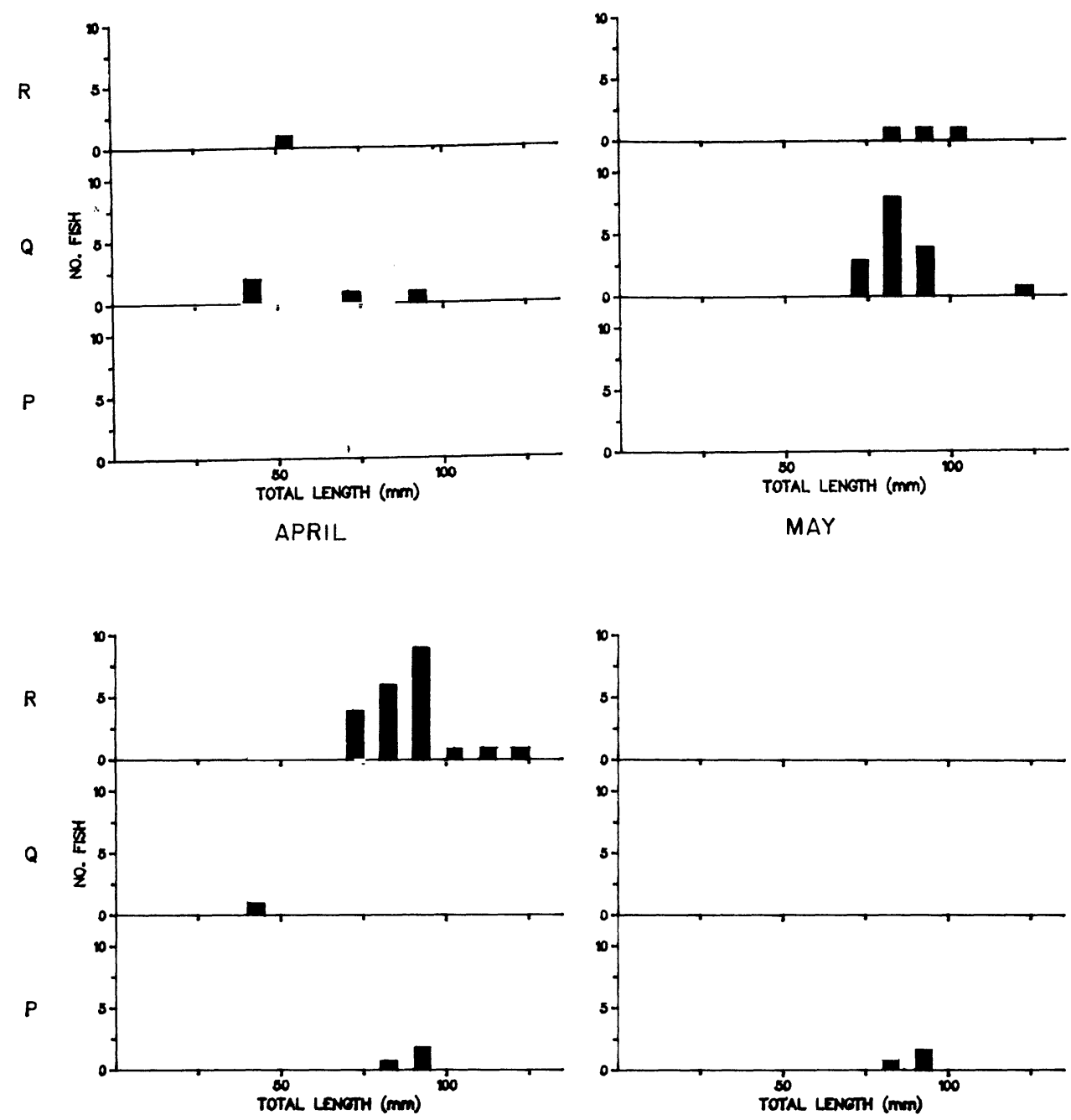

JUNE

JULY
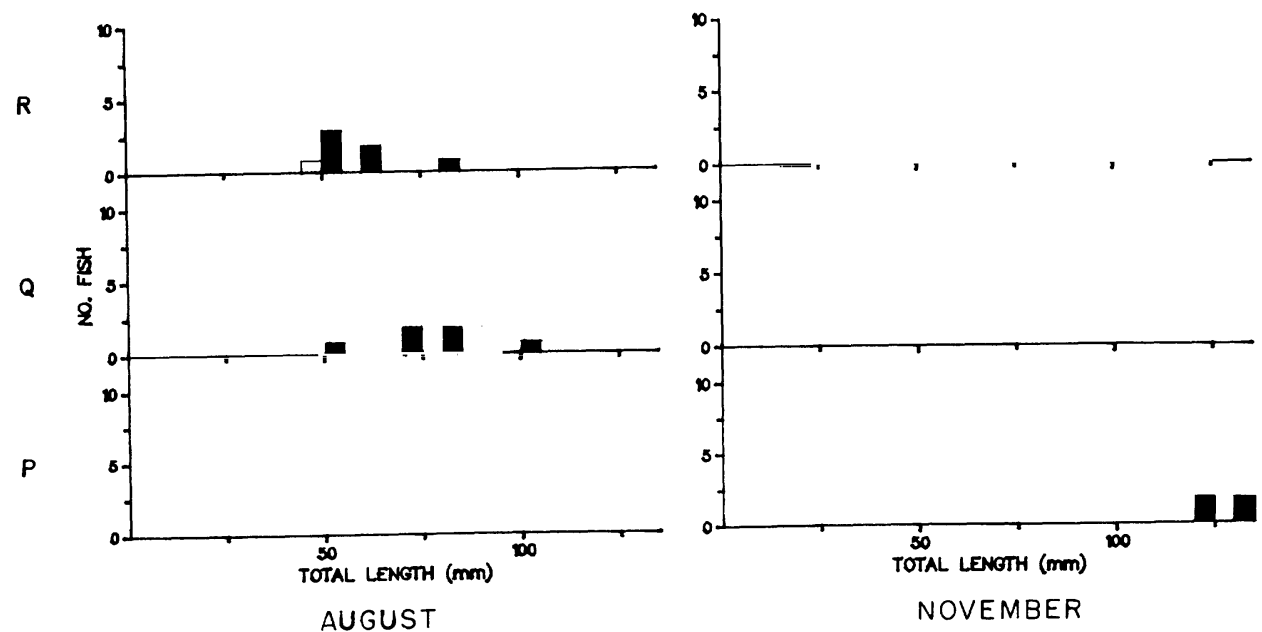

Fig. 69. Length-frequency histograms for trout-perch caught in duplicate seine hauls during April to November 1978 in iake Michigan near the J. H. Campbell Plant, eastern Lake Michigan. $\square=$ day $\square=$ night 
On the basis of trout-perch age-length data collected in southeastern Lake Michigan (House and Wells 1973), most of our adult trout-perch 70-90 mm were 2-yr old (some trout-perch in the 70-mm interval may be yearlings) and those 100-160 mm were 3-yr old and older. The 2-yr-old group was most abundant inshore during May and the remainder of the study period (Figs. 69, 70 and 71). Abundance of age-2 fish in 1978 and dominance of yearlings in 1977 trout-perch populations in the study area (Jude et al. 1978) suggested that there was a strong trout-perch year class in 1976. Stronger than average year classes of trout-perch frequently occurred in Lower Red Lake, Minnesota during the period 1946-1957 (Magnuson and Smith 1963). Based on statistical analysis, these authors concluded that variations in year class strength was influenced more by wind and temperature than by the reproductive capacity of the stock.

Die-offs of trout-perch have not been observed in our study area or in southeastern Lake Michigan (Jude et al. 1975). Scarcity of individuals $3 \mathrm{yr}$ or older (100-160 mm) in the 1977 and 1978 collections however, tended to corroborate the high mortality of adult trout-perch (age 2 and 3 ) reported in Lower Red Lake, Minnesota (Magnuson and Smith 1963).

June--Peak catches of many sizes of trout-perch occurred during June both in 1977 (Jude et al. 1978) and 1978 (Figs. 66 and 68), indicating the bulk of the trout-perch population had migrated to inshore water by this time. These data agreed with similar high catches during June in southeastern Lake Michigan (Jude et a1. 1975).

Adults exhibited a depth distribution similar to that observed in May. At night adult trout-perch occurred from the beach zone to $15 \mathrm{~m}$ and were most common at $6 \mathrm{~m}$ (Figs. 69 and 71). During the day they were found only from 9 to $15 \mathrm{~m}$. This depth distribution was comparable to that observed in June 1977. Relatively large seine catches of adult trout-perch in June (Fig. 69) may be related to intense spawning activity. Unlike findings observed during April and May, in June more trout-perch were seined at beach station $R$ ( $N$ discharge) than at station Q (S discharge) (Fig. 69). Catches at beach station $P$ (S reference) were comparable to those of station $Q$. Causes of this shift in trout-perch distribution in the beach zone were not apparent from limnological data we collected. Water temperatures measured at seining time were similar at all three beach stations (Appendix 2). Increase of trout-perch catches in June 1978 (452) over those of June 1977 (326) was mainly due to higher adult catches in 1978. Lower number of yearlings were caught in 1978 than in 1977.

Trout-perch spawning reaches a peak in June or July in southeastern Lake Michigan (House and Wells 1973; Jude et a1. 1979) and in Lower Red Lake, Minnesota (Magnuson and Smith 1963). In our study area peak spawning activity occurred in June both during 1977 (Jude et a1. 1978) and in 1978 (Table 32).

Yearlings exhibited the same pattern of nocturnal inshore migration as adults. They were scattered from the beach zone to $15 \mathrm{~m}$ at night and were restricted to $12 \mathrm{~m}$ and deeper during the day (Figs. 69 and 71). Although most trout-perch had reached inshore by June, catches of yearlings (30-60 mm) in June and July 1978 (Figs. 69, 70 and 71) were relatively low compared to catches of similar size trout-perch in June and July 1977 (Jude et al. 1978). This low 


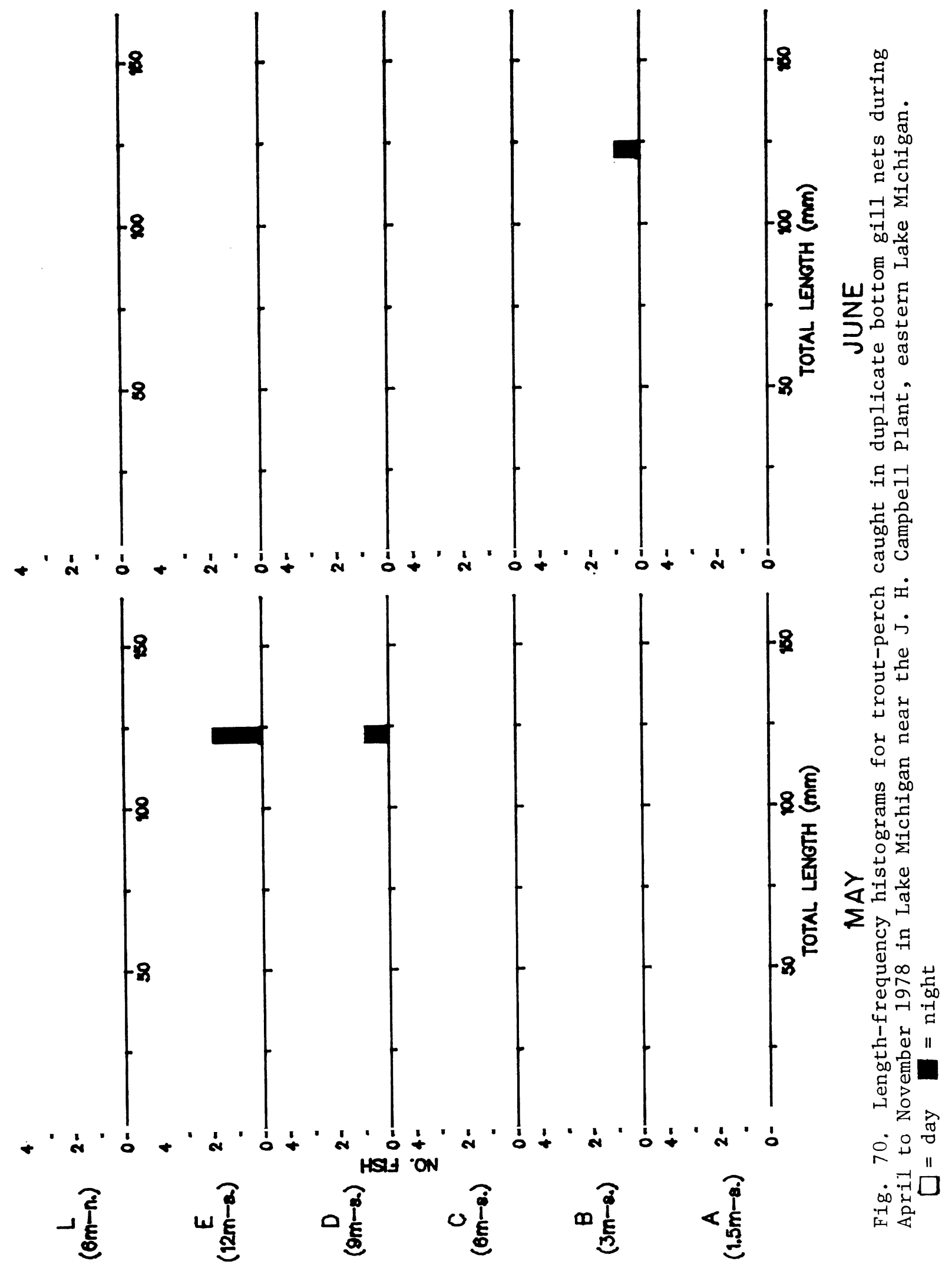



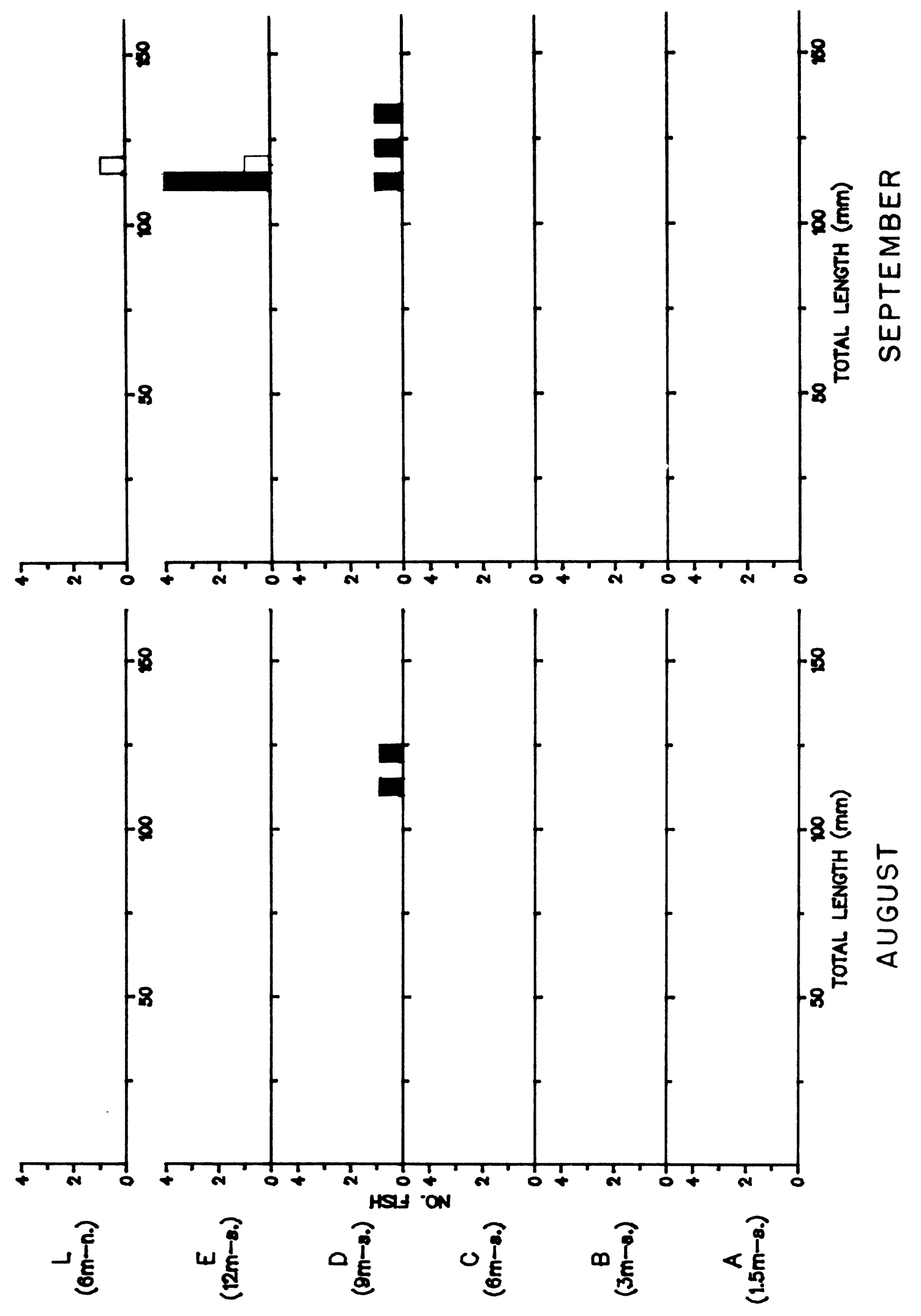

苞

$\stackrel{\circ}{1}$

唒 


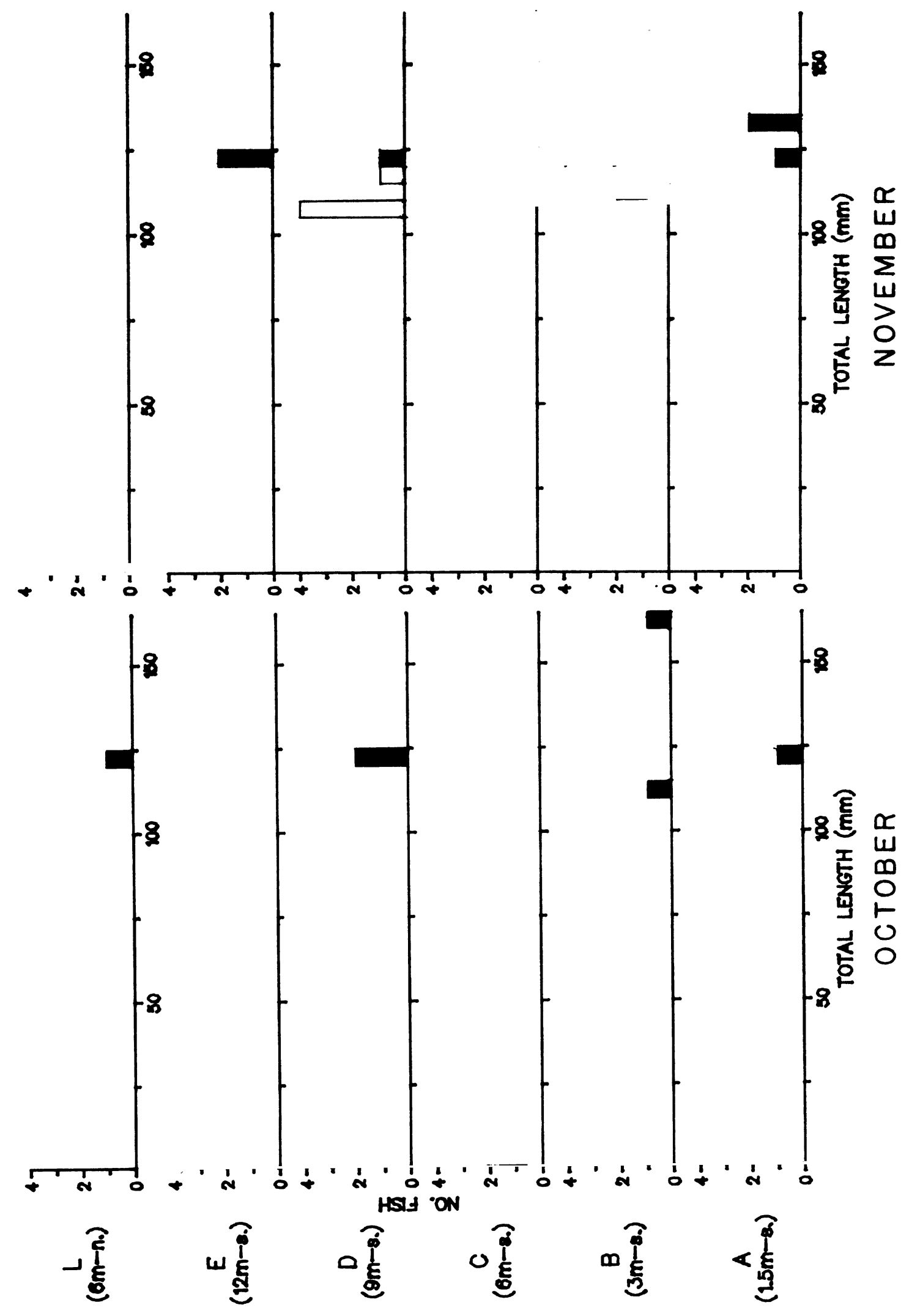

苂

$\stackrel{\circ}{\circ}$

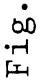




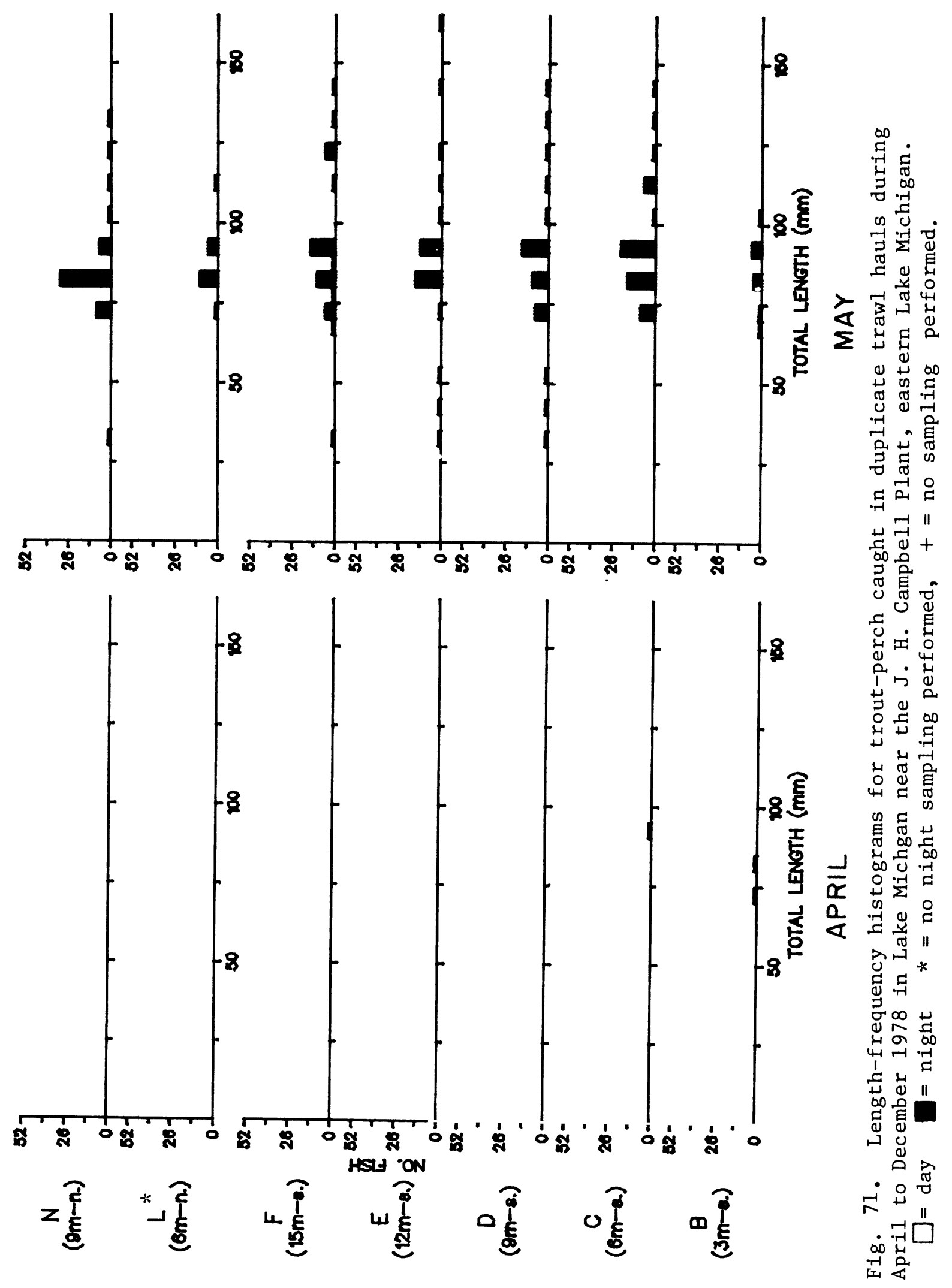



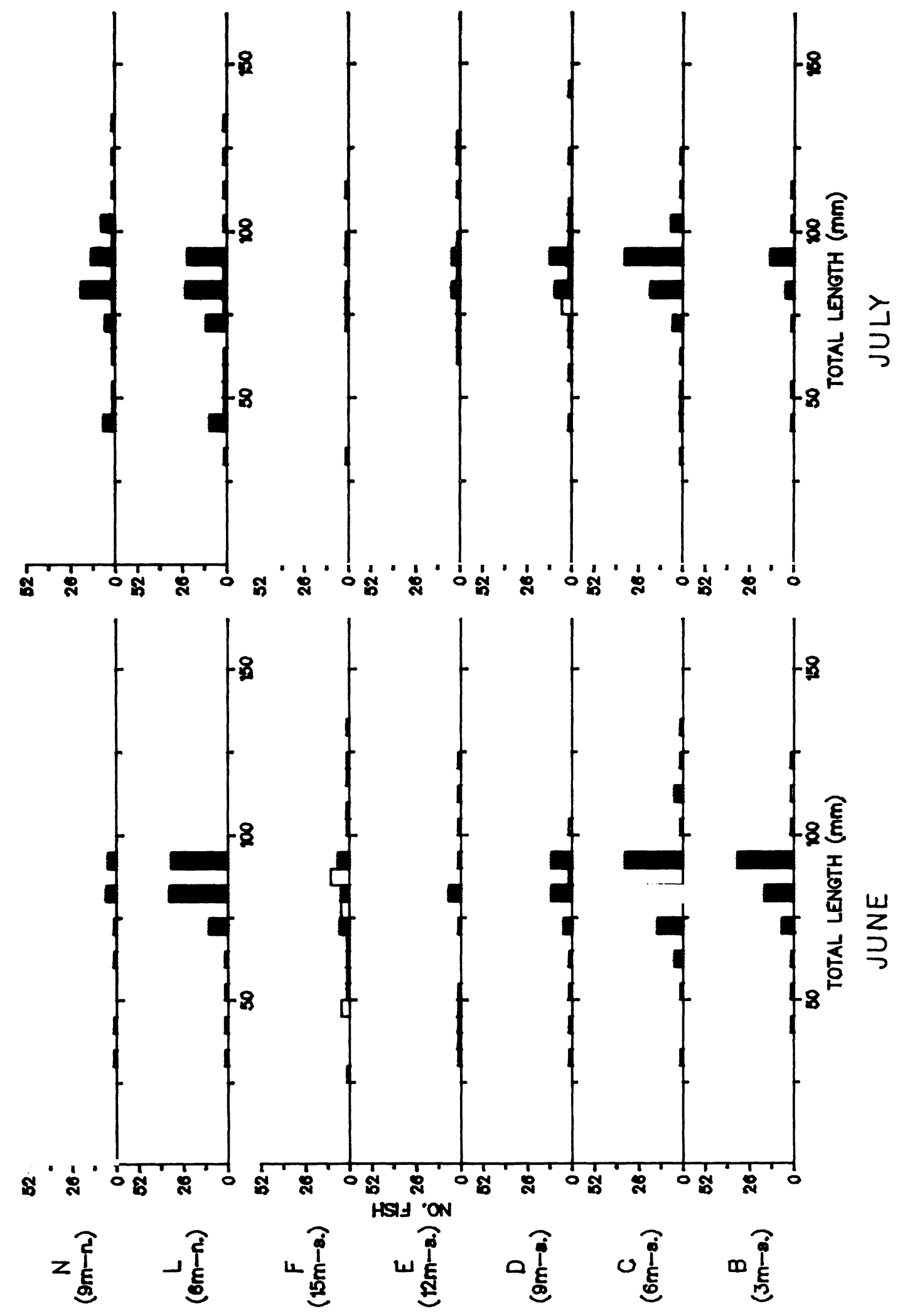

ن 

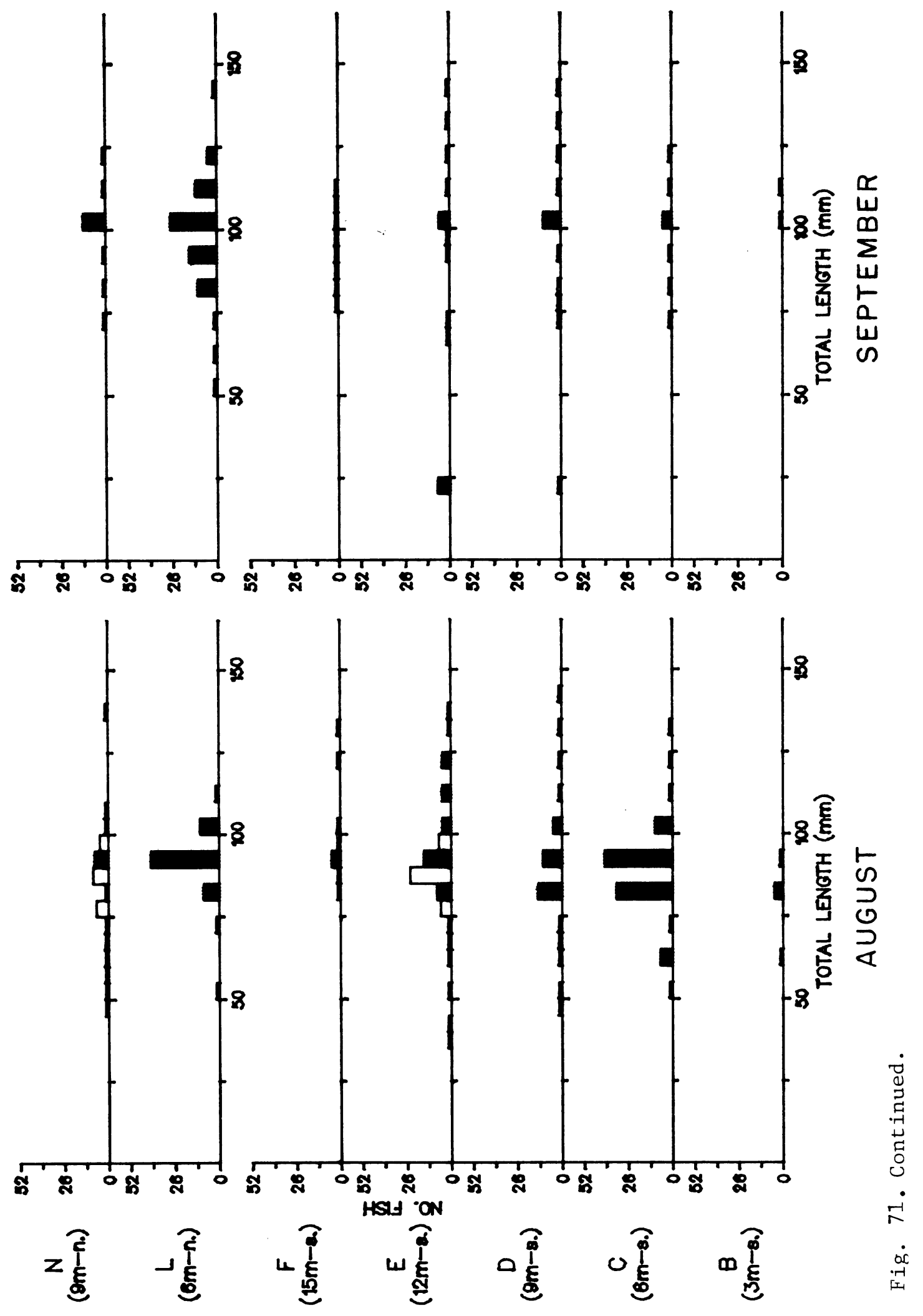

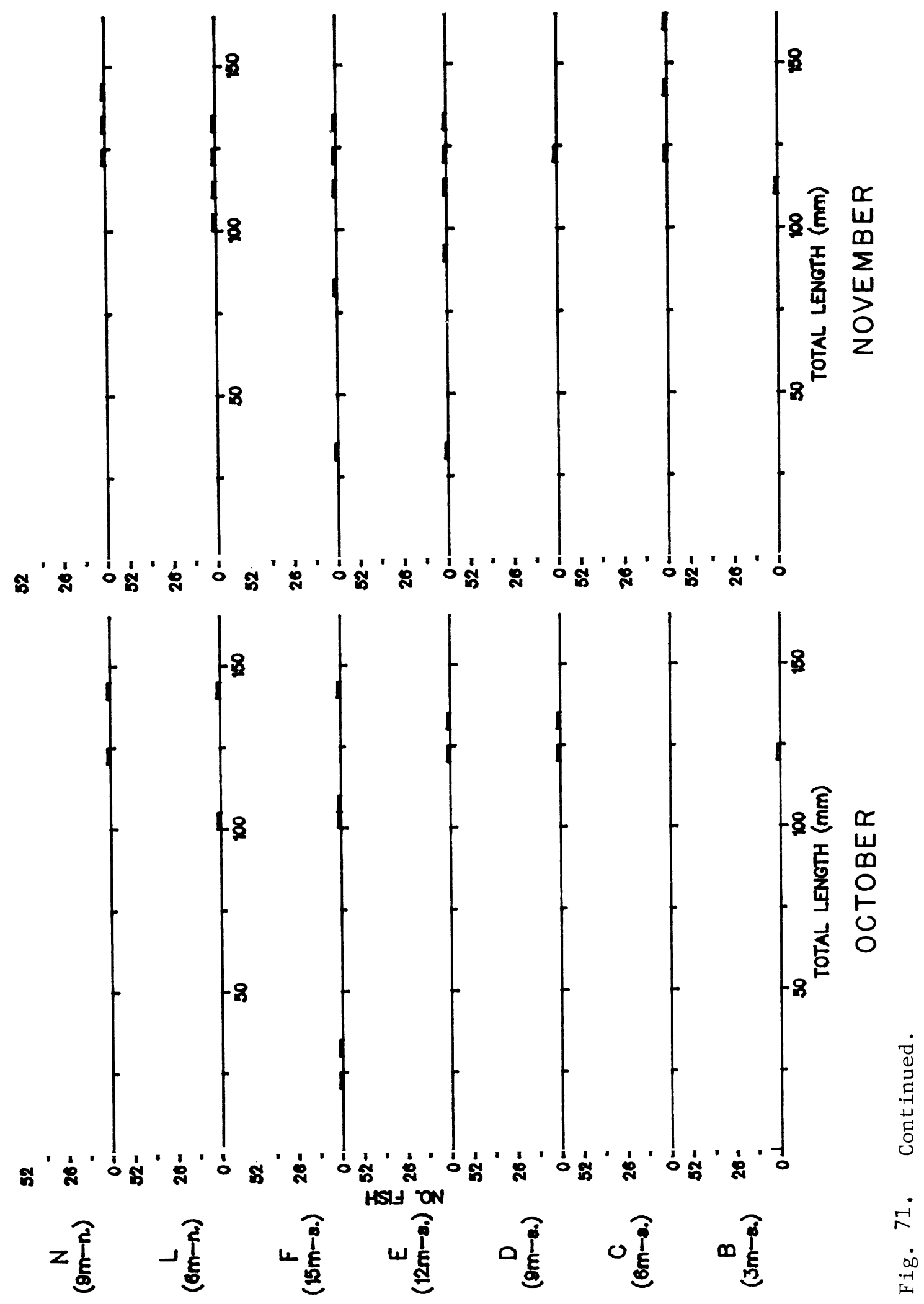


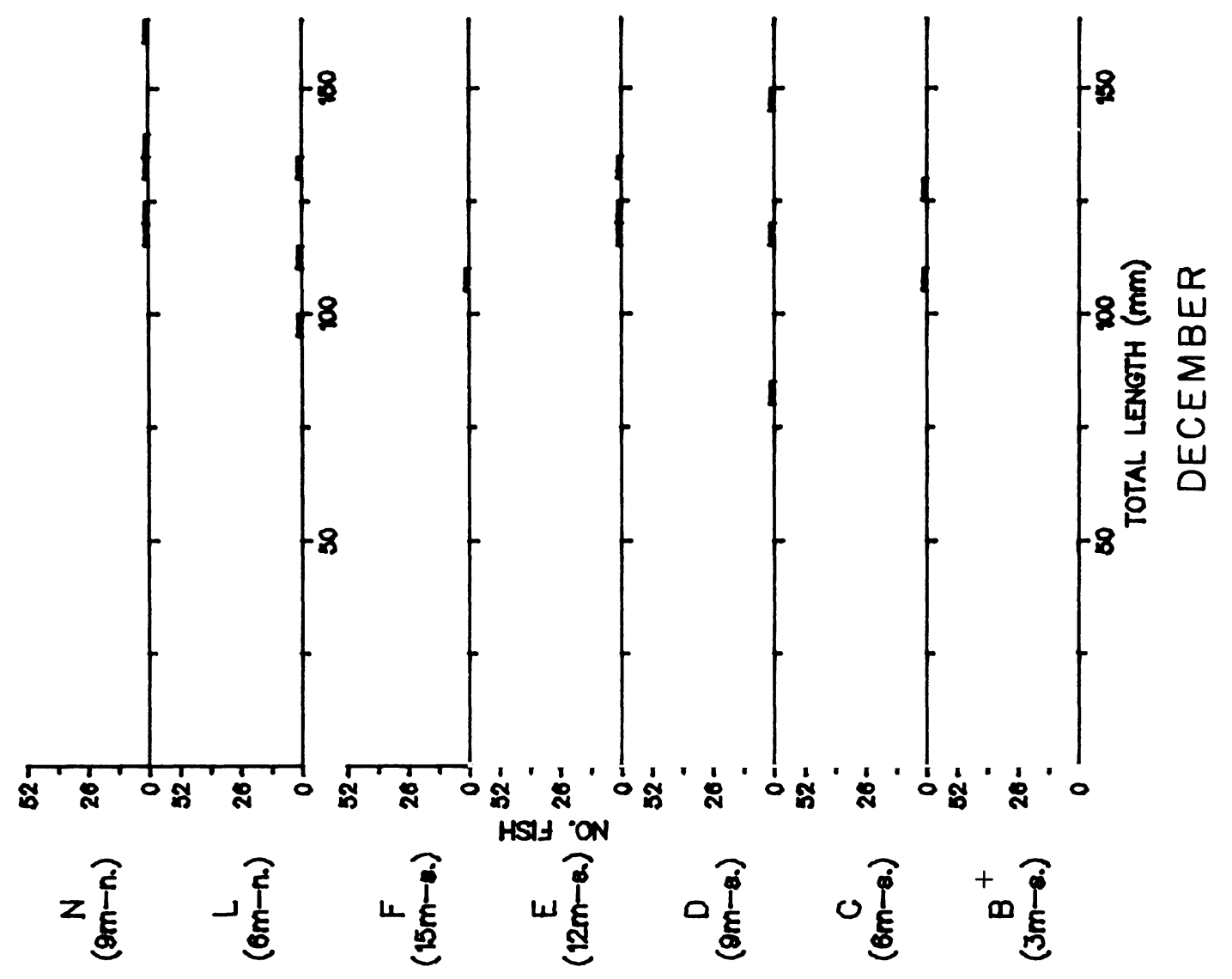

苞

$\underset{1}{-1}$ 
abundance of 1978 yearlings may be due to the weak 1977 trout-perch year class.

July--Trout-perch catches (Appendix 7) declined slightly in July compared to earlier months. Adult depth distribution as indicated by traw1 and seine catches remained approximately the same as in June. Night catches increased from a small number (3) in the beach zone to reach a peak (78) at $6 \mathrm{~m}$, then decreased at deeper stations. Day catches were recorded only at $9 \mathrm{~m}$ and deeper (Figs. 69 and 71). Similar depth distribution of adults was recorded during July 1977 . Low seine catches indicated fewer adults entered the beach zone than in June. Since adult trout-perch usually prefer warmer water (Jude et al. 1978), the slight decline of adult catch in July may be related to the drop in bottom temperatures recorded in July $(6.5-11.5 \mathrm{C})$ when compared to June temperatures $(8.3-14.8 \mathrm{C}$ ) (see Temperature-Catch Relationship). Gonad data (Table 32) indicated lower spawning activity than in June.

Catches of yearlings $(40-60 \mathrm{~mm})$ in July were slightly lower than in June (Fig. 71). Yearlings exhibited a similar depth distribution as was found in July 1977. They were found from 3 to $15 \mathrm{~m}$ at night and from 9 to $15 \mathrm{~m}$ during the day (Fig. 71). No yearlings were caught in the beach zone during July 1978 (Fig. 69). Unlike July 1977 distributions, yearling populations did not appear to be affected by changes in water temperature (see TemperatureCatch Relationship).

Total catches of trout-perch in July were substantially higher in 1978 (357) than in 1977 (221). As has been mentioned in the discussion of May and June data, catches of trout-perch in July 1977 were largely comprised of yearlings, while the July 1978 catches were mostly 2-yr-old trout-perch.

August--Trout-perch catches in August 1978 (400) increased slightly over August 1977 catches (129) due mainly to higher catches of age-2 fish. More adults may have moved into the study area following the warming of bottom water in August $(8-24 \mathrm{C})$, since July bottom temperatures were cool $(6.5-11.5 \mathrm{C})$ (see Temperature-Catch Relationship). Adult depth distribution in August was similar to that observed during June and July. At night trout-perch occurred from the beach zone to $15 \mathrm{~m}$ with highest concentrations at $6 \mathrm{~m}$ (Figs. 69 and 71). Day catches were restricted to $9 \mathrm{~m}$ and deeper stations. During August 1977 adults appeared to prefer deeper water than they did in August 1978, being found most commonly at $9 \mathrm{~m}$. Seine catches (Fig. 69) indicated that more adults entered the beach zone in August than in July. Despite the increased number of adults in the inshore area, fewer adults with well developed gonads were collected in August than in July (Table 32) suggesting that spawning activity continued to decline in August.

Unlike adult collections, yearlings catches were lower in August than in July (Figs. 69 and 71). Yearling distribution extended from the beach zone to $12 \mathrm{~m}$ at night and from 9 to $12 \mathrm{~m}$ during the day (Figs. 69 and 71).

September--Trout-perch started to migrate offshore in September in southeastern Lake Michigan (Jude et al. 1975) and during late September and early October in Lake Superior (Bostock 1967). A substantial decline in adult 
and yearling trout-perch catches in september 1978 (Fig. 71) indicated that a major portion of the trout-perch populations had left the study area by the time sampling was performed (19 September). At night adults occurred from 3 to $15 \mathrm{~m}$ and were most common at 6 and $9 \mathrm{~m}$ (Fig. 71). During the day a small number were caught from 9 to $15 \mathrm{~m}$. A few adults were caught in bottom gill nets in September (Fig. 70). None were caught in seine hauls. A small number of adults with well developed gonads were caught during September both in 1977 (Jude et a1. 1978) and 1978 (Table 32) indicating low trout-perch spawning activity in our study area. The only two larvae collected in 1978 were taken on 17 August (station $\mathrm{W}-15 \mathrm{~m}$ ) and 19 September ( $\mathrm{N}-9 \mathrm{~m}$ ) (see Trout-perch - FISH LARVAE AND ENTRAINMENT STUDY).

Yearlings were relatively scarce in September occurring only in water $6 \mathrm{~m}$ or deeper at night, and from 9 to $15 \mathrm{~m}$ during the day (Fig. 71). In September 1977 yearlings were relatively common in the inshore area and their offshore migration did not start until October.

YOY trout-perch 20-30 mm first appeared in trawl catches in September 1977 and 1978 (Fig. 71). This size group of trout-perch was scarce in the inshore water near the Cook Plant (Jude et al. 1975), in our study area during 1977 (Jude et al. 1978) and in 1978 (Figs. 68 and 71). Nine YOY were caught in adult and juvenile sampling gear in 1978 and nine in 1977 (Jude et a1. 1978); all came from $9 \mathrm{~m}$ or deeper water (Fig. 71). Since YOY trout-perch moved offshore during summer (Magnuson and Smith 1963), we suspected that most YOY had already reached deepwater outside the study area by the time they became large enough to be retained by trawls. In addition, the prolonged spawning period may cause trout-perch YOY to be uncommon in the study area at any given time.

October, November and December--Most trout-perch had left the study area by October. Low catches in October, November and December in 1977 and 1978 (Figs. 66-68) revealed that only a small number of trout-perch inhabited the inshore area during fall. During october and November trout-perch, which consisted mainly of 2-yr-old and older individuals, were scattered from 1.5 to $15 \mathrm{~m}$ (Fig. 70 and 71). A few adults were also seined during November (Fig. 69). In December adults occurred from 6 to $15 \mathrm{~m}$ (Fig. 71).

Very few yearlings inhabited inshore water during October, November and December 1978 (Figs. 69, 70 and 71). Ten yearling trout-perch 50-90 mm were caught during fall 1977 (Jude et al. 1978) and only three in fall 1978 (Appendix 6). YOY were also scarce during the fall. Only five YOY trout-perch 20-40 mm were collected, all at deepwater stations, in October, November and December (Fig. 71). A comparable number of YOY were caught during fall 1977. The above distribution of adults, yearlings and YOY trout-perch agreed with distribution data collected in southeastern Lake Michigan (Jude et a1. 1975).

Total catches of trout-perch from Lake Michigan were substantially higher in 1978 (1861) than in 1977 (899). This near doubling of the catch in 1978 was in part due to higher monthly catches during the period June-December 1978 (Appendix 6) than during the same period in 1977 (Jude et a1. 1978). Sampling during April and May, which was not performed in 1977, was also 
responsible for part of the catch increase in 1978 .

On1y four trout-perch were caught in Pigeon Lake during 1977. In 1978 , 15 trout-perch including 10 adults $(80-100 \mathrm{~mm}$ ) and 6 yearlings (30$60 \mathrm{~mm}$ ) were collected in this tributary water. Of the 9 adults, 7 were caught during May at beach station S (influenced by Lake Michigan) and 2 occurred in bottom gill nets at station M (influenced by Lake Michigan) in November and December. Of the six yearlings collected in Pigeon Lake in 1978, four were caught at station S (influenced by Lake Michigan), one in April, two in May and one in September; and two were seined in May at station $V$ (undisturbed Pigeon Lake).

During early spring trout-perch were probably attracted to warm water in Pigeon Lake. In April and May water temperatures in Pigeon Lake were generally higher than in Lake Michigan (Appendixes 1, 2 and 3). Gonad data (Table 33) suggested that some trout-perch spawning may take place in Pigeon Lake during early spring. However, data collected in 1977 and 1978 provided no evidence of spawning in summer. Impingement data (see RESULTS AND DISCUSSION IMPINGEMENT) showed that more trout-perch entered Pigeon Lake during fal1 than during spring and summer. Reasons for low catches of trout-perch in November and December were not known.

Table 33. Monthly gonad conditions of trout-perch caught during 1978 in Pigeon Lake near the J. H. Campbell Plant, eastern Lake Michigan. All fish examined in a month were included except poorly received specimens.

\begin{tabular}{|c|c|c|c|c|c|c|c|c|c|c|}
\hline & Gonad conditions & Apr & May & Jun & $\mathrm{Jul}$ & Aug & Sep & Oct & Nov & Dec \\
\hline Males & $\begin{array}{l}\text { Slight development } \\
\text { Mod. development } \\
\text { Well developed } \\
\text { Ripe-running } \\
\text { Spent }\end{array}$ & & 1 & & & & & & & 1 \\
\hline Females & $\begin{array}{l}\text { Slight development } \\
\text { Mod. development } \\
\text { We11 developed } \\
\text { Ripe-running } \\
\text { Spent } \\
\text { Absorbing }\end{array}$ & & $\begin{array}{l}2 \\
2 \\
1\end{array}$ & & & & & & 1 & \\
\hline Immature & & 1 & 4 & & & & 1 & & & \\
\hline Unable tc & o distinguish & & 1 & & & & & & & \\
\hline
\end{tabular}


Temperature-catch relationship--Trout-perch appeared to tolerate a wide range of water temperatures. During 1977 and 1978 most trout-perch were caught in water temperatures of 6 to $15 \mathrm{C}$ in our study area. This species seemed to prefer warmer water in southeastern Lake Michigan, being most commonly caught at water temperatures of 10-15 C off Saugatuck, Michigan (Wells 1968) and at water temperatures 16-19.9 C near the Cook Nuclear Plant (Jude et a1. 1979).

In 1977 increased adult trout-perch catches in the study area appeared to be associated with an increase in water temperature, while low adult catches usually coincided with decreased water temperatures. Variations of adult catches in the inshore water in 1978 may also be in part explained by changes in water temperatures. As had been mentioned in the previous section (see Seasonal Distribution) decreased bottom temperatures observed in July $(6.5$ to $11.5 \mathrm{C}$ ) due to an upwelling probably caused a slight decline in the number of adults collected compared to June when temperatures were 8.3-14.8 C. Increased adult catches in August may be related to the increase of bottom temperatures from 6.5 to $11.5 \mathrm{C}$ in July to 8-24 C in August (Appendix 3). As has been mentioned in a previous section (see Seasonal Distribution) movements of trout-perch to shallow water in spring and into Pigeon Lake in spring and late fall were probably influenced by warm water in these areas.

Trout-perch responses to water temperature changes may, however, vary considerably. Emery (1970) reported that trout-perch in Lake Huron did not leave the area when water temperature dropped $11.7 \mathrm{C}$ due to an internal seiche. This decrease of temperature caused other species to move away. In southeastern Lake Michigan, trout-perch tended to move to warm water areas at spawning time and remained indifferent or were attracted to cool water at other times (Jude et al. 1979). In our study area during 1977 yearling trout-perch tended to occur in cooler water than adults; however, trout-perch did not appear to display any pattern of temperature preference in 1978. Yearling catches remained approximately the same in June and July, despite lower bottom temperatures (Appendix 3) in July.

Other considerations--In 1977 yearlings in our study area reached a modal length of $50 \mathrm{~mm}$ in June and $80 \mathrm{~mm}$ in September and October. This growth was comparable to the calculated lengths of $49 \mathrm{~mm}$ and $83 \mathrm{~mm}$ attained at similar times by trout-perch from southeastern Lake Michigan aged by House and Wells (1973). Due to low number collected, yearlings exhibited no distinctive growth during late fall and winter. The 2-yr-old age-group collected in May 1978 showed the same modal length (80 mm - Appendix 6) as yearlings in October 1977 (Jude et al. 1978).

Trout-perch were not known to be an important forage species in various areas in southeastern Lake Michigan (Jude et al. 1979, House and Wells 1973). During 1977 and 1978 trout-perch seldom occurred in stomachs of predatory fishes collected from our study area.

Impingement--Although trout-perch were one of the more common species in the study area, only a small number were impinged at the J.H. Campbell Plant. Only 12 trout-perch were found in weekly impingement collections from June to 
December 1977 (Zeitoun et al. 1978) and 1283 were estimated impinged during the present study (January-December 1978).

Impingement of trout-perch was generally related to their temporal and spatial distribution during most months. Although only a small number of trout-perch inhabited inshore water during December (see Seasonal Distribution) and probably in January, they were most commonly impinged during those 2 mo. Twenty-eight trout-perch were observed in impingement samples in December and 56 in January (Table 21), corresponding to a projected total number impinged per month of approximately 217 and $434 \mathrm{fish}$ respectively (see RESULTS AND DISCUSSION - IMPINGEMENT, Appendix 9).

Three trout-perch were removed from traveling screens in February, eight in March and five in April (Table 21). The respective estimated numbers impinged per month were 16,62 and 37 (see RESULTS AND DISCUSSION - IMPINGEMENT, Appendix 9). Low impingement of trout-perch during this period may be explained by scarcity of this species in the inshore water of Lake Michigan (see Seasonal Distribution). Numbers of impinged trout-perch estimated for April (37) were higher compared to numbers collected in field sampling (11) during this month. A11 impinged trout-perch captured in April showed well developed and riperunning gonads indicating these fish may be searching for spawning sites.

During warmer months (May-September), movements of trout-perch into Pigeon Lake were probably not influenced by water temperatures except during early May. Low catches of trout-perch in Pigeon Lake (see Seasonal Distribution) explained the low rate of trout-perch impingement during late spring and summer. From May through September only 25 trout-perch were removed from the traveling screens (Table 21) resulting in a projected total of approximately $160 \mathrm{fish}$ (see RESULTS AND DISCUSSION - IMPINGEMENT, Appendix 9).

During October, November, and December despite the scarcity of trout-perch in inshore water, more trout-perch were impinged than during spring and summer. Thirteen trout-perch were collected in October, 37 in November and 28 in December (Table 21), with the numbers impinged per month being estimated at 80,277 and 217 respectively (see RESULTS AND DISCUSSION - IMPINGEMENT, Appendix 9). Causes of increased impingement of trout-perch in October, November and December were not known. Water temperatures in Pigeon Lake and in Lake Michigan were approximately the same during these $3 \mathrm{mo}$. Trout-perch impinged ranged from 70 to $150 \mathrm{~mm}$ and were probably all adults. Absence of yearling troutperch in impingement samples was probably due to the scarcity of this size group in the shallow area during most of the year. Most trout-perch were impinged during darker periods (dusk, night and dawn) confirming the predominantly nocturnal habit of this species.

Clearly, operation of the Campbell Plant Units 1 and 2 have had little effect on trout-perch abundance. They were a major species in our Lake Michigan collections and populations appear to have increased in 1978 compared to 1977 levels. Larval trout-perch were entrained only during May and July, resulting in an estimated total kill of 5,710 larvae in 1978. The projected impingement total for 1978 was $1,283 \mathrm{fish}$, with most being collected during fall and winter months. Most, if not all of these fish, were part of the Lake Michigan population, 
since few are taken in Pigeon Lake. Trout-perch have no present commercial or sport value; a few are consumed by predaceous fish.

Summary--Trout-perch were one of the most common species collected near the J.H. Campbell Plant. Trout-perch migrated inshore during April and their abundance in the study area peaked in June. Relatively high trout-perch populations inhabited the inshore area during July and August. Trout-perch catches declined sharply in September as a result of offshore movements. Only small numbers of trout-perch were caught during fall.

Adult trout-perch were more abundant in 1978 collections than yearlings. Two-yr-old trout-perch were the dominant age-group in the inshore trout-perch populations in 1978. Adults occurred from the beach zone to $15 \mathrm{~m}$ with high concentrations being observed between 6 and $12 \mathrm{~m}$ during spring and summer. Small populations of adults continued to inhabit the inshore area during fall. Yearlings occurred in small numbers during 1978. They were most commonly caught between 6 and $12 \mathrm{~m}$ during spring and summer, and were almost absent in the study area during fall. Small numbers of YOY trout-perch were caught in September, October and November, all in water $9 \mathrm{~m}$ or deeper. More trout-perch were caught at night than during the day. Yearlings and adults moved close to shore at night and returned to deeper water during the day. Most trout-perch were caught in water temperatures 6-15 C. This species appeared however, to show considerable variations in temperature preference. Only small numbers of trout-perch were collected in impingement samples.

\section{Bluntnose Minnow--}

Introduction--A common inhabitant of the Lake Michigan watershed, the bluntnose minnow was the fourth-most abundant species in our 1978 adult fish collections in Pigeon Lake. Its importance to the Pigeon Lake system as forage for a number of piscivorous species was previously documented by Jude et al. (1978). A few were collected in Lake Michigan.

Seasonal distribution--A11 but one of the bluntnose minnows caught during 1978 were collected by seine hauls; the additional one was trawled. During 1977 no bluntnose minnows were collected in Lake Michigan, however, 1978 data indicated that this species does occasionally enter Lake Michigan. During September 197812 YOY bluntnose minnows were caught at beach station $\mathrm{R}$ (N discharge) which represented the largest Lake Michigan catch. One bluntnose minnow was also caught at the following times: August at Lake Michigan beach station Q (S discharge) and P (S reference); November in trawl hauls at station $\mathrm{D}(9 \mathrm{~m}-\mathrm{S})$. The occasional presence of bluntnose minnows was also reported in the area of the D.C. Cook Plant, southeastern Lake Michigan (unpublished data Great Lakes Research Division, University of Michigan, Ann Arbor, Michigan). Pigeon Lake provides an extremely favorable habitat for the propagation of bluntnose minnows, as evidenced by their abundance in our samples from April through August. In general, habitat near beach station V (undisturbed Pigeon Lake) was selected over the habitat of beach station $S$ (influenced by Lake Michigan) as 804 bluntnose minnows were caught at beach station $V$ compared with 60 caught at beach station $S$ from April through November (Fig. 72). 
S

INFLUENCED BY

LAKE MICHIGAN

$V$
UNDISTURBED
PIGEON LAKE

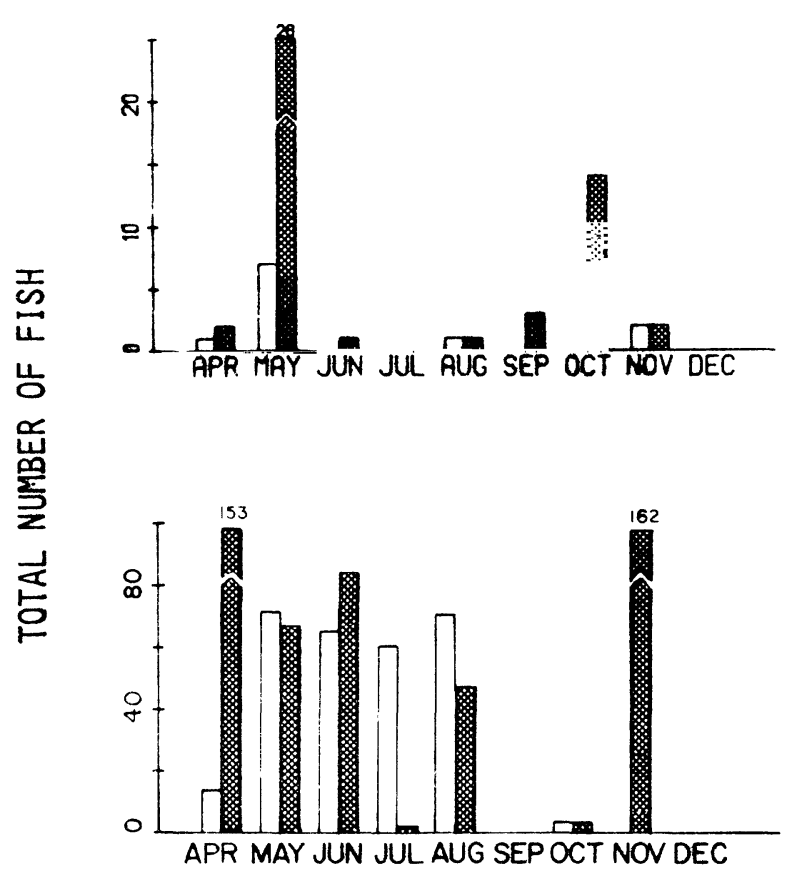

Fig. 72. Total number of bluntnose minnows caught in duplicate seine hauls during day and night once per month April to November 1978 in Pigeon Lake near the J. H. Campbell Plant, eastern Lake Michigan. $\square=$ day $\square=$ night

During April the abundant catch of bluntnose minnows at beach station V (undisturbed Pigeon Lake) was dominated by fish less than $55 \mathrm{~mm}$ (Fig. 73). Age-at-length data summarized by Carlander (1969), due to its variability, gives no clear indication of which age-group these fish belong to, but it is probable they were a mixture of yearlings and age 1 . It is unknown why night catches of bluntnose minnows were higher than day catches at station $\mathrm{V}$ (undisturbed Pigeon Lake), but a high degree of variability between day and night catches was common throughout the sampling period (Fig. 72). Westman (1938) reported that, during the spawning season, this species exhibited increased nocturnal activity; however, this could not explain day-night differences in catch observed in July, October and November. Abundance of bluntnose minnows at beach station $S$ (influenced by Lake Michigan) during April was low (only three caught), which may be related to the colder temperature at station $\mathrm{S}$ (average $8.6 \mathrm{C}$ ) compared with station $\mathrm{V}$ (average $10.8 \mathrm{C}$ ) as well as the difference in habitat (Fig. 74). The area around station $V$ (undisturbed 

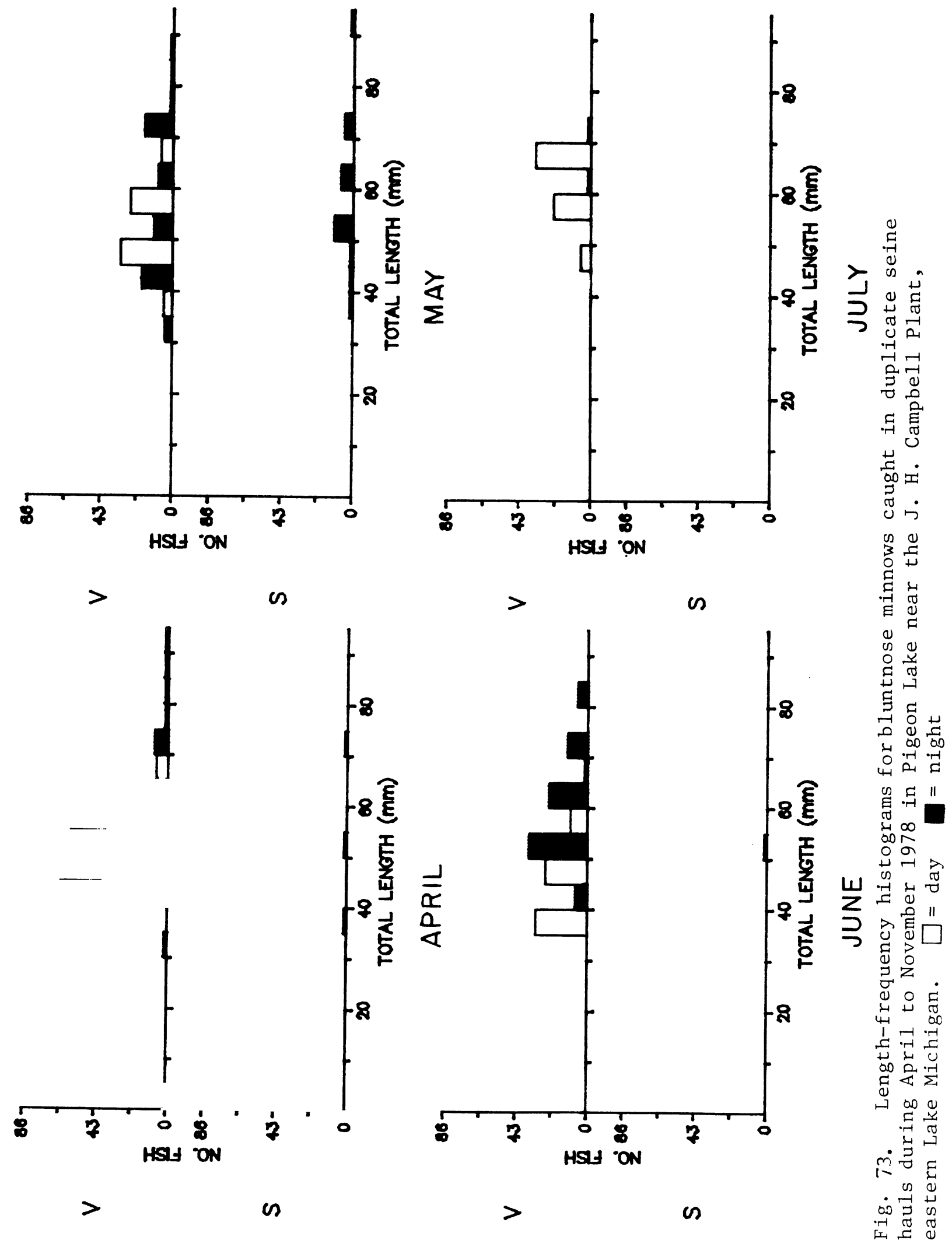

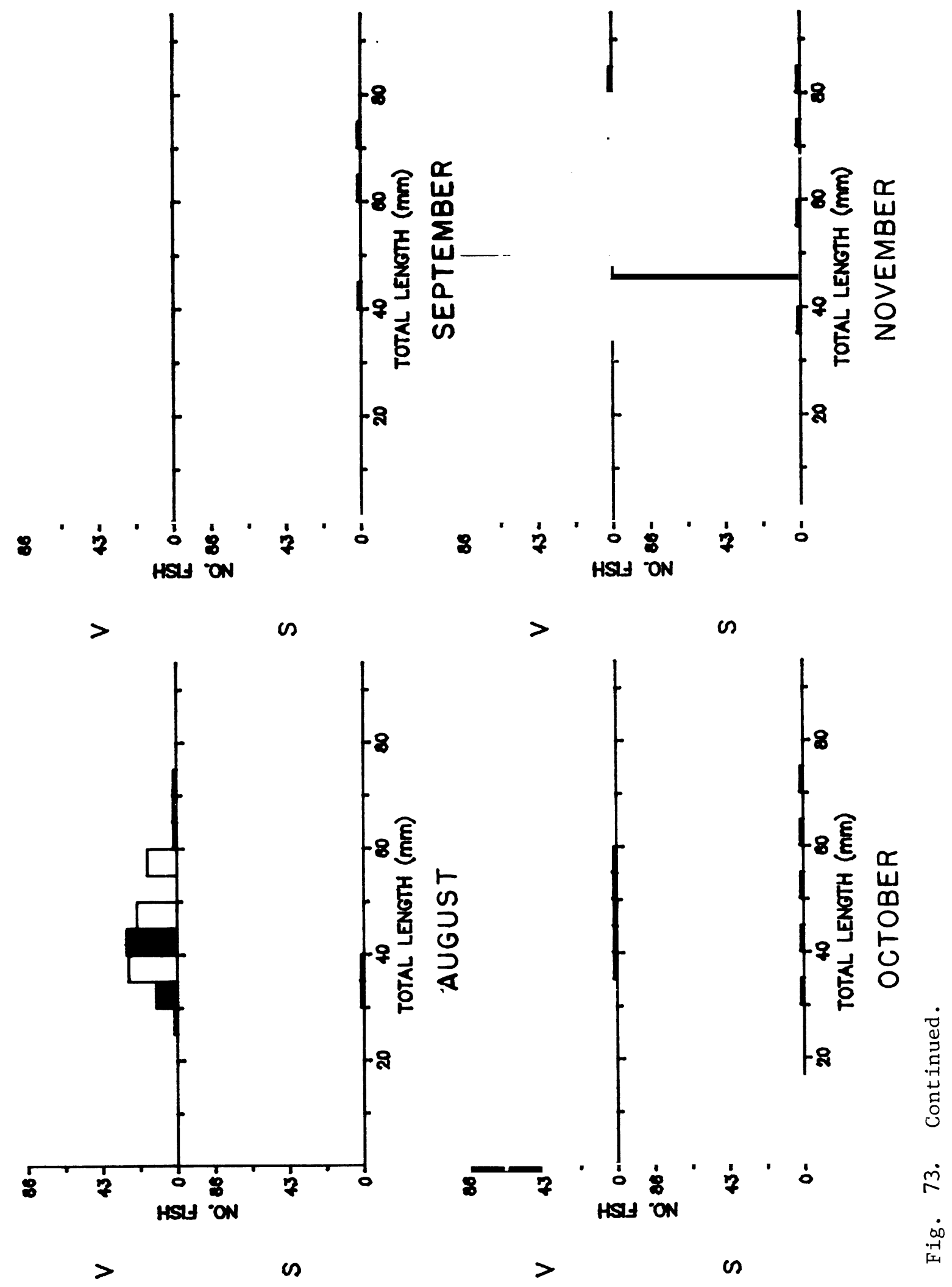


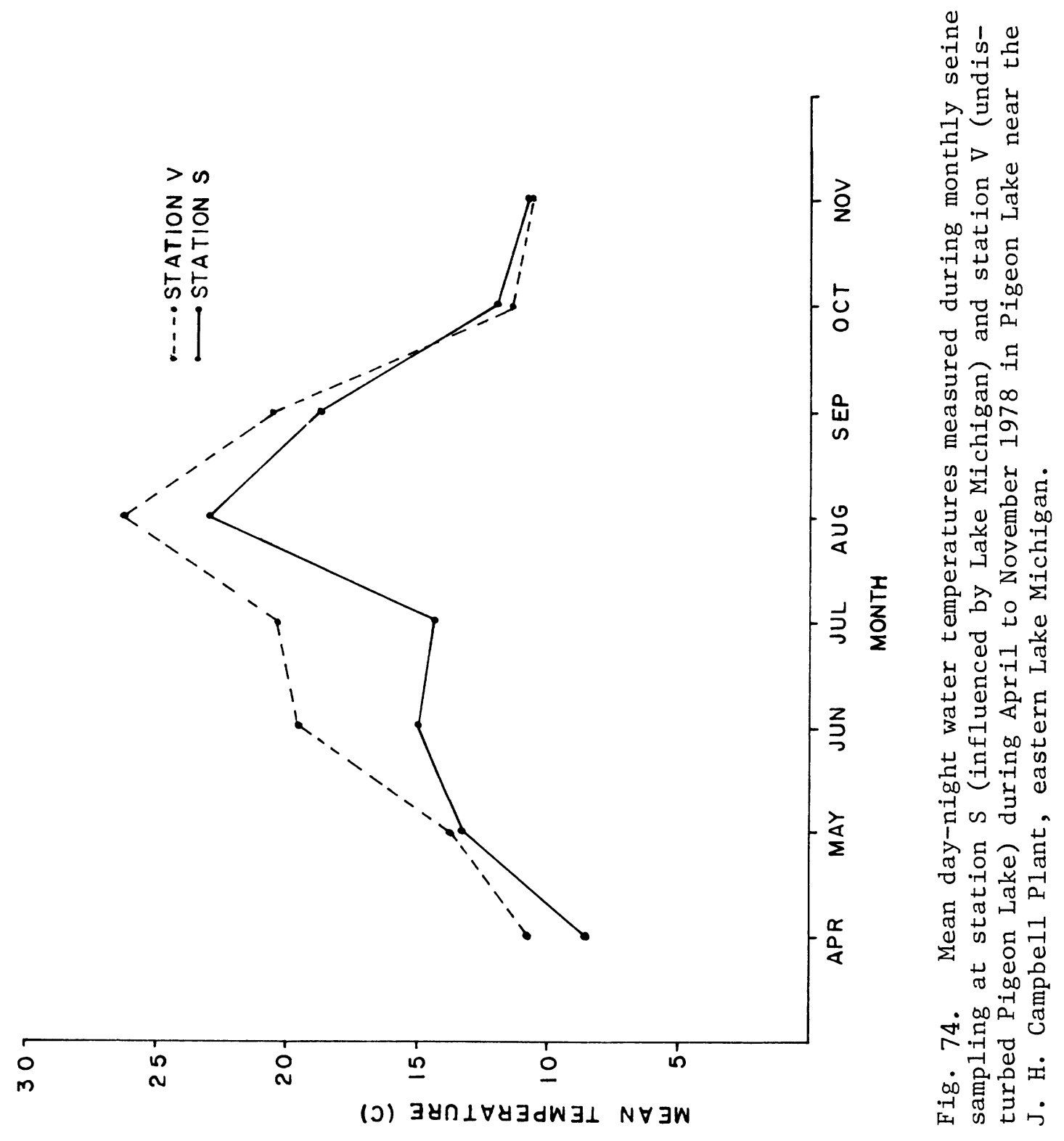


Pigeon Lake) is characterized by more abundant vegetative cover compared with station S (influenced by Lake Michigan).

Highest catch of bluntnose minnows at station $S$ (influenced by Lake Michigan) occurred in May. Although the reason for this high catch is unclear, it may be that warmer water temperatures there allowed dispersal to shoreline areas of Pigeon Lake for spawning. Gonad data (Table 34) indicated that this species spawned in May as five ripe-running females were collected. Initial indication of spawning was at temperatures 11-17 $\mathrm{C}$, which was cooler than temperatures of initial spawning $(20 \mathrm{C})$ reported by Scott and Crossman (1973). Presence of many submerged logs at beach station V make it highly conducive to bluntnose minnow spawning.

Table 34. Monthly gonad conditions of bluntnose minnows caught during 1978 in Pigeon Lake near the J. H. Campbell Plant, eastern Lake Michigan. All fish examined in a month were included except poorly received specimens.

\begin{tabular}{|c|c|c|c|c|c|c|c|c|c|c|}
\hline & Gonad condition & Apr & May & Jun & Jul & Aug & Sep & Oct & Nov & Dec \\
\hline Males & $\begin{array}{l}\text { Slight development } \\
\text { Mod. development } \\
\text { We11 developed } \\
\text { Ripe-running } \\
\text { Spent }\end{array}$ & 9 & $\begin{array}{r}13 \\
1\end{array}$ & 7 & 2 & & & & $\begin{array}{l}6 \\
1\end{array}$ & \\
\hline Females & $\begin{array}{l}\text { Slight development } \\
\text { Mod. development } \\
\text { Well developed } \\
\text { Ripe-running } \\
\text { Spent } \\
\text { Absorbing }\end{array}$ & $\begin{array}{l}9 \\
5\end{array}$ & $\begin{array}{l}2 \\
6 \\
1 \\
5\end{array}$ & 9 & 2 & & 1 & & $\begin{array}{l}7 \\
5\end{array}$ & \\
\hline Immature & & 23 & 14 & 15 & 2 & 28 & 1 & 11 & 36 & \\
\hline Unable $t$ & o distinguish & 15 & 32 & 29 & 7 & 21 & 1 & 9 & 7 & \\
\hline
\end{tabular}

After May, catches of bluntnose minnows were low from June to December at beach station $S$ (influenced by Lake Michigan) which indicated this habitat was not preferred by this species. Catch of bluntnose minnows at station $V$ (undisturbed Pigeon Lake) fluctuated without evident trend from June to August. YOY bluntnose minnows were first observed in seine hauls in August at both station $\mathrm{S}$ and station $\mathrm{V}$.

Seine hauls during September at station $V$ indicated that bluntnose minnows had moved from seinable depths into deeper water which was also observed during 1977 (Jude et al. 1978). Three bluntnose minnows were observed during September at station $S$ indicating that some bluntnose minnows remained at 
seinable depths.

Examination of the entire year's data suggested that occurrence of bluntnose minnows at station S (influenced by Lake Michigan) was closely related to temperature. At those times when average temperatures at station $\mathrm{V}$ approached temperature at station S (Fig. 74), higher catches of bluntnose minnows were observed at station S. During June-August when temperature differences between the two stations were greatest few bluntnose minnows were observed at station S. Thus, it appeared that bluntnose minnows preferred warmer temperatures typical of station $\mathrm{V}$, but when little temperature difference between station $\mathrm{S}$ and station $\mathrm{V}$ existed, such as during May, September, October and November (Fig. 74), some bluntnose minnows dispersed to areas near station S. Habitat preference, however, is still invoked as the reason for the overall greater number of bluntnose minnows observed at station $\mathrm{V}$ throughout the year.

The reason for the unusually high occurrence of bluntnose minnows (162 caught) during November at station V (disturbed Pigeon Lake) is unknown. A similar occurrence, although not as intense, was observed at beach station $\mathrm{T}$ (influenced by Pigeon River - not sampled in 1978) during November 1977.

Both occurrences suggest that occasionally large numbers of smaller bluntnose minnows during autumn may inhabit seinable depths. It is possible that some remain at these depths throughtout winter.

Impingement--The tendency of bluntnose minnows to inhabit slow-moving water, as well as its demersal behavior contribute to the low impingement of this species. Only one bluntnose minnow was examined from 24-h impingement samples during 1978, resulting in a projected total for the year of $6 \mathrm{fish}$ impinged. These results corresponded well with data collected from January 1974 to March 1975 (Consumers Power 1975) when only one bluntnose minnow was observed in impingement samples. No bluntnose minnows were observed in impingement samples from June to December 1977 (Zeitoun et al. 1978).

Summary--Bluntnose minnows were the fourth-most common fish collected in Pigeon Lake samples. This species was abundant in the area near beach station V (undisturbed Pigeon Lake) from April to August. Bluntnose minnows preferred the habitat of station $\mathrm{V}$ over station $\mathrm{S}$ (influenced by Lake Michigan), as only 60 bluntnose minnows were caught at station S compared with 804 caught at station $\mathrm{V}$ during April to November. Higher occurrences of bluntnose minnows at station $S$ were apparently related to times when temperature differences between station $\mathrm{S}$ and $\mathrm{V}$ were minimal, as occurred in May (33 caught), September ( 3 caught), October (14 caught) and November ( 4 caught). Because of the demersal behavior and preference for backwater, isolated areas of little or no current by this species it is subject to only minimal impingement losses.

Johnny Darter--

Introduction--Johnny darter populations in the vicinity of the J.H. Campbell Plant are represented by two quite distinct forms, which have been named as subspecies, the central johnny darter, Etheostoma nigmum nigrum, Rafinesque, and the scaly johnny darter Etheostoma nigrum eulipis (Hubbs and Greene). The 
range of the scaly johhny darter lies completely within that of the nominal scaleless subspecies and includes western Lake Erie, northwestern Indiana, Michigan, Wisconsin, Iowa, Minnesota and Missouri (Underhil1 1963).

A preliminary examination of 200 johnny darters collected in the Campbel1 Plant area revealed a majority of the Pigeon Lake population contained intergrades and pure scaly johnny darters, with a few central johnny darters. The majority of the Lake Michigan population was pure central johnny darters, with a few intergrades. Further study is in progress to determine if there are any significant ecological differences between these two forms in the vicinity of the J.H. Campbell Plant. In the present study, no distinction will be made between the two forms, all will be considered Etheostoma nigmum.

Seasonal distribution--In 1978, 598 johnny darters were collected, 362 from Lake Michigan and 236 from Pigeon Lake; 407 johnny darters were collected in our 1977 study (Jude et a1. 1978). The larger catch of fish in 1978 is most likely due to increased sampling in April and May (Figs. 75 and 76); no samples were taken during these months in 1977. No johnny darters were collected in impingement samples during 1977 (Zeitoun et al. 1978) or 1978; however, seven darters were observed in impingement samples collected from January 1974 to March 1975 (Consumers Power, 1975).

S

INFLUENCED BY LAKE MICHIGAN

V

UNDISTURBED

PIGEON LAKE

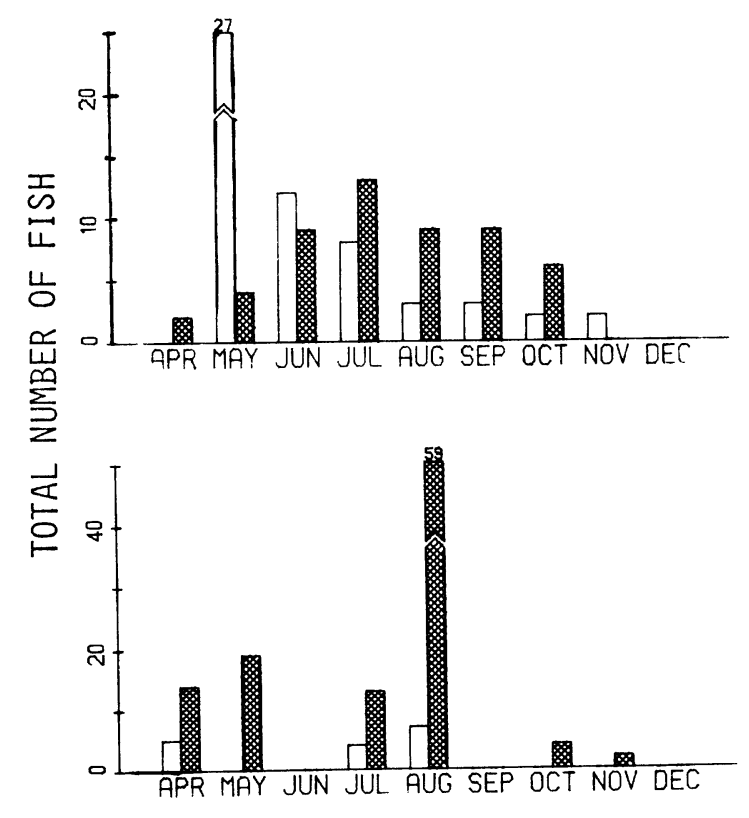

Fig. 75. Total number of johnny darters caught in duplicate seint hauls during day and night once per month April to November 1978 in Pigeon Lake near the J. H. Campbell Plant, eastern Lake Michigan. $\square=$ day $\square=$ night 


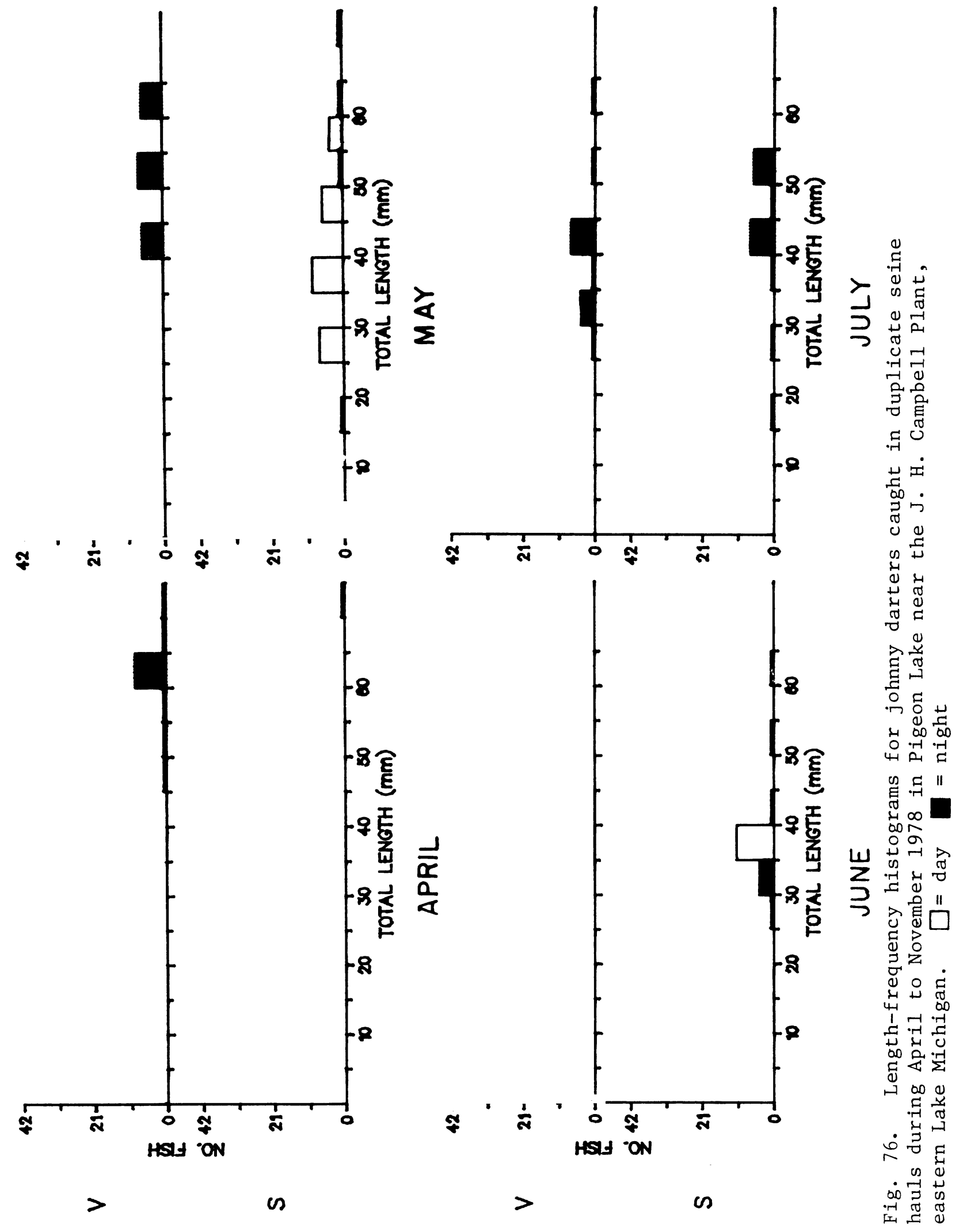



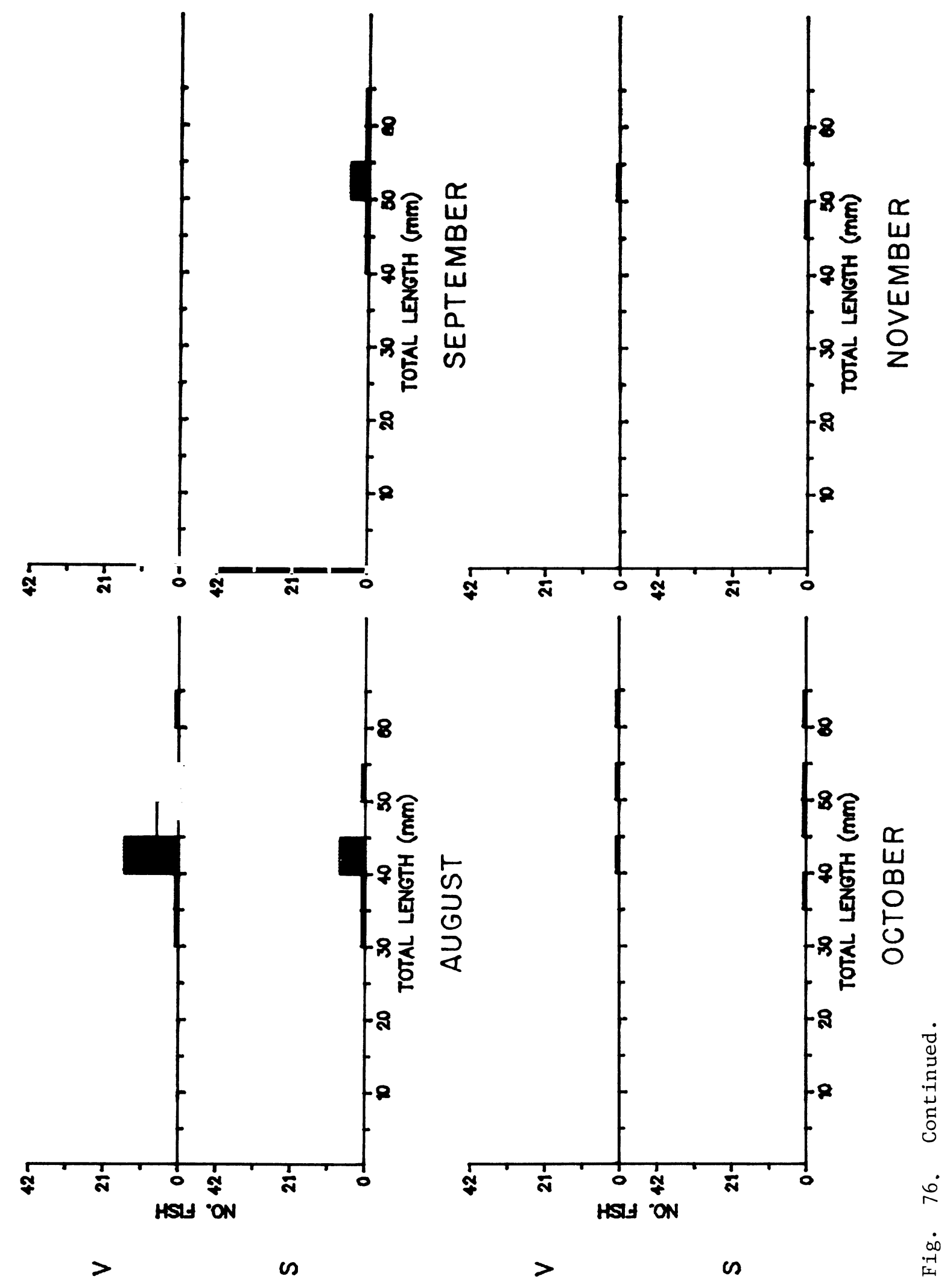
In Pigeon Lake all johnny darters were collected by seine at beach stations S (influenced by Lake Michigan) and V (undisturbed Pigeon Lake) with catches of 109 and 127 respectively. Johnny darters are inactive and sluggish at night (Jude et al. 1979) making them susceptible to nocturnal seining. At station V 111 were caught at night and 16 during the day. At station S 57 were caught during the day and 52 at night. The abundance of darters taken at beach station $S$ during the day could be due to diel water temperature differences at this station. In May during the day, 27 johnny darters were collected when water temperature was $15.3 \mathrm{C}$; only 4 were caught at night when the temperature dropped to $9.8 \mathrm{C}$. Jude et a1. (1975) reported that largest catches of johnny darters occurred at higher water temperatures of $20-22 \mathrm{C}$.

August was the month of maximum catch in Pigeon Lake when 78 darters were collected; water temperatures ranged from 23.0 to $27.3 \mathrm{C}$. Catches of johnny darters increased with increasing water temperatures. Eighty-eight percent of the darters caught in Pigeon Lake were taken at water temperatures between 11 and $25 \mathrm{C}$; the range was 1-27 C. Size range of Pigeon Lake darters was $25-74 \mathrm{~mm}$; $87 \%$ were between 35 and $65 \mathrm{~mm}$. Age determination of Pigeon Lake darters is now in progress and will be included in the 1979 study.

Gonad data suggest that spawning occurred from late-April to mid-May in Pigeon Lake. One ripe-running female and 10 with well developed ovaries were collected in April; 5 ripe-running females and 11 with well developed ovaries were collected in May (Table 35). Winn (1958) gives a spawning time of late April-June for johnny darters, depending on local conditions.

In Lake Michigan during 1978 four johnny darters were collected by seine at beach stations; two at $\mathrm{P}$ (S reference) in June and August, one at $\mathrm{Q}$ ( $\mathrm{S}$ discharge) in June and one at $\mathrm{R}$ ( $\mathrm{N}$ discharge) in August. Water temperatures ranged from 15 to $25 \mathrm{C}$ at time of capture. Eight darters were gillnetted at south reference station $\mathrm{B}(3 \mathrm{~m})$ in October when water temperature was $13 \mathrm{C}$. There were no darters caught by gill net in our 1977 study or in the D.C. Cook Plant study (Jude et al. 1975). Because of their small size and shape, these fish are probably not very susceptible to gill nets. The majority of johnny darters we caught in Lake Michigan were taken in bottom traw1s. Darters were caught by trawling in all months with the exception of April; August was the month of maximum catch when 87 were collected.

Gonad data (Table 36) suggest that spawning took place in June and July in Lake Michigan. Five ripe-running females were collected in June along with 15 darters with well developed ovaries; 1 spent male was also caught in June. In July two females with ripe ovaries and seven with well developed ovaries were collected.

Johnny darter larvae were first observed in early August in Lake Michigan (see RESULTS AND DISCUSSION - FISH LARVAE AND ENTRAINMENT STUDY, Johnny Darter). Hatching of eggs occurs in 5 to 8 days at water temperatures of 22-24 C (Scott and Crossman 1973). These temperatures were first recorded in Lake Michigan during July 1978; consequently, johnny darters may have spawned somewhat later than usual. Johnny darters spawned during May and early June near the D.C. Cook 
Plant in 1973 (Jude et al. 1975).

Table 35. Monthly gonad conditions of johnny darters caught during 1978 in Pigeon Lake near the J. H. Campbell Plant, eastern Lake Michigan. All fish examined in a month were included except poorly received specimens.

\begin{tabular}{|c|c|c|c|c|c|c|c|c|c|c|}
\hline & Gonad condition & Apr & May & Jun & Ju1 & Aug & Sep & Oct & Nov & Dec \\
\hline Males & $\begin{array}{l}\text { Slight development } \\
\text { Mod. development } \\
\text { Well developed } \\
\text { Ripe-running } \\
\text { Spent }\end{array}$ & $\begin{array}{l}2 \\
7\end{array}$ & $\begin{array}{l}7 \\
3\end{array}$ & & 4 & $\begin{array}{r}15 \\
1\end{array}$ & 3 & 2 & 1 & \\
\hline Females & $\begin{array}{l}\text { Slight development } \\
\text { Mod. development } \\
\text { We11 developed } \\
\text { Ripe-running } \\
\text { Spent } \\
\text { Absorbing }\end{array}$ & $\begin{array}{r}1 \\
10 \\
1\end{array}$ & $\begin{array}{r}1 \\
1 \\
11 \\
5\end{array}$ & $\begin{array}{l}5 \\
1\end{array}$ & $\begin{array}{l}1 \\
1\end{array}$ & 3 & $\begin{array}{l}5 \\
1\end{array}$ & $\begin{array}{l}2 \\
7\end{array}$ & 3 & \\
\hline Immature & & & 21 & 9 & 9 & 3 & 2 & 1 & & \\
\hline Unable $t$ & o distinguish & & 1 & 6 & 23 & 17 & 1 & & & \\
\hline
\end{tabular}

Jude et a1. (1975) reported that more johnny darters were captured at $6 \mathrm{~m}$ than at $9 \mathrm{~m}$ during May, June and July. During May-July we collected 72 darters at $6-\mathrm{m}$ stations $\mathrm{C}(6 \mathrm{~m}-\mathrm{S})$ and $\mathrm{L}(6 \mathrm{~m}-\mathrm{N})$ and on $1 \mathrm{y} 18$ fish from $9-\mathrm{m}$ stations $\mathrm{N}(9 \mathrm{~m}-\mathrm{N})$ and $\mathrm{D}(9 \mathrm{~m}-\mathrm{S})$. After spawning, johnny darters move into deeper water overlying sand and gravel (Winn 1958). This pattern was well documented in the Lake Michigan area of the Campbell Plant in 1978. In August catches at stations $\mathrm{C}(6 \mathrm{~m}-\mathrm{S}), \mathrm{D}(9 \mathrm{~m}-\mathrm{S})$ and $\mathrm{E}(12 \mathrm{~m}-\mathrm{S})$ were 10,28 and 37 respectively, demonstrating a movement to deeper water.

Densities of johnny darters increased with depth from September to December. In September 39 of 56 were caught at $9 \mathrm{~m}$ or more; during October 48 of 56 were caught at $12 \mathrm{~m}$ or greater; 34 of 36 were taken from $12 \mathrm{~m}$ or more in November. In December five of six darters captured were collected at $15 \mathrm{~m}$. Absence of johnny darters from nearshore waters in April combined with their near absence in December suggest that these fish move to deeper offshore waters during the period December-April. A review of data from the D.C. Cook Plant studies (1973-1978, unpublished data) shows a similar offshore movement from December to April.

Size range of darters we caught in Lake Michigan was $23-80 \mathrm{~mm} ; 86 \%$ were between 40 and $70 \mathrm{~mm}$. Scott and Crossman (1973) list $69 \mathrm{~mm}$ as maximum length for johnny darters; 34 of the johnny darters collected in Lake Michigan were $70 \mathrm{~mm}$ or greater. 
Table 36. Monthly gonad conditions of johnny darters caught during 1978 in Lake Michigan near the J. H. Campbell Plant, eastern Lake Michigan. All fish examined in a month were included except poorly received specimens.

\begin{tabular}{|c|c|c|c|c|c|c|c|c|c|c|}
\hline & Gonad condition & Apr & May & Jun & $\mathrm{Jul}$ & Aug & Sep & Oct & Nov & Dec \\
\hline Males & $\begin{array}{l}\text { Slight development } \\
\text { Mod. development } \\
\text { Well developed } \\
\text { Ripe-running } \\
\text { Spent }\end{array}$ & & $\begin{array}{l}9 \\
5\end{array}$ & $\begin{array}{l}1 \\
1 \\
2\end{array}$ & $\begin{array}{l}4 \\
2 \\
1\end{array}$ & $\begin{array}{l}9 \\
3\end{array}$ & $\begin{array}{r}18 \\
12 \\
1\end{array}$ & $\begin{array}{r}11 \\
2\end{array}$ & $\begin{array}{l}5 \\
6\end{array}$ & $\begin{array}{l}1 \\
2\end{array}$ \\
\hline Females & $\begin{array}{l}\text { Slight development } \\
\text { Mod. development } \\
\text { Well developed } \\
\text { Ripe-running } \\
\text { Spent } \\
\text { Absorbing }\end{array}$ & & $\begin{array}{l}5 \\
3\end{array}$ & $\begin{array}{r}1 \\
3 \\
15 \\
5\end{array}$ & $\begin{array}{l}1 \\
4 \\
7 \\
2\end{array}$ & $\begin{array}{r}16 \\
4 \\
1 \\
1 \\
1\end{array}$ & $\begin{array}{r}12 \\
4\end{array}$ & $\begin{array}{l}11 \\
21\end{array}$ & $\begin{array}{r}3 \\
13\end{array}$ & 2 \\
\hline Immature & & & 5 & 13 & 1 & 1 & 3 & 9 & 5 & \\
\hline Unable $t$ & o distinguish & & 2 & 6 & 14 & 40 & 6 & 8 & 4 & 1 \\
\hline
\end{tabular}

Johnny darters were more susceptible to trawling at night than during the day; 298 were taken at night and 52 during the day. Over $75 \%$ of the darters caught in trawls were collected from water with temperatures from 11 to 19 C. In our 1977 study (Jude et al. 1978) maximum trawl catches were taken when water temperatures were 5-11 C.

Summary--Johnny darters spawned earlier in Pigeon Lake (April and May) than in Lake Michigan (June-July). This species was most susceptible to our sampling gear at night in Pigeon Lake and Lake Michigan. There seemed to be little correlation between length of fish and water temperature at which they were caught. In Lake Michigan johnny darters moved into the inshore area to spawn and returned to deeper water after spawning; from December to April johnny darters were probably absent from inshore areas.

Largemouth Bass--

Introduction--Pigeon Lake supports a substantial largemouth bass population which has been documented by mark and recapture studies performed during two consecutive years (see RESULTS AND DISCUSSION - GAME FISH POPULATION STUDY), as well as by monthly field sampling for adults, juveniles and larvae. Largemouth bass were the sixth most numerous (532) Pigeon Lake species caught in 1978. Seines collected 531 (Fig. 77), while 1 occurred in a day gill net. None were collected from Lake Michigan. Bass ranged in length from 30 to $410 \mathrm{~mm}$, but YOY (40-100 mm) made up most of the catch. YOY were susceptible to our gear 
when they were present in large numbers during July, August and September; whereas, larger, older individuals were better able to avoid seines and gill nets. Considering Pigeon Lake seining stations V (undisturbed Pigeon Lake) and $\mathrm{S}$ (influenced by Lake Michigan), $88 \%$ of the bass sampled were caught at station $\mathrm{V}$ where water temperatures were consistently higher (by 3-7 C) than at station $\mathrm{S}$ through the summer (see Fig. 74). Only in November did the bass catch at station $S$ surpass that from station $V$.

S

INFLUENCED BY

LAKE MICHIGAN

$\mathrm{V}$

UNDISTURBED

PIGEON LAKE

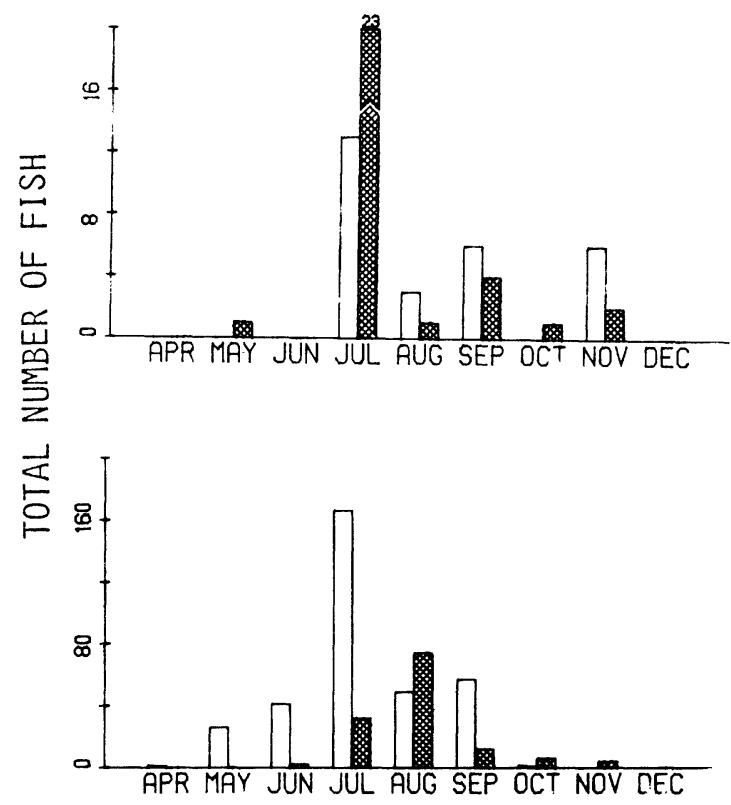

Fig. 77. Total number of largemouth bass caught in duplicate seine hauls during day and night once per month April to November 1978 in Pigeon Lake near the J. H. Campbell Plant, eastern Lake Michigan.

$\square=$ day $\square=$ night

Seasonal distribution--One largemouth bass $(130 \mathrm{~mm})$ was caught in April at station V (Fig. 77) when water temperature was $10.5 \mathrm{C}$. It is likely that the bulk of the bass population was still occupying deeper water at this time of year. This bass was probably a yearling, based on data we collected. A number of largemouth bass were aged using scales; they ranged from 1 to 8 yr (Table 37). Mean lengths of bass in Pigeon Lake were somewhat lower than bass of comparable age reported in Carlander (1977), Scott and Crossman (1973) and Becker (1976), perhaps due in part to the abundance of and competition from northern pike (see Northern pike, this section and GAME FISH POPULATION STUDY).

May samples included 27 largemouth between 70 and $270 \mathrm{~mm}$ (Fig. 78). The majority of these fish, all but one of which came from station $V$, fell between 70 and $130 \mathrm{~mm}$ and although gonad development of these bass was generally slight (Table 38), spawning behavior may account for their presence in the beach zone. 
Table 37. Age-length ranges for largemouth bass collected during fall 1978 from Pigeon Lake near the J.H. Campbell Plant, Port Sheldon, Michigan.

\begin{tabular}{|c|c|c|c|c|c|c|c|c|c|}
\hline \multicolumn{10}{|c|}{ Age of fish } \\
\hline & $0+$ & $1+$ & $2+$ & $3+$ & $4+$ & $5+$ & $6+$ & $7+$ & $8+$ \\
\hline $\begin{array}{l}\text { Total } \\
\text { length } \\
\text { range ( } \mathrm{m}\end{array}$ & $\begin{array}{l}60-110 \\
\mathrm{~mm})\end{array}$ & $146-216$ & $141-289$ & $155-375$ & $179-387$ & $281-410$ & $320-446$ & $365-457$ & 433 \\
\hline $\begin{array}{l}\text { Mean } \\
\text { length }\end{array}$ & $\begin{array}{l}83(1) \\
(\mathrm{mm})\end{array}$ & $180(5)$ & $191(7)$ & $229(12)$ & $278(22)$ & $353(17)$ & $385(14)$ & $410(16)$ & $433(0)$ \\
\hline $\begin{array}{l}\text { No. } \\
\text { examined } \\
\text { (standar }\end{array}$ & $\begin{array}{l}d^{76} \\
\text { rd error }\end{array}$ & $\begin{array}{l}20 \\
\text { in pare }\end{array}$ & $\begin{array}{c}24 \\
\text { enthesis) }\end{array}$ & 25 & 13 & 7 & 7 & 5 & 1 \\
\hline
\end{tabular}

Table 38. Monthly gonad conditions of largemouth bass caught during 1978 in Pigeon Lake near the J. H. Campbell Plant, eastern Lake Michigan. All fish examined in a month were included except poorly received specimens.

\begin{tabular}{|c|c|c|c|c|c|c|c|c|c|c|}
\hline & Gonad condition & Apr & May & Jun & Jul & Aug & Sep & Oct & Nov & Dec \\
\hline Males & $\begin{array}{l}\text { Slight development } \\
\text { Mod. development } \\
\text { Well developed } \\
\text { Ripe-running } \\
\text { Spent }\end{array}$ & 1 & $\begin{array}{l}9 \\
1\end{array}$ & 35 & 1 & 5 & 2 & $\begin{array}{l}4 \\
1\end{array}$ & 3 & \\
\hline Females & $\begin{array}{l}\text { Slight development } \\
\text { Mod. development } \\
\text { We11 developed } \\
\text { Ripe-running } \\
\text { Spent } \\
\text { Absorbing }\end{array}$ & & $\begin{array}{l}5 \\
1\end{array}$ & $\begin{array}{l}6 \\
1\end{array}$ & & 1 & 2 & 1 & & \\
\hline Immature & & & 8 & 1 & 107 & 66 & 61 & 1 & 8 & \\
\hline Unable tc & distinguish & & 3 & & & 16 & 4 & 1 & 1 & \\
\hline
\end{tabular}



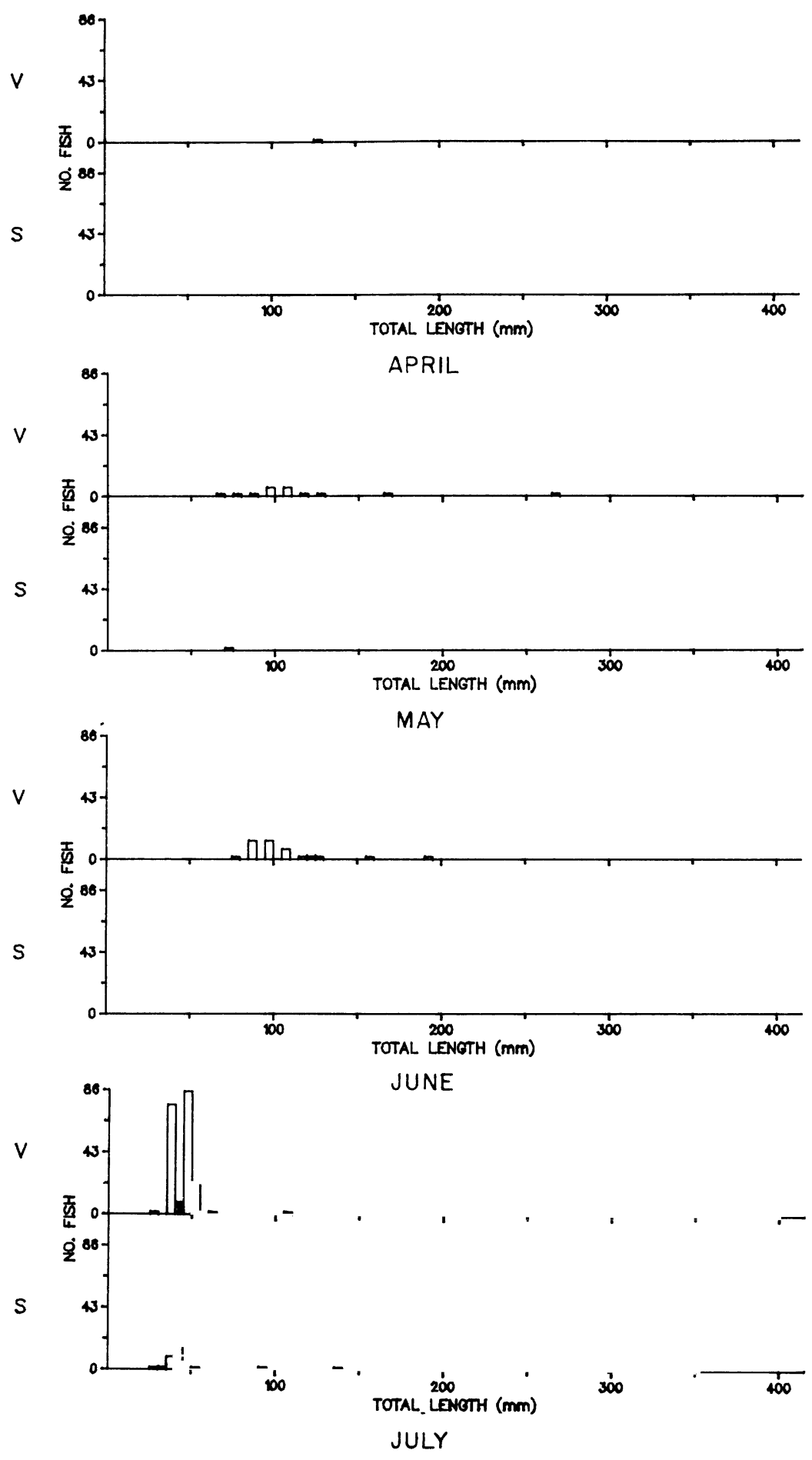

Fig. 78. Length-frequency histograms for largemouth bass caught in duplicate seine hauls during April to November 1978 in Pigeon Lake near the J. H. Campbe11 Plant, eastern Lake Michigan. $\square=$ day $\square=$ night 

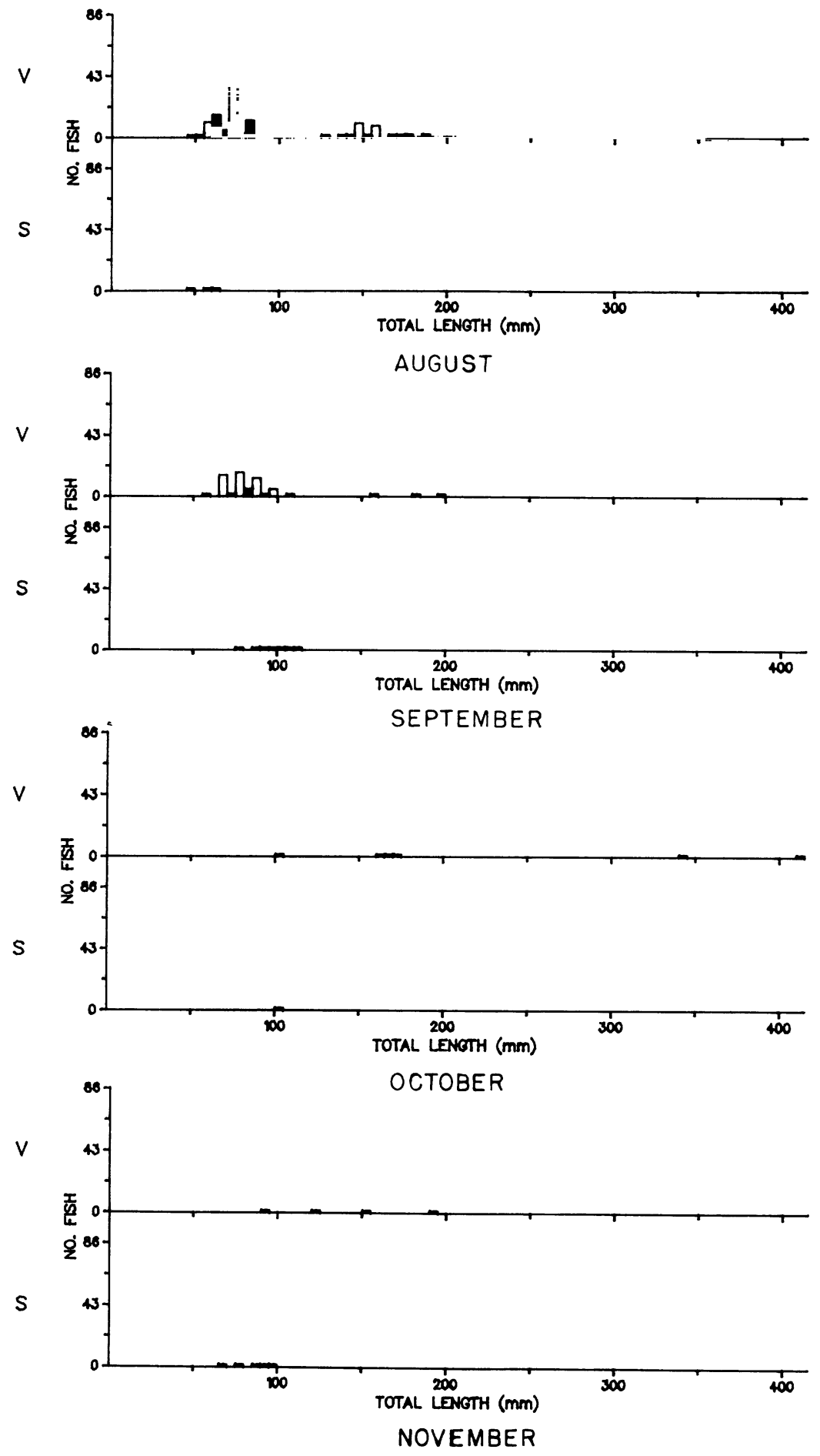

Fig. 78. Continued. 
Jude et a1. (1978) in agreement with Scott and Crossman (1973) reported peak largemouth bass spawning in June; water temperatures for May and June 1978 (17-21 C) fell within the range favorable for spawning (Scott and Crossman 1973). In the Pigeon Lake study area in 1977 , beach station $\mathrm{T}$ (influenced by Pigeon River), which was eliminated from the 1978 sampling scheme, was found to be the most favored spawning site for largemouth bass (Jude et al. 1978). Observations of large schools (1000-2000 individuals) of largemouth bass larvae in the area near station $\mathrm{T}$ during early June 1979 substantiates this contention. It might therefore be assumed that in 1978, the larger male bass in the Pigeon Lake population, [which during the spawning season establish and aggressively defend nesting sites about $9 \mathrm{~m}$ apart (Scott and Crossman 1973)], probably dominated the preferred spawning habitat near beach station $\mathrm{T}$. Younger or smaller male bass may thus have been forced to occupy less favored spawning grounds like beach station $V$, and as such, were the fish that we collected. In 1977, 20-30-mm YOY were caught in June (Jude et a1. 1978); however, this size bass was missed during 1978 sampling.

Largemouth bass YOY first appeared as 30-50-mm fish in July (Fig. 78). Total catch of largemouth, comprised mostly of YOY, was greater in July than any other month, and day catch (179) exceeded night catch (55) (Fig. 78). Utilization of beach station V (undisturbed Pigeon Lake) as a largemouth bass spawning ground appeared to have been more extensive in 1978 than in 1977. Two-hundred YOY bass were caught at station V in 1978 compared with 12 in 1977 (Jude et al. 1978). Mean length of YOY bass in July was $44 \mathrm{~mm}$. Water temperatures for July ranged from $13.8 \mathrm{C}$ (station S) to $20.8 \mathrm{C}$ (station V).

August samplings reflected YOY bass growth (range: $50-80 \mathrm{~mm}$; mean $=68 \mathrm{~mm}$ ) and diminution of total number (92 caught) (Fig. 78). More YOY were caught at night than during the day (Fig. 78) probably due to largemouth behavior. In a study of bass movement, Elliott (1976) found that largemouth bass fry fed throughout the day, but were inactive and aggregated closely in one location at night. Seines, passing through these aggregations at night (when fish could not easily see to avoid the net) could catch large numbers of bass. Besides YOY, 35 largemouth bass between 130 and $190 \mathrm{~mm}$ were caught in August (Fig. 78). Only four bass in August were caught at station $S$ where water temperature was $22.5 \mathrm{C}$. Temperature at station $\mathrm{V}$ was $27.3 \mathrm{C}$.

Further growth of YOY and further decline in total numbers caught were noted in September when 76 largemouth bass between 60 and $100 \mathrm{~mm}$ (mean length = $83 \mathrm{~mm}$ ) were caught (Fig. 78). In addition, three larger bass (160-200 mm) were seined (Fig. 78).

In October seine hauls, when water temperature had fallen between 10.5 and $12.0 \mathrm{C}$, two 100-mm largemouth bass were caught at night and five other bass (160-410 mm) were caught during the day (one at station S) (Fig. 78). A 330-mm individual was gillnetted in a day set at station $M$ (influenced by Lake Michigan) (Appendix 7). Through two full seasons of sampling, this was the only largemouth bass to be caught in a gill net, demonstrating the inefficiency of this gear in capturing this species. The ability of bass to avoid nets during the day, their general inactivity at night and their relatively low abundance at gill netting station $M$ (where depths are greater and macrophytic growth is less than 
other Pigeon Lake stations) all contributed to the observed gill net inefficiency.

Ten largemouth bass $(70-120 \mathrm{~mm})$ caught in November were the last of the 1978 YOY to appear in field samples (Fig. 78). Natural mortality, predation, disease and dispersal combined to reduce the number of YOY in the study area by this time. Water temperatures ranged from $10.0 \mathrm{C}$ to $11.5 \mathrm{C}$ in November. No largemouth bass were caught in December field samples probably because general dispersal to deeper water had occurred.

Impingement--Impingement of largemouth bass was fairly low, but persistent (estimated total of 5-54 fish/mo) from January to August after which numbers of impinged bass increased dramatically. Respectively, in September, October, November and December, an estimated 397, 514, 562 and 1418 largemouth bass were impinged on intake screens. Although most bass were YOY, larger individuals (up to $170 \mathrm{~mm}$ ) were also impinged with regularity. It appears that some portion of the largemouth bass population inhabited the Campbell Plant intake canal and that some of the YOY dispersed to this habitat. As water temperature drops and food becomes less available, fish with low metabolic rates may become more suseptible to being swept in by intake currents. In November-December we believe that some of the impinged bass originated from the discharge canal and entered the intake forebay via an open gate. A similar pattern of increased impingement was noted for alewife and gizzard shad, fish that were rare or not present in Pigeon Lake during November-December, yet they were impinged in high quantities.

Temperature-catch relationships--Largemouth bass were found in water temperatures between 10.0 and $27.3 \mathrm{C}$ with $55 \%$ being caught at $21 \mathrm{C}$. There was some correlation between size of fish and temperature, since larger fish were better able to behaviorally regulate temperature by moving to different parts of the lake, and consequently occupied somewhat cooler water (Fig. 79).

Other considerations--Growth of bass is closely related to temperature. Niimi and Beamish (1974) found that if largemouth bass were fed to satiation, best growth occurred at $25 \mathrm{C}$, but with a fixed or limited amount of food, best growth was achieved at $18 \mathrm{C}$ (where metabolic requirements are smaller). Growth of YOY bass caught in 1978 lagged behind those caught in 1977 during July and August (1978 water temperatures at stations V were between $20.8 \mathrm{C}$ and $27.3 \mathrm{C}$ ) but greater growth of 1978 fish occurred by September (1978 water temperature was $20.0 \mathrm{C}$ ). We may assume then for Pigeon Lake largemouth YOY, that availability of food was not sufficient for satiation feeding during the 1978 season and that during months of relatively high temperatures, optimum growth rates were not possible. When water temperatures dropped in september, metabolic requirements of bass decreased and better growth was realized. YOY growth rates in 1977 and 1978 were not totally suited for comparison however, since 1977 bass growth was based largely on fish caught at beach station $\mathrm{T}$, while 1978 YoY growth was calculated from fish captured at beach station V. Most largemouth bass collected in 1978 were found with food in their stomachs. Food items identified were predominately amphipods, while corixids, dragonfly naiads and damselfly nymphs were also found. 


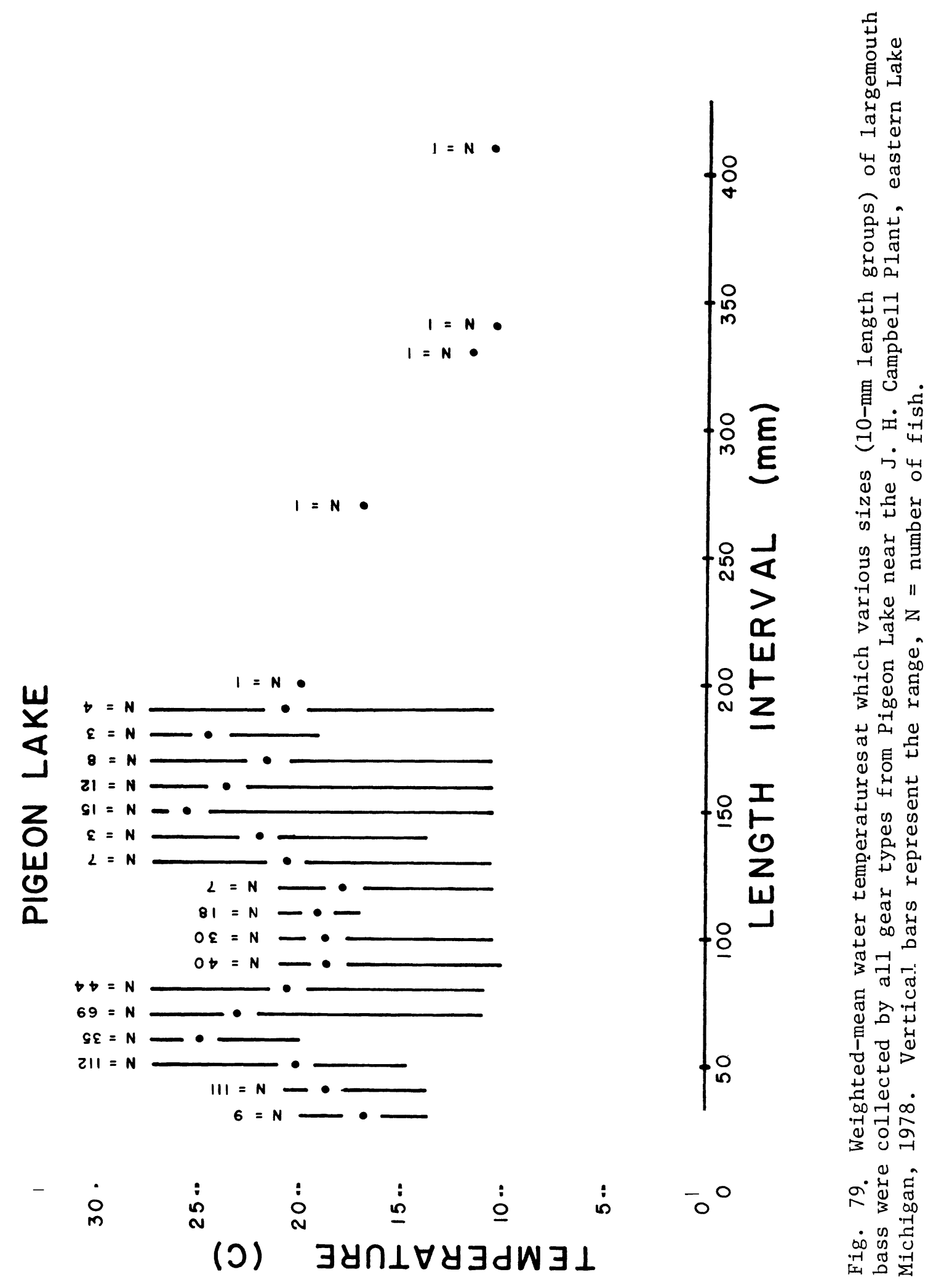


Plant impacts--During 1978 the Campbe11 Plant was responsible for the destruction of 3061 YOY and juvenile bass through impingement and 816 larval bass (a11 in June) through entrainment. Regarding impingement losses, it is important to note that most of the fish lost were YOY. Length range of impinged bass was from 50 to about $170 \mathrm{~mm}$. Scott and Crossman (1973) state that largemouth from Ohio were $51-127 \mathrm{~mm}$ as YOY, the Ontario average 1-yr-old bass was $170 \mathrm{~mm}$ and our data (Table 37) 1ist YOY as 60-110 mm (mean = 83). Considering the length-frequency distribution of impinged bass (Appendix 7), less than $5 \%$ were greater than $100 \mathrm{~mm}$, making the vast majority of impinged fish YOY, undoubtedly the most abundant age-group of bass in Pigeon Lake. Another important point is that most (94\%) of the bass were impinged during September-December. Only $170 \mathrm{fish}$ were impinged during January-August. It has already been noted that we feel many of the largemouth impinged in late fall-winter passed from the discharge canal, where they were probably hatched, into the intake forebay via an open gate there. Thus, it may be invalid to consider these fish as lost from the Pigeon Lake population.

In our game fish population study (see RESULTS), we generated an estimate for two size groups of bass in Pigeon Lake, one was $842 \mathrm{fish}$ for the 175-219-mm group and the other was $290 \mathrm{fish}$ for fish greater than $219 \mathrm{~mm}$. Since six fish in the 170-mm interval were estimated impinged by the Campbell Plant in 1978, we feel this loss is insignificant to the population of bass this size in the lake. There was a decline from 1977 ( $471 \mathrm{fish}$ ) to 1978 (290 fish) in the numbers of bass greater than $219 \mathrm{~mm}$ in the lake. Reasons for this decline could be fishing mortality, habitat destruction by the dredging that occurred in the lake in 1978, sampling variability, or a combination of factors. We saw no dramatic decline in the YOY and juvenile bass population as reflected in our field sampling of 1977-1978. In 1977, 760 bass, most1y YOY, were caught; in 1978, when our most productive station was deleted, we collected 532 bass, again mostly YOY. Thus, we have not seen any significant changes in the YOY and juvenile fish populations, despite their relatively high impingement rates at the Campbell Plant. Likewise, entrainment of 816 larval bass did not seem to affect year class strength of largemouth bass in Pigeon Lake.

Summary--Largemouth bass occupy the deeper sections of Pigeon Lake during April, exhibiting a movement to shallow areas during May. This movement to shallow water was probably related to spawning. The area near station $V$ (undisturbed Pigeon Lake) appeared to be preferred over the area near station $\mathrm{S}$ (influenced by Lake Michigan). Young-of-the-year were first captured in seine hauls during July, and remained common in seine samples through September.

Again, the area near station $\mathrm{V}$ was preferred by this age-group over station $\mathrm{S}$. Paucity of largemouth bass in beach areas in October and November indicates that this species probably resided in deeper water during late autumn and winter months. Large numbers of YOY largemouth bass were impinged from September to December which indicates that many of these bass resided in or near the intake canal or discharge canal in late autumn and winter months, and were susceptible to impingement.

Emerald Shiner--

Introduction--The emerald shiner was the seventh most abundant species 
collected from Pigeon Lake during 1978. The 466 specimens comprised $4.7 \%$ of the total number of all fish captured in Pigeon Lake. Fifty emerald shiners were captured in Lake Michigan.

These data contrast sharply to those of 1977, when only four emerald shiners were collected, three from Pigeon Lake and one from Lake Michigan (Jude et al. 1978). From 1973 to 1978 abundance of emerald shiners in the vicinity of the D.C. Cook Plant has also been low, with yearly catches ranging from zero to 49 individuals. Prior to 1960, and before alewives became dominant in Lake Michigan, emerald shiners were extremely abundant in the lake (Smith 1968). Both species spawn at the same time and have pelagic larvae; clearly alewives were the superior competitor, since emerald shiners are now scarce or absent over much of their former range in the shallow bays and nearshore water of Lake Michigan.

Seasonal distribution--A11 emerald shiners collected in the vicinity of the Campbell Plant during 1978 were seined from April to November at beach stations $\mathrm{Q}$ and $\mathrm{R}$ in Lake Michigan and beach stations $\mathrm{S}$ and $\mathrm{V}$ in Pigeon Lake (Fig. 80). Fish taken from Lake Michigan (50) ranged from 28 to $90 \mathrm{~mm}$; 36 of these fish were between 60 and $90 \mathrm{~mm}$. The 466 emerald shiners taken from Pigeon Lake ranged from 20 to $98 \mathrm{~mm}$; however, most (437) were between 20 and $53 \mathrm{~mm}$. These length data (small fish in Pigeon Lake, larger fish in Lake Michigan) may suggest a separation by age-group of the emerald shiner population in the vicinity of the plant during 1979.

S

INFLUENCED BY

LAKE MICHIGAN

$V$
UNDISTURBED
PIGEON LAKE

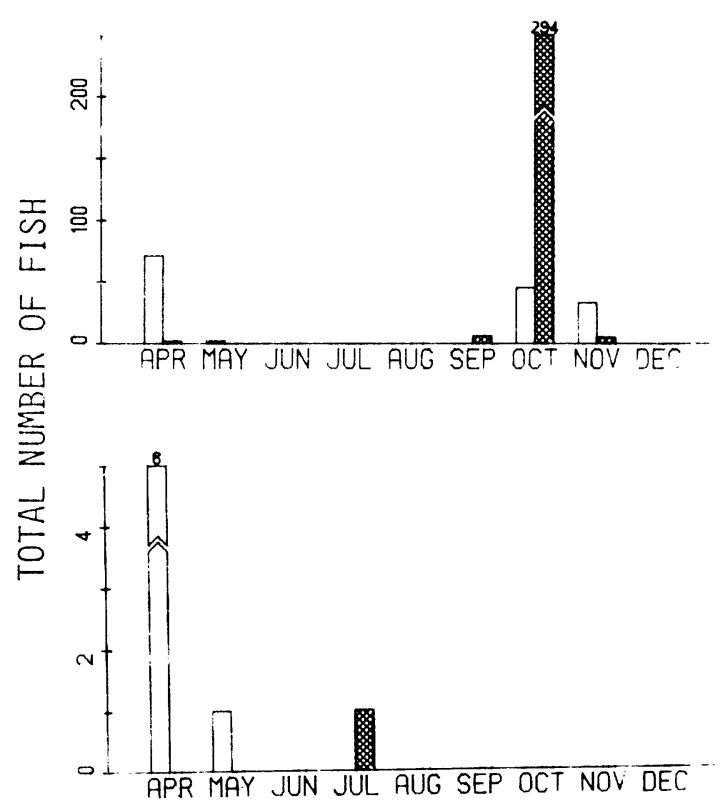

Fig. 80. Total number of emerald shiners caught in duplicate seine hauls during day and night once per month April to November 1978 in Pigeon Lake near the J. H. Campbell Plant, eastern Lake Michigan.

$$
\square=\text { day } \square=\text { night }
$$


April--Seventy-nine emerald shiners were seined in Pigeon Lake during April. Six were collected during the day at beach station $\mathrm{V}$ (undisturbed Pigeon Lake) and 73 were taken at station $S$ (influenced by Lake Michigan) (Fig. 81). All but two of those seined at station $S$ were taken during the day. Water temperatures at time of capture were 8.5-10.5 C.

Size range of emerald shiners caught at these two stations were vastly different. Lengths of the six fish collected at station $V$ ranged from 51 to $83 \mathrm{~mm}$, while the range at station $\mathrm{S}$ was 25 to $53 \mathrm{~mm}$ (average $42 \mathrm{~mm}$ ). Since it has been found that emerald shiners spawn after April in the Great Lakes (Scott and Crossman 1973) these two distinct size groups of emerald shiner (spawned the previous year since we collected few in 1978) may have been the result of cooler Lake Michigan water inhibiting growth of fishes at station $\mathrm{S}$, but not those at station $V$. On the other hand, this range in lengths may indicate separation of emerald shiners by age; station $S$ sustaining YOY and station $\mathrm{V}$ age-group-1 individuals. Unless their presence was undetected during our monthly sampling in 1977 we should have seen these age-group-1 individuals as yearlings in 1978. These data would also indicate that emerald shiners in Pigeon Lake reach a minimum average length of $42 \mathrm{~mm}$ at the end of their first year of life.

These lengths agree closely with Fuchs (1967) who found emerald shiners reached $30-40 \mathrm{~mm}$ by the end of their first year. Age-group-1 fish averaged $66 \mathrm{~mm}$ and age-group 2, $84 \mathrm{~mm}$. On the other hand, Flittner (1964) who worked on western Lake Erie emerald shiner populations from 1958 to 1960 measured an average length of $63 \mathrm{~mm}$ for age-group $0,91 \mathrm{~mm}$ for age-group 1 and $104 \mathrm{~mm}$ for age-group-2 fish. These higher growth rates may have been due to the more eutrophic condition of Lake Frie. Flittner (1964) also found 1-yr-old males and females to attain average lengths of 74 and $78 \mathrm{~mm}$ respectively. Age-group-2 males averaged $88 \mathrm{~mm}$ and females $98 \mathrm{~mm}$. In Lake Simcoe, Ontario, YoY emerald shiners reached an average length of $51 \mathrm{~mm}$ by mid-November (Scott and Crossman 1973).

May--Three emerald shiners were seined in Pigeon Lake during May; 29and 48-mm individuals at station $\mathrm{S}$ and a 76-mm fish at station V (Fig. 81). Al1 were collected during day seining in water 15.3 to $17.0 \mathrm{C}$. These limited data may again support the contention that two distinct growth rates or age-groups of emerald shiner exist in Pigeon Lake.

There was a marked reduction in emerald shiner catch from April to May, which continued throughout the summer months (Appendix 6). Spawning by emerald shiner was found to occur during the summer by several workers. Carlander (1969) and Fuchs (1967) determined that spawning takes place from late June to mid-August in Lake Erie and Lewis and Clark Lake, South Dakota, respectively. Flittner (1964) states that adults move inshore to spawn in late May through early June and then move offshore remaining near the thermocline at 11-13 $\mathrm{m}$ in western Lake Erie. Dispersing of adult fish to the deeper water of Lake Michigan and Pigeon Lake may be the reason for our low catches throughout summer months.

Due to identification problems, emerald shiner larvae under $9.0 \mathrm{~mm}$ could not be positively identified. Emerald shiner larvae $9.0 \mathrm{~mm}$ or greater were 


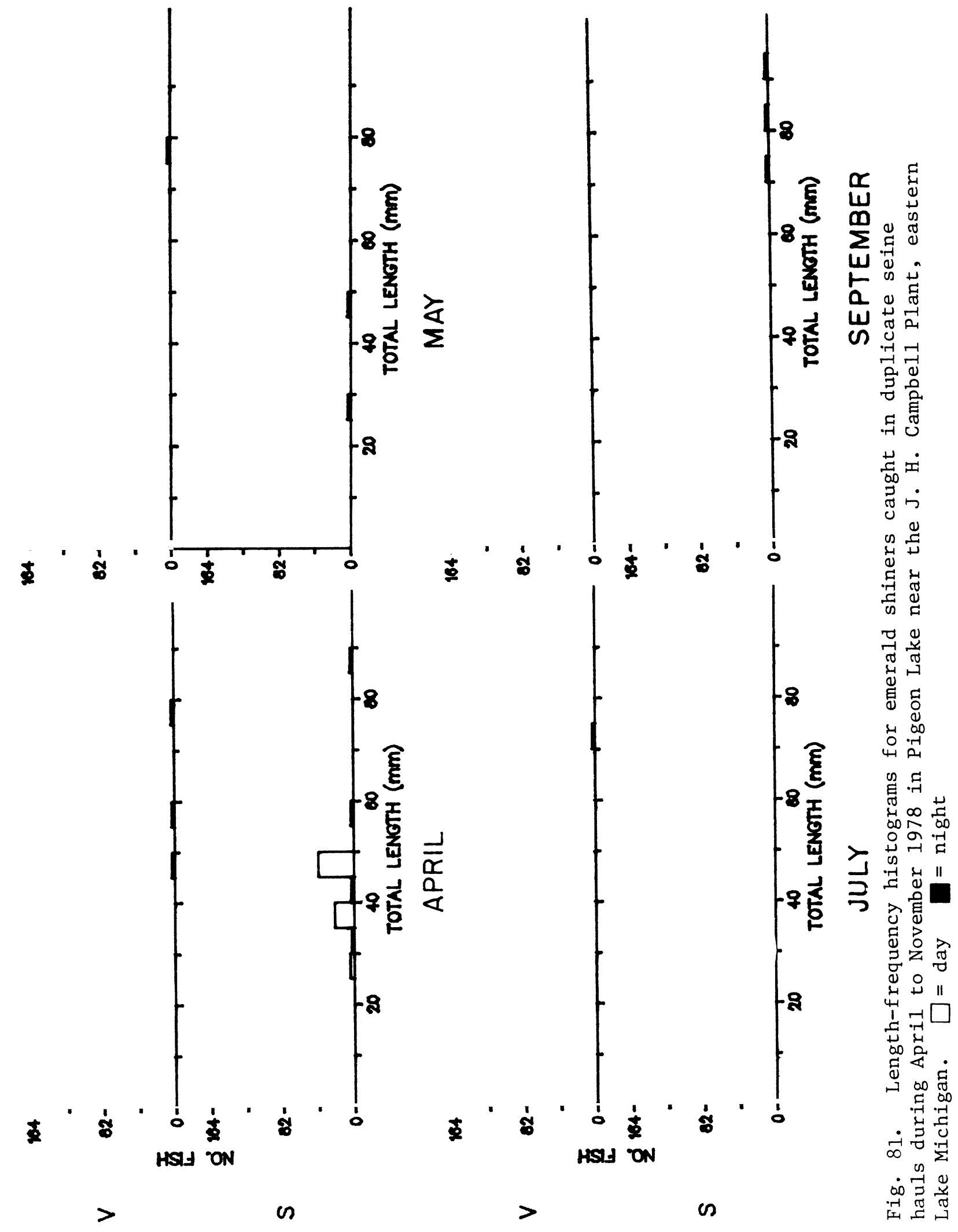




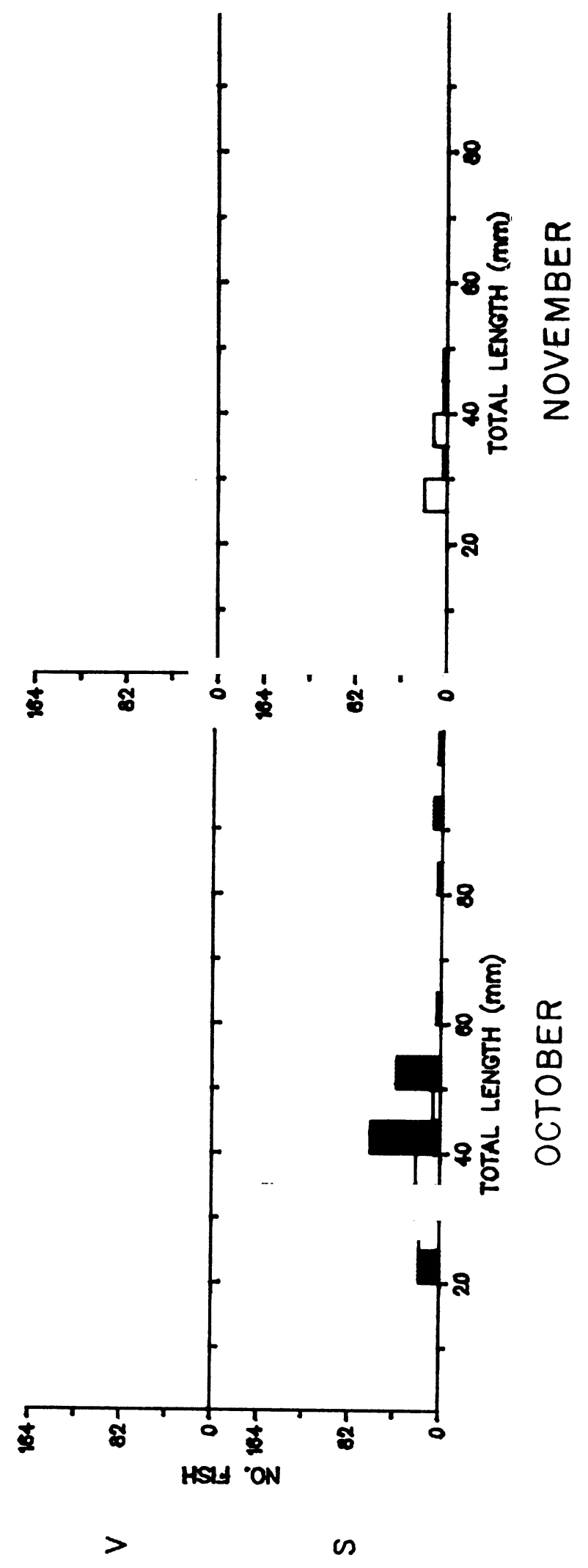

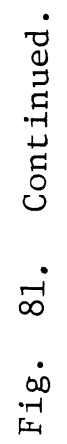


recovered in larvae and sled tow samples from late June to late July. This might possibly indicate that spawning took place sometime after early June. For a further discussion of this problem, see RESULTS AND DISCUSSION - FISH LARVAE AND ENTRAINMENT STUDY, Cyprinidae Complex, Emerald shiner.

June--Three 63-64-mm emerald shiners were taken in day seines at Lake Michigan beach station $\mathrm{R}$ ( $\mathrm{N}$ discharge) during June. Temperature of the water was $21.7 \mathrm{C}$. Occurrence of these individuals, which were probably age-group-1 fish may be the result of movement out of Pigeon lake after spawning activities. These fish could have migrated northward to beach station $\mathrm{R}$ with the alongshore current.

July--A 70-mm emerald shiner was collected at Pigeon Lake station $\mathrm{V}$ during July night seining (Fig. 81) when water temperature was $20.8 \mathrm{C}$. This individual again may be an age-group-1 fish spawned in 1977 , showing good growth at station $\mathrm{V}$ (undisturbed Pigeon Lake). This fish may also have been involved in spawning activities in 1978, as a length of $70 \mathrm{~mm}$ in July would place this fish among possible age-group-1 spawners according to Flittner (1964).

August--Five and 11 emerald shiners were seined at Lake Michigan beach stations $Q$ (S discharge) and $\mathrm{R}$ ( $\mathrm{N}$ discharge) respectively during August. At station $Q$ three large $(75-78 \mathrm{~mm})$ and two small $(32 \mathrm{~mm}$ ) individuals were collected. Of the eleven fish collected at station $R$, eight $(60-82 \mathrm{~mm})$ were taken during the day, while three $(60-77 \mathrm{~mm})$ were taken at night. Water temperature ranged from 22 to $26 \mathrm{C}$. Again these fish may have migrated from Pigeon Lake and drifted north with alongshore current. The two 32-mm fish were probably spawned in 1978 .

September--Twenty-seven emerald shiners were seined at Lake Michigan beach stations in September when water temperatures were 18.7-19.0 C. Eight fish, ranging in length from 32 to $68 \mathrm{~mm}$, were taken at night at station Q (S discharge). Of the 19 emerald shiners $(40-90 \mathrm{~mm}$ ) seined at station $\mathrm{R}$ ( $\mathrm{N}$ discharge), 14 were taken at night. These fish may constitute a part of agegroup-1 fish, which moved inshore in the fall. Flittner (1964) found that although young emerald shiner dispersed widely in summer, by fall these fish reappeared inshore in schools.

In Pigeon Lake six large $(68-86 \mathrm{~mm})$ emerald shiners were collected at beach station $\mathrm{S}$ at night (Fig. 81), when the water was $19.0 \mathrm{C}$. These individuals may also have come from a school of age-group-1 individuals in Pigeon Lake.

October--The largest catch (339) of emerald shiners ever to occur at one station in 1978 occurred during October at Pigeon Lake beach station S (influenced by Lake Michigan) (Fig. 81). This was the only station where emerald shiners were taken during October. Most were caught at night (294). Emerald shiners were collected from water 11.5 to $12.5 \mathrm{C}$, and most ranged from 20 to $51 \mathrm{~mm}$. Fish of this size range, so late in the year, were obviously yoY resulting from spawning in Pigeon Lake. One $28-\mathrm{mm}$ emerald shiner was also taken in a night plankton net tow at station S.

Ten large individuals (possibly adults) ranging in length from 80 to $98 \mathrm{~mm}$, 
were also seined in October. Many of these fish possessed slightly developed gonads.

November--Catches of emerald shiner in November were limited to beach station $Q$ in Lake Michigan and beach station $S$ in Pigeon Lake. One 82-mm individual and three sma11 ones (28-33 mm) were seined at night in Lake Michigan at temperatures of 10 to $13.2 \mathrm{C}$.

In Pigeon Lake 38 emerald shiners $(25-50 \mathrm{~mm})$ were captured; 33 were taken during the day (Fig. 80). These fish were taken at water temperatures of $10-11.5 \mathrm{C}$.

Again appearance of sma11 emerald shiners in Lake Michigan may be a function of schooling and/or dispersal and drift from Pigeon Lake or spawning in the inshore region of Lake Michigan or in the discharge canal.

Temperature-catch relationships--Water temperatures at capture for emerald shiners ranged from 10 to $26 \mathrm{C}$ in Lake Michigan and 8.5-21 C in Pigeon Lake; however, most specimens were captured between 19-25 C in Lake Michigan and 9-13 $\mathrm{C}$ in Pigeon Lake. Most young emerald shiners (20-60 mm) were captured at cooler temperatures of 8.5-12.5 C, while older fish $(70-98 \mathrm{~mm})$ were caught at warmer temperatures between 9.0 and $25.3 \mathrm{C}$ (Fig. 82).

Impingement--Eleven emerald shiners were collected in 24-h impingement samples during 1978 resulting in an estimated total of 72 impinged. A11 but one of the sampled fish, a 75-mm individual, ranged in length from 90 to $125 \mathrm{~mm}$. These fish were at or exceeded the reported maximum size for emerald shiners (Carlander 1969). Emerald shiners were collected in each month of January, February, Apri1, September, October and December. No emerald shiners were collected in impingement samples from June to December 1977 (Zeitoun et a1. 1978). Seven emerald shiners were found in impingement samples from February to September 1974 (Consumers Power Company 1975).

Other considerations--On1y 17 emerald shiners were identified as adults, 7 males and 10 females, yet $45 \mathrm{fish}$ at lengths of $75 \mathrm{~mm}$ or greater were collected. As previously discussed, Flittner (1964) found 1-yr-old male and female emerald shiners at average lengths of 74 and $78 \mathrm{~mm}$ respectively in western Lake Erie. Due to the small size of the minnow at maturity, gonad condition determinations were often difficult. Of the $45 \mathrm{fish} 75 \mathrm{~mm}$ or greater 6 were called immature and 22 fish were in poor condition or not examined (Tables 39 and 40). The six fish called immature $(75-90 \mathrm{~mm})$ were all caught during September and may have been spent adults.

Increase in abundance of emerald shiners noted in 1978 compared with 1977 in the vicinity of the Campbell Plant would appear to be area specific as most were caught in Pigeon Lake and the two north transect beach stations in Lake Michigan. According to Smith (1970), Wells and McLain (1972) and Flittner (1964) once alewife and smelt became abundant in the Great Lakes, emerald shiner populations declined drastically. Alewife and emerald shiner were found by Flittner (1964) and Fuchs (1967) to possibly compete for such food as cladoceran and copepod zooplankton which constitute the major portion of the diet of both 


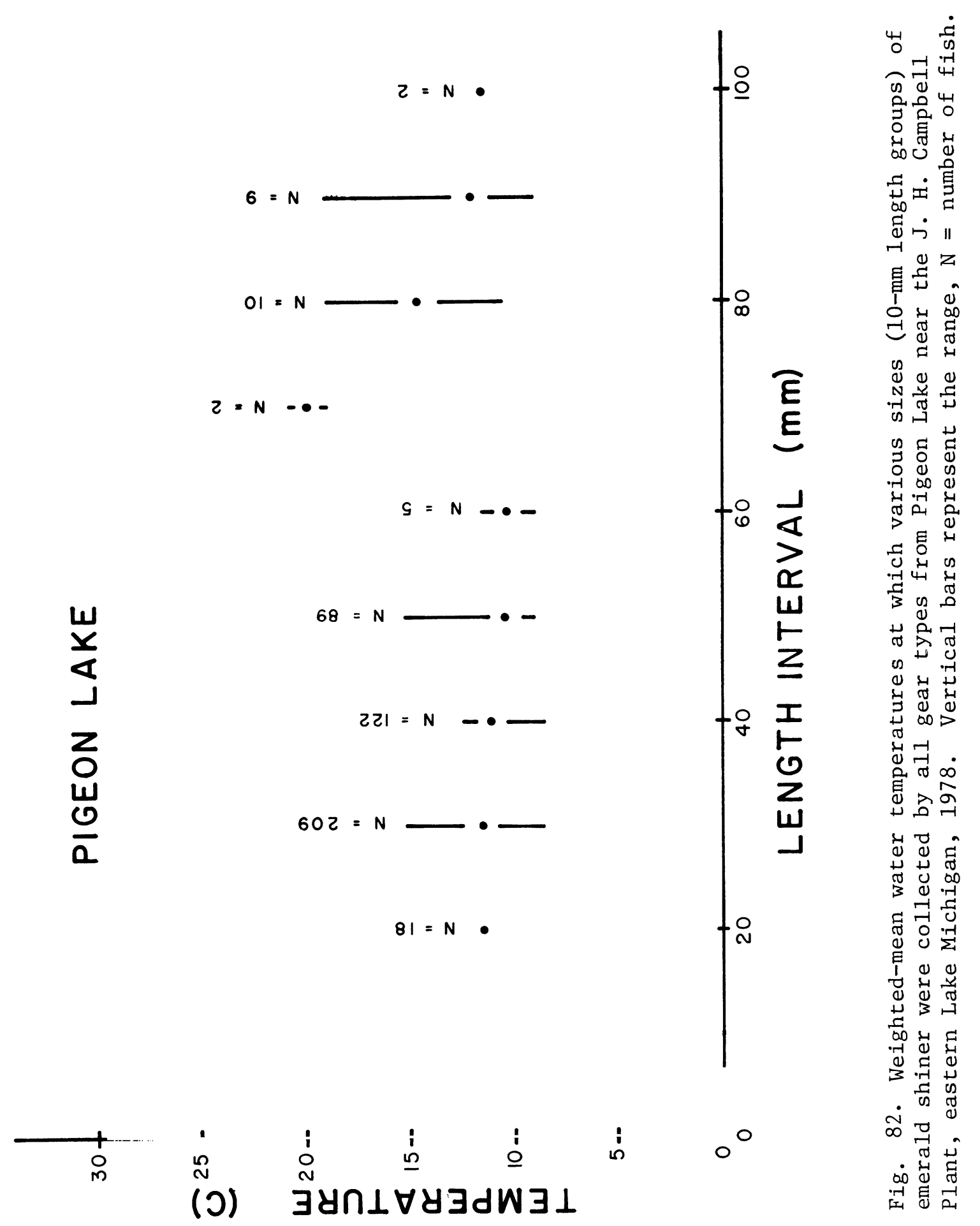


Table 39. Monthly gonad conditions of emerald shiners caught during 1978 in Pigeon Lake near the J. H. Campbell Plant, eastern Lake Michigan. All fish examined in a month were included except poorly received specimens.

\begin{tabular}{|c|c|c|c|c|c|c|c|c|c|c|}
\hline & Gonad condition & Apr & May & Jun & $\mathrm{Ju} 1$ & Aug & Sep & Oct & Nov & Dec \\
\hline Males & $\begin{array}{l}\text { Slight development } \\
\text { Mod. development } \\
\text { Well developed } \\
\text { Ripe-running } \\
\text { Spent }\end{array}$ & 2 & & & & & & 1 & & \\
\hline Females & $\begin{array}{l}\text { Slight development } \\
\text { Mod. development } \\
\text { Well developed } \\
\text { Ripe-running } \\
\text { Spent } \\
\text { Abosrbing }\end{array}$ & 1 & 1 & & & & & $\begin{array}{l}2 \\
2\end{array}$ & & \\
\hline Immature & $\ldots$ & 36 & 2 & & 1 & & 1 & 91 & 22 & \\
\hline Unable to & o distinguish & 4 & & - & & & 5 & 5 & & \\
\hline
\end{tabular}

Table 40. Monthly gonad conditions of emerald shiners caught during 1978 in Lake Michigan near the J. H. Campbell Plant, eastern Lake Michigan. All fish examined in a month were included except poorly received specimens.

Gonad condition Apr May Jun Jul Aug Sep Oct Nov Dec

$\begin{array}{llll}\text { Slight development } & 2 & 2 & 2 \\ \text { Mod. development } & & & \end{array}$

Males Well developed

Ripe-running

Spent

\begin{tabular}{|c|c|c|c|c|c|}
\hline Females & $\begin{array}{l}\text { Slight development } \\
\text { Mod. development } \\
\text { Well developed } \\
\text { Ripe-running } \\
\text { Spent } \\
\text { Absorbing }\end{array}$ & 1 & & 4 & \\
\hline Immature & & & 2 & 14 & 3 \\
\hline Unable tc & o distinguish & & 12 & 7 & 1 \\
\hline
\end{tabular}


species as adults. The alewife may have out-competed the emerald shiner for these food items, thus indirectly causing the decline in abundance of emerald shiners. Larvae of these species may also compete for food, however, no food studies documenting this have been reported.

Alewife abundance in Lake Michigan near the Campbell Plant remained at approximately the same levels in both years decreasing slightly from 53,864 caught in 1977 to 44,617 caught in 1978. In Pigeon Lake, however, the alewife catch decreased from 7094 in 1977 to 605 in 1978. Elimination of stations $T$ and $Y$ from the Pigeon Lake sampling program had no effect on the alewife catch, since none were caught there. The possible reason for the decline in alewife abundance in Pigeon Lake is discussed in RESULTS AND DISCUSSION - ADULT AND JUVENILE FISH, Alewife. The decline however appears to have significantly decreased competion between the two species and enabled emerald shiner populations to rebound in 1978 .

All emerald shiners were collected during seining in the beach zone area of both Pigeon Lake and Lake Michigan. Flittner (1964) reported catching many emerald shiners in bottom trawls in water less than $16 \mathrm{~m}$. During our $2 \mathrm{yr}$ of study however, no emerald shiners were recovered from depths greater than $1.5 \mathrm{~m}$. The traw1 used in this study has a smaller mesh size than Flittner reported and our relatively slow trawl speed may possibly contribute to net avoidance by emerald shiner even if they did inhabit the nearshore area of Lake Michigan.

Summary--Abundances of emerald shiners increased dramatically in Pigeon Lake from 1977 to 1978. Most were caught either in the early months of April and May or late in the year during September and October. In the area of the Campbell Plant, spawning appears to have taken place from early June through July.

YOY emerald shiners, $20-51 \mathrm{~mm}$, appeared in October and November seines in water ranging in temperature from 10.0 to $12.5 \mathrm{C}$. Prior to this, larvae were found in late June and July plankton and sled tows in Pigeon Lake and Lake Michigan as well as in entrainment samples.

Yearling emerald shiners appeared early in April in Pigeon Lake. This age-group did not reappear until August in Lake Michigan. Adult emerald shiners were infrequent in catches throughout the year. Some appeared during April and May in Pigeon Lake, but then were conspicuously absent until September and October when they appeared in seine catches at both Lake Michigan and Pigeon Lake beach stations. Adults probably moved to deeper water in Pigeon Lake and Lake Michigan after spawning in June.

It is felt that the decline in numbers of adult alewife in Pigeon Lake reduced competition with emerald shiners, which allowed the emerald shiner to produce a successful year class in 1978. Yearling and adult emerald shiners migrated from Pigeon Lake into deep Lake Michigan water during summer, then congregated in schools and moved back into shallower water in fall. 
Black Crappie--

Introduction--Black crappie was a common species in Pigeon Lake during 1978 comprising $2.4 \%$ of the total number of fish caught. Black crappies were only captured in seines (243) and gill nets (3); $84 \%$ were caught at night. None were caught from Lake Michigan. This species showed preference for warmer water temperatures as 95\% were sampled when water was between 19 and $25 \mathrm{C}$ with half caught at the upper end $(25 \mathrm{C})$ of the range. The lowest temperature at which black crappies were collected was $11 \mathrm{C}$. Size range of captured fish was $30-240 \mathrm{~mm}$ and $95 \%$ were found with food, mostly amphipods, in their stomachs.

Seasonal distribution--One relatively large adult bıack crappie (180 mm) was caught in April while 17 smaller adults $(70-100 \mathrm{~mm})$ were subsequently sampled; 1 in May and 16 in June (Figs. 83 and 84). Age-length relationships found in Scott and Crossman (1973) indicate these smaller adults were 1-yr old. Most of the 53 black crappies collected in July at beach station V (undisturbed Pigeon Lake) were YOY (Fig. 84). August was the month of highest catch (121) as even greater numbers of YOY were captured. YOY were collected in reduced numbers by September as only 47 were caught. In September dispersal of crappies was documented since more crappies were caught at beach station $S$ (influenced by Lake Michigan) than had been caught in earlier months and fish appeared in station $\mathrm{M}$ (influenced by Lake Michigan) catches where black crappies had not previously been captured. By October, most of the Pigeon Lake black crappie population had migrated to deeper water; only one adult was seined at beach station $V$. A slight increase in catch occurred in November ( $\operatorname{six} f i s h$ ), but by December no black crappies were collected in adult sampling gear.

Impingement--Relatively small numbers of black crappies were impinged in January, February and March 1978, while in April an estimated 45 crappies were impinged (Appendix 9). Fish (estimated to be age 1) that appeared in May and June field samples were also observed in May and July impingement samples and some YOY were impinged in August (6), October (37) and November (37). Estimated black crappie impingement in December increased to $186 \mathrm{fish}$.

Other considerations--Combining field and impingement catches with gonad development data yields a fairly complete picture of black crappie biology in Pigeon Lake. In April fish were gravid, as five of seven black crappies caught had either well or moderately developed gonads (Tables 41 and 42). Young-of-the-year appeared in July field samples indicating spring spawning occurred at beach station V. Spring spawning by black crappies was also reported by Becker (1976). After spawning, adult black crappies moved out of the sampling area or became less susceptible to sampling gear. Male crappies establish nests and spawning territories and defend eggs and young for a short time (Scott and Crossman 1973). After moving off their nests, these males are probably less likely to get caught in seines. Yearling fish that were sampled in May and June may have been fish that were unsuccessful in establishing a territory or securing mates during the main spawning period and were occupying the spawning grounds after most of the black crappie population had already dispersed. As YOY grew and became more active, some ventured into water influenced by intake currents and some of these fish began appearing in 


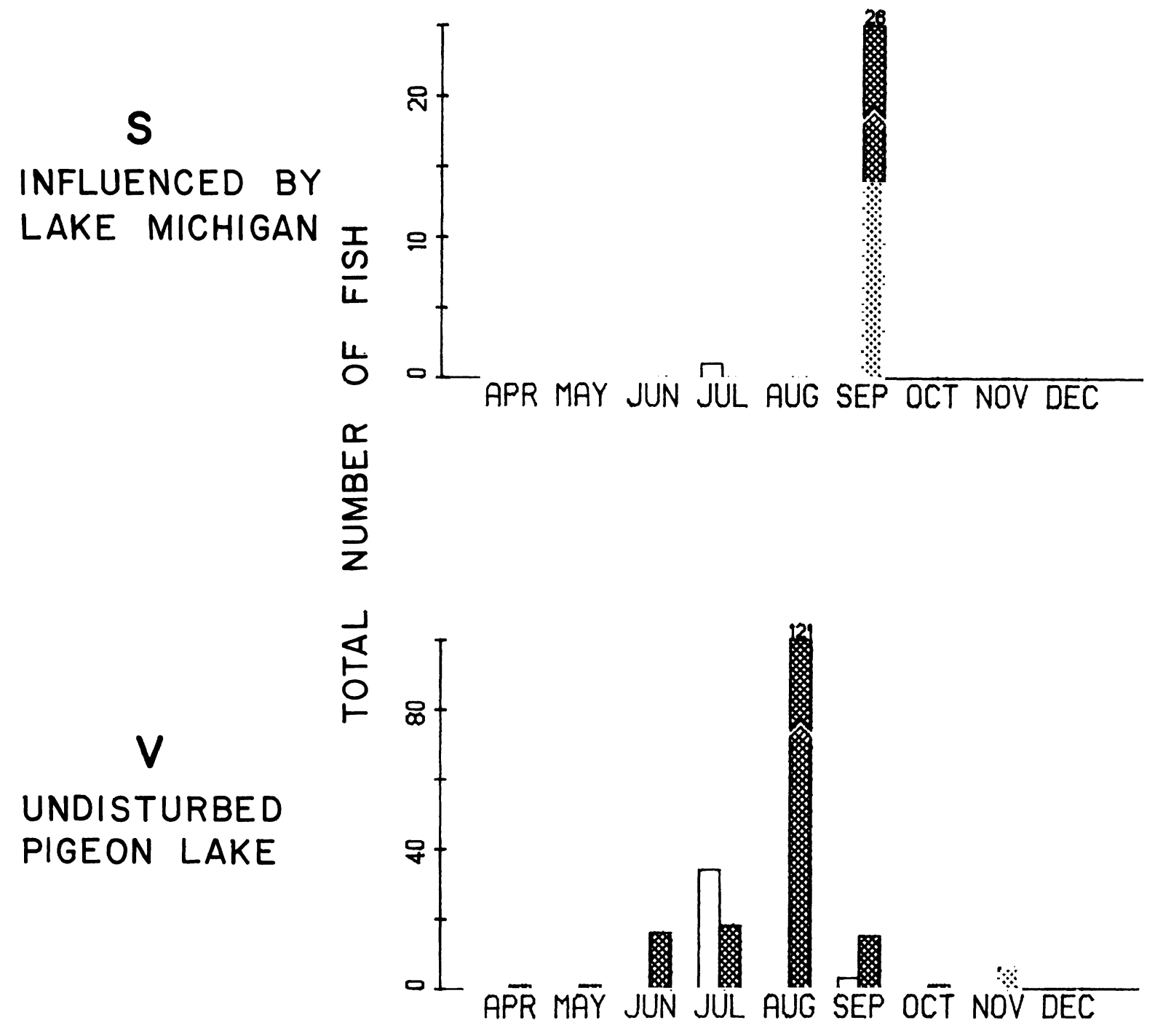

Fig. 83. Total number of black crappies caught in duplicate seine hauls during day and night once per month April to November 1978 in Pigeon Lake near the J. H. Campbell Plant, eastern Lake Michigan. $\square=$ day $\square=$ night 

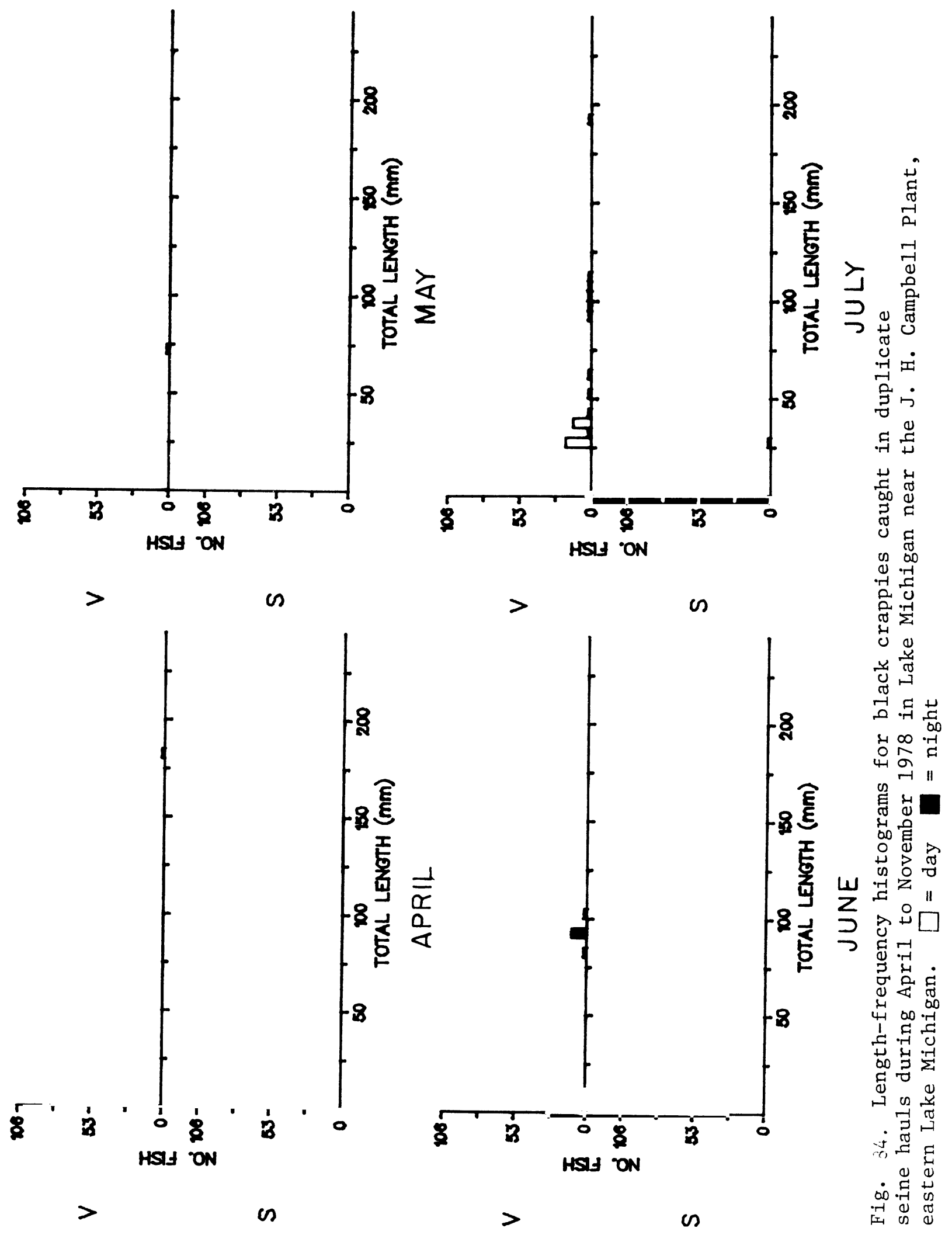

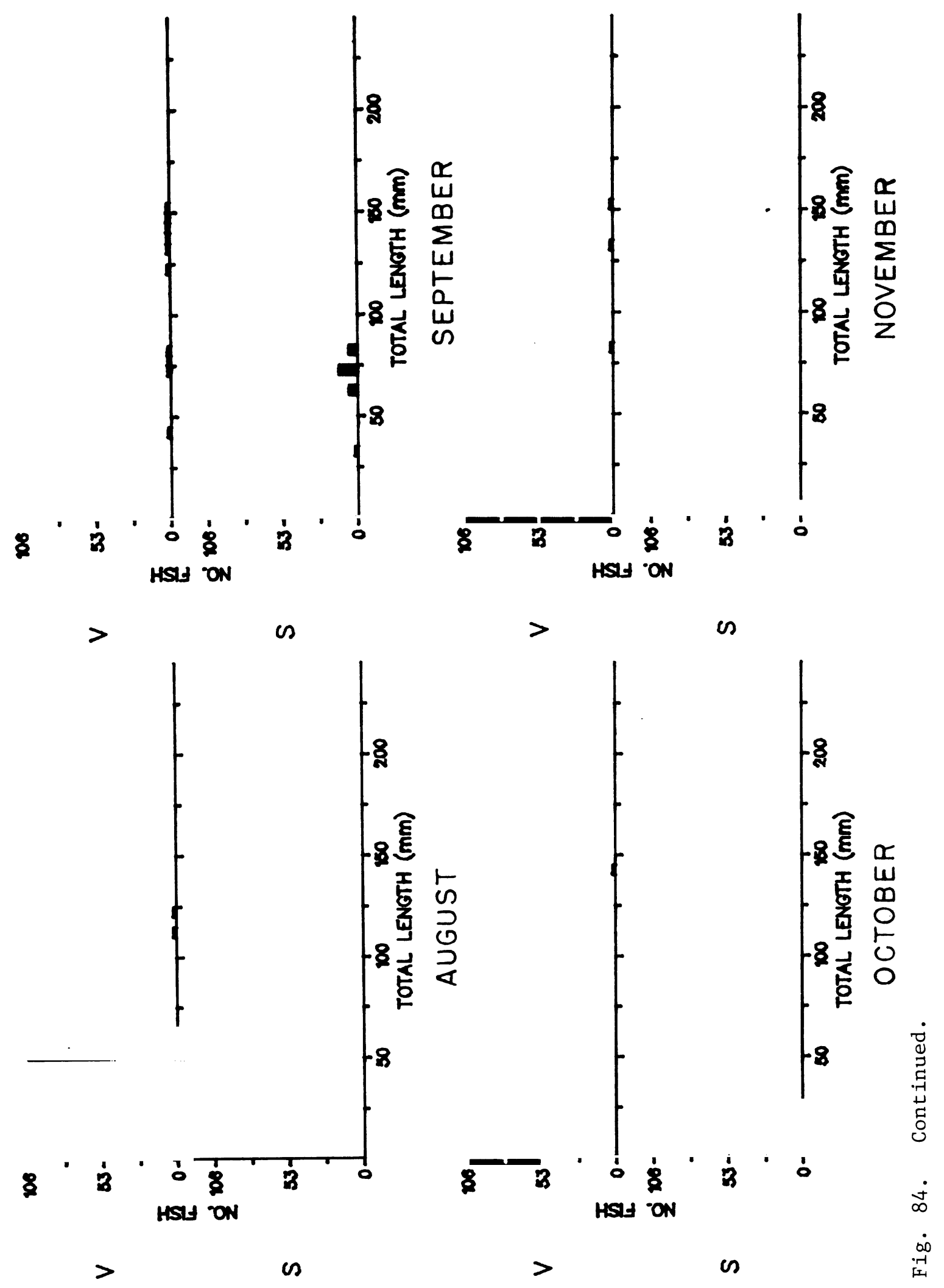
Table 41. Monthly gonad conditions of black crappies caught during 1978 in Pigeon Lake near the J. H. Campbell Plant, eastern Lake Michigan. All fish examined in a month were included except poorly received specimens.

\begin{tabular}{|c|c|c|c|c|c|c|c|c|c|c|}
\hline & Gonad condition & Apr & May & Jun & Ju1 & Aug & Sep & Oct & Nov & Dec \\
\hline Males & $\begin{array}{l}\text { Slight development } \\
\text { Mod. development } \\
\text { Well developed } \\
\text { Ripe-running } \\
\text { Spent }\end{array}$ & & & 4 & $\begin{array}{l}1 \\
2\end{array}$ & 1 & 10 & 1 & 2 & \\
\hline Females & $\begin{array}{l}\text { Slight development } \\
\text { Mod. development } \\
\text { Well developed } \\
\text { Ripe-running } \\
\text { Spent } \\
\text { Absorbing }\end{array}$ & 1 & & 2 & 1 & & & & $\cdot$ & \\
\hline Immature & & & 1 & 5 & 30 & 20 & 33 & & 3 & \\
\hline Unable $t c$ & o distinguish & & & 5 & & 1 & & & 1 & \\
\hline
\end{tabular}

Table 42. Monthly gonad conditions of black crappies collected in impingement samples during 1978 at the J. H. Campbell Plant, eastern Lake Michigan. All fish examined in a month were included except poorly received specimens.

\begin{tabular}{|c|c|c|c|c|c|c|c|c|c|c|c|c|c|}
\hline & Gonad condition & Jan & Feb & Mar & Apr & May & Jun & Ju1 & Aug & Sep & Oct & Nov & Dec \\
\hline Males & $\begin{array}{l}\text { Slight development } \\
\text { Mod. development } \\
\text { Well developed } \\
\text { Ripe-running } \\
\text { Spent }\end{array}$ & & & & 1 & $\begin{array}{l}1 \\
1\end{array}$ & & & & & 1 & & 1 \\
\hline Females & $\begin{array}{l}\text { Slight development } \\
\text { Mod. development } \\
\text { Well developed } \\
\text { Ripe-running } \\
\text { Spent } \\
\text { Absorbing }\end{array}$ & & & & $\begin{array}{l}1 \\
2\end{array}$ & & & 1 & & & & & 1 \\
\hline Immature & & & & & 2 & 1 & & 3 & 1 & & 5 & 5 & 22 \\
\hline Unable tc & o distinguish & 3 & 3 & 1 & & & & & & & & & \\
\hline
\end{tabular}


impingement samples. Widespread dispersal of black crappies was documented in September, while by October, November and December only a few were caught in sampling gear.

Summary--Black crappie data from 1977 and 1978 corresponded closely; water temperature ranges and months of greatest catch were very similar. More black crappies were caught in 1978 (246) than in 1977 (183) despite elimination of beach station $\mathrm{T}$ (influenced by Pigeon River) from the 1978 sampling scheme. In $197766 \%$ of the black crappies were caught at station $\mathrm{T}$.

Pumpkinseed--

Introduction--Pumpkinseeds were collected only in Pigeon Lake during 1978. Numbers caught in 1978 (114 individuals) were lower than in 1977 when 232 were caught. This reduction in numbers probably reflects elimination of beach station $\mathrm{T}$ (influenced by Pigeon River) and open water station $\mathrm{Y}$ (influenced by Pigeon River) from our sampling scheme in 1978.

Seasonal distribution--Pumpkinseeds were collected during every month from April through September (Fig. 85). None were caught in October or November, while no sampling was done in Pigeon Lake during December.

$\mathrm{S}$

INFLUENCED BY LAKE MICHIGAN

\section{$\checkmark$ \\ UNDISTURBED \\ PIGEON LAKE}

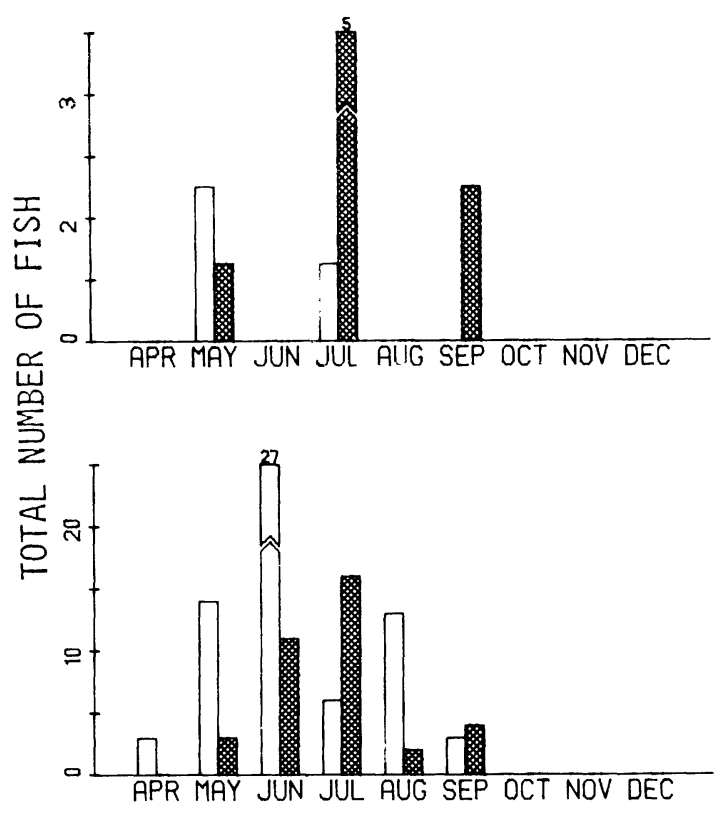

Fig. 85. Total number of pumpkinseeds caught in duplicate seine hauls during day and night once per month April to November 1978 in Pigeon Lake near the J. H. Campbell Plant, eastern Lake Michigan. $\square=$ day $\square=$ night 
Only one pumpkinseed was caught in bottom gill nets at station $M$ (influenced by Lake Michigan) - a 258-mm male in May. All remaining pumpkinseeds were collected in seines at beach stations $\mathrm{V}$ (undisturbed Pigeon Lake) and $\mathrm{S}$ (influenced by Lake Michigan). Sizes ranged from 34 to $172 \mathrm{~mm}$. Most pumpkinseeds were collected at station V (102), which is more typical pumpkinseed habitat, being shallow and vegetated.

In April, only three pumpkinseeds were collected, all in day seines at station V. In May at station V, 16 were collected in day seines and 4 in night seines. None were collected at either station S or M. During June, pumpkinseeds sought suitable spawning habitat. Gonad data (Table 43) showed the presence of ripe-running individuals this month.

Table 43. Monthly gonad conditions of pumpkinseeds caught during 1978 in Pigeon Lake near the J. H. Campbell Plant, eastern Lake Michigan. All fish examined were included except poorly received specimens.

\begin{tabular}{|c|c|c|c|c|c|c|c|c|c|c|}
\hline & Gonad condition & Apr & May & Jun & Ju1 & Aug & Sep & Oct & Nov & Dec \\
\hline Males & $\begin{array}{l}\text { Slight development } \\
\text { Mod. development } \\
\text { Well developed } \\
\text { Ripe-running } \\
\text { Spent }\end{array}$ & 1 & $\begin{array}{l}5 \\
1\end{array}$ & $\begin{array}{r}10 \\
2\end{array}$ & $\begin{array}{l}6 \\
4 \\
4\end{array}$ & $\begin{array}{l}6 \\
4\end{array}$ & 5 & & & \\
\hline Females & $\begin{array}{l}\text { Slight development } \\
\text { Mod. development } \\
\text { We11 developed } \\
\text { Ripe-running } \\
\text { Spent } \\
\text { Absorbing }\end{array}$ & 1 & 2 & $\begin{array}{r}7 \\
1 \\
1 \\
14\end{array}$ & $\begin{array}{l}2 \\
2\end{array}$ & $\begin{array}{l}3 \\
2\end{array}$ & & & & \\
\hline Immature & & 1 & 8 & 2 & 8 & & 3 & & & \\
\hline Unable $t$ & o distinguish & & 3 & 1 & 1 & & 1 & & & \\
\hline
\end{tabular}

The first YOY $(34 \mathrm{~mm}$ ) was seined during the day in July at beach station S. Five additional pumpkinseeds $(54-67 \mathrm{~mm})$ were collected there at night. At station V, 6 were taken in day seines and 16 at night. Gonad data indicated that spawning was still occurring as fish with well developed gonads were collected.

During August, pumpkinseeds (42-162 mm) were collected only in seines at station V, 13 during the day and 2 at night. In September, seven pumpkinseeds were seined at station $\mathrm{V}$ (three during the day, four at night) including one YOY. Two (81 and $91 \mathrm{~mm}$ ) were collected at station $\mathrm{S}$ in a night seine. 
No pumpkinseeds were collected during October and November. In 1977, pumpkinseeds were found moving into deeper water as fall progressed (Jude et a1. 1978). In addition, they seemed to prefer the highly vegetated eastern end of Pigeon Lake, not sampled in 1978.

Temperature-catch relationships--Pumpkinseeds were caught at temperatures of 9.5-27.3 C. Most (46\%) were caught at 21 C. Examination of catch-pertemperature and size-frequency data indicated no clear relationship. Pigeon Lake, being shallow, does not offer a wide temperature range to fish at a given time.

Impingement--Estimated impingement of pumpkinseeds by the Campbe11 Plant in 1978 was 115 . Sizes of $\mathrm{fish}$ ranged from 50 to $155 \mathrm{~mm}$. Impingement of pumpkinseeds was probably a random occurrence. No clear seasonal pattern of impingement was evident. None were impinged during summer months which may indicate a tendency for pumpkinseeds to remain on or near their nests. Destruction of 115 pumpkinseed probably would not have a large impact on the pumpkinseed population of Pigeon Lake.

Summary--Pumpkinseeds were collected only in Pigeon Lake during 1978 and appeared to prefer the shallow, vegetated habitat of station $\mathrm{V}$ (undisturbed Pigeon Lake). Impingement losses of pumpkinseeds during 1978 were low and were not believed to significantly affect the pumpkinseed population of Pigeon Lake.

\section{Minor Species}

Ninespine stickleback--

Although ninespine sticklebacks are common to Lake Michigan, very little is known about their seasonal movements. The ninespine stickleback was common in our samples taken near the Campbell Plant during June-December 1977, with 133 caught in Lake Michigan and 1 caught in Pigeon Lake. Inclusion of early spring sampling in 1978 , as well as some seasonal distribution and abundance differences between years were responsible for the increased number (457) of sticklebacks caught during 1978 in our study area.

In the past, utilization of Pigeon Lake by spawning ninespine sticklebacks could only be inferred from impingement data and limited field collections. Data from spring 1978, however, strongly indicated that sticklebacks were present and spawning in Pigeon Lake. During April, 18 sticklebacks were observed in samples taken at beach station S (influenced by Lake Michigan). Gonad data (Table 44) showed that six of the females were ripe-running and two were spent. Spawning of ninespine sticklebacks in Pigeon Lake probably began sometime in April. Capture of nine ripe-running females during May suggests spawning had continued to this time. Griswold and Smith (1973) and Nelson (1968) suggested that the spawning season for this species lasted approximately $8 \mathrm{wk}$. Temperatures at beach stations in April and May ranged from 8.5-17 C, which included temperatures at which the ninespine stickleback was reported to spawn (Griswold and Smith 1973). There appeared to be some preference by sticklebacks for beach station $S$ (influenced by Lake Michigan) compared with station $\mathrm{V}$ (undisturbed Pigeon Lake), which may be related to 
cooler temperatures at station S (Appendix 2).

Table 44. Monthly gonad conditions of ninespine sticklebacks caught during 1978 in Pigeon Lake near the J. H. Campbell Plant, eastern Lake Michigan. A11 fish examined in a month were included except poorly received specimens.

\begin{tabular}{llllllll}
\hline & Gonad condition & Apr & May Jun Ju1 Aug Sep Oct Nov Dec \\
\hline \multirow{4}{*}{ Ma1es } & S1ight development & 2 & 1 & & & \\
& $\begin{array}{l}\text { Mod. development } \\
\text { We11 developed }\end{array}$ & 1 & 1 & & & \\
& Ripe-running & & & & \\
& Spent & & & & \\
\hline
\end{tabular}

\begin{tabular}{llll}
\multicolumn{2}{c}{ Slight development } & & \\
Females & Mod. development & & \\
We11 developed & 7 & 5 \\
Ripe-running & 6 & 9 \\
Spent & 2 & \\
Absorbing & &
\end{tabular}

Immature $\quad 4 \quad 2$

Unable to distinguish $\quad 1 \quad 2$

Origin of sticklebacks in Pigeon Lake during April and May is unknown. Generally, the majority of the Lake Michigan population was not inshore during May, as indicated by trawl data, although five sticklebacks were observed at beach stations in Lake Michigan near the present discharge canal. There may be a resident population of sticklebacks in Pigeon Lake. After spawning in the shallows of Pigeon Lake, they may return to deeper water and not be susceptible to our sampling gear. Another possibility is that some migration of sticklebacks into Pigeon Lake from Lake Michigan may occur. In either event, occurrence of only one stickleback in Pigeon Lake seine hauls from June-December indicated that after spawning in Pigeon Lake, sticklebacks migrated from seinable depths into deeper water.

Collections from Lake Michigan in April indicated that sticklebacks were absent at 3 to $15 \mathrm{~m}$; however, as noted five sticklebacks were seined in the area of the present discharge (station Q-S discharge and station R-N discharge). It is likely that some sticklebacks were attracted to the warm water discharge, but the majority of the Lake Michigan stickleback population was at depths exceeding $15 \mathrm{~m}$ or migrated to northern sections of Lake Michigan where Smith (1968) stated they were mainly concentrated. Griswold and Smith (1973) observed greatest numbers of ninespine sticklebacks at 54-500 m during April in Lake Superior.

During May, ninespine sticklebacks were commonly encountered in Lake 
Michigan at 3-15 m, indicating a shoreward movement in the spring. Sticklebacks tended to be more common at 9 to $15 \mathrm{~m}$ than at 3 and $6 \mathrm{~m}$. Average day-night temperatures at this time ranged from 6.0 to $8.3 \mathrm{C}$ (Fig. 86).

The continued shoreward migration of the stickleback population during June was indicated by considerable increases in numbers of sticklebacks caught at $15 \mathrm{~m}$ or less. Depth distribution of sticklebacks during June appeared similar to that observed during May, with the exception of the higher occurrence of sticklebacks observed during June at $6 \mathrm{~m}$ where they were less abundant during May.

Studies near the Apostle Island area of Lake Superior (Griswold and Smith 1973) also indicated a shoreward migration of ninespine sticklebacks had increased in intensity from May to August. Gonad data indicated that spawning of Lake Michigan sticklebacks occurred primarily during June-July 1978 (Table 45) which agreed closely with 1977 data (Jude et al. 1978). Water temperatures at times of capture in June 1978 ranged from 9.2 to $13.2 \mathrm{C}$.

Table 45. Monthly gonad conditions of ninespine sticklebacks caught during 1978 in Lake Michigan near the J. H. Campbell Plant, eastern Lake Michigan. All fish examined in a month were included except poorly received specimens.

\begin{tabular}{|c|c|c|c|c|c|c|c|c|c|c|}
\hline & Gonad condition & Apr & May & Jun & Jul & Aug & Sep & Oct & Nov & Dec \\
\hline Males & $\begin{array}{l}\text { Slight developement } \\
\text { Mod. development } \\
\text { Well developed } \\
\text { Ripe-running } \\
\text { Spent }\end{array}$ & & 9 & $\begin{array}{r}16 \\
5 \\
3 \\
1 \\
1\end{array}$ & $\begin{array}{r}11 \\
8 \\
2\end{array}$ & $\begin{array}{r}14 \\
2\end{array}$ & & 1 & & \\
\hline Females & $\begin{array}{l}\text { Slight development } \\
\text { Mod. development } \\
\text { Well developed } \\
\text { Ripe-running } \\
\text { Spent } \\
\text { Absorbing }\end{array}$ & 4 & $\begin{array}{r}3 \\
6 \\
10\end{array}$ & $\begin{array}{r}9 \\
23 \\
34 \\
22 \\
3\end{array}$ & $\begin{array}{r}4 \\
17 \\
33 \\
2 \\
14 \\
4\end{array}$ & $\begin{array}{r}15 \\
3 \\
2 \\
1 \\
2\end{array}$ & & 1 & & \\
\hline Immature & & & & 6 & 4 & 8 & & & & \\
\hline Unable $t$ & o distinguish & 1 & 5 & 20 & 25 & 30 & & & & \\
\hline
\end{tabular}

The reason for this difference between years is not known. During July 1977, upwelled colder water $(8 \mathrm{C})$ at inshore stations coincided with the collections of lower numbers of sticklebacks. During July 1978, cooler upwelled water was also present at inshore stations; however, temperatures were mostly over $8 \mathrm{C}$. These data may suggest a rather sharp temperature preference by this species, but more likely a general increase in abundance of sticklebacks occurred in the area during July 1978 compared with 1977. 

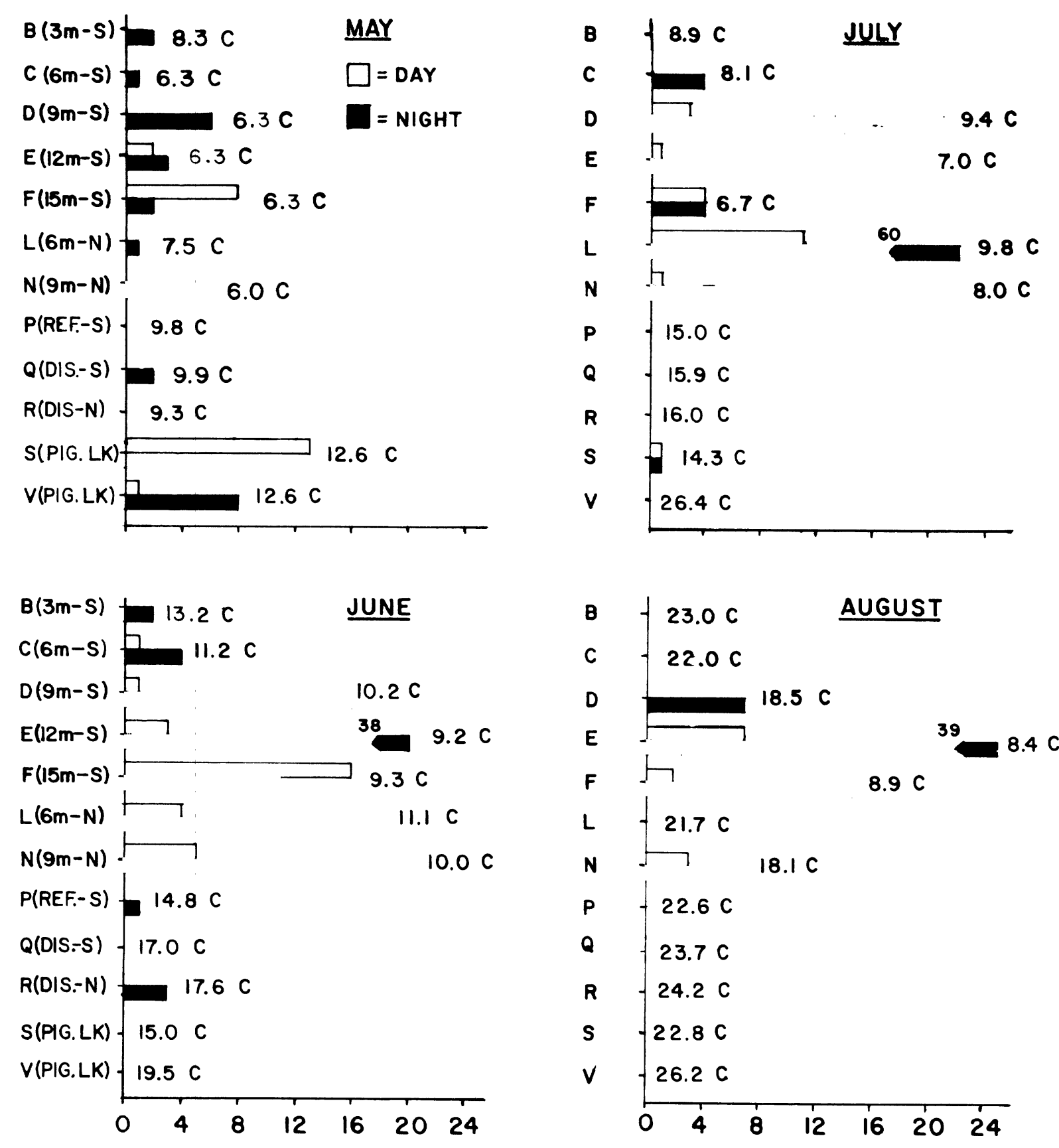

NUMEER OF FISH

Fig. 86. Total number of ninespine sticklebacks caught in duplicate seine and trawl hauls in Lake Michigan and duplicate seine hauls in Pigeon Lake from April to December 1978 near the J. H. Campbell Plant, eastern Lake Michigan. 
A substantial decrease in sticklebacks was observed in Lake Michigan samples during August. No sticklebacks were observed at 3 and $6 \mathrm{~m}$, probably due to high temperatures $(>20 \mathrm{C}$ ) at these stations. Greatest abundance of sticklebacks was observed at $12 \mathrm{~m}$. Temperatures at this station indicated that a thermocline was present. All sticklebacks caught during August were caught at 9-15 $\mathrm{m}$, suggesting that the stickleback population was beginning an offshore movement. Griswold and Smith (1973) found that sticklebacks in Lake Superior moved offshore during September; peak numbers were caught in August at depths of $5.5-16.5 \mathrm{~m}$. Occurrence of only two sticklebacks in our Lake Michigan samples from September to December indicated that the stickleback migration was completed by September. The population probably remained at depths greater than $15 \mathrm{~m}$ or in the northern part of the lake throughout winter until the shoreward migration in spring.

Data collected during June and July 1978 were in contrast to those collected during 1977. During 1977 there was a decrease in the number of sticklebacks caught at depths $15 \mathrm{~m}$ and less from June to July. This trend was reversed during June and July 1978.

During 1975, the time of greatest impingement loss of sticklebacks was April and early May (Consumers Power 1975). This agreed closely with our impingement results during 1978 when an estimated 310 ninespine were impinged during April and May compared with an estimated 21 impinged during the rest of the year. Sticklebacks were most common in beach seine hauls in Pigeon Lake during April-May. This coincidence suggests that ninespine stickleback were most susceptible to impingement during their spawning season in Pigeon Lake and when they are moving into shallower areas of Lake Michigan.

White Sucker--

The white sucker is a common species in Lake Michigan near the Campbel1 Plant (Jude et a1. 1978). During 1978, 319 white suckers were collected from Lake Michigan and 6 from Pigeon Lake, which compares with 294 caught in Lake Michigan and 18 in Pigeon Lake in 1977. Most suckers in Lake Michigan and Pigeon Lake were collected in bottom gill nets (253 of 325). More suckers were caught by seine and trawl (59 and 12, respectively) in 1978 than in 1977, but the relatively smaller rumbers of fish caught by these methods suggest suckers have greater ability to avoid these gear. More white suckers (220) were caught during the night than during the day (105) in Lake Michigan and Pigeon Lake.

White suckers were collected from Lake Michigan during all months sampled except April and December (Table 13). Catches were greatest during August and September with numbers of fish caught during October and November much smaller compared to the previous $4 \mathrm{mo}$. White suckers caught in Lake Michigan ranged from 30 to $740 \mathrm{~mm}$ with $81 \%$ between 300 and $580 \mathrm{~mm}$ (Appendix 6). According to data compiled by Carlander (1969), these fish would be ages 4 to 11 .

During July, $67 \%$ of the suckers were caught at beach station Q (S discharge) and station $\mathrm{L}(6 \mathrm{~m}-\mathrm{N})$ areas near the present discharge canal. Small fish (30-90 mm) dominated seine catches. These fish were probably YoY and yearlings. Only one yearling (70 mm - July) was caught in 1977. Carlander (1969) 
reports a size range of $30-71 \mathrm{~mm}$ for YOY in July. The tendency for smaller adult fish to be found inshore at Campbell was noted in 1977 (Jude et a1. 1978) and in the vicinity of the D.C. Cook Plant (Jude et a1. 1975). July was the only month a concentration of suckers in the present discharge area was noted; interestingly water temperatures were not notably different from temperatures at the south reference transect.

During August and September, a movement of suckers offshore was observed with the majority of fish found at stations $C(6 \mathrm{~m}-\mathrm{S})$ and $\mathrm{D}(9 \mathrm{~m}-\mathrm{S})$; a similar offshore movement was noted in 1977 (Jude et a1. 1978). As in the 1977 study, water temperature did not appear to be a major factor in this movement or in the sharp decline in numbers of suckers collected in October and November. Yearling fish probably moved offshore in August as few were caught in August seines. The reason for the absence of yearling suckers in gill net catches is not known; however, it may be that they were not yet of a size vulnerable to gill nets.

White sucker spawning has been suggested to occur in late March, April and May for southeastern Lake Michigan locations (Jude et a1. 1975). Gonad data for suckers caught in 1978 showed the presence of ripe fish from May through September (Table 46).

Table 46. Monthly gonad conditions of white suckers caught during 1978 in Lake Michigan near the J. H. Campbell Plant, eastern Lake Michigan. All fish examined in a month were included except poorly received specimens.

\begin{tabular}{|c|c|c|c|c|c|c|c|c|c|c|}
\hline & Gonad condition & Apr & May & Jun & $\mathrm{Ju} 1$ & Aug & Sep & Oct & Nov & Dec \\
\hline Males & $\begin{array}{l}\text { Slight development } \\
\text { Mod. development } \\
\text { Well developed } \\
\text { Ripe-running } \\
\text { Spent }\end{array}$ & & $\begin{array}{r}18 \\
5 \\
2\end{array}$ & $\begin{array}{l}6 \\
7\end{array}$ & $\begin{array}{l}8 \\
6 \\
1 \\
1\end{array}$ & $\begin{array}{r}13 \\
10 \\
4 \\
1\end{array}$ & $\begin{array}{l}11 \\
14 \\
12\end{array}$ & $\begin{array}{l}1 \\
1\end{array}$ & $\begin{array}{l}3 \\
2\end{array}$ & \\
\hline Females & $\begin{array}{l}\text { Slight development } \\
\text { Mod. development } \\
\text { We11 developed } \\
\text { Ripe-running } \\
\text { Spent } \\
\text { Absorbing }\end{array}$ & & $\begin{array}{l}2 \\
1 \\
1\end{array}$ & $\begin{array}{r}2 \\
10 \\
\\
2\end{array}$ & $\begin{array}{l}5 \\
8 \\
6\end{array}$ & $\begin{array}{r}11 \\
20 \\
2 \\
4\end{array}$ & $\begin{array}{r}7 \\
30 \\
3\end{array}$ & 2 & 5 & \\
\hline Immature & & & 2 & & 24 & 10 & 2 & & & \\
\hline Unable $t$ & distinguish & & 1 & 2 & 6 & 3 & & & & \\
\hline
\end{tabular}

Six white suckers were caught in Pigeon Lake during 1978. In April, a 67-mm yearling was seined at beach station $\mathrm{S}$ (influenced by Lake Michigan). In May, two white suckers were taken, a 419-mm male in a bottom gill net at 
station M (influenced by Lake Michigan), and a 85-mm yearling at beach station $\mathrm{V}$ (undisturbed Pigeon Lake). During July, a 408-mm female was caught in a bottom gill net at station M. In August, two white suckers, a 743-mm female and a 438-mm male, were caught in bottom gill nets at station $M$.

In 1977,10 white suckers were gillnetted at station $M$ and 6 at station $Y$ (undisturbed Pigeon Lake). The low numbers of white suckers caught in Pigeon Lake during both 1977 and 1978 suggest that the Pigeon River is not a major sucker spawning site, although limited spawning may occur.

Sucker larvae (prohably white) were collected in April at station $\mathrm{N}$ $(9 \mathrm{~m}-\mathrm{N})$, during May in entrainment samples and in samples from station A (1.5 mS) and at Pigeon Lake beach station S (influenced by Lake Michigan) (see FISH LARVAE AND ENTRAINMENT STUDY, White Sucker), indicating that spawning had occurred by May. Presence of ripe fish in June and later may indicate some later spawning or reflect fish that had not spawned which were reabsorbing their gonads.

During 1978, an estimated total of 199 white suckers were impinged by the Campbel1 Plant (Appendix 9). Greatest impingement occurred during late March and April when numerically the catch accounted for $56 \%$ of the yearly total. This period corresponds to the spring spawning migration of suckers into streams.

Slimy Sculpin--

The slimy sculpin is a small, demersal species of the family Cottidae which is common to the Lake Michigan watershed (Becker 1976). It has little or no commercial importance, however, preliminary observations during April 1979 as well as 1978 indicate it is a prominent food item of salmonids, particularly brown trout. Although reported to occur in Pigeon Lake during 1977, no slimy sculpins were captured there during 1978. Since slimy sculpins were impinged in low numbers during 1978, they do occasionally enter Pigeon Lake. The preferred habitat of slimy sculpin however, is in Lake Michigan, where they are reported to occupy the nearshore habitat to a depth of approximately $90 \mathrm{~m}$ (Deason 1939).

The increased occurrence of slimy sculpins in samples taken near the Campbell Plant during 1978 (279 collected) compared with 1977 (53 collected) was undoubtedly due to sampling in early spring 1978 but not 1977 . Data reported by Wells (1968) suggest, however, that even during winter and spring months, the bulk of the slimy sculpin population does not inhabit water depths less than $18 \mathrm{~m}$. Thus our collections from April to December probably only sample fringes of the sculpin population.

Our initial Lake Michigan sampling during April 1978 showed that slimy sculpins were collected at 6-15 m, with a progressive increase in the number of sculpins caught with increasing depth. Sculpin catches in April samples also showed an inverse correlation with average day-night water temperatures, since the greatest number of sculpins were caught at lower temperatures (Fig. 87). Twenty-five sculpins were caught at $3.6 \mathrm{C}$ (station $\mathrm{F}, 15 \mathrm{~m}-\mathrm{S}$ ) compared to three 

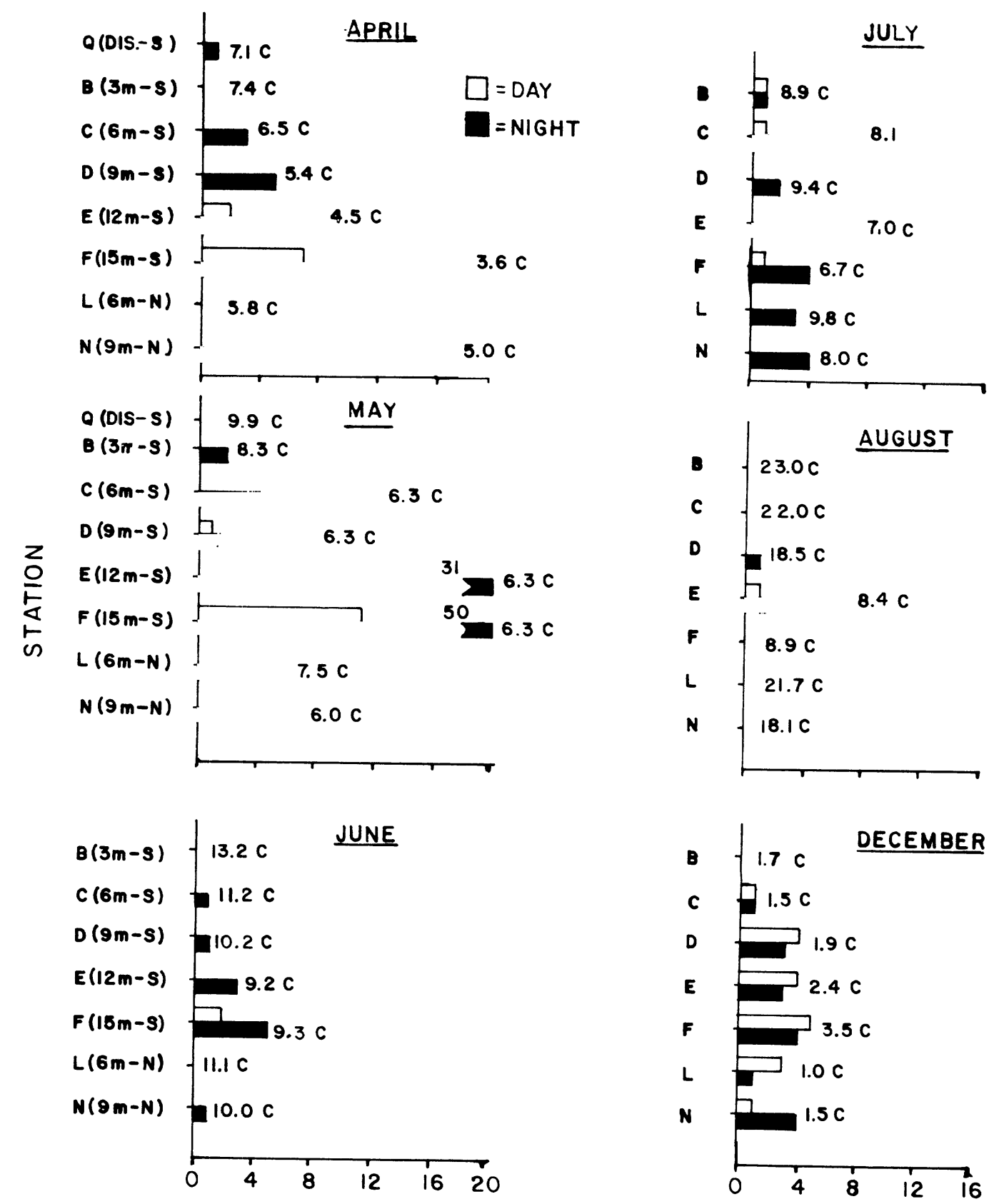

\section{NUMBER OF FISH}

Fig. 87. Total number of slimy sculpins caught in duplicate seine and trawl hauls from April to December 1978 in Lake Michigan near the J. H. Campbell Plant, eastern Lake Michigan. 
caught at $6.5 \mathrm{C}$ (station $\mathrm{C}, 6 \mathrm{~m}-\mathrm{S}$ ). During all months, slimy sculpins were more prominent in night samples than in day samples. Gonad data (Table 47) indicated that although many sculpins had well developed gonads on 25 April 1978 , only 1 of the 36 examined was ripe running; thus, the peak spawning period had not yet occurred.

Table 47. Monthly gonad conditions of slimy sculpins caught during 1978 in Lake Michigan near the J. H. Campbell Plant, eastern Lake Michigan. All fish examined in a month were included except poorly received specimens.

\begin{tabular}{|c|c|c|c|c|c|c|c|c|c|c|}
\hline & Gonad condition & Apr & May & Jun & $\mathrm{Ju} 1$ & Aug & Sep & Oct & Nov & Dec \\
\hline Males & $\begin{array}{l}\text { Slight development } \\
\text { Mod. development } \\
\text { Well developed } \\
\text { Ripe-running } \\
\text { Spent }\end{array}$ & $\begin{array}{l}6 \\
4\end{array}$ & $\begin{array}{r}1 \\
12 \\
21 \\
1\end{array}$ & & 5 & $\begin{array}{l}2 \\
2\end{array}$ & & & 1 & 1 \\
\hline Females & $\begin{array}{l}\text { Slight development } \\
\text { Mod. development } \\
\text { We11 developed } \\
\text { Ripe-running } \\
\text { Spent } \\
\text { Absorbing }\end{array}$ & $\begin{array}{r}25 \\
1\end{array}$ & $\begin{array}{r}1 \\
3 \\
51 \\
31 \\
4 \\
1\end{array}$ & & & & & & & \\
\hline Immature & & & 2 & 13 & 18 & 1 & & & 1 & 1 \\
\hline Unable $t$ & o distinguish & & 2 & & 9 & 4 & & & & 33 \\
\hline
\end{tabular}

Catch of slimy sculpins during May was the highest monthly catch during 1978 with 128 sculpins trawled. Again, as during April, more sculpins were caught at greater depths (Fig. 87). No correlation of average day-night water temperature with catch was observed. Bottom temperatures at stations $\mathrm{C}(6 \mathrm{~m}-$ $\mathrm{S})$ to $\mathrm{F}(15 \mathrm{~m}-\mathrm{S})$ were $6.3 \mathrm{C}$, yet catch varied from 61 sculpins at station $\mathrm{F}$ $(15 \mathrm{~m}-\mathrm{S})$ to 9 at station $\mathrm{D}(9 \mathrm{~m}-\mathrm{S})$. Thus it appeared that depth of water was the major factor affecting distribution. Wells (1968) reported that on 26 May 1964, the shallowest depth that slimy sculpinswere captured at was $22 \mathrm{~m}$. The bulk of the sculpin population was at $31-91 \mathrm{~m}$. Gonad data during May (Table 47) indicated that spawning was occurring in the area of the Campbell Plant during late May in 1978.

Catch of slimy sculpins in Lake Michigan during June 1978 compared closely with that of June 1977, and indicated that few slimy sculpins inhabited depths of $15 \mathrm{~m}$ or less. Of the 13 sculpins collected in June 1978, seven were trawled at $15 \mathrm{~m}$ and three were trawled at $12 \mathrm{~m}$.

The increasing water temperatures inshore in June (Fig. 87) probably restricted the distribution of sculpins to primarily offshore cooler water. 
Wells (1968) noted that slimy sculpins in Lake Michigan were most frequently caught at 4-5 C temperatures. Our data from 1977 indicated that most sculpins were caught at temperatures less than $7 \mathrm{C}$. Thus the few sculpins collected in June were probably the result of sampling the extreme inshore fringe of the sculpin population. In close agreement with 1977 data (Jude et a1. 1978) was the observation that the majority of slimy sculpins caught in warmer summer months were less than $65 \mathrm{~mm}$. This may suggest that smaller sculpins preferred warmer temperatures than larger fish. Wells (1968) also occasionally encountered sculpins at shallow depths (12.8 and $18 \mathrm{~m}$ ) in June 1964, but reported the bulk of the population was at depths exceeding $30 \mathrm{~m}$.

In July when upwelled cooler water $(<10 \mathrm{C})$ moved into the study area, an increased catch of sculpins was observed compared with June collections (Fig. 87). It is thus evident that generally temperature appears to be a controlling factor in the distribution of the majority of slimy sculpins with cooler temperatures selected by this species. Sporadic occurrences of sculpins do however occur in warmer water as evidenced by the few sculpins caught in June at temperatures exceeding $10 \mathrm{C}$.

As was observed during 1977, slimy sculpins were rare in our 1978 collections from September to November. Again, water temperatures at these times exceeded $10 \mathrm{C}$ at our stations, which were temperatures probably not preferred by slimy sculpins since cooler offshore water was available. Wells (1968) did not catch any slimy sculpins at depths less than $27 \mathrm{~m}$ from August to November during 1964, and reported that slimy sculpins were seldom taken at temperatures greater than $10 \mathrm{C}$.

With cooling of inshore water during December, slimy sculpins were again common in the inshore water near the Campbe11 Plant. Traw1 data indicated no substantial difference between numbers of sculpins caught at 6-15 m. Temperatures at inshore stations ranged from 1.0 to $3.5 \mathrm{C}$.

Due to the benthic nature of the slimy sculpin and the nature of the present onshore intake at the Campbell Plant, very few sculpins were impinged during 1978. Nine slimy sclupins were observed in impingement samples during 1978, resulting in an estimated total of 66 sculpins impinged by the plant during 1978.

The present plant intake results in minimal impingement loss of slimy sculpins. Near the D.C. Cook Plant, southeastern Lake Michigan, the protective apron of riprap around the intake structures apparently encourages many slimy sculpins to remain inshore even in warmer months. Impingement of slimy sculpins is thus considerably more at this plant, and probably would be comparable to what would occur at the Campbell Plant if a similar apron of riprap was employed. However, a somewhat different intake structure is proposed for the Campbell Plant.

Lake Trout--

During the 1978 sampling season 265 lake trout were collected. Of these, 258 were caught in Lake Michigan and 7 in Pigeon Lake. Lake trout were caught during all months sampled (except December) in Lake Michigan and only during 
October in Pigeon Lake (Table 13, 14). One lake trout (758 mm, $4180 \mathrm{~g}$ ) was impinged by the Campbe11 Plant in November which resulted in a projected total for the year of $7 \mathrm{fish}$. Bottom gill net catches accounted for $81 \%$ of the total catch of lake trout. Sizes of lake trout caught ranged from 121 to $850 \mathrm{~mm}$ with $95 \%$ between 440 and $850 \mathrm{~mm}$.

In April, 30 lake trout were caught in bottom gill nets in Lake Michigan (2 during the day, 28 at night). They were found at all depths, but the largest catch (10) was at station $\mathrm{E}(12 \mathrm{~m}-\mathrm{S})$. Nine were caught in surface gill nets, seven at station $\mathrm{L}(6 \mathrm{~m}-\mathrm{N})$ and two at $\mathrm{C}(6 \mathrm{~m}-\mathrm{S})$.

Three yearling lake trout $(124-162 \mathrm{~mm})$ were caught in trawls in June, two at station $\mathrm{E}(12 \mathrm{~m}-\mathrm{S})$ and one at station $\mathrm{F}(15 \mathrm{~m}-\mathrm{S})$. One adult was caught in a night surface gill net at station L. Eighteen were caught in bottom gill nets with the largest catch (8) at station E (12 m-S).

On 17 July 1978 an upwelling occurred and inshore temperatures dropped $10 \mathrm{C}$ to values around $7 \mathrm{C}$ (Appendix 1). Lake trout moved inshore with the moving thermocline and were caught in day bottom gill nets at station B ( $3 \mathrm{~m}-$ S). By $19 \mathrm{July}$, when night gill nets were set, water temperatures had risen to $17 \mathrm{C}$ and lake trout had moved from the area.

Few lake trout were caught in August. Five were caught in night bottom gill nets and two yearlings were caught in trawls, all at station $\mathrm{E}(12 \mathrm{~m}-\mathrm{S})$. Only two lake trout were caught in september, both in day bottom gill nets; one at station $B(3 \mathrm{~m}-\mathrm{S})$ and one at $\mathrm{L}(6 \mathrm{~m}-\mathrm{N})$. Largest catches of lake trout (96) were taken in October during the spawning season. Most were caught in night bottom gill nets at stations $A(1.5 \mathrm{~m}-\mathrm{S})$ and $B(3 \mathrm{~m}-\mathrm{S})$ (21 and $15 \mathrm{fish}$, respectively). Few fish were taken at deeper stations. Night surface gill net catches were highest this month with 19 lake trout caught. The shoreward movement of lake trout this month was further documented by the capture of adult lake trout in Lake Michigan night beach seines. Five were taken at station $P$ (S reference) and four at Q (S discharge). October was the only month lake trout were caught in Pigeon Lake. Bottom gill nets at station $M$ (influenced by Lake Michigan) caught two lake trout in day sets and five at night.

November catches of lake trout were also large (53 fish) reflecting a continuation of spawning activities. Most (24) were taken in night gill nets at station $A(1.5 \mathrm{~m}-\mathrm{S})$. Only one was caught in day net sets. None were caught in surface gill nets and one was caught in a night seine at station $Q$ (S discharge).

Lake trout spawn during October and November; $76 \%$ of the individuals caught then had well developed or ripe-running gonads (Table 48). Numerous questions exist concerning the success of lake trout reproduction in Lake Michigan. Of $238 \mathrm{fish}$ examined for fin clips, 13 had no recognizable clips. Whether these unclipped fish represent naturally-reproduced, non-stocked fish or are simply mistakes in the clipping procedure is uncertain. 
Table 48. Monthly gonad conditions of lake trout caught during 1978 in Lake Michigan near the J. H. Campbell Plant, eastern Lake Michigan. All fish examined in a month were included except poorly received specimens.

\begin{tabular}{|c|c|c|c|c|c|c|c|c|c|c|}
\hline & Gonad condition & Apr & May & Jun & Ju1 & Aug & Sep & Oct & Nov & Dec \\
\hline Males & $\begin{array}{l}\text { S1ight development } \\
\text { Mod. development } \\
\text { We11 developed } \\
\text { Ripe-running } \\
\text { Spent }\end{array}$ & $\begin{array}{r}13 \\
5\end{array}$ & $\begin{array}{r}11 \\
6\end{array}$ & $\begin{array}{l}2 \\
5\end{array}$ & $\begin{array}{l}1 \\
2\end{array}$ & $\begin{array}{l}1 \\
3\end{array}$ & 1 & $\begin{array}{r}1 \\
12 \\
41\end{array}$ & $\begin{array}{r}7 \\
1 \\
1 \\
33 \\
2\end{array}$ & \\
\hline Females & $\begin{array}{l}\text { S1ight development } \\
\text { Mod. development } \\
\text { We11 developed } \\
\text { Ripe-running } \\
\text { Spent } \\
\text { Absorbing }\end{array}$ & $\begin{array}{l}5 \\
6\end{array}$ & $\begin{array}{l}6 \\
6\end{array}$ & $\begin{array}{r}1 \\
10 \\
1\end{array}$ & $\begin{array}{l}1 \\
6\end{array}$ & & & $\begin{array}{r}3 \\
1 \\
34\end{array}$ & $\begin{array}{l}2 \\
1 \\
3 \\
3\end{array}$ & \\
\hline Immature & & & & 3 & 4 & 3 & 1 & & & \\
\hline Unable $t$ & o distinguish & 2 & & 1 & & & & & & \\
\hline
\end{tabular}

Data on sea lamprey attacks on lake trout showed that of $238 \mathrm{fish}$ examined, $36 \%$ had lamprey scars or wounds (Table 49). This is slightly higher than the 27\% lake trout scarring rate found in 1977 (Jude et a1. 1978). At the Cook Plant during 1973-1974, Jude et al. (1979) found 22\% of all lake trout collected had one or more fresh or old lamprey scars. McComish and Miller (1975) found $25 \%$ of the lake trout sampled in the Indiana waters of Lake Michigan had lamprey scars. Of these, $6 \%$ were fresh wounds. In the vicinity of the Campbell Plant, 15\% of the scarred fish had fresh wounds, indicating lamprey activity in the area.

Examination of lake trout stomachs showed that alewife and smelt were predominant items in the diet. Other prey items were sculpins, spottail shiners and some insect larvae. Most lake trout collected during October and November did not have food in their stomachs in contrast to earlier months when they appeared to be actively feeding. This cessation of feeding corresponds to the onset of the spawning season. A similar pattern was observed at the Cook Plant, southeastern Lake Michigan (Jude et al. 1979).

Temperature is a major factor influencing the distribution of lake trout. McCauley and Tait (1970) determined that the preferred temperature for yearling trout was $11.7 \mathrm{C}$. During 1978, 98\% of the lake trout collected were caught at temperatures between 4 and $15 \mathrm{C}$ (Appendixes 1 and 2). Consequently, localized warming of water in the area of the present and future discharge may result 
in movement of lake trout away from the immediate area affected by the thermal discharge.

Table 49. Occurrence of sea lamprey scars on lake trout caught near the J.H. Campbell Plant. eastern Lake Michigan. 1978.

\begin{tabular}{|c|c|c|c|c|c|c|c|}
\hline $\begin{array}{l}\text { Length } \\
\text { Interval } \\
(\mathrm{mm})\end{array}$ & $\begin{array}{c}\text { Total } \\
\text { No. }\end{array}$ & $\begin{array}{c}\text { No. } \\
\text { Scarred }\end{array}$ & $\begin{array}{l}\text { Percent } \\
\text { Scarred }\end{array}$ & \multicolumn{3}{|c|}{ No. scars per } & $\frac{\text { fish }}{4}$ \\
\hline $800-850$ & 4 & 4 & 100 & 2 & 1 & 1 & \\
\hline $750-799$ & 32 & 19 & 59 & 10 & 6 & 2 & 1 \\
\hline $700-749$ & 58 & 30 & 52 & 21 & 8 & & 1 \\
\hline $650-699$ & 57 & 19 & 33 & 16 & 2 & & 1 \\
\hline $600-649$ & 42 & 7 & 17 & 5 & 2 & & \\
\hline $550-599$ & 21 & 4 & 19 & 4 & & & \\
\hline $500-549$ & 14 & 2 & 14 & 2 & & & \\
\hline $450-499$ & 6 & & & & & & \\
\hline $400-449$ & 2 & & & & & & \\
\hline $350-399$ & & & & & & & \\
\hline $300-349$ & 1 & & & & & & \\
\hline $250-299$ & 1 & 1 & 100 & 1 & - & - - & - \\
\hline Total & 238 & 86 & 36 & 61 & 19 & 3 & 3 \\
\hline
\end{tabular}

Gizzard Shad--

During 1978, 190 gizzard shad (50-560 mm) were caught; some by each of our adult sampling gear. One was taken in Pigeon Lake and the remainder in Lake Michigan. Bottom gill nets were the most successful gear, accounting for $66 \%$ of the gizzard shad catch, while trawls caught $23 \%$, surface gill nets $8 \%$ and seines $3 \%$. In Lake Michigan this species was absent from April, May and June field samples and only one 450-mm male was caught in July. Impingement of gizzard shad was also small (by number and by weight) or nonexistent during April-July 1978. After July, gizzard shad were impinged in larger numbers through December (see IMPINGEMENT - Gizzard shad). August and September were months of greatest field sample catches (65 and 58), followed by December (32), November (18) and October (15). Estimated gizzard shad impingement in January, February and March 1978 was also high (7339,4760 and 18,561 fish respectively). It is felt that these impinged fish originated partly from a substantial gizzard shad population which inhabited the warm water of the discharge canal during the winter. Large numbers of gizzard shad have been observed in the discharge canal and its construction and operation allow fish access to the intake forebay which sometimes results in impingement of these fish. Only eight gizzard shad (seven in 1977, one in 1978) have been caught in Pigeon Lake in the last $2 \mathrm{yr}$ (Jude et al. 1978), so it seems unlikely that impinged gizzard shad came through Pigeon Lake and into the intake canal as most other impinged species did. [Note: Appendix 6, under Gizzard Shad - Pigeon Lake, contains erroneous data - only one shad $(383 \mathrm{~mm}, 730 \mathrm{~g}$, a male) was caught in Pigeon Lake in 1978. This fish was gillnetted in August at night at station M.] 
Food is available through the winter in the discharge canal as evidenced by a high proportion of impinged gizzard shad which had food in their stomachs from November through March. This species does not normally feed in the winter (Jude 1973, Scott and Crossman 1973).

Apart from the discharge canal, it appears that gizzard shad were absent from the study area during winter. They were probably in deeper water until spring when they moved inshore possibly to tributary rivers and remained there until late fall. Becker (1976) described a prolonged spawning period from mid-March to mid-August for gizzard shad and such a prolonged spawning season in the area near the Campbell Plant in 1978 was suggested by the extended presence of YOY gizzard shad. Twelve immatures (50-130 mm) were caught in September and a month later 13 immatures, showing increased size $(90-150 \mathrm{~mm})$, were observed in our samples. By November, combined factors of growth, natural mortality and dispersal of this stage resulted in no immatures being caught. Then in December 31 immatures (70-130 mm) were sampled. No adult gizzard shad with ripe-running or spent gonads were captured in 1978 (Tables 50 and 51) and only four males, caught in September and November, were found to have well developed gonads. More fish (57) of both sexes were found with well developed gonads in 1977 samples (Jude et a1. 1978) and these fish were all captured in November. Most immature gizzard shad in 1977 were caught in September.

Table 50. Monthly gonad conditions of gizzard shad caught during 1978 in Lake Michigan and Pigeon Lake near the J. H. Campbell Plant, eastern Lake Michigan. All fish examined in a month were included except poorly received specimens.

\begin{tabular}{|c|c|c|c|c|c|c|c|c|c|c|}
\hline & Gonad condition & Apr & May & Jun & Jul & Aug & Sep & Oct & Nov & Dec \\
\hline Males & $\begin{array}{l}\text { Slight development } \\
\text { Mod. development } \\
\text { Well developed } \\
\text { Ripe-running } \\
\text { Spent }\end{array}$ & & & & 1 & $\begin{array}{r}9 \\
10\end{array}$ & $\begin{array}{r}5 \\
12 \\
2\end{array}$ & $\begin{array}{l}1 \\
1\end{array}$ & $\begin{array}{l}5 \\
2\end{array}$ & 1 \\
\hline Females & $\begin{array}{l}\text { Slight development } \\
\text { Mod. development } \\
\text { Wel1 developed } \\
\text { Ripe-running } \\
\text { Spent } \\
\text { Absorbing }\end{array}$ & & & & & $\begin{array}{l}11 \\
36\end{array}$ & $\begin{array}{r}4 \\
16\end{array}$ & 3 & $\begin{array}{l}3 \\
8\end{array}$ & \\
\hline Immature & & & & & & & 12 & 10 & & 31 \\
\hline Unable tc & o determine & & & & & & 7 & & & \\
\hline
\end{tabular}

In agreement with earlier 1977 findings by Jude et al. (1978) the majority $(81 \%)$ of the gizzard shad caught in 1978 near the Campbell Plant 
occurred in night samples. Water temperatures at capture ranged from 1 to $25 \mathrm{C}$, though $52 \%$ of the catch was collected between 21 and $23 \mathrm{C}$.

Table 51. Monthly gonad conditions of gizzard shad collected in impingement samples during 1978 at the J. H. Campbell Plant, eastern Lake Michigan. A11 fish examined in a month were included except poorly received specimens.

\begin{tabular}{|c|c|c|c|c|c|c|c|c|c|c|c|c|c|}
\hline & Gonad condition & Jan & Feb & Mar & Apr & May & Jun & Ju1 & Aug & Sep & Oct & Nov & Dec \\
\hline Males & $\begin{array}{l}\text { Slight development } \\
\text { Mod. development } \\
\text { Well developed } \\
\text { Ripe-running } \\
\text { Spent }\end{array}$ & & & & $\begin{array}{l}1 \\
3\end{array}$ & & 1 & & 2 & 17 & $\begin{array}{l}8 \\
1\end{array}$ & $\begin{array}{r}27 \\
6\end{array}$ & $\begin{array}{l}85 \\
49\end{array}$ \\
\hline Females & $\begin{array}{l}\text { Slight development } \\
\text { Mod. development } \\
\text { Weli developed } \\
\text { Ripe-running } \\
\text { Spent } \\
\text { Absorbing }\end{array}$ & & & & 4 & & & & 3 & $\begin{array}{r}23 \\
1\end{array}$ & 30 & $\begin{array}{r}25 \\
1\end{array}$ & $\begin{array}{l}48 \\
25\end{array}$ \\
\hline Imnature & & & & & 18 & & & & 96 & 47 & 218 & 172 & 386 \\
\hline Unable $t$ & o distinguish & & & & & & & & 6 & 6 & 20 & 10 & 59 \\
\hline
\end{tabular}

Gizzard shad were impinged in relatively high numbers, comprising over $50 \%$ (by number and weight) of the total impingement kill during 6 mo (February, March, August, October, November, December) of 1978. In February, March and December, gizzard shad made up respectively, 96,89 and $90 \%$ of the total number of fish impinged. August, October and November were the other 3 mo during which gizzard shad dominated impingement samples. Seven gizzard shad were estimated to have been impinged in June, while none were impinged in May and July 1978.

Brown Trout--

During 1978, 114 brown trout were caught in Lake Michigan; no brown trout were caught in Pigeon Lake. Brown trout were represented in all monthly samples; most often caught from April through June, with maximum catch (41) occurring in April (Appendix 6). There was an almost equal distribution between day and night catches; 60 fish were caught at night and 54 during the day. Two brown trout were captured in surface gill nets, 13 in seines and the remainder in bottom gill nets.

Brown trout caught in 1978 ranged in size from $106 \mathrm{~mm}(3.9 \mathrm{~g})$ to $704 \mathrm{~mm}$ $(5800 \mathrm{~g})$, but most were large fish 310-704 mm. Smaller fish (106-293 mm) were all collected by seine in the beach zone where water temperatures were warmest. 
Data from our 1977 study (Jude et a1. 1978) and a similar study in the vicinity of the Cook Plant (Jude et al. 1975) show a preference by juvenile brown trout for beach zone water.

In the present study, all but seven brown trout were caught at $6 \mathrm{~m}$ or less; $89(78 \%)$ were caught at $3 \mathrm{~m}$ or less and all were caught with gill nets. During August a1l brown trout were taken from $9 \mathrm{~m}$ by bottom gill nets indicating a movement from warmer nearshore water to deeper water as temperatures increased in summer. During October and November all brown trout were caught at $6 \mathrm{~m}$ or less reflecting a movement back into cooler nearshore waters. Most brown trout caught during 1978 were taken from water with a temperature range between 5.8 and $15.0 \mathrm{C}$, which coincides closely with findings in 1977 (Jude et a1. 1978) when brown trout were most often caught at temperatures between 7 and $13 \mathrm{C}$, and from 6 to 16 in the vicinity of the Cook Plant (Jude et a1. 1975).

Fewer brown trout (49) were caught during 1977 (Jude et al. 1978) than in 1978 when 114 were collected. No sampling in April and May 1977, months of peak abundance in 1978, accounted for the lower number of brown trout collected during 1977.

About $73 \%$ of the brown trout captured had food in their stomachs. Slimy sculpins dominated the diet in April and some smelt were also found. Alewives and spottails made up the bulk of the summer and fall diets. Idyll (1942) and Brynildson et al. (1973) found that larger brown trout are largely piscivorous.

Brown trout spawn in the fall when water temperatures are between 6.7 and 8.9 C (Scott and Crossman 1973) and in the Wisconsin waters of Lake Michigan in October and November (Becker 1976). Gonad development data from the present study (Table 52) suggest a fall spawning run which is consistent with our 1977 results (Jude et al. 1978) and the Cook Plant study (Jude et al. 1975).

Table 52. Month1y gonad conditions of brown trout caught during 1978 in Lake Michigan near the J. H. Campbell Plant, eastern Lake Michigan. All fish examined in a month were included except poorly received specimens.

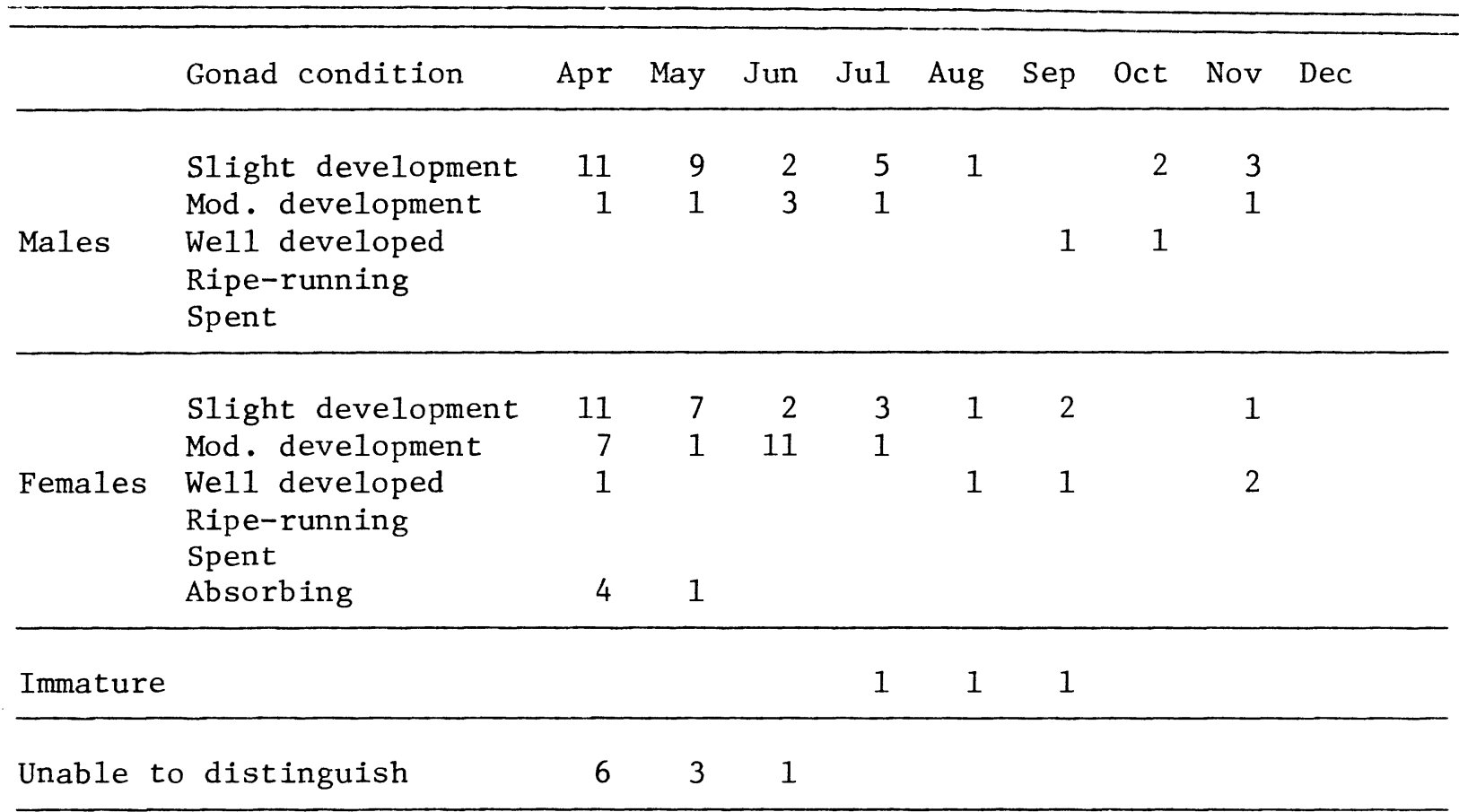


Sport fishermen caught brown trout in April and May in the vicinity of the Campbe11 Plant. The area of the warm-water discharge accounted for most of the angler-caught brown trout. Seasonally high densities of forage fishes near thermal discharges into Lake Michigan can attract salmonid fishes and may provide energetic advantages to plume-residents (Romberg et a1. 1974). Brown trout were also observed in the discharge canal in November. Low numbers of brown trout (only nine collected in 24-h samples during the entire year) occurred sporadically in impingement samples (Table 21). Projected total for the year was $64 \mathrm{fish}$ impinged.

Brook Silverside--

From May through November 1978, 80 brook silversides were seined from Pigeon Lake; of these 68 were collected from station V (undisturbed Pigeon Lake) and the remaining 12 from station $\mathrm{S}$ (influenced by Lake Michigan). Catches at beach stations $S$ and $V$ were fairly comparable in 1977 and 1978. Of the 159 brook silversides collected in 1977, $92 \mathrm{fish}$ came from station $\mathrm{T}$ (beach station influenced by Pigeon River eliminated from the 1978 sampling scheme), 42 from station $V$ and 24 from station $S$. In $1978,72 \%$ of the brook silversides were caught during the day, while in 1977 a greater percentage (78) was caught at night.

YOY brook silverside exhibit rapid growth after hatching, reach adult size before winter, spawn the next spring and die shortly thereafter (Scott and Crossman 1973). Our sampling periods did not coincide with the silverside's spring spawning since just one mature fish was caught, a 70-mm female in May. One brook silverside ( $70-80 \mathrm{~mm}$ ) occurred in collections in May, June and July; these fish probably represented remnants of the spawning population. During June and July it is likely that YOY were in relatively deep water (outside the beach zone) where they were less exposed to predation (Scott and Crossman 1973) and coincidentally less susceptible to our sampling gear. During August when water temperatures ranged from 22 to $27 \mathrm{C}$, 30 silversides $(20-50 \mathrm{~mm})$ were caught in seine hauls. This cohort reached $40-70 \mathrm{~mm}$ in September when $39 \mathrm{fish}$ were collected. Water temperatures were 18-20 C. Inshore movement to better avoid predators is normal during August and September for larger silversides (Scott and Crossman 1973). One 100-mm silverside was also caught in September which could have been a rare individual that survived beyond the normal life span for the species.

Fewer brook silversides were caught in October (2) and November (6) reflecting natural mortality and movement to deeper water. Water temperatures when silversides were captured ranged from 10.5 to $11.5 \mathrm{C}$ during October and November.

Rock Bass--

During 1978, 76 rock bass were captured; all were taken from Pigeon Lake. 
Peak numbers of fish were caught in June (36), $47 \%$ of the total and in July (16). Almost all fish (71) were seined at beach station V (undisturbed Pigeon Lake); two were gillnetted at Lake Michigan influenced station $M$ and three were seined at beach station S (influenced by Lake Michigan). As in our 1977 study (Jude et a1. 1978), most rock bass were caught at night (66 night captures, 10 day captures).

The range in size of rock bass captured during 1978 was $32 \mathrm{~mm}(0.7 \mathrm{~g})$ to $252 \mathrm{~mm}(304 \mathrm{~g}) ; 57 \%$ (43) were in the $98-\mathrm{mm}$ to $164-\mathrm{mm}$ size range and were probably age -2 and -3 rock bass (Beckman 1949). The majority of the rock bass caught in 1977 were age-1 and -2 fish with a range in length of 45-94 mm (Jude et a1. 1978). In our 1977 study 83 rock bass were captured via seine at Pigeon River influenced station $\mathrm{T}$ and 89 were caught at stations $\mathrm{S}$ (influenced by Lake Michigan) and V combined. In 1978, only 76 were caught, most (73) at station $\mathrm{V}$ and only 3 at station $\mathrm{S}$. Deletion of station $\mathrm{T}$ from our 1978 sampling series undoubtedly accounted for the lesser abundance of fish caught during 1978.

Rock bass spawn in late May and early June when water temperatures reach 15.6 to 21.1 C (Skille 1968). Water temperatures in Pigeon Lake during June ranged from 18-21 C, and gonad data (Table 53) indicate that spawning may have occurred at this time as two adult fish were captured with well developed gonads. The remaining adults possessed gonads of slight or moderate development. Rock bass either spawned later in the year or in areas (such as station $\mathrm{T}$ which is influenced by the Pigeon River) which were not sampled in 1978. Three rock bass (110-160 mm) were removed from impingement samples in January, September and December 1978 (Appendix 8). Projected loss for the year was 21 fish.

Table 53. Monthly gonad conditions of rock bass caught during 1978 in Pigeon Lake near the J. H. Campbell Plant, eastern Lake Michigan. All fish examined in a month were included except poorly recieved specimens.

\begin{tabular}{|c|c|c|c|c|c|c|c|c|c|c|}
\hline & Gonad condition & Apr & May & Jun & $\mathrm{Ju} 1$ & Aug & Sep & Oct & Nov & Dec \\
\hline Males & $\begin{array}{l}\text { Slight development } \\
\text { Mod. development } \\
\text { We11 developed } \\
\text { Ripe-running } \\
\text { Spent }\end{array}$ & 1 & 2 & $\begin{array}{r}14 \\
3\end{array}$ & $\begin{array}{l}3 \\
3\end{array}$ & $\begin{array}{l}7 \\
2\end{array}$ & & 1 & & \\
\hline Females & $\begin{array}{l}\text { Slight development } \\
\text { Mod. development } \\
\text { We11 developed } \\
\text { Ripe-running } \\
\text { Spent } \\
\text { Absorbing }\end{array}$ & 2 & & $\begin{array}{l}1 \\
2\end{array}$ & & 1 & & & & \\
\hline Immature & & & & 12 & 9 & 1 & 2 & 4 & & \\
\hline Unable $\mathrm{t}$ & o distinguish & & 1 & 4 & 1 & & & & & \\
\hline
\end{tabular}


Coho Salmon--

During 1978, 74 coho salmon were caught, 56 in Lake Michigan and 18 from Pigeon Lake. Coho were represented in all monthly samples except December. Peak catches of coho occurred during June and July at all Lake Michigan beach stations ( $P, Q$ and $R$ ) and Pigeon Lake station $S$ (Lake Michigan influenced). With the exception of a $620-\mathrm{mm}$ fish caught in a bottom gill net, all coho caught during the June-July period were sma11 (41-116 mm) juvenile fish collected by seine. Juvenile coho were found to inhabit beach zone waters in June off the Cook Plant (Jude et al. 1975) and we found small coho in the beach zone during the 1977 study (Jude et al. 1978). Scott and Crossman (1973) reported that coho remain close to shore for the first few months of the summer when they feed on small forage fish and crustaceans.

A11 coho caught in Pigeon Lake were smal1, 74-165 mm; 13 of 18 were less than $96 \mathrm{~mm}$. All coho except one, which was seined during May at beach station $\mathrm{V}$ (undisturbed Pigeon Lake), were seined at station $\mathrm{S}$ (influenced by Lake Michigan) at night during June when the water temperature was $15.0 \mathrm{C}$.

The largest catch of adults occurred in September when seven coho with a size range of $635-842 \mathrm{~mm}$ were caught in Lake Michigan, water temperatures were 18.5-23.0 C. Three adult coho were taken from Lake Michigan in October at water temperatures of $11.2-12.5 \mathrm{C}$. Seven adults were caught in surface gill nets, 1 was seined and 10 were caught by bottom gill nets at $6 \mathrm{~m}$ or less.

The adult salmon in this study moved into inshore waters in spring and fa11, and to offshore waters in summer months. Godfrey (1965) determined that coho in coastal waters occurred mainly in or above the thermocline and Engel and Magnuson (1971) reported inshore movement in the spring and fall and offshore movement following the thermocline in the summer.

In the spring of 1978 the four states bordering Lake Michigan initiated a coho salmon study with two principle objectives: (1) estimate the relative magnitude of naturally reproducing coho salmon in Lake Michigan and (2) determine the contribution made by each agency's planting for respective harvests made by anglers in various state waters. To accomplish this, fin clips were assigned to the four agencies, all fish were to be fin clipped prior to being released, and an intensive effort was launched to locate both marked and unmarked fish. We collected seven marked coho salmon in the vicinity of the Campbell Plant in 1978, al1 during May. Four of the marked fish were planted in the Grand/Muskegon Rivers, one each from the Platte and St. Joseph/Black Rivers and one from Indiana.

Coho are planted in the spring at about 101-152 mm (M. Patriarche, personal communication, Institute for Fisheries Research, Michigan Department of Natural Resources, University of Michigan, Ann Arbor, Mich.). In the present study 
we collected 17 coho between 41 and $99 \mathrm{~mm}$, which bore no fin clips, suggesting natural reproduction, or the possibility that these fish were actually chinook salmon, which are planted when they are about $50 \mathrm{~mm}$. It is very difficult to differentiate between these two species when they are so small. Returns from adult fish in fall 1979 should provide some data to estimate natural recruitment in the vicinity of the Campbell Plant.

Longnose Sucker--

Although longnose suckers are common to the Lake Michigan basin (Becker 1976), only a small number were caught in our study area, all in Lake Michigan. Thirty-six longnose suckers were collected in 1977 (Jude et a1. 1978) and 73 in 1978 (Table 13). This catch increase in 1978 was mainly due to the 32 longnose suckers collected during April and May. Sampling was not performed during these 2 mo in 1977.

Most longnose suckers in 1978 (68 of 73) were collected in bottom gill nets. Of the remaining five, one was caught in a surface gill net, two were caught in trawls and two in seine hauls. Jude et al. (1975) suggested this species may effectively avoid trawls and seines. Low catches of longnose suckers in surface gill nets confirmed the bottom distribution and probable demersal behavior of this species.

Of the 68 longnose suckers taken in bottom gill nets, 8 were caught at station A $(1.5 \mathrm{~m}-\mathrm{S}), 11$ at station $B(3 \mathrm{~m}-\mathrm{S}), 21$ at station C $(6 \mathrm{~m}-\mathrm{S}), 15$ at station $\mathrm{D}(9 \mathrm{~m}-\mathrm{S}), 8$ at station $\mathrm{E}(12 \mathrm{~m}-\mathrm{S})$ and 5 at station $\mathrm{L}(6 \mathrm{~m}-\mathrm{N})$. These data and the seine catches indicated that longnose suckers were distributed from the beach zone to at least $12 \mathrm{~m}$, with highest concentrations at 6 and $9 \mathrm{~m}$. In 1977 longnose suckers were found most of ten in slightly shallower water ( 3 and $6 \mathrm{~m}$ - Jude et al. 1978). Near the Cook Plant, southeastern Lake Michigan, highest catches of longnose suckers occurred in relatively deeper water (21 m - Jude et a1. 1975).

Fewer longnose suckers were collected in bottom gill nets at station $\mathrm{L}$ $(6 \mathrm{~m}-\mathrm{N})$ than at reference station $\mathrm{C}(6 \mathrm{~m}-\mathrm{S})$ during both 1977 and 1978 . In 1978, 21 longnose suckers were caught at station $C$ and 5 at station $\mathrm{L}$, while corresponding catches for 1977 were 15 and 1 . Reasons for catch discrepancies are unknown, but this finding may be a consistent difference between the treatment and reference areas. Water temperatures at time of capture at the two stations were comparable for 1977 and 1978.

Longnose suckers were represented in all monthly samples during the study period. Only one was caught in April, while the highest number (31) occurred in May. Catches of longnose suckers declined throughout summer and fal1 (Appendix 6).

Longnose suckers were reported to spawn in April and May (Scott and Crossman 1973). Gonad data (Table 54) indicated spawning probably took place in May. Some of the unidentified sucker larvae caught during May may be longnose suckers. Low catches of longnose suckers in April suggested this species may be spawning outside our study area during this month, probably in streams 
and rivers in the area. Like 1977 (Jude et a1. 1978), our 1978 data showed no evidence of longnose sucker spawning in the Pigeon River. No longnose suckers were caught in Pigeon Lake in 1977 and 1978. Only one longnose sucker, a 90-mm yearling, occurred in 24-h impingement samples; it was impinged during May 1978 (Appendix 8). One adult longnose sucker was caught in a bottom gill net set between the jetties in March 1979.

Table 54. Monthly gonad conditions of longnose suckers caught during 1978 in Lake Michigan near the J. H. Campbell Plant, eastern Lake Michigan. All fish examined in a month were included except poorly received specimens.

\begin{tabular}{|c|c|c|c|c|c|c|c|c|c|c|}
\hline & Gonad condition & Apr & May & Jun & Jul & Aug & Sep & Oct & Nov & Dec \\
\hline Males & $\begin{array}{l}\text { Slight development } \\
\text { Mod. development } \\
\text { Weli developed } \\
\text { Ripe-running } \\
\text { Spent }\end{array}$ & & $\begin{array}{l}3 \\
6 \\
4 \\
1\end{array}$ & $\begin{array}{l}4 \\
2\end{array}$ & $\begin{array}{l}7 \\
1\end{array}$ & & 3 & 1 & 1 & \\
\hline Females & $\begin{array}{l}\text { Slight development } \\
\text { Mod. development } \\
\text { We11 developed } \\
\text { Ripe-running } \\
\text { Spent } \\
\text { Absorbing }\end{array}$ & 1 & $\begin{array}{r}14 \\
1 \\
1\end{array}$ & $\begin{array}{l}1 \\
2\end{array}$ & $\begin{array}{l}3 \\
3 \\
2\end{array}$ & & $\begin{array}{l}1 \\
3 \\
1\end{array}$ & 1 & 2 & \\
\hline Immature & & & 1 & & & & 1 & & & \\
\hline Unable $t$ & o distinguish & & & & & 2 & & & & \\
\hline
\end{tabular}

Longnose suckers collected during 1978 ranged from 80 to $580 \mathrm{~mm}$, the majority (64 of 73) were $390 \mathrm{~mm}$ and above. Based on length-age data of longnose suckers reported by Carlander (1969), these large individuals were probably 6 yr old or older. Young longnose suckers occurred in relatively low numbers in our study area. Only three longnose suckers under $260 \mathrm{~mm}$ were collected in 1978 and one in 1977. Scarcity of young longnose suckers was also observed near the Cook Plant, southeastern Lake Michigan (Jude et a1. 1975).

More longnose suckers were caught at night (66) than during the day (7) (Appendix 6). Longnose suckers were caught in water temperatures ranging from 5 to $21 \mathrm{C}$. Although longnose suckers are known to prefer relatively cold water, approximately $31 \%$ of the 1978 longnose sucker samples were collected in water temperatures 17 to $21 \mathrm{C}$.

Bluegill--

During 1978, 54 bluegills were collected, 52 in Pigeon Lake and 2 in 
Lake Michigan. One Lake Michigan bluegill was seined at beach station Q (S discharge) in September and probably came from the discharge canal. Jude et al. (1978) observed bluegills in the discharge canal. The other Lake Michigan bluegill was a YOY trawled at station $\mathrm{F}(15 \mathrm{~m}-\mathrm{S})$ in October.

Pigeon Lake possesses the weedy, eutrophic habitat typically preferred by bluegills. One bluegill was caught in a bottom gill net at open water station M (influenced by Lake Michigan) in August. Eight were seined at beach station $S$ (influenced by Lake Michigan) and 43 were seined at beach station V (undisturbed Pigeon Lake). Bluegills were collected during every month except November and December.

Sizes of bluegills collected ranged from 24 to $184 \mathrm{~mm}$. Of the 52 bluegills collected in Pigeon Lake, 35 were immature. Bluegills spawn from late May to early August (Snow et al. 1970). No ripe-running fish were collected and only one showed moderate gonad development (Table 55). Deletion of Pigeon River beach and open water stations in 1978 may be a partial cause for the apparent lack of spawning adults collected in 1978. Beach station $\mathrm{T}$ was shallow and weedy which is ideal spawning and nursery habitat for bluegills. Quite possibly, the majority of bluegill spawning occurred in areas outside our sampling stations. Elimination of beach station. T may also explain the reduction in numbers of bluegills caught in 1978 (54 fish) when compared to 1977 (134 fish) as we were no longer sampling favorable bluegill habitat.

Table 55. Monthly gonad conditions of bluegills caught during 1978 in Pigeon Lake near the J. H. Campbell Plant, eastern Lake Michigan. All fish examined in a month were included except poorly received specimens.

\begin{tabular}{|c|c|c|c|c|c|c|c|c|c|c|}
\hline & Gonad condition & Apr & May & Jun & Ju1 & Aug & Sep & Oct & Nov & Dec \\
\hline Males & $\begin{array}{l}\text { Slight development } \\
\text { Mod. development } \\
\text { We11 developed } \\
\text { Ripe-running } \\
\text { Spent }\end{array}$ & 1 & & 3 & 5 & $\begin{array}{l}4 \\
1\end{array}$ & & & & \\
\hline Females & $\begin{array}{l}\text { Slight development } \\
\text { Mod. development } \\
\text { We11 developed } \\
\text { Ripe-running } \\
\text { Spent } \\
\text { Absorbing }\end{array}$ & & & & & & & 2 & & \\
\hline Immature & & & 3 & 10 & 9 & 5 & 5 & 3 & & \\
\hline Unable $t$ & o distinguish & & & & 1 & & & & & \\
\hline
\end{tabular}


During 1978, 183 bluegills (46-188 mm) were estimated impinged by the Campbell Plant (Appendix 9). Bluegills were impinged every month except July and appeared to be impinged randomly. This number probably does not represent a threat to the bluegill population of Pigeon Lake.

Banded Killifish--

Banded killifish inhabit the quiet water areas of lakes and ponds with sand, gravel or detrital-covered substrate associated with aquatic vegetation (Scott and Crossman 1973). This species is restricted in range to the northcentral and northeastern United States, the Maritime provinces, Newfoundland and the southern section of Ontario, Canada, and occurs in both freshwater and estuarine environments (Fritz and Garside 1975). Spawning occurs in late May when water temperatures reach 21-23 C (Scott and Crossman 1973). The members of the killifish family often exhibit schooling behavior and the banded killifish has been found to feed in schools on chironomid larvae, ostracods, cladocerans, copepods, amphipods, polychaetes and non-aquatic insects (Scott and Crossman 1973, Baker-Dittus 1978).

During 1978 sampling, 51 banded killifish were seined in Pigeon Lake; three at station S (influenced by Lake Michigan) and 48 at station V (undisturbed Pigeon Lake). The extensive catch of so many individuals at a single station may confirm the habitat preference discussed for this species. Beach station $\mathrm{V}$ is an area of shallow water and dense aquatic vegetation. Only two banded killifish were captured in 1977. These $\mathrm{fish}$, one male $(40 \mathrm{~mm})$ and one female $(43 \mathrm{~mm}$ ) were also caught by seine at beach station $\mathrm{V}$ during the day in November at a water temperature of $12.6 \mathrm{C}$.

Forty banded killifish were captured during August, 36 of these were caught at night (Appendix 6). The fish taken during 1978 ranged in length from 30 to $50 \mathrm{~mm}$. According to Scott and Crossman (1973) these lengths are characteristic of age-group-0 and -1 individuals. Eighteen fish were determined to be adults, ten females and eight males. Some stomachs were examined for food content. Much of the material was unrecognizable, however several fish had been feeding on ostracods.

One other banded killifish was taken during a night plankton tow at beach station $\mathrm{V}$ in early June. The $65 \mathrm{~mm}, 2.5 \mathrm{~g}$ female was the largest individual collected in 1978 .

Northern Pike--

Most northern pike (54) were caught in Pigeon Lake during 1978; two were caught in Lake Michigan. They were collected during April through December in Pigeon Lake. Most were caught during April (18) and August (13). Gill nets at station M (Lake Michigan influenced) collected 39 pike, 9 were seined at beach station V (undisturbed Pigeon Lake) and 6 were seined at Lake Michigan influenced beach station S. In Lake Michigan one was collected in August at station $B(3 \mathrm{~m}-\mathrm{S})$ and one during October from south transect station C $(6 \mathrm{~m})$. 
Northern pike were caught over a broad range of water temperatures (1.8-27.3 C) with most taken between 10.3 and 27.3 C. Becker (1976) gives a range of 12.8-23.3 C for peak activity. The fact that station $M$ (influenced by Lake Michigan) remains relatively warm during colder months, due to the influence of a warm discharge at the mouth of Pigeon Lake, and cooler during the warmer months again because of influent Lake Michigan water, could account for peak numbers of fish caught in August at this station.

Although most pike caught in standard series sampling were taken from the deeper water of Pigeon Lake ( $6 \mathrm{~m}$-station $\mathrm{M})$, they were also common in shallow water. The majority of pike caught while electrofishing, were caught off undisturbed Pigeon Lake beach station $\mathrm{V}$ in $1.5 \mathrm{~m}$ of water or less.

In the 1977 study (Jude et al. 1978) considerably more pike (117) were caught in Pigeon Lake than in 1978 (54). Exclusion of beach station $\mathrm{T}$ (influenced by Pigeon River) and station Y (undisturbed Pigeon Lake) probably accounted for the smaller catch of northern pike during 1978. Half of the 1977 total was caught at stations $\mathrm{Y}$ and $\mathrm{T}$.

Pike caught in 1978 ranged from 83 to $820 \mathrm{~mm}$; all but nine were larger than $300 \mathrm{~mm}$. Average lengths of northern pike from Pigeon Lake were: Age 0 $216 \mathrm{~mm}(\mathrm{SE}=13, \mathrm{~N}=11)$; Age $1-337 \mathrm{~mm}(\mathrm{SE}=24, \mathrm{~N}=10) ;$ Age $2-516 \mathrm{~mm}$ $(\mathrm{SE}=25, \mathrm{~N}=5)$; Age $3-501 \mathrm{~mm}(\mathrm{SE}=19, \mathrm{~N}=3)$; Age $4-804 \mathrm{~mm} \quad(\mathrm{SE}=95$, $\mathrm{N}=3$ ). Decline in total length for age-3 fish compared to age -2 was probably due to small sample size; only three fish were captured from that age-group.

Growth rates of Pigeon Lake pike compared favorably with growth rates of pike from other lakes in the Great Lakes region (Table 56). Growth rates of Pigeon Lake northern pike are probably higher than these data would indicate because of small sample size (35), and most fish used for age determination were collected before the end of the growing season. A 256-mm YOY was collected in September compared to an average of $216 \mathrm{~mm}$ for YOY pike collected in July and August.

Northern pike spawn in early spring immediately after the ice melts in March to May when water temperatures are 4.4-11.1 C (Becker 1976). Gonad development data (Table 57) from the present study showed that spawning probably occurred in March before sampling had begun. In the 1977 study all adult pike had spawned by May, which was also the case in the present study.

Examination of food data from pike showed variety of fish were preyed upon in Pigeon Lake. In order of prominence were gizzard shad, spottail shiner, white sucker, golden shiner, alewife and yellow perch.

Impact of the Campbell Plant on northern pike populations was limited to those impinged, since, because of the larval behavioral trait of attaching themselves to vegetation after hatching, none were entrained. During 1978, a projected total of 68 pike were impinged. Using our age-length data (Table 56) would give 46 YOY, 8 yearlings and 14 age-4 northern pike impinged. Our field data showed that a much wider length range of pike were present in the lake, indicating that mostly YOY were being impinged and larger fish were 
avoiding the intakes. In our game fish population study (see RESULTS AND DISCUSSION) we estimated the population for two size groups of pike: 175$299 \mathrm{~mm}$ and those greater than $299 \mathrm{~mm}$. Sixteen pike in the first group were impinged and 14 from the second group were impinged. Since the estimate of abundance for pike greater than $299 \mathrm{~mm}$ was 690 ( $95 \%$ confidence limits of 524 and 906), the 14 impinged represented only $2 \%$ of this number, certainly a small percentage of those present in the lake. Similarly, the sixteen fish impinged in the 175-299-mm group, represented on $1 \mathrm{y} 1.3 \%$ of the estimated number (1259) of fish in this group in the lake in 1978. Since we have no estimate for YOY pike present in Pigeon Lake, it is difficult to evaluate the loss of these impinged fish from the Pigeon Lake population. However, it is reasonable to assume that YOY are more abundant than any of the other agegroups, banning a major year class failure in any year. Thus, the impinged YOY fish probably represent a small percentage of those present in Pigeon Lake. Further support for this view is the increase in pike 175-299 mm which occurred in 1978 (1259 fish) compared to 1977 levels (628 fish). In addition, many YOY northern pike were observed during electrofishing activities in 1978. YOY pike were also observed in seine hauls at beach station $\mathrm{T}$ (influenced by Pigeon River) in 1977 and supplementary hauls at station $\mathrm{T}$ in 1979 . We concluded that results of the present study agreed with 1977 findings in that northern pike are growing and propagating well in Pigeon Lake and there is a large population of pike considering the size of Pigeon Lake (see RESULTS AND DISCUSSION - Game Fish Population Study).

Table 56. Age and growth of northern pike from various locations in the Great Lakes region. Data are total length in $\mathrm{mm}$.

Years of growth completed

\begin{tabular}{|c|c|c|c|c|c|c|c|c|c|c|}
\hline Location and reference & 1 & 2 & 3 & 4 & 5 & 6 & 7 & 8 & 9 & 10 \\
\hline $\begin{array}{l}\text { Northern Canadian Lakes } \\
\text { (Miller and Kennedy 1948) }\end{array}$ & 100 & 156 & 223 & 296 & 342 & 416 & 469 & 524 & 570 & 611 \\
\hline $\begin{array}{l}\text { Minnesota Lakes } \\
\text { (Kuehn 1949) }\end{array}$ & 198 & 336 & 450 & 536 & 615 & 681 & 737 & 790 & 841 & 892 \\
\hline $\begin{array}{l}\text { Lake Erie } \\
\text { (Clark \& Steinbach 1959) }\end{array}$ & 290 & 447 & 539 & 600 & 648 & 671 & 727 & 765 & 792 & 833 \\
\hline $\begin{array}{l}\text { I1linois Lakes } \\
\text { (Van Enge1 1940) }\end{array}$ & 252 & 445 & 534 & 600 & & & & & & \\
\hline $\begin{array}{l}\text { Wisconsin Lakes } \\
\text { (Van Enge1 1940) }\end{array}$ & 254 & 457 & 584 & 686 & 765 & 838 & 914 & 965 & 1016 & 1118 \\
\hline $\begin{array}{l}\text { Lake Ontario } \\
\text { (Greely 1949) }\end{array}$ & 286 & 424 & 505 & 568 & 650 & & & 775 & & \\
\hline This study & 216 & 337 & 516 & 501 & 639 & 804 & & & & \\
\hline
\end{tabular}


Table 57. Monthly gonad conditions of northern pike caught during 1978 in Pigeon Lake near the J. H. Campbell Plant, eastern Lake Michigan. All fish examined in a month were included except poorly received specimens.

\begin{tabular}{|c|c|c|c|c|c|c|c|c|c|c|}
\hline & Gonad condition & Apr & May & Jun & $\mathrm{Ju} 1$ & Aug & Sep & Oct & Nov & Dec \\
\hline Males & $\begin{array}{l}\text { Slight development } \\
\text { Mod. development } \\
\text { Well developed } \\
\text { Ripe-running } \\
\text { Spent }\end{array}$ & & $\begin{array}{l}1 \\
2\end{array}$ & 1 & & $\begin{array}{l}8 \\
1\end{array}$ & $\begin{array}{l}1 \\
2\end{array}$ & 1 & 1 & 1 \\
\hline Females & $\begin{array}{l}\text { Slight development } \\
\text { Mod. development } \\
\text { Well developed } \\
\text { Ripe-running } \\
\text { Spent } \\
\text { Absorbing }\end{array}$ & & & 1 & & $\begin{array}{l}1 \\
3\end{array}$ & & $\begin{array}{l}1 \\
1\end{array}$ & 1 & 1 \\
\hline Immature & & & & 1 & 4 & & & & & \\
\hline Unable $t$ & o distinguish & 7 & & & & & 1 & & 1 & \\
\hline
\end{tabular}

Chinook Salmon--

The 32 chinook salmon caught in 1978 samples were a substantial increase over the 1977 total of 4 (Jude et al. 1978). The difference this year was the considerable number of immature chinook $(80-100 \mathrm{~mm})$ that were collected in Lake Michigan night seine hauls in June and July. Although some natural reproduction is known to occur in the area, the immature chinook sampled were more likely representatives of fish stocked by the Michigan Department of Natural Resources (MDNR). In rivers which run into Lake Michigan within $40 \mathrm{~km}$ north and south of the Campbell Plant, over one million chinook were planted by MDNR in 1978. Our predominantly night catches indicate daytime net avoidance, but may also reflect night movement into the beach zone by young chinook possibly to feed. Twenty of 21 immature chinook that were collected during June and July were found with food in their stomachs.

Chinook were present in the study area throughout the sampling season (April-November) as they were caught in all months except August and October. A few jacks appeared in early spring samples (water temperatures 6.0 to $8.5 \mathrm{C}$ ), immatures dominated late spring and summer months (water temperatures 11.5 to $17.0 \mathrm{C}$ ) and a few mature spawners were collected in late summer and fall (water temperatures 11.5 to $18.8 \mathrm{C}$ ). Chinook salmon were collected by all gear, but seines were the most successful. 
An adult male chinook $(693 \mathrm{~mm})$ with well developed gonads and a female $(750 \mathrm{~mm})$ in ripe-running condition appeared in september gill nets. The male was caught at $18.8 \mathrm{C}$ in Pigeon Lake where a limited number of chinook appear to spawn (see Jude et al. 1978). The female was caught during the day at $16.5 \mathrm{C}$ at Lake Michigan station $\mathrm{A}(1.5 \mathrm{~m}-\mathrm{S})$. Many other chinook in spawning condition were observed in the Campbell Plant's discharge canal during fall months.

Although relatively large compared with 1977 samples, the number of immature chinook collected in 1978 appears small considering the large number of small chinook planted in nearby areas. Since chinook and coho salmon are extremely difficult to differentiate at this life stage, it is possible that some of the numerous coho reported in 1978 samples were actually misidentified chinook.

Carp--

The carp, a cyprinid native to eastern Asia, has been widely introduced into the United States and Canada (McCrimmon 1968). According to McCrimmon this species prefers an environment which contains both a shallow, marshy area with dense aquatic vegetation in which to feed and spawn as well as an area of deepwater for overwintering. The Pigeon Lake area would seem to fit this description quite well.

During 1978 eight carp were collected in Pigeon Lake and 13 in Lake Michigan. In 197715 carp were taken in Pigeon Lake while only 7 were collected in Lake Michigan (Jude et al. 1978). All but three of the carp captured in 1978 were taken at night; 13 were taken in August at water temperatures between 13.5 and $25.0 \mathrm{C}$.

Five of the fish taken in Lake Michigan were collected at night by seine at beach station $Q$ ( $S$ discharge) in April, May and August. One fish was collected during October by traw1 at station $\mathrm{C}(6 \mathrm{~m}-\mathrm{S})$ in water $13.0 \mathrm{C}$. The remaining seven fish were caught in bottom gill nets set at stations $A$ $(1.5 \mathrm{~m}-\mathrm{S}), \mathrm{D}(9 \mathrm{~m}-\mathrm{S}), \mathrm{E}(12 \mathrm{~m}-\mathrm{S})$ and $\mathrm{L}(6 \mathrm{~m}-\mathrm{N})$ during August and September at water temperatures of 12.2-21.2 C. These data seem to indicate a stronger preference for deep water in 1978 than was found in 1977 when carp were collected in Lake Michigan only from nearshore areas (Jude et al. 1978). In Pigeon Lake seven of the eight fish collected were taken during July and August night seining at beach station V (undisturbed Pigeon Lake) when water temperatures were 20.8 to $25.0 \mathrm{C}$. The other fish was taken in a bottom gill net set at $6-\mathrm{m}$ station $M$ (influenced by Lake Michigan) in April at a water temperature of $7.4 \mathrm{C}$.

During 1977 the majority of carp were captured at station M, in contrast to sampling during 1978 when only one individual was caught at this station. Five of the $15 \mathrm{fish}$ taken in 1977 were collected at beach stations $\mathrm{T}$ (influenced by Pigeon River) and $\mathrm{Y}$ (undisturbed Pigeon Lake), neither of which were sampled in 1978.

Eight carp, ranging in length from 50 to $640 \mathrm{~mm}$, were collected in regular 
sampling in Pigeon Lake during 1978. Two of these fish were females, one caught in April exhibited well developed gonads and the other caught in July was determined to be in ripe-running condition. Five of the eight carp were found to be immature and one other carp was in poor condition and the determination of sex could not be made. During 1978 six fish between 50 and $140 \mathrm{~mm}$ were collected; whereas only one small (32 mm) individual was collected from Pigeon Lake in 1977. The capture of immature fish from Pigeon Lake may indicate that suitable habitat for reproduction and growth of carp may be found in the study area. Catch of larval carp increased from 47 in 1977 to 318 in 1978 (see RESULTS AND DISCUSSION - FISH LARVAE AND ENTRAINMENT STUDY, Carp).

Carp captured from Lake Michigan ranged in size from 550 to $740 \mathrm{~mm}$; a similar size group was collected during 1977. Six of the carp collected in 1978 were females, all with well developed ovaries, and seven were male. of the males, five showed fully developed testes and the gonads of two fish appeared to be only slightly to moderately developed.

Another 781-mm, female carp was collected in the field during early April 1978. The fish appeared in a supplemental gill net set at night at station $\mathrm{M}$, when water temperature was only $4.3 \mathrm{C}$.

Four other carp from impingement samples in January, May, August and October were examined in 1978. Gonad condition of the individuals collected in January and May was not determined. However these two fish as well as a large male $(520 \mathrm{~mm})$ collected in October were probably all adult carp. An 80-mm carp impinged in August 1978 and four carp ranging in length from 50 to $90 \mathrm{~mm}$ impinged in 1977 (Zeitoun et al. 1978) may be evidence that the area around the Campbell Plant is suitable habitat for carp reproduction and for a nursery area.

Capture of proportionately large numbers of carp during 1977-1978 at beach stations influenced by the present onshore thermal discharge gives support for the known attraction of carp to thermal discharges (Jude et al. 1979). When Unit 3 becomes operational, we expect the offshore thermal discharge will attract carp, just as has been observed at the Cook Plant.

Tadpole Madtom--

The 1977 study of fish populations near the Campbe11 Plant (Jude et al. 1978) indicated that beach station $T$ (influenced by Pigeon River) was the preferred habitat of tadpole madtoms in Pigeon Lake, since 37 of the 55 madtoms collected in 1977 were caught there. Because this station was not included in our sampling area in 1978, a smaller number of madtoms (17) were caught.

Al1 tadpole madtoms in 1978 were taken in seines, 1 during the day and the remaining 16 at night. Tadpole madtoms were probably not affected by bottom dredging and water turbidity near beach station $S$ (influenced by Lake Michigan) since the same number of madtoms (2) were collected from beach station $S$ in 1977 and 1978. This species was reported to survive in areas of increasing turbidity until the last remnant of its habitat had been eliminated (Trautman 
1957). Madtom populations at beach station V (undisturbed Pigeon Lake) also showed little change from 1977 to 1978, since 17 and 15 specimens were collected respectively.

Tadpole madtoms were caught every month of the sampling season except July and August. Largest catch (12) occurred in June. Only three adult tadpole madtoms, a 56-mm male, a $81-\mathrm{mm}$ female and a 94-mm damaged specimen were included in 1978 samples. The first two adults were collected in May and June and showed slight gonad development. The third, with undetermined gonad condition was caught in June. Tadpole madtoms were reported to spawn in May in Wisconsin (Becker 1976) and in June or early July in Canada (Scott and Crossman 1973).

Of the 14 immature tadpole madtoms, 12 (ranging from 30 to $52 \mathrm{~mm}$ ) were caught in April, May and June. The remaining two, 51 and $48 \mathrm{~mm}$, were caught in September and October. Based on our 1977 data (Jude et al. 1978), those caught in April, May and June were probably yearlings, while those caught in September and October may have been YOY. Tadpole madtoms were caught at water temperatures of $10.5-21.0 \mathrm{C}$.

Forty-five tadpole madtoms 50-90 mm were estimated impinged during 1978 (Appendix 9). This number was relatively low compared to 134 tadpole madtoms found in the weekly impingement samples during January 1974- March 1975

(Consumers Power Company 1975). Of the tadpole madtoms impinged in 1978, the smallest was a 50-mm yearling collected in January. The remaining fish (70-90 mm), probably all adults, were collected in February, March, May, June, July and October.

Smallmouth Bass--

In Lake Michigan, the smallmouth bass is confined to shoal waters and protected bays (Becker 1976). Data from the present study (1978) confirm this trend since 14 smallmouth bass were collected from Pigeon Lake ( 9 at night) and 2 from the beach zone of Lake Michigan (1 at night). All smallmouth hass collected in Pigeon Lake were seined; nine at beach station $\mathrm{V}$ (undisturbed Pigeon Lake) and five at Lake Michigan influenced station S.

Although range in size of smallmouth bass caught was $38-366 \mathrm{~mm}$, most were juvenile fish 38-195 mm. According to White (1970) smallmouth bass are sexually mature at $211 \mathrm{~mm}$ in Lake Huron. A 366-mm (765 g) female with slightly developed ovaries taken in September from Lake Michigan at station A (1.5 m-S) was the largest smallmouth bass we collected during 1978 .

Only five smallmouth bass were collected during 1977 (Jude et al. 1978). Appearance of smallmouth bass in Lake Michigan, along with fish observed 3-4 $\mathrm{km}$ upstream in the Pigeon River, suggests considerable movement of this species throughout the vicinity of the Campbell Plant. Smallmouth bass tagged in the St. Lawrence River migrated up and down the river for distances up to $48 \mathrm{~km}$ (Cuerrier 1943). As water temperature increases bass may migrate up the Pigeon River to spawn and return to Pigeon Lake or nearshore waters of Lake Michigan. A11 of these areas possess an abundance of food and suitable habitat. Smallmouth 
bass prefer rocky and sandy areas of lakes and rivers with moderately shallow water. They were usually found around rocks or shoals or talus slopes or submerged logs which afford protection. They are less often associated with dense growths of aquatic vegetation than are largemouth bass and prefer cooler water than the largemouth (Becker 1976; Schneberger 1972). In general, food of this fish consists of insects, crayfish and fishes (Scott and Crossman 1973).

Although not as abundant as the largemouth bass in our study areas, the smallmouth bass population may be higher than our 1977 and 1978 data would indicate. Low numbers caught may reflect a lower vulnerability of smallmouth bass to our sampling methods. During 1978, 41 smallmouth bass were impinged. They ranged from 70 to $320 \mathrm{~mm}$ with most being YOY $\mathrm{fish}, 70-100 \mathrm{~mm}$.

Rainbow Trout--

During 1978, 15 rainbow trout ranging from 123 to $753 \mathrm{~mm}$ were collected (Appendix 6). Of these, nine were collected from Lake Michigan and six from Pigeon Lake. All but one were caught at night. Eight rainbow trout were taken from Lake Michigan and two from Pigeon Lake during the 1977 study (300 to $587 \mathrm{~mm}$ - Jude et al. 1978).

Of the six rainbow trout caught in Pigeon Lake, five were immature and ranged in size from $123 \mathrm{~mm}(19.0 \mathrm{~g})$ to $175 \mathrm{~mm}(58.8 \mathrm{~g})$. They were collected by seine in June (three) and July (two) at beach station S (influenced by Lake Michigan). Presumably these fish were part of the 10,000 rainbow trout released into Pigeon Lake in 1978 by Michigan Department of Natural Resources. Rainbow trout can reproduce naturally in the upper regions of Pigeon Creek (R.S. Lincoln, personal communication, Michigan Department of Natural Resources, Grand Rapids, Mich.). One adult male $(600 \mathrm{~mm})$ was gillnetted at station $\mathrm{M}$ (influenced by Lake Michigan) in October.

In Lake Michigan all rainbow trout were caught in nearshore water, except two which were gillnetted at station $\mathrm{L}(6 \mathrm{~m}-\mathrm{N})$ and station $\mathrm{E}$ $(12 \mathrm{~m}-\mathrm{S})$; water temperature range at time of capture was 5.4-12.1 C. Two rainbow trout were seined at beach station $Q$ (S discharge) and one at beach station $R$ (N discharge). Three rainbows were gillnetted at station $A(1.5 \mathrm{~m}-\mathrm{S}$ ) and one at station $B(3 \mathrm{~m}-\mathrm{S})$. The rainbow trout seined at station $\mathrm{R}(\mathrm{N}$ discharge) was the only one caught during the day.

A male rainbow trout with ripe-running gonads and a female with spent ovaries were collected in Lake Michigan in November, suggesting some fall spawning in the Campbell Plant areas. However, according to Becker (1976) the major spawning run occurs from January to late March. Supplementary sampling yielded 14 rainbow trout ranging in size from $550 \mathrm{~mm}$ to $810 \mathrm{~mm}$. They were collected from the discharge canal of the Campbell plant during November. These fish were most likely the result of MDNR plants made during past years. Rainbow trout are attracted to thermal discharges into Lake Michigan and reside in heated plumes for variable periods of time (Spigarelli 1975).

On1y 13 rainbow trout (150-270 mm) were impinged during 1978. These fish, probably 1- to 3-yr-old fish, were impinged during August and September. 
The bowfin is a predatory species found in a variety of habitats in Pigeon Lake (Jude et a1. 1978). Catch of bowfins in 1978 (13) declined substantially from the 70 specimens collected in 1977 . Low catches of bowfin in 1978 may in part be explained by the deletion of beach station $T$ (influenced by Pigeon River) and open water station Y (undisturbed Pigeon Lake) which together yielded 34 bowfin in 1977 .

Removal of aquatic vegetation by bottom dredging and increase of water turbidity due to operations of tugboats near Pigeon Lake station $M$ (influenced by Lake Michigan) and beach station S (influenced by Lake Michigan) were probably significant factors affecting the bowfin populations in 1978 at these two stations. Pflieger (1975) reported bowfin tended to avoid excessively turbid water. Only 3 bowfin were caught (all in gill nets in July) at station M (influenced by Lake Michigan) and none at beach station S in 1978 compared to 33 and 1 bowfin caught at respective stations in 1977 .

At beach station $\mathrm{V}$ (undisturbed Pigeon Lake) more bowfin were collected in 1978 (10) than in 1977 (1). Of the 10 bowfin caught at station V, 4 were seined in April, 2 in June, 1 in July, 2 in August and 1 in October.

Several bowfin larvae 11-25 mm were collected in Pigeon Lake on 4 June 1979 indicating that in our study area spawning probably took place during May. These data agreed with spring spawning of bowfin reported by Scott and Crossman (1973). Occurrence of a spent female in our July 1978 samples suggested that spawning may continue into summer. A male determined to be in ripe condition was caught in October. Other bowfin collected in 1978 had slight to moderate gonad development.

No patterns in diel catches of bowf in were obseryed in 1978. Young bowfin are believed to remain in deepwater areas with dense vegetation and are therefore rarely seen after schools disperse (Scott and Crossman 1973). Al1 specimens caught in 1978 were large individuals ranging from 317 to $761 \mathrm{~mm}$.

Bowfin were caught at water temperatures of 10.0 to $25.0 \mathrm{C}$. They were found in a wider temperature range $(2.4-26.9 \mathrm{C}$ ) in 1977 (Jude et al. 1978).

Twenty-seven bowfin were estimated impinged during 1978 (Appendix 9). Adults 620 and $570 \mathrm{~mm}$ were collected in March and April samples respectively. The other bowfins were 90 to $100 \mathrm{~mm}$ and were impinged during July and August. Based on age-length data reported by Carlander (1969) these small bowfin were YOY. A11 were found in night samples.

Round Whitefish--

Round whitefish prefer deep, cool water but are considered to be a shallow-water coregonid usually found in water less than 120-150 $\mathrm{m}$ in the Great Lakes region (Scott and Crossman 1973).

In 1978 eight round whitefish were collected from bottom gill nets in Lake Michigan at stations $\mathrm{A}(1.5 \mathrm{~m}-\mathrm{S}), \mathrm{C}(6 \mathrm{~m}-\mathrm{S}), \mathrm{E}(12 \mathrm{~m}-\mathrm{S})$ and $\mathrm{L}(6 \mathrm{~m}-\mathrm{N})$ in 
Lake Michigan. A11 gillnetted fish but one, an individual collected in October at station $C$, were collected at night. Two other specimens were taken during night trawling at stations $\mathrm{D}(9 \mathrm{~m}-\mathrm{S})$ and $\mathrm{N}(9 \mathrm{~m}-\mathrm{N})$.

Aside from one individual taken during December at a water temperature of $1.0 \mathrm{C}$, a11 fish were captured at 5.8 to $13.0 \mathrm{C}$. Fish ranged in length from 230 to $470 \mathrm{~mm}$. Of the $10 \mathrm{fish}$ collected, 5 were male and 3 were female, a11 exhibiting moderate to well developed gonad conditions. The sex and gonad conditions of the remaining two individuals could not be determined.

Data from 1978 compared similarly with that collected in 1977. In 1977 eight fish within a similar size range were gillnetted and trawled at 6.6 to $11.0 \mathrm{C}$ (Jude et a1. 1978).

Round whitefish seldom if ever entered Pigeon Lake since none were ever caught there during 1977 or 1978. None were impinged either.

Lake Whitefish--

The commercially important lake whitefish is a common inhabitant of the inshore waters of the Great Lakes and usually occurs at depths between 18 and $53 \mathrm{~m}$ (Scott and Crossman 1973).

In 1977,11 lake whitefish were captured, a11 at night in Lake Michigan. Nine were trawled at 6-, 12- and 15-m north and south transect stations and two were gillnetted at $6 \mathrm{~m}-\mathrm{S}$ (Jude et al. 1978). All lake whitefish caught in 1978 were taken between April and August at 4.5 to $10.8 \mathrm{C}$; whereas, those in 1977 were collected during June, July and September from water 6.0 to $8.2 \mathrm{C}$. In general, adult whitefish prefer $11 \mathrm{C}$ water (Ferguson 1958).

In 1978 six lake whitefish were taken in bottom gill nets set at stations C $(6 \mathrm{~m}-\mathrm{S}), \mathrm{D}(9 \mathrm{~m}-\mathrm{S}), \mathrm{E}(12 \mathrm{~m}-\mathrm{S})$ and $\mathrm{L}(6 \mathrm{~m}-\mathrm{N})$; all but one of these were taken at night. One fish was collected in a night surface gill net at station L. Two other lake whitefish were trawled at night at stations $\mathrm{E}$ and $\mathrm{N}(9 \mathrm{~m}-\mathrm{N})$. The specimens collected in 1978 ranged from 200 to $690 \mathrm{~mm}$ (Appendix 6); those taken in 1977 also fell within this size range, being 261 to $466 \mathrm{~mm}$. Five whitefish were males exhibiting slight to moderate development of the testes and two were females; one caught in April showed slight development of the ovaries while the one caught in August exhibited well developed ovaries.

Walleye--

The largest populations of walleyes in Lake Michigan existed in northern Green Bay, southern Green Bay and in association with the Muskegon River on the eastern shore (Schneider and Leach 1977). Walleye prefer clear water with gravel, rock, sand or hard clay bottoms; they are rarely found in muddy streams or lakes (Becker 1976).

In the present study seven walleyes were caught from Lake Michigan, none in Pigeon Lake. One walleye was seined at Lake Michigan beach station P (S reference), three at beach station Q (S discharge) and two at beach station 
$\mathrm{R}$ ( $\mathrm{N}$ discharge). A11 walleyes in August were seined; two during the day and four at night. One was trawled at $6-\mathrm{m}$ station $\mathrm{L}$ ( $\mathrm{N}$ transect) during the night in December.

The seven field-caught walleye were from 122 to $216 \mathrm{~mm}$. Fifteen walleyes (190-310 mm; mean of $246 \mathrm{~mm}$ ) were impinged during November and December resulting in an estimate for 1978 of 115 walleyes. These fish may be attracted to the warm water in the discharge canal and then entered the intake forebay via the common opening in November-December. Age determinations by the scale method were made by J. Schneider (MDNR, Institute for Fisheries Research, Ann Arbor, Michigan) and all were found to be YOY. Wolfert (1977) reported an average year's growth of $245 \mathrm{~mm}$ for YOY walleyes in Lake Erie which was considerably greater growth than that reported from most other waters. Ranges in total length of walleyes at the end of their first growing season were 118 to $163 \mathrm{~mm}$ in Oneida Lake (Forney 1966); 92 to $176 \mathrm{~mm}$ in Lake Gogebic, Michigan (Eschmeyer 1950); and 160 to $168 \mathrm{~mm}$ in Pike Lake, Wisconsin (Mraz 1968). One of the largest YOY reported was a $310-\mathrm{mm}$ individual from Canton Reservoir, Oklahoma (Lewis 1970). The 310-mm YOY we caught suggests optimum growth is taking place near the Campbell Plant.

At lengths over $76 \mathrm{~mm}$ walleye feed mostly on fish, including trout-perch and yellow perch (Becker 1976). In a food habit study of piscivorous fishes in Lake Michigan, Wagner (1972) found alewives contributed $71 \%$ of the food (by weight) of walleyes in summer and sme1t contributed 94\% (by weight) of the food in spring. Abundance of these forage species in the eastern Lake Michigan area and the rapid growth rate of the walleye in this area, could produce a good fishery in the future. The $R / V$ Juday collected over 30 walleyes in the 2-4-kg range during summer 1978 off Saugatuck, Michigan (R. Lincoln, personal communication, Michigan Department of Natural Resources, Grand Rapids, Mich.), giving further support to eastern Lake Michigan's potential for a successful walleye fishery.

Natural spawning of walleyes does occur in eastern Lake Michigan ( $R$. Lincoln, personal communication). Walleyes caught and impinged in the present study were either a result of natural reproduction in Lake Michigan or plants made in Lake Macatawa, the Grand or Muskegon rivers.

\section{Yellow Bullhead--}

The catch of on $1 y$ yellow bullhead in 1978 indicated an appreciable decline from the 35 specimens collected in Pigeon Lake during 1977 (Jude et a1. 1978). All specimens in 1978 were seined at night at beach station V (undisturbed Pigeon Lake). Three of the bullheads (45, 53 and $75 \mathrm{~mm}$ ) were caught during April at $12.5 \mathrm{C}$. Because yellow bullheads spawn in May or June in our study area (Jude et al. 1978) these small specimens were probably all age-group 1. The other four yellow bullheads collected were probably all adults and included three females (293, 299 and $380 \mathrm{~mm}$ ) and a 201-mm male, all caught in June at $18.0 \mathrm{C}$. One female $(293 \mathrm{~mm})$ had well developed gonads and the other adults showed a moderate amount of gonad development.

Like brown bullheads, the decrease in catch of yellow bullheads resulted 
mainly from deletion of beach station $T$ (influenced by Pigeon River) and station Y (undisturbed Pigeon Lake) from our sampling area in 1978. Twenty yellow bullhead were caught at these stations in 1977 .

At beach station S (influenced by Lake Michigan) much of the yellow bullhead habitat which typically consists of clear water with profuse aquatic vegetation (Trautman 1957) may have been temporarily eliminated by construction activities. Three yellow bullheads were caught at this station in 1977 and none in 1978. Absence of yellow bullheads from seine samples at station $S$ may be due in part to the change in location of this station toward Lake Michigan (see STUDY AREA).

Catch of yellow bullheads at beach station $V$ in 1978 ( $7 \mathrm{fish}$ ) was also lower than in 1977 (12 fish). No yellow bullheads were collected at 6-m station M (influenced by Lake Michigan) during either year.

During 197820 adult yellow bullheads (180-230 mm) were impinged during March, May and September (Appendix 9). Larger numbers (29) of yellow bullheads were removed from the traveling screens during January 1974-March 1975 (Consumers Power 1975).

Brown Bullhead--

The brown bullhead was the most common bullhead species collected in Pigeon Lake in the 1977 study (Jude et al. 1978). Only 6 brown bullheads however, were observed in our 1978 samples compared to 120 specimens collected in 1977. This drastic decline in catch was largely due to exclusion of beach station $\mathrm{T}$ (influenced by Pigeon River) and station $\mathrm{Y}$ (influenced by Pigeon River) from our sampling scheme. These areas were habitats most preferred for all bullhead species since they accounted for 105 of the total number of brown bullheads collected in 1977 .

Of the six brown bullheads collected in 1978, one was caught in a night gill net at openwater station M (influenced by Lake Michigan), one in a night seine haul at beach station $S$ (influenced by Lake Michigan) and four in night seine hauls at beach station V (undisturbed Pigeon Lake). In 1977, six brown bullheads were caught at beach station $V$, nine at station $M$ and none at station S. Decline of brown bullhead catches at station M in 1978 may be related to high water turbidity caused by construction activities in the area. In Lake Erie, this species occurs in great abundance only in clearer water (Trautman 1957). Causes of variations in brown bullhead catches at stations $\mathrm{V}$ and $\mathrm{S}$ are not known.

Four of the six brown bullheads collected were immature individuals, the smallest two ( 44 and $46 \mathrm{~mm}$ ) being seined in April and May, and the others (both $66 \mathrm{~mm}$ ) in April and June. Since brown bullhead spawning takes place in May and June in our study area (Jude et a1. 1978), all of these immature bullheads were probably yearlings. Both remaining bullheads were females measuring 312 and $365 \mathrm{~mm}$ respectively. The first had well developed ovaries and was caught in June and the other showed moderate gonad development and was caught in August. Brown bullheads were collected at 11.5 to $21.8 \mathrm{C}$. 
During 1978 more brown bullheads (225) were impinged than black bul1heads (136) or yellow bullheads (20) (Appendix 9). These data suggested that despite their relatively low abundance in 1978 field samples, brown bullheads remained the dominant bullhead species in Pigeon Lake as was found in 1977 (Jude et a1. 1978). Few brown bullheads (4) occurred in impingement samples during January 1974-March 1975 (Consumers Power 1975). Of the brown bullheads collected in 1978, almost half were adults $140-300 \mathrm{~mm}$; they were impinged during January, February, April, May, June and December (Appendix 8). Remaining brown bullheads ranged from 40 to $90 \mathrm{~mm}$ and were impinged during January, February, May and June. Comparison of the above size range to the length of yearlings collected in April, May and June (44, 46 and $66 \mathrm{~mm}$ ) in Pigeon Lake, indicated that these impinged brown bullheads were also yearlings. Based on age-length data reported by Carlander (1969), the 60-mm immature brown bullheads found in December samples may be YoY. More brown bullheads were impinged at night and dusk than during other diel periods (Appendix 8).

Golden Redhorse--

A 564-mm, 1200-g male golden redhorse was captured in a bottom gill net set at Pigeon Lake station M (influenced by Lake Michigan) in October 1977. Water temperature was $9.7 \mathrm{C}$ (Jude et al. 1978). This species spawns during April and May and is common to clear rivers and creeks (Pflieger 1975).

During 1978 five golden redhorses were collected; however, only one came from Pigeon Lake. A 603-mm, 2510-g female showing moderate ovary development was the only golden redhorse taken from Pigeon Lake. This fish was seined at night during June at beach station $\mathrm{V}$ (undisturbed Pigeon Lake) when water temperature was $18.0 \mathrm{C}$.

The four other golden redhorses were captured by bottom gill nets set at stations $\mathrm{A}(1.5 \mathrm{~m}-\mathrm{S})$ and $\mathrm{L}(6 \mathrm{~m}-\mathrm{N})$ in Lake Michigan. A male, $515 \mathrm{~mm}$ and $1520 \mathrm{~g}$, was captured in July during the night at station $\mathrm{L}$ when water temperature was $16.7 \mathrm{C}$. The remaining three fish were taken in September at 13.5 and $20.0 \mathrm{C}$. A male $(425 \mathrm{~mm}, 1125 \mathrm{~g})$ and a female $(636 \mathrm{~mm}, 3175 \mathrm{~g})$ were captured at night at station $\mathrm{A}$ and a female $(495 \mathrm{~mm}, 1925 \mathrm{~g})$, was taken at station L during the day.

A11 five fish were captured in water 13-20 C, well after their determined spawning time. Since all five were $425 \mathrm{~mm}$ or longer it may be assumed these were adults--all showed slight to moderate gonad development. These fish may have moved downstream and into Lake Michigan after spawning in the upper reaches of the Pigeon River.

\section{Burbot--}

Four burbot were caught during the 1978 sampling season, all by trawling in Lake Michigan (Appendix 6). Three were immature and one was a male with undeveloped gonads. During 1978, 121 burbot were impinged at the Campbell Plant. They were impinged during January, March, April and October. Impingement of burbot early in the year in addition to entrainment of burbot larvae in February and again in April, May and June suggest that burbot may 
use Lake Michigan in the vicinity of the Campbell Plant or Pigeon Lake as a spawning area. McCrimmon and Devitt (1954) report movement of burbot into rivers beneath the ice in winter, but believe that the primary spawning grounds for this species is an openlake habitat. Jude et al. (1975) documented spawning in the vicinity of the Cook Plant, southeastern Lake Michigan. More extensive winter sampling would have to be done to document the importance of Pigeon Lake as a spawning area for burbot.

Fathead Minnow--

The fathead minnow occurred infrequently in our collections near the Campbell Plant, with only four specimens captured during 1978. No fathead minnows were caught in 1977. One fathead minnow, $65 \mathrm{~mm}$, was seined at Lake Michigan beach station P (S reference) during August at $23.0 \mathrm{C}$. The other fathead minnows were seined at Pigeon Lake beach stations $S$ (influenced by Lake Michigan) and V (undisturbed Pigeon Lake) during April (36 and $71 \mathrm{~mm}$ ) and May $(48 \mathrm{~mm})$ at water temperatures of 9.0-17.0 C. Although fathead minnows are reported to be common in the Lake Michigan watershed (Becker 1976) and prefer a wide variety of lentic and lotic habitats throughout their range (Scott and Crossman 1973, Trautman 1957), their occurrence in our study area appears to be incidental.

\section{Grass Pickere1--}

Observations of grass pickerel during 1978 indicate that they are fairly common inhabitants of Pigeon Lake. The decline in number of grass pickerel caught during 1978 (4 caught) compared with 1977 (50 caught) was primarily due to deletion of sampling at stations $\mathrm{Y}$ and $\mathrm{T}$ (influenced by Pigeon River), which accounted for $80 \%$ of the grass pickerel caught during 1977. Four were captured during 1978, with many additional pickerel observed, but not collected, while electrofishing. One grass pickerel was caught during each of the following months: May $(140 \mathrm{~mm})$, June $(76 \mathrm{~mm})$, July $(170 \mathrm{~mm})$ and November $(124 \mathrm{~mm})$. Although specimens caught during July and November were seined at beach station S (influenced by Lake Michigan), observations made while electrofishing indicated that the preferred habitat of this species in Pigeon Lake may be near stations $\mathrm{V}$ and $\mathrm{X}$ (undisturbed Pigeon Lake), where the remaining two were seined. No grass pickerel were collected in Lake Michigan. The small sample size precluded the collection of meaningful pickerel food habit data during 1978, but Jude et al. (1978) indicated that grass pickerel in Pigeon Lake during 1977 had fed on yellow perch, lake chubsuckers, bluntnose minnows and golden shiners, and that in turn, grass pickerel were found in the stomachs of some northern pike. Thus, grass pickerel in Pigeon Lake function ecologically as both piscivorous predator and prey.

Estimated impingement of grass pickerel in 1978 was $45 \mathrm{fish}$. They ranged from 140 to $240 \mathrm{~mm}$ and were impinged in March (31), April (7) and June (7).

\section{Silver Redhorse--}

Twelve silver redhorses were collected from Lake Michigan during 1977, eight in bottom gill nets and four in seine hauls (Jude et al. 1978). In 1978 the number of silver redhorses captured decreased to four, all of which 
were taken in night bottom gill nets during September at Lake Michigan stations $A(1.5 \mathrm{~m}-\mathrm{S})$ and $\mathrm{B}(3 \mathrm{~m}-\mathrm{S})$. These four fish were all males showing slight to moderate development of the testes. All ranged in length from 442 to $546 \mathrm{~mm}$ and all were taken at 19.2-20.0 C. According to Pflieger (1975) this species is common in lakes and large rivers, often spawning in gravelly riffles in early April. Their appearance in the vicinity of the Campbell Plant was sporadic.

Mottled Sculpins--

In contrast to 1977 sampling (four caught) which indicated the presence of mottled sculpins in Lake Michigan near the Campbel1 Plant (Jude et a1. 1978), no mottled sculpins were collected at Lake Michigan stations during 1978. In Pigeon Lake during 1978, four mottled sculpins (65, 67, 81 and $100 \mathrm{~mm}$ ) were seined at beach station $\mathrm{S}$. Specimens were caught in October (three) and November (one) at $11.5 \mathrm{C}$ and $10.0 \mathrm{C}$ respectively. Of the four fish caught, two were male, and two were female; all had only slight gonad development. During 1977, due to difficulty by our personnel in distinguishing between this species and the slimy sculpin (Jude et al. 1978), it is possible that mottled sculpin was erroneously reported to occur at Lake Michigan 15- and 18-m stations. Deason (1939) indicated that mottled sculpins are probably confined to the inshore marginal areas and mouths of shallow tributaries; whereas, slimy sculpins inhabit areas from nearshore to $100 \mathrm{~m}$. Current construction of offshore intake/discharge structures by Consumers Power Company in Lake Michigan, may result in the colonization of these structures and associated riprap by mottled sculpins as has happened at Cook Nuclear Power plant intake structures (Jude et al. 1975).

During 1978, an estimated 22 mottled sculpin (70-100 mm) were impinged (Appendix 8, 9). All were impinged during April.

Quillback--

Four quillbacks were caught in Lake Michigan (two in July and one each during June and September); water temperatures ranged between 12.0 and $22.4 \mathrm{C}$. A 435-mm fish was seined at beach station Q (S discharge) and three fish (446-504 mm) were gillnetted; two at station B (3 m-S) and one at station A $(1.5 \mathrm{~m}-\mathrm{S})$. An estimated 173 quillback were impinged in 1978 during January to March. Fish ranged from 170 to $220 \mathrm{~mm}$.

Spawning for this species usually occurs in April and May (Scott and Crossman 1973; Becker 1976). Presence of well developed gonads in three quillbacks during June-July suggests a somewhat later spawning period in the study area. Observation of large numbers of YOY in the discharge canal in July suggests the possibility of quillback spawning there.

\section{Shorthead Redhorse--}

In 1977 , one male shorthead redhorse $(438 \mathrm{~mm}, 900 \mathrm{~g})$ was captured in a bottom gill net set at night at south transect station A ( $1.5 \mathrm{~m}-\mathrm{S})$ during August when water temperature was $12.5 \mathrm{C}$ (Jude et a1. 1978). During 1978 sampling, four shorthead redhorses were collected near the Campbell Plant. 
A female $(628 \mathrm{~mm}, 2540 \mathrm{~g})$ with moderately developed ovaries was taken in a night bottom gill net set at station $A$ in June. The water temperature was $12.3 \mathrm{C}$. The remaining three shorthead redhorses were collected in bottom gill nets set in Pigeon Lake at station M (influenced by Lake Michigan). One male $(420 \mathrm{~mm}, 910 \mathrm{~g})$ was gillnetted in June at night and a male (435 mm, $1000 \mathrm{~g})$ and a female $(545 \mathrm{~mm}, 1825 \mathrm{~g})$ were caught during the day in september. These fish were caught at 13.0 and $20.8 \mathrm{C}$ respectively. All possessed moderate to well developed gonads. According to Scott and Crossman (1973) these fish migrate from large bodies of water into small rivers or streams for spawning, which usually occurs from late April until late July. The male and female captured in June may have been involved in this type of migration.

\section{Channel Catfish--}

Gill net catches at station $\mathrm{C}(6 \mathrm{~m}-\mathrm{S})$ accounted for all three channel catfish captured during 1978. One 432-mm male channel catfish was collected in August (water temperature $21.3 \mathrm{C}$ ), while the 422-and 484-mm individuals (also males) were gillnetted in September (19.8 and $15.6 \mathrm{C}$ respectively Appendix 6). Of the seven channel catfish caught in 1977, five were males and all but one fish were taken in August (Jude et a1. 1978).

Movement of channel catfish into the study area during August-September was not related to spawning activities since spawning for this species normally occurs in late spring-early summer in water temperatures from 23.9 to $29.5 \mathrm{C}$ (Scott and Crossman 1973). A similar peak in channel catfish catch was also noted in the fall in the vicinity of the Cook Plant, southeastern Lake Michigan (Jude et al. 1979). Other species, such as gizzard shad and quillback were also involved in this migration. These fish are suspected to have migrated out of rivers (mainly the St. Joseph) in the fall. A similar migration may also be occurring from the Grand River near the Campbell Plant.

An estimated 100 channel catfish from $60-390 \mathrm{~mm}$ were impinged during winter and spring. No channel catfish were impinged during summer or fall, but observation during the summer of one 7000-g individual and several smaller adults in the plant's discharge canal indicated the existence of a resident population of channel catfish in this habitat.

\section{Creek Chub--}

A creek chub was first observed in the study area during April 1978 supplementary seine hauls in an area to the west of beach station $S$ in Pigeon Lake. We did not observe this species in Pigeon Lake during 1977. Creek chubs are widely distributed in the Lake Michigan basin with preferred habitat being creeks with sand and gravel bottoms and moderate to rapid-flowing water (Becker 1976). Other authors indicate that the creek chub occasionally inhabits shore waters of smal1 lakes (Scott and Crossman 1973). Standard sampling in July 1978 indicated that some creek chubs were present at beach station V (undisturbed Pigeon Lake), since three specimens (70, 86 and $88 \mathrm{~mm}$ ) were caught in day seine hauls when water temperature was $21 \mathrm{C}$. Its absence from all other samples indicates that creek chubs are probably not common in Pigeon Lake; however, an estimated 28 fish were impinged during 1978. They ranged from 90 to $210 \mathrm{~mm}$ and were impinged during April-June. 
Black Bullhead--

Like other bullhead species, (see RESULTS AND DISCUSSION - ADULT AND JUVENILE FISH, Brown and Yellow Bullhead), black bullheads were collected in much smaller numbers in 1978 than in 1977. Seventeen black bullheads were caught in 1977 as compared with only two black bullheads (a 60-mm, age-group-1 immature fish and a 300-mm spent male) collected in 1978. Both 1978 black bullheads were caught in night seine hauls at beach station $V$ (undisturbed Pigeon Lake), the first in May and the second in July (Appendix 6).

The decline in black bullhead catch observed in 1978 was probably caused by the reduction of sampling stations at the western part of Pigeon Lake, disturbance of the bottom by construction activities at station M (influenced by Lake Michigan) and displacement of station S (influenced by Lake Michigan) toward Lake Michigan (see STUDY AREA). Sampling at beach station $\mathrm{T}$ (influenced by Pigeon River) and station $Y$ (influenced by Pigeon River) which were not sampled in 1978, contributed 12 of the 17 bullheads caught in 1977 (see Jude et al. 1978). No black bullheads were caught at stations $S$ and $M$ where five specimens were collected in 1977.

Black bullheads were reported to spawn in May-June in Illinois and in June-July in Wisconsin (Breder and Rosen 1966). Occurrence of a spent male in July suggested spawning also took place in June or July in our study area. The immature black bullhead in our collection was caught at a water temperature of $9.8 \mathrm{C}$ and the adult at $20.8 \mathrm{C}$.

Impingement sampling during 1978 resulted in the collection of $19 \mathrm{black}$ bullheads of which 9 were collected during April, 4 during May, 3 during June and 3 during December. Estimated total for the year was 136 impinged fish. of the three black bullheads sampled in December, two were adults, both $180 \mathrm{~mm}$ and the other was a $100-\mathrm{mm}$ yearling. The remaining 16 black bullheads included 15 yearlings $70-120 \mathrm{~mm}$ and 11 adults $140-180 \mathrm{~mm}$. Of the 13 adults, 1 showed ripe-running gonads and the rest had slightly and moderately developed gonads. Most black bullheads (68\%) were impinged at dusk and night confirming the nocturnal habit of this species.

Although black bullheads appeared to be less common than yellow bullheads in Pigeon Lake during 1977 (Jude et a1. 1978) and 1978 (Table 14), more black bullheads (136) were found in 1978 impingement samples than yellow bullheads (20).

\section{Common Shiner--}

The common shiner is common to abundant throughout the Lake Michigan basin (Becker 1976). Two specimens (93 and $100 \mathrm{~mm}$ ) were collected in Pigeon Lake during 1978; one each was seined at beach stations S (influenced by Lake Michigan) and V (undisturbed Pigeon Lake). None were collected during 1977. Only two common shiners were observed in impingement samples during the period January 1974 to March 1975 at the Campbell Plant (Consumers Power Company 1975). No common shiners were impinged during 1977 or 1978.

Goldfish--

The goldfish is an east Asian species which has become widely introduced 
into the aquatic systems of the United States (Scott and Crossman 1973). This species has become abundant in shallow, heavily vegetated, warm-water areas of the Great Lakes region such as Lake Erie (Trautman 1957), Lake St. Clair and the Detroit River (Scott and Crossman 1973).

Two goldfish were collected during 1978, both in seines. A 285-mm adult female was taken at station V (undisturbed Pigeon Lake) in April at a water temperature of $19.0 \mathrm{C}$ and an immature at Lake Michigan beach station Q (S discharge). The 1977 catch of goldfish consisted of two YOY seined at Pigeon Lake station $\mathrm{S}$ (influenced by Lake Michigan) during August (Jude et al. 1978). A few goldfish were also seen during electrofishing activities in Pigeon Lake in both 1977 and 1978.

The immature, 73-mm goldfish captured at station $Q$ may have originated from a population of goldfish suspected to inhabit the warm water of the discharge canal. It should also be noted that no goldfish were collected in impingement samples during 1978; however, eight goldfish ranging in size from 60 to $80 \mathrm{~mm}$ were impinged in 1977 (Zeitoun et al. 1978).

\section{Sand Shiner--}

The sand shiner is found in tributary streams close to Lake Michigan in upper Michigan and occasionally in lakes and along the shores of Lake Michigan. Two sand shiners ( 49 and $51 \mathrm{~mm}$ ) were seined in Pigeon Lake at station S (influenced by Lake Michigan), one each in September and October when water temperatures were 19.0 and $11.5 \mathrm{C}$. Approximately 10 sand shiners were also caught during May 1979.

Warmouth--

Jude et al. (1978) reported a small resident population of warmouth in Pigeon Lake based on six specimens collected in 1977. Fewer warmouths (two) were caught this year, due in part to the elimination of stations $\mathrm{T}$ and $\mathrm{Y}$ (influenced by Pigeon River) from the 1978 sampling scheme. These stations most closely resemble the warmouth's preferred habitat described by Becker (1976), since three of the six warmouth caught in 1977 came from stations $\mathrm{T}$ and $\mathrm{Y}$.

During May 1978, one female $(178 \mathrm{~mm})$ with spent ovaries was seined at station V (undisturbed Pigeon Lake) during the day. The capture date (May 17), is within the spawning season reported by Pflieger (1975). When conspecific mates are not available, warmouth may successfully hybridize with other sunfishes, especially bluegill and pumpkinseed (Scott and Crossman 1973).

An immature warmouth $(65 \mathrm{~mm})$ was collected in July. It was caught in a night seine at station S (influenced by Lake Michigan) when water temperature was $15 \mathrm{C}$. A 200-mm male warmouth was taken from a 24-h impingement sample in December. This was the only warmouth collected in 1978 impingement samples.

Iowa Darter--

Iowa darters are inhabitants of clear, standing or slowly moving water 
of lakes or rivers having rooted aquatic vegetation and a bottom of organic debris, sand, peat or a composite of these (Scott and Crossman 1973). This species is well distributed throughout the Lake Michigan basin and is locally common to uncommon (Becker 1976). One specimen (47 mm, $0.8 \mathrm{~g})$ was seined at Pigeon Lake beach station S (influenced by Lake Michigan) during April at a water temperature of $8.5 \mathrm{C}$. This species was not collected during 1977 and is apparently rare in the area near the Campbell Plant.

Lake Chubsucker--

The lake chubsucker usually inhabits areas of lakes and rivers with submerged aquatic vegetation and substrates of sand or fine grave1 (Trautman 1957). Such areas are common to the eastern portion of Pigeon Lake.

Although only one specimen was collected from Pigeon Lake in 1978, many individuals were seen during electrofishing throughout the year. In 1977, 46 chubsuckers were taken by seine at beach stations in Pigeon Lake (Jude et a1. 1978), 43 of those were captured at station $\mathrm{T}$ (influenced by Pigeon River). During 1978 station $\mathrm{T}$ was eliminated from our sampling regime obviously accounting for the decrease in numbers of lake chubsuckers collected.

The lake chubsucker collected in 1978 was taken in a bottom gill net set at station M (influenced by Lake Michigan) during the day in mid-May at a water temperature of $9.5 \mathrm{C}$. This $130-\mathrm{mm}$ female possessed well developed ovaries. Two other large lake chubsuckers, (130-140 mm), one identified as a female with well developed ovaries, were taken from 24-h impingement samples on May 16. Spawning for this species may take place from March to early July (Scott and Crossman 1973); therefore, capture of the two females so far from areas they usually inhabit may have been due to spawning or related movements.

\section{Freshwater Drum--}

One freshwater drum was caught in a night gill net at station $\mathrm{L}(6 \mathrm{~m}-\mathrm{N})$ in september 1978. This fish was $460 \mathrm{~mm}$ and $1675 \mathrm{~g}$ (Appendix 6) and would be over 10-yr old according to age-at-length estimations listed in Scott and Crossman (1973). One drum $(270 \mathrm{~mm})$ was observed in a 24-h impingement sample from December. Although no freshwater drum were collected during our 1977 sampling (Jude et a1. 1978), a drum caught by hook and line near station X (undisturbed Pigeon Lake) in August 1978 provides additional evidence that at least a small population of this species exists in the study area. Freshwater drum are documented as ranging throughout the Mississippi drainage basin and are found in all of the Great Lakes except Lake Superior (Scott and Crossman 1973).

\section{Central Mudminnow--}

One central mudminnow ( $60 \mathrm{~m}, 2.5 \mathrm{~g}$ ) was caught during 1978 in Pigeon Lake. This specimen, a female with ripe-running ovaries, was seined at beach station $\mathrm{V}$ (undisturbed Pigeon Lake) in May. Water temperature at time of capture was $11.0 \mathrm{C}$. The mudminnow inhabits shallow, densely vegetated areas in lakes and the margins of streams (Peckham and Dineen 1947), but does not appear to be abundant in the area near the Campbell Plant. None were observed in 1977. 
White Crappie--

We caught only one immature white crappie (105 mm) in June 1978 in a seine haul at beach station $\mathrm{V}$ (undisturbed Pigeon Lake). Water temperature on the night of capture was $18 \mathrm{C}$. No white crappie were caught in 1977 . The white crappie is a near relative to the more abundant and widely distributed black crappie. Hybridization occurs between the two species (Scott and Crossman 1973) and it may be that the substantial black crappie population documented in the study area both this year (see RESULTS AND DISCUSSION ADULT AND JUVENILE FISH, Black Crappie) and last (Jude et al. 1978) dominated the less abundant white crappie population.

\section{Blackside Darter--}

In the Lake Michigan basin the blackside darter is at the northern limits of its range (Becker 1976). One immature blackside darter (29 mm, $0.3 \mathrm{~g}$ ) was seined during July from Pigeon Lake at Lake Michigan influenced station $S$. This species is uncommon in Pigeon Lake, this being the first occurrence in the study area. However, SCUBA observations in the Pigeon River, less than $1 \mathrm{~km}$ from station $\mathrm{T}$, revealed the presence of considerable numbers of this species.

Logperch--

One logperch, impinged during February of 1974, was the only logperch collected in impingement sampling conducted from January 1974 to March 1975 (Consumers Power Company 1975). During 1977, a 100-mm logperch was collected in an October impingement sample (Zeitoun et a1. 1978) while 50 logperch were estimated impinged in 1978. Of the seven logperch examined from impingement samples in 1978, one 100-mm male collected on 19 April had well developed testes and a $111-\mathrm{mm}$ male taken on 16 May showed only slight development of the testes. A 92-mm female collected on 11 April possessed ovaries showing only moderate development. The four other logperch examined (sex undetermined) ranged in size from 92 to $124 \mathrm{~mm}$.

Two logperch, collected in standard series sampling near the Cook Plant in 1975, were the only ones caught during 6 yr of sampling (1973-1978) in that area (Jude et a1. 1979).

Logperch were not collected in field sampling efforts near the J. H. Campbell Plant during either 1977 or 1978; however, logperch were observed in rocky areas of the intake jetties during diving operations in June 1978. According to Scott and Crossman (1973) this species may remain just off shore at $1-1.3 \mathrm{~m}$ (transition zone) or deeper until ready to spawn. Spawning usually takes place in June in sandy inshore areas. There may be several reasons for the absence of logperch in our field samples. Logperch may live just beyond seining depths or more likely they are rare in the study area. A single larval logperch occurred in a night plankton net tow at $6 \mathrm{~m}$ at station $\mathrm{F}(12 \mathrm{~m}-\mathrm{S})$ on 1 July 1978 when water temperature was $17.9 \mathrm{C}$.

Pirate Perch-- 
Pirate perch is an uncommon species in the study area. One 72-mm male was seined at beach station $T$ (influenced by Pigeon River) during 1977. Numerous pirate perch were observed near beach station $\mathrm{T}$ and open-water station $\mathrm{Y}$ (undisturbed Pigeon Lake) during electrofishing operations in both 1977 and 1978.

Five pirate perch were impinged during February, April, May and December in 1974 while 12 were observed during January, February and March 1975 (Consumers Power Company, 1975). No pirate perch were impinged during the 1977 June through December sampling (Zeitoun et al. 1978). In 1978, however, pirate perch again appeared in impingement samples. Two of the three fish impinged were females ( 81 and $83 \mathrm{~mm}$ ) with well developed ovaries and the other was a 101-mm male exhibiting well developed testes. All three were impinged during April and May resulting in an estimated impingement loss of $21 \mathrm{fish}$ for 1978. Pirate perch between 63 and $114 \mathrm{~mm}$ were stated by Pflieger (1975) to be adults which would spawn during May in Missouri. The individuals impinged during our study were perhaps caught during spawning related activities.

Sea Lamprey--

Four sea lampreys were impinged between January 1974 and March 1975 (Consumers Power Company 1975). They were collected during April and May 1974 and during February 1975. One sea lamprey, $460 \mathrm{~mm}$ and $230 \mathrm{~g}$, was observed in impingement samples on 14 October 1977 (Zeitoun et a1. 1978).

In 1978, two sea lamprey $(430 \mathrm{~mm}$ and $510 \mathrm{~mm})$ were collected in 24-h impingement samples. The $510-\mathrm{mm}$ specimen was determined to be a female with slightly developed ovaries.

Chestnut Lamprey--

Three chestnut lampreys were impinged between January 1974 and March 1975 (Consumers Power Company 1975). They were impinged in May and June 1974 and March 1975. In 1978 one chestnut lamprey (157 mm) was collected in a 24-h, April impingement sample. This species appears to be rare in the vicinity of the Campbe11 Plant.

Spotted Gar--

A 725-mm spotted gar was collected in a dawn impingement sample on 26 April 1978. This female, which possessed well developed ovaries, was the first spotted gar collected in the vicinity of the Campbell Plant (Consumers Power Company 1975, Jude et a1. 1978, Zeitoun et al. 1978), although gar were observed during 1977 sampling (Jude et al. 1978). Spotted gar appear to be rare in the Campbell Plant vicinity.

Green Sunfish--

Although no green sunfish were caught in adult sampling gear in 1978, an estimated 46 were impinged. Evidently green sunfsih are uncommon in the study area since they were absent from 1977 field and impingement samples (Jude et a1. 1978). Estimated impingement of green sunfish occurred in March (7), 
May (12), August (6), October (6) and December (15). Lengths of specimens collected ranged from 70 to $150 \mathrm{~mm}$. Green sunfish are slow growing fish which may hybridize with several other species of sunfish (Scott and Crossman 1973).

\section{IMPINGEMENT}

Introduction

Impingement of fish is an unavoidable result of using water inhabited by fish for once-through cooling and other domestic and industrial purposes (Sharma and Freeman 1977). Section 316 (b) of Pub1ic Law 92-500 requires that location, construction, design and capacity of cooling water intake structures reflect the best technology available for minimizing adverse environmental impact. This report presents results of an impingement study at the J. H. Campbel1 Plant Units 1 and 2 from 1 January 1978 through 31 December 1978. The objectives of this study were to document the magnitude of impingement and examine the seasonal and diel patterns and possible explanations for their existence. These data can then be used to assist in any mitigative action, should that be deemed necessary. The effect of impingement on the fish communities of Lake Michigan and Pigeon Lake in the vicinity of the plant was discussed under each individual species (see RESULTS AND DISCUSSION ADULT AND JUVENILE FISH.

Monthly Impingement Results

January--

Impingement in January was marked by an abundance of alewife and gizzard shad (Table 58). These two species accounted for $94 \%$ numerically of all fish collected in impingement samples this month. Field data collected from Pigeon Lake during October and November 1978 and data collected in 1977 (Jude et al. 1978) are distinguished by the absence of gizzard shad and very low numbers of alewife (one caught per month). These data suggest impinged fish came from somewhere other than Pigeon Lake. During colder months, discharge water is recirculated back into the intake forebay through a gate connecting intake and discharge canals. Opening this gate allows fish present in the discharge canal access to the intake forebay, making them susceptible to impingement. We concluded that alewife and gizzard shad and possibly other species impinged in January originated from the discharge canal and gained access to the intake forebay via the open gate.

Estimated total impingement for the month based on four 24-h samples was 11,439 alewives (total weight $113.05 \mathrm{~kg}$ ) and 7339 gizzard shad $(162.6 \mathrm{~kg}$ ). Other species of importance were trout-perch (434) and spottail shiners (317). Seventeen other species were also impinged.

February--

Gizzard shad accounted for $96 \%$ of the number of fish impinged in February. As in January, these fish are believed to have entered the intake forebay via 
Table 58. Total number of fish impinged during 1978 at the J. H. Campbell Plant, eastern Lake Michigan. Numbers were extrapolated to monthly totals based on one 24-h impingement sample collected each week. See Table 12 for species code definitions.

\begin{tabular}{|c|c|c|c|c|c|c|c|c|c|c|c|c|c|}
\hline \multirow[b]{2}{*}{ Species } & \multicolumn{12}{|c|}{ MONTH } & \multirow[b]{2}{*}{ Total } \\
\hline & Jan & Feb & Mar & Apr & May & Jun & Jul & Aug & Sep & Oct & Nov & $\overline{\mathrm{Dec}}$ & \\
\hline SP & 317 & 16 & 441 & 1680 & 601 & 697 & 550 & 49 & 60 & 86 & 502 & 674 & 5673 \\
\hline $\mathrm{AL}$ & 11439 & 44 & 1030 & 22 & 638 & 14490 & 13523 & 737 & 1852 & 539 & 1207 & 201 & 45722 \\
\hline SM & 69 & 5 & 0 & 202 & 186 & 45 & 155 & 322 & 45 & 198 & 37 & 69 & 1333 \\
\hline YP & 31 & 5 & 480 & 487 & 186 & 45 & 31 & 43 & 22 & 6 & 67 & 116 & 1519 \\
\hline $\mathrm{TP}$ & 434 & 16 & 62 & 37 & 55 & 30 & 7 & 68 & 0 & 80 & 277 & 217 & 1283 \\
\hline GS & 7339 & 4760 & 18561 & 195 & 0 & 7 & 0 & 1866 & 1807 & 2982 & 7342 & 29868 & 747.27 \\
\hline LB & 54 & 5 & 23 & 37 & 6 & 7 & 7 & 31 & 397 & 514 & 562 & 1418 & 3061 \\
\hline BR & 62 & 0 & 31 & 22 & 0 & 0 & 0 & 0 & 0 & 6 & 0 & 0 & 121 \\
\hline $\mathrm{RB}$ & 7 & 0 & 0 & 0 & 0 & 0 & 0 & 0 & 7 & 0 & 0 & 7 & 21 \\
\hline LP & 15 & 0 & 7 & 22 & 6 & 0 & 0 & 0 & 0 & 0 & 0 & 0 & 50 \\
\hline MT & 7 & 5 & 7 & 0 & 6 & 7 & 7 & 0 & 0 & 6 & 0 & 0 & 45 \\
\hline $\mathrm{BN}$ & 46 & 11 & 0 & 45 & 93 & 15 & 0 & 0 & 0 & 0 & 0 & 15 & 225 \\
\hline SB & 0 & 11 & 15 & 0 & 0 & 0 & 0 & 0 & 15 & 0 & 0 & 0 & 41 \\
\hline WS & 0 & 0 & 54 & 67 & 18 & 15 & 7 & 0 & 0 & 0 & 7 & 31 & 199 \\
\hline $\mathrm{CM}$ & 0 & 0 & 15 & 7 & 6 & 82 & 224 & 0 & 0 & 0 & 0 & 0 & 334 \\
\hline ES & 7 & 5 & 0 & 15 & 0 & 0 & 0 & 0 & 7 & 31 & 0 & 7 & 72 \\
\hline $\mathrm{CP}$ & 7 & 0 & 0 & 0 & 6 & 0 & 0 & 6 & 0 & 6 & 0 & 0 & 25 \\
\hline BT & 23 & 0 & 0 & 22 & 6 & 7 & 0 & 6 & 0 & 0 & 0 & 0 & 64 \\
\hline sS & 7 & 0 & 7 & 30 & 0 & 7 & 0 & 0 & 0 & 0 & 0 & 15 & 66 \\
\hline $\mathrm{CC}$ & 31 & 11 & 0 & 15 & 12 & 0 & 0 & 0 & 0 & 0 & 0 & 31 & 100 \\
\hline QL & 15 & 50 & 108 & 0 & 0 & 0 & 0 & 0 & 0 & 0 & 0 & 0 & 173 \\
\hline $\mathrm{CH}$ & 0 & 0 & 0 & 7 & 6 & 105 & 7 & 12 & 0 & 6 & 0 & 0 & 143 \\
\hline PS & 23 & 0 & 0 & 30 & 24 & 0 & 0 & 0 & 15 & 0 & 0 & 23 & 115 \\
\hline $\mathrm{BC}$ & 23 & 16 & 7 & 45 & 18 & 0 & 31 & 6 & 0 & 37 & 37 & 186 & 406 \\
\hline BG & 7 & 5 & 7 & 15 & 37 & 7 & 0 & 6 & 7 & 55 & 22 & 15 & 183 \\
\hline NS & 0 & 0 & 7 & 255 & 55 & 7 & 7 & 0 & 0 & 0 & 0 & 0 & 331 \\
\hline NP & 0 & 0 & 15 & 7 & 6 & 0 & 7 & 18 & 15 & 0 & 0 & 0 & 68 \\
\hline GN & 0 & 0 & 7 & 0 & 12 & 0 & 0 & 6 & 0 & 6 & 0 & 15 & 46 \\
\hline $\mathrm{BF}$ & 0 & 0 & 7 & 7 & 0 & 0 & 7 & 6 & 0 & 0 & 0 & 0 & 27 \\
\hline GP & 0 & 0 & 31 & 7 & 0 & 7 & 0 & 0 & 0 & 0 & 0 & 0 & 45 \\
\hline YB & 0 & 0 & 7 & 0 & 6 & 0 & 0 & 0 & 7 & 0 & 0 & 0 & 20 \\
\hline MS & 0 & 0 & 0 & 22 & 0 & 0 & 0 & 0 & 0 & 0 & 0 & 0 & 22 \\
\hline BB & 0 & 0 & 0 & 67 & 24 & 22 & 0 & 0 & 0 & 0 & 0 & 23 & 136 \\
\hline $\mathrm{CL}$ & 0 & 0 & 0 & 7 & 0 & 0 & 0 & 0 & 0 & 0 & 0 & 0 & 7 \\
\hline PP & 0 & 0 & 0 & 7 & 0 & 0 & 0 & 0 & 0 & 0 & 0 & 0 & 7 \\
\hline GL & 0 & 0 & 0 & 7 & 0 & 0 & 0 & 0 & 7 & 0 & 0 & 7 & 21 \\
\hline $\mathrm{CR}$ & 0 & 0 & 0 & 15 & 6 & 7 & 0 & 0 & 0 & 0 & 0 & 0 & 28 \\
\hline SL & 0 & 0 & 0 & 15 & 0 & 0 & 0 & 0 & 0 & 0 & 0 & 0 & 15 \\
\hline PR & 0 & 0 & 0 & 15 & 6 & 0 & 0 & 0 & 0 & 0 & 0 & 0 & 21 \\
\hline WM & 0 & 0 & 0 & 0 & 0 & 0 & 0 & 0 & 0 & 0 & 0 & 7 & 7 \\
\hline LS & 0 & 0 & 0 & 0 & 6 & 0 & 0 & 0 & 0 & 0 & 0 & 0 & 6 \\
\hline ER & 0 & 0 & 0 & 0 & 12 & 0 & 0 & 0 & 0 & 0 & 0 & 0 & $\times 12$ \\
\hline $\mathrm{RT}$ & 0 & 0 & 0 & 0 & 0 & 0 & 0 & 6 & 7 & 0 & 0 & 0 & 13 \\
\hline $\mathrm{XC}$ & 0 & 0 & 0 & 0 & 0 & 0 & 0 & 0. & 7 & 55 & 7 & 0 & 69 \\
\hline BM & 0 & 0 & 0 & 0 & 0 & 0 & 0 & 0 & 0 & 6 & 0 & 0 & 6 \\
\hline LT & 0 & 0 & 0 & 0 & 0 & 0 & 0 & 0 & 0 & 0 & 7 & 0 & 7 \\
\hline WL & 0 & 0 & 0 & 0 & 0 & 0 & 0 & 0 & 0 & 0 & 22 & 93 & 115 \\
\hline FD & 0 & 0 & 0 & 0 & 0 & 0 & 0 & 0 & 0 & 0 & 0 & 7 & 7 \\
\hline Total & 19963 & 4965 & 20929 & 3433 & 2043 & 15609 & 14570 & 3188 & 4277 & 4619 & 10096 & 33045 & 136737 \\
\hline
\end{tabular}


the discharge canal and were subsequently impinged. Estimated total number of gizzard shad impinged during February was 4760 (total weight $112.87 \mathrm{~kg}$ ). Estimated total monthly impingement for other major species collected was 205 fish (Table 58).

March--

Impingement samples in March were again dominated by gizzard shad, which numerically accounted for $89 \%$ of the fish collected. The monthly estimate of total impingement was 18,561 gizzard shad (total weight $476.21 \mathrm{~kg}$ ). Alewives, yellow perch and spottail shiners were present in moderate numbers in 24-h impingement samples $(113,62,57$, respectively) yielding estimated monthly totals (Table 58) of 1030,480 and $441 \mathrm{fish}$ with corresponding total weights of $17.78,16.55$ and $5.29 \mathrm{~kg}$.

Apri1--

By April, the connecting gate between the discharge canal and the intake forebay had been closed. Impingement of gizzard shad dropped sharply, since only 26 fish were collected. The species impinged most of ten was spottail shiner with 224 fish collected, mostly adults 75-135 mm (Fig. 88), resulting in an estimated monthly total of 1680 spottails (total weight $18.31 \mathrm{~kg}$ - Tables 58 and 59). Yellow perch were impinged in the next highest numbers, $65 \mathrm{fish}$ giving an estimated monthly total of $487 \mathrm{fish}$ (tota1 weight $8.38 \mathrm{~kg}$ ). Yellow perch collected ranged from 55 to $204 \mathrm{~mm}$ with most individuals probably yearlings 75-104 mm. Thirty-four ninespine sticklebacks were collected during April in impingement samples. Field sampling in Pigeon Lake during this month resulted in 19 ninespine sticklebacks being collected, the second highest number caught during the year. They undoubtedly moved into Pigeon Lake to spawn.

May--

May had the lowest monthly impingement total (2043) for the entire year. Alewives and spottail shiners were the most numerous species collected in 24-h impingement samples (103 and $97 \mathrm{fish}$, respectively) while yellow perch and rainbow smelt were taken in moderate numbers (30 fish each).

Most alewives taken were large individua1s (150-205 mm) which had probably moved into Pigeon Lake to spawn. Although no alewives were caught during May in Pigeon Lake moderate numbers of $150-205-\mathrm{mm}$ fish were caught in Lake Michigan.

June--

Adult alewives (150-210 mm) (93\% of the total catch) were the most abundant species collected in impingement samples during June (Fig. 89). The monthly estimate for total alewife impingement was 14,490 fish (total weight $500.44 \mathrm{~kg}$ ). Spottail shiners were the only other species observed in any number in 24-h impingement samples (93 fish). Total monthly impingement of spottail shiners was estimated at $697 \mathrm{fish}$. 


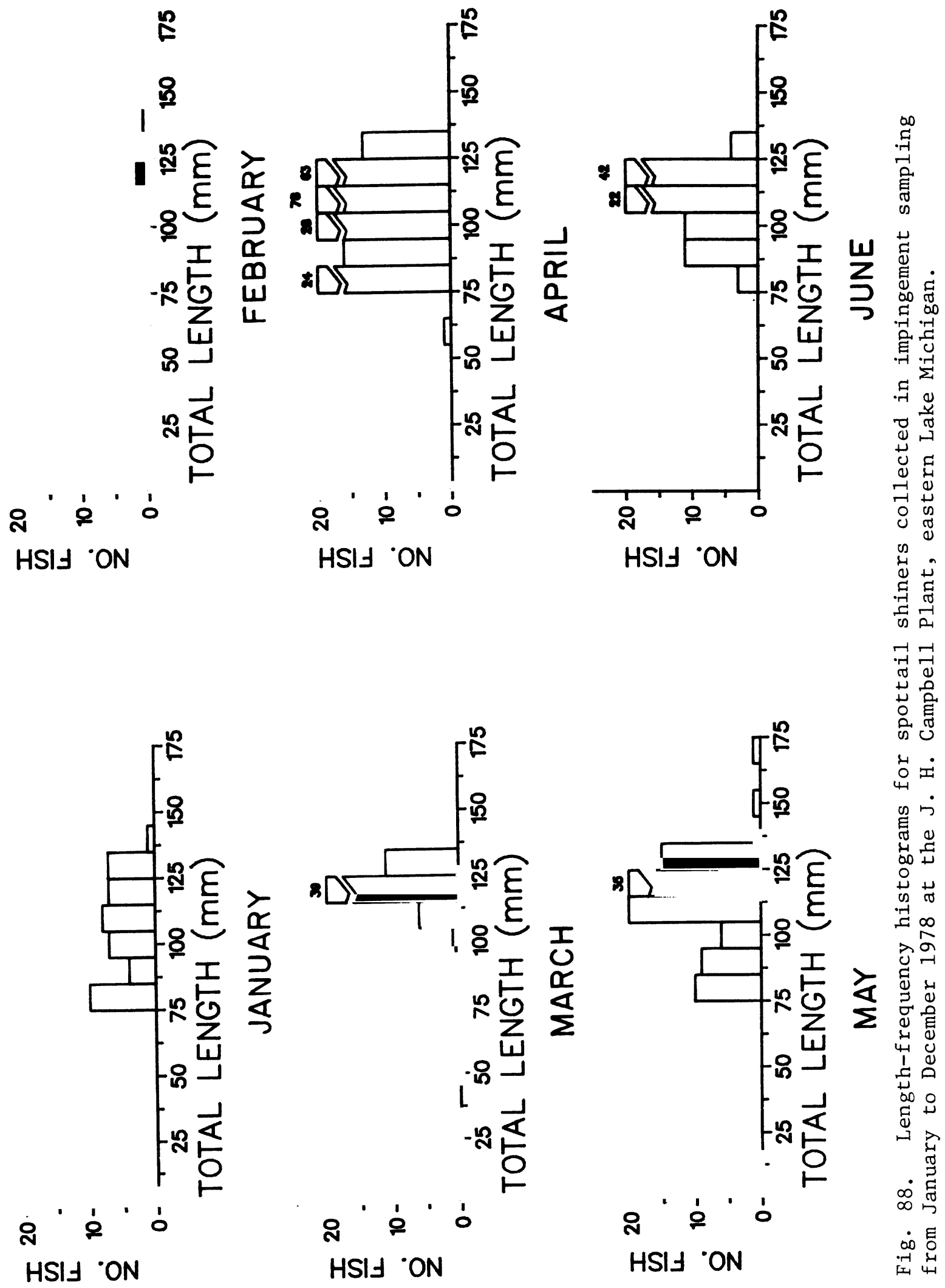




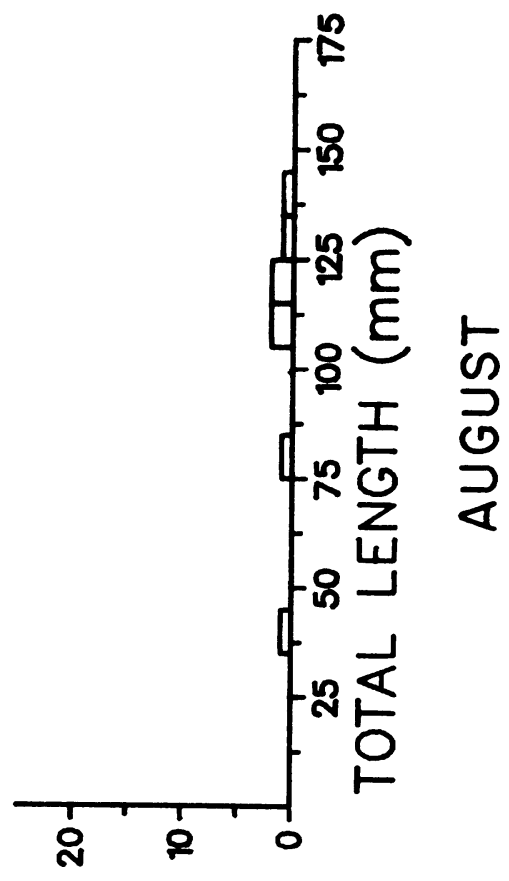

HSIS ON

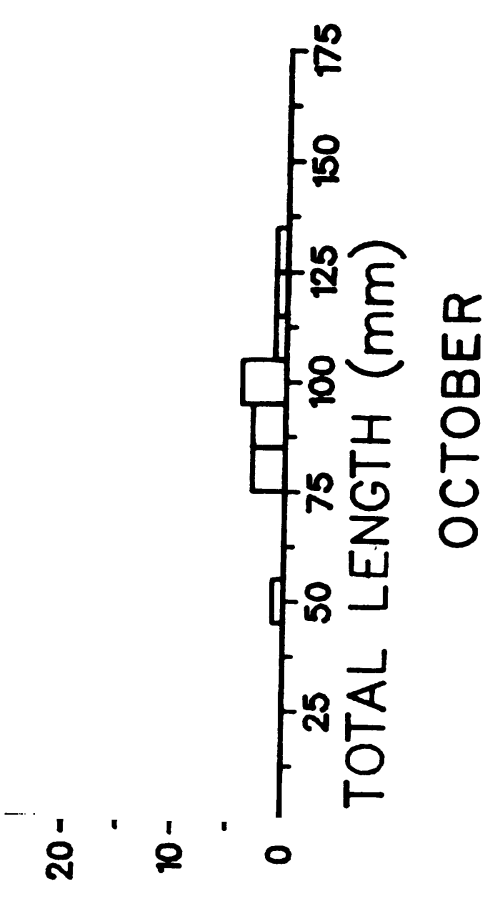

HSIJ_ON

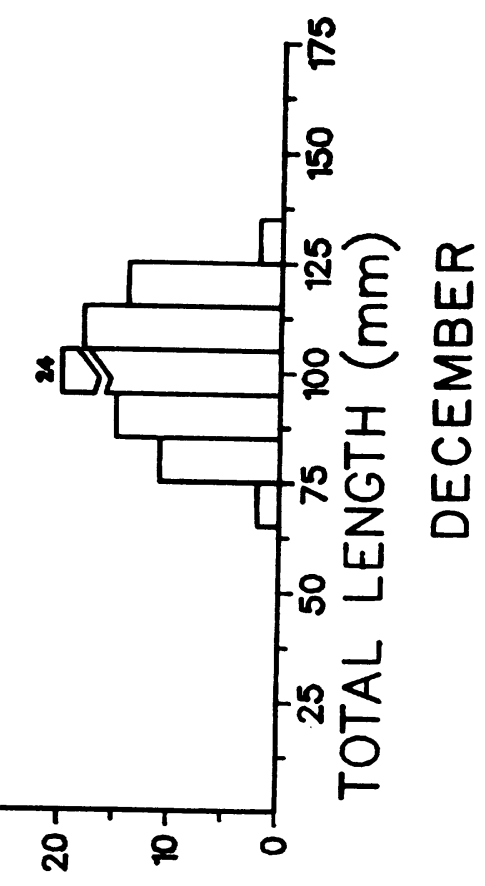

HSIJ $\mathrm{ON}$

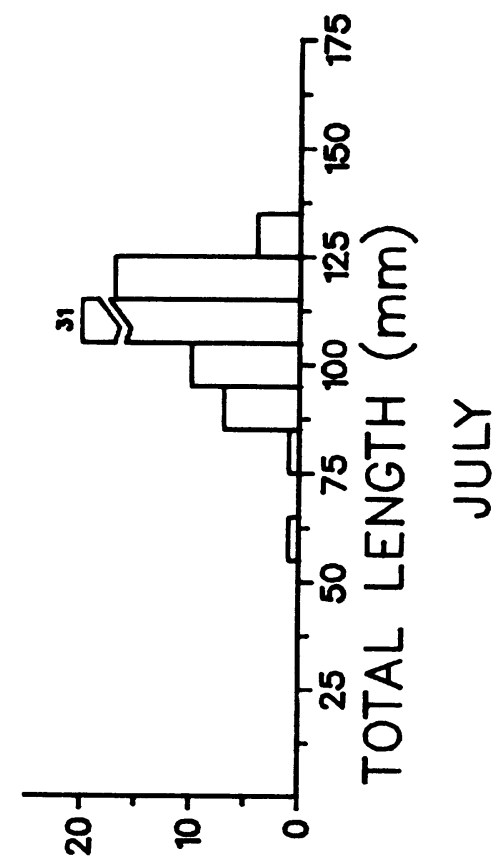

HSIJ $\mathrm{ON}$

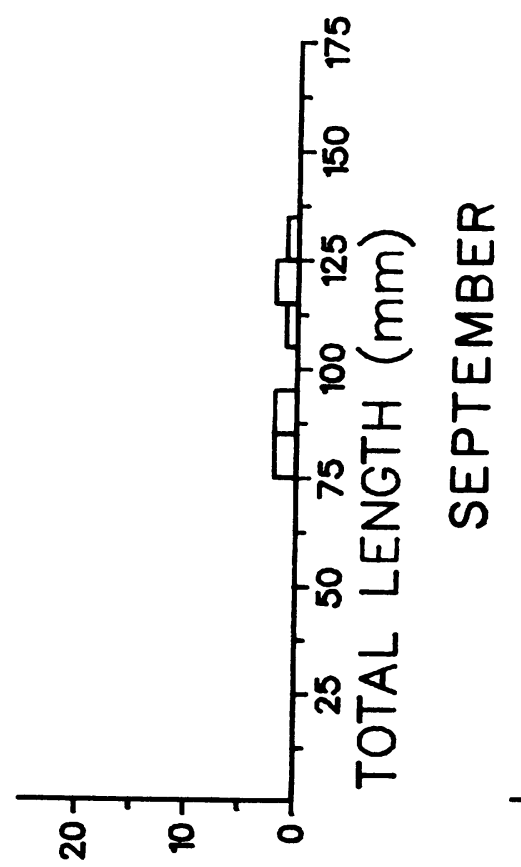

HSIJ ${ }^{\circ} \mathrm{ON}$

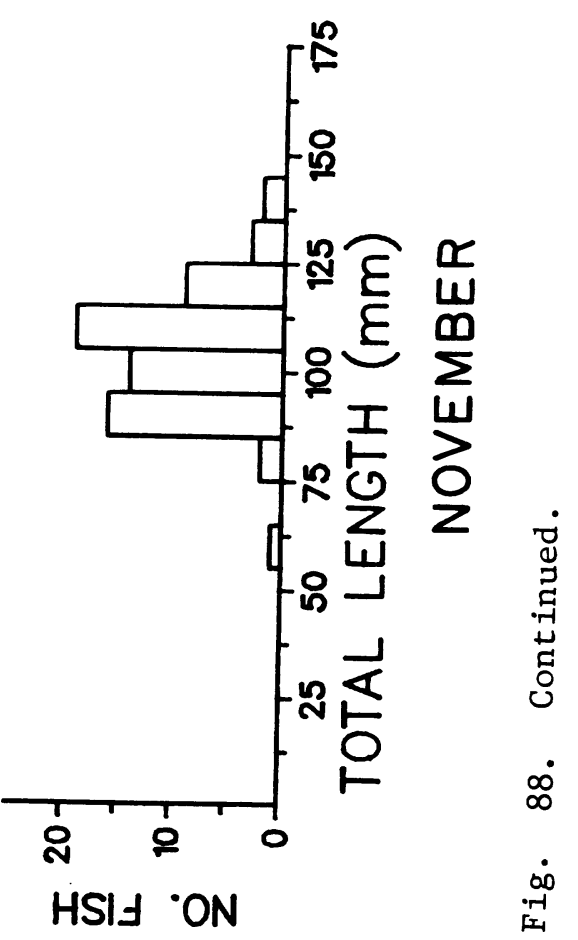




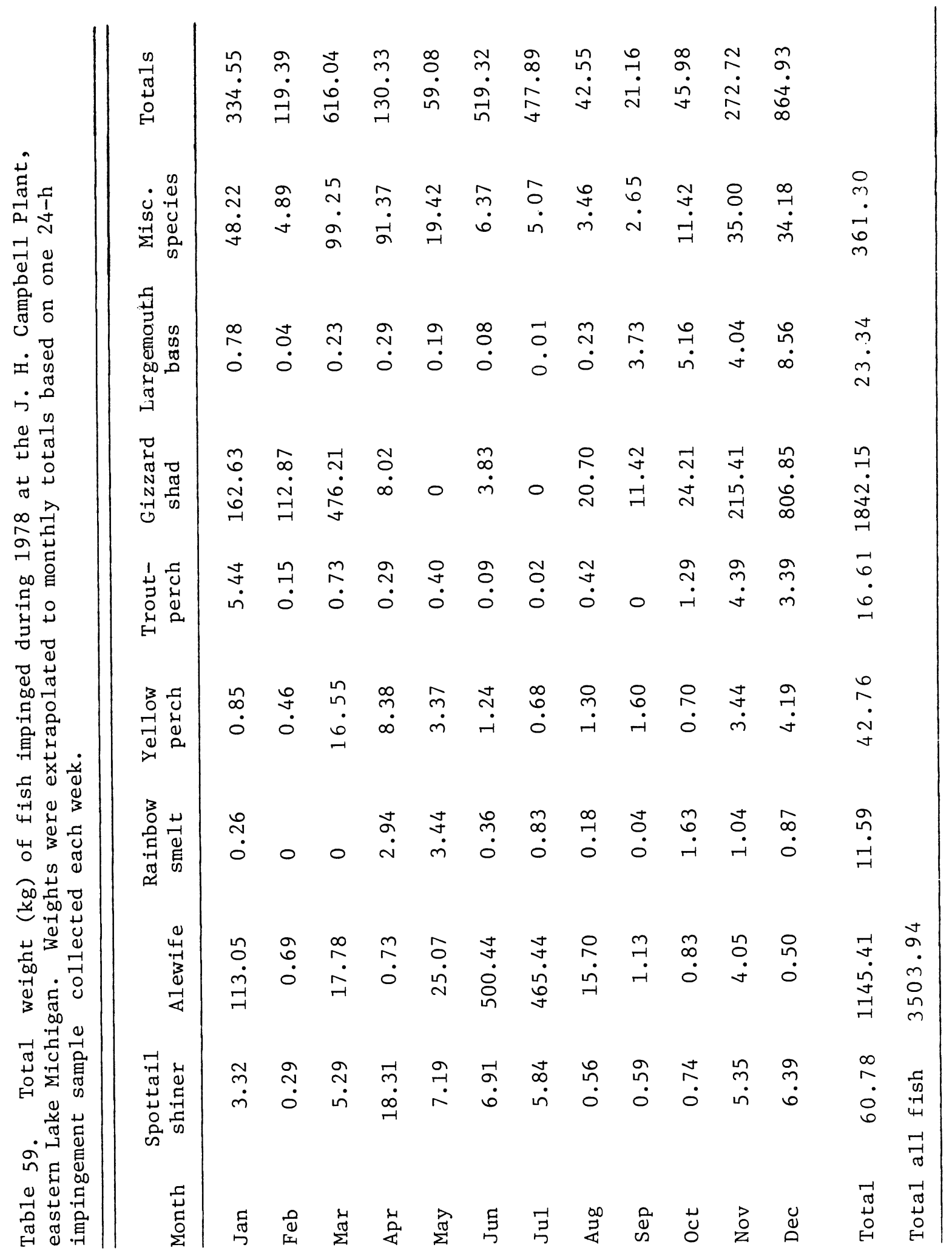



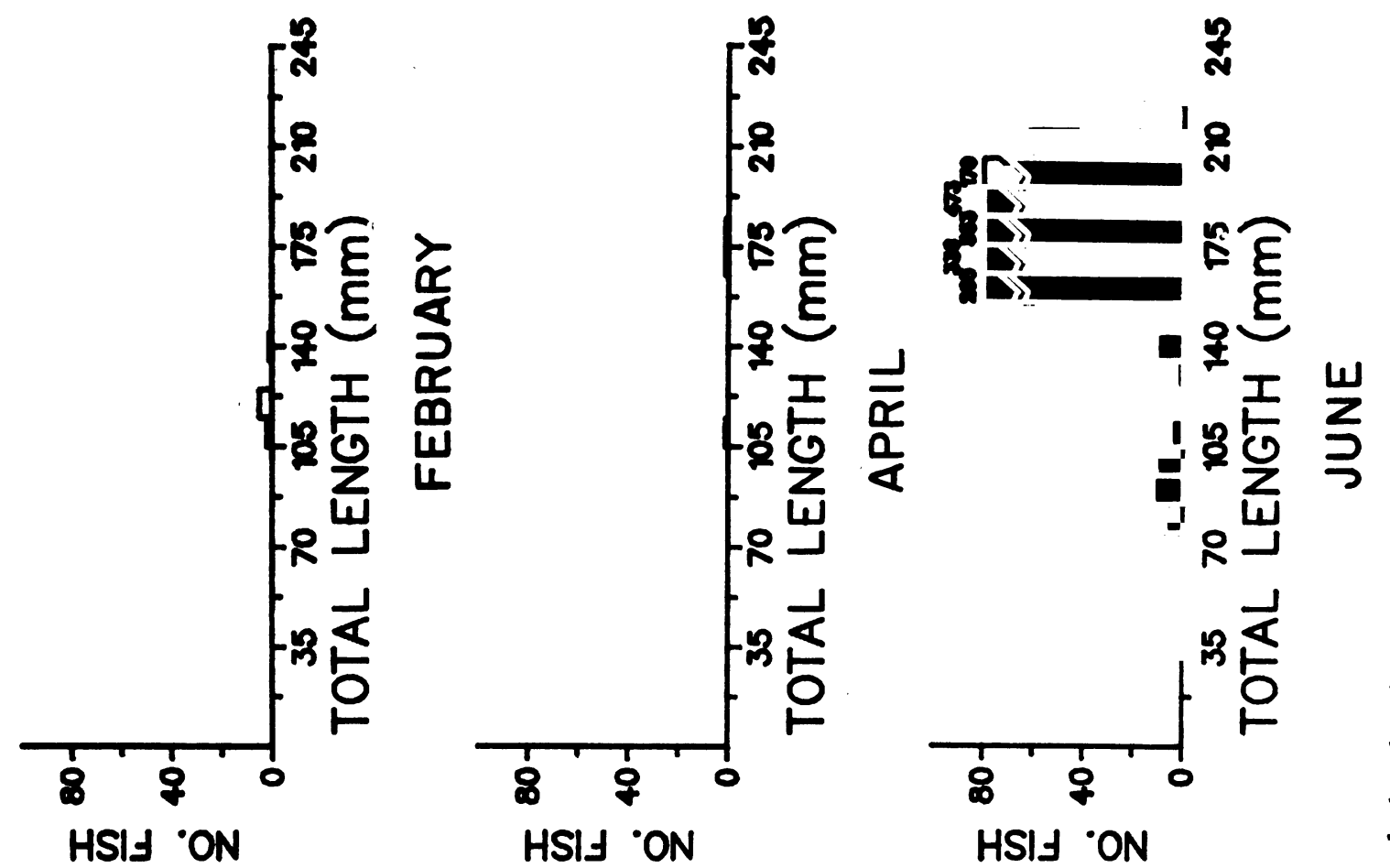

HSIJ ON

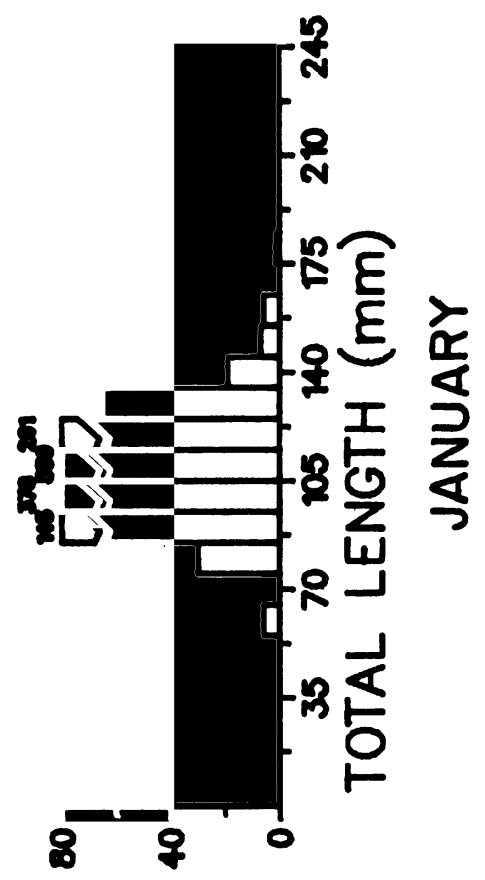

HSIJ $\mathrm{ON}$

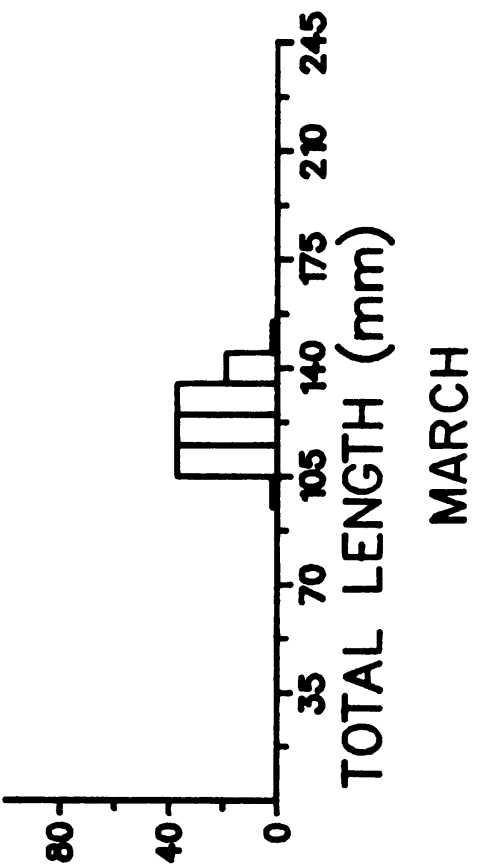

HSI」 $\mathrm{ON}$

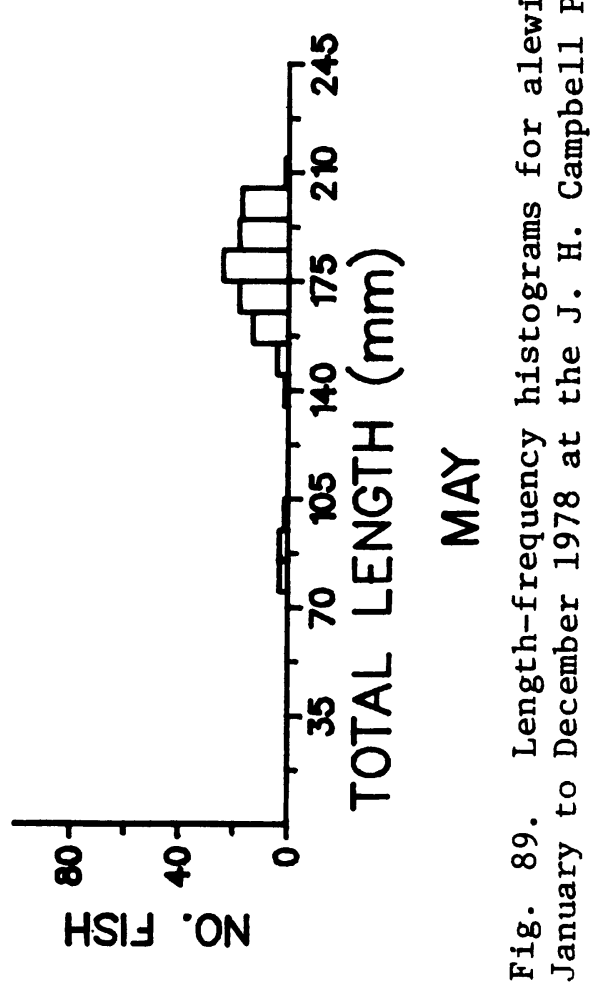



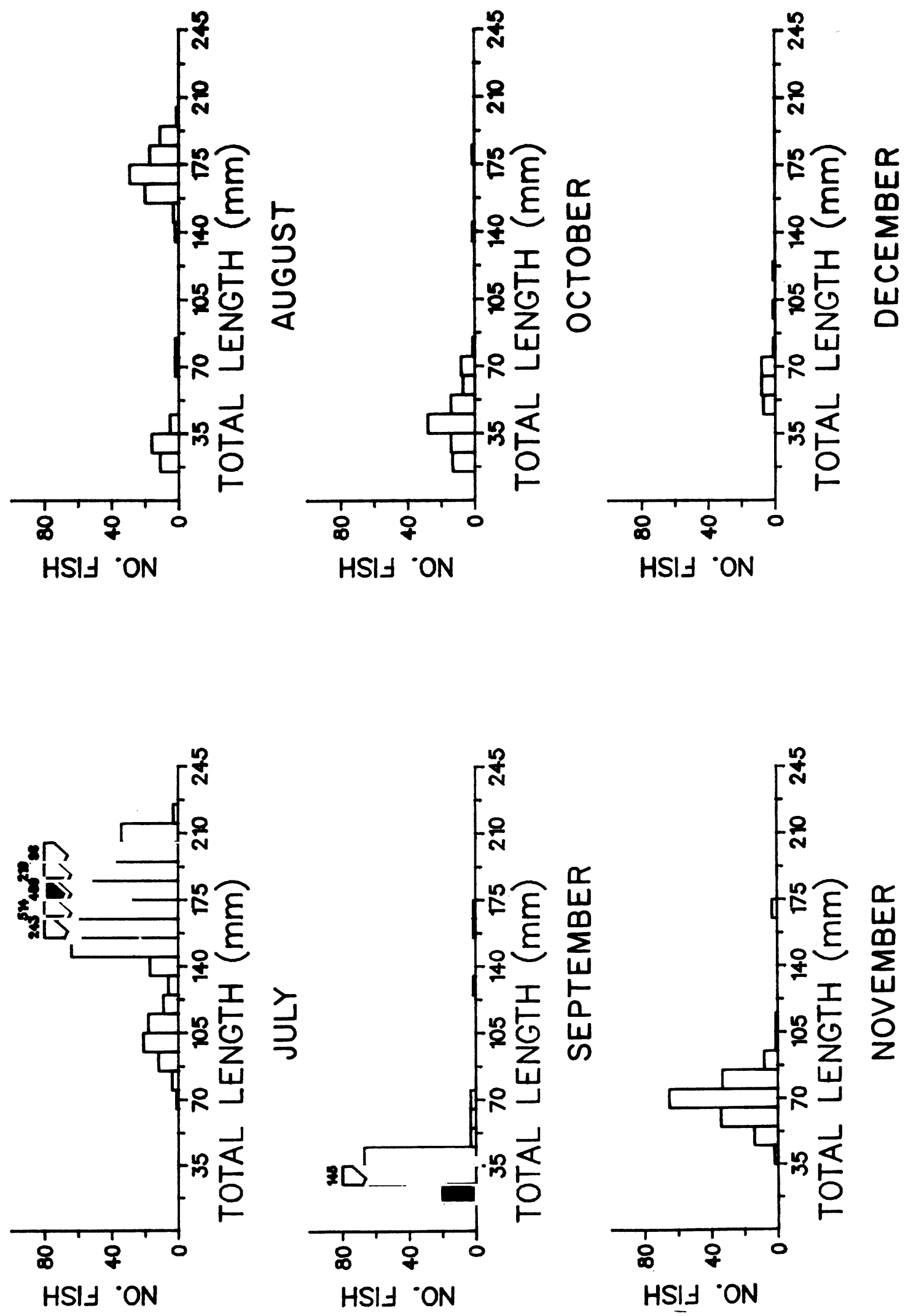

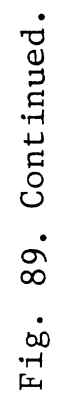


Field sampling during June indicated active spawning by alewives in Pigeon Lake. Most impinged alewives examined had well developed gonads with some ripe-running and spent individuals present. The high alewife impingement was probably due to the transient use of Pigeon Lake as a spawning site by alewives.

July--

Adult alewives (150-210 mm) comprised $93 \%$ by number and $97 \%$ by weight of the impinged fish sampled during July (Appendix 9); $46 \%$ were impinged at night. An estimated 13,523 fish weighing $465 \mathrm{~kg}$ were impinged. YOY alewives (20-30 mm) were the most abundant species in our Pigeon Lake field samples in July (Appendix 6); moderate numbers of adult fish (160-200 mm) were also sollected from Lake Michigan.

Spottail shiners comprised $12 \%$ of the impingement total (14,570 - Table 58) in July. Field samples indicated that spottails were very abundant in Lake Michigan (the largest monthly catch was taken this month) and Pigeon Lake. The very low number of spottails impinged relative to their abundance in adjacent water bodies is undoubtedly due to their closeness to the beach zone during spawning and their demersal behavior. $\Lambda$ s a result, they are not affected by the cooling water intake.

There were 224 small coho salmon (size range 60-130 mm) estimated impinged on the traveling screens; 16 fish $100-120 \mathrm{~mm}$ were collected in field samples this month in Lake Michigan seine hauls.

August--

A decline in the numbers of alewives impinged was observed in August; on $1 y$ 737 fish ( $23 \%$ of the monthly total) were impinged compared to 13,523 in July. Yearling gizzard shad $(85-115 \mathrm{~mm})$ were most abundant in impingement samples with 1866 fish (58\% of the monthly total) collected (Fig. 90), while rainbow smelt comprised $10 \%$ of the total. Smelt were mostly YOY fish with a size range of $20-35 \mathrm{~mm}$.

The largest catch of gizzard shad (65 fish), mostly adults $370-470 \mathrm{~mm}$, was taken from Lake Michigan during August (Appendix 6). Large numbers of smelt and alewife were caught in Lake Michigan while minimal numbers of these fish were caught in Pigeon Lake.

September--

YOY gizzard shad and alewife made up $85 \%$ of the fish impinged in September; an estimated 1852 alewives and 1806 gizzard shad were collected. Largemouth bass (50-100 mm) accounted for $9.2 \%$ of the total impingement collections this month. Fiftytnree fish were examined; total monthly impingement of largemouth bass was estimated at $397 \mathrm{fish}$. Alewives were mostly YOY 24-59 mm (total range 24-168 mm) with a combined weight for the month of $1.13 \mathrm{~kg}$ compared to $11.42 \mathrm{~kg}$ for gizzard shad and $3.73 \mathrm{~kg}$ for largemouth bass (Appendix 9). 

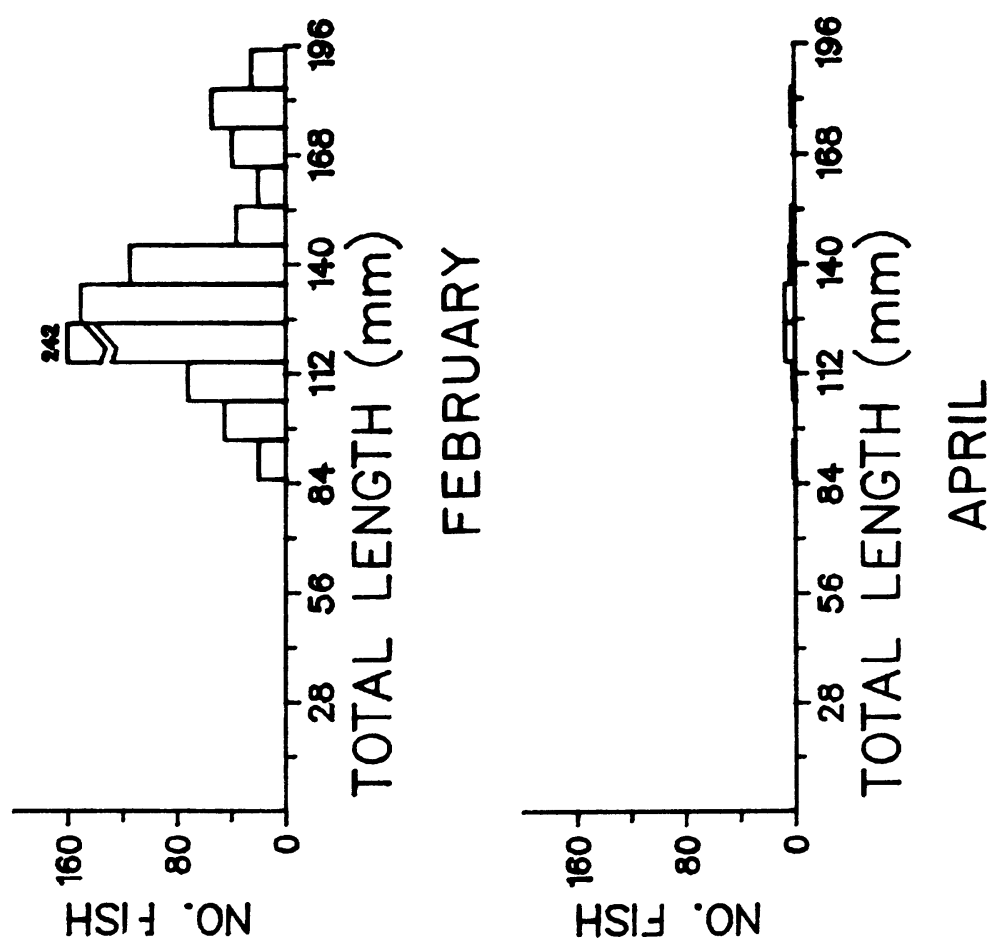

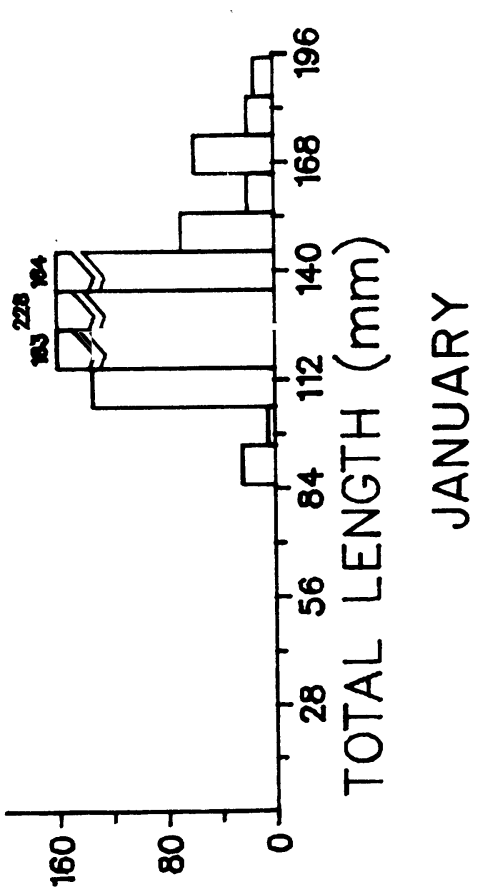

HSl」 ${ }^{\circ} \mathrm{ON}$

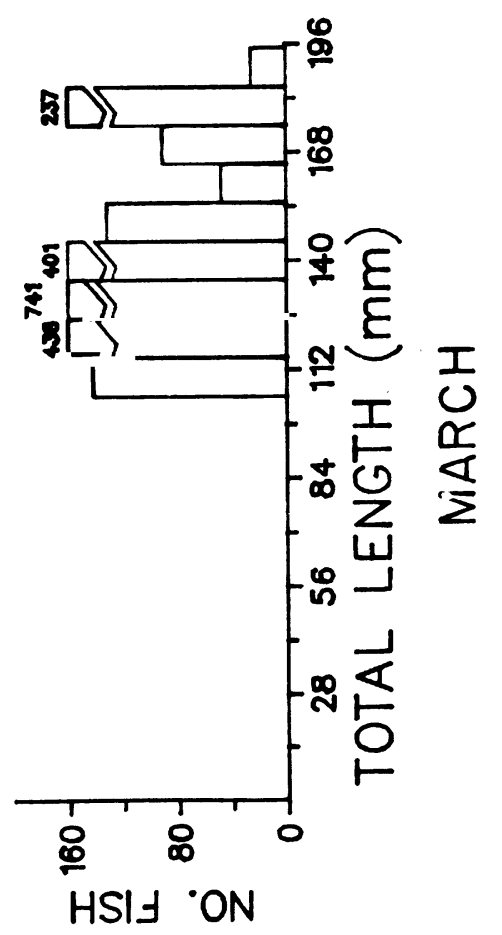

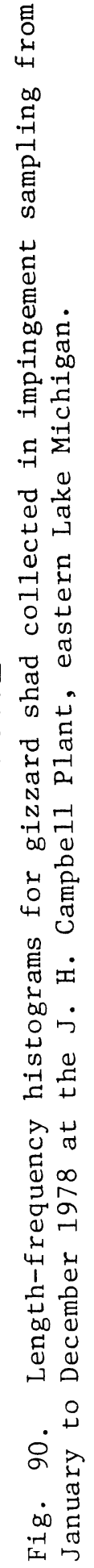



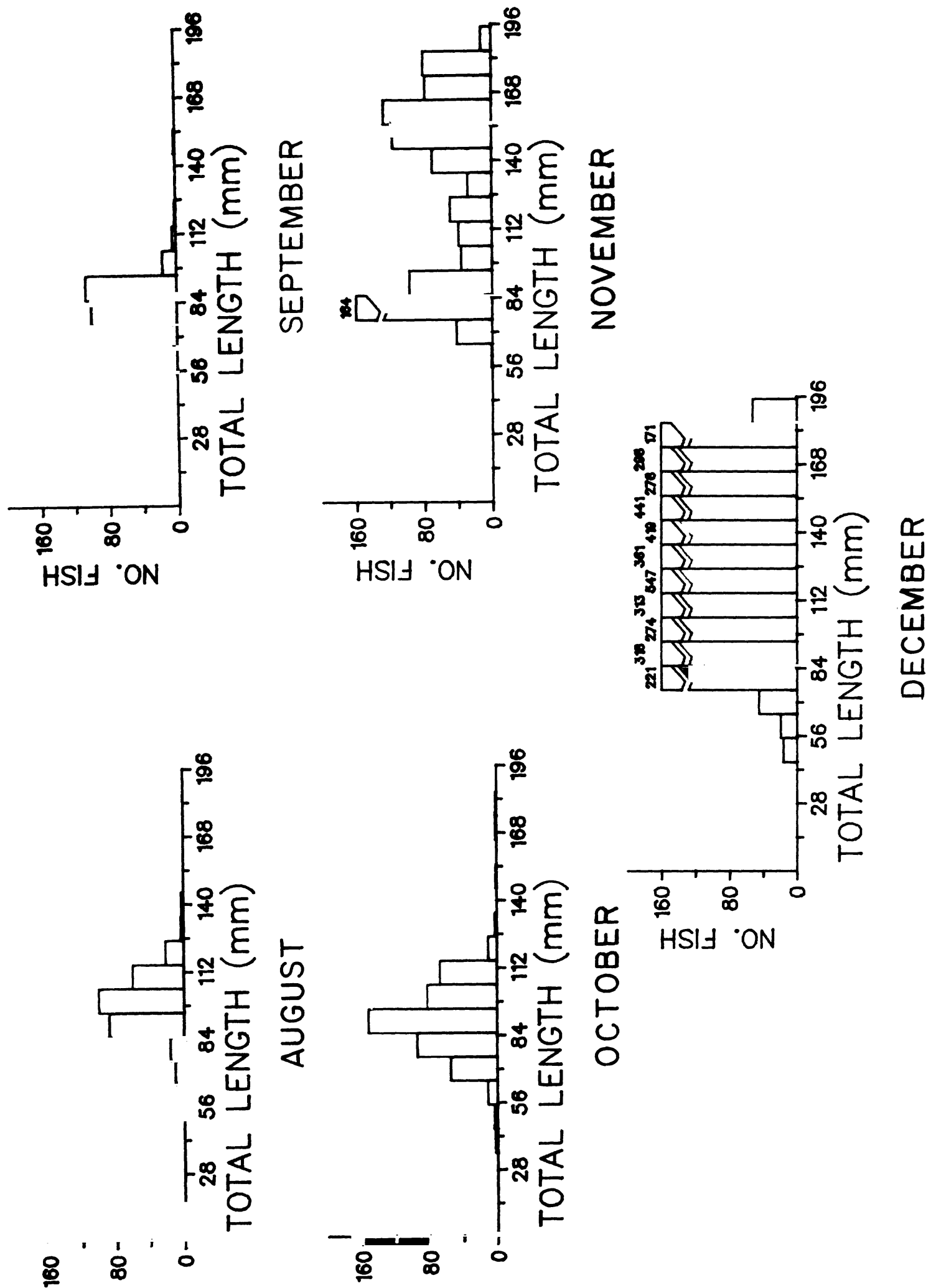

HSIJ ON

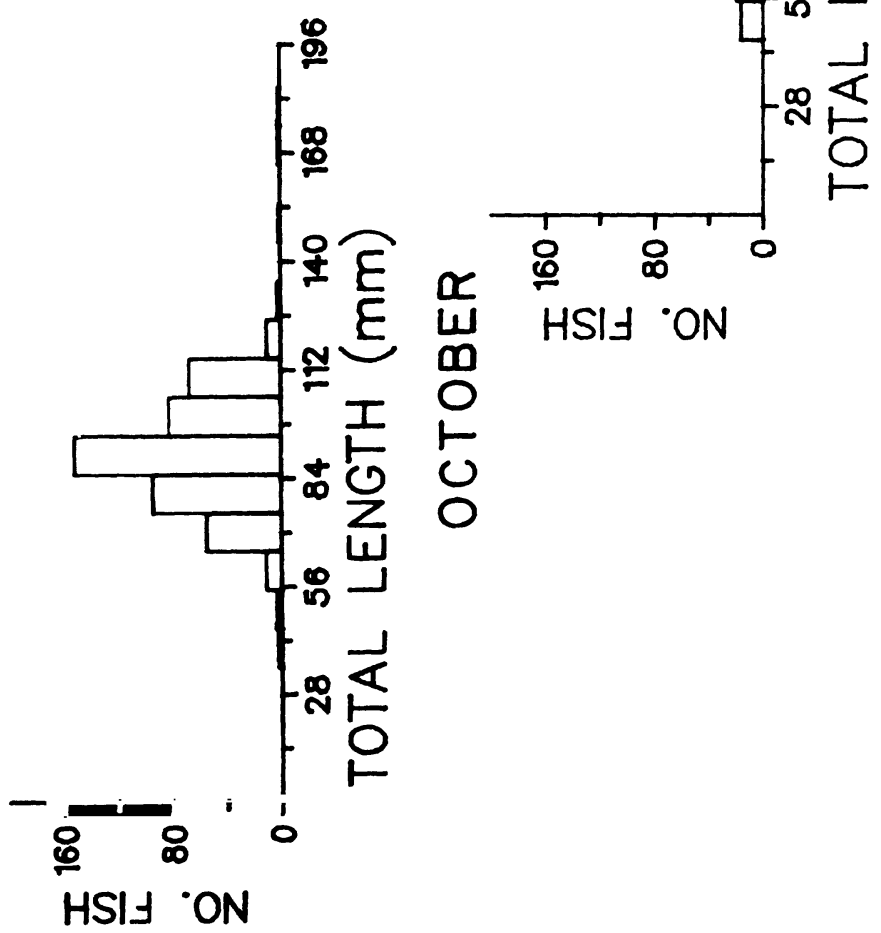

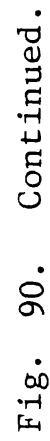


Moderate numbers of alewives (1856 fish) mostly YOY 30-50 mm were caught in Lake Michigan during September field sampling; 79 largemouth bass, mostly YOY 70-100 mm, were caught in Pigeon Lake during the same time reriod. Apparently YOY bass, in their dispersal activities, came in contact with the traveling screens. It may also be that 1978 was a good year for bass reproduction, causing large numbers to be impinged. Bass were not collected in such high numbers in previous studies (Zeitoun, et al. 1978).

October--

As in September, gizzard shad, alewife and largemouth bass were the most abundant fish observed in impingement samples with 2982, 539 and 514 fish estimated impinged. A decrease in the number of impinged alewives collected was due to offshore movement by adults; mostly YOY fish (20-40 mm) were collected from the traveling screens. Most alewives caught during field sampling during October (9305 tota1) were YOY. Only 15 gizzard shad and 9 largemouth bass were observed in October field samples despite the large number (over 500) impinged. Monthly estimates of impinged gizzard shad, alewife and largemouth bass by weight were respectively: $24.2 \mathrm{~kg}, .83 \mathrm{~kg}$ and $1.46 \mathrm{~kg}$ (Table 59). For the month 5619 fish representing 17 species and weighing $45.9 \mathrm{~kg}$ were impinged.

November--

Gizzard shad (65-180 mm) comprised $73 \%$ of the November impingement collections; largemouth bass (55-124 mm) made up $12 \%$. Total monthly impingement estimates for gizzard shad and largemouth bass were 7342 and 562 fish respectively.

The largest catch of alewives in Lake Michigan was recorded in November field samples (26,846 fish); nearly all were YOY fish (Appendix 6). Gizzard shad (15) and largemouth bass (12) also appeared in field samples. YOY alewives had started their offshore migration and apparently were not susceptible to impingement because of their offshore distribution.

The 5627 largemouth bass estimated impinged were mostly YOY or juvenile fish (60-90 $\mathrm{mm}$ ) (Appendix 8). These fish may have been attracted to the warmer intake water once water temperatures began to decline in Pigeon Lake. Warm water is pumped out to the mouth of Pigeon Lake to prevent ice build-up at the jetties during cold months (see METHODS - Impingement). Gammon (1971) studied heated effluent in the Wabash River and noted that smallmouth and spotted bass avoided heated zones except in colder months when water temperatures dropped below $27 \mathrm{C}$. The majority ( $65 \%$ of the monthly total) of gizzard shad were impinged on 30 November, the largest sample during the day. This sudden increase in gizzard shad coincided with opening of a gate between the intake forebay and discharge canal, which to prevent ice formation, allows warmer discharge water (and fish) into the intake forebay. A large number of gizzard shad and possibly YOY bass inhabit the discharge canal during colder months (see RESULTS AND DISCUSSION - Gizzard Shad). Miller (1960) noted a tendency for younger gizzard shad to invade warm-water effluents. Stone and Webster (1976) reported that alewife and gizzard shad become stressed at temperatures below 
3.3 C which could account for the increased mortality during coldest months. Gizzard shad we collected in November were mostly juvenile $(65-175 \mathrm{~mm}) \mathrm{fish}$. A screen which would prevent fish from entering the intake forebay through this gate would considerably reduce the number of gizzard shad impinged during colder months.

December--

Gizzard shad constituted $90 \%$ of the 33,053 fish impinged in December (Appendix 9) while largemouth bass made up 4.3\%. An estimated 29,868 (807 kg) gizzard shad and 1418 ( $8.56 \mathrm{~kg}$ ) largemouth bass were impinged during December. There were 93 walleyes impinged during December (Table 58); they were all YOY (190-305 mm) fish (see RESULTS AND DISCUSSION - ADULT AND JUVENILE FISH, Walleye). The fact that walleye have been caught during supplementary sampling in the discharge canal suggests that they may have entered the intake forebay from the discharge canal.

\section{Other considerations}

The relationship between intake water temperature and number of fish impinged (Fig. 91) was most pronounced for gizzard shad, with the majority collected at low (0-6 C) temperatures. Much of this effect is seasonal, since gizzard shad tend to migrate in the fall. In addition, they were concentrated in the discharge canal and gained access to the intakes only during winter months. Alewives were collected at a wide range of water temperatures; no patterns were apparent. Largemouth bass, like shad, tended to be collected in fall and winter. Some bass were suspected of entering the intake forebay from the discharge canal area. As a result, peak catch occurred at low temperatures, with some other high catches observed between 10 and $15 \mathrm{C}$.

Examination of the diel pattern of impingement (Table 60) showed that alewife were impinged in highest numbers during the night $(126 / \mathrm{h})$ and dawn $(106 / \mathrm{h})$. Field sampling data showed alewives were active at night and concentrated in surface waters. This may account for the increased impingement of this species at night. On the contrary, gizzard shad were impinged at the lowest rate $(45 / \mathrm{h})$ during the night compared to other periods (205-290/h). No reason can be given for this behavior, other than gizzard shad are considered day-active. Similarly, largemouth bass were impinged in fewest numbers during the day $(6 / \mathrm{h})$ vs. other times $(11-21 / \mathrm{h})$. Most spottail shiners were impinged at night.

Impact of Impingement

Knowledge of the abundance and distribution of fish species in the adjacent water bodies near the Campbell Plant concurrent with impingement study results are important in evaluating the impact of impingement on various fish. Fish of commercial or sport value were impinged in very low numbers relative to their abundance in the study area; included in this category were largemouth bass, northern pike, yellow perch, rainbow smelt, coregonids and the salmonids. Impingement sampling during 1978 resulted in the collection of 1 lake trout, 9 brown trout, 2 rainbow trout, 20 chinook salmon and 34 coho 


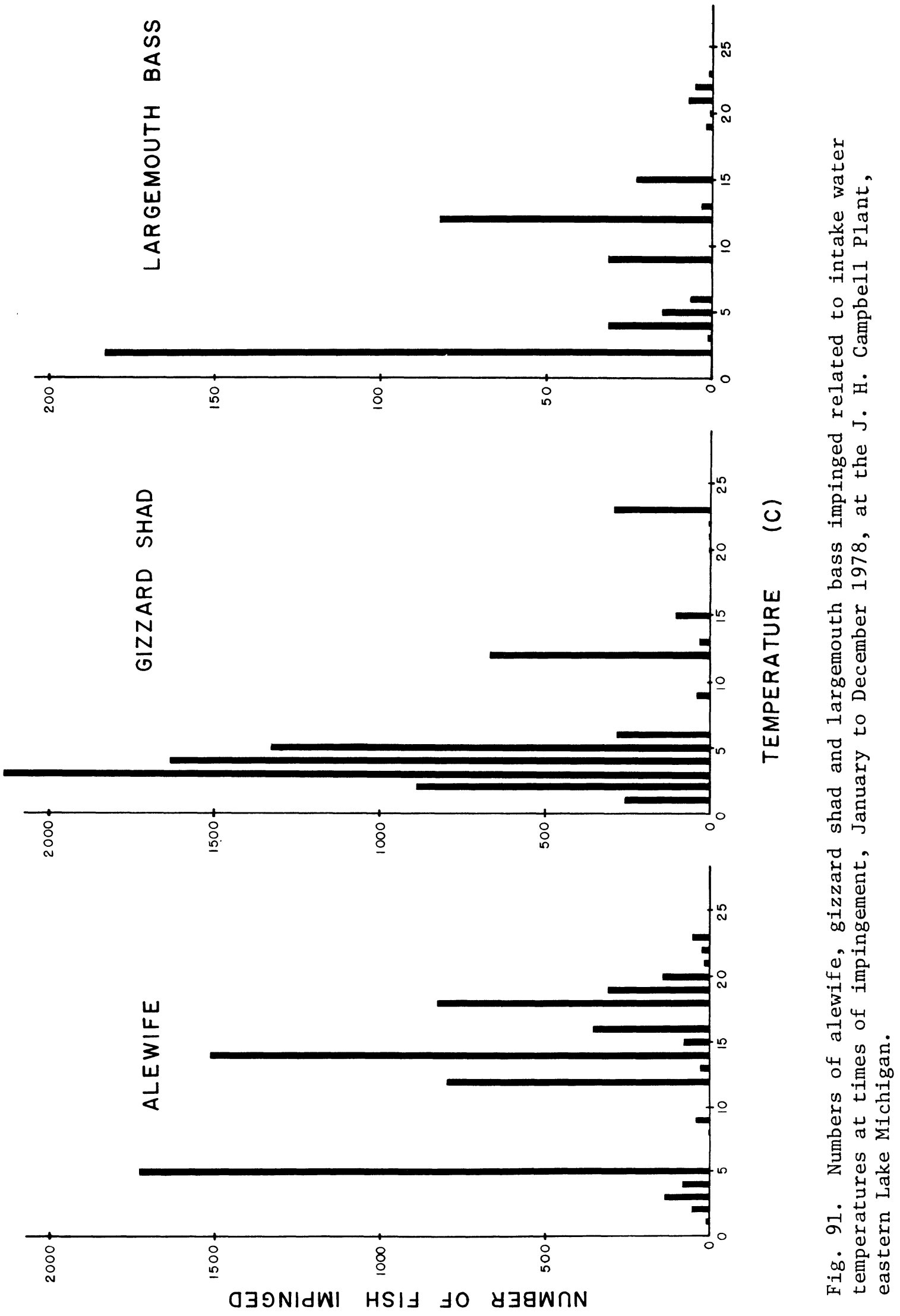


salmon. Estimated total impingement values for the entire year for these five species were 7,64, 13, 143 and $334 \mathrm{fish}$, respectively. Unidentified coregonids were also taken in low numbers in 24-h impingement sampling (nine fish). Total yearly impingement was estimated at $69 \mathrm{fish}$. No large individuals which could be positively identified as bloaters or whitefish were observed in impingement samples.

Table 60. Total number of fish collected during each impingement sampling period in 1978 at the J. H. Campbell Plant, eastern Lake Michigan. Numbers in parentheses are numbers of fish collected during each impingement sampling period divided by the number of hours in that period. These numbers represent relative impingement rates for the species given.

\begin{tabular}{|c|c|c|c|c|}
\hline \multirow[b]{2}{*}{ Species } & \multicolumn{4}{|c|}{ Period (duration in $\mathrm{hr}$ ) } \\
\hline & Day $(8 \mathrm{hr})$ & Dusk (5 hr) & Night (7 hr) & Dawn (4 hr) \\
\hline Alewife & $740(92)$ & $301(60)$ & $881(126)$ & $423(106)$ \\
\hline Gizzard shad & $1642(205)$ & $1359(272)$ & 1017 (45) & $1160(290)$ \\
\hline Largemouth bass & $169(21)$ & $96(20)$ & $56(6)$ & 44 (11) \\
\hline Spottail shiner & $60(7.5)$ & $17(3)$ & 115 (16) & $6(1)$ \\
\hline
\end{tabular}

During 1978, an estimated 68 northern pike were impinged. Of these, approximately 46 were YOY, 8 were yearlings and 14 were age $-4 \mathrm{fish}$. The 16 impinged fish in the 175-299-mm group represented approximately $1.3 \%$ of the estimated number of these fish $(175-299 \mathrm{~mm})$ in the lake. The 14 impinged age-4 fish represented about $2 \%$ of this group $(>299 \mathrm{~mm})$ present in the lake. There was no estimate available for YOY pike, but it is our belief that a considerable number, certainly more than was found for the 175-299-mm group, are present in the lake. Population levels have remained stable.

For largemouth bass, 3061 fish were impinged; almost all were YOY. We estimated abundance of large bass in Pigeon Lake and found there were $842 \mathrm{fish}$ $175-219 \mathrm{~mm}$ in the lake. Only six in this size range, $0.7 \%$, were impinged. YOY population levels have remained similar between 1977 and 1978 , so apparently the impingement of over $3000 \mathrm{fish}$ did not affect their stability in the lake.

Even though large numbers of alewives were impinged, Campbel1 Units 1 and 2 seemed to have very little impact on this species. Greatest numbers were impinged when these fish were spawning and in a stressed condition. Alewives accounted for $93.4 \%$ of all fish impinged during studies at Lake Michigan power plants between January 1975 and June 1976; these fish represented on $1 y$ $0.064 \%$ of the entire Lake Michigan alewife population (CDM/limnetics 1977).

The number of gizzard shad impinged would be significantly reduced if a screen were placed over the passageway connecting the discharge channel with the forebay. It was clearly demonstrated that these fish and possibly some others were impinged in large numbers only when the gate between the intake forebay and discharge channel was open. 
$\underline{\text { Summary }}$

In 1978, an estimated $136,737 \mathrm{fish}(3144.28 \mathrm{~kg}$ ) representing 48 species were impinged, including coho and chinook salmon, rainbow, brown and lake trout, largemouth and smallmouth bass and coregonids. Gizzard shad and alewives were impinged in greatest numbers between November and April; greatest abundance of alewives occurred during June, July and August when spawning occurred.

Population estimates of northern pike and largemouth bass were found to be large for Pigeon Lake; numbers impinged were very low in relation to their abundance in Pigeon Lake. Fishes of economic importance were impinged in very low numbers relative to their abundance in the vicinity of the plant.

Seasonal movements of fish in the vicinity of the Campbell Plant affect their vulnerability to impingement. Total impingement was highest in terms of both numbers and weight during late fall to early winter when over $64 \%$ of the total number impinged were collected.

During 1978, gizzard shad and alewife were the dominant species impinged, representing $54.8 \%$ and $32.8 \%$ respectively, of the total number of fish impinged. This agrees with the impingement study conducted during 1977 (Zeitoun et a1. 1978). Other species which each accounted for more than $1 \%$ of the yearly total number were: spottail shiner, largemouth bass, yellow perch and rainbow smelt. Most gizzard shad impinged were YOY and yearlings (size range 65-175 mm) (Appendix 8). Most were collected during December; 56\% of the mature fish were male.

Alewife impingement exhibited two distinct peaks. The first was during June and July when mostly adults (150-220 mm) were impinged; 67\% were females. Spawning by alewives was occurring during this time in Pigeon Lake causing alewives to be vulnerable to impingement. The second peak occurred in January when YOY and yearlings (50-140 mm) were impinged. These fish were most likely residents of the discharge canal. Alewives entered the intake forebay via an open gate and were subsequently impinged.

Spottail shiners were the third most abundant species impinged diring the present study. Although common in Pigeon Lake and Lake Michigan throughout the study they were impinged in greatest numbers during April. Most spottails collected were adults $(75-130 \mathrm{~mm}) ; 53 \%$ were females. These fish were most likely residents of Pigeon Lake since very few were caught in Lake Michigan field samples during April. Largemouth bass were the fourth most abundant species impinged during 1978 comprising 2.2\% (3061 fish) of the total estimated number of impinged fish. The majority of fish were YOY or yearlings $85 \mathrm{~mm}$ or less; $81 \%$ were impinged in the fall with greatest numbers of fish (183) impinged during December.

GAME FISH POPULATION STUDY

\section{Introduction}

In an effort to better understand the important sport fish populations in 
Pigeon Lake and evaluate what effect impingement has on them, we conducted a mark and recapture study to estimate their numbers. With these data and the impingement results, we hope to elucidate more clearly important sport fish biology and put into perspective what the loss of sport fish from Pigeon Lake means to their population stability.

Sufficient numbers of northern pike and largemouth bass in Pigeon Lake were marked and recaptured in 1978 to allow reliable population estimates using the Schumacher/Eschmeyer Method (Ricker 1975). This method requires that a population remain constant throughout the sampling period and we assumed that this condition was met for pike and bass populations studied. Population estimates for two size classes of both northern pike and largemouth bass were based on five sampling periods during September and October. Only four smallmouth bass were marked and released in 1978 so a population estimate was not possible.

\section{$\underline{\text { Results }}$}

Fishing mortality of northern pike $(>299 \mathrm{~mm})$ was low or nonexistent and natural mortality should have been nominal during the time period (6 Sep to 25 0ct - 49 days) of the mark and recapture study. Six northern pike from 383 to $610 \mathrm{~mm}$ were killed in gill nets in September and October, but this number is considered low enough so that population estimate assumptions were not violated.

Of 116 northern pike (>299 mm) marked with spaghetti ṫags, 8 were recaptured (Table 61). The 1978 population estimate for this size northern pike using the Schumacher/Eschmeyer equation was 690 ( $95 \%$ confidence limits 524 , 906), which is quite close to the 1977 population estimate of 672 ( $95 \%$ confidence limits 610,749 ) (Jude et al. 1978). The closeness of estimates made during these $2 \mathrm{yr}$ is an indication of stability of the adult $(>299 \mathrm{~mm})$ northern pike population in Pigeon Lake, and also implies accuracy of sampling technique and appropriateness of equations and assumptions employed. Also consistent with 1977 observations, northern pike (>299 mm) in 1978 were found to move around within Pigeon Lake rather than being restricted to individua1 territories. Of the fish that were captured more than once, $75 \%$ were caught in different areas of the lake on different capture dates. This is good evidence that thorough mixing of marked individuals with the rest of the population had occurred. An extreme case of northern pike mobility was documented. A pike $(494 \mathrm{~mm}, 750 \mathrm{~g})$ was tagged in Pigeon Lake in September 1977 and subsequently caught by Michigan Department of Natural Resources by electrofishing on 11 April 1979 in Lake Macatawa, approximately $16 \mathrm{~km}$ south of Pigeon Lake by way of Lake Michigan. We hope that this was an extraordinary occurrence since we assumed that fish populations we studied were generally isolated resident populations.

Natural mortality of smaller northern pike $(175-299 \mathrm{~mm})$ may be expected to be minimal over the 2-mo electrofishing sampling period, and angling mortality should have been nonexistent due to sub-legal size of these fish. Only eight fish in this size range were impinged in 1978; all in September. population of northern pike (175-299 mm) was estimated to be 1259 (95\% 
confidence limits 1126,1429$)$. This estimate was based on 103 marked fish and 3 recaptures (Table 61). The 1977 estimate was 628 (95\% confidence limits 589,670 ) (Jude et a1. 1978). The large increase in number of pike 175-299 mm estimated in 1978 compared to 1977 indicates that a strong year class was produced in spring 1977. Mortality of pike eggs and young may be as high as $99 \%$ before they leave spawning grounds and mortality may also be $99 \%$ for the fry stage (Carbine 1944). Thus the substantial number of pike (175-299 mm) estimated to be present in Pigeon Lake represents good survival of the 1977 year class and shows clearly that portions of Pigeon Lake are favorable pike spawning grounds.

Table 61. Population estimate data for northern pike greater than $299 \mathrm{~mm}$, northern pike less than $299 \mathrm{~mm}$, largemouth bass greater than $219 \mathrm{~mm}$ and largemouth bass less than $219 \mathrm{~mm}$ in Pigeon Lake near the J. H. Campbe11 Plant, Fal1 1978.

Mt $=$ total number of marked fish at the start of the period, $\mathrm{Ct}=$ total number of fish captured during the period and $\mathrm{R}_{\mathrm{t}}=$ number of fish recaptured during the period.

\begin{tabular}{|c|c|c|c|c|c|c|c|c|c|c|c|c|c|}
\hline \multirow[b]{3}{*}{ Period (t) } & \multirow[b]{3}{*}{ Date } & \multicolumn{6}{|c|}{ NORTHERN PIKE } & \multicolumn{6}{|c|}{ LARGEMOUTH BASS } \\
\hline & & \multicolumn{3}{|c|}{$175-299 \mathrm{~mm}$} & \multicolumn{3}{|c|}{$\begin{array}{r}299 \mathrm{~mm} \\
\end{array}$} & \multicolumn{3}{|c|}{$175-219 \mathrm{~mm}$} & \multicolumn{3}{|c|}{$\quad>219 \mathrm{~mm}$} \\
\hline & & $M_{t}$ & $\mathrm{C}_{t}$ & $R_{t}$ & $\mathrm{M}_{t}$ & $\mathrm{C}_{t}$ & $\mathrm{Rt}$ & $M_{t}$ & $c_{t}$ & $R_{t}$ & $\overline{M_{t}}$ & $C_{t}$ & $\overline{R_{t}}$ \\
\hline I & $6-8$ Sep & 0 & 4 & 0 & 0 & 3 & 0 & 0 & 11 & 0 & 0 & 5 & 0 \\
\hline II & 13-15 Sep & 4 & 26 & 0 & 3 & 21 & 1 & 11 & 26 & 0 & 5 & 26 & 0 \\
\hline I I I & 19-21 Sep & 30 & 8 & 0 & 23 & 16 & 1 & 37 & 46 & 5 & 31 & 16 & 1 \\
\hline IV & $4-5$ oct & 38 & 35 & 1 & 38 & 25 & 0 & 78 & 22 & 3 & 46 & 39 & 8 \\
\hline $\mathrm{v}$ & $24-25$ oct & 72 & 33 & 2 & 63 & 59 & 6 & 97 & 51 & 4 & 77 & 33 & 8 \\
\hline
\end{tabular}

During months when electrofishing was performed, some angling pressure on bass existed (a tagged smallmouth bass was caught by an angler in September), but was not considered great enough or successful enough to violate the low mortality assumption necessary for the Schumacher/Eschmeyer equation. Natural mortality of largemouth bass (>219 mm) should have been negligible during the period electrofishing was performed; only one largemouth (330 mm) was killed in a gill net and none $(>219 \mathrm{~mm})$ were impinged during the mark and recapture experiment. Two other bass (340 mm and $410 \mathrm{~mm}$ - Appendix 6) were captured via seine in October, marked and released. of 102 largemouth bass $(>219 \mathrm{~mm})$ that were marked with spaghetti tags, 17 were recaptured (Table 61). The population of this size bass was estimated at 290 ( $95 \%$ confidence limits 257 , 331) while the corresponding estimate made from 1977 data was 471 (95\% confidence limits 349, 724) (Jude et al. 1978). Non-overlapping confidence limits for the different year's estimates indicate that the decreased population size found in 1978 was significant $(\alpha=0.05)$. Angling pressure during summer 
months was thought to have been greater in 1978 than 1977 and may have contributed to the decrease in the largemouth population. Better than average success was reported by certain anglers who were questioned by GLRD personnel. Competition from the substantial northern pike population may have contributed to the decline in largemouth numbers and it is also possible that large bass were distributed in or moving to areas of Pigeon Lake or Pigeon River that we did not or could not sample by electrofishing.

Fishing pressure and natural mortality should have been negligible for small largemouth bass (175-219 mm) from September through October; no bass in this size range were killed in adult sampling gear during these months. Only six 170-mm fish were impinged; all in 0ctober. The population of largemouth bass (175-219 mm) was estimated at 842 (95\% confidence limits 623, 1300) based on $144 \mathrm{fish}$ marked and 12 recaptured (Table 61). There had been no previous estimate of this population in Pigeon Lake due to lack of recaptures in 1977.

The largemouth bass and especially the northern pike populations in Pigeon Lake seem to be thriving. Age-length relationships determined from scale readings indicated better than average growth by northern pike (see ADULT AND JUVENILE FISH, Northern pike), but below normal growth by largemouth bass (see ADULT AND JUVENILE FISH, Largemouth bass) in Pigeon Lake. Between these two predator species (considering growth and population sizes), it appears that northern pike are maintaining their populations at higher levels than largemouth bass in the Pigeon Lake habitat. Impact of impingement on individual species is discussed under each appropriate adult species (see RESULTS - ADULT AND JUVENILE FISH).

In addition to largemouth bass and northern pike, four smallmouth bass $(169-374 \mathrm{~mm})$ and one tiger musky $(289 \mathrm{~mm}$ ) were caught, marked and released in 1978. The 374-mm smallmouth bass was subsequently caught by a local fisherman. 
FISH LARVAE AND ENTRAINMENT STUDY

\section{$\underline{\text { Introduction }}$}

The larval fish stage may be the most important period in the life of a fish. Since year class strength is ultimately determined by egg and larval survival, it becomes extremely important to understand the factors which affect the growth and development and mortality of each species.

As of 1975, there were 45 power-generating plants on Lake Michigan which draw water from the lake for cooling purposes (Lake Michigan Federation 1975). Most fish species use the inshore zone of the Great Lakes as a spawning ground and nursery area. Consequently, every power plant, domestic or industrial intake on the lake has the potential for entraining large numbers of fish larvae and eggs. Many larvae suffer severe stress and mortality when subjected to entrainment at these water intakes.

The primary purpose of this portion of the study was to gather data to determine what impacts were being made on fish larvae populations by the present and proposed water cooling system of the J. H. Campbell Power Plant. The secondary objectives include:

1) describe what species were present and in what abundance, as well as their spatial (vertical and horizontal) and temporal (seasonal and diel) distribution.

2) determine which species utilized Pigeon Lake and Lake Michigan in the Port Sheldon area as spawning and nursery grounds.

3) gather information to correlate the appearance of fish larvae in field samples with occurrence in entrainment samples.

4) completion of information about life cycles, including spawning times and locations.

Fish larvae were defined as any fish less than $25.4 \mathrm{~mm}$ in total length for simplicity in data manipulation. Periodically, fish greater than $25.4 \mathrm{~mm}$ were caught in net and sled tow samples. These fish were called fry for our purposes and analyzed separately from larvae. A fry was defined as any fish between 25.4 and $100 \mathrm{~mm}$. Larval fish data in this section are discussed by taxonomic group. Within a species or group, seasonal distribution and entrainment were discussed. A standard unit of density, no./1000 $\mathrm{m}^{3}$, was used to compare larval collections at the various stations and times. Actual densities obtained were biased because of differences in efficiencies of the net in the diverse habitats sampled, with more and longer larvae captured at the more densely vegetated and turbid Pigeon Lake stations. More larvae were usually collected at night because of daytime net avoidance. These differences were taken into consideration when data are discussed. Another data compilation which was used to display differences in length of larvae collected from the various habitats was the length-frequency histogram. Many times we were able to separate from which lake entrained larvae were derived by examination of these histograms. These data were also useful for determining growth relationships of fish larvae from the two ecosystems. 
Stations were established in Lake Michigan along two transects which were identical to those used for adult fish (Fig. 1). One transect was in the area of the present onshore discharge (north transect) and one, the reference transect, was $3.1 \mathrm{~km}$ south of the plant. Sampling locations in the open water of Pigeon Lake were also established (Fig. 2.). Preoperational and operational data comparisons were and will be made on the basis of these data. Beach stations were established in a similar manner for the above discussed comparisons as well as to determine the distribution and abundance of larval species at beach zone stations. Sampling was also conducted in the intake canal to determine what fish larvae were present just prior to entry of water into the coolingwater system of the Campbell Power Plant. Information about resident larval fish in the intake canal could also be ascertained. Sampling the discharge water, using the same $0.5-\mathrm{m}$ diameter nets used in field collections, provided data on larval fish entrainment. Two types of gear were used to sample larval fish; regular plankton nets and a benthic sled-towing device (Fig. 5). These gear were able to sample the entire inshore aquatic habitat from surface waters to just off the bottom and from the beach zone out to $15 \mathrm{~m}$ (as far as we chose to go). These gear, which covered most areas of the physical habitat, combined with day and night sampling and more frequent collections during months of peak larvae abundance, should provide a well-balanced understanding of the densities and distribution of fish larvae in the area of the Campbell Plant. A discussion of each taxonomic group (see Table 62 for a species list and larvae codes) follows.

\section{$\underline{\text { Alewife }}$}

Introduction--

As was found during 1977, alewife was the most abundant species of larval fish collected during 1978 in the area of the Campbe11 Plant. Larval alewives were most common in the area from June to August of both years, as would be expected from a number of studies showing that spawning usually takes place in Lake Michigan from May to August (Jude et al. 1978, Jude et al. 1979).

Of paramount importance in interpreting distribution and abundance data of larval alewife is a clear understanding of both the reproductive strategy of the species, as well as factors affecting their survival and dispersal. Alewife are broadcast spawners, distributing their eggs in a random fashion over the spawning site (Scott and Crossman 1973). Since no nest is built and no parental care occurs, mortality due to natural causes is high. Alewives, as well as other broadcast spawners, compensate for this high natural mortality by producing a large number of eggs. Female alewives from Lake Michigan are reported to produce from 11,000 (from a $160-\mathrm{mm}$ fish) to 22,000 eggs (192$\mathrm{mm}$ fish) (Norden 1967). This can be compared with the slimy sculpin which builds a nest and protects the eggs, and whose larger adult females (100-104 mm) on1y deposit an average of 660 eggs (Rottiers 1965).

Alewife eggs are reportedly demersal and essentially non-adhesive. A study by Edsall (1964) indicates that predation after spawning may be quite intense, at least in rivers. Hatching, which occurs in approximately 7 days at $15 \mathrm{C}$ (Edsal1 1970), results in a larva of approximately $4.0 \mathrm{~mm}$. Our study during 1977 (Jude et al. 1978) as well as a study by Jude et al. (1979) near the Cook Plant suggests that newly hatched alewife larvae are planktonic, and are moved about passively by water currents. This "passive 
Table 62. Taxons and abbreviations for al1 groups of fish larvae captured from Campbell Plant study areas from January through December 1978. An L denotes presence of $\mathrm{f}$ ish larvae in Lake Michigan, Pigeon Lake or entrainment samples and an F represents fry. Names assigned according to Bailey et al. 1970.

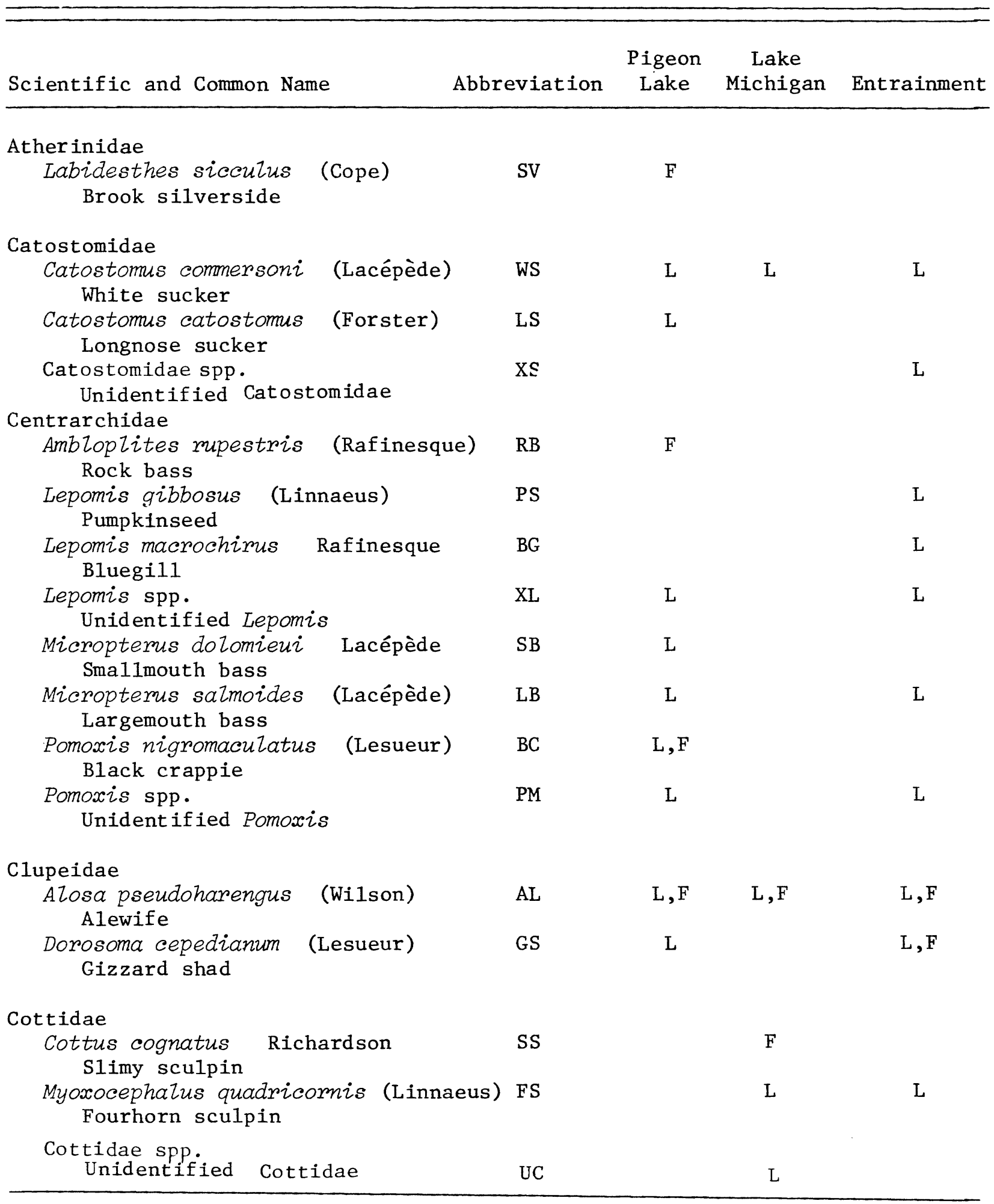


Table 62. Continued.

\begin{tabular}{|c|c|c|c|c|}
\hline Scientific and Common Name & eviation & $\begin{array}{l}\text { Pigeon } \\
\text { Lake }\end{array}$ & $\begin{array}{l}\text { Lake } \\
\text { Michigan }\end{array}$ & Entrainment \\
\hline \multicolumn{5}{|l|}{ Cyprinidae } \\
\hline $\begin{array}{l}\text { Cyprinus carpio Linnaeus } \\
\text { Carp }\end{array}$ & $\mathrm{CP}$ & $\mathrm{L}$ & $\mathrm{L}$ & $\mathrm{L}$ \\
\hline $\begin{array}{l}\text { Notemigonus crysoleucas (Mitchill) } \\
\text { Golden shiner }\end{array}$ & GL & $\mathrm{L}, \mathrm{F}$ & & \\
\hline $\begin{array}{l}\text { Notropis atherinoides Rafinesque } \\
\text { Emerald shiner }\end{array}$ & ES & $\mathrm{L}, \mathrm{F}$ & $\mathrm{L}$ & L \\
\hline $\begin{array}{l}\text { Notropis hudsonius (C1inton) } \\
\text { Spottail shiner }\end{array}$ & SP & $\mathrm{L}, \mathrm{F}$ & $\mathrm{L}, \mathrm{F}$ & $\mathrm{L}, \mathrm{F}$ \\
\hline $\begin{array}{l}\text { Pimephales notatus (Rafinesque) } \\
\text { Bluntnose minnow }\end{array}$ & BM & $\mathrm{L}, \mathrm{F}$ & & \\
\hline $\begin{array}{l}\text { Carassius auratus (Linnaeus) } \\
\text { Goldfish }\end{array}$ & GF & & & $\mathrm{L}$ \\
\hline $\begin{array}{l}\text { Cyprinidae spp. } \\
\text { Unidentified Cyprinidae }\end{array}$ & $\mathrm{XM}$ & $\mathrm{L}$ & $\mathrm{L}$ & $\mathrm{L}$ \\
\hline \multicolumn{5}{|l|}{ Cyprinodontidae } \\
\hline $\begin{array}{l}\text { Fundulus diaphanus (Lesueur) } \\
\text { Banded killifish }\end{array}$ & BK & $\mathrm{F}$ & & \\
\hline \multicolumn{5}{|l|}{ Gadidae } \\
\hline $\begin{array}{c}\text { Lota Zota (Linnaeus) } \\
\text { Burbot }\end{array}$ & BR & $\mathrm{L}$ & $\mathrm{L}$ & $\mathrm{L}$ \\
\hline $\begin{array}{l}\text { Gasterosteidae } \\
\text { Pungitius pungitius (Linneaus) } \\
\quad \text { Ninespine stickleback }\end{array}$ & NS & F & $\mathrm{L}, \mathrm{F}$ & $\mathrm{L}, \mathrm{F}$ \\
\hline $\begin{array}{l}\text { Ictaluridae } \\
\text { Ictalumus nebulosus (Lesueur) } \\
\text { Brown bullhead }\end{array}$ & $\mathrm{BN}$ & & & $\mathrm{F}$ \\
\hline $\begin{array}{l}\text { Osmeridae } \\
\text { Osmerus mordax (Mitchill) } \\
\text { Rainbow smelt }\end{array}$ & SM & $\mathrm{L}, \mathrm{F}$ & $\mathrm{L}, \mathrm{F}$ & $\mathrm{L}, \mathrm{F}$ \\
\hline $\begin{array}{l}\text { Percidae } \\
\text { Etheostoma nigmu Rafinesque } \\
\text { Johnny darter }\end{array}$ & JD & F & $\mathrm{L}, \mathrm{F}$ & $\mathrm{L}$ \\
\hline $\begin{array}{ll}\text { Perca flavescens } & \text { (Mitchill) } \\
\text { Yellow perch } & \\
\text { Percina caprodes } & \text { (Rafinesque) } \\
\text { Logperch } & \end{array}$ & LP & $\mathrm{L}, \mathrm{F}$ & $L, F$ & $\mathrm{~L}$ \\
\hline
\end{tabular}


Table 62. Continued.

\begin{tabular}{|c|c|c|c|c|}
\hline Scientific and Common Name & Abbreviation & $\begin{array}{l}\text { Pigeon } \\
\text { Lake }\end{array}$ & $\begin{array}{l}\text { Lake } \\
\text { Michigan }\end{array}$ & Entrainment \\
\hline $\begin{array}{l}\text { Percopsidae } \\
\text { Percopsis omiscomaycus (Walbaum) } \\
\text { Trout-perch }\end{array}$ & TP & & $\mathrm{L}$ & $\mathrm{L}$ \\
\hline $\begin{array}{l}\text { Salmonidae } \\
\text { Unidentified coregoninae }\end{array}$ & $\mathrm{XC}$ & & $\mathrm{L}$ & $\mathrm{L}$ \\
\hline Larvae damaged beyond recognition & $\mathrm{XP}$ & $\mathrm{L}$ & $\mathrm{L}$ & $\mathrm{L}, \mathrm{F}$ \\
\hline Unidentified Pisces & $\mathrm{XX}$ & & $\mathrm{L}$ & $\mathrm{L}$ \\
\hline
\end{tabular}

stage" has been documented by Sette (1943) for the Atlantic mackerel and Walford (1938) for the American haddock. It is the passive stage in larval development of the alewife which makes distribution and abundance data difficult to interpret.

Meterological events are probably the most inconsistent and unpredictable variable which affected parameters measured during our study. Since these events, such as wind, air temperature and barometric pressure are intimately related to the production of water currents, extreme variability is expected to be imparted to the distribution of this passive, planktonic life stage. Thus, when discussing distribution of alewife larvae, what appear to be somewhat predictable trends are often confounded by variability induced by meteorological events. This is exemplified by the references in this report, as well as Jude et al. (1979) for larval alewife distributions near the D.C. Cook Plant, referring to alewife larvae distributions which did not wholly fit the expected "pattern". In spite of the variability inherent in sampling early larval stages of alewife, our experience has shown that, over time, patterns do emerge and indeed show some consistency. The following pages describe the seasonal changes in abundance and distribution of alewife larvae near the Campbell Plant during 1978, comparing them closely with data collected in 1977 (Jude et al. 1978) as well as with 1973-1974 studies (Jude et al. 1979) near the Cook Plant. These comparisons greatly aided in recognizing those patterns in distribution and abundance of alewife larvae that only become evident when looking at data over long periods of time. 
Seasonal Distribution--

April--The first occurrence of alewife larvae in the vicinity of the Campbell Plant was observed in a sled tow sample from station B ( $3 \mathrm{~m}-\mathrm{S})$ on 27 April. Due to the large size of this larva $(18 \mathrm{~mm})$ and cold water temperatures it is probable that this larva was spawned late in 1977, rather than the result of early spawning in 1978 .

May--The first indication of spawning during 1978 was the occurrence of larvae (5-7 mm) in day entrainment samples on 2 May (Fig. 92). This occurrence suggests that some alewife spawning may have occurred as early as late April. Where this early spawning occurred is unknown, but it probably occurred in the Pigeon Lake area, as water temperatures there are generally warmer than in Lake Michigan during April. Length-frequency data (Fig. 92) indicated that those larvae entrained in early May were small (less than $8 \mathrm{~mm}$ ) and were probably hatched within the previous week. No additional alewife larvae were found in entrained water until 30 May even though three samples were collected during intervening times (9, 15 and 24 May). Entrainment samples taken on 30-31 May, as well as one sample taken at the surface near station $Z$ (intake canal) on 30 May showed that alewife concentrations in entrained water were as high as 541 arvae/1000 $\mathrm{m}^{3}$ at this time (Appendixes 14 and 15). Prior to this late May sampling no alewife larvae were found in field samples taken in mid-May, however there were some fish eggs observed in sled tow samples taken at beach and 1.5-m stations, which may be indicative of some alewife (or perhaps spottail shiner) spawning (Appendix 10).

June--The first major occurrence of alewife larvae at Lake Michigan stations in 1978 was observed in early June (6-7). At this time alewife larvae showed highest densities at depths of 1.5-9 $\mathrm{m}$ at both transects (Fig. 93). Densities in deeper water were generally less, and occurrences of alewife larvae were more sporadic. Larval sled tows data also indicated that alewife larvae in early June were common and distributed at $9 \mathrm{~m}$ or less (Fig. 93). Lengthfrequency data from all Lake Michigan surface and midwater larval tows (Fig. 92) showed that mean size of larval alewife in early June was $4.4 \mathrm{~mm}(\mathrm{SE}=<0.1)$. Norden (1967) reported that newly hatched alewife larvae averaged $3.8 \mathrm{~mm}$ and a study by Lam and Rolf (1976) reported a growth rate of $0.5 \mathrm{~mm}$ per day. These studies suggest that those larvae observed in our study area during early June were probably hatched within 1 wk before we collected them. Edsall (1970) indicated that the time from fertilization to hatching averaged about 3.9 days at temperatures of 20-21.1 C, which closely approximated water temperatures in our area in early June. In Pigeon Lake during early June, high concentrations of larvae were observed at 6-m station M (influenced by Lake Michigan) as well as station Z (intake canal) and station X ( undisturbed Pigeon Lake) (Fig. 94). These occurrences suggest that alewife hatching was also occurring in Pigeon Lake during early June. The high densities of larval alewife at stations $M$ and $Z$, however, may not totally be the result of spawning of alewives just in Pigeon Lake. Data collected in 1977 (Jude et al. 1978) suggested that newly hatched alewife larvae from Lake Michigan may get drawn into Pigeon Lake with condenser cooling water, and thus be observed at station M. Many of these alewife larvae may be subsequently entrained. 

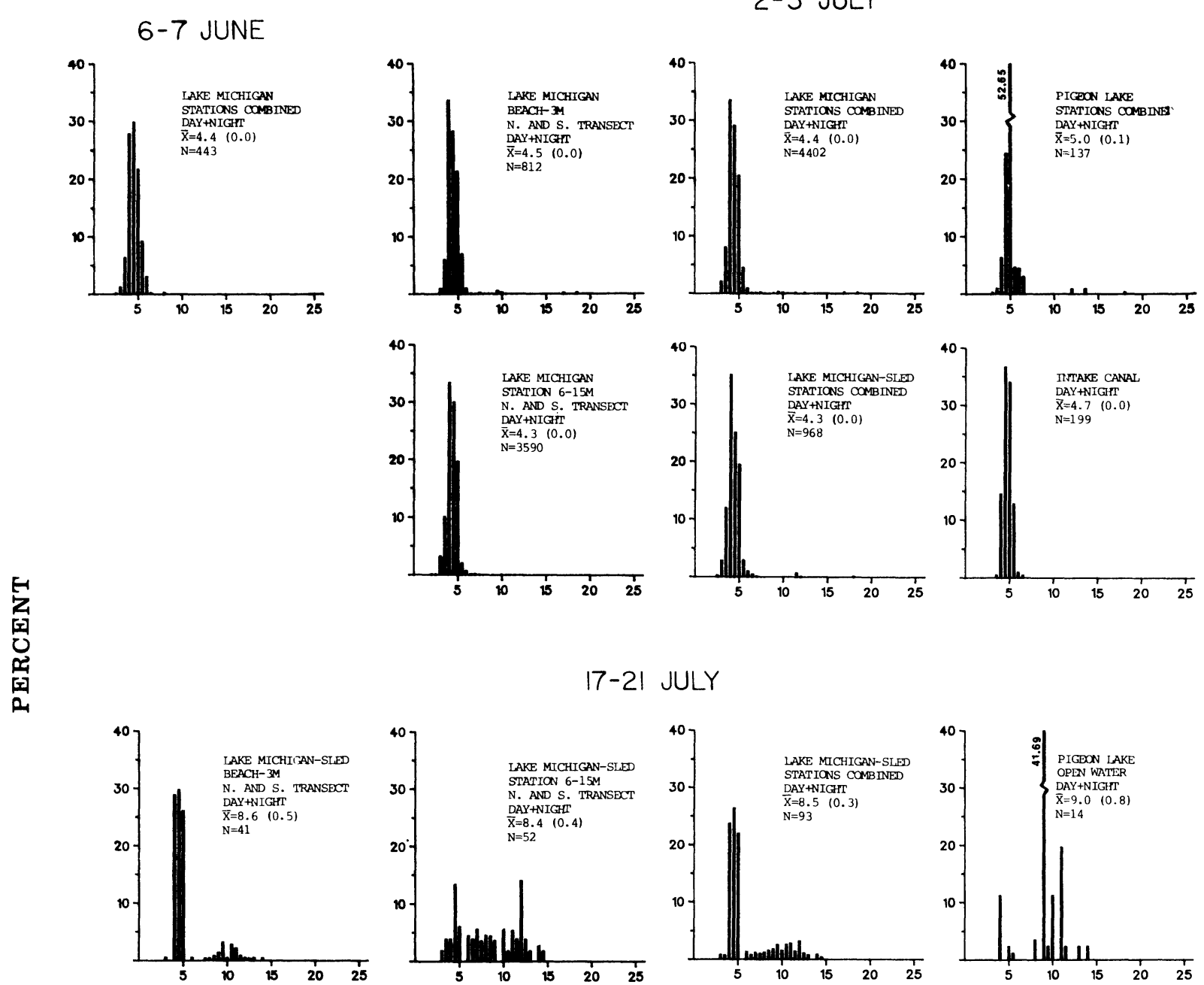

$17-21$ JULY
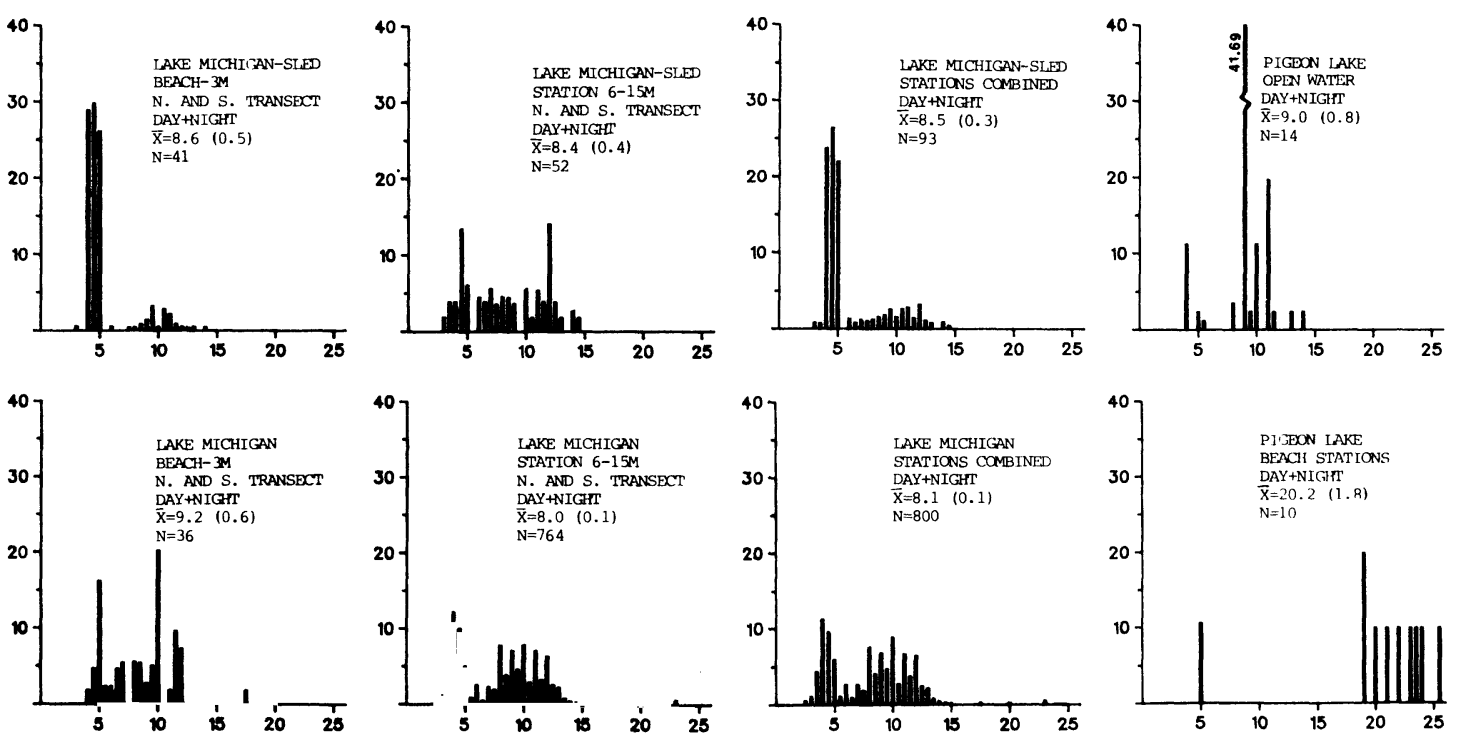

TOTAL LENGTH (mm)

Fig. 92. Length-frequency histograms for larval alewives observed in field and entrainment samples collected during 1978 near the J. H. Campbell Plant, eastern Lake Michigan. All tows were plankton net tows unless sled tows were specified. $\overline{\mathrm{X}}=$ mean, $\mathrm{N}=$ total number of larvae, standard error is given in parentheses. 


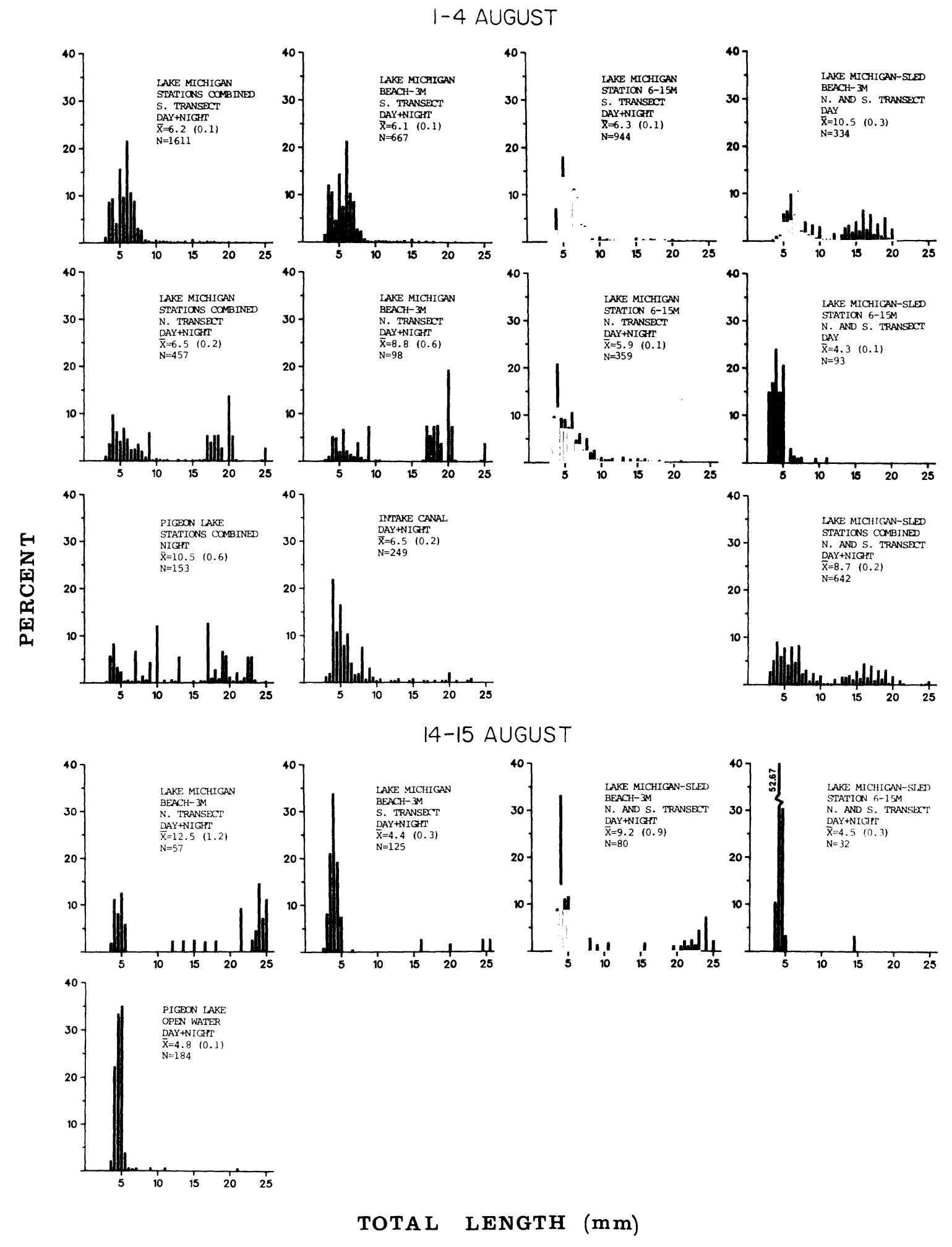

Fig. 92. Continued. 


\section{ENTRAINMENT}
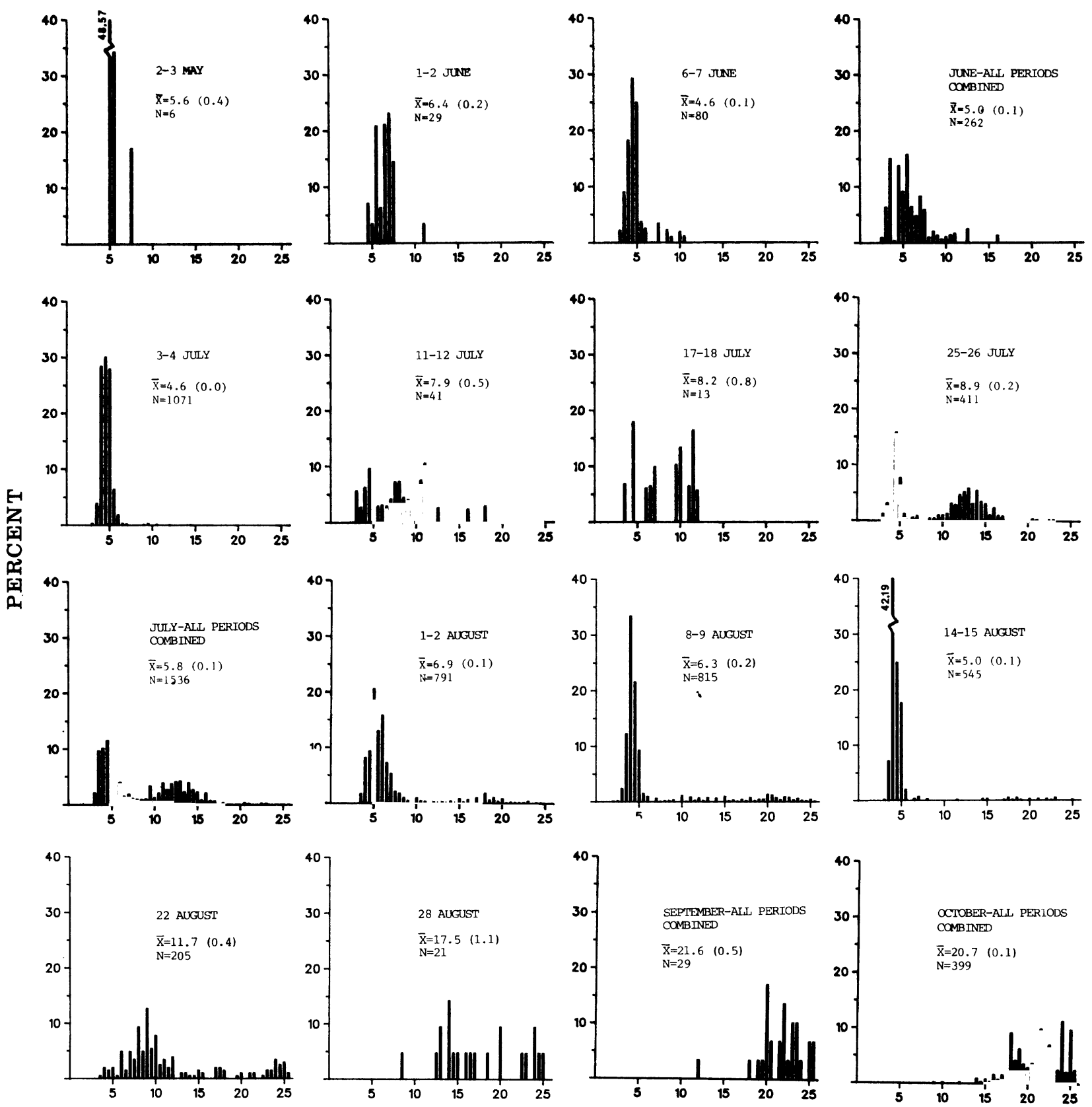

TOTAL LENGTH (m m)

Fig. 92. Continued. 


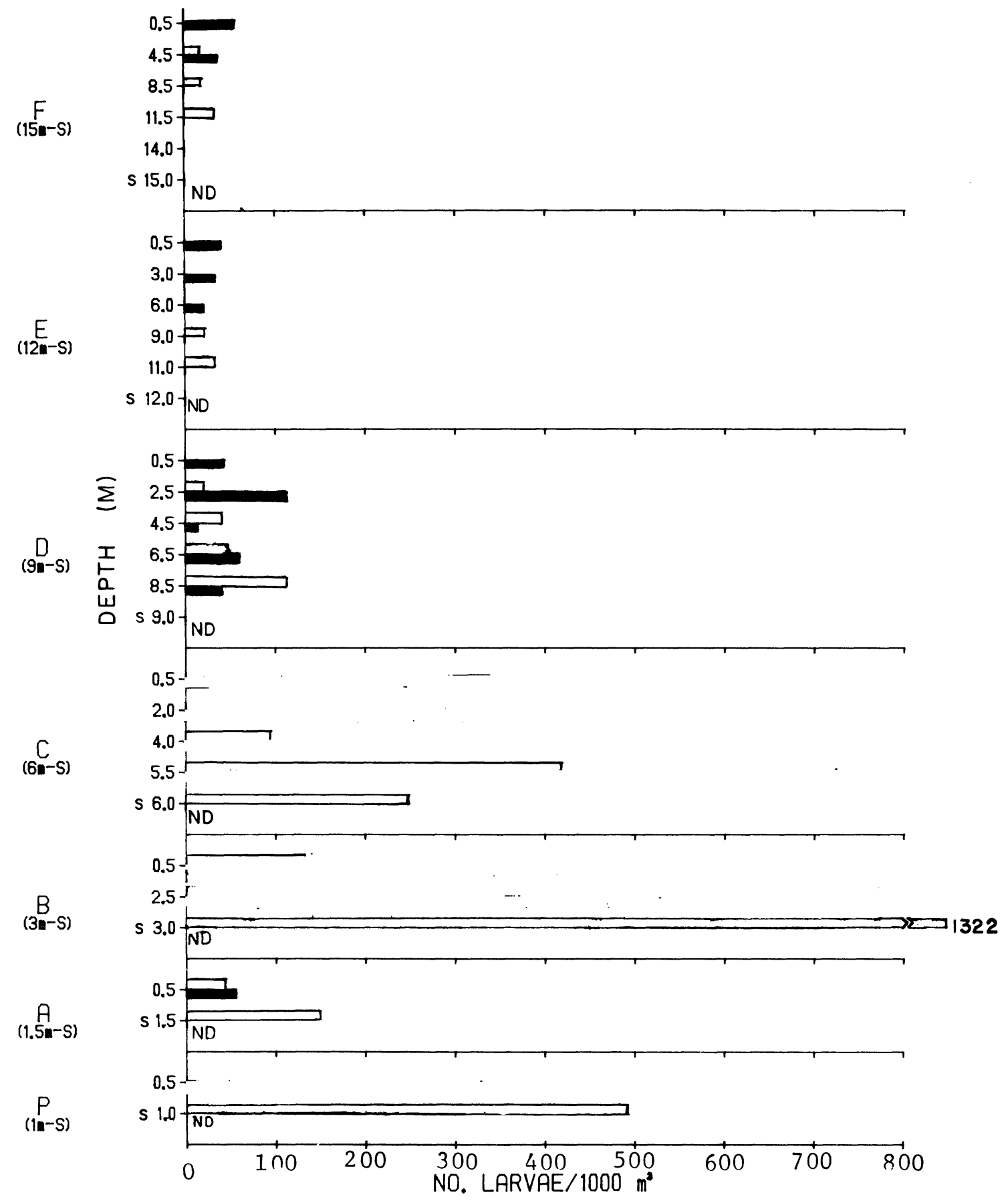

Fig. 93. Density of larval alewives (no./1000 $\mathrm{m}^{3}$ ) at Lake Michigan stations near the J. H. Campbell Plant, eastern Lake Michigan, 6-7 June 1978.

$\square=$ day $\quad$ night $S=$ sled $N D=$ no data 


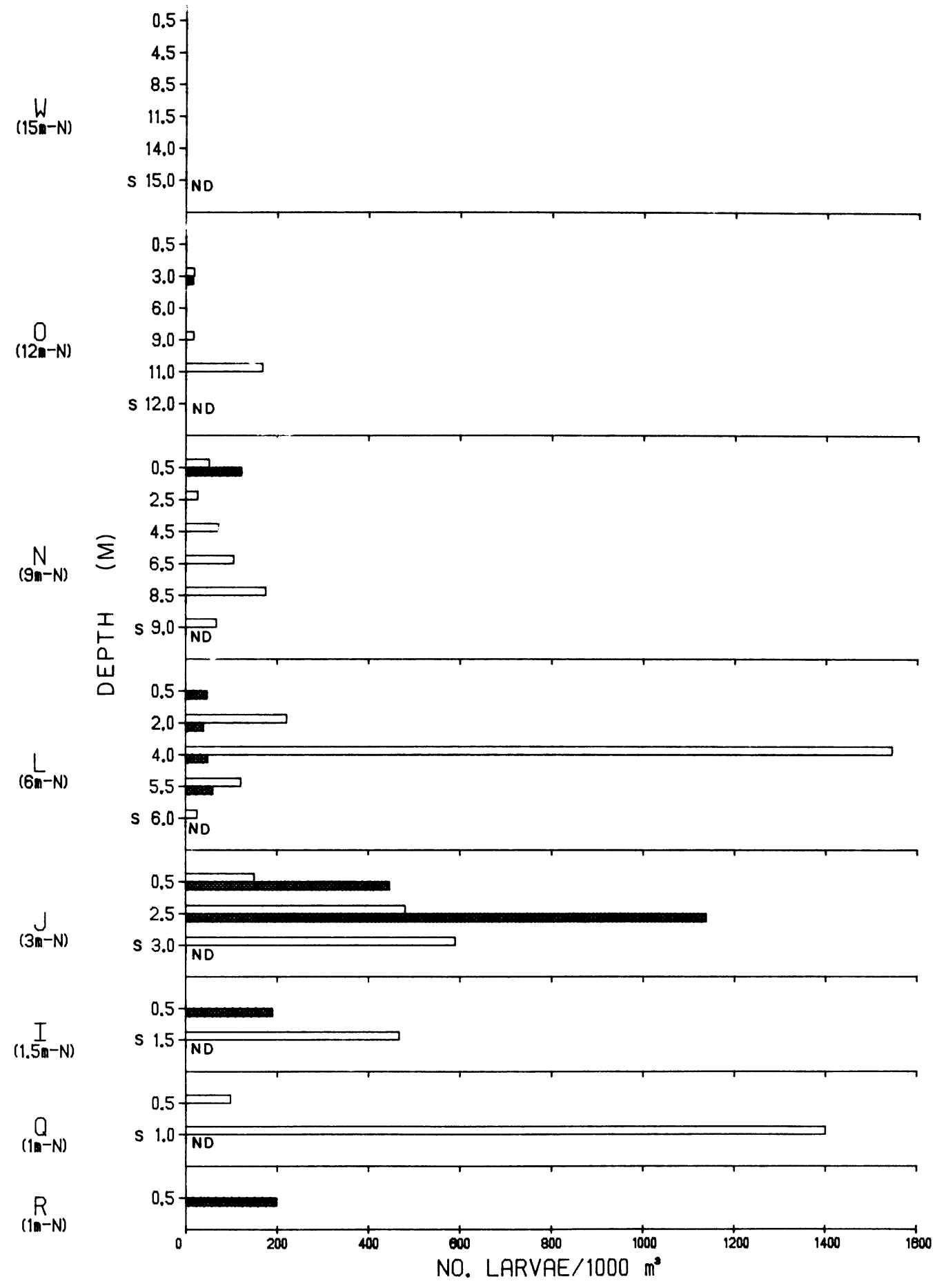

Fig. 93. Continued. 

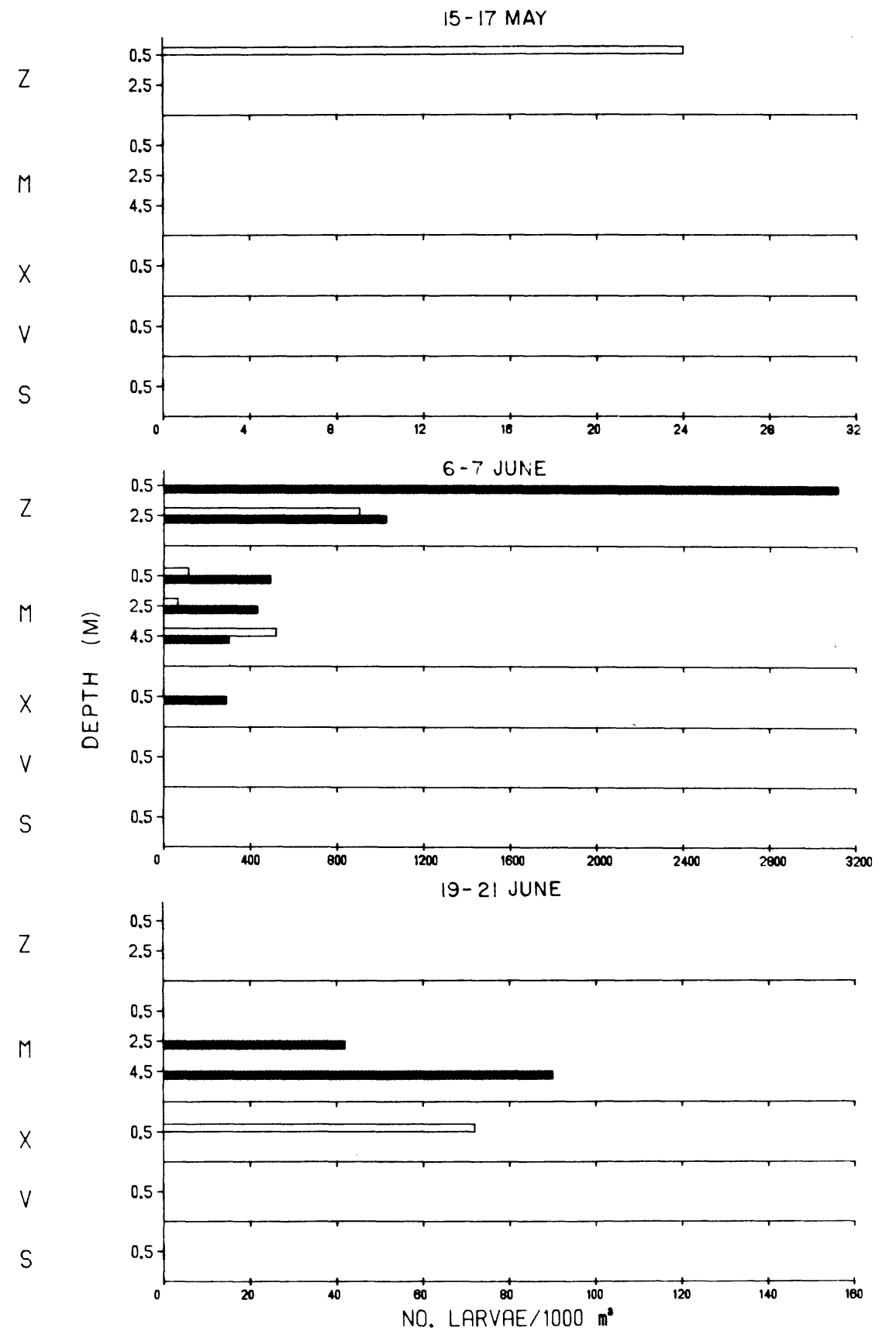

Fig. 94. Density of alewife larvae (no./1000 $\mathrm{m}^{3}$ ) at Pigeon Lake and intake canal stations near the J. H. Campbell Plant, eastern Lake Michigan April to September 1978.

$\square=$ day $\square=$ night 
3-4 JULY

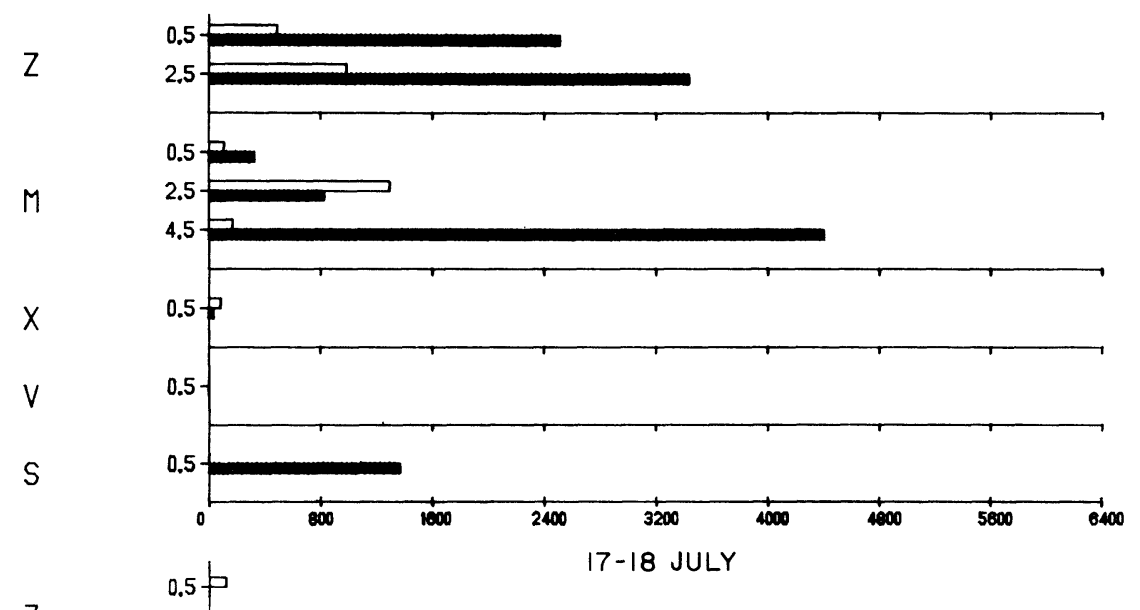

Z

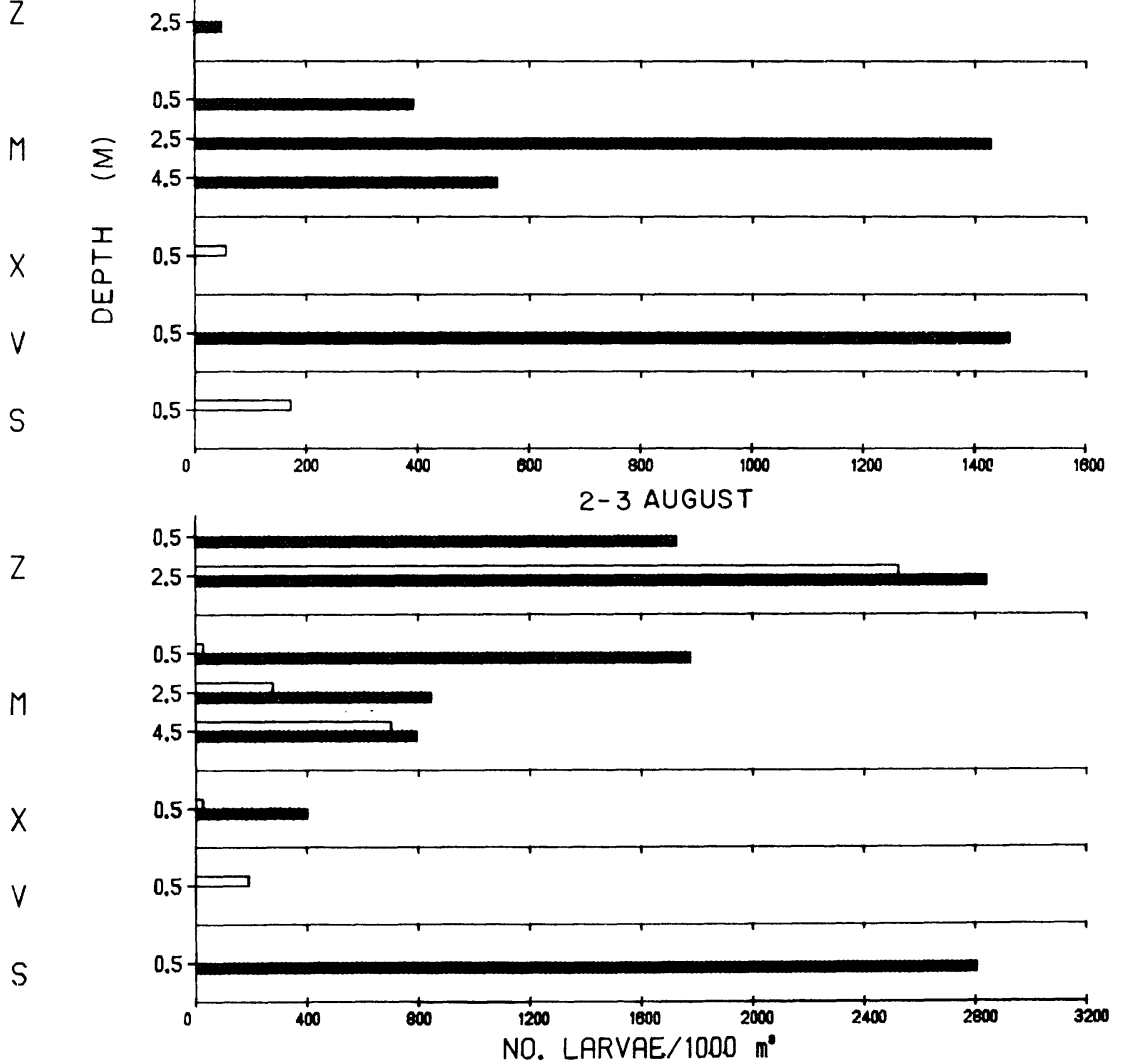

Fig. 94. Continued. 


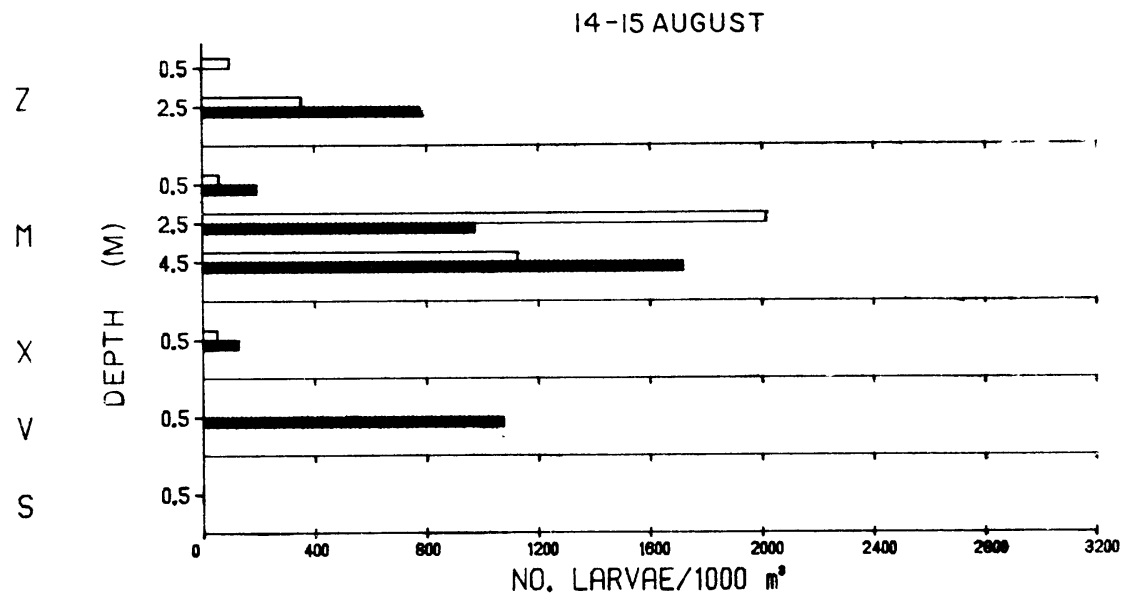

Fig. 94. Continued.

Data collected in early- June (5-7) 1978 are in stark contrast with data collected in early June (1-3) 1977. During June 1977 no larvae were observed at Lake Michigan stations, with the exception of beach station Q (S discharge); whereas, 1978 collections showed that alewife were common at Lake Michigan stations in early June. Differences between years are undoubtedly related to water temperature. Water temperatures at times of sampling during 1977 were mostly less than $12 \mathrm{C}$; whereas, during 1978, water temperatures greater than $16 \mathrm{C}$ were common. Threinen (1958) reported that alewife began spawning at temperatures between 12.8 and $15.5 \mathrm{C}$. Thus it was evident that spawning in Lake Michigan had not taken place by early June 1977. In Pigeon Lake during early June 1977 it was evident that spawning and hatching of alewives was taking place (Jude et al. 1978). Thus, alewives spawned over the same time period in Pigeon Lake during both 1977 and 1978.

Origin of alewife larvae observed in Lake Michigan in early June may not necessarily be the result of alewife spawning in Lake Michigan. Larger rivers entering into Lake Michigan (Grand River, Kalamazoo River, Black River, Pigeon River, Michigan River) may be sites of earlier spawning (late May) of alewives. Alewife eggs and larvae from these areas may be passively carried out into Lake Michigan and transported great distances by alongshore currents. The contention that larvae in early June may not be the result of just Lake Michigan spawning is partially supported by gonad data. No ripe-running alewives were caught at inshore stations during May (see RESULTS AND DISCUSSION - ADULT AND JUVENILE FISH). Earlier (May) alewife spawning in Pigeon Lake was clearly documented by 1977 data (Jude et al. 1978), and suggested by high densities of alewife larvae at 6-m station M (influenced by Lake Michigan) in early June 1978 (Fig. 94). 
Densities of alewife larvae decreased dramatically during late June at both Lake Michigan (Fig. 95) and Pigeon Lake (Fig. 94) stations. These decreased concentrations were probably the result of lower water temperatures retarding the spawning activity of alewives. In general, highest larval alewife concentrations at this time at Lake Michigan stations were found at $3 \mathrm{~m}$ and less. Lower densities were observed at north transect stations, with a more dispersed distribution indicated at south transect stations. In Pigeon Lake in late June, as was observed during early June, no larval alewife were collected at beach stations.

July--The first indication of a major alewife hatching peak during 1978 was observed in early July (Fig. 96), when alewives were observed at all Lake Michigan stations, at all depths, both day and night. Although distributional trends were not conspicuous, it appeared that station Q (S discharge) had the highest densities of alewife larvae in early July (Fig. 96). This may be due to the proximity of this station to the discharge canal, where much spawning activity was observed in early June 1978. The prevailing north to south alongshore current would carry larvae from the discharge canal toward station Q.

Observation of peak numbers of alewife larvae in early July (1-3) during 1978, agrees closely with observations during early July (7-9) 1977 when maximum densities of alewife larvae also were observed. Examination of larval alewife length-frequency data from Lake Michigan in early July (Fig. 92) indicates that mean size of alewife in surface and midwater larval fish tows was $4.4 \mathrm{~mm}(\mathrm{SE}=<0.1)$ similar to that found in early June, and indicative of recent hatching. A comparison of alewife length-frequencies between Lake Michigan open water tows in early July and larval sled tows (Fig. 92) showed no major difference in mean length between those larvae close to the bottom and those distributed at shallower depths in the water column. Length-frequency comparisons of larvae caught in the Lake Michigan beach zone to a depth of $3 \mathrm{~m}$ with those larvae caught at depths 6 to $15 \mathrm{~m}$ in early July also showed no differences between mean lengths (Fig. 92). In general, abundance data as well as length-frequency data indicated that alewives present in early July at Lake Michigan stations were newly hatched and distributed uniformly by length. Random distribution of larvae at this stage would be expected since these larvae $(4-6 \mathrm{~mm})$ are relatively planktonic and subject to passive dispersal by water currents. There were no obvious diel differences in densities of larval alewives at any station or depth with the possible exception of sled tow samples which generally contained higher densities of alewife larvae at night than during the day at depths of $3 \mathrm{~m}$ or greater (Fig. 96).

In Pigeon Lake during early July, alewife concentrations showed considerable increases in densities compared with late June (Fig. 94). Length-frequency data (Fig. 92) indicated that most alewife larvae captured in Pigeon Lake in early July, as was found in Lake Michigan, were recently hatched. There were however, some low percentages of larger (greater than $10 \mathrm{~mm}$ ) larvae in both Pigeon Lake and Lake Michigan which were probably the result of earlier hatching. Larval entrainment data showed that densities of larvae in entrained water in early July were the highest compared with the remainder of July. Length-frequency data from entrainment samples in early July (Fig. 92) were similar to those from Pigeon Lake and Lake Michigan in early July; mean length of alewife larvae being entrained was $4.6 \mathrm{~mm}(\mathrm{SE}=<0.1)$ Entrainment samples taken on 12- 


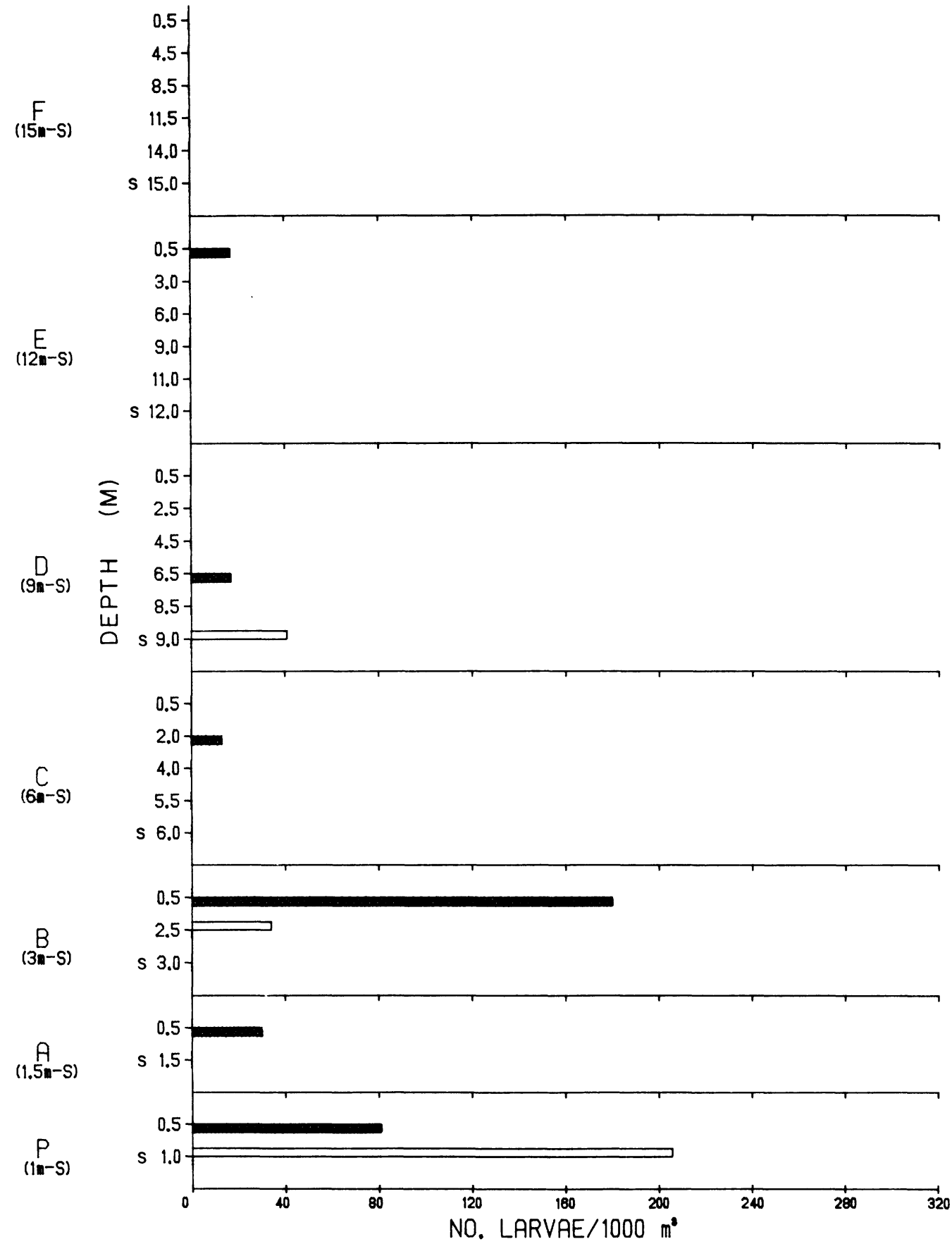

Fig. 95. Density of larval alewives (no./1000 $\mathrm{m}^{3}$ ) at Iake Michigan stations near the J. H. Campbell Plant, eastern Lake Michigan, 19-22 June 1978.

$\square=$ day $\square=$ night $S=$ sled 


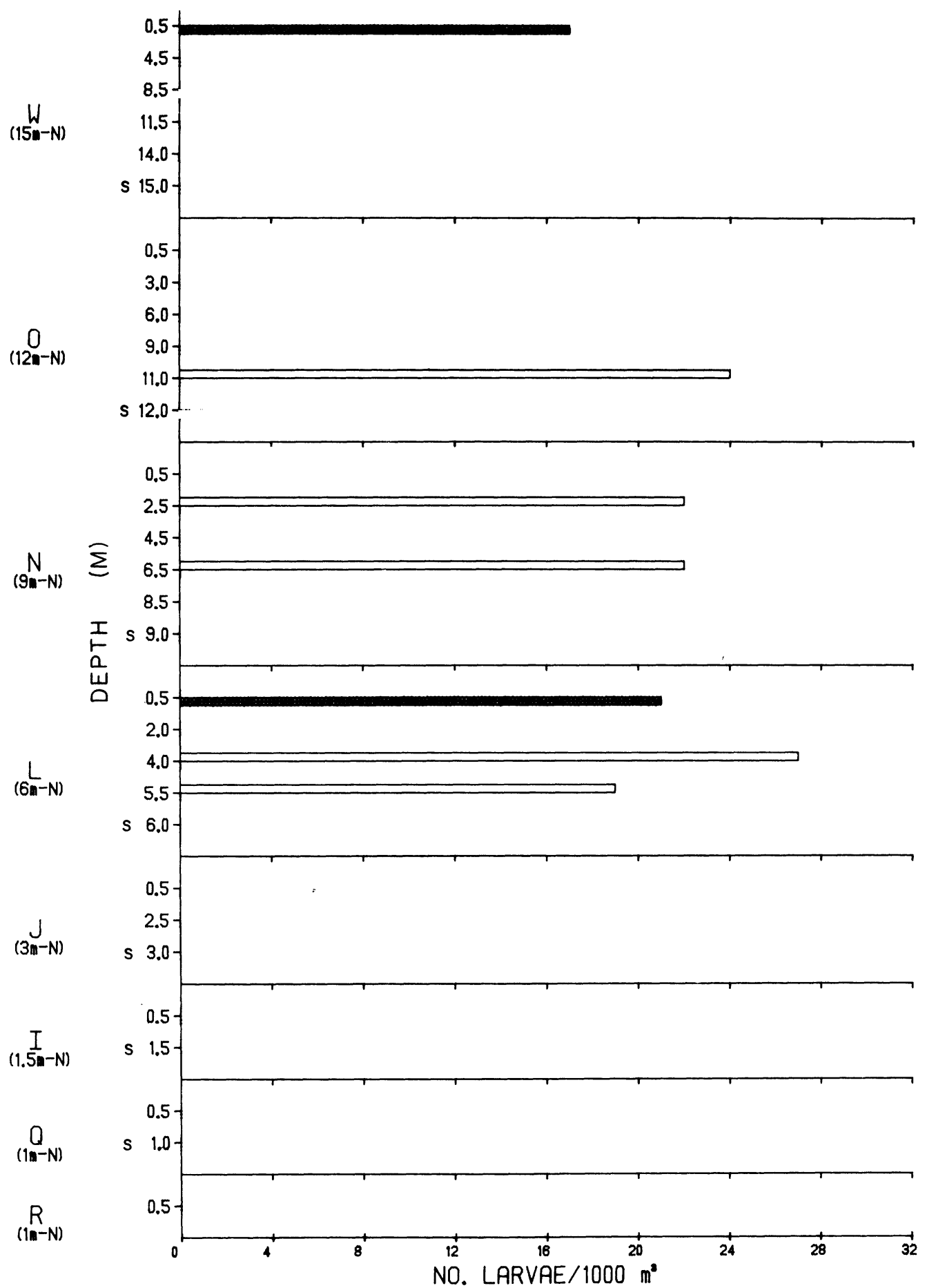

Fig. 95. Continued. 


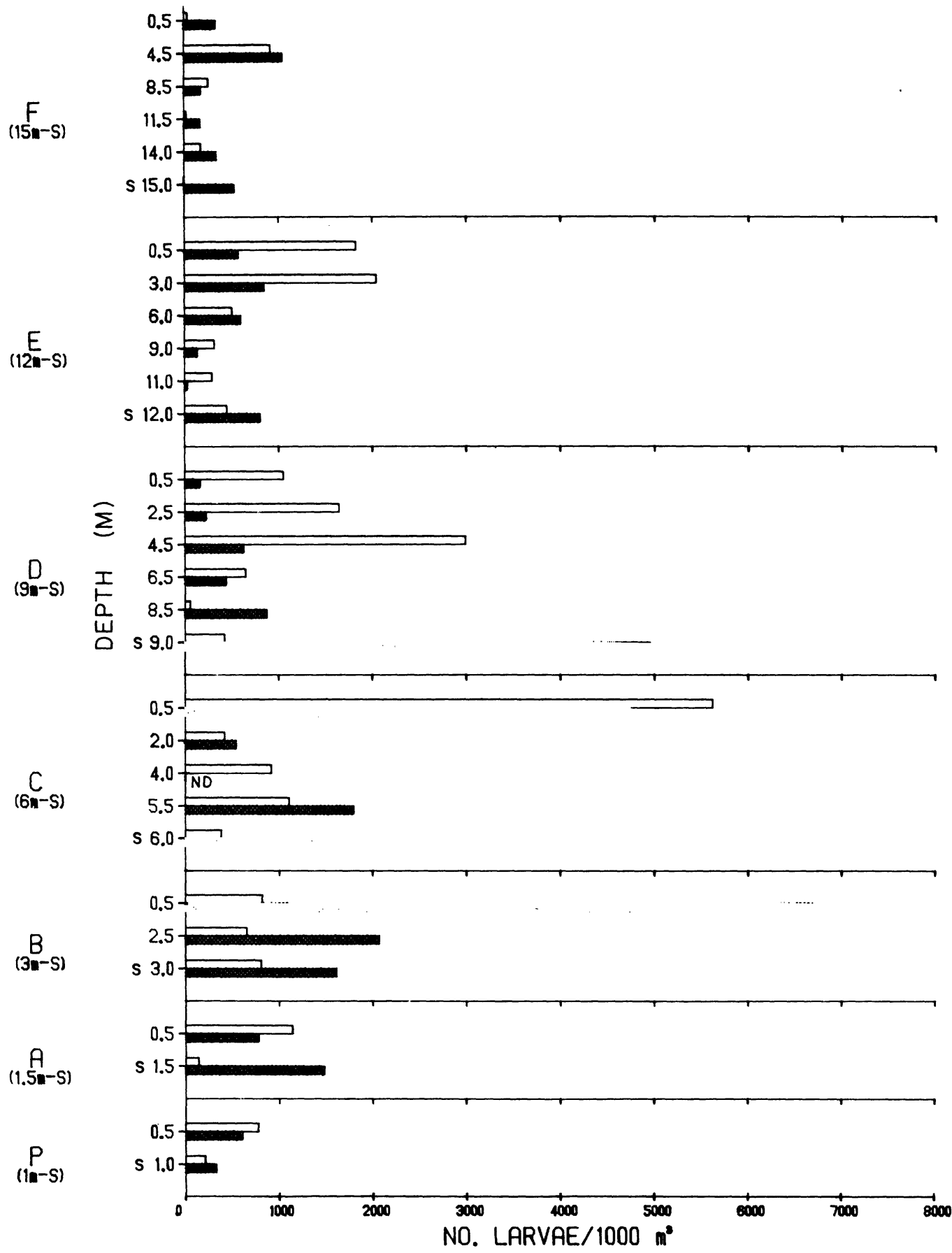

Fig. 96. Density of larval alewives (no./1000 $\mathrm{m}^{3}$ ) at Lake Michigan stations near the J. H. Campbell Plant, eastern Lake Michigan, 1-3 July 1978.

$\square=$ day $\square=$ night $S=$ sled $\quad \mathrm{ND}=$ no data 


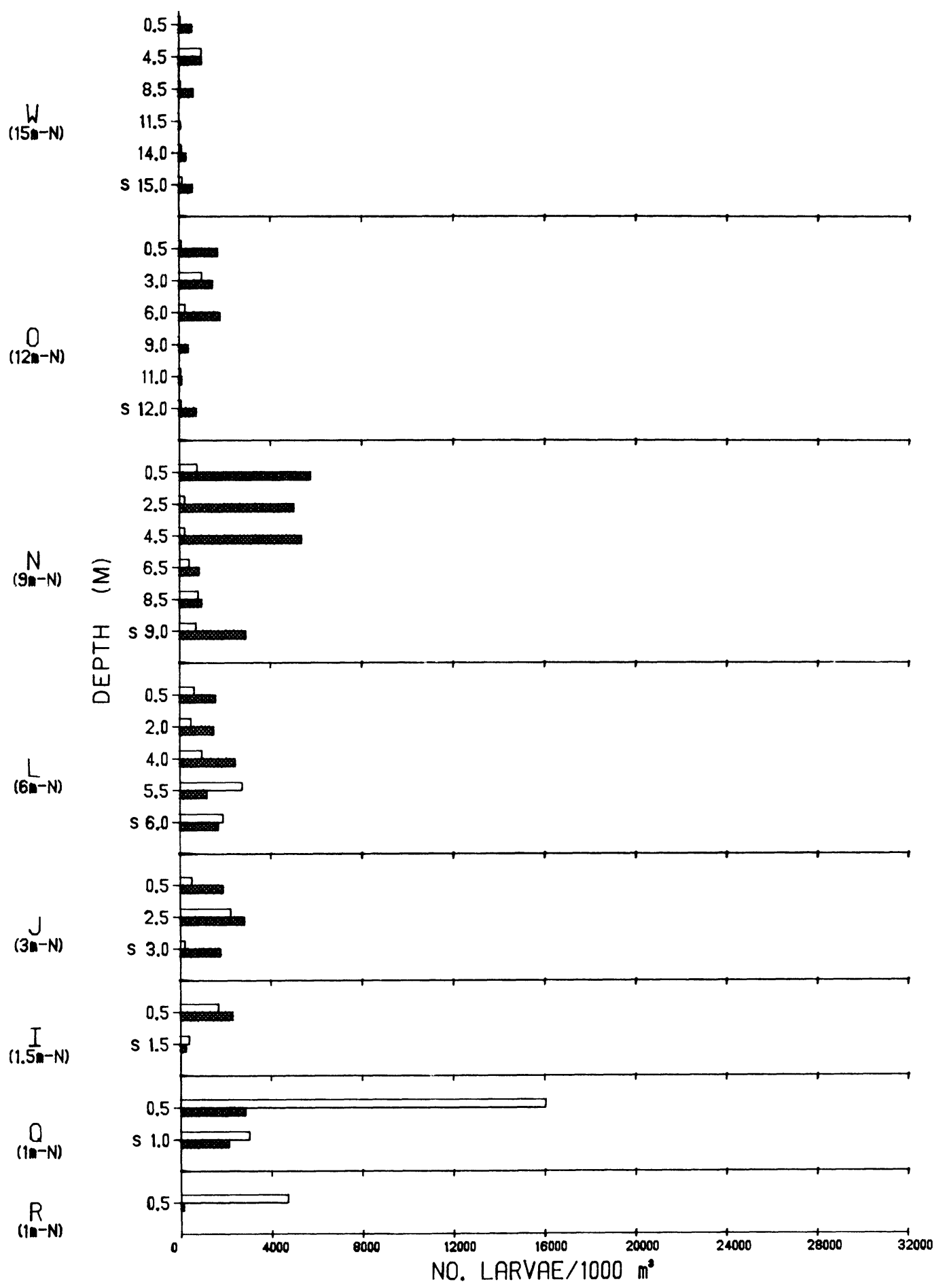

Fig. 96. Continued. 
13 July showed a high variability in lengths of larvae (Fig. 92), as well as decreased larval densities (Appendix 14). No field samples were taken coincident with this 11-12 July entrainment sampling period.

In comparing early July Pigeon Lake field samples and entrainment samples collected in 1978 with those collected in 1977, considerable differences were evident. The most obvious difference was that during early July 1977 the occupation at beach stations S (influenced by Lake Michigan) and V (undisturbed Pigeon Lake) by alewife larvae was much more pronounced compared with early July 1978. The necessary relocation of station $S$ to a less sheltered area during July 1978 may explain the decrease in larval alewife densities observed throughout 1978 compared with 1977. The reason for absence of larval alewives at station $\mathrm{V}$ (undistrubed Pigeon Lake) in early July during 1978 is not understood.

During late July, densities of larval alewives at Lake Michigan stations remained high (Fig. 97). There was, however, a noticeable decrease in numbers of alewife larvae in surface tows at the beach and 1.5-m stations of both transects compared with early July. No larvae were found during the day in surface and 2.5-m tows at our 3-m stations at both transects. Although these data suggested that alewife larvae were for the most part not distributed at depths of $1.5 \mathrm{~m}$ and less, sled tow data for late July indicated that larval alewives were present there (Fig. 97). Densities as high as 3729 larvae/1000 $\mathrm{m}^{3}$ at beach station $P$ (S reference) during day sampling, coincident with no larvae found in surface samples at this station, suggested that at shallower depths, larval alewives in late July were more demersal in behavior.

Examination of length-frequency data from Lake Michigan surface, mid-water and sled tow samples (Fig. 92) showed a much wider range of larval fish lengths in late July than was observed during early July. The continued presence of small (less than $5 \mathrm{~mm}$ ) larvae indicated continued alewife spawning activity during July. Length-frequency data from surface and mid-water larval fish tows in Lake Michigan during late July indicated some difference in the size of larvae at depths of $3 \mathrm{~m}$ and less compared with depths of $6 \mathrm{~m}$ and more (Fig. 92). Mean length of alewife larvae at shallower stations was $9.2 \mathrm{~mm}(\mathrm{SE}=0.6)$; whereas, alewives at deeper stations averaged $8 \mathrm{~mm}(\mathrm{SE}=0.1)$. Length-frequency data from sled tows were consistent with results from surface and mid-water Iarval fish tows, as the mean length of alewife larvae at shallower stations (Fig. 92) was slightly greater (mean $=8.6 \mathrm{~mm}, \mathrm{SE}=0.5$ ) compared with deeper stations (mean $=8.4 \mathrm{~mm}, \mathrm{SE}=0.4$ ).

In Pigeon Lake during late July changes were observed in both abundance and distribution of larval alewives compared with early July (Fig. 94). Larval alewives were abundant at 6-m station M (influenced by Lake Michigan) and beach station $\mathrm{V}$ (undisturbed Pigeon Lake), but only in samples taken during the night (Fig. 94). This distribution pattern is contrary to patterns observed in early July when larval alewife were concentrated at $6-\mathrm{m}$ station M during the day and absent from beach station $V$. The reason for the general decrease in larval alewife concentrations may be related to water temperature. Temperature at station M (influenced by Lake Michigan) dropped below $12 \mathrm{C}$ in late July (Appendix 13). If this temperature was indicative of lower temperatures prior to our sampling date, alewife spawning and hatching may have ceased 


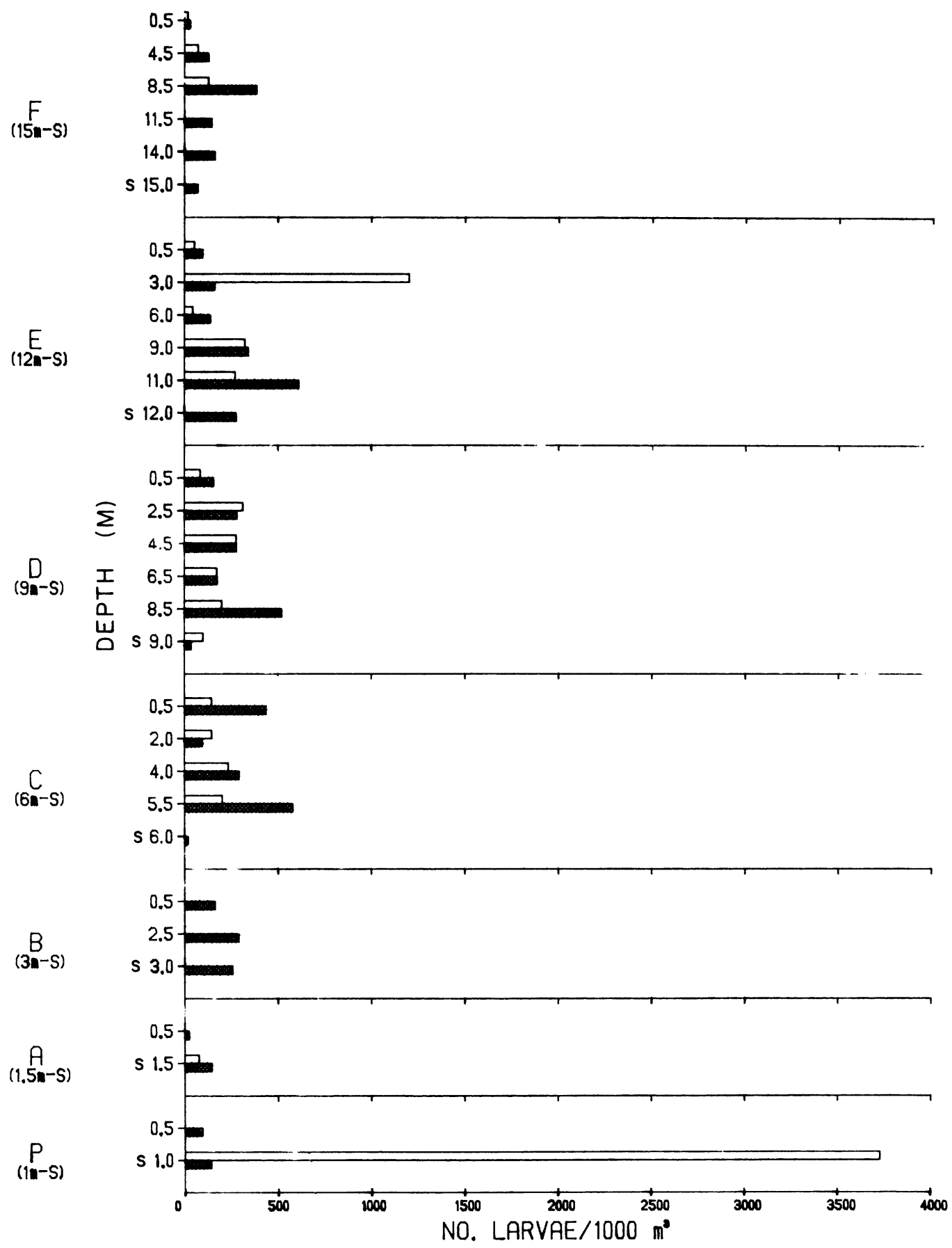

Fig. 97. Density of larval alewives (no./1000 $\mathrm{m}^{3}$ ) at Lake Michigan stations near the J. H. Campbell Plant, eastern Lake Michigan, 17-19 July 1978. $\square=$ day $\square=$ night $S=$ sled 


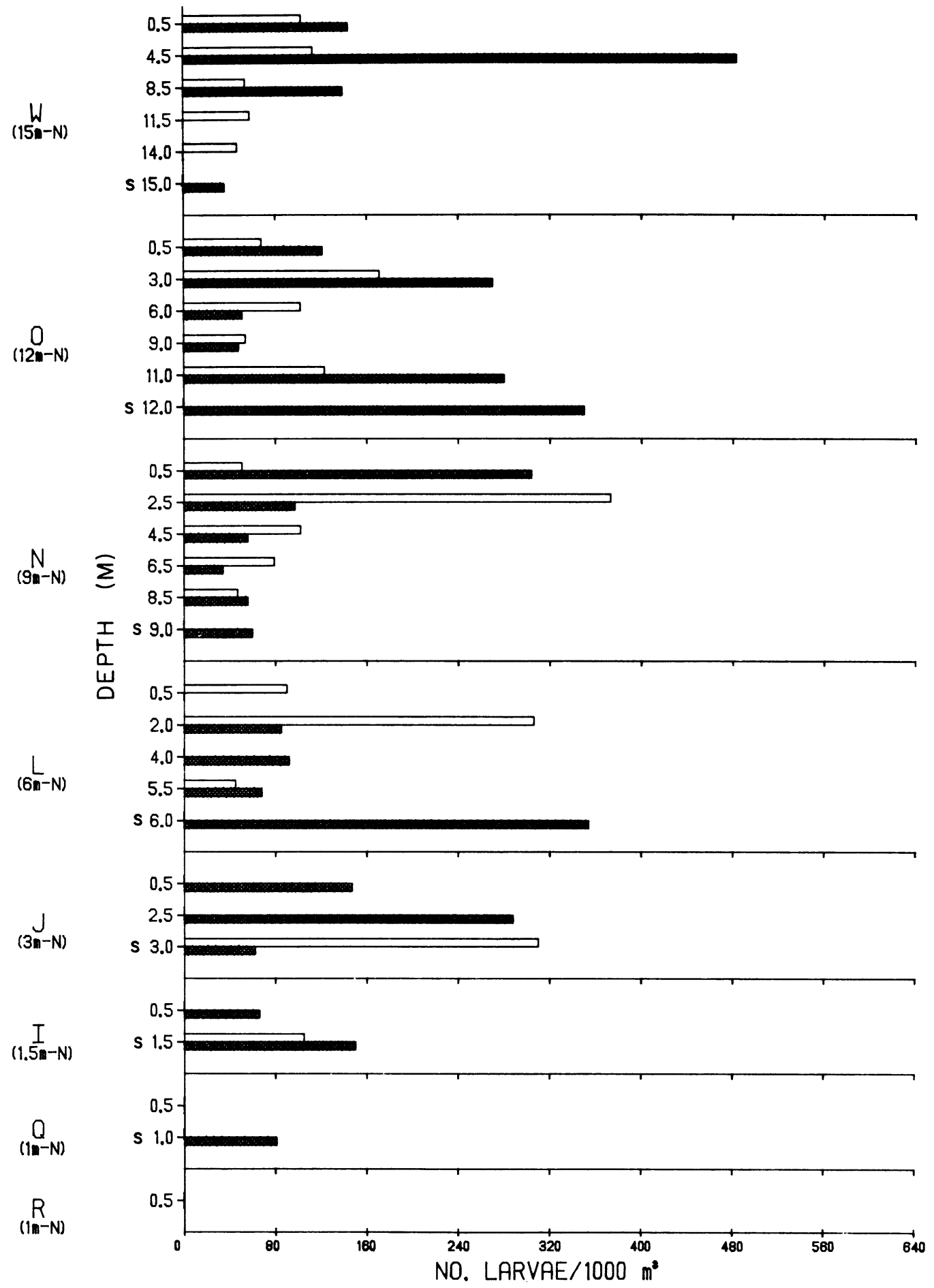

Fig. 97. Continued. 
until temperatures increased again. Low densities of larval alewives were observed during late July at station X (undisturbed Pigeon Lake) and beach station $S$ (influenced by Lake Michigan). Length-frequency data clearly show a segregation of larval alewife with depth (Fig. 92). Larger larvae tended to be distributed closer to shore in the beach zone, compared with smaller larvae which were dispersed more in open water. Tows done at station Z (intake canal) yielded only two alewife larvae which were both less than $10 \mathrm{~mm}$. This pattern in which a higher percentage of smaller alewife larvae tend to be distributed at deeper stations; whereas, larger alewife larvae tend to be more concentrated near shore was also observed by Jude et al. (1978) during 1977 and Jude et al. (1979) at the Cook Plant. It is possible that either small larvae are swept away from shore areas, or that their movement is more random compared with older larger larvae which may have developed the ability to orient themselves toward shore.

Entrainment samples in late July showed considerable variation in their larval alewife densities (Appendix 14). The two sampling periods 11-12 July and 17-18 July had low densities (6-95 larvae/1000 $\mathrm{m}^{3}$ ) of larvae compared with 3-4 Julv (362-1460 larvae/1000 $\mathrm{m}^{3}$ ) and 25-26 July (181-564 larvae/1000 $\mathrm{m}^{3}$ ). Compared with early July data, decreased densities of alewife larvae were found in field samples from Pigeon Lake, 6-m station M (influenced by Lake Michigan) during late July and in entrainment samples from 11-12 and 17-18 July. These declines were undoubtedly related to a water temperature drop. Water temperatures during 11-12 July and 17-18 July were $13 \mathrm{C}$ or less, temperatures which may have depressed alewife hatching and retarded spawning activity; whereas, temperatures during 3-4 July and 25-26 July were $17.9 \mathrm{C}$ or warmer and were much more conducive to hatching and spawning of alewife.

Length-frequency data from all entrainment samples in July (Fig. 92) showed alewives with a wide range of sizes were entrained; however, highest percentages of entrained larvae were less than $10 \mathrm{~mm}$ (mean $=5.8, \mathrm{SE}=0.1$ ). We concluded from last year's data (Jude et al. 1978) that small alewife larvae, less than $10 \mathrm{~mm}$, were probably passively carried into the plant by intake currents.

August--During early August, concentrations of alewife larvae at Lake Michigan stations remained high (Fig. 98). Generally alewife larvae were more abundant near the surface at $9 \mathrm{~m}$ or less. At 12 and $15 \mathrm{~m}$ larval alewives in early August were still fairly abundant. in upper strata, with a trend toward decreased and more sporadic occurrence in the lower strata at these stations. Larval sled tow samples concurred with observations deduced from surface and mid-water tows, showing that at 12 and $15 \mathrm{~m}$ there were decreased densities of alewife larvae on the bottom compared with upper strata densities at these depths and sled tow densities at the 1- to 9-m contours (Fig. 98).

There were distinct differences in alewife length-frequency histograms between north and south transect stations in early August, with a higher percentage of larger alewife larvae observed at north transect stations near the present thermal discharge (Fig. 92). A further breakdown of these data showed that the major difference in length frequencies between these two transects was at shallower stations ( $3 \mathrm{~m}$ and less) (Fig. 92). Length-frequency histograms for 


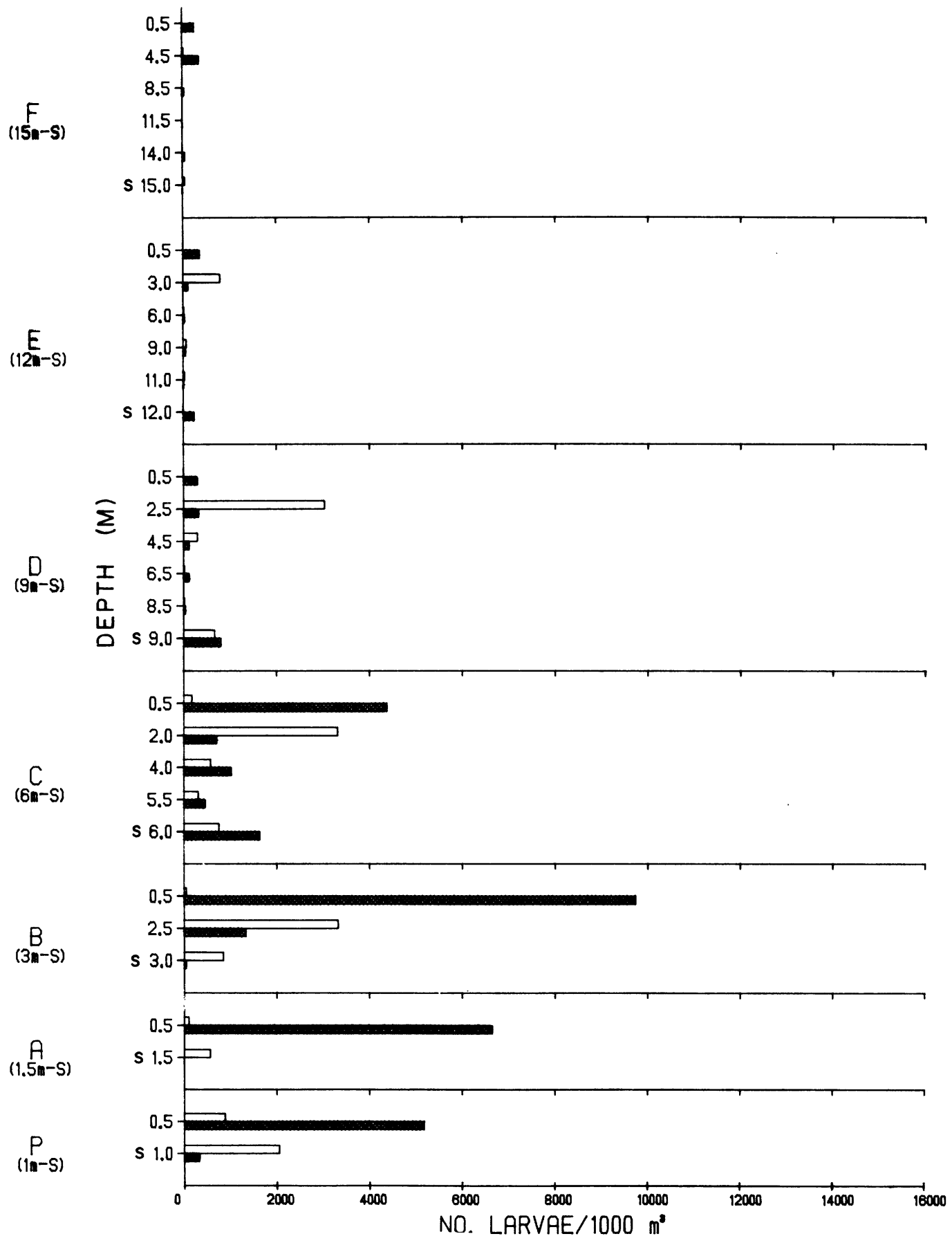

Fig. 98. Density of larval alewives (no./1000 $\mathrm{m}^{3}$ ) at lake Michigan stations near the J. H. Campbell Plant, eastern Lake Michigan, 1-4 August 1978.

$\square=$ day $\square=$ night $S=$ sled $\quad \mathrm{ND}=$ no data 


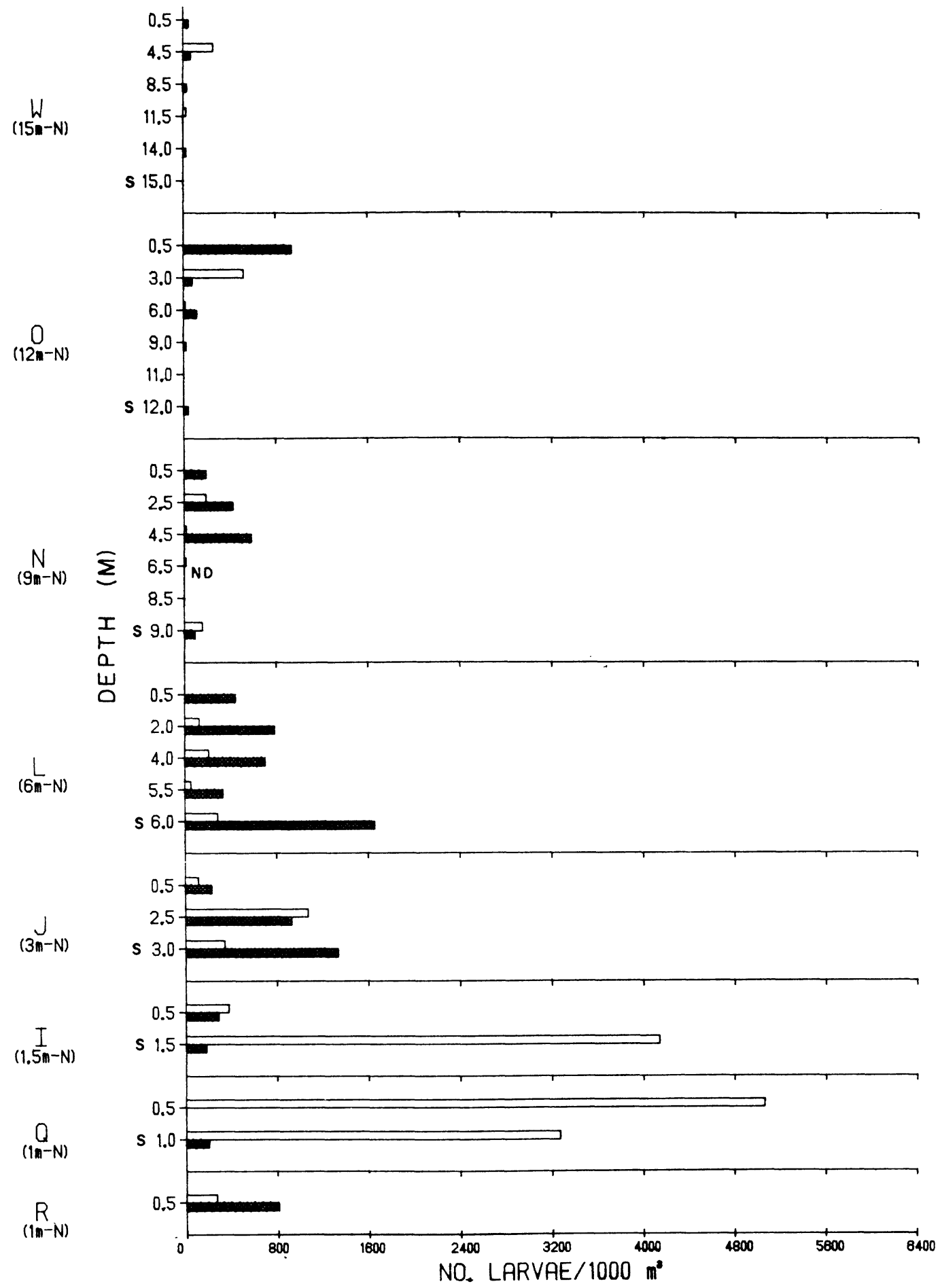

Fig. 98. Continued. 
alewives from north transect stations $6 \mathrm{~m}$ and deeper were similar to those from equivalent south transect stations. A comparison of alewife length frequencies from shallow stations ( $3 \mathrm{~m}$ and less) indicated that a greater proportion of larger (greater than $15 \mathrm{~mm}$ ) larvae were present at north transect stations compared with the reference transect. This trend was also observed in July 1977 (Jude et al. 1978). The reason for this distributional pattern is not known, but it may be that the area of the discharge was a site for early alewife spawning which is corroborated by a higher percentage of larger larval alewive present there in early August. Another possibility is that higher turbidity in the discharge area (secchi disc reading $0.8 \mathrm{~m}$ compared with 1.5 $\mathrm{m}$ at south transect stations during August 1978) increased the efficiency of our larvae nets by decreasing net avoidance. The latter possibility however would not explain the occurrence of this pattern in July 1977.

Examination of length-frequency data from larval sled tows in early August clearly shows a size segregation of alewife larvae by depth (Fig. 92). Sled tow samples taken at $6 \mathrm{~m}$ or greater had no alewife larvae exceeding $12 \mathrm{~mm}$; whereas, sled tow samples taken at $3 \mathrm{~m}$ or less in early August had high percentages of alewife larvae exceeding $12 \mathrm{~mm}$. This trend was widespread among all surface and midwater samples examined in early August in Lake Michigan (Fig. 92), however the high occurrence of larger alewife larvae in the immediate area of the discharge (stations $3 \mathrm{~m}$ and less, north transect) confounded a general inshore-offshore comparisons.

In Pigeon Lake during early August alewife larvae were also still abundant, particularly in samples taken at night. Perusal of corresponding length-frequency data (Fig. 92) indicated that larger alewife larvae were more prominent at night (Fig. 94). This suggestes that net avoidance may be responsible for our decreased alewife larvae catch during the day. Particularly high densities (1514-4097 larvae/1000 m3) of alewife larvae were present at beach station S (influenced by Lake Michigan) in early August, particularly in night samples. This shallower habitat in Pigeon Lake appears to be preferred by larger alewife larvae, although length-frequency data from 6-m station $M$ (influenced by Lake Michigan) and station $X$ (undistrubed Pigeon Lake) indicated that high percentages of larger alewife larvae were also present at deeper stations.

Densities of alewife larvae in entrained water were relatively high (257-612 larvae/1000 $\mathrm{m}^{3}$ ) in early August (Appendix 14), as were concentrations of larvae in the intake canal (station $\mathrm{Z}$ ). Alewife length-frequency distributions from these two stations in early August were similar (Fig. 92), suggesting that larvae (particularly those less than $10 \mathrm{~mm}$ ) observed in the intake canal probably were those eventually entrained.

In agreement with what was observed at Lake Michigan stations in the late August sampling period (16-19) 1977 (Jude et al. 1978), alewife larvae continued to be abundant during late August (13-15) 1978 at Lake Michigan stations. Larvae tended to be more concentrated at $6 \mathrm{~m}$ or less during the day, with sporadic high densities observed at deeper stations (Fig. 99). The reason for no alewives being caught during the day and increased frequency of alewife larvae encountered at night at deeper stations may be due to daytime net avoidance. 


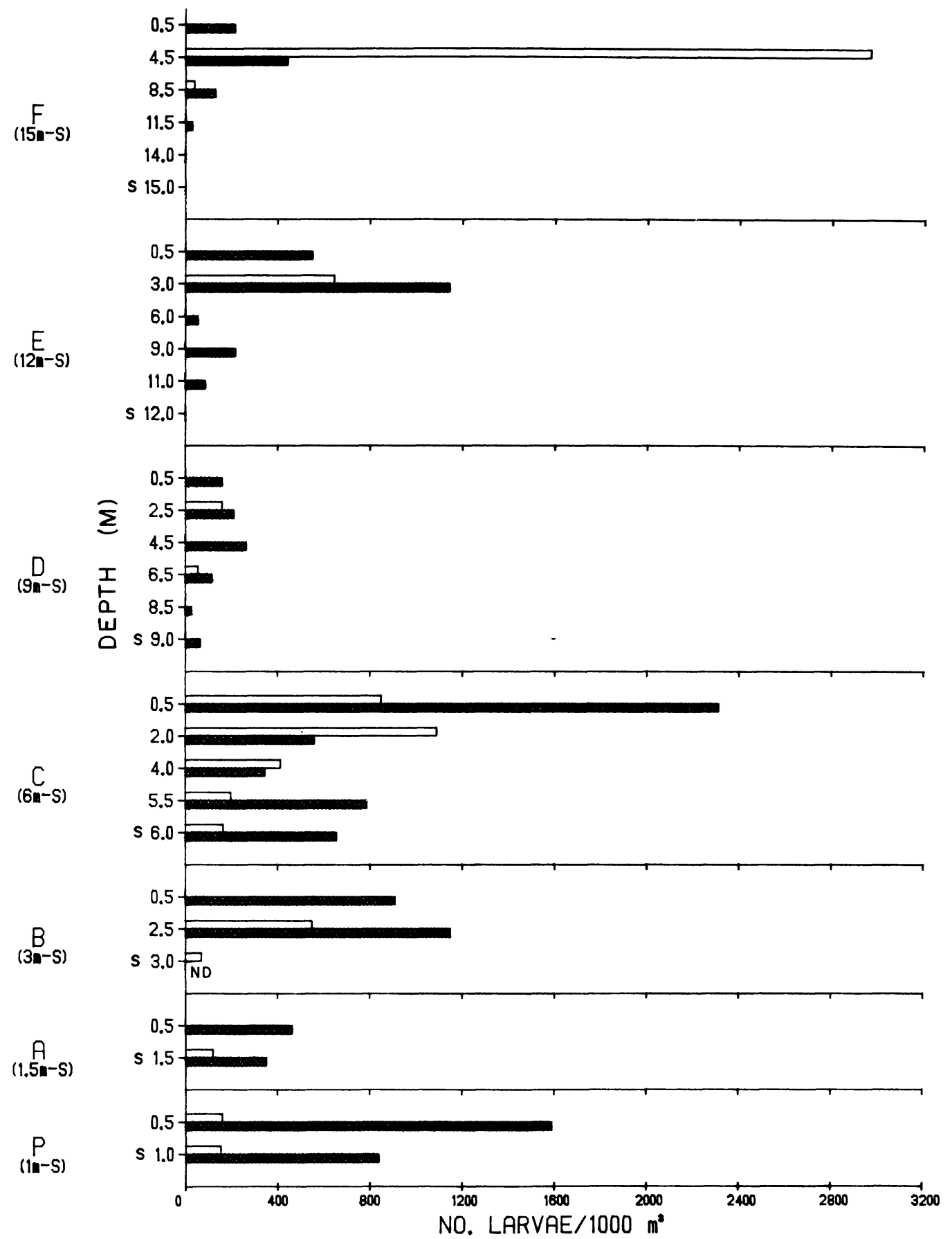

Fig. 99. Density of larval alewives (no./1000 $\mathrm{m}^{3}$ ) at Lake Michigan stations near the J. H. Campbell Plant, eastern Lake Michigan, 14-15 August 1978.

$\square=$ day $\square=$ night $\mathrm{S}=$ sled $\mathrm{ND}=$ no data 


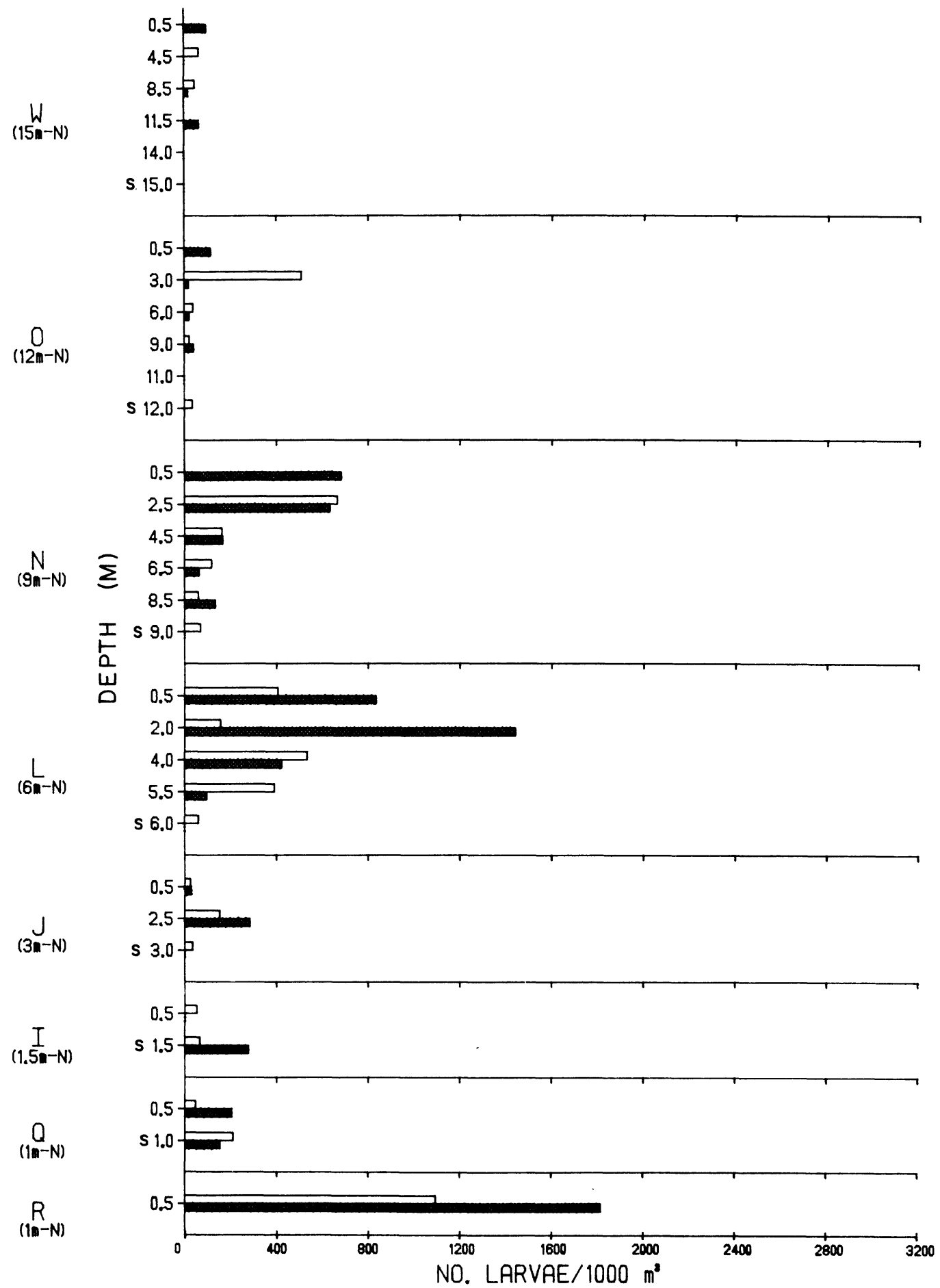

Fig. 99. Continued. 
During late August many of the trends in length-frequency data evident in early August were again repeated. A higher occurrence of larger (10 mm or larger) alewives was observed at $3 \mathrm{~m}$ or less at north transect stations when compared with corresponding stations on the south transect. Sled tow data again indicated that smaller larvae were more frequent at deeper ( $6 \mathrm{~m}$ or more) stations, and that larger alewife larvae were distributed more toward shore ( $3 \mathrm{~m}$ or less).

In Pigeon Lake the abundance of alewife larvae at station M (influenced by Lake Michigan) in late August (Fig. 94) remained high (60-2016 larvae/1000 m3). In contrast to early August however, no alewife larvae were found at beach station S (influenced by Lake Michigan). Length-frequency data from station $M$ and station $X$ (undisturbed Pigeon Lake) showed that most larvae at these stations were smal1 (mean $=4.8 \mathrm{~mm}, \mathrm{SE}=0.1$ ). In contrast, of the three larvae caught at Pigeon Lake beach stations, two exceeded $22 \mathrm{~mm}$. These larvae were caught at night, and may suggest that larger larvae may be present at beach stations in Pigeon Lake during the day, but may be avoiding the net. Entrainment of alewife larvae for the latter part of August continued at high levels (67-629 larvae/1000 $\mathrm{m}^{3}$ ) for sampling periods 8-9, 14-15 and 22 August (Appendix 14). Significant decreases in densities of alewife larvae in entrained water were observed on 28 August (5-24 larvae/1000 $\mathrm{m}^{3}$ ). This decreased concentration observed on the last sampling period in August may be due to decreased recruitment of newly hatched larvae to entrained water. Length-frequency data from the late August sampling period indicate that only $5 \%$ of the larvae entrained were shorter than $10 \mathrm{~mm}$. The shift toward a prominence of larger larvae and decreased percentage of newly hatched larvae was first observed in 22 August entrainment samples (Fig. 92). In general, larger larvae are less susceptible to entrainment, and thus as larger larvae become more prominent in collections, less entrainment would be expected.

September, October-- The final sampling period for Lake Michigan stations on 20 September indicated that alewife larvae were present in low densities (13-31 larvae/1000 m3) at $6-12 \mathrm{~m}$. Densities of 68 and 65 alewife larvae/ $1000 \mathrm{~m}^{3}$ (Fig. 100) were observed at heach station Q. (S discharge). Sled tow data indicated low abundance of alewife larvae (33 and 441 arvae/1000 $\mathrm{m}^{3}$ ) at beach station Q (S discharge) and station L $(6 \mathrm{~m})$. As would be expected from 1977 data (Jude et a1. 1978) recruitment of newly hatched larvae was not evident during late September. All larvae caught in September in Lake Michigan were $15 \mathrm{~mm}$ or longer. Spawning probably ceased sometime in August.

Alewife larvae were absent from samples collected during September and October in Pigeon Lake. Larvae apparently had moved out of Pigeon Lake (or at least to deeper water) as few YOY alewives were seined during this time.

\section{Entrainment--}

April, May-- Larval alewives were first observed in very low ( 8 larvae/ $1000 \mathrm{~m}^{3}$ ) densities in entrainment samples collected on 2 May 1978 (Fig. 101). Since larvae had a mean length of $5.6 \mathrm{~mm}(\mathrm{SE}=0.4)$ (Fig. 92), we assumed that they had been recently hatched, probably at some location in Pig.eon Lake. Water temperatures in Lake Michigan during April were too cold (1ess than $10 \mathrm{C}$ ) 

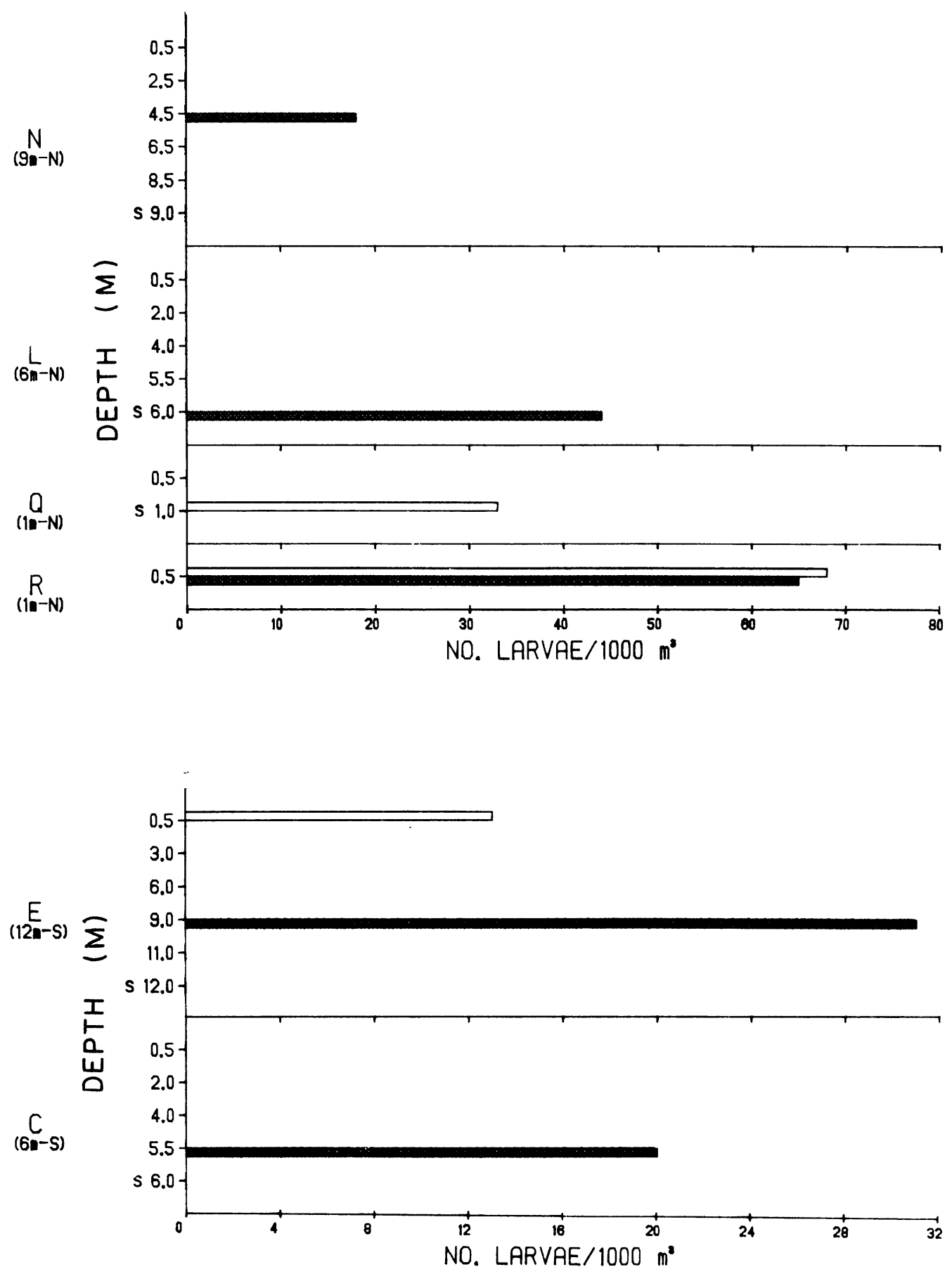

Fig. 100. Density of larval alewives (no./1000 $\mathrm{m}^{3}$ ) at Lake Michigan stations near the J. H. Campbell Plant, eastern Lake Michigan, 18-20 September 1978. Stations $1-3 \mathrm{~m} \mathrm{~S}, 9 \mathrm{~m} \cdot \mathrm{S}$ and $15 \mathrm{~m} \cdot \mathrm{S}$ as well as $1.5-3 \mathrm{~m} \cdot \mathrm{N}$ and $12-15 \mathrm{~m} \cdot \mathrm{N}$ were omitted due to absence of larvae in samples. $\square=$ day $\square=$ night $S=$ sled 

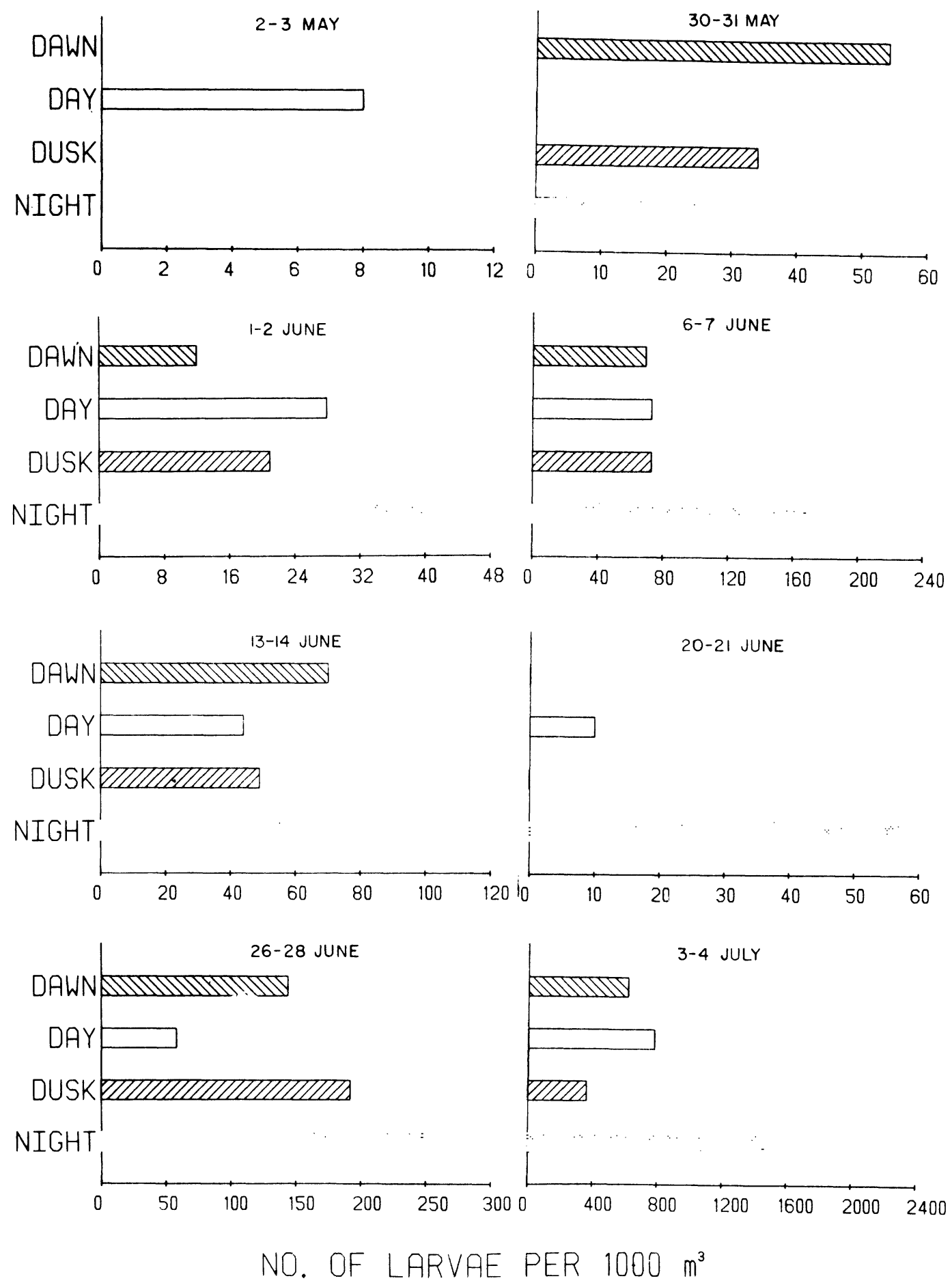

Fig. 101. Density of alewife larvae (no./1000 $\mathrm{m}^{3}$ ) collected in weekly dawn, day, dusk and night entrainment samples at the J. H. Campbell Plant, eastern Lake Michigan, 1978. 

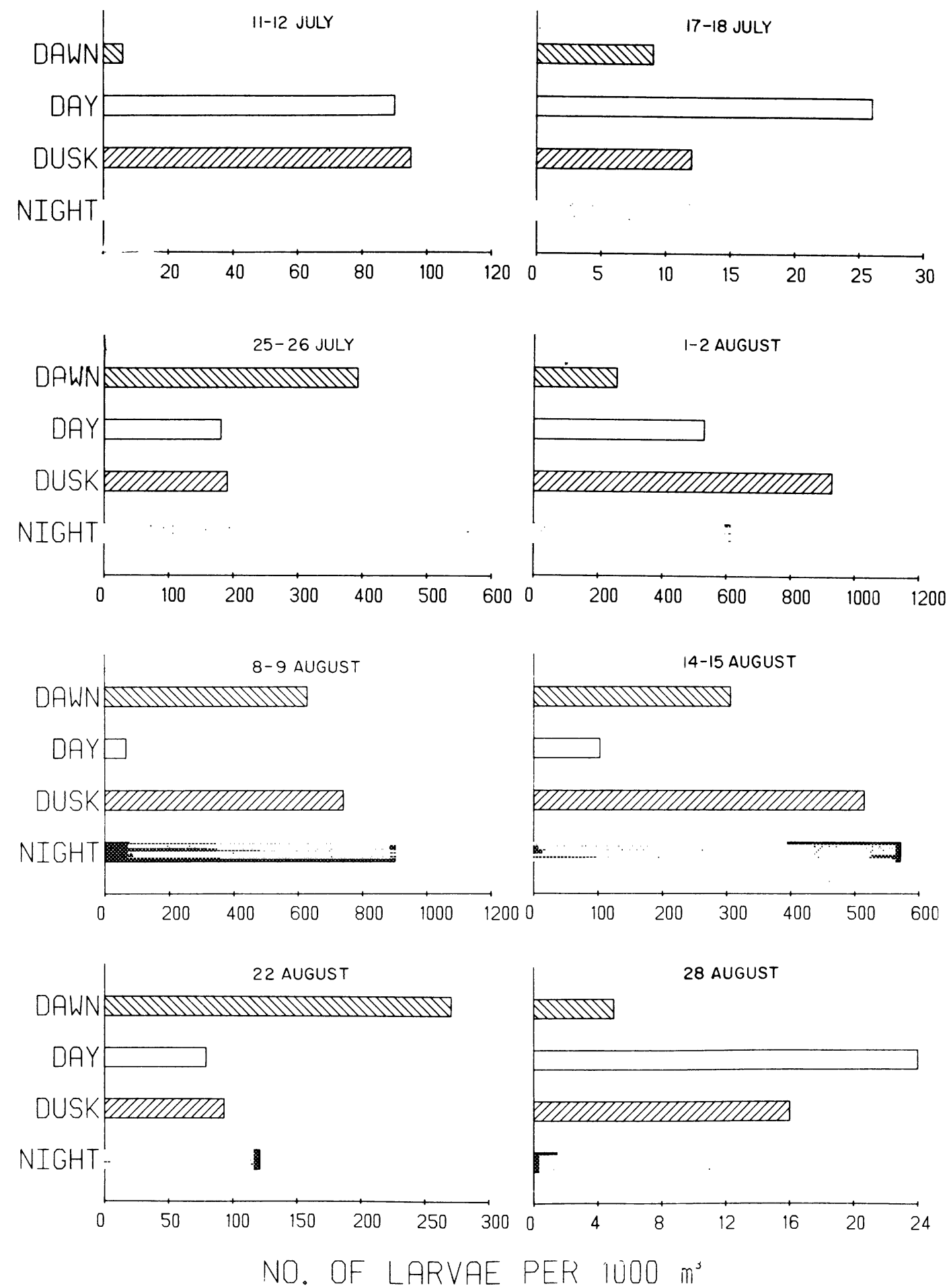

Fig. 101. Continued. 

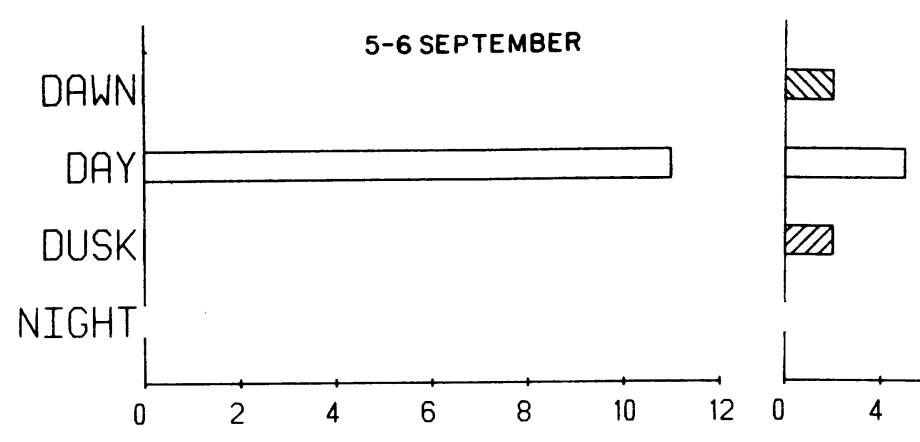

12-13 SEPTEMBER
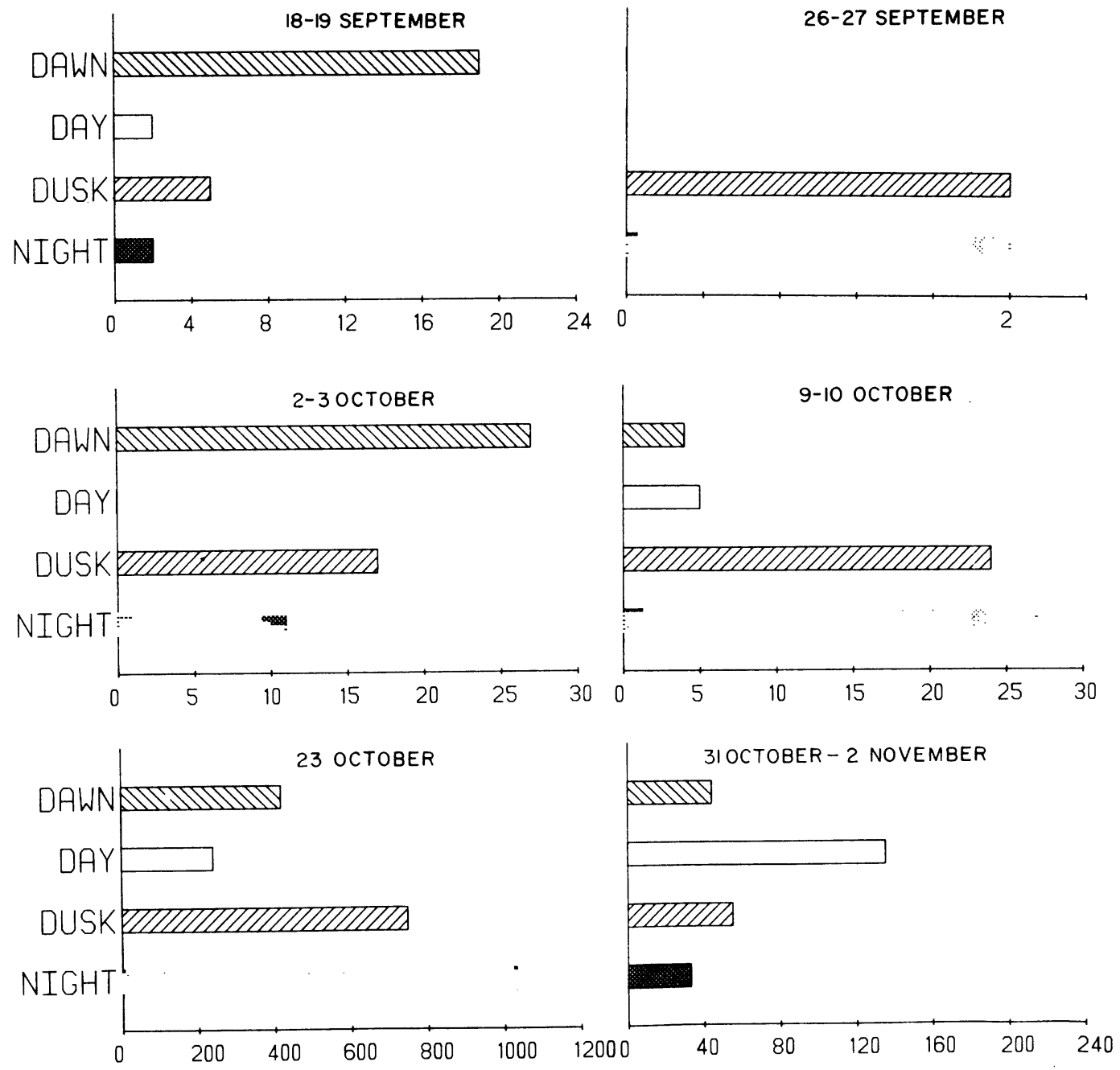

NO. OF LARVAE PER $1000 \mathrm{~m}^{3}$

Fig. 101. Continued. 


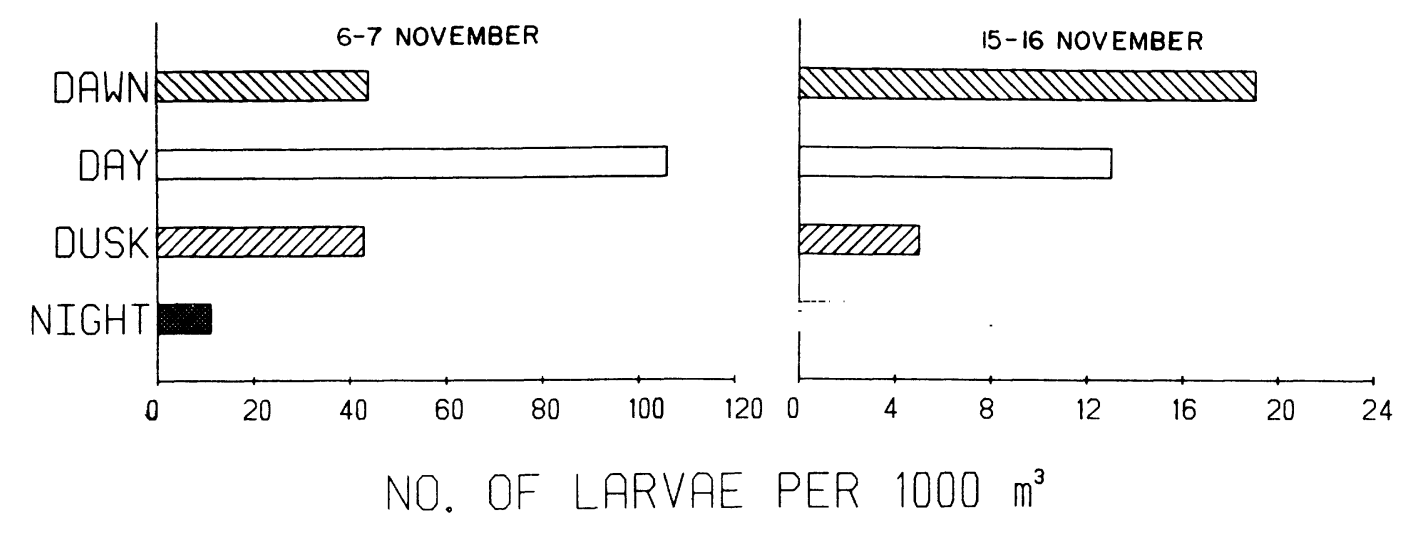

Fig. 101. Continued.

to allow alewife spawning. No alewife larvae were observed in subsequent sampling periods 9-10, 15-16, and 23-24 May, indicating that alewife spawning during April in Pigeon Lake was probably not a common occurrence. Occurrence of fish eggs in samples collected during all May sampling periods, with the exception of 23-24 May, is probably indicative of alewife spawning during this month. In general eggs were most concentrated in dawn and night samples, suggesting a nocturnal spawning time which was also hypothesized for alewives near the Cook Plant (Jude et al. 1979). Highest numbers af alewife larvae entrained during May occurred on 30-31 May when over 27,000 alewife larvae were estimated to have passed through the plant in $24 \mathrm{~h}$ (Fig. 102).

June-- The first sampling period in June (1-2) showed some increase in total number of larvae entrained over May values when over 48,000 alewife larvae were entrained in that $24-\mathrm{h}$ period. A trend toward increased larval alewife entrainment continued in our 6-7 and 13-14 June sampling dates when over 143,000 alewives $/ 24 \mathrm{~h}$ were entrained. This increased entrainment in early and midJune occurred conincident with increased incidence of alewife larvae in field samples taken in Pigeon Lake and Lake Michigan. The somewhat dramatic decrease in number of alewife larvae entrained during the 20-21 June sampling period (over $35,500 / 24 \mathrm{~h}$ ) corresponded with observations of decreased alewife concentrations in most Pigeon Lake and Lake Michigan field samples. Reasons for these decreased concentrations are not known, however, speculations are presented in the previous section. Resumption of an upward trend in larval alewife entrainment continued, since on 26-28 June over 210,000 alewife larvae were entrained in $24 \mathrm{~h}$.

A summary of alewife length-frequency data from June indicated that larvae less than $7 \mathrm{~mm}$ (mean $=5.0 \mathrm{~mm}, \mathrm{SE}=0.1$ ) dominated the catch. These smaller larvae were probably hatched within a week of capture, and in relation to intake currents, were still in their "passive stage".

July-- The predominance of small (mean $=4.6 \mathrm{~mm}, \mathrm{SE}=<0.1$ ) alewife larvae in entrainment samples (Fig. 92) continued to be observed in early July (3-4) when the highest number of alewife larvae entrained for any single sampling period was observed (over 1.5 million alewife larvae). Samples taken during the two sampling periods after 3-4 July (11-12 and 17-18 July) had considerably lower densities compared with the 3-4 July peak (Fig. 101). Length-frequency histograms indicated a decreased dominance of newly hatched alewife larvae. This 


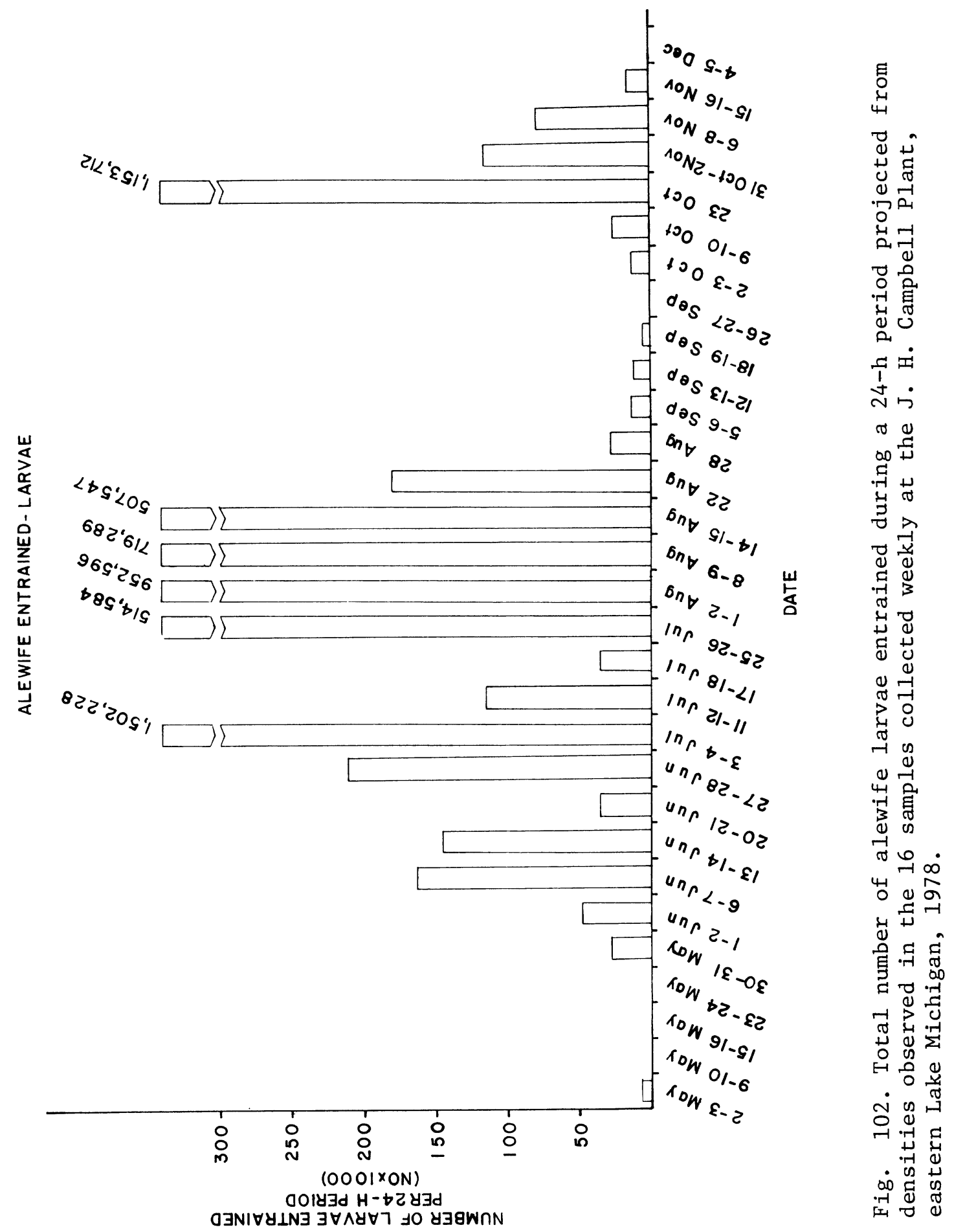


lower recruitment of newly hatched alewife larvae during July is probably related to water temperature. The decreased temperatures during 11-12 July and 17-18 July (less than $14 \mathrm{C}$ ) compared with early (3-4) July (greater than $17 \mathrm{C}$ ) may have retarded spawning and hatching activity.

The final sampling period during July (25-26) showed increased alewife densities in entrained water, resulting in the estimated entrainment of over 510,000 larval alewife in $24 \mathrm{~h}$ (Fig. 102). Length-frequency data indicated that alewife spawning had resumed at this time, since over $50 \%$ of the larvae were probably newly hatched.

August -- During the first sampling period in August (1-2) entrainment of alewife Increased considerably (over $900,000 / 24 \mathrm{~h}$ ) compared to the last sampling period in July. Alewife entrainment during August sampling was highest on this date, showing progressive decreases on 8-9 August (over 710,000/24 h), 14-15 August (over 500,000 larvae/24 h), 22 August (over 180,000 larvae/24 h) and 28 August (over 27,000 larvae/24 h). Examination of length-frequency data for the first three August entrainment sampling dates when alewife densities were highest, again showed a dominance of small (less than $7 \mathrm{~mm}$ ) larvae, indicating that hatching was still occurring. However, on the latter two August sampling dates, densities were low (Fig. 101) coincident with the dominance of larger (greater than $7 \mathrm{~mm}$ ) larvae in the samples. Thus it appears, as was suggested by Jude et al. (1978), that there is a specific length up to which alewife larvae are passively drawn into the plant with entrained water. Longer larvae are, for the most part, able to move against the intake current. Another factor affecting decreased entrainment of larger larvae is natural mortality. Highest mortality is experienced by newly-hatched larvae in the "passive" stage. Thus, fewer larger larvae are available to be entrained. Entrainment of larger larvae is probably due to other behavioral characteristics of the alewife such as movements in response to food, light, current or schooling tendencies. The first major occurrence of alewife fry (YOY greater than $25.4 \mathrm{~mm}$ and less than $100 \mathrm{~mm}$ ) in entrainment samples occurred during 22 August sampling (Fig. 103) when over 50,000 were entrained in $24 \mathrm{~h}$. The occurrence of fry in entrainment samples prior to this date was low (less than 3000 entrained per $24 \mathrm{~h}$ ). Size range of fry entrained during August was $26-35 \mathrm{~mm}$.

September-- Entrainment for the entire month of September remained at low levels, not exceeding 14,000 larvae/24 h. Larvae entrained during September averaged $21.6 \mathrm{~mm}(\mathrm{SE}=0.5)$. These decreases in densities of larvae in entrained water coincided with decreased concentration of larval alewife in fjeld samples. Occurrence of alewife fry in entrainment samples during September exhibited considerable variation (Fig. 103), with highest entrainment losses on 5-6 September and 26-27 September. No alewife fry were entrained on 12-13 September. Size range of fry in September varied from 25.5 to $39.5 \mathrm{~mm}$.

October, November, December-- During October alewife concentrations in entrained water exhibited considerable increases compared to late September samples. Entrainment of alewives was estimated at over $13,000 / 24 \mathrm{~h}$ on $9-10$ October. The dramatic increase in larval alewife concentrations on 23 October resulting in the entrainment of over 1.1 million alewife larvae/24 $\mathrm{h}$ is puzzling. The average size of these larvae was $20.7 \mathrm{~mm}(\mathrm{SE}=0.1)$. It was assumed that this size larvae as well as the entrained fry at this time (Fig. 103) could 

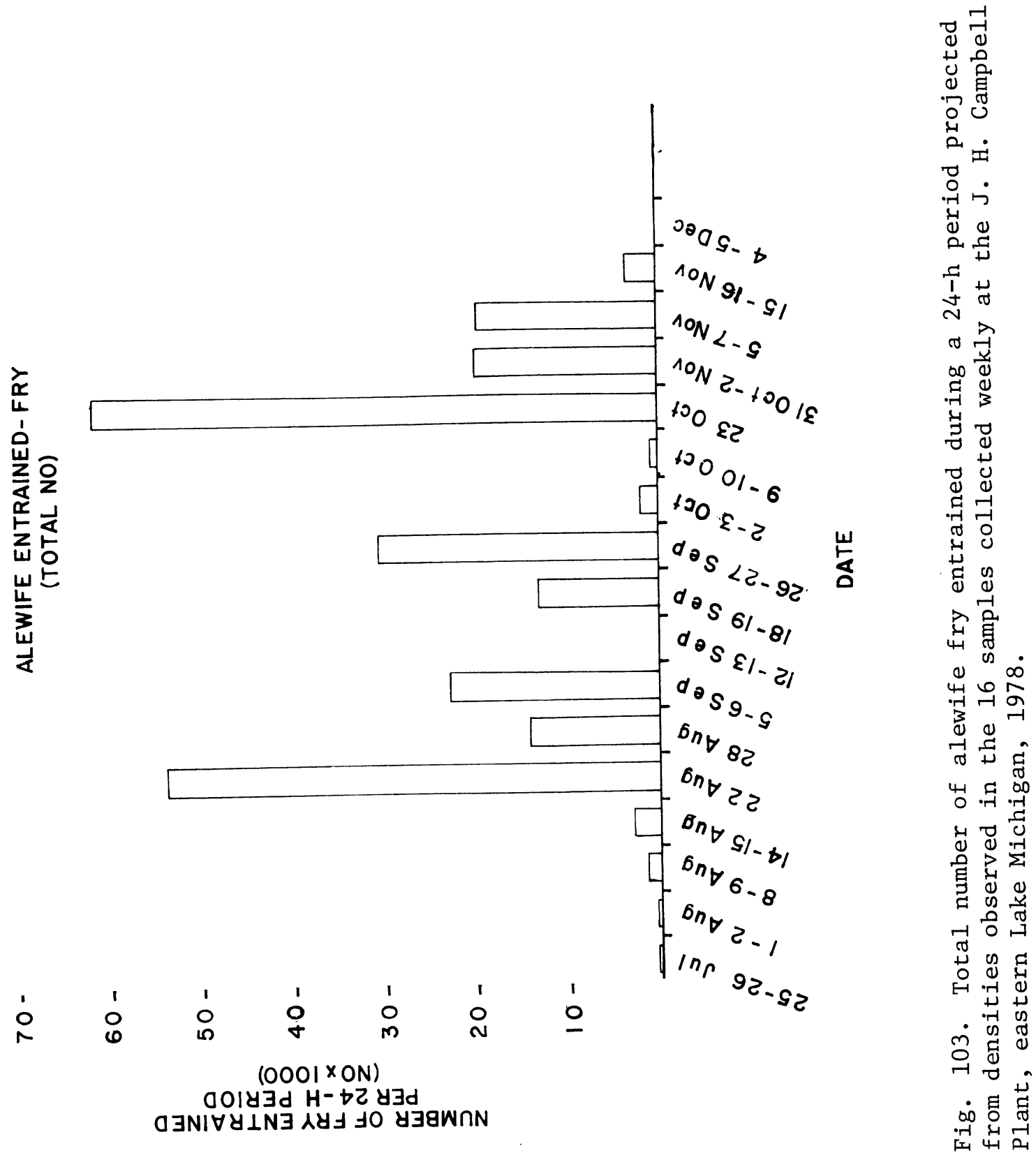
easily have moved against the intake current and avoided entrainment. The schooling behavior of this species may be responsible for occasional inordinate occurrences in entrainment samples. Decline in the number of large 1arval alewives in entrainment samples as time progressed was gradual. Entrainment of alewife larvae decreased during the first sampling period in November (31 October-1 November), resulting in the entrainment of over 110,000 larvae/ $24 \mathrm{~h}$. Numbers entrained showed a further decrease to over $79,000 / 24 \mathrm{~h}$ and over 16,000/24 h on 6-7 November and 15-16 November respectively. No alewife larvae were entrained in December.

During October and November a wide degree of fluctuation in the number of alewife fry entrained was observed (Fig. 103). Range in size of fry during these 2 mo was $25.5-51.0 \mathrm{~mm}$.

In general, occurrence of alewife fry in entrainemnt samples throughout our sampling period exhibited no predictable trend. Unlike smaller (less than $9 \mathrm{~mm}$ ) alewife larvae, which we believe were passively drawn into the plant, the distribution and hence entrainment of larger alewife larvae and fry are affected by other environmental and behavioral factors. These factors, such as food, temperature, current, turbidity etc., as well as the primary behavioral characteristics of schooling, cause complex interactions which do not allow accurate predictions of alewife fry entrainment. This high variability was exemplified by the occasional high occurrences of alewife fry in entrainment samples, which could not be explained by any one immediate or obvious reason.

\section{Cyprinidae Complex}

Unidentified Cyprinidae--

Introduction-- Cyprinids were the most difficult fish larvae to identify at the generic level. Recent studies, notably Snyder et a1. (1977) and Perry (1979), suggest that variability in characters used most commonly to separate genera and species of minnows could possibly lead to erroneous identifications of some minnows commonly found near the Campbell Plant. To circumvent this possibility larval cyprinids $9 \mathrm{~mm}$ or less were collectively classified unidentified minnows (XM), with the exception of carp and goldfish larvae, which were easily distinguished from other minnows. The following discussion of these larvae is integrated with a review of the spawning and larval fish ecology of species of minnows common in the area of the Campbell Plant. With studies now in progress, we hope to resolve the larval minnow identification problem by rearing eggs and larvae which come from known parental stock. These studies will be invaluable in describing local variations in larval minnow meristic characters and pigmentation.

Adult fish surveys showed five species of cyprinids to be common in the Campbel1 plant area. Listed in order of numerical abundance in our adult catch these species were: spottail shiner, golden shiner, bluntnose minnow, emerald shiner and carp. Although other minnows such as the creek chub, sand shiner, fathead minnow, bigmouth shiner, blacknose shiner and longnose dace have been observed in the area, their presence is considered incidental and they are not expected to produce appreciable numbers of offspring. 
The aquatic habitat of Pigeon Lake exhibits considerable variation, and there is evidence from adult gonad data (see RESULTS AND DISCUSSION - ADULT AND JUVENILE FISH, Spottail Shiner, Bluntnose Minnow, Golden Shiner) for the spawning of spottail shiners, bluntnose minnows and golden shiners within the lake. Although little evidence of emerald shiner spawning in Pigeon Lake was found after examination of adult fish data, the abundance of YOY enerald shiners in October indicated that successful spawning had occurred in 1978.

In contrast, the Lake Michigan habitat was not as diverse as that of Pigeon Lake. Bluntnose minnows and golden shiners probably did not spawn in Lake Michigan near the Campbell Plant due to lack of required spawning habitat, as well as the apparent unsuitability of the habitat for the adults, as evidenced by their dearth in adult Lake Michigan collections. Cooper (1935) reported that aquatic vegetation was essential for golden shiner spawning. Spawning of bluntnose minnows usually occurs on the undersides of flat objects (Scott and Crossman 1973). Both of these spawning habitats were notably absent from the Lake Michigan shoreline near the Campbell Plant.

$\underline{\text { Seasonal Distribution-- }}$

April, May and June-- No larval unidentified minnows were collected during April-May 1978 in either Pigeon Lake or Lake Michigan. June marked the first month in which they were caught (Figs. 104 and 105). Identity of larvae designated as unidentified minnows caught in Pigeon Lake in early June was not as evident as those caught in Lake Michigan. Pigeon Lake offers adequate spawning habitat for all four of the common cyprinids, spottail shiner, emerald shiner, bluntnose minnow and golden shiner, and thus they may occur coincident with one another. Due to the numerical dominance of adult spottail shiners in catches from May to August at Pigeon Lake stations influenced by Lake Michigan, the majority of larvae designated as unknown minnows caught at these stations were probably spottail shiners. Extremely high (greater than 130,000 larvae/1000 $\mathrm{m}^{3}$ ) densities of larvae observed at beach station S (influenced by Lake Michigan) may suggest successful reproduction by more than one minnow species. Description of preferred spawning habitat for emerald shiners reported by Flittner (1964) closely agreed with habitat present near beach station S (influenced by Lake Michigan), suggesting that emerald shiners may also be comprising part of the high numbers of unknown minnow larvae observed at station $S$ in early June. Highest catch of adult bluntnose minnows and golden shiners at station $\mathrm{S}$ (influenced by Lake Michigan) occurred during May. This suggests some dispersal by these two species in search of spawning areas. Thus a small percentage of unidentified minnows at station $S$ in early June may have been bluntnose minnows and golden shiners.

In the undisturbed area of Pigeon Lake, the adult cyprinid species composition during May was considerably different than at Lake Michigan influenced stations, which undoubtedly affected the species composition of larvae produced in early June. With submerged logs and vegetation abundant, bluntnose minnows and golden shiners had optimal spawning habitat, which probably resulted in a higher percentage of unidentified minnows actually being bluntnose minnows and golden shiners. Very few adult emerald shiners were present at beach station $V$ (undisturbed Pigeon Lake), thus we would expect that the percentage this species comprised of all larvae present in samples collected at undisturbed Pigeon Lake stations was probably low. 

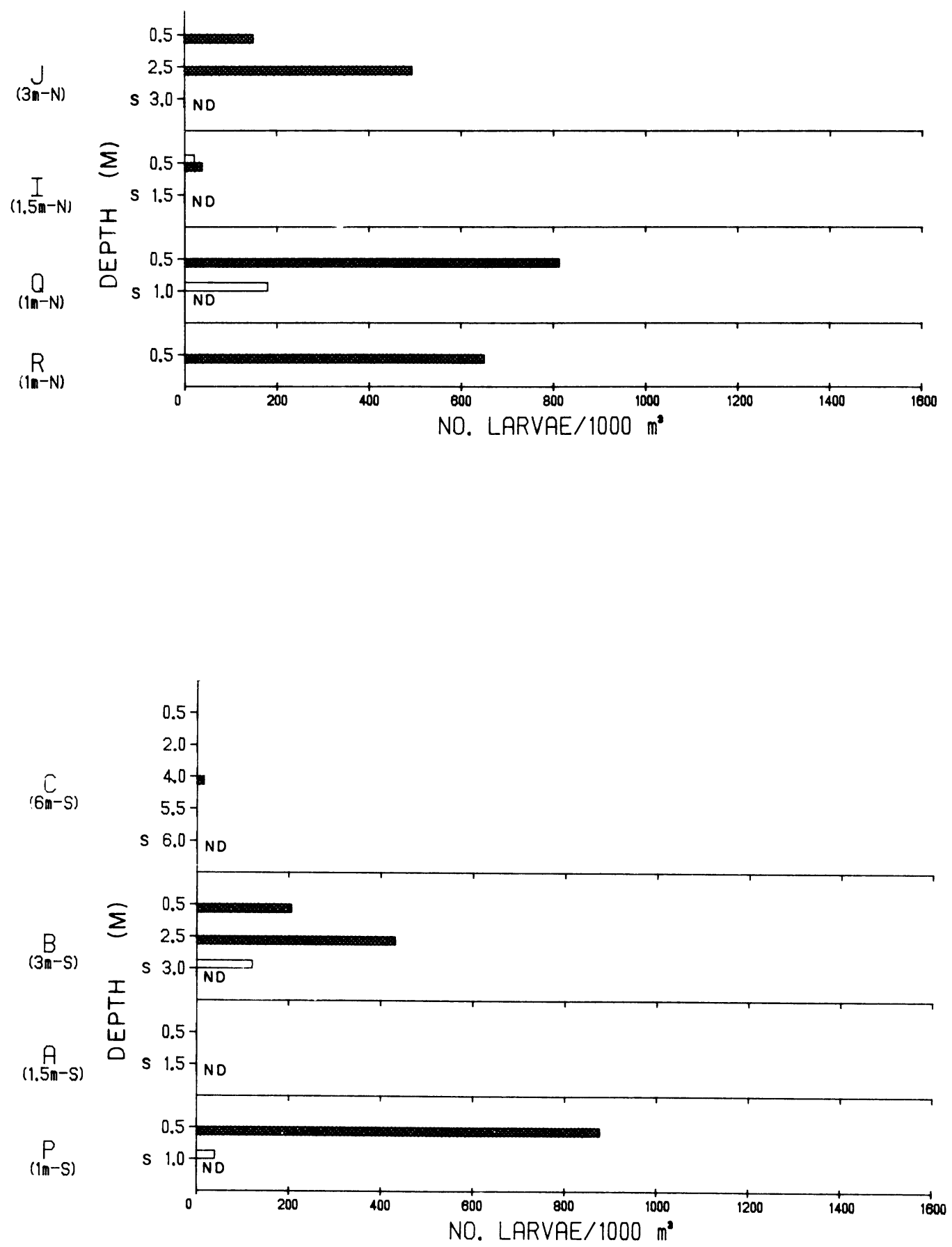

Fig. 104. Density of unidentified cyprinid larvae (no./1000 $\mathrm{m}^{3}$ ) at Iake Michigan stations near the J. H. Campbell Plant, eastern Jake Michigan, 5-7 June 1978. Stations 9 to $15 \mathrm{~m} \mathrm{~S}$ and 6 to $15 \mathrm{~m} \cdot \mathrm{N}$ were omitted due to absence of larvae in samples. $\square=$ day $\square=$ night $s=$ sled 

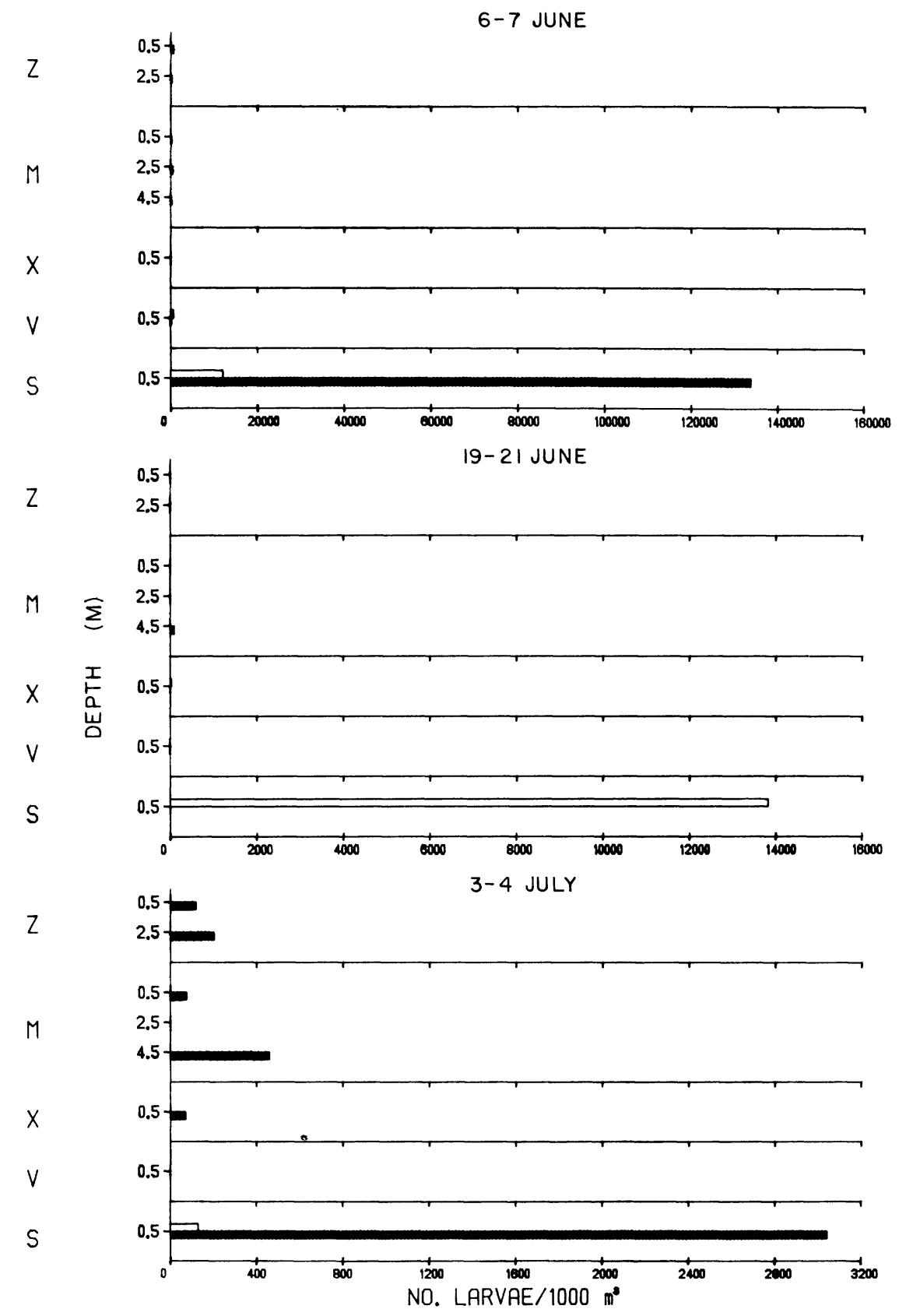

Fig. 105. Density of unidentified cyprinid larvae (no./1000 $\mathrm{m}^{3}$ ) at Pigeon Lake and intake canal stations near the J. H. Campbell Plant, eastern Lake Michigan April to September 1978.

$$
\square=\text { day } \square=\text { night }
$$




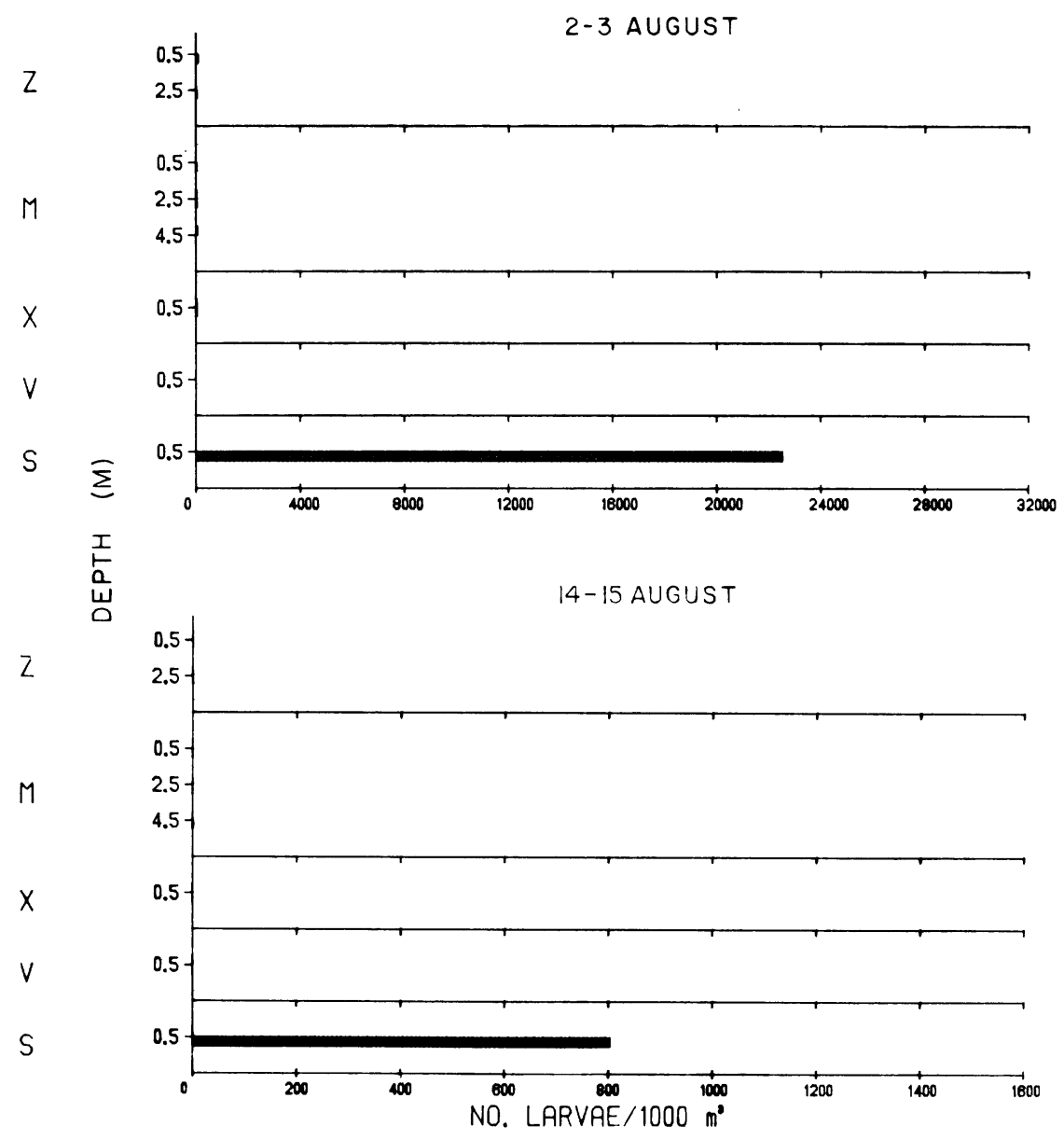

Fig. 105. Continued. 
The percentage that each of the four minnows makes up of the total concentration of unidentified minnow larvae entrained and in samples taken at station $\mathrm{Z}$ (intake canal) is difficult to determine. Water passing by station $\mathrm{Z}$ and into the plant is a mixture of water from the Pigeon River, Pigeon Lake and Lake Michigan. It is thus possible that spottail shiners, bluntnose minnows, emerald shiners and golden shiners may all be subject to entrainment loss. Due to the tendency of golden shiners to spawn amidst vegetation, it is possible that larval golden shiners remained in a more protected habitat. If this is the case, it would be expected that golden shiner larvae should not be subjected to heavy entrainment losses. A similar situation may also be true for bluntnose minnows. Spawning in slower moving water in more protected areas may afford more protection for early larvae, and thus limit entrainment losses. Both spottail and emerald shiners however, disperse eggs randomly, and larvae are often dispersed in open, current-swept areas, thus making them more vulnerable to entrainment. The intake canal itself may also be providing habitat for cyprinid spawning. Some protected areas along the intake canal may provide protection necessary for bluntnose minnow and golden shiner spawning.

Minnow larvae were absent from Lake Michigan samples during late June, possibly due to a slight decrease in water temperatures compared with early June (Appendix 4). The drastic decline in larval minnow concentrations (Fig. 105) observed at beach station S (influenced by Lake Michigan), station M (influenced by Lake Michigan) and station $X$ (undisturbed Pigeon Lake) and absence of minnow larvae from beach station $\mathrm{V}$ (undisturbed Pigeon Lake) and station $\mathrm{Z}$ (intake canal) may also be attributed to slightly lower temperatures in late June compared with early June. In days prior to our sampling in late June lower temperatures may have caused a cessation of spawning by adult minnows. Of those unidentified cyprinid larvae observed in Pigeon Lake in late June there was a dominance by larger (mean $=8.0 \mathrm{~mm}, \mathrm{SE}=$ 0.1) larvae and a relatively low number of smaller, newly hatched larvae (Fig. 106) which gives further evidence of the prior cessation of minnow spawning.

July-- In early July newly hatched larval cyprinids (1ess than $9 \mathrm{~mm}$ ) were abundant in Pigeon Lake at beach station S (influenced by Lake Michigan) and observed in lower densities at all other Pigeon Lake stations, with the exception of beach station $\mathrm{V}$ (undisturbed Pigeon Lake) where none were observed (Fig. 105). Data from 26-28 June entrainment samples indicated that subsequent to our field samples of 19-21 June, an upward trend in temperature began (Appendix 14), resulting in resumption of cyprinid spawning as evidenced by increased densities of cyprinid larvae entrained on 26-28 June compared with 20-21 June. This upward trend in temperature continued at least until the time of early July field sampling.

With a trend of increasing water temperature in Lake Michigan during the last week of June, resumption of minnow spawning occurred, since larval minnows were common at depths of $3 \mathrm{~m}$ and less at both transects (Fig. 107). Low densities of unidentified cyprinid larvae were also found sporadically at deeper Lake Michigan stations. Length-frequency data (Fig. 106) from these Lake Michigan unidentified cyprinids (probably spottails) revealed that they were small (mean $=5.1 \mathrm{~mm}$, $\mathrm{SE}=0.1)$, newly hatched larvae.

During late July larval minnows (probably spottail shiners) were observed primarily at Lake Michigan beach stations $P$ (S reference) and $Q$ (S discharge) with sporadic occurrence of low concentrations (less than 401 arvae/1000 $\mathrm{m}^{3}$ ) at depths to $12 \mathrm{~m}$ (Fig. 108). Reasons for absence of unidentified minnow larvae at beach 

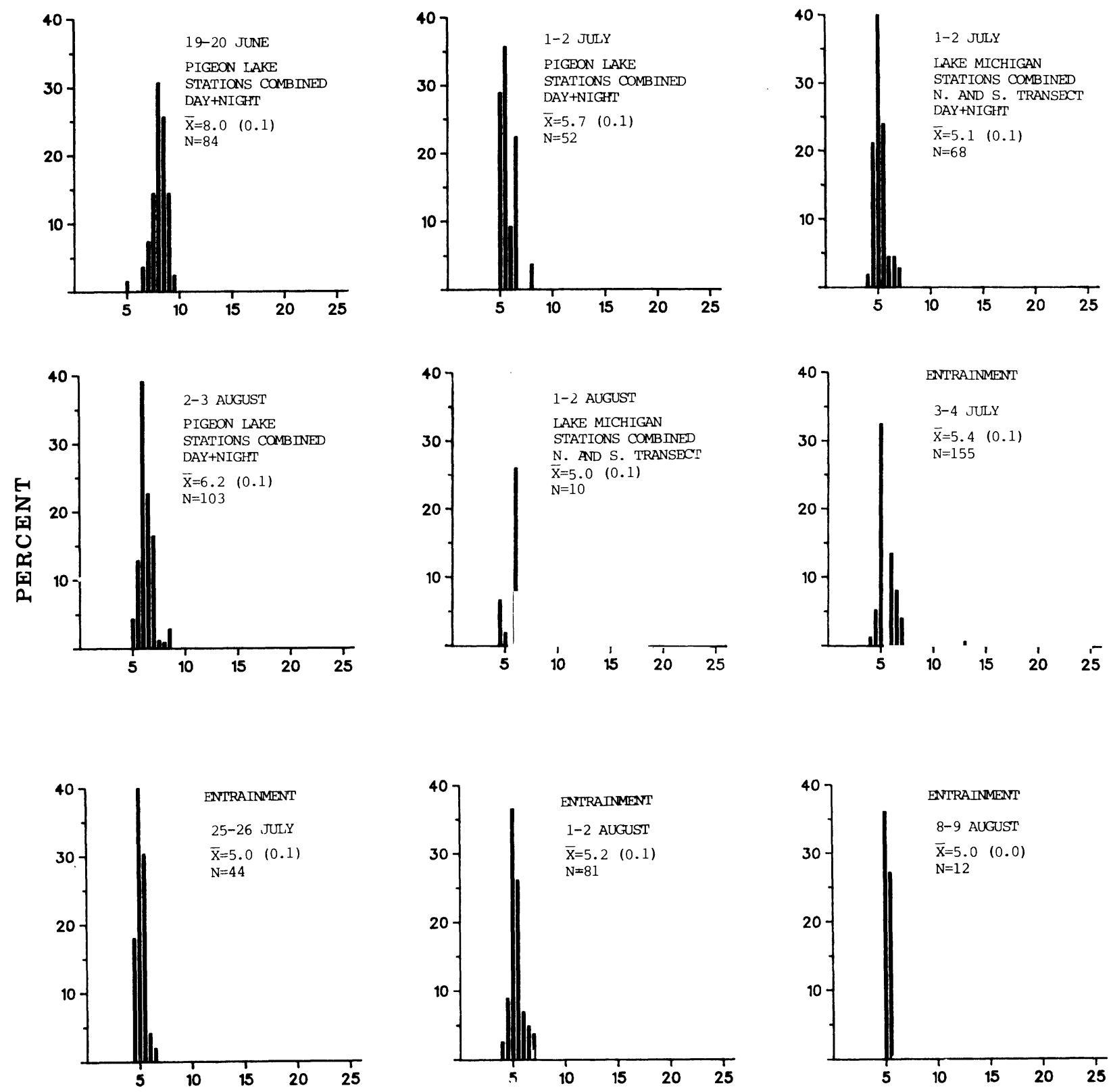

TOTAL LENGTH [mm]

Fig. 106. Length-frequency histograms for larval unidentified cyprinids observed in field and entrainment samples collected during 1978 near the J. H. Campbell Plant, eastern Lake Michigan. All tows were plankton net tows unless sled tows were specified. $\overline{\mathrm{X}}=$ mean, $\mathrm{N}=$ total number of larvae, standard error is given in parentheses. 


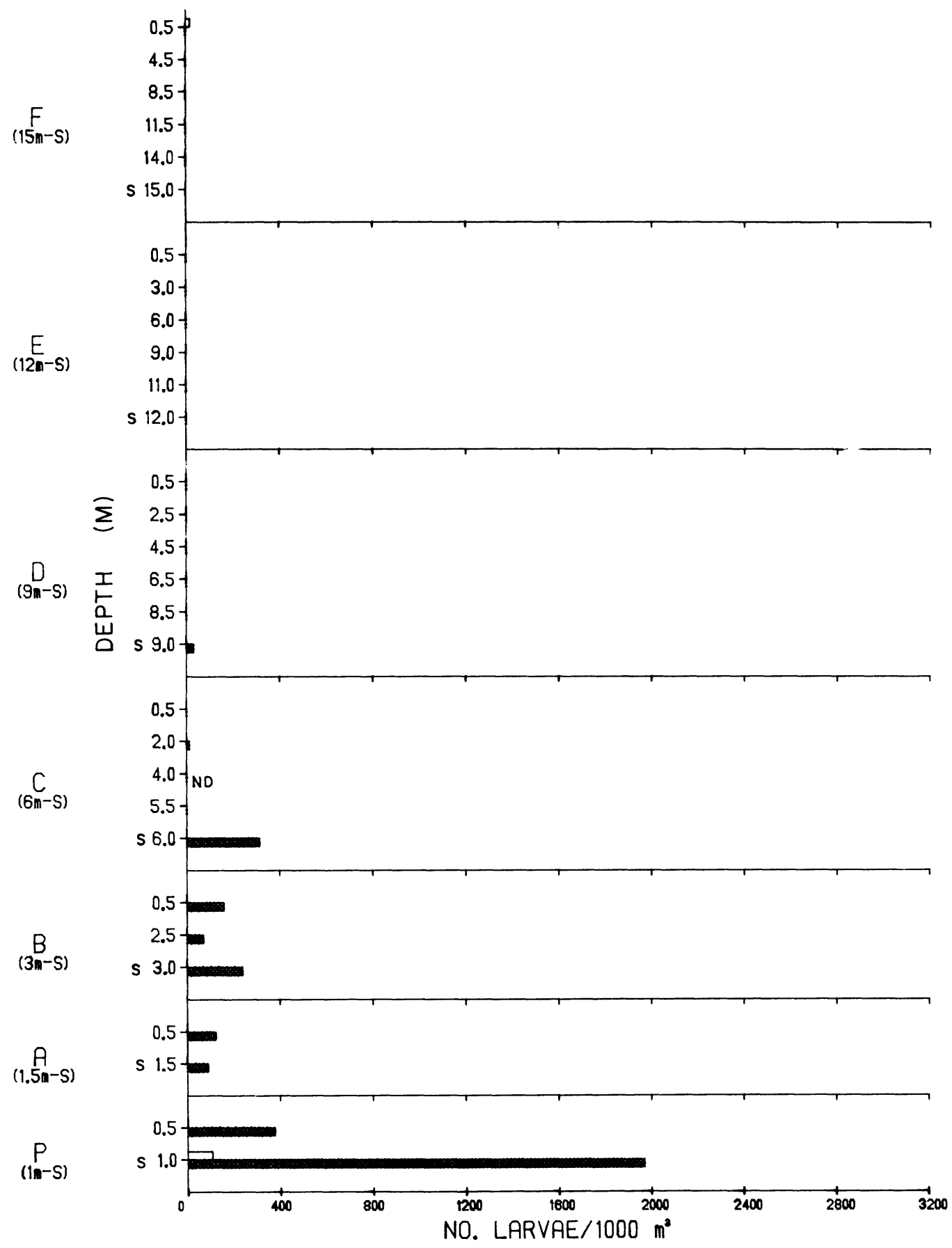

Fig. 107. Density of unidentified cyprinid larvae (no./1000 $\mathrm{m}^{3}$ ) at Lake Michigan stations near the J. H. Campbell Plant, eastern Lake Michigan, 1-3 July 1978. $\square=$ day $\square=$ night $S=$ sled $\mathrm{ND}=$ no data 


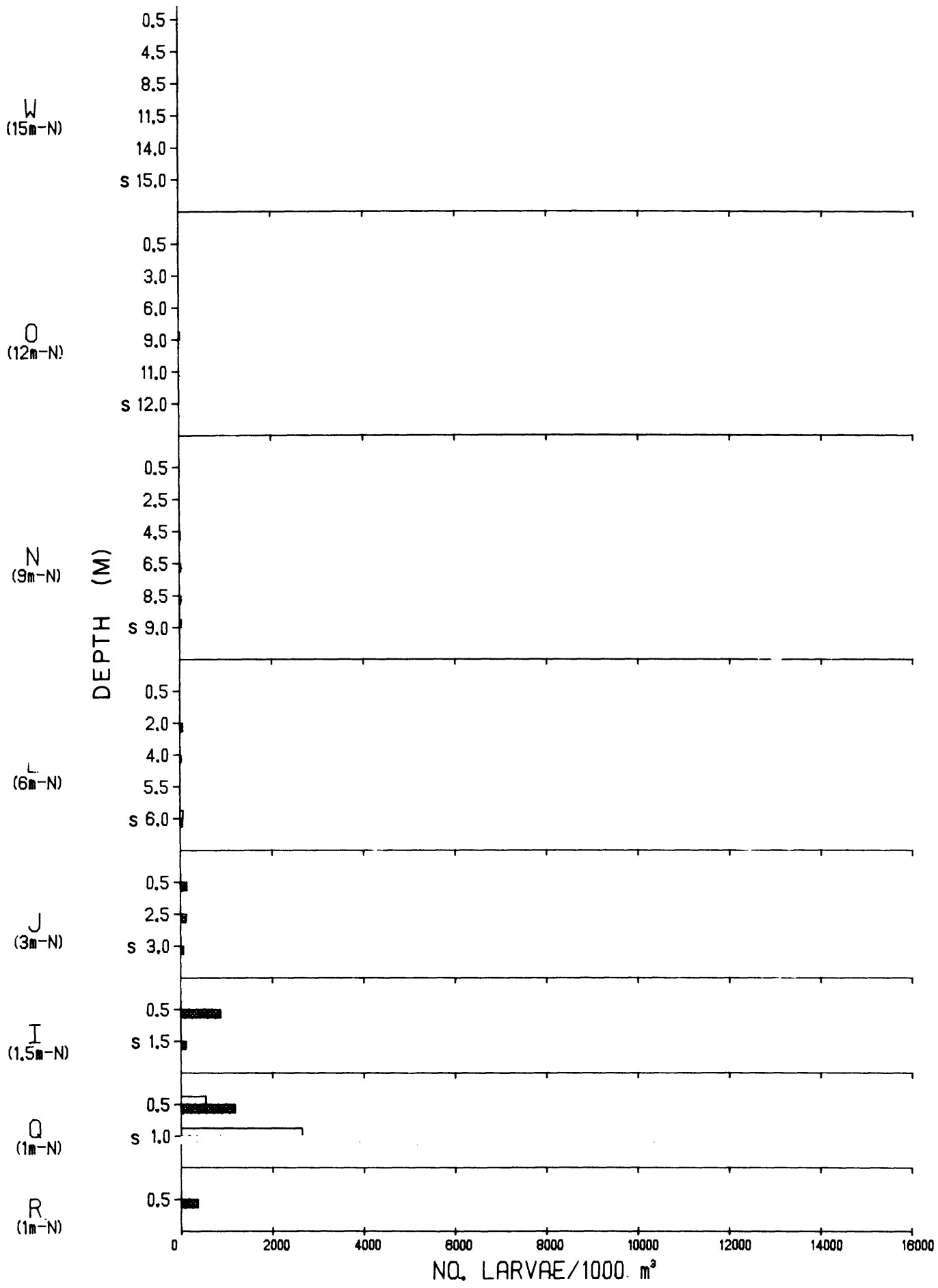

Fig. 107. Continued. 

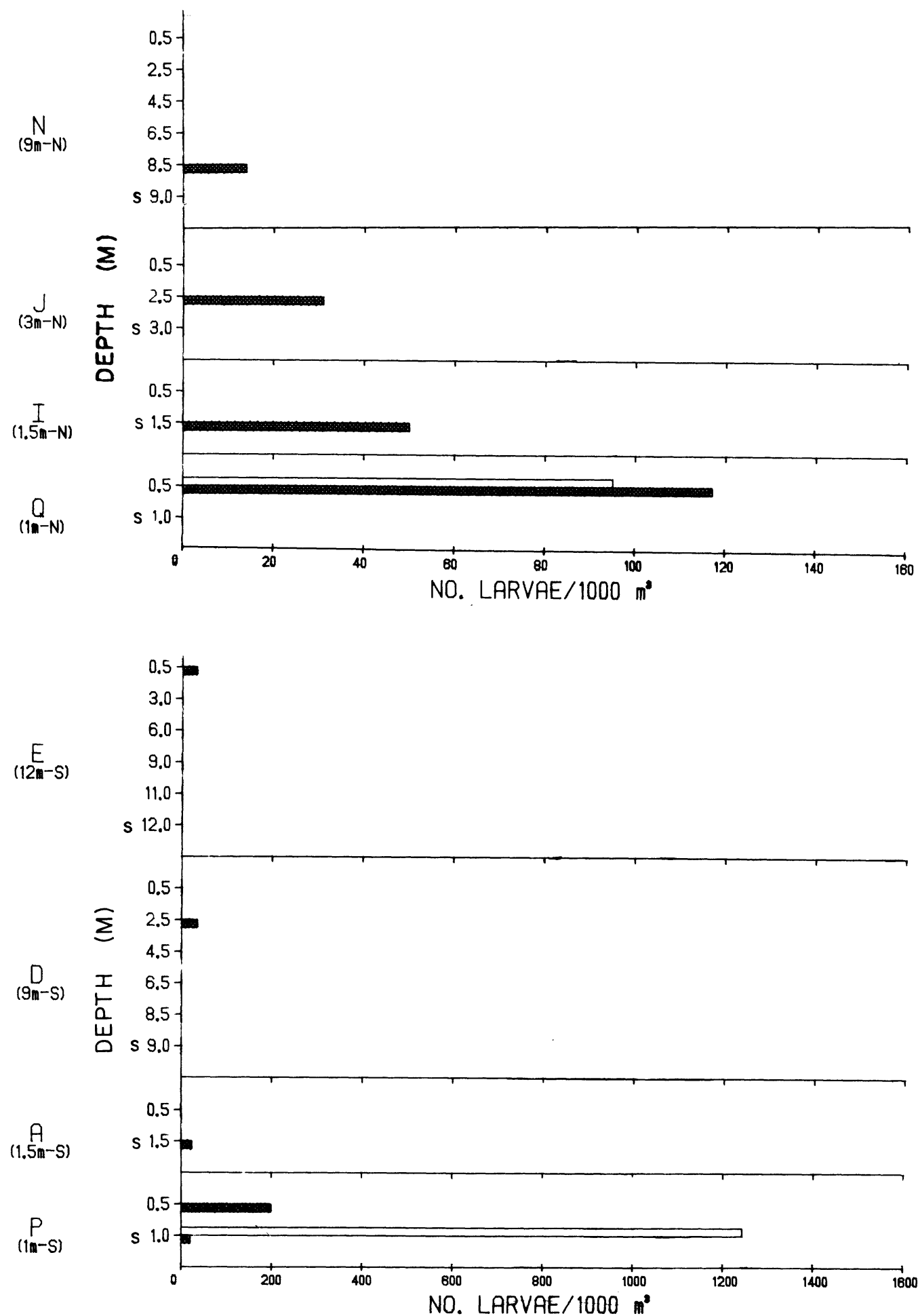

Fig. 108. Density of unidentified cyprinid larvae (no./1000 $\mathrm{m}^{3}$ ) at Lake Michigan stations near the J. H. Campbell Plant, eastern Lake Michigan, 17-19 July 1978. Stations 3-6 m S, $15 \mathrm{~m} \mathrm{~S}$ and $1 \mathrm{~m} \mathrm{~N}, 6 \mathrm{~m} \mathrm{~N}$ and 12-15 $\mathrm{m} \cdot \mathrm{N}$ were omitted due to absence of larvae in samples.

$\square=$ day $\square=$ night $S=$ sled 
station $\mathrm{R}$ ( $\mathrm{N}$ discharge) in Lake Michigan in late July are not clear. A trend toward decreased densities of larval fish at station $\mathrm{R}$ ( $\mathrm{N}$ discharge) compared with $Q$ (S discharge) persisted throughout the time when larval minnows were present, and may reflect an effect of alongshore currents on larval fish distributions or slight temperature differences between the two discharge stations. Differences in larval unidentified minnow concentrations between Lake Michigan beach station $\mathrm{R}$ ( $\mathrm{N}$ discharge) and $\mathrm{Q}$ ( $\mathrm{S}$ discharge) were also observed for other species of larvae, notably alewife and smelt.

In Pigeon Lake during late July, no larvae designated as unidentified minnows were observed. Undoubtedly lower water temperatures at Lake Michigan influenced stations caused a cessation of minnow spawning in these areas. Although temperatures remained high (greater than $19 \mathrm{C}$ ) at undisturbed Pigeon Lake stations, no unidentified cyprinid larvae were collected. Absence of minnow larvae from Pigeon Lake beach station $\mathrm{V}$ (undisturbed Pigeon Lake) in all samples subsequent to early June suggests that this area, despite its abundant cover and optimal spawning habitat, was not used extensively by spawning minnows during 1978. This does not agree with findings of 1977 (Jude et al. 1978) which showed that this station was consistently used, even through July, by spawning minnows during 1977.

August, September-- The only appreciable densities of larvae designated as unidentified minnows (probably spottail shiner) in Lake Michigan during early August were at depths of $3 \mathrm{~m}$ or less (Fig. 109). Highest concentrations of minnow larvae were observed at beach station Q (S discharge) during early August. Lengthfrequency data from those larvae caught in early August in Lake Michigan showed a high percentage of newly hatched larvae (mean $=5.0 \mathrm{~mm}, \mathrm{SE}=0.1$ ) indicating that spottail shiner spawning had continued until at least late July during 1978.

With warmer water temperatures at Pigeon Lake stations in early August, compared with late July, larvae designated as unidentified minnows were found in high densities (greater than 20,000 larvae/1000 $\mathrm{m}^{3}$ ) at Pigeon Lake beach station $\mathrm{S}$ (influenced by Lake Michigan) and in low densities (less than 60 larvae/1000 $\mathrm{m}^{3}$ ) at stations $M$ (influenced by Lake Michigan) and X (undisturbed Pigeon Lake). Although mean length of these larvae was slightly higher (mean $=6.2 \mathrm{~mm}, \mathrm{SE}=0.1$ ) than Lake Michigan minnow larvae, length-frequency data (Fig. 106) indicated that there was still recruitment of newly hatched minnow larvae in early August in Pigeon Lake.

Concentrations of unidentified minnow larvae in entrained water in early August ranged from 2 to 142 larvae/1000 $\mathrm{m}^{3}$. Length-frequency data (Fig. 106) seemed to indicate that smaller (mean $=5.2 \mathrm{~mm}, \mathrm{SE}=0.1$ ) minnow larvae were entrained compared with larvae caught in Pigeon Lake in early August (mean $=6.2 \mathrm{~mm}$, $\mathrm{SE}=0.1)$.

During the last sampling period in August occurrence of unidentified minnow larvae decreased dramatically compared with early August, being observed only at beach and $1.5 \mathrm{~m}$ stations in Lake Michigan and beach station $\mathrm{S}$ (influenced by Lake Michigan) in Pigeon Lake (Fig. 110). No unknown minnows were caught at any stations during September. 

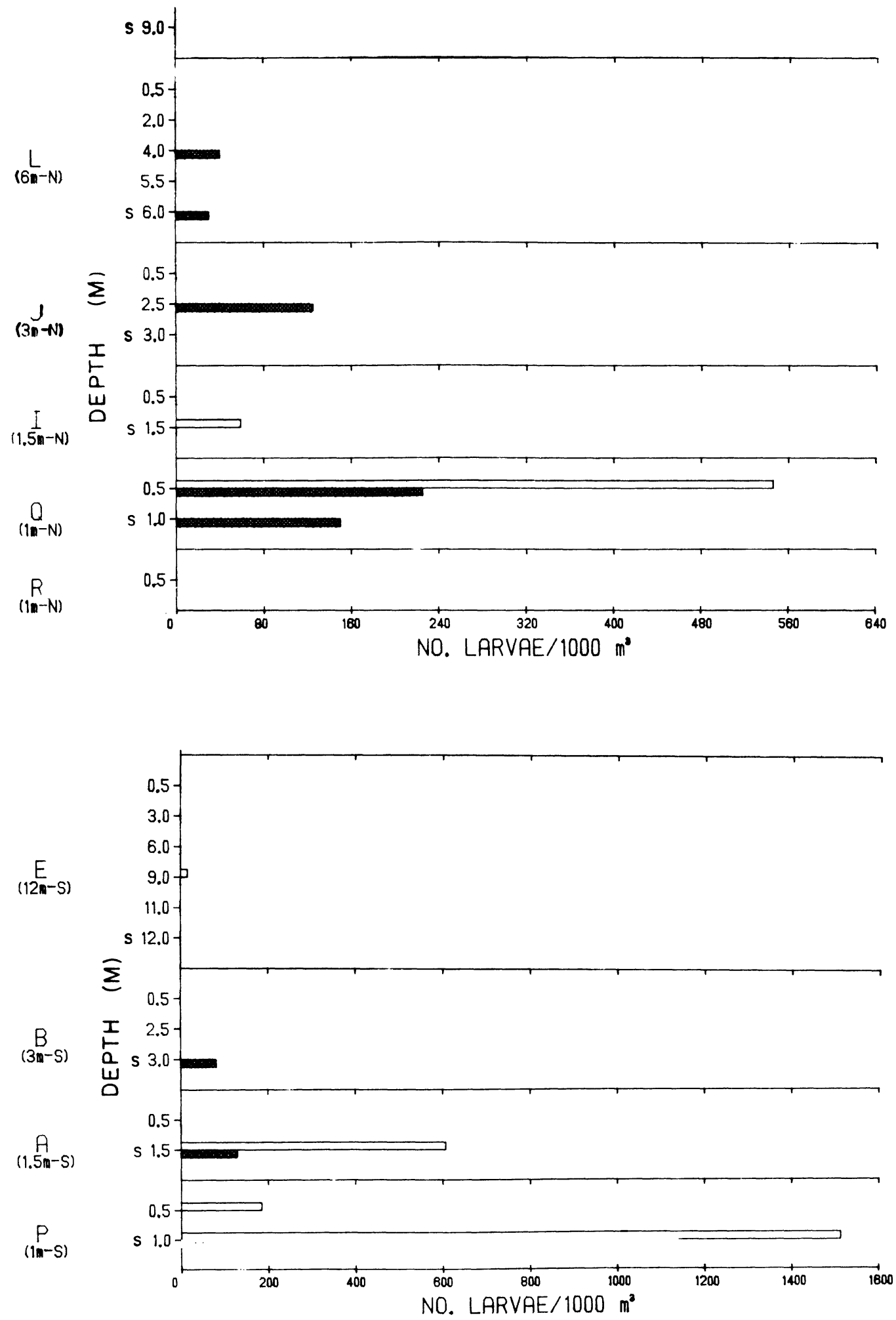

Fig. 109. Density of unidentified cyprinid larvae (no./1000 $\mathrm{m}^{3}$ ) at Lake Michigan stations near the J. H. Campbell Plant, eastern Lake Michigan, 1-4 August 1978. Stations 6-9 m S, $15 \mathrm{~m} \mathrm{~S}$ and 9-15 $\mathrm{m} \mathrm{N}$ were omitted due to absence of larvae in samples. $\square=$ day $\square=$ night $\mathrm{S}=$ sled 

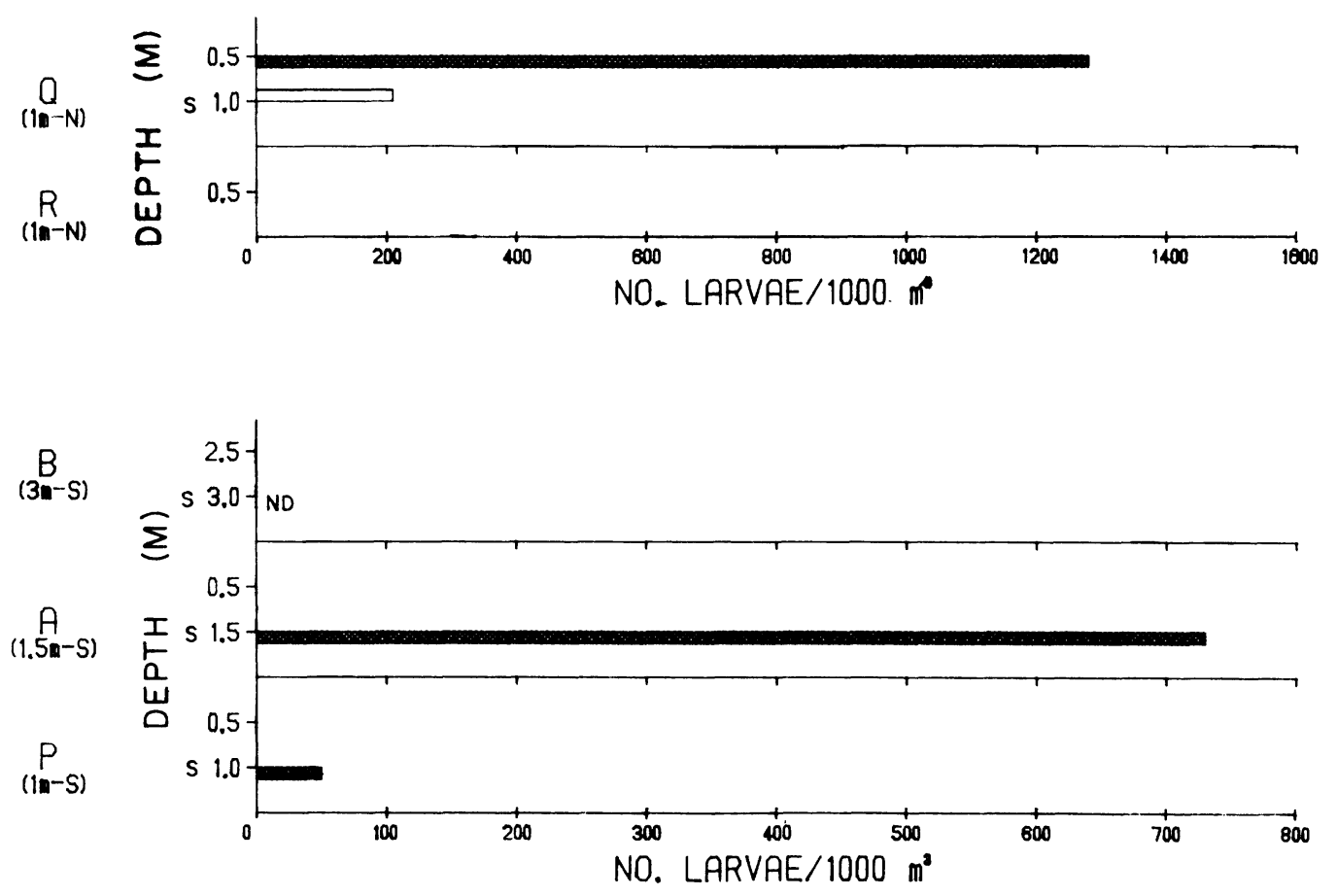

Fig. 110. Density of unidentified cyprinid larvae (no./1000 $\mathrm{m}^{3}$ ) at Lake Michigan stations near the J. H. Campbell Plant, eastern Lake Michigan, 14-17 August 1978. Stations 6 to $15 \mathrm{~m} \mathrm{~S}$ and 1.5 to $15 \mathrm{~m}$ N were omitted due to absence of larvae in samples. $\square=$ day $\square=$ night $S=$ sled

Entrainment-- The mixture of Pigeon River/Pigeon Lake water with Lake Michigan water posed a particular difficulty in trying to assess what proportion each of the minnow larvae observed in entrainment samples comprised of the total. If the proportion of adult minnows caught in the area of the Campbell Plant were used as an index to determine the percentage each species contributed to the unidentified minnow larvae in entrainment samples, spottail shiners would account for $81 \%$ of the unidentified minnow larvae entrained followed by golden shiner (12\%), bluntnose minnows (4\%) and emerald shiner (3\%). We believe that because of the particular spawning habits of spottail shiner and emerald shiner the actual proportion each of these species constitutes of the total number of entrained larvae classified as unidentified minnow may possibly be considerably higher than suggested by adult percent compostition data. Both species spawn in relatively unprotected areas, and have no nest building tendencies, which may allow for exposure to entrainment currents and thus precipitate higher entrainment losses. Bluntnose minnows and golden shiners lay their eggs on substrates in slower moving water, which should protect early larvae from being entrained because they would not be exposed to entrainment currents. Thus it is probable that in excess of $90 \%$ of the entrained larvae classified as unidentified minnows were actually spottail or emerald shiner larvae. Combined golden shiner larvae and bluntnose minnow larvae probably constituted less than $10 \%$ of the larvae classified as unidentified in entrainment samples. These proportions were assumed and integrated into the following discussion. 
May-- Larvae classified as unidentified minnows were first observed in low densities (0-5 larvae/1000 $\mathrm{m}^{3}$ ) in entrainment samples on 2-3 May (Fig. 111) indicating that some cyprinid spawning had occurred in the area during late April. Low concentrations of entrained unidentified minnows occurred sporadically through the 1-2 June sampling period (Fig. 111). Total number of cyprinid larvae (excluding carp) entrained in a 24-h period through early June was low (less than 4000/24-h period). The subsequent sampling period on 6-7 June marked the first major occurrence of unidentified minnow larvae in entrained water as densities of 14-104 larvae/1000 $\mathrm{m}^{3}$ were observed. These densities resulted in over 78,000 unidentified minnow larvae being entrained in $24 \mathrm{~h}$ on 6-7 June. Low densities (less than 15 larvae/1000 $\mathrm{m}^{3}$ ) of unknown minnow larvae observed during 13-14 June and 20-21 June (Fig. 111) were undoubtedly due to low water temperatures causing cessation of cyprinid spawning. Resumption of higher water temperatures on 26-28 June coincided with increased concentrations (6-24 larvae/1000 $\mathrm{m}^{3}$ ) of unidentified minnow larvae, resulting in over 67,000 being entrained in a $24-\mathrm{h}$ period. Larval spottail shiner over $9 \mathrm{~mm}$ were first observed on 26-28 June in 1 ow $\left(41\right.$ arvae/1000 $\mathrm{m}^{3}$ ) concentrations.

In general, throughout the sampling period, cyprinid larvae (excluding carp) greater than $9 \mathrm{~mm}$ were present only in low $\left(5\right.$ larvae/1000 $\mathrm{m}^{3}$ ) concentrations in entrained water. Our data indicated that larvae of a length greater than approximately $7 \mathrm{~mm}$ were not subject to transfer by intake currents. Highest densities of entrained unidentified minnow larvae were observed during the first sampling period in July (3-4) when over $140,000 / 24 \mathrm{~h}$ were entrained (Fig. 112). Lengthfrequency data indicated that most of these were newly hatched.

Decreased water temperatures during 11-12 July and 17-18 July (Appendixes 4 and 14) probably caused a cessation of minnow spawning and thus decreased entrainment rates (less than 301 arvae $/ 1000 \mathrm{~m}^{3}$ ). Total number of minnow larvae entrained during these sampling periods was less than $10,000 / 24 \mathrm{~h}$ period. Emerald shiner (greater than $9 \mathrm{~mm}$ ) were also present in low (3 1arvae/1000 $\mathrm{m}^{3}$ ) concentrations on 11-12 July. Increased water temperatures (Appendix 14) during 25-26 July and 1-2 August apparently caused a resumption in spawning and hatching and thus increased entrainment of unidentified minnow larvae. Length-frequency data from these dates confirmed the contention that spawning had resumed since mean size of larvae caught on 25-26 July was $5.0 \mathrm{~mm}$ ( $\mathrm{SE}=0.1$, Fig. 106), while on 1-2 August it was $5.2 \mathrm{~mm}(\mathrm{SE}=0.1, \mathrm{Fig}$. 106). Spottail shiner larvae greater than $9 \mathrm{~mm}$ were also observed in low concentrations on these dates (less than 5 larvae/1000 $\left.\mathrm{m}^{3}\right)$. Samples collected on 8-9 August showed a decreased number of unidentified minnow larvae entrained (Fig. 112), suggesting that minnow spawning tapered off to some extent by early August. Larvae caught on 8-9. August however, were small (mean $=5.0 \mathrm{~mm}, \mathrm{SE}=<0.1$ ) which indicated that some spawning had recently occurred.

Only one additional occurrence of a minnow larva was observed subsequent to 8-9 August entrainment sampling. This larva was $4.8 \mathrm{~mm}$, and was found in a 12-13 September entrainment sample. Its occurrence suggested that some minnow spawning occurred in late August-early September in 1978.

In summary, entrainment of unidentified minnow larvae (those cyprinid larvae 9 mor smaller excluding carp) was highest during early June through early August. Decreased entrainment losses during intervening times were related to decreased water temperature. These decreased temperatures probably caused cessation of spawning and a concomitant decrease in the entrainment of small larvae. 

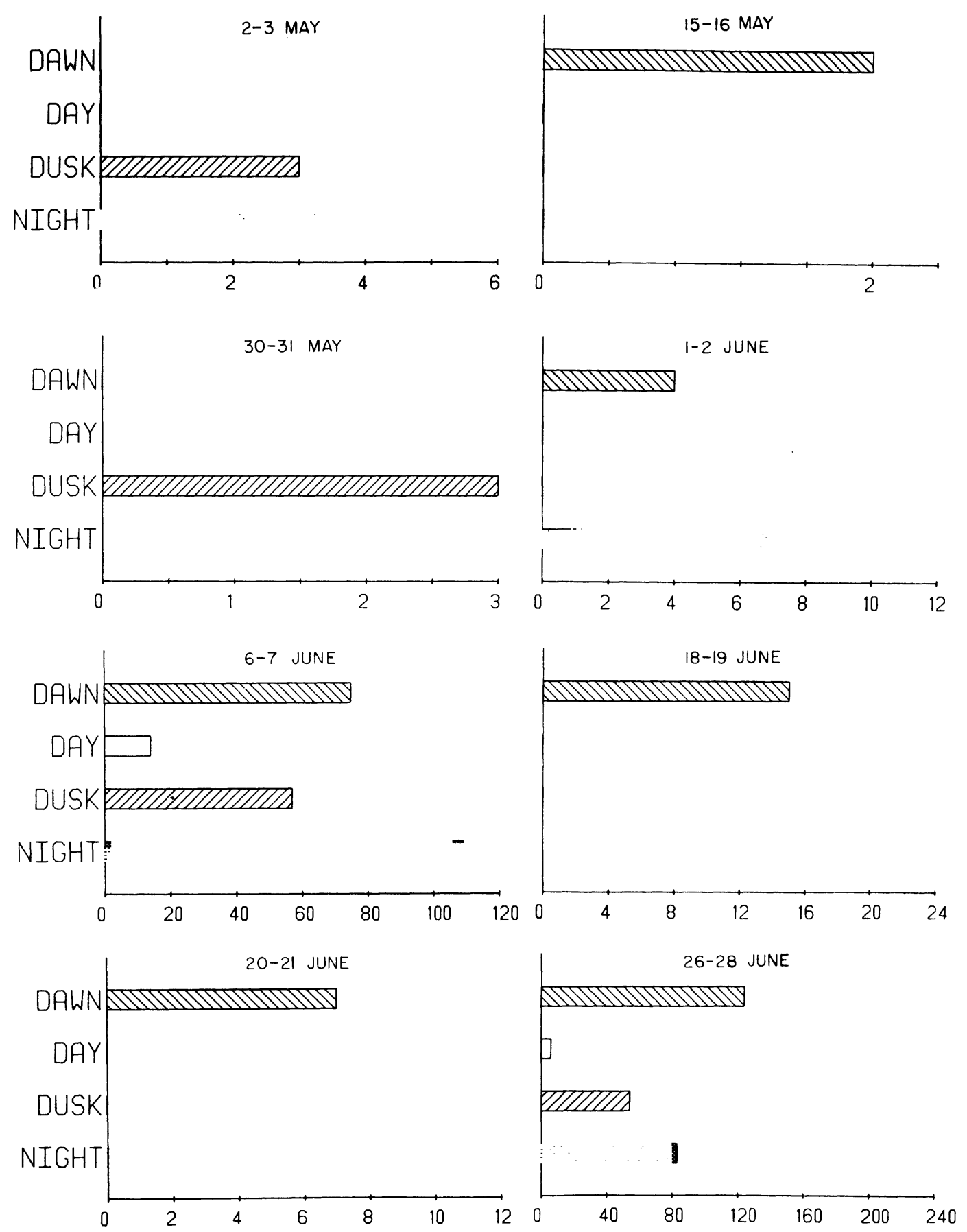

NO. OF LARVAE PER $1000 \mathrm{~m}^{3}$

Fig. 111. Density of unidentified cyprinid larvae (no./1000 $\mathrm{m}^{3}$ ) collected in weekly dawn, day, dusk and night entrainment samples at the J. H. Campbell Plant, eastern Lake Michigan, 1978. 

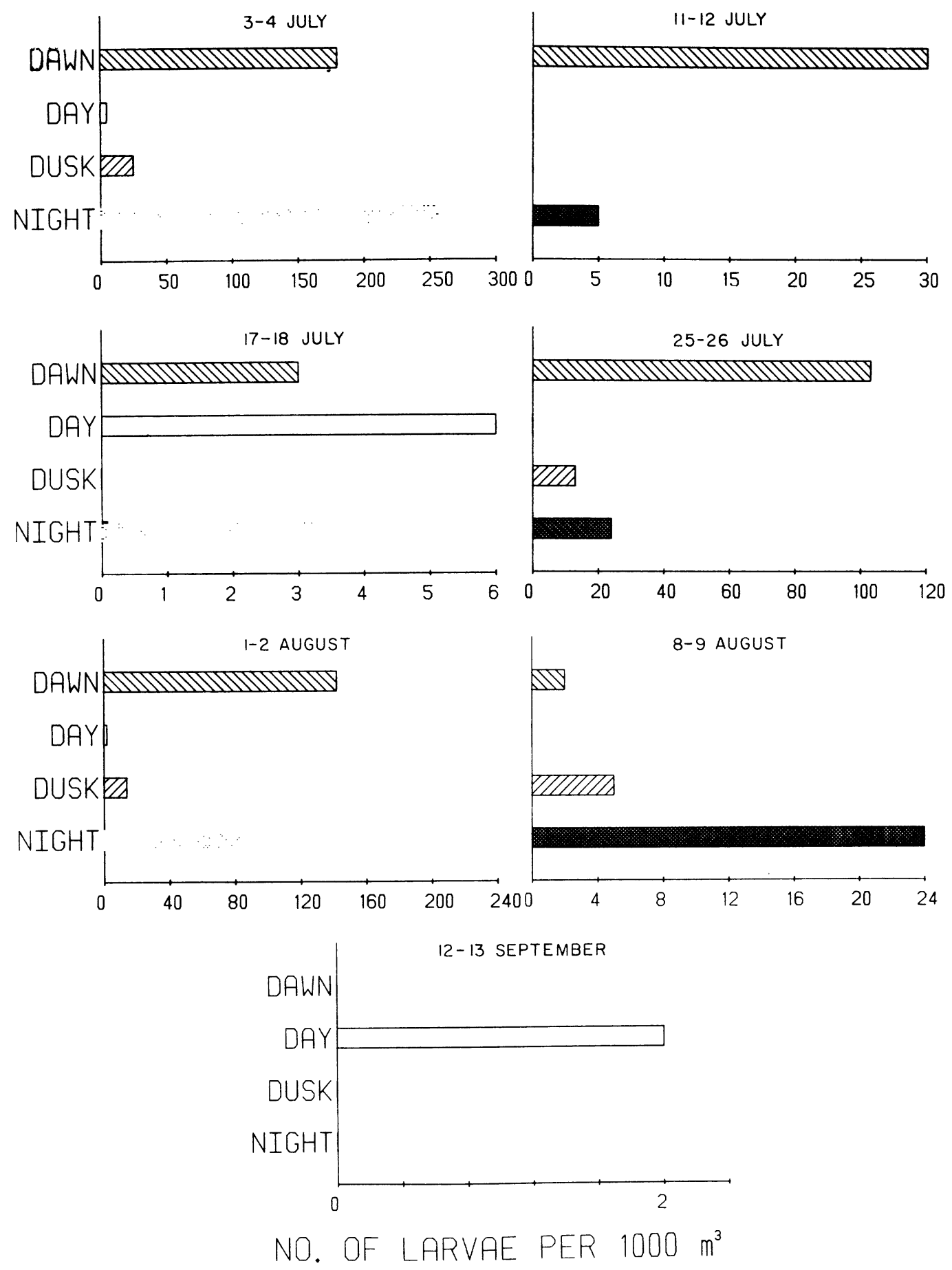

Fig. 111. Continued. 


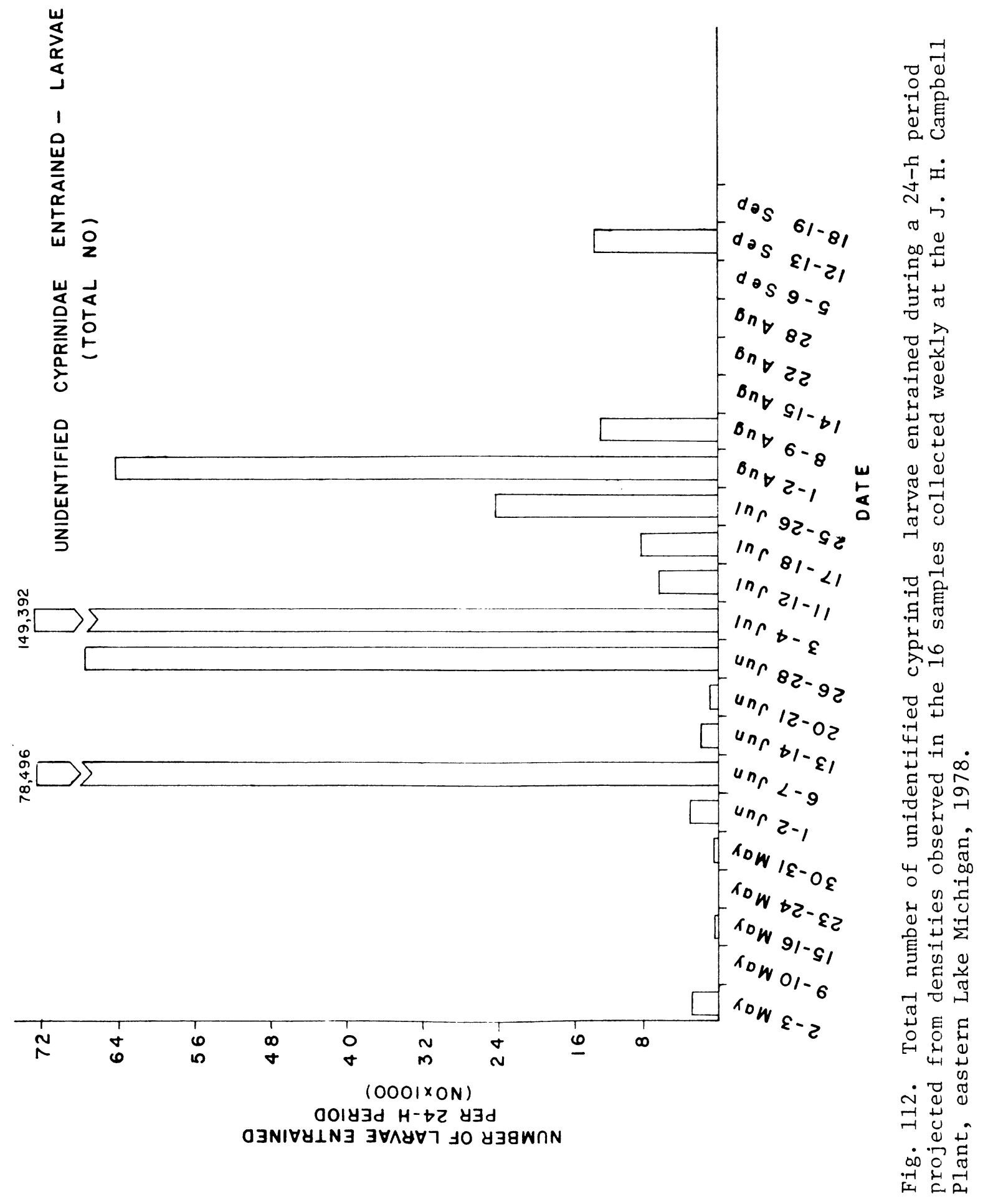


Because unidentified minnow larvae by our definition were just those cyprinid larvae (excluding carp) less than $9 \mathrm{~mm}$, their observed densities were not necessarily representative of the entire complement of cyprinid larvae in the area at any one time. Commencing in early July when earlier spawned cyprinid larvae grew to a length where we could positively identify them, they were correctly classified. The following is a discussion by species of those cyprinid larvae (excluding carp) exceeding $9 \mathrm{~mm}$.

Spottail Shiner--

In order to summarize the distribution of spottail shiner larvae at Lake Michigan stations, we relied on the assumption that most larvae designated as unidentified minnow larvae found at Lake Michigan stations were spottail shiners. Evidence for this contention was discussed in the previous section.

Lake Michigan-- In general, spottail larvae were common at $6 \mathrm{~m}$ and less in Lake Michigan from early June to late August (Figs. 113-115), with sporadic occurrences in deeper water. In the majority of cases, highest densities of larvae were observed at night. It appeared from length-frequency data that even recently hatched spottail larvae in Lake Michigan exhibited net avoidance.

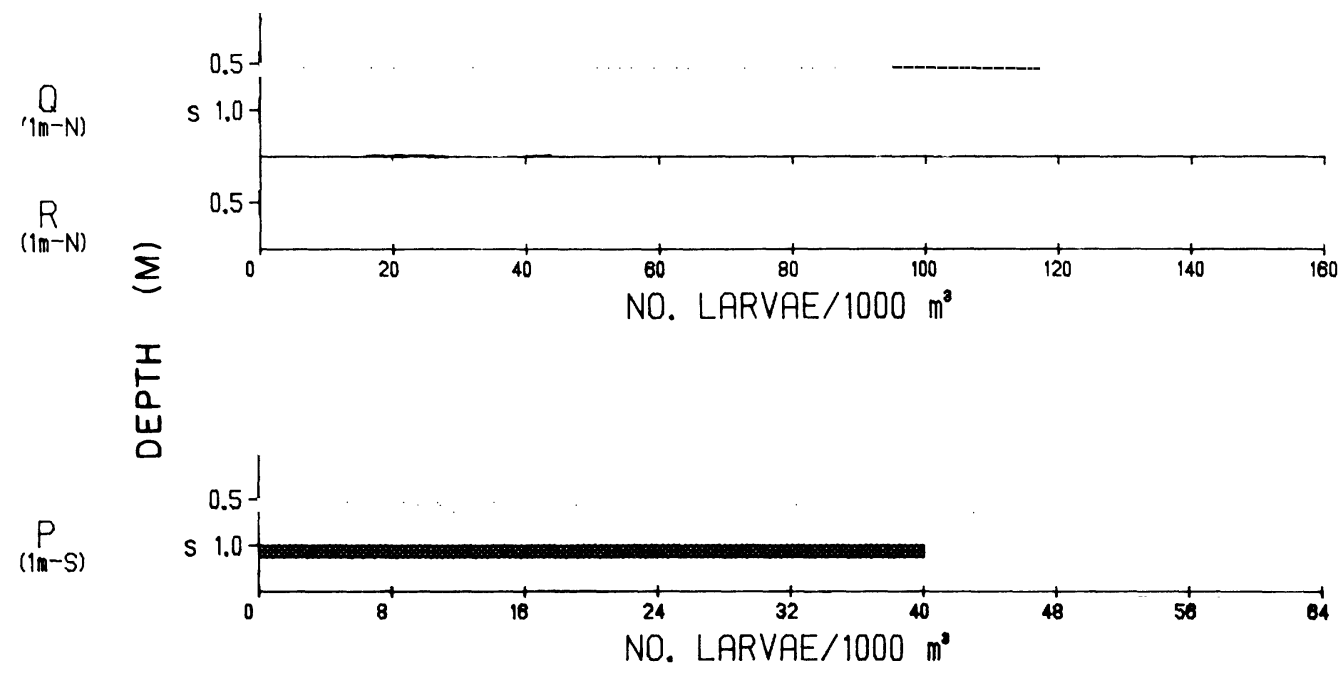

Fig. 113. Density of larval spottail shiners (no./1000 $\mathrm{m}^{3}$ ) at Lake Michigan stations near the J. H. Campbel1 Plant, eastern Lake Michigan, 17-19 July 1978. Stations 1.5 to $15 \mathrm{~m} \mathrm{~S}$ and 1.5 to $15 \mathrm{~m}$. N were omitted due to absence of larvae in samples. $\square=$ day $\square=$ night $S=$ sled 


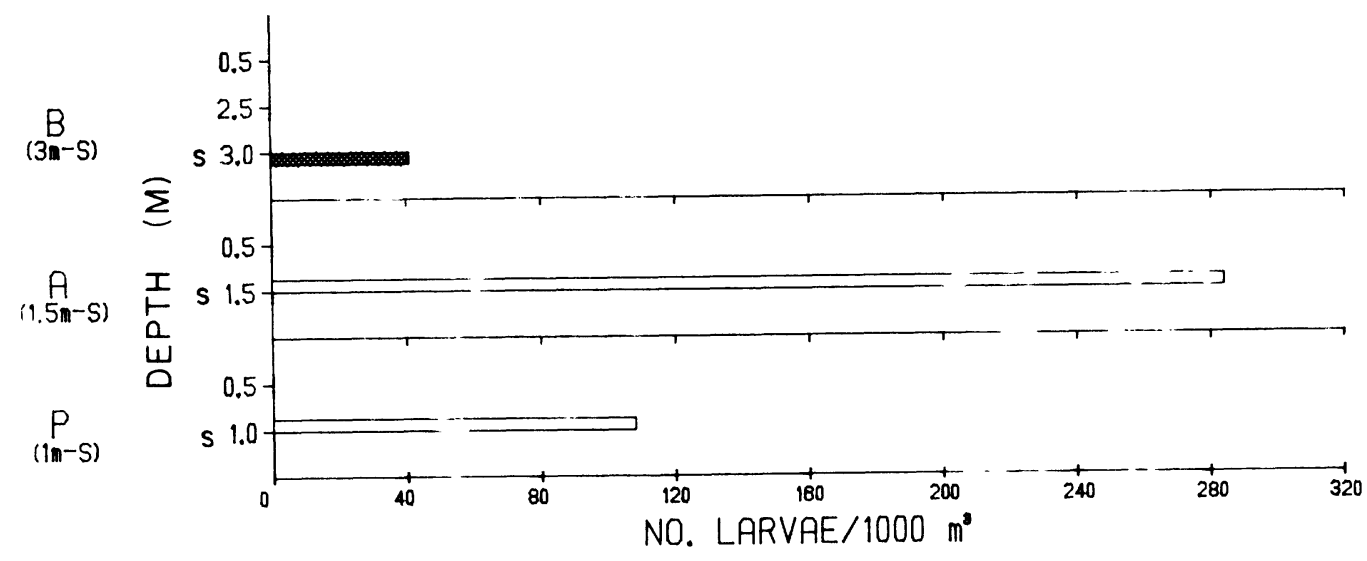

Fig. 114. Density of larval spottail shiners (no./1000 $\mathrm{m}^{3}$ ) at Lake Michigan stations near the J. H. Campbel1 Plant, eastern Lake Michigan, 1-4 August 1978 . Stations 6-15 $\mathrm{m}$ were omitted due to absence of larvae in samples.

$\square=$ day $\square=$ night $\quad \mathrm{S}=$ sled
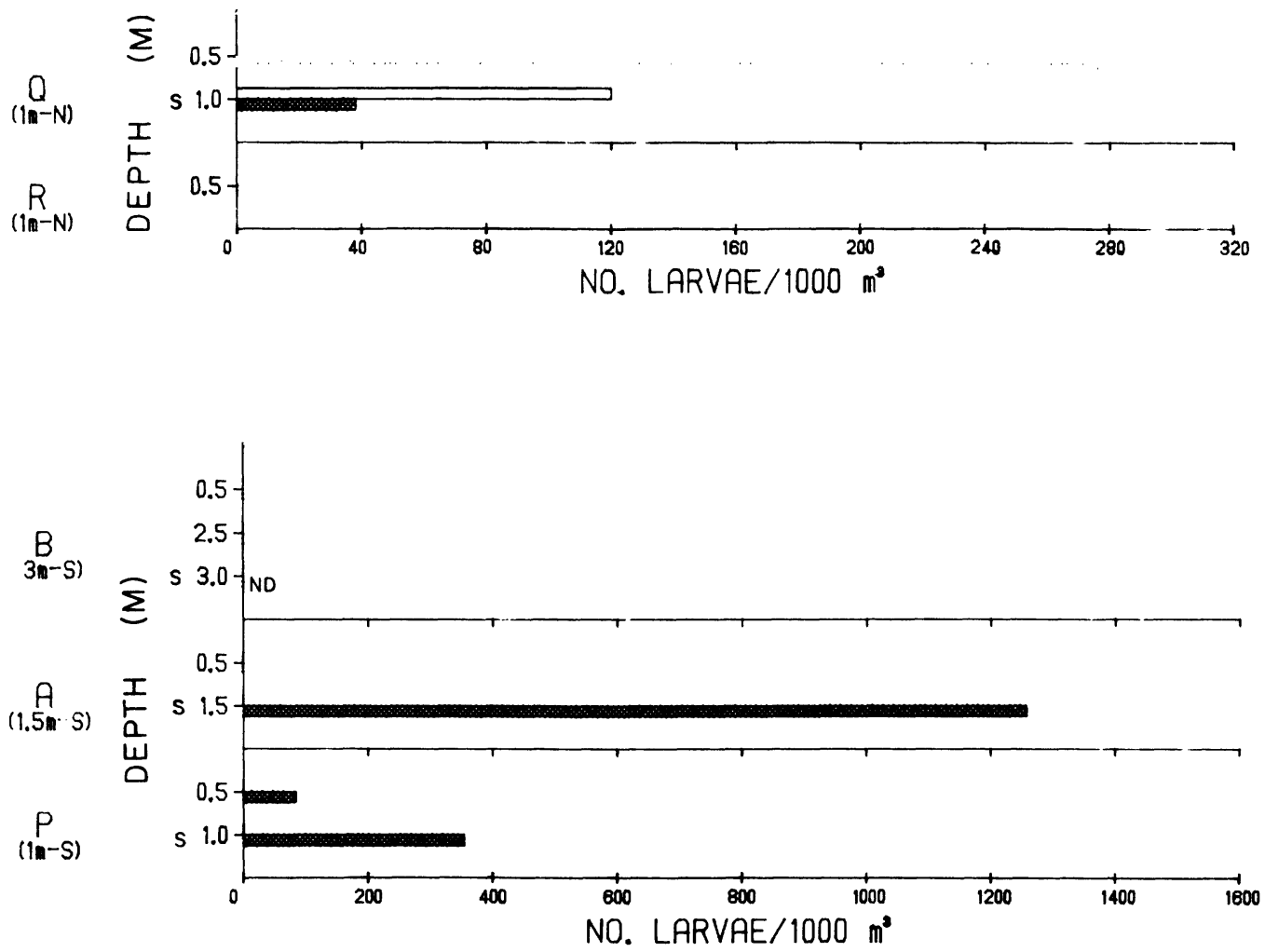

Fig. 115. Density of larval spottail shiners (no./1000 $\mathrm{m}^{3}$ ) at Lake Michigan stations near the J. H. Campbell Plant, eastern Lake Michigan, 14-15 August 1978. Stations 6 to $15 \mathrm{~m} \mathrm{~S}$ and 1.5 to $15 \mathrm{~m} \mathrm{~N}$ were omitted due to absence of larvae in samples. $\square=$ day $\square=$ night $s=$ sled 
Only four occurrences of spottail larvae over $9 \mathrm{~mm}$ were recorded from Lake Michigan surface tows; all came from beach stations. During late July an average concentration of 47 and 117 larvae/1000 $\mathrm{m}^{3}$ were observed respectively at beach station $\mathrm{P}$ ( $\mathrm{S}$ reference) and beach station $\mathrm{Q}$ (S discharge). In mid-August, 84 spottail shiner larvae/1000 $\mathrm{m}^{3}$ were recorded at beach station $P$ (S reference), while $284 / 1000 \mathrm{~m}^{3}$ were collected at station Q (S discharge).

Sled tow samples taken in early August in Lake Michigan indicated spottail larvae were concentrated on the bottom at nearshore and beach stations. At beach
station P (S reference) 108 larvae/1000 $\mathrm{m}^{3}$ were observed, while 284 larvae/1000 $\mathrm{m}^{3}$ occurred at the $1.5-\mathrm{m}$ south reference station; 41 larvae/1000 $\mathrm{m}^{3}$ were found at the 3-m south reference station. Presence of spottails in surface tows at beach stations $Q$ ( $S$ discharge) and $P$ (S reference) in mid-August correlated well with the large numbers collected in sled tow samples at these stations in mid-August (Fig. 115). As was observed in early August sled tows, spottail larvae were more concentrated at the $1.5-\mathrm{m}$ south transect station (1257 larvae/1000 $\mathrm{m}^{3}$ ) than the south reference beach station (354 larvae/1000 $\mathrm{m}^{3}$ ) in mid-August.

No spottail shiner larvae were collected during September at Lake Michigan stations which was probably due to growth of larvae out of our "larvae" classification, as well as greatly increased net avoidance. Trawl and seine haul data indicated that in Lake Michigan larger YOY remained at depths of $6 \mathrm{~m}$ and less until October, when they began to migrate to deeper water.

Pigeon Lake-- In Pigeon Lake, spottail larvae exceeding $9 \mathrm{~mm}$ were first observed at beach stations in early July. The extremely high densities (over 27,000 larvae/1000 $\mathrm{m}^{3}$ ) at station S (influenced by Lake Michigan) (Fig. 116) support the contention that most larvae designated as unidentified minnows were spottail shiner. If this is the case, smaller spottail larvae (9 $\mathrm{mm}$ or less) were first found in Pigeon Lake at high densities (the total unidentified cyprinid density was over 130,000 larvae $/ 1000 \mathrm{~m}^{3}$ ) at beach station $\mathrm{S}$ (influenced by Lake Michigan) in early June. Lower concentrations (less than 400 larvae/1000 $\mathrm{m}^{3}$ ) were observed at other Pigeon Lake stations in early June. In late June collections of spottail larvae declined dramatically as did catch of other cyprinid larvae due to increased net avoidance by older larvae and decreased water temperature, causing cessation of spawning.

Growth of spottail larvae into a length range at which we could identify them was evidenced by our observation in early July of high concentrations (11,000-27,000 larvae/1000 $\mathrm{m}^{3}$ ) at beach station $\mathrm{S}$ (influenced by Lake Michigan). Lower concentrations (over 300 larvae/1000 $\mathrm{m}^{3}$ ) were observed at beach station $\mathrm{V}$ (undisturbed Pigeon Lake). Larger spottail larvae (over $9 \mathrm{~mm}$ ) were not observed at open water stations in Pigeon Lake at any time during larvae sampling from April to November. From late July sampling until their final occurrence in September larger spottail larvae were only caught at station $\mathrm{S}$ (influenced by Lake Michigan). Their decreasing concentrations in Pigeon Lake as summer progressed, as well as their absence in samples taken after September in Pigeon Lake was again probably due to growth out of the "larvae" classification, as evidenced by an increase in fry concentrations (Appendix 16). 

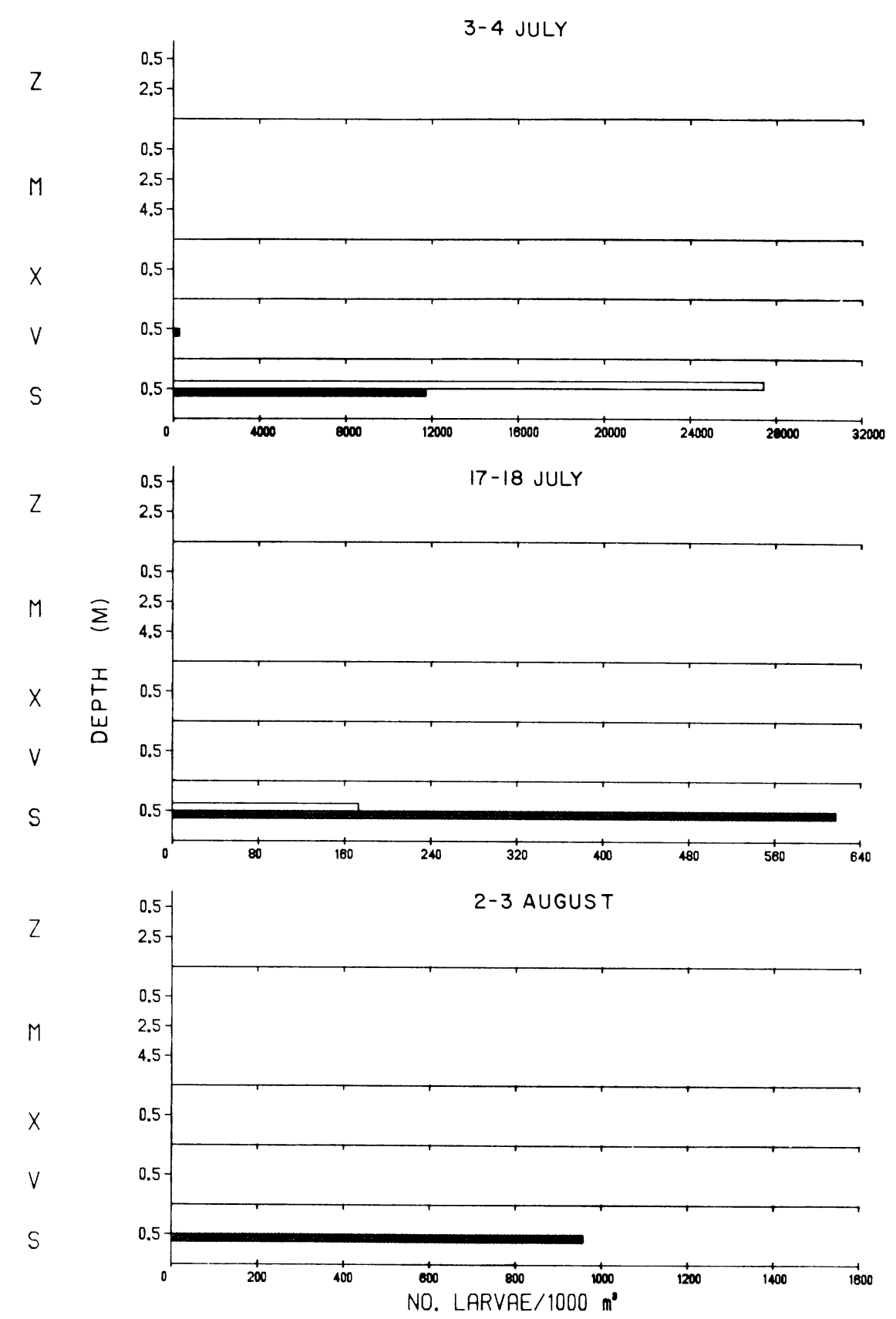

Fig. 116. Density of spottail shiner larvae (no./1000 $\mathrm{m}^{3}$ ) at Pigeon Lake and intake canal stations near the J. H. Campbell Plant, eastern Lake Michigan April to September 1978.

$\square=$ day $\square=$ night 

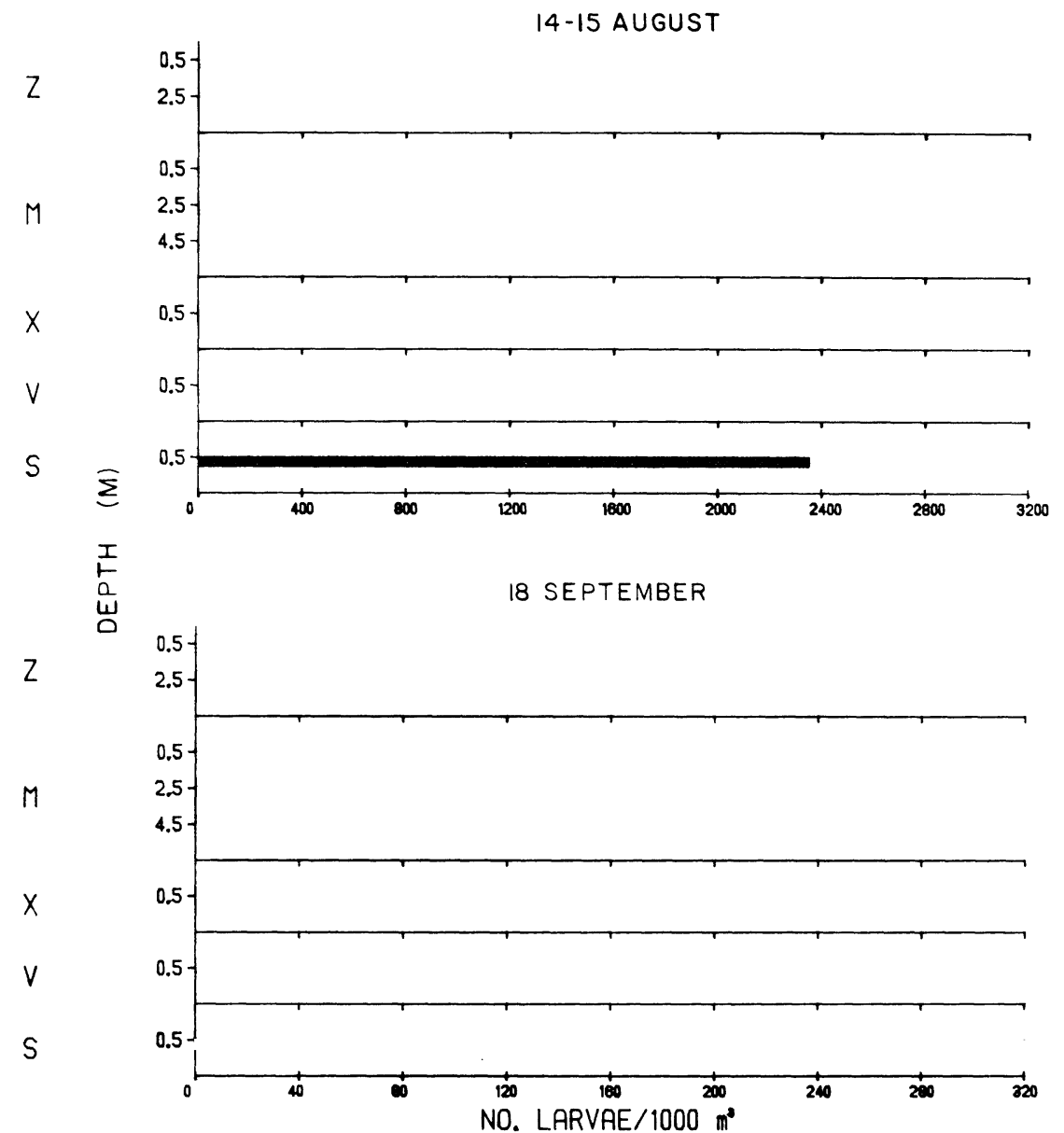

Fig. 116. Continued. 
The bluntnose minnow is another possible constituent of the group of larvae designated as unidentified minnows at Pigeon Lake stations. Distribution of earlier larval stages of this species is difficult to infer from the scant occurrence of larger (greater than $9 \mathrm{~mm}$ ) larvae. Larger bluntnose minnow larvae were observed only in late July, when concentrations averaging 600 larvae/1000 $\mathrm{m}^{3}$ at beach station S (influenced by Lake Michigan) and over 7001 arvae/1000 $\mathrm{m}^{3}$ at station $\mathrm{V}$ (undisturbed Pigeon Lake) were recorded. Because of more favorable spawning habitat, station $\mathrm{V}$ rather than station $\mathrm{S}$ was thought to be a more active site for bluntnose minnow spawning. This species usually spawns in slow moving water, and maintains a nesting site on the undersides of flat objects. This particular spawning characteristic probably affords young larvae a relatively protected habitat. If this contention is true, little entrainment loss of young bluntnose minnow would be expected. It is possible that small larvae probably were distributed in shallow areas near station $\mathrm{V}$ (undisturbed Pigeon Lake), possibly at depths shallower than were sampled by our standard gear. No larger ( $>9 \mathrm{~mm}$ ) bluntnose minnow larvae were found in entrainment samples. This is undoubtedly due to the strict demersal behavior of this species and its tendency to inhabit slower moving water.

Golden Shiner--

Due to the relatively high number of adult golden shiners caught in Pigeon Lake from April to November it is possible that the larvae of this species also comprised part of our unidentified minnow collections in Pigeon Lake samples. It is doubtful whether this species spawns in Lake Michigan for reasons (lack of suitable habitat) previously discussed. As with bluntnose minnow larvae the distribution of smaller ( $9 \mathrm{~mm}$ or less) golden shiner larvae is difficult to infer from distributional data of larger (greater than $9 \mathrm{~mm}$ ) golden shiner larvae. The only occurrence of larger golden shiner larvae in 1978 was observed in Pigeon Lake in early July at beach station S (influenced by Lake Michigan). The requirement of vegetation for spawning by golden shiner again indicates station $V$ (undisturbed Pigeon Lake) as the most likely spawning site compared with station $S$ (influenced by Lake Michigan) which was only sparsely vegetated. This would suggest that, similar to bluntnose minnows, smaller ( $9 \mathrm{~mm}$ or less) golden shiner larvae were distributed in the shallow protected areas of Pigeon Lake and probably comprised a higher percentage of those larvae designated as unidentified minnow larvae at undisturbed Pigeon Lake stations than at Lake Michigan influenced stations.

Fry of golden shiners were only encountered twice in larvae samples during 1978. The first occurrence in May was probably a yearling, the result of late spawning in 1977. A fry was also collected at 2-m station X (undisturbed Pigeon Lake) in late July. No larger larvae (greater than $9 \mathrm{~mm}$ ) or fry of this species were observed in entrainment samples, indicating that they were not vulnerable to present intake currents.

Emerald Shiner--

Temporal distribution of emerald shiner larvae in Pigeon Lake probably paralleled that of spottail shiner larvae, due to their similar spawning habits. However, Flittner (1964) stated that, unlike spottails which were demersal, emerald shiner larvae are pelagic and occur in much deeper water than spottails. As was 
found for bluntnose minnow and golden shiner, larger (greater than $9 \mathrm{~mm}$ ) emerald shiners were only rarely encountered, with one occurrence in Pigeon Lake at beach station S (influenced by Lake Michigan) in late June when an average of over 2200 larvae/1000 $\mathrm{m}^{3}$ was observed. They were also collected at station $\mathrm{Z}$ (intake canal) in early June (194 larvae/1000 $\left.\mathrm{m}^{3}\right)$. These distribution data suggest that some larvae designated as unidentified minnows caught at beach station $S$ (influenced by Lake Michigan) in early June may have been emerald shiners. The proportion of the total number of unidentified minnow larvae represented by emerald shiners was, however, difficult to determine.

Occurrence of 33 emerald shiner larvae/1000 $\mathrm{m}^{3}$ in the $8-\mathrm{m}$ tow at station $\mathrm{F}$ $(15 \mathrm{~m}-\mathrm{S})$ in late June and 21 emerald shiner larvae/1000 $\mathrm{m}^{3}$ in a sled tow at station B ( $3 \mathrm{~m}-\mathrm{S})$ in late July indicate that some Lake Michigan spawning by emerald shiners occurred in 1978. It is thus probable that a very small portion of larvae designated as unidentified minnows in Lake Michigan could have been emerald shiners.

Entrainment losses of small emerald shiners, less than $9 \mathrm{~mm}$, were difficult to determine. Since this species disperses its eggs at random, similar to spottail shiners, proportionally high entrainment loss would be expected. Since the area near station S (influenced by Lake Michigan) was probably one of the primary spawning sites for emerald shiners in Pigeon Lake, many larvae and eggs of emerald shiners were probably entrained at rates comparable to those of spottail shiner, which also used this area for spawning.

Carp--

Introduction-- Larval carp were collected in the vicinity of the Campbelı Plant during May, June, July and August 1978. In 1977, 47 larval carp were identified from July, August and September, however, field and entrainment sampling did not commence until 1 June and 8 July respectively in 1977 (Jude et a1. 1978).

Catch of carp larvae (318) increased in the area of the Campbell Plant from 1977 to 1978. July 1978 samples alone contained 157 larval carp. Paralleled significant changes in adult carp catches from 1977 and 1978 were not observed (see RESULTS AND DISCUSSION, ADULT AND JUVENILE FISH, Carp).

Carp larvae were readily distinguishable from larvae of other cyprinids, except goldfish. The more difficult distinction between carp and goldfish larvae however, can be made. Few adult goldfish frequent the study area (see RESULTS AND DISCUSSION, ADULT AND JUVENILE FISH, Goldfish) and for this reason we are confident in our larval carp and goldfish separations

Mature carp have been found to spawn from May to August in Lake St. Lawrence, Ontario (Swee and McCrimmon 1966). Spawning seemed to occur once water temperatures reach $17.0 \mathrm{C}$ or more, optimally between 19 and $23 \mathrm{C}$, and rarely occurred at water temperatures higher than $26.0 \mathrm{C}$. These workers also noted that spawning was interrupted when cool weather prevailed long enough to lower water temperatures below $17.0 \mathrm{C}$. Larval carp have been reported to hatch at average lengths of 4.4 to $7.5 \mathrm{~mm}$. Carp are robust larvae; few were caught during the day or at lengths greater than $8.0 \mathrm{~mm}$. No fry or YOY carp were collected in plankton nets or adult field gear during 1978 . 


\section{Seasonal Distribution--}

May, June-- The only carp larvae collected during May were taken in entrainment samples during the last week (Fig. 117). However, some carp eggs and larvae were found in a plankton net tow conducted along the edge of the intake canal among the shoreline vegetation. Carp larvae were much more abundant in June, being recovered from entrainment, Pigeon Lake and intake canal samples. During early June, 22 larval carp were observed in Pigeon Lake samples collected at beach station S (influenced by Lake Michigan), station V (undisturbed Pigeon Lake) and in surface and 2-m tows at station M (influenced by Lake Michigan); most were collected at night (Fig. 118). Highest densities of larval carp were seen in samples taken at night at beach station S $\left(3968 / 1000 \mathrm{~m}^{3}\right)$, where larvae averaged $6.8 \mathrm{~mm}$ (range $6-8 \mathrm{~mm}$ ). At beach station $\mathrm{V}$ concentrations of larval carp were also high $\left(966 / 1000 \mathrm{~m}^{3}\right)$; however, larger larvae averaging $8.5 \mathrm{~mm}$ (range $7.5-9.2 \mathrm{~mm}$ ) were collected. The four carp collected at night at station $\mathrm{M}(6 \mathrm{~m})$ ranged from 5.5 to $8.1 \mathrm{~mm}$. Temperature of the water at time of sampling ranged from 17.5 to $20.8 \mathrm{C}$.

In late June a 6-mm carp larva was captured in a night surface tow at station $\mathrm{Z}$ (intake canal) (Fig. 118). This was the only larval carp captured at this station in June. In Pigeon Lake, only five carp larvae (5-7.5 mm) were collected; four of these were taken at beach station $\mathrm{V}$ at water temperatures of 18-21 C. One carp larva $(24.5 \mathrm{~mm})$ was also collected at station X (undisturbed Pigeon Lake) at night when the water was $20.0 \mathrm{C}$. No carp larvae were recorded from beach station S samples; however, temperatures had dropped to $15.0 \mathrm{C}$ at sampling time. In contrast to the 28 collected in field samples during June 1978 only 1 carp larvae was recovered in June 1977 field samples. This fish was taken in a night surface tow a $2-\mathrm{m}$ station $\mathrm{X}$ when water temperature was $18.0 \mathrm{C}$.

July-- The only carp larvae collected in July were taken during the first week of sampling. In early July one carp larva was recovered from Lake Michigan station I (1.5 m - N) in a night surface tow (Fig. 119). This 5.5-mm larva out of the only larval carp recovered from Lake Michigan and may have been washed from the discharge canal. Adult carp have been observed in the canal and undoubtedly spawned there. In 1977, 11 larval carp were collected from Lake Michigan at stations D $(9 \mathrm{~m}-\mathrm{S})$, E $(12 \mathrm{~m}-\mathrm{S})$, G $(18 \mathrm{~m}-\mathrm{S})$, I $(1.5 \mathrm{~m}-\mathrm{N})$, L $(6 \mathrm{~m}-\mathrm{N})$ and beach station $R$ ( $N$ reference). All were taken in early July except those at station $I$ which were collected during late July (Jude et al. 1978).

Sixty-five larval carp were recovered during early July 1978 from night surface and 2-m tows at station $\mathrm{Z}$ (intake canal) (Fig. 118). These fish averaged $6.0 \mathrm{~mm}$ and ranged from 5.2 to $7.0 \mathrm{~mm}$. Carp larvae (16) of similar lengths (5.3$6.9 \mathrm{~mm}$ ) were also observed at Pigeon Lake stations $\mathrm{V}, \mathrm{M}$ and $\mathrm{X}$ (Fig. 118) in water 17.2 to $21.0 \mathrm{C}$. Again no carp were seen in station S samples even though water temperatures in early July at this station ranged from 17.6 to $19.3 \mathrm{C}$. During 1977, 17 larval carp were taken during July in Pigeon Lake. These were collected at stations $\mathrm{M}$ and $\mathrm{V}$ in early July and at stations $\mathrm{S}$ and $\mathrm{V}$ in late July (Jude et al. 1978). 

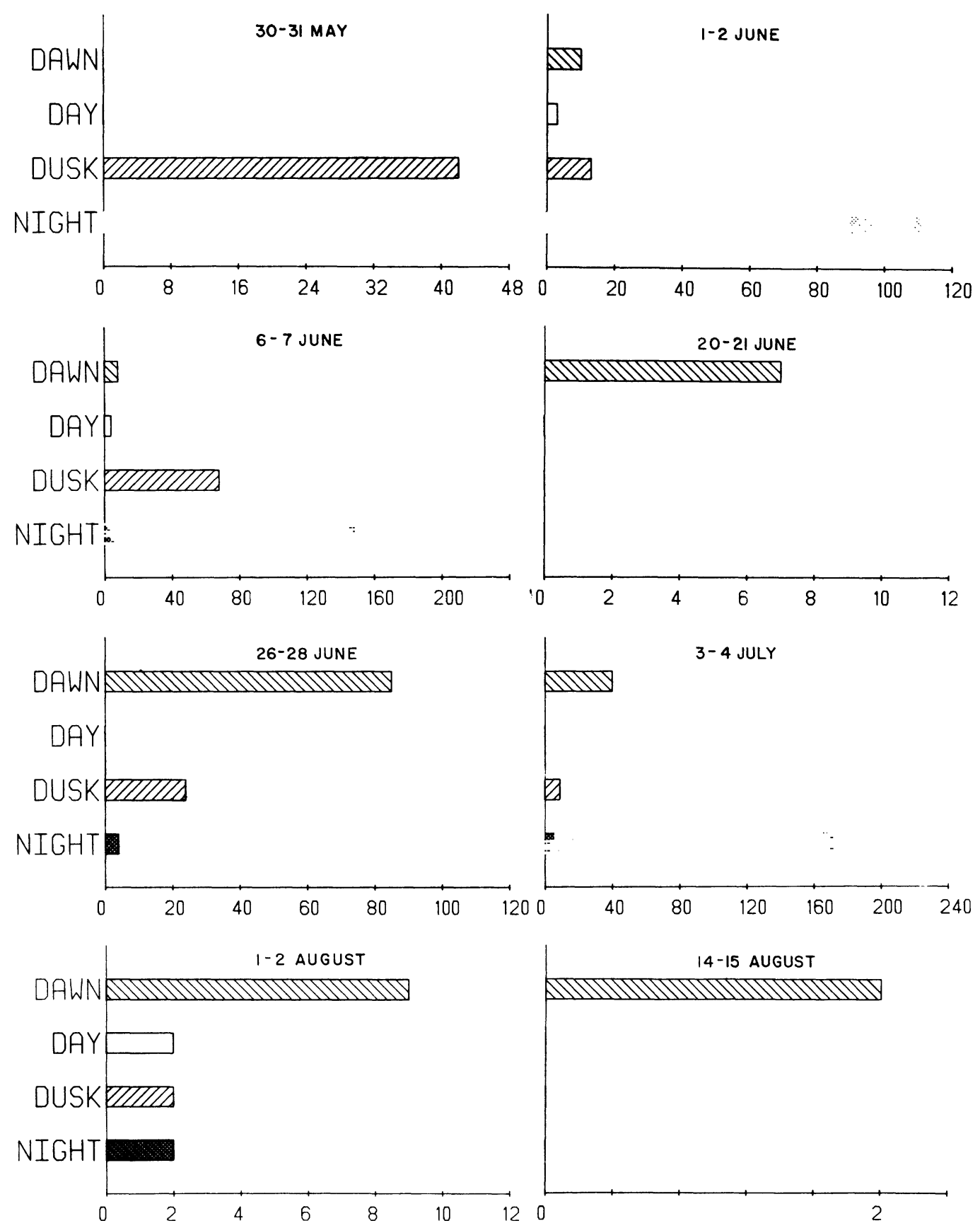

\section{NO. OF LARVAE PER $1000 \mathrm{~m}^{3}$}

Fig. 117. Density of carp larvae (no./1000 $\mathrm{m}^{3}$ ) collected in weekly dawn, day, dusk and night entrainment samples at the J. H. Campbell Plant, eastern Lake Michigan, 1978. 

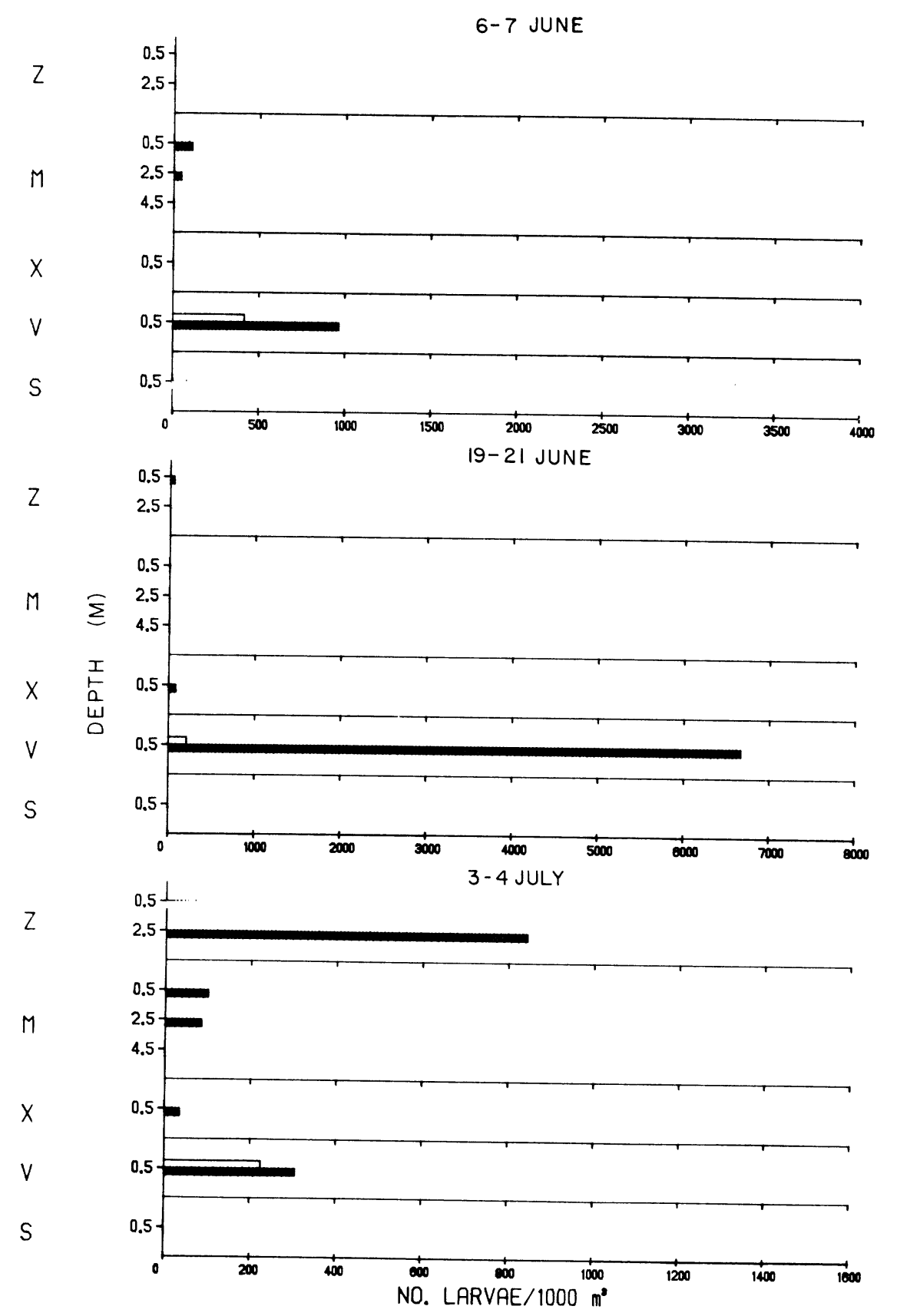

Fig. 118. Density of carp larvae (no./1000 $\mathrm{m}^{3}$ ) at Pigeon Lake and intake canal stations near the J. H. Campbell Plant, eastern Lake Michigan April to September 1978.

$$
\square=\text { day } \square=\text { night }
$$




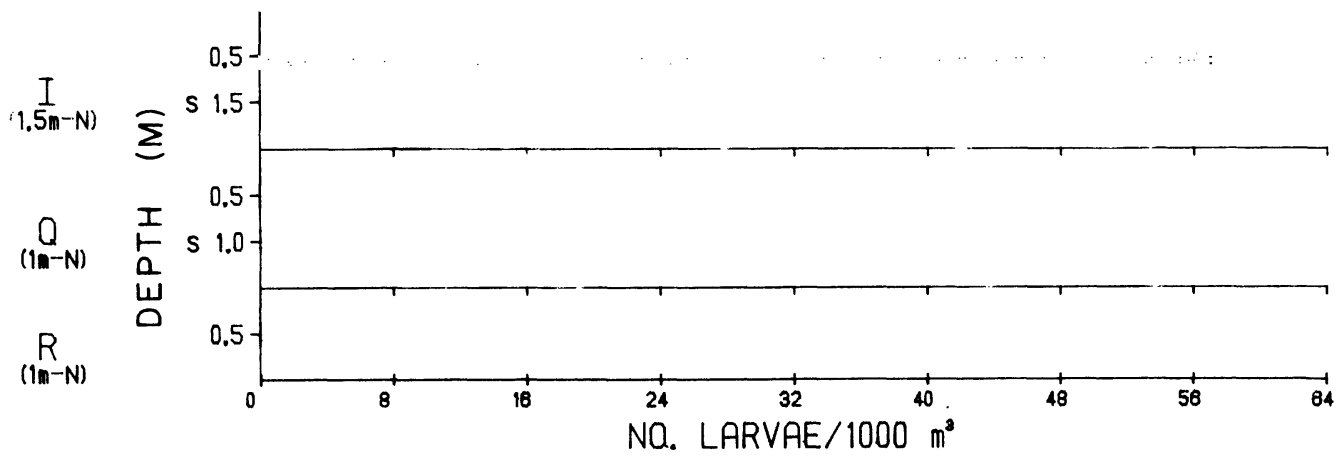

Fig. 119. Density of larval carp (no./1000 $\mathrm{m}^{3}$ ) at Lake Michigan stations near the J. H. Camphell Plant, eastern Lake Michigan, 1-2 July 1978. Stations 3 to $15 \mathrm{~m} \mathrm{~N}$ were omitted due to ahsence of larvae in samples. $\square=$ day $\square=$ night $S=$ sled

August-- A few carp larvae were entrained during August, indicating some spawning continued into this month. These were the only carp larvae recovered during the rest of 1978 .

\section{Entrainment--}

May-- Fourteen larval carp were entrained in dusk samples and seven in night samples during May. None were collected during the day. These were the only larval carp collected in May and they ranged from 5.2 to $8.1 \mathrm{~mm}$, averaging $6.7 \mathrm{~mm}$. Intake water temperatures at this time were 18.0 to $18.9 \mathrm{C}$. These carp probably originated from a mid-May spawning. Capture of most larvae during nocturnal hours indicated carp larvae may be more active during these times, thus making them susceptible to being entrained in intake waters.

June-- In June, carp larvae were recovered from entrainment samples during al1 4 wk of monitoring (Fig. 117). These larvae were entrained heavily during the first $2 \mathrm{wk}$, especially at night, when concentrations of 112 to $148 / 1000 \mathrm{~m}^{3}$ were recorded. During the first week larval carp averaged $6.7 \mathrm{~mm}$, while those entrained during the second week averaged $7.0 \mathrm{~mm}$. Only one larval carp (6.1 mm) was collected in entrainment samples (dawn) during the third week. Water temperatures during the first 2 wk ranged from 16.3 to $20.0 \mathrm{C}$. By the third week however, intake temperatures had dropped to between 12.0 and $14.5 \mathrm{C}$, which may have restricted adult spawning and larval movements.

By the fourth week intake water temperatures had again risen to between 17.5 and $19.5 \mathrm{C}$, which corresponded with the entrainment of 21 larval carp, 16 being taken during dawn sampling. Larvae were newly hatched, averaging only $6.4 \mathrm{~mm}$.

July-- During the first week of July, 75 larval carp were recovered from entrainment samples, mostly at night (Fig. 117). Only 13 carp larvae were col- 
lected in entrainment samples during July 1977 (Jude et a1. 1978). Average length of carp larvae caught in 1978 was $6.2 \mathrm{~mm}$; all ranged from 5.0 to $7.0 \mathrm{~mm}$, except one 11.5-mm individual. Intake water temperatures ranged from 18.0 to $19.0 \mathrm{C}$ during the first week of July, however during the following 2 wk intake water temperatures fell to 10.4-12.0 C and no carp were entrained. During the fourth week intake water temperatures rose to 17.9-19.2 C. Although no carp were entrained, this rise in temperature may have initiated spawning activities resulting in the few carp larvae seen in August.

August-- During August carp larvae were only recovered from entrainment samples (Fig. 117). Six, ranging from 5 to $6.1 \mathrm{~mm}$, were noted in samples col-lected at all time periods during the first week. Intake water temperatures remained between 20.0 and $19.2 \mathrm{C}$. One larval carp was recovered from dawn samples during the third week. Intake water temperatures remained between 19.2 and $25.0 \mathrm{C}$ throughout August.

Summary-- Periodic occurrences of larval carp in the vicinity of the Campbel1 plant indicate that several carp spawnings took place in 1978. McCrimmon (1968) mentions that fluctuations in water temperature may interrupt spawning activities of carp. The larvae noted in the study area were probably the result of spawning by different cohorts of adult carp; however, McCrimmon documented that some individual female carp occasionally spawn more than once in any one season.

Carp probably spawned in Pigeon Lake and the intake canal from mid-May to early June when water temperatures rose above $17.0 \mathrm{C}$ for the first time in 1978. Average lengths of larval carp ranged from 6.7 to $7.9 \mathrm{~mm}$. Numerous adult carp were observed in the intake canal during 1977 to 1979. In late May 1979, plankton net tows along the edge of the intake canal revealed the presence of carp eggs and larvae among the shoreline vegetation.

During the third and fourth weeks of June water temperatures fell to between 12.0 and $14.8 \mathrm{C}$, concomitant with a decline in the collection of larval carp. Not until the fifth week of June did water temperatures again rise above $17.0 \mathrm{C}$. Another pulse of larval carp appeared shortly thereafter during the first week of July. Average lengths of larvae were $6.2 \mathrm{~mm}$ in entrainment samples and $6.0 \mathrm{~mm}$ in intake canal samples.

During the second and third weeks of July the June distribution pattern was repeated. Water temperatures at the intake and Pigeon Lake stations S, M and $\mathrm{X}$ dropped to between 10.4 and $13.0 \mathrm{C}$. No larval carp were detected in the Campbell Plant vicinity at this time. Intake water temperatures rose again during the last week of July and first week of August which corresponded with a small pulse of carp larvae in entrainment samples. These larvae were 5.0 to $6.1 \mathrm{~mm}$ and undoubtedly newly hatched, the result of a late July spawning, This spawning may have been specific to the intake canal region where many adults were concentrated.

Goldfish--

In 1978 one adult and one juvenile goldfish were collected at Pigeon Lake beach station V (undisturbed Pigeon Lake) and Lake Michigan beach station Q 
(S discharge) respectively (see RESULTS AND DISCUSSION - ADULT AND JUVENILE FISH, Goldfish). The adult goldfish, a female with moderately developed ovaries, was caught in April.

Four larval goldfish were collected during 1978; all occurred in entrainment samples (Appendix 14). Three small larvae ranging in size from 5.5 to $6 \mathrm{~mm}$ were collected in dusk samples in late May. One other larval goldfish $(6.0 \mathrm{~mm})$ was recovered in mid-July day samples.

According to Wang and Kernehan (1977) goldfish in the Delaware River system hatched at lengths between 4.0 and $4.5 \mathrm{~mm}$. The larvae collected in the vicinity of the Campbell Plant were probably a few days old. Since these larvae were taken only in entrainment samples, spawning seems likely to have taken place in the intake canal.

\section{Yellow Perch}

Introduction--

For 1977 it was hypothesized by Jude et a1. (1978) that multiple-aged cohorts of yellow perch larvae were present in the vicinity of the Campbell Plant. These authors felt that one group of yellow perch originated from an early spawning in Pigeon Lake (late April-early May) and another group originated from a later spawning in Lake Michigan (late May-early June). Although larval fish sampling did not commence until 31 May 1977, these two groups were found to mix in Pigeon Lake during June as water was drawn into the plant. Two distinct length groups of yellow perch larvae were collected from Pigeon Lake in June 1977, however at no time in 1978 were two such length groups evident. Lengths of yellow perch larvae collected in field samples throughout the year ranged from 4.0 to $8.0 \mathrm{~mm}$ except for one 13.0-mm larvae taken in early June at Lake Michigan beach station Q (S discharge). Most yellow perch larvae observed in entrainment samples ranged from 4.0 to $8.0 \mathrm{~mm}$; however, six larger larvae $(9.5-11.0 \mathrm{~mm})$ were collected from May to early June (Fig. 120). In June 1977, larvae of this larger size group, (greater than or equal to $10.0 \mathrm{~mm}$ ) were recovered exclusively at Pigeon Lake stations $\mathrm{T}$ (influenced by Pigeon River) and $\mathrm{Y}$ (undisturbed Pigeon Lake), both of which were deleted from our sampling scheme in 1978. Deletion of these stations coupled with continued gear avoidance and behavior changes, as discussed by Jude et al. (1978), probably led to our missing the existence of this larger size (greater than or equal to $10 \mathrm{~mm}$ ) larvae in the area during 1978 .

Seasonal Distribution--

May-- Larval yellow perch first appeared in field and entrainment samples during May. They were recovered from plankton net tows at all four Pigeon Lake stations, station $Z$ (intake canal) and at north and south transect stations in Lake Michigan.

In Pigeon Lake larvae were most numerous at beach station $\mathrm{V}$ (undisturbed Pigeon Lake) where average concentrations reached approximately 15,400 larvae/ $1000 \mathrm{~m}^{3}$ in day plankton net tows (Fig. 121). Yellow perch larvae were again abundant at this station during the night; $5500 / 1000 \mathrm{~m}^{3}$. Over this same sampling period, larval yellow perch were found in substantial yet lower densities 

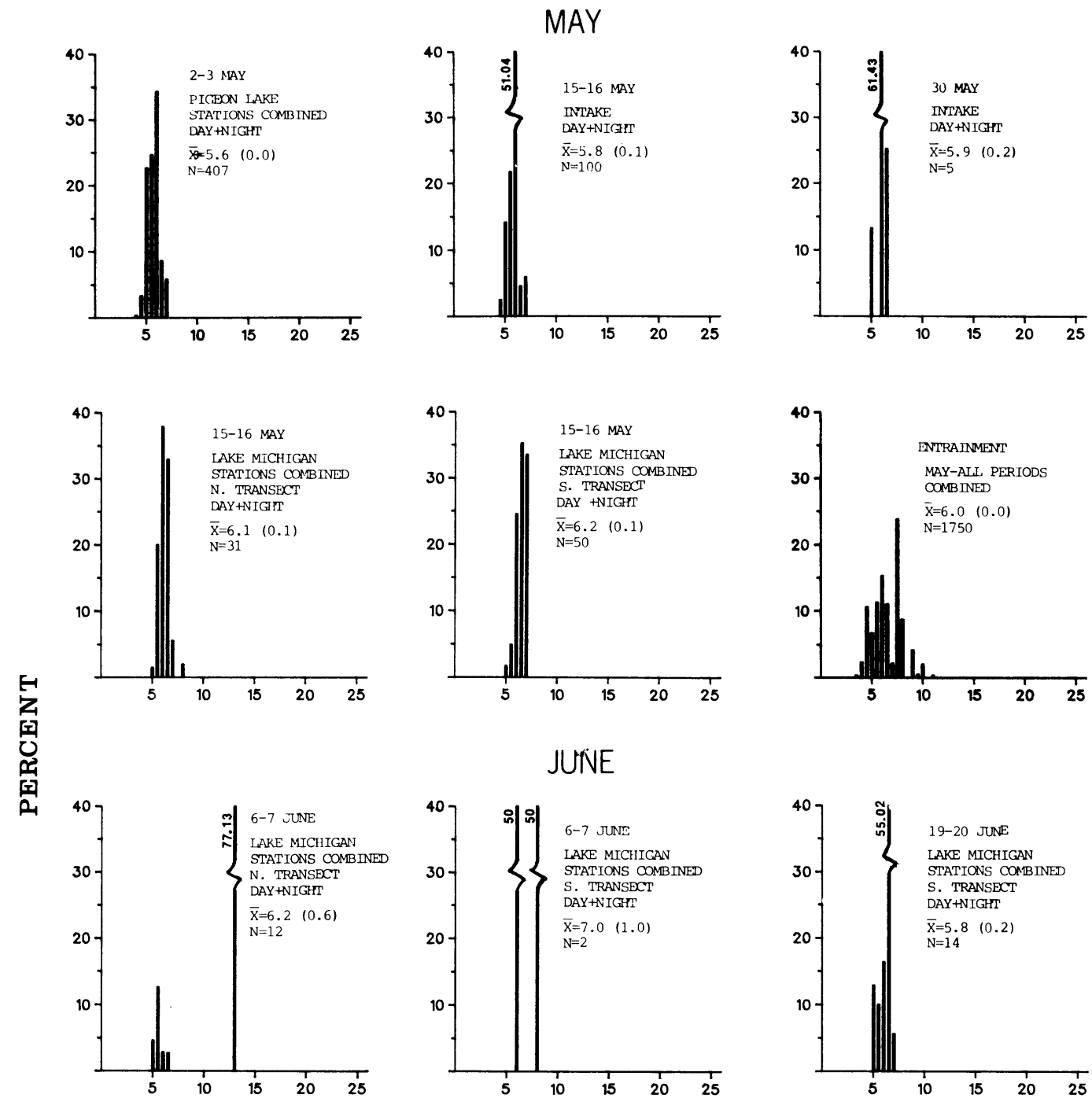

\section{JUNEE}
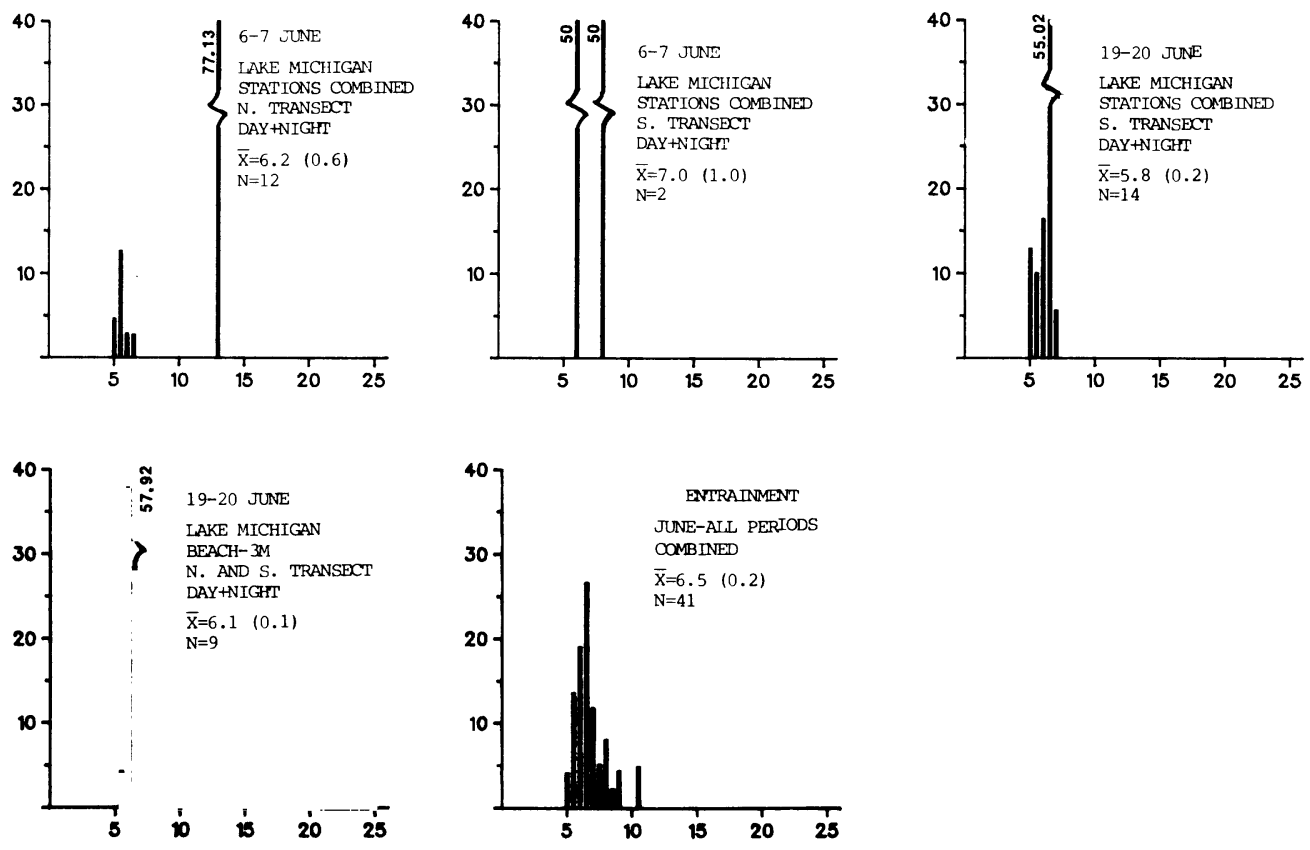

TOTAL LENGTH (mm)

Fig. 120. Length-frequency histograms for larval yellow perch observed in field and entrainment samples collected during 1978 near the J. H. Campbell Plant, eastern Lake Michigan. All tows were plankton net tows unless sled tows were specified. $\overline{\mathrm{X}}=$ mean, $N=$ total number of larvae, standard error is given in parentheses. 

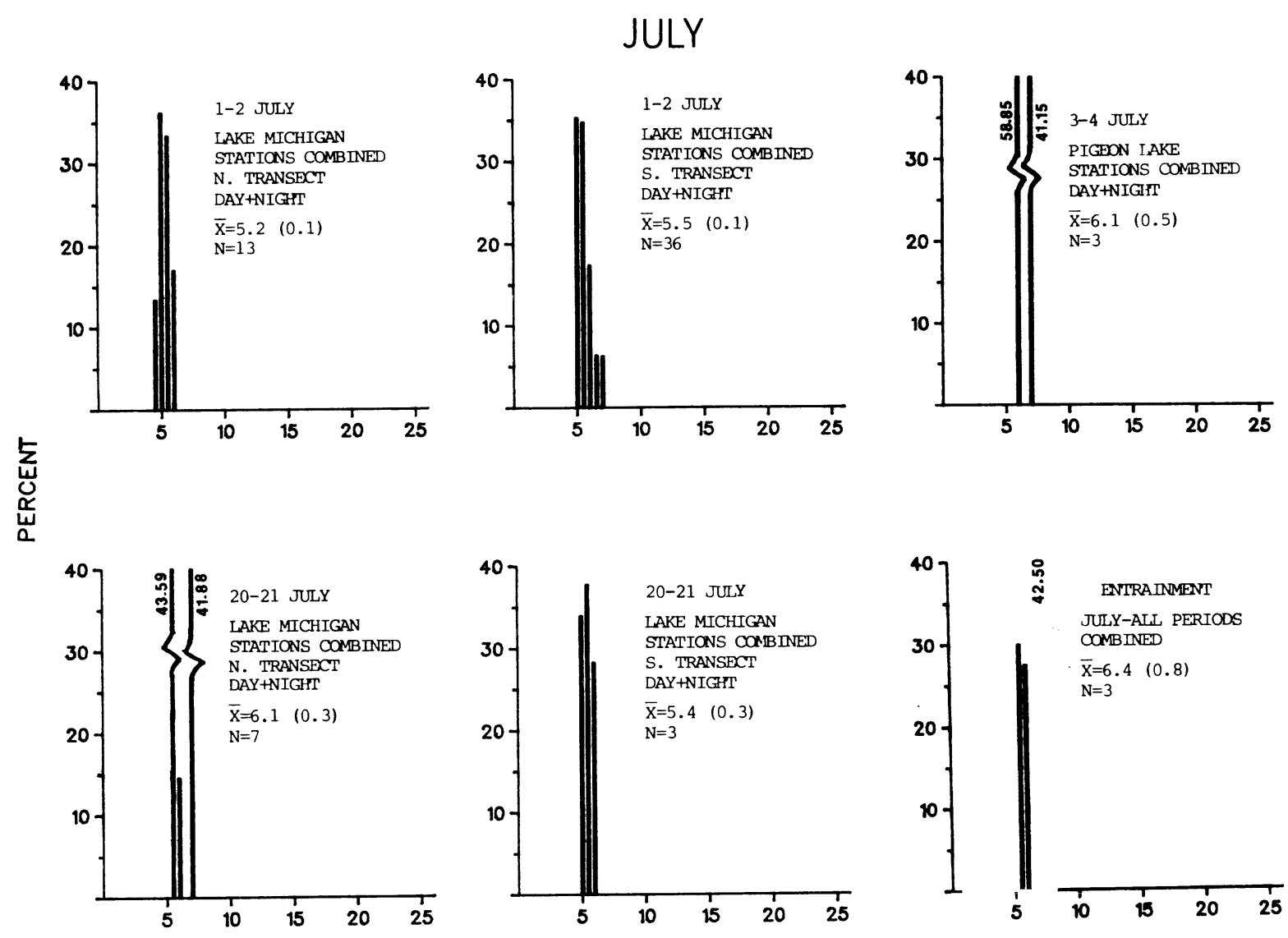

TOTAL LENGTH (MM)

Fig. 120. Continued.

at beach station S (influenced by Lake Michigan) and open water stations $M$ (influenced by Lake Michigan) and X (undisturbed Pigeon Lake) (Fig. 121). Water temperature at these stations during time of capture ranged from 9.0 to $17.0 \mathrm{C}$. Except for a few larvae (less than $90 / 1000 \mathrm{~m}^{3}$ ) appearing at night during July at stations $\mathrm{M}$ and $\mathrm{X}$, May was the only time yellow perch larvae were present in Pigeon Lake as revealed by our sampling regime. Obviously, spawning by Pigeon Lake yellow perch occurred sometime in late April, resulting in peak numbers of larvae observed in early May. Harmonious with this abundance of larvae in Pigeon Lake during May, yellow perch larvae were also recovered from intake canal (station Z) tows conducted during the day and night on 15 and 30 May 1978. Maximum concentrations of 2172 and 84 larvae/1000 $\mathrm{m}^{3}$ for these dates respectively, occurred at night (Fig. 121). Water temperatures at time of sampling ranged from 11.0 to $20.0 \mathrm{C}$.

Yellow perch larvae were recovered from Lake Michigan north and south transects during May in both plankton net and sled tow samples. At the north transect, 


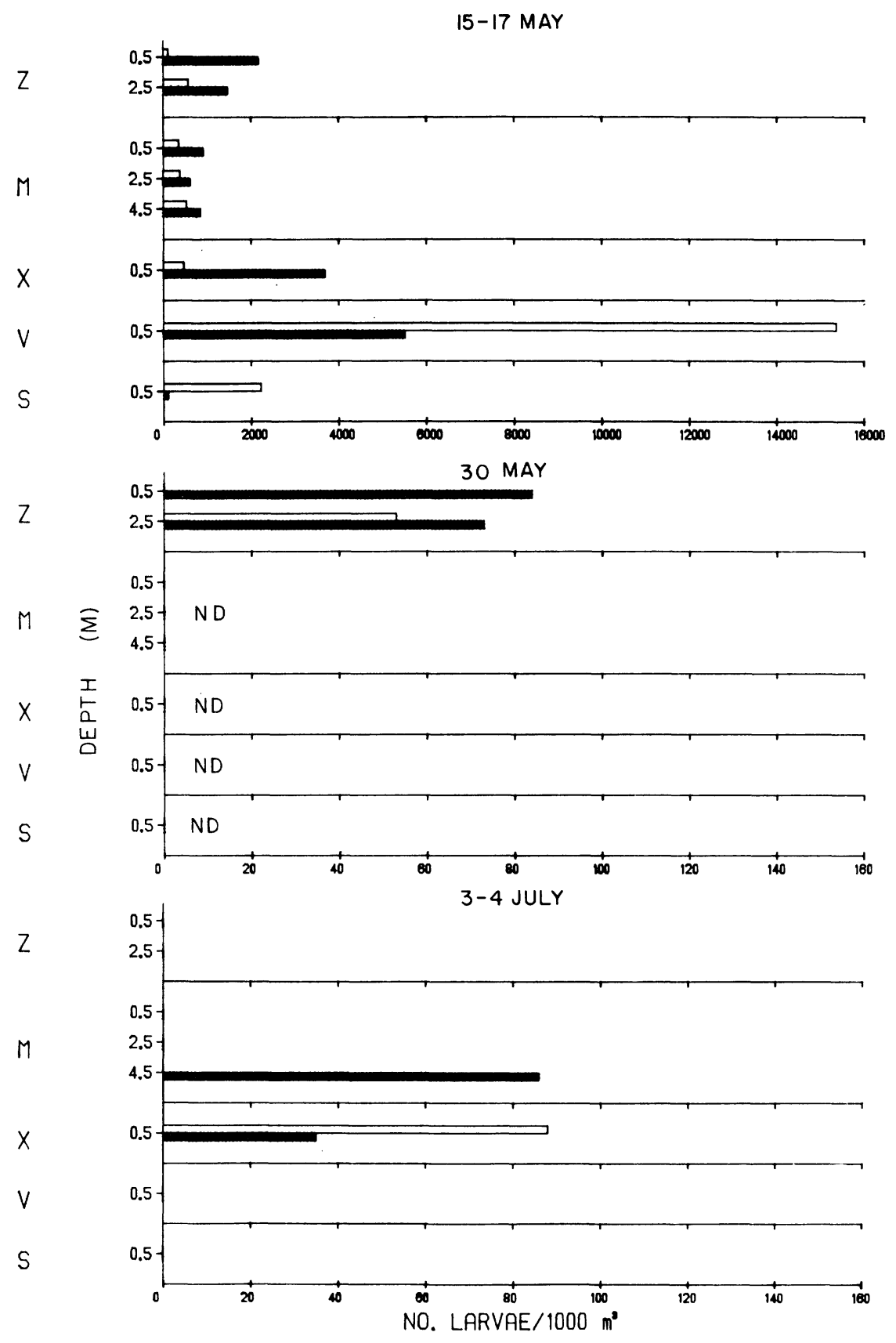

Fig.121. Density of larval yellow perch (no./1000 $\mathrm{m}^{3}$ ) at Pigeon Lake and intake canal stations near the J. H. Campbell Plant, eastern Lake Michigan April to September 1978.

$$
\text { = day } \square=\text { night } \quad \text { ND = no data }
$$


larvae were collected in appreciable numbers only at beach stations Q (S discharge and $R$ ( $N$ reference) and nearshore station $I(1.5 \mathrm{~m}-\mathrm{N})$. Larvae were collected in both day and night sled and plankton net tows at beach station $Q$ in densities of approximately 500 and 380 larvae/1000 $\mathrm{m}^{3}$ respectively (Fig. 122). At beach station $R_{3}$ ( $N$ reference) (Fig. 122), concentrations at night were approximately $200 / 1000 \mathrm{~m}^{3}$ in plankton net tows. Water temperatures at time of capture ranged from 7.5 to $12.2 \mathrm{C}$.

Abundance of yellow perch larvae in plankton net tows in May decreased with increasing depth and distance from shore. Concentrations declined from $315 / 1000 \mathrm{~m}^{3}$ at station I $(1.5 \mathrm{~m}-\mathrm{N})$ at night to less than $14 / 1000 \mathrm{~m}^{3}$ in a night $6-\mathrm{m}$ tow at station $\mathrm{N}(9 \mathrm{~m}-\mathrm{N})$. No yellow perch larvae were collected at either station $O(12 \mathrm{~m}-\mathrm{N})$ or $\mathrm{W}(15 \mathrm{~m}-\mathrm{N})$ (Fig. 122). Perch larvae appeared irregularly in sled tow samples, occurring in a day sled tow at station $I$ and a night sled tow at station $\mathrm{N}$. No temperature related distribution pattern was apparent along north transect stations although larvae were predominately recovered at night at depths of $6 \mathrm{~m}$ or less.

A similar sporadic occurrence of yellow perch larvae occurred along the south transect with densities highest near the beach. Yellow perch larvae were collected at beach station $\mathrm{P}$ (S reference) in both day and night sled and plankton net tows in concentrations of approximately 300 and $600 / 1000 \mathrm{~m}^{3}$ respectively (Fig. 122). Water temperatures at this station ranged from 8.5 to $11.0 \mathrm{C}$ during sampling times. Perch larvae were also recovered from inshore sled tow samples taken at stations $\mathrm{A}(1.5 \mathrm{~m}-\mathrm{S})$ and $\mathrm{B}(3 \mathrm{~m}-\mathrm{S})$ (Fig. 122).

Yellow perch larvae were collected in plankton net tows during May in numbers less than $100 / 1000 \mathrm{~m}^{3}$ at stations $\mathrm{C}(6 \mathrm{~m}), \mathrm{D}(9 \mathrm{~m})$ and $\mathrm{E}(12 \mathrm{~m})$; none were caught at 15-m station F (Fig. 122). Again at the south transect, yellow perch larvae were less abundant at offshore stations and their occurrence did not seem to be temperature specific. Yellow perch larvae seemed to be more frequently captured at night and rarely in water strata $6 \mathrm{~m}$ or deeper (Fig. 122).

Abundance of yellow perch larvae at inshore Lake Michigan beach stations $P, Q$ and $R$ may suggest that these larvae drifted out into Lake Michigan. Jude et al. (1979) in southeastern Lake Michigan found most yellow perch at 6 and $9 \mathrm{~m}$; perch were rarely caught at beach stations. The small size of the larvae $(5-8 \mathrm{~mm})$ at station $P(3.1 \mathrm{~km}$ south of the Pigeon Lake outlet) and the fact that larvae were not distributed evenly along the south transect makes this hypothesis tenuous. However, alongshore currents are strongest closest to shore; thus yellow perch larvae which enter Lake Michigan would tend to be distributed in nearshore areas and could travel considerable distances.

As has been mentioned, Lake Michigan yellow perch appear to spawn in late May-early June when temperatures warm at offshore, rocky substrate spawning. grounds. Wells (1973) found yellow perch fry at depths of 5.5 to $9.2 \mathrm{~m}$ during sampling trips conducted in late June (18-20) and July (20-23) 1972, indicating that such spawning probably does take place in late May-early June in Lake Michigan. In his study several yellow perch fry were also recovered in early May near Saugatuck, Michigan (32 km south of the Campbell Plant). Wells theorized that these fry were produced from perch spawning in inland lakes (Silver Lake) where 


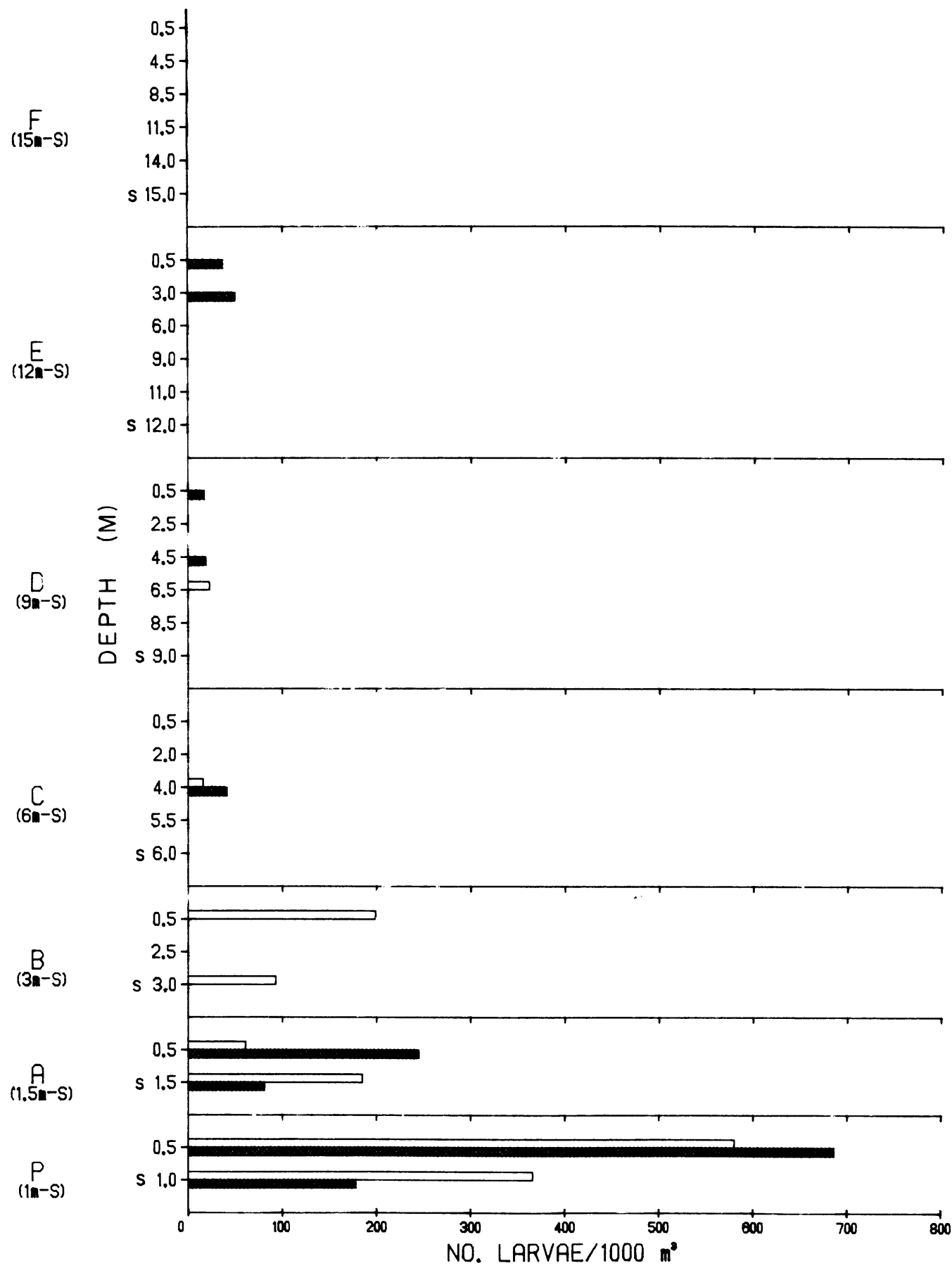

Fig. 122. Density of larval yellow perch (no./1000 $\mathrm{m}^{3}$ ) at Lake Michigan stations near the J. H. Campbell Plant, eastern Lake Michigan, 15-18 May 1978. $\square=$ day $\square=$ night $S=$ sled 

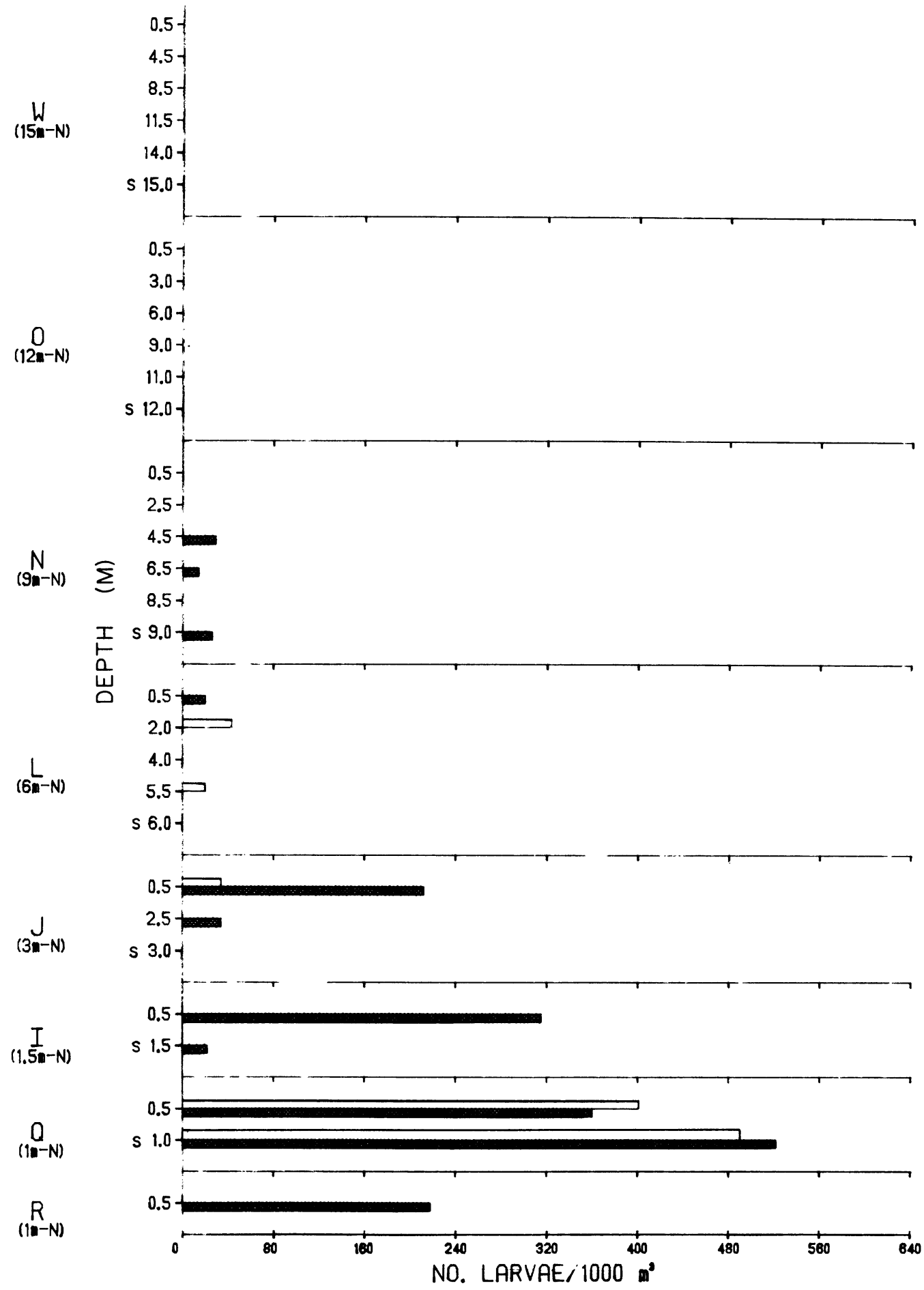

Fig. 122. Continued. 
water had warmed earlier, and then drifted out into Lake Michigan. Yellow perch fry were recovered from Lake Macatawa (Holland, Michigan) in early May 1972, also. These findings combined with our own observation of abundant yellow perch larvae in Pigeon Lake during May of 1977 (Jude et al. 1978) and 1978, may then lend credence to the hypothesis that larvae collected in Lake Michigan in the study area during May may be the result of drift out of Pigeon Lake or possibly the discharge canal. Water temperatures in Lake Michigan were approximately 6.0 to $7.0 \mathrm{C}$ which are below the spawning optimum $(7.2$ to $11.1 \mathrm{C})$ found by Herman et al. (1953) for yellow perch in Wisconsin inland lakes.

In Lake Michigan during early May abundance of mature adult yellow perch was low at sampling depths less than $18 \mathrm{~m}$, but several were impinged and collected in Pigeon Lake (see RESULTS AND DISCUSSION - ADULT AND JUVENILE FISH Yellow Perch). Spawning may have occurred at Lake Michigan beach zone stations but this is unlikely for several reasons: few adult perch were observed in the area, spawning is known to occur later (early June) in this area of Lake Michigan (Jude et al. 1975, 1979), Lake Michigan yellow perch require some type of physical structure for egg laying (i.e., vegetation, riprap, rock outcropping) and peak numbers of yellow perch larvae, which were suspected as being derived from Lake Michigan, occurred in June in Lake Michigan.

The length-frequency histograms for field-collected and entrained perch larvae revealed similar size larvae in all areas around the Campbell Plant during May (Fig. 120). This finding would support the fact that only one spawning took place in May and that it occurred in Pigeon Lake where larvae were most abundant.

June-- No yellow perch larvae were recovered from Pigeon Lake or intake canal plankton net tows during June, which contrasts sharply with data obtained in June 1977. Yellow perch larvae were abundant at Pigeon Lake beach stations $\mathrm{T}$ (influenced by Pigeon River) and Y (undisturbed Pigeon Lake) during June 1977. As noted earlier both these stations were deleted from our sampling program in 1978 and thus may account for the fact that no yellow perch larvae were collected in Pigeon Lake during June 1978.

Field sampling for larval fish was conducted twice during June 1978. During the first week of June larval yellow perch were more abundant at Lake Michigan north transect stations than south transect stations. In beach zone areas, larvae were recovered from sled and plankton net tows only at beach station Q (Fig. 123), the greatest concentration of larvae occurring at night $-406 / 1000 \mathrm{~m}^{3}$. Along the north transect in early June larval yellow perch were much more abundant and more evenly distributed. The greatest concentration of larvae $\left(99 / 1000 \mathrm{~m}^{3}\right)$ was observed at night at station $\mathrm{J}(3 \mathrm{~m}-\mathrm{N})$ in a surface net tow (Fig. 123). Yellow perch larvae were also collected during the day only, in the deepest tows at stations $\mathrm{L}$ $(6 \mathrm{~m}-\mathrm{N})$ and $\mathrm{N}(9 \mathrm{~m}-\mathrm{N})$. Water temperatures along the north transect at this time ranged between 4.9 and $18.1 \mathrm{C}$; whereas, larvae were collected only between 16.4 and $17.8 \mathrm{C}$.

In early June, yellow perch larvae were collected in low concentration (less than $\left.20 / 1000 \mathrm{~m}^{3}\right)$ only at stations $\mathrm{C}(6 \mathrm{~m}-\mathrm{S})$ and $\mathrm{D}(9 \mathrm{~m}-\mathrm{S})$ along the south transect. Plankton net tows revealed their presence at the 4-m stratum during the day at station $\mathrm{C}$ and at $0.5 \mathrm{~m}$ during the night at station $\mathrm{D}$ (Fig. 123). Water temperature at the time of these tows was $18.5 \mathrm{C}$ (Appendix 4). 


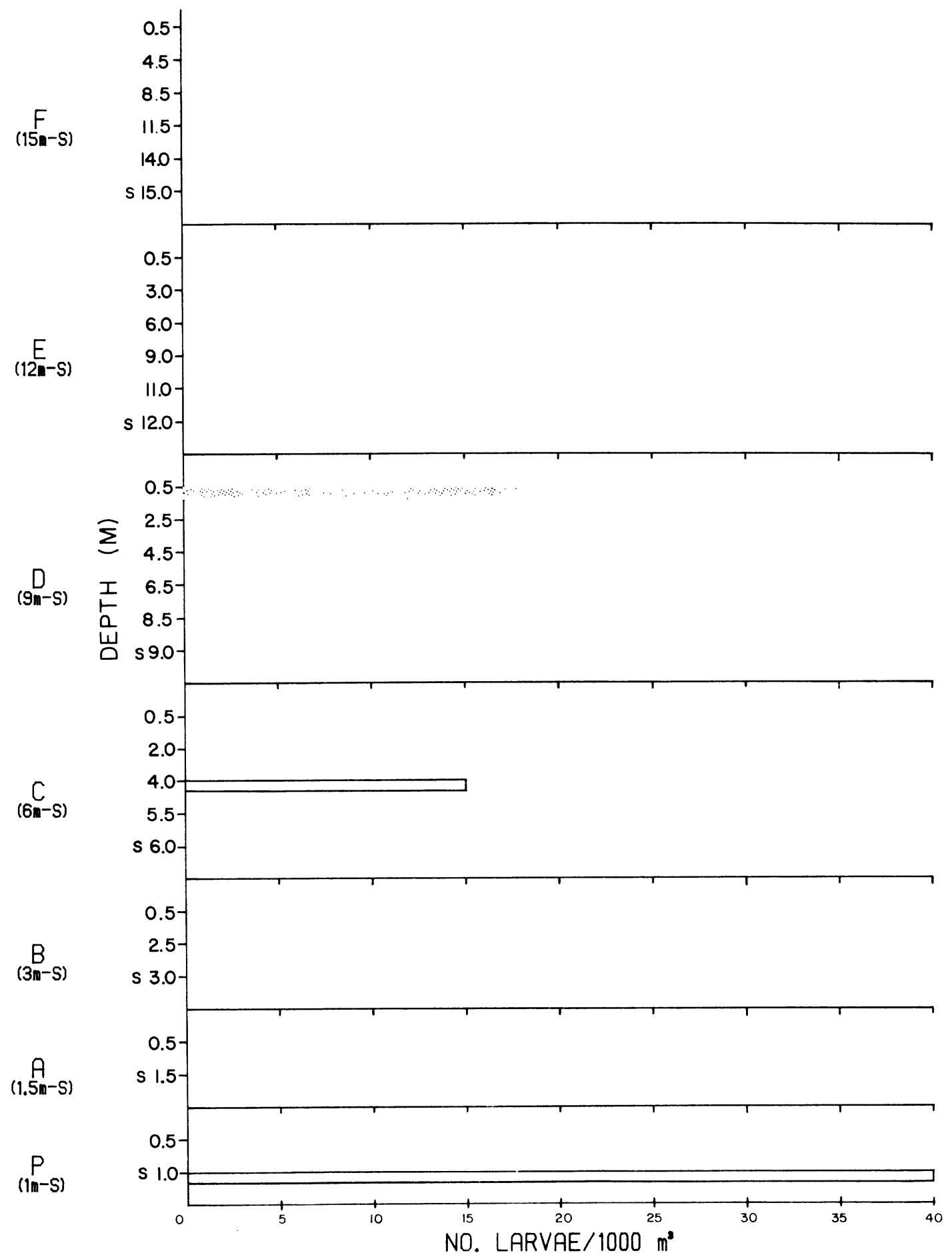

Fig. 123. Density of larval yellow perch (no./1000 $\mathrm{m}^{3}$ ) at Lake l'ichigan stations near the J. H. Campbel1 Plant, eastern Lake Michigan, 6-10 June 1978. $\square=$ day $\square=$ night $S=$ sled $\mathrm{ND}=$ no data 


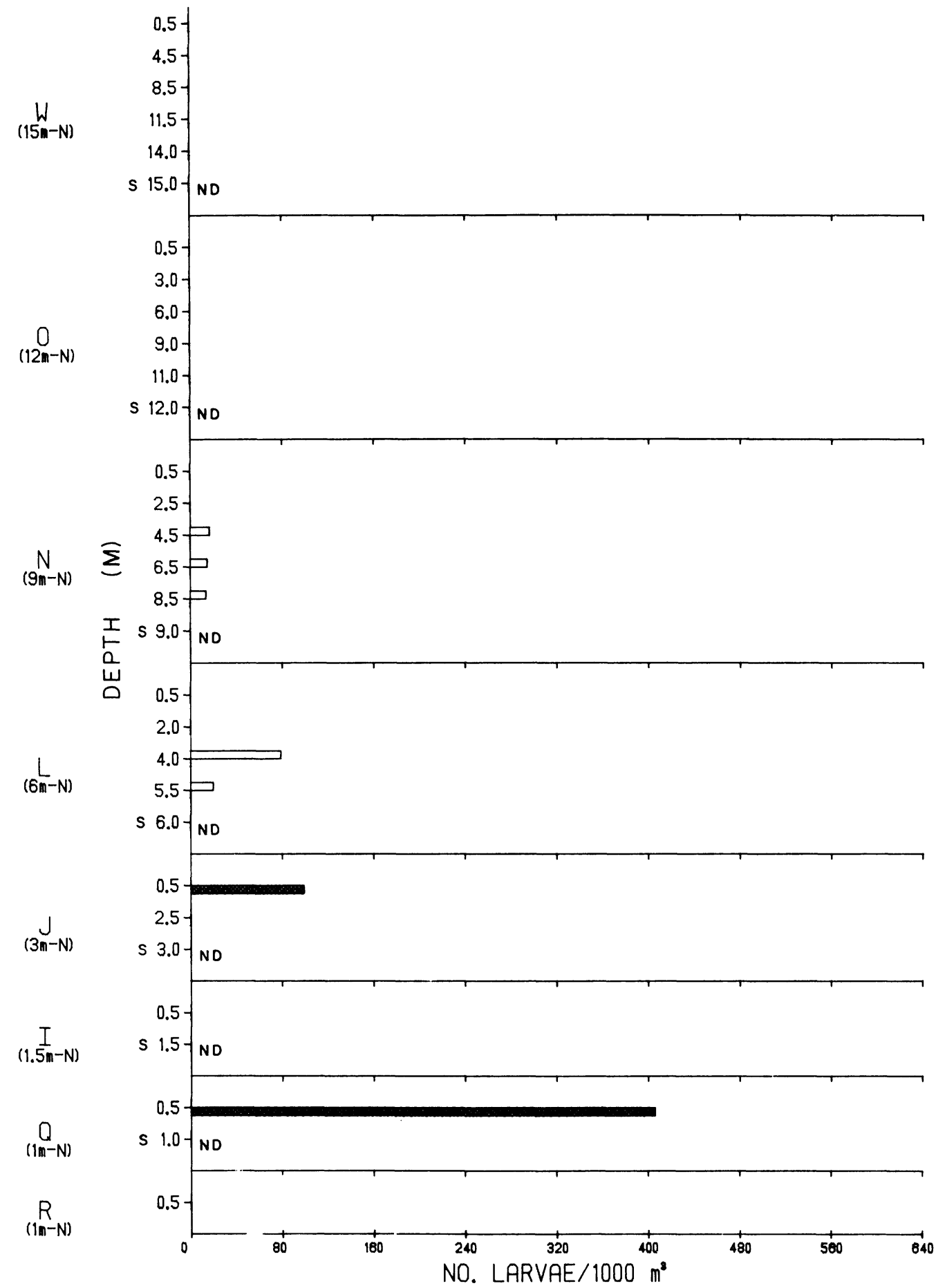

Fig. 123. Continued. 
Field sampling for larvae was also carried out the third week of June. At this time yellow perch larvae were recovered from plankton net tows at beach stations $Q$ (S discharge) and $P$ (S reference). Concentrations of larvae were lower than those found in early June (less than 150/1000 $\mathrm{m}^{3}$ ); however, larvae were again captured only at night (Fig. 124). A wider range of temperatures was exhibited at these beach stations, 13.0 to $21.5 \mathrm{C}$, than those observed in early June, 18.020.5 C. Yellow perch larvae were also collected in day sled tows at beach station Q in late June (Fig. 124).

The offshore Lake Michigan distribution of larval yellow perch showed a reversal between transects in late June. Larvae were less abundant and more infrequent along the north transect. Yellow perch larvae occurred in low concentrations in surface plankton net tows at stations $0(12 \mathrm{~m}-\mathrm{N})$ and $\mathrm{W}(15 \mathrm{~m}-\mathrm{N})$ and in a $2-\mathrm{m}$ tow at station $\mathrm{L}(6 \mathrm{~m}-\mathrm{N})$ during the night. During the day larvae were seen in an $11-\mathrm{m}$ tow at station $\mathrm{O}(12 \mathrm{~m}-\mathrm{N})$ and a 2.5-m tow at station $\mathrm{J}(3 \mathrm{~m}-\mathrm{N})$ (Fig. 124).

At south transect stations yellow perch larvae were abundant, occurring at night at stations A $(1.5 \mathrm{~m}-\mathrm{S}), \mathrm{B}(3 \mathrm{~m}-\mathrm{S}), \mathrm{D}(9 \mathrm{~m}-\mathrm{S})$ and $\mathrm{E}(12 \mathrm{~m}-\mathrm{S})$ at various tow depths (Fig. 124). During the day larvae were collected only at station $B(3 \mathrm{~m}-\mathrm{S})$ at $2.5 \mathrm{~m}$ and at station $\mathrm{E}(12 \mathrm{~m}-\mathrm{S})$ in a $9-\mathrm{m}$ tow. Although a similar range of temperatures existed at both transects $(10.0-17.5 \mathrm{C})$ yellow perch larvae were predominantly collected in water between 11.0 and $13.5 \mathrm{C}$ during the day and 14.4 to $16.7 \mathrm{C}$ during the night.

July-- No yellow perch larvae were collected in intake canal (station $\mathrm{Z}$ ) plankton net tows during July. Field sampling for larval fish was also conducted twice in July 1978. The few yellow perch larvae collected in Pigeon Lake occurred only during the first week of July and only at open water stations $M$ (influenced by Lake Michigan) and X (undisturbed Pigeon Lake). Yellow perch larvae were collected at $2-\mathrm{m}$ station $X$ in concentrations ranging from $35 / 1000 \mathrm{~m}^{3}$ at night to $88 / 1000 \mathrm{~m}^{3}$ during day surface tows. At station $M$, yellow perch larvae occurred only at night in a $4.5-\mathrm{m}$ tow at a density of $86 / 1000 \mathrm{~m}^{3}$ (Fig. 121).

In early July no yellow perch were recovered in Lake Michigan beach or nearshore plankton net or sled tow samples. Perch larvae in July were primarily caught at deep water stations: $0(12 \mathrm{~m}-\mathrm{N}), \mathrm{W}(15 \mathrm{~m}-\mathrm{N}), \mathrm{D}(9 \mathrm{~m}-\mathrm{S}), \mathrm{E}(12 \mathrm{~m}$ $-\mathrm{S})$ and $\mathrm{F}(15 \mathrm{~m}-\mathrm{S})$ (Fig. 125). No yellow perch larvae were collected in sled tows during July. At north transect stations yellow perch larvae were collected only in plankton net tows at station $W$ during the day and at station 0 and station $W$ during the night. Temperatures along the north transect ranged from 12.3 to 17.9 but larvae were predominantly caught at 16.8 to $17.9 \mathrm{C}$.

Along the south transect larvae appeared more frequently in day tows than they did along the north transect. Concentrations of less than $50 / 1000 \mathrm{~m}^{3}$ were seen in tows at station $D(9 \mathrm{~m}-\mathrm{S})$, station $\mathrm{F}(12 \mathrm{~m}-\mathrm{S})$ and $\mathrm{F}(15 \mathrm{~m}-\mathrm{S})$ (Fig. 125). At night larvae were collected at stations $C, D, E$ and $F$. The greatest concentrations of larval yellow perch in early July occhrred in the $6-\mathrm{m}$, station $\mathrm{D}$ tow. Here larvae occurred at a density of $281 / 1000 \mathrm{~m}^{3}$, while at all other stations concentrations were less than $50 / 1000 \mathrm{~m}^{3}$. Temperatures at the south reference transect ranged from 12.5 to $18.0 \mathrm{C}$, yet larvae were captured only at temperatures of 17.4 to $18.0 \mathrm{C}$. 

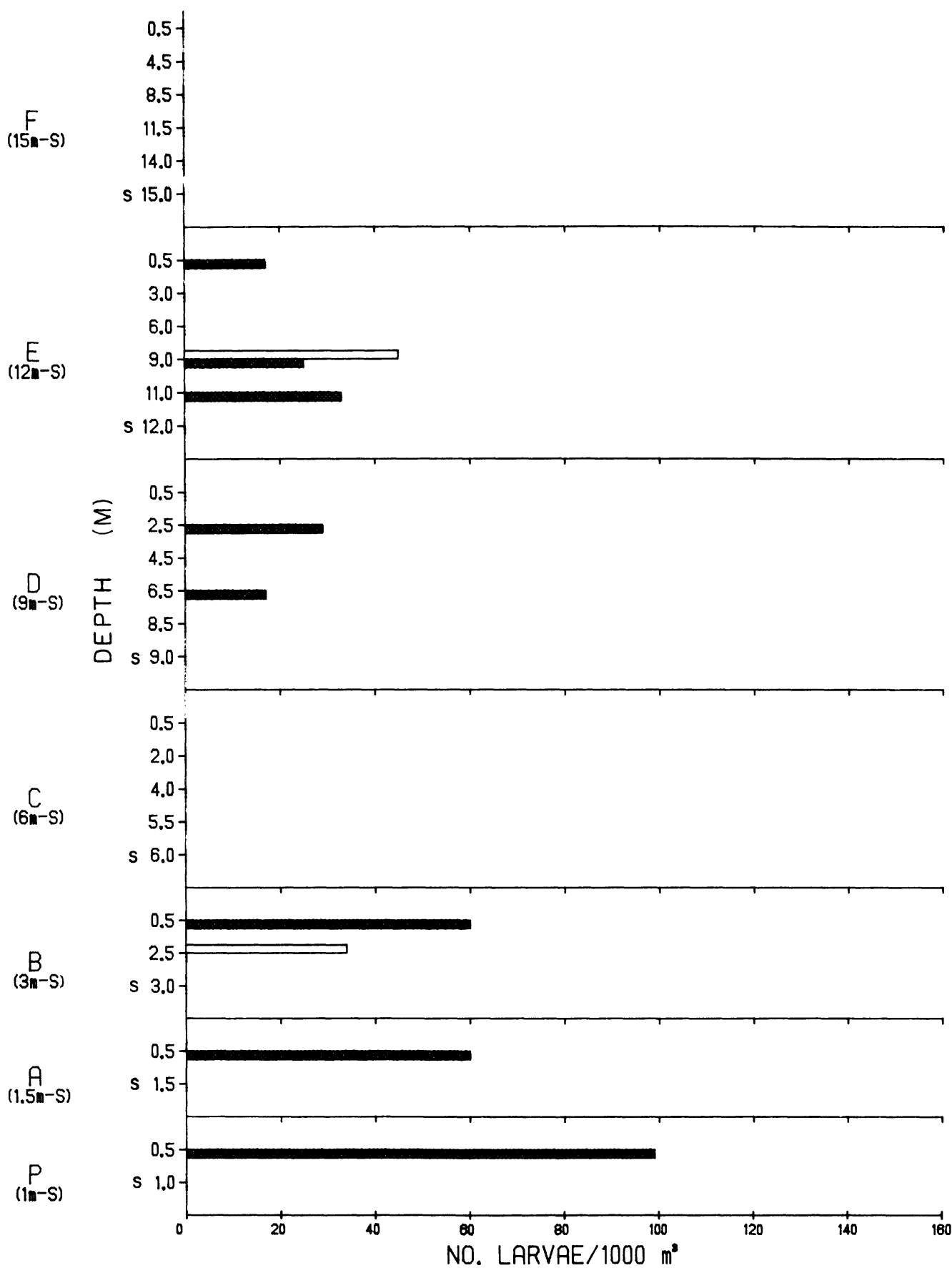

Fig. 124. Density of larval yellow perch (no./1000 $\mathrm{m}^{3}$ ) at Lake Michigan stations near the J. H. Campbell Plant, eastern Lake Michigan, 19-22 June 1978 .

$\square=$ day $\square=$ night $S=$ sled 


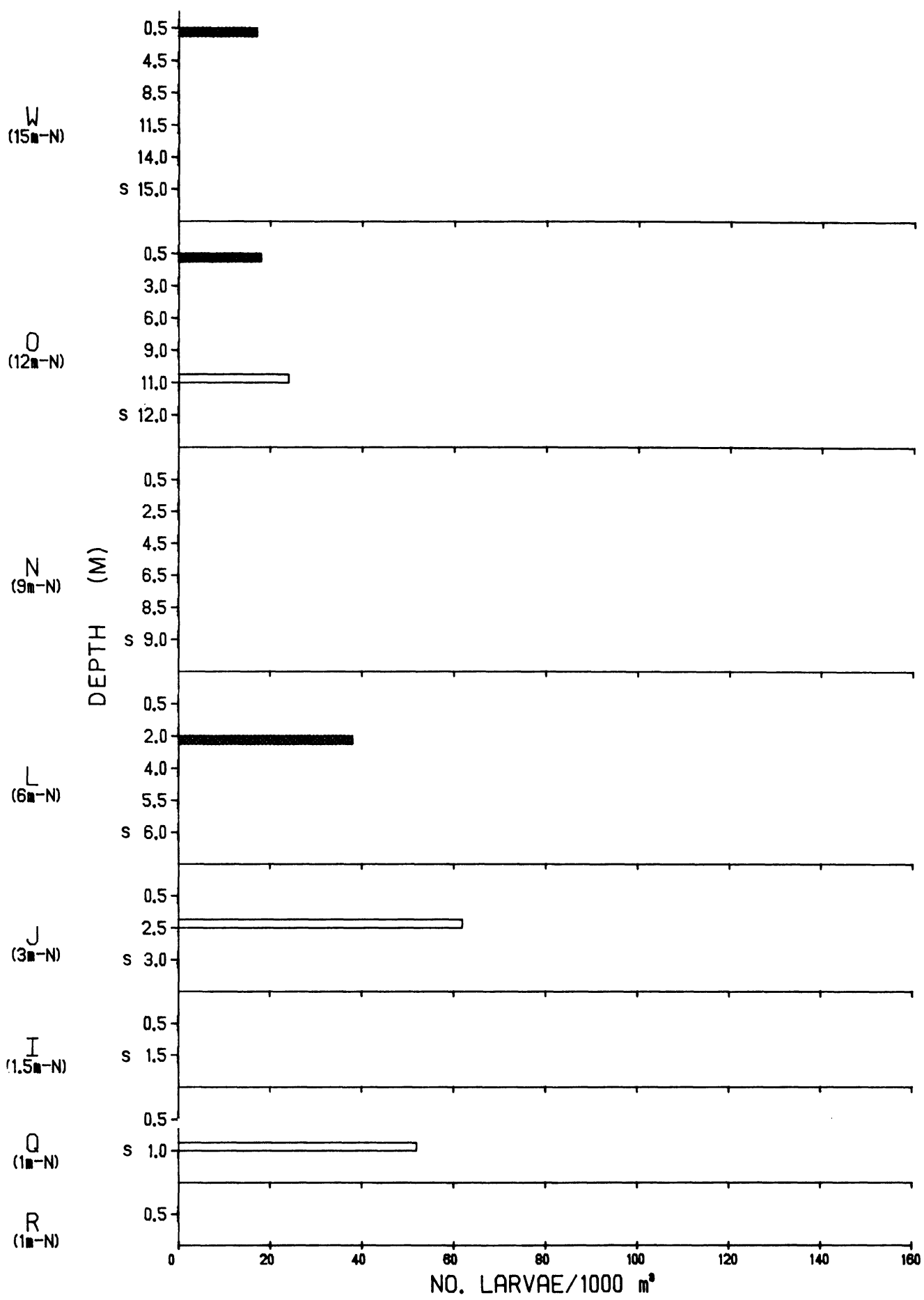

Fig. 124. Continued. 

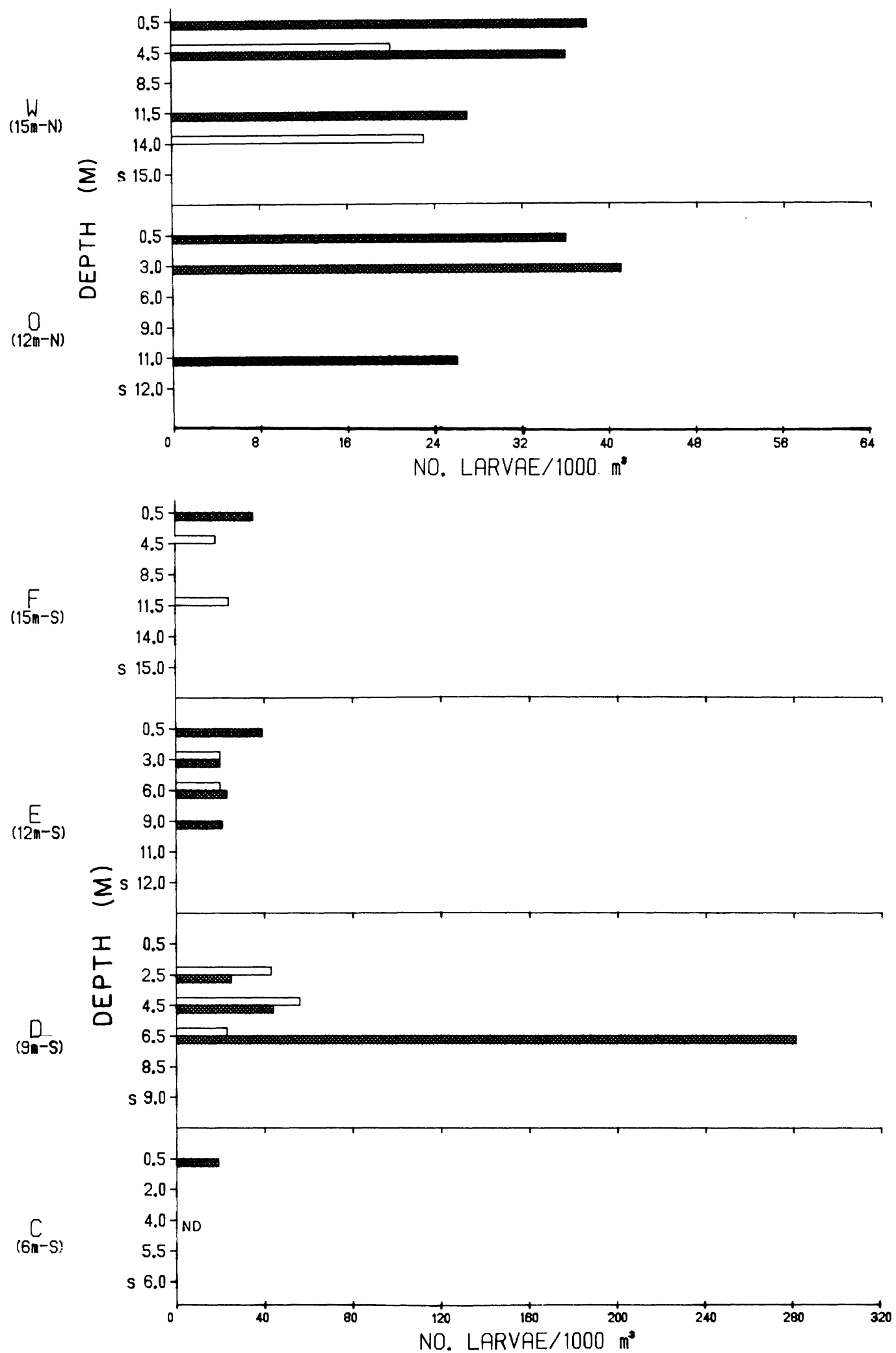

Fig. 125. Density of larval yellow perch (no./1000 $\mathrm{m}^{3}$ ) at Lake Michigan stations near the J. H. Campe11 Plant, eastern I.ake Michigan, 1-3 July 1978. Stations $1-3 \mathrm{~m} \mathrm{~S}$ and 1-9 $\mathrm{m} \mathrm{N}$ were omitted due to absence of larvae in samples. $\square=$ day $\square=$ night $S=$ sled ND = no data 
During the later sampling period in July (17-19), yellow perch were much less abundant and more randomly distributed. Another reversal of distribution seemed to take place, since yellow perch larvae were slightly more abundant at the north transect than at the south. Along the north transect perch larvae in a density of $17 / 1000 \mathrm{~m}^{3}$ were seen in a day plankton tow at station $0(12 \mathrm{~m}-\mathrm{N})$. At night yellow perch larvae were taken in the $6-\mathrm{m}$ tow at station $\mathrm{N}(9 \mathrm{~m}-\mathrm{N})$, the 0.5 and $6.0-\mathrm{m}$ tows at station 0 and a $0.5-\mathrm{m}$ tow at station $\mathrm{W}(15 \mathrm{~m}-\mathrm{N})$ in densities less than $34 / 1000 \mathrm{~m}^{3}$ (Fig. 125). Temperatures along the transect varied from 10.3 to $20.8 \mathrm{C}$; whereas, larvae were most of ten captured at water temperatures between 14.0 and $18.5 \mathrm{C}$.

During late July at the south transect yellow perch larvae were much more uncommon than at the north transect. A density of $18 / 1000 \mathrm{~m}^{3}$ was detected in a day $4.5-\mathrm{m}$ tow at station $\mathrm{F}(15 \mathrm{~m}-\mathrm{S})$ and concentrations of $20 / 1000 \mathrm{~m}^{3}$ and $15 / 1000 \mathrm{~m}^{3}$ were seen in night $11-$ and $14-\mathrm{m}$ tows at stations $\mathrm{E}(12 \mathrm{~m})$ and F (15 m) respectively (Fig. 126). Here again a wide range of water temperatures, 9.2 to $17.6 \mathrm{C}$, was available at the transects, but larvae were predominantly caught in water 14.6 to $16.6 \mathrm{C}$.

In 1977 several yellow perch fry were also collected from Pigeon Lake in July, primarily at beach station T. Again this area was not sampled in 1978, however one yellow perch fry was collected in our sampling. This 33-mm fish was taken in a night 4-m plankton net tow at station F (15 m - S) on 15 August. Other YOY (30-60 mm) began to appear in Lake Michigan trawls primarily at stations $\mathrm{N}$ $(9 \mathrm{~m}-\mathrm{N}), \mathrm{L}(6 \mathrm{~m}-\mathrm{N})$ and $\mathrm{C}(6 \mathrm{~m}-\mathrm{S})$ during September. No fry were recovered from Pigeon Lake in either adult or larval fish sampling gear.

\section{Entrainment--}

Entrainment of yellow perch larvae occurred during each sampling week in May. Concentrations were lowest during the day and highest during night sampling (Fig. 127). Entrainment of yellow perch larvae was greatest during May (Fig. 128). Peak entrainment of larval yellow perch occurred on 16 May when the average daily concentration was $958 / 1000 \mathrm{~m}^{3}$. On this day the overall $24-\mathrm{h}$ entrainment rate was estimated to be 1,567,294 larvae (Fig. 128). Occurrence of these larvae in entrainment samples clearly indicates that yellow perch spawned in Pigeon Lake during late April to early May, which was also suggested by Jude et al. (1978) for 1977. Yellow perch eggs have been found to hatch in 8 to 10 days and the newly hatched larvae are approximately $5.0 \mathrm{~mm}$ (Scott and Crossman 1973).

Yellow perch larvae were entrained during all four sampling periods the first week of June and in all but the day sampling period during the second week (Fig. 127). Numbers entrained over a 24-h period were much less in June than those in May (Fig. 128). No yellow perch larvae were entrained during the third week of June and only a few were collected in dusk samples the fourth week and night samples the fifth week.

During the late June and both July sampling periods larval yellow perch were abundant in open water Lake Michigan samples. Absence of yellow perch larvae from entrainment samples at this time would clearly indicate that few if any Lake Michigan spawned yellow perch were drawn into the Campbell Plant during 1978. 

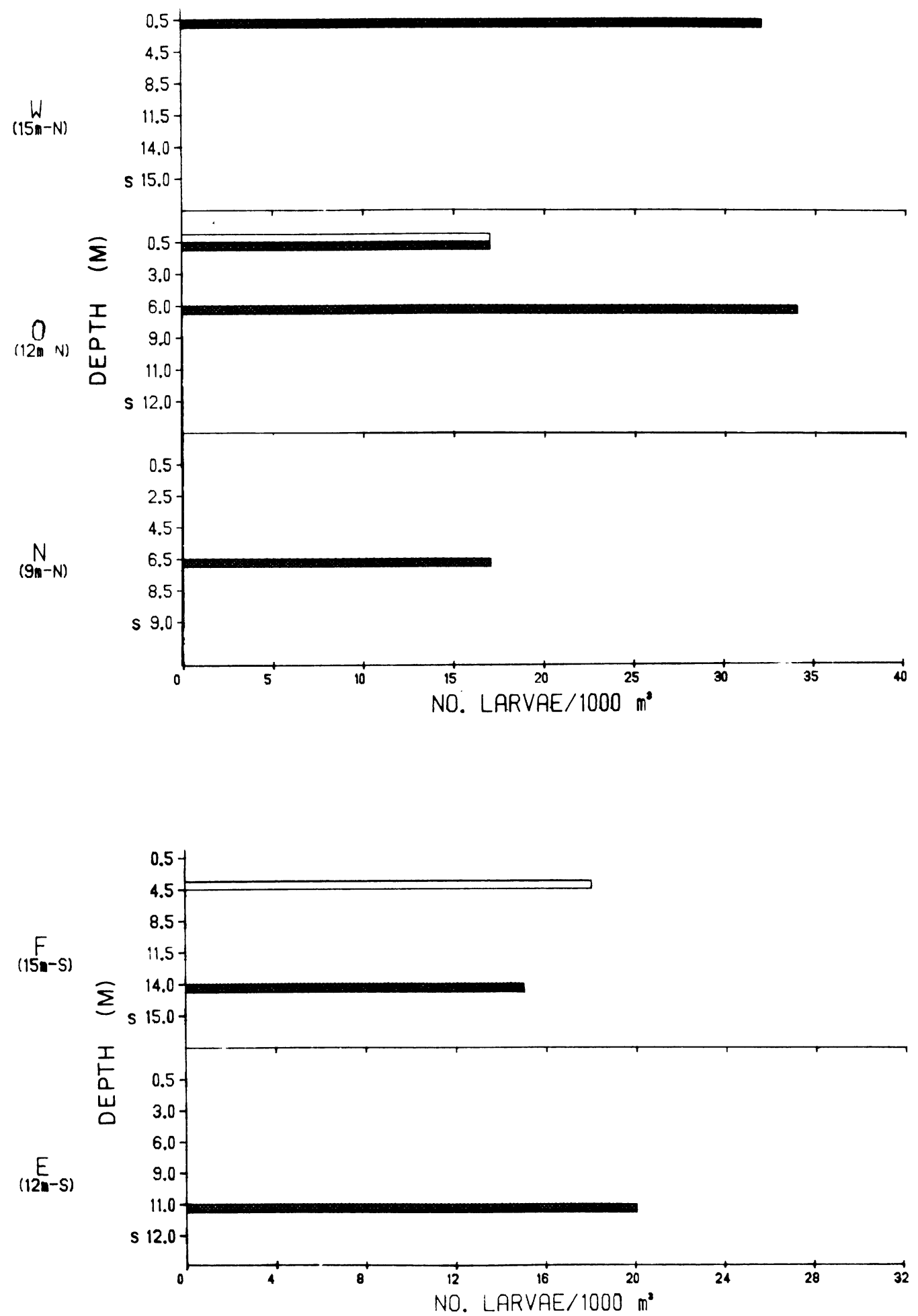

Fig. 126. Density of larval yellow perch (no./1000 $\mathrm{m}^{3}$ ) at Lake Michigan stations near the J. H. Campbell Plant, eastern Lake Michigan, 17-19 July 1978. Stations 1-9 $\mathrm{m} \mathrm{S}$ and 1-6 $\mathrm{m} \mathrm{N}$ were omitted due to absence of larvae in samples. $\square=$ day $\square=$ night $S=$ sled 

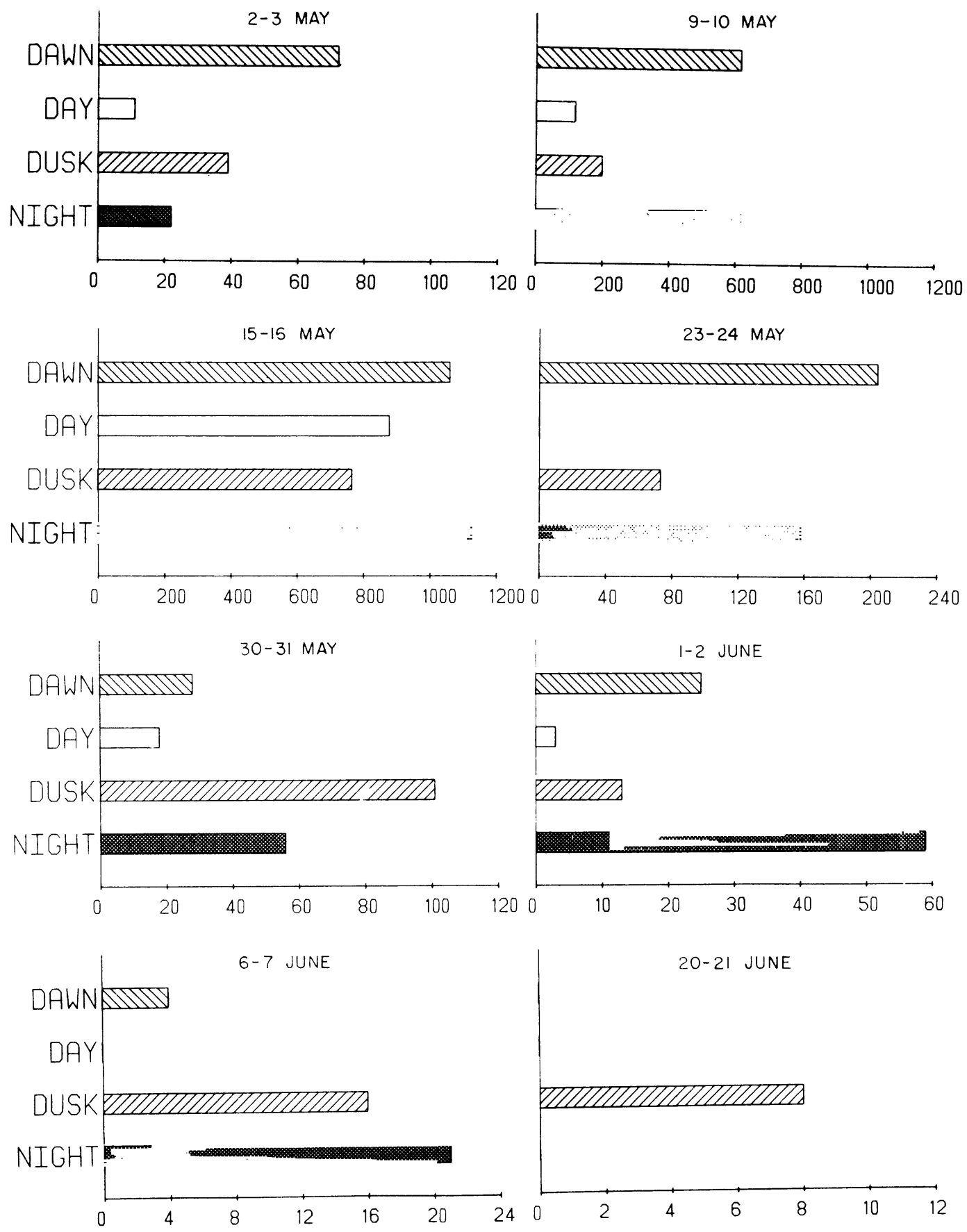

NO. OF LARVAE PER $1000 \mathrm{~m}^{3}$

Fig. 127. Density of yellow perch larvae (no./1000 $\mathrm{m}^{3}$ ) collected in weekly dawn, day, dusk and night entrainment samples at the J. H. Campbel1 Plant, eastern Lake Michigan, 1978. 


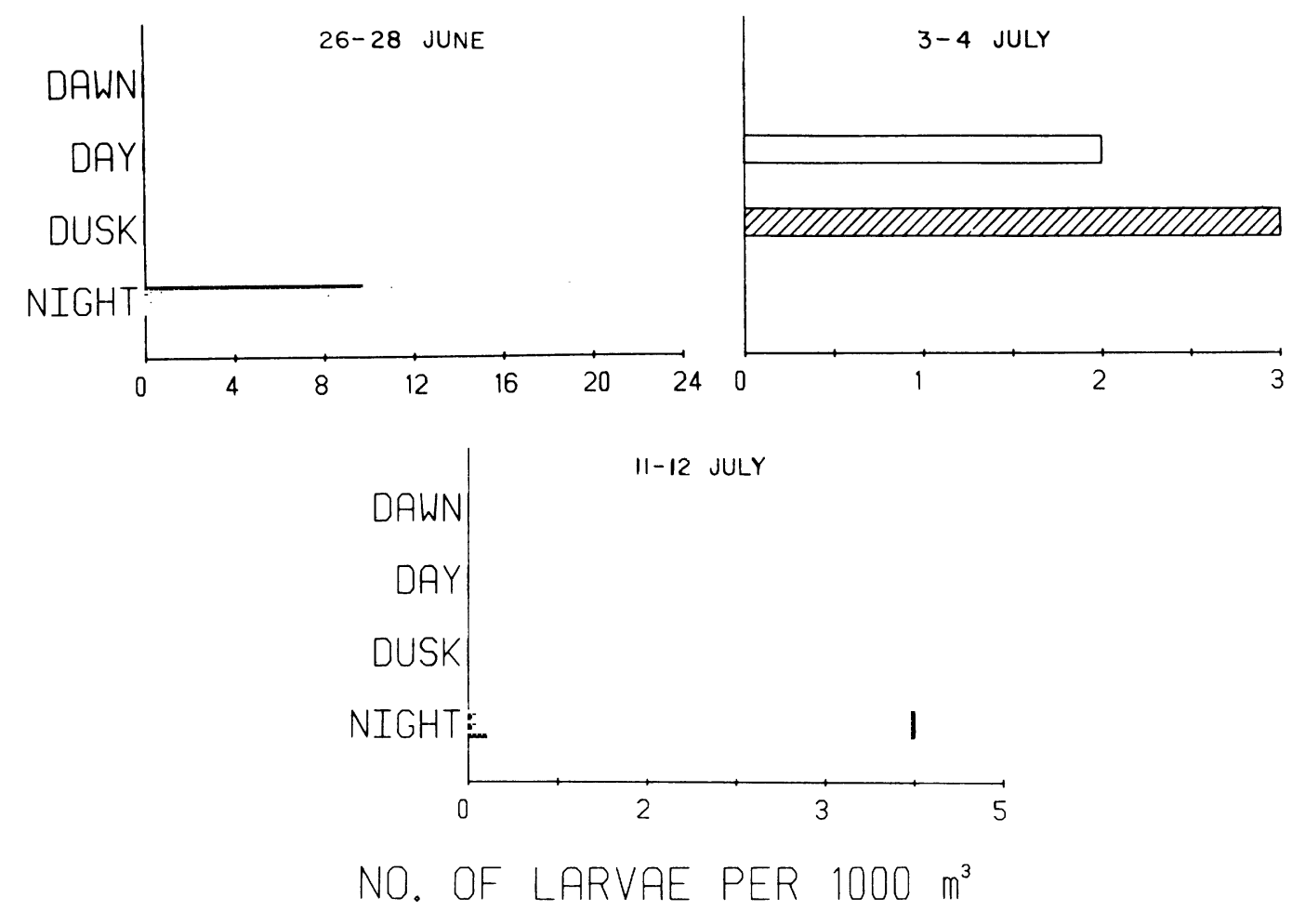

Fig. 127. Continued.

During the first sampling period in June concentrations of larvae ranged from $3 / 1000 \mathrm{~m}^{3}$ during the day to $59 / 1000 \mathrm{~m}^{3}$ at night. During the second week of June, night concentrations dropped to $21 / 1000 \mathrm{~m}^{3}$. These data clearly supported the May finding that most perch larvae were recovered in night samples while fewest were observed during the day. Since we believe there can be little or no net avoidance by entrained larvae (heated water and high velocity) in the discharge canal nets, preponderance of larvae caught at night indicates perch larvae move around and are more active at night. This is contrary to behavior of adults which are day active. However, data of Wong (1972) may support this, since he found larval. perch fed during the day and night.

During the four weekly entrainment sampling periods in July yellow perch larvae occurred in low abundance, $2-4 / 1000 \mathrm{~m}^{3}$ the first 2 wk only (Fig. 127). No yellow perch larvae were detected in entrainment samples collected during the rest of 1978 .

For an estimate of the total number of larval yellow perch entrained in 1978 see RESULTS AND DISCUSSION - PRODUCTION FOREGONE ESTIMATES DUE TO ENTRAINMENT AND IMPINGEMENT. Since most larval yellow perch entrainment occurred in May it appears these larvae originated from Pigeon Lake stocks. 


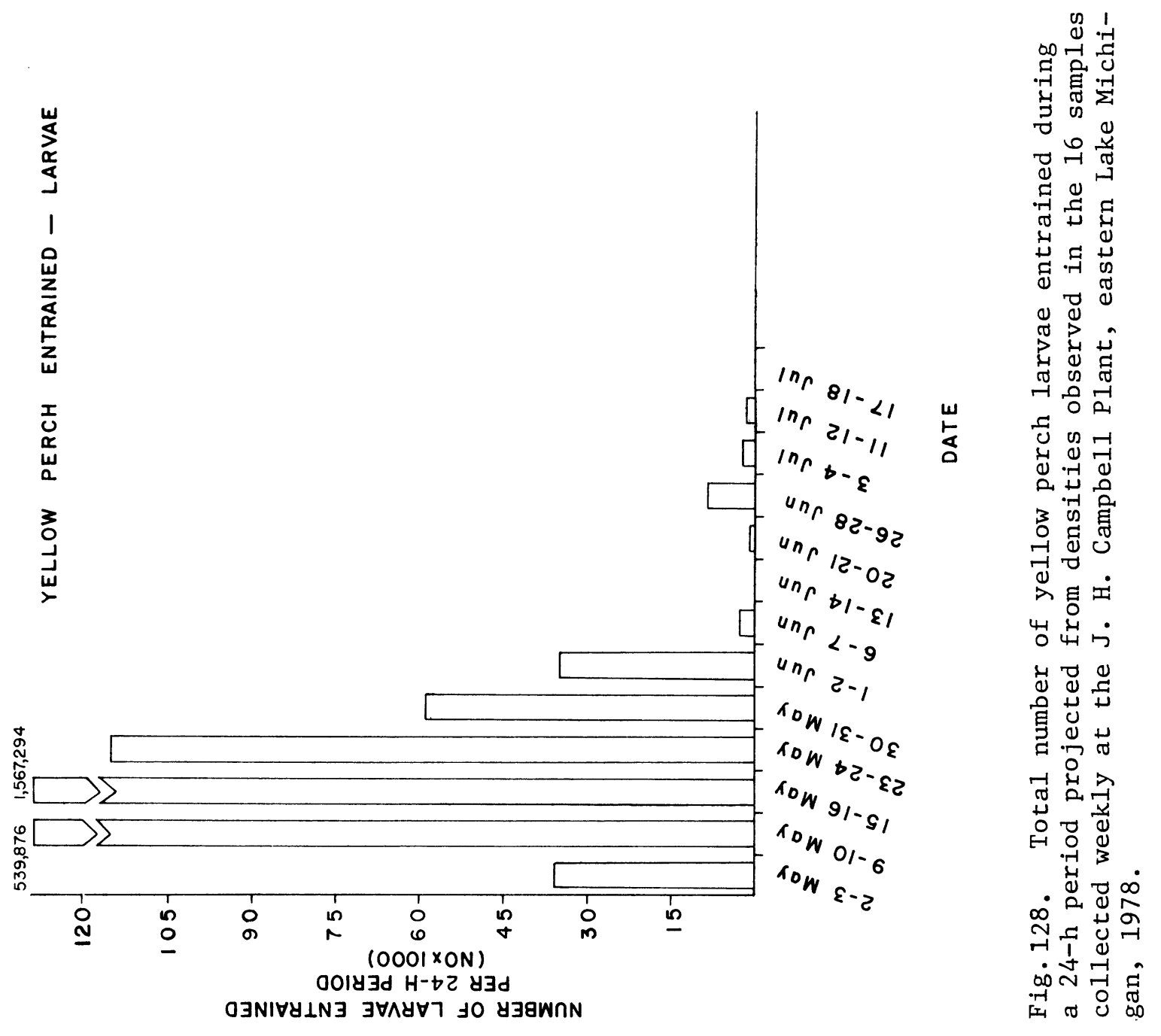


Larval yellow perch distribution data for 1978 appear to support the double population hypothesis presented by Jude et a1. (1978) for 1977. There appeared to be two pulses of yellow perch larvae in the vicinity of the Campbell Plant. One group appeared to originate from a late April-early May spawning in Pigeon. Lake, while another resulted from a late May-early June spawning in Lake Michigan. Although these populations were readily distinguishable in 1977 using lengthfrequency data, 1978 length-frequency plots did not exhibit this trend. As was mentioned earlier, all yellow perch larvae, except one 13-mm specimen and six 9.5-11-mm entrained larvae, collected in 1978 were between 4 and $8 \mathrm{~mm}$. Gear avoidance probably played the most significant part in the lack of capture of larger perch, but the fact that Pigeon Lake stations $\mathrm{T}$ and $\mathrm{Y}$ were deleted from the sampling program may have accounted for the larger larvae not being observed as they were in 1977.

In comparing 1978 yellow perch data to that of 1977 a few new and different patterns arose. Larval yellow perch were abundant not only in Pigeon Lake during May but also at Lake Michigan beach and inshore stations as well. Even in June yellow perch larvae were present in significant concentrations at Lake Michigan beach stations. In 1977 perch larvae were never recovered from the inshore or beach stations of Lake Michigan and only one larva was recovered in a sled tow; however, sampling did not commence until 31 May in 1977. Yellow perch larvae were most abundant at offshore stations in late June 1977 (Jude et al. 1978).

The larvae seen at Lake Michigan beach stations $P, Q$ and $R$ during May and early June 1978 were probably yellow perch which drifted out of Pigeon Lake either through the jetties or those spawned and passed through the discharge. They may also have drifted out of similar areas along the Lake Michigan coastline. From 1 May to 7 May intake flow for the plant was reduced to half its normal capacity. The reduced volume of water being taken in by the plant, coupled with possible increased Pigeon River flowage due to spring runoff from heavy rains, may have allowed Pigeon Lake water to circulate into Lake Michigan carrying with it newly hatched larvae. Yellow perch larvae were only found in nearshore waters in May 1978 (Fig. 122).

During May no temperature preference was evident for larvae distributed in Lake Michigan, most larvae occurring in water 4.5 to $10.0 \mathrm{C}$. In June and Julv vellow perch larvae in Lake Michigan were predominantly observed at depths less than $6 \mathrm{~m}$ at night in water 14 to $20 \mathrm{C}$. The theory that yellow perch larvae found in the inshore water of Lake Michigan during May were the result of larval drift out of Pigeon Lake is supported by this distributional pattern.

\section{Centrarchidae Complex}

Since there are seven species of centrarchids in Pigeon Lake, and early stages of these larvae are difficult to identify, we included all known species and taxonomic groups (Lepomis spp. and Pomoxis spp.) under this discussion. Among the sunfishes there are green sunfish, pumpkinseed and bluegill. The warmouth, another Lepomis adult present, was never identified in the larval form. Among Pomoxis spp., there are the black crappie which we collected as adults from Pigeon Lake and the reported presence of white crappie (Consumers Power Company 1975). There are two Micropterus present, the smallmouth and largemouth bass. In addition, the rock bass, Ambloplites, was collected as adult, however no larval rock bass were captured. 


\section{Black Crappie--}

In 1977 one black crappie was identified from a day surface sample collected on 23 June at beach station $\mathrm{T}$ (influenced by Pigeon River) (Jude et al. 1978). Four larvae in 1978 were also determined to be those of the black crappie. Two small specimens $(4.3$ and $4.8 \mathrm{~mm}$ ) were recovered in a late May, 2-m tow at night at station $Z$ (intake canal) and two large specimens (22.0 and $25.1 \mathrm{~mm}$ ) were collected in a night surface tow at Pigeon Lake station X (undisturbed Pigeon Lakein mid-July.

In 1978, four larger YOY (ranging from 36.8 to $39.5 \mathrm{~mm}$-fry) were also observed in Pigeon Lake samples. These were collected in late July and early August in surface plankton net tows at stations $\mathrm{X}$ and $\mathrm{V}$ (undisturbed Pigeon Lake).

Since it is difficult to distinguish larval black crappie from those of the white crappie, most crappie larvae were simply designated as Pomoxis spp. Pomoxis larvae were most probably those of the black crappie, since white crappie occurred only rarely in the study area (see RESULTS AND DISCUSSION, ADULT AND JUVENILE FISH, Black Crappie and White Crappie).

Unidentified Pomoxis spp. -

As discussed in the larval section dealing with black crappie most larvae designated as unidentified Pomoxis spp. were probably black crappie. Besides larvae identified as black crappie, several other Pomoxis larvae (172) were collected during 1978. Of these, 166 were collected in entrainment samples during the last week of May through the first week of August, while 6 were recovered during early June from Pigeon Lake field samples (Fig. 129).

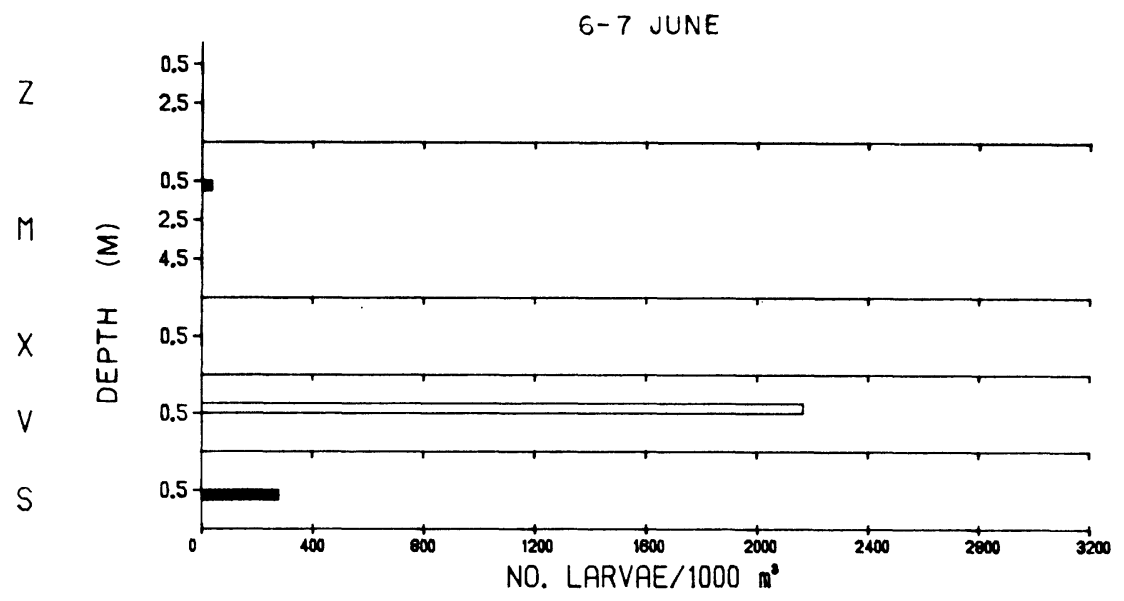

Fig. 129. Density of unidentified Pomoxis spp. larvae (no./ $1000 \mathrm{~m}^{3}$ ) at Pigeon Lake and intake canal stations near the J. H. Campbel1 Plant, eastern Lake Michigan 6-7 June 1978 . $\square=$ day $\square=$ night 
During late May, 57 Pomoxis larvae were observed in entrainment samples. These larvae ranged from 4.0 to $6.0 \mathrm{~mm}$, averaging $5.2 \mathrm{~mm}$. Intake water temperatures at this time ranged from 18.0 to $18.9 \mathrm{C}$. Highest concentrations occurred at dusk $\left(61 / 1000 \mathrm{~m}^{3}\right)$ and at night $\left(57 / 1000 \mathrm{~m}^{3}\right)$ (Fig. 130) indicating possible increased activity during nocturnal hours.

In June, 99 Pomoxis larvae were entrained, while $6(4.2-5.7 \mathrm{~mm})$ were collected from Pigeon Lake surface net tow samples taken at stations $\mathrm{S}$ (influenced by Lake Michigan), M (influenced by Lake Michigan) and V (undisturbed Pigeon Lake) (Fig. 129).

Pomoxis larvae were numerous in entrainment samples collected during each time period during the first and second weeks of June (Fig. 130). Sixty-five larvae, averaging $5.3 \mathrm{~mm}$, were taken the first week and 33 larval Pomoxis, averaging $4.8 \mathrm{~mm}$, were noted in entrainment samples collected during the second week. Intake water temperatures remained between 16.3 and $20.0 \mathrm{C}$ over the sampling times. During the third week when only one 4.5-mm Pomoxis larvae was entrained at dusk, water temperatures had dropped dramatically to between 14.2 and $16.3 \mathrm{C}$.

No Pomoxis larvae were collected in June, probably because intake water temperatures had again dropped to between 10.4 and $13.0 \mathrm{C}$ during the second and third weeks. Any eggs or newly hatched larvae in the intake area may have been killed.

During early August, four Pomoxis larvae $(5.2-7 \mathrm{~mm})$ appeared in entrainment samples. These larvae may have been the result of late July spawning after intake water temperatures had risen to between 17.9 and $19.2 \mathrm{C}$.

Since the majority of Pomoxis larvae in the area of the J. H. Campbell Plant were recovered from entrainment samples it may be possible that a small population of adult Pomoxis are surviving and even spawning in the intake canal. This long, wide canal has several slow moving, backwater, weedy areas where spawning could occur. A late May 1979 plankton net tow within the intake canal revealed the presence of several very small Pomoxis larvae.

\section{Unidentified Lepomis spp.--}

Unidentified Lepomis spp. larvae probably included bluegill, pumpkinseed, green sunfish and warmouth larvae. Since bluegill and pumpkinseed dominated the adult sunfish populations in Pigeon Lake (see RESULTS AND DISCUSSION, ADULT AND JUVENILE FISH) most unidentified Lepomis larvae probably belonged to these two species. Only small numbers of adult green sunfish and warmouth were collected in 1977 and 1978 suggesting that larvae of these species were also scarce in the study area. No fish larvae were identified as green sunfish and warmouth during 1978 .

During 6-7 June, unidentified Lepomis spp. larvae 4.2-5.2 mm occurred at a concentration of 416 larvae per $1000 \mathrm{~m}^{3}$ during the day and 49 larvae per $1000 \mathrm{~m}^{3}$ at night at beach station V (undisturbed Pigeon Lake) (Fig. 131). On 6 June unidentified Lepomis spp. Larvae $(4.1 \mathrm{~mm}$ ) were also found during the day at a density of 25/1000 $\mathrm{m}^{3}$ (Fig. 131) at station X (undisturbed Pigeon Lake). These data indicated that beach station $\mathrm{V}$ was probably a more important spawning ground 

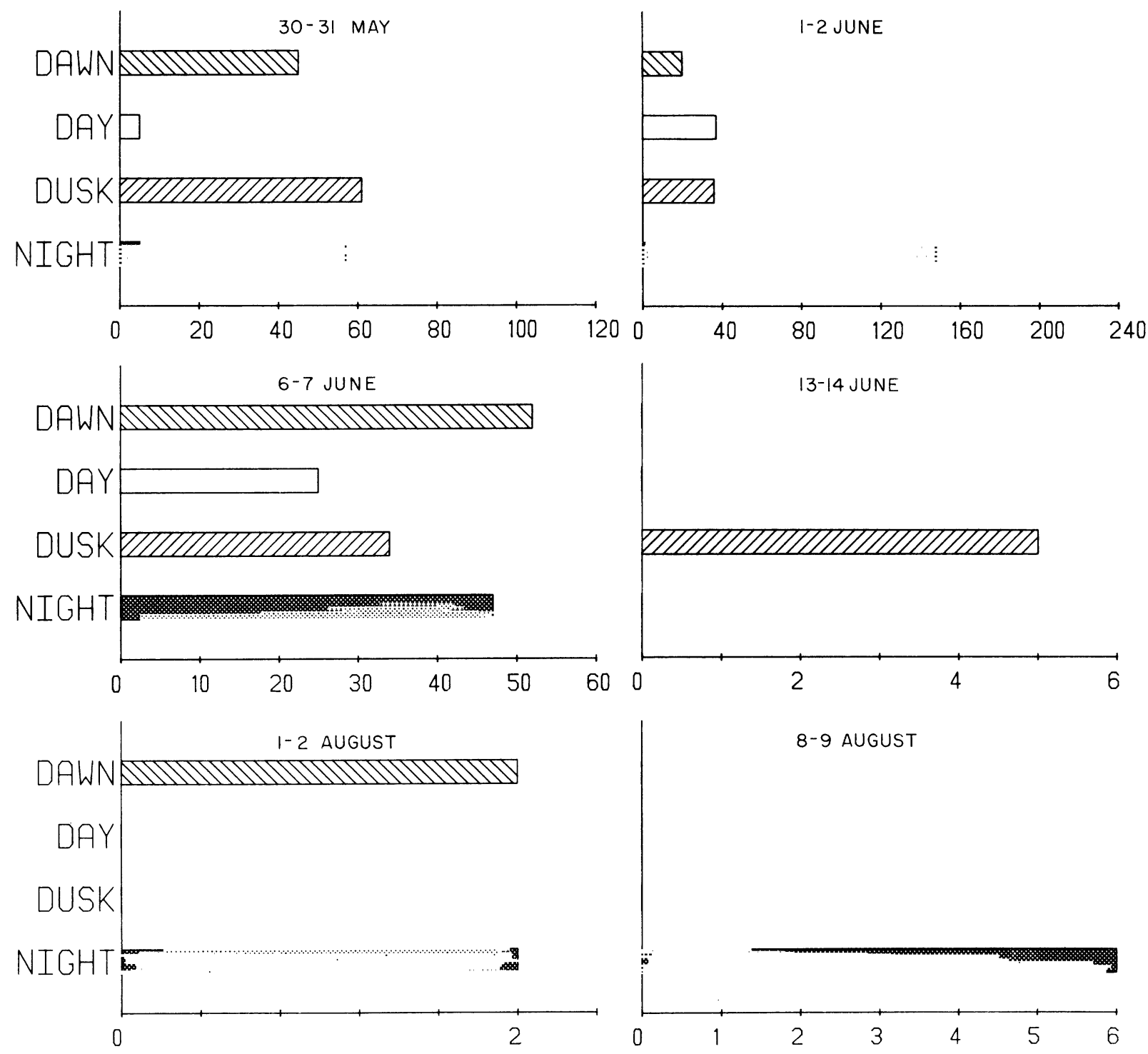

NO. OF LARVAE PER $1000 \mathrm{~m}^{3}$

Fig. 130. Density of unidentified Pomoxis spp. larvae (no./1000 $\mathrm{m}^{3}$ ) collected in weekly dawn, day, dusk and night entrainment samples at the J. H. Campbell Plant, eastern Lake Michigan, 1978. 

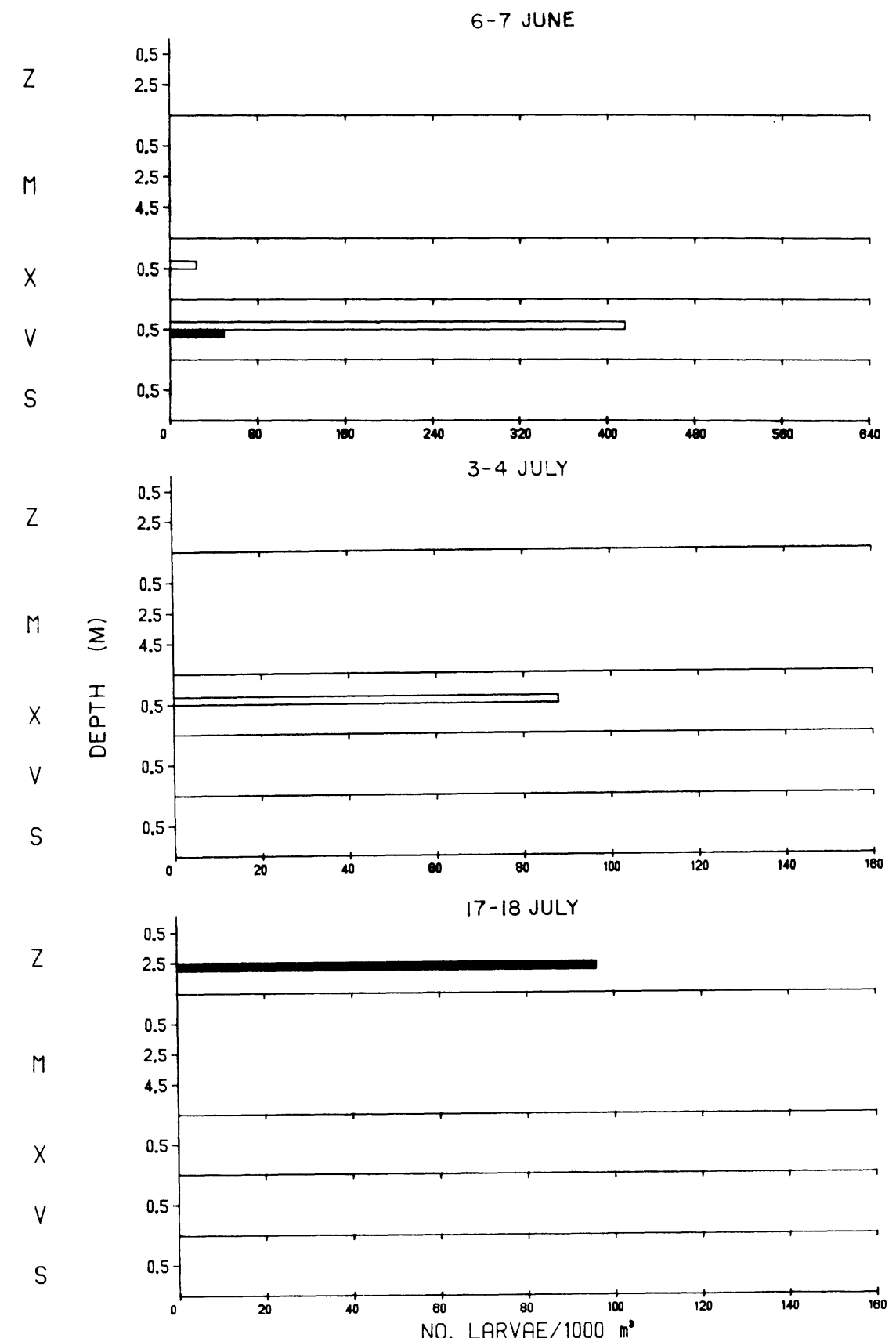

Fig. 131. Density of unidentified Lepomis spp. larvae (no./ $1000 \mathrm{~m}^{3}$ ) at Pigeon Lake and intake canal stations near the J. H. Campbell Plant, eastern Lake Michigan April to September 1978. $\square=$ day $\square=$ night 
for sunfish than 2-m station $X$. No larvae were collected at beach station $S$ (influenced by Lake Michigan) or 6-m station M (influenced by Lake Michigan) during 1978. As previously mentioned (see STUDY AREA) beach station S was moved to a new location in 1978 which did not seem to be favorable as a sunfish spawning ground. Station $M$ was too deep and was disturbed constantly by construction activities. No larval Lepomis spp. were collected at station Z (intake canal) during June.

During early July unidentified Lepomis spp. larvae approximately $5.2 \mathrm{~mm}$ were collected during the day at open water station $\mathrm{X}$ (undisturbed Pigeon Lake) at a denisty of 85 larvae per $1000 \mathrm{~m}^{3}$ (Fig. 131). No larvae were collected at beach station $\mathrm{V}$ in July. Two unidentified Lepomis spp. larvae (both $5.0 \mathrm{~mm}$ ) occurred in late July night tows at station $Z$ (intake canal) resulting in a concentration of 96 larvae per $1000 \mathrm{~m}^{3}$ (Fig. 131). Sunfish are not expected to spawn in the intake canal due to the absence of optimum spawning grounds. Most larvae collected in the intake canal were probably drawn from Pigeon Lake.

Unidentified Lepomis spp. larvae collected in Pigeon Lake and the intake canal during June and July ranged from 4.1 to $5.2 \mathrm{~mm}$. Comparison of this size range to the lengths at hatching of 3 to $4.8 \mathrm{~mm}$ of bluegill, pumpkinseed, green sunfish and warmouth larvae (Carlander 1977) indicated that all unidentified. Lepomis spp. larvae collected in June and July were newly hatched. Larvae larger than $5.2 \mathrm{~mm}$ were probably able to avoid plankton nets. Large larvae appeared however, to be more commonly caught during 1977. Unidentified Lepomis spp. larvae $(4.5 \mathrm{~mm})$ were first observed in entrainment samples on 1 May (Fig. 132) indicating that spawning probably took place during late April. This spawning appeared to be rather early compared to the reported late May-August spawning season for sunfish inhabiting the study area (Carlander 1977).

During early June unidentified Lepomis spp. (mostly $5 \mathrm{~mm}$ ) were entrained at a density of 4 larvae per $1000 \mathrm{~m}^{3}$ (Fig. 132). Comparison with the concentration of larvae collected in Pigeon Lake during the same period suggested that only a small fraction of the unidentified Lepomis spp. larvae were entrained by the plant. Most sunfish larvae probably remained in the shallow, weedy water and were not vulnerable to entrainment. Sunfish larvae occurred more frequently in entrainment samples in July than during previous months suggesting higher spawning activity during July than during May or June. Density of entrained larvae increased from 2 larvae per $1000 \mathrm{~m}^{3}$ during early July to $4 / 1000 \mathrm{~m}^{3}$ by mid-July and $12 / 1000 \mathrm{~m}^{3}$ during late July. Like June results, density of larvae was lower than that observed in Pigeon Lake during July. Entrainment sampling during early August captured unidentified Lepomis entrained larvae at a rate of approximately 3 larvae per $1000 \mathrm{~m}^{3}$, indicating that sunfish spawning continued to take place in the study area during this month. Contrary to diel trends in catch in Pigeon Lake, more unidentified Lepomis larvae were collected during dusk and night than during other diel periods. Entrained unidentified Lepomis larvae captured during May-August ranged from 4.0 to $6.5 \mathrm{~mm}$, suggesting that only smaller sunfish larvae were drawn into the plant, as has been found for many species.

Pumpkinseed--

Pumpkinseeds spawn during late spring and summer in shallow water. Although pumpkinseed were commonly caught as adults and juveniles (see RESULTS AND DISCUS- 

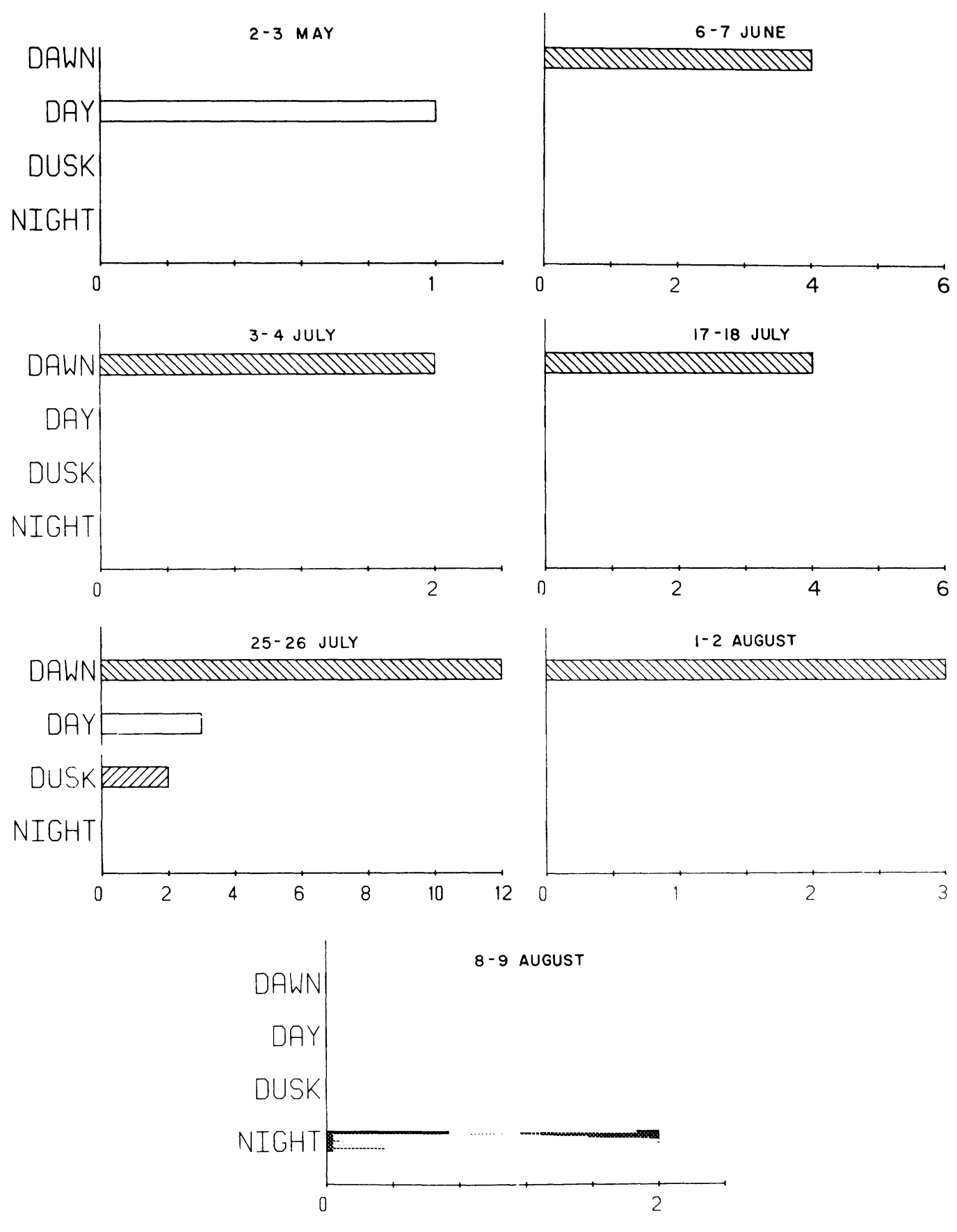

NO. OF LARVAE PER $1000 \mathrm{~m}^{3}$

Fig. 132. Density of unidentified Lepomis spp. 1arvae (no./1000 $\mathrm{m}^{3}$ ) collected in weekly dawn, day, dusk and night entrainment samples at the J. H. Campbell Plant, eastern Lake Michigan, 1978. 
SION ADULT AND JUVENILE FISH, Pumpkinseed), pumpkinseed larvae were relatively scarce in the study area. Only one 5.2-mm fish larva collected in an entrainment sample during June (Appendix 14) could be positively identified as a pumpkinseed. Most pumpkinseed larvae, because of their close resemblance to other sunfish larvae, were probably included in the unidentified Lepomis spp. category (see Unidentified Lepomis spp.).

Bluegil1--

Bluegill was a common species in Pigeon Lake that occassionally occurred in Lake Michigan. Spawning takes place from late May to early August (Snow et al. 1970). In 1978, bluegill larvae were collected only during 1 June entrainment sampling; density of larvae was approximately 14/1000 $\mathrm{m}^{3}$ (Appendix 14). No bluegill larvae were captured in Pigeon Lake or the intake canal. Most bluegill larvae, like pumpkinseed larvae, were probably included in the unidentified sunfish larvae (see Unidentified Lepomis spp.). Bluegill larvae collected ranged from 4 to $5.2 \mathrm{~mm}$, which compared to lengths of $4-4.8 \mathrm{~mm}$ of 3-day-old bluegill larvae (Wang and Kernehan 1979), indicated that larvae we collected were all recently hatched.

Largemouth Bass--

Our studies conducted in Pigeon Lake during 1977 (Jude et al. 1978) indicated that spawning of largemouth bass occurred primarily in the heavily weeded area near beach station $\mathrm{T}$ (influenced by Pigeon River), as larval largemouth bass were commonly encountered there from early June to late July during 1977. Deletion of this station during 1978 was undoubtedly the reason for the decreased collections of larval largemouth bass in 1978. Largemouth bass larvae were only observed once in field collections in 1978, when a density of over 1000 larvae per $1000 \mathrm{~m}^{3}$ was observed at 2-m station $X$ (undisturbed Pigeon Lake) during early June. In general, the heavily weeded, sheltered habitat in areas more influenced by the Pigeon River are probably primary spawning sites for largemouth bass. This spawning site selection probably affords considerable protection against water currents which would result in larval largemouth bass entrainment. Larval bass were only entrained once in 1978 during early June; low (less than 5 larvae/1000 $\mathrm{m}^{3}$ ) densities of larvae were observed. No larval largemouth bass were observed in entrainment samples from July to December during 1977 (Jude et al. 1978), further suggesting that larval forms of this species are subject to only minimal entrainment loss. Periodic high numbers of largemouth bass YOY were impinged, however, during fall and winter.

Smallmouth Bass--

Similar to findings during 1977 (Jude et al. 1978), larval smallmouth bass were rarely encountered in the study area during 1978. Only once were smallmouth bass larvae observed during 1978 when a concentration of over 300 larvae/1000 $\mathrm{m}^{3}$ was noted at 2-m station X (undisturbed Pigeon Lake). This species reportedly spawns most often from late May to early July in protected areas of lakes and rivers (Scott and Crossman 1973). These authors indicated that larvae hatched in approximately 4 days, and that young at time of hatching are 5.6-5.9 mm. The four larval smallmouth bass caught in our study ranged from 5.8 to $8.2 \mathrm{~mm}$, suggesting that they were newly hatched larvae. No entrainment samples taken from July 
to December 1978 contained larval smallmouth bass. It is probable that larvae of this species is subject only to minimal entrainment loss.

$\underline{\text { Rainbow Sme1t }}$

Introduction--

Rainbow smelt spawn mostly during April and May near the Campbell Plant. In 1977 and 1978 some spawning probably also occurred during early June in our study area. Egg incubation lasts from 2 to 3 wk depending on water temperature (Scott and Crossman 1973). Rainbow smelt larvae were one of the most abundant larval species collected near the Campbell Plant, occurring mainly during late May and early June. They were collected mostly in Lake Michigan. An appreciable number were also entrained by the Campbell Plant.

Seasonal Distribution--

May-- Rainbow sme1t larvae 5.5 to $8.0 \mathrm{~mm}$, with a modal length of $7.0 \mathrm{~mm}$ were first collected during 15-17 May 1978 (Fig. 133). Comparison with length at hatching of 5.0 to $6.0 \mathrm{~mm}$ (Scott and Crossman 1973; Van Oosten 1940) indicated that these larvae were newly hatched. Since no smelt larvae were captured in weekly entrainment sampling prior to 15 May (see Entrainment, this section), larvae collected during 15-17 May were probably among the earliest brood of 1978. Hatching in southeastern Lake Michigan appeared to occur earlier than in our study area. Near the Cook Plant smelt larvae were first collected during 26-29 April 1973 and 2-3 May 1974 (Jude et a1. 1979). Entrainment data revealed that peak hatching in our study area occurred at the end of May.

During May smelt larvae were more abundant in shallow areas (beach zone to $3 \mathrm{~m})$ than in deeper water $(6-15 \mathrm{~m})$. On the south transect larval concentrations varied from 40 to $218 / 1000 \mathrm{~m}^{3}$ in the nearshore area (beach zone to $3 \mathrm{~m}$ ), but declined to $12-28 / 1000 \mathrm{~m}^{3}$ at 6 and $9 \mathrm{~m}$ (Fig. 134). No smelt larvae were collected at 12 and $15 \mathrm{~m}$. On the north transect smelt larvae were most abundant (318 larvae/ $1000 \mathrm{~m}^{3}$ ) at beach station Q (S discharge), but were completely absent from beach station $\mathrm{R}$ ( $\mathrm{N}$ discharge). Outside the beach zone, smelt larvae were found only at the 1.5-, 9- and 12-m contour with concentrations ranging from 20 to 31 larvae per $1000 \mathrm{~m}^{3}$ (Fig. 134). Smelt larvae appeared to be more abundant at the south than north transect during May (Fig. 134). High larvae density at beach stations $P$ and $Q$ suggested that the beach zone constituted the main smelt spawning ground. Concentration of smelt spawning in the beach zone was also observed in southeastern Lake Michigan (Jude et a1. 1979) and in Maine lakes (Rupp 1959). Decline of larva1 concentrations at 6 and $9 \mathrm{~m}$ and their absence at 12 and $15 \mathrm{~m}$ at the south transect appeared to indicate a progressive dispersal of larvae to deeper water. Reasons for the absence of smelt larvae at beach station $R$, station $J(3 \mathrm{~m}-\mathrm{N})$ and $\mathrm{L}(6$ $\mathrm{m}-\mathrm{N}$ ) were not understood.

Smelt larvae collected from shallow water and deep-water stations showed a similar size range (5.5-7.5 mm and $5.5-8.0 \mathrm{~mm}$ respectively) (Fig. 133), suggesting that sampling captured larvae of similar size indicating that no net avoidance occurred during the day (Fig. 133). Larval smelt were reported to move to the surface at night and remain near the bottom during the day at 6- and 9-m stations (Jude et al. 1979). Similar diel vertical migration was observed in our study 

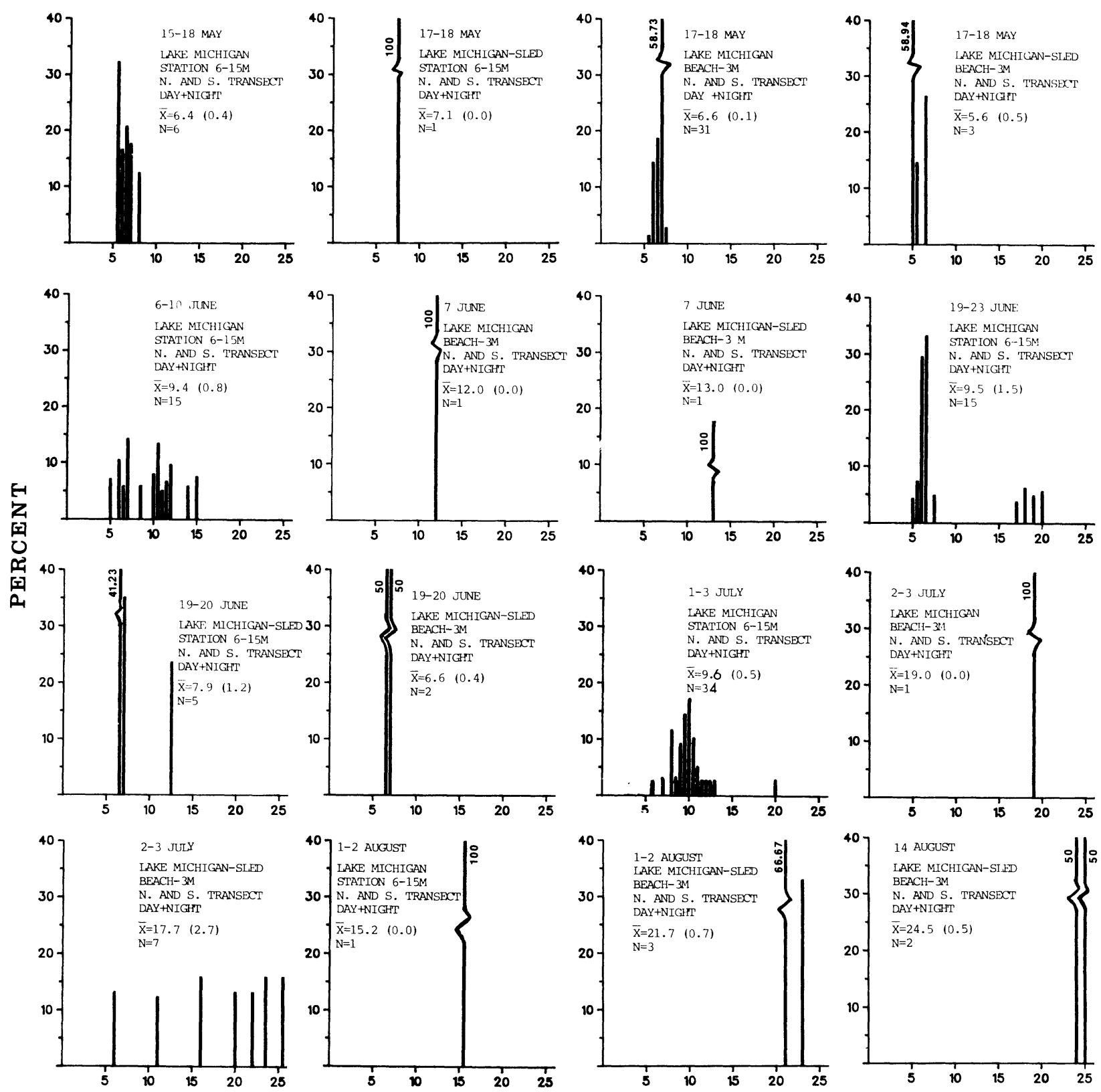

\section{TOTAL LENGTH [mm]}

Fig. 133. Length-frequency histograms for larval rainbow smelt observed in field and entrainment samples collected during 1978 near the J. H. Campbell Plant, eastern Lake Michigan. All tows were plankton net tows unless sled tows were specified. $\overline{\mathrm{X}}=$ mean, $\mathrm{N}=$ total number of larvae, standard error is given in parentheses. 


\section{ENTRAINMENT}
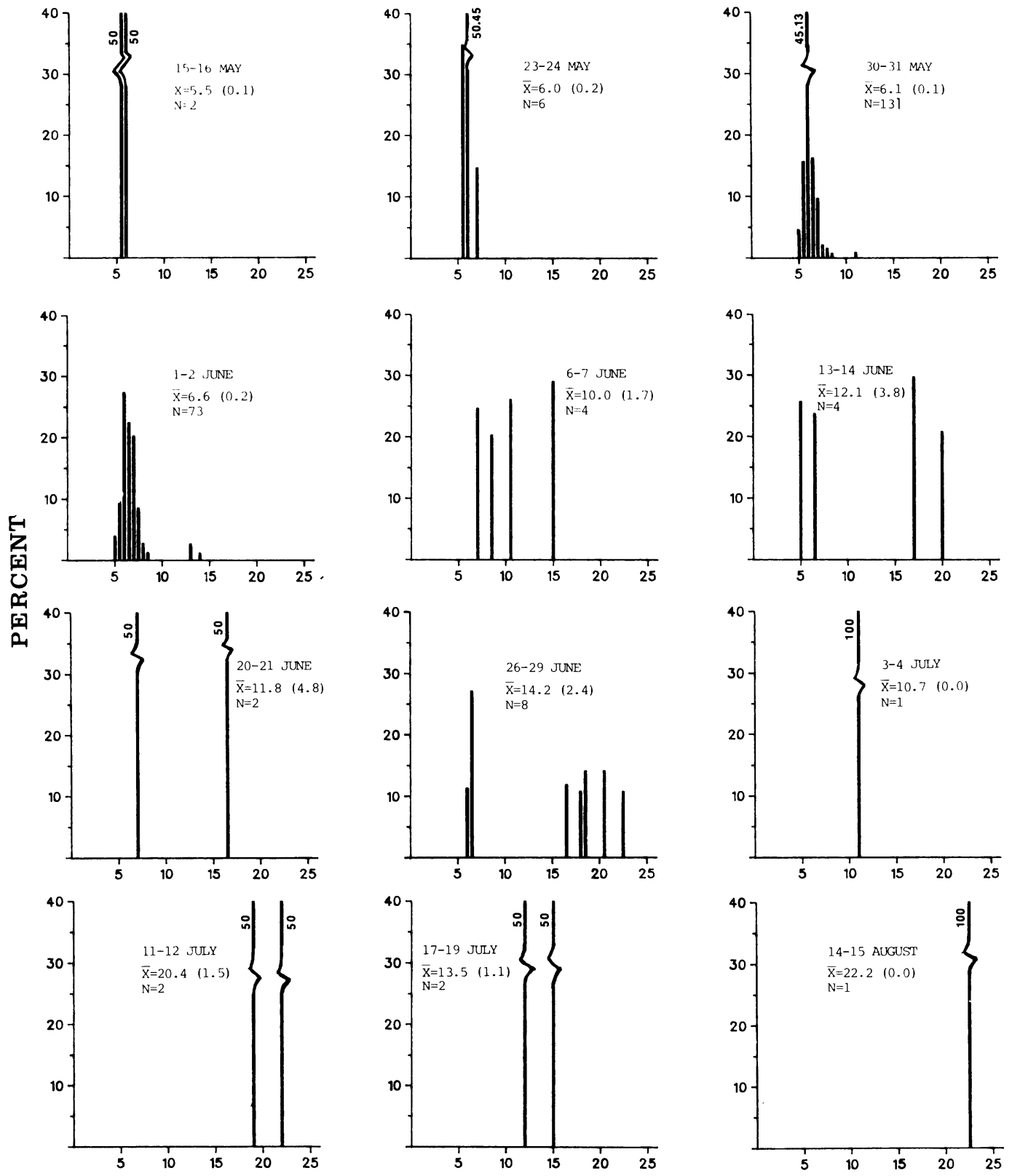

TOTAL LENGTH $[\mathrm{mm}]$

Fig. 133. Continued. 

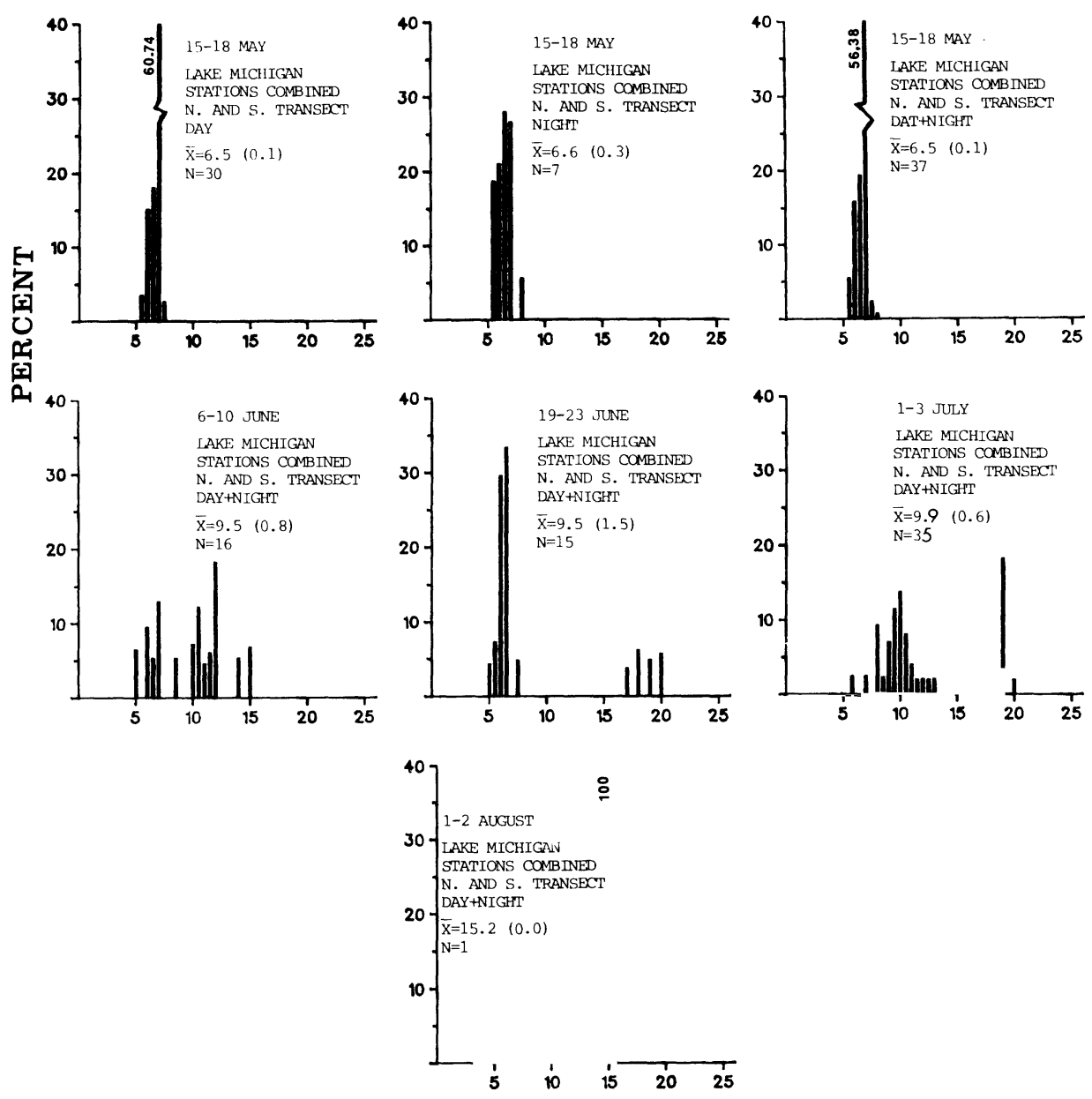

TOTAL LENGTH ( $\mathrm{mm}$ )

Fig. 133. Continued. 
area in 1977, but rarely occurred during 1978. Nocturnal movement to upper strata probably took place at station C $(6 \mathrm{~m}-\mathrm{S})$ where smelt larvae were collected at the surface and $2.5 \mathrm{~m}$ at night (Fig. 134). From the beach zone to the 3-m contour however, smelt larvae tended to be found at the surface during the day and near bottom at night (Fig. 134).

Rainbow smelt larvae were scarce in Pigeon Lake during May. No larvae were collected in the undisturbed area of Pigeon Lake (stations X and V) (Appendix 13) corroborating the absence of smelt spawning in this tributary water as has been mentioned in the discussion of adult and juvenile fish. Smelt larvae 5.5 to $6.0 \mathrm{~mm}$ collected at station M (influenced by Lake Michigan) and station Z (intake canal) during May (Fig. 135) probably originated from Lake Michigan. Larval densities at these two stations (28 larvae per $1000 \mathrm{~m}^{3}$ ) were significantly lower than those observed at most of the nearshore stations ( $3 \mathrm{~m}$ and shallower water) in Lake Michigan (Fig. 134). This decrease in larval density at these Pigeon Lake stations may be due in part to a patchy distribution of larvae in the shallow water of Lake Michigan. The extreme variations in catch observed on the north transect are a good example (Fig. 134). The mixing of Lake Michigan and Pigeon Lake water may also cause a decline in larval density at stations $\mathrm{M}$ and $\mathrm{Z}$.

Yearling rainbow smelt 46-78 mm, classified as fry, were occasionally captured in plankton nets during April and May (Appendix 16).

June-- In June smelt larvae showed a wider size range $(5-15 \mathrm{~mm})$ than in May indicating hatching was continuing in the study area (Fig. 133). Smaller larvae (5-7 mm) probably hatched at the end of May and beginning of June, shortly before our first June sampling period (6-10 June), while those 8-15 mm were probably members of the cohort that hatched around 15 May.

During early June smelt larvae appeared to be more widely dispersed at deeper stations than during May. On the south transect smelt larvae were found in small numbers at 3 to $15 \mathrm{~m}$ with the highest concentration $\left(29 / 1000 \mathrm{~m}^{3}\right)$ observed at the 9-m stratum at station E (12 m - S) (Fig. 136). On the north transect smelt larvae occurred at 6 to $15 \mathrm{~m}$ in densities ranging from 8 to 23 larvae/1000 $\mathrm{m}^{3}$ (Fig. 136). Smelt larvae were also caught at a density of $33 / 1000 \mathrm{~m}^{3}$ at station $\mathrm{I}(1.5 \mathrm{~m}-\mathrm{N})$. No larvae were collected during June at the $3-\mathrm{m}$ contour (station $\mathrm{J}$ ) on the north transect. Near the Cook Plant, southeastern Lake Michigan smelt larvae were observed to migrate to 6 and $9 \mathrm{~m}$ after a short residence in the beach zone (Jude et al. 1979). Decreased larval smelt populations in the shallow area (beach zone to $3 \mathrm{~m}$ ) and increased larval abundance at deeper stations (6-15 m) indicated that migration of larval smelt to deep water was underway in our study area during early June. Smelt hatching began to decline during early June. Newly hatched smelt larvae 5-7 mm, comprised lower percentages of the catch during 6-10 June than during 15-18 May (Fig. 133). Absence of smelt larvae from the three beach stations ( $P, Q$ and $R$ ) in Lake Michigan and exclusive occurrence of relatively large larvae $(12.5-13.5 \mathrm{~mm}$ ) at 1.5 and $3 \mathrm{~m}$ (Fig. 133) suggested that little or no smelt hatching took place in the nearshore area during 6-10 June. However, both small and large larvae (5-15 mm) were captured at deep stations (6-15 m) (Fig. 133).

On the south transect smelt larvae occurred only in the night surface tow at the 3-m contour (Fig. 136). From 6 to $15 \mathrm{~m}$, smelt larvae were found 


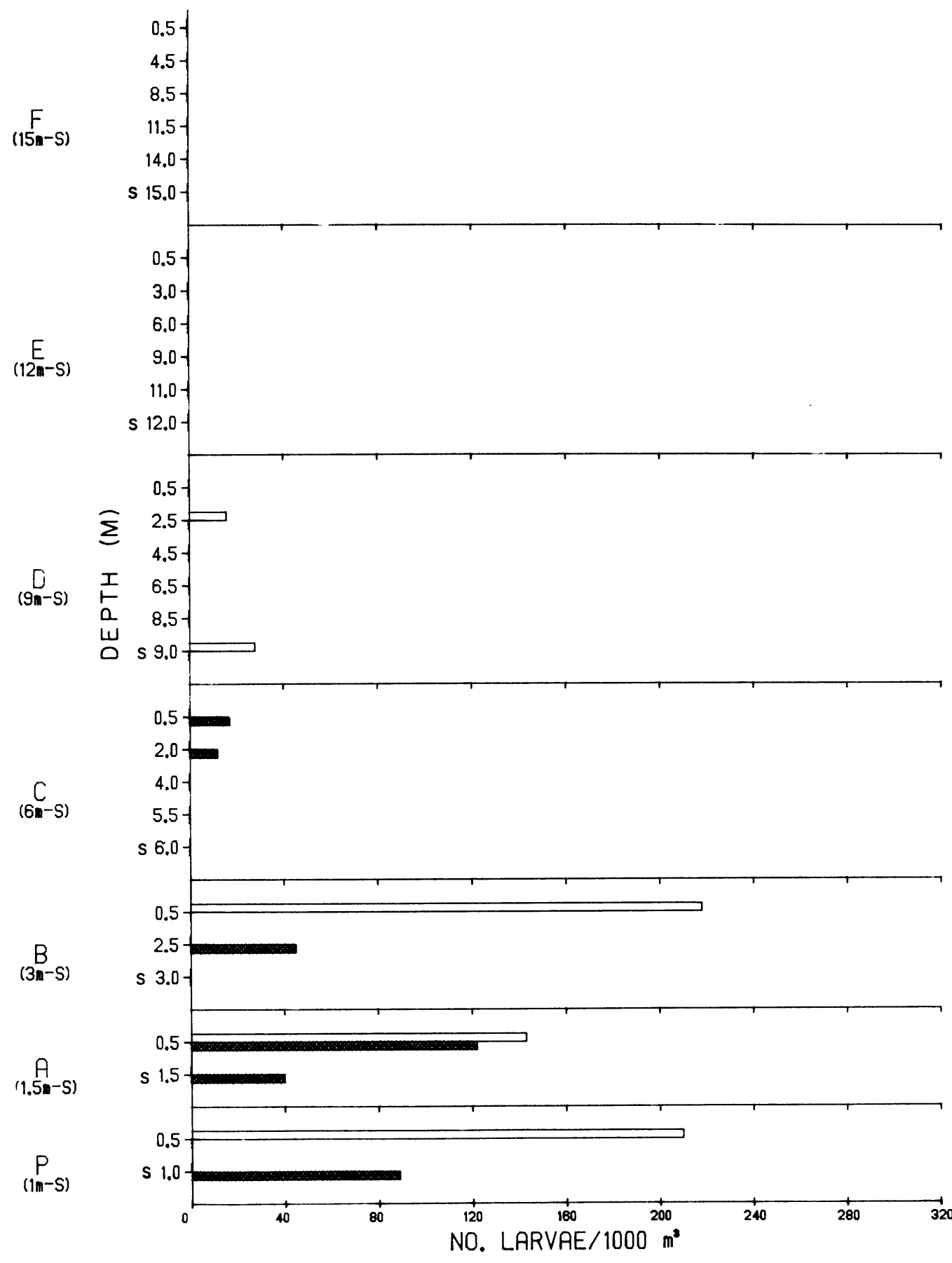

Fig. 134. Density of larval smelt (no./1000 $\mathrm{m}^{3}$ ) at Lake Michigan stations near the J. H. Campbell Plant, eastern Lake Michigan, 15-18 May 1978.

$\square=$ day $\square=$ night $\quad \mathrm{S}=$ sled 


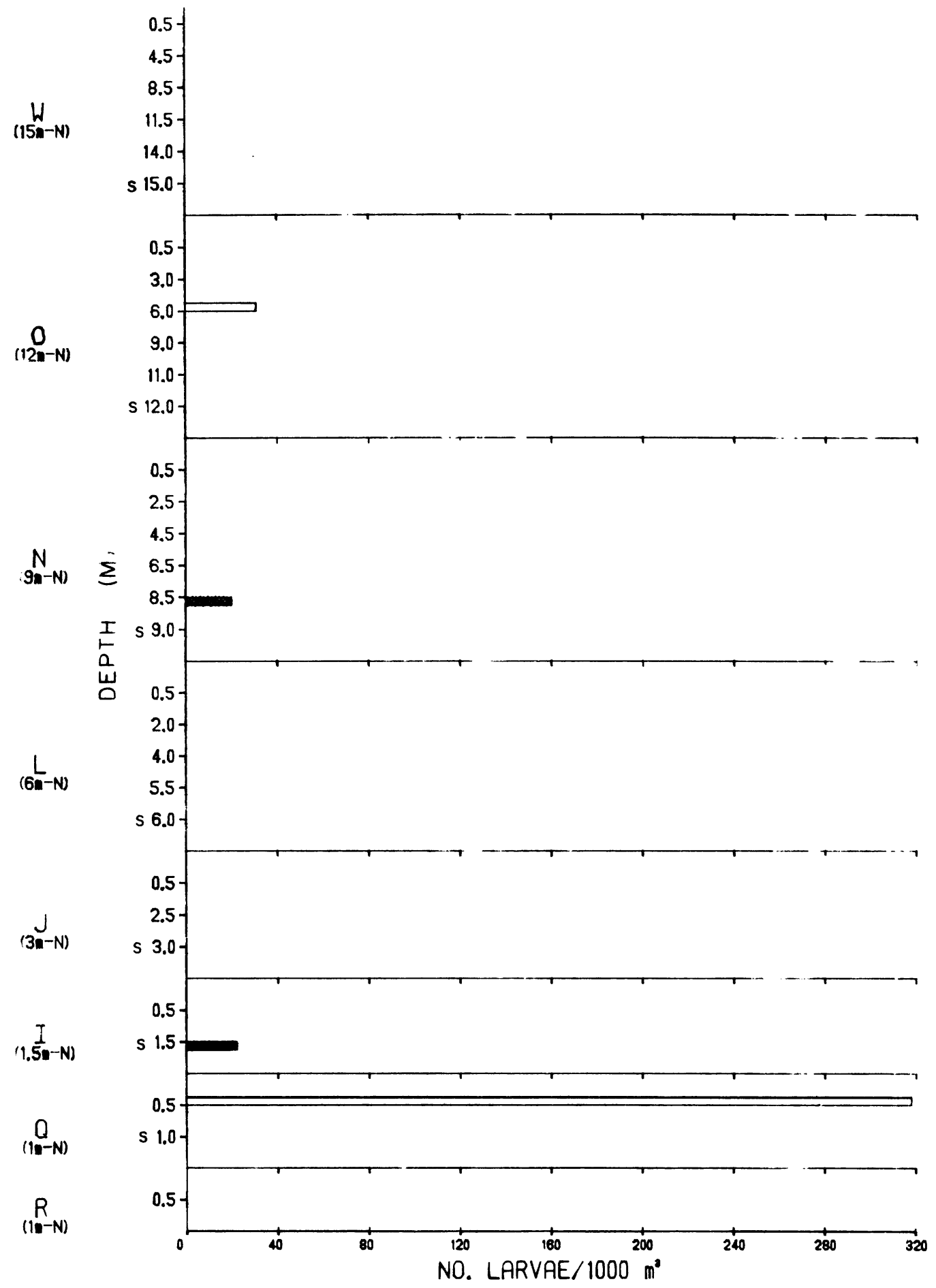

Fig. 134. Continued. 
15-17 MAY
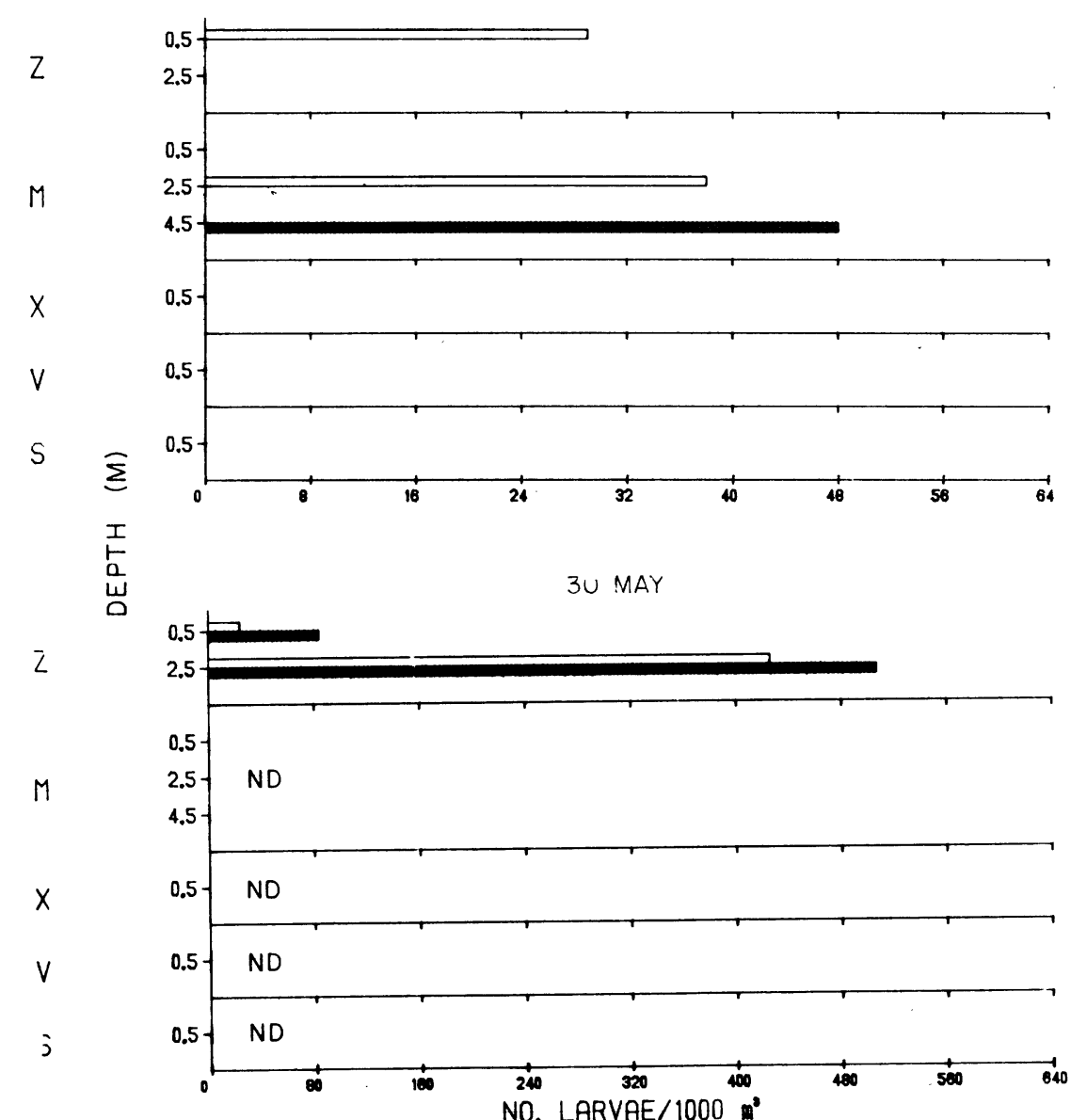

Fig. 135. Density of rainbow smelt larvae (no./1000 $\mathrm{m}^{3}$ ) at Pigeon Lake and intake canal stations near the J. H. Campbell Plant, eastern Lake Michigan April to September 1978.
$\square=$ day
$\mathrm{ND}=$ no data 


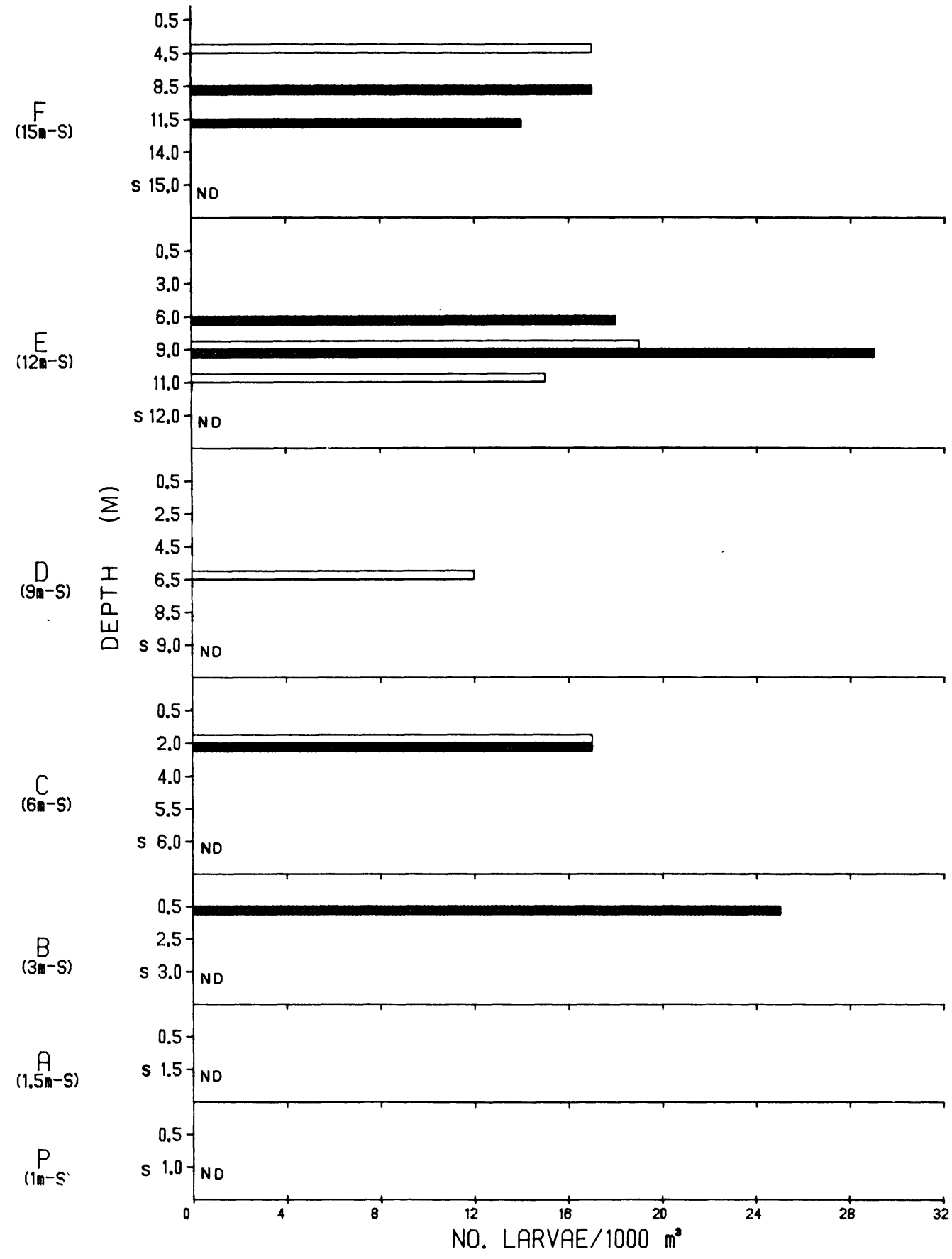

Fig. 136. Density of larval rainhow smelt (no/1000 $\mathrm{m}^{3}$ ) at Lake Michigan stations near the J. H. Campbell Plant, eastern Lake Michigan, 5-7 June 1978. $\square=$ day $\square=$ night $S=$ sled $N D=$ no data 


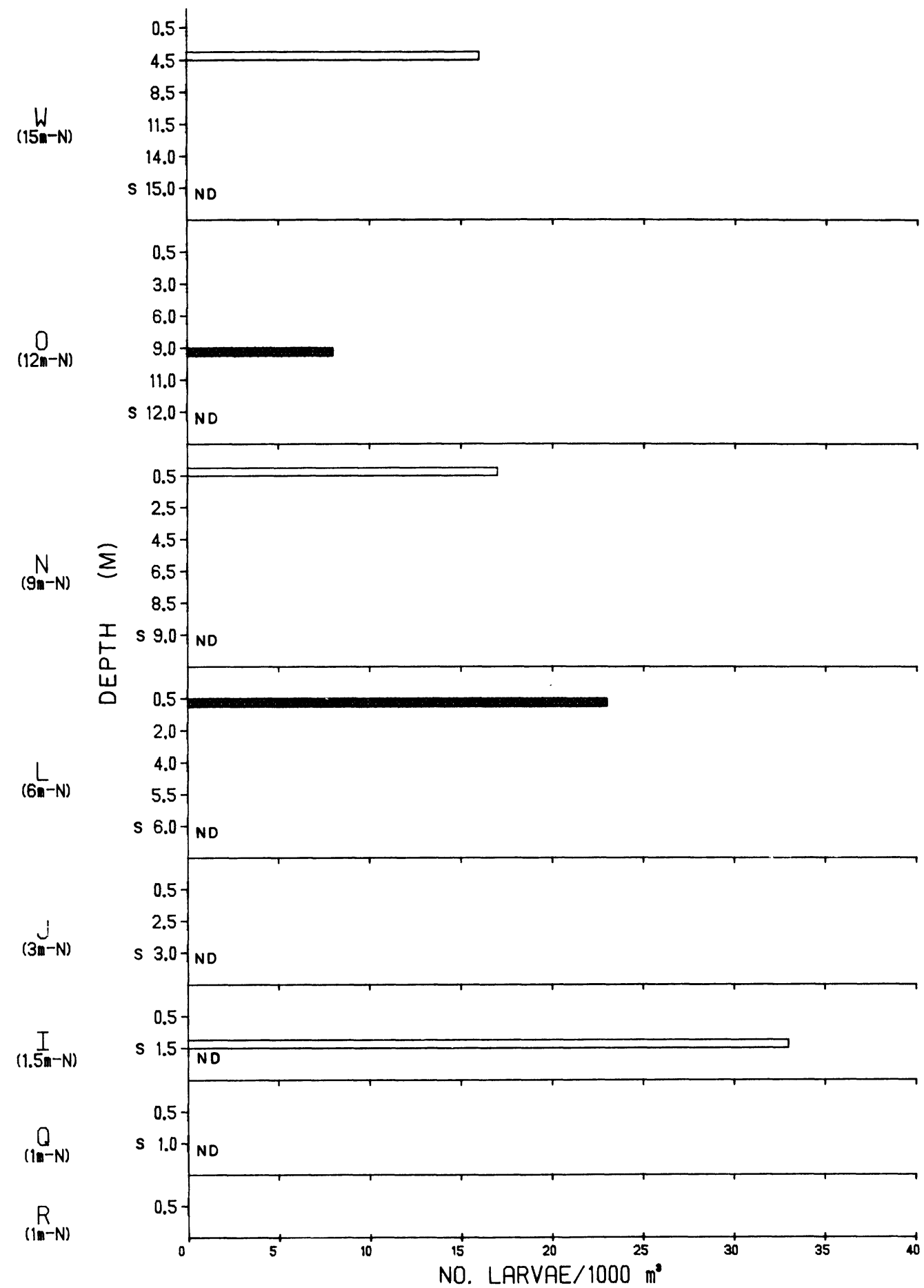

Fig. 136. Continued. 
mostly in mid-water strata both during the day and at night and were never caught at the surface (Fig. 136). On the north transect they also appeared to occupy mid-water at the 12- and 15-m contours (Fig. 136). No particular pattern of vertical distribution was observed at shallower stations on this transect. Smelt larvae appeared to be more abundant and dispersed in the water column on the south transect than on the north transect (Fig. 136). No smelt larvae were collected during early June in 1977.

During late June, smelt larvae were found in small numbers at $3 \mathrm{~m}$ and shallower water and became more abundant at deeper stations. On the south transect they were caught mostly at 12 and $15 \mathrm{~m}$ with the highest concentration of 108 larvae per $1000 \mathrm{~m}^{3}$ observed at the $8.5-\mathrm{ni}_{\mathrm{i}}$ stratum at station $\mathrm{F}$ (15 m - S) (Fig. 137). They were found in lower concentrations (22 and 18 larvae per $1000 \mathrm{~m}^{3}$ ) at the 3- and 6-m contours. No smelt larvae were caught in the beach zone, 1.5 or $9 \mathrm{~m}$. On the north transect smelt larvae occurred at $1.5 \mathrm{~m}$ and from 6 to $15 \mathrm{~m}$ (Fig. 137); densities ranged from 14 to $62 / 1000 \mathrm{~m}^{3}$. Highest catches were taken at 9 and $12 \mathrm{~m}$. No larvae were caught at $3 \mathrm{~m}$ or in the beach zone on this transect during late June. On both transects, smelt larvae collected at deep stations (6-15 m) ranged from 5 to $20 \mathrm{~mm}$. Only two larvae were captured at 1.5 and $3 \mathrm{~m}$ and they showed narrower size ranges (6.5 and $7.0 \mathrm{~mm})$ (Fig. 133).

Occurrence of newly hatched larvae 5-7 mm during late June in our study area both in 1977 and 1978 confirmed our previous observations on the extension of smelt spawning into late May and early June (see RESULTS AND DISCUSSION ADULT AND JUVENILE FISH, Rainbow Smelt). Low catches of small larvae (5-7 mm) in the nearshore area 19-20 June (Fig. 133) and a low rate of entrainment of smelt larvae in this size range during the same period (see Entrainment) indicated that only small numbers of larvae hatched during late June. In Lake Erie, rainbow smelt were reported to spawn in water 9 to $22 \mathrm{~m}$ (MacCallum and Regier 1970). Although smelt larvae that were collected in deeper water $(6-15 \mathrm{~m})$ may have migrated from shallow areas as has been previously observed, occurrence of small larvae (5-6 $\mathrm{mm}$ ) at these deep stations and their ahsence from the nearshore area (Fig. 133) suggested that some late spawning may also take place in deep water in the study area. As was found during May and early June, smelt larvae appeared to be more abundant at the south transect than at the north transect (Fig. 137). They continued to be caught more frequently in mid-water strata and near bottom than near the surface.

Length-frequency histograms of larvae collected during late June (Fig. 133) showed three size groups which corresponded to three hatching periods from 15 May to 20 June. Larvae 5-7 mm probably hatched shortly before our sampling period (19-20 June), while those 17-20 mm probably belonged to the 15 May cohort which were slightly more than $1-\mathrm{mo}$ old by this time. The size range of this latter group was comparable to lengths of $14-18 \mathrm{~mm}$ found for 1-mo-old larvae reported by Kendall (1927). A small number of larvae approximately $12.5 \mathrm{~mm}$ caught in sled tows during late June (Fig. 133) probably represented the group of larvae that hatched around the end of May and beginning of June. As has been pointed out in the discussion of May data, peak hatching of smelt larvae seemed to have occurred around the end of May. Reasons for low catches of larvae from this cohort were not known. No smelt larvae were observed in Pigeon Lake and intake canal samples during June (Appendix 15). An appreciable number of smelt larvae were however entrained in June (see Entrainment), indicating that they continued to enter Pigeon Lake during this month. Absence of smelt larvae from June samples taken in Pigeon Lake and in the intake canal may be due to the patchy distribution of these larvae at $6-\mathrm{m}$ 


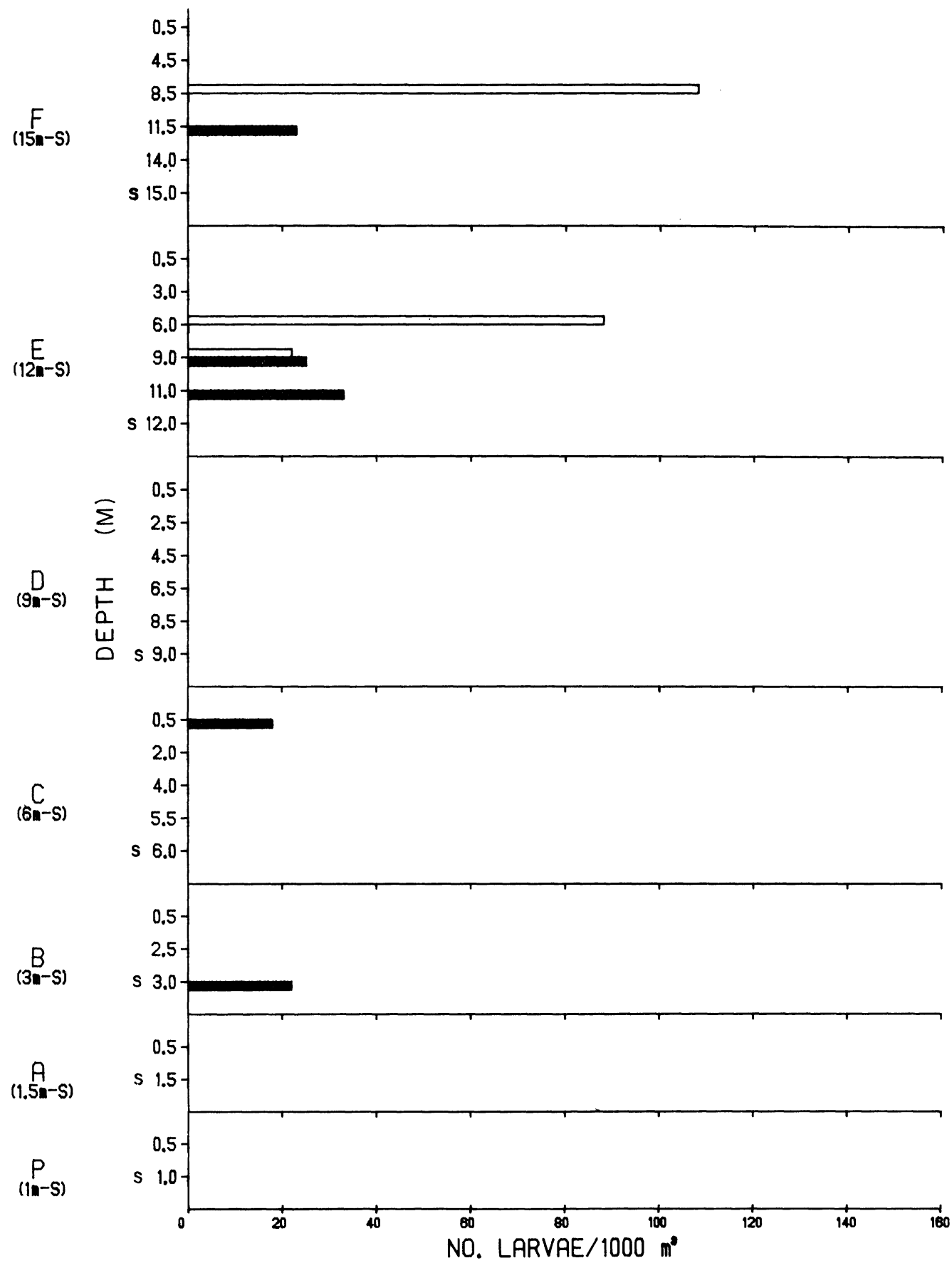

Fig. 137. Density of larval rainbow smelt (no./1000 $\mathrm{m}^{3}$ ) at Lake Michigan stations near the J.H. Campbell Plant, eastern Lake Michigan, 19-23 June 1978. $\square=$ day $\square=$ night $s=$ sled 


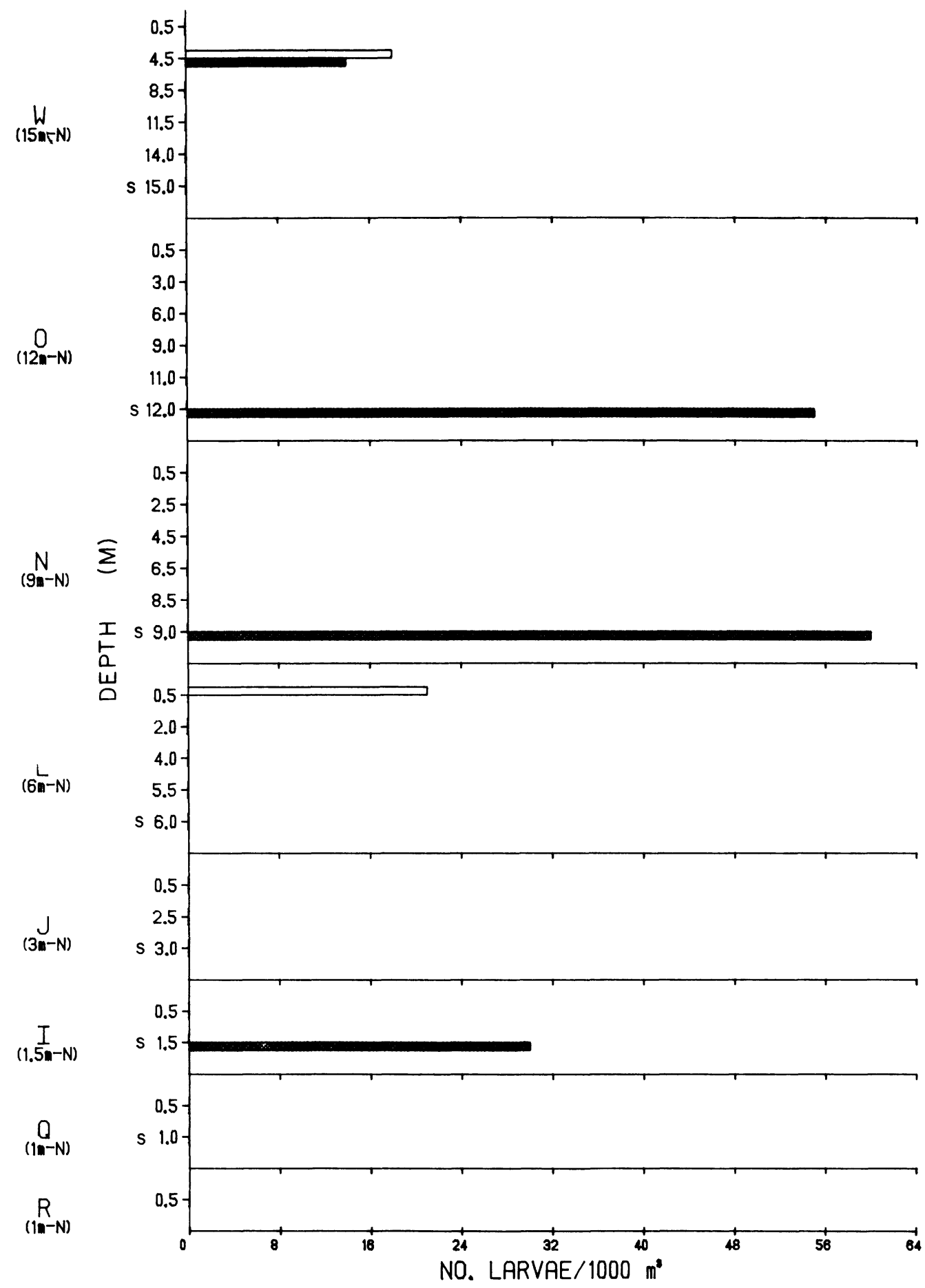

Fig. 137. Continued. 
station M (influenced by Lake Michigan) and station $\mathrm{Z}$ (intake canal). Only one smelt fry $(83 \mathrm{~mm})$ was caught in Lake Michigan during June (Appendix 16).

July-- During early July smelt larvae 6-25 mm were relatively common in the inshore area. On the south transect smelt larvae were found from 6 to $15 \mathrm{~m}$ at night with highest catches taken at $15 \mathrm{~m}$ (Fig. 138). They also occurred in substantial numbers (90 larvae per $1000 \mathrm{~m}^{3}$ ) at station A $(1.5 \mathrm{~m}-\mathrm{S}$ ) at night. During the day smelt larvae occurred in densities ranging from 20 to $40 / 1000 \mathrm{~m}^{3}$ at 6,9 and $15 \mathrm{~m}$. On the north transect night distribution of smelt larvae extended from the beach zone to $15 \mathrm{~m}$ with highest concentrations ( 110 larvae/1000 $\mathrm{m}^{3}$ ) at station I (1.5 m-N) (Fig. 138). During the day smelt larvae occurred only at 9 to $15 \mathrm{~m}$ with peak catches $\left(60\right.$ larvae/1000 $\left.\mathrm{m}^{3}\right)$ at station $\mathrm{W}(15 \mathrm{~m}-\mathrm{N})$.

In the nearshore area (beach zone to $3 \mathrm{~m}$ ), smelt larvae occurred only at night. At deeper stations $(6-15 \mathrm{~m})$, both on the north and south transects, smelt larvae were caught at more strata sampled at night than during the day (Fig. 138) probably because of higher larval activity at night. Both the absence of smelt larvae from the nearshore area and their restricted distribution in the water column during the day may be due to daytime net avoidance. During early July smelt larvae appeared to be more commonly caught at mid-water strata and near bottom than at the surface (Fig. 138). Like previous months however, no definite pattern of diel vertical migration of larval smelt was observed during July.

Length-frequency distribution of smelt larvae collected during early July showed four size groups were present (Fig. 133). The smallest larvae (6-8 mm) probably hatched during late June. Larvae in the 8.5-13.0-mm length interval probably hatched around mid-June and those in the 18-20 mm range probably represented the 30 May cohort. Most larvae that hatched by 15 May were probably large enough in July to escape plankton nets, but still too small to be retained by our trawls. Larger smelt larvae (23.5 to $25.2 \mathrm{~mm}$ ) (Fig. 133) which occurred in sled tows at approximately 70 larvae/1000 $\mathrm{m}^{3}$ at station I $(1.5 \mathrm{~m}-\mathrm{N})$ during early July and a 35.5-mm fry entrained during July (see Entrainment) were probably representatives of the 15 May cohort which were slightly less than 2 mo old by this time. The above sizes agreed with the lengths 25.0 to $45.0 \mathrm{~mm}$ reported for 2-mo-old smelt YOY by Scott and Crossman (1973).

Rainbow smelt spawning generally occurs intermittently during the spawning season. In Maine lakes Rupp (1959) reported the absence of smelt runs on several days during the spawning season. The discrete length-frequency distribution of smelt larvae we observed in July (Fig. 133) may in part be due to the discontinuity of smelt spawning in the study area. Difference of incubation period caused by differences in bottom water temperatures in the shallow and deeper areas may also influence the length-frequency distribution of smelt larvae. Smelt larvae probably continued to inhabit the inshore water during July, but most were probably large enough to avoid our nets. No smelt larvae were collected during late July 1978 and only a few were captured in plankton nets in July 1977 (Jude et a1. 1978). Smelt larvae were entrained in low numbers throughout July (see Entrainment), indicating that they continued to be drawn into Pigeon Lake during this month. As was observed during June, no smelt larvae were collected in Pigeon Lake or the intake canal during July. 


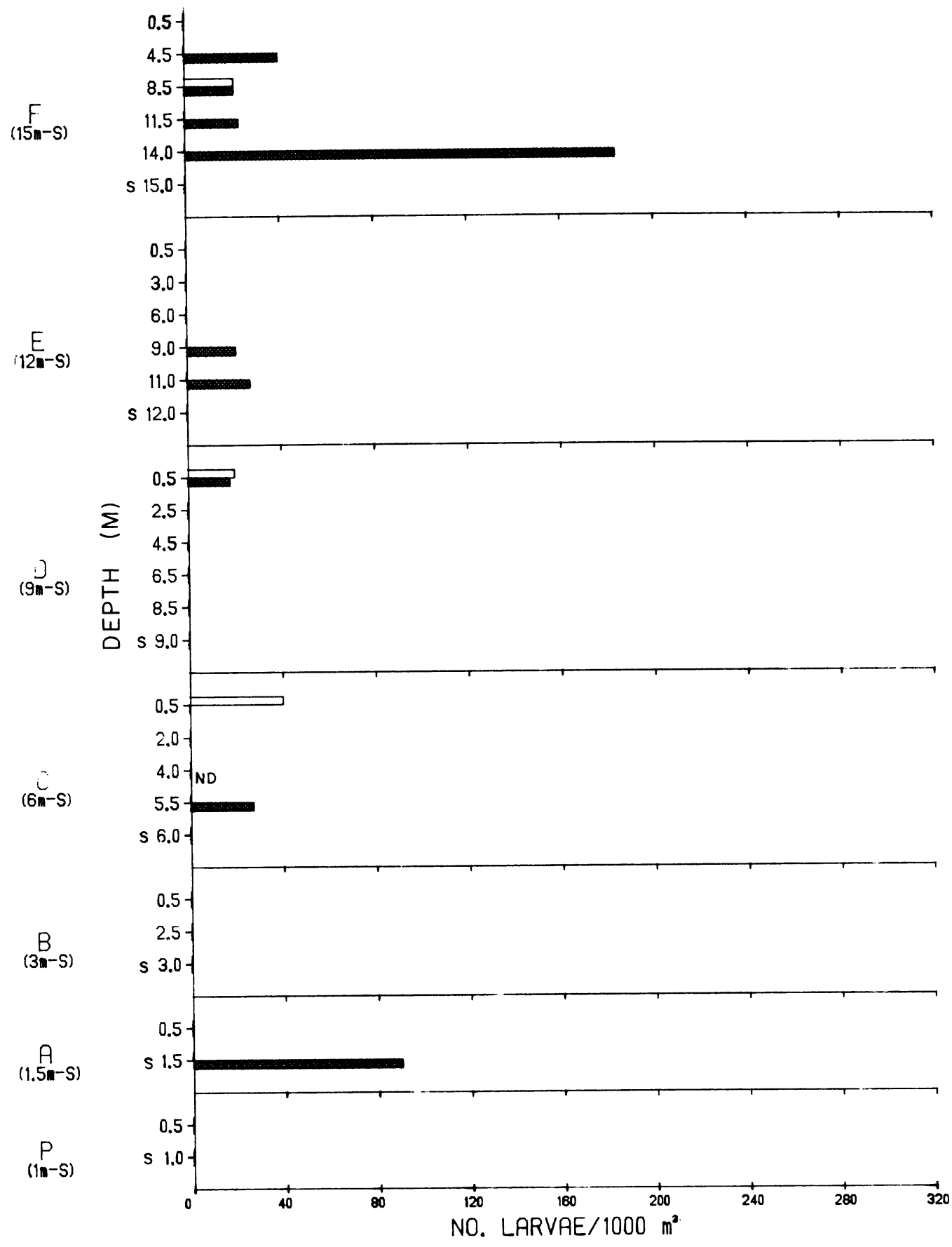

Fig. 138. Density of larval rainbow smelt (no./1000 $\mathrm{m}^{3}$ ) at Jake Michigan stations near the J. H. Campbell Plant, eastern Lake Michigan, 1-3 July 1978.

$\square=$ day $=$ night $\mathrm{S}=$ sled $\mathrm{ND}=$ no data 


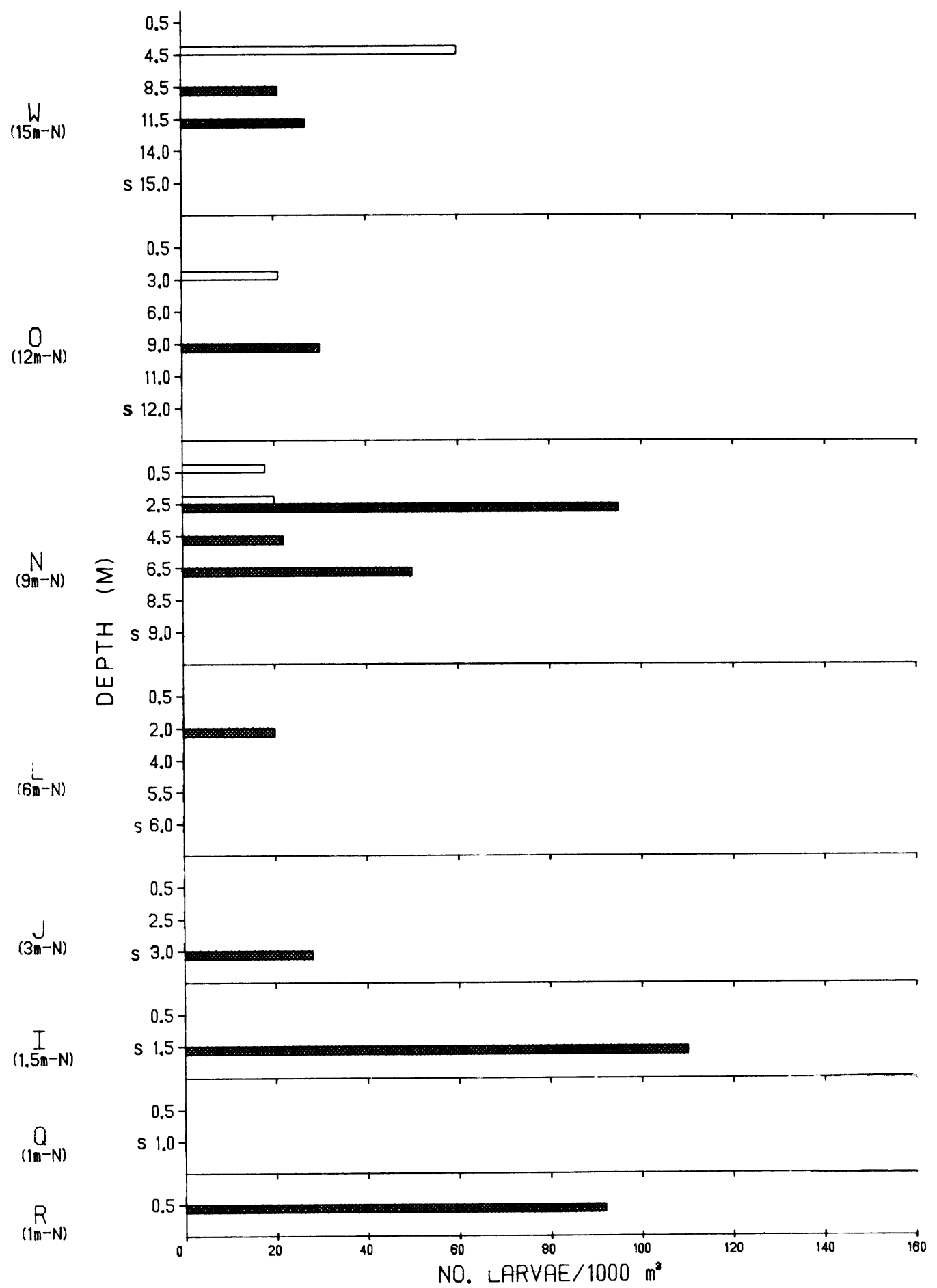

Fig. 138. Continued. 
A smal1 number of smelt fry 40.0 to $78.0 \mathrm{~mm}$ were captured in larvae nets during July (Appendix 16). Based on growth data of YoÝ smelt reported by Scott and Crossman (1973), the 40-mm fry collected in July was probably a YoY that hatched around mid-May. Larger fry $(63-78 \mathrm{~mm})$ were probably yearlings.

August, September-- Smelt were scarce in August samples both ir 1977 and 1978. During early August smelt larvae 15.5 to $25.0 \mathrm{~mm}$ occurred in densities of $16 / 1000 \mathrm{~m}^{3}$ at station $\mathrm{N}(9 \mathrm{~m}-\mathrm{N})$ and $89 / 1000 \mathrm{~m}^{3}$ at station $\mathrm{I}(1.5 \mathrm{~m}-\mathrm{N})$ (Appendix 10). During late August smelt were found only at station $\mathrm{J}(3 \mathrm{~m}-\mathrm{N})$ with a concentration of approximately 67 larvae/1000 $\mathrm{m}^{3}$. No smelt larvae were collected in Pigeon Lake or in the intake canal during late August (Appendixes 13 and 15).

During August smelt fry 25.5 to $82.0 \mathrm{~mm}$ were caught exclusively in sled tows; densities ranged from 30 to $1220 \mathrm{fry} / 1000 \mathrm{~m}^{3}$ (Appendix 16). Most August smelt fry were captured in shallow areas (beach zone to $3 \mathrm{~m}$ ). A substantial number of smelt fry of comparable size also occurred in August samples in 1977. Except for a few yearlings $(82 \mathrm{~mm})$ and small YOY from 25.5 to $28.0 \mathrm{~mm}$, most fry collected during August 1978 were $30-$ to $40-\mathrm{mm}$ YOY. As was found in July, catches of YOY smelt 20 to $29 \mathrm{~mm}$ remained low in August. Smelt fry continued to occur in appreciable numbers (13 to $207 \mathrm{fry} / 1000 \mathrm{~m}^{3}$ ) in September samples. YoY rainbow smelt 30-40 mm were also caught in large numbers in trawls during August and September 1978. These high catches of YOY smelt in sled tows and trawls in August and September agreed with Wells (1968), who reported YOY smelt moved from upper levels to the bottom during late summer and fall. Seasonal depth distribution of this size group ( $30-40 \mathrm{~mm}$ ) has already been discussed (see RESULTS AND DISCUSSION ADULT AND JUVENILE FISH, Rainbow Sme1t). No larvae or fry were collected in field samples during the remainder of 1978.

Entrainment--

May-- Newly hatched smelt larvae 5.5 to $6.0 \mathrm{~mm}$ were first entrained during the third week of May 1978 (Fig. 133), coinciding with their first appearance in larval fish collections in Lake Michigan. Total number of smelt entrained in a 24-h period increased rapidly from approximately 25001 arvae/24 h on 15 May to a peak of 141,000/24 h on 30 May (Fig. 139). Peak entrainment densities observed at Campbel1 $\left(98 / 1000 \mathrm{~m}^{3}\right)$ were comparable to those observed at Cook Plant during 7-8 May $1974\left(115 / 1000 \mathrm{~m}^{3}\right.$ ) (Jude 1976). Larval densities in the discharge cana1 on 15 May ( 5 larvae/1000 $\mathrm{m}^{3}$ ) were substantially lower than observed in the shallow areas of Lake Michigan (40 to 318 larvae/1000 $\mathrm{m}^{3}$ ) during the same period. The decreased density of entrained larvae was probably due to the patchy distribution of larvae in Lake Michigan and dilution of initial densities of larvae by the mixing of Lake Michigan and Pigeon River water.

Smelt larvae collected in Lake Michigan during 15-16 May ranged from 5.5 to $7.5 \mathrm{~mm}$ (Fig. 133), but only larvae in the range 5.5-6.0 mm were entrained during the same period (Fig. 133). This discrepancy in size composition of smelt larvae may be due to too low sample size since only two smelt larvae were actually collected during 15-16 May. Size range of entrained larvae became wider toward the end of May because of continued hatching in Lake Michigan and high numbers of larvae collected in entrainment samples. Lengths of larvae captured in the discharge canal were 5.5-7.0 mm during 23-24 May and 5.0-11.0 mm during the peak entrain-ment period (30-31 May) (Fig. 133). Most larvae entrained during May were recently 


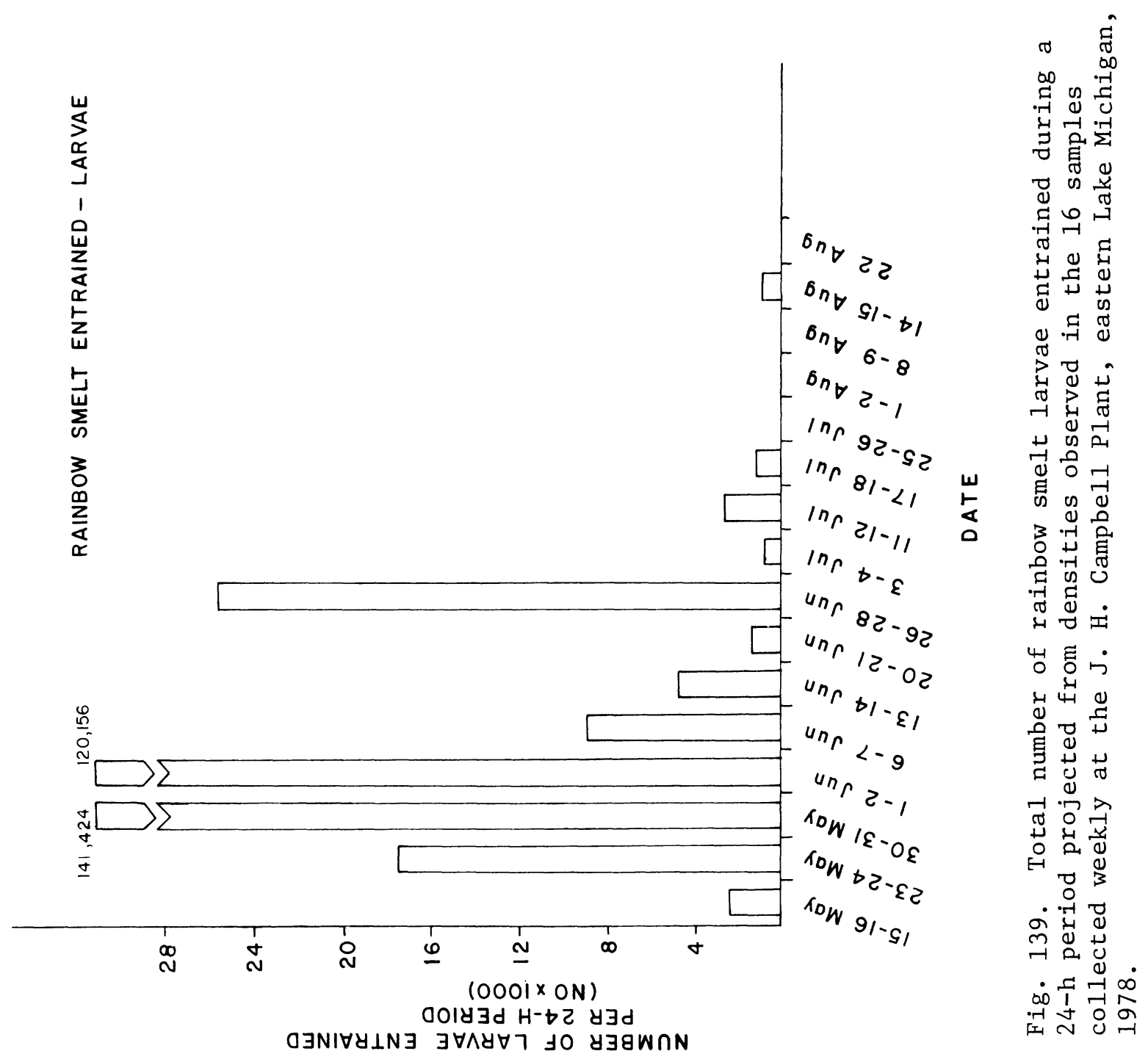


hatched $(5.5-7.0 \mathrm{~mm})$. A small number of 11-mm larvae, which occurred in entrainment samples at the end of May, probably hatched during 15-16 May. Smelt larvae appeared to be entrained more frequently at night and dawn than during other diel periods in May (Fig. 140). Smelt fry were entrained in small numbers during May (Fig. 141). These fry ranged from 26 to $77 \mathrm{~mm}$ and were probably all yearlings.

June-- Smelt larvae entrainment started to decline during the first week of June (Fig. 139). On 1 June 120,000 smelt/24 h were entrained; by 20 June numbers entrained had declined to approximately $1900 / 24 \mathrm{~h}$. A slight increase in the number of larvae entrained $(26,000 / 24 \mathrm{~h})$ was observed during the late June period (Fig. 139). The general decline in June larval entrainment rates compared to earlier months was related to the offshore migration of smelt larvae in Lake Michigan which started during early June and the decline in smelt hatching in the nearshore area. Similar to trends observed in May, smelt larvae appeared in lower densities in entrainment samples during 5-7 June $\left(4 / 1000 \mathrm{~m}^{3}-\mathrm{Fig}\right.$. 140) than in samples from nearshore stations (beach zone to $3 \mathrm{~m}$ ) where densities ranged from 0 to $33 / 1000 \mathrm{~m}^{3}$ (Fig. 136).

Smelt larvae entrained during 1-2 June had length-frequency distributions comparable to those entrained during 30-31 May. Most larvae captured were recently hatched larvae, $5-7.5 \mathrm{~mm}$. Only a small number of larger larvae 12-14 mm were found in the 1-2 June entrainment samples. During 6-7 June entrained smelt larvae ranged from 6.5 to $15 \mathrm{~mm}$ as compared with the 5-15-mm size range of larvae collected during the same period in Lake Michigan. Larvae 5 and $6 \mathrm{~mm}$ were not entrained in large numbers on 6-7 June because they were relatively scarce in the inshore area of Lake Michigan (Fig. 133). Smelt larvae entrained during 6-7 June showed a wider range (Fig. 133) than those collected in nearshore water during the same period suggesting that larvae inhabiting water deeper than $3 \mathrm{~m}$ may be drawn into the intake canal. Length-frequency distributions of larvae entrained in June did not seem to reflect the size composition of larvae observed in Lake Michigan, probably because of the low number of larvae actually collected in entrainment samples.

During the 13-14 and 26-28 June sampling periods, a small number of smelt larvae 5.0-6.5 mm occurred in entrainment samples suggesting that some hatching actually took place in Lake Michigan during this period (Fig. 133). Longer larvae, 16-22 mm, were also entrained in small numbers. Longer larvae (16-22 mm) probably hatched around 15-16 May. No smelt larvae in the 8-15-mm length interval were collected during 26-28 June. Length-frequency distribution of larvae entrained during May-July was similar to that of larval smelt collected in Lake Michigan during similar periods (Fig. 133). These data agreed with Kelso and Leslie (1979) who reported that entrainment of smelt was not size selective. This finding, however, was not true for the vast number of species we collected in entrainment samples. Generally they were susceptible to entrainment for a short period after hatching, then were seldom observed in entrainment samples during the remainder of the year. As noted, smelt, and to some degree alewife, were the only exceptions to this pattern. For entrained smelt in June, contrary to May results, there appeared to be no relationship between entrainment rates and diel period (Fig. 140). As in May, a few fry, $51 \mathrm{~mm}$, were entrained in June (Appendix 17). 

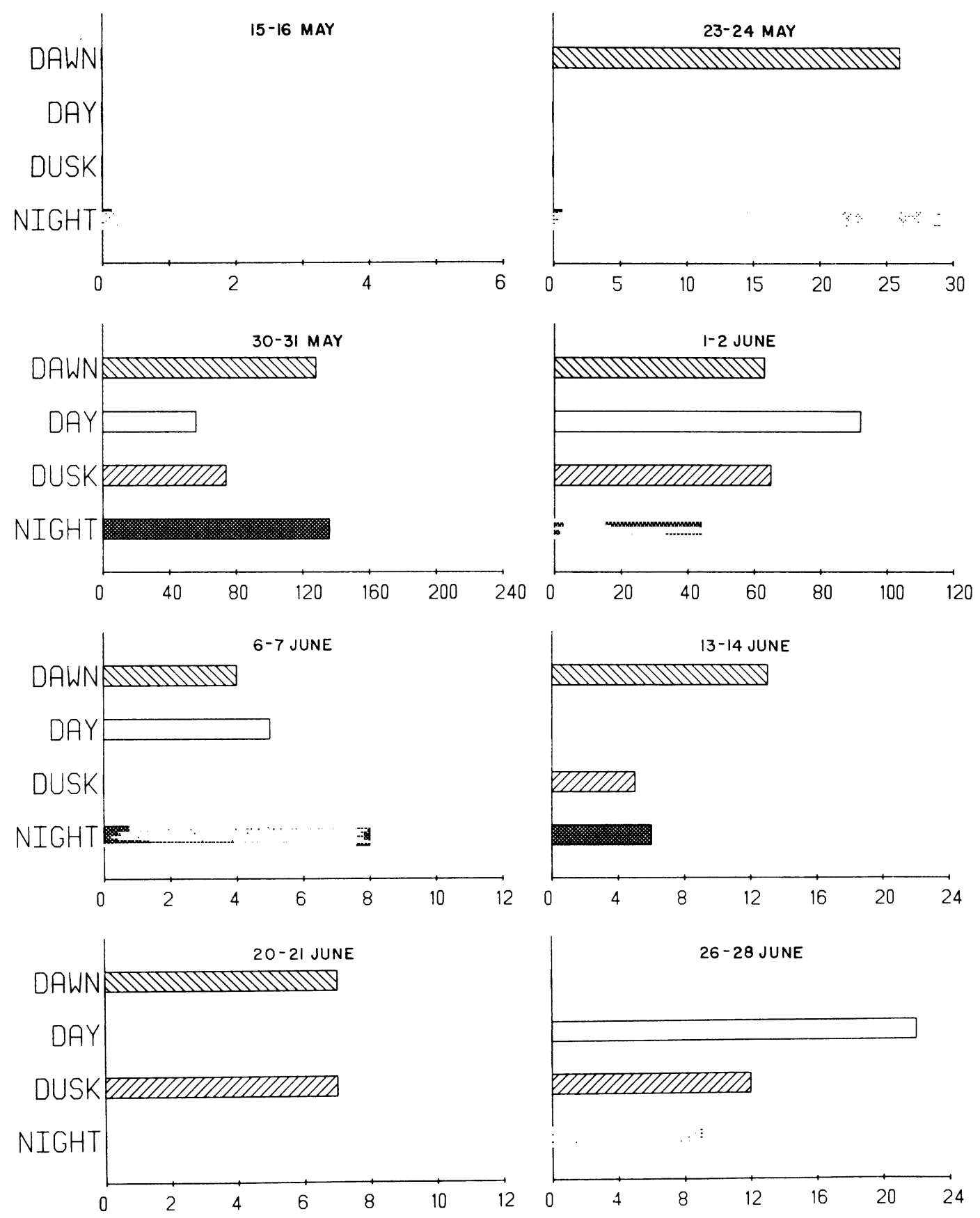

NO. OF LARVAE PER $1000 \mathrm{~m}^{3}$

Fig. 140. Density of rainbow smelt larvae (no./1000 $\mathrm{m}^{3}$ ) collected in weekly dawn, day, dusk and night entrainment samples at the J. H. Campbel1 Plant, eastern Lake Michigan, 1978. 

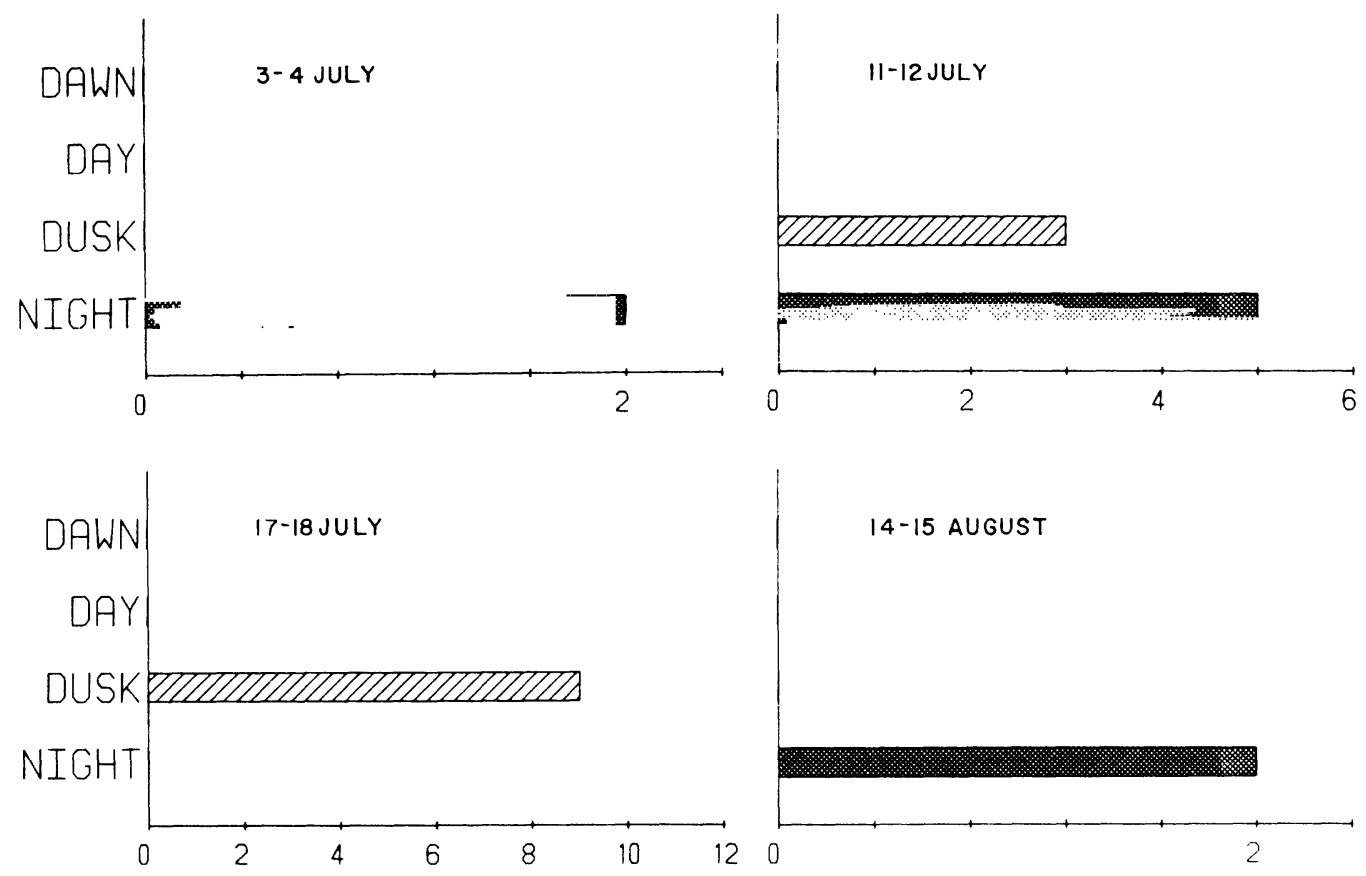

NO. OF LARVAE PER $1000 \mathrm{~m}^{3}$

Fig. 140. Continued.

July-- Small numbers of smelt larvae (from 900 to $2700 / 24 \mathrm{~h}$ ) continued to be entrained during the first 3 wk of July (Fig. 139). Unlike findings from previous months, only large larvae (11 to $23 \mathrm{~mm}$ ) were entrained during July. Smaller larvae $(5-7 \mathrm{~mm})$, which occurred in Lake Michigan during early July, were not found in July entrainment samples, probably because of their low abundance and residence in relatively deep water. Comparable densities of smelt larvae entrained were observed during 1977. During July one smelt fry, $35.5 \mathrm{~mm}$, probably a YOY was observed in an entrainment sample.

August-- The last time smelt larvae were entrained during 1978 occurred during the third week of August at a rate of 1000 larvae/24 h (Fig. 139). This low entrainment rate corresponded with the scarcity of smelt larvae in the inshore area of Lake Michigan during August. A slightly higher entrainment rate was observed during August 1977 (Jude et al. 1978). During August 1978, smelt larvae collected in Lake Michigan ranged from 15.5 to $25.4 \mathrm{~mm}$. Only one smelt larva, approximately $23 \mathrm{~mm}$, was observed in entrainment samples during August.

Fry entrainment rate increased rapidly from 4000/24 h during 8-9 August to a peak of approximately $29,000 / 24 \mathrm{~h}$ on 28 August (Fig. 141). Smelt fry 26 


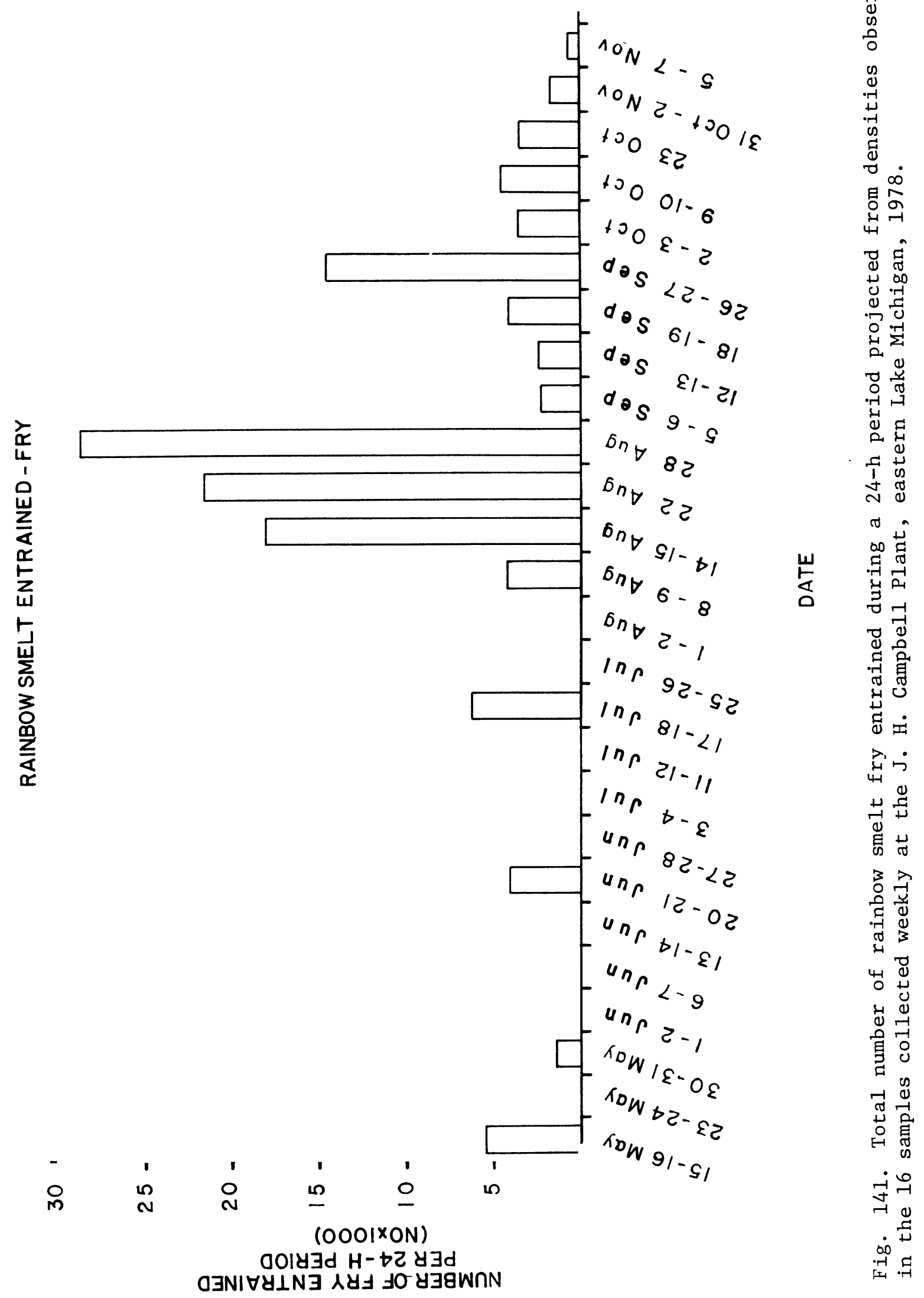


to $40 \mathrm{~mm}$ were entrained in large numbers during the last 2 wk of August. High densities of fry in entrainment samples coincided with peak catches of this size YOY in trawls and larvae nets in Lake Michigan. YOY smelt became vulnerable to entrainment during August because they moved close to shore during this month. This size group was probably not retained by the traveling screens as only low numbers of smelt of comparable size were found in impingement samples (see RESULTS AND DISCUSSION - ADULT AND JUVENILE FISH, Rainbow Smelt).

September, October, November-- Entrainment of sme1t YOY 27-47 mm occurred at a lower rate (200-14,000 fry/24 h) during September (Fig. 141). This decline from higher August values may be due to a shift in YOY smelt distribution to deeper water in September. Smelt fry continued to be occasionally entrained at densities from 1000 to 4000 individuals/24 h in October and November (Fig. 141).

Burbot

Introduction--

Burbot adults remain in deep, cool water most of the year. They move inshore in late December through March to spawn in water approximately $1 \mathrm{~m}$ deep over sand and gravel in shallow bays or rivers (Muth 1973; Scott and Crossman 1973). Eggs hatch in approximately 30 days at $6.1 \mathrm{C}$ and young appear from late February to June (Scott and Crossman 1973). In the Tanana River, Alaska, Chen (1969) found burbot spawned in early February and eggs hatched in late April. Newly hatched larvae averaged $4.06 \mathrm{~mm}$ and attained a length of $110 \mathrm{~mm}$ by the end of their first year of life. Burbot in Lake Superior were found by Bailey (1972) to attain 145 $\mathrm{mm}$ at the end of their first year. Muth and Smith (1974) also found newly hatched larvae ranging from 3.87 to $4.19 \mathrm{~mm}$.

Seasonal Distribution--

Although few adult burbot were captured in the vicinity of the Campbell Plant during 1978 (see RESULTS AND DISCUSSION - ADULT AND JUVENILE FISH, Burbot) larval burbot were numerous in entrainment and Lake Michigan plankton samples during April, May and June (Appendixes 10, 11, 12 and 14). No larval burbot and only two adult burbot were collected during 1977; however, field and entrainment sampling efforts did not commence until June and July 1977 respectively (Jude et al. 1978). Burbot larvae were most abundant in April and May 1978 and were probably in the area during those same months in 1977. Adult field sampling during 1977 and 1978 was not carried out during December, January, February and March, the normal spawning period of burbot. This may account for their low nutubers in our data summaries. Burbot may actually be quite abundant in the area during winter months. Limited sampling during December in southeastern Lake Michigan (Jude et al. 1979) showed adult ripe-running burbot collected in field gear and burbot eggs in plankton tows.

Burbot larvae first appeared and were most numerous in April entrainment samples at the Campbell Plant, but they were also numerous in April field samples. Burbot larvae were taken from Pigeon Lake beach and open water tows, the intake canal ( $\mathrm{Z}$ ), inshore Lake Michigan sled tows and along the north and south transects. 
In Pigeon Lake 174 burbot larvae/1000 $\mathrm{m}^{3}$ were detected at beach station $\mathrm{V}$ (undisturbed Pigeon Lake) and 109 burbot larvae/1000 $\mathrm{m}^{3}$ were found in surface water tows at open water station M (influenced by Lake Michigan) (Fig. 142). These larvae ranged from 4.5 to $4.8 \mathrm{~mm}$ and were captured during the day in water 6.5 to $10.6 \mathrm{C}$. Burbot larvae $\left(73 / 1000 \mathrm{~m}^{3}\right)$ were also collected in a $2.5-\mathrm{m}$ tow at station $Z$ (intake canal) during the day in April. These larvae were $4.4 \mathrm{~mm}$ and were taken in water $6.5 \mathrm{C}$ (Fig. 142).

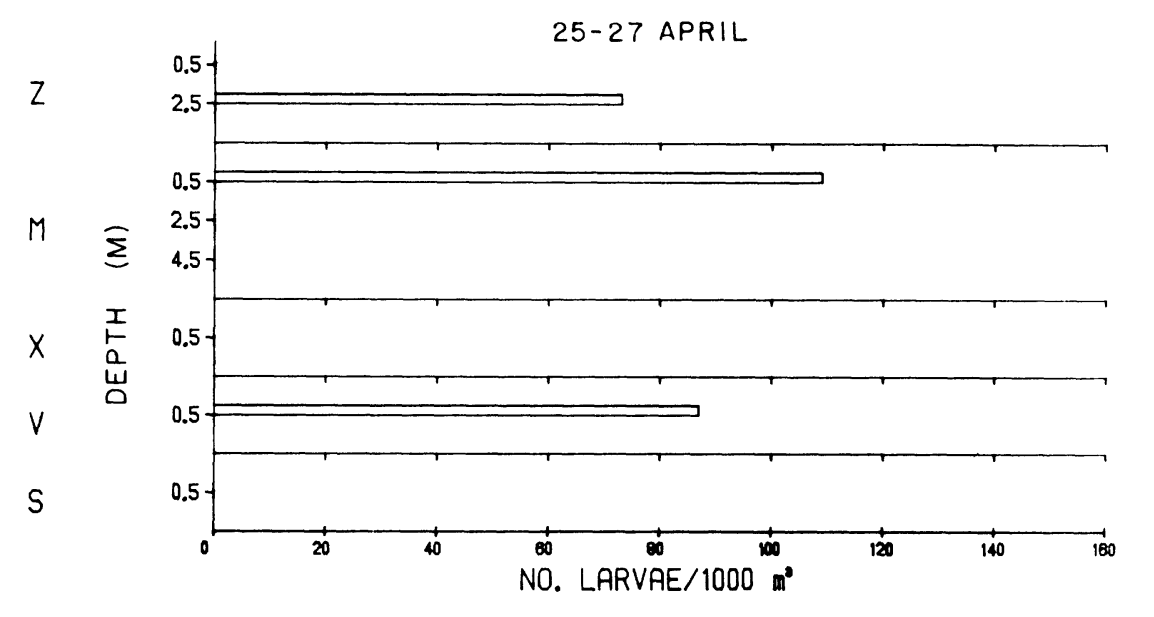

Fig.142.Density of burbot larvae (no./1000 $\mathrm{m}^{3}$ ) at Pigeon Lake and intake canal stations near the J. H. Campbell Plant, eastern Lake Michigan April 25-27, 1978.

$\square=$ day $\square=$ night

April sled samples at both north and south inshore stations A $(1.5 \mathrm{~m}-\mathrm{S})$, B $(3 \mathrm{~m}-\mathrm{S})$, I $(1.5 \mathrm{~m}-\mathrm{N})$ and $\mathrm{J}(3 \mathrm{~m}-\mathrm{N})$ also contained burbot larvae. Burbot larvae were more numerous at south transect stations A and B, 177 and 183 larvae/ $1000 \mathrm{~m}^{3}$, respectively, than at the north transect stations $\mathrm{I}$ and $\mathrm{J}, 30$ and 79 larvae/1000 $\mathrm{m}^{3}$, respectively. This distribution pattern may have resulted from more restricted water temperatures at the south transect, 7.5-8.5 C, than along the north transect, 5.0-13.5 C. Larvae collected along the south transect were somewhat smaller (average $4.2 \mathrm{~mm}$ ) than those at the north transect (average 4.7 $\mathrm{mm})$. Although burbot at the south transect were more abundant in sled tows during April, they appeared more often in mid-water plankton tows at north transect stations. Burbot larvae were taken during April in night plankton net tows at the surface at station $\mathrm{D}(9 \mathrm{~m}-\mathrm{S})$ and at $11 \mathrm{~m}$ at station $\mathrm{E}(12 \mathrm{~m}-\mathrm{S})$. Concentrations were 16 and 19 larvae/1000 $\mathrm{m}^{3}$ respectively (Fig. 143) with larvae averaging $4.8 \mathrm{~mm}$; water temperature varied from 5.0 to $7.0 \mathrm{C}$. 


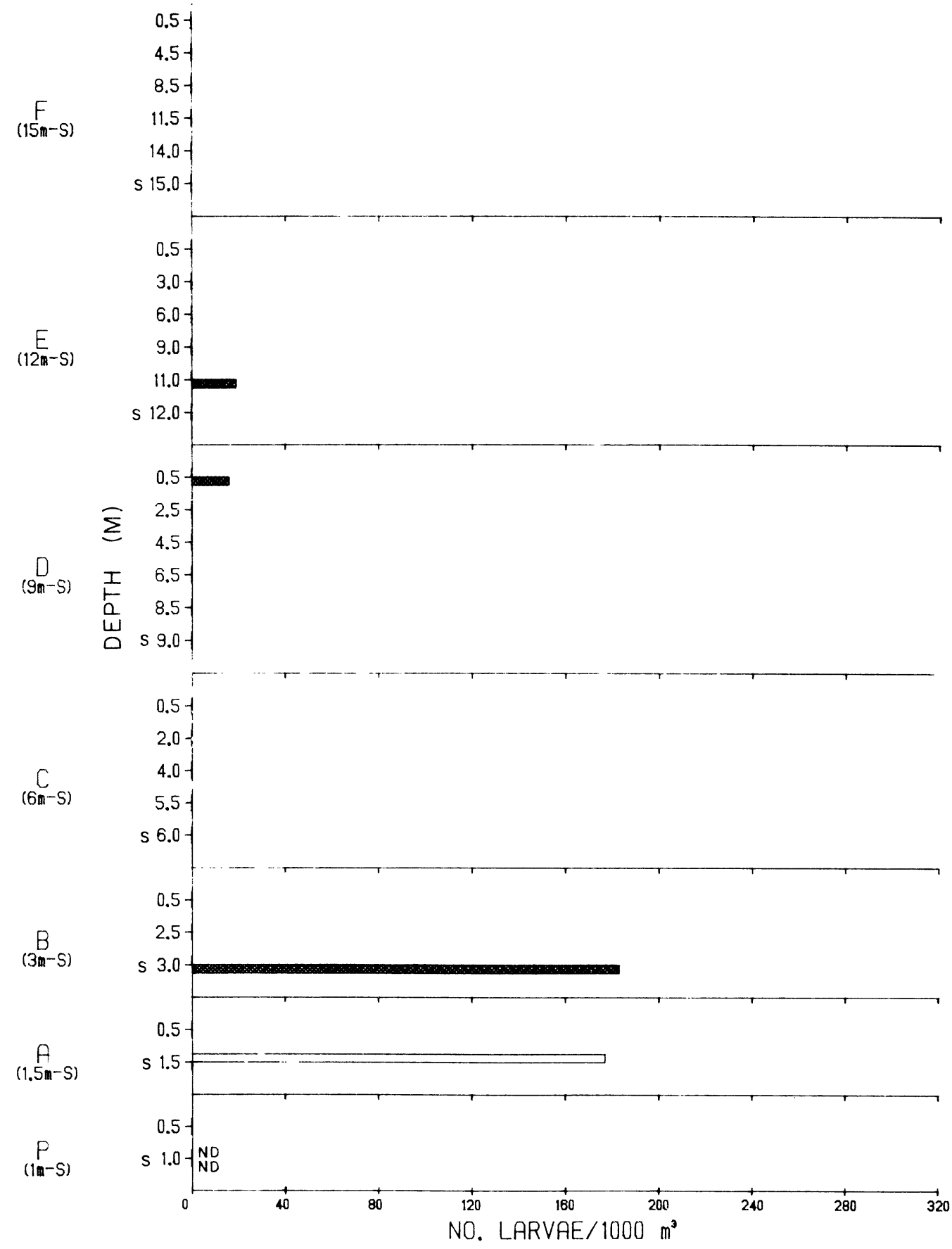

Fig. 143. Density of larval burbot (no./100n $\mathrm{m}^{3}$ ) at Lake Michigan stations near the J. H. Campbell Plant, eastern Jake Michigan, 24-28 April 1978. $\square=$ day $\square=$ night $S=$ sled $N$ ) = no data 


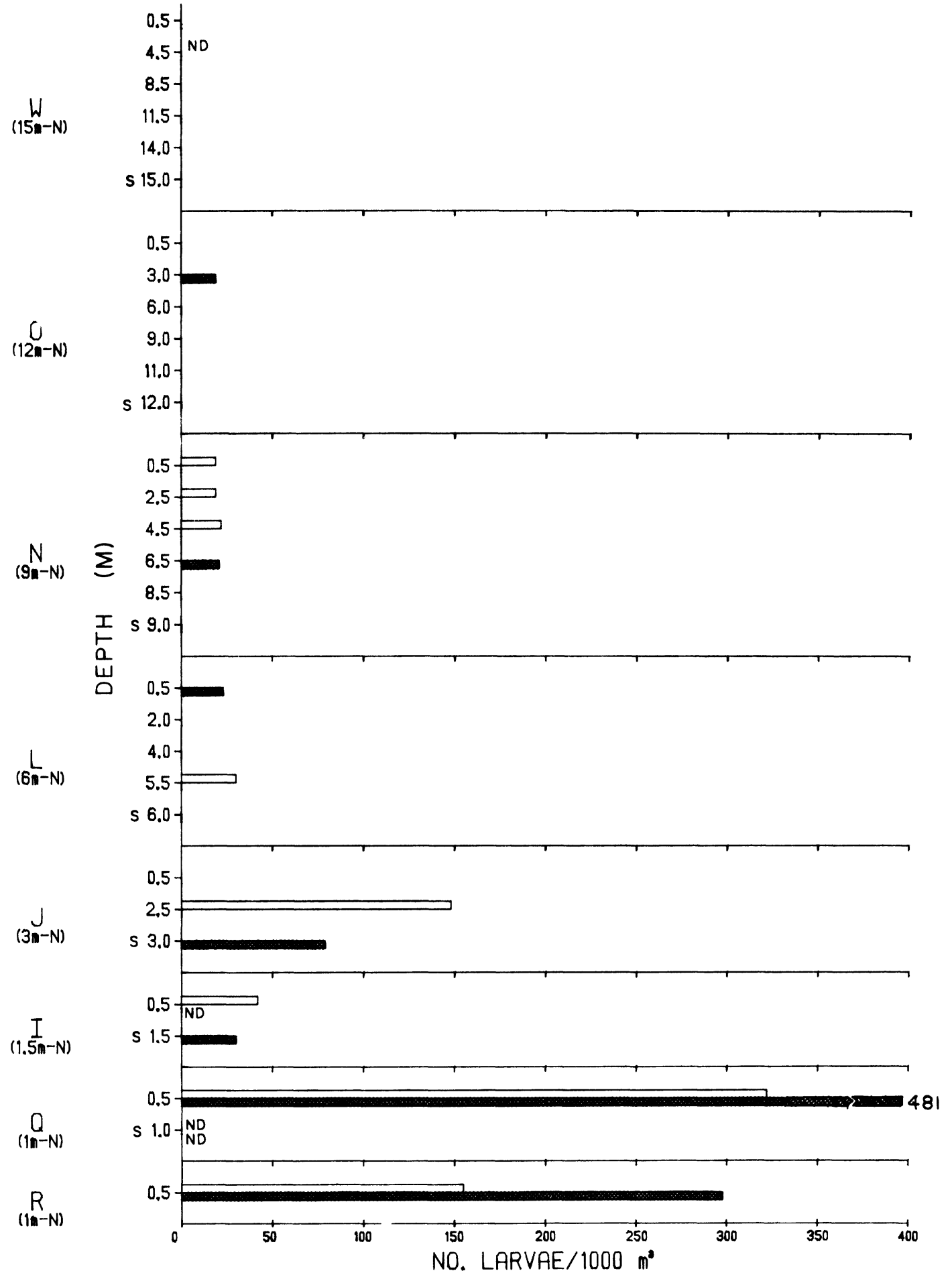

Fig. 143. Continued. 
Along the north transect, burbot larvae occurred at all stations during April, except $W(15 \mathrm{~m}-\mathrm{N})$ (Fig. 143). At beach stations $Q$ and $\mathrm{R}$ burbot larvae were recovered from both day and night tows (Fig. 143). Larvae at these stations ranged from 4.0 to $4.8 \mathrm{~mm}$, with an average of $4.3 \mathrm{~mm}$, and they were caught at water temperatures of 7.0 to $8.0 \mathrm{C}$. The average density of larvae at beach station $Q$ was $407 / 1000 \mathrm{~m}^{3}$, while at $R$ it was $227 / 1000 \mathrm{~m}^{3}$. Burbot larvae were taken only during the day at nearshore stations $\mathrm{I}(1.5 \mathrm{~m}-\mathrm{N})$ and $\mathrm{J}(3 \mathrm{~m}-\mathrm{N})$. Concentrations of burbot larvae were 42 and $148 / 1000 \mathrm{~m}^{3}$ respectively. Larvae in this zone averaged $4.6 \mathrm{~mm}$ and were caught at water temperatures of 7.5 to $9.9 \mathrm{C}$.

Farther offshore burbot larvae were collected during April at stations L $(6 \mathrm{~m}-\mathrm{N}), \mathrm{N}(9 \mathrm{~m}:-\mathrm{N})$ and $\mathrm{O}(12 \mathrm{~m}-\mathrm{N})$. These fish averaged $4.4 \mathrm{~mm}$ and were taken in water 5.0-6.5 C. Densities averaged 221 arvae/1000 $\mathrm{m}^{3}$. These larvae were scattered throughout the water column both during the day and night. At 6-m station L larvae were taken at the 6-m stratum during the day and at the surface at night. At 9-m station $\mathrm{N}$ larvae were collected at the surface, $2 \mathrm{~m}$ and $4 \mathrm{~m}$ during the day and at $6 \mathrm{~m}$ during the night. Burbot were collected only at $3 \mathrm{~m}$ during the night at station 0 .

During May burbot larvae were less abundant than in April. They were caught in sled tows at stations $A(1.5 \mathrm{~m}-\mathrm{S})$ and $\mathrm{J}(3 \mathrm{~m}-\mathrm{N})$ and in plankton tows at south transect beach station $P$ (S reference), offshore stations $C$

$(6 \mathrm{~m}-\mathrm{S})$ and $\mathrm{E}(12 \mathrm{~m}-\mathrm{S})$ and north transect beach station $\mathrm{R}$ ( $\mathrm{N}$ discharge) and offshore stations $\mathrm{J}(3 \mathrm{~m}-\mathrm{N})$ and $\mathrm{O}(12 \mathrm{~m}-\mathrm{N})$. This species was also collected during all four entrainment sampling periods in May.

Burbot larvae were recovered from both day and night sled tows at $1.5-\mathrm{m}$ station $A$ and during night tows at beach station $P$. The fish at station A were taken from water between 9.0 and $11.4 \mathrm{C}$ and ranged from 4.0 to $4.5 \mathrm{~mm}$; densities ranged from 53 to $162 / 1000 \mathrm{~m}^{3}$. At $3-\mathrm{m}$ station $\mathrm{J}$ fish were taken at $7.0 \mathrm{C}$ and averaged $5.8 \mathrm{~mm}$.

The most larvae collected in plankton tows along the south transect came from beach station $P$ at night when water temperature was $8.5 \mathrm{C}$ (Fig. 144). At this time densities were $322 / 1000 \mathrm{~m}^{3}$ and fish were 3.9 to $4.0 \mathrm{~mm}$. Larvae were also taken in a surface tow at station $\mathrm{C}(6 \mathrm{~m}-\mathrm{S})$ during the night $\left(17 / 1000 \mathrm{~m}^{3}\right)$ and in a $9-\mathrm{m}$ tow at station $\mathrm{E}(12 \mathrm{~m}-\mathrm{S})$ during the day when the density was $33 / 1000 \mathrm{~m}^{3}$ and temperature was $5.0 \mathrm{C}$ (Fig. 144).

Along the north transect, larvae were collected in day and night tows at beach station $\mathrm{R}$, nearshore station $\mathrm{J}$ at $2 \mathrm{~m}$ and at $6 \mathrm{~m}$ at station $\mathrm{O}$ (12 $\mathrm{m}$ ) (Fig. 144). Water temperatures at time of capture ranged from 8.0 to $10.5 \mathrm{C}$ at station $R$, and 7.5 and $7.8{ }_{3}$ at stations $J$ and 0 respectively. Densities of 1.arvae ranged from $442 / 1000 \mathrm{~m}^{3}$ at station $\mathrm{R}$ to $40 / 1000 \mathrm{~m}^{3}$ at station $\mathrm{J}$ to $15 / 1000 \mathrm{~m}^{3}$ at station 0 . The fish caught at these three stations were from 4.0 to $4.6 \mathrm{~mm}$.

Few burbot larvae were collected in June. Plankton tows at north transect stations $\mathrm{N}(9 \mathrm{~m}-\mathrm{N})$ and $\mathrm{W}(15 \mathrm{~m}-\mathrm{N})$ collected 20 and 17 larvae/1000 $\mathrm{m}^{3}$ respectively (Fig. 145). These larvae were taken during the second week of June only in deep water strata tows at 8 and $12 \mathrm{~m}$. At station $\mathrm{N}(9 \mathrm{~m})$ a 4.7-mm specimen was collected at night in water $5.0 \mathrm{C}$. In addition a $5.0-\mathrm{mm}$ burbot was taken during the day at $15.3 \mathrm{C}$ and a $10.0-\mathrm{mm}$ larva was collected at night at $4.9 \mathrm{C}$. 


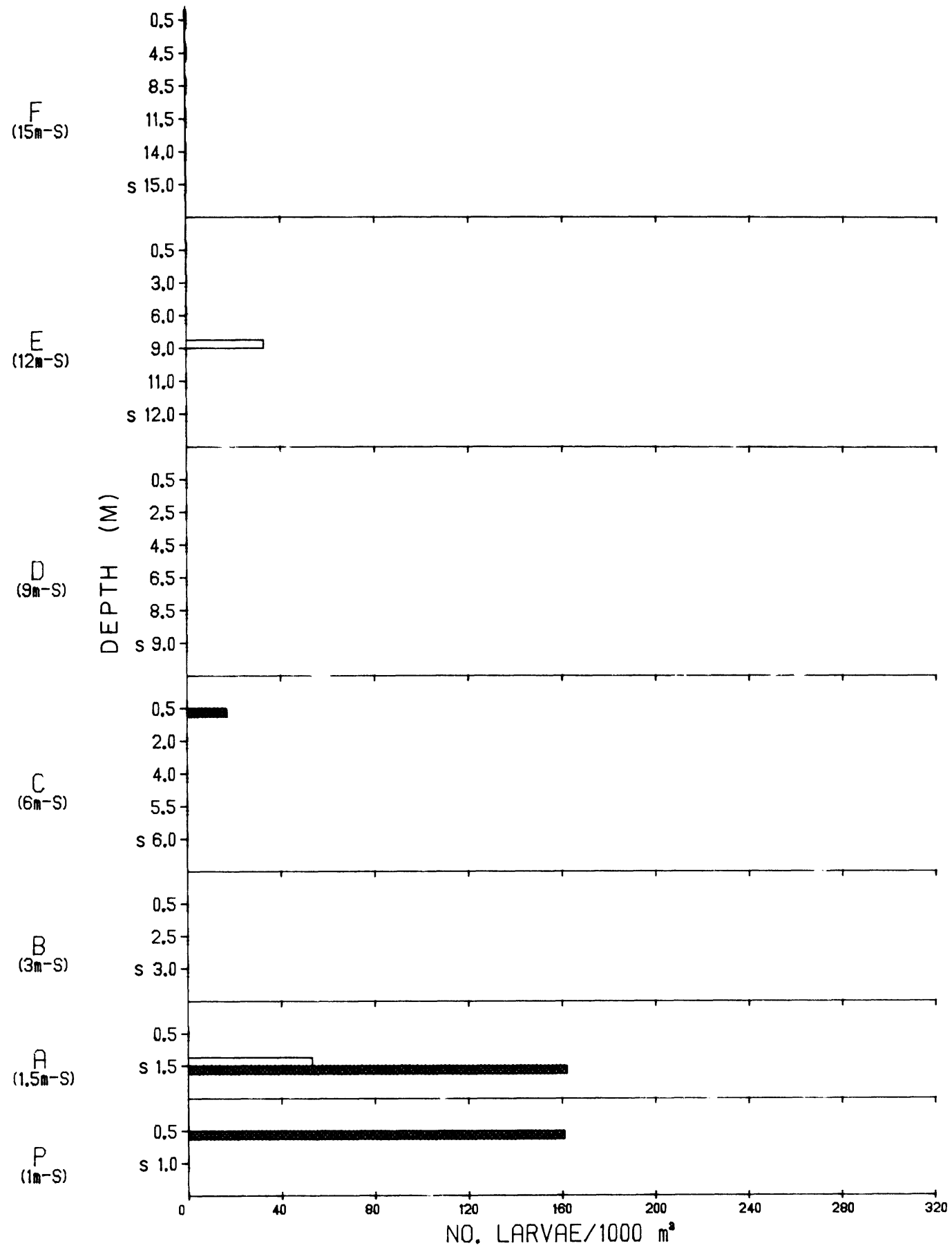

Fig. 144. Density of larval burbot (no./1000 $\mathrm{m}^{3}$ ) at Lake Michigan stations near the J. H. Campbell Plant, eastern Lake Michigan, 15-18 May 1978.

$\square=$ day $\square=$ night $S=$ sled 


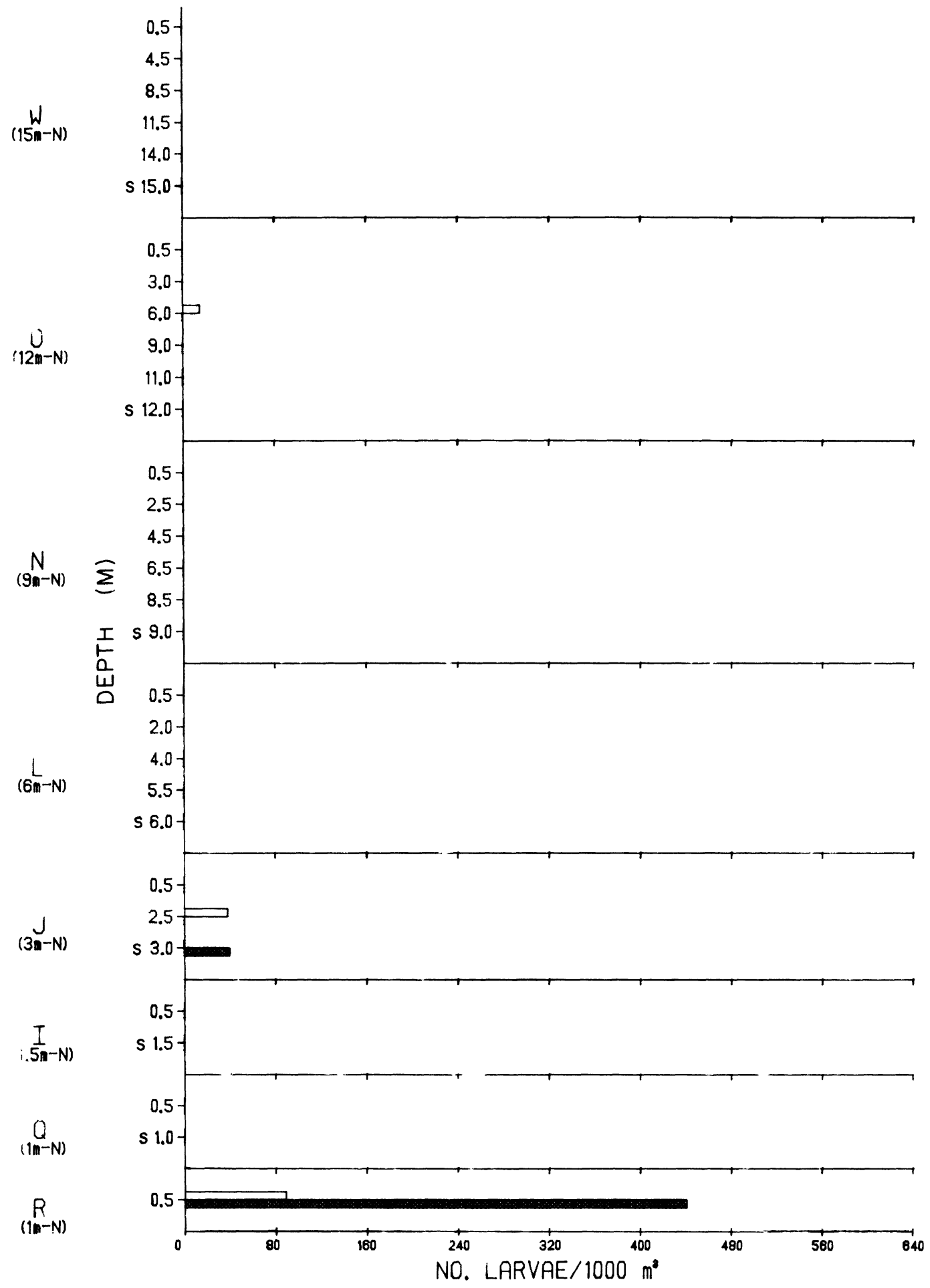

Fig. 144. Continued. 


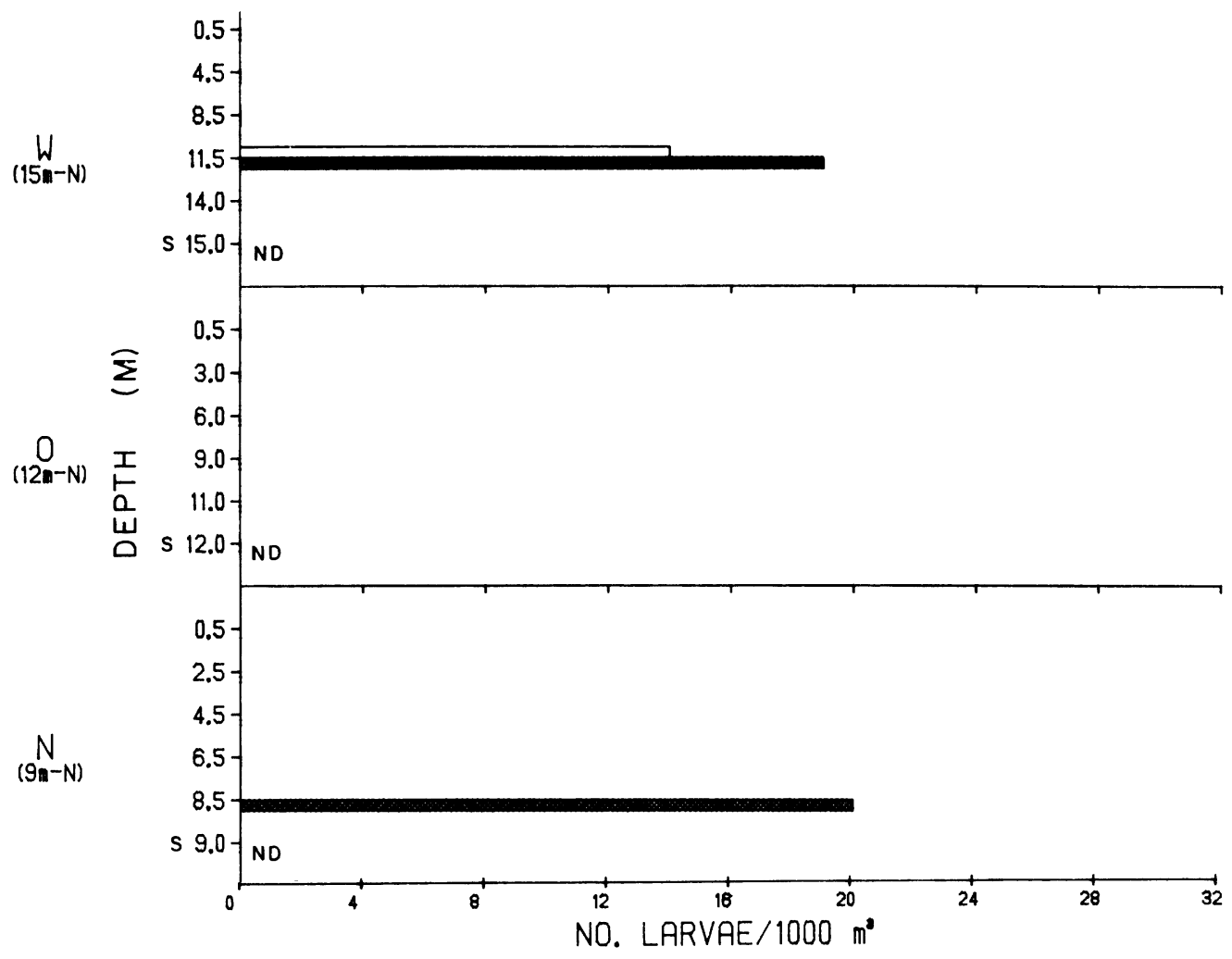

Fig. 145. Density of larval hurbot (no./1000 $\mathrm{m}^{3}$ ) at Jake Michigan stations near the J. H. Campbel1 Plant, eastern Lake Michigan, 6-10 June 1978. Stations 0.5 to $6 \mathrm{~m}-\mathrm{N}$ were omitted due to absence of larvae in samples. $\square=$ day $\square=$ night $S=$ sled

\section{Entrainment--}

Burbot larvae were entrained during the second, third and fourth weeks of April (Fig. 146). Larval burbot, at a density of $8 / 1000 \mathrm{~m}^{3}$ were first collected in dawn entrainment samples on 11 April when intake water temperature was $3.6 \mathrm{C}$. During the day $48 / 1000 \mathrm{~m}^{3}$ were taken; water temperature had risen to $6.8 \mathrm{C}$. These larvae averaged $4.3 \mathrm{~mm}$. In the third week of April burbot larvae were recovered from samples taken in all four periods sampled with concentrations lowest during the day and at dusk; 7 and 10 larvae/1000 $\mathrm{m}^{3}$ respectively. These larvae, all captured between 5.0 and $6.9 \mathrm{C}$, averaged $4.3 \mathrm{~mm}$. Overall estimates of burbot larvae entrained over a $24-\mathrm{h}$ period reached 66,563 during the third week (Fig. 147).

During the last week in April entrained burbot larvae were again recovered from samples taken over the four sampling periods in $24 \mathrm{~h}$. Again they were found to be least abundant during the day and at dusk, 19 and 33 larvae $/ 1000 \mathrm{~m}^{3}$ respectively (Fig. 146). These fish averaged $4.3 \mathrm{~mm}$ and were taken from water 6.5 to $7.0 \mathrm{C}$. 

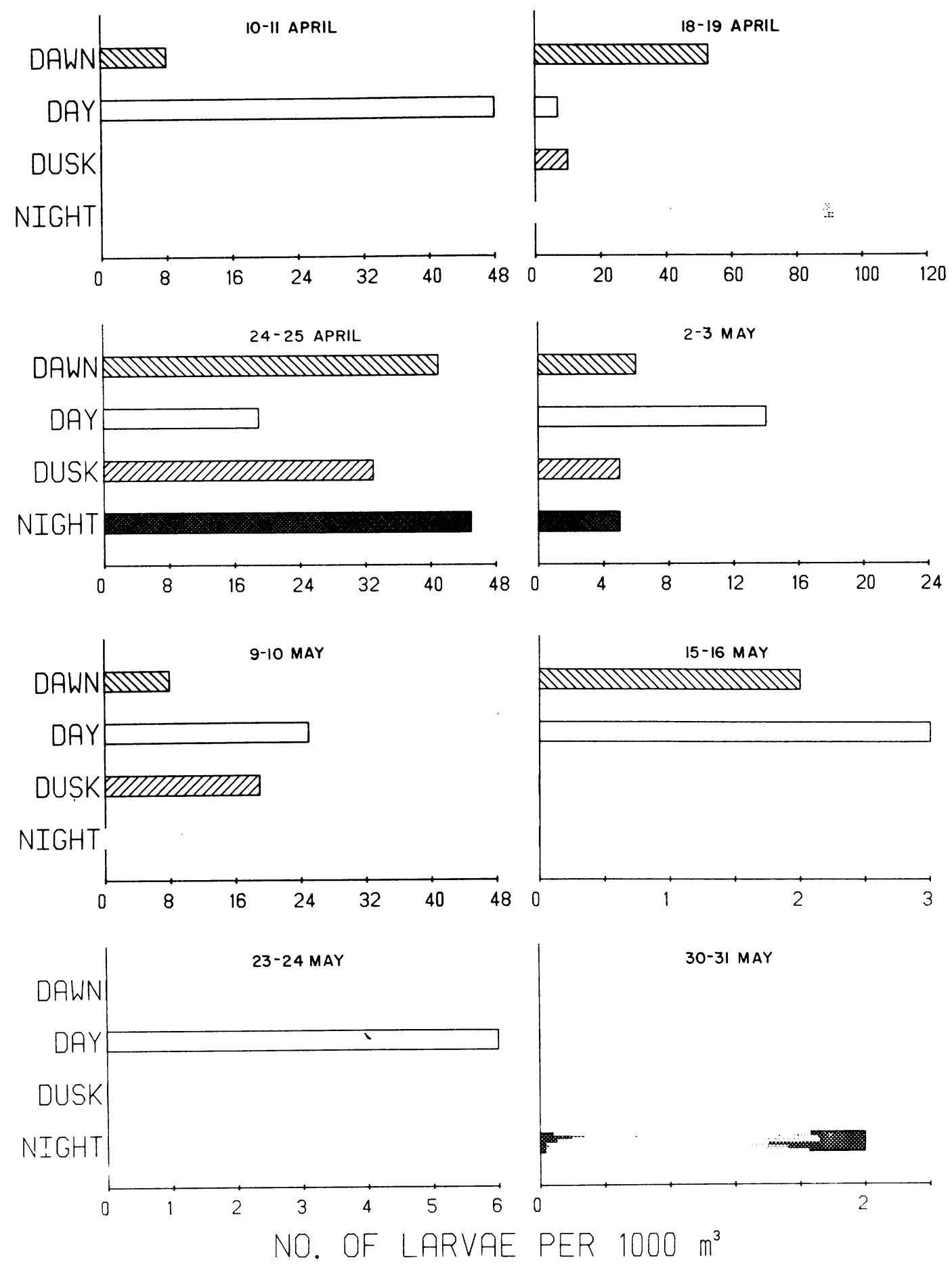

Fig. 146. Density of burbot larvae (no./1000 $\mathrm{m}^{3}$ ) collected in weekly dawn, day, dusk and night entrainment samples at the J. H. Campbell Plant, eastern Lake Michigan, 1978. 


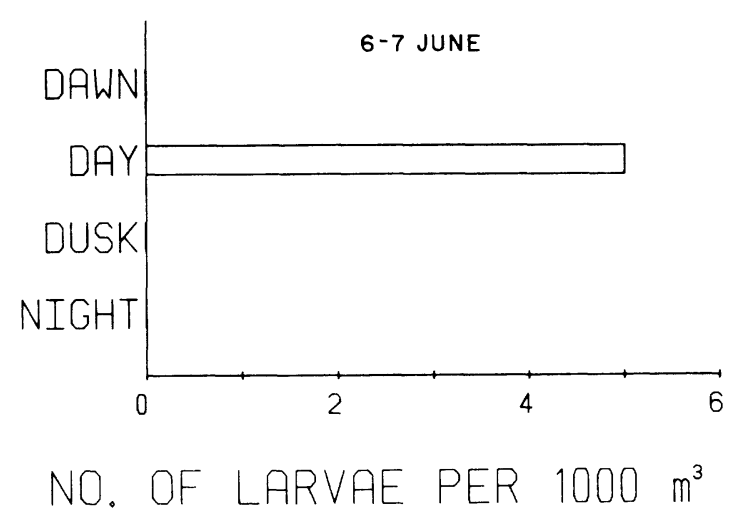

Fig. 146. Continued.

Burbot larvae were most numerous during the first and second weeks of May entrainment sampling (Fig. 146). They were taken at all time periods during the first week when intake temperatures ranged from 9.0 to $10.5 \mathrm{C}$. Larvae were most numerous during the day, $14 / 1000 \mathrm{~m}^{3}$, and ranged from 5 to $6 / 1000 \mathrm{~m}^{3}$ during the remaining time periods sampled. These larvae averaged $4.9 \mathrm{~mm}$ and ranged from 4.0 to $6.0 \mathrm{~mm}$.

In the second week of May burbot larvae were again collected during all time periods when intake water temperature remained consistently at $10.5 \mathrm{C}$. Densities ranged from $32 / 1000 \mathrm{~m}^{3}$ at night to $8 / 1000 \mathrm{~m}^{3}$ at dawn. Day and dusk densities were 25 and $19 / 1000 \mathrm{~m}^{3}$ respectively. These larvae averaged $5.0 \mathrm{~mm}$ with a range from 4.0 to $5.9 \mathrm{~mm}$.

Incidence of entrained burbot larvae began to decline after the third week of May (Fig. 146). At this time larvae were taken only in dawn and day samples at low densities of 2 and $3 / 1000 \mathrm{~m}^{3}$, respectively. Intake temperatures were 13.0 and $7.0 \mathrm{C}$ respectively; burbot averaged $4.5 \mathrm{~mm}$.

Longer burbot larvae were taken in a day sample on 23 May $\left(6 / 1000 \mathrm{~m}^{3}\right)$ and at night on 31 May $\left(2 / 1000 \mathrm{~m}^{3}\right)$. These fish were 4.9 and $5.4 \mathrm{~mm}$ and were caught in water between 15.4 and $18.9 \mathrm{C}$.

A burbot larva also appeared in a day entrainment sample on 6 June when the intake water temperature was $19.0 \mathrm{C}$ (Fig. 146). This fish was $5.6 \mathrm{~mm}$ and densities were calculated to be $5 / 1000 \mathrm{~m}^{3}$. 


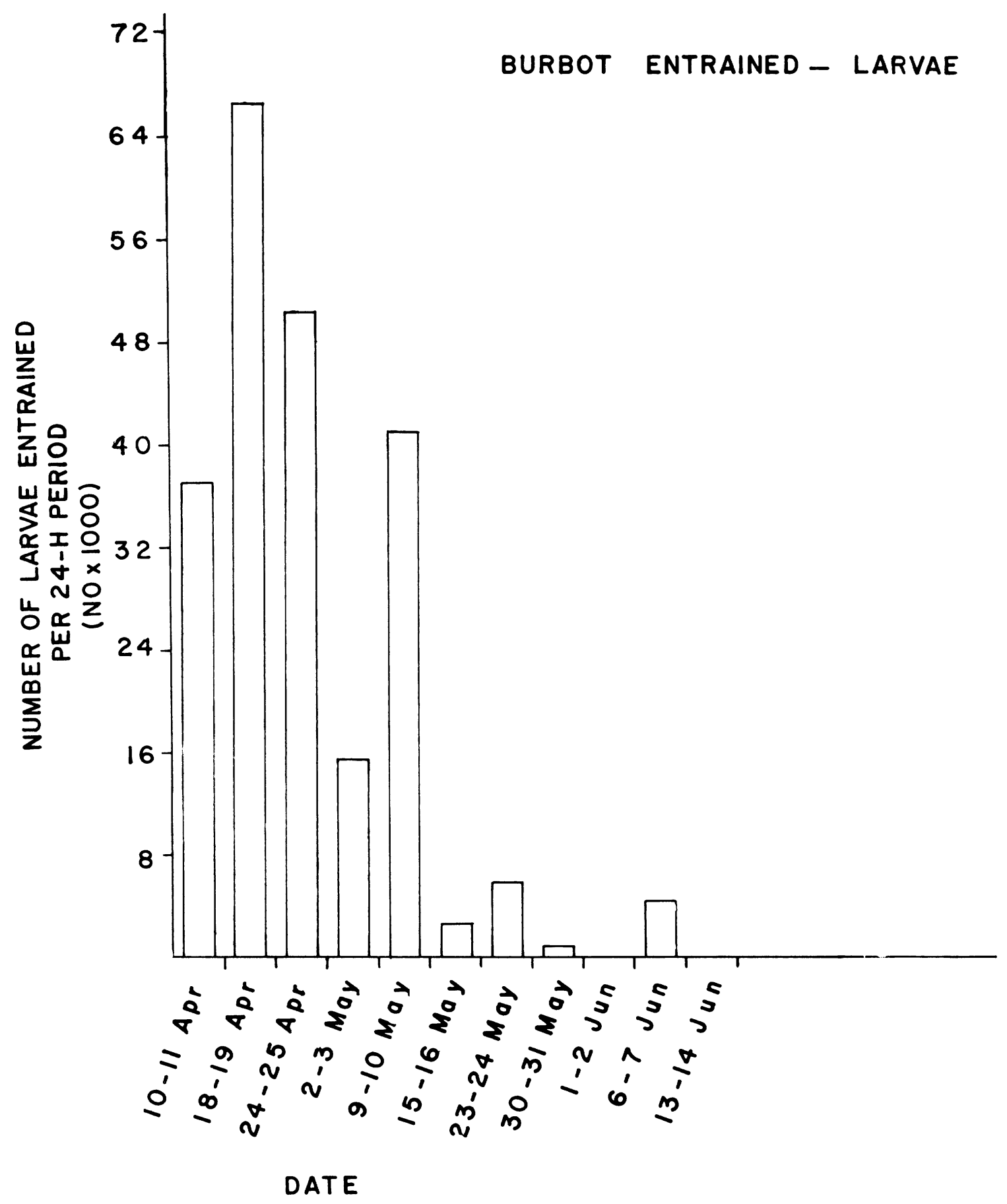

Fig. 147 Total number of larval burbot entrained during a 24-h period projected from densities observed in the 16 samples collected weekly at the J. H. Campbe11 Plant, eastern Lake Michigan, 1978. 
During April burbot larvae were collected most of ten at water temperatures between 6.5 and $8.5 \mathrm{C}$. In May most were taken from water 8.5 to $10.0 \mathrm{C}$ and in June the larvae were too infrequently collected and randomly distributed for any projection to be useful. The larvae collected in April averaged $4.3 \mathrm{~mm}$, those in May $5.0 \mathrm{~mm}$ and those in June $6.3 \mathrm{~mm}$. Temperature and length information coupled with the capture of most burbot larvae at beach and inshore stations indicate that adult burbot moved nearshore in December or early in the year to spawn. The abundant catch of burbot seen in Pigeon Lake as well as entrainment samples may indicate that burbot are using Pigeon Lake and even Pigeon River as a spawning ground. The average length of burbot larvae found during April was only slightly greater than the newly hatched, 4.06-mm larvae Chen (1969) found in April in Alaska. Most burbot larvae captured in plankton net tows were presumably newly hatched as only one individual greater than $6.0 \mathrm{~mm}$ was caught. Most larvae ranged from 4.0 to $5.0 \mathrm{~mm}$. Burbot larger than $5.0 \mathrm{~mm}$ may move into deeper, cooler water or they may be able to avoid sampling gear. This species may be more abundant in the vicinity of the Campbell Plant than adult sampling results indicate.

\section{$\underline{\text { Trout-Perch }}$}

Although trout-perch were one of the more common adult species in the study area, very few trout-perch larvae were collected in 1977 and 1978. A 6.8-mm specimen occurred in a night surface tow at station $W(15 \mathrm{~m}-\mathrm{N})$ on 17 August (Appendix 10). The only other trout-perch larva collected in Lake Michigan in 1978 was a 6-mm larva caught at station $\mathrm{N}(9 \mathrm{~m}-\mathrm{N})$ on 19 September. Calculated trout-perch larvae concentrations for these two samples were respectively 17 and 45 larvae $/ 1000 \mathrm{~m}^{3}$.

Two trout-perch larvae were also captured during entrainment sampling, including a 6-mm larva on 30 May and a 5.4-mm larva on 4 July (Appendix 14). Concentrations of entrained trout-perch larvae were estimated at $3 / 1000 \mathrm{~m}^{3}$ on both dates.

Newly hatched trout-perch are 5.5-6 mm (Jude et al. 1979; Fish 1928) indicating that all trout-perch larvae collected in the study area were newly hatched. Their dates of occurrence confirmed the protracted spawning season of troutperch (from 30 May to 19 September in the Campbell Plant vicinity) also documented in the Adult and Juvenile section.

Trout-perch larvae, like adults, appeared to be mostly confined to the bottom. In Lower Red Lake, Minnesota, YOY trout-perch were caught most commonly near bottom in water 3 to $5 \mathrm{~m}$, from 20 days after hatching until the end of August (Magnuson and Smith 1963). In our study area most trout-perch larvae collected in 1977 and 1978 were captured near the bottom in sled tows. These demersal habits were thought to cause lower catches of trout-perch larvae in southeastern Lake Michigan during 1973 (Jude et al. 1975). Offshore migration of larvae similar to that observed in Lower Red Lake, Minnesota (Magnuson and Smith 1963) probably occurred in our study area and may be in part responsible for low catches of this size group. In addition, the prolonged spawning season of this species may cause trout-perch larvae to always be present in low densities throughout the spawning season. 
$\underline{\text { Fourhorn Sculpin }}$

Very little is known of the reproductive ecology of the fourhorn sculpin in Lake Michigan. Because of the absence of adult specimens in our collections, and hence lack of gonad data, the time of spawning of the species in Lake Michigan can only be inferred from our larvae data as well as studies done in other areas. Khan and Faber (1974) in reviewing unpublished results on the seasonal occurrence and distribution of fourhorn sculpin suggested that this species spawns through winter, spring and early summer. Westin (1969) reported that fourhorn sculpin spawned from mid-December until the end of January. Fourhorn sculpin larvae were first observed in the area of the Campbell Plant in an entrainment sample in early February 1978. The larva observed was $9.1 \mathrm{~mm}$ and its occurrence suggests that spawning occurred sometime in December. Spawning in aquaria was reported by this author to occur at 1.5-2 C, and development lasted 97 days. An average temperature of $4.7 \mathrm{C}$ reduced the time of development to 54 days. Nests are probably over clean sand bottoms of Lake Michigan, as Westin (1970) described nestbuilding by this species over clean sand near the Aska Laboratory near Stockholm. Khan and Faber (1974) indicated that after hatching (minimum length at hatching was $7.6 \mathrm{~mm}$ ), fourhorn sculpin larvae disperse widely into open water. This contention is substantiated by our observations of larval fourhorn sculpin at various distances off the bottom during April and May sampling at both north and south transects in Lake Michigan (Appendixes 10 and 11). Length-frequency data of larvae caught in surface, mid-water and sled tows taken in April (Fig. 148) showed that a wide range of sizes of larvae were present (11 to $18 \mathrm{~mm}$ ) suggesting that fourhorn sculpin have a prolonged spawning season. A relative decrease in the number of small (less than $12 \mathrm{~mm}$ ) larvae in samples taken during May (Fig. 148), suggests that hatching had ceased sometime before February or March. Larval growth rate studies, however, are notably lacking, and it is difficult to determine spawning times from various size larvae.

The highest entrainment of fourhorn sculpin larvae was observed during the 10-11 April and 18-19 April sampling periods when densities of $0-201$ arvae/1000 $\mathrm{m}^{3}$ resulted in the loss of over 17,000 larval sculpins/24 h on 18-19 April and over 12,000 larvae/24-h period on 10-11 April.

No fourhorn sculpin larvae were caught during any sampling period after May, which may suggest that larval fourhorn sculpin migrate offshore in Lake Michigan during summer months. Fish (1932) reported collecting larval fourhorn sculpin from the end of July to mid-August in Lake Erie. It is probable that as the inshore water of Lake Michigan warmed, larger larval fourhorn sculpin move to deeper cooler water and exhibit the demersal, deepwater habit of the juvenile and adult forms.

Unidentified Cottidae

Two occurrences of sculpin larvae which could not be identified to species were observed during 1978. During April one 11-mm sculpin larva was caught at $14-\mathrm{m}$ at station $\mathrm{F}(15 \mathrm{~m}-\mathrm{S})$. In addition an 18-mm sculpin larva was caught in a sled tow at station $F$ in May. Because spines could not be seen on either of these two specimens, they could not be definitely classified as fourhorn sculpin. However, the more elongate form of these larvae, compared to reference larval slimy sculpin, leads us to believe that these larvae were undoubtedly fourhorn 


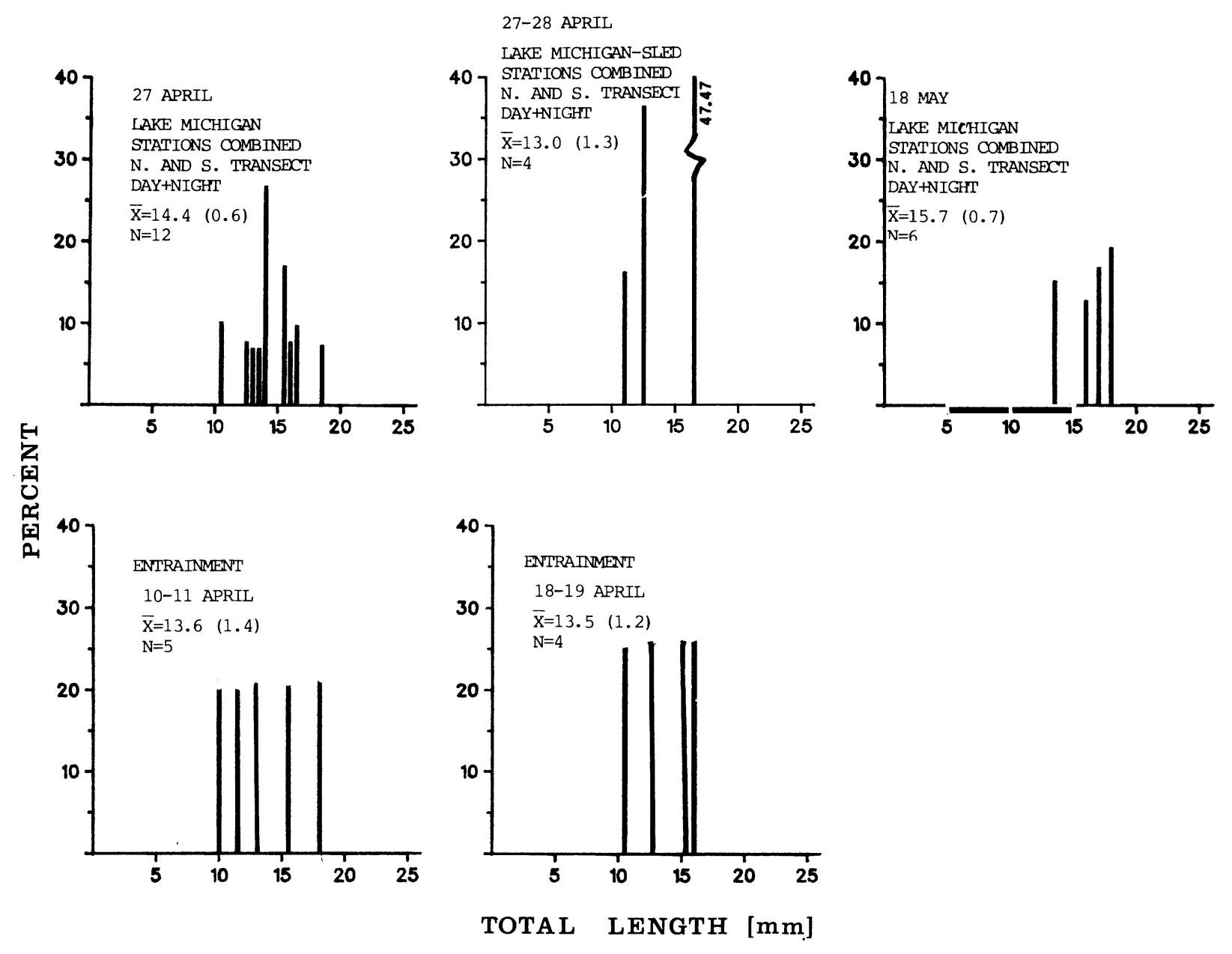

Fig. 148. Length-frequency histograms for larval fourhorn sculpins observed in field and entrainment samples collected during 1978 near the J. H. Campbell Plant, eastern Lake Michigan. All tows were plankton net tows unless sled tows were specified. $\overline{\mathrm{X}}=$ mean, $\mathrm{N}=$ total number of larvae, standard error is given in parentheses. 
sculpin with abnormal preopercular spine formation. Pectoral ray counts were also made which precluded their identification as slimy sculpin. Slimy sculpin, $11 \mathrm{~mm}$ in length, already look much like the adult and are easily identified. A comparison of the lengths of these larvae as well as times and places of capture (see FISH LARVAE AND ENTRAINMENT STUDY - Fourhorn Sculpin) further suggested that those larvae designated as unknown sculpin larvae were probably fourhorn sculpins.

\section{Johnny Darter}

Although johnny darters were common in adult fish samples in the vicinity of the Campbell Plant, only two larvae were collected. A 6.4-mm larva was collected in early August at Lake Michigan station D (9 m - S) from the 8-m depth stratum. Johnny darters are about $5.0 \mathrm{~mm}$ at hatching (Lippson and Moran 1974). Johnny darters spawned during June and July in Lake Michigan (see RESULTS AND DISCUSSION - ADULT AND JUVENILE FISH, Johnny Darter). It is estimated that this larva hatched in late July. One other larva $(6.4 \mathrm{~mm})$ was entrained on 27 June. Since spawning was completed by mid-May in Pigeon Lake (see RESULTS AND DISCUSSION ADULT AND JUVENILE FISH, Johnny Darter) this larva appears to have originated from Lake Michigan.

Two johnny darter fry were collected during 1978. A 31-mm fish was caught at Pigeon Lake beach station S (influenced by Lake Michigan) on 17 May and a 32.5$\mathrm{mm}$ specimen was collected in a sled tow on 20 June at Lake Michigan station C $(6 \mathrm{~m}-\mathrm{S})$. Because of their size at date of capture these fry were undoubtedly yearlings from the 1977 year class.

Because johnny darters spawn in areas having rocks, logs or other objects under which they can deposit their eggs (Winn 1958) our gear is not very effective for sampling johnny darter larvae which resulted in the low number of larval versus adult fish collected.

Ninespine Stickleback

Six ninespine stickleback larvae were collected in 1978 . Three $(7.5-11 \mathrm{~mm})$ were caught in Lake Michigan, one in July and two in August. Three others (6$7.2 \mathrm{~mm}$ ) were taken in entrainment samples collected the last week of May and the first week of June. In contrast to 1977 when nine ninespine stickleback larvae were caught in Pigeon Lake, none were collected there during 1978. Dredging activity at station $\mathrm{S}$ may have resulted in unsuitable habitat for this species. Al-though no larvae were collected, presence of nine ripe-running females during May (see RESULTS AND DISCUSSION - ADULT AND JUVENILE FISH, Ninespine Stickleback) indicates that spawning did occur in Pigeon Lake in late spring.

A 10.7-mm larva was caught in a sled tow on 2 July at Lake Michigan station $\mathrm{J}(3 \mathrm{~m}-\mathrm{S})$, a 7.5-mm larva was recovered from an August day net tow at beach station $P$ and a $11.0-\mathrm{mm}$ specimen was caught in the same manner on 14 August at Lake Michigan station A $(1.5 \mathrm{~m}-\mathrm{S})$ indicating that spawning occurred during June and July in Lake Michigan which was corroborated by gonad development data (see RESULTS AND DISCUSSION - ADULT AND JUVENILE FISH, Ninespine Stickleback). Ninespine sticklebacks spawned in Lake Michigan during the same time period in 1977 (Jude et al. 1978). 
Four ninespine sticklebacks ranging from 35 to $63 \mathrm{~mm}$ were caught in plankton gear during 1978. Two specimens (61 and $63 \mathrm{~mm}$ ) collected during May were adult fish; the $63-\mathrm{mm}$ fish was caught at Lake Michigan beach station $P$ (S reference). A 38.5-mm ninespine stickleback was collected during entrainment sampling on $25 \mathrm{July}$ and a $35-\mathrm{mm}$ fish was caught in the intake canal (station $\mathrm{Z}$ ) on $4 \mathrm{July}$. These fish were most likely the result of April spawning in Pigeon Lake. Griswold and Smith (1973) reported growth of YOY up to $62 \mathrm{~mm}$ by 8 August in Lake Superior.

\section{Unidentified Coregoninae}

Coregonid larvae were uncommon in our 1977 and 1978 larvae samples. Only two larvae were recovered from 1978 field samples; both were taken in 8-m plankton net tows, one at station $\mathrm{W}(15 \mathrm{~m}-\mathrm{N})$ in early June and one at station $\mathrm{F}$ (15 $\mathrm{m}-\mathrm{S}$ ) in late June. The $11-$ and $14.5-\mathrm{mm}$ larvae were taken at water temperatures of 16.8 and $14.5 \mathrm{C}$, respectively. In 1977 one 13.0-mm larva was collected in late June in a $4-\mathrm{m}$ day plankton tow at station F $(15 \mathrm{~m}-\mathrm{S})$.

Three other coregonid larvae were collected, all in entrainment samples taken the third week of April and first week of May 1978. These 11.2- to 14.2-mm larvae were collected in water which ranged between 4.4 and $10 \mathrm{C}$.

Although collection dates of these similar-sized larvae varied, all were probably the result of late winter-early spring, nearshore spawning (Wells 1966; Scott and Crossman 1973). Coregonid larvae caught in June probably strayed from deep water or remained after an upwelling. Wells (1966) collected uniform size larvae, most ranging from 11.0 to $11.3 \mathrm{~mm}$, in April through August sampling. He concluded that larger larvae evaded sampling gear. These small coregonids are probably bloaters because among the four coregonids whose larvae these could be (lake and round whitefish, lake herring and bloaters), bloaters were by far the most frequently captured adult (see Table 13). Recovery of coregonid larvae lends support to the possible increase of bloater populations in the area during 1977 and 1978 (see RESULTS AND DISCUSSION - ADULT AND JUVENILE FISH, Unidentified Coregonids).

\section{Unidentified Catostomidae}

Sucker larvae were collected in the area of the J. H. Campbell Power Plant for the first time in 1978. Larvae were collected during both entrainment and field sampling efforts, all during April and May. Since sampling was not started until June 1977 their presence in the study area that year may have gone undetected.

Larvae identified as suckers probably were either white sucker, adults of which were collected in appreciable numbers during 1978 (319), or longnose sucker, adults of which occurred less frequently (73). Lack of clear descriptions as to the identification of sucker larvae has resulted in these fish being designated sucker larvae. Only four sucker larvae were collected in field samples. Two were collected from Pigeon Lake and two from nearshore Lake Michigan stations. All other sucker larvae occurred in early May entrainment samples.

One unidentified sucker larva, $7.1 \mathrm{~mm}$, was collected in a late April plankton net tow at north transect beach station Q (S discharge). This larva was captured in water $7.0 \mathrm{C}$ and was the only sucker observed in April samples. 
Sucker larvae appeared frequently in May field and entrainment samples. Two were collected at Pigeon Lake beach station S (influenced by Lake Michigan) and one was captured at Lake Michigan station A $(1.5 \mathrm{~m}-\mathrm{S})$. In Pigeon Lake the density of sucker larvae at station S during the day was determined to be 202/ $1000 \mathrm{~m}^{3}$, while the density at night reached $211 / 1000 \mathrm{~m}^{3}$. Water temperature at this time ranged from 12.5 to $14.5 \mathrm{C}$. At Lake Michigan station A $(1.5 \mathrm{~m}-\mathrm{S})$ a night sled tow recovered sucker larvae at a density of $40 / 1000 \mathrm{~m}^{3}$; water temperature was $9.0 \mathrm{C}$.

Sucker larvae were recovered in dawn, dusk and night entrainment samples taken during the first week of May. These larvae were most abundant in dusk $\left(30 / 1000 \mathrm{~m}^{3}\right)$ and dawn samples $\left(12 / 1000 \mathrm{~m}^{3}\right)$; a decrease was observed $\left(7 / 1000 \mathrm{~m}^{3}\right)$ in night samples and none were collected during the day. These larvae were all entrained when water temperatures were between 9.5 and $10.5 \mathrm{C}$; average length was $7.9 \mathrm{~mm}$. Only three larger (greater than $10 \mathrm{~mm}$ ) larvae were captured. All others ranged between 5.0 and $9.1 \mathrm{~mm}$. It may be that these two size groups represent two species - the larger and later occurring larvae being longnose suckers and the smaller earlier occurring larvae being white suckers. According to information gathered by Scott and Crossman (1973) longnose suckers spawn before white suckers, usually from mid-April through mid-May. Since the majority of unidentified sucker larvae occurred in Pigeon Lake and entrainment samples it may be assumed that these larvae were the result of adult sucker spawning in Pigeon Lake or more likely Pigeon River. No longnose suckers were caught in Pigeon Lake during 1.978, while six white suckers were collected there.

\section{Logperch}

One larva ( $6 \mathrm{~mm})$, tentatively identified as a logperch, was collected during early July in Lake Michigan. This fish was captured in a 6-m, night, plankton net tow at station $\mathrm{E}(12 \mathrm{~m}-\mathrm{S})$. Water temperature at time of capture was $17.9 \mathrm{C}$.

According to Scott and Crossman (1973) logperch spawn during June. This species is thought to normally inhabit offshore water deeper than $1-1.3 \mathrm{~m}$. Although no logperch adults were recovered in field sampling efforts during 1978, seven adult logperch were collected from impingement samples during January through May 1978 (see RESULTS AND DISCUSSION - ADULT AND JUVENILE FISH, Logperch). One logperch was also observed in an October impingement sample in 1977 (Zeitoun et al. 1978).

The logperch larva collected was only tentatively identified as a logperch, since larval logperch can be easily confused with larval johnny darters and troutperch. In addition, turbidity and handling can affect pigmentation concentrations, one of the primary diagnostic characteristics of these species.

\section{Gizzard Shad}

As seen in Appendix 14, ten larvae (ranging in length from 4.1 to $9.0 \mathrm{~mm}$ ) were determined to be gizzard shad. As previously mentioned in the larval alewife section, confusion and difficulty exists in distinguishing the larvae of such closely related species. Several keys (Wang and Kernehan 1979; Lippson and Moran 1974) describe and illustrate the differences between these species, however from the time the fish are $9.0 \mathrm{~mm}$ to the time full fin ray development takes place, distinctions are difficult. Adult gizzard shad are abundant in the area, especially 
the discharge canal (see RESULTS AND DISCUSSION - ADULT AND JUVENILE FISH, Gizzard Shad). All ten gizzard shad larvae were collected in entrainment samples during May, June,-July and August 1978 (Appendix 14). A plankton net tow taken in the Grand River, Grand Haven, Michigan on 22 June 1978 contained many gizzard shad larvae.

\section{Brook Silverside}

In contrast to our 1977 study (Jude et al. 1978) when 22 brook silverside larvae were caught, none were collected in 1978. In 1977 nearly all silverside larvae were caught at Pigeon Lake station $\mathrm{T}$ (influenced by the Pigeon River). Deletion of this station resulted in the absence of brook silverside larvae from 1978 collections. The weedy, somewhat more turbid waters of station $\mathrm{T}$ were found to be the preferred habitat of this species (Jude et al. 1978).

A 64.5-mm brook silverside was caught in a larvae tow at Pigeon Lake beach station $\mathrm{V}$ on 18 0ctober. This fish was most likely a YOY. Growth of silversides is extremely rapid. The young hatch and grow to their maximum size ( $89 \mathrm{~mm})$ the same year (Scott and Crossman 1973). In southeastern Michigan Hubbs (1921) observed that spawning commenced in May and extended into July.

\section{Brown Bullhead}

Brown bullhead is a common species in Pigeon Lake, however, larval brown bullhead have never been collected in the study area. During 1978, one 64-mm brown bullhead was entrained on 1 August. Compared to brown bullheads 44 and 46 $\mathrm{mm}$ collected in May and June (see RESULTS AND DISCUSSION - ADULT AND JUVENILE FISH, Brown Bullhead) this specimen was probably 1-yr old.

Damaged Larvae

Introduction--

Damaged larvae were those larvae which could not be identified due to physical damage to the specimens. Abrasion with the net and its contents, particularly macrophytes and sand, probably caused most of the damage. Occurrence of damaged larvae was generally low in 1977 and presence of these larvae was felt not to bias abundance estimates of known species (Jude et al. 1978); however, in 1978 occurrence of damaged larvae increased significantly. The density of damaged larvae for any one sample was usually low compared to the density of identified larvae within the same sample.

Seasonal Distribution--

May-- During May five damaged larvae were recovered from samples taken at Pigeon Lake beach station $\mathrm{V}$ (undisturbed Pigeon Lake) and one was observed in a night plankton net tow at station M (influenced by Lake Michigan) (Fig. 149). All were probably yellow perch as this was the only larval species detected in Pigeon Lake in May. High densities of perch were found at all Pigeon Lake stations (Appendix 13 and see RESULTS AND DISCUSSION - FISH LARVAE AND ENTRAINMENT STUDY, Yellow Perch). 

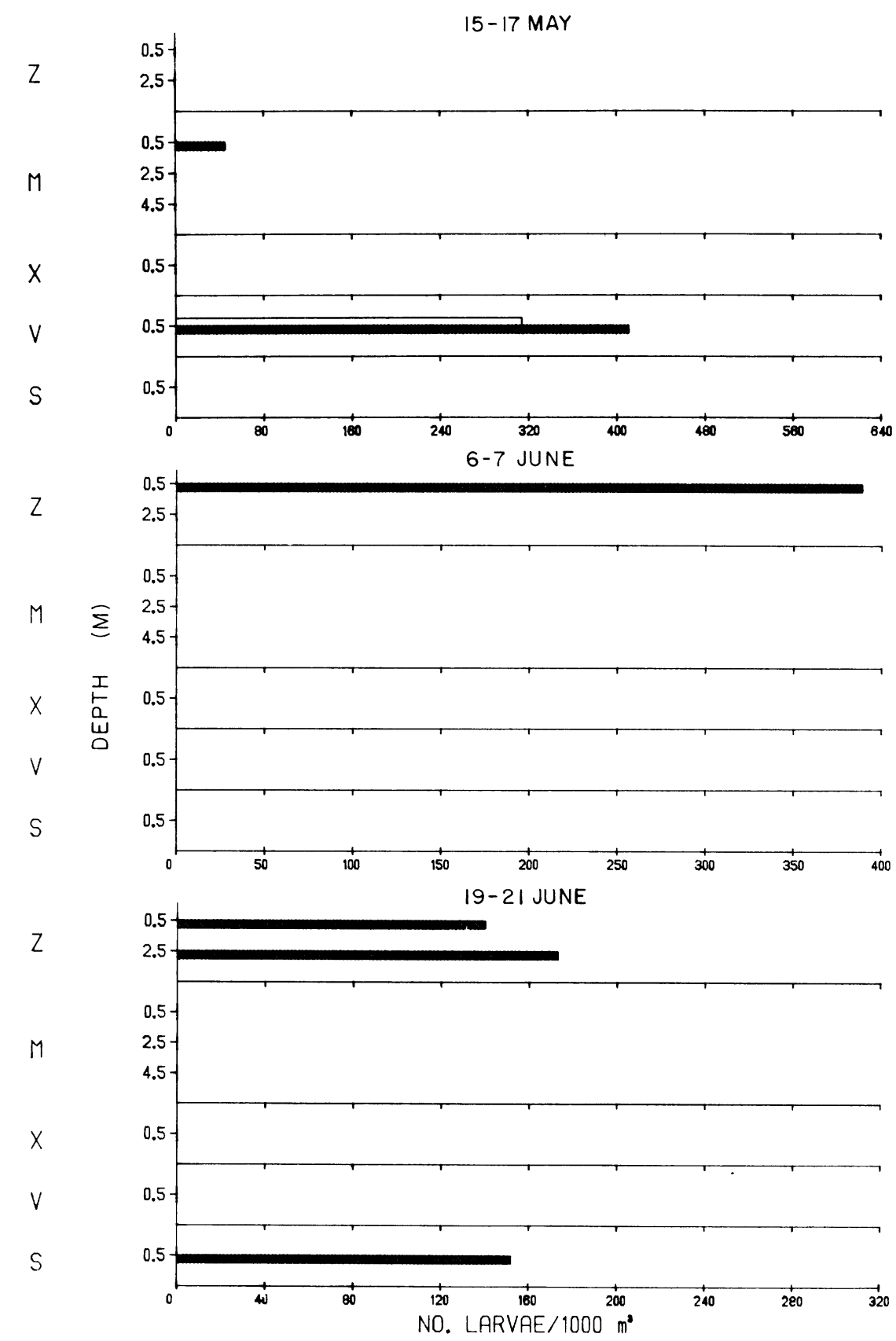

Fig. 149. Density of damaged larvae (no./1000 $\mathrm{m}^{3}$ ) at Pigeon Lake and intake canal stations near the J. H. Campbell Plant, eastern Lake Michigan April to September 1978.

$$
\square=\text { day } \square=\text { night }
$$



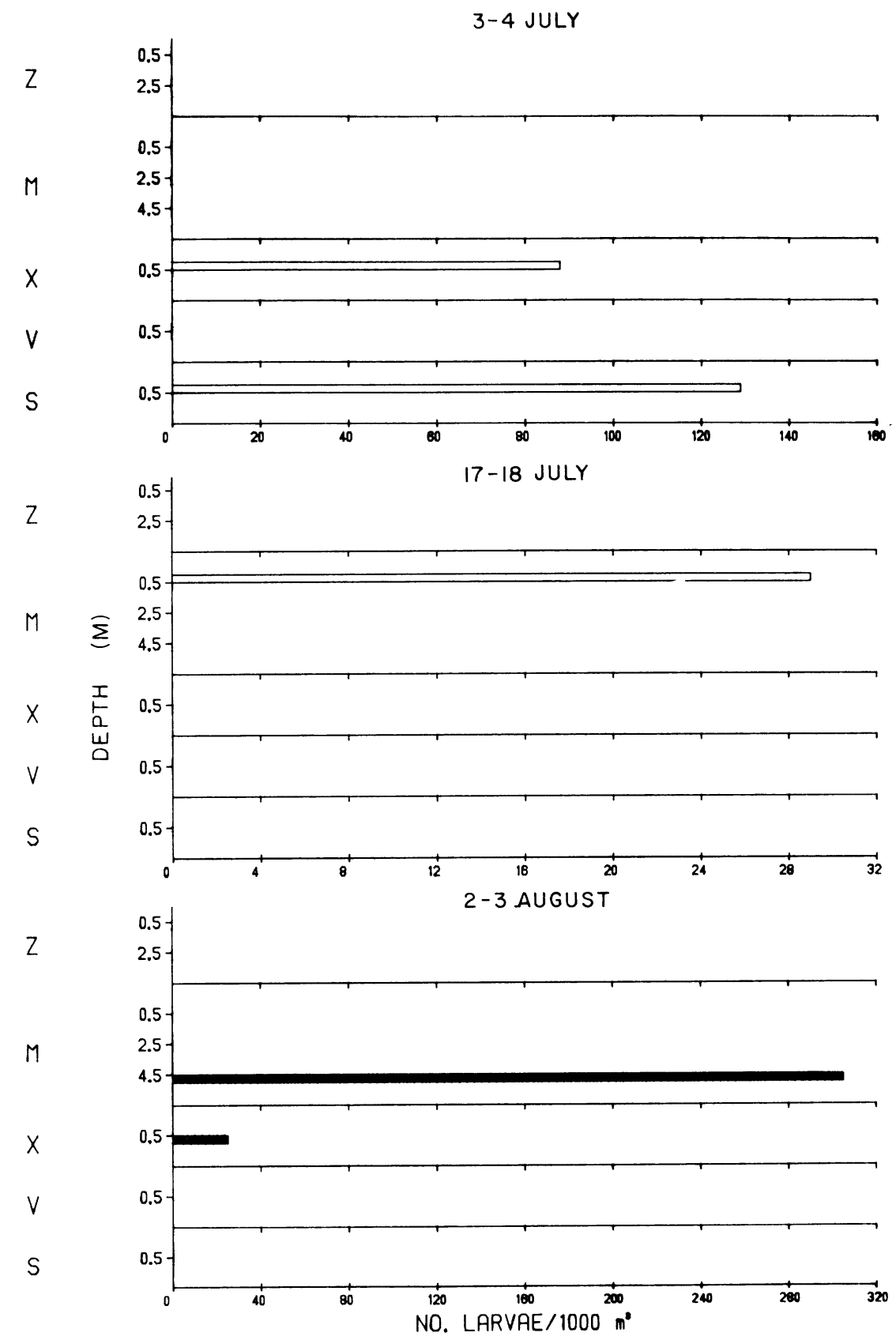

Fig. 149. Continued. 


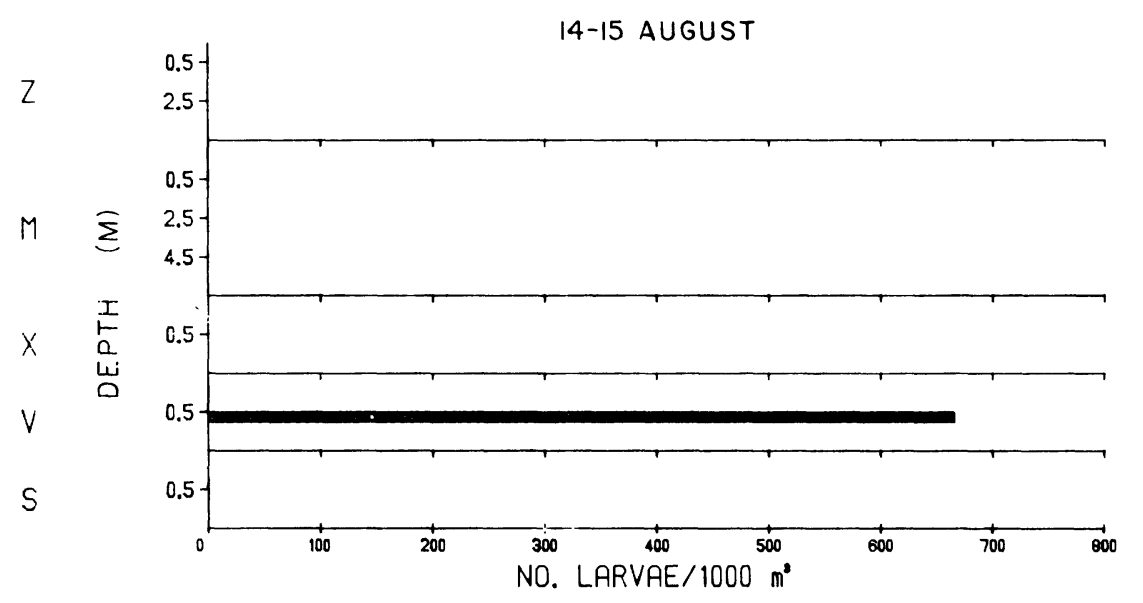

Fig. 149. Continued.

In Lake Michigan, four damaged larvae were recovered during May, all from south transect station samples. One larva was in a plankton net tow at beach station $\mathrm{P}$ (S reference), two were found in a sled tow sample taken at station A $(1.5 \mathrm{~m}-\mathrm{S})$ and one occurred in a surface net tow at station D (9 $\mathrm{m}-\mathrm{S})$ (Fig. 150). Again all these were believed to be yellow perch. Since high concentrations of yellow perch larvae were observed there in May (Fig. 122) presence of a few damaged larvae should not bias conclusions.

June-- During the early June sampling period, the number of damaged larvae collected increased in Lake Michigan samples. No damaged larvae were seen in early June Pigeon Lake samples. Two damaged larvae were recovered from a night surface tow taken at station Z (intake canal) (Fig. 149). These two large larvae, 15 and $8 \mathrm{~mm}$, may have been those of carp or an unknown minnow as larvae of similar lengths were found in intake and station M samples.

In Lake Michigan damaged larvae occurred in net samples from both the north and south transect. No damaged larvae were noted in sled tow samples. Along the south transect one damaged larva was recovered at each of the following stations: B $(3 \mathrm{~m}-\mathrm{S}), \mathrm{C}(6 \mathrm{~m}-\mathrm{S}), \mathrm{D}(9 \mathrm{~m}-\mathrm{S})$ and $\mathrm{F}(15 \mathrm{~m}-\mathrm{S})$ (Fig. 151). Larvae collected at stations $B, C$ and $D$ were felt to be alewife. All were small, 3.5 to $5.0 \mathrm{~mm}$, and all were recovered from samples in which alewife larvae predominated. The other damaged larva, collected at station F, may have been a smelt, as it was considerably larger than the others, $9.5 \mathrm{~mm}$. Other deepwater samples at this same time and transect contained larval smelt 6.5 to $15.0 \mathrm{~mm}$.

Along the north transect, nine damaged larvae were observed in early June samples. Two were detected in a night tow and two were observed in a day sled tow; both were collected at beach station Q (S discharge) (Fig. 151). The two small specimens $(3.5 \mathrm{~mm})$ present in the sled tow were believed to be alewife, as 


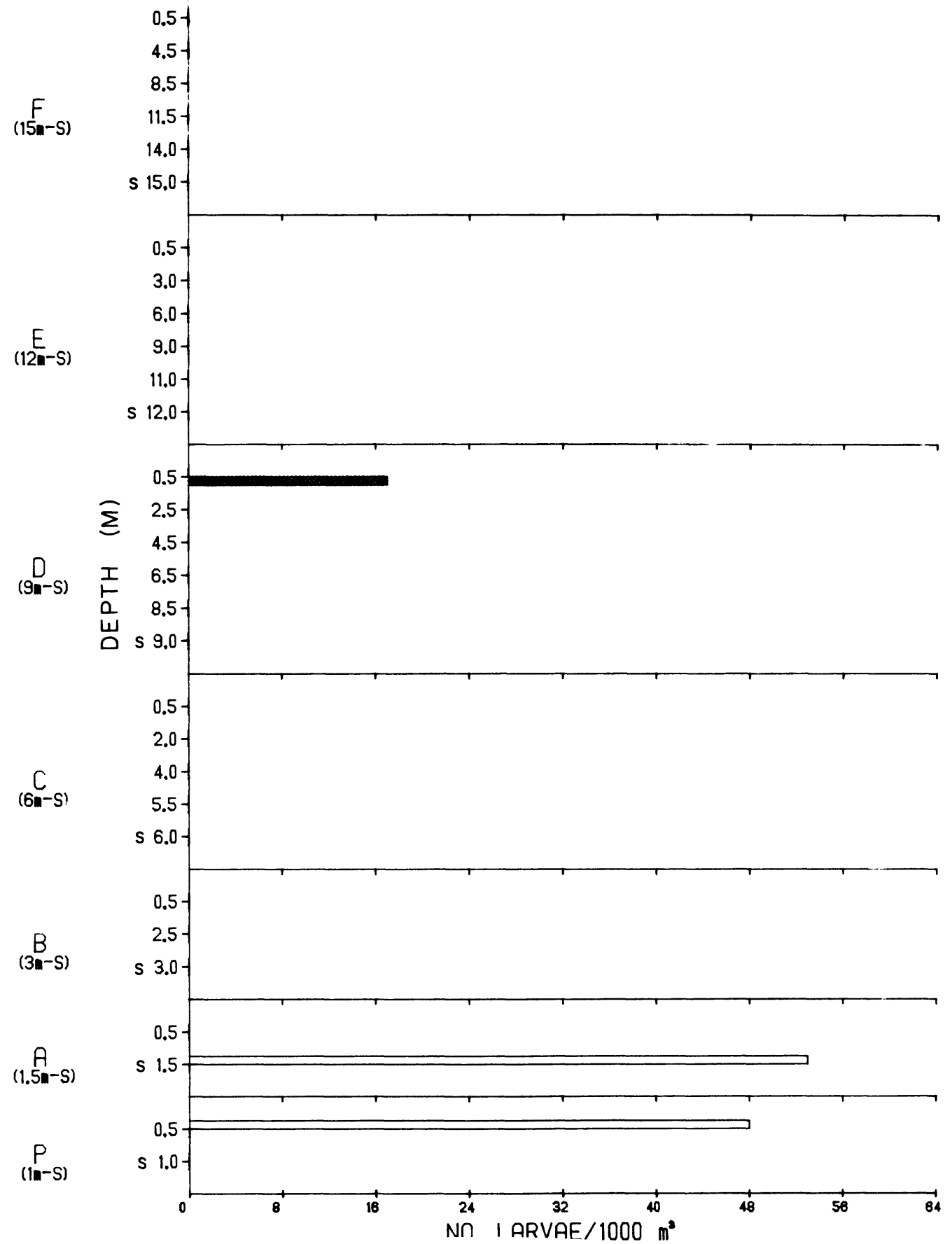

Fig. 150. Density of damaged larvae (no./1000 $\mathrm{m}^{3}$ ) at Lake Michigan stations near the J. H. Campbell Plant, eastern Lake Michigan, 15-18 May 1978. $\square=$ day $\square=$ night $\mathrm{S}=$ sled 


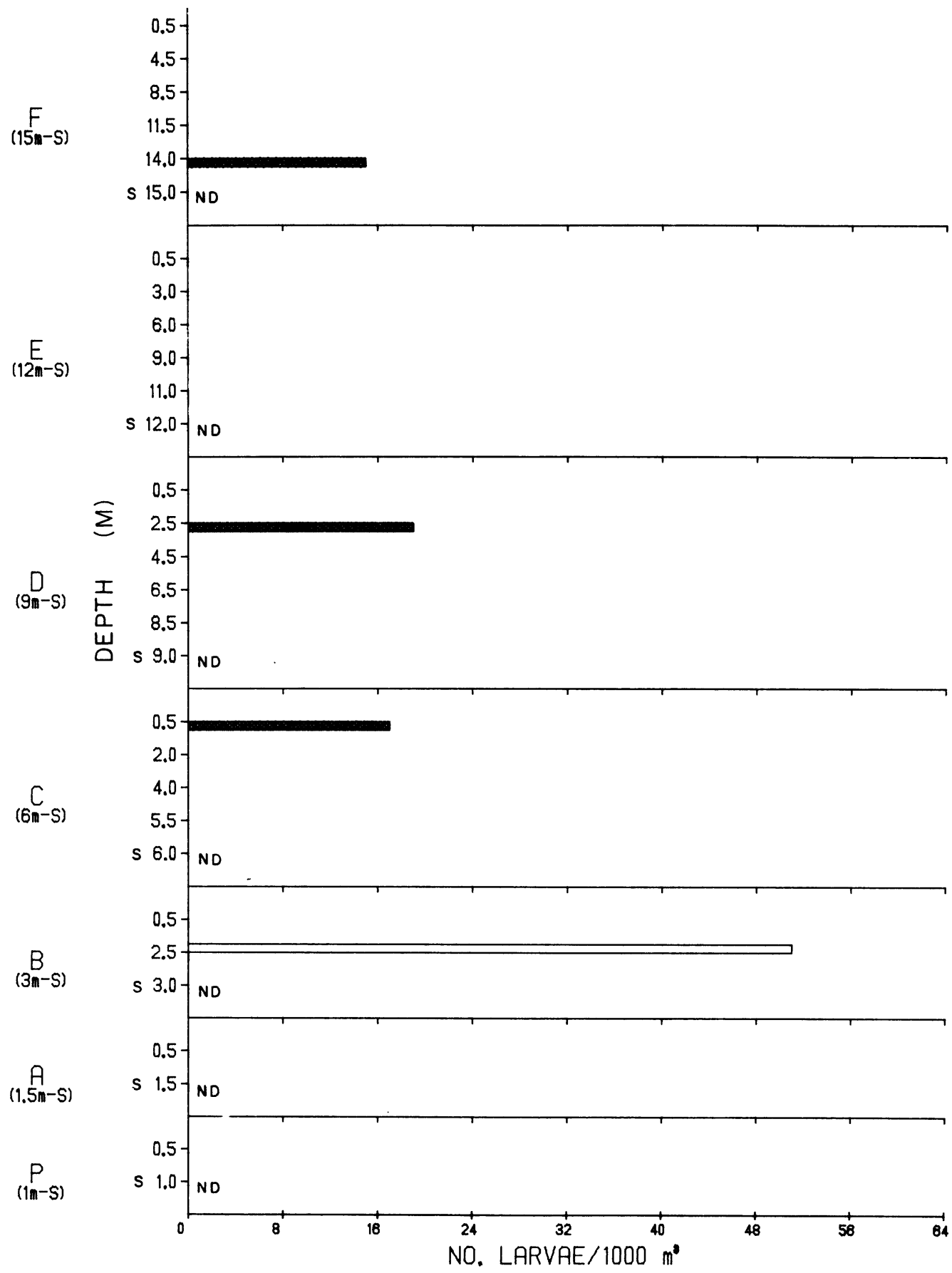

Fig. 151. Density of damaged larvae (no./1000 $\mathrm{m}^{3}$ ) at Iake Michigan stations near the J. H. Camphell Plant, eastern Lake Michigan, 5-7 June 1978. $\square=$ day $\square=$ night $S=$ sled $\quad N D=$ no data 


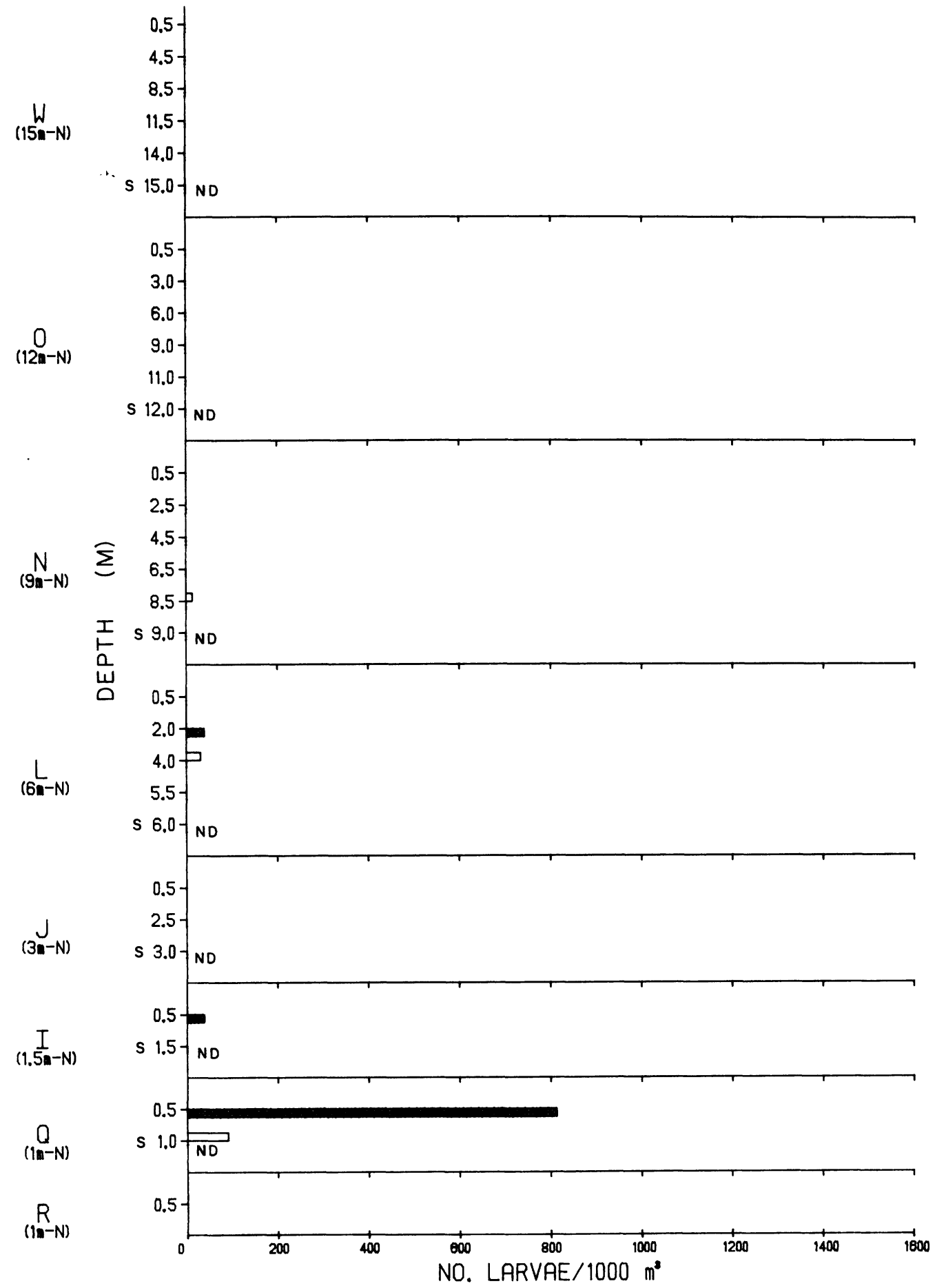

Fig. 151. Continued. 
larvae this size were abundant in the sample. The two larger individuals (5.0 $\mathrm{mm}$ ) caught in the plankton net were felt to be unidentified minnows, possibly spottail larvae which were also recovered in the sample.

The five remaining damaged larvae collected in early June were taken from samples collected at station $\mathrm{I}(1.5 \mathrm{~m}-\mathrm{N}), \mathrm{L}(6 \mathrm{~m}-\mathrm{N})$ and $\mathrm{N}(9 \mathrm{~m}-\mathrm{N})$. All were small larvae 3.0 to $5.0 \mathrm{~mm}$ and all occurred in samples in which alewife larvae were dominant.

During late June (19-22) only one damaged larva was observed in Pigeon Lake. The 9.2-mm larva was observed in a night plankton net tow collected at beach station S (influenced by Lake Michgan) (Fig. 152). No other larvae oscurred in this sample, however in both day samples collected at station $\mathrm{S}$ high concentrations of unindentified minnow larvae were present.
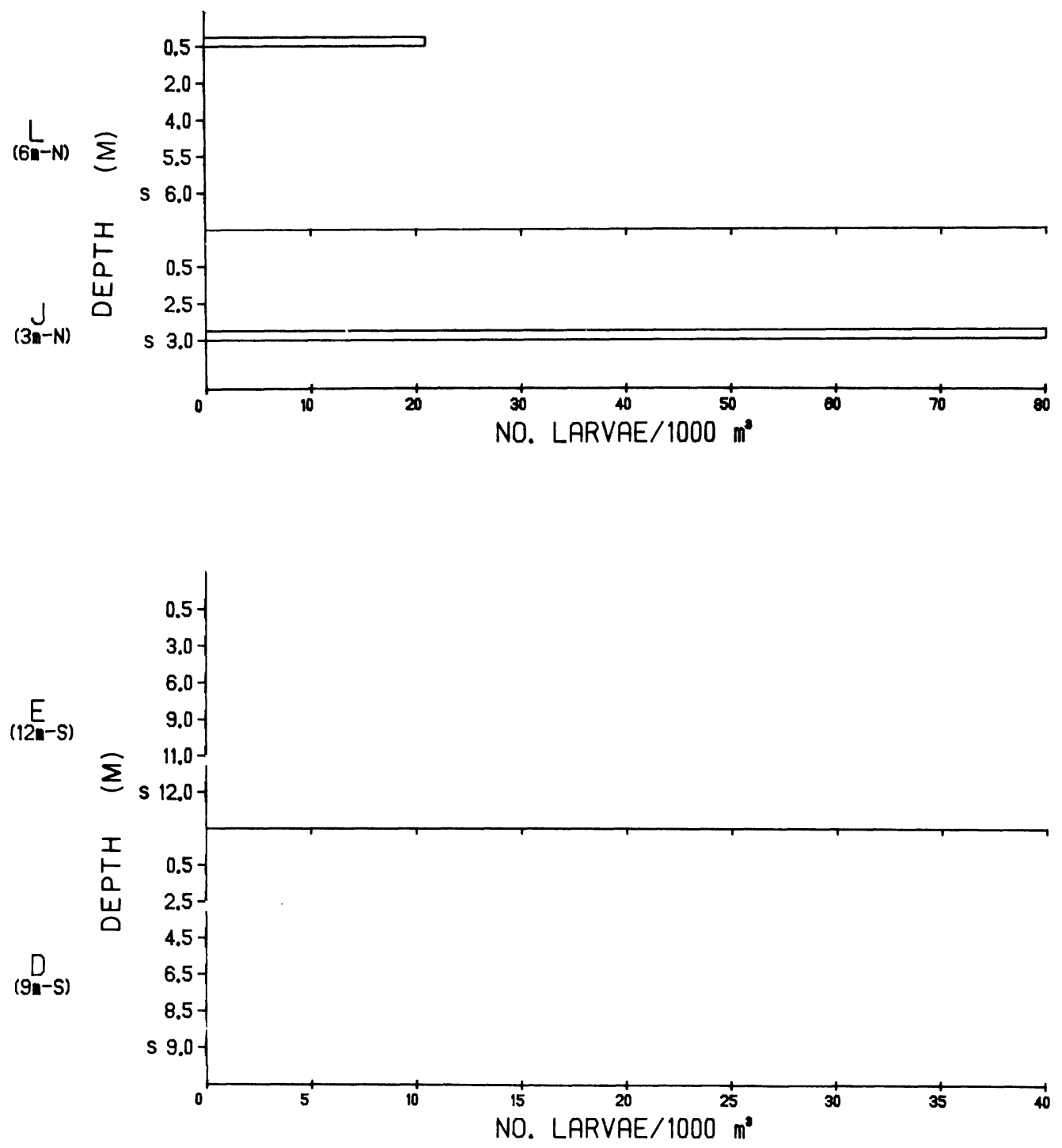

Fig. 152. Density of damaged larvae (no./1000 $\mathrm{m}^{3}$ ) at Lake Michigan stations near the J. H. Campbell Plant, eastern Lake Michigan, 19-22 June 1978. Stations $1-6 \mathrm{~m}$ and $15 \mathrm{~m} \mathrm{~S}$ as well as $1-1.5 \mathrm{~m}$ and $9-15 \mathrm{~m} \mathrm{~N}$ were omitted due to absence of larvae in samples. $\square=$ day $\square=$ night $\mathrm{S}=$ sled 
Four damaged larvae also were noted in a night station $\mathrm{Z}$ (intake canal) sample collected during late June. These larvae ranged from 3.0 to $5.0 \mathrm{~mm}$ and may have been larval alewife; however, the only other species collected in intake canal tows during this week was that of a 6-mm carp (Fig. 149).

Only five damaged larvae were recovered in Lake Michigan samples from late June (Fig. 152). These were present at south transect stations; one in a night tow at station $D(9 \mathrm{~m}-\mathrm{S})$ and two in a night tow at $E(12 \mathrm{~m}-\mathrm{S})$. All three of these larvae were believed to be yellow perch since this was the only species of larvae of similar size, 4.5 to $5.0 \mathrm{~mm}$. caught at these stations. Along the north transect a damaged larva was reported in a day sled tow at station $\mathrm{J}(3 \mathrm{~m}-\mathrm{N})$ and another was seen in a day plankton tow at station $\mathrm{L}(6 \mathrm{~m}-\mathrm{N})$ (Fig. 152). Both larvae were small, 3.0 to $4.0 \mathrm{~mm}$, and therefore probably alewife larvae. Although smelt larvae were most abundant at this time and at these stations, they were larger in size, 5.0 to $7.5 \mathrm{~mm}$.

July-- Most damaged larvae recorded in 1977 were observed in July samples. This was true for 1978, however only for Lake Michigan. No damaged larvae were seen in intake canal samples and only three occurred in Pigeon Lake samples.

In early July a 15-mm damaged larva was observed in a day sample at beach station S (influenced by Lake Michigan) (Fig. 149) and a 6-mm larva was found in a day sample at station $X$ (undisturbed Pigeon Lake). As can be seen in Appendix 14 the larva collected at station $\mathrm{S}$ is probably that of a minnow, while the one collected at station $\mathrm{X}$ may be a yellow perch larva.

In Lake Michigan during early July, 97 damaged larvae were observed in samples collected along the south transect and 69 were found in north transect samples (Fig. 153). Along the south transect highest concentrations occurred at stations $\mathrm{C}(6 \mathrm{~m}-\mathrm{S}), \mathrm{D}(9 \mathrm{~m}-\mathrm{S})$ and $\mathrm{E}(12 \mathrm{~m}-\mathrm{S})$ during surface to 3-m day plankton net tows. At the north transect the highest concentration of damaged larvae occurred at night in a $2-\mathrm{m}$ tow at station $\mathrm{N}(9 \mathrm{~m}-\mathrm{N})$. At south transect stations length of damaged larvae ranged from 3.0 to $5.0 \mathrm{~mm}$. These larvae were probably all alewives since they dominated samples at this time. Damaged larvae along the north transect ranged mostly from 3.0 to $5.0 \mathrm{~mm}$, however two larvae were greater than $5.0 \mathrm{~mm}$. These $7.0-$ and $10.0-\mathrm{mm}$ larvae were both taken at station 0 $(12 \mathrm{~m}-\mathrm{S})$. The small larvae are probably alewives, but the two larger larvae are undoubtedly those of smelt; other smelt larvae greater than $5.0 \mathrm{~mm}$ were recovered from samples taken at similar depths.

During 17-18 July one 6-mm larva was collected at Pigeon Lake station M (influenced by Lake Michigan) (Fig. 149). Due to lack of any other larvae in this sample or those collected in late July it is difficult to speculate what species this larva was.

In Lake Michigan during mid-July only 15 damaged larvae occurred in samples collected at south transect stations C $(6 \mathrm{~m}-\mathrm{S}), \mathrm{D}(9 \mathrm{~m}-\mathrm{S}), \mathrm{E}(12 \mathrm{~m}-\mathrm{S})$ and $\mathrm{F}(15 \mathrm{~m}-\mathrm{S})$. In sampling at north transect stations $\mathrm{I}(1.5 \mathrm{~m}-\mathrm{N}), \mathrm{L}(6 \mathrm{~m}-\mathrm{N})$, $\mathrm{N}(9 \mathrm{~m}-\mathrm{N})$ and $\mathrm{O}(12 \mathrm{~m}-\mathrm{N})$ seven damaged larvae were recovered (Fig. 154). Highest densities occurred at station $\mathrm{N}$ during the day in the north and at station $\mathrm{E}$ during the night at the south transect. These larvae collected in late July 


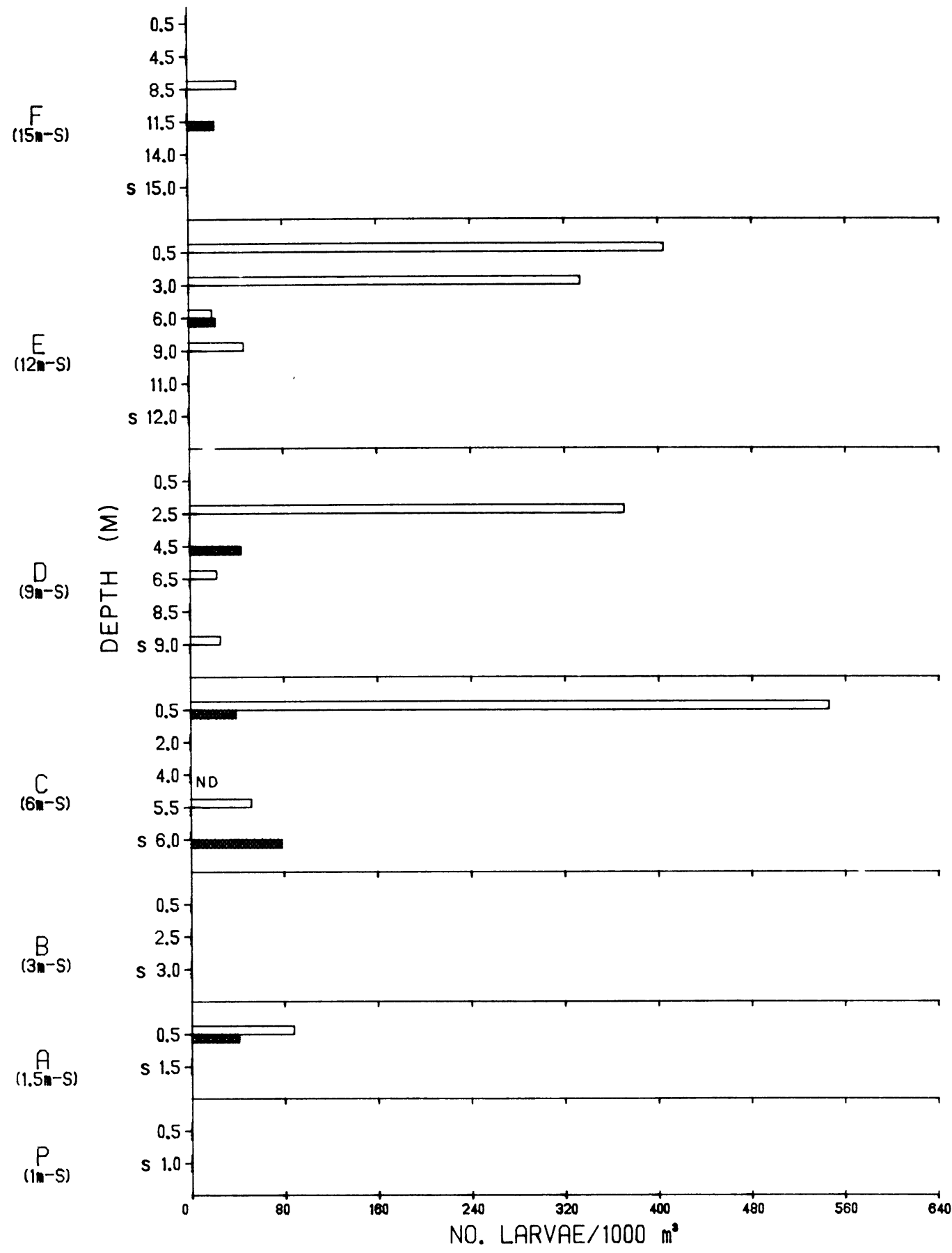

Fig. 153. Density of damaged larvae (no./1000 $\mathrm{m}^{3}$ ) at Iake Michigan stations near the J. H. Campbell Plant, eastern Lake Michigan, 1-3 July 1978.

$\square=$ day $\square=$ night $S=$ sled $\quad \mathrm{ND}=$ no data 


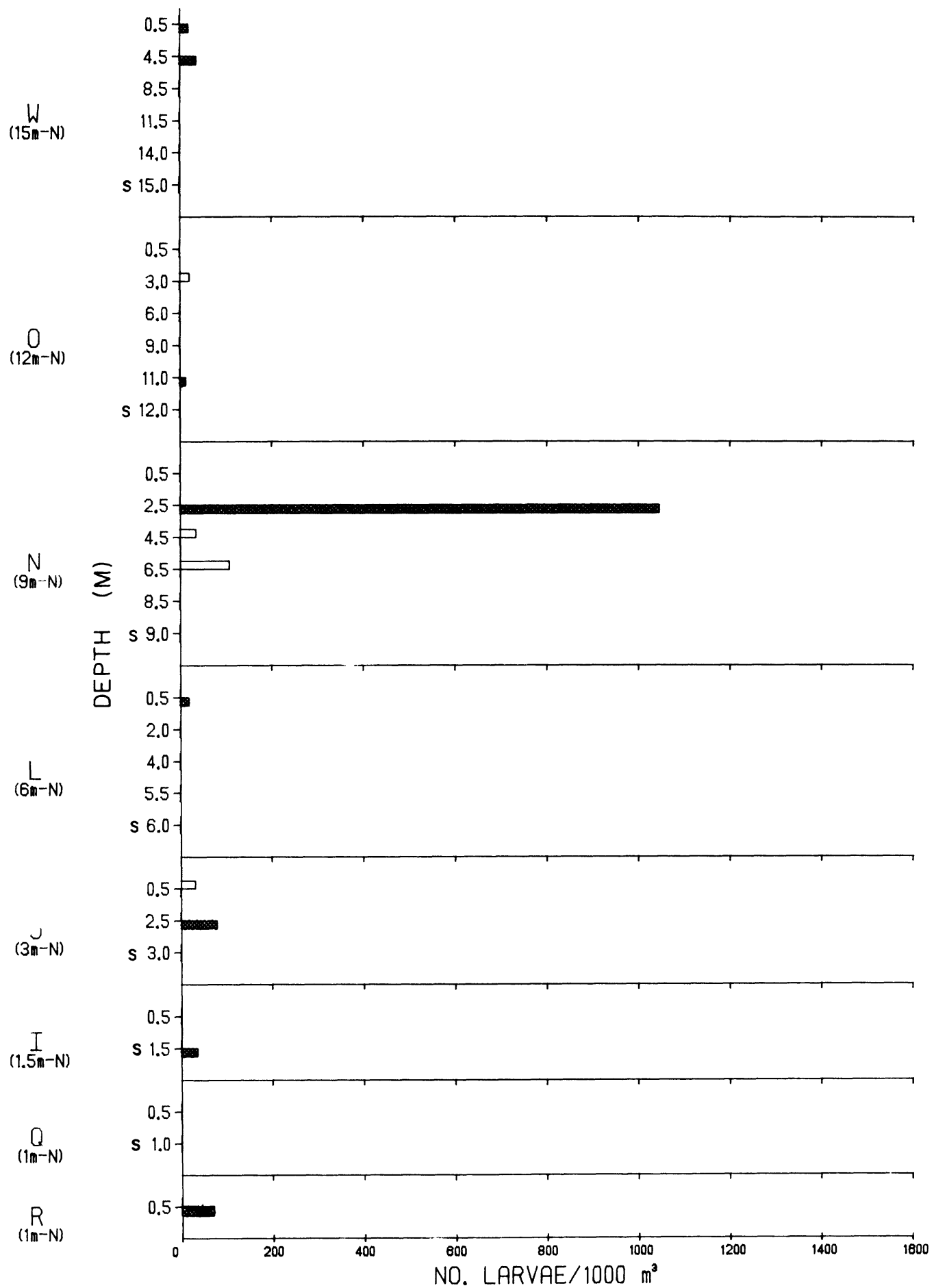

Fig. 153. Continued. 


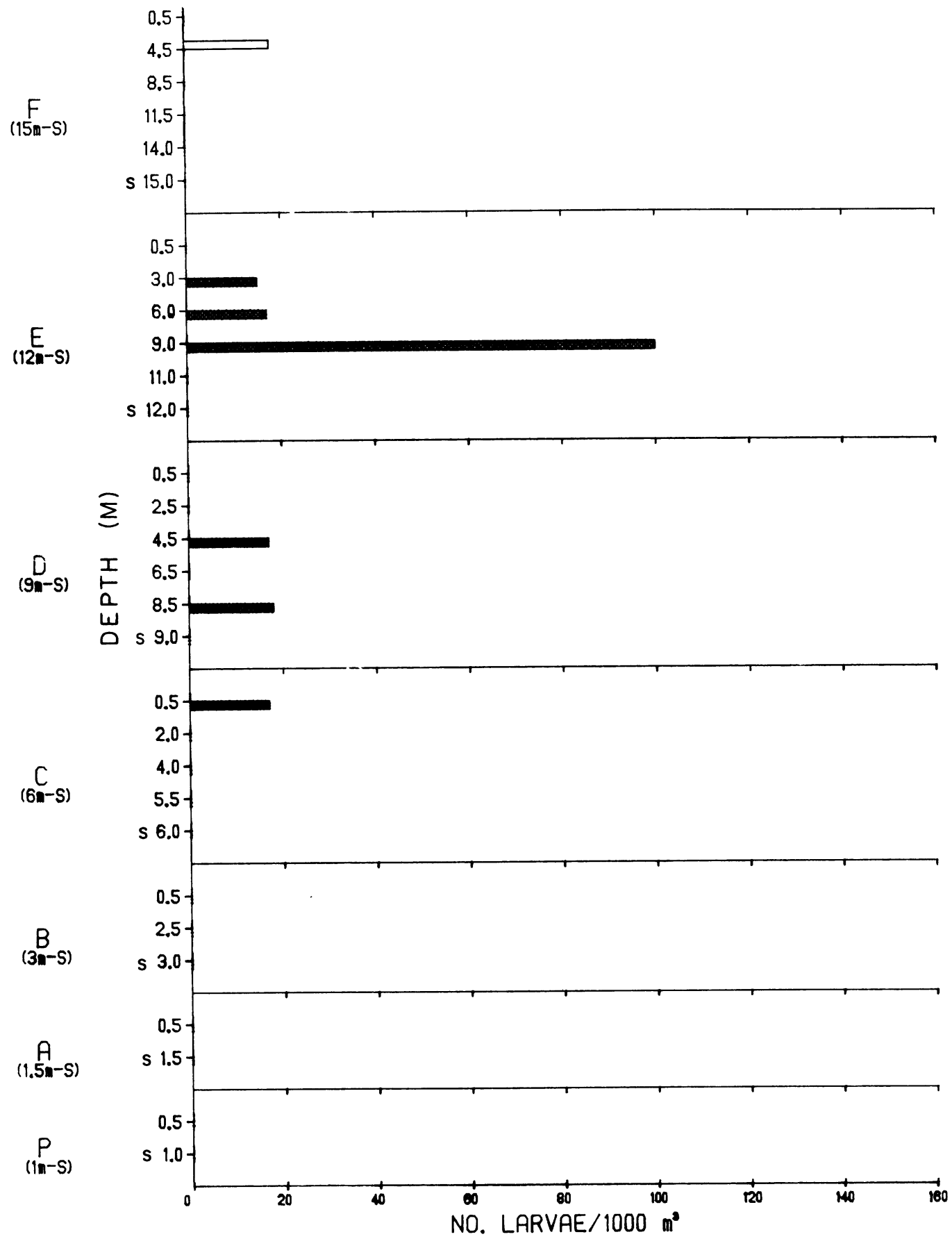

Fig. 154. Density of damaged larvae (no./1000 $\mathrm{m}^{3}$ ) at Lake Michigan stations near the J. H. Campbell Plant, eastern Lake Michigan, 17-19 July 1978.

$\square=$ day $\square=$ night $S=$ sled 


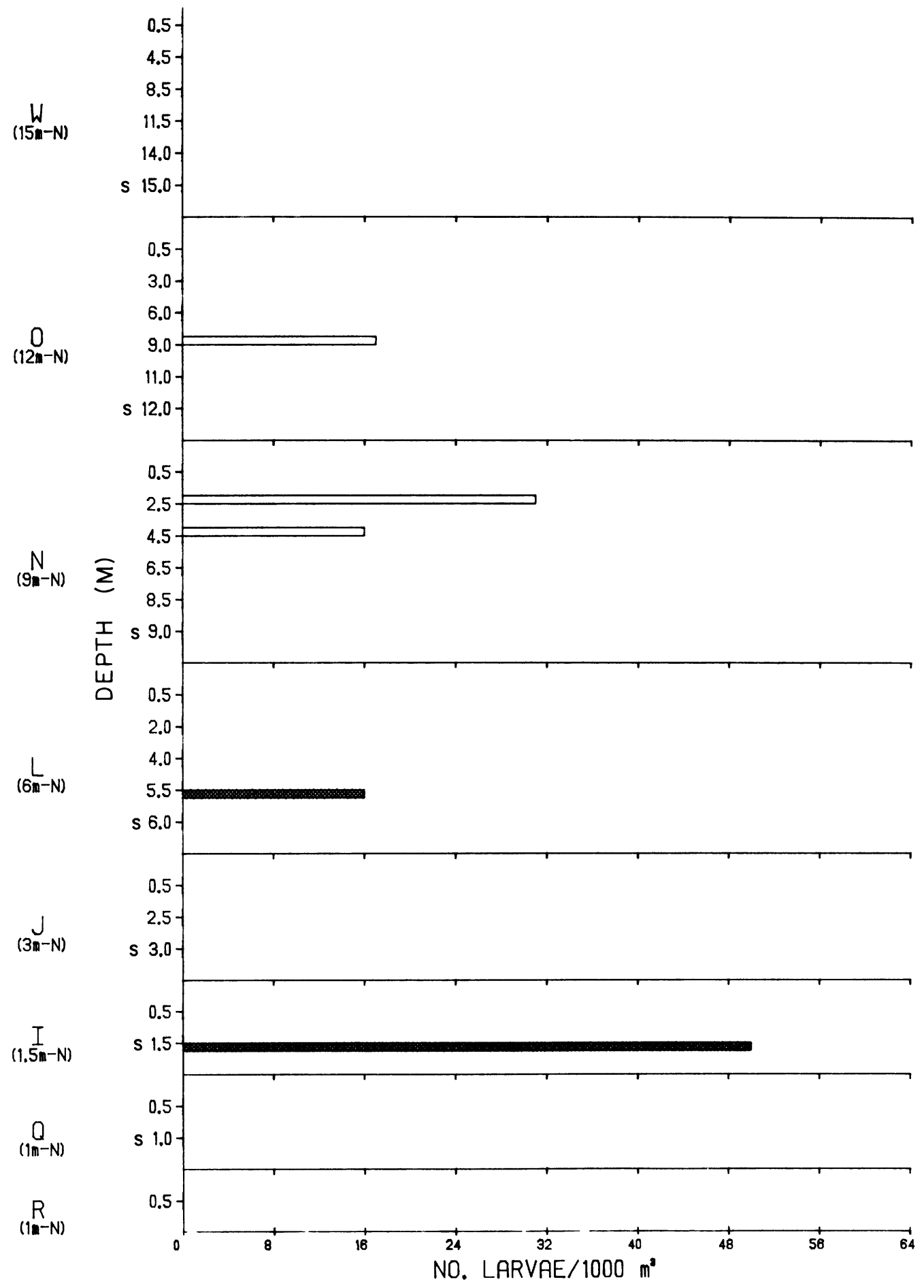

Fig. 154. Continued. 
ranged in length from 3 to $10 \mathrm{~mm}$; most were $5 \mathrm{~mm}$ or longer. At this point in time it is highly probable that these larvae were all larval alewife.

August-- In early August, damaged larvae occurred in samples taken at Pigeon Lake station $M$ (influenced by Lake Michigan) and $\mathrm{X}$ (undisturbed Pigeon Lake) (Fig. 149). Nine larvae $(4.5$ to $22 \mathrm{~mm}$ ) were designated damaged in a 4-m, night tow at station $M$ and one $20-\mathrm{mm}$ larva was found in a surface night tow at station $\mathrm{X}$. Although lengths varied, species composition data indicated these larvae were probably alewife.

In Lake Michigan during early August, 33 damaged larvae occurred at all south transect stations except E (12 m - S) (Fig. 155). On1y 14 damaged larvae were seen in samples collected at north transect stations. Here larval damage was evident at all stations except beach stations Q (S discharga) and R (N discharge). At south transect stations larvae ranged in length from 4 to $24 \mathrm{~mm}$ and most (25) of the 33 were damaged during sled tow sampling. At the north transect damaged larvae ranged in length from 3 to $13.2 \mathrm{~mm}$ and only three larvae were damaged in sled tow samples. As can be seen in Appendixes 10-12, these larvae were again probably alewife.

In late August, 17 damaged larvae occurred in samples taken at station $\mathrm{C}$ $(6 \mathrm{~m}-\mathrm{S}), \mathrm{D}(9 \mathrm{~m}-\mathrm{S})$ and $\mathrm{F}(15 \mathrm{~m}-\mathrm{S})$ along the south transect, while 45 were discerned in samples taken at north transect stations $\mathrm{L}(6 \mathrm{~m}-\mathrm{N})$ and $\mathrm{N}(9 \mathrm{~m}-\mathrm{N})$ (Fig. 156). Lengths ranged from 3.0 to $14.0 \mathrm{~mm}$, except for a 19.0-mm larva collected in a sled tow at station $C(6 \mathrm{~m}-\mathrm{S})$. Again viewing the numbers and densities of other species collected at this time it can be assumed these larvae were alewife.

In Pigeon Lake during late August only one damaged larva was observed, a 4.5-mm specimen taken in a night surface tow at beach station $\mathrm{V}$ (undisturbed Pigeon Lake) (Fig. 149). We believe this larva was probably an alewife. These were all the damaged larvae found in field samples. Throughout the rest of 1978 damaged larvae occurred only in entrainment samples.

Entrainment--

Damaged larvae (718 of 23,581 collected) were much more frequent in 1978 entrainment samples than in those of 1977 when only 9 larvae were found to be damaged beyond recognition. In May, 122 damaged larvae were observed in samples taken during each of the five sampling periods (Fig. 157). These larvae were felt to be yellow perch as this was the most abundant larval species in the area during May. A few of the damaged specimens may have been larval burbot, the only other species occurring in significant numbers, especially during the second sampling period. However burbot usually occurred at lengths less than $5.0 \mathrm{~mm}$; whereas, most damaged larvae were greater than $5.0 \mathrm{~mm}$.

June-- In June damaged larvae were recovered from entrainment samples co1lected at each of the four sampling times during the first 3 wk and in dawn, dusk and night samples taken during the fifth week of June (Fig. 157). These 82 damaged larvae observed ranged from 2.9 to $10.1 \mathrm{~mm}$. They could be smelt, yellow perch, alewife or even Pomoxis larvae as all were present in entrainment samples during June (Appendix 14). 


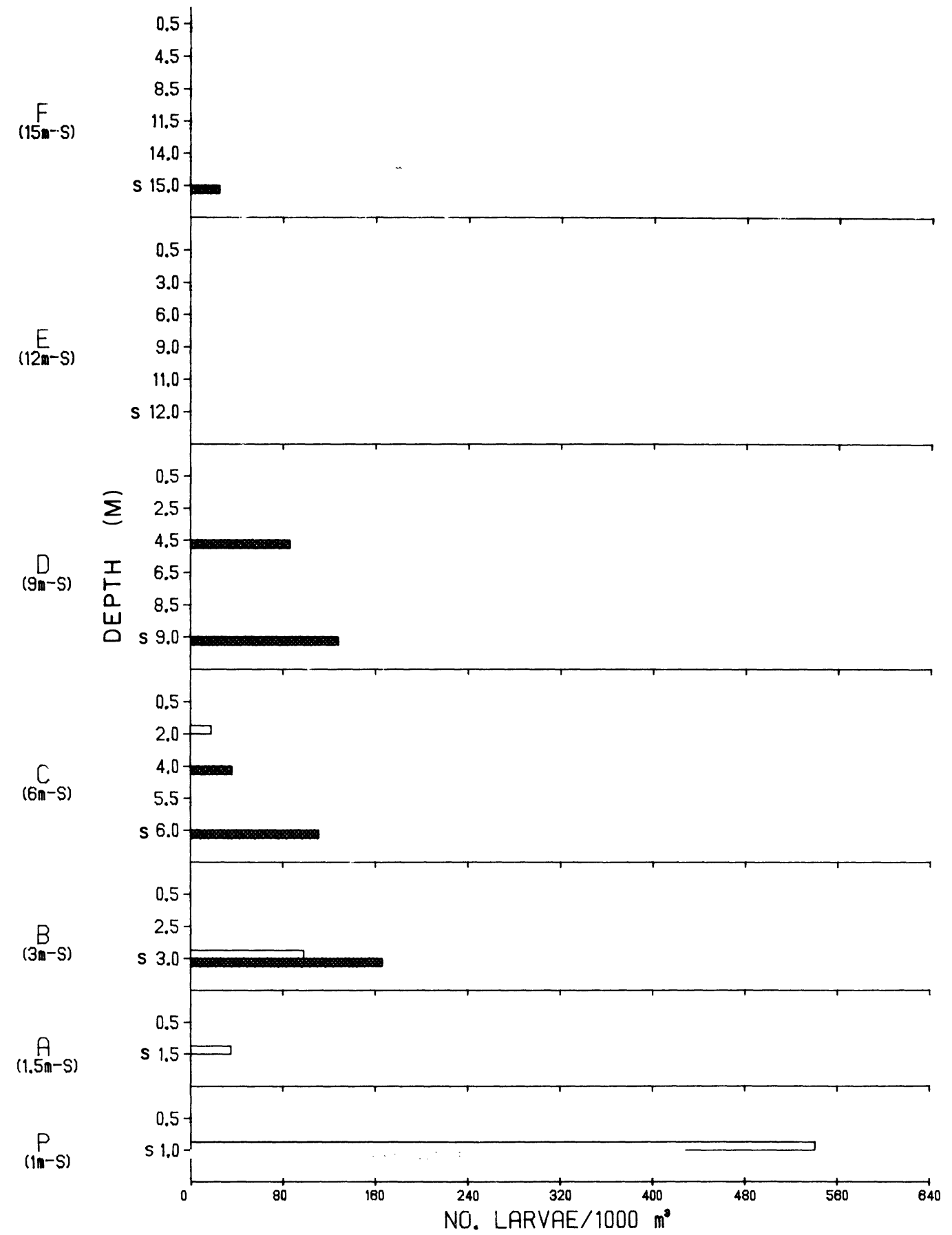

Fig. 155. Density of damaged larvae (no./1000 $\mathrm{m}^{3}$ ) at Lake Michigan stations near the J. H. Campbe11 Plant, eastern Lake Michigan, 1-4 August 1978.

$\square=$ day $\square=$ night $\mathrm{S}=$ sled 


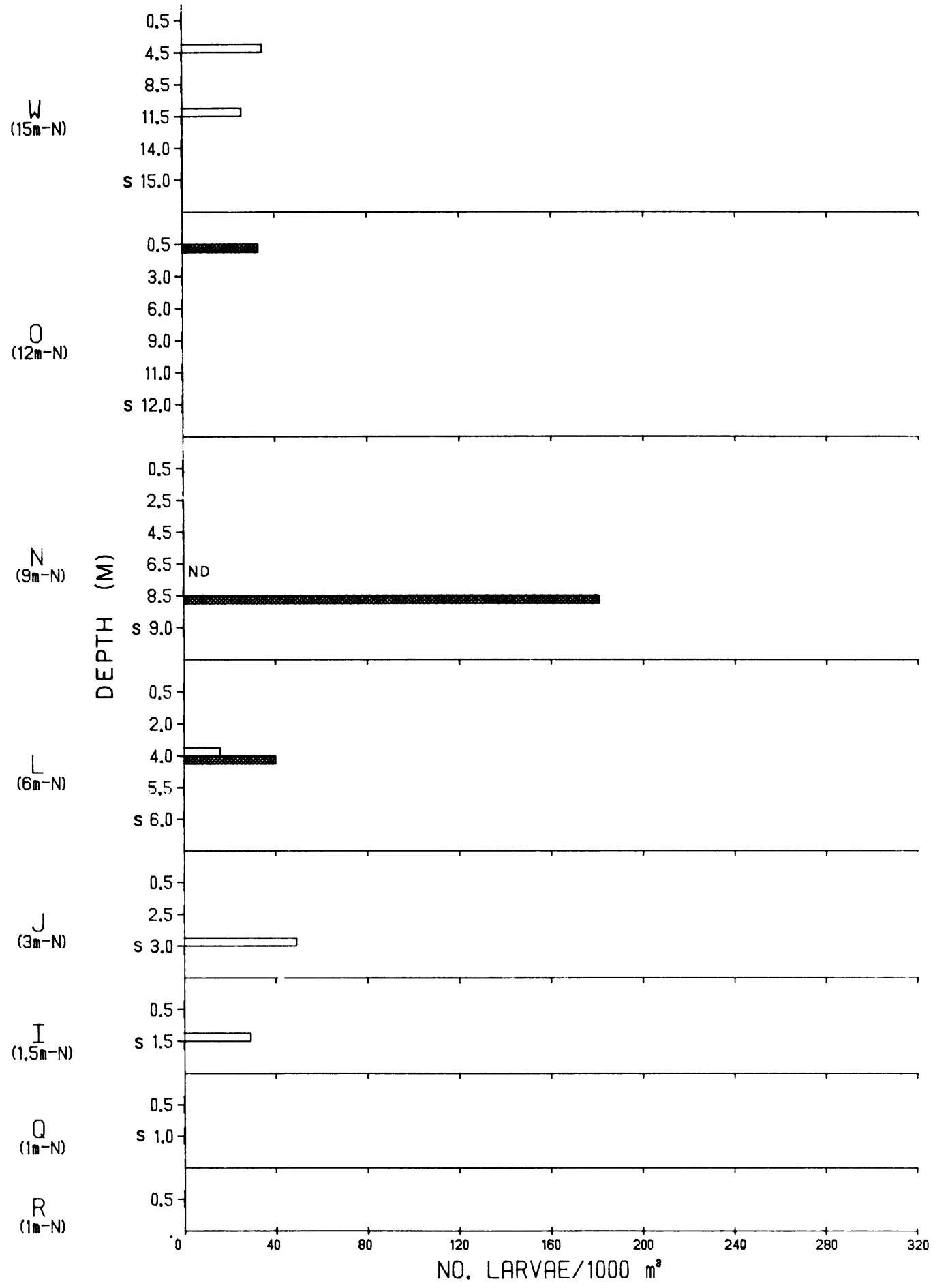

Fig. 155. Continued. 

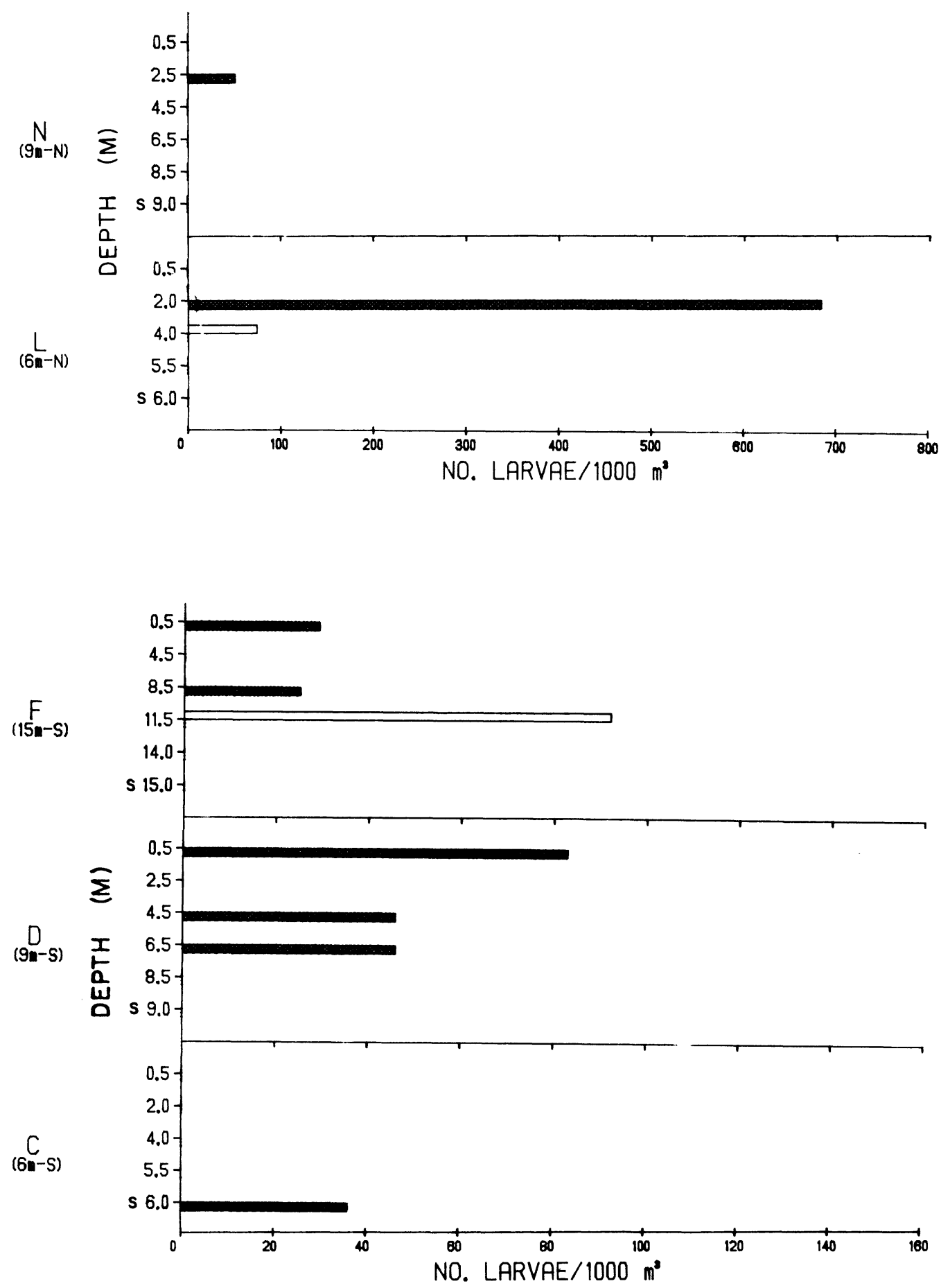

Fig. 156. Density of damaged larvae (no./1000 $\mathrm{m}^{3}$ ) at Lake Michigan stations near the J. H. Campbe11 Plant, eastern Lake Michigan, 14-15 August 1978 . Stations $1-3 \mathrm{~m} \mathrm{~S}, 12 \mathrm{~m} \mathrm{~S}, 1-3 \mathrm{~m} \mathrm{~N}$ and $12-15 \mathrm{~m} \mathrm{~N}$ were omitted due to absence of larvae in samples. $\square=$ day $\square=$ night $S=$ sled 

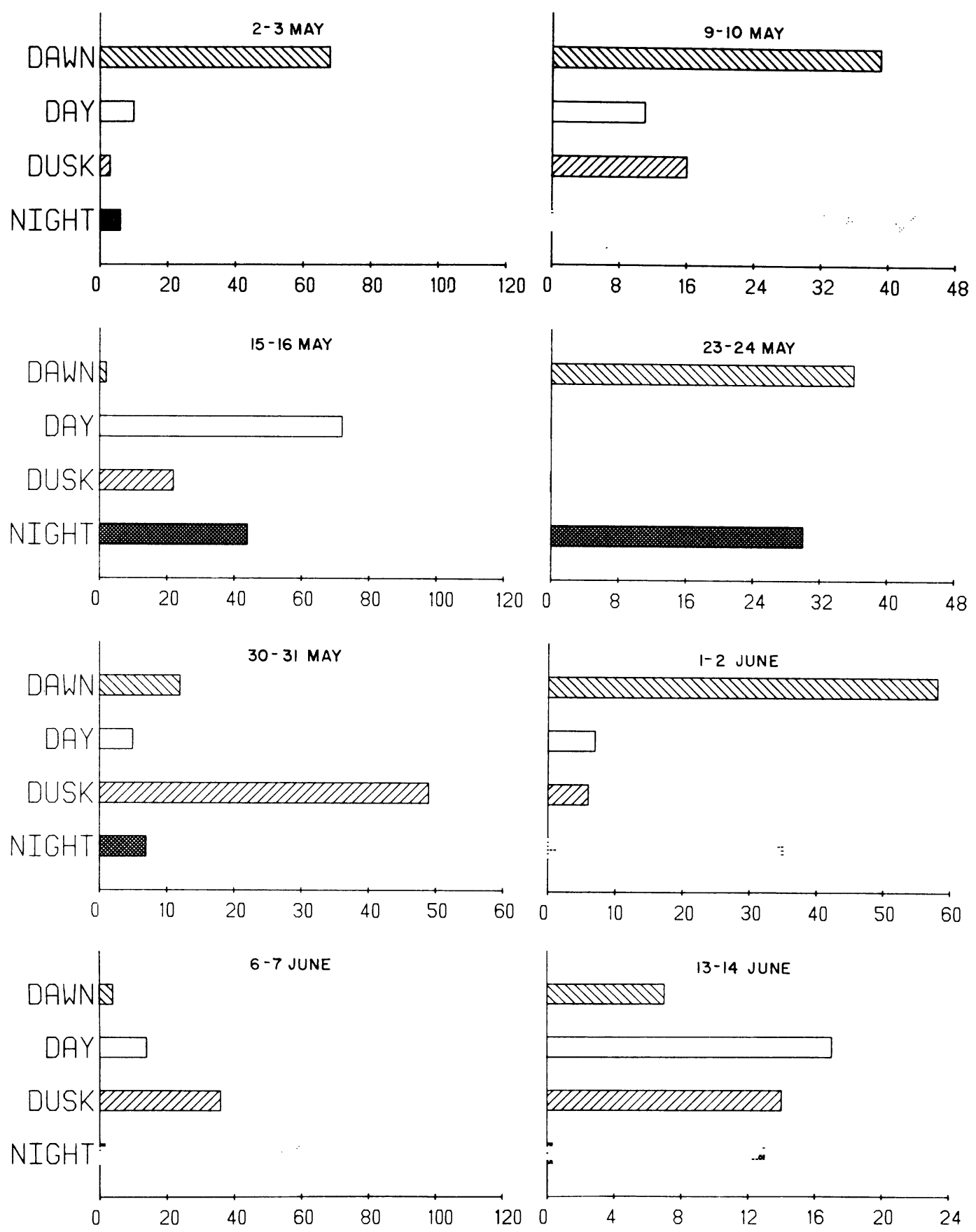

NO. OF LARVAE PER $1000 \mathrm{~m}^{3}$

Fig. 157. Density of damaged larvae (no./1000 $\mathrm{m}^{3}$ ) collected in weekly dawn, day, dusk and night entrainment samples at the J. H. Campbell Plant, eastern Lake Michigan, 1978. 

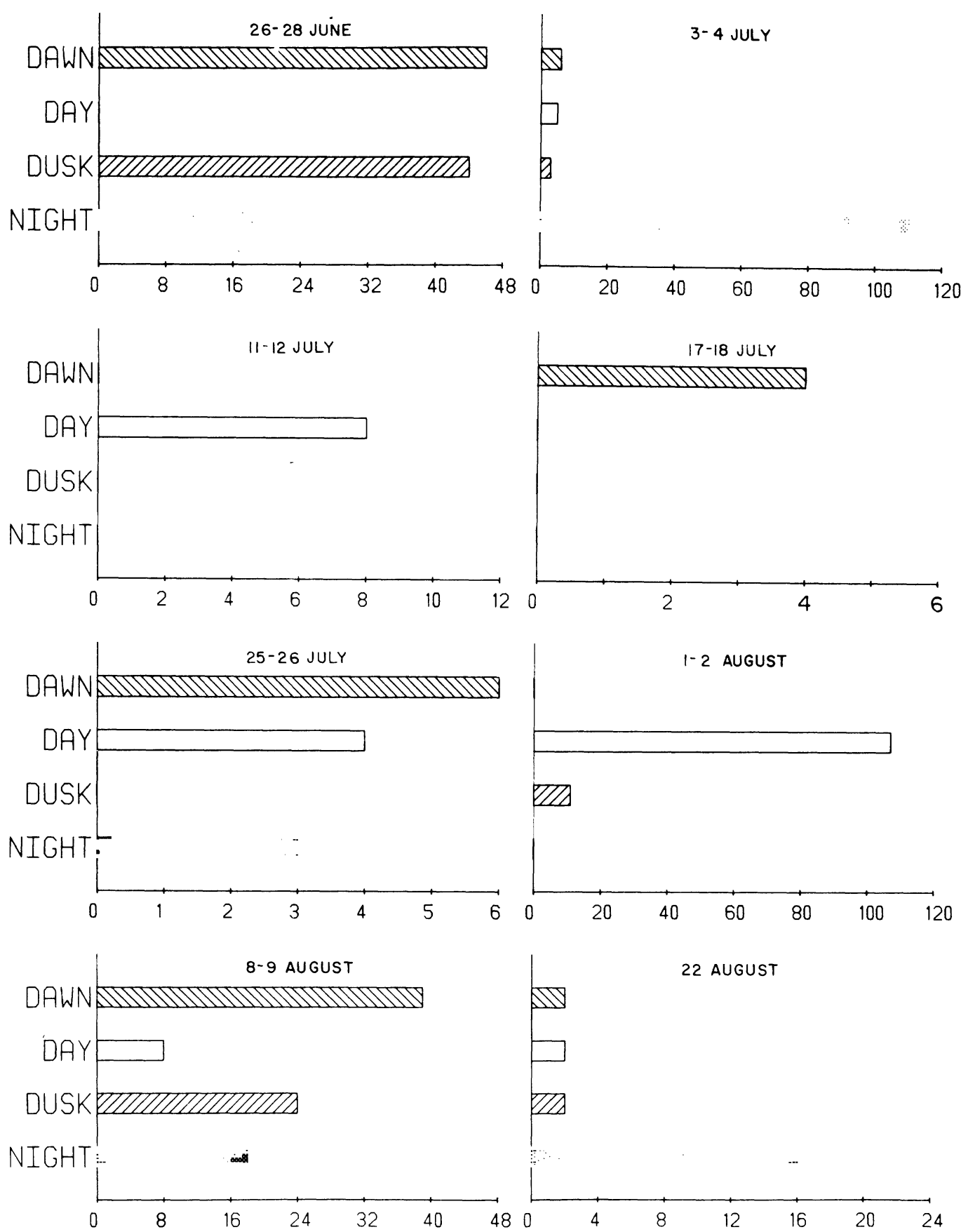

NO. OF LARVAE PER $1000 \mathrm{~m}^{3}$

Fig. 157. Continued. 

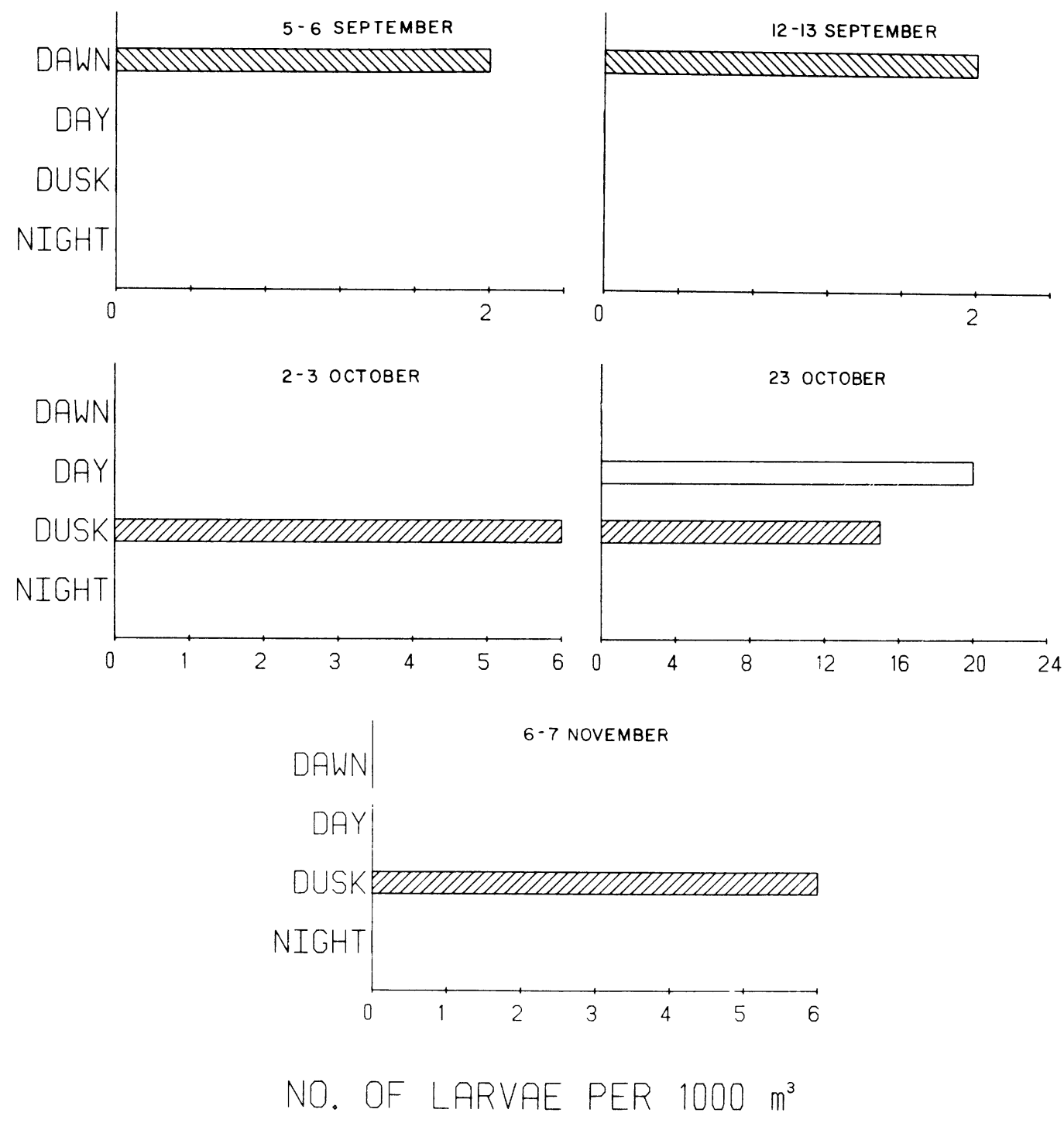

Fig. 157. Continued. 
July-- Occurrence of damaged larvae in entrainment samples decreased during July. Only 45 larvae were damaged and unidentified. Thirty-five of these larvae occurred in samples taken at night during the first week of July (Fig. 157). Alewife larvae again made up the greatest percentage of larvae entrained so it may be assumed these damaged larvae were also alewife.

August-- During August entrainment sampling 78 larvae were reported damaged. Most occurred in a day sample during the first week of August (Fig. 157). These larvae were probably alewife, however some unidentified minnow larvae were also present in entrainment samples, especially during the first 2 wk (Appendix 14).

September, October, November-- For the remainder of the year damaged larvae occurred only in entrainment samples. Two were found in samples collected the first half of September (Fig. 157), nine were seen in samples collected in October (Fig. 157) and one was detected in an early November sample (Fig. 157). Perusal of entrainment data for these times (Appendix 14) indicates that these larvae were also alewife.

Summary--

Although actual numbers of damaged larvae may not have increased significantly from 1977 to 1978, damaged larvae occurred much more frequently throughout 1978. In 1977 peak abundance of damaged larvae occurred in July. The same peak was evident in 1978, however damaged larvae were much more abundant in June and August than they were in 1977. Although abundance of damaged larvae appeared high, they were still only a small fraction of all larvae actually recovered from our samples. of the total 23,581 larvae collected in 1978,718 or $3.04 \%$ were damaged. Numbers of damaged larvae were greatest in entrainment samples. Of the 8050 larvae entrained 365 or $4.53 \%$ were damaged. Most damaged larvae were believed to be alewife, a fragile, abundant species. Inclusion of these larvae in our data analysis would not significantly alter any interpretations or conclusions drawn.

\section{Unidentified Pisces}

Unidentified larvae (XX) are those larvae which were intact but could not be identified. They may have been curled, twisted or doubled over, thus making myomeres and other characteristics difficult to distinguish. In 1977 there were three such larvae (Jude et al. 1978) while in 1978 there were five. Three unidentified larvae in 1978 were recorded from Lake Michigan stations E (12 m - S), $\mathrm{L}(6 \mathrm{~m}-\mathrm{N}$ ) and beach station Q (S discharge). A 9.5-mm larva, perhaps a rainbow smelt, was collected in a night surface tow at station L during early June. In late June another unidentified larva $(4.1 \mathrm{~mm})$ was collected in a beach tow at station Q. This larva was from a sample where yellow perch dominated. Finally in late July a 7.5-mm larva was found in a 3-m tow at station E. All other larvae in this sample were alewife.

The two other unidentified larvae collected in 1978 were observed in entrainment samples. A 5-mm larva was observed in dawn entrainment samples during May and a 4.7-mm larva was recovered from a dusk sample during the first week of July. These fish may have been respectively yellow perch and alewife, since these larvae predominated in samples. 


\section{Fish Eggs}

Introduction--

Due to the nondescript appearance of some of the species of fish eggs found in the vicinity of the Campbell Plant, we can only speculate on the identity of many of the eggs found in our samples in our discussion of seasonal distribution. Our experience has made possible the identification of yellow perch and rainbow smelt eggs. With other species, however, which are common to the area of the Campbell Plant, identity of eggs could only be inferred using data gathered during adult fish sampling to determine spawning times.

In consideration of the reproductive ecology of some of the species of fish in the area of the Campbell Plant, the possibility of the eggs of some species occurring in samples can be eliminated. Included in this group were bluntnose minnows, slimy sculpin, mottled sculpins, fourhorn sculpins, johnny darters, ninespine sticklebacks, all members of the catfish family, as well as all members of the centrarchid family. All these species are nest-building species, with one or both parents exhibiting parental care of the eggs. Unless nesting sites were severely disrupted, and demersal eggs suspended in the water column for the duration of the sampling period, we would not expect to collect eggs of these species in our samples. The species whose eggs would probably occur in our samples due to their random spawning habit, as well as abundance of adults in the area were spottail shiner, alewife and emerald shiner. Larval fish data would also indicate that burbot eggs are probably present near the Campbell Plant in winter.

Seasonal Distribution--

The first occurrence of fish eggs in Lake Michigan near the Campbell Plant was during April when low concentrations (less than 75 eggs/1000 $\mathrm{m}^{3}$ ) were observed at north transect stations (Fig. 158). Eggs found in April were probably late-spawned eggs of burbot. Sma11, newly hatched burbot larvae were common in the area during April (see RESULTS AND DISCUSSION - FISH LARVAE AND ENTRAINMENT STUDY, Burbot). Eggs of this species are reportedly semi-pelagic (Scott and Crossman 1973) which would make them vulnerable to our sampling gear. No fish eggs were found in Pigeon Lake during April sampling.

Fish eggs first occurred in Pigeon Lake samples during May, when an average of over 500 eggs/1000 $\mathrm{m}^{3}$ were observed at beach station $\mathrm{V}$ (undisturbed Pigeon Lake). Since these eggs were not identified as yellow perch or smelt eggs, they were probably minnow eggs, possibly spottail shiner. This contention is somewhat substantiated by the subsequent occurrence of high concentrations of minnow larvae at beach station $\mathrm{V}$ in early June (Appendix 13).

From early June to early August, fish eggs were common at Lake Michigan stations at depths of $6 \mathrm{~m}$ and less (Figs. 159-164), with only a few occurrences of densities over 500 eggs/1000 $\mathrm{m}^{3}$ at deeper stations, A few eggs were found at three stations in mid-August (Fig. 165). The two most probable contributors of these eggs were alewife and spottail shiner, which spawned throughout this period. It is also possible that some trout-perch and emerald shiner eggs were part of the 


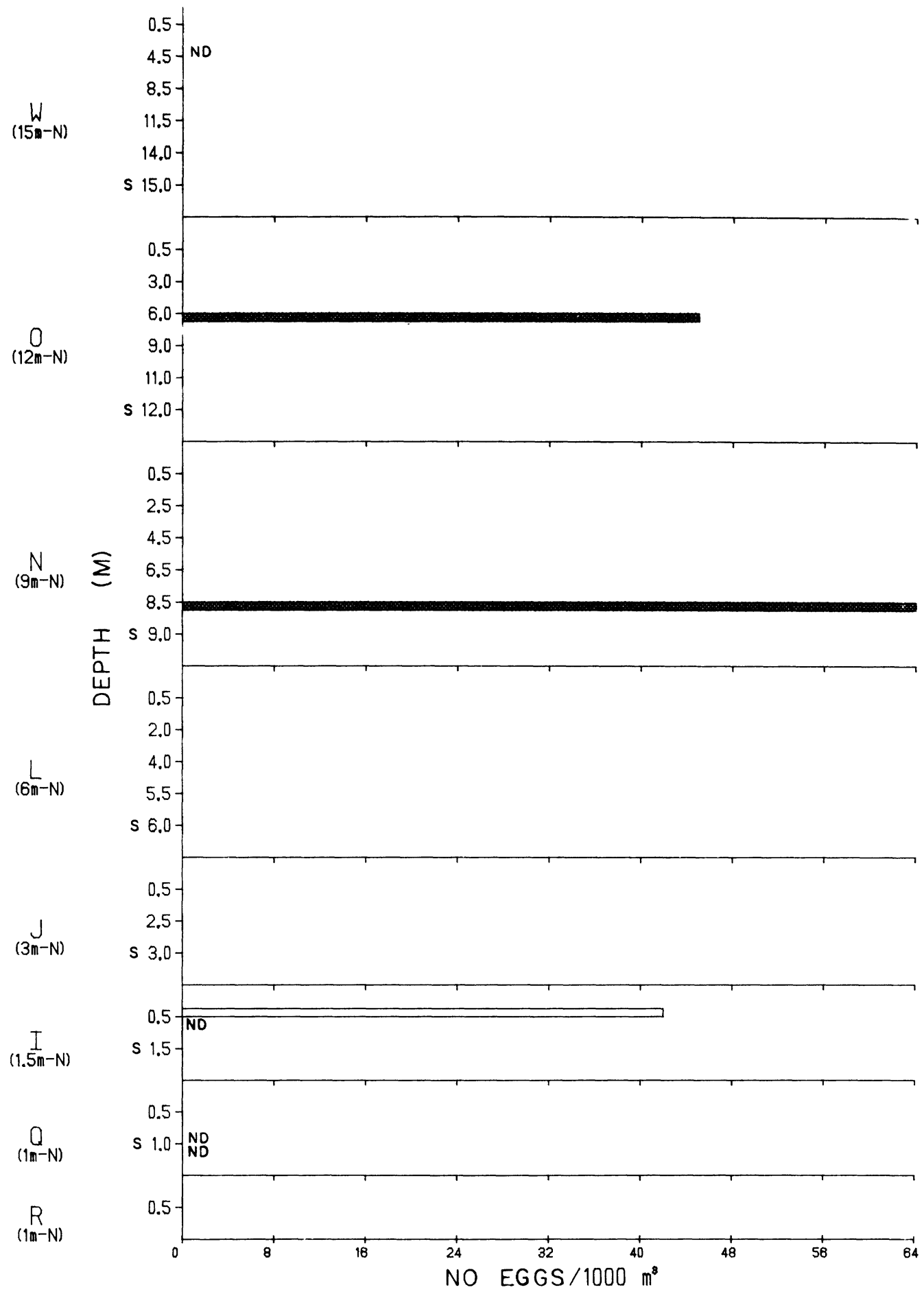

Fig. 158. Density of fish eggs (no./1000 $\mathrm{m}^{3}$ ) at Lake Michigan stations near the J. H. Campbell Plant, eastern Iake Michigan, 24-2.8 April 1978 . $\square=$ day $\square=$ night $\quad S=$ sled $\quad N D=$ no data 

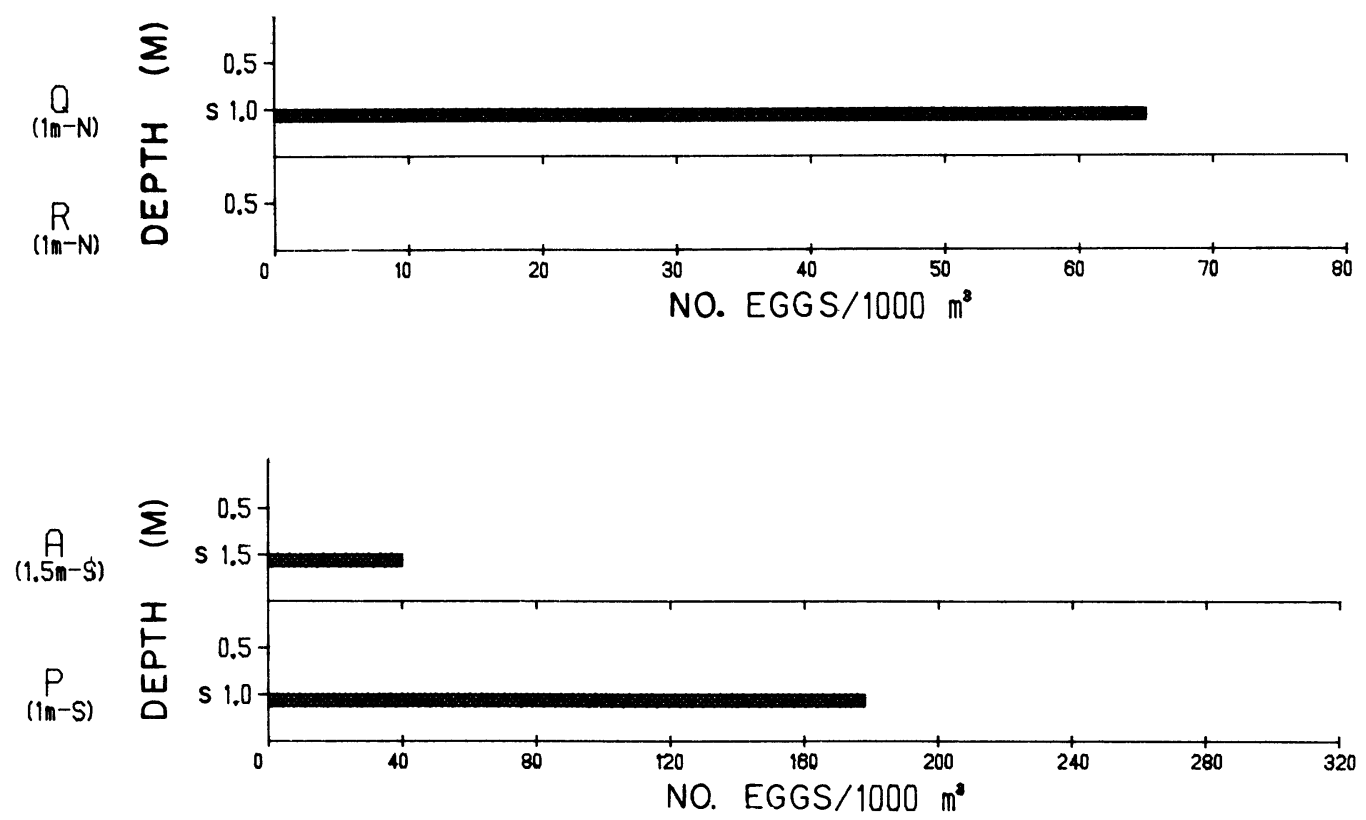

Fig. 159. Density of fish eggs (no./1000 $\mathrm{m}^{3}$ ) at Lake Michigan stations near the J. H. Campbell Plant, eastern Lake Michigan, 15-18 May 1978. Stations 3 to $15 \mathrm{~m} \mathrm{~S}$ and 1.5 to $15 \mathrm{~m} \mathrm{~N}$ were omitted due to absence of eggs in samples. $\square=$ day $\square=$ night $S=$ sled

sample. Egg, as well as larval fish data confirmed that the inshore area of Lake Michigan near the Campbell Plant is used extensively as a spawning area by spottail shiners and alewives. The comparatively higher occurrence of eggs at beach station Q (S discharge) during all sampling periods when eggs were present at Lake Michigan beach stations (with the exception of 1-2 August) suggested that intensive spawning activity was occurring in or near the present discharge canal. Semipelagic eggs would be carried toward station $Q$ from the discharge canal by predominant southern alongshore currents. In Pigeon Lake, fish eggs were found commonly at beach stations S (influenced by Lake Michigan) and V (undisturbed Pigeon Lake) from early June to August (Fig. 166). Most of these eggs were probably spottail shiner and alewife; however, presence of high numbers of emerald shiner adults indicated that eggs of emerald shiner were possibly more prominent in Pigeon Lake samples compared with their occurrence in Lake Michigan samples. Our data suggest that beach areas of Pigeon Lake were used extensively by alewives, spottail shiners and emerald shiners. Open water stations in Pigeon Lake in general had lower densities of eggs throughout the sampling period, compared with Pigeon Lake beach stations. Of notable exception to this was an extremely high (over 300,000 eggs $/ 1000 \mathrm{~m}^{3}$ ) occurrence of eggs at station $X$ (undisturbed Pigeon Lake) during late June sampling. These were probably alewife eggs, as this species was seen spawning in the area near station X during June. Samples taken from September-November in Pigeon Lake did not contain any fish eggs, indicating that spawning activity probably ceased by late August. 


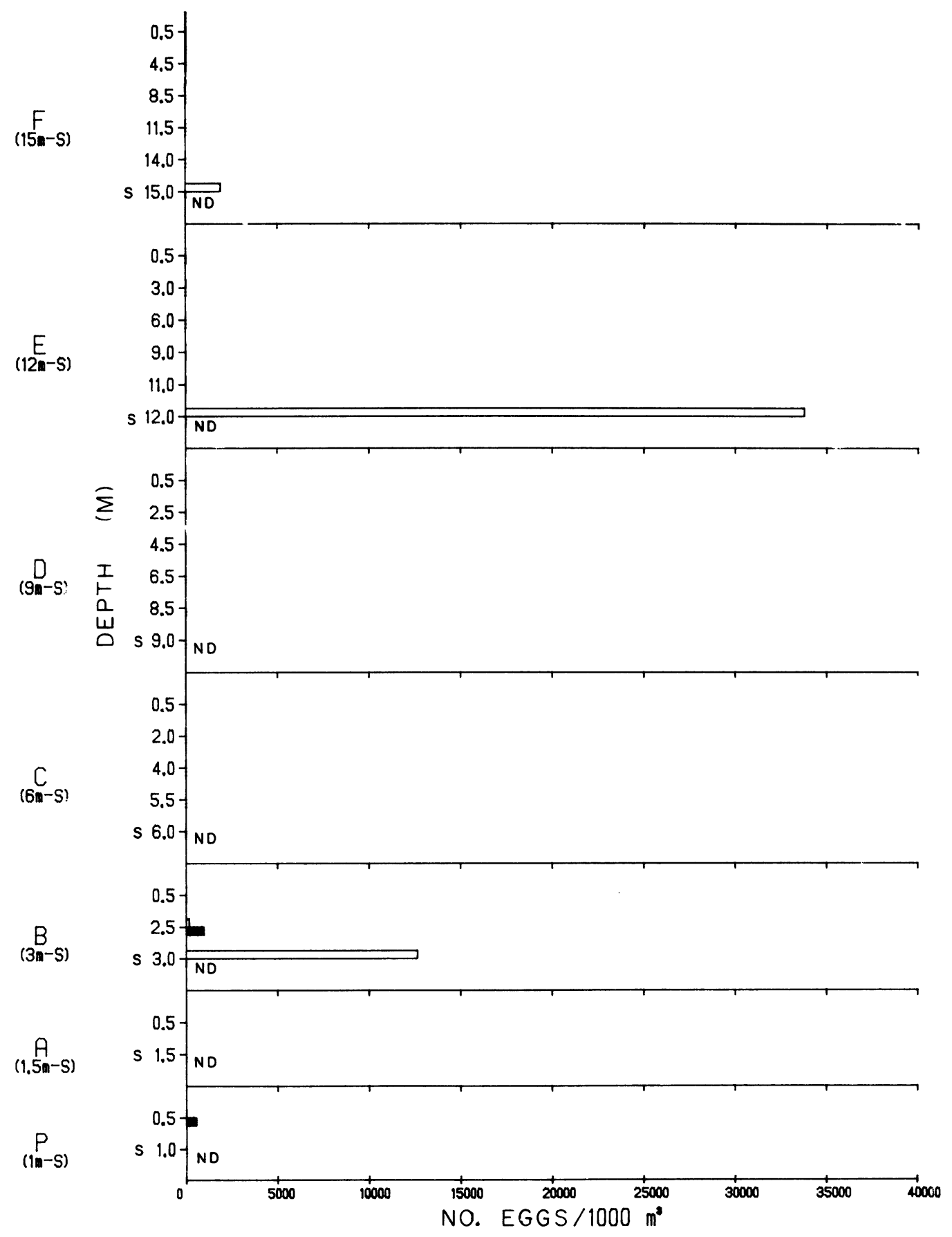

Fig. 160. Density of $\mathrm{fish}$ eggs (no./1000 $\mathrm{m}^{3}$ ) at take Michigan stations near the J. H. Campbell Plant, eastern Iake Michigan, 5-7 June 1978.

$\square=$ day $\square=$ night $S=$ sied $N D=$ no data 


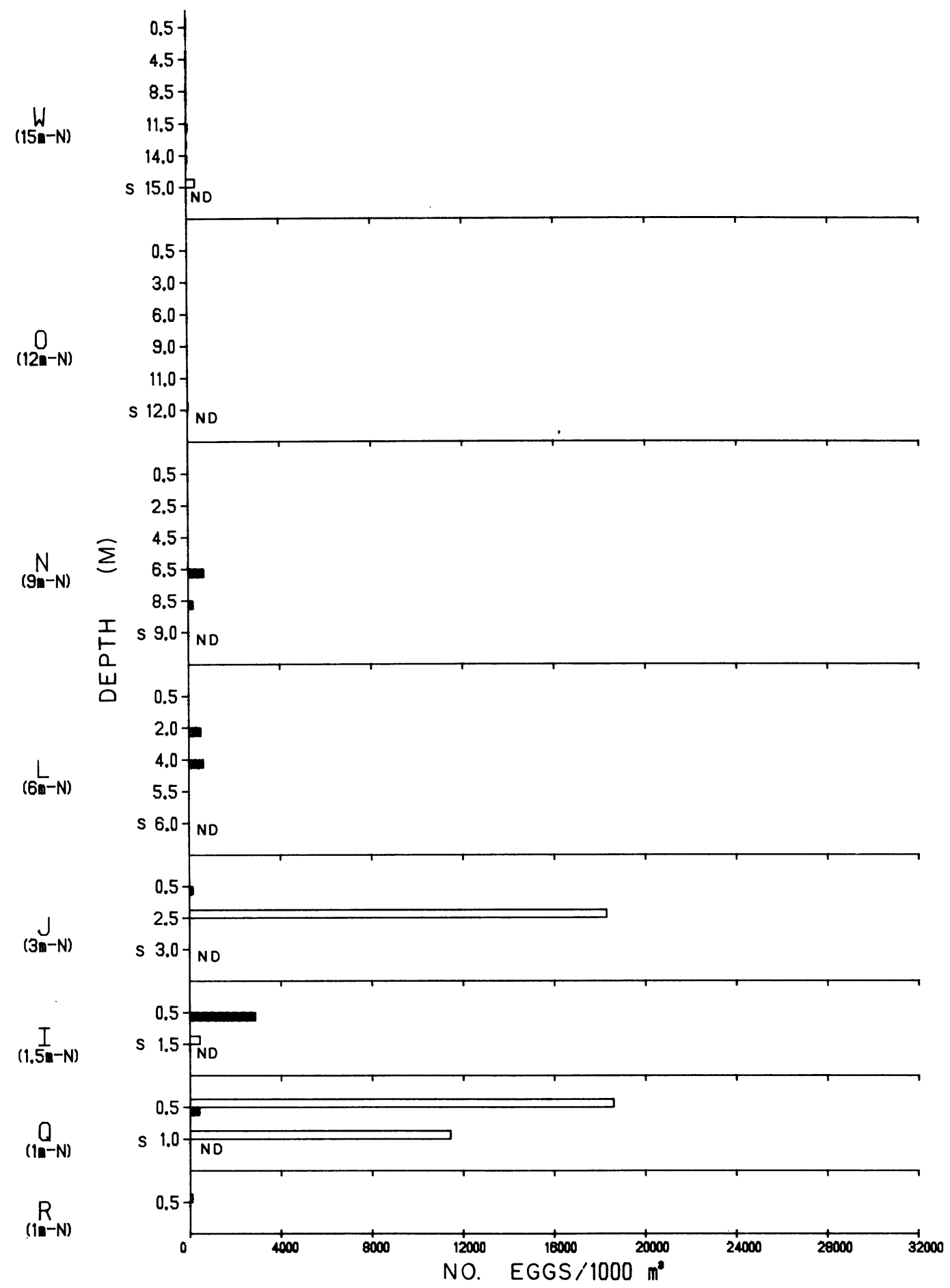

Fig. 160. Continued. 


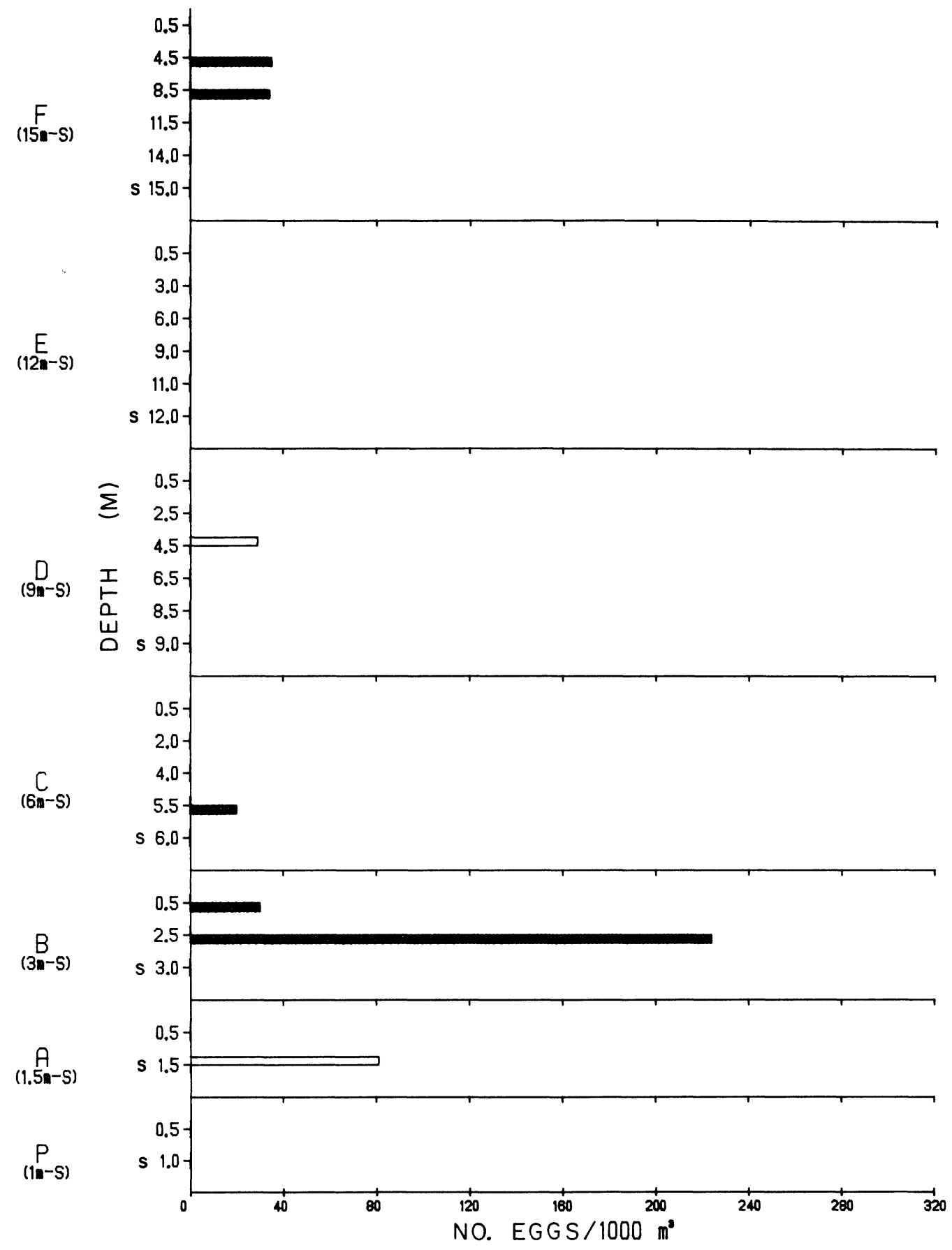

Fig. 161. Density of fish eggs (no./1000 $\mathrm{m}^{3}$ ) at Lake Michigan stations near the J. H. Campbell Plant, eastern Lake Michigan, 19-22 June 1978. $\square=$ day $\square=$ night $\mathrm{S}=$ sled 


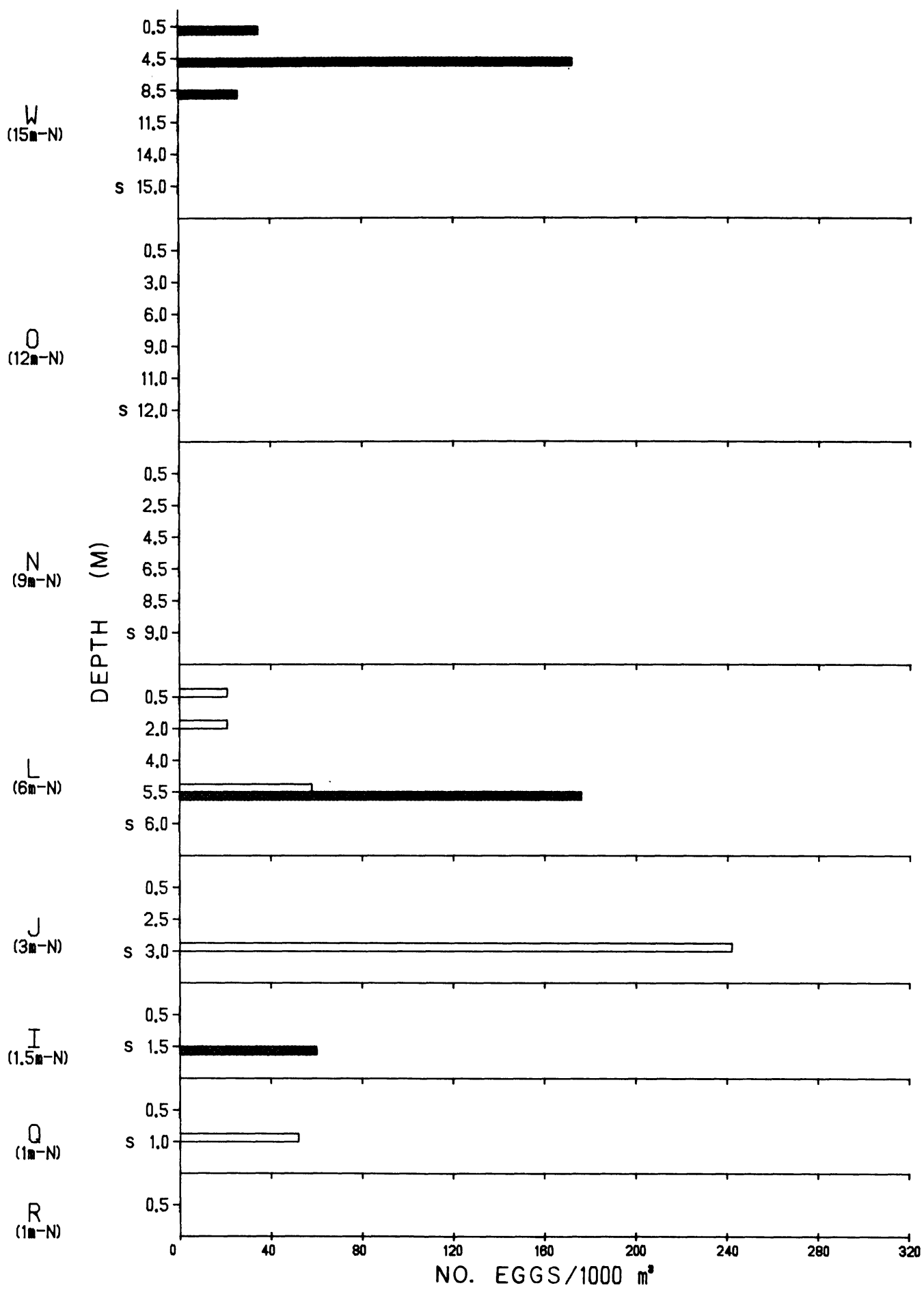

Fig. 161. Continued. 


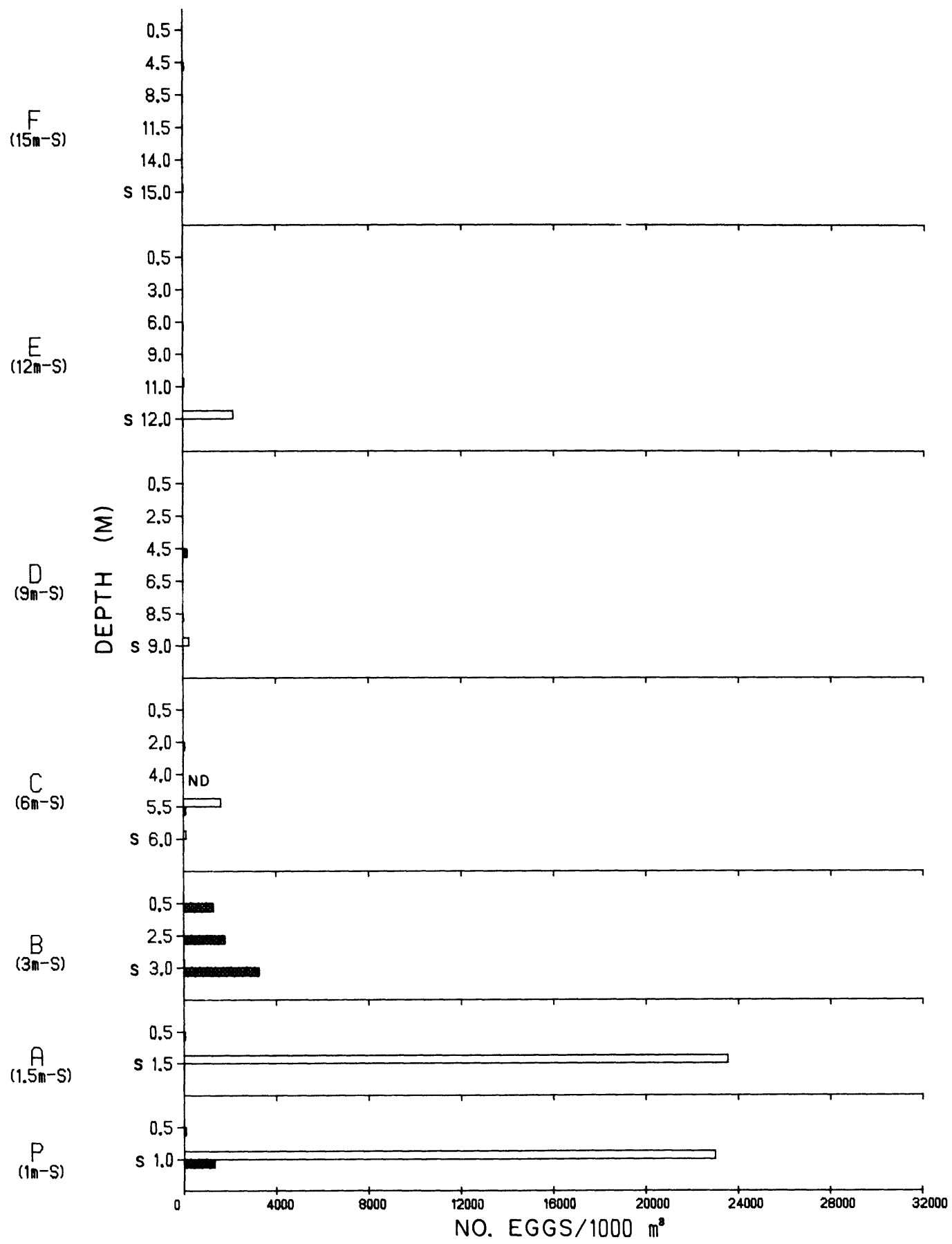

Fig. 162. Density of figh eggs (no./100C $\mathrm{m}^{3}$ ) at Lake Michigan stations near the J. H. Campbell Plant, eastern Lake Michigan, 1-3 July 1978.

$\square=$ day $\square=$ night $S=$ sled $\mathrm{ND}=$ no data 


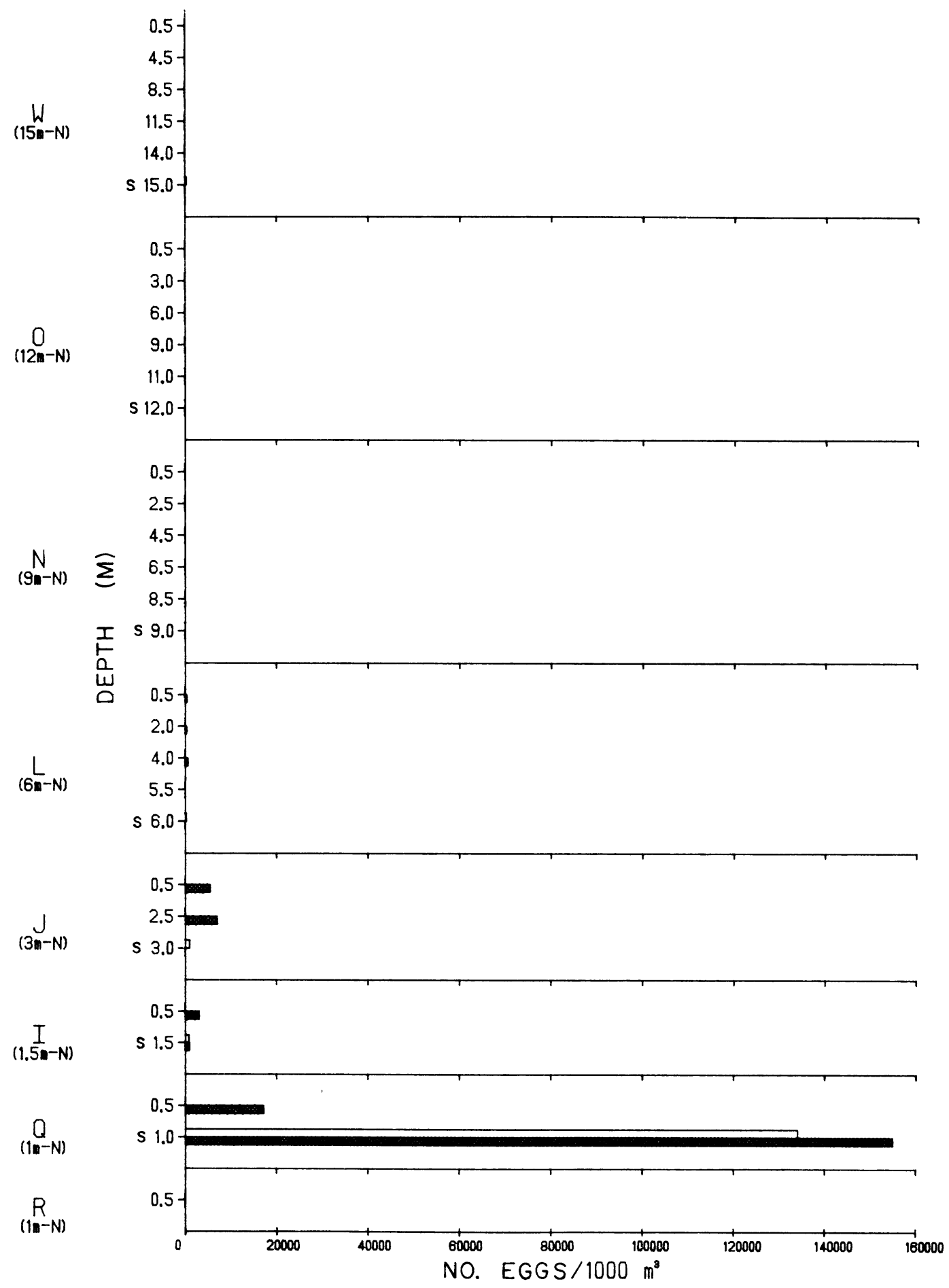

Fig. 162. Continued. 

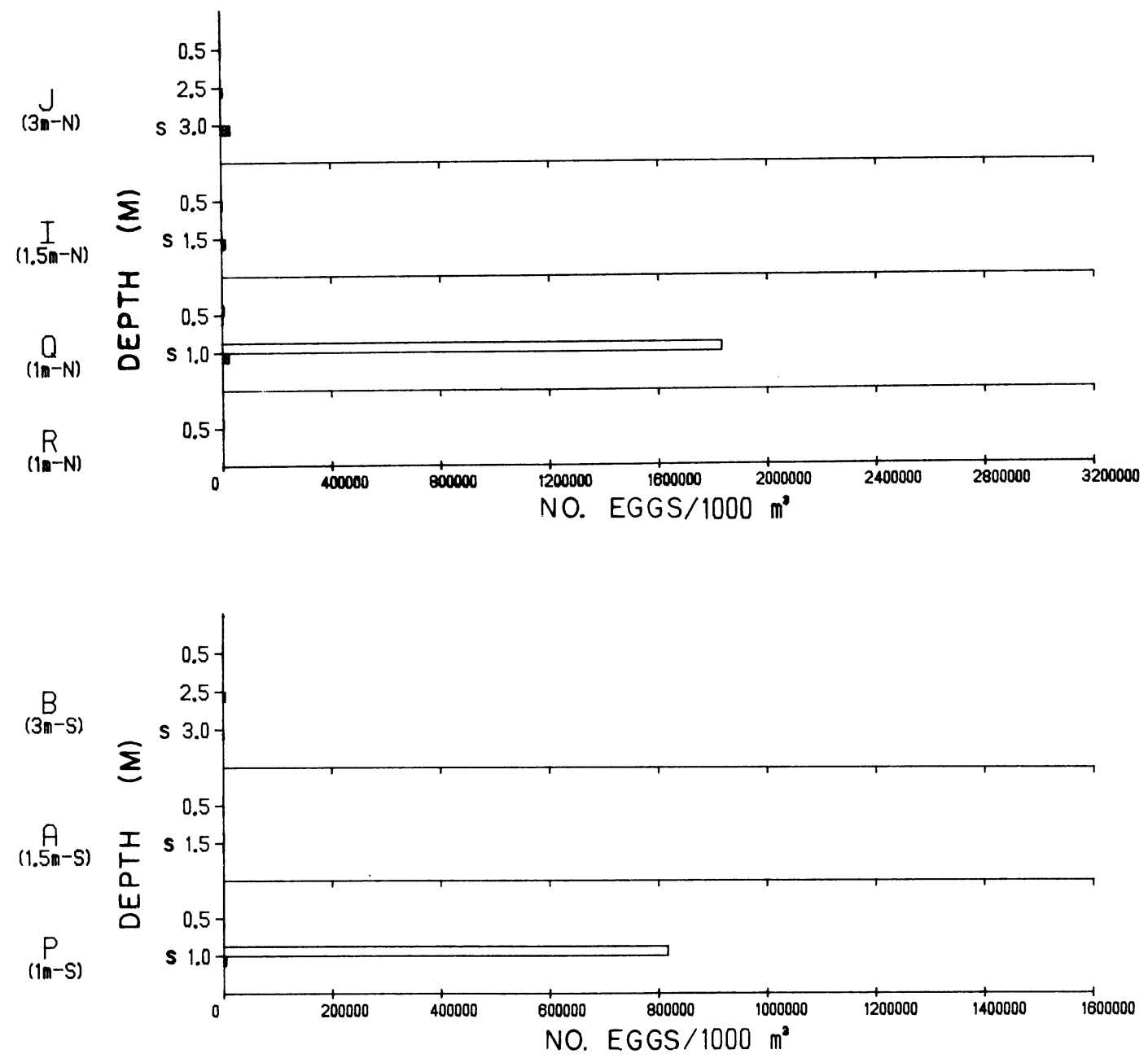

Fig. 163. Density of $\mathrm{fish}$ eggs (no./1000 $\mathrm{m}^{3}$ ) at Lake Michigan stations near the J. H. Campbell Plant, eastern Lake Michigan, 17-19 July 1978 . Stations 6 to $15 \mathrm{~m} S$ and 6 to $15 \mathrm{~m} \cdot \mathrm{N}$ were omitted due to absence of eggs in samples. $\square=$ day $\square=$ night $S=$ sled

\section{Entrainment--}

Initial entrainment of fish eggs at the Campbell Plant was observed in early May when a density of eggs exceeding 700 eggs/1000 $\mathrm{m}^{3}$ was observed in a night sample. Concentrations of eggs remained relatively low (less than 300 eggs/1000 $\mathrm{m}^{3}$ ) for remaining May samples, indicating that spawning activity was probably minimal. It is probable that eggs entrained during May were from earlier spawning alewife or perhaps smelt. The major entrainment of eggs at the Campbell Plant occurred during June and July (Fig. 167). Estimated number of eggs entrained in a 24-h period exceeded 2 million on five of the nine sampling dates (Fig. 167). We feel that most of these eggs were probably from alewives because of their open water, broadcast spawning habits. It is probable however, that spottail shiner and 


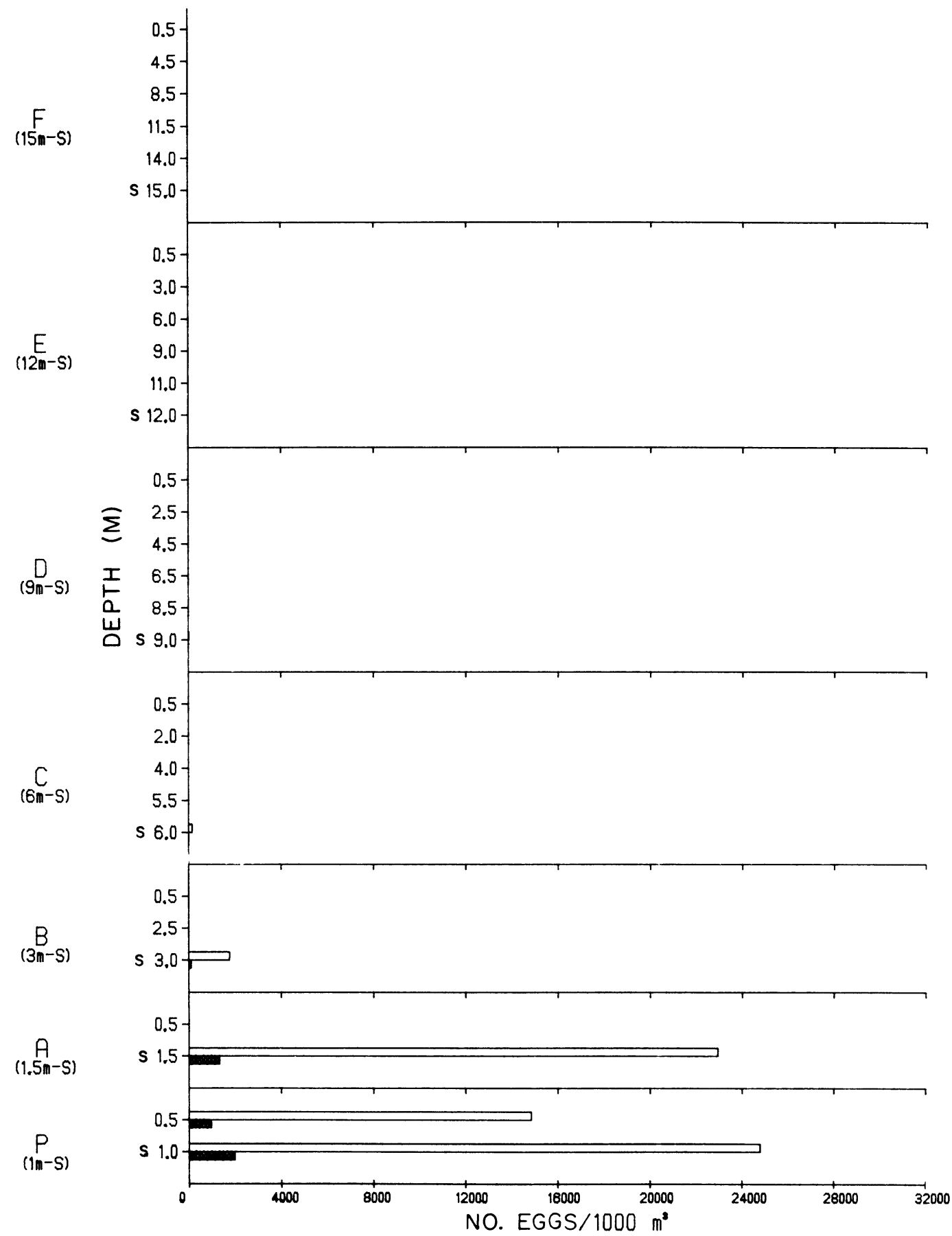

Fig. 164. Density of fish eggs (no./1000 $\mathrm{m}^{3}$ ) at Lake Michigan stations near the J. H. Campbell Plant, eastern Lake Michigan, 1-4 August 1978.

$\square=$ day $\square=$ night $S=$ sled $\mathrm{ND}=$ no data 


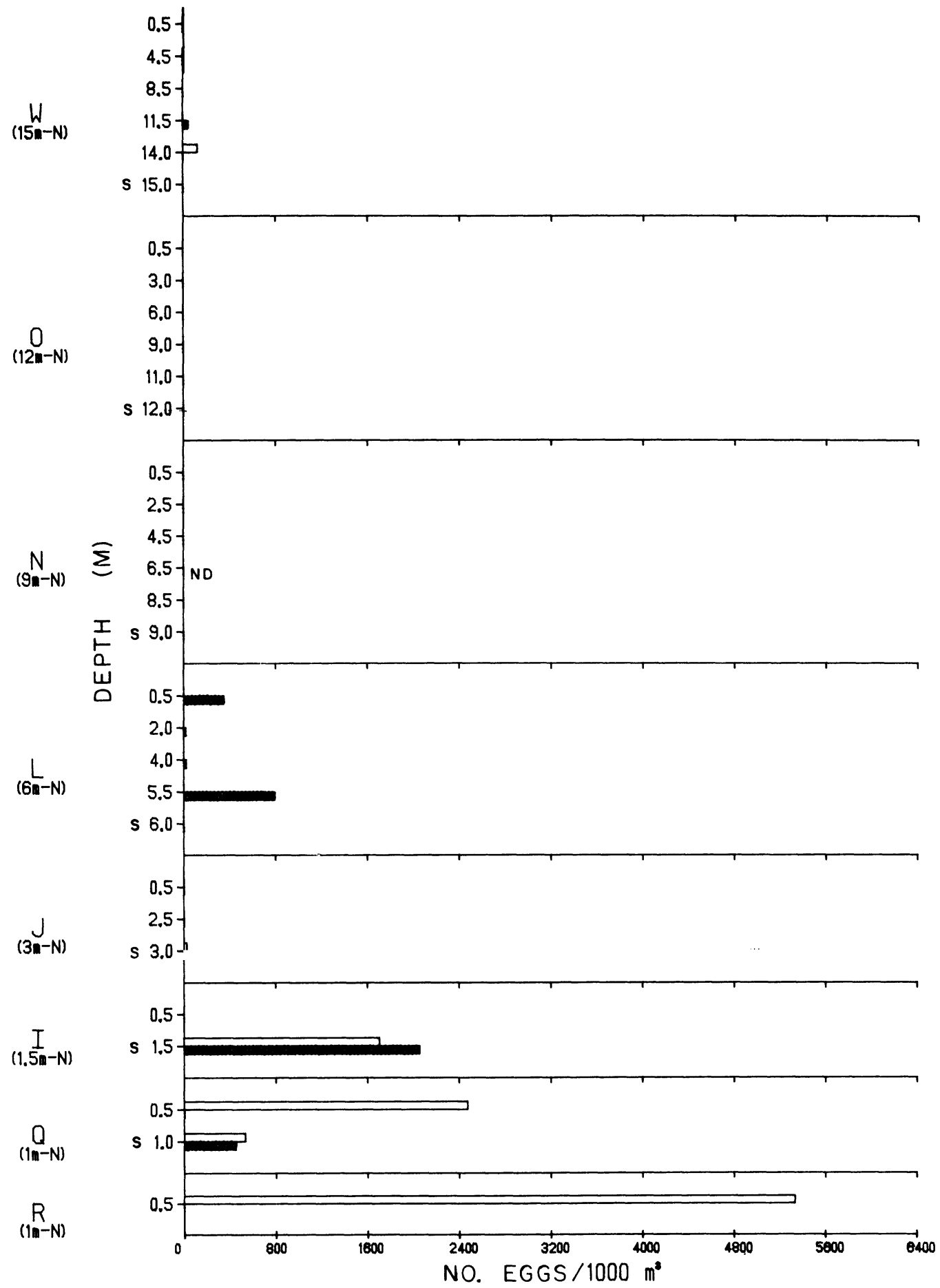

Fig. 164. Continued. 

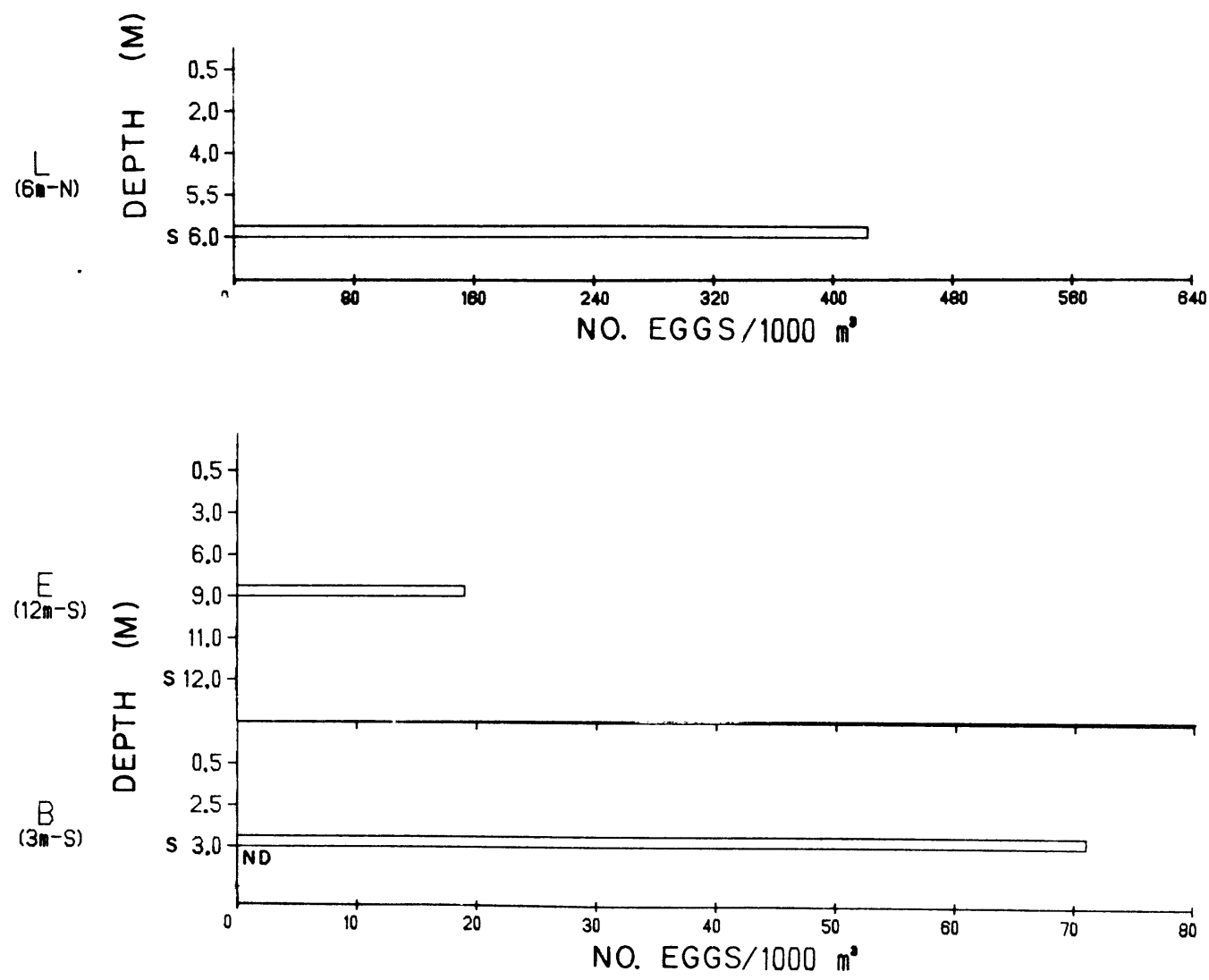

Fig. 165. Density of fish eggs (no./1000 $\mathrm{m}^{3}$ ) at Lake Michigan stations near the J. H. Campbell Plant, eastern Lake Michigan, 14-15 August 1978 . Stations 1-1.5 m-S, 6-9 m-S, $15 \mathrm{~m}-\mathrm{S}$ and $1-3 \mathrm{~m}-\mathrm{N}, 9-15 \mathrm{~m}-\mathrm{N}$ were omitted due to absence of eggs in samples.

$\square=$ day $\square=$ night $\mathrm{s}=$ sled $\mathrm{ND}=$ no data

emerald shiner eggs also comprised a small percentage of the catch. Entrainment of eggs during August indicated somewhat intense spawning activity in the earlier part of the month, with a tapering off to no spawning activity by late August. From late-August to mid-November no eggs were observed in entrainment samples. An observation of 14 eggs/1000 $\mathrm{m}^{3}$ in December was undoubtedly due to burbot spawning, since this species spawns during winter months.

\section{Yearly Entrainment Summary}

During 1978, an estimated 78,872,936 larvae of 23 different taxons were entrained at the Campbell Plant (Table 63). Of these, alewives comprised over $60 \%$ of the total, 49,804,000 larvae. Yellow perch were second with 16,435,800 entrained, followed by damaged larvae $(3,536,520)$, unidentified Cyprinidae $(2,998,200)$ and burbot $(1,569,000)$. In addition over 1.5 million rainbow smelt 

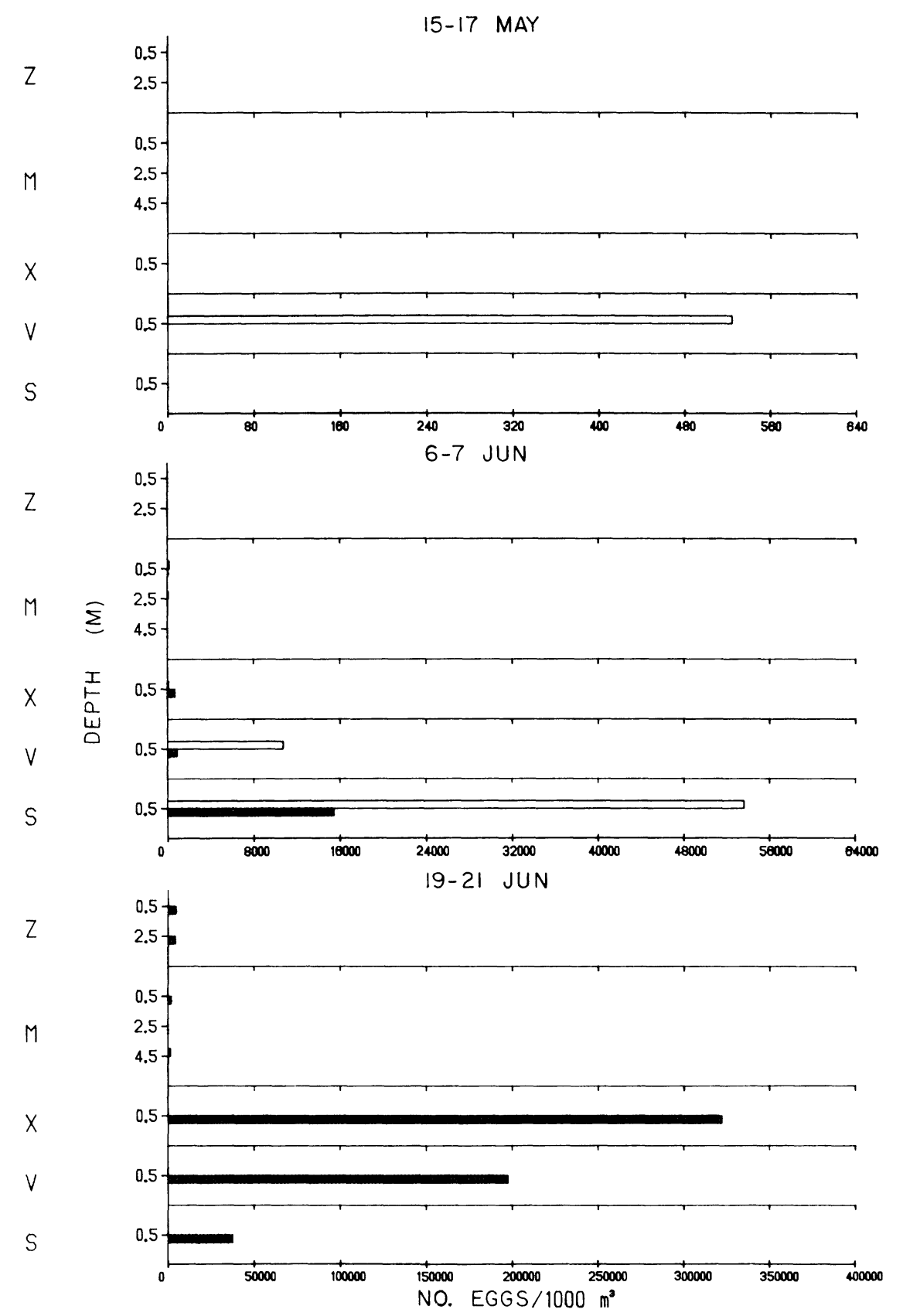

Fig. 166. Density of fish eggs (no./1000 $\mathrm{m}^{3}$ ) at Pigeon Lake and intake canal stations near the J. H. Campbell Plant, eastern Lake Michigan April to September 1978.

$$
\square=\text { day } \square=\text { night }
$$




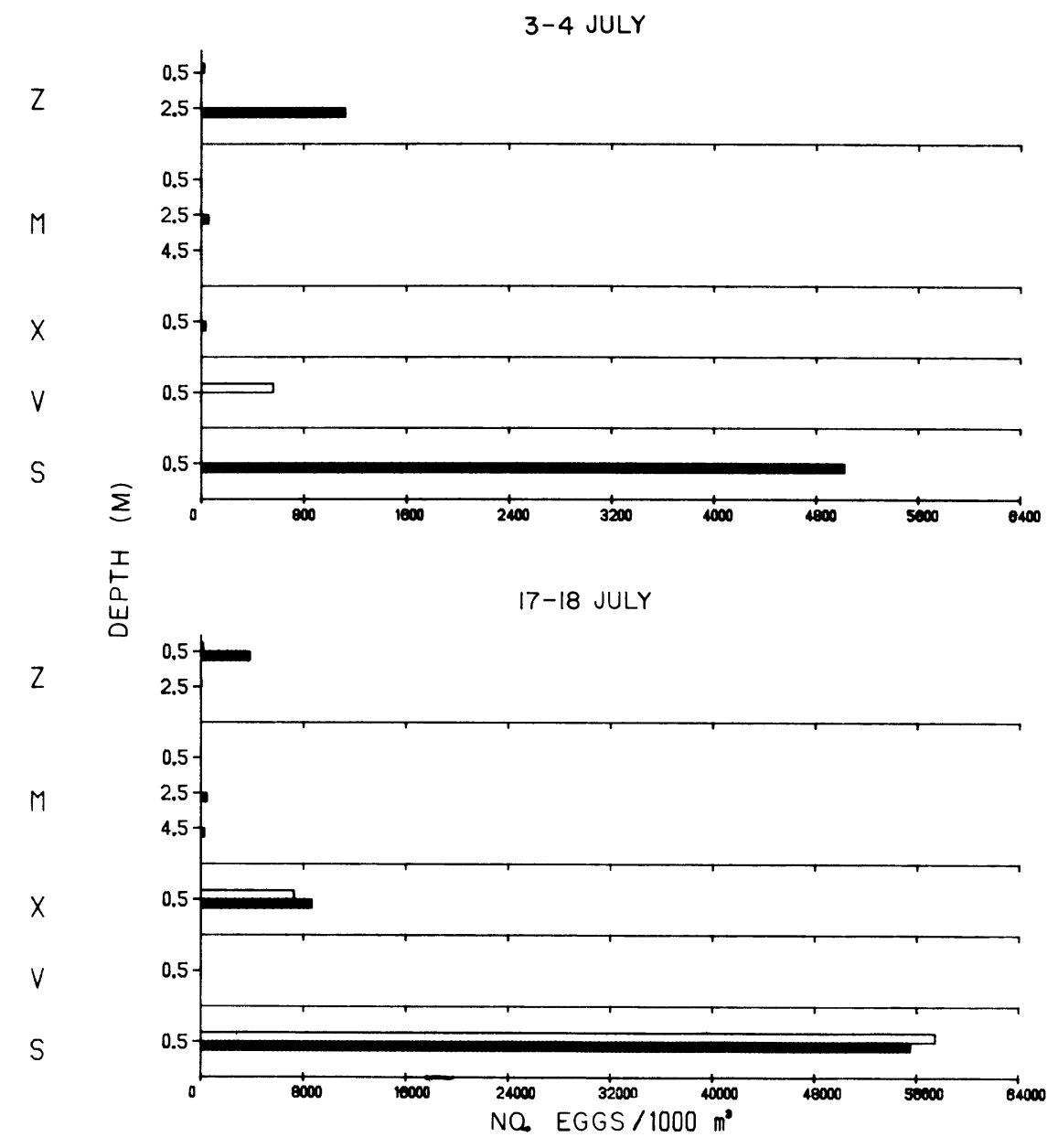

Fig. 166. Continued. 


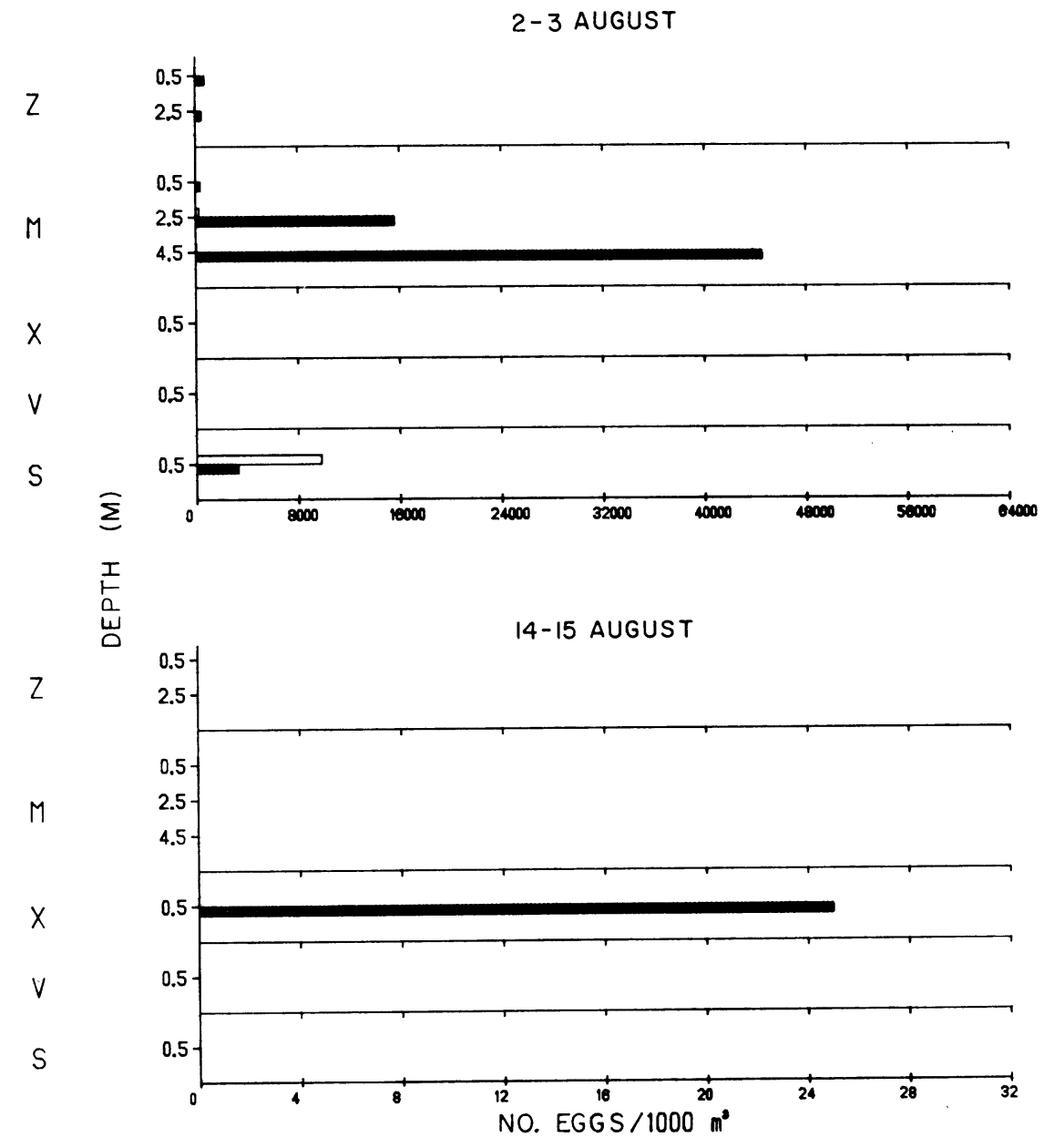

Fig. 166. Continued. 


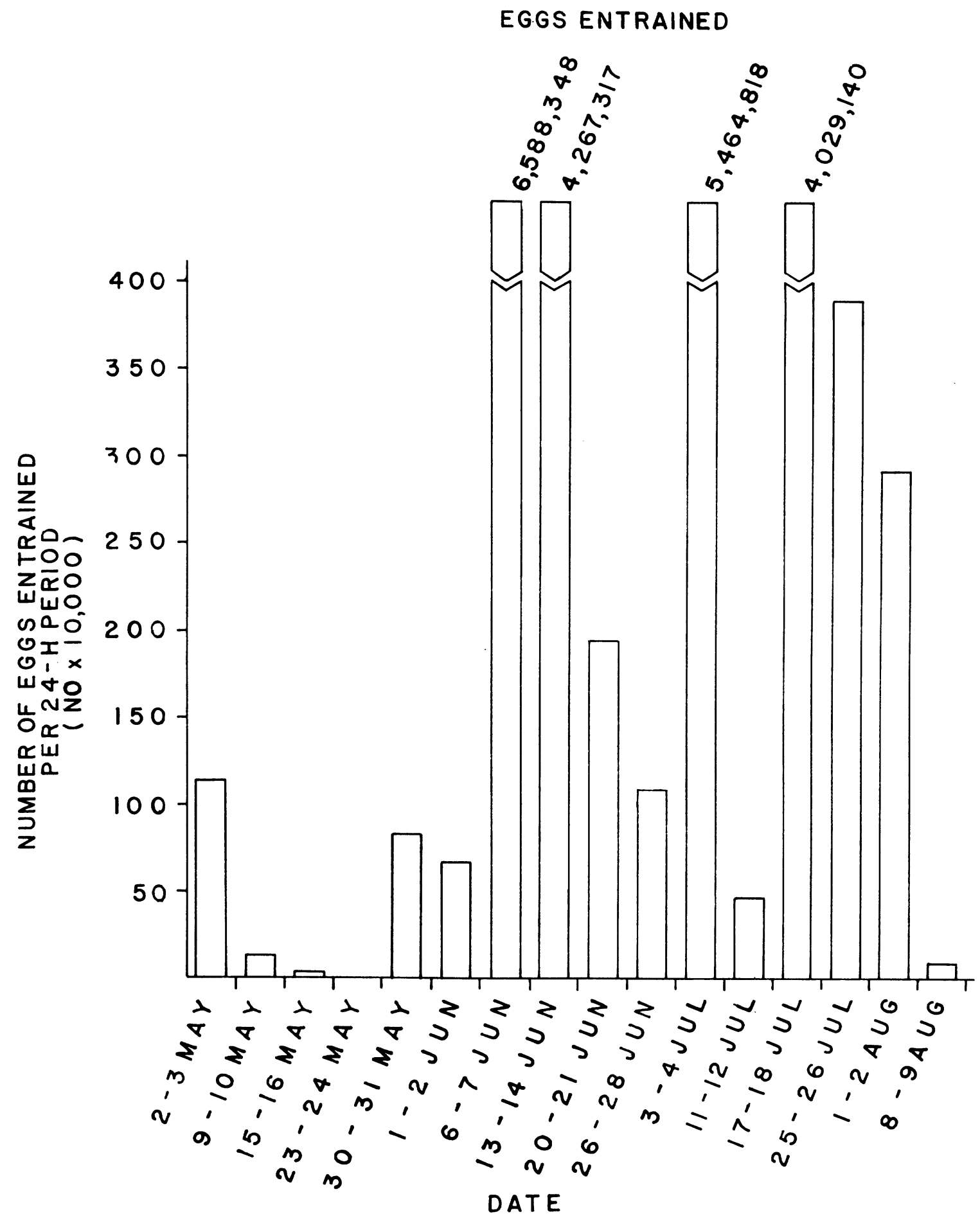

Fig. 167. Total number of fish eggs entrained during a 24-h period projected from densities observed in the 16 samples collected weekly at the J. H. Campbell Plant, eastern Lake Michigan, 1978. 


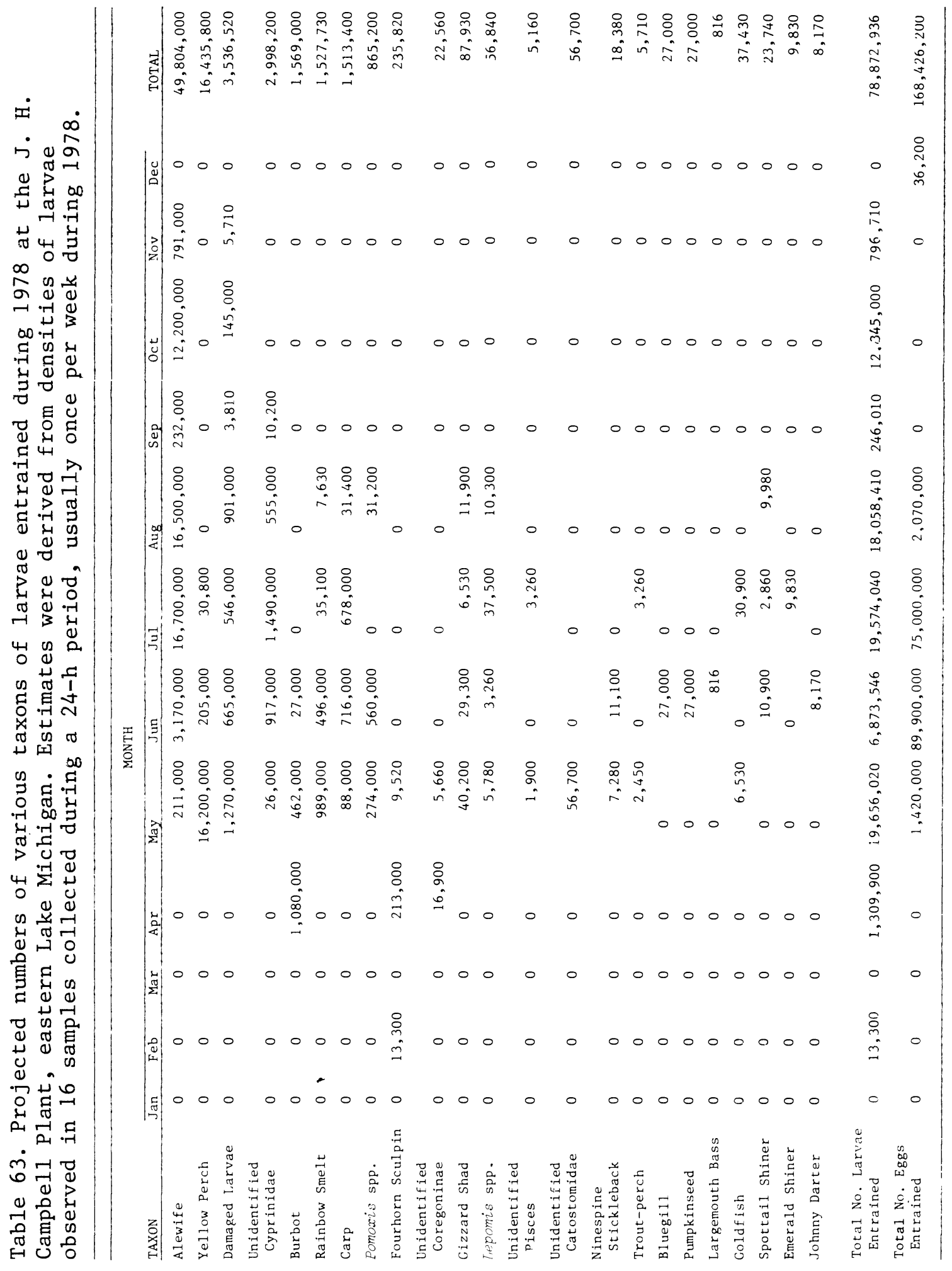


and carp were also entrained. Over 800 thousand Pomoxis spp. and about 200 thousand fourhorn sculpin were the only other taxons exhibiting significant entrainment rates. The remaining 14 taxons all were entrained in estimated numbers ranging from a low of 816 (largemouth bass) to a high of 87,930 (gizzard shad).

In January, no larvae were entrained, while February marked the first time larvae (burbot - 13,300) were observed in entrainment samples (Table 63). No larvae were collected in March. By April, three species, burbot $(1,080,000)$, fourhorn sculpin $(213,000)$ and unidentified Coregoninae $(16,900)$ appeared in entrainment samples. These species are believed to have originated from Lake Michigan. In May, the most taxons were represented in entrainment samples. Yellow perch dominated the samples with over 16 million entrained, while almost 1 million smelt were also observed. These perch originated in Pigeon Lake, while smelt clearly came from Lake Michigan. Numbers of larvae entrained in June (almost 7 million) were considerably lower than May levels (over 19 million). Alewives were entrained in highest numbers ( 3.17 million) in June, followed by unidentified cyprinids (917 thousand), carp (716 thousand), damaged larvae (665 thousand) and crappie larvae (560 thousand). Entrainment rates for July and August were similar with over 18 million larvae passing through the plant. Alewives again were overwhelmingly dominant in both months, when over 16 million were entrained. Damaged larvae and unidentified cyprinids were the next most frequent taxons observed in entrainment samples. By September entrainment rates had declined considerably, since on1y 246,010 larvae (alewife, damaged larvae, unidentified cyprinids) were estimated entrained at the plant. A significant increase in larvae entrained in October $(12,345,000)$ over September levels $(246,010)$ was documented. Alewives (over 12 million) and damaged larvae were the only two groups continued to be entrained in November, but in lesser numbers $(796,710)$. No larvae were collected during December. For more discussion and details on individual species and groups see RESULTS AND DISCUSSION - FISH LARVAE AND ENTRAINMENT STUDY.

Fish eggs were only entrained during May through August and December. For the year over 168 million eggs were estimated to have been entrained. Most eggs ( 89.9 million) were entrained during June and were thought to be those of alewife. Another 75 million eggs were entrained in July and over 2 million were entrained in August. The 36,200 eggs estimated entrained in December were thought to belong to burbot, which spawn during this time period in Lake Michigan. 
FISH LARVAE TOTAL LENGTH-BODY DEPTH RELATIONSHIP

Fish larvae (293) of eight different species were measured. Alewife (Fig. 168), carp, rainbow smelt, spottail shiner (Fig. 168), trout-perch and yellow perch all showed a linear relationship between total length (TL) and body depth with high coefficients of determination $\left(\mathrm{R}^{2}\right.$ greater than or equal to 0.85) (Table 64). Cottus spp. (Fig. 169) and to a lesser extent johnny darter showed a curvilinear total length-body depth relationship due to yolk sac influence (Table 64).

Table 64. Summary of total length-body depth regression analyses for common Lake Michigan larval fishes. $\mathrm{R}^{2}$ = coeffient of determination, $\mathrm{N}=$ sample size.

\begin{tabular}{|c|c|c|c|c|c|}
\hline Species & Slope & Y-intercept & $\mathrm{R}^{2}$ & $\begin{array}{l}\text { Mean square } \\
\text { error }\end{array}$ & $\mathrm{N}$ \\
\hline Alewife & 0.12066 & -0.19394 & 0.85 & 0.12826 & 45 \\
\hline Carp & 0.21047 & -0.43143 & 0.88 & 0.12606 & 29 \\
\hline Cottus spp.* & 0.09081 & 1.1199 & 0.26 & 0.77507 & 28 \\
\hline Cottus spp. $\dagger$ & 0.16284 & -0.21346 & 0.83 & 0.12939 & 13 \\
\hline Johnny darter* & 0.13094 & 0.24291 & 0.85 & 0.15362 & 30 \\
\hline Johnny dartert & 0.16447 & -0.38820 & 0.92 & 0.07067 & 19 \\
\hline Rainbow smelt & 0.10106 & -0.19790 & 0.89 & 0.06530 & 35 \\
\hline Spottail shiner & 0.16694 & -0.27915 & 0.95 & 0.05531 & 54 \\
\hline Trout-perch & 0.18882 & -0.21302 & 0.97 & 0.04973 & 21 \\
\hline Yellow perch & 0.16895 & -0.29021 & 0.95 & 0.05394 & 51 \\
\hline
\end{tabular}

* Calculated from all available data.

+ Calculated excluding yolk-sac larval data.

of species analyzed alewife, carp, rainbow smelt, spottail shiner and yellow perch were among fish most frequently entrained at the J. H. Campbell Plant with the existing cooling water intake which draws water from Lake Michigan and Pigeon Lake. Cottus spp., johnny darter and trout-perch are species potentially susceptible to entrainment when offshore intakes (presently under construction) are made operational. 

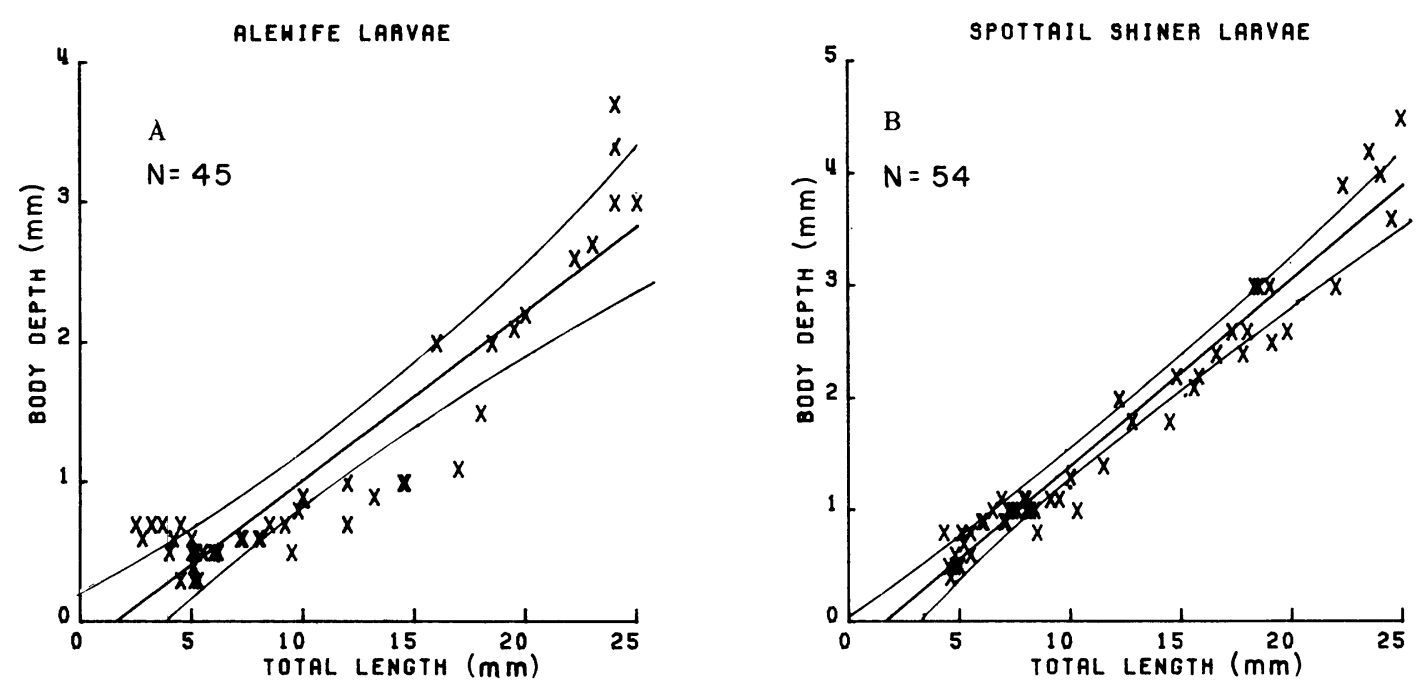

Fig. 168. Scatter plots, regression lines and $95 \%$ confidence bands for total lengths and body depths of two species of fish larvae from Lake Michigan. $\mathrm{N}=$ sample size.
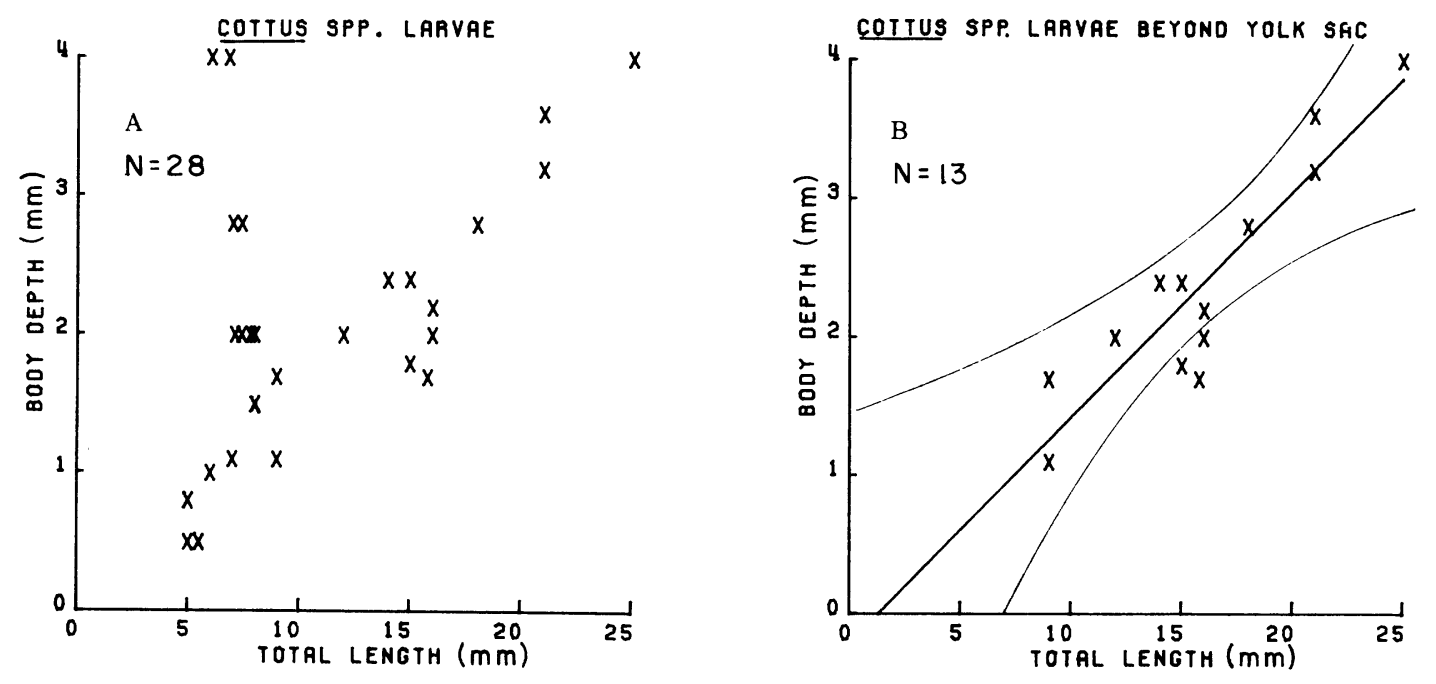

Fig. 169. Relationship between body depth and total length for Cottus spp. found in Lake Michigan. A) scatter plot of all available data, B) scatter plot, regression line and $95 \%$ confidence bands for the total length-body depth relationship excluding yolk-sac data. $\mathrm{N}=$ sample size. 
For alewife, the most abundant larval species entrained at the Campbel1 Plant, 45 fish were measured. The smallest was $2.5 \mathrm{~mm}$ TL with a corresponding body depth of $0.3 \mathrm{~mm}$. In literature reviewed by Jones et al. (1978) $2.5 \mathrm{~mm}$ was the lower limit of the hatching size range for alewife. Recently hatched larvae of this and most other species were entrained at the Campbell Plant in far greater numbers than were larger larvae (Jude et al. 1978), and newly hatched alewife could pass, head on, through a $0.5-\mathrm{mm}$ screen. The largest alewife larva measured was $25.0 \mathrm{~mm}$ with a body depth of $3.7 \mathrm{~mm}$. The regression of body depth on total length was linear with a $\mathrm{R}^{2}$ value of 0.85 (Table 64, Fig. 168). Many alewife fry (greater than $25 \mathrm{~mm}$ ) were also entrained at the Campbell Plant but these would be excluded by any mesh screens less than $2.9 \mathrm{~mm}$ employed at intakes.

Twenty-nine carp larvae from 3.5 to $24.5 \mathrm{~mm}$ TL and from 0.3 to $4.8 \mathrm{~mm}$ in depth were measured. Newly hatched carp may range from 3.0 to $6.4 \mathrm{~mm}$ (Lippson and Moran 1974). Few 15.1-to 25.0-mm carp larvae were available, but of carp measured a linear relationship $\left(R^{2}=0.88\right)$ was found between total length and body depth (Table 64).

Rainbow smelt larvae were entrained in greatest numbers during their peak hatching period in May 1978. The relationship between smelt total length and body depth was linear $\left(\mathrm{R}^{2}=0.89\right.$ ) (Table 64$)$. Of fish measured, the smallest (newly hatched) was $4.0 \mathrm{~mm}$ with a body depth of $0.2 \mathrm{~mm}$. As with alewife, newly hatched rainbow smelt could pass, head on, through a $0.5-\mathrm{mm}$ screen. The longest rainbow smelt larva measured $25 \mathrm{~mm}$ and was $2.7 \mathrm{~mm}$ in depth. Large numbers of fry (greater than $25 \mathrm{~mm}$ ) of this species were entrained at Campbell during late summer and fall, but these would be excluded by small mesh sizes $(0.5,1.0$ and $2.0 \mathrm{~mm})$.

The 54 spottail shiner larvae measured showed a linear relationship between total length and body depth with a high (0.95) coefficient of determination (Table 64, Fig. 168). Minimum length of larvae measured was $4.3 \mathrm{~mm}$; minimum depth was $0.4 \mathrm{~mm}$. Maximum values were $24.9 \mathrm{TL}$ and $4.5 \mathrm{~mm}$ for body depth. Hatching length of spottail shiners is generally 4.6 to $6.1 \mathrm{~mm}$ according to Wang and Kernehan (1979). Positively identified spottail shiner larvae were rarely entrained at the Campbell Plant (Jude et al. 1978), but unidentified minnow larvae (most of which may have been spottail shiners) were entrained periodically in high numbers.

Trout-perch larvae showed a linear relationship between total length and body depth with the highest coefficient of determination (0.97) of any species examined (Table 64). The 21 fish measured ranged from 4.5 to $25.0 \mathrm{~mm} \mathrm{TL}$ and from 0.6 to $4.5 \mathrm{~mm}$ in depth.

Apparently only newly hatched yellow perch were entrained at the Campbell Plant. In swimming speed tests conducted by Houde (1969), 6.5-mm yellow perch did not respond to currents $(2-7 \mathrm{~cm} / \mathrm{s})$, but allowed themselves to be rolled along the length of the testing tube. Larvae of increasing length (up to $14 \mathrm{~mm}$ ) oriented to current and became successively stronger at resisting given currents for longer periods of time (Houde 1969). Minimum hatching length of yellow perch near the Campbell Plant was $4.8 \mathrm{~mm}$. Jones et al. (1978) also reported $4.8 \mathrm{~mm}$ as minimum hatching length for yellow perch. Minimum body depth found was $0.5 \mathrm{~mm}$. Maximum length measured for yellow perch larvae was $25.0 \mathrm{~mm}$; maximum body depth was $3.8 \mathrm{~mm}$. Total length and body depth of larval perch exhibits a linear relationship. 
Species showing curvilinear relationships between total length and body depth had large body depth values at relatively short total lengths due to the presence of a sizeable yolksac. As the yolk sac was absorbed, body depth decreased as length increased. After yolk sac absorption, body depth increased with length as with other species. Cottus spp., for which 28 specimens were measured, ranged from 5.0 to $25.0 \mathrm{~mm}$ TL and from 0.5 to $4.0 \mathrm{~mm}$ in depth. The smaller body depths observed may have been due to broken yolk sacs of specimens examined. Greatest body depth, $4.0 \mathrm{~mm}$, corresponded to lengths of 6.0 to $6.8 \mathrm{~mm}$. Body depth then fell sharply with yolk sac absorption and increasing length. At $9.0 \mathrm{~mm} \mathrm{TL}$, body depths had decreased to $1.1-1.7 \mathrm{~mm}$ while above $9.1 \mathrm{~mm}$ TL, both length and body depth increased proportionately (Fig. 169). The regression of body depth on total length for 13 sculpin larvae greater than $9.0 \mathrm{~mm}$ TL (beyond yolksac absorption) indicated a linear relationship with a high coefficient of determination $\left(\mathrm{R}^{2}=0.83\right.$ ) (Table 64, Fig. 169).

Thirty johnny darters were measured with a length range of 3.0 to $25.0 \mathrm{~mm}$ and a body depth range of 0.6 to $3.9 \mathrm{~mm}$. Much variation in measurements was observed. For example, body depth was as great as $1.8 \mathrm{~mm}$ for lengths of around $5.0 \mathrm{~mm}$ while other specimens of comparable length had body depths of only 0.7 , 0.9 and $1.1 \mathrm{~mm}$. As with sculpin larvae, smaller body depths observed for johnny darter may have been due to broken yolk sacs of specimens examined. At lengths of about $8.0 \mathrm{~mm}$, when the yolk sac was absorbed, body depths were between 0.7 and $0.8 \mathrm{~mm}$. Beyond this length, both total length and body depth increased proportionately to maximum values measured. For 19 johnny darters beyond the yolksac stage, body depth and total length were linearly related with a high $\left(\mathrm{R}^{2}=0.92\right)$ coefficient of determination (Table 64).

Of species examined, alewife and smelt required growth well beyond the most frequently entrained, newly hatched size before body depths of $0.5,1.0$ and $2.0 \mathrm{~mm}$ (corresponding to commonly proposed mesh sizes) were attained (Table 65). Consequently these two species must reach greater size, relative to other species analyzed, before they could be excluded by small screen meshes. Newly hatched alewives that were entrained in May, June and July 1978 (Fig. 92) could pass through a $0.5-\mathrm{mm}$ mesh screen. Of a projected 211,000 alewife larvae entrained in May 1978, it was estimated that only $27 \%$ would have been large enough to have been excluded by a $0.5-\mathrm{mm}$ mesh screen, while mesh screens of 1.0 and $2.0 \mathrm{~mm}$ may not have excluded any alewife of this early life stage (Table 66). Protection for only $18 \%$ of the estimated 3.17 million alewife larvae entrained in June 1978 would have been provided by a 0.5-am screen (Table 66). Numbers of entrained alewife were greatest in July ( 16.7 million) and August (16.5 million) and predicted percentages of exclusion by 0.5 -and $1.0-\mathrm{mm}$ mesh screens increased somewhat (15-33\%) during these months due to larval growth (Table 66). However, not until September, when 232,000 alewife larvae were entrained, was $100 \%$ exclusion predicted if 0.5 -or $1.0-\mathrm{mm}$ mesh screens had been employed (Table 66).

Eighty-five percent of a projected 989,000 entrained rainbow smelt larvae, in May (newly hatched), could have passed through 0.5-mm mesh screens, but quickly growing smelt larvae would have become increasingly less susceptible to entrainment through fine-mesh screens in later months (Table 66). By June, $46 \%$ of 496,000 entrained smelt larvae, and all rainbow smelt entrained in July $(35,100)$ and August $(7,630)$ could have been excluded by a $0.5-\mathrm{mm}$ mesh screen (Table 66). 
Table 65. Total length in millimeters at which common Lake Michigan larval fish would attain a body depth of $0.5,1.0$ and $2.0 \mathrm{~mm}$. Total length values were calculated from regression equations.

\begin{tabular}{lccc}
\hline & \multicolumn{3}{c}{ Body depth (mm) } \\
\cline { 2 - 4 } Species & 0.5 & 1.0 & 2.0 \\
\hline Alewife & 5.8 & 9.9 & 18.2 \\
Carp & 4.4 & 6.8 & 11.6 \\
Cottus spp. * & $\dagger$ & $\dagger$ & 13.6 \\
Johnny darter $*$ & $\dagger$ & 8.4 & 14.5 \\
Rainbow smelt & 6.9 & 11.9 & 21.8 \\
Spottail shiner & 3.7 & 7.7 & 13.7 \\
Trout-perch & 4.7 & 6.4 & 11.7 \\
Yellow perch & 7.6 & 13.6 \\
\hline
\end{tabular}

* Calculated excluding yolk sac data.

+ Predicted lengths not within valid range of regression equation because yolk sac larvae were deleted.

Table 66. Percentages of some common Lake Michigan fish larvae entrained at the J. H. Campbell Plant that could be excluded by $0.5-, 1.0-$ and $2.0-\mathrm{mm}$ mesh screens. Percentage calculated from 1978 length-frequency entrainment data. Blank spaces represent no data.

\begin{tabular}{|c|c|c|c|c|c|c|c|c|c|}
\hline \multirow[b]{2}{*}{ Species } & \multirow{2}{*}{$\begin{array}{c}\text { Mesh size } \\
(\mathrm{mm})\end{array}$} & \multicolumn{8}{|c|}{ Month } \\
\hline & & May & Jun & $\mathrm{Ju} 1$ & Aug & Sep & Oct & Nov & Combined \\
\hline \multirow[t]{3}{*}{ Alewife } & 0.5 & 27 & 18 & 21 & 33 & 100 & 100 & 100 & 35 \\
\hline & 1.0 & 0 & 4 & 15 & 16 & 100 & 100 & 100 & 24 \\
\hline & 2.0 & 0 & 0 & 0 & 7 & 97 & 88 & 86 & 13 \\
\hline \multirow[t]{3}{*}{ Carp } & 0.5 & 100 & 99 & 100 & 100 & & & & 99 \\
\hline & 1.0 & 45 & 59 & 18 & 0 & & & & 41 \\
\hline & 2.0 & 0 & 0 & 0 & 0 & & & & 0 \\
\hline \multirow[t]{3}{*}{ Rainbow smelt } & 0.5 & 15 & 46 & 100 & 100 & & & & 29 \\
\hline & 1.0 & 0 & 17 & 87 & 100 & & & & 9 \\
\hline & 2.0 & 0 & 1 & 24 & 100 & & & & 1 \\
\hline \multirow[t]{3}{*}{ Spottail shiner } & 0.5 & & 100 & 100 & 100 & & & & 100 \\
\hline & 1.0 & & 100 & 100 & 100 & & & & 100 \\
\hline & 2.0 & & 0 & 0 & 0 & & & & 0 \\
\hline \multirow[t]{3}{*}{ Yellow perch } & 0.5 & 99 & 100 & 100 & & & & & 99 \\
\hline & 1.0 & 13 & 36 & 42 & & & & & 14 \\
\hline & 2.0 & 0 & 0 & 0 & & & & & 0 \\
\hline
\end{tabular}


Other species for which length-frequency data were available (carp, spottail shiner and yellow perch) would theoretically have been almost totally protected from entrainment by a $0.5-\mathrm{mm}$ mesh screen during all months in 1978

(Table 66). Minnow larvae less than $9.0 \mathrm{~mm}$ were difficult to positively identify, but if all unidentified minnow larvae that were entrained at the Campbell Plant in 1978 were considered spottail shiners in calculations, the predicted exclusion by $0.5-\mathrm{mm}$ mesh screens would have been $85 \%$ in May and higher in subsequent months. For carp and yellow perch, 99-100\% protection from entrainment would have been provided by a $0.5-\mathrm{mm}$ mesh screen (Table 66).

Estimates of exclusion (Table 66) were made assuming that fish larvae pass through screens head first and that larvae with body depths equal to mesh size would be excluded. However, Tomljanovich et al. (1977) found that fish with body depths up to $84 \%$ greater than mesh size could be compressed and pass through the mesh depending in part on approach velocity of intake water. Behavioral avoidance by fish larvae of screens or currents created by them may also have a large effect on numbers of larvae entrained. The percentage of fish larvae excluded by small-mesh screens would thus span a certain range of larval total lengths and not be as precise as this paper presents. A further point not considered here is mortality of excluded larval fish due to impingement on small mesh screens. Tomljanovich et al. (1977) found that survival of fish larvae on screens was related inversely to impingement duration. Both Tomljanovich et al. (1977) and Hadderingh (1974) recorded mortality due to impingement of some species as great as $100 \%$. If the decision were made to employ small-mesh screens at cooling water intakes, a solution to prevent larval fish from dying or being severely damaged against the screens must be found.

More data on total length-body depth relationships for other species of fish larvae are needed. Based on species examined in this paper however, it appeared that a relationship could be established between total length and body depth of larval fish and that this relationship could be useful in predicting the effectiveness of various sizes of intake screens in preventing entrainment of fish larvae. 
PRODUCTION FOREGONE ESTIMATES DUE TO ENTRAINMENT AND IMPINGEMENT

\section{Introduction}

Objectives--

The objectives of this section are to (1) estimate productivity potentially lost for three major species, (2) examine the sensitivity of these estimates to the numerous assumptions required and (3) relate these potential losses to the real world.

Statement of Problem--

The cooling 'water requirements of the Campbell Power Plant require the withdrawal of large quantities of Lake Michigan and sometimes Pigeon Lake water. The subsequent entrainment and impingement of fishes represent an unknown impact on the structure and function of the nearshore Lake Michigan and Pigeon Lake ecosystems. One way to examine this impact is to estimate the biomass production foregone due to operation of the plant. Production of a population is defined as the total elaboration of biomass irrespective of its fate (Ivlev 1966). These computations are based on data we collected on entrainment and impingement at the Campbel1 Plant during 1978.

Production calculations require some parameter estimates which neither have been estimated nor can be estimated from the Great Lakes Research Division data base. Consequently literature values have been used where appropriate. Use of the GLRD data base and literature values required some modifications of standard procedures for calculation of production. Those changes are described in detail in the METHODS section (see Production Foregone Estimates Due to Entrainment and Impingement) of this report.

\section{$\underline{\text { Results }}$}

Parameter Estimates--

A number of parameters were required for an analysis of production foregone due to entrainment and impingement of fish at the Campbel1 Plant. Parameters were needed for the three most abundant species collected. Some parameters were estimated from the Great Lakes Research Division data base for the D.C. Cook Nuclear Power Plant. Mean weights of prolarvae and postlarvae were derived from this data base, as were the length-weight regression parameters. Previous sensitivity analyses (Rago 1978) demonstrated that mean weights of prolarvae and postlarvae had little effect on the production foregone estimate. Similarly, statistically significant differences between length-weight regression parameters between fish populations in the vicinity of the Cook and Campbell Power Plants are unlikely. Estimates of the age structure of entrained larvae (Table 67) were determined from cumulative length-frequencies of $\mathrm{f}$ ish larvae taken from entrainment samples. Estimates of total larvae entrained were taken from our computer data summaries. 
Table 67. Estimated numbers of prolarvae and postlarvae entrained at the J.H. Campbe11 Power Plant during 1978.

\begin{tabular}{llllll}
\hline & $\begin{array}{l}\text { Estimated } \\
\text { Total No. }\end{array}$ & $\begin{array}{l}\text { Critical Length } \\
\text { between prolarvae } \\
\text { and postlarvae (mm) }\end{array}$ & $\begin{array}{l}\text { Class of } \\
\text { larvae }\end{array}$ & $\begin{array}{l}\text { Estimated } \\
\text { percent }\end{array}$ & $\begin{array}{l}\text { Estimated } \\
\text { number }\end{array}$ \\
Species & larvae & & \\
\hline
\end{tabular}

\begin{tabular}{lrrlrr} 
Alewife & $49,804,000$ & 5.0 & & & \\
& & & PRO & 54.9 & $27,809,296$ \\
Rainbow & $1,527,730$ & 6.4 & POST & 45.1 & $22,866,208$ \\
Smelt & & & PRO & 82.5 & $1,399,100$ \\
Yellow & $16,435,800$ & 7.0 & POST & 17.5 & 297,660 \\
Perch & & & PRO & 95.0 & $16,992,000$ \\
& & & POST & 5.0 & 901,720 \\
\hline
\end{tabular}

*

Critical lengths for the transition from prolarvae to postlarvae were determined via consultations with John Dorr, Great Lakes Research Division.

Calculation of the mean weight of prolarvae and postlarvae required estimates of the mean weight of larvae by length class and the distribution of length classes within each age-group (i.e. prolarvae and postlarvae). Mean weights of larvae by length class (Table 68) showed that the standard deviations increased with length as often found in length-weight relations for adult fish. Limited numbers of specimens of rainbow smelt and yellow perch were obtained from our collections. Absence of larvae from certain length intervals may be due to sampling variability or behavioral modifications which decrease a larva's susceptibility to entrainment or capture by nets. The frequency estimates by length class were obtained from cumulative length-frequencies of fish larvae from intake and discharge entrainment samples in 1975 at the D.C. Cook Nuclear Power Plant.

The mean weight of prolarvae and postlarvae were obtained by multiplying the mean weight of larvae by their frequency (as given in Table 68) and summing over the appropriate length range.

Age-length keys obtained from the Great Lakes Fishery Laboratory (GLFL), U.S. Fish and Wildlife Service, Ann Arbor, Michigan are summarized in Tables 69 through 71. All data are unpublished and preliminary but are probably the best data available for Lake Michigan stocks. Age-length keys were chosen to coincide as closely as possible with the years in which entrainment and impingement occurred. Sample locations are relatively close to the Campbell Plant. Pertinent information regarding each data set is summarized in the table headings. 
Table 68. Estimated weights of prolarvae and postlarvae derived from preserved specimens collected at the Cook Plant from 1973 through 1977. Length frequencies of fish larvae were estimated from the cumulative length frequency of larvae from intake and discharge samples collected during 1975.

\begin{tabular}{|c|c|c|c|c|c|}
\hline Species & $\begin{array}{l}\text { Length } \\
\text { Range } \\
(\mathrm{mm})\end{array}$ & $\underset{\%}{\text { Frequency }}$ & $\begin{array}{l}\text { Number } \\
\text { specimens } \\
\text { weighed }\end{array}$ & $\begin{array}{c}\text { Mean } \\
\text { weight } \\
\left(g \times 10^{-3}\right)\end{array}$ & $\begin{array}{l}\text { Standard } \\
\text { deviation } \\
\left(\times 10^{-3}\right)\end{array}$ \\
\hline Alewife & $\begin{array}{l}0.5-5.0 \\
5.1-7.0 \\
7.1-9.0 \\
9.1-11.0 \\
11.1-13.0 \\
13.1-15.0 \\
15.1-17.0 \\
17.1-19.0 \\
19.1-21.0 \\
21.1-23.0 \\
23.1-25.0\end{array}$ & $\begin{array}{r}94.62 \\
2.32 \\
.79 \\
.36 \\
.39 \\
.30 \\
.16 \\
.74 \\
.15 \\
.19 \\
0.0\end{array}$ & $\begin{array}{l}5 \\
5 \\
5 \\
5 \\
5 \\
5 \\
5 \\
5 \\
5 \\
5 \\
5\end{array}$ & $\begin{array}{r}.03 \\
.09 \\
.69 \\
1.03 \\
2.20 \\
4.50 \\
8.59 \\
12.89 \\
22.29 \\
34.62 \\
64.84\end{array}$ & $\begin{array}{r}.02 \\
.07 \\
.20 \\
.19 \\
.39 \\
.97 \\
.90 \\
2.89 \\
2.84 \\
4.54 \\
12.43\end{array}$ \\
\hline $\begin{array}{l}\text { Rainbow } \\
\text { Smelt }\end{array}$ & $\begin{array}{l}2 \cdot 5-4 \cdot 4 \\
4 \cdot 5-6 \cdot 4 \\
6 \cdot 5-8 \cdot 4 \\
8 \cdot 5-10 \cdot 4 \\
10 \cdot 5-12.4 \\
12 \cdot 5-14 \cdot 4 \\
14 \cdot 5-16 \cdot 4 \\
16 \cdot 5-18 \cdot 4 \\
18 \cdot 5-20 \cdot 4 \\
20 \cdot 5-22 \cdot 4 \\
22 \cdot 5-24.4\end{array}$ & $\begin{array}{l}0.0 \\
69.54 \\
9.39 \\
0.0 \\
0.0 \\
4.31 \\
0.0 \\
0.0 \\
6.60 \\
9.90 \\
0.0\end{array}$ & $\begin{array}{l}0 \\
5 \\
5 \\
3 \\
0 \\
0 \\
3 \\
2 \\
3 \\
2 \\
1\end{array}$ & $\begin{array}{c}-- \\
.17 \\
.28 \\
.67 \\
-- \\
-- \\
5.48 \\
5.43 \\
15.10 \\
14.73 \\
27.55\end{array}$ & $\begin{array}{l}-- \\
.08 \\
.06 \\
.33 \\
-- \\
-- \\
1.43 \\
2.02 \\
4.68 \\
8.31 \\
--\end{array}$ \\
\hline $\begin{array}{r}\text { Yellow } \\
\text { Perch }\end{array}$ & $\begin{array}{l}0.5-5.0 \\
5.1-7.0 \\
7.1-9.0 \\
9.1-11.0 \\
11.1-13.0 \\
13.1-15.0 \\
15.1-17.0 \\
17.1-19.0 \\
19.1-21.0 \\
21.1-23.0 \\
23.1-25.0\end{array}$ & $\begin{array}{r}0.0 \\
100.0 \\
0.0 \\
0.0 \\
0.0 \\
0.0 \\
0.0 \\
0.0 \\
0.0 \\
0.0 \\
0.0\end{array}$ & $\begin{array}{l}0 \\
5 \\
4 \\
4 \\
0 \\
0 \\
0 \\
2 \\
1 \\
5 \\
5\end{array}$ & $\begin{array}{c}-- \\
.91 \\
1.54 \\
3.99 \\
-- \\
-- \\
-- \\
70.73 \\
97.80 \\
100.04 \\
129.53\end{array}$ & $\begin{array}{c}-- \\
.65 \\
.40 \\
1.18 \\
-- \\
-- \\
-- \\
9.65 \\
-- \\
23.46 \\
22.86\end{array}$ \\
\hline
\end{tabular}


Table 69. Age-length key for alewives expressed as percentage of fish in size class $m$ which are members of age-group $i$. Scales were taken from trawlcaught alewives collected off Benton Harbor by Great Lakes Fishery Laboratory (GLFL) personnel. Fishing was conducted on 22 October 1975 and 30 Octoher 1975 using a 12-m trawl towed by the R/V Cisco (Preliminary unpublished data GLFL, Ann Arbor, Michigan).

\begin{tabular}{|c|c|c|c|c|c|c|c|c|}
\hline \multirow{2}{*}{$\begin{array}{l}\text { Length } \\
\text { Range* } \\
(\mathrm{mm})\end{array}$} & \multicolumn{7}{|c|}{ Age-group } & \multirow{2}{*}{$\begin{array}{l}\text { No. of } \\
\text { fish } \\
\text { aged }\end{array}$} \\
\hline & 1 & 2 & 3 & 4 & 5 & 6 & 7 & \\
\hline $110-119$ & 100 & & & & & & & $0 \dagger$ \\
\hline $120-129$ & 84.6 & 7.7 & 7.7 & & & & & 13 \\
\hline $130-139$ & & 100 & & & & & & 2 \\
\hline $140-149$ & & 50 & 41.7 & 8.3 & & & & 12 \\
\hline $150-159$ & & 6.9 & 62.1 & 24.1 & 6.9 & & & 29 \\
\hline $160-169$ & & 5.4 & 27.3 & 45.5 & 20 & 1.8 & & 55 \\
\hline $170-179$ & & & 4.6 & 44.4 & 38.9 & 11.1 & 0.9 & 108 \\
\hline $180-189$ & & & 0.8 & 24.8 & 55.2 & 16 & 3.2 & 125 \\
\hline $190-199$ & & & 2.0 & 11.8 & 39.2 & 29.4 & 17.6 & 51 \\
\hline $200-209$ & & & & & 38.1 & 33.3 & 28.6 & 21 \\
\hline $210-219$ & & & & & & 50 & 50 & 4 \\
\hline $220-229$ & & & & & & & 100 & 0非 \\
\hline $230-239$ & & & & & & & 100 & 0\# \\
\hline
\end{tabular}

* All alewives below $110 \mathrm{~mm}$ are considered to be YOY by GLFL (Edward Brown, personal communication, Great Lakes Fishery Laboratory, U.S. Fish and Wildlife Service, Ann Arbor, Michigan).

$+\quad$ These fish are pelagic and not recruited to the experimental trawl fishery. All fish were assigned to age-group 1.

\# No fish aged in this interval; assignment made by GLRD. 
Table 70. Age-length key for rainbow smelt expressed as percentage of fish in size class $m$ who are memhers of agegroüp i. Scales were taken from rainbow smelt caught in trawls off Michigan City, Indiana during summer 1976. Both sexes were combined (unpublished data - Great Lakes Fishery Laboratory, Ann Arbor, Michigan).

\begin{tabular}{|c|c|c|c|c|c|c|}
\hline \multirow{2}{*}{$\begin{array}{l}\text { Length } \\
\text { Interval } \\
(\mathrm{mm})\end{array}$} & \multicolumn{5}{|c|}{ Age-group } & \multirow{2}{*}{$\begin{array}{l}\text { No. of } \\
\text { fish } \\
\text { aged }\end{array}$} \\
\hline & 0 & 1 & 2 & 3 & 4 & \\
\hline $20-29$ & 100 & & & & & $0 *$ \\
\hline $30-39$ & 100 & & & & & $0 *$ \\
\hline $40-49$ & 100 & & & & & $0 *$ \\
\hline $50-59$ & 100 & & & & & $0 *$ \\
\hline $60-69$ & & 100 & & & & 1 \\
\hline $70-79$ & & 100 & & & & 2 \\
\hline $80-89$ & & 100 & & & & 0非 \\
\hline $90-99$ & & 100 & & & & 0非 \\
\hline $100-109$ & & 100 & & & & 4 \\
\hline $110-119$ & & 40.6 & 59.4 & & & 7 \\
\hline $120-129$ & & & 100 & & & 12 \\
\hline $130-139$ & & & 100 & & & 23 \\
\hline $140-149$ & & & 87.3 & 12.7 & & 23 \\
\hline $150-159$ & & & 60.9 & 39.1 & & 23 \\
\hline $160-169$ & & & 20.7 & 79.3 & & 10 \\
\hline $170-179$ & & & & 62.7 & 37.3 & 9 \\
\hline $180-189$ & & & & 41.7 & 58.3 & 4 \\
\hline 190-199 & & & & 23.5 & 76.5 & 4 \\
\hline $200-209$ & & & & 20.4 & 79.6 & 6 \\
\hline $210-219$ & & & & & 100 & 1 \\
\hline $220-229$ & & & & & 100 & 3 \\
\hline $230-239$ & & & & & 100 & 1 \\
\hline $240-249$ & & & & & 100 & 0非 \\
\hline $250-259$ & & & & & 100 & 1 \\
\hline $260-269$ & & & & & 100 & 0非 \\
\hline
\end{tabular}

* No fish were aged in this interval by GLFL; all fish assigned to YOY by GLRD.

\# No fish were aged in this interval by GLFL; fish assigned to a single age-group by GLFL. 
Table 71. Age-length key for yellow perch expressed as a percentage of $\mathrm{f}$ ish in size class $m$ which are members of age-group $i$. Scales were taken from fish caught in gill nets off Benton Harbor - St. Joseph, Michigan on 11 July 1975. Data for males and females were pooled by assuming a 50:50 sex ratio for perch $<290 \mathrm{~mm}$ in length. Above this length, all $\mathrm{f}$ ish were assumed to be females. (Unpublished data - Great Lakes Fishery Laboratory, Ann Arbor, Michigan.)

\begin{tabular}{|c|c|c|c|c|c|c|c|c|}
\hline \multirow{2}{*}{$\begin{array}{l}\text { Length } \\
\text { Range } \\
(\mathrm{mm})\end{array}$} & \multicolumn{6}{|c|}{ Age-group } & \multirow{2}{*}{$\begin{array}{c}\text { No. of } \\
\text { fish } \\
\text { aged o }\end{array}$} & \multirow{2}{*}{$\begin{array}{c}\text { No. of } \\
\text { fish } \\
\text { aged } 9\end{array}$} \\
\hline & 2 & 3 & 4 & 5 & 6 & 7 & & \\
\hline $150-159$ & 100 & & & & & & 1 & 0 \\
\hline $160-169$ & 100 & & & & & & 7 & 0 \\
\hline $170-179$ & 100 & & & & & & 1 & 2 \\
\hline $180-189$ & 100 & & & & & & 1 & 3 \\
\hline 190-199 & 100 & & & & & & 1 & 5 \\
\hline $200-209$ & 57.1 & 42.9 & & & & & 3 & 4 \\
\hline $210-219$ & & 100 & & & & & 5 & 0 \\
\hline $220-229$ & & 25 & 75 & & & & 6 & 2 \\
\hline $230-239$ & & 10 & 80 & 10 & & & 9 & 1 \\
\hline $240-249$ & & & 70 & 30 & & & 9 & 1 \\
\hline $250-259$ & & & 16.7 & 83.3 & & & 10 & 2 \\
\hline $260-269$ & & & 41.7 & 33.3 & 25 & & 6 & 6 \\
\hline $270-279$ & & & 10 & 60 & 30 & & 6 & 4 \\
\hline $280-289$ & & & 30 & 40 & 30 & & 1 & 9 \\
\hline $290-299$ & & & & 100 & & & 0 & 4 \\
\hline $300-309$ & & & & 89.9 & 11.1 & & 0 & 9 \\
\hline $310-319$ & & & & & 100 & & 0 & 5 \\
\hline $320-329$ & & & & & 66.7 & 33.3 & 0 & 3 \\
\hline $330-339$ & & & & & 50 & 50 & 0 & 2 \\
\hline $340-349$ & & & & & & 100 & 0 & 2 \\
\hline $350-359 *$ & & & & & & 100 & 0 & 0 \\
\hline
\end{tabular}

* Fish of this length range were assigned to age-group 7 by GLRD. 
The length-weight regression parameters which were used to transform length-frequencies to weight-frequencies are summarized in Table 72. The most representative month for each species was determined subjectively by considering the annual reproductive cycle of each species and the seasonal abundance pattern.

The empirical relations between fecundity and length (Table 73) were obtained directly or derived from data given in the literature. This distribution of lengths within an age-group $\left(b_{m, j}\right.$ in equation 17$)$ were derived from the same data as the $a_{i, m}$ in equation 11 . Hence these $b_{m}, j$ are undoubtedly biased. It is not possible at this time to ascertain an unbiased $b_{m, j}$ without additional information from the staff at GLFL. Consequently the $b_{m}, j$ should be regarded as first approximations. The bias in $b_{m}, j$ affects the agespecific fecundity estimates in Table 74. Values of overall survival from egg to mean adult (S) given in Table 75 were used in conjunction with the adult survival rates to calculate $S_{X}$ in Table 74 (see METHODS - Production Foregone Estimates Due to Entrainment and Impingement).

Several points must be made concerning the calculation of $\mathrm{S}_{\mathrm{X}}$ (Table 75). In each case, the calculated values were orders of magnitude higher than values given in the literature. Survival rates in the literature are difficult to interpret and apply directly to this production estimate. However the entire body of evidence suggests that survival rates are much less than 1\%. Nalco (1976 - cited in Nalco Environmental 1975) stated that alewife survival from egg to the larval migratory stage was $0.06 \%$. In Bride Lake, Connecticut, Kissil (1974) estimated survival from egg to seaward migrant as $.0013 \%$ (or 1 migrant per 80,000 eggs). Havey (1973) estimated that the number of juvenile emigrants per spawning female alewife ranged from 12 to 3209. Assuming an average anadromous alewife fecundity of 100,000 (Smith 1970) implies a first-year survival from 0.12 to $3.2 \%$. Survival data for yellow perch are similarly disjointed. Clady (1976) estimated the average survival of yellow perch to $8 \mathrm{~mm}$ to be $7.7 \%$. Average survival for perch $8-20 \mathrm{~mm}$ was $37 \%$ for perch captured between 1965 and 1967 (Noble 1968). Juvenile survival of perch was estimated to be roughly $8 \%$ from a rate given by Forney (1971). Considering these three rates together implies a first-year survival rate of about $0.2 \%$. A survival estimate for rainbow smelt from egg through prolarvae was about 0.5\% in Branch Lake, Maine (Rothschild 1961). Thus applying an overall firstyear survival rate of $1 \%$ for each species is very conservative and may considerably overestimate the power plant's effect on impacted populations. The length-frequencies of impinged alewives, rainbow smelt and yellow perch are given in Table 76.

Estimated Production Foregone--

The calculation of production foregone due to operation of the Campbell Plant involves many assumptions. The assumptions and variability related to model development have already been discussed. At this point, it is necessary to explicitly state the assumptions regarding the actual estimates of foregone production. 
Table 72. Summary of length-weight regression parameters derived from $\mathrm{D}$. C. Cook Plant data. These parameters were used for transforming length to weight for species impinged and entrained at the J. H. Campbell Plant. The regression equation is $\log _{10} \mathrm{~W}=\hat{\mathrm{a}}+\hat{\mathrm{b}} \log _{10} \mathrm{~L}$. It was assumed that fish in the vicinity of the J. H. Campbell Plant could be described by regression equations similar to those derived for fish at the D. C. Cook Plant.

\begin{tabular}{|c|c|c|c|c|c|c|c|}
\hline Species & Month & Year & Sex* & $\mathrm{N}$ & â & $\mathrm{b}$ & $\mathrm{R}^{2}$ \\
\hline & & & & & & & \\
\hline \multirow[t]{4}{*}{ Alewife } & Jun & 1973 & M & 469 & -4.2282 & 2.5647 & .84974 \\
\hline & & & $\mathrm{F}$ & 257 & -4.1601 & 2.5456 & .83670 \\
\hline & & & $\mathrm{C}$ & $\mathrm{NA}$ & -4.19415 & 2.5552 & NA \\
\hline & Oct & 1973 & I & 535 & -5.4537 & 3.1967 & .94605 \\
\hline \multirow{4}{*}{$\begin{array}{c}\text { Spottail } \\
\text { Shiner }\end{array}$} & May & 1974 & M & 136 & -5.3416 & 3.1505 & .93859 \\
\hline & & & $\mathrm{F}$ & 453 & -5.5841 & 3.2742 & .93843 \\
\hline & & & C & NA & -5.4629 & 3.2124 & NA \\
\hline & Aug & 1974 & I & 131 & -5.4561 & 3.1830 & .98006 \\
\hline \multirow{4}{*}{$\begin{array}{l}\text { Rainbow } \\
\text { Sme1t }\end{array}$} & Apr & 1973 & M & 250 & -5.5506 & 3.1491 & .93032 \\
\hline & & & $\mathrm{F}$ & 258 & -5.6340 & 3.1917 & .95294 \\
\hline & & & $\mathrm{C}$ & NA & -5.5923 & 3.1704 & NA \\
\hline & Aug & 1973 & I & 436 & -5.4556 & 3.0606 & .89269 \\
\hline \multirow{4}{*}{$\begin{array}{l}\text { Yellow } \\
\text { Perch }\end{array}$} & Jun & 1973 & M & 203 & -4.7978 & 2.9266 & .89628 \\
\hline & & & $\mathrm{F}$ & 525 & -5.0206 & 3.0487 & .92183 \\
\hline & & & $\mathrm{C}$ & NA & -4.9092 & 2.9877 & NA \\
\hline & Oct & 1973 & I & 60 & -5.1478 & 3.0824 & . 96096 \\
\hline
\end{tabular}

* $\mathrm{M}=$ Male, $\mathrm{F}=$ Female, $\mathrm{C}=$ Combined, $\mathrm{I}=$ Immature. Combined estimate is simple arithmetic average of $\hat{a}$ and $\hat{b}$ for males and females.

** Critical lengths above which the adult length-weight regression estimates used were: $110 \mathrm{~mm}$-alewife, $70 \mathrm{~mm}$-spottail shiner, $90 \mathrm{~mm}$-rainbow smelt and 140 mm-yellow perch. 
Table 73. Summary of fecundity-length relationships used in model of production foregone ( $E=$ number of eggs produced; $\mathrm{L}=1$ ength in $\mathrm{mm}$. )

\begin{tabular}{lccc}
\hline Species & Equation & Location & Reference \\
\hline Alewife & $\mathrm{E}=3.518 * \mathrm{~L}-45366$ & Lake Michigan & Norden 1967 \\
$\begin{array}{c}\text { Rainbow } \\
\text { Smelt }\end{array}$ & $\mathrm{E}=10^{\left(4.4 \log _{10}(\mathrm{~L})-5.3660\right)}$ & $\begin{array}{l}\text { Miramichi R. } \\
\text { New Brunswick }\end{array}$ & McKenzie 1964 \\
$\begin{array}{c}\text { Yellow } \\
\text { Perch }\end{array}$ & $\mathrm{E}=10^{\left(3.451 \log _{10}(\mathrm{~L})-3.712\right)}$ & Lake Michigan & Brazo et a1. 1975 \\
\hline
\end{tabular}

Table 74. Average fecundity for each species by age-group. Fecundity is based upon distribution of lengths within each age-group and an empirically determined fecundity-length relationship. Discounted fecundity and survival calculated as in Goodyear (1978).

\begin{tabular}{|c|c|c|c|c|}
\hline Species & $\begin{array}{l}\text { Age- } \\
\text { group }\end{array}$ & $\begin{array}{c}\text { Mean } \\
\text { fecundity } \\
\text { per age-group }\end{array}$ & $\begin{array}{r}\text { Discounted } \\
\text { fecundity }\end{array}$ & $\begin{array}{l}\text { Estimated survival } \\
\text { from egg to adult }\end{array}$ \\
\hline Alewife & $\begin{array}{l}2 \\
3 \\
4 \\
5 \\
6 \\
7\end{array}$ & $\begin{array}{c}6750 \\
11274 \\
16229 \\
18930 \\
21013 \\
23875 \\
\text { Mean 非 Eggs/Recruit }\end{array}$ & $\begin{array}{r}6750 \\
5637 \\
3246 \\
1136 \\
340 \\
89 \\
17198\end{array}$ & $1.1629 \times 10^{-4}$ \\
\hline $\begin{array}{l}\text { Rainbow } \\
\text { Smelt }\end{array}$ & $\begin{array}{l}2 \\
3 \\
4\end{array}$ & $\begin{array}{ll} & 10247 \\
& 26811 \\
& 65728 \\
\text { Mean 非 Eggs/Recruit }\end{array}$ & $\begin{array}{r}10247 \\
7239 \\
4792 \\
22278\end{array}$ & $8.9777 \times 10^{-5}$ \\
\hline $\begin{array}{l}\text { Yellow } \\
\text { Perch }\end{array}$ & $\begin{array}{l}2 \\
3 \\
4 \\
5 \\
6 \\
7\end{array}$ & $\begin{array}{c}15112 \\
22027 \\
47284 \\
56785 \\
79560 \\
103317 \\
\text { Mean Ek Eggs/Recruit }\end{array}$ & $\begin{array}{r}15112 \\
17181 \\
18809 \\
3388 \\
712 \\
139 \\
55342\end{array}$ & $3.6139 \times 10^{-5}$ \\
\hline
\end{tabular}


Table 75. Summary of derived mortality rates for each species.

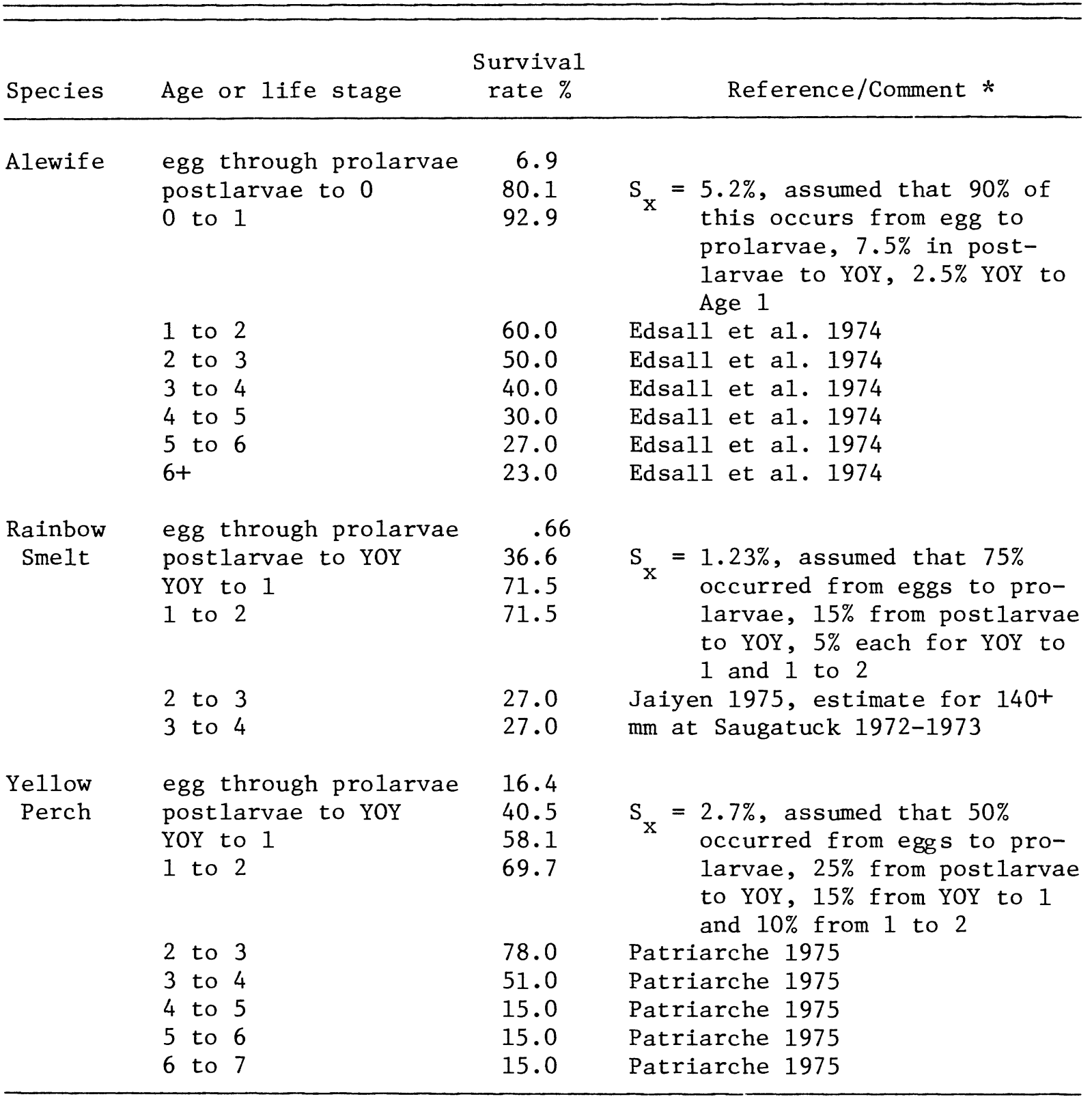

* All first year survival rates are undoubtedly unrealistic and orders of magnitude higher than published values. First year survival was conservatively estimated to be $1 \%$ for all species. The split between prolarvae, postlarvae and young-of-the-year was assumed to be 50:25:25. Thus the survival rates were $10,31.6$ and $31.6 \%$ respectively. 
Table 76. Length-frequency distribution of impinged alewife, rainbow smelt and yellow perch at the J. H. Campbell Plant in 1978. Lengths are midpoints of $10-\mathrm{mm}$ intervals (e.g., 25-34 $\mathrm{mm}$ fish were assigned to the $30-\mathrm{mm}$ interva1).

\begin{tabular}{lrrr}
\hline & \multicolumn{3}{c}{ Number of fish impinged } \\
\cline { 2 - 4 } Length & & Rainbow smelt & Yellow perch \\
\cline { 2 - 4 } interval $(\mathrm{mm})$ & Alewife & 15 & \\
\hline & 111 & 31 & \\
30 & 139 & 22 & \\
40 & 70 & 12 & 6 \\
50 & 48 & 16 & 22 \\
60 & 73 & 12 & 35 \\
70 & 84 & 7 & 25 \\
80 & 131 & 7 & 13 \\
90 & 298 & 5 & 11 \\
100 & 519 & 5 & 8 \\
110 & 469 & 6 & 7 \\
120 & 213 & 11 & 12 \\
130 & 92 & 16 & 18 \\
140 & 109 & 13 & 17 \\
150 & 318 & 8 & 8 \\
160 & 695 & 8 & 7 \\
170 & 994 & 6 & 4 \\
180 & 904 & 2 & 2 \\
190 & 503 & 1 & 1 \\
200 & 191 & & 1 \\
210 & 58 & & 1 \\
220 & 10 & & 1 \\
230 & 1 & & \\
240 & & & \\
250 & & & \\
\hline
\end{tabular}


1. The mean weight of an age-group as determined from the entrainment and impingement samples is time invariant over the production interval. Thus a larvae weighing $x$ grams at time $t$ would have ultimately weighed $\mathrm{y}$ grams at time $t+n$ where $y$ is the average weight of an individual of age $n$ at time $t$. In other words, it is assumed that entrained larvae would have attained the same average weights as those attained by agegroups of impinged fish.

2. Survival rates are also time invariant. This is one of the most controversial areas of fisheries research and will be discussed in a later section.

3. There are no positive or negative feedback effects. Thus, the production foregone calculation implicitly assumes that reduction in production in one generation does not reduce the number of adults recruited to the following generations (Goodyear 1978).

4. Each species exists separately from its community and its environment, and may be considered independently of its community and environment.

5. System or community productivity decreases in response to removal of fish via power plant operation. Hence the loss of $\mathrm{x}$ pounds of alewives (as estimated by $\mathrm{P}_{\mathrm{T}}$ ) is equivalent to a decrease of $\mathrm{x}$ pounds in the system production.

6. Larval mortality due to entrainment was assumed to be $100 \%$.

Each of these assumptions will be examined in the discussion and should be borne in mind when evaluating the following production estimates.

Alewife--Production foregone estimates for alewives are summarized in Table 77. Potential production lost due to operation of the Campbell Plant during 1978 was $102,603 \mathrm{~kg}$. Nearly all (99.9\%) of this was contributed by entrained prolarvae and postlarvae; only a negligible amount of foregone production was contributed by impinged juveniles and adults. Instantaneous growth rates between adjacent age-groups decreased with increasing age. The largest rate of increase in weight occurred between postlarvae and yoy (age 0) age-groups. The instantaneous mortality was a concave function of age, i.e., high for very young and old fish and much lower for age 2,3 and and 4 fish.

While most of the production foregone was due to losses of prolarvae and postlarvae, most of their estimated future production was attributable to age 0 and 1 fish (Table 78). Nearly $74 \%$ of the total production losses attributed to prolarvae and postlarvae occurred in the predicted 0 and 1 agegroups. For other age--groups most (over 50\%) of their estimated production losses would have occurred between the time of their deaths and the next agegroup. The last row of Table 78 shows the age-frequency distribution of foregone production. Of the $102,602 \mathrm{~kg}$ estimated to be 1 ost, only $25.9 \%$ would have been contributed by age 2 or older fish. In other words, most of the potential production would have been very small fish less than $11 \mathrm{~g}$ mean weight. 


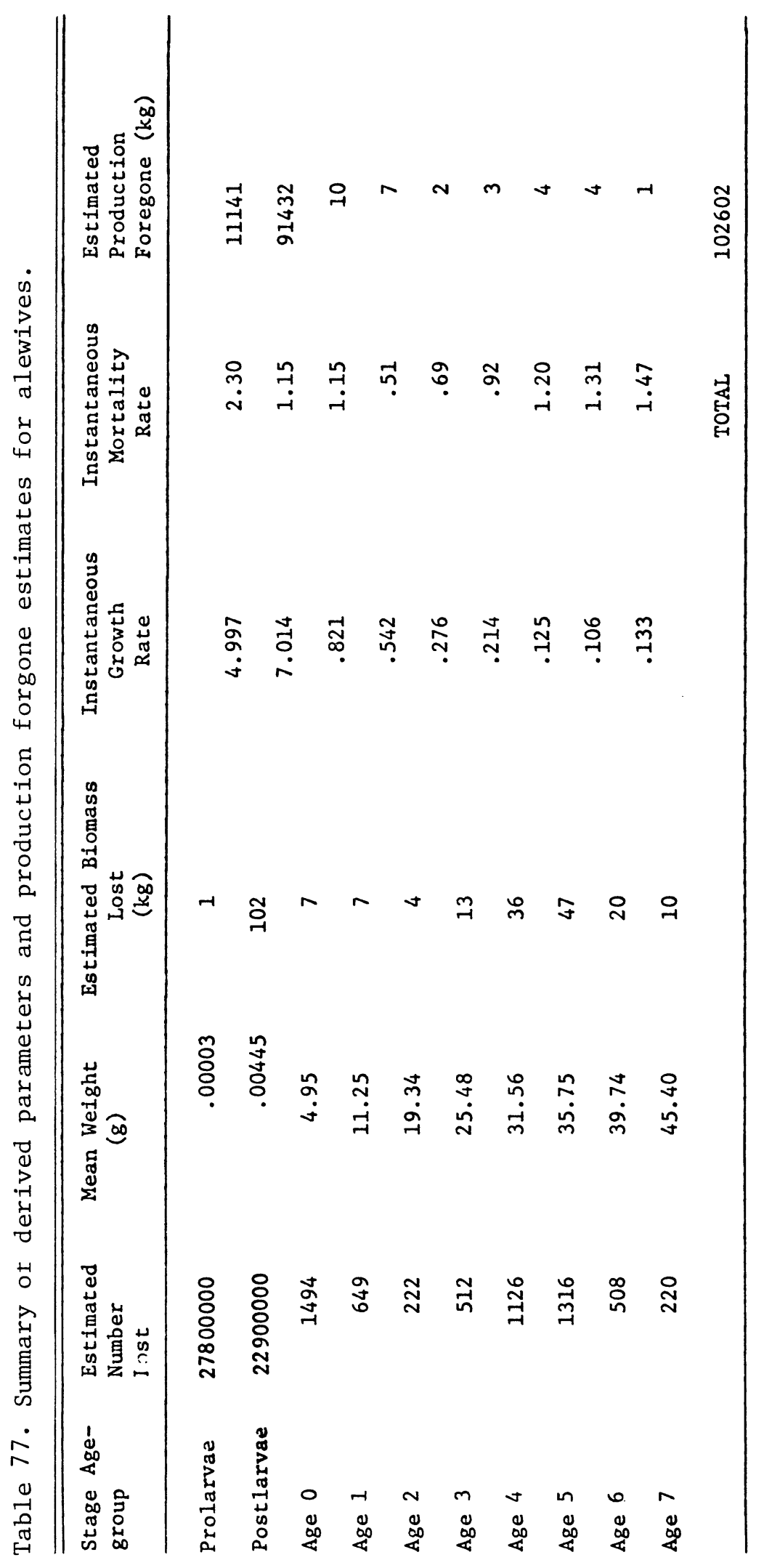




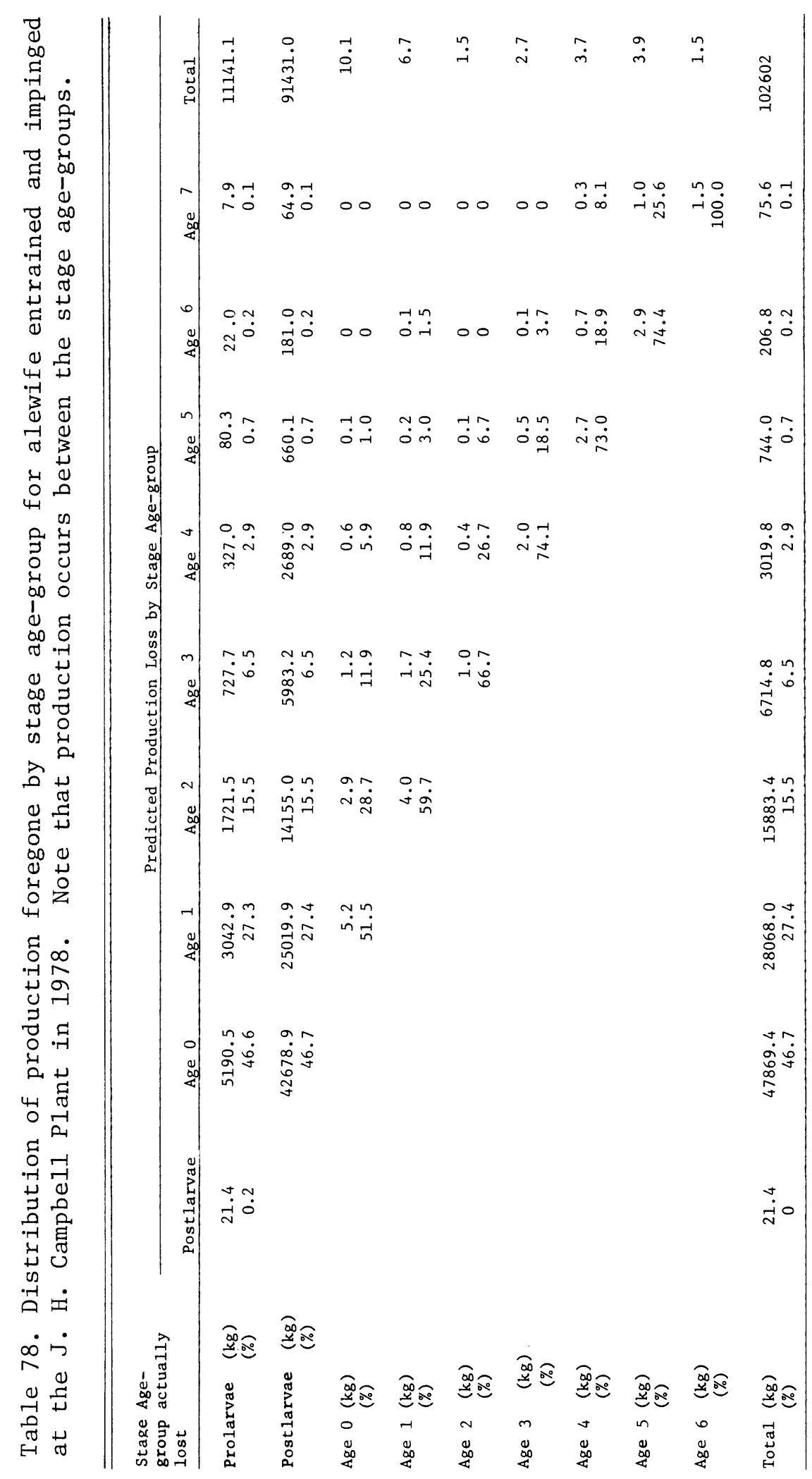


Rainbow Smelt--Estimated production loss attributable to entrainment and impingement of rainbow smelt at the Campbell Plant in 1978 was only $863 \mathrm{~kg}$ (Table 79). As with alewives, most (99.7\%) of this was due to entrainment of prolarvae and postlarvae. Only about $6 \mathrm{~kg}$ of smelt biomass was actually destroyed by the Campbell Plant. Growth rates decreased monotonically with age; whereas, mortality rates decreased with age up to age 2 , then rose again for ages 3 and 4 .

Unlike alewives, most predicted smelt production losses occured between ages 1 and 2 (Table 80), as a result of actual losses of prolarvae, postlarvae and age-0 fish. The age-frequency distribution of the predicted smelt production loss was more symmetric than that for alewives. Peak production losses were estimated to occur between ages 1 and 2 (52.4\%) (see last row of Table 80 ). Most of the predicted smelt lost would have had mean weights between 2.34 and $26.12 \mathrm{~g}$.

Yellow Perch--Assuming a $1 \%$ survival rate between prolarvae and age 0 , estimated production losses for yellow perch were $27,676 \mathrm{~kg}$ (Table 81). Once again, most of the estimated production losses were due to entrainment of prolarvae and postlarvae. Impingement losses, both actual and predicted, were inconsequential; total estimates were 6 and $15 \mathrm{~kg}$ respectively for ages 0 through 7. The pattern of instantaneous growth and mortality rates was similar to that observed for alewife and rainbow smelt.

The frequency distributions of production foregone are summarized in Table 32. For ear.. stage age-group actually lost most of the predicted production would have occurred from ages 2 and 3 . This is probably due to the rapid gains in weight associated with on set of sexual maturity in perch. Surprisingly, the distribution by predicted age-group was bimodal with peaks occurring for age $0(3395 \mathrm{~kg})$ and age $3(8496 \mathrm{~kg})$. Most of the predicted production losses would be attributable to ages 2 through 4 . Less than $23 \%$ was attributed to predicted postlarvae, age 0 and 1 groups.

Sensitivity Analyses--

The empirical sensitivity indices for each parameter and species are summarized in Table 83 and plotted in Fig. 170 through 172 . Recall that sensitivity coefficients were defined as the slope of the graph of percent change in total production as a function of percent change in a given parameter while all other parameters remain fixed. In essence, the sensitivity coefficients are dependent upon the configuration of other parameters in the model. A concurrent change in the other parameters may change the sensitivity of total production to the altered parameter. For example, a major change in the numbers of individuals entrained and impinged will alter the sensitivity coefficients for survival and mean weight values.

Several broad patterns emerged from the sensitivity analyses (Table 83). Total production foregone was generally most sensitive to changes in early survival rates (especially between postlarvae and age-0 fish). For rainbow smelt and yellow perch, the distribution of survival sensitivity coefficients $\left(a_{i}\right)$ vs. age was dome-shaped. For alewives, however this distribution was more peaked (Fig. 170). A second pattern was the overwhelming influence of numbers of prolarvae and postlarvae entrained on the total production. For alewives and rainbow smelt the model was most sensitive to changes in the 


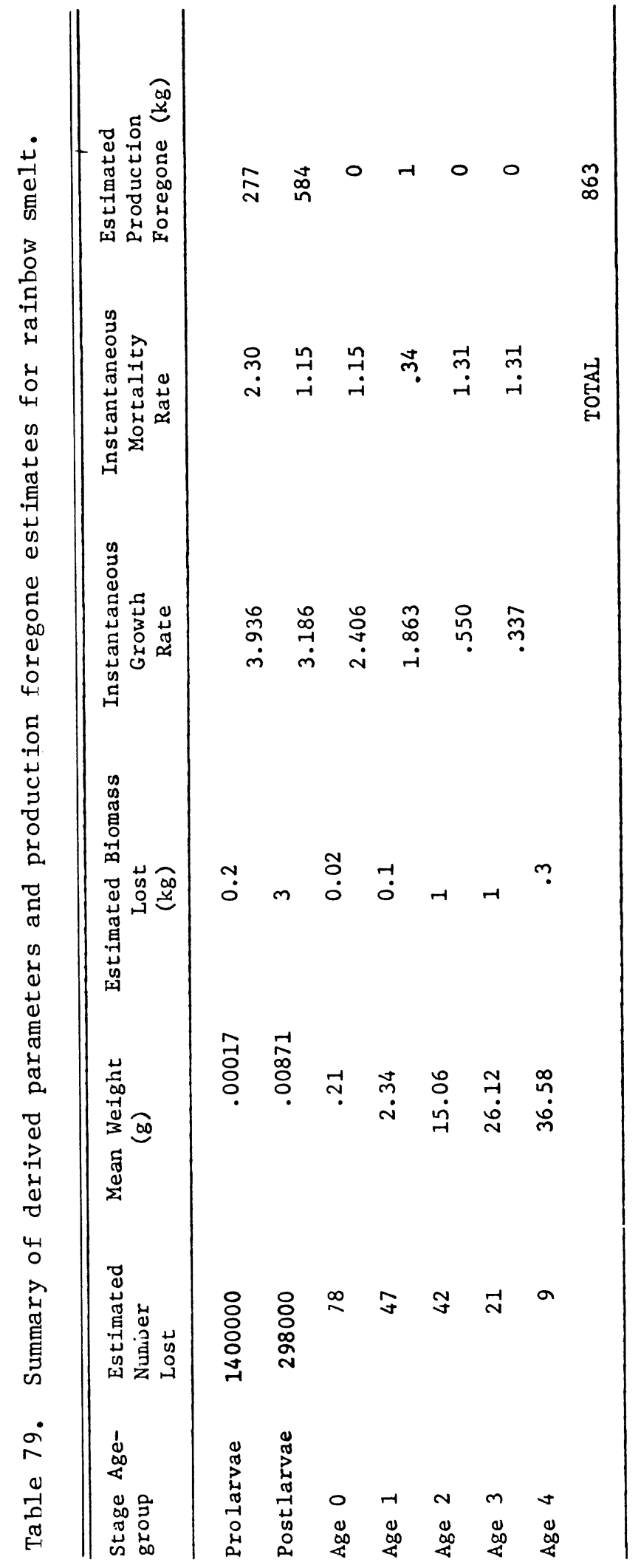




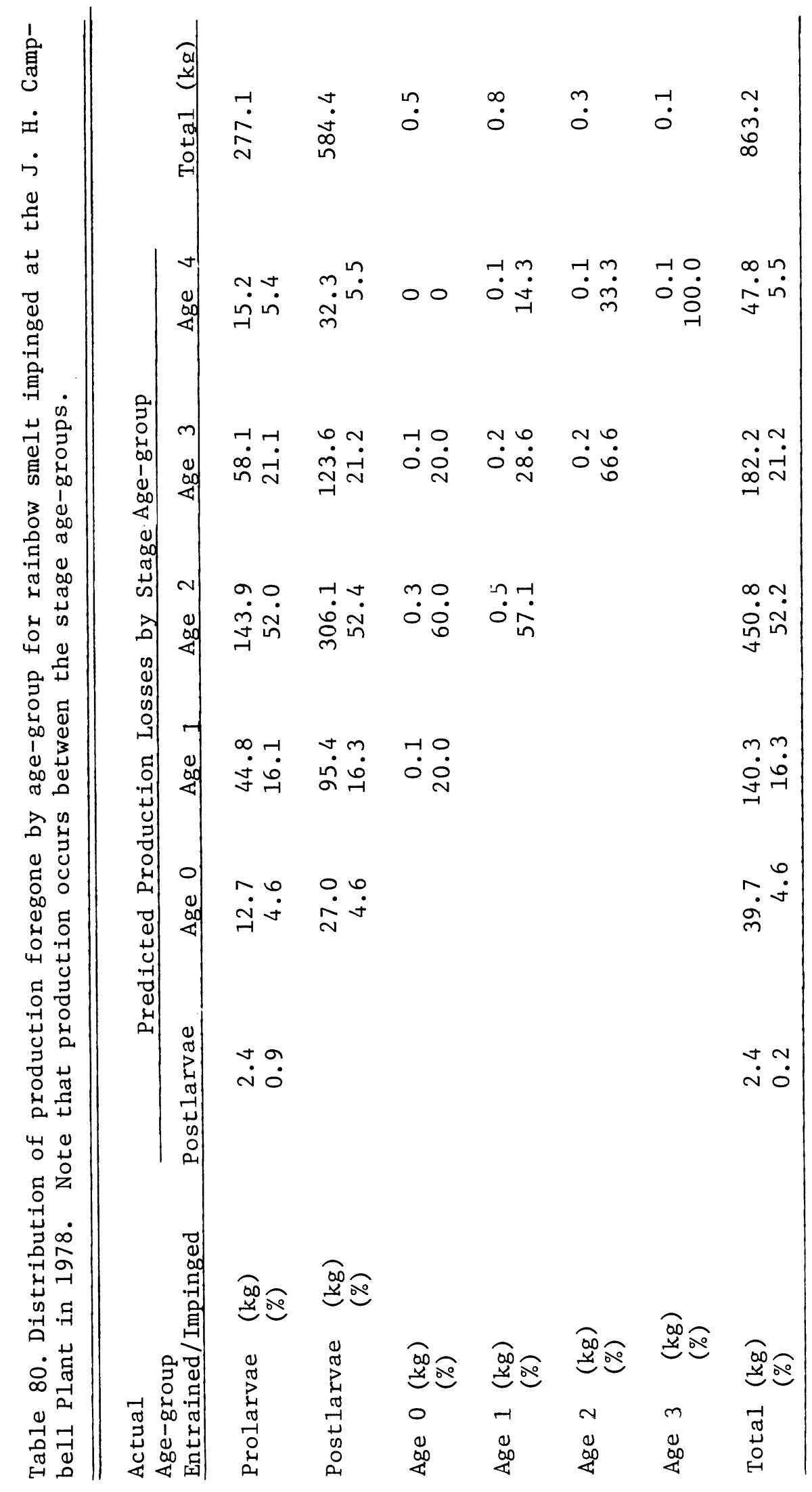




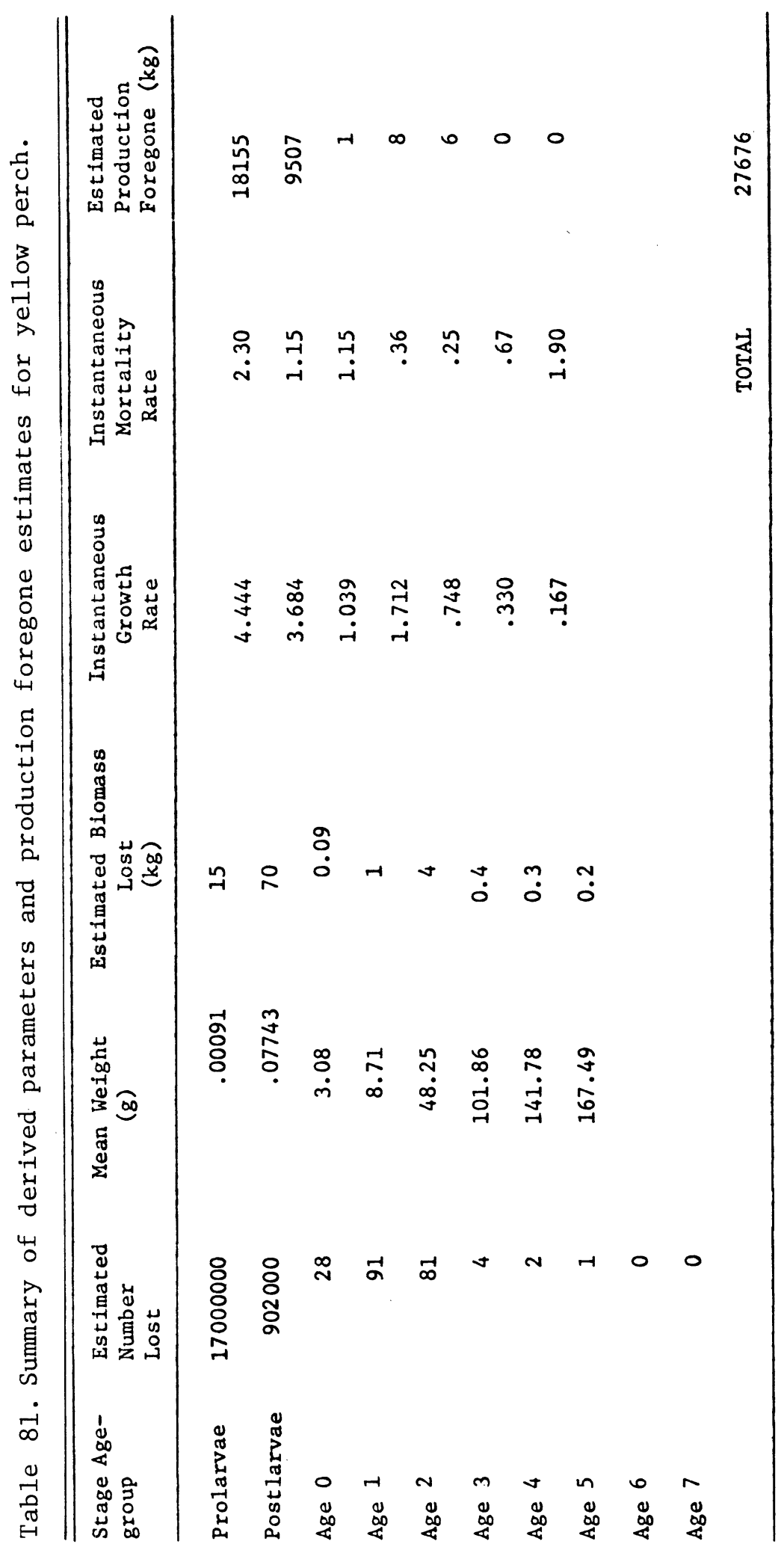




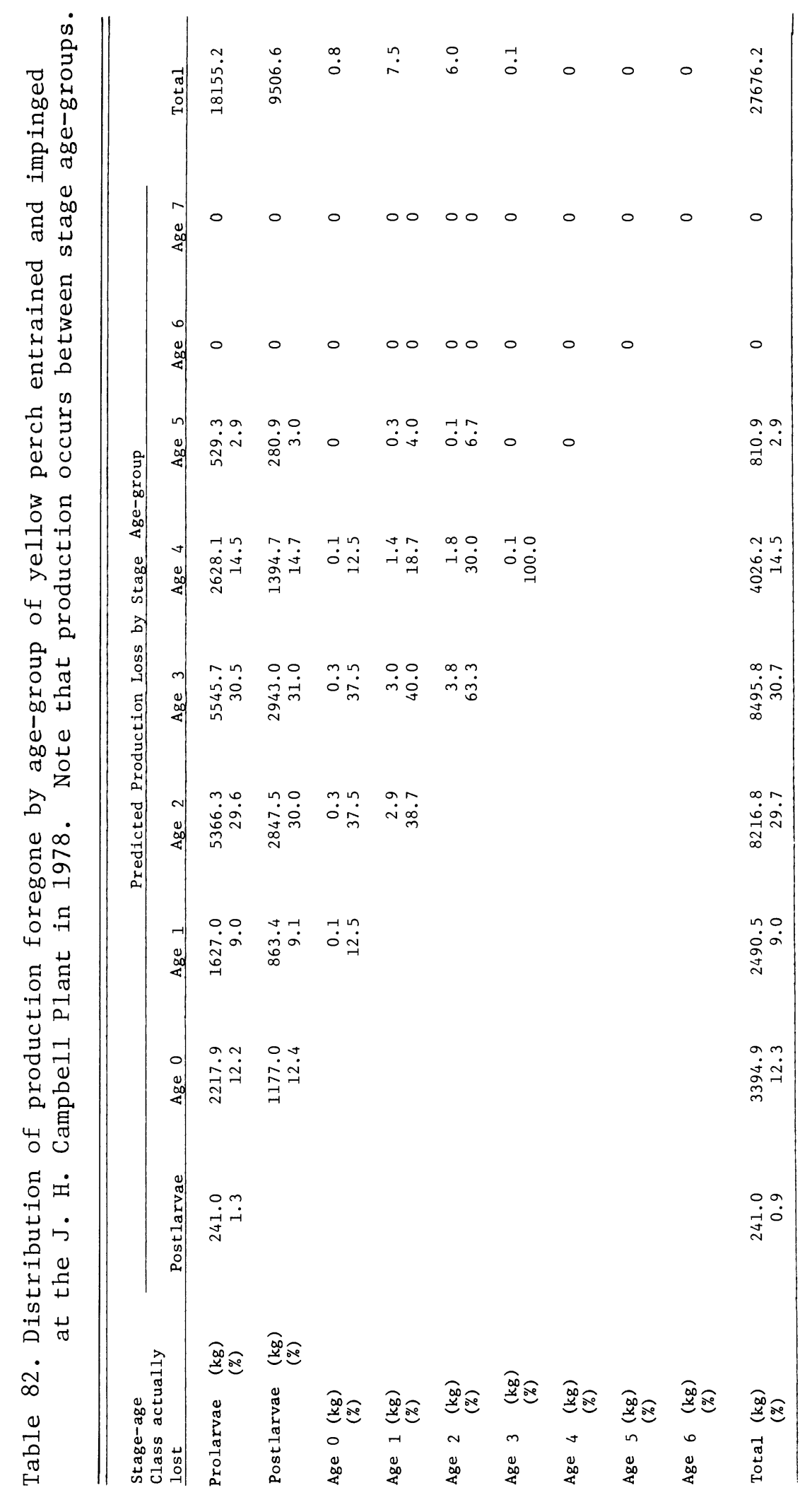


Table 83. Summary of sensitivity coefficients for alewives, rainbow smelt and yellow perch. The sensitivity coefficient was defined as the slope of the graph of percent change in estimated production foregone versus percent change in parameter value. Survival and mean weight estimates were varied $\pm 25 \%$; number estimates were varied $\pm 50 \%$. Coefficients 1 isted are computed slopes X $10^{3}$.

\begin{tabular}{|c|c|c|c|c|}
\hline \multicolumn{2}{|c|}{ PARAMETER } & ALEWIFE & RAINBOW SMELT & YELLOW PERCH \\
\hline \multicolumn{5}{|l|}{ Survival } \\
\hline \multirow[t]{9}{*}{ Rates } & $S(1)$ & 109 & 320 & 653 \\
\hline & $S(2)$ & 922 & 980 & 953 \\
\hline & $S(3)$ & 389 & 885 & 822 \\
\hline & $S(4)$ & 183 & 592 & 663 \\
\hline & $S(5)$ & 70 & 148 & 342 \\
\hline & $S(6)$ & 23 & 23 & 98 \\
\hline & $S(7)$ & 6 & & 11 \\
\hline & $S(8)$ & 2 & & 0 \\
\hline & $S(9)$ & 0.3 & & 0 \\
\hline \multicolumn{5}{|l|}{ Mean } \\
\hline \multirow[t]{10}{*}{ Weight } & $\underline{\bar{W}}(1)$ & 0.02 & .3 & 1 \\
\hline & $\overline{\mathrm{W}}(2)$ & 11.9 & 4 & 12 \\
\hline & $\bar{W}(3)$ & 267 & 42 & 78 \\
\hline & $\underline{\bar{W}}(4)$ & 255 & 82 & 74 \\
\hline & $\underline{\bar{W}}(5)$ & 162 & 341 & 85 \\
\hline & $\underline{\bar{W}}(6)$ & 147 & 345 & 213 \\
\hline & $\underline{\bar{W}}(7)$ & 97 & 188 & 354 \\
\hline & $\underline{\bar{W}}(8)$ & 43 & & 187 \\
\hline & $\overline{\mathrm{W}}(9)$ & 15 & & 0 \\
\hline & $\overline{\mathrm{W}}(10)$ & 6 & & 0 \\
\hline \multicolumn{5}{|l|}{ Numbers } \\
\hline \multirow[t]{10}{*}{ Lost } & Prolarvae & 109 & 321 & 656 \\
\hline & Postlarvae & 891 & 677 & 343 \\
\hline & Age 0 & .03 & .5 & .03 \\
\hline & Age 1 & .07 & .8 & .27 \\
\hline & Age 2 & .02 & .4 & .22 \\
\hline & Age 3 & .03 & .1 & .004 \\
\hline & Age 4 & .04 & 0 & .0009 \\
\hline & Age 5 & .04 & & 0 \\
\hline & Age 6 & .01 & & 0 \\
\hline & Age 7 & .00 & & 0 \\
\hline
\end{tabular}



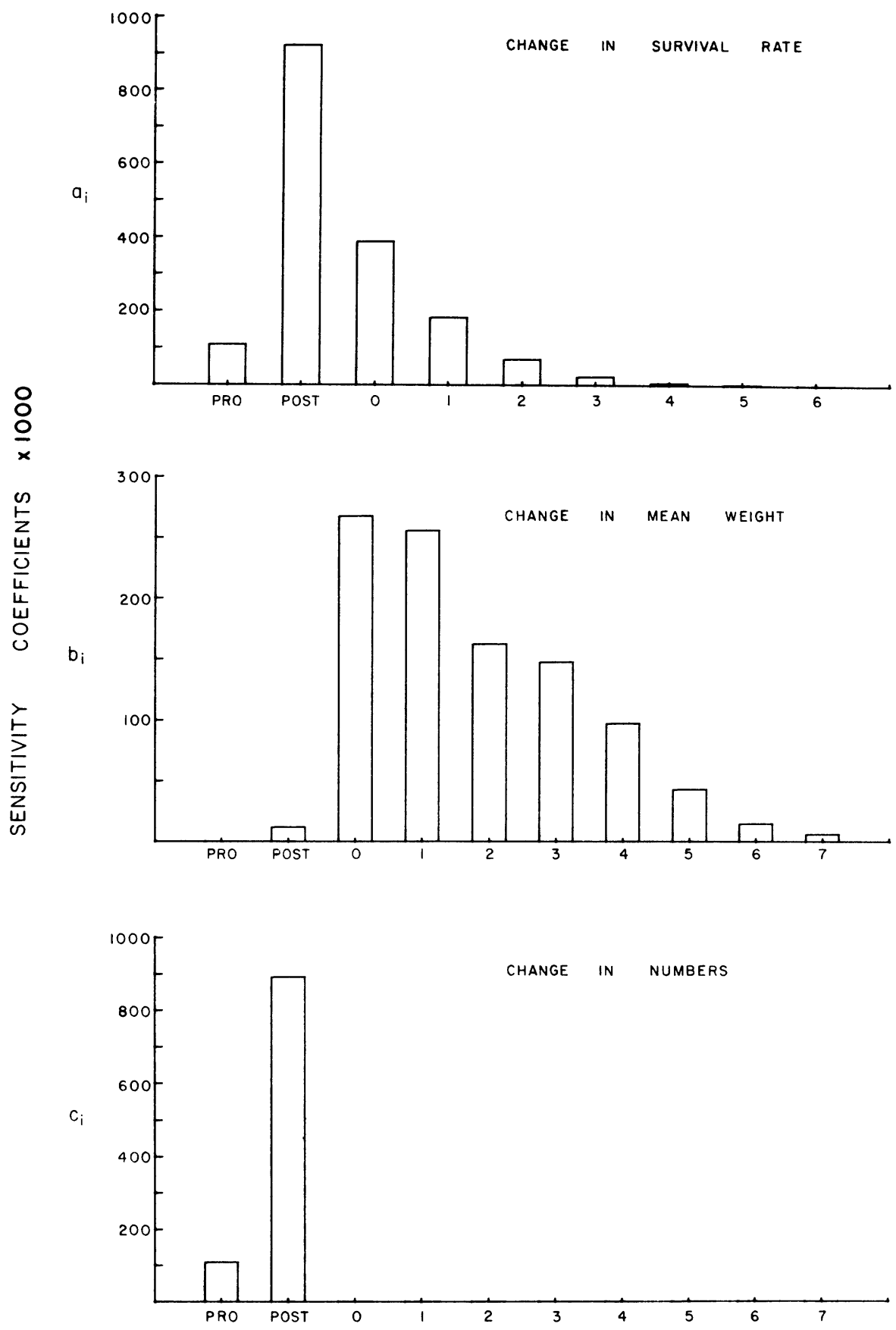

$A G E$

Fig. 170. Summary of sensitivity coefficients for production foregone of alewives in 1978. The $\mathrm{a}_{i}$ are slopes of percent change in estimated production versus percent change in survival rate. For survival, "PRO" designates survival from prolarvae to postlarvae,"POST" designates survival from postlarvae to age 0 . The $b_{i}$ and $c_{i}$ are slopes of the percent change in estimated production with respect to percent changes in mean weight and numbers respectively. 

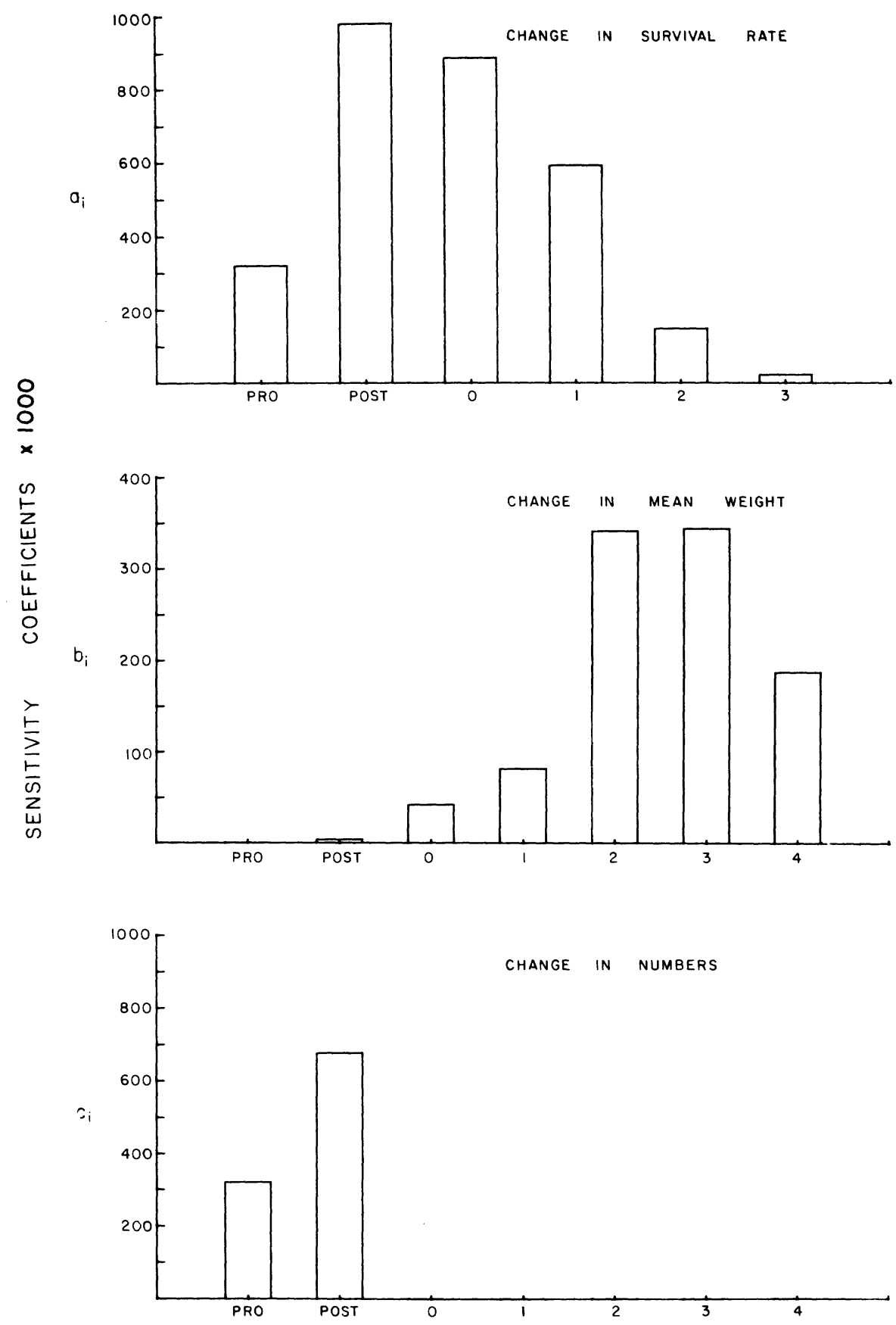

$A G E$

Fig. 171. Summary of sensitivity coefficients for production foregone of rainbow smelt in 1978. The $a_{i}$ are slopes of percent change in estimated production versus percent change in survival rate. For survival, "PRO" designates survival from prolarvae to postlarvae, "POST" designates survival from postlarvae to age 0 . The $b_{i}$ and $c_{i}$ are slopes of percent change in estimated production with respect to percent changes in mean weight and numbers respectively. 

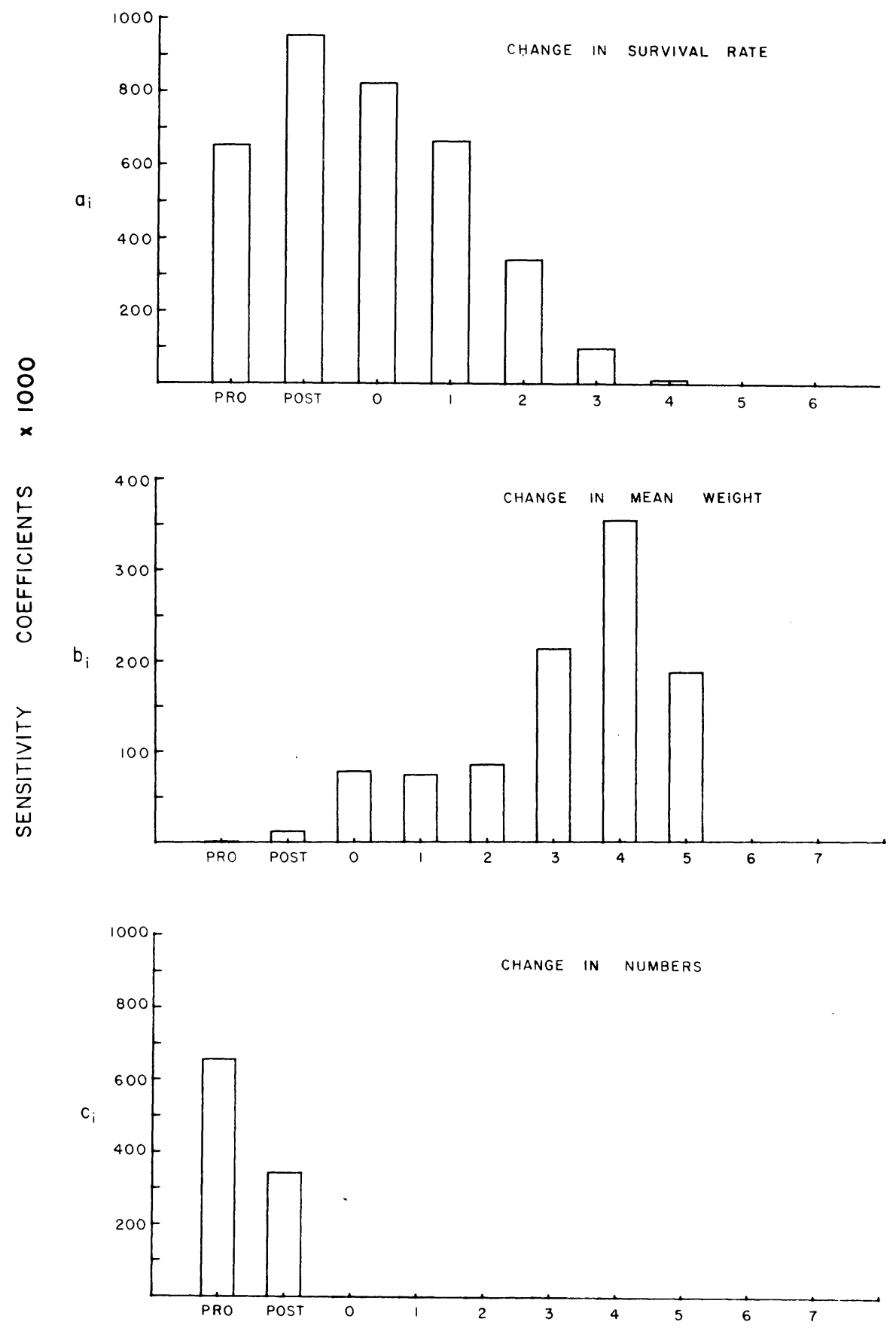

Fig. 172. Summary of sensitivity coefficients for production foregone of yellow perch in 1978. The $a_{i}$ are slopes of percent change in estimated production versus percent change in survival rate. For survival, "PRO" designates survival from prolarvae to postlarvae, "POST" designates survival from postlarvae to age 0 . The $b_{i}$ and $c_{i}$ are slopes of percent change in estimated production with respect to percent changes in mean weight and numbers respectively. 
numbers of postlarvae lost; whereas, for yellow perch, changes in numbers of prolarvae exerted a greater influence. Undoubtedly this was due to the very few yellow perch postlarvae entrained. Hence a percent change in the large numbers of prolarvae entrained had a greater impact on production foregone than did an equal percent change in a small number of postlarvae. In all cases, percent changes in the numbers of age-0 and older fish had negligible effects on the overall production estimate. In contrast, changes in the mean weights of larvae and young fish had relatively little effect on total production. This occurred for two reasons. First, a change in a mean weight $\bar{w}_{i}$ alters both $G_{i}$ and $G_{i+1}$ (see METHODS - PRODUCTION FOREGONE ESTIMATES DUE TO ENTRAINMENT AND IMPINGEMENT, equation 15). A decrease in one implies an increase in the other. Secondly, effects of changes in mean weights are dependent upon the age-specific survival schedule. A change in a mean weight essentially shifts the distribution of production among three adjacent stages or age-groups.

In general, production foregone was most sensitive to those parameters which were most difficult to estimate and in which we have the least confidence. Mean weight estimates were relatively easy to obtain but exerted little influence on the total production estimate. Numbers impinged can be estimated with reasonable precision, but larval entrainment estimates are less precise. The major unknown factor for all species is first-year survival rate and its partition among prolarvae, postlarvae and age-0 fish. Changes of $\pm 25 \%$ in these survival rates altered total production estimates anywhere from $\pm 2.7 \%$ to $\pm 24.5 \%$. To test model sensitivity to simultaneous variations in these survival rates, an extensive sensitivity analyses was performed. The effect of 630 different combinations of first-year survival rates was computed. These values were then analyzed statistically with a multiple linear regression model in which total production was the dependent variable and various survival rates were independent variables. Results of this exercise (Table 84) showed that for each case the proposed regression model accounted for nearly all the variation in production foregone. It must be emphasized that production is not a random variable and no statistical inferences can be drawn. This exercise can be thought of as the simultaneous estimation of the model sensitivity to variations in first-year survival rates for prolarvae, postlarvae and age-0 fish. If estimates do become available, this regression model could serve as an adequate surrogate for the overall production foregone model.

The dramatic effect of varying the partitioning of survival among agegroups is evident in Figs. 173-175. The abscissa consists of the overall instantaneous first-year mortality rate. The spread in points is due solely to changing the proportion of mortality occurring in each class. Each adjacent abscissa value represents a change of $\frac{1}{2}$ in the next largest value. In other words, overall survival rates were $10 \%, 5 \%, 2.5 \%, 1.25 \%$, etc. Witness the tremendous overlap for different survival rates. For alewives it was possible to generate the same production estimates for overall survivals of $10 \%$ and $.00061 \%$ (Fig. 173). For rainbow smelt and yellow perch, separation of production estimates was more pronounced, but surprisingly clustered especially between $.00061 \%$ and $1.25 \%$. This is particularly true over the range of survivals commonly guessed to be appropriate measures of first-year survival (i.e., 0.01 to $1.0 \%$ ). 
Table 84. Summary of sensitivity coefficients derived for 630 possible partitionings of first-year survival. Sensitivity coefficients were derived from multiple linear regression of total production on survival variables.

\begin{tabular}{lccc}
\hline & \multicolumn{3}{c}{ SPECIES } \\
\cline { 2 - 4 } Variable & Alewife & Rainbow Smelt & Yellow Perch \\
\hline CONSTANT - INTERCEPT & 1385.3 & -1.8735 & 113.77 \\
$\begin{array}{l}\text { Survival: through } \\
\text { prolarvae - SPRO }\end{array}$ & 14,892 & 55.736 & 9706.4 \\
$\begin{array}{l}\text { Survival: prolarvae } \\
\text { through postlarvae - SPST }\end{array}$ & 166,530 & 204.320 & 4594.6 \\
$\begin{array}{l}\text { Survival: postlarvae to } \\
\text { end of Age 0 - SJUV }\end{array}$ & 13,063 & 35.323 & 669.96 \\
SPRO x SPST & 187,970 & 990.44 & 75,001 \\
SPST x SJUV & 316,380 & 5091.3 & 77,105 \\
SPRO x SPST x SJUV & 389,970 & 24,001 & $1,474,900$ \\
Coefficient of & .99991 & .99999 & 1.00000 \\
Determination & & & \\
\hline
\end{tabular}

Another way of analyzing production foregone is to examine the distribution of production over time. In any type of prediction, uncertainty increases rapidly as we move outside the domain of our original observations. For estimation of production foregone we have observations for only 1 yr which are extrapolated 5 to $8 \mathrm{yr}$ into the future. Table 85 summarizes the predicted production foregone over time for each species. Most alewife production losses (74\%) are predicted to occur 1 to 2 yr after the actual biomass is destroyed. Only about $10 \%$ of this production loss is predicted to occur after $3 \mathrm{yr}$. Conversely, only $21 \%$ of rainbow smelt production losses were predicted to occur 3 yr or more past the original impact. Similarly, most yellow perch production losses were 3 or more yr removed from the original time of impact. Nearly $48 \%$ of these losses were predicted to. occur 4 or more yr into the future. There are three important implications of this analysis. First, the degree of uncertainty in a production estimate is directly related to the predicted distribution of losses in the future. Thus production losses of alewives, which are concentrated in the first few years are more "certain" than predicted losses of yellow perch which occur several years in the future (Fig. 176). Second, one must consider to whom or what the production would have been available. For example, the production of postlarvae and juvenile alewives would not have been a major food item of larger salmonids. Hence these production losses would not have as great an effect on salmonids as they would 


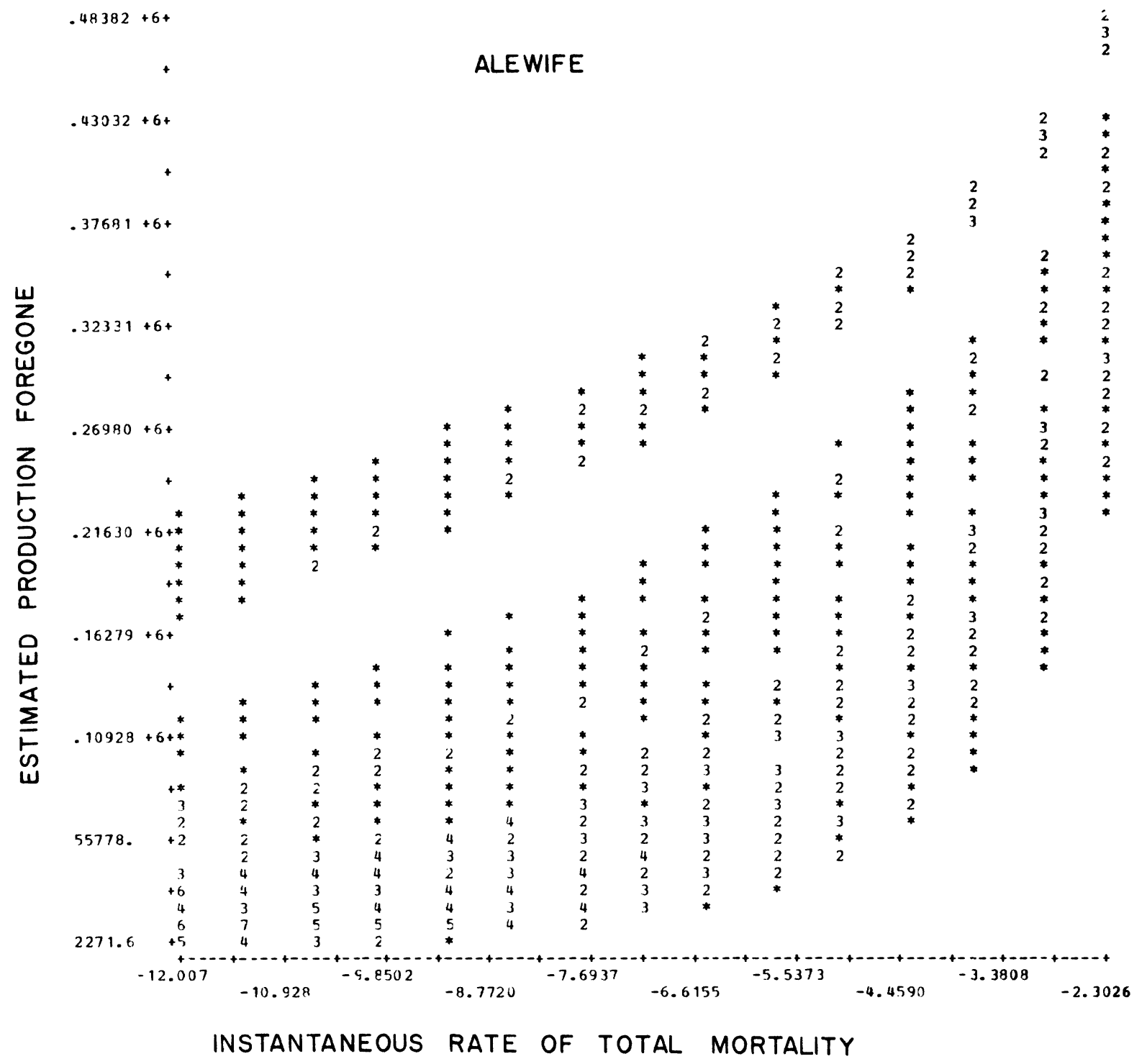

Fig. 173. Production foregone for alewife as a function of instantaneous rate of mortality for the first year. Each point on the abscissa corresponds to a survival rate of one half that of the adjacent point (on the right). The spread of production estimates for each overall survival rate is due to various partitions of mortality among prolarvae, postlarvae and age-0 fish. Numbers indicate the number of estimates for that survival estimate. 


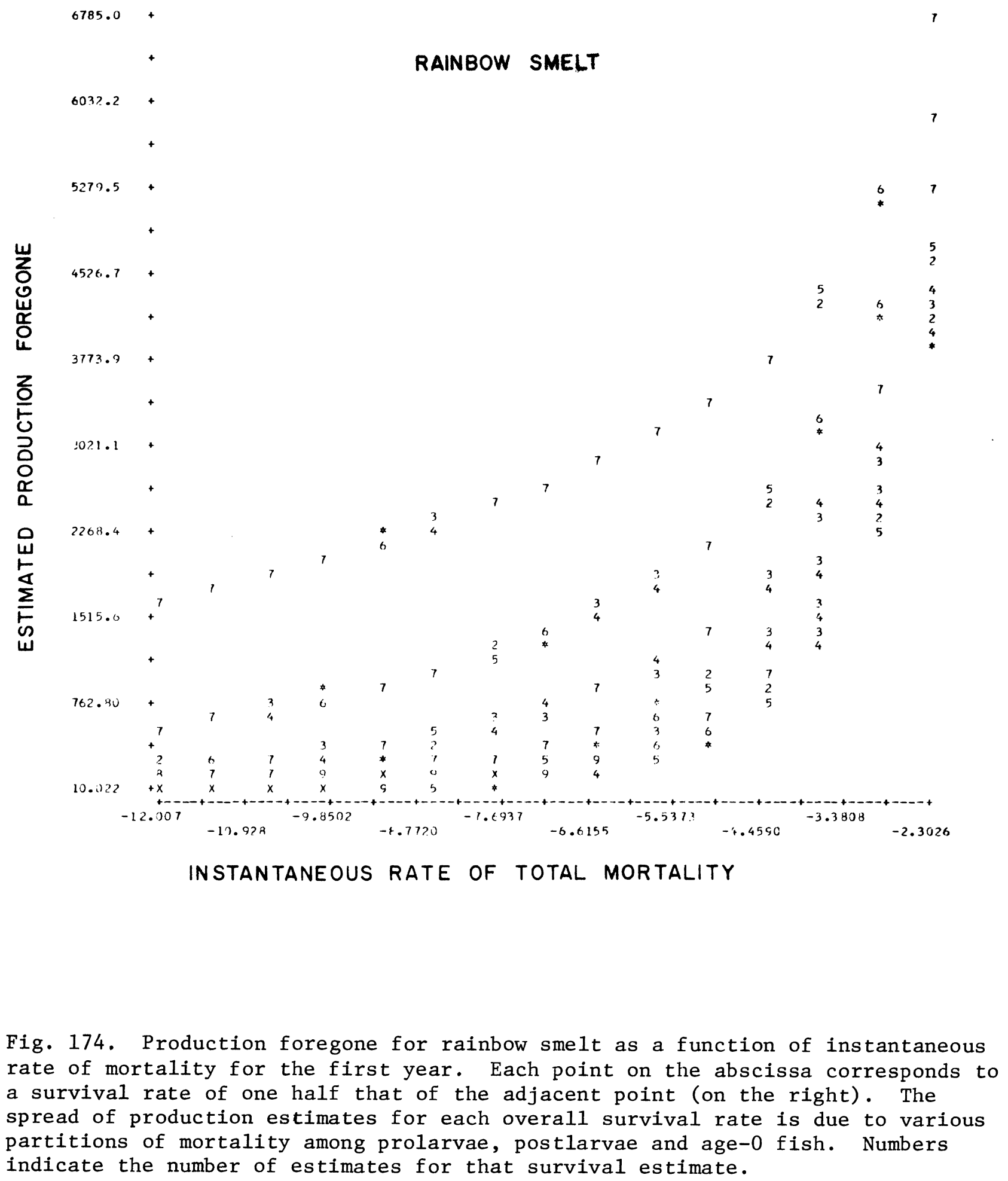




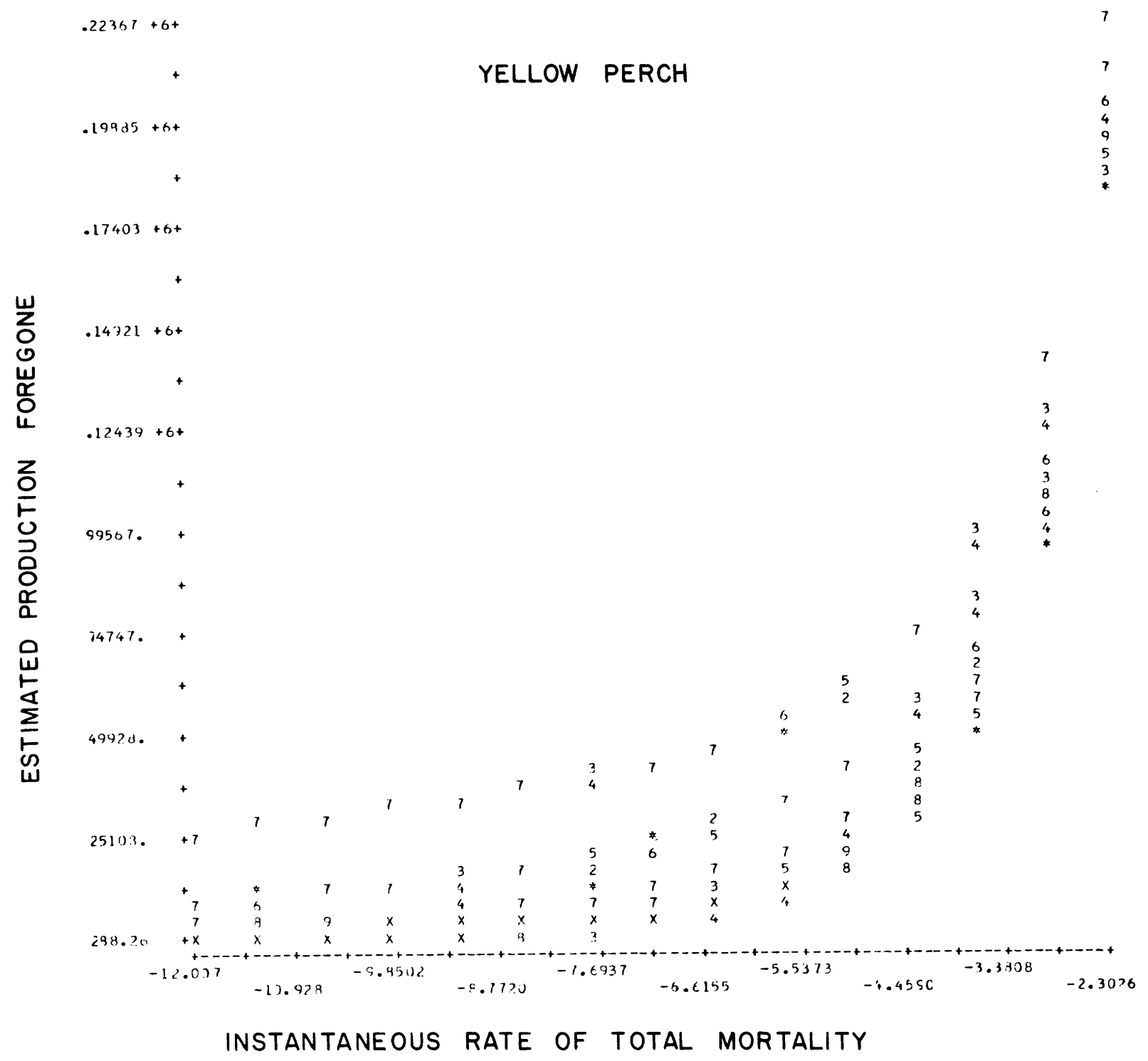

Fig. 175. Production foregone for yellow perch as a function of instantaneous rate of mortality for the first year. Each point on the abscissa corresponds to a survival rate of one half that of the adjacent point (on the right). The spread of production estimates for each overall survival rate is due to various partitions of mortality among prolarvae, postlarvae and age-0 fish. Numbers indicate the number of estimates for that survival estimate. 


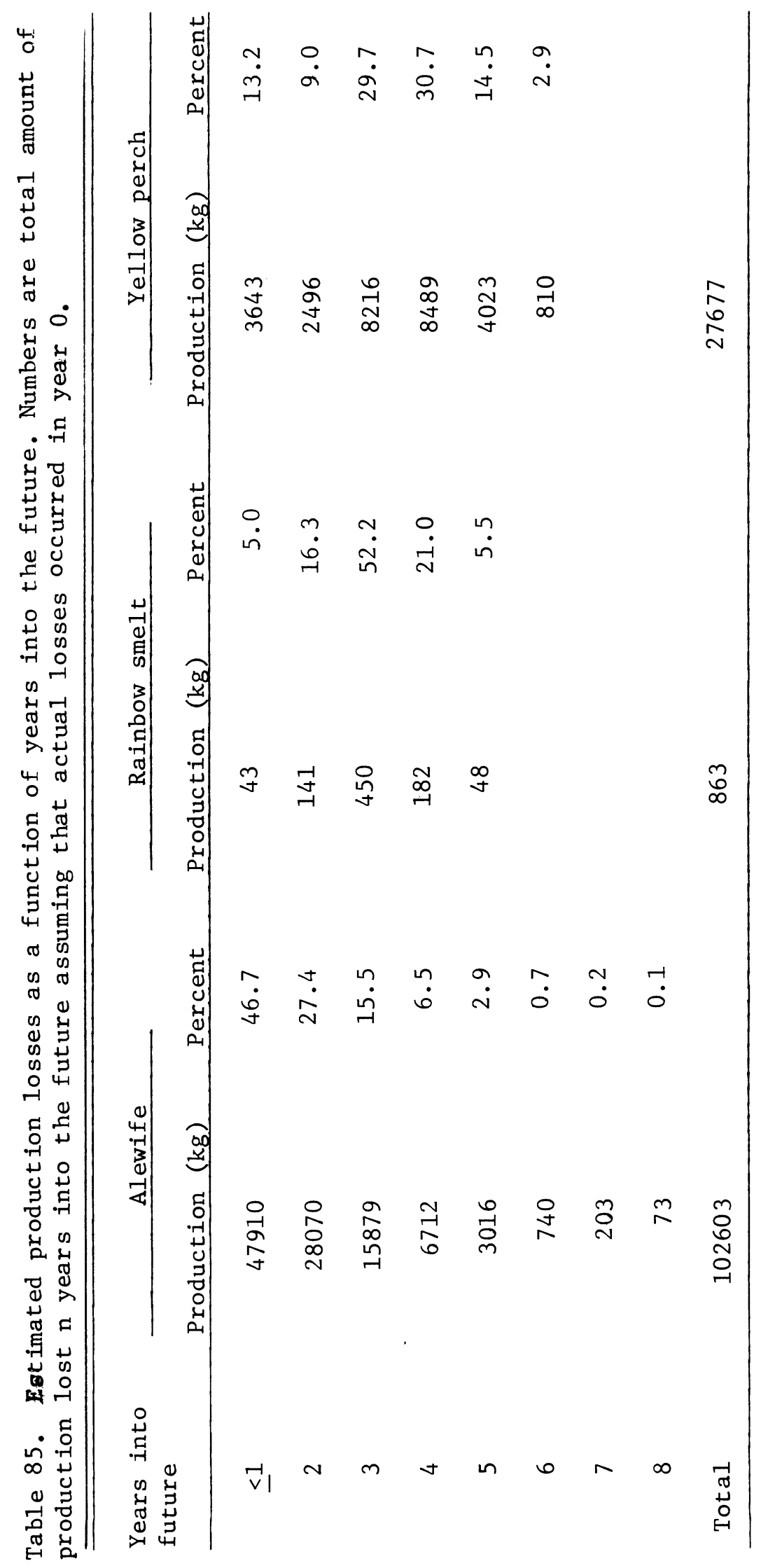



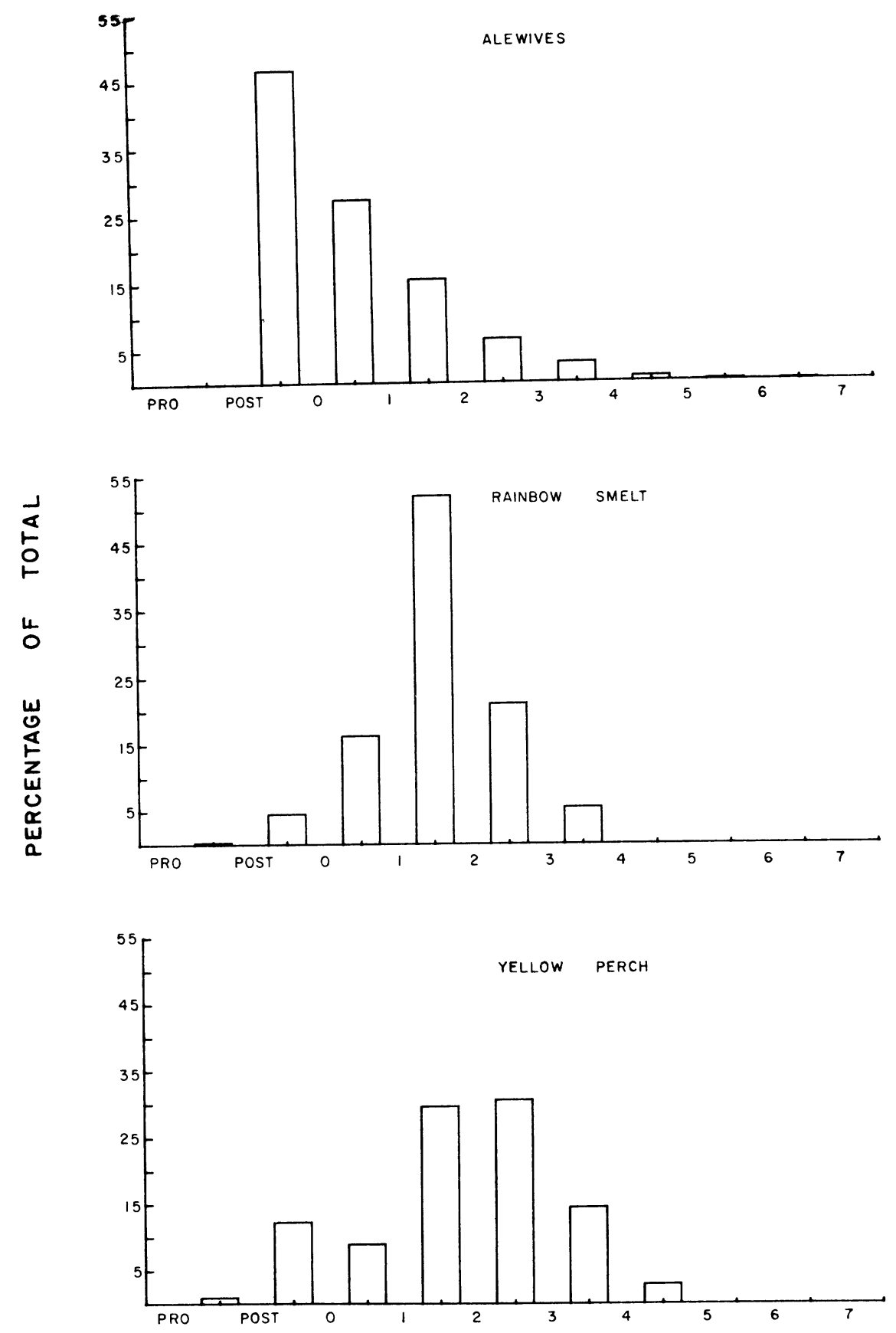

$A G E$

Fig. 176. Age-frequency distribution of predicted production losses. Note that production losses occur between age-groups. 
have had if these fish had been age 2 and 3 alewife. Finally, the potential loss to the sport fishery is directly related to distribution of fish. If age 2 and younger fish are not recruited, then about 14,343 of the $27,677 \mathrm{~kg}$ of yellow perch production would not be available to the sport fishery. Similarly about 680 of the $863 \mathrm{~kg}$ of smelt production might not be lost to the fishery. However, these losses are potential, not actual; any inference must be tempered by this realization: production is not equal to yield in the fishery. See Fig. 177 for plot of production losses over time for each species.

\section{$\underline{\text { Discussion }}$}

Genera1 Relevance of Results--

Production foregone estimates attributable to operation of the Campbell Plant are much higher than actual biomass 1ost. Depending upon age structure of entrained and impinged fish, the ratio of estimated production to actual biomass lost ranged from 153 to 415 among the three species. Production foregone per year ranged from 863 to $102,602 \mathrm{~kg}$. The question which immediately arises is: How do these estimated losses relate to the real world? The strength of our inferences about the real world depends upon our original assumptions. Even the most flexible models have artificial assumptions which always leave room for doubt whether a result depends upon the essentials of a model or details of the simplifying assumptions (Levins 1966).

The critical assumption related to estimated production foregone was that system productivity decreases in direct proportion to the removal of larval and adult fish. This implies that all population processes are density-independent. Furthermore, the remaining members of the population and community are assumed to be unable to utilize energy (i.e. food) that would have been transferred to the entrained and impinged individuals over their life span. Given the discrete nature of spawning and annual variation in population processes, it is possible that production of the residual population will decrease in response to power plant induced mortality over the span of a single year. However, as extrapolations extend further and further from the present, strength of our predictions similarly decrease. Certainly the impact of entrainment and impingement is somewhat greater than simply the actual biomass 1ost; on the other hand, it almost certainly is less than the production foregone estimated herein. If the density-independent model of production foregone is accepted as realistic then the dual of this model can be argued with equal logical force. Thus we can argue that production foregone corresponds to an even greater amount of production of prey items not utilized. If $\mathrm{p} \%$ of prey biomass can be converted into fish flesh, then production loss of fish equal to $\mathrm{X} k \mathrm{~kg}$ corresponds to $\mathrm{X} /(\mathrm{p} / 100) \mathrm{kg}$ of prey biomass not utilized. In other words, if fish can convert prey biomass into fish biomass at an efficiency of $10 \%$ and the estimated production is $500 \mathrm{~kg}$, then this is equivalent to $500 \mathrm{~kg} /$ $(10 \% / 100)=5000 \mathrm{~kg}$ of prey biomass production not utilized. Thus $500 \mathrm{~kg}$ of fish production lost corresponds to $5000 \mathrm{~kg}$ of $\overline{\text { prey }}$ biomass not utilized! Clearly, this makes little sense. Species which could not readily respond to changes in resource base would become extinct quickly! 

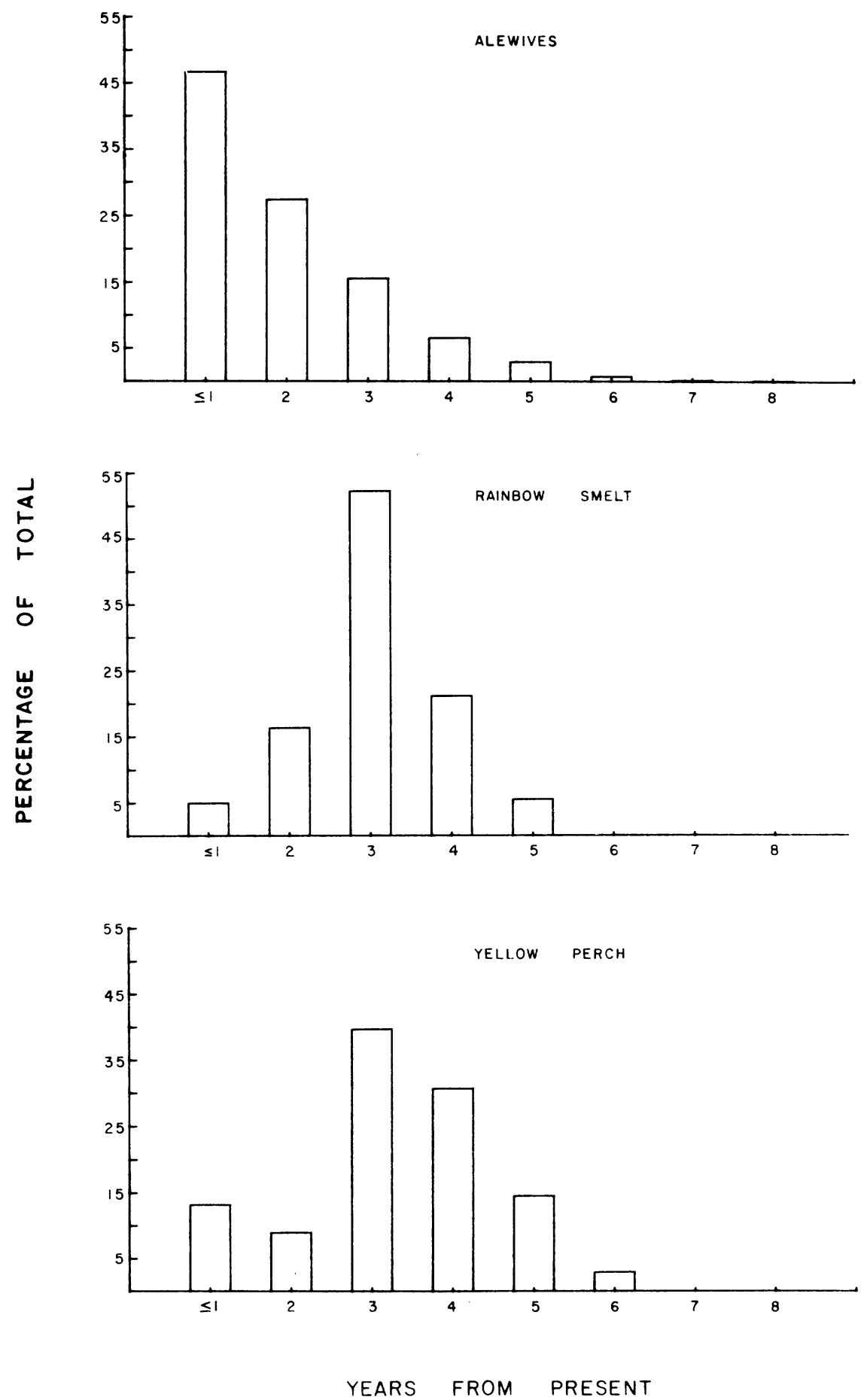

Fig. 177. Predicted production losses for each species as a function of years from the present. Ordinate gives percentage of total production foregone which occurs $n$ years into the future. 
A completely satisfactory method for judging relevance of estimated production foregone does not exist. Certainly these losses must be viewed in an ecological context, but no one can fully describe the communitites of which alewife, yellow perch and rainbow smelt are a part. Moreover, an ecologically significant "impact" implies a commonly accepted standard from which deviations can be measured (Cooper 1976). Clearly this is not the case. One way of relating foregone production to the real world is to compare production with commercial catch data (Table 86). Admittedly this is a simplistic and very conservative approach, but it readily relates these numbers to current levels of exploitation in Lake Michigan. We have assumed that all production foregone occurred in 1978; value was determined by the 1978 average market price. The values (Table 86) are extremely conservative estimates of potential impact by the Campbell Plant. First, we assumed that all estimated production actually was removed from the lake. In reality, only the total weight of entrained and impinged individuals are removed. Second, errors in estimation of foregone production were ignored. Third, no compensatory population processes were assumed to occur. Fourth, all production foregone was assumed to be available to the commercial fishery. In other words, life stages not susceptible to the fishery due to seasonal distribution patterns or gear selectivity were included.

Finally, assuming that all production was available to the fishery implies that production equals yield. In turn, this implies that natural mortality, (i.e., that due to predators such as salmonids) is equal to zero. In other words, each fish eventually ends up in the commercial fishery. Obviously this is an erroneous assumption and one which considerably inflates the magnitude of the 1oss. A more reasonable approach would be to estimate what fraction of the total annual production of all fish in the lake accrues to the commercial fishery. Unfortunately, these numbers are not available. Even with these assumptions, the production foregone constitutes a negligible fraction of the actual harvest from the lake. Current yields from Lake Michigan are determined not only by the standing stock but also by fishing regulations, vessel numbers and capacity, market prices and in the case of alewives, by the location of reduction processors. Consequently, percentages in Table 86 must be viewed as approximations. For example, changes in the demand for fish meal could dramatically alter catches of alewives, thereby altering the percent value in Table 86. However the true underlying ecological impact might be unchanged.

Estimated value of production lost for alewives, perch and smelt in 1978 was $\$ 53,825$. Yellow perch constituted the largest percentage of this value, followed by alewives and rainbow smelt. Note that market value of yellow perch was nearly 50 times that of alewives. Thus smaller production losses of yellow perch translated into a much larger share of the dollar value.

Initially, production estimates for yellow perch appeared high relative to commercial production. Several factors inflated this percentage. First, no commercial fishery existed for perch on the Michigan side of Lake Michigan. Only $42 \mathrm{~kg}$ of perch were reported caught in 1978 by Michigan fishermen. This was not due to an absence of fish, but rather to gear restrictions, particularly on use of $5-\mathrm{cm}(2-i n)$ mesh gill nets and fyke nets which prevent any significant 
harvest of yellow perch. In contrast, Illinois and Indiana harvested 110,423 $\mathrm{kg}$ of perch in 1978, while the Wisconsin yield was $210,394 \mathrm{~kg}$. Second, not all foregone production would accrue to the fishery. Based on mesh-size limits we estimated that for perch only 14,355 of the predicted $27,677 \mathrm{~kg}$ would have accrued to the fishery. This quantity would be worth $\$ 25,856$ at 1978 prices and represents $4.5 \%$ of the commercial catch. Finally, production foregone estimates for yellow perch are perhaps the most uncertain of all species since most of the predicted losses are forecasted 3 or more yr from the present.

Table 86. Comparison of estimated production foregone with commercial fish yield in 1978. Catch statistics were derived from unpublished reports which will be summarized in Current Fisheries Statistics.

\begin{tabular}{|c|c|c|c|c|c|c|}
\hline \multirow[t]{2}{*}{ Species } & \multicolumn{3}{|c|}{ Commercial Catch } & \multicolumn{2}{|c|}{ Estimated Production } & Foregone \\
\hline & Pounds* & Value (\$) & $\begin{array}{l}\text { Average**} \\
\text { price (\$) }\end{array}$ & & $\begin{array}{l}\% \text { Commercial } \\
\text { Catch }\end{array}$ & $\begin{array}{l}\text { Value } \\
(\$)\end{array}$ \\
\hline Alewife & $\begin{array}{c}43,879,220 \\
(19,903,614 \mathrm{~kg})\end{array}$ & 754,116 & .017 & $\begin{array}{c}226,201 \\
(102,605 \mathrm{~kg})\end{array}$ & .5 & 3845 \\
\hline $\begin{array}{l}\text { Rainbow } \\
\text { Sme1t }\end{array}$ & $\begin{array}{r}1,370,143 \\
(621,497 \mathrm{~kg})\end{array}$ & 92.146 & .068 & $\begin{array}{c}1903 \\
(863 \mathrm{~kg})\end{array}$ & .1 & 129 \\
\hline $\begin{array}{l}\text { Ye11ow } \\
\text { Perch }\end{array}$ & $\begin{array}{r}707,373 \\
(320,864 \mathrm{~kg})\end{array}$ & 572,740 & .817 & $\begin{array}{c}61,017 \\
(27677 \mathrm{~kg})\end{array}$ & 8.6 & 49,851 \\
\hline TOTAL & $\begin{array}{c}45,956,736 \\
(20,845,975 \mathrm{~kg})\end{array}$ & $1,419,002$ & & $\begin{array}{c}289,121 \\
(131145 \mathrm{~kg})\end{array}$ & & 53,825 \\
\hline
\end{tabular}

* Pounds are sums of three general catch classes: (a) those caught for human consumption (b) those caught for animal feed and (c) incidental catches which were not sold. Incidental catches for alewives, smelt and perch were $587,090(266304 \mathrm{~kg}) ; 10,408(4721 \mathrm{~kg})$ and $6655(3019 \mathrm{~kg})$ pounds respectively.

* Average price is the ratio of total value over the quantity, total catch less incidental catches.

To recapitulate, annual commercial yields are highly influenced by exogenous factors unrelated to the standing stock of fish. Consequently, comparisons of estimated production foregone with annual yield provide only very gross measures of impact. Actual value of the potentially lost production was extremely low relative to the cost of the plant, alternative cooling systems and benefits derived from electric power. 
Ecological models and impact assessment -- The goal of ecologists is to develop a parsimonious description of nature in which order may be perceived through a few comprehensible collective properties. Enactment and enforcement of the National Environmental Policy Act (NEPA) have made us painfully aware of our limitations in understanding nature. The fundamental problem in environmental impact assessment is to evaluate the significance of unnatural change in a naturally changing system (Botkin and Sobel 1976). In general, our approaches to this problem have been inadequate. Data bases underlying our theoretical concepts are generally weak, even in resource management fields (Auerbach 1977). Our inability to predict in ecology follows from the richness and complexity of nature. The ensuing paragraphs delineate some of the problems germane to modelling in ecology and particularly environmental impact assessment.

Any mode1, whether verbal, graphical or mathematical, imposes a structure upon knowledge. Man abstracts the pertinent system elements and develops a set of rules under which he perceives these elements to interact. A model implies a judgement of the relevance of system components and their relationships to objectives. Consequently, deductions and inferences ascertainable about a system are predominantly determined by the machinery employed in our models. In a sense, a model constrains our perception of the system in question. On the other hand, a model systematizes our thinking and forces precise statements of our perceptions of nature.

While models are essential for our understanding of nature, they should not be confused with it (Levins 1966). Furthermore, models cannot create data about unobserved system conditions (Walters and Efford 1972). Within this context, extrapolations of production foregone should be viewed as an exercise in theoretics, a discipline to which mathematics and biology are subordinate. In essence, this model allowed us to investigate the outcomes of our assumptions and determine which assumptions were most important. However, one must continually recognize that the production foregone model is only a subset of possible models which could be used to describe the effects of power-plant-induced mortality.

The mathematical complexity of nature is immediately evident to any modeler. Relationships among system components are often nonlinear and processes are often discontinuous. Random disturbances generated by abiotic factors can impart a stochastic structure on ecological processes. Relationships among system components are difficult to comprehend at equilibrium much less under perturbation. Perturbations by man and other factors can alter the structure and function of the ecosystem. In addition, individual responses change seasonally, diurnally and ontologically (Oster and Takahashi 1974).

Oftentimes the number of state variables required to describe a system is enormous which leads to problems of dimensionality. Problems quickly become intractable when dimensionality and complexity coincide. Recently, attempts have been made to develop very general theories of population dynamics but these have yet to be tested empirically (See Rashevsky 1969, 1967; Eraslan 1970; Streifer 1974; Jester et al. 1977). 
Man's time tables and those of nature are often not coincident. The time frame for capital expenditures and industrial development may not be on the same time scale as population processes. This is particualrly true for investments made under uncertainty. Uncertainty increases as the planning horizon lengthens. Consequently decisions about biological processes must also be made under severe uncertainty.

The effects of error propogation in nonautonomous systems have only recently been addressed with respect to ecological models (0'Neill 1978; O'Neill and Gardner 1978; O'Neill et al. 1978; O'Neill and Rust 1978). Little is known about confidence intervals of products of random variables. The Monte Carlo simulations currently underway at Oak Ridge National Laboratory are illuminating but have disturbing consequences for predictions via ecological models. Their results have indicated that confidence intervals for model predictions are very wide. Moreover, we would expect a priori that our predictions would be less certain as we forecast further into the future. This phenomenon is clearly evident in the analyses of univariate time series (Box and Jenkins 1970; Nelson 1973).

Closely related to uncertainty problems are problems regarding sampling. Given the inherent variability of mobile, contagiously distributed populations, it is unlikely that the system can ever be sampled sufficiently to detect anything but gross changes in abundance.

Finally, the most disturbing problem facing ecologists is that a generally accepted paradigm regarding population responses to exploitation does not exist. The controversial and often bitter debates concerning power plants on the Hudson River clearly illustrate this (Hall and Day 1977, Wallace 1975). The following section examines some of these problems.

Exploitation of natural populations -- General theories of exploitation with respect to fisheries management are typified by models of Ricker (1954, 1975) and Beverton and Holt (1957). Other models such as Schaeffer's (1954) surplus production model have also been used to predict yield and guide management decisions. While these models have been useful in fishery management they have been less useful in environmental impact assessments. The principle reason for this is that the models (in an unmodified form) fail to address problems relevant to environmental impacts. Populations are subject to complex dynamic processes that cannot be encompassed by simple models (Clark 1976). Slobodkin and Richman (1956) argued that "any theory purporting to deal with the purely biological aspects of exploitation must be powerful enough to account for at least the minimum of biological complexity that might be expected to arise in the natural world". Clearly, effects of incremental mortality on a population subject to other species interactions, abiotic effects and other factors are difficult to ascertain. Patten (1969) asserted that fishery population dynamics cannot be dissociated from ecosystem dynamics. Along these same lines, Regier and Henderson (1973) argued that fisheries management should be conducted at the community level. Their basic premise was that population stability was more a function of community dynamics than of single species characteristics. Bernard et al. (1978) further stated that parameters of traditional population models are unrealistic in that they presuppose that we know how the parameter affects dynamics. 
They contended that parameters are outputs of biological processes such as predation and not input values. A summary of modifications now being incorporated into ecological models is given in Pielou (1977). Among these factors are spatial effects, age distributions, time lags, temporally distributed population processes, variations in resource availability and effects of other species.

The problems of predicting population responses to exploitation are evident even in simple microcosm experiments. Following a series of experiments of artificial exploitation imposed on an extremely simplified system of zooplankton, Slobodkin and Richman (1956) concluded that "a general theory of exploitation seems farther away than it did before the experiments were started." They found that removal of new-born animals at varying rates tended to reduce the population size but not in direct proportion to either the number or percentage of new born removed. Lack of proportionality was attributed to shifts in age structure of the residual population, increases in growth or reproductive rates and increases in longevity. Slobodkin and Richman also observed that stability of the residual population increased with exploitation rate.

Ability of fish populations to respond to changes in density is universally accepted but ambiguously defined and the actual mechanisms are hotly debated (Cushing 1975). McFadden (1976, 1977) summarized much of the available literature on compensation in fisheries. He presented an extensive number of case histories which demonstrated the ability of populations to maintain themselves when subjected to man-induced mortality. Populations cannot return to equilibrium over all ranges of stock density. Processes which operate over a limited range of densities may not act in the same fashion for densities outside this range. In other words, compensatory responses may be manifest only over a limited range of densities. Assembling literature evidence to support generalities can be tenuous, however McFadden's article showed that many natural populations of fish can withstand exploitation rates of $20 \%$ or more.

While it is relatively simple to enumerate possible compensatory responses of populations, our knowledge of the actual regulatory mechanisms of nature is extremely limited (Ricker 1975). McFadden (1976) identified four broad classes of variables which are relevant to compensatory processes in fishes. These were: (1) physiological limits, (2) behavioral characteristics, (3) habitat requirements and (4) dynamic numerical characteristics. Parameters on physiological limits concern responses to temperature, dissolved oxygen concentrations and pollutants. Behavioral characteristics include swimming sneeds and endurances and taxis responses to stimuli (e.g., light, sounc, etc.). Tabitat recuirements include cover, substrate types, flow recuiremenis anc temperature preferenca. Dynamic numerical characteristics encompass a broad range of parameters relating to single populations (e.g., sex ratio, percent mature, fecundity, survival, longevity) as well as other populations (e.g., predation, competition, etc.). The plasticity of fish can allow for any or all of these mechanisms to act. The compensatory reserve of a population varies among and within species. Long-lived, slowmaturing species will generally have less compensatory reserve than a fast growing and maturing species. Similarly, populations in optimum geographic locations will generally have greater reserves than populations of the same species at the limits of their distribution.

Despite these problems, some progress has been made in evaluating the compensatory reserve of fishes. Cushing (1971) studied several groups of fishes 
and developed an index of density dependence related to the cube root of fecundity. In general, he stated that more fecund species (such as gadoids) have a greater capacity for stabilization, a greater ability to withstand environmental pressure and can be exploited more heavily than less fecund species. Goodyear (1977) developed an empirical measure of the compensatory reserve which was based upon the potential fecundity of a recruit and densityindependent mortality rates in both harvested and virgin stocks. Christensen et al. (1977) developed an "impact factor" which related stock depletion rates between populations with and without compensatory mechanisms operating.

Given current knowledge of abundances and exploitation rates, no one can make unequivocal statements about the compensatory response of Lake Michigan fish species. However, several factors suggest that alewives, rainbow smelt and yellow perch should be able to respond to additional mortality sources. First, no commercial fishery exists in Michigan for either alewives or yellow perch and the rainbow smelt fishery is relatively small (estimated value in 1978 - \$48,614). Hence a major source of additional mortality does not exist. Second, the biotic potential of these species has been well documented. Witness the numerous accounts of the spread of alewives in Lake Michigan (Brown 1972, Smith 1968). Fdsall et al. (1974) stated "There is no question, however, that the alewife, which feeds primarily on zooplankton, is a highly productive species with a short turnover period and has the power to quickly replenish itself". Smelt, also an introduced marine species, similarly spread rapidly throughout the lake (Lievense 1954). Jaiyen (1975) emphasized the high biotic potential of smelt. Yellow perch populations on the other hand, have fluctuated greatly in the past $30 \mathrm{yr}$ due in part to commercial exploitation and the advance of alewives (Wells 1978). Brazo et al. (1975) noted that Lake Michigan perch were growing faster and maturing earlier than populations from other habitats. Much of the current literature on highly variable growth rates of yellow perch is summarized in Rago (1979).

Numerous factors affect the biological structure and function of Lake Michigan communities. These factors have been discussed by numerous authors (Smith 1968 and 1970; Wells and McLain 1973) and there is no need to reiterate their conclusions. Rather, some of the exogenous factors affecting production foregone estimates are schematically represented in Fig. 178. The combined effects of these factors on production estimates are unknown.

Compensation in populations is part of a larger problem of resiliency in ecosystems. Cairns (1977) has addressed this problem in aquatic systems. He argued that structural and functional integrity should be considered. Several system characteristics were proposed as potential measures of system integrity but Cairns concluded that we really do not know the critical system characteristics to measure. As a consequence, the ultimate consideration - the impact of intake-related mortality on community dynamics or trophic structure of the receiving water ecosystem - has not been determined (Hansen et a1. 1977).

$\underline{\text { Summary }}$

The cooling water requirements of the J.H. Campbell Power Plant result in the entrainment and impingement of Lake Michigan fishes. One measure of the impact of plant-induced mortality is production foregone due to removal of these 

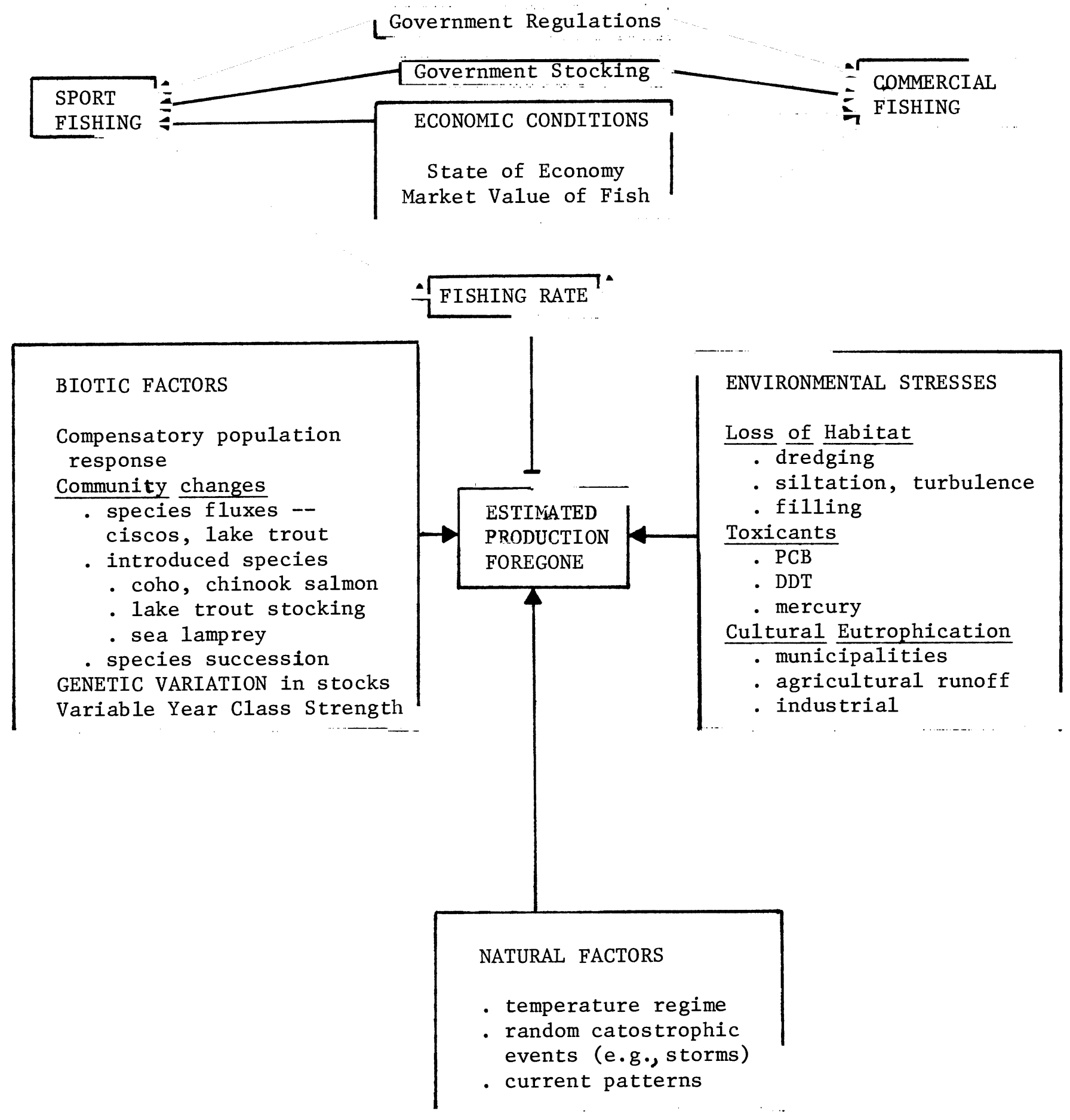

Fig. 178. Summary of some factors affecting production forgone estimates for Lake Michigan fish species. Arrows indicate direction of causation. 
fishes. A procedure is outlined herein for estimating these production losses. The procedure is modified to make the best possible use of the Great Lakes Research Division data base. Data from environmental studies at the D.C. Cook Nuclear Power Plant were also used to augment our fisheries data.

In outline form, the procedure requires the following steps:

(1) Transform length frequency of impinged fish into age frequency using an age-length key.

(2) Estimate the frequency of prolarvae and postlarvae based upon a critical length at which the larva transfers from prolarva to postlarva.

(3) Estimate the mean weight of an age-group of fish by considering the length-weight relation and distribution of lengths within and age-group.

(4) Estimate the mean weight of prolarvae and postlarvae by measuring preserved specimens and averaging this value over the distribution of larval lengths within an age-group.

(5) Estimate rate of growth by assuming that the change in mean weight of an age-group is proportional to the mean weight.

(6) Estimate age-specific survival rates by combining literature estimates with values obtained via a modified equivalent adult model. Survival through the first year of life was conservatively set to $1 \%$ for all species.

(7) Use the estimates obtained in items (1) through (6) to calculate production foregone.

Sensitivity of the production model to changes in parameters and initial conditions was determined by examining the percent change in estimated production as a function of changes of $\pm 25 \%$ in survival and mean-weight estimates and $\pm 50 \%$ in numbers entrained and impinged. An extensive sensitivity analysis of variation in first-year survival was also performed by simultaneously varying three survival rates.

Parameter and initial condition estimates were derived from a variety of sources including: the Great Lakes Research Division data base, literature, unpublished data from the Great Lakes Fish Laboratory, U.S. Fish and Wildlife Service, the Great Lakes Commission and personal communications with fishery scientists in the Ann Arbor area.

Derived survival rates for first-year survival were far higher than any reported in the literature. Use of these estimates were not justified. Thus first-year survival was conservatively set to $1 \%$ for all species. The few available first-year survival rates given in the literature were difficult to interpret and ambiguously defined. Also, citations for anadromous stocks of alewives and smelt were not applicable to landlocked populations in Lake Michigan.

Assuming a $1 \%$ first-year survival rate, the estimated production losses for alewives, rainbow smelt and yellow perch were estimated to be: $102,603 \mathrm{~kg}, 863 \mathrm{~kg}$ and $27,676 \mathrm{~kg}$, respectively. Over $99 \%$ of these estimated losses were due to entrainment of prolarvae and postlarvae. Production losses due to impingement were negligible for each species. 
Production losses attributable to entrainment of prolarvae and postlarvae do not occur immediately. Rather, production losses are distributed over time. The degree of certainty of these predictions are related to the length of the forecast. For alewives, $74 \%$ of production losses attributed to prolarvae and postlarvae entrainment occurred in the age 0 and 1 groups. In contrast, most (52.4\%) production losses for smelt occurred between ages 1 and 2 ; most (74.9\%) perch production losses occurred from ages 2 through 4.

Sensitivity analyses identified critical parameters in the production model. In general, the model was most sensitive to parameters and initial conditions which were the most difficult to estimate and about which we have the least confidence.

Al1 production foregone estimates were approximately linear with respect to the parameter varied. As a result, empirical sensitivity coefficients, defined as the slope of the estimated production lost with respect to the parameter, were used to characterize the system. The apparent linearity of the production function seems to hold over a broad range of most parameters examined.

The most sensitive single parameter for all species was survival rate from postlarvae to age $0[\mathrm{~S}(2)]$. Other highly sensitive parameters were survival of prolarvae to postlarvae [S(1)], survival of age-0 to age-1 fish [S(3)] and numbers of prolarvae and postlarvae entrained, $N(1)$ and $N(2)$ respectively. The three most sensitive parameters for each species were: alewife- $\mathrm{S}(2), \mathrm{S}(3)$, $\mathrm{S}(1)$; rainbow smelt- $\mathrm{S}(2), \mathrm{S}(3), \mathrm{N}(2)$; yellow perch- $\mathrm{S}(2), \mathrm{S}(3), \mathrm{N}(1)$. See Table 83 for a complete listing of sensitivity coefficients.

Dependence of production estimates upon first-year survival was examined by simultaneously varying all three rates [i.e., $\mathrm{S}(1), \mathrm{S}(2)$ and $\mathrm{S}(3)$ ] . The production estimate is dependent not only upon the overall survival estimate [S(1) $\times \mathrm{S}(2) \times \mathrm{S}(3)]$, but also on the partitioning of survival within the first year. By varying this partitioning the same production estimate could be generated for overall survivals ranging from $5 \%$ to .00061\%.

Comparisons of estimated production foregone with respect to commercial catch statistics indicated that these losses constituted a negligible fraction of the annual yield for each species. The distribution of production must be considered; not all production foregone would be available to the fishery. Also, yield can never equal production in natural systems, except when all deaths are due to the fishery. Due to the limited access to the fishery and exogenous factors, annual yields were not considered to be representative of actual stock biomass or population production.

Calculation of production foregone requires many assumptions about the state of nature and operation of the power plant. Perhaps the most critical of these are that system productivity decreases in response to removal of fish by the power plant and that all entrained fish larvae are killed due to plant passage.

Model results are subject to considerable error due to possible model specification error, parameter estimation errors and natural variability. The richness and complexity of nature result in considerable difficulty in the development of predictive models. 
A generally accepted paradigm regarding population response to exploitation does not exist. Even processes acting within simple microcosms have been difficult to identify. Fishery population dynamics cannot be dissociated from ecosystem dynamics since population stability may be due to community dynamics rather than single species characteristics.

Ability of fish populations to respond to changes in density is universally accepted, but the mechanisms of this response are difficult to measure. Many different processes tend to interact to produce compensatory responses in fish populations. While it is dangerous to assume that compensation acts over all ranges of population densities, the evidence suggests that many natural populations can withstand exploitation rates of about $20 \%$.

Numerous other factors cause changes in populations of indigenous species. These are broadly classified as environmental stressors, natural abiotic factors, species fluxes and commercial and sport harvests.

Measuring the impact of one power plant on the Lake Michigan ecosystem is a difficult task. Impacts at the J.H. Campbell Plant include loss of fishes due to entrainment and impingement. One approach to evaluate these losses is to calculate the production which would have accrued had the entrained fish larvae and impinged adults survived. This calculation was performed for data gathered on entrainment and impingement losses at the Campbel1 Plant in 1978. A large number of assumptions and estimates were made in order to complete the calculations. Sensitivity analyses for various parameters pointed out the amount by which results varied, depending on the amount of change in key parameters (mortality rates, weight estimates and numbers entrained). Estimates, about which the least is known (mortality rates for prolarvae, postlarvae and YOY), had the largest effect on production foregone results.

The impact of intake-related mortality on community dynamics and trophic structure of the receiving ecosystem is unknown. Subtle effects of these losses are not likely to be detectable. 


\section{GENERAL SUMMARY AND CONCLUSIONS}

The second year (1978) of biological surveillance at the J. H. Campbell Plant, unlike 1977, encompassed the entire $12 \mathrm{mo}$. We were thus able to establish distribution, spawning and entrainment patterns during late winterearly spring and contrast 1977 with 1978 results to help determine the yearly magnitude of variation inherent in the Pigeon Lake and Lake Michigan ecosystems. We deleted two stations ( $\mathrm{T}$ and $\mathrm{Y}$ ), those near Pigeon River, from our Pigeon Lake monitoring and the 18- and 21-m stations ( $G$ and $H$ ) in Lake Michigan. Also in 1978, construction began on the Unit 3 intake and discharge system which has affected our sampling efforts. Dredging in Pigeon Lake has changed the habitat of both Lake Michigan influenced stations ( $M$ and $S$ ). At station $M(6 \mathrm{~m})$, most of the aquatic macrophytes were eliminated and depth was increased. Because of dock construction and barge storage, beach station $S$ was moved from its 1977 location. These changes have confounded interpretation of 1978 findings. In Lake Michigan, dredging and boat traffic have altered station locations along the north transect; sediment deposition and noise have had an undeterminable effect on the outcome of fishing efforts. However, we feel the main objectives of the study were satisfied. The Pigeon Lake and Lake Michigan data will form a basis for understanding distribution and dynamics of the fish populations. These data will also help determine the magnitude of any plant impact on these fish populations now or after the construction of Unit 3 intake and discharge structures are finished.

Statistical analyses of field data for adult and juvenile fish caught in Lake Michigan centered on establishing the suitability of the present fish sampling design, i.e., are there any preoperational differences in fish distribution or abundance between the south reference area and the north transect treatment area (zone of influence) in the vicinity of the present thermal discharge canal? Any preoperational differences must be documented, so that after Unit 3 is completed statistical comparisons on preoperational and operational data sets can be effectually interpreted. Another goal of the statistics effort was to establish the amount of change in fish catches that could be detected by present designs.

Results of ANOVA on trawl and gill net data showed that for the most abundant species (alewife, rainbow smelt, spottail shiner, yellow perch and bloater) there was no area effect (j.e., no significant difference in mean catch between the two areas), thus establishing a basis for operational conparisons. For seines, a station or area effect was documented for smelt adults and yearlings, which were found in increased numbers in the vicinity of the present thermal discharge. In addition, spottail shiner and alewife (basically YOY), were found in significantly higher numbers at beach stations near the discharge canal. We feel the latter finding is related to attraction of YOY spottails and alewives to the currents, food organisms or warm water of the present onshore discharge canal. After Unit 3 is built and the thermal discharge is placed offshore, this stimulus should be removed. A similar increase in abundance and number of species of larval fish was observed at north transect (zone of influence) stations when contrasted with the south reference transect. 
A number of year differences in collections were observed; all were abundance increases in 1978 over 1977 catches, except seined alewives, which decreased significantly in 1978. For yellow perch and adult smelt caught in seines, no differences between years were recorded. Gill net and traw1 data analyses for spottail shiners showed a significant numerical increase occurred in 1978 over 1977. A similar increase was documented for troutperch and bloaters (unidentified coregonids) collected in trawls; this 1978 increase was quite dramatic for bloaters, confirming a lake-wide trend of population expansion for this species.

Power calculations, our ability to detect a change in population levels near the Campbell Plant, showed that for trawled spottails, alewives, smelt, yellow perch and trout-perch an 18 to $32 \%$ decline or a 22 to $48 \%$ increase in numbers caught would be detected as significant by our present statistical designs. Similar detection levels existed for all these species for our other gear, except that surface gill nets could only detect significantly about a $50 \%$ decline or $100 \%$ increase in the populations of fish most often caught in these nets.

Catches in the area of the Campbe11 Plant during 1978 showed marked differences in species composition from those collected in 1977. In Pigeon Lake many species which were common in 1977 samples (brown bullhead, northern pike, brook silverside, grass pickerel) occurred less frequently in 1978 samples. This change was primarily due to the elimination of the two stations influenced by Pigeon River ( $\mathrm{T}$ and $\mathrm{Y}$ ) from our 1978 sampling scheme.

Earlier spring sampling during 1978 allowed better insight as to which species use the area of the Campbell Plant for spawning. In addition to those species reported by Jude et al. 1978, other winter-early spring spawners used the area. Many more ninespine sticklebacks were observed in Pigeon Lake in early spring, indicating that this species may move into Pigeon Lake to spawn. Burbot and fourhorn sculpin larvae which were commonly found during April and May, suggests that the inshore area of Lake Michigan near the Campbell Plant is a spawning area for these species.

Pronounced differences in numbers of adult fish caught for some species occurred even between comparable times during 1977 and 1978. Emerald shiners, which were rare during 1977 ( 4 caught), made up 4.6\% (466 caught) of the Pigeon Lake catch during 1978. Unidentified coregonids (probably bloaters - see Jude et a1. 1978) accounted for only $0.6 \%$ (461 caught) of the 1977 catch, yet during 1978 they accounted for 3.4\% (3121) of the catch. Walleye, only 1 of which was observed in 1977, occurred more frequently in impingement samples during 1978 when 15 individuals (projected total for the year was 115) were recorded. This increase may be due to the stocking of walleye by the Michigan Department of Natural Resources in Lake Macatawa, Holland, Michigan, or they may be the result of natural reproduction in the area. No walleye larvae were identified from our larvae tows which suggests that spawning in the Pigeon Lake area is not occurring. More chinook salmon were also observed in the area of the Campbell Plant during 1978, which is probably the result of the Michigan Department of Natural Resources planting of over one million chinook salmon within $40 \mathrm{~km}$ of the plant. 
For alewife in 1978, there was a dramatic decline in the number of YOY and larvae found in Pigeon Lake compared to 1977 when large numbers of YOY and larvae were present and intense spawning occurred in the lake. Part of the 1978 decline in alewife YOY and larvae observed in Pigeon Lake was probably due to movement of beach station $S$ to a less productive area, but we believe that this decline may be related to a possible lake-wide decrease in the alewife populations in Lake Michigan. However similar numbers of adults were present in Pigeon Lake and Lake Michigan during both years. From 1977 to 1978, a statistically significant decline in numbers of alewives caught at Lake Michigan beach stations was observed. A concomitant increase in emerald shiners was also documented.

Yellow perch collections in Lake Michigan declined in 1978, while the number of trout-perch and smelt increased in sample catches. There was almost a 10-fold increase in the number of bloaters collected during 1978 compared with 1977. Three coregonid larvae, usually restricted to much deeper water than that which we sample, were also collected, corroborating this finding. Lake trout in 1978 contained more fresh lamprey scars than fish examined during 1977. More data will be required to establish this trend.

Results of the game fish population study showed that about 672 to 690 northern pike greater than $299 \mathrm{~mm}$ and 628 to 1259 pike 175 to $299 \mathrm{~mm}$ lived in Pigeon Lake during the years 1977 and 1978. In 1977, an estimated 59 were impinged (projected for the year), while 68 were impinged in 1978. Those impinged in 1977 (June-December) were 170-240 mm, while those impinged in 1978 were 110$550 \mathrm{~mm}$, mostly YOY $110-140 \mathrm{~mm}$, members of younger and therefore more abundant groups. In 1977, 1300 pike greater than $175 \mathrm{~mm}$ were in the lake and 59 (including many YOY less than $175 \mathrm{~mm}$ ) were impinged. In 1978, of 1949 pike greater than $175 \mathrm{~mm}$ believed present, 30 or $1.5 \%$ were impinged. Another 38 YoY northern pike were also impinged in 1978. For largemouth bass in 1977, at least 471 fish greater than $219 \mathrm{~mm}$ were present in Pigeon Lake; 122 ranging in length from 100 to $150 \mathrm{~mm}$ were impinged. YOY bass were about $80 \mathrm{~mm}$. For 1978, at least 1132 bass $175 \mathrm{~mm}$ and larger were estimated to be present in Pigeon Lake; 3061 fish ranging from 50 to $170 \mathrm{~mm}$, mostly YOY, were impinged. Populations of northern pike and largemouth bass have remained stable over the 2 yr of the study. They have exhibited good growth, probably because of the diverse and abundant food supply available in Pigeon Lake.

Impingement data showed that an estimated 252,674 fish were impinged from 13 June to 22 December 1977 (Zeitoun et a1. 1978) and 136,737 fish (3503 kg) in 1978 at the Campbell Plant. During colder months gizzard shad comprised the major biomass of impinged fish. These gizzard shad probably originated from the discharge canal both from spawning which occurred there and migrants to the canal from the Grand River. Due to use of discharge water to prevent ice buildup in the intake forebay (via an open duct), some gizzard shad migrated along the discharge canal and into the intake forebay. They were subsequently impinged in large numbers. Present impingement rates at Campbell could be reduced by approximately $50 \%$ by screening the connection between forebays. Such a procedure would decrease impingement rates to around 100 thousand or less fish per year. From May through August, as expected from field observations, the major impingement loss was alewives. During September through December, YOY largemouth bass appeared to be quite vulnerable to impingement (2891 of the 3061 impinged in 1978 were taken in these months). The reason for this is 
unknown, but may be related to a large 1978 year class and their dispersal from summer rearing areas. They may have also originated from spawning in the discharge canal.

As was found in 1977, similar dual abundance peaks of larval yellow perch were observed in entrainment samples. Larvae hatched in Pigeon Lake during May comprised the earlier and higher peak of perch entrained $\left(6183 / 1000 \mathrm{~m}^{3}\right)$, while those caught in Lake Michigan during June comprised the second, considerably smaller peak $\left(168 / 1000 \mathrm{~m}^{3}\right)$ of entrained perch. In Lake Michigan larval perch were found at deeper stations $(9$ to $15 \mathrm{~m}$ ) in late June-early July. This is contrary to earlier 1977 results, when larvae were found more inshore and concentrated in surface water.

Alewife larvae were the most abundant of all larval species collected during 1978 as was found in 1977. Peak hatching time was also similar - early July - and corresponded with peak entrainment of the species. A large proportion of entrained alewife larvae were newly hatched fish as was found with most larval fish entrained. Some larger larvae and fry, however, continued to be entrained from late July through fall. There was a decrease in densities of larvae at Pigeon Lake beach stations, which was also noted for YOY alewives. Station relocation may explain part of this difference. There was no significant early spring alewife spawning (May) in 1978 as was found in 1977 . In Lake Michigán during 1977 and 1978 consistently larger alewife larvae were collected from north transect stations than from reference transect stations which we attributed to the influence of the discharge canal. This area was used for spawning, and because of the warmer temperatures, larval alewives spawned there probably gain a growth advantage over those spawned in Lake Michigan. In addition, consistently larger numbers of larval alewives were found at beach station Q (S discharge). In 1978 larval alewives in Lake Michigan were more evenly dispersed throughout the water column than was observed in 1977. Most of this effect was due to water temperature, specifically stratification patterns. Alewives were seldom collected below the epilimnion and concentrated in warmest water available. In 1978, thermal stratification and upwellings during sampling were not as severe as those which occurred in 1977, thus leading to the alewife distribution patterns observed. Water temperature was an important factor during 1978, as we were able to document at least three fluctuations in temperature which caused initiation and cessation of spawning. These temperature fluctuations caused successive periods of abundance for larval carp, alewives, unidentified cyprinids, yellow perch and rainbow smelt. Water temperatures were warmer in June 1978 than in 1977 which initiated spawning and presence of manv alewife larvae in 1978; none were collected in June 1977. There was an inshoreoffshore distribution pattern documented for larval alewives in Lake Michigan. Most larvae collected during July and August at beach stations were larger (10$15 \mathrm{~mm}$ ) than those (mostly newly hatched) observed at deeper stations.

The distribution of spottail shiners in Lake Michigan conformed to patterns observed in 1977; they were almost exclusively found in water $3 \mathrm{~m}$ or less, being most abundant in sled tows, but common in surface tows at beach stations. There were large numbers of spottails in Pigeon Lake, particularly at beach station S. They were entrained when newly hatched and apparently semi-planktonic and have not attained their predominantly demersal behavioral patterns observed at later life stages. 
Smelt larvae were present mainly during May in Lake Michigan; highest entrainment rates occurred during the same period. Sporadic spawning continued past peak spawning times into early June, or offshore spawning and delayed hatching because of the cold water occurred as evidenced by a few smelt larvae captured at offshore Lake Michigan stations. Smelt fry (fish 25.5 to $100 \mathrm{~mm}$ ) were entrained in large numbers in August and September 1977 and 1978.

Burbot larvae were numerous in entrainment,sled and plankton net samples in April, May and June. Apparently a considerable amount of spawning occurred in the Lake Michigan-Pigeon Lake vicinity during winter. A few fourhorn sculpin larvae were also collected in early spring at deeper (greater than $9 \mathrm{~m}$ ) stations in Lake Michigan.

In Pigeon Lake more carp and crappie larvae were collected in 1978 than in 1977. Many carp larvae were entrained or taken in Pigeon Lake samples and one was caught in Lake Michigan.

Al1 minnow larvae, except carp and goldfish, were arbitrarily designated unidentified cyprinidae if they were less than $9 \mathrm{~mm}$. Most were believed to be spottail shiners. They were found sporadically in Lake Michigan and Pigeon Lake field samples and were entrained in large numbers.

Entrainment data indicated few or no larval fish entrained from January through March 1978. Eggs $(952 / 24$ h), believed to be those of burbot, were collected in December. During April both field and entrainment collections indicated that burbot and fourhorn sculpin larvae were common to the area of the Campbel1 Plant. During May 1978 heaviest entrainment losses were exhibited by yellow perch, with over 1.5 million entrained in a 24-h period on 15-16 May. From June to August alewife was the most prominent species in entrainment samples, with peak rates observed in early July (over $1.5 \mathrm{million} / 24 \mathrm{~h}$ ), early August (over 920 thousand/24 h) and late October (over $1 \mathrm{million} / 24 \mathrm{~h}$ ). Those entrained in late October were approximately $22 \mathrm{~mm}$. Highest fish egg entrainment (over $6.5 \mathrm{million} / 24 \mathrm{~h}$ ) was found during early June. Most eggs were believed to be those of alewife. In contrast to 1977 data, higher entrainment losses of alewife occurred in September and October 1978 which supports continued alewife spawning through late summer. Unidentified minnows exhibited peak entrainment rates during early June (over 80 thousand/24 h), early July (over 146 thousand $/ 24 \mathrm{~h}$ ) and early August (over 65 thousand $/ 24 \mathrm{~h}$ ).

For the year 1978, a projected total for all species of fish entrained at the Campbel1 Plant was 78,872,936 larvae and 168,426,200 fish eggs. Alewife (over 49 million), followed by yellow perch (over 16 million), damaged larvae (almost 3 million) and unidentified cyprinids comprised the majority of fish entrained. Over 1 million burbot, smelt and carp larvae were also passed through the plant during 1978. Peak months were May (over 19 million, mostly yellow perch), July (over 19 million, mostly alewife), August (over 18 million, mostly alewife) and October (over 12 million, mostly alewife).

Fry of all species ( 24.5 to $100 \mathrm{~mm}$ ) were entrained at peak rates in midAugust (167-300 thousand $/ 24 \mathrm{~h}$ ). Large numbers of fry were also entrained in September (8-177 thousand/24 h). 
Empirically derived statistical relationships between total length and body depth measurements of fish larvae were calculated and used to predict effectiveness of fine-mesh screens in preventing entrainment of fish larvae at water intakes. Nine larval fish species common to Lake Michigan near the J. H. Campbell Plant were studied. Regression analyses of these measurements showed linear or curvilinear relationships between total length and body depth for different fish species. From these relationships it was calculated that 50\% of the alewife larvae and 10\% respectively of the rainbow smelt, yellow perch and spottail shiner larvae that were entrained by the Campbell Plant in 1977 would still have been entrained if $0.5-\mathrm{mm}$ mesh screening were employed in the plant's cooling water intake system. In 1978 only $18 \%$ of the alewife larvae entrained in June would have been excluded by a $0.5-\mathrm{mm}$ mesh screen. The percentage was higher in July and August, but only in September would a 0.5-mm screen exclude, on the basis of body depth, $100 \%$ of the larvae entrained. In fact, Tomljanovich et al. (1977) found that some larvae with body depths up to $84 \%$ larger than the screen size were compressed and passed through the screen, depending on approach velocity. Therefore even more larvae than we predicted would not be excluded by using an $0.5-\mathrm{mm}$ screen. Impingement of larvae on the screens, biofouling, and probably most important, avoidance, are other problems that must be resolved before this method becomes acceptable.

Production foregone calculations were performed for 1978 entrainment and impingement losses due to the Campbell Plant. Estimates were highest for alewife $(102,603 \mathrm{~kg})$, followed by yellow perch $(27,676 \mathrm{~kg})$ and smelt $(863 \mathrm{~kg})$. Most of the production lost was due to entrainment; impingement was generally negligible. Monetary value of alewives is low $(1.7 \mathrm{c} / 1 \mathrm{~b})$, while yellow perch is high $(81.7 \mathrm{c} / 1 \mathrm{~b})$; therefore the largest proportion of the total cost $(\$ 53,825$ based on 1978 commercial catch values) was due to yellow perch production lost. As noted, most perch larvae entrained in 1978 came from Pigeon Lake; few were from Lake Michigan.

The main thrust of our studies has been to gather data on the spatial and temporal distribution and abundance of adult and larval fish in Pigeon Lake and Lake Michigan. Once these are established, we can evaluate the present impact of Units 1 and 2 and the potential impact of Unit 3 on the aquatic resources in the plant vicinity. We have been able to document with accuracy present entrainment rates and impingement losses of adult and juvenile fish. The final step, the most difficult, is to draw together our knowledge of present population distributions and stability in Pigeon Lake and Lake Michigan and ascertain whether the larvae and adult fish destroyed represent a significant impact on the fish populations. In a further attempt to evaluate these effects, we calculated the biomass of various species of fish that would have accrued had these fish not been entrained or impinged, but allowed to complete their life cycle. Production foregone was then discussed in terms of the commercial value of the fish lost. Yellow perch larvae were entrained in large numbers and they were responsible for a significant proportion of the final cost of the fish loss as determined from production foregone calculations. Most of the larval perch were derived from Pigeon Lake in 1978 and we feel that endemic perch populations in Pigeon Lake are composed of an abundance of small individuals - we seldom captured any large perch. Thus, the impact of yellow perch entrainment, even though seasonally high, was not important to perch populations in Pigeon Lake. Yellow 
perch certainly are fecund under conditions such as exist in Pigeon Lake.

These types of calculations and deliberations involve a tremendous number of assumptions concerning mortality rates of the various life stages, age of maturity, fecundity, etc. Another central question is the degree of compensation exhibited by the remaining population. Little is known about the amount of "harvest" a particular species, such as alewife, can sustain. Certainly predation by salmonids is one component of their mortality. Another confounding factor is the habitat created by the power plant, including a cool, continuous source of water through Pigeon Lake and the intake and discharge canal. These areas are enhanced by the presence of Lake Michigan water, leading to a considerable amount of spawning and subsequent use of these areas as nursery grounds. In addition, we feel many of the larvae entrained were derived from spawning in the intake canal. Many more larvae were found in Lake Michigan at north transect stations near the present onshore thermal discharge, than were found at the south reference transect, corroborating the extensive use of the discharge canal as a spawning site.

In the final analysis for 1978 we present the following information:

1.) Over 78 million larvae were estimated entrained, comprised of 49.8 million alewife, 1.5 million rainbow smelt, 16.4 million yellow perch and a number of miscellaneous species and groups.

2.) 136,737 adult and juvenile fish were estimated to have been impinged, including 45,722 alewife, 74,727 gizzard shad, 1333 smelt, 1519 yellow perch, 3061 largemouth bass, 5673 spottail shiners, 1283 trout-perch and 3419 fish of various other species.

3.) The production foregone estimate projected for 1978 entrainment and impingement losses for the three most important and abundant species was $131,142 \mathrm{~kg}$ with a cost, based on commercial catch values, of $\$ 53,825$. Of this $102,603 \mathrm{~kg}$ was attributed to alewife, $27,676 \mathrm{~kg}$ to yellow perch and $863 \mathrm{~kg}$ to sme1t. Over $90 \%$ of the production lost was attributed to entrainment.

4.) In 1977 (June to December) and 1978 an estimated 59 to 68 northern pike were impinged. In 1978, 30 of the 68 pike impinged were greater than $175 \mathrm{~mm}$. Our game fish population study revealed that from 1300 to 1949 pike (greater than $175 \mathrm{~mm}$ ) were estimated to be present in the lake respectively in 1977 and 1978 .

For largemouth bass, 122 (1977) to 3061 (1978) were impinged. Most were YOY. Our game fish population study showed that 1132 (1978) largemouth bass greater than $175 \mathrm{~mm}$ were estimated to be present in the lake. Only six bass greater than $175 \mathrm{~mm}$ were impinged in 1978 .

Examination of our field data and summarizing our knowledge of the various populations affected by operation of the Campbell Plant, we can make the following statements:

1.) For alewife populations, we have observed a significant decline from 1977 to 1978 in the number of larval and YOY alewives collected in both Pigeon Lake and Lake Michigan, which we believe is not attributable to plant effects, 
but is rather part of a possible lake-wide decline in alewife populations plus yearly fluctuations. Statistically, no significant differences in the number of adult alewives collected between years in both areas were found.

2.) There was a decline from 1977 to 1978 in the number of yellow perch collected in Lake Michigan; very few fish in the 150-250-mm range were collected in 1978, while they were common in 1977. Fewer and smaller fish were also noted in Pigeon Lake. The differences observed in Lake Michigan however were not supported statistically.

3.) The catch of unidentified coregonids showed a statistically significant increase from 1977 to 1978 in both field and impingement samples. An increase in unidentified coregonid abundance has been documented in other areas of southern Lake Michigan (Jude et al. 1979).

4.) Number of trout-perch collected increased in 1978 over 1977 values. A similar increase was noted for smelt, particularly YOY. The trout-perch increase was supported statistically, but not the smelt increase.

5.) Spottails in Lake Michigan increased in numbers in 1978 over 1977 levels. Almost $25 \%$ more were collected which was supported statistically by traw1 and gill net ANOVA.

6.) Northern pike populations have remained stable and fish continue to grow well in Pigeon Lake, in spite of the impingement of some of these fish. Largemouth bass greater than $219 \mathrm{~mm}$ declined in numbers from 1977 to 1978. Reasons for this decline may be related to habitat destruction, competition from pike and bowfin or sport fishing mortality. Other age-groups of bass exhibited similar population levels in both years.

7.) Gizzard shad were impinged in large numbers, but we believe most fish were present in the discharge canal and gained access to the intake canal through an open connection between the two. Very few were ever collected in Pigeon Lake, while some were collected in Lake Michigan in the fall.

8.) A large majority of larvae entrained were small and newly hatched in their planktonic, passive stages. Larvae of this stage are also the most numerous and probably subjected to highest natural mortality rates. For most species, this stage was brief, after which time larvae became more active, resisting currents and seeking specific habitats (the bottom, vegetation, etc.), thereby reducing their vulnerability to entrainment. This was generally not true for species such as alewife, certain cyprinids and at times rainbow smelt. These species continued to be entrained in large numbers throughout their larval period. They were also very abundant and as discussed earlier, we were unable to attribute any changes in adult and juvenile populations to a lack of recruitment of young because of the operation of the Campbel1 Plant. However, this effect would be difficult to document, particularly if it were small.

9.) A large number of yellow perch, mostly from Pigeon Lake, were entrained. Perch populations there appeared to be stable, with an abundance of fish in the 50-110-mm range. Maximum size of perch caught in 1978 was only $170 \mathrm{~mm}$. Perch are a very fecund species and produce large numbers of larvae, 
some of which were entrained. Populations now present in Pigeon Lake, appear to be stunted. This hypothesis will be verified during our 1979 studies. In addition, we feel that spawning by yellow perch occurred in the intake canal, which may have been partly responsible for the high entrainment rates observed.

10.) Pigeon Lake and the intake and discharge canal have served as spawning and nursery grounds for a large number of Pigeon Lake and Lake Michigan fish including: ninespine sticklebacks, yellow perch, minnows (including spottail shiners and carp), white suckers, alewives, and possibly burbot, largemouth bass, a number of centrarchids and quillbacks.

A final evaluation of the effects of the plant on fish in the area, based on changes we observed in larval and adult populations, shows that few of the fish species of concern exhibited a decline in their populations; in fact many increased. Of those that increased or decreased no effects could be directly attributed to operation of the plant. Many of the increases and decreases observed were in agreement with lake-wide population trends established by other studies. Documentation of entrainment and impingement was relatively straight-forward compared to evaluating the meaning of these losses and what effects they had on the affected populations, particularly in view of compensation and the immense populations in Lake Michigan, of which they are a part. 


\section{LITERATURE CITED}

Anderson, R.C. and D. Brazo. 1978. Abundance, feeding habits and degree of segregation of the spottail shiner (Notropis hudsonius) and longnose dace (Rhinichthyscataractae) in a Lake Michigan surge-zone near Ludington, Michigan. Mich. Academician 10:337-346.

Auerbach, S.I. 1977. Welcoming remarks. in Van Winkle ed. Proc. Conf. assessing effects of power-plant-induced mortality of fish populations. May 3-6, Gatlinburg, TN. 380 pp.

Bailey, R.M. 1972. Age, growth, reproduction, and food of the burbot, (Lota lota (Linnaeus), in southwestern Lake Superior. Trans. Amer. Fish. Soc. $101: 667-674$.

, J.E. Fitch, E.S. Herald, E.A. Lachner, C.C. Lindsey, C.R. Robins and W.B. Scott. 1970. A list of common and scientific names of fishes from the United States and Canada. 3rd ed. Spec. Pub. No. 6. Amer. Fish. Soc. Wash. D.C. $150 \mathrm{pp}$.

Baker-Dittus, Anne M. 1978. Foraging patterns of three sympatric killifish. Copeia (3) pp. 383-389.

Baumgart, J. and P. Schultz. 1974. Lake Michigan chub fishery: A population status report, 1973-74. Wis. Dept. Nat. Res. Green Bay District. Green Bay, Wis. 29 pp.

Becker, G.C. 1976. Environmental status of the Lake Michigan region. Vol. 17. Inland fishes of the Lake Michigan drainage basin. Environ. Cont. Techn. Earth Sci. Argonne Nat. Lab. Argonne, I11. 237 pp.

Beckman, W.C. 1949. The rate of growth and sex ratio for seven Michigan fishes. Trans. Amer. Fish. Soc. 76:63-81.

Bernard, D.R., A.R. Tipton and R.T. Lackey. 1978. Analysis of predator prey relationships: where do we go from here? Unpublished M.S. Dept. of Fish and Wild1. Sci. Va. Polyt. Inst. and St. Univ.

Beverton, R.J.H. and S.J. Holt. 1957. On the dynamics of exploited fish populations. Ministry of Agriculture, Fisheries and Food (London) Fisheries Investigations Series 2 (19):533 pp.

Bostock, A.R. 1967. The ecology of the trout-perch, Percopsis omiscomaycus, in Lake Superior. M.A. Thesis. Univ. Mich. Ann Arbor, Mich. 40 pp.

Botkin, D.B. and M.J. Sobel. 1976. Stability in ecosystems: semantics and reality. pp. 239-250. In R.K. Sharma et al. (eds.) Proc. Conf. Biol. Signif. of Environ. Impacts. Univ. Mich., Ann Arbor. 4-6 June, 1975. NR-CONF-002. 
Box, G.E.P. and G.C. Tiao. 1975. Intervention analysis with applications to economic and environmental problems. J. Am. Stat. Assoc. 70:70-79.

and J.M. Jenkins 1970. Time series analysis, forecasting and control. Holden-Day, Inc. San Francisco.

Brazo, D.C., P.I. Tack and C.R. Liston. 1975. Age, growth and fecundity of yellow perch, Perca flavescens, in Lake Michigan near Ludington, Michigan. Trans. Amer. Fish. Soc. 104:726-730.

Breder, C.M., Jr. and D.E. Rosen. 1966. Modes of reproduction in fishes. Natur. Hist. Press. New York, N.Y. 941 pp.

Brown, E.H., Jr. 1972. Population biology of alewives, Alosa pseudoharengus, in Lake Michigan, 1949-70. J. Fish. Res. Bd. Can. 29:477-500.

Brynildson, O.M., V.A. Hacker and T.A. Klick. 1973. Brown trout life history, ecology and management. Pub. 234. Wisc. Dept. Nat. Res., Madison, Wisc. $15 \mathrm{pp}$.

Burbridge, R.G. 1969. Age, growth, length-weight relationship, sex ratio, and food habits of American smelt, Osmerus mordax (Mitchil1), from Gul1 Lake, Michigan. Trans. Amer. Fish. Soc. 98:631-640.

Cairns, J. 1977. Quantification of biological integrity. pp. 171-187. In R.K. Ballantine and L.J. Guarraia (eds.) The integrity of water. U.S.E.P.A., Office of Water and Hazardous Materia1s. Stock No. 055-001-01068-1.

Carbine, W.F. 1944. Egg production of the northern pike, Esox Zucius L., and the percentage survival of eggs and young on spawning grounds. Papers of the Michigan Academy of Science, Arts, and Letters. Vo1. 29, pp. 123-137.

Carlander, K.D. 1969. Handbook of freshwater fishery biology. Vo1. I. Iowa State Univ. Press. Ames, Iowa. $431 \mathrm{pp}$.

- 1977. Handbook of freshwater fishery biology. Vo1. II. Iowa State Univ. Press. Ames, Iowa. 431 pp.

CDM/Limnetics. 1977. The lakewide effects of impingement and entrainment on the Lake Michigan fish populations. (Unpub1. rep.) CDM/Limnetics Environ. Consult., Milwaukee, Wisc. (Unnum. pp.).

Chapman, P.G. 1973. Production pp. 119-214. In W.E. Richer, ed., Methods for assessment of fish production in fresh waters. IBP Handbook No. 3. Blackwell Scientific Publ. Oxford. 348 pp.

Chen, L. 1969. The biology and taxonomy of the burbot, Lota lota leptura, in the interior of Alaska. Biol. Pap. Univ. Alaska, College, Alaska. 11:1-51.

Chiotti, T.L. 1973. Food habits, reproductive biology and lamprey scarring of planted lake trout, Salvelinus namaycush, in the inshore waters of Lake Michigan at Ludington, Michigan. M.S. Thesis. Michigan State Univ. 62 pp. 
Christensen, S.W., D.L. DeAngelis and A.G. Clark. 1977. Development of a stock progeny model for assessing power plant effects on fish populations. In W. Van Winkle (ed.). Assessing the effects of power plant induced mortality on fish populations.

Clady, M.D. 1976. Influence of temperature and wind on the survival of early stages of yellow perch, Perca flavescens. J. Fish. Res. Bd. Can. 33:18871893.

Clark, C.W. 1976. Mathematical bioeconomics: The optimal management of renewable resources. Wiley and Sons, Inc. New York. 352 pp.

Clark, C.F. and F. Steinbach. 1959. Observations on the age and growth of the northern pike, Esox Zucius L., in East Harbor, Ohio. Ohio J. Sci. 59:129-134.

Consumers Power Company. 1975. J.H. Campbell Plant Unit No. 3. Environ. Rep. Vo1. 1. Consumers Power Co. Jackson, Mich. Unnum. pp.

Cooper, G.P. 1935. Age and growth of the golden shiner (Notemigonus crysoleucas auratus) and its suitability for propagation. Mich. Acad. of Sci., Arts and Letters. Vo1. 21. pp. 587-597.

Cooper, R.A. 1961. Early life history and spawning of the alewife, AZosa pseudoharengus. M.S. Thesis. Univ. of Rhode Island. Kingston, R.I. 58 pp.

Cooper, W.E. 1976. Ecological effects. p. 73-88. In R.K. Sharma et al. (eds.) Proc. Conf. Biol. Signif. of Environ. Impacts. Univ. Mich., Ann Arbor. 4-6 June, 1975. NR-CONF-002.

Cuerrier, J.P. 1943. Résultats de 1'etiquetage d'achigans pratiqué dans 1a Rivière Châteauguay, à Châteauguay, Québec, depuis 1941. Rev. Can. Biol. $2(5): 545-548$.

Cushing, D.H. 1971. The dependence of recruitment on parent stock in different groups of fishes. J. Cons. Perma. Int. Explor. Mer. 33: 340-362.

- 1975. Marine ecology and fisheries. Cambridge Univ. Press, London.

Daly, R.I. and L.W. Wiegert. 1958. The smelt are running! Wisc. Cons. Bul1., Vo1. 23, No. 3, 2 pp.

Deason, H.J. 1939. The distribution of cottid fishes in Lake Michigan. Pap. Mich. Acad. Sci. Arts Lett. 24:105-115.

Dorr, J.A. III, D.J. Jude, F.J. Tesar, and N.J. Thurber. 1976. Identification of larval fishes taken from the inshore waters of southeastern Lake Michigan near the Donald C. Cook Nuclear Plant, 1973-1975. pp. 61-82. In J. Boreman (ed.) Great Lakes fish egg and larvae identification. Nat. Power Plant Team. Off. Biol. Serv. U.S. Fish Wildl. Serv. Ann Arbor, Mich.

Draper, N. and H. Smith. 1966. Applied regression analysis. Wiley Inc. New York. $407 \mathrm{pp}$. 
Dryer, W.R. 1966. Bathymetric distribution of fish in the Apostle Islands region, Lake Superior. Trans. Amer. Fish. Soc. 95:248-259.

, J. Beil. 1968. Growth changes of the bloater (Coregonus hoy $i$ ) of the Apostle Islands region of Lake Superior. Trans. Amer. Fish. Soc. 97:146-158.

Dymond, J.R. 1926. The fishes of Lake Nipigon. Univ. Toronto. Biol. Ser. No. 27. Publ. Ont. Fish. Lab. 108 pp.

Eddy, S. 1957. How to know the freshwater fishes. Wm. C. Brown. Co. Dubuque, Ia. 253 pp.

Edsall, T.A. 1964. Feeding by three species of fishes on the eggs of spawning alewives. Copeia 1964:226-227.

- 1970. The effect of temperature on the rate of development and survival of alewife eggs and larvae. Trans. Amer. Fish. Soc. 99:376-380.

, E.H. Brown, Jr., T.G. Yocum and R.S. Wolcott, Jr. 1974. Utilization of alewives by coho salmon in Lake Michigan. Unpub. ms. U.S. Fish Wild1. Serv. Great Lakes Fish. Lab. Ann Arbor, Michigan. 28 pp.

Ellicott, G.V. 1976. Diel activity and feeding of schooled largemouth bass fry. Trans. Amer. Fish. Soc. 105:625-627.

Emery, A.R. 1970. Fish and crayfish mortalities due to an internal seiche in Georgian Bay, Lake Huron. J. Fish. Res. Bd. Can. 27:1165-1168.

Engel, S. and J.J. Magnuson. 1971. Ecological interactions between coho salmon and native fishes in a small lake. Proc. 14th Conf. Great Lakes Res. Internat. Assoc. Great Lakes. pp. 14-20.

Eraslan, A.H. 1970. Mathematical field theory for dynamic behavior of living species. Dept. Eng. Sci. and Mech. ESM/ENV-74-02. 97 pp.

Eschmeyer, P.H. 1950. The life history of the walleye in Michigan. Mich. Dept. Conserv. Inst. Fish. Res. Bull. 3. 99 pp.

Ferguson, R.G. 1958. The preferred temperature of fish and their mid-summer distribution in temperate lakes and streams. J. Fish. Res. Bd. Can. 15:607-634. , 1965. Bathymetric distribution of American smelt Osmerus mordax in Lake Erie. Proc. 8th Conf. Great Lakes Res. Internat. Assoc. Great Lakes Res. pp. 47-60.

Fish, M.P. 1929. Contributions to the early life histories of Lake Erie fishes. Bul1. Buffalo Soc. Nat. Sci. 14:136-187.

- 1932. Contributions to the early life histories of sixty-two species of fishes from Lake Erie and its tributary waters. U.S. Bur. Fish. Bu11. 47:293398. 
F1ittner, G.A. 1964. Morphometry and life history of the emerald shiner, Notropis atherinoides Rafinesque. Ph.D. Thesis. Univ. Mich. Ann Arbor, Mich. $213 \mathrm{pp}$.

Forney, J.L. 1966. Factors affecting first-year growth of walleyes in Oneida Lake, New York. N.Y. Fish Game J. 13(2):146-167.

- 1971. Development of dominant year classes in a yellow perch population. Trans. Amer. Fish. Soc. 100:739-749.

Fox, D.J. and K.E. Guire. 1973. Documentation for MIDAS (Michigan Interactive Data Analysis System). Stat. Res. Lab. Univ. Mich. 2nd ed. 173 pp.

Fritz, E.S. and E.T. Garside. 1975. Comparison of age composition, growth, and fecundity between two populations each of Fundulus heteroclitus and $F$. diaphanus (Pisces: Cyprinodontidae). Can. J. Zool. 53:361-369.

Fuchs, E.H. 1967. Life history of the emerald shiner, Notropis atherinoides, in Lewis and Clark Lake, South Dakota. Trans. Amer. Fish. Soc. 96:247-256.

Gammon, J.R. 1971. The response of fish populations in the Wabash River to heated effluents. Pages 513-523 in D.J. Nelson, ed. Radionuclides in ecosystems. Proc. 3rd Nat. Sym. Radioecol. Vol. 1, U.S. Atom. Ener. Comm., Oak Ridge, Tenn.

Gardner, R.H., J.B. Mankin and W.R. Emanuel. 1978. A comparison of three carbon models. Ecol. Modelling (submitted). Environmental Sci. Div. Oak Ridge Nat. Lab. Oak Ridge, TN.

, R.V. O'Neill, J.B. Mankin and D. Kuman. 1978. Comparative error analysis of six predator-prey models. (MS) Environmental Sci. Div. Oak Ridge Nat. Lab. Oak Ridge, TN.

Godfrey, H. 1965. Salmon of the north Pacific Ocean - Part IX coho, chinook, and masu salmon in offshore waters. 1. Coho salmon in offshore waters. Intern. N. Pacific Fish. Comm. Bull. No. 16:1-39.

Goodyear, C.P. 1977. Assessing the impact of power plant mortality on the compensatory reserve of fish populations. pp. 186-195. In Proc. Conf. Assessing the effects of power-plant-induced mortality on fish populations. (ed.) W. Van Winkle. Pergamon Press. 380 pp.

- 1978. Entrainment impact estimates using the equivalent adult approach. Power Plant Project, Office Biol. Serv., Fish and Wild. Serv., U.S. Dept. Interior. FWS/OBS-78/65. $14 \mathrm{pp}$.

Greely, J.R. 1940. Fishes of the watershed with annotated 1ist, p. 42-81. In A biological survey of the Lake Ontario watershed. Supp1. 29th Ann. Rep. N.Y. Conserv. Dept. 1939. 261 pp. 
Griswold, B.R. and L.L. Smith. 1973. The life history and trophic relationship of the ninespine stickleback Pungitius pungitius, in the Apostle Islands area of Lake Superior. Fish. Bu11. 71:1039-1060.

Hadderingh, R.H. 1974. Effects of entrainment and screening on young fish at Flevo Power Station. Memorandum: N.V. Kema. Vo1. 74-56:12 p.

Ha11, C.A.S. and J.W. Day. 1977. Ecosystem modeling in theory and practice: an introduction with case histories. John Wiley and Sons, Inc. New York. $684 \mathrm{pp}$.

Hansen, C.H., J.R. White and H.N. Li. 1977. Entrapment and impingement of fishes by power plant cooling water intakes. Marine Fisheries Rev. 39(10): 1-17. MFR Paper 1266.

Havey, K.A. 1973. Production of juvenile alewives, Alosa pseudoharengus, at Love Lake, Washington County, Maine. Trans. Amer. Fish. Soc. 102:434-437.

Herman, E., W. Wisby, L. Wiegert and M. Burdick. 1959. The yellow perch: its life history, ecology and management. Dept. Nat. Res., Madison, Wisc., Pub1. 228-68. $14 \mathrm{pp}$.

Hogue, J.J. Jr., R. Wallus and K.K. Kay. 1976. Larval fishes in the Tennessee River. Tech. Note 319, Div. of Forestry, Fisheries, and Wildlife Development. TVA. $67 \mathrm{pp}$.

Horst, T.J. 1975. The assessment of impact due to entrainment of icthyoplankton. pp. 107-118. In S.B. Saila, ed. Fisheries and energy production: a symposium. D.C. Heath, Lexington, Mass.

Houde, E.D. 1969. Sustained swimming ability of larvae of walleye (Stizostedion vitreum) and yellow perch (Perca flavescens). J. Fish. Res. Bd. Can. 26: 1647-1659.

House, R. and L. We11s. 1973. Age, growth, spawning season, and fecundity of the trout-perch (Percopsis omiscomaycus) in southeastern Lake Michigan.

J. Fish. Res. Bd. Can. 30:1221-1225.

Hubbs, C.L. 1921. An ecological study of the life history of the freshwater Atherine fish Labidesthes sicculus. Ecology 2:262-276.

, and G.P. Cooper. 1936. Minnows of Michigan. Cranbrook Inst. of Sci. Bu11. No. 8: $95 \mathrm{pp}$.

, and K.F. Lagler. 1958. Fishes of the Great Lakes region. Univ. Mich. Press, Ann Arbor, Mich. 213 pp.

Hunt, B.P. and W.F. Carbine. 1951. Food of young pike, Esox Zucius L., and associated fishes in Peterson's Ditches, Houghton Lake, Michigan. Trans. Amer. Fish. Soc. 80:67-83. 
Idy11, C. 1942. Food of rainbow, cutthroat, and brown trout in the Cowichan River system, B.C. J. Fish. Res. Bd. Can. 5(5):448-458.

Ivlev, V.S. 1966. The biological productivity of waters. J. Fish. Res. Bd. Canada. 23(11):1727-1759.

Jaiyen, K. 1975. The history and importance of the rainbow smelt, Osmerus mordax (Mitchill), in the Lake Michigan fish community, with special reference to its management as a resource. Ph.D. Thesis. Univ. Mich. Ann Arbor, Mich. 155 pp.

Jester, D.J., D.L. Garling, Jr., A.R. Tipton and R.T. Lackey. 1977. A general population dynamics theory for largemouth bass. Dept. Fish. and Wild1. Sci., Virginia Polytechnic Inst. and State University. Blacksburg, VA 24061. 29 pp.

Jobes F.W. 1949. The age, growth and bathymetric distribution of the bloater Leucichthys hoyi (Gill), in Lake Michigan. Pap. Mich. Acad. Sci. Arts Lett. $33: 135-172$.

Jones, P.W., F.D. Martin and J.D. Hardy, Jr. 1978. Development of fishes of the mid-Atlantic bight: an atlas of egg, larval and juvenile stages. FWS/ OBS Vol.1. $366 \mathrm{pp}$.

Jude, D.J. 1973. Food and feeding habits of gizzard shad in pool 19, Mississippi River. Trans. Amer. Fish. Soc. 102:378-383.

, F.J. Tesar, J.A. Dorr III, T.J. Miller, P.J. Rago and D.J. Stewart. 1975. Inshore Lake Michigan fish populations near the Donald C. Cook Nuclear Power Plant, 1973. Spec. Rep. No. 52. Great Lakes Res. Div. Univ. Mich. Ann Arbor, Mich. 267 pp.

, B.A. Bachen, G.R. Heufelder, H.T. Tin, M.H. Winnel, F.J. Tesar and J.A. Dorr, III. 1978. Adult and juvenile fish, ichthyoplankton and benthos populations in the vicinity of the J.H. Campbell Power Plant, eastern Lake Michigan, 1977. Spec. Rep. No. 65. Great Lakes Res. Div., Univ. Mich., Ann Arbor, Mich. 639 pp.

, F.J. Tesar, J.C. Tomlinson, T.J. Miller, N.J. Thurber, G.G. Godun and J.A. Dorr III. 1979. Inshore Lake Michigan $f_{i} s h$ populations near the Donald C. Cook Nuclear Power Plant during preoperational years - 1973,74. In press. Great Lakes Res. Div. Univ. Mich. Ann Arbor, Mich.

Kelso, J.R.M. and J.K. Leslie. 1979. Entrainment of larval fish by the Douglas Point generating station, Lake Huron, in relation to seasonal succession and distribution. J. Fish. Res. Bd. Can. 36:37-41.

Kendall, W.C. 1927. The smelts. U.S. Bur. Fish., Fish Bull. 42:217-375. 
Khan, N.Y. and D.J. Faber. 1974. A comparison of larvae of the deepwater and fourhorn sculpin, Myoxocephalus quadricornis L. from North America. 1. Morphological development. 703-712 pp. In J.H.S. Blaxter. The early life history of fish. Spriner-Verlag, New York. 765 pp.

Kinney, E.C. Jr. 1950. Life history of the trout-perch, Percopsis omiscomaycus (Walbaum), in western Lake Erie. M.S. Thesis. Ohio State Univ. Columbus, Oh. $75 \mathrm{pp}$.

Kissil, G.W. 1974. Spawning of the anadromous alewife, Alosa pseudoharengus in Bride Lake, Connecticut. Trans. Amer. Fish. Soc. 103(2):312-317.

Kuehn, J.H. 1949. A study of a population of longnose dace (Rhynichthys c. cataractae). Proc. Minn. Acad. Sci. 17:81-87.

Kumar, K.D. and S.M. Adams. 1977. Estimation of age structure of fish populations from length frequency data. pp. 256-281. In W. Van Winkle ed., Proc. Conf. assessing the effects of power-plant-induced mortality on fish populations. Gattlinburg. Tennessee, May 3-6, 1977. Permagon Press, New York. $380 \mathrm{pp}$.

Lake Michigan Federation. 1975. The Lake Michigan Basin (map). The Lake Michigan Federaticn, Chicago, I11.

Lam, C.H.H. and J.C. Roff. 1976. Distribution, abundance and growth rates of the alewife (Alosa pseudoharengus), and other larval fish species in the Bay of Quinte. Internat. Assoc. Great Lakes Res. Abs. Univ. Guelph. Guelph, Ont. $1 \mathrm{p}$.

Langlois, T.H. 1954. The western end of Lake Erie and its ecology. Edwards Brothers Inc., Ann Arbor, Mich. $479 \mathrm{pp}$.

Larimore, R.W. 1957. Ecological life history of the warmouth (Centrarchidae). I11. Nat. Hist. Survey Bul1. 27:1-83.

Lawrie, A.H. and J.F. Rahrer. 1973. Lake Superior: a case history of the lake and its fisheries. Tech. Rep. No. 19. Great Lakes Fish. Comm. Ann Arbor, Mich. $69 \mathrm{pp}$.

Levins, R. 1966. The strategy of model building in population biology. Amer. Scient. 54:421-431.

Lewis, S.A. 1970. Age and growth of walleye in Canton Reservoir, Oklahoma. Proc. Okla. Acad. Sci. 50:84-86.

Lievense, S.J. 1954. Spawning of American smelt, Osmerus mordax, in Crystal Lake, Benzie County, Michigan. Copeia 1954:232-233.

Limnetics, Inc. 1976. Draft review of literature on Lake Michigan fish populations. Unpublished MS, January 1, 1976. 
Lippson, A.J. and R.L. Moran. 1974. Manual for identification of early developmental stages of fishes of the Potomac River Estuary. Environ. Tech. Cent., Martin Marietta Corp., Baltimore, Md. 282 pp.

MacCallum, W.R. and M.A. Regier. 1970. Distribution of smelt, Osmerus mordax, and the smelt fishery in Lake Erie in the early 1960's. J. Fish. Res. Bd. Can. 非2 2 :1823-1846.

Magnuson, J.L. and L.L. Smith Jr. 1963. Some phases of the life history of the trout-perch. Ecology 44:83-85.

McCauley, R.W. and L.A.A. Read. 1973. Temperature selection by juvenile and adult yellow perch (Perca flavescens) acclimated to $24 \mathrm{C}$. J. Fish. Res. Bd. Can. 30:1253-1255.

, and J.S. Tait. 1970. Preferred temperature of yearling lake trout, SaZvelinus namaycush. J. Fish. Res. Bd. Can. 27:1729-1733.

McComish, T.S. 1975. Interspecies relationships of fish in Indiana waters of Lake Michigan. Final Rept. Fed. Aid Proj. 3-150-R. U.S. Dept. Commerce, Nat. Marine Fish. Serv. Washington, D.C. 125 pp.

- 1978. Yellow perch population characteristics in Lake Michigan. Seg. 1. Ann. Rept. Fed. Aid Prog. 3-283-R. Nat. Mar. Fish. Serv. U.S. Dept. Comm. Washington, D.C. 43 pp.

, and W.B. Miller.1975. Notes on the biology of the lake trout and other selected Salmonidae in Indiana waters of Lake Michigan. Proc. Indiana Acad. Sci. 85:161-169.

McCrimmon, H.R. 1968. Carp in Canada. Fish. Res. Bd. Can. Bu11. 165:1-94. , and O.E. Devitt. 1954. Winter Studies on the burbot, Lota Zota Zacustris, of Lake Simcoe, Ontario. Can. Fish Culturist (16):34-41.

McFadden, J.T. 1976. Environmental impact assessment for fish populations. p. 89137. In R.K. Sharma, J.D. Buffington and J.T. McFadden (ed.) Proc. Workshop Biol. Significance Environ. Impacts. NR-CONF-002. U.S. Nuclear Regulatory Comm. Washington, D.C.

- 1977. Compensation in striped bass populations. P. 10.1-10.67 in J.T. McFadden, ed. Influence of Indian Point Unit 2 and other steam electric generating plants on the Hudson River Estuary, with emphasis on striped bass and other fish populations. Cons. Ed. Co. Approx. $1000 \mathrm{pp}$.

McKenzie, R.A. 1958. Age and growth of smelt, Osmerus mordax (Mitchill) of the Miramichi River, New Brunswick. J. Fish. Res. Bd. Can. 15(6):1313-1327.

- 1964. Smelt 1ife history and fishery in the Miramichi River, New Brunswick. Fish. Res. Bd. Canada Bull. No. 144, 77 pp. 
Miller, R.B. and W.A. Kennedy. 1948. Pike (Esox lucius) from four northern Canadian lakes. J. Fish. Res. Bd. Can. 7:190-199.

Miller, R.R. 1960. Systematics and biology of the gizzard shad (Dorosoma cepedianum) and related fishes. U.S. Fish. Wild1. Serv. Fish. Bull. 173:371-392.

Mood, A.M., F.A. Graybi11 and D.C. Boes. 1974. Introduction to the theory of statistics. 3rd Ed. McGraw Hill. New York. 564 pp.

Mraz, D. 1964a. Age and growth of the round whitefish in Lake Michigan. Trans. Amer. Fish. Soc. Vo1. 93, No. 1, pp. 46-52.

, 1964b. Age, growth, sex ratio, and maturity of the whitefish in central Green Bay and adjacent waters of Lake Michigan. Fishery Bul1. Vo1. 63, No. 3, pp. 619-634.

- 1968. Recruitment, growth, exploitation and management of walleyes in a southeastern Wisconsin 1ake. Wisc. Dept. Nat. Res. Tech Bu11. 40.38 pp.

Muth, K.M. 1973. Population dynamics and life history of burbot, Lota Zota (Linnaeus), in Lake of the Woods, Minnesota. Ph.D. Thesis. Univ. Minn., St. Paul, Minn. $164 \mathrm{pp}$.

, and L.L. Smith, Jr. 1974. The burbot fishery of Lake of the Woods. Tech. Bu11. 296. Agr. Exp. Sta., Univ. Minn., St. Paul, Minn. 68 pp.

Nalco Environmental. 1975. Operational environmental monitoring in Lake Michigan near Zion Station. July 1974 through June 1975. Vo1. IV. Annual report to Commonwealth Edison Company, Chicago, I1linois, 260 pp.

Ne1son, C.R. 1973. Applied time series analyses for managerial forecasting. Holden-Day, Inc. San Francisco.

Ne1son, D.D. and R.A. Cole. 1975. The distribution and abundance of larval fishes along the western shore of Lake Erie at Monroe, Michigan. Tech. Rep. No. 32-4. Institute of Water Research, Mich. State Univ. 66 pp.

Nelson, J.S. 1968. Deep-water ninespine sticklebacks, Pungitius pungitius, in the Mississippi drainage, Crooked Lake Indiana. Copeia 2:326-334.

Niimi, A.J. and F.W.H. Beamish. 1974. Bioenergetics and growth of largemouth bass (Micropterus salmoides) in relation to body weight and temperature. Can. J. Zoo1. 52(4):447-456.

Noble, R.L. 1968. Mortality rate of pelagic fry of yellow perch, Perca flavescens (Mitchil1), in Oneida Lake, New York, and an analysis of the sampling problem. Ph.D. Thesis. Cornel1 Univ., Ithaca, N.Y. 111 pp. 
Norden, C.R. 1967. Age, growth and fecundity of the alewife, AZosa pseudoharengus (Wilson), in Lake Michigan. Trans. Amer. Fish. Soc. 96:387-393.

Nursall, J.R. 1973. Some biological interactions of spottail shiners (Notropis hudsonius), yellow perch (Perca flavescens) and northern pike (Esox Iucius). J. Fish. Res. Bd. Can. 30:1161-1178.

and M.E. Pinsent. 1969. Aggregations of spottail shiners and yellow perch. J. Fish. Res. Bd. Can. 26:1672-1676.

O'Neill, R.V. 1978. Natural variability as a source of error in model predictions. Unpublished MS. Envir. Sci. Div. Oak Ridge Nat. Lab. Oak Ridge, TN.

, and R.H. Gardner. 1978. Sources of uncertainty in ecologica1 mode1s. (MS) Environ. Sci. Div., Oak Ridge Nat. Lab. Oak Ridge, TN.

, and B. Rust. 1978. Aggregation error in ecological models. In press. Ecological modelling Publ. 1201, Environmental Sciences Div. Oak Ridge, TN.

, R.H. Gardner and J.B. Mankin. 1978. Propagation of parameter error in a nonlinear mode1. MS. Environ. Dvi. Fib. Oak Ridge Nat. Lab. Oak Ridge, TN.

Oster, G. and Takahashi, Y. 1974. Models for age-specific interactions in a periodic environment. Ecological Monographs 44:483-501.

Otto, R.G., M.A. Kitche1 and J.O. Rice. 1976. Lethal and preferred temperatures of the alewife (Alosa pseudoharengus) in Lake Michigan. Trans. Amer. Fish. Soc. 105:96-106.

Parsons, J.W. 1971. Selective food preferences of walleyes of the 1959 yearclass in Lake Erie. Trans. Amer. Fish. Soc. 100:474-485.

Patriarche, M. 1975. Reaction of nearby Lake Michigan fish stocks to a heated discharge at the Palisade Plant. Fish. Res. Rept. No. 1820, Mich. Dept. of Nat. Res., Fisheries Div. 38 pp.

Patten, B.C. 1969. Ecological systems analysis and fisheries science. Trans. Amer. Fish. Soc. 98(3):570-581.

Peckham, R.S. and C.F. Dineen. 1957. Ecology of the central mudminnow, Umbra Zimi (Kirtland). Amer. Midland Naturalist 58:222-231.

Perry, L.G. 1979. Identification of nine larval cyprinids inhabiting small northern rivers. II. Spatial and temporal pattern of larval fish drift in the upper Skunk River. M.S. Thesis. Iowa State Univ. Ames Iowa. 73 pp.

Pflieger, L.W. 1975. The fishes of Missouri. Missouri Dept. of Conserv. 343 pp. Pielou, E.C. 1977. Mathematical ecology. Wiley and Sons. New York. 385 pp. 
Price, J.W. 1963. A study of the food habits of some Lake Erie fish. Bull. Ohio Biol. Surv. 2(1):1-89.

Rago, P.J. 1978. On the calculation of production foregone due to entrainment and impingement of fishes at the Donald C. Cook Nuclear Plant. Report submitted to Mich. Dept. Nat. Res. Great Lakes Res. Div., Univ. of Mich., Ann Arbor, Mich. 80 pp.

- 1979. A matrix model for inshore Lake Michigan fish populations. M.S. Thesis. Colorado St. Univ., Ft. Collins. In preparation.

Rashevsky, N. 1967. Organismic sets: outline of a general theory of biological and social organisms. Bul1. Math. Biophysics 29:139-152.

- 1969. Outline of unified approach to physics, biology and sociology. Bull. Math. Biophysics 31:159-196.

Regier, H.A. and H.F. Henderson. 1973. Towards a broad ecological model of fish communities and fisheries. Trans. Amer. Fish. Soc. 102(1):56-72.

Ricker, W.E. 1954. Stock and recruitment. J. Fish Res. Bd. Can. 11(5):559-623. - 1975. Computation and interpretation of biological statistics of fish populations. Fish. Res. Bd. Canada Bull. 191. Ottawa, Canada. xviii + 382 p.

Rickham, J.A. 1970. Ecology of young lake whitefish (Coregonus clupeaformis) in South Bay, Manitoulin Island, Lake Huron. In C.C. Lindsay and C.S. Woods (eds.) Biology of coregonid fishes, p. 437-460.

Robinson R.D. 1973. Age, growth, and sex composition of the American smelt, Osmerus mordax (Mitchill), from along the Western shore of Lake Michigan. M.S. Thesis. Univ. Wisc. Milwaukee, Wisc. $62 \mathrm{pp}$.

Romberg, G.P., S.A. Spigare11i, W. Prepjcha1, and M.M. Thommes. 1974. Fish behavior at a thermal discharge into Lake Michigan, p. 296-312. In J.W. Gibbons and R.R. Shapitz (ed.). Thermal Ecology. AEC Symposium Series. CONF-730505.

Rothschild, B.J. 1961. Production and survival of eggs of the American smelt, Osmerus mordax (Mitchill), in Maine. Trans. Amer. Fish. Soc. 90(1):42-48.

Rottiers, D.V. 1965. Some aspects of the life history of Cottus cognatus in Lake Michigan. M.S. Thesis. Univ. Mich. Ann Arbor, Mich. 49 pp.

Rupp, R.S. 1958. Smelt family (Osmeridae), American smelt, Osmerus mordax (Mitchill). Fishes of Maine, 2nd ed., ed. W.H. Everhart:55-6.

- 1959. Variation in the life history of the American smelt in inland waters of Maine. Trans. Amer. Fish. Soc. 88:241-252. 
Schaefer, M.B. 1954. Some aspects of dynamics of populations important to the management of commercial marine fishes. Bull. Inter-Amer. Trop. Tuna Comm. $1(2): 26-56$.

Schneberger, E. 1972. The white sucker: its life history, ecology and management. Pub. No. 245-72. Wisc. Dept. Nat. Res., Madison, Wisc.

Schneider, J.C. and J.H. Leach. 1977. Walleye (Stizostedion vitreum vitreum) fluctuations in the Great Lakes: and possible causes, 1800-1975. J. Fish. Res. Bd. Can. 34(10):1878-1889.

Scott, W.B. and E.J. Crossman. 1973. Freshwater fishes of Canada. Bu11. 184. Fish. Res. Bd. Can. Ottawa, Ontario. 966 pp.

Sette, O.E. 1943. Biology of the Atlantic mackerel (Scomber scombmus) of North America. Part I: early life history, including growth, drift, and mortality of the egg and larval populations. Fish. Bull. 50:145-237.

Sharma, R.K. and R.F. Freeman. 1977. Survey of fish impingement at power plants in the United States. Vol. I. The Great Lakes. Argonne Nat. Laboratory, Argonne, I11. $218 \mathrm{pp}$.

Skille, J. 1968. A study of the rock bass, Ambloplites mpestris(Rafinesque). Univ. of Wisc. - Stevens Point, Dept. Biol. 13 pp. (mimeo).

Slobodkin, L.B. and S. Richman. 1956. The effect of removal of fixed percentages of new-born on size and variability in populations of Daphnia pulicaria

(Forbes). Limnol. Ocean. 1(3):209-237.

Smith, L.L. And R.L. Pycha. 1960. First-year growth of the walleye and associated factors in the Red Lakes, Minnesota. Limnol. Oceanogr. 5(3):281-290.

Smith, S.H. 1956. Life history of lake herring of Green Bay, Lake Michigan. U.S. Fish \& Wild1. Serv., Fish. Bul1. 57:87-138.

1968. Species succession and fishery exploitation in the Great Lakes.

J. Fish. Res. Bd. Can. 25:667-693.

- 1970. Species interactions of the alewife in the Great Lakes. Trans. Amer. Fish. Soc. 99:754-765.

Snow, H., A. Ensign and J. Klingbiel. 1970. The bluegill its life history, ecology and management. Publ. 230-70. Wisc. Dept. Nat. Res. Madison, Wisc. 14 pp.

Snyder, D.E., M.B.M. Snyder, and S.C. Douglas. 1977. Identification of golden shiner, Notemigonus chrysoleucas, spotfin shiner Notropis spilopterus, and fathead minnow, Pimephales promelas larvae. J. Fish. Res. Bd. Can. $34: 1397-1409$.

Spigarelli, S.A. 1975. Behavioral responses of Lake Michigan fishes to a nuclear power plant discharge. In Environmental effects of cooling systems at nuclear 
power plants, Symp. Proc., 0s1o, Aug. 26-30, 1974, pp. 479-498, Int. Atomic Energy Agency, Vienna. IAEA-SM-187/18.

Statistical Research Laboratory. 1975. Analysis of variance - BMD8V - General description. Unpub. ms. Stat. Res. Lab. Univ. Mich. Ann Arbor, Mich. 3 pp.

Stone and Webster Corp. 1976. Final Report. Studies to alleviate potential fish entrapment problems at Lake Ontario power plant intakes. Stone and Webster Engineering, Boston, MA.

Streifer, N. 1974. Realistic models in population ecology. Adv. Ecol. Res. 8:199-266.

Stroud, R.H. 1949. Growth of Norris Reservoir walleye during the first twelve years of impoundment. J. Wild1. Mgt. 13(2):157-177.

Swee, U.B. and H.R. McCrimmon. 1966. Reproductive biology of the carp, Cyprinus carpio L., in Lake St. Lawrence, Ontario. Trans. Amer. Fish. Soc. 95:372-388.

Threinen, C.W. 1958. Life history, ecology, and management of the alewife. Wis. Conserv. Dept. Pub1., 223:1-7.

Tomljanovich, D.A., J.H. Heuer and C.W. Voigtlander. 1977. Investigations on the protection of fish larvae at water intakes using fine-mesh screening. Tech. Note. No. B22. Div. For., Fish. Wild. Dev. T.V.A. Norris, Tenn.

Trautman, M.B. 1957. The fishes of Ohio with illustrated keys. Ohio State Univ. Press. Columbus, OH. $683 \mathrm{pp}$.

Tucker, T.R. 1968. Aspects of the life history of the walleye, in Hoover Reservoir, Ohio. M.S. Thesis. Ohio State Univ., Columbus. 33 pp.

Underhill, J.C. 1963. Distribution in Minnesota of the subspecies of the percid fish Etheostoma nigrum and of their intergrades. Amer. Midland Natur. 70(2): $470-478$.

U.S. Army Corps of Engineers. 1971 National Oceanic and Atmospheric Administration. National Ocean Survey. Washington D.C.

Van Enge1, W.A. 1940. The rate of growth of the northern pike, Esox Zucius Linnaeus, in Wisconsin waters. Copeia 1940:177-188.

Van Oosten, J. 1938. The age, growth, sexual maturity and sex ratio of the common whitefish, Coregonus clupeaformis (Mitchill) of Lake Huron. Mich. Acad. of Sci., Arts \& Letters 24, Part II, pp. 195-221.

- 1940. The smelt, Osmerus mordax (Mitchill). Great Lakes Fish. Invest. U.S. Bur. Fish. 13 pp. (Mimeo).

Wagner, W. 1972. Utilization of alewives by inshore piscivorous fishes in Lake Michigan. Trans. Amer. Fish. Soc. 101(1):55-63. 
Walford, L.A. 1938. Effect of currents on distribution and survival of the eggs and larvae of the haddock (Melanogrommus aeglefinus) on Georges Bank. Fish. Bul1. 49:1-73.

Wallace, D.N. 1975. A critical comparison of the biological assumptions of Hudson River striped bass models and field survey data. Trans. Amer. Fish. Soc. 104:710-717.

Walters, C.J. and I.E. Efford. 1972. Systems analysis in the Marion Lake IBP project. Oecologia 11:33-44.

Wang, J.C.S. and R.J. Kernehan. 1979. Fishes of the Delaware Estuaries: a guide to early life histories. Ecological Analysts Communications. 410 pp.

Water Resources Commission. 1968. The water resources of the lower Lake Michigan drainage basin. Michigan Water Resource Commission. Lansing, Mich. 172 pp.

Wells, L. 1966. Seasonal and depth distribution of larval bloaters (Coregonus hoy $i)$ in southeastern Lake Michigan. Trans. Amer. Fish. Soc. 95:388-396.

- 1968. Seasonal depth distribution of fish in southeastern Lake Michigan. U.S. Fish and Wild. Serv. Fish. Bull. 67:1-15.

- 1970. Effects of alewife predation on zooplankton populations in Lake Michigan. Limnol. and Oceanogr. 15:556-565.

- 1973. Distribution of fish fry in nearshore waters of southeastern and east-central Lake Michigan, May-August 1972. Unpub. admin. rep. Great Lakes Fish. Lab. U.S. Bur. Sport Fish. Wildl. Ann Arbor, Mich. 24 pp.

- 1977. Changes in yellow perch populations of Lake Michigan, 1954-75. Unpub. ms. Great Lakes Fish. Lab. U.S. Fish Wild. Serv. Ann Arbor, Mich. 26 pp.

- 1978. Status of alewives and yellow perch in Lake Michigan. Agenda Item VI in Minutes, Lake Michigan Committee annual meeting, Milwaukee, Wisc. Mimeo Rep. Great Lakes Fish. Comm., Ann Arbor, Mich. Unnum. pp.

and A.M. Beeton. 1963. Food of the bloater, Coregonus hoyi, in Lake Michigan. Trans. Amer. Fish. Soc. 92:245-255.

and R. House. 1974. Life history of the spottail shiner (Notropis hudsonius) in southeastern Lake Michigan, the Kalamazoo River, and western Lake Erie. Res. Rep. No. 78. Bur. Sport Fish. and Wild. Washington, D.C. 10 pp.

and A.L. McLain. 1972. Lake Michigan: effects of exploitation, introductions, and eutrophication on the salmonid community. J. Fish. Res. Bd. Can. 29:889-898.

and _ 1973. Lake Michigan - man's effects on native fish stocks and other biota. Tech. Rep. 20. Great Lakes Fish. Comm. Ann Arbor, Mich. 55 pp.

Westin, L. 1969. The mode of fertilization, parental behavior and time of egg development in fourhorn sculpin, Myoxocephalus quadricornis (L.). Rep. Inst. Freshw. Res. Drottningholm. 49:175-182. 
Westin, L. 1970. Observations on the nest digging of fourhorn sculpin Myoxocephalus quadricornis (L.). Rep. Inst. Freshw. Res. Drottningholm. $50: 211-214$.

Westman, H.R. 1938. Studies on the reproduction and growth of the blunt-nosed minnow Hyborhynchus notatus (Rafinesque). Copeia 1938:57-60.

White, W.J. 1970. A study of a population of smallmouth bass (Micropterus dolomieui) (Lacepede) at Baie du Dore, Ontario. M.S. Thesis. Univ. Toronto, Toronto, Ont. $83 \mathrm{pp}$.

Winn, H.E. 1958. Comparative reproductive behavior and ecology of fourteen species of darters (Pisces - Percidae). Ecol. Monographs 28(2):151-191.

Winnel1, M.H. and D.J. Jude. 1979. Spatial and temporal distribution of benthic macroinvertebrates and sediments collected in the vicinity of the J. H. Campbell Plant, eastern Lake Michigan, 1978. Spec. Rep. No. 75, Great Lakes Res. Div., Univ. Mich., Ann Arbor, Mich. 199 pp.

Wright, K.J. 1968. Feeding habits of immature lake trout in Michigan waters of Lake Michigan. M.S. Thesis. Mich. State Univ. E. Lansing, Mich. 42 pp.

Wolfert, D.R. 1977. Age and growth of the walleye in Lake Erie, 1963-1968. Trans. Amer. Fish. Soc. 106(6):569-577.

Yager, R. 1976. Food habits of the spottail shiner in Indiana waters of Lake Michigan in 1973. M.S. Thesis. Ball State Univ., Muncie, Indiana. $103 \mathrm{pp}$.

Zeitoun, I.H., J.A. Gulvas and N.C. VanWagner. 1978. Fish impingement at the J.H. Campbell Plant Units 1 and 2; June 13-December 22, 1977. Tech. Rep. No. 14, Dept. of Environ. Serv., Consumers Power Co. Jackson, Michigan. $32 \mathrm{pp}$. 